\title{
SCDAP/RELAP5/MOD2 Code
}

Manual, Volume 4: MATPRO-A

Library of Materials Properties

for Light-Water-Reactor

Accident Analysis

Manuscript Completed: January 1990

Date Published: February 1990

Edited by

J. K. Hohorst

Contributing Authors

A. Buccafurni, E. R. Carlson, R. Chambers, S. V. Chmielewski,

D. L. Hagrman; N. L. Hampton, J. K. Hohorst, E. T. Laats,

R. E. Mason, M. L. McComas, K. A. McNeil, R. L. Miller,

M. A. Morgan, C. S. Olsen, G. A. Reymann

\section{DISCLAIMER}

EG\&G Idaho, Inc.

Idaho Falls, ID 83415

\section{Prepared for}

Division of Systems Research

Office of Nuclear Regulatory Research

U.S. Nuclear Regulatory Commission

Washington, DC 20555

NRC FIN A6360
This report was prepared as an account of work sponsored by an agency of the United States Government. Neither the United States Government nor any agency thereof, nor any of their employees, makes any warranty, express or implied, or assumes any legal liability or responsibility for the accuracy, completeness, or usefulness of any information, apparatus, product, or process disclosed, or represents that its use would not infringe privately owned rights. Reference herein to any specific commercial product, process, or service by trade name, trademark, manufacturer, or otherwise does not necessarily constitute or imply its endorsement, recommendation, or favoring by the United States Government or any agency thereof. The views and opinions of authors expressed herein do not necessarily state or reflect those of the United States Government or any agency thereof. 


\section{DISCLAIMER}

This report was prepared as an account of work sponsored by an agency of the United States Government. Neither the United States Government nor any agency Thereof, nor any of their employees, makes any warranty, express or implied, or assumes any legal liability or responsibility for the accuracy, completeness, or usefulness of any information, apparatus, product, or process disclosed, or represents that its use would not infringe privately owned rights. Reference herein to any specific commercial product, process, or service by trade name, trademark, manufacturer, or otherwise does not necessarily constitute or imply its endorsement, recommendation, or favoring by the United States Government or any agency thereof. The views and opinions of authors expressed herein do not necessarily state or reflect those of the United States Government or any agency thereof. 


\section{DISCLAIMER}

Portions of this document may be illegible in electronic image products. Images are produced from the best available original document. 



\section{ABSTRACT}

This report describes the materials properties correlations and computer subcodes (MATPRO) developed for use with various light water reactor (LWR) accident analysis computer programs. Formulation of the materials properties are generally semiempirical in nature. The materials properties subcodes contained in this document are for uranium, uranium dioxide, mixed uranium-plutonium dioxide fuel, zircaloy cladding, zirconium dioxide, stainless steel, stainless steel oxide, silver-indium-cadmium alloy, boron carbide, Inconel 718, zirconium-uranium-oxygen melts, and fill gas mixtures.

FIN A6360--SCDAP/RELAP5 


\section{EXECUTIVE SUMMARY}

It is desirable that a common set of materials properties be used by the various computer codes that calculate the steady-state, transient, and severe fuel damage responses of nuclear reactor cores. Though most of the fuel component and corium properties used by these codes are based on the common set of materials properties descriptions contained in the MATPRO package of subcodes, some programmers have written materials properties routines for use in their codes based on the same or similar correlations used in MATPRO. This duplication of materials properties routines or variance from the common source came about because material property subcodes added to the MATPRO library since the publication of MATPRO-11 Revision 2 in 1981 were not documented in a single source, but in a series of informal reports and letters to requestors for specific property routines. This document contains descriptions of all materials properties subcodes currently available for use in doing U.S. Nuclear Regulatory Commission (NRC)-sponsored light water reactor (LWR) analysis.

This document contains descriptions of the materials properties subcodes for the fuel (uranium, uranium dioxide, and uranium-plutonium dioxide mixture), cladding (zircaloy, zirconium dioxide, stainless steel, and stainless steel oxide), absorber materials (silver-indium-cadmium alloy and boron carbide), Inconel 718 , zirconium-uranium-oxygen-iron compounds, gap gases, and some fission product vapor species. This MATPRO document also contains descriptions of the reaction and solution rate models that are needed to analyze a reactor accident. 


\section{ACKNOWLEDGMENT}

The editor and authors would like to thank Nadine Wade, of EG\&G Idaho, Inc., for her careful review and organization of this document. Thanks is also given to the U.S. Nuclear Regulatory Commission monitor, Dr. J. T. Han, who encouraged and supported this effort, and to monitors who supported previous versions of the MATPRO package: M. L. Picklesimer, G. P. Marino, T. J. Walker, R. 0. Meyer, and R. N. Oehlberg. 


\section{CONTENTS}

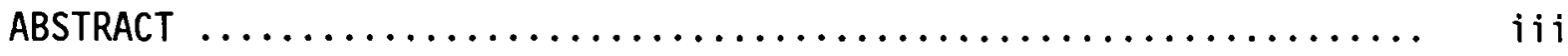

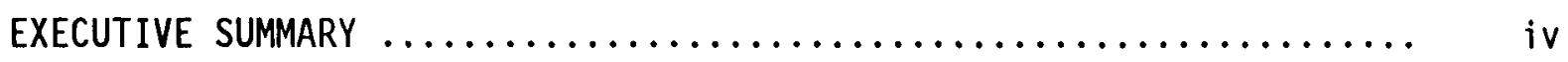

ACKNOWLEDGMENTS $\ldots \ldots \ldots \ldots \ldots \ldots \ldots \ldots \ldots \ldots \ldots \ldots \ldots \ldots \ldots \ldots \ldots \ldots \ldots \ldots \ldots$

1. INTRODUCTION ...................................... 1-1

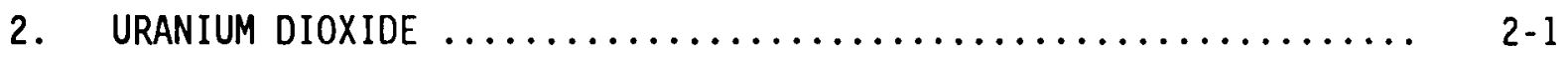

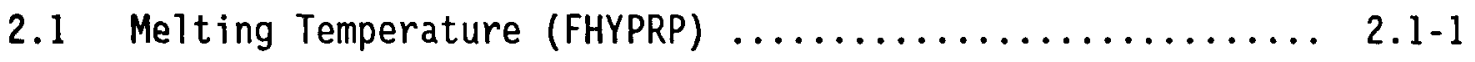

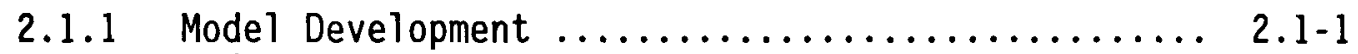

2.1.2 References ........................... 2.1-2

2.2 Specific Heat Capacity and Enthalpy (FCP, FENTHL) ....... 2.2-1

2.2.1 Summary $\ldots \ldots \ldots \ldots \ldots \ldots \ldots \ldots \ldots \ldots \ldots \ldots \ldots \ldots \ldots \ldots, 2.2-1$

2.2.2 Literature Review ...................... 2.2-4

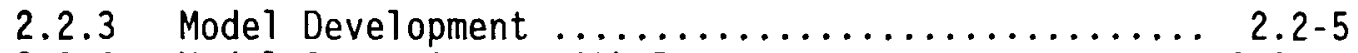

2.2.4 Model Comparisons with Data ................. 2.2-14

2.2.5 Model Uncertainty ........................ 2.2-17

2.2.6 References ............................. 2.2-19

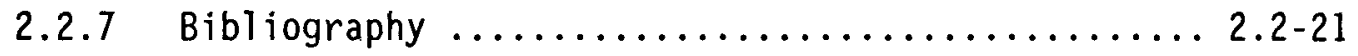

2.3 Thermal Conductivity (FTHCON) $\ldots \ldots \ldots \ldots \ldots \ldots \ldots \ldots \ldots \ldots \ldots \ldots .3 .1$

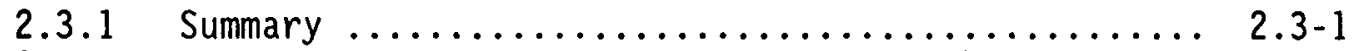

2.3.2 Literature Review: Theory and Available Data .... 2.3-4

2.3.3 Model Development ....................... 2.3-24

2.3.4 Model Uncertainty .......................... 2.3

2.3.5 References ............................. 2.36

2.4 Emissivity (FEMISS) $\ldots \ldots \ldots \ldots \ldots \ldots \ldots \ldots \ldots \ldots \ldots \ldots \ldots \ldots \ldots \ldots \ldots, 2.4$

2.4.1 Summary $\ldots \ldots \ldots \ldots \ldots \ldots \ldots \ldots \ldots \ldots \ldots \ldots \ldots \ldots \ldots, 2.4-1$

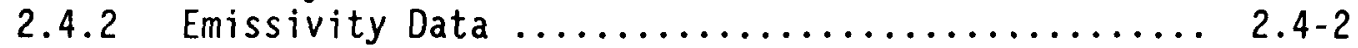

2.4.3 Model Development $\ldots \ldots \ldots \ldots \ldots \ldots \ldots \ldots \ldots \ldots \ldots . . .2 .4-3$

2.4.4 References .......................... 2.4-6

2.5 Thermal Expansion and Density (FTHEXP, FDEN) $\ldots \ldots \ldots \ldots .2 .5-1$

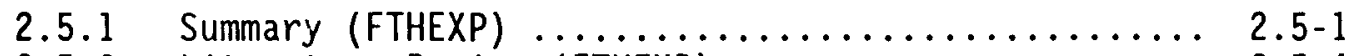

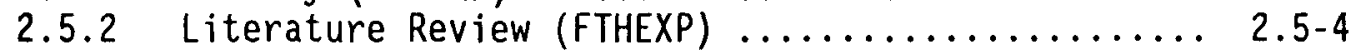

2.5.3 Model Development (FTHEXP) ................. 2.5-5

2.5.4 Mode1-Data Comparison and Uncertainty (FTHEXP) ... 2.5-8

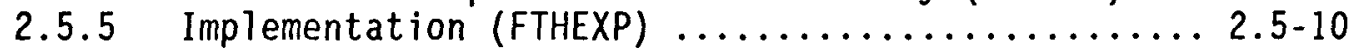

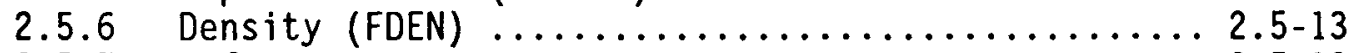

2.5.7 References .............................. 2.5 
2.6 Elastic Moduli (FELMOD, FPOIR) $\ldots \ldots \ldots \ldots \ldots \ldots \ldots \ldots \ldots \ldots \ldots \ldots .6 .1$

2.6.1 Summary (FELMOD) $\ldots \ldots \ldots \ldots \ldots \ldots \ldots \ldots \ldots, 2.6-1$

2.6.2 Survey of Available Data (FELMOD) .............. 2.6-3

2.6.3 Model Development (FELMOD) $\ldots \ldots \ldots \ldots \ldots \ldots \ldots \ldots .2 .6 .9$

2.6.4 Model Uncertainty (FELMOD) $\ldots \ldots \ldots \ldots \ldots \ldots \ldots \ldots .2 .6-14$

2.6.5 Poisson's Ratio (FPOIR) $\ldots \ldots \ldots \ldots \ldots \ldots \ldots \ldots \ldots .6 \ldots \ldots .6 .17$

2.6.6 References ............................. 2.6-18

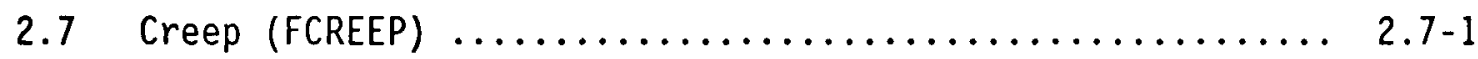

2.7.1 Summary $\ldots \ldots \ldots \ldots \ldots \ldots \ldots \ldots \ldots \ldots \ldots \ldots . \ldots \ldots, 2.7-1$

2.7.2 Model Development ........................... $2.7-5$

2.7.3 Evaluation of Constants and Data Comparison ...... 2.7-11

2.7.4 References ................................ 2.7-17

2.8 Densification (FUDENS) $\ldots \ldots \ldots \ldots \ldots \ldots \ldots \ldots \ldots \ldots \ldots \ldots \ldots \ldots \ldots, 2.8-1$

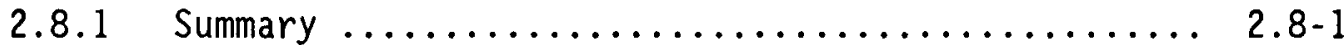

2.8.2 Uranium Dioxide and Mixed-0xide Densification

Data and Models ........................... 2.8 2.3

2.8.3 Model Development ....................... 2.8-14

2.8.4 References ............................ 2.8.

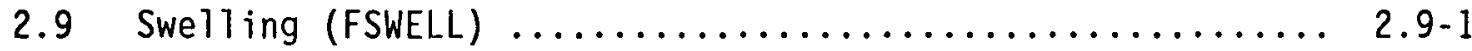

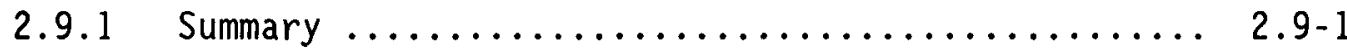

2.9.2 Solid Fission Product Swelling Model ........... 2.9-2

2.9.3 Fission Gas Swelling Model ................. 2.9-4

2.9.4 References ............................ 2.9-8

2.10 Pressure Sintering (FHOTPS) $\ldots \ldots \ldots \ldots \ldots \ldots \ldots \ldots \ldots \ldots \ldots \ldots \ldots \ldots \ldots .1$

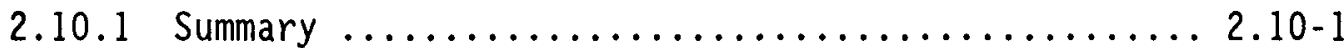

2.10.2 Pressure Sintering Process and Data ............ 2.10-4

2.10.3 Model Development and Uncertainties ............2.10-12

2.10.4 References .............................. $2.10-18$

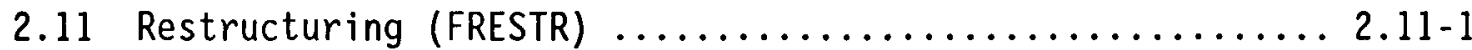

2.11.1 Summary $\ldots \ldots \ldots \ldots \ldots \ldots \ldots \ldots \ldots \ldots \ldots \ldots \ldots, 2.11-1$

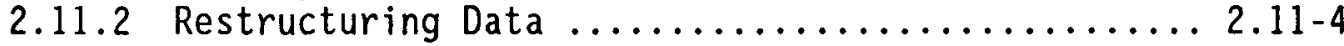

2.11.3 Model Development $\ldots \ldots \ldots \ldots \ldots \ldots \ldots \ldots \ldots \ldots \ldots \ldots \ldots \ldots \ldots, 2.11-8$

2.11.4 References ...............................2.11-14

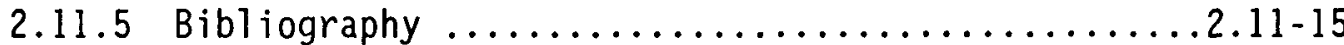

2.12 Fracture Strength (FFRACS) $\ldots \ldots \ldots \ldots \ldots \ldots \ldots \ldots \ldots \ldots \ldots \ldots \ldots \ldots \ldots .12-1$

2.12.1 Summary $\ldots \ldots \ldots \ldots \ldots \ldots \ldots \ldots \ldots \ldots \ldots \ldots \ldots \ldots \ldots \ldots .12-1$

2.12.2 Out-of-Pile Uranium Dioxide Deformation ........ 2.12-2

2.12.3 Uranium Dioxide Fracture Strength Model ........2.12-11

2.12.4 References ............................... 2.11 


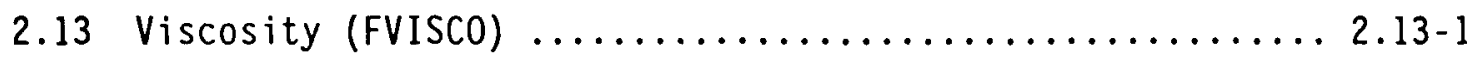

2.13.1 Summary ............................... 2.13-1

2.13.2 Fuel Viscosity Data $\ldots \ldots \ldots \ldots \ldots \ldots \ldots \ldots \ldots \ldots .2 .13-3$

2.13.3 Model Development and Uncertainty ............... 2.13-4

2.13.4 References ..............................2.13-10

2.14 Vapor Pressure (FVAPRS) $\ldots \ldots \ldots \ldots \ldots \ldots \ldots \ldots \ldots \ldots \ldots \ldots \ldots \ldots \ldots \ldots, 14-1$

2.14.1 Summary $\ldots \ldots \ldots \ldots \ldots \ldots \ldots \ldots \ldots \ldots \ldots \ldots \ldots \ldots \ldots \ldots, 2.14-1$

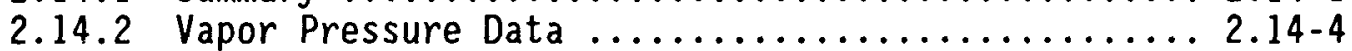

2.14.3 Model Development .........................2.14-19

2.14 .4 References ................................. $14-31$

2.14 .5 Bibliography $\ldots \ldots \ldots \ldots \ldots \ldots \ldots \ldots \ldots \ldots \ldots \ldots \ldots \ldots \ldots \ldots \ldots \ldots, 14-38$

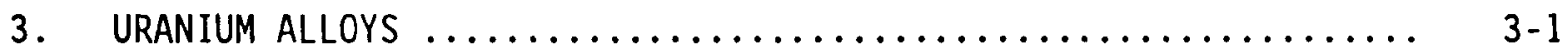

3.1 Specific Heat Capacity and Enthalpy (UCP, UENTHL) ....... 3.1-1

3.1.1 Specific Heat Capacity (UCP) $\ldots \ldots \ldots \ldots \ldots \ldots \ldots . . .1 .1$

3.1 .2 Enthalpy (UENTHL) $\ldots \ldots \ldots \ldots \ldots \ldots \ldots \ldots \ldots \ldots, 3.1-4$

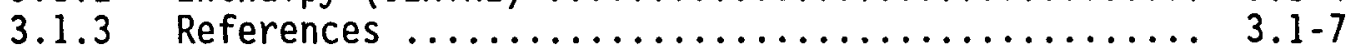

3.2 Thermal Conductivity (UTHCON) $\ldots \ldots \ldots \ldots \ldots \ldots \ldots \ldots \ldots \ldots \ldots .2-1$

3.2.1 Model Development ....................... 3.2-1

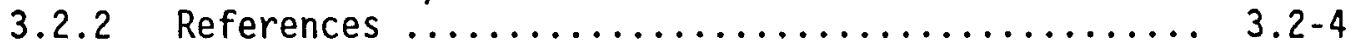

3.3 Thermal Expansion and Density (UTHEXP, UDEN) $\ldots \ldots \ldots \ldots .3 .3-1$

3.3.1 Thermal Expansion (UTHEXP) $\ldots \ldots \ldots \ldots \ldots \ldots \ldots \ldots .3 .3-1$

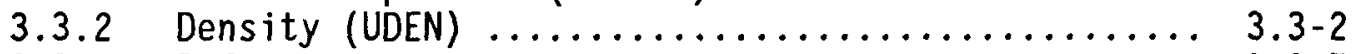

3.3.3 References ............................. 3.3

3.4 Oxidation Parabolic Rate Constant (UOXWTK) ............ 3.4-1

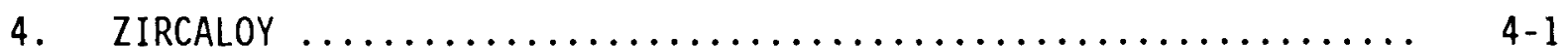

4.1 Melting and Phase Transformation Temperatures (CHYPRP) ... 4.1-1

4.1.1 Model Development ........................ 4.1-1

4.1.2 References .............................. 4.1-6

4.2 Temperature Required to Prevent Hydriding of a Given

Concentration of Hydrogen in Zircaloy (CTSOL) .......... 4.2-1

4.3 Cladding Specific Heat, the Effect of Hydride Solution on Cladding Specific Heat, and Enthalpy (CCP, CHSCP, CENTHL)

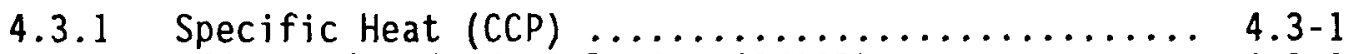

4.3.2 Effect of Hydride Solution (CHSCP) $\ldots \ldots \ldots \ldots \ldots$. $4.3-8$ 
4.3.3 Uncertainties in Specific Heat Predictions ......4.3-11

4.3.4 Zircaloy Enthalpy (CENTHL) ..............4.3-13

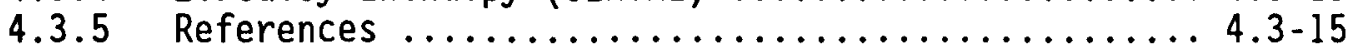

4.4 Thermal Conductivity (CTHCON) $\ldots \ldots \ldots \ldots \ldots \ldots \ldots \ldots \ldots \ldots .4 .4$

4.4.1 Summary .......................... 4.4-1

4.4.2 Literature Review ...................... 4.4-2

4.4.3 Model Development .................... 4.4-4

4.4.4 References .......................4.4-10

4.5 Thermal Expansion and its Relation to Texture

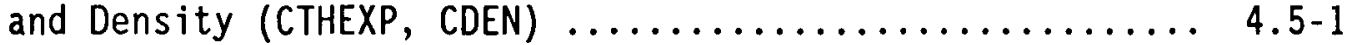

4.5.1 Summary (CTHEXP) ................... 4.5-1

4.5.2 Literature Review (CTHEXP) ............... 4.5-4

4.5.3 Model Development (CTHEXP) ............... 4.5-11

4.5.4 Model-Data Comparison and Uncertainty (CTHEXP) ... 4.5-22

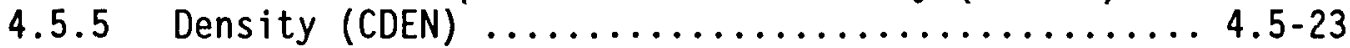

4.5.6 References ......................... 4. 5-25

4.6 Elastic Moduli (CELMOD, CSHEAR, CELAST) $\ldots \ldots \ldots \ldots \ldots \ldots$ 4.6-1

4.6 .1 Summary .......................... 4.6.1

4.6.2 Review of Available Data ................. 4.6-6

4.6.3 Model Development ...................... 6 . 14

4.6.4 Comparison of Models and Data Base ............. 4.6-27

4.6.5 Expected Standard Error of the CELMOD and CSHEAR

Codes ............................4.6-30

4.6.6 References ........................ 4.6-32

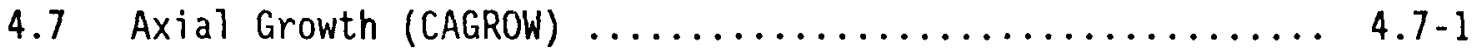

4.7.1 Summary .......................... 4.7-1

4.7.2 Background and Approach ................ 4.7-2

4.7.3 Review of Experimental Data ................ 4.7-4

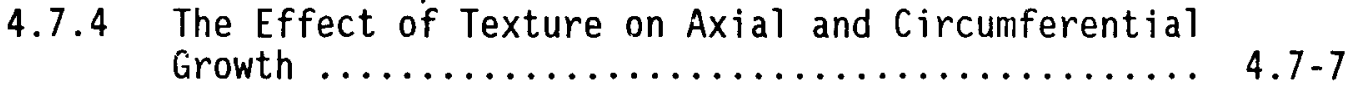

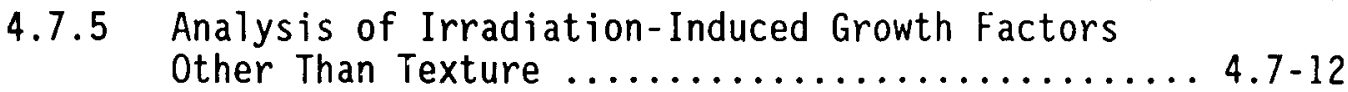

4.7.6 Evaluation of the Model and Its Uncertainty .... 4.7-19

4.7.7 References ........................ 4.7-22

4.8 Creep (CCSTRN, CCSTRS, CABTP, CTP) $\ldots \ldots \ldots \ldots \ldots \ldots \ldots \ldots$ 4.8-1

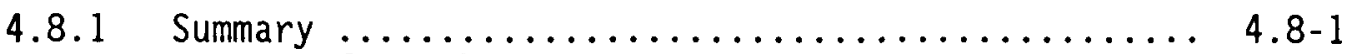

4.8.2 Survey of Available Data ............... 4.8 4 .6

4.8.3 Model Development ..................... 4. 8 -12

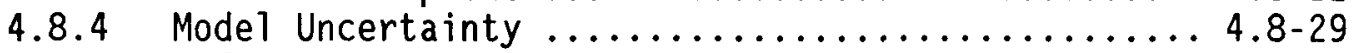

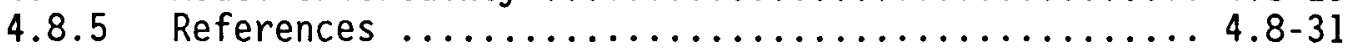

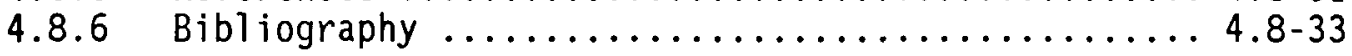


4.9 Plastic Deformation (CSTRES, CSTRAN, CSTRNI, CANISO, CKMN) $\ldots \ldots \ldots \ldots \ldots \ldots \ldots \ldots \ldots \ldots \ldots \ldots \ldots \ldots \ldots \ldots \ldots \ldots \ldots, 4.9-1$

4.9.1 Summary $\ldots \ldots \ldots \ldots \ldots \ldots \ldots \ldots \ldots \ldots \ldots, 4.9 .2$

4.9.2 Available Data ............................. 4.9-13

4.9.3 Model Development ....................... 4.9-18

4.9.4 Comparison to Burst Test Data ................ 4.9-62

4.9.5 Uncertainties ........................... 4.9-68

4.9.6 References ............................. 4.9-68

4.10 Annealing (CANEAL) $\ldots \ldots \ldots \ldots \ldots \ldots \ldots \ldots \ldots \ldots \ldots \ldots \ldots \ldots \ldots .10 .1$

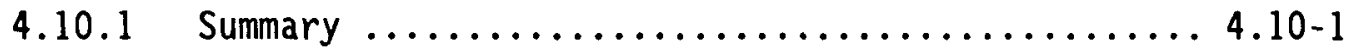

4.10.2 Available Data .......................... 4.10-4

4.10.3 Model Development .......................10-12

4.10.4 Comparison of Annealing Models to Data .........4.10-27

4.10.5 References .............................10-31

4.11 Mechanical Limits and Embrittlement (CMLIMT, CBRTTL) .... 4.11-1

4.11 .1 Summary (CMLIMT) $\ldots \ldots \ldots \ldots \ldots \ldots \ldots \ldots \ldots \ldots \ldots \ldots \ldots \ldots \ldots \ldots .11-1$

4.11.2 Available Data ........................... 4.11-4

4.11.3 Model Development .........................11

4.11.4 Application of the Failure Criterion to Determine

4.11 .5 Summary (CBRTTL)

4.11 .6 Literature Review .............................11-35

4.11.7 Model Development .........................11-37

4.11.8 Model for Fast-Cooled Cladding .................11-39

4.11.9 Model for Slow-Cooled Cladding .................11-43

4.11.10 Model Uncertainties ........................11-46

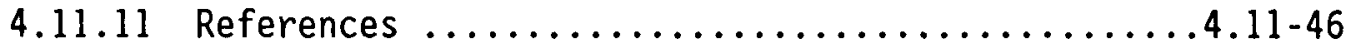

4.12 Cyclic Fatigue (CFATIG) $\ldots \ldots \ldots \ldots \ldots \ldots \ldots \ldots \ldots \ldots \ldots \ldots \ldots \ldots \ldots .12-1$

4.12.1 Summary $\ldots \ldots \ldots \ldots \ldots \ldots \ldots \ldots \ldots \ldots \ldots \ldots \ldots \ldots .12-1$

4.12.2 Basis for High-Cycle Fatigue Material

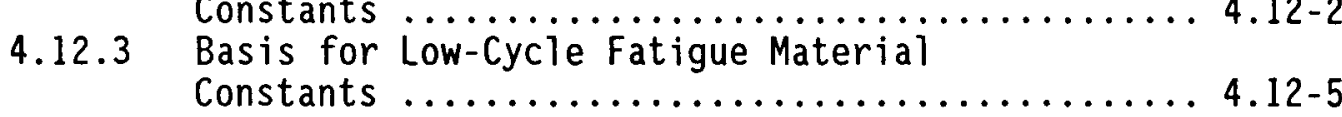

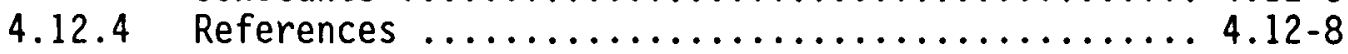

4.13 Col1apse Pressure (CCLAPS) $\ldots \ldots \ldots \ldots \ldots \ldots \ldots \ldots \ldots \ldots \ldots .13-1$

4.13.1 Model Development $\ldots \ldots \ldots \ldots \ldots \ldots \ldots \ldots \ldots \ldots .4 .13-1$

4.13.2 References ............................. 4.13-2

4.14 Meyer Hardness (CMHARD) $\ldots \ldots \ldots \ldots \ldots \ldots \ldots \ldots \ldots \ldots \ldots \ldots \ldots \ldots \ldots \ldots .14$

4.14.1 Model Development ........................ 4.14-1

4.14 .2 References ........................... 4.14-4 


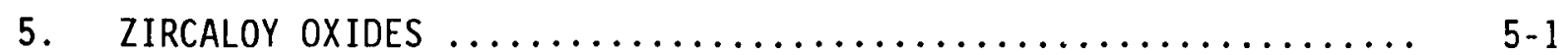

5.1 Me1ting and Phase Transformation Temperatures (ZOPRP) ... 5.1-1

5.1.1 Model Development .................... 5.1-1

5.1.2 References ............................. 5.1-3

5.2 Specific Heat Capacity and Enthalpy (ZOCP, ZONTHL) ..... 5.2-1

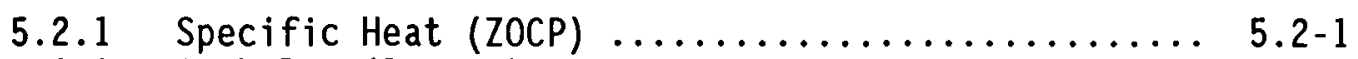

5.2 .2 Enthalpy (ZONTHL) ......................

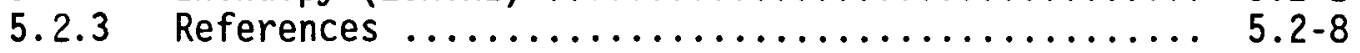

5.3 Thermal Conductivity (ZOTCON) $\ldots \ldots \ldots \ldots \ldots \ldots \ldots \ldots \ldots .3-1$

5.3.1 Model Development ..................... 5.3-1

5.3.2 References .......................... 5.3-9

5.4 Surface Emissivity (ZOEMIS) $\ldots \ldots \ldots \ldots \ldots \ldots \ldots \ldots \ldots \ldots \ldots .4 .1$

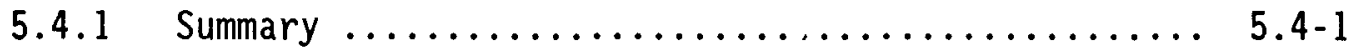

5.4.2 Literature Review .................... 5.4-3

5.4.3 Model Development ................... 5.4-7

5.4 .4 Uncertainty ........................ 5.4 12

5.4 .5 References .......................

5.5 Thermal Expansion and Density (ZOTEXP, ZODEN) $\ldots \ldots \ldots \ldots$ 5.5-1

5.5.1 Thermal Expansion (ZOTEXP) ............... 5.5.1

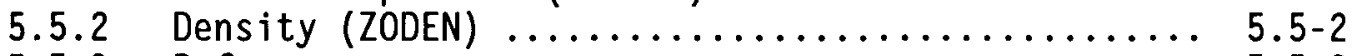

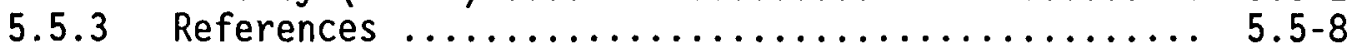

5.6 Elastic Moduli (ZOEMOD, ZOPOIR) ............... 5.6-1

5.6 .1 Young's Modulus (ZOEMOD) ................ 5.6-1

5.6 .2 Poisson's Ratio (ZOPOIR) ................. 5.6-2

5.6 .3 References ......................... 5.6.

5.7 Mechanical Limits and Embrittlement (ZORUP) $\ldots \ldots \ldots \ldots \ldots$ 5.7-1

5.7.1 Model Development ................... 5.7-1

5.7 .2 References ......................... 5.

6. CONTROL ROD CLADDING ........................... $6-1$

6.1 Melting Temperatures (SHYPRP) $\ldots \ldots \ldots \ldots \ldots \ldots \ldots \ldots \ldots .1-1$

6.1 .1 Model Development .................... 6.1-1

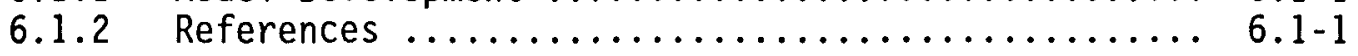

6.2 Specific Heat Capacity and Enthalpy (SCP, SENTHL) ...... 6.2-1 
6.2.1 Model Development ......................... 6.2-1

6.2 .2 References $\ldots \ldots \ldots \ldots \ldots \ldots \ldots \ldots \ldots \ldots \ldots \ldots .6 .2-3$

6.3 Thermal Conductivity (STHCON) $\ldots \ldots \ldots \ldots \ldots \ldots \ldots \ldots \ldots .6 .3$

6.3.1 Model Development $. . . \ldots \ldots \ldots \ldots \ldots \ldots \ldots \ldots .6 .6 .3-1$

6.3 .2 References $\ldots \ldots \ldots \ldots \ldots \ldots \ldots \ldots \ldots \ldots \ldots \ldots, 6.3-2$

6.4 Thermal Expansion and Density (STHEXP, SDEN) $\ldots \ldots \ldots \ldots .6 .4-1$

6.4.1 Model Development ........................ 6.4-1

6.4 .2 References ............................ 6.4-2

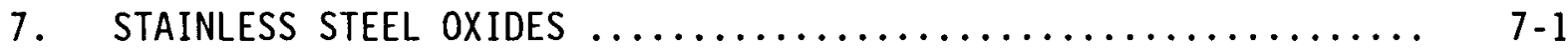

7.1 Specific Heat Capacity and Enthalpy (SOCP, SONTHL) ...... 7.1-1

7.1.1 Specific Heat Capacity (SOCP) ............... 7.1-1

7.1 .2 Enthalpy (SONTHL) ........................ $7.1-3$

7.1 .3 References ............................. 7.1-9

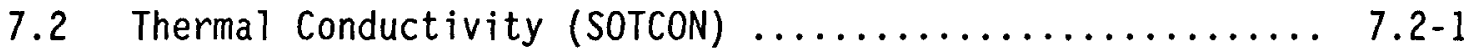

7.2.1 Model Development $\ldots \ldots \ldots \ldots \ldots \ldots \ldots \ldots \ldots \ldots$ 7.2-1

7.2 .2 References $\ldots \ldots \ldots \ldots \ldots \ldots \ldots \ldots \ldots \ldots \ldots \ldots, 7.2-4$

7.3 Thermal Expansion and Density (SOTHEX, SODEN) ......... 7.3-1

7.3.1 Thermal Expansion (SOTHEX) ................. 7.3-1

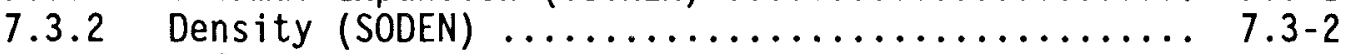

7.3.3 References ............................ $7.3-4$

8. NEUTRON ABSORBERS (SILVER-INDIUM-CADMIUM CONTROL RODS AND

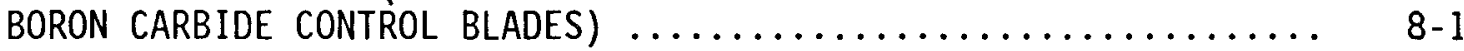

8.1 Melting Temperature (AHYPRP) $\ldots \ldots \ldots \ldots \ldots \ldots \ldots \ldots \ldots . \ldots .1$

8.1.1 Model Development $\ldots \ldots \ldots \ldots \ldots \ldots \ldots \ldots \ldots \ldots . .6 .1-1$

8.1.2 References ............................ 8.1-1

8.2 Specific Heat Capacity and Enthalpy (ACP, AENTHL)....... 8.2-1

8.2.1 Specific Heat Capacity of Ag-In-Cd (ACP) ........ 8.2-1

8.2.2 Specific Heat Capacity of Boron Carbide (ACP) ... 8.2-2

8.2.3 Enthalpy of Ag-In-Cd (AENTHL) ............... 8.2-6

8.2.4 Enthalpy of Boron Carbide (AENTHL) $\ldots \ldots \ldots \ldots \ldots . .28 .2-6$

8.2 .5 References $\ldots \ldots \ldots \ldots \ldots \ldots \ldots \ldots \ldots \ldots \ldots \ldots . \ldots \ldots . \ldots .2-6$

8.3 Thermal Conductivity (ATHCON) $\ldots \ldots \ldots \ldots \ldots \ldots \ldots \ldots \ldots \ldots .3 .1$

8.3.1 Thermal Conductivity of Ag-In-Cd ............ 8.3-1

8.3.2 Thermal Conductivity of Boron Carbide ........... 8.3-2

8.3.3 References ............................... 8.3-7 
8.4 Thermat Expansion and Density (ATHEXP, ADEN) $\ldots \ldots \ldots \ldots$ 8.4-1

8.4.1 Thermal Expansion Strain of Ag-In-Cd ......... 8.4-1

8.4.2 Thermal Expansion Strain of Boron Carbide ........ 8.4-2

8.4.3 Density Calculations for Ag-In-Cd and Boron

Carbide ............................... 8.4-2

8.4.4 References ........................... 8.4-5

8.5 Surface Tension (ASTEN) $\ldots \ldots \ldots \ldots \ldots \ldots \ldots \ldots \ldots \ldots \ldots \ldots \ldots .5 .1$

8.5.1 Model Development ..................... 8.5-1

8.5.2 References .............................. 8.5

8.6 Viscosity (AVISC) $\ldots \ldots \ldots \ldots \ldots \ldots \ldots \ldots \ldots \ldots \ldots \ldots \ldots .6 .6 .1$

8.6.1 Viscosity of Ag-In-Cd .................. 8.6-1

8.6.2 Viscosity of Boron Carbide ................. 8.6-2

8.6.3 References ........................... 8.6-4

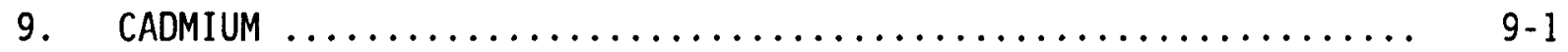

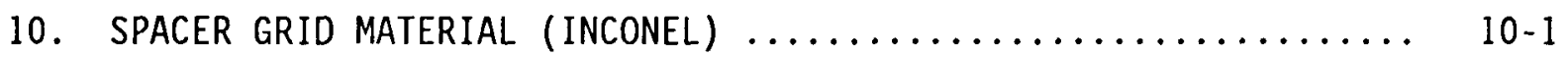

10.1 Melting Temperature (HPROP) $\ldots \ldots \ldots \ldots \ldots \ldots \ldots \ldots \ldots, 10 \ldots \ldots \ldots \ldots$

10.2 References ................................... 10-1

11. CORE COMPONENTS (ZIRCONIUM, URANIUM, ZIRCONIUM DIOXIDE, URANIUM DIOXIDE, STAINLESS STEEL, STAINLESS STEEL OXIDE, AND AG-IN-CD AND/OR BORON CARBIDE)

11.1 Zirconium-Uranium-0xygen Compound Melting, Solution, and Precipitation (PSOL, PLIQ, ZUSOLV, COEF) $\ldots \ldots \ldots \ldots \ldots \ldots \ldots \ldots .11 .1$

11.1.1 Introduction .............................. 11.1

11.1.2 Data for the $2 r-U-0$ System................... 11.2

11.1.3 Model Development .........................11.1-21

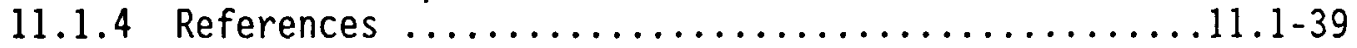

11.2 Specific Heat Capacity and Enthalpy (ZUCP, ZUNTHL,

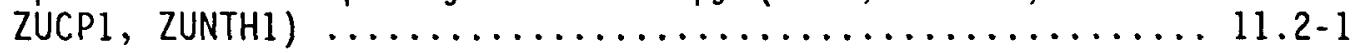

11.2.1 Zirconium-Uranium-0xygen Compounds ............11.2-1

11.2.2 Core Component Compounds .................... 11.2-9

11.2 .3 References ................................

11.3 Thermal Conductivity (ZUTCON, ZUTCO1) ..............11.3-1

11.3.1 Zirconium-Uranium-0xygen Compounds ...........11.3-1

11.3.2 Core Component Compounds ..................... 11.3-9

11.3 .3 References .............................. 
11.4 Therma1 Expansion and Density (ZUTEXP, ZUDEN, ZUTEX1, ZUDEN1)

11.4.1 Zirconium-Uranium-0xygen Compounds ........... 11.4-1

11.4 .2 Core Component Compounds .................... 11.4-5

11.4.3 References ...............................11.4

11.5 Zirconium-Uranium-0xygen Compounds Coefficient of

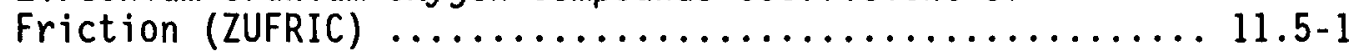

11.6 Zirconium-Uranium-0xygen Compounds Interfacial Surface

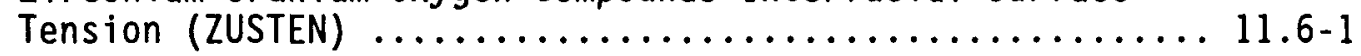

11.7 Zirconium-Uranium-0xygen Compounds Viscosity (ZUVISC) .... 11.7-1

11.7.1 Model Development ...................... 11.7-1

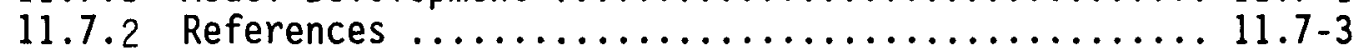

11.8 Heat of Solution of Solid Uranium Dioxide by

Zirconium-Uranium-Oxygen Compounds (ZUSOLN) $\ldots \ldots \ldots \ldots .11 .8-1$

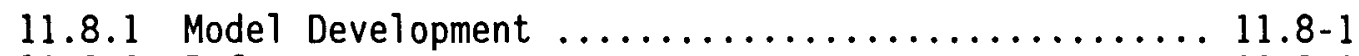

11.8 .2 References $\ldots \ldots \ldots \ldots \ldots \ldots \ldots \ldots \ldots \ldots \ldots \ldots \ldots \ldots \ldots \ldots \ldots \ldots \ldots \ldots \ldots, 11.8-2$

11.9 Heat of Fusion of Zirconium-Uranium-0xygen Compounds

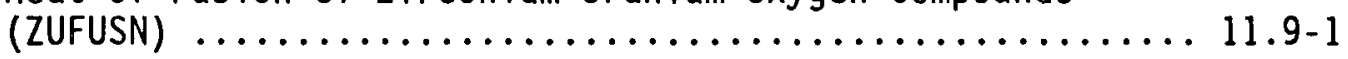

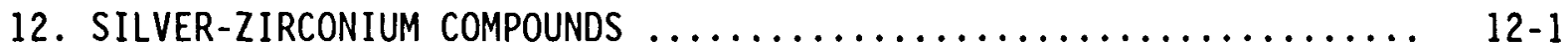

12.1 Solubility of Zircaloy Cladding in Ag-In-Cd Absorber

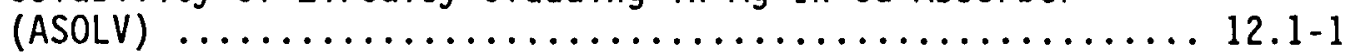

12.1.1 Summary $\ldots \ldots \ldots \ldots \ldots \ldots \ldots \ldots \ldots \ldots \ldots \ldots \ldots \ldots \ldots \ldots .12 .1-1$

12.1.2 Solubility Data for Ag-In-Cd on Zircaloy ......... 12.1-2

12.1.3 Model Development ........................... 12.1-5

12.1.4 References ............................. 12.1-8

13. NONCONDENSABLE GASES--HELIUM, ARGON, KRYPTON, XENON, HYDROGEN,

NITROGEN, OXYGEN, CARBON MONOXIDE, CARBON DIOXIDE,

WATER MIXTURES

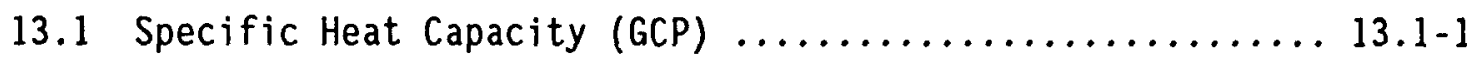

13.1.1 Mode1 Development ....................... 13.1-1

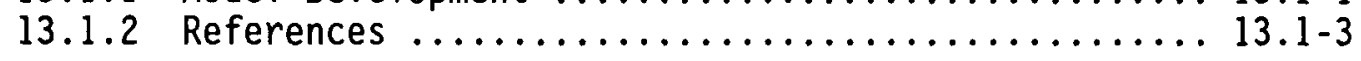

13.2 Thermal Conductivity, Gas Conductance, and Jump

Distance (GASCON, GTHCON, GJUMP) ................... 13.2-1

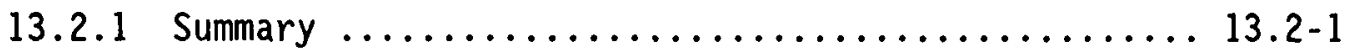

13.2.2 Thermal Conductivity and Accommodation

Coefficient Data .......................... 13.2-7 
13.2.3 Model Development and Uncertainty Estimates ......13.2-15

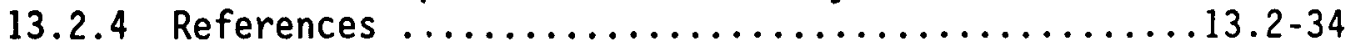

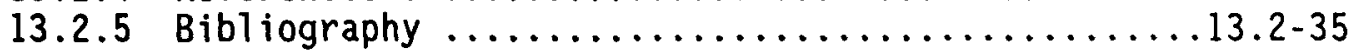

13.3 Effective Emissivity (GMISS) $\ldots \ldots \ldots \ldots \ldots \ldots \ldots \ldots \ldots \ldots \ldots \ldots \ldots \ldots .1$

13.3.1 Model Development ......................... 13.3-1

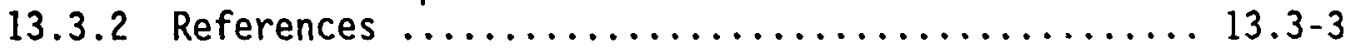

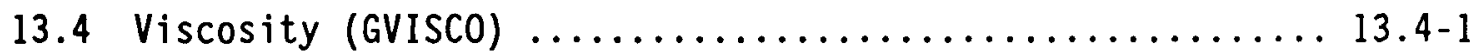

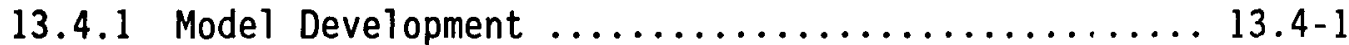

13.4 .2 References $\ldots \ldots \ldots \ldots \ldots \ldots \ldots \ldots \ldots \ldots \ldots \ldots, 13.4-4$

13.5 Mean Free Path (GMFP) $\ldots \ldots \ldots \ldots \ldots \ldots \ldots \ldots \ldots \ldots \ldots \ldots \ldots \ldots \ldots \ldots \ldots .13 .1$

13.5.1 Model Development ........................ 13.5-1

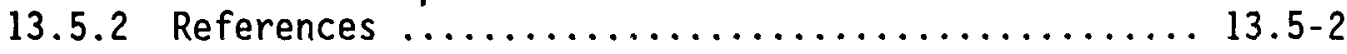

14. GASES--I/I2, CESIUM IODIDE, CESIUM HYDROXIDE, TELLURIUM, CADMIUM, SILVER, H2TE, HI, TIN, TIN TELLURIDE, WATER,

ZIRCONIUM DIOXIDE, URANIUM DIOXIDE, $\mathrm{C} / \mathrm{C}_{2} / \ldots \mathrm{C}_{6}$,

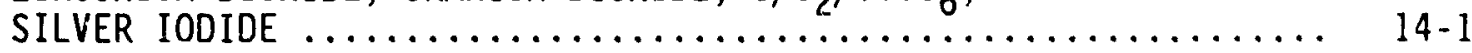

14.1 Equilibrium Vapor Concentrations (GCEQ) .............. 14.1-1

14.1.1 Introduction ............................ 14.1-1

14.1.2 Summary of Equations Used to Calculate Equilibrium Vapor Pressures and Concentrations ..............14.1-2

14.1.3 Available Data and Correlations .............. 14.1-7

14.1.4 Model Development .........................14.1-23

14.1 .5 Results .................................14.144

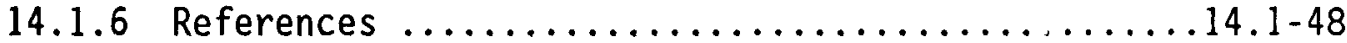

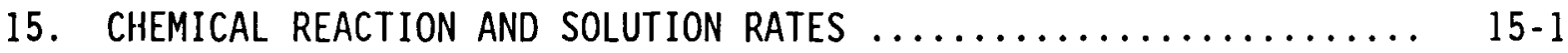

15.1 Fuel 0xidation (FOXY, FOXYK) $\ldots \ldots \ldots \ldots \ldots \ldots \ldots \ldots \ldots \ldots \ldots \ldots \ldots \ldots \ldots .1$

15.1 .1 Summary $\ldots \ldots \ldots \ldots \ldots \ldots \ldots \ldots \ldots \ldots \ldots \ldots \ldots, 15.1-1$

15.1.2 Review of Literature $\ldots \ldots \ldots \ldots \ldots \ldots \ldots \ldots \ldots \ldots, 15.1-2$

15.1.3 Model Development ....................... 15.1-3

15.1.4 Description of the FOXY and FOXYK Subcodes ....... 15.1-6

15.1.5 References ..............................15.1-10

15.2 Zircaloy 0xidation in water and Steam (CORROS, COBILD,

COXIDE, COXWTK, COXTHK) .......................... 15.2-1

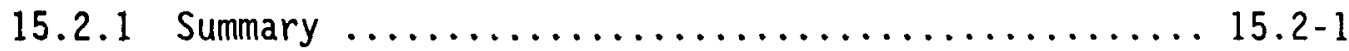

15.2.2 Zircaloy Dxidation Literature and Data $\ldots \ldots \ldots \ldots .15 .2-12$

15.2.3 Model Development ........................15.2-15

15.2.4 Description of the CORROS, COBILD, COXJDE, COXWTK, and COXTHK Subcodes ........................... 15.2-40 
15.2.5 References .............................. 15.2-43

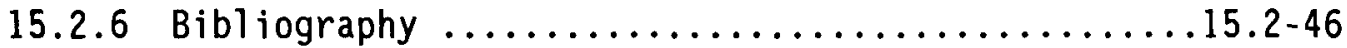

15.3 Cladding Hydrogen Uptake (CHUPTK) $\ldots \ldots \ldots \ldots \ldots \ldots \ldots \ldots . . .15 .3-1$

15.3.1 Summary $\ldots \ldots \ldots \ldots \ldots \ldots \ldots \ldots \ldots \ldots \ldots \ldots \ldots \ldots \ldots \ldots \ldots . .15 .3-1$

15.3.2 Background and Approach .................... 15.3-4

15.3.3 Out-of-Pile Basis for the Model ............. 15.3-5

15.3.4 Generalization to an In-Pile Model ............ 15.3-8

15.3.5 References ..............................15.3-10

15.4 Stainless Steel Oxidation in Steam (SOXIDE, SOXWGN,

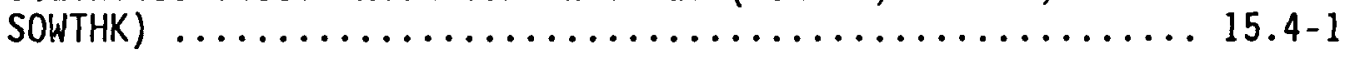

15.4.1 Model Development $\ldots \ldots \ldots \ldots \ldots \ldots \ldots \ldots \ldots \ldots \ldots$ 15.4-1

15.4 .2 References $\ldots \ldots \ldots \ldots \ldots \ldots \ldots \ldots \ldots \ldots \ldots \ldots \ldots \ldots \ldots, 15.4-5$

15.5 Rate of Dissolution of $\mathrm{UO}_{2}$ in $\mathrm{Zr}-\mathrm{U}-\mathrm{O}$ (DISUO2, U02DIS,

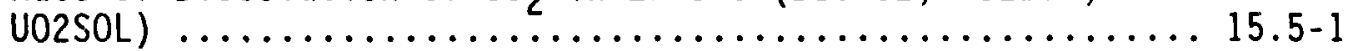

15.5.1 Introduction $\ldots \ldots \ldots \ldots \ldots \ldots \ldots \ldots \ldots \ldots \ldots \ldots \ldots \ldots .15 .5-1$

15.5.2 Data for the U-Zr-O System ............... 15.5-2

15.5.3 Model Development ........................ 15.5-9

15.5.4 Uranium Dioxide Dissolution Kinetics ...........15.5-15

15.5.5 References ................................

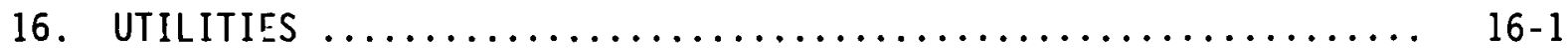

16.1 Linear Interpolation (POLATE, POL8) $\ldots \ldots \ldots \ldots \ldots \ldots \ldots .16 .1$

16.2 Texture Factors (CTXTUR) $\ldots \ldots \ldots \ldots \ldots \ldots \ldots \ldots \ldots \ldots \ldots \ldots \ldots \ldots .2-1$

16.2.1 Model Description ......................... 16.2-1

16.2.2 References $. . . \ldots \ldots \ldots \ldots \ldots \ldots \ldots \ldots \ldots \ldots, 16.2-8$

16.3 Collected Heats of Fusion (QFUSON) $\ldots \ldots \ldots \ldots \ldots \ldots \ldots \ldots . .16 .3-1$

16.3.1 Model Development ......................... 16.3-1

16.3 .2 References $\ldots \ldots \ldots \ldots \ldots \ldots \ldots \ldots \ldots \ldots \ldots \ldots .16 .3-1$

16.4 Mass Fraction-Mole Fraction Conversion (PMOLE, PMASS) ... 16.4-1

16.5 Integral of the Reciprocal of Thermal Conductivity

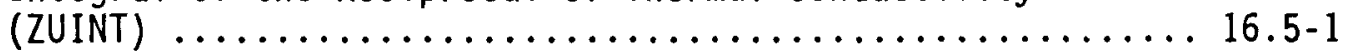

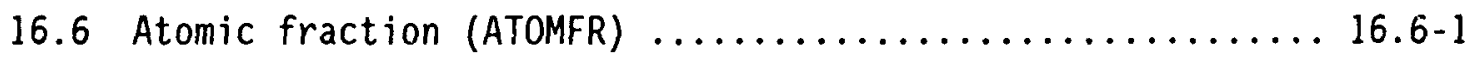

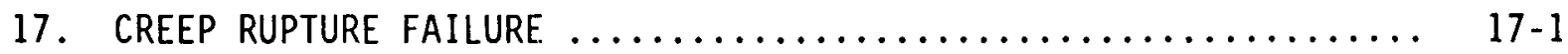


17.1 Rupture Time and the Creep Damage Term Calculations

(RUPTUR, TRUPT, CALTAV) ...........................17.1

17.1.1 Mode1 Description ......................... 17.1-1

17.1.2 Mode1 Development ......................... 17.1-6

17.1.3 References .............................17.1-12

FIGURES

2.2-1. Specific heat capacity as a function of temperature and

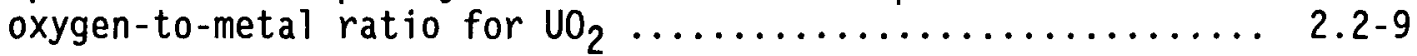

2.2-2. Specific heat capacity as a function of temperature and oxygen-to-metal ratio for $\left.\mathrm{U}_{0.8} \mathrm{Pu}_{0.2}\right)_{2+x} \ldots \ldots \ldots \ldots \ldots \ldots \ldots \ldots \ldots \ldots \ldots .2-10$

2.2-3. Enthalpy of $\mathrm{UO}_{2}$ as a function of temperature to $4000 \mathrm{~K} \ldots$ 2.2-13

2.2-4. Specific heat capacity of $\mathrm{UO}_{2}$ from three experimenters compared with the FCP correlation (solid line) for $\mathrm{VO}_{2} \ldots \ldots$ 2.2-15

2.2-5. Specific heat capacity of $\mathrm{PuO}_{2}$ from Kruger and Savage compared with the FCP correlation (solid line) for $\mathrm{PuO}_{2} \ldots .2 .2-16$

2.2-6. Specific heat capacity of $\mathrm{U}_{0} 8_{\mathrm{Pu}_{0}} \mathrm{O}_{2}$ from three experimenters compared with the FCF correlation (solid line)

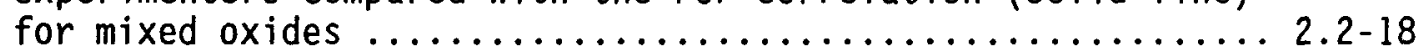

2.3-1. Model prediction for thermal conductivity of $0.99 \% \mathrm{TD}_{2}$ compared to data from specimens with densities in the range $0.985 \%$ to $0.995 \%$ TD ................................... 2.32

2.3-2. Model prediction for thermal conductivity of $0.98 \% \mathrm{TD}_{2}$ compared to data from specimens with densities in the range $0.975 \%$ to $0.985 \%$ TD ................................... 2.33

2.3-3. Model prediction for thermal conductivity of $0.96 \% \mathrm{TD}_{2}$ compared to data from specimens with densities in the range $0.955 \%$ to $0.965 \%$ TD $\ldots \ldots \ldots \ldots \ldots \ldots \ldots \ldots \ldots \ldots \ldots \ldots \ldots \ldots \ldots \ldots \ldots \ldots . .3-34$

2.3-4. Model prediction for thermal conductivity of $0.95 \% \mathrm{TD}_{2}$ compared to data from specimens with densities in the range $0.945 \%$ to $0.955 \%$ TD .................................... 2.35

2.4-1. Emissivity data and corresponding FEMISS predictions $\ldots \ldots \ldots$ 2.4-5

2.5-1. Correlation for the thermal expansion strain of $\mathrm{UO}_{2}$ compared with its data base

2.5-2. Correlation for the thermal expansion strain of $\mathrm{PuO}_{2}$ compared with its data base 
2.5-3. Comparisons of the $\mathrm{UO}_{2}, \mathrm{PuO}_{2}$, and $\left(\mathrm{U}_{0.8}, \mathrm{Pu}_{0.2}\right) \mathrm{O}_{2}$

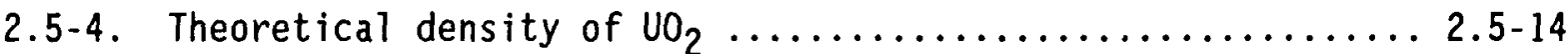

2.6-1. Young's modulus for stoichiometric $\mathrm{UO}_{2}$ fuel at several temperatures and fractions of theoretical density ......... 2.6-5

2.6-2. Young's modulus for $(U, P u) O_{2}$ with various oxygen-to-metal ratios......................................... 2.6-6

2.6-3. Young's modulus data and least-squares linear fit for stoichiometric $\mathrm{UO}_{2}$ fuel at room temperature and several different densities

2.6-4. Ratio of Young's modulus for stoichiometric and nonstoichiometric fuels measured at room temperature compared to values predicted by de Novion's correlation .... 2.6-12

2.6-5. Poisson's ratio as a function of temperature $\ldots \ldots \ldots \ldots \ldots 2.6-19$

2.7-1. Comparison of unirradiated $\mathrm{UO}_{2}$ experimental data with corresponding calculated values from FCREEP ............. 2.7-13

2.7-2. Comparison of irradiated $\mathrm{UO}_{2}$ experimental data with corresponding calculated vaTues from FCREEP ............. 2.7-14

2.7-3. Comparison of (U,Pu) $\mathrm{O}_{2}$ experimental data with corresponding calculated values from FCREEP ............. 2.7-16

2.7-4. Comparison of $\mathrm{UO}_{2}$ strain data of Rod $3 \mathrm{C}$ with corresponding calculated values from FCREEP ............ 2.7-18

2.7-5. Comparison of $\mathrm{UO}_{2}$ strain data of Capsule 2 with corresponding calculated values from FCREEP

2.8-1. The effect of burnup and fission rate on the fuel density

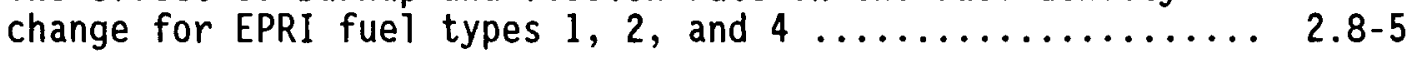

2.8-2. Change in fuel stack length of Halden fuel as a function of

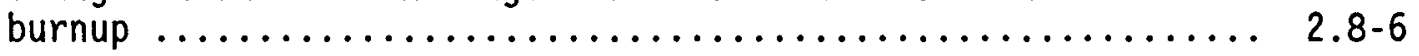

2.8-3. Fuel stack length changes for $92 \% \mathrm{TD} \mathrm{UO}_{2}$ processed by different techniques

2.8-4. Graphical solution of Rolstad's model, where TD is percent of theoretical density, TS is sintering temperature ( $\mathrm{C}$ ), and

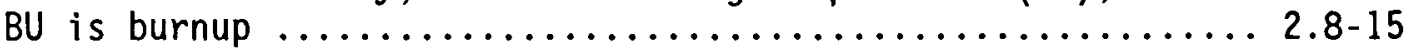

2.8-5. FUDENS calculations using EPRI fuel fabrication parameters and resintering values correlated with experimental EPRI

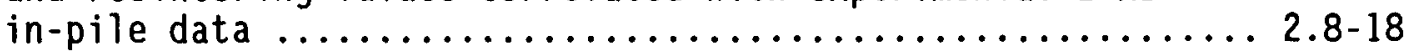

2.9-1. Unrestrained fission gas swelling $\ldots \ldots \ldots \ldots \ldots \ldots \ldots \ldots .2 .9 .6$ 
2.9-2. Fuel volume changes calculated by FSWELL compared with experimental fuel swelling data $\ldots \ldots \ldots \ldots \ldots \ldots \ldots \ldots . . . . .2 .9 .7$

2.10-1. Urania pressure sintering rates calculated using the FHOTPS model compared with data ........................2.10-14

2.10-2. Mixed-oxide pressure sintering rates calculated using the FHOTPS model compared with data $\ldots \ldots \ldots \ldots \ldots \ldots \ldots \ldots . . . . .2 .10-16$

2.11-1. Threshold of columnaf grain growth with temperature gradient of $4.0 \times 10^{5} \mathrm{~K} / \mathrm{m} \ldots \ldots \ldots \ldots \ldots \ldots \ldots \ldots \ldots \ldots \ldots \ldots \ldots .11-13$

2.12-1. Comparison of Equation (2.12-5) in the elastic behavior regime with out-of-pile $\mathrm{UO}_{2}$ fracture strength data normalized to $10-\mu \mathrm{m}$ grain size and $95 \%$ TD .............. 2.12-6

2.12-2. Comparison of Equation (2.12-6) in the elastic behavior regime with out-of-pile $\mathrm{UO}_{2}$ fracture strength data normal ized to $10-\mu \mathrm{m}$ grain size and $95 \%$ TD ............... 2.12-8

2.12-3. Least-squares regression fit of $\mathrm{UO}_{2}$ fracture strength in the elastic-plastic regime to out-of-pile data of Cannon et al ........................................ 12-10

2.12-4. Calculated curves showing the predictions of FFRACS as a function of temperature for two fuel densities ...........2.12-12

2.13-1. Uranium dioxide viscosities measured as a function of temperature ..................................... 2.13-7

2.13-2. Data from uranium dioxide samples compared with least-squares fit ................................. 2.13

2.13-3. Viscosities calculated with Equation (5.13-1) (solid line) and upper and lower uncertainty estimates (dashed lines) compared with data $\ldots \ldots \ldots \ldots \ldots \ldots \ldots \ldots \ldots \ldots \ldots \ldots \ldots . . .13-11$

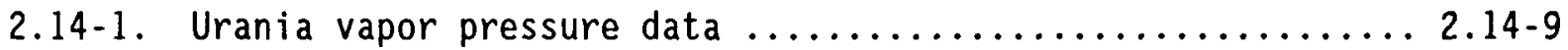

2.14-2. Plutonia vapor pressure data $\ldots \ldots \ldots \ldots \ldots \ldots \ldots \ldots \ldots \ldots \ldots \ldots \ldots \ldots .14$

2.14-3. Mixed-oxide vapor pressure data $\ldots \ldots \ldots \ldots \ldots \ldots \ldots \ldots \ldots \ldots \ldots \ldots \ldots \ldots .14$

2.14-4. FVAPRS calculations (solid line) compared to urania data $\ldots 2.14-25$

2.14-5. FVAPRS calculations (solid line) compared to plutonia data

2.14-6. FVAPRS calculations (solid line) compared to mixed-oxide data. An oxygen-to-metal ratio of 2.0 was used in the FVAPRS calculations $.2 .14-28$

2.14-7. FVAPRS hypostoichiometric oxygen vapor pressure calculations (UOXVAP) compared to the data .............. 2.14-32 
2.14-8. FVAPRS hyperstoichiometric oxygen vapor pressure calculations (DIOVAP) compared to the data

2.14-9. FVAPRS vapor pressure calculations of plutonia (PUOVAP), urania (U02VAP), mixed oxides (VAPMIX), and monatomic oxygen over urania (UOXVAP), using an oxygen-to-metal ratio of $2.0 \ldots \ldots \ldots \ldots \ldots \ldots \ldots \ldots \ldots \ldots \ldots \ldots \ldots \ldots \ldots \ldots \ldots \ldots \ldots \ldots . .14-34$

3.1-1. Specific heat capacity for uranium metal calculated by UCP ....................................... $3.1-5$

3.1-2. Enthalpy change for uranium metal calculated by UENTHL .... 3.1-8

3.2-1. Thermal conductivities for uranium metal calculated by UTHCON ..................................... $3.2-3$

3.3-1. Thermal expansion strain as a function of temperature calculated by UTHEXP

3.3-2. Density calculated by UDEN using the thermal strain

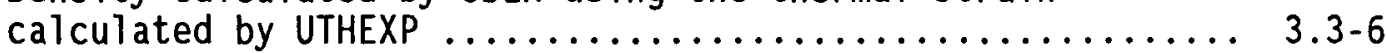

4.1.1 Zircaloy solidus and liquidus temperatures $\ldots \ldots \ldots \ldots \ldots$....

4.3-1. Specific heat of zircaloy as calculated by CCP for alloys

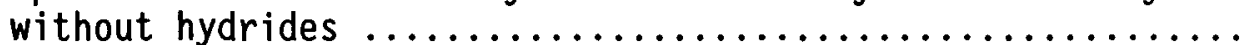

4.3-2. Available data, MATPRO expressions for specific heat, and estimated uncertainty of the MATPRO expression for temperatures from 300 to $1000 \mathrm{~K}$

4.3-3. Available data, MATPRO expressions for specific heat, and estimated uncertainty of the MATPRO expression for temperatures from 1000 to $2000 \mathrm{~K}$.

4.3-4. Data base for MATPRO prediction of the effect of hydride solution on specific heat, Scott's proposed curve for the specific heat of zirconium, and the MATPRO predictions for the effect of 28 and $300 \mathrm{ppm}$ of hydrogen on the specific heat curve

4.3-5. MATPRO predictions for apparent zircaloy specific heat for several hydrogen concentrations compared with the curve measured with as-received zircaloy-2

4.3-6. Derivation of Equation $(4.3-4) \ldots \ldots \ldots \ldots \ldots \ldots \ldots \ldots .3-16$

4.3-7. Zircaloy enthalpy as a function of temperature ......... 4.3-19

4.4-1. Thermal conductivity data, least-squares fit, and the two standard deviation limits

4.5-1. Comparison of CTHEXP prediction with Douglass' data in the axial direction 
4.5-2. Comparison of CTHEXP prediction with Douglass' data in the

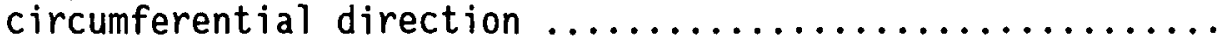

4.5-3. Comparison of CTHEXP prediction with Kearns' model in the axial direction

4.5-4. Comparison of CTHEXP prediction with Kearns' model in the circumferential direction.

4.5-5. Angles and orientation of the unit cell of zircaloy relative to a system of coordinates fixed in the lab frame of reference

4.6-1. Elastic moduli for isotropic material compared to corresponding moduli for typical PWR cladding

4.6-2. Reference directions selected for CELMOD/CSHEAR/CELAST

analysis

4.6-3. Measured values of axial Young's modulus compared to values predicted by the CELAST subcode for several oxygen concentrations and temperatures in the range of 300 to $1500 \mathrm{~K}$

4.6-4. Measured values of circumferential Young's modulus compared to values predicted by the CELAST subcode for several oxygen concentrations and temperatures in the range of 300

to $1500 \mathrm{~K}$

4.6-5. Comparison of the Young's modulus predicted with the CELAST code to the beta-phase zirconium data of Padel and Groff, and Armstrong and Brown

4.7-1. Model predictions and measured values of zircaloy tube axial growth as a function of fast neutron fluence, irradiation temperature, cold work, and texture coefficient, $f_{z} \ldots \ldots$.

4.7-2. The growth of schematic unit cells in a grain ...........

4.7-3 Model predictions and measured values of the growth of zircaloy tubes adjusted to a common texture coefficient of $f_{z}=0.05$

4.7-4. Zircaloy growth versus square root of fast neutron fluence for data adjusted to a common tube texture coefficient of $f_{z}=0.05$ with 1 inear least-squares fits superimposed .... 4.7-14

4.7-5. Zircaloy growth versus square root of fast neutron fluence for data adjusted to a common tube texture coefficient of $f_{z}=0.05$ and to a common temperature of $300^{\circ} \mathrm{C}$ with linear least-squares fits superimposed

4.8-1. Average tangential creep strain as a function of time at $140 \mathrm{MPa}$ and $643 \mathrm{~K}$ reported by Stehle. 
4.8-2. Radial displacement of cladding surface at $200 \mathrm{~h}$ in

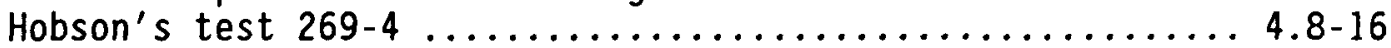

4.8-3. Average tangential creep strain as a function of time at $15.86 \mathrm{MPa}$ differential pressure .................. 4. 20

4.8-4. Average tangential creep strain as a function of time at $14.48 \mathrm{MPa}$ differential pressure .................. 4.8-21

4.8-5. Average tangential creep strain as a function of time from Hobson's in-reactor experiment at 13 - to $13.5-\mathrm{MPa}$ differential pressure and $5.4 \times 10^{17}$ fast neutrons $\left(\mathrm{m}^{2} / \mathrm{s}\right)$

4.8-6. Steady-state creep rates reported by Fidleris for Tests R-6 and $\mathrm{Rx}-14$ compared to model predictions for steady-state creepdown rates derived from these data

4.9-1. Increase of the strain anisotropy constant AlE as a function of radial compressive strain in two tests ............ 4.9-24

4.9-2. Strain rate sensitivity exponent as a function of temperature and strain rate ..................... 4.26

4.9-3. Increase of the strain rate sensitivity exponent at $1173 \mathrm{~K}$ as a function of strain rate based on Chung, Garde, and Kassner's data

4.9-4. Base data, MATPRO prediction, and uncertainty estimate for strain hardening exponent of annealed tubes

4.9-5. Base data, MATPRO prediction, and uncertainty estimate for strain coefficient of annealed, isotropic cladding ....... 4.9-33

4.9-6. Data and least-squares fit to strength coefficients as a function of cold work and irradiation at room temperature . . 4.9-36

4.9-7. Data and analytical functions for strain hardening coefficient as a function of cold work and irradiation at room temperature

4.9-8. Calculated ratios of the strength coefficients of zircaloy, containing oxygen ( $K$ ) and the strength coefficients of as-fabricated zircaloy $\left(K_{0}\right)$ as a function of oxygen concentration for several temperatures

4.9-9. Calculated curve and data showing the rate of change of the zircaloy strength coefficient with oxygen content as a function of temperature

4.9-10. Calculated ratios of the strain hardening exponents of zircaloy containing oxygen $(n)$ and the strain hardening exponents of as-fabricated zircaloy $\left(n_{0}\right)$ as a function of oxygen concentration for several temperatures ............ 
4.9-11. Calculated curve and data showing the rate of change of the zircaloy strain hardening exponent as a function of temperature

4.9-12. Strain rate sensitivity exponent, $m$, data as a function of oxygen concentration from Chung ................. 4.9-57

4.9-13. The ratio $\mathrm{m} / \mathrm{m}_{0}$ as a function of oxygen concentration showing Chung data and the line used to fit these data .... 4.9-58

4.9-14. Zircaloy-oxygen phase diagram, taken from Chung $4.9-59$

4.9-15. Stress as a function of strain at a strain rate of $10^{-3} / \mathrm{s}$ for two oxygen concentrations at $600 \mathrm{~K} \ldots \ldots \ldots \ldots . \ldots . . .64 .61$

4.9-16. Stress as a function of strain at a strain rate of $10^{-3} / \mathrm{s}$ for two oxygen concentrations at $1400 \mathrm{~K} \ldots \ldots \ldots \ldots . \ldots . . \ldots 49.63$

4.9-17. Stress as a function of strain at a strain rate of 0.1 for two oxygen concentrations at $600 \mathrm{~K}$

4.9-18. Measured diametral strain versus MATPRO predictions for two initial values of cold work in tests conducted by

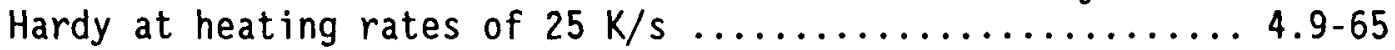

4.9-19. Measured diametral strain versus MATPRO predictions for Chung's test at $1023 \mathrm{~K}$ and $5.2 \mathrm{MPa} \ldots \ldots \ldots \ldots \ldots \ldots \ldots . . \ldots .6 .67$

4.11-1. Local radial strains at burst versus temperature .......4.11-14

4.11-2. Average circumferential strains at failure versus temperature

4.11-3. Local tangential stress at failure versus temperature ....4.11-19

4.11-4. Base data and MATPRO correlation for effect of temperature variation on average circumferential elongation ........4.11-26

4.11-5. Schematic cross sections of cladding at burst .........4.11-28

4.11-6. Typical average circumferential strains predicted by the MATPRO correlations for typical engineering burst stress, true burst stress, and typical strain distributions at three different temperature differences .................11-33

4.11-7. Hobson-Rittenhouse isothermal data for fast-cooled cladding compared with the 0.65 and $0.70 \mathrm{wt} \%$ and the $90 \%$ and $95 \%$ filled criteria

4.11-8. Hobson-Rittenhouse and PBF data for fast-cooled rods compared with the critical fractional wall thickness as calculated from the 0.65 and 0.70 wt\% and the $90 \%$ and $95 \%$ filled criteria 
4.11-9. Comparison of the Argonne data for slow-cooled cladding with the criterion that at least $0.3 \mathrm{~mm}$ of zircaloy with less than 1 wt\% oxygen is required to survive thermal shock ....4.11-45

4.14-1. Values of the CMHARD correlation and its data base ....... 4.14-3

5.1-1. Zircaloy oxide solidus and liquidus temperatures ......... 5.1-4

5.2-1. Zircaloy oxide specific heat capacity as a function of temperature .................................. 5.2-4

5.2-2. Zircaloy oxide enthalpy as a function of temperature $\ldots . \ldots$ 5.2-7

5.3-1. Zircaloy oxide thermal conductivity data and correlations .. 5.3-8

5.3-2. Zircaloy oxide thermal conductivity as a function of

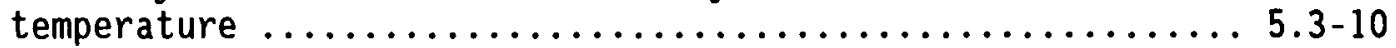

5.4-1. Total hemispherical emittance of zircaloy-4 versus time

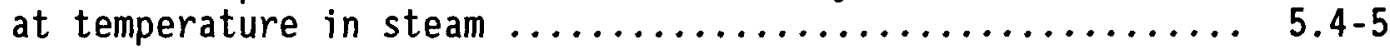

5.4-2. ZOEMIS calculations compared with the data base of the

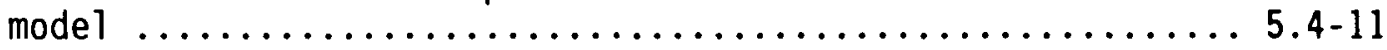

5.4-3. Expected standard errors of emissivity for temperatures

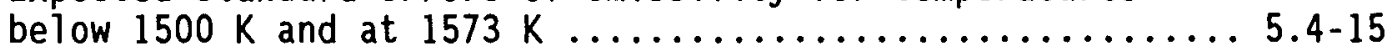

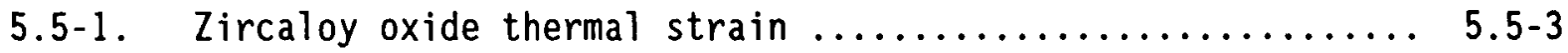

5.5-2. Zircaloy oxide density as a function of temperature $\ldots . \ldots .5 .5-4$

5.5-3. Zircaloy oxide thermal strain data compared to code prediction .................................... 5.5-7

5.6-1. Data and calculated values of Young's modulus for zircaloy oxide ........................................ $5.6-4$

5.7-1. Zircaloy oxide failure stress data and correlations versus

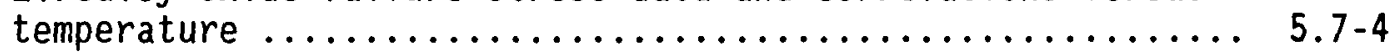

5.7-2. Zircaloy oxide failure stress calculated with the ZORUP

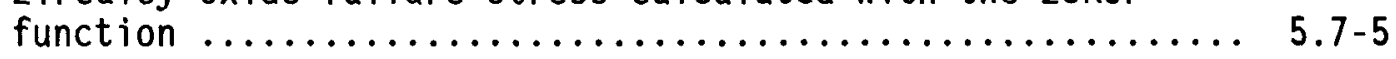

6.2-1. Stainless steel specific heat capacity at constant

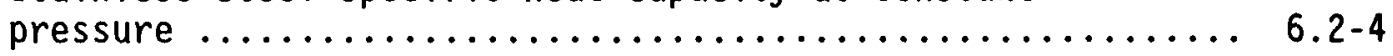

6.2-2. Stainless steel enthalpy change at constant pressure $\ldots \ldots .6 .2-5$

6.3-1. Stainless steel thermal conductivity $\ldots \ldots \ldots \ldots \ldots \ldots .6 .3-3$

6.4-1. Stainless steel thermal expansion strain $\ldots \ldots \ldots \ldots \ldots \ldots 6.4-3$

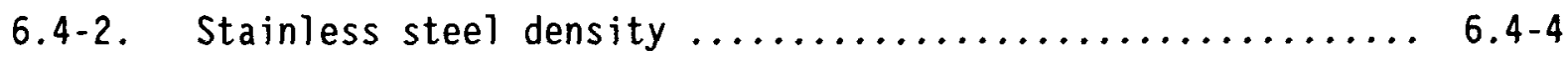


7.1-1. Specific heat capacity for stainless steel oxide calculated by SOCP ..................................... 7.1-4

7.1-2. Enthalpy change for stainless steel oxide calculated by

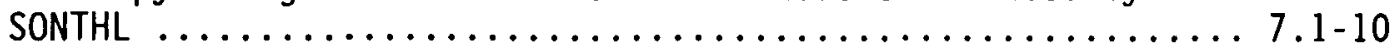

7.2-1. Thermal conductivities for stainless steel oxide calculated SOTCON ....................................... $7.2-3$

7.3-1. Thermal expansion strain as a function of temperature

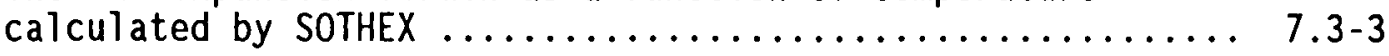

7.3-2. Density calculated by SODEN using the thermal strain

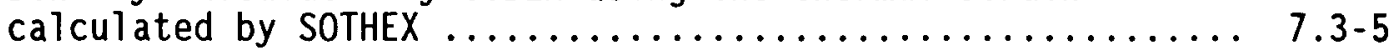

8.2-1. Silver-indium-cadmium absorber heat capacity $\ldots \ldots \ldots \ldots .68 .2-4$

8.2-2. Boron carbide absorber heat capacity $\ldots \ldots \ldots \ldots \ldots \ldots . . .6 .2-5$

8.2-3. Silver-indium-cadmium absorber enthalpy $\ldots \ldots \ldots \ldots \ldots \ldots$ 8.2-7

8.2-4. Boron carbide absorber enthalpy $\ldots \ldots \ldots \ldots \ldots \ldots \ldots \ldots . \ldots .2 .6$

8.3-1. Thermal conductivity of silver-indium-cadmium alloy ...... 8.3-4

8.3-2. Thermal conductivity of silver-indium-cadmium absorber $\ldots . .8$ 8.3-5

8.3-3. Thermal conductivity of boron carbide absorber $\ldots \ldots \ldots \ldots$ 8.3-6

8.4-1. Thermal expansion strain of silver-indium-cadmium

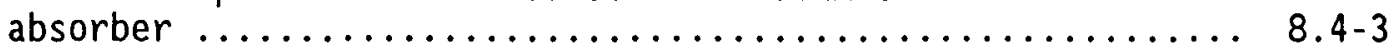

8.4-2. Thermal expansion strain of boron carbide absorber ....... 8.4-4

8.4-3. Density of silver-indium-cadmium absorber $\ldots \ldots \ldots \ldots \ldots$ 8.4-6

8.4-4. Density of boron carbide absorber $\ldots \ldots \ldots \ldots \ldots \ldots \ldots . . \ldots .4 .7$

8.6-1. Viscosity of silver-indium-cadmium absorber ........... 8.6-3

8.6-2. Viscosity of boron carbide absorber $\ldots \ldots \ldots \ldots \ldots \ldots \ldots .6 .6-5$

11-1. Compositions of $Z r-U-0$ compounds on a Gibbs triangle plot .. 11-3

11.1-1. Zirconium-zirconium dioxide phase diagram ............. 11.1-4

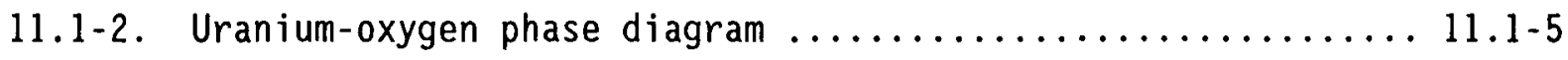

11.1-3. Solidus and liquidus temperatures of uranium oxides
according to Latta and Fryxel1 ....................... 11.1-6

11.1-4. Oxygen-saturated, alpha-phase zirconium-uranium dioxide

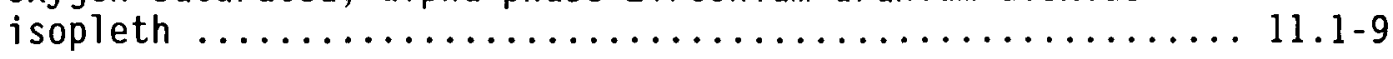


11.1-5. Uranium dioxide-zirconium dioxide quasi-binary phase diagram .........................................11.1-10

11.1-6. Uranium-zirconium system liquidus and solidus $\ldots \ldots \ldots \ldots 11.1-11$

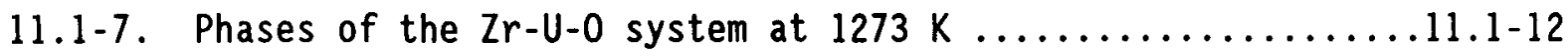

11.1-8. Phases of the $\mathrm{Zr}-\mathrm{U}-0$ system at $1773 \mathrm{~K} \ldots \ldots \ldots \ldots \ldots \ldots \ldots \ldots .11 .13$

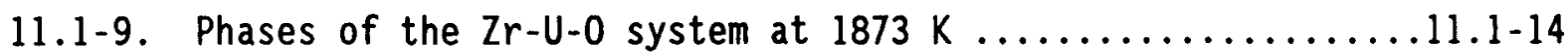

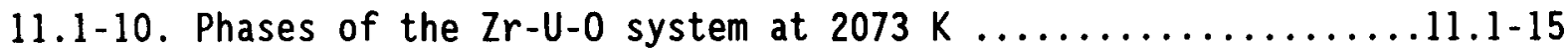

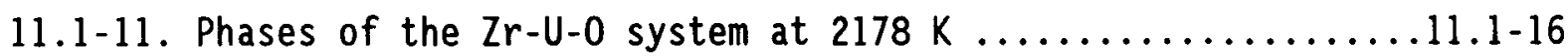

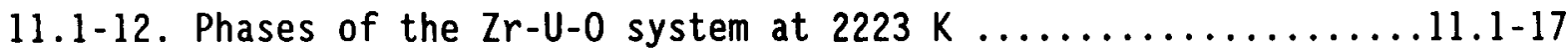

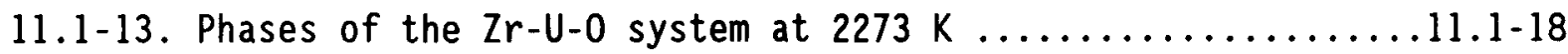

11.1-14. Points that are connected to form the ternary $\mathrm{Zr}-0-\mathrm{U}$

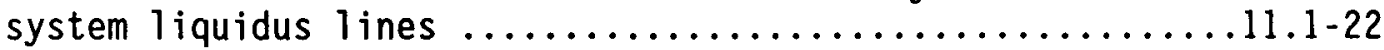

11.1-15. Points that are connected to form the ternary $2 r-0-U$

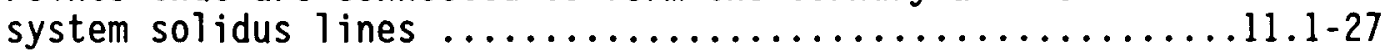

11.1-16. Solid and liquid phase boundaries with tie lines connecting compositions on the boundaries as they are represented for $2500 \mathrm{~K}$ in the ZUSOLV code ..........................11.1-40

11.2-1. Specific heat capacity calculated for a $0.2 \mathrm{UO}_{2}-0.8 \mathrm{ZrO}_{2}$

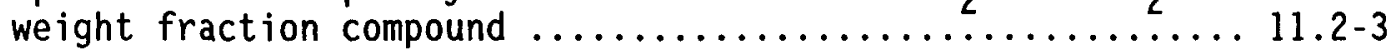

11.2-2. Enthalpy calculated for a $0.2 \mathrm{UO}_{2}-0.8 \mathrm{ZrO}_{2}$ weight fraction compound ............................... 11.2-4

11.3-1. Thermal conductivity calculated for a $0.2 \mathrm{UO}_{2}-0.8 \mathrm{ZrO}_{2}$ weight fraction compound

11.4-1. Thermal strain calculated for a $0.2 \quad \mathrm{UO}_{2}-0.8 \quad \mathrm{ZrO}_{2}$ weight fraction compound $11.4-6$

11.4-2. Density calculated for a $0.2 \mathrm{UO}_{2}-0.8 \mathrm{ZrO}_{2}$ weight fraction compound

11.5-1. Coefficient of friction calculated with the ZUFRIC

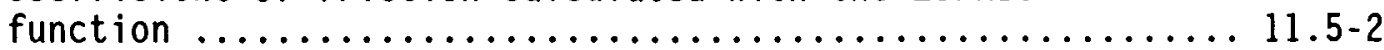

11.7-1. Viscosity of a compound composed of $0.33 \mathrm{~mol} \%$ zirconium and $0.67 \mathrm{~mol} \%$ uranium dioxide

11.8.1 Effect of solvent composition of heat required to dissolve a kilogram of uranium dioxide $11.8-3$

12.1-1. Silver-zirconium phase diagram.................... 12.1-4 
12.1-2. Computer-generated graph of the calculated solubility of zircaloy in silver-indium-cadmium absorber material ....... 12.1-9

13.2-1. Thermal conductivity of helium as a function of temperature .......................................13

13.2-2. Thermal conductivity of argon as a function of

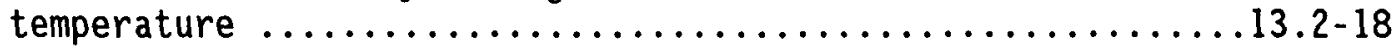

13.2-3. Thermal conductivity of krypton as a function of temperature

13.2-4. Thermal conductivity of xenon as a function of temperature

13.2-5. Thermal conductivity of hydrogen as a function of temperature .

13.2-6. Thermal conductivity of nitrogen as a function of temperature

13.2-7. Thermal conductivity of oxygen as a function of temperature

13.2-8. Thermal conductivity of carbon monoxide as a function of

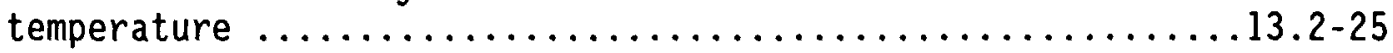

13.2-9. Thermal conductivity of carbon dioxide as a function of temperature .....................................23.26

13.2-10. Thermal conductivity of helium-xenon mixtures at $793 \mathrm{~K} \ldots 13.2-28$

13.4-1. Gas viscosity as a function of temperature for pure helium, a binary mixture of helium and xenon, and for an equal molar mixture of helium, argon, krypton, and xenon ........13.4-3

14.1-1. A comparison of calculated iodine vapor pressures ........14.1-11

14.1-2. A comparison of calculated cesium iodide vapor pressures ...14.1-18

14.1-3. A comparison of calculated cesium hydroxide vapor pressures

14.1-4. Iodine vapor pressure data and pressures calculated with the correlation used to describe the data ..............14.1-36

14.1-5. Cesium iodide vapor pressure data and pressures calculated with the correlation used to describe the data ...........14.1-38

14.1-6. Equilibrium concentrations versus temperatures for several species .......................................14.1-45

14.1-7. Calculated effect of mixing of cesium hydroxide and cesium iodide condensate on equilibrium vapor concentrations .....14.1-46 
14.1-8. Reduction of discontinuity at the melt point with the techniques developed in this section ..................14.1-47

15.1-1. Computed weight gain as a function of temperature for constant time step size

15.1-2. Computed weight gain as a function of time step size for constant temperature ..........................15.1-8

15.2-1. Idealized schematic of a uranium dioxide pellet in contact with the cladding, showing the layered structure ......... 15.2-6

15.2-2. Schematic of posttransition oxide, showing an intact, ratedetermining layer of varying thickness, with another oxide layer that does not affect the oxidation rate .............15.2-19

15.2-3. Estimates of enhancements over out-of-pile oxidation rates when cladding is irradiated in typical BWR and PWR environments

15.2-4. Comparison of the predicted oxide layer thickness with the base data from average values of six Shippingport zircaloy-2

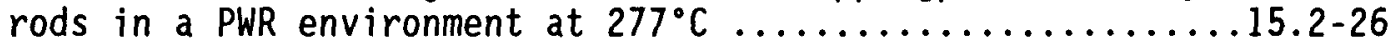

15.2-5. Comparison of the predicted oxide layer thickness with the base data from Saxton zircaloy-4 rods in a PWR at $340^{\circ} \mathrm{C} 2 \ldots 15.2-27$

15.2-6. Comparison of the predicted oxide layer thickness with the base data from zircaloy-2 rods irradiated in the Vallecitos

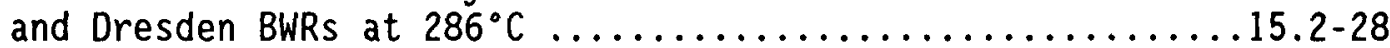

15.2-7. Comparison of calculated (solid lines) and measured $\mathrm{ZrO}_{2}$

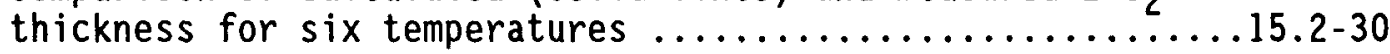

15.2-8. Data used by Urbanic and Heidrick to determine hightemperature zircaloy oxidation rates

15.2-9. Growth of $\operatorname{Zr}(0)$ and $\operatorname{Zr}(0)_{b}$ layers as a function of temperature from Hofmann and Politis $15.2-35$

15.2-10. Linear power generation for a rod of initial diameter of $1.25 \times 10^{-2} \mathrm{~m}$ as a function of temperature for various initial oxide thicknesses $15.2-38$

15.4-1. Parabolic constant for oxygen weight gain $\ldots \ldots \ldots \ldots \ldots \ldots$ 15.4-6

15.4-2. Parabolic constant for oxide layer thickness .......... 15.4-7

15.4-3. Average power per meter during $1 \mathrm{~s}$ for a $1.25 \times 10^{-2}-\mathrm{m}$ stainless steel rod with no initial oxide layer .......... 15.4-8

15.4-4. Oxygen uptake after 1 s with no initial oxidation ....... 15.4-9 15.4-5. Oxide layer thickness after $1 \mathrm{~s}$ with no initial oxidation ..15.4-10 
15.5-1. Zirconium-zirconium dioxide phase diagram $\ldots \ldots \ldots \ldots \ldots . . \ldots 15.5-3$

15.5-2. Uranium-oxygen phase diagram $\ldots \ldots \ldots \ldots \ldots \ldots \ldots \ldots \ldots \ldots \ldots \ldots \ldots .6 \ldots \ldots$

15.5-3. Oxygen-saturated alpha phase zirconium - uranium dioxide

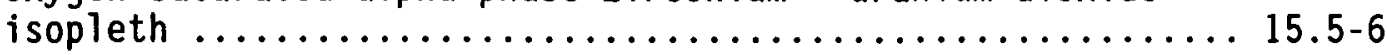

15.5-4. Quasi-binary phase diagram for the $\mathrm{ZrO}_{2}-\mathrm{UO}_{2}$ system from Reference 15.5-6........................... 15.5-7

15.5-5. Zr-U-0 isothermal section at $2273 \mathrm{~K}$ according to Hofmann and Politis ...................................... 15.5

15.5-6. Points that are connected to form the ternary $\mathrm{Zr}-\mathrm{U}-\mathrm{O}$ system ......................................... 15. 10

15.5-7. Zr-U-0 isothermal section at $2273 \mathrm{~K}$ according to Hofmann and Politis (revised) ..............................15

16.2-1. Schematic illustration showing the relation between basal pole intensity at one orientation $(\theta, \phi)$ and the plotted value of the intensity at $(r, \phi)$ on a pole figure $\ldots \ldots \ldots \ldots .16 .2-2$

16.2-2. Input grid for CTXTUR subcode $\ldots \ldots \ldots \ldots \ldots \ldots \ldots \ldots \ldots \ldots \ldots \ldots \ldots \ldots \ldots .2-4$

16.2-3. Relation between angles used in the definition of Kearn's texture factor $\left(f_{\phi}\right)$ and angles averaged by CTXTUR subcode

17.1-1. Master creep rupture curve for A-508, Class 2 carbon steel ........................................17.1-10

17.1-2. Master creep rupture curve for 316 stainless steel $\ldots \ldots \ldots 17.1-11$

17.1-3. Master creep rupture curve for Inconel $600 \ldots \ldots \ldots \ldots .17 .1-13$

\section{TABLES}

2.2-1. Constants used in $\mathrm{UO}_{2}$ and $\mathrm{PuO}_{2}$ heat capacity and enthalpy correlations .................................... 2.2

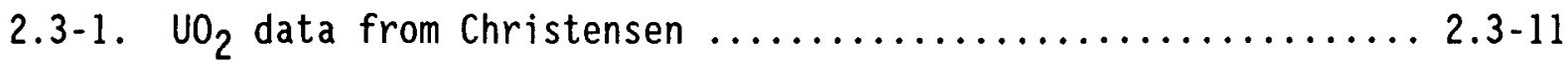

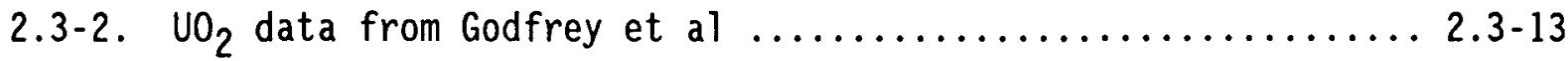

2.3-3. $\mathrm{UO}_{2}$ data from Bates' thermal diffusivity measurements $\ldots . \ldots$. 2.3-14

2.3-4. $\mathrm{UO}_{2}$ data from Gibby's thermal diffusivity measurements $\ldots \ldots$ 2.3-18

2.3-5. $\mathrm{UO}_{2}$ data from Weilbacher's thermal diffusivity

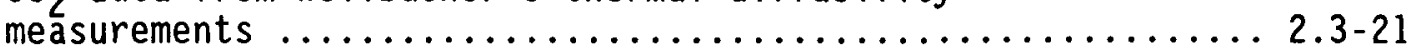


2.3-6. $\mathrm{UO}_{2}$ data from Goldsmith and Douglas' thermal diffusivity

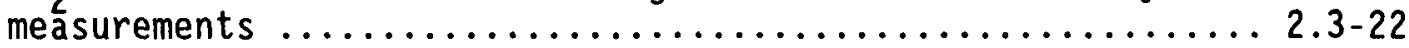

2.3-7. $\mathrm{UO}_{2}$ data from Hobson's thermal diffusivity measurements . . 2.3-25

2.3-8. Values of $\beta_{0}$ and $\beta_{1}$ from various density groups $\ldots \ldots \ldots \ldots .327$

2.5-1. Parameters used in $\mathrm{UO}_{2}$ and $\mathrm{PuO}_{2}$ solid-phase thermal expansion correlations ............................. 2.5

2.6-1. Summary of Young's moduli measured in nonstoichiometric fuel

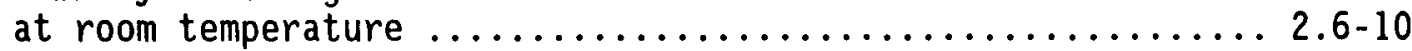

2.6-2. Least-squares constants for data of Figure 5.6-1 ....... 2.6-15

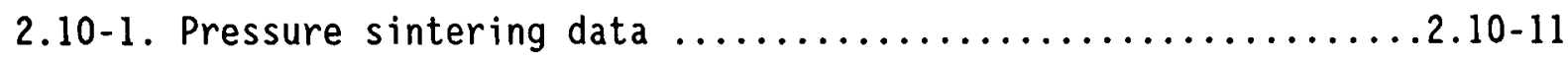

2.13-1. $\mathrm{UO}_{2}$ viscosity data from Tsai and 01 ander $\ldots \ldots \ldots \ldots \ldots \ldots \ldots$

2.13-2. $\mathrm{UO}_{2}$ viscosity data from Woodley $\ldots \ldots \ldots \ldots \ldots \ldots \ldots \ldots \ldots$

3.1-1. Alpha-phase uranium specific heat capacity data ......... 3.1-2

3.1-2. Beta-phase uranium specific heat capacity data $\ldots . \ldots \ldots \ldots$ 3.1-3

3.1-3. Gamma-phase uranium specific heat capacity data ......... 3.1-3

3.2-1. Uranium metal thermal conductivity from Touloukian et al ... 3.2-2

3.3-1. Uranium metal thermal expansion data from Touloukian

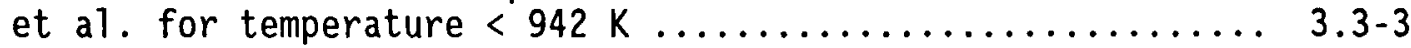

3.3-2. Uranium metal thermal expansion data from Touloukian et al. $942 \mathrm{~K}<\mathrm{T}<1045 \mathrm{~K} \ldots \ldots \ldots \ldots \ldots \ldots \ldots \ldots \ldots \ldots \ldots . \ldots \ldots . \ldots \ldots$

3.3-3. Uranium metal thermal expansion data from Touloukian

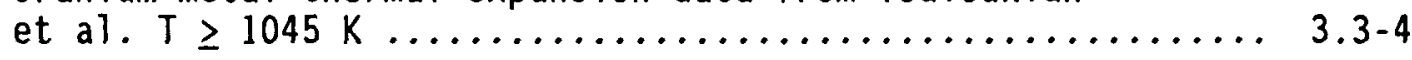

4.1-1. 0xygen content parameters for zircaloy $\ldots \ldots \ldots \ldots \ldots \ldots \ldots \ldots$ 4.1-2

4.3-1. Zircaloy specific heat capacities for CCP $\ldots \ldots \ldots \ldots \ldots \ldots$ 4.3-2

4.3-2. Specific heat as a function of temperature--beta phase .... 4.3-4

4.3-3. Uncertainties in specific heat of zircaloy $\ldots \ldots \ldots \ldots \ldots \ldots .4 . \ldots \ldots$

4.3-4. Values of enthalpy summation for zircaloy $\ldots \ldots \ldots \ldots \ldots \ldots$ 4.3-17

4.3-5. Uncertainty of zircaloy enthalpy $\ldots \ldots \ldots \ldots \ldots \ldots \ldots \ldots \ldots \ldots \ldots \ldots$

4.4-1. Zircaloy thermal conductivity data base............. 4.4-5

4.5-1. Comparison of Mehan and Wiesinger plate expansion with
MATPRO model $\ldots \ldots \ldots \ldots \ldots \ldots \ldots \ldots \ldots \ldots \ldots \ldots \ldots \ldots \ldots \ldots \ldots \ldots \ldots$ 
4.5-2. Bunnell's circumferential thermal expansion data ......... 4.5-17

4.5-3. Bunnell's axial thermal expansion data ................ 4.5-18

4.5-4. Comparison of model predictions and Bunnell's alpha phase data in the diametral direction ....................... 4.5-24

4.5-5. Comparison of model predictions and Bunnell's alpha phase data in the axial direction .......................... 4.5-24

4.6-1. Beta phase zirconium Young's Modulus measured by Armstrong and Brown ................................. 4.6

4.6-2. Beta phase zirconium Young's Modulus measured by Padel and Groff ................................... 4.6-8

4.6-3. Young's modulus measurements by Busby $\ldots \ldots \ldots \ldots \ldots \ldots \ldots .6 .11$

4.6-4. Young's modulus measurements by Spasic et al. .......... 4.6-12

4.6-5. Young's modulus measurements by Mehan $\ldots \ldots \ldots \ldots \ldots \ldots \ldots .6 .6 \ldots \ldots$

4.6-6. Elastic moduli measurements by Northwood et al. ........ 4.6-15

4.6-7. Relations between fourth-rank tensor elements and traditional matrix elements ......................... 4.6-19

4.7-1. Measurements of growth in zircaloy tubing $\ldots \ldots \ldots \ldots \ldots \ldots .4 .5$

4.7-2. Zircaloy growth data as a function of cold work and

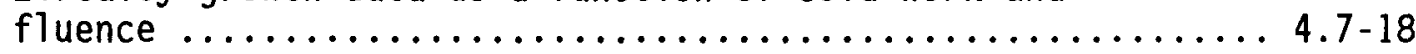

4.7-3. Determination of cold-work coefficient $\ldots \ldots \ldots \ldots \ldots \ldots .7 . \ldots \ldots$

4.8-1. Surface coordinates of probes which measure radial

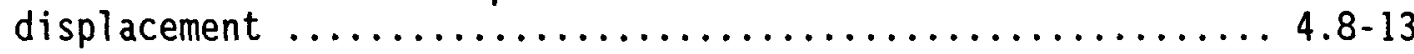

4.8-2. Radial displacements at $200 \mathrm{~h}$ in Hobson's test 269-4

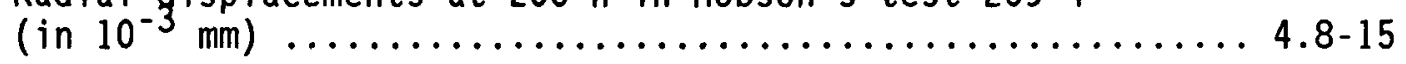

4.9-1. Strength coefficient calculated with data of L. S. Rubenstein .................................... 4.9-44

4.9-2. Rate of change of $K / K_{0}$ with oxygen content $\ldots \ldots \ldots \ldots \ldots$ 4.9-47

4.9-3. Rate of change of $n / n_{0}$ with oxygen content ........... 4.9-51

4.10-1. Room temperature ultimate strengths of cladding annealed for $1 \mathrm{~h}$ from Howe and Thomas ......................... 4. 10-5

4.10-2. 644-K test results for unirradiated transient annealed cladding 
4.10-3. 644-K test results for irradiated transient annealed cladding

4.10-4. 644-K test results for irradiated isothermally annealed cladding ....................................... 4.

4.10-5. Strength and residual strength coefficients after isothermal anneals

4.10-6. Strength and residual strength coefficients with modified cold-work annealing model

4.10-7. Strength and residual strength coefficients after transient anneals (tests with equal maximum temperature) ...4.10-21

4.10-8. Strength and residual strength coefficients after transient anneals (tests with equal heating rates)

4.10-9. Comparison of model predictions of $K$ and $n$ with data base for unirradiated cladding .......................... 10-28

4.10-10. Comparison of model predictions of $K$ and $n$ with data base for transient anneals of irradiated cladding ..............4.10-29

4.11-1. Summary of Multirod Burst Test data employed in CMLIMT .... 4.11-6

4.11-2. Summary of data from the Hobson-Rittenhouse tests $\ldots \ldots \ldots$ 4.11-7

4.11-3. Summary of data from the Chung-Kassner tests $\ldots \ldots \ldots \ldots .4 .11-8$

4.11-4. Summary of data from the Bauer tests ..................11-10

4.11-5. Uncertainties in digitized Argonne data $\ldots \ldots \ldots \ldots \ldots . . . .4 .11-47$

4.12-1. Crack growth rate versus stress intensity range from Rao ... 4.12-4

4.12-2. Low cycle fatigue material parameters $\ldots \ldots \ldots \ldots \ldots \ldots \ldots .12-7$

5.2-1. Zircaloy cladding oxide specific heat capacity data from Gilchrist ................................... 5.2-5

5.3-1. Stabilized zircaloy dioxide thermal conductivity data from Adams

5.3-2. Zircaloy oxide thermal conductivity data reported by Maki

5.3-3. Zircaloy oxide thermal conductivity data of Lapshov and

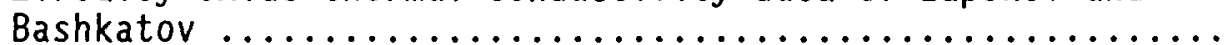

5.3-4. Zircaloy oxide thermal conductivity data of Gilchrist ..... 5.3-6

5.4-1 Emissivity of thin oxide films as reported by Murphy and Havelock 
5.4-2. Emissivity data from Burgoyne and Garlick ............ 5.4-8

5.4-3. Emissivity versus oxide thickness from Juenke and

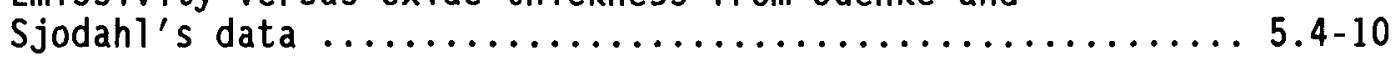

5.4-4. Standard errors of ZOEMIS predictions $\ldots \ldots \ldots \ldots \ldots \ldots \ldots .4-13$

5.5-1. Zircaloy dioxide thermal expansion data by Fulkerson ...... 5.5-5

5.5-2. Zircaloy dioxide thermal expansion data from Brassfield et al. ................................. 5.5-6

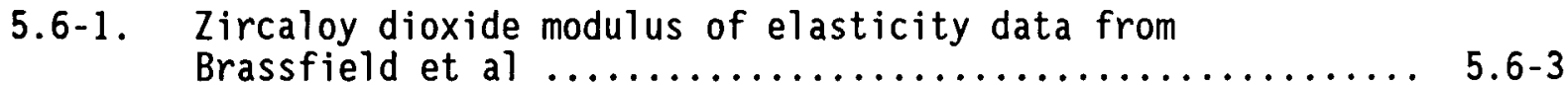

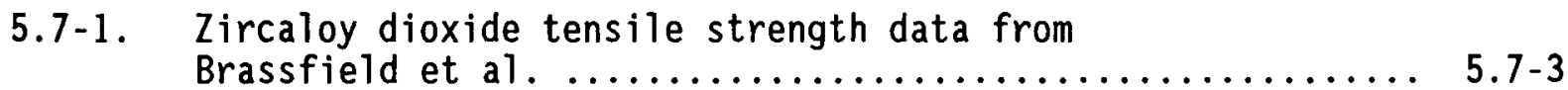

7.1-1. Fe0 specific heat capacity data $\ldots \ldots \ldots \ldots \ldots \ldots \ldots \ldots \ldots .1 . \ldots \ldots$

7.1-2. $\mathrm{Fe}_{2} \mathrm{O}_{3}$ specific heat capacity data $\ldots \ldots \ldots \ldots \ldots \ldots \ldots \ldots .1 .6 \ldots$

7.1-3. $\mathrm{Fe}_{3} \mathrm{O}_{4}$ specific heat capacity data $\ldots \ldots \ldots \ldots \ldots \ldots \ldots \ldots \ldots \ldots \ldots \ldots .1-8$

7.2-1. Stainless steel oxide thermal conductivity from Touloukian ..................................... 7.2

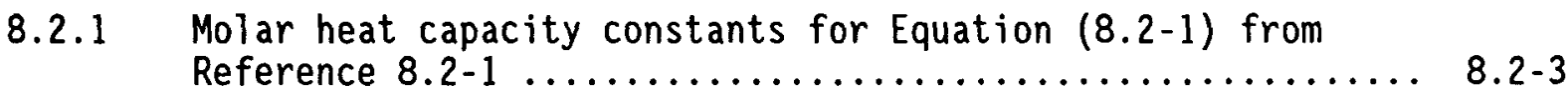

8.3-1. Thermal conductivity values for $\mathrm{Ag}-\mathrm{In}$ - $\mathrm{Cd}$ recommended by Cohen et al. .................................. 8.3

11.1-1. Solidus and liquidus temperatures of $\mathrm{UO}_{2 \mathrm{x}}$ from Latta and Fryxel1 .....................................11.1-7

11.1-2. Correlations for liquidus compositions $\ldots \ldots \ldots \ldots \ldots \ldots \ldots 11.1-23$

11.1-3. Correlations for solidus compositions .................11.1-28

11.1-4. Data used to produce liquidus correlations $\ldots \ldots \ldots \ldots \ldots 11.1-32$

11.1-5. Data used to produce solidus correlations ..............11.1-35

11.2-1. ZUNTHL calculations and Deem's data for a $0.2 \mathrm{UO}_{2}-0.8 \mathrm{ZrO}_{2}$

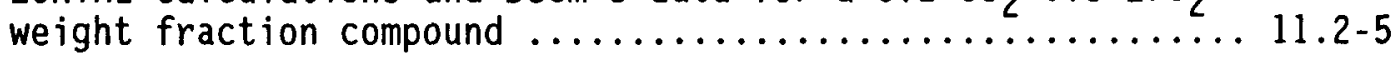

11.2-2. ZUNTHL calculations and Deem's data for a $0.32 \mathrm{UO}_{2}-0.68 \mathrm{ZrO}_{2}$

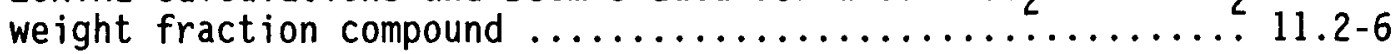

11.2-3. ZUNTHL calculations and Deem's data for a $0.5 \mathrm{UO}_{2}-0.5 \mathrm{ZrO}_{2}$ weight fraction compound $\ldots \ldots \ldots \ldots \ldots \ldots \ldots \ldots \ldots . . .11 .2-7$ 
11.2-4. ZUNTHL calculations and Deem's data for a $0.94 \mathrm{UO}_{2}-0.06$

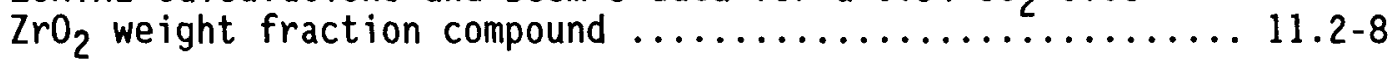

11.3-1. ZUTCON calculations and Deem's results for a $0.2 \mathrm{UO}_{2}-0.8 \mathrm{ZrO}_{2}$ weight fraction compound $\ldots \ldots \ldots \ldots \ldots \ldots \ldots \ldots \ldots \ldots$

11.3-2. ZUTCON calculations and Deem's results for a $0.32 \mathrm{U0}_{2}-0.68 \mathrm{ZrO}_{2}$ weight fraction compound $\ldots \ldots \ldots \ldots \ldots \ldots \ldots \ldots .11 .3-5$

11.3-3. ZUTCON calculations and Deem's results for a $0.5 \mathrm{UO}_{2}-0.5 \mathrm{ZrO}_{2}$ weight fraction compound $\ldots \ldots \ldots \ldots \ldots \ldots . . .11 .3-6$

11.3-4. ZUTCON calculations and Deem's results for a low-density $0.32 \mathrm{UO}_{2}-0.68 \mathrm{ZrO}_{2}$ weight fraction compound $\ldots \ldots \ldots \ldots \ldots .11 .3-7$

11.3-5. ZUTCON calculations and Deem's results for a $0.94 \mathrm{UO}_{2}-0.06 \mathrm{ZrO}_{2}$ weight fraction compound $\ldots \ldots \ldots \ldots \ldots . . .11 .3-8$

11.4-1. ZUTEXP calculations and Deem's data for a $0.2 \mathrm{UO}_{2}-0.8 \mathrm{ZrO}_{2}$ weight fraction compound $\ldots \ldots \ldots \ldots \ldots \ldots \ldots \ldots .11 .4-8$

11.4-2. ZUTEXP calculations and Deem's data for a $0.32 \mathrm{UO}_{2}-0.68 \mathrm{ZrO}_{2}$ weight fraction compound $\ldots \ldots \ldots \ldots \ldots .11 .4-9$

11.4-3. ZUTEXP calculations and Deem's data for a $0.5 \mathrm{UO}_{2}-0.5 \mathrm{ZrO}_{2}$ weight fraction compound $\ldots \ldots \ldots \ldots \ldots .11 .4-10$

11.4-4. ZUTEXP calculations and Deem's data for a $0.94 \mathrm{UO}_{2}-0.06 \mathrm{ZrO}_{2}$ weight fraction compound

11.4-5. ZUDEN calculations and Deem's compound density data $\ldots \ldots \ldots 11.4-12$

11.4-6. Constants for thermal expansion strain ................11.4-14

12.1-1. Data used to find the liquidus in the Ag-rich region ...... 12.1-6

12.1-2. Data used to find the 1iquidus in the $2 r$-rich region $\ldots \ldots$ 12.1-6

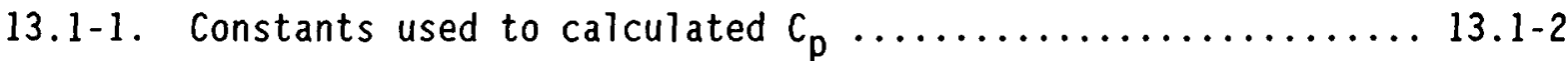

13.2-1. Constants used in gas thermal conductivity correlations ... 13.2-3

13.2-2. Uncertainty of the gas thermal conductivity correlations ... 13.2-5

13.2-3. Surface accommodation coefficients $\ldots \ldots \ldots \ldots \ldots \ldots \ldots . . \ldots 13.2-8$

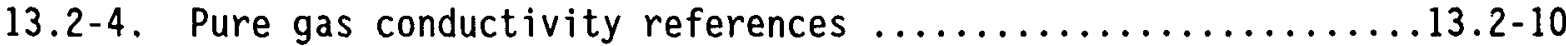

13.3-1. Coefficients used to calculate $\mathrm{CW} \ldots \ldots \ldots \ldots \ldots \ldots \ldots \ldots . . \ldots \ldots$

14.1-1. Values of constants used in Equation (14.1-1) ...........14.1-3

14.1-2. Van der Waals constants and molar masses $\ldots \ldots \ldots \ldots \ldots \ldots$ 14.1-5 
14.1-3. Vapor pressure of iodine measured by Ramsay and Young ..... 14.1-8

14.1-4. Vapor pressure of iodine measured by Baxter et al ....... 14.1-9

14.1-5. Vapor pressure of iodine measured by Stern and Gregory ....14.1-10

14.1-6. Vapor pressure of iodine calculated by Stull ............14.1-13

14.1-7. Vapor pressure of cesium iodide measured by

Cummings et al.

14.1-8. Vapor pressure of cesium iodide measured by

Cogan and Kimball

$14.1-16$

14.1-9. Vapor pressure of cesium iodide calculated by Stu11 .......14.1-19

14.1-10. Vapor pressure of cesium iodide calculated by Margrave ....14.1-19

14.1-11. Gibbs energy functions from Powers ...................14.1-21

14.1-12. Vapor pressure of cesium hydroxide measured by

Cummings et al.

15.1-1. Measured and calculated weight gain $\ldots \ldots \ldots \ldots \ldots \ldots \ldots .15 .1-4$

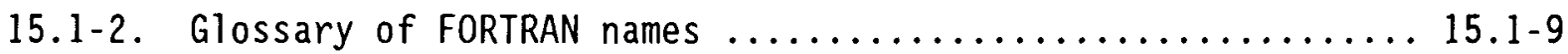

15.2-1. Rate constants for oxidation by steam $\ldots \ldots \ldots \ldots \ldots \ldots \ldots \ldots \ldots .2-8$

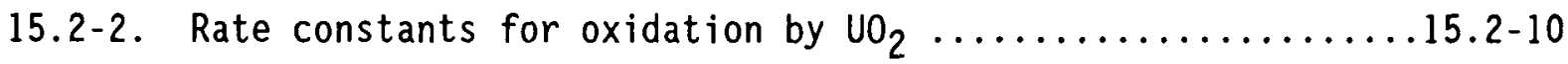

15.2-3. 90\% joint confidence intervals for the parabolic rate constants for oxide layer growth, alpha layer growth, and

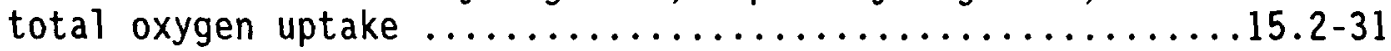

15.2-4. Time-temperature layer thickness data from Hofmann's

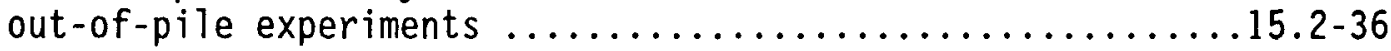

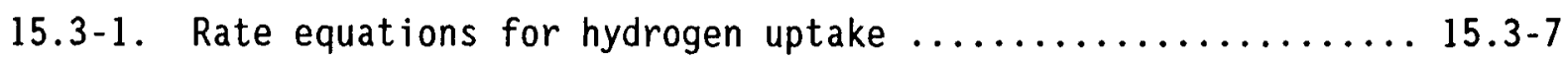

15.4-1. Rate constants for use with Equation (15.4-1) to predict oxidation ....................................... 15.4-3

15.5-1. Correlations for solidus composition ..................15.5-11

15.5-2. Data used to produce solidus compositions ..............15.5-12

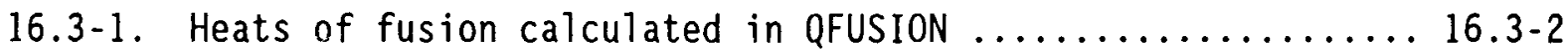

17.1-1. Constants used to solve creep rupture equation........... 17.1-5

17.1-2. Creep rupture data of A-508 pressure vessel carbon stee1 .. 17.1-7

17.1-3. Tensile test data of A-508 pressure vessel carbon steel ... 17.1-8 
17.1-4. Stainless steel creep rupture data $\ldots \ldots \ldots \ldots \ldots \ldots \ldots \ldots 17 . \ldots$

17.1-5. Inconel 600 creep rupture data $\ldots \ldots \ldots \ldots \ldots \ldots \ldots \ldots \ldots$ 


\section{SCDAP/RELAP5/MOD2 CODE MANUAL VOLUME IV: MATPRO--A LIBRARY OF MATERIALS PROPERTIES FOR LIGHT-WATER-REACTOR ACCIDENT ANALYSIS}

\section{INTRODUCTION}

The U.S. Nuclear Regulatory Commission has sponsored the development and validation of a number of computer codes that calculate the steady-state, transient, and severe fuel damage responses of nuclear reactor cores. Most of the fuel component and corium properties used by these codes are based on a common set of materials properties descriptions that have been collected to form the MATPRO package of subcodes.

Publication of a set of materials properties descriptions intended to provide a common base for reactor analysis began in 1974. The descriptions have been revised from time to time, as required by new data or consideration of new materials and temperature ranges. 1-1 to 1-7 This MATPRO document is the only formal description of the package published since the August 1981 revision. It contains descriptions of all MATPRO subcodes available for accident analys is at this time. The fuel, cladding, and gap gas properties descriptions available in the August 1981 package have been extended to temperatures characteristic of severe fuel damage, more than $3000 \mathrm{~K}$; and silver-indium-cadmium control rod materials, boron carbide control blade materials, zirconium-uranium-oxygen-iron compounds, and some fission product vapor species properties have been added to the list of materials considered. Also, a number of reaction rate models have been added to the mostly static properties considered in 1981. These models for reaction and solution rates between different materials have been collected in Section 15 of this document.

The descriptive detail provided for the subcodes presented in this document varies because the subcode documentation came from many different resources, including the MATPRO-11 Revision 2 document, a series of informal reports dealing with materials properties subcodes that have been 
incorporated into SCDAP/RELAP5, and previously undocumented materials properties subcodes that are contained in the SCDAP/RELAP5 computer code or in the MATPRO library of materials properties subcodes. The correlations used in MATPRO-11 Revision 2 were developed using an extensive literature search, whereas later correlations were developed as their need became evident or new and relevant experimental data became available, such as the dissolution model for $\mathrm{UO}_{2}$ in zircaloy. A less extensive literature search was used to develop the correlations used to calculate the materials properties in the models developed after the publication of the MATPRO-11 Revision 2 document.

A personal computer disk containing the FORTRAN source coding for all described subcodes for use with other accident analysis codes or for stand-alone materials properties calculations is available on request from the editor.

\section{REFERENCES}

1-1. R. L. Miller, R. R. Hobbins, V. F. Baston, and W. A. Yuill, FRAP-T: A Computer Code for the Transient Analysis of Oxide Fuel Rods. Volume 2. MATPRO Materials Properties Subcode, I-243-2, 1974.

1-2. P. E. MacDonald and L. B. Thompson (eds.), MATPRO A Handbook of Materials Properties for Use in the Analysis of Light Water Reactor Fuel Rod Behavior, ANCR-1263, February 1976.

1-3. P. E. MacDonald and L. B. Thompson (eds.), MATPRO-Version O9 A Handbook of Materials Properties for Use in the Analysis of Light Water Reactor Fuel Rod Behavior, TREE-NUREG-1005, December 1976.

1-4. G. A. Reymann (ed.), MATPRO-Version 10 A Handbook of Materials Properties for Use in the Analysis of Light Water Reactor Fuel Rod Behavior, TREE-NUREG-1180, February 1978.

1-5. D. L. Hagrman and G. A. Reymann (eds.), MATPRO-Version 11 A Handbook of Materials Properties for Use in the Analysis of Light Water Reactor Fuel Rod Behavior, NUREG/CR-0497, TREE-1280, February 1979.

1-6. D. L. Hagrman, G. A. Reymann, and R. E. Mason (eds.), MATPRO-Version 11 (Revision 1) A Handbook of Materials Properties for Use in the Analysis of Light Water Reactor Fuel Rod Behavior, NUREG/CR-0497, TREE-1280, Rev. 1, February 1980. 
1-7. D. L. Hagrman, G. A. Reymann, and R. E. Mason (eds.), MATPRO Version 11 (Revision 2) a Handbook of Materials Properties for Use in the Analysis of Light Water Reactor Fuel Rod Behavior, NUREG/CR-0497, TREE-1280, Rev. 2, August 1981. 



\section{URANIUM DIOXIDE}

Seventeen materials properties of LWR fuel have been modeled for inclusion in MATPRO. The approaches range from (a) a least-squares fit to available data using a polynomial or other function having little or no theoretical basis to (b) a semiempirical correlation employing an analytical expression suggested by theory with constants determined by comparison with data. The intent of current and future work is to take the second approach wherever possible.

Copies of each materials properties subcode are available on PC disk. The supplied subcodes may be used to calculate the value of the desired material property for various input conditions. All 17 MATPRO fuel subcodes have temperature as an argument. In addition, many are functions of burnup, plutonia content, density, time, and other variables. 


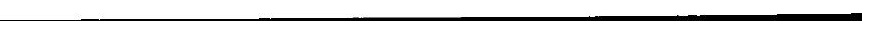


FHYPRP

\subsection{Melting Temperature (FhyprP)}

The subroutine FHYPRP calculates the temperature of the appearance of the first liquid phase (solidus) and the temperature of the melting point of the last solid phase (liquidus) of $\mathrm{UO}_{2}$ and $(U, P u) O_{2}$. These temperatures are calculated as a function of burnup and plutonia content.

\subsubsection{Model Development}

The equations used to calculate the $\mathrm{UO}_{2}$ and $(\mathrm{U}, \mathrm{Pu}) \mathrm{O}_{2}$ melting points were derived by using $3113.15 \mathrm{~K}$ as the melting temperature of uranium, which was determined experimentally by Brassfield, ${ }^{2.1-1}$ and a least-squares fit to parabolic equations for the solidus and liquidus boundaries from the Lyon and Baily $2.1-2$ phase diagram for the stoichiometric $(U, \mathrm{Pu}) \mathrm{O}_{2}$ mixed oxide. The equations used are as follows:

For plutonia compositions $>0$,

$\mathrm{T}_{\text {Sol }}=3113.15-5.41395 c+7.468390 \times 10^{-3} c^{2}-3.2 \times 10^{-3} \mathrm{FBu}$

$\mathrm{T}_{1 \mathrm{iq}}=3113.15-3.21660 \mathrm{c}-1.448518 \times 10^{-2} \mathrm{c}^{2}-3.2 \times 10^{-3} \mathrm{FBu}$

For plutonia compositions $=0$,

$\mathrm{T}_{\text {sol }}=3113.15-3.2 \times 10^{-3} \mathrm{FBu}$

$T_{1 i q}=T_{\text {sol }}$

where 


\section{FHYPRP}

$$
\begin{aligned}
& T_{\text {Sol }}=\text { the solidus temperature }(\mathrm{K}) \\
& \mathrm{T}_{1 \mathrm{iq}}=\text { the } 1 \text { iquidus temperature }(\mathrm{K}) \\
& \mathrm{C}=\mathrm{PuO}_{2} \text { content (wt\%) } \\
& \mathrm{FBu}=\text { burnup (MWd/tU }
\end{aligned}
$$

\subsubsection{References}

2.1-1. H. C. Brassfield et a7., Recommended Property and Reactor Kinetics Data for Use in Evaluating a Light-Water-Coolant Reactor Loss-of-Coolant Incident Involving Zircaloy-4 or 304-SS-Clad $\mathrm{UO}_{2}$, GEMP-482, April 1968.

2.1-2. W. F. Lyon and W. E. Baily, "The Solid-Liquid Phase Diagram for the $\mathrm{UO}_{2}-\mathrm{PuO}_{2}$ System," Journal of Nuclear Materials, 22, 332, 1967. 
FCP， FENTHL

\title{
2.2 Specific Heat Capacity and Enthalpy (FCP, Fenthl)
}

\author{
(G. A. Reymann)
}

The specific heat capacity of nuclear fuel is needed for time-dependent temperature calculations. The stored energy, or enthalpy, is calculated from the specific heat capacity. Stored energy is important in reactor transient analysis because the severity of the transient is greatly affected by the initial stored energy of the fuel.

\subsubsection{Summary}

The specific heat capacity and enthalpy of nuclear fuel are modeled empirically as functions of four parameters: temperature, composition, molten fraction, and oxygen-to-metal ratio. Since $\mathrm{UO}_{2}$ and $\mathrm{PuO}_{2}$ are the principal LWR fuels, they are the constituents considered. The correlations for fuel specific heat and enthalpy are valid for temperatures from $300 \mathrm{~K}$ to more than $4000 \mathrm{~K}$.

Equations for the specific heat and enthalpy of solid $\mathrm{UO}_{2}$ and $\mathrm{PuO}_{2}$ are assumed to have the same form, but with different constants. The basic equations are

$F C P=\frac{K_{1} \theta^{2} \exp (\theta / T)}{T^{2}[\exp (\theta / T)-1]^{2}}+K_{2} T+\frac{Y K_{3} E_{D}}{2 R T^{2}} \exp \left(-E_{D} / R T\right)$

and

FENTHL $=\frac{K_{1} \theta}{\exp (\theta / T)-1}+\frac{K_{2} T^{2}}{2}+\frac{Y}{2}\left[K_{3} \exp \left(-E_{D} / R T\right)\right]$ 


\section{FCP， FENTHL}

where

$$
\begin{aligned}
\text { FCP } & =\text { specific heat capacity }(\mathrm{J} / \mathrm{kg} \cdot \mathrm{K}) \\
\text { FENTHL } & =\text { fuel enthalpy }(\mathrm{J} / \mathrm{kg}) \\
T \quad & \text { temperature }(\mathrm{K}) \\
Y & =\text { oxygen-to-metal ratio } \\
\mathrm{R} & =\text { universal gas constant }=8.3143(\mathrm{~J} / \mathrm{mol} \cdot \mathrm{K}) \\
\theta \quad & \text { the Einstein temperature }(\mathrm{K})
\end{aligned}
$$

and the constants are given in Table 2.2-1.

The specific heat capacities of $\mathrm{UO}_{2}$ and $\mathrm{PuO}_{2}$ in the liquid state are given by

$$
F C P=503 \mathrm{~J} / \mathrm{kg} \cdot \mathrm{K}
$$

For a mixture of $\mathrm{UO}_{2}$ and $\mathrm{PuO}_{2}$, the specific heat capacity of the solid is determined by combining the contribution from each constituent in proportion to its weight fraction. When the material is partially molten, the heat capacity is determined similarly with a weighted sum. The standard error of the $\mathrm{UO}_{2}$ specific heat capacity correlation is $\pm 3 \mathrm{~J} / \mathrm{kg} \cdot \mathrm{K}$; and, for the mixed-oxide specific heat capacity correlation, it is 6 to $10 \mathrm{~J} / \mathrm{kg} \cdot \mathrm{K}$, depending on the fraction of $\mathrm{PuO}_{2}$. For nonstoichiometric fuels, these uncertainties are approximately doubled.

Inspection of Equations (2.2-1) and (2.2-2) shows that the fuel enthalpy correlation is simply the integral of fuel specific heat correlation from $0 \mathrm{~K}$ to $\mathrm{T}(\mathrm{K})$. Because the specific heat correlation is 
FCP， FENTHL

Table 2.2-1. Constants used in $\mathrm{UO}_{2}$ and $\mathrm{PuO}_{2}$ heat capacity and enthalpy correlations

\begin{tabular}{|c|c|c|c|}
\hline Constant & $\mathrm{UO}_{2}$ & $\mathrm{PuO}_{2}$ & Units \\
\hline$k_{1}$ & 296.7 & 347.4 & $\mathrm{~J} / \mathrm{kg} \cdot \mathrm{K}$ \\
\hline$k_{2}$ & $2.43 \times 10^{-2}$ & $3.95 \times 10^{-4}$ & $\mathrm{~J} / \mathrm{kg} \cdot \mathrm{K}^{2}$ \\
\hline$K_{3}$ & $8.745 \times 10^{7}$ & $3.860 \times 10^{7}$ & $\mathrm{~J} / \mathrm{kg}$ \\
\hline$\theta$ & 535.285 & 571.000 & K \\
\hline$E_{D}$ & $1.577 \times 10^{5}$ & $1.967 \times 10^{5}$ & $\mathrm{~J} / \mathrm{mol}$ \\
\hline
\end{tabular}




\section{FCP， FENTHL}

only valid above a fuel temperature of about $300 \mathrm{~K}$, the fuel enthalpy correlation is not valid below a temperature of about $300 \mathrm{~K}$. Therefore, it is necessary to calculate fuel enthalpy with respect to a reference temperature $\geq 300 \mathrm{~K}$. Thus, the fuel enthalpy at any desired temperature, $T$, is calculated by evaluating Equation (2.2-2) at $T$ and a reference temperature, $T_{R E F}$, of $300 \mathrm{~K}$ and taking the difference [FENTHL (T) - FENTHL $\left.\left(T_{R E F}\right)\right]$. For temperatures greater than $2 \mathrm{~K}$ below melting, the molten fraction and heat of fusion are used to interpolate between the enthalpy of unmelted fuel and just-melted fuel at the melting temperature.

Section 2.2.2 is a review of the surveyed literature. The model development is presented in Section 2.2.3. Model predictions are compared with data in Section 2.2.4. An uncertainty analysis is given in Section 2.2.5.

\subsubsection{Literature Review}

An important source for fuel specific heat capacity data is the extensive review by Kerrisk and Clifton. ${ }^{2.2-1}$ Additional data from Kruger and Savage $2.2-2$ are used to find the parameters for $\mathrm{PuO}_{2}$ in Equation (2.2-1). The heat capacity of liquid fuel is taken from Leibowitz. 2.2-3

2.2.2.1 Limitations of the Data Source. The data used by Kerrisk and $\mathrm{Cl}$ ifton cover a wide range of temperatures (483 to $3107 \mathrm{~K}$ ), but these data are restricted to nearly stoichiometric material (oxygen-to-metal ratio between about 2.00 and 2.015). The data of Kruger and Savage are limited in that the highest reported temperature was only $1400 \mathrm{~K}$, which is well below the melting point of $\mathrm{PuO}_{2}$, about $2600 \mathrm{~K}$. Their data are also restricted to approximately stoichiometric $\mathrm{PuO}_{2}$. The oxygen-to-metal ratio has been shown to be significant by Gronvold $\mathrm{d}^{2-4}$ and by Affortit and Marcon. 2.2-5 
The specific heat capacity of liquid fuel taken from Leibowitz is applicable to $\mathrm{UO}_{2}$ only. The assumption is made that the liquid $\mathrm{UO}_{2}$ value is also valid for 1 iquid $\mathrm{PuO}_{2}$. Although departures from stoichiometry were found to be significant for solid fuel, no experimental effort has been made to assess the importance of this parameter in the liquid state.

2.2.2.2 Other Data Sources. Several other data sources are used to estimate the uncertainty of the model but not in its development. These sources are cited in Section 2.2.5, where the uncertainty is analyzed.

\subsubsection{Model Development}

The most common technique of determining specific heat capacity is to measure the enthalpy of a sample by drop calorimetry and deduce the heat capacity by finding the rate of enthalpy change with temperature. Generally, the enthalpy data are fitted using an empirical function, often a simple polynomial equation. Whereas the accuracy of this approach is good, a function based on first principles is preferable because it allows the identification of the physical processes involved and can be extrapolated beyond its temperature base with some degree of confidence. This approach was used by Kerrisk and Clifton and is adopted here.

\subsubsection{Specific Heat Capacity of a Typical Solid. The lattice} specific heat capacity of solids at constant volume can be characterized theoretically quite well using the Debye model for specific heat. Except at low temperatures, a similar but simpler theory developed earlie: by Einstein is also adequate. These theories are described in the most basic solid-state textbooks, such as Kittel.2.2-6 The Einstein formulation is used here because of its simplicity. This formulation is

$$
C_{v}=\frac{k_{1} \theta^{2} \exp (\theta / T)}{T^{2}[\exp (\theta / T)-1]^{2}}
$$




\section{FCP， FENTHL}

where

$$
\begin{aligned}
& \mathrm{C}_{\mathrm{v}}=\text { specific heat capacity }(\mathrm{J} / \mathrm{kg} \cdot \mathrm{K}) \\
& \mathrm{K}_{1}=\text { constant to be determined }(\mathrm{J} / \mathrm{kg} \cdot \mathrm{K}) .
\end{aligned}
$$

Equation (2.2-4) gives the specific heat capacity at constant volume. In most reactor situations, the specific heat capacity at constant pressure, $C_{p}$, is more appropriate. The relationship between the two is $2.2-7$

$$
C_{p}=C_{v}+\left(\alpha^{2} V / \beta\right) T
$$

where

$$
\begin{aligned}
\alpha & =\text { coefficient of thermal expansion }\left(\mathrm{K}^{-1}\right) \\
\beta & =\text { coefficient of compressibility }\left(\mathrm{Pa}^{-1}\right) \\
V & =\text { molar volume }\left(\mathrm{m}^{3}\right) .
\end{aligned}
$$

The temperature-dependence of $\alpha^{2} \mathrm{~V} / \beta$ in Equation (2.2-5) is complicated. The compressibility of a liquid or a solid is nearly constant with temperature, but the molar volume and the coefficient of thermal expansion change with temperature. However, expressing the quantity $\left(C_{p}\right.$ $C_{v}$ ) as a function of a constant times temperature yields results well within the scatter of the data. Therefore, $c_{p}$ is expressed as

$C_{p}=C_{v}+K_{2} T$

where $C_{v}$ is given by Equation (2.2-4) and $K_{2}$ is a constant to be determined by comparison with data. 
FCP, FENTHL

\subsubsection{Defect Energy Contribution to the Specific Heat Capacity.} At temperatures $>1500 \mathrm{~K}$, the specific heat capacity data show a rapid increase not described by Equation (2.2-6). This increase is generally attributed to the energy necessary to form Frenkel defects. $2.2-7,2.2-8,2.2-9$ Some investigators $2.2-4,2.2-8$ have suggested that Schottky defects may also contribute to this rapid increase. However, the assumption used in this model is that the rapid increase in specific heat capacity $>1500 \mathrm{~K}$ is due to formation of Frenkel defects. The functional form of the extra term that should be added to Equation (2.2-6) may be found from the defect energy contribution to the enthalpy given by $2.2-6$

$H_{D}=K_{3} \exp \left(-E_{D} / R T\right)$

where

$$
\begin{aligned}
& H_{D}=\text { defect energy contribution to enthalpy }(\mathrm{J}) \\
& E_{D}=\text { activation energy for Frenkel defects }(\mathrm{J} / \mathrm{mol}) \\
& K_{3}=\text { constant to be determined }(\mathrm{J})
\end{aligned}
$$

and $R$ and $T$ were previously defined in Equation (2.2-1). To determine the defect contribution to the specific heat capacity, the derivative of $H_{D}$ with respect to temperature, $C_{D}$ is given by

$C_{D}=\frac{K_{2} E_{D}}{R T^{2}} \exp \left(-E_{D} / R T\right)$

Combining Equations $(2.2-4),(2.2-6)$, and $(2.2-8)$ gives the general expression for specific heat capacity

$C_{p}=\frac{K_{1} \theta^{2} \exp (\theta / T)}{T^{2}[\exp (\theta / T)-1]^{2}}+K_{2} T+\frac{K_{3} E_{D}}{R T^{2}} \exp \left(-E_{D} / R T\right)$. 
FCP， FENTHL

2.2.3.3 Determination of the Constants in the Model. For $\mathrm{UO}_{2}$, the values of the five constants, $K_{1}, K_{2}, K_{3}, \theta$, and $E_{0}$, are taken from Kerrisk and $\mathrm{Cl}$ ifton. For $\mathrm{PuO}_{2}$, the constants are determined by fitting the data of Kruger and Savage. In both cases, the fuel was nearly stoichiometric. Data sources for pure $\mathrm{PuO}_{2}$ are scarce. One potential source is the work of Affortit and Marcon. However, they give only correlations determined from fitting the data and not the actual data. Also, they do not present an uncertainty analysis. Without knowing the number or accuracy of the data on which their correlations are based, it is not possible to estimate what weight to give to their results. Therefore, their correlations were not used to determine the constants of Equation (2.2-9). However, their work was useful for the assessment of the effects of departure from stoichiometry.

It should be noted that the constants determined for Equation (2.2-9) are only valid at fuel temperatures $>300 \mathrm{~K}$. Data $<300 \mathrm{~K}$ were not used to determine the constants of Table 2.2-1, and the Einstein formulation assumes temperatures above the Einstein temperature, $\theta$.

\subsubsection{Effect of Nonstoichiometry. Several investigators have} found the oxygen-to-metal ratio of fuel to influence the specific heat capacity. 2.2-1,2.2-5,2.2-8,2.2-10 At temperatures > $1300 \mathrm{~K}$, departures from stoichiometry typical of those found in LWR fuel have caused changes in the specific heat capacity greater than the data scatter. The most complete analysis of this effect has been done by Affortit and Marcon. Even though their results are quantitatively different (see Figures 2.2-1 and 2.2-2, made from their correlations) from sources used to develop this model, they illustrate well the qualitative aspects of this effect. Figure 2.2-1 is for $\mathrm{UO}_{2}$, and Figure 2.2-2 is for mixed-oxide fuels. These figures show that the specific heat capacity increases as the oxygen-to-metal ratio becomes larger than 2. 
FCP， FENTHL

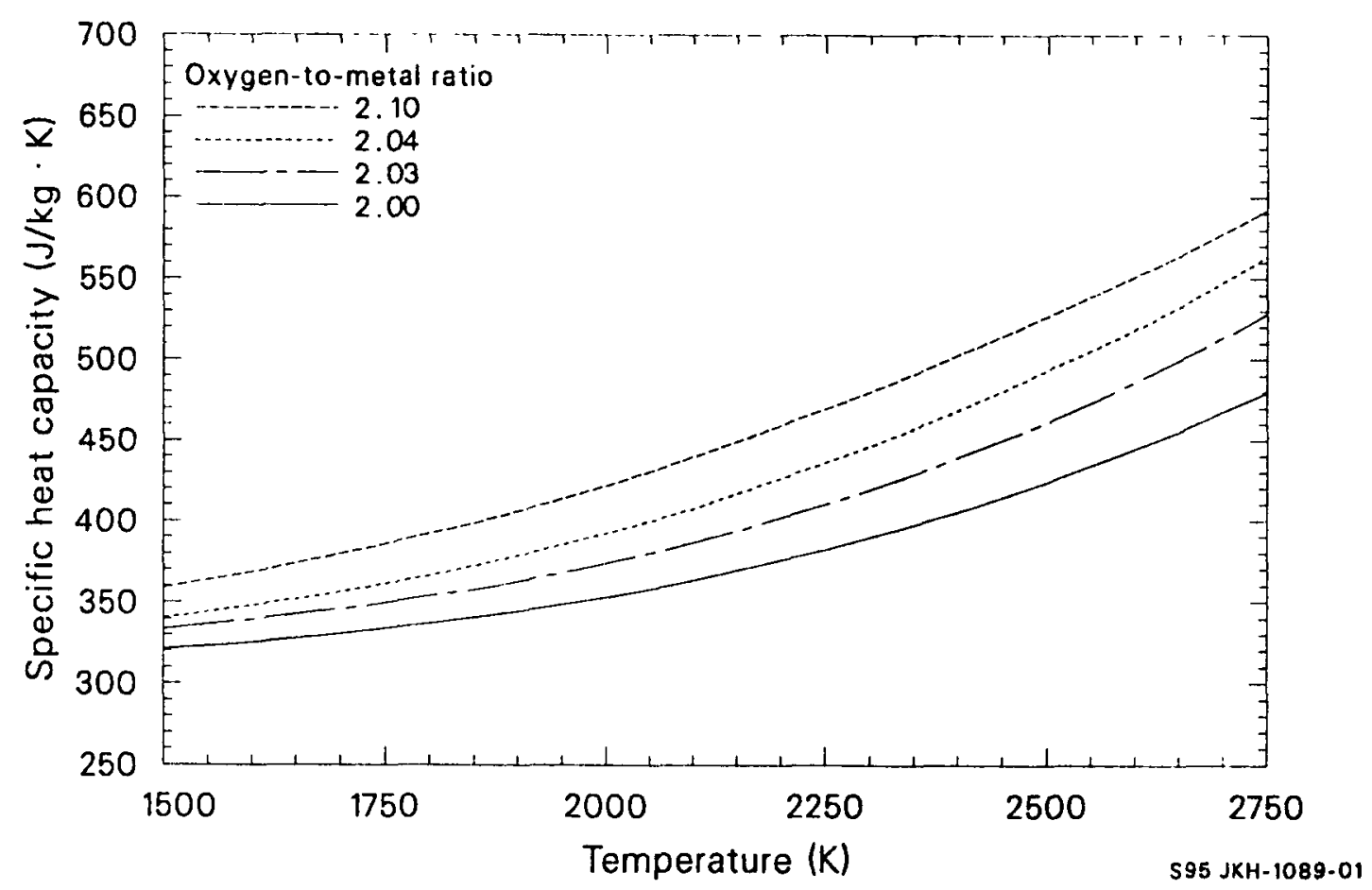

Figure 2.2-1. Specific heat capacity as a function of temperature and oxygen-to-metal ratio for $\mathrm{UO}_{2}$. 
FCP, FENTHL

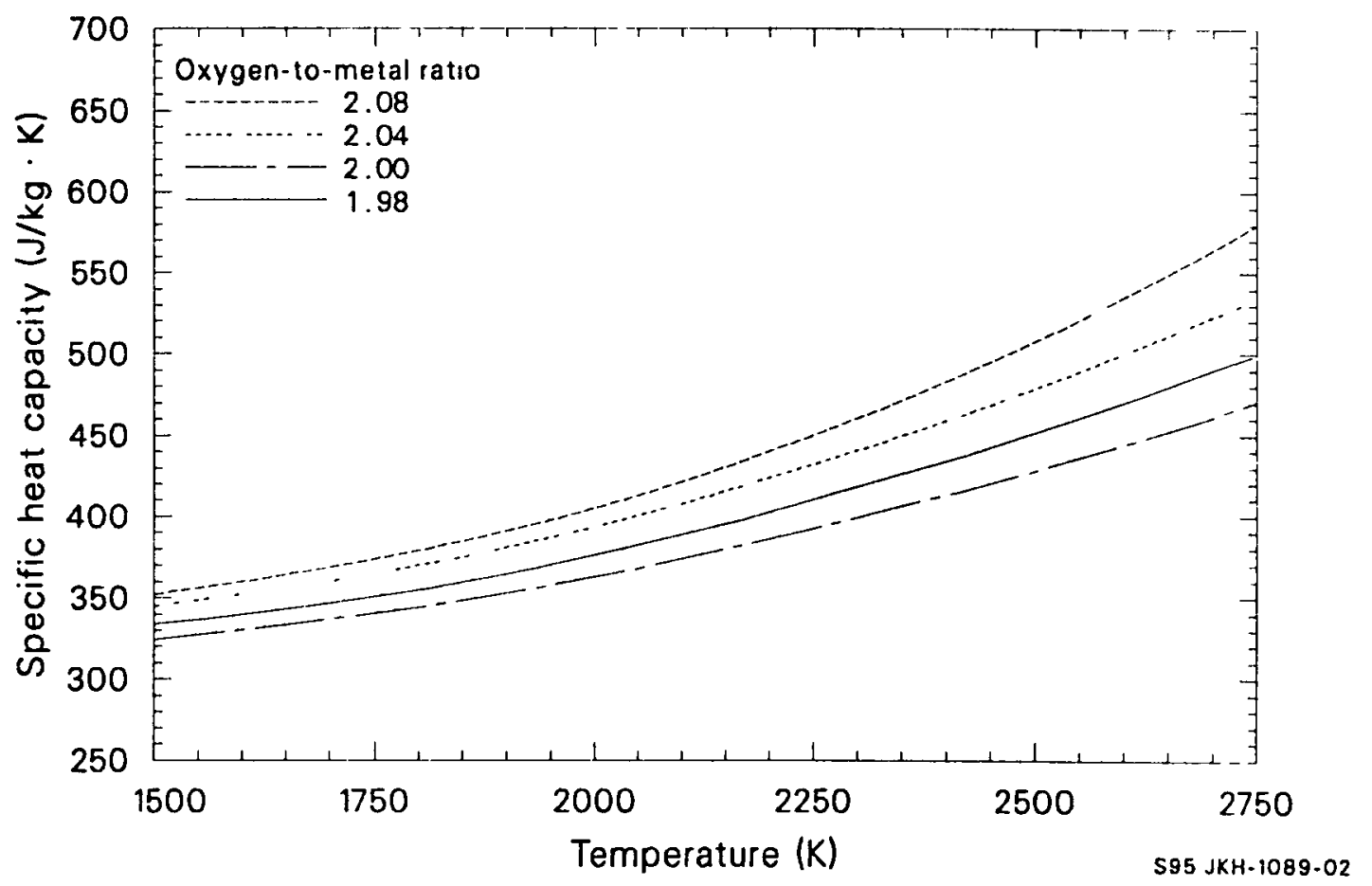

Figure 2.2-2. Specific heat capacity as a function of temperature and oxygen-to-metal ratio for $\left.\mathrm{U}_{0.8} \mathrm{Pu}_{0.2}\right) \mathrm{O}_{2+\mathrm{x}}$. 


\section{FCP, FENTHL}

Very hyperstoichiometric materials, such as $\mathrm{U}_{4} \mathrm{O}_{9}$ and $\mathrm{U}_{3} \mathrm{O}_{8}$, have specific heat capacities considerably larger than that of $\mathrm{UO}_{2} \cdot 2 \cdot 2-4,2 \cdot 2-11$ In addition, these materials exhibit peaks in specific heat capacity at temperatures associated with phase transitions. However, the incidence of these states in LWR fuel is infrequent; and their influence is neglected in this model.

In reactor fuel, nonstoichiometry is believed to be due to oxygen interstitials for hyperstoichiometric fuel and oxygen vacancies for hypostoichiometric fuel. 2.2-8 Excess oxygen tends to increase and an oxygen deficiency tends to decrease the probability of formation of Frenke 1 and Schottky defects, thereby changing the specific heat capacity. Thus, the logical adjustment to Equation (2.2-9) to account for the oxygen-to-metal ratio effect is in its last term, which includes the effect of defect formation. By multiplying the term by the oxygen-to-metal ratio divided by 2.0 , the following desirable features are produced.

1. The correlation is unaffected for stoichiometric fuel.

2. The proper temperature-dependence is obtained.

3. The specific heat capacity is increased for hyperstoichiometry and decreased for hypostoichiometry, in accordance with the data.

Therefore, this correction has been made to Equation (2.2-9), giving Equation (2.2-1). This is the model used for the specific heat capacity of solid $\mathrm{UO}_{2}$ and $\mathrm{PuO}_{2}$.

If the fuel consists of a mixed oxide $\left(\mathrm{MO}_{2}\right)$ with a weight fraction of $\mathrm{PuO}_{2}$ equal to FCOMP, then the specific heat capacity of the mixed-oxide fuel is calculated by the expression

$\mathrm{FCP}_{\mathrm{MO}_{2}}=\mathrm{FCP}_{\mathrm{UO}_{2}}(1-\mathrm{FCOMP})+\mathrm{FCP}_{\mathrm{PuO}_{2}} \cdot \mathrm{FCOMP}$. 


\section{FCP， FENTHL}

If the fuel temperature is greater than the fuel melting temperature, FTMELT, plus the liquid-solid coexistence temperature, then the fuel specific heat capacity is not calculated using Equation (2.2-1) but is set equal to the specific heat of 1 iquid fuel, $503 \mathrm{~J} / \mathrm{kg} \cdot \mathrm{K}$, for both $\mathrm{UO}_{2}$ and $\mathrm{PuO}_{2}$ fuel. If the fuel temperature is equal to the fuel melting temperature, TMELT, then the specific heat capacity is calculated by the expression

$F C P=(1.0-R) F C P(T-T M E L T)+R \cdot F C P M O L$

where

$R=$ fraction of fuel that is molten (unitless)

FCPMOL = specific heat capacity of 1 iquid fuel $(503 \mathrm{~J} / \mathrm{kg} \cdot \mathrm{K})$.

Fuel enthalpy, FENTHL, for solid fuel is found by integrating Equation (2.2-1) with respect to temperature over the interval $0 \mathrm{~K}$ to $\mathrm{T} \mathrm{K}$. The result of the integration is the expression

FENTHL $=\frac{K_{1} \theta}{\exp (\theta / T)-1}+\frac{K_{2} T^{2}}{2}+\frac{Y}{2}\left[K_{3} \exp \left(-E_{D} / R T\right)\right]$

Figure 2.2-3 shows the enthalpy of $\mathrm{UO}_{2}$ versus temperature calculated using Equation $(2.2-2)$.

If the fuel consists of a mixed oxide with a weight fraction of $\mathrm{PuO}_{2}$ equal to FCOMP, then the enthalpy of the mixed-oxide fuel is calculated by the expression

FENTHL $_{M_{2}}=$ FENTHL $_{\mathrm{UO}_{2}}(1-\mathrm{FCOMP})+\mathrm{FENTHL}_{\mathrm{PuO}_{2}} \cdot \mathrm{FCOMP}$. 
FCP， FENTHL

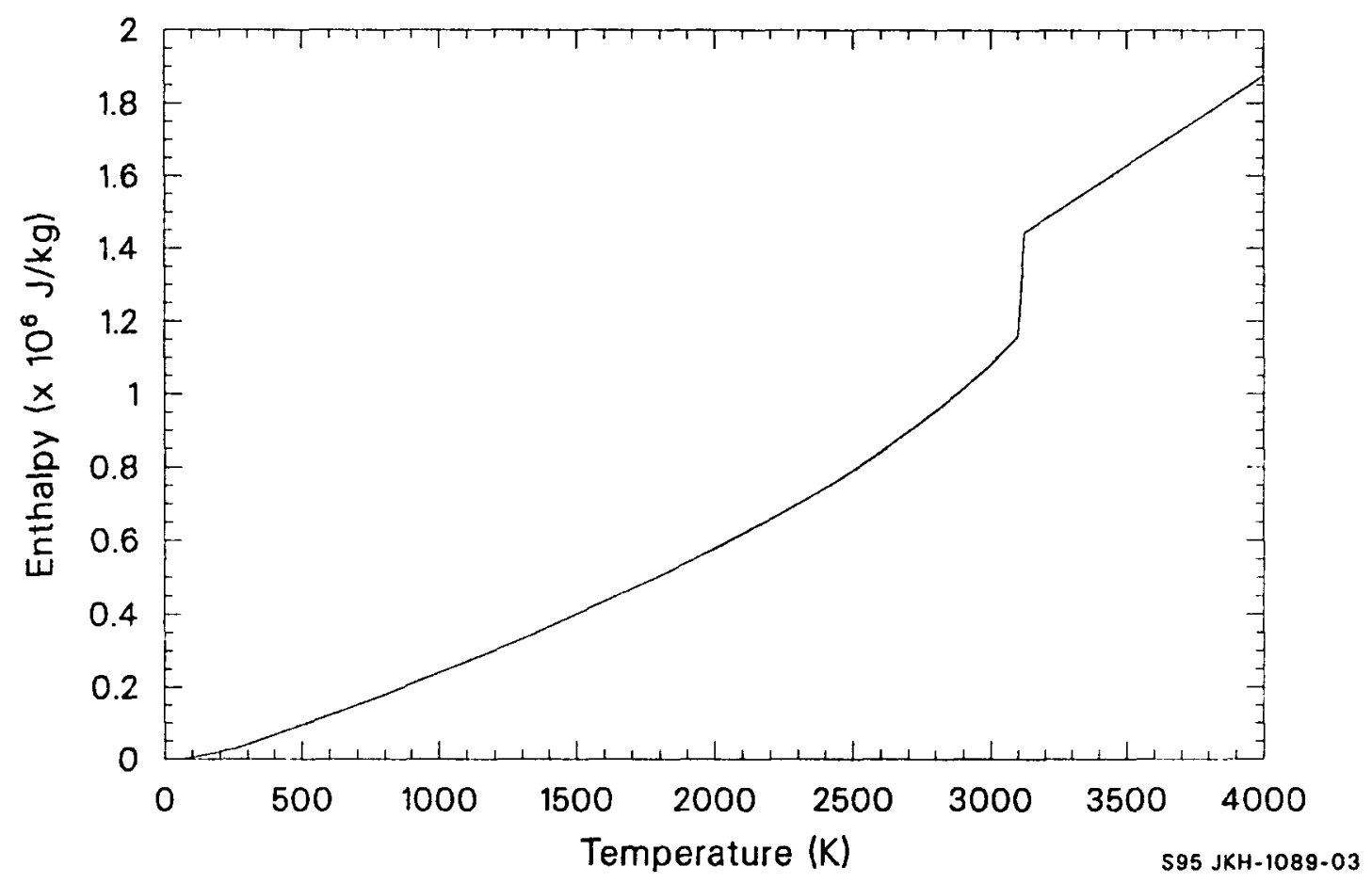

Figure 2.2-3. Enthalpy of $\mathrm{UO}_{2}$ as a function of temperature to $4000 \mathrm{~K}$. 


\section{FCP， FENTHL}

If the fuel temperature is equal to the fuel melting temperature, FTMELT, then the fuel enthalpy is calculated by the expression

FENTHL $=$ FENTHL $($ FTMELT $)+$ FHEFUS - FACMOT

where

FTMELT = melting temperature minus a vanishingly small increment (K)

FHEFUS $=$ heat of fusion of the fuel $(\mathrm{J} / \mathrm{kg})$

FACMOT $=$ fraction of the fuel that is molten (unitless).

If the fuel temperature, FTEMPT, is greater than the fuel melting temperature, then the fuel enthalpy is calculated by the expression

FENTHL $=$ FENTHL $($ FTMELT $)+$ FHEFUS + $($ FTEMP - FTMELT $) \cdot$ FCPMOL

where FCPMOL is the specific heat capacity of molten fuel $(\mathrm{J} / \mathrm{kg} \cdot \mathrm{K})$.

\subsubsection{Model Comparisons with Data}

Figure 2.2-4 shows the specific heat capacity correlation, FCP, for $\mathrm{UO}_{2}$ compared with data from three sources. $2.2-4,2.2-12,2.2-13$ These data were taken from experiments using stoichiometric $\mathrm{UO}_{2}$. At the high end of the temperature interval (a few hundred $K$ below the melting temperature), the data fall below the model calculations. (This is probably the result of partial melting due to a nonuniform temperature distribution within the sample.) For example, the measured specific heat capacity would be smaller because the specific heat capacity in a liquid is considerably lower than in a solid. A similar comparison is shown in Figure 2.2-5 for $\mathrm{PuO}_{2}$. In this instance, the correlation is compared with its own data 


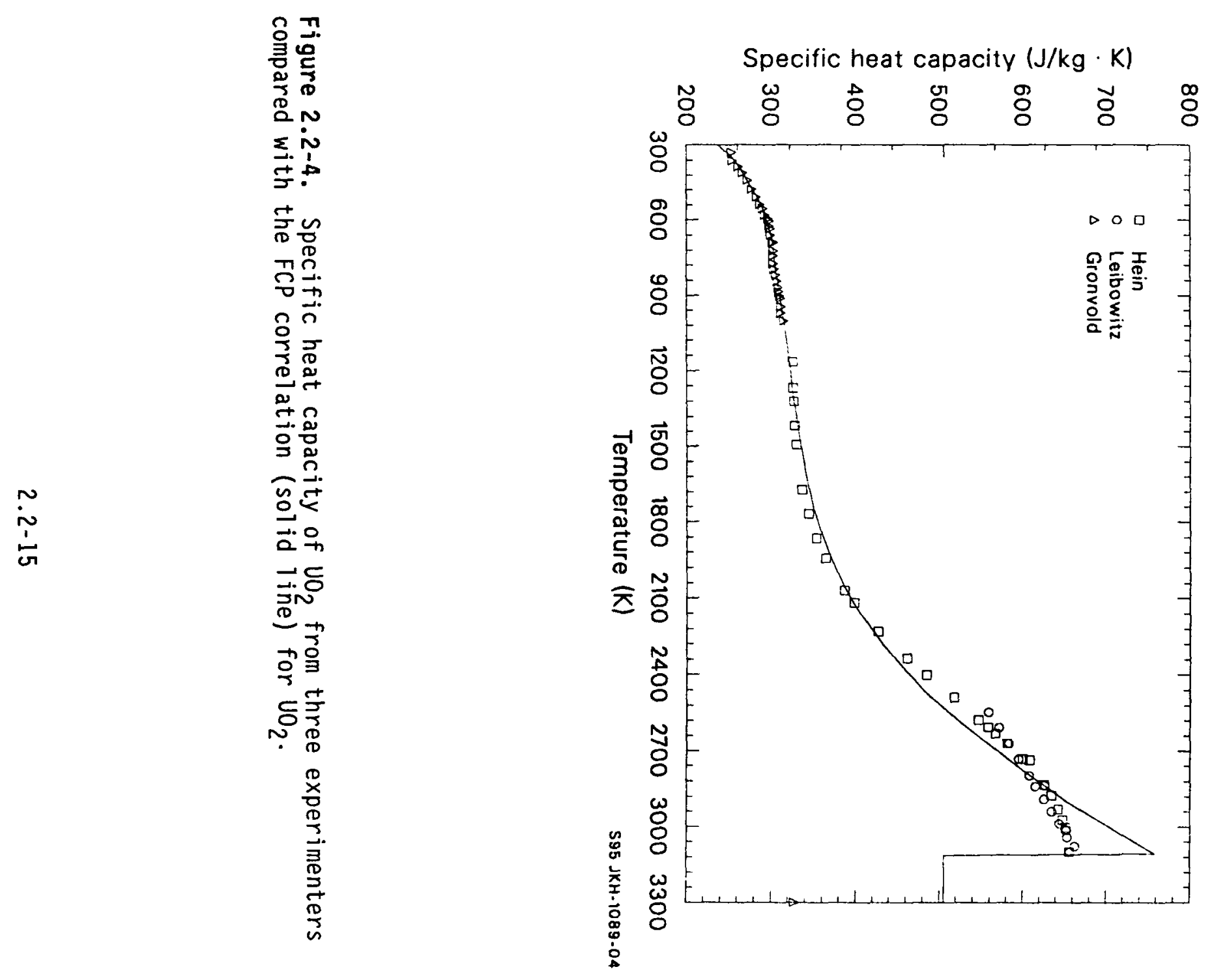

离 


\section{FCP， FENTHL}

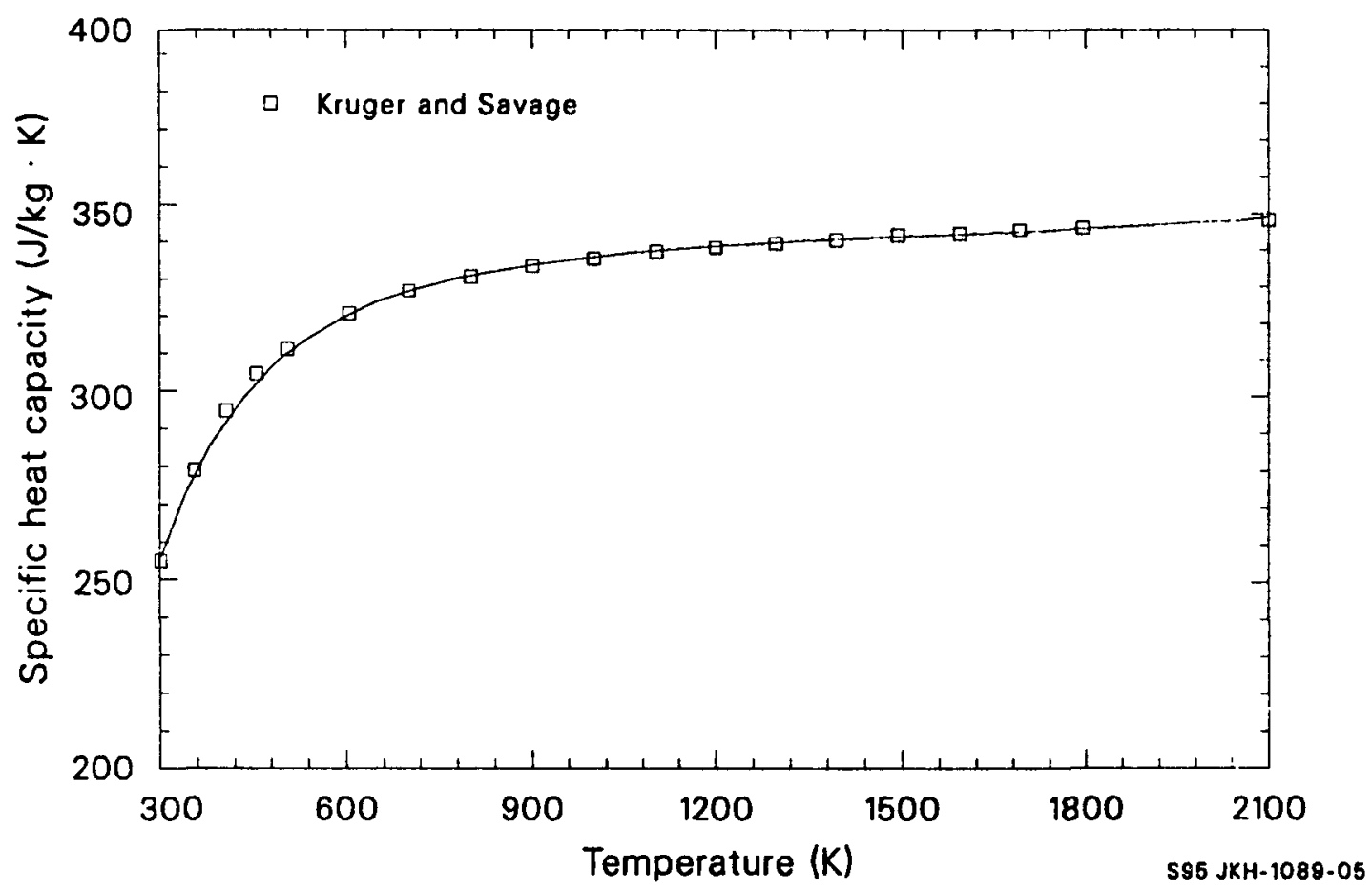

Figure 2.2-5. Specific heat capacity of $\mathrm{PuO}_{2}$ from Kruger and Savage compared with the FCP correlation (solid line) for $\mathrm{PuO}_{2}$. 
base. This was necessary due to the lack of a broad data base for $\mathrm{PuO}_{2}$ fuel. A better test of the accuracy of the model is found by comparing its predictions with mixed oxide data, 2.2-5,2.2-10,2.2-14 as shown in Figure 2.2-6. None of the data shown in this figure were used in the development of the model. The agreement is relatively good except for the low values reported by Affortit and Marcon. Other experimenters $2.2-3,2.2-10$ have pointed out that the results of Affortit and Marcon are generally low when compared with their data and have excluded the Affortit and Marcon measurements from their data base. No one has proposed an adequate explanation for the discrepancy. On the other hand, at least one investigator 2.2-9 has given considerable weight to the work done by Affortit and Marcon. In this document, the Affortit and Marcon results are used only in the analysis of the effect of departure from stoichiometry on the specific heat capacity.

\subsubsection{Model Uncertainty}

As would be expected, the accuracy of the FCP model when compared with its own data base is quite good. A better test was found by comparing the correlations with data not used during their development. The $\mathrm{UO}_{2}$ and mixed-oxide fuel correlations are analyzed separately in this section.

2.2.5.1 Uncertainty in $\mathrm{UO}_{2}$ Model. Kerrisk and $\mathrm{Clifton}$ report an accuracy of $\pm 3 \%$ for their correlation over the temperature range 300 to $3000 \mathrm{~K}$, with an approximately uniform distribution relative to temperature. When the calculations of the correlation are compared with the data of Gronvold for stoichiometric oxide, the agreement is even better, having a standard error of only $2.0 \mathrm{~J} / \mathrm{kg} \cdot \mathrm{K}$. This is a good test of the model, since these data were not used to develop the correlation. The paper by Affortit and Marcon gives correlations fit to their data. Arbitrarily taking $200-\mathrm{K}$ intervals over their temperature range from 600 to $3000 \mathrm{~K}$ and using their correlations, the standard error is $46 \mathrm{~J} / \mathrm{kg} \cdot \mathrm{K}$. Affortit and Marcon's 
FCP， FENTHL

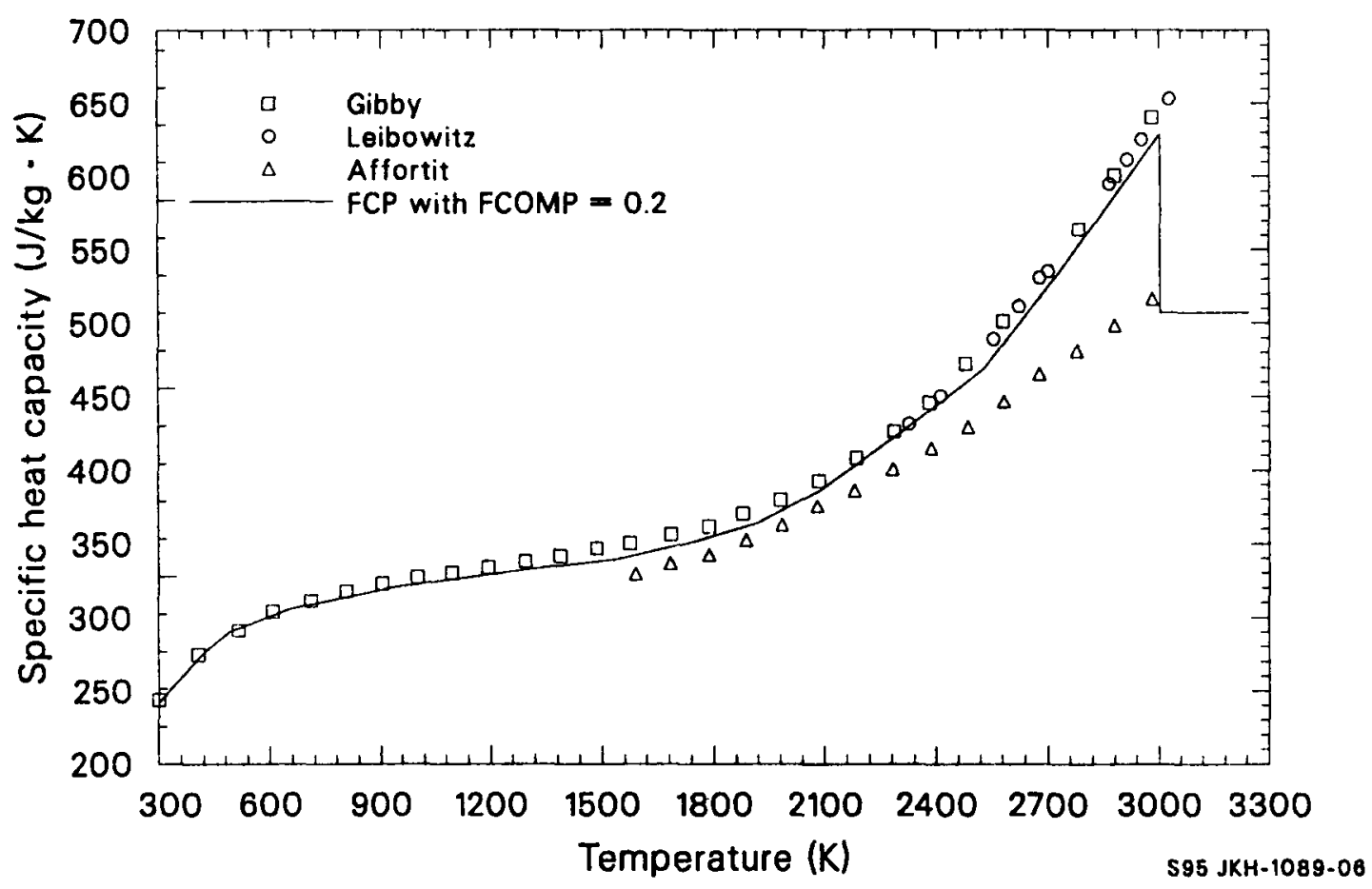

Figure 2.2-6. Specific heat capacity of $\mathrm{U}_{0}{ }_{8} \mathrm{Pu}_{0}, 2 \mathrm{O}_{2}$ from three experimenters compared with the FCP correlation (solid line) for mixed oxides. 


\section{FCP， FENTHL}

predictions are smaller at all temperatures, and the residuals increase with temperature.

\subsubsection{Uncertainty in the Mixed-oxide Model. Because of the} limited number of data for $\mathrm{PuO}_{2}$, the accuracy of the correlation for mixed-oxide fuel was used as a test for this correlation. Data were taken from Leibowitz, 2.2-14 Gibby, 2.2-10 and Affortit and Marcon.2.2-5 The model presented in this paper, using a weighted sum of the $\mathrm{UO}_{2}$ and $\mathrm{PuO}_{2}$ results, calculates specific heat capacities that are slightly larger than all but two of the 55 data points reported by Gibby and Leibowitz. At the highest and lowest applicable temperatures (3000 and $300 \mathrm{~K}$ ), the differences are negligible, $<1.0 \mathrm{~J} / \mathrm{kg} \cdot \mathrm{K}$. At intermediate temperatures, around $1600 \mathrm{~K}$, the residuals are approximately $10.0 \mathrm{~J} / \mathrm{kg} \cdot \mathrm{K}$, falling off smoothly from this temperature. The standard error of the model relative to these three data sets is $5.6 \mathrm{~J} / \mathrm{kg} \cdot \mathrm{K}$. This is equivalent to a maximum percentage error of $<2.5 \%$. Since these residuals are smaller than the scatter in the data, the model represents these data sets adequately. When the model is compared with that of Affortit and Marcon, again taking $200-\mathrm{K}$ steps from $1600 \mathrm{~K}$ to melting, the standard error is $46 \mathrm{~J} / \mathrm{kg} \cdot \mathrm{K}$. Affortit and Marcon always have the smaller value, and the residuals increase with increasing temperature, as with the $\mathrm{UO}_{2}$ results. Because of the lack of actual data, the results of Affortit and Marcon are not included in the standard error estimate.

\subsubsection{References}

2.2-1. J. F. Kerrisk and D. G. Clifton, "Smoothed Values of the Enthalpy and Heat Capacity of $\mathrm{UO}_{2}$," Nuclear Technology, 16, December 1972, pp. 531-535.

2.2-2. 0. L. Kruger and H. Savage, "Heat Capacity and Thermodynamic Properties of Plutonium Dioxide," Journal of Chemical Physics, 45, November 1968, pp. 4540-4544.

2.2-3. L. Leibowitz et al., "Enthalpy of Liquid Uranium Dioxide to $3500 \mathrm{~K}, "$ Journal of Nuclear Materials, 39, 1971, pp. 115-116. 


\section{FCP, FENTHL}

2.2-4. F. Gronvold et al., "Thermodynamics of the $\mathrm{UO}_{2}$ Phase I. Heat Capacities of $\mathrm{UO}_{2} .017$ and $\mathrm{UO}_{2} 254$ from 300 to $1000 \mathrm{~K}$ and Electronic Contributions, "Journal of Chemical Thermodynamics, 2, 1970, pp. 665-679.

2.2-5. C. Affortit and J. Marcon, "Chaleur Specifique a Haute Temperature des Oxydes D'Uranium et de Plutonium," Revue Internationale des Hautes Temperatures et des Refractaires, 7, 1970, pp. 236-241.

2.2-6. C. Kittel, Introduction to Solid State Physics, 3rd Edition, New York: John Wiley and Sons Inc., 1966.

2.2-7. D. R. 01 ander, Fundamental Aspects of Nuclear Reactor Fuel Elements, TID-26711-P1, 1976.

2.2-8. R. Szwarc, "The Defect Contribution to the Excess Enthalpy of Uranium Dioxide-Calculation of the Frenkel Energy, "Journal of Chemistry and Physics of Solids, 30, 1969, pp. 705-711.

2.2-9. E. A. Fischer, P. R. Kinsman, R. W. Ohse, "Critical Assessment of Equations of State for $\mathrm{UO}_{2}$," Journal of Nuclear Materials, 59, 1976, pp. 125-136.

2.2-10. R. L. Gibby et al., "Anatytical Expressions for Enthalpy and Heat Capacity for Uranium--Plutonium Oxide," Journal of Nuclear Materials, 50, 1974, pp. 155-161.

2.2-11. H. Inaba, H. Shimizu, K. Naito, "Lambda-Type Heat Capacity Anomalies in $\mathrm{U}_{3} \mathrm{O}_{8}$," Journal of Nuclear Materials, 64, 1977, pp. $66-70$.

2.2-12. R. A. Hein, L. H. Sjodah1, R. Szwarc, "Heat Content of Uranium Dioxide from $1200 \mathrm{~K}$ to $3100 \mathrm{~K}$," Journal of Nuclear Materials, 25. 1968, pp. 99-102.

2.2-13. L. Leibowitz, L. W. Mischler, M. G. Chasanov, "Enthalpy of Solid Uranium Dioxide from $2500 \mathrm{~K}$ to its Melting Point," Journal of Nuclear Materials, 29, 1969, pp. 356-358.

2.2-14. L. Leibowitz, D. F. Fischer, M. G. Chasanov, "Enthalpy of Uranium-Plutonium Oxides $\left(U_{0}, 8, P_{0}, 2\right) 0_{1} .07$ from 2350 to $3000 \mathrm{~K}, "$ Journal of Nuclear Materials, 42; 1972, pp. 113-116. 


\section{FCP, FENTHL}

\subsubsection{Bibliography}

The following data sources were used in previous EG\&G Idaho reports dealing with fuel specific heat models but are not quoted in this version. They are included here for completeness.

(1) C. E. Wicks and F. E. Block, Thermodynamics of 65 Elements--Their oxides, Halides, Carbides, and Nitrides, Bureau of Mines Bulletin No. $605,1963$.

(2) M. L. Bleiberg, R. M. Berman, B. Lustman, Effects of High Burnup on Oxide Ceramic Fuels, WAPD-T-1455, 1962.

(3) A. E. Ogard and J. A. Leary, Thermodynamics of Nuclear Materials, IAEA, Vienna, 1968, p. 651 .

(4) R. L. Gibby, Enthalpy and Heat Capacity of $U_{0.75} P u_{0.25}{ }^{\circ}-x$ (25-1490C), HEDL-TIME-73-19, 1973.

(5) L. Leibowitz, D. F. Fischer, M. G. Chasanov, Enthalpy of Molten Uranium-Plutonium Oxides, ANL-8042, 1974. 



\section{FTHCON}

\subsection{Thermal Conductivity (FTHCON)}

(D. L. Hagrman)

In this section, a correlation is presented for the thermal conductivity of uncracked $\mathrm{UO}_{2}$ and $(\mathrm{U}, \mathrm{Pu}) \mathrm{O}_{2}$ fuels. This property and the closely associated models for the effect of fuel cracking on temperature distributions within the fuel are critical to accurate predictions of fuel rod behavior in both steady-state operation and off-normal transients because fuel rod behavior is strongly dependent on temperature.

\subsubsection{Summary}

The FTHCON subcode determines the fuel thermal conductivity and its derivative with respect to temperature as a function of temperature, density, oxygen-to-metal (O/M) ratio, and plutonium content of the fuel. Burnup is also required input but is used only to calculate the melt temperature.

The data base shows no significant effect of porosity at temperatures above about $1600 \mathrm{~K}$, probably because of the effects of radiation and gas conductivity, which increase pore conductivity at high temperatures. The thermal conductivity of 1 iquid fuel was estimated from physical considerations because no data for the conductivity of molten fuel were found.

With the exception of minor modifications made to el iminate discontinuities in slope in the temperature range from 1364 to $2300 \mathrm{~K}$, the expression used to model thermal conductivity of solid fuel is 


\section{FTHCON}

$$
\begin{aligned}
k= & \left(\frac{D}{1+\left(6.5-0.00469 T^{\prime}\right)(1-D)}\right)\left(\frac{C_{v}}{\left(A+B T^{\prime \prime}\right)\left(1+3 e_{t h}\right)}\right) \\
& +5.2997 \times 10^{-3} T[\exp (-13358 / T)]\left\{1+0.169[(13358 / T)+2]^{2}\right\}
\end{aligned}
$$

where

$k=$ thermal conductivity $(W / m \cdot K)$

D = fraction of theoretical density (unitless)

$C_{V}=$ phonon contribution to the specific heat at constant volume $(\mathrm{J} / \mathrm{kg} \cdot \mathrm{K})$. The first term of the MATPRO correlation for fuel specific heat capacity is used for this factor. ${ }^{\text {a }}$

$e_{\text {th }}=$ linear strain caused by thermal expansion when temperature is $>300 \mathrm{~K}$ (unitless). The MATPRO correlation for fuel thermal expansion is used for this factor.

a. The analytical expression for $c_{v}$ as a function of temperature, $T$, and plutonium content, COMP, is

$$
\begin{aligned}
C_{v}= & \frac{296.7(535.285)^{2}}{T^{2}[\exp (535.285 / T)-1]^{2}}[\exp (535.285 / T)](1-\text { COMP }) \\
& +\frac{347.4(571)^{2}}{T^{2}[\exp (571 / T)-1]^{2}}[\exp (571 / T)] \operatorname{COMP} .
\end{aligned}
$$


FTHCON

$\mathrm{T}=$ fuel temperature $(\mathrm{K})$

$\mathrm{T}^{\prime}=$ fuel temperature if $<1364 \mathrm{~K}$. For temperatures $>1834 \mathrm{~K}$, the porosity factor, $D / 1+\left(6.5-0.00469 T^{\prime}\right)(1-D)$, is equal to -1 ; and for temperatures in the range 1364 to $1834 \mathrm{~K}$, the factor is found by interpolation, as explained in Subsection 2.3.3.

$\mathrm{T}^{\prime \prime}=$ fuel temperature if $<1800 \mathrm{~K}$. For temperatures $>2300 \mathrm{~K}, \mathrm{~T}^{\prime \prime}$ is equal to $2050 \mathrm{~K}$; for temperatures in the range 1800 to $2300 \mathrm{~K}, T^{\prime \prime}$ is found by interpolation, as explained in Subsection 2.3.3.

$A=a$ factor proportional to the point defect contribution to the phonon mean free path $(\mathrm{m} \cdot \mathrm{s} / \mathrm{kg} \cdot \mathrm{K})$. The correlation used for this factor is $0.339+12.6 \times$ absolute value $(2.0-0 / \mathrm{M}$ ratio).

$B=a$ factor proportional to the phonon-phonon scattering contribution to the phonon mean free path $(\mathrm{m} \cdot \mathrm{s} / \mathrm{kg} \cdot \mathrm{K})$. The correlation used for this factor is $0.06867 \times(1+0.6238 \times$ plutonium content of fuel).

The first term of Equation (2.3-1) represents the phonon contribution to specific heat, and the second term represents the electronic (electron-hole) contribution. The expression is valid only in the range $90 \%$ to $100 \%$ of theoretical density. When the fuel is molten, the first term is neglected.

The expected error of the thermal conductivity model has been estimated by computing the standard error of the model with respect to its data base. For stoichiometric $\mathrm{UO}_{2}$ samples, the standard error was $0.2(\mathrm{~W} / \mathrm{m} \cdot \mathrm{K})$; and for stoichiometric $(\mathrm{U}, \mathrm{Pu}) \mathrm{O}_{2}$ with $2 \% \mathrm{Pu}$, the standard error was 0.3 


\section{FTHCON}

$(\mathrm{W} / \mathrm{m} \bullet \mathrm{K})$. On the basis of these results, the following expression is used to calculate the expected standard error of the thermal conductivity of the solid fuel:

$U K=[0.2(1-$ COMP $)+0.7$ COMP $] \times(1.0+\mid 2-0$ TM $\mid 10)$

where

$$
\begin{aligned}
& \text { UK }=\begin{array}{l}
\text { expected standard error of solid fuel thermal conductivity } \\
(\mathrm{W} / \mathrm{m} \cdot \mathrm{K})
\end{array} \\
& \text { COMP }=\quad \begin{array}{l}
\mathrm{PuO}_{2} \text { content of the fuel (ratio of weight of } \mathrm{PuO}_{2} \text { to } \\
\text { total weight) }
\end{array} \\
& \text { OTM }=0 / \mathrm{M} \text { ratio of fuel (unitless). }
\end{aligned}
$$

The following subsection is a review of the general theories and data used to derive the model for thermal conductivity. Section 2.3.3 describes the development of the model, and Section 2.3.4 is a discussion of the uncertainty of the model.

\subsubsection{Literature Review: Theory and Available Data}

The mechanistic basis for a description of the thermal conductivity of solid unirradiated $\mathrm{UO}_{2}$ and $(\mathrm{U}, \mathrm{Pu}) \mathrm{O}_{2+x}$ is we 11 documented. 2.3-1,2.3-2, 2.3-3,2.3-4 The thermal conductivity is the sum of contributions due to lattice vibrations, electron-hole pairs, and radiant heat transfer. At temperatures below $1500 \mathrm{~K}$, the lattice component

$k_{p}=\rho C_{v} u \lambda / 3$

where 
FTHCON

$k_{p}=$ lattice vibration (phonon) contribution to thermal conductivity $(\mathrm{W} / \mathrm{m} \bullet \mathrm{K})$

$\rho=$ density of the solid $\left(\mathrm{kg} / \mathrm{m}^{3}\right)$

$C_{v}=$ phonon contribution to the specific heat at constant volume $(\mathrm{J} / \mathrm{kg} \cdot \mathrm{K})$

$\mathrm{u}=$ mean phonon speed $(\mathrm{m} / \mathrm{s})$

$\lambda=$ phonon mean free path $(\mathrm{m})$

is the most important contribution. At temperatures above $2000 \mathrm{~K}$, sufficient thermal energy exists to create significant numbers of electron-hole pairs. These pairs contribute

$k_{e}=2\left(\frac{k_{B}}{e}\right)^{2} T\left[\sigma+\frac{2 \sigma_{e} \sigma_{h}}{\sigma}\left(\frac{E_{q}}{2 k_{B} T}+2\right)^{2}\right]$

where

$$
\begin{aligned}
k_{e}= & \text { electronic contribution to thermal conductivity }(\mathrm{W} / \mathrm{m} \bullet \mathrm{K}) \\
\mathrm{k}_{\mathrm{B}}= & \text { Boltzmann's constant, } 1.38 \times 10^{-23}(\mathrm{~J} / \mathrm{K}) \\
\mathrm{e}= & \text { electron charge, } 1.6 \times 10^{-19}(\text { coul }) \\
\sigma_{\mathrm{e}}= & \text { electron contribution to electrical conductivity } \\
& (1 / \mathrm{ohm} \bullet \mathrm{m}) \\
\sigma_{\mathrm{h}}= & \text { hole contribution to electrical conductivity } \\
& (1 / \mathrm{ohm} \bullet \mathrm{m})
\end{aligned}
$$




\section{FTHCON}

$$
\begin{aligned}
\sigma & =\sigma_{\mathrm{e}}+\sigma_{\mathrm{h}}(\mathrm{l} / \mathrm{Ohm} \cdot \mathrm{m}) \\
\mathrm{E}_{\mathrm{g}} & =\text { energy gap between conduction and valence bands }(\mathrm{J}) \\
\mathrm{T} & =\text { temperature }(\mathrm{K})
\end{aligned}
$$

to the thermal conductivity2.3-4 if the solid is not doped with donors or acceptors. ${ }^{a}$ The radiant heat transfer contribution to the thermal conductivity is small in polycrystalline fuel, 2.3-1 presumably because the material is transparent only at long wavelengths.

The application of Equation (2.3-4) is simplified by the existence of accurate measurements of the electrical conductivity of $\mathrm{UO}_{2}$. Bates, Hinman, and Kawada ${ }^{2 \cdot 3-5}$ report electrical conductivities above $1400 \mathrm{~K}$ to be given by

$\sigma=3.569 \times 10^{7} \exp \left(-\frac{E_{q}}{2 k_{B} T}\right)$

where

$$
\begin{aligned}
& \sigma=\text { electrical conductivity }(1 / \mathrm{ohm} \cdot \mathrm{m}) \\
& \mathrm{E}_{\mathrm{g}}=\begin{array}{l}
\text { energy gap between conduction and valence bands, } 3.688 \mathrm{x} \\
10^{-19}(\mathrm{~J}) .
\end{array}
\end{aligned}
$$

Equation (2.3-4) can be combined with Equation (2.3-5) to obtain

a. Equation (2.3-4) models both the kinetic transport of thermal energy and the bipolar heat-conduction effect caused by the creation of electron-hole pairs at high temperature and their recombination at low temperatures. The bipolar effect is not present in heavily doped semiconductors. 
FTHCON

$k_{e}=2\left(\frac{k_{B}}{e}\right)^{2}\left(T \times 3.569 \times 10^{7}\right)\left[\exp \left(\frac{-E_{q}}{2 k_{B} T}\right)\right]\left[1+\frac{2 f}{(1+f)^{2}}\left(\frac{E_{q}}{2 k_{B} T}+2\right)^{2}(2.3-6)\right.$

where $f=\sigma_{h} / \sigma_{e}$ and the other symbols have been defined in

conjunction with the two previous equations. Equation (2.3-6) contains only one undetermined parameter, the ratio $f$.

Unfortunately, the application of Equation (2.3-3) for the lattice contribution to thermal conductivity is complex. $C_{v}$ and $\rho$ are available from the MATPRO routines for fuel specific heat and fuel thermal expansion and $u$ is approximately the speed of sound in the lattice, but the phonon mean free path, $\lambda$, is not a directly measured quantity. For the purpose of applying Equation (2.3-3) to $(\mathrm{U}, \mathrm{Pu}) \mathrm{O}_{2}$, it is sufficient to point out that the quantity $u \lambda / 3$ in Equation (2.3-3) at temperatures in the range from 500 to $3000 \mathrm{~K}$ is determined by two main contributions-- the deflection or scattering of lattice vibrations from permanent defects in the regular lattice pattern and the scattering of lattice vibrations from each other. ${ }^{a}$ The first contribution is primarily a function of the $0 / M$ ratio and the impurity content of the fuel, and the second contribution is a function of temperature and the plutonium content of the fuel.2.3-1 When the two main contributions to the phonon mean free path are incorporated in Equation (2.3-3), the appropriate expression for the lattice vibration contribution to the thermal conductivity of solid fuel is

$k_{p}=\frac{\rho C_{v}}{A+B T}$

where $A$ is a function of the number of permanent defects in the lattice and $B$ is a measure of the probability that lattice vibrations interfere with

a. The interested reader will find detailed physical discussions in References (2.3-3) and (2.3-4). 


\section{FTHCON}

each other. The second term in the denominator is proportional to temperature because the density of lattice vibrations is proportional to temperature in the range of 500 to $3000 \mathrm{~K}$.

For porous materials, some modification of Equation (2.3-7) is required because the pores do not have the same conductivity as the lattice. This physical problem has been discussed extensively in the literature, 2.3-1,2.3-6 to 2.3-10 where the effect of porosity has been shown to be a function of the porosity fraction (volume of pores/total volume), the pore shape, the thermal conductivity of any gas trapped within the pores, and the emissivity of the lattice.

Unfortunately, the detailed mechanistic analysis presented in the literature cannot be applied to most of the published thermal conductivity data because the pore shape and the composition of the gas trapped within the pores are usually not reported. Most authors interested in obtaining usable expressions 2.3-11 to 2.3-14 have adopted some form of either the modified Loeb equation

$\frac{\mathrm{k}}{\mathrm{k}_{100}}=1-\alpha \mathrm{P}$

or the Maxwe11-Eucken equation

$\frac{k}{k_{100}}=\frac{1-P}{1+\beta P}$

where

$k=$ thermal conductivity of a porous sample $(\mathrm{W} / \mathrm{m} \cdot \mathrm{K})$

$k_{100}=$ thermal conductivity of a sample with no pores $(\mathrm{W} / \mathrm{m} \cdot \mathrm{K})$ 


$$
\begin{aligned}
& P \quad=\quad \text { volume of pores/total sample volume (unitless) } \\
& \alpha, \beta \quad=\quad \begin{array}{l}
\text { factors depending on the shape and } \\
\text { distribution of the pores (unitless). }
\end{array}
\end{aligned}
$$

These authors usually assume $\alpha$ or $\beta$ to be linear functions of temperature and fit the linear functions to data from a limited set of samples.

None of the known previous studies of the effect of porosity on thermal conductivity has used the large collection of available experimental data. These data will be used in Section 2.3.3. The correlation will be based on the Maxwell-Eucken relation because from mechanistic studies both Marino ${ }^{2.3-6}$ and Ondracek ${ }^{2.3-10}$ recommend using this relation.

The remainder of this literature review discusses the available experimental measurements of thermal conductivity. Two general types of experiments will be encountered: the radial heat flow method and the transient heat pulse method. In the radial heat flow method, heat is supplied internally to a specimen and the thermal conductivity is deduced from measurements of the heat input and the steady-state temperature difference across the sample. In the transient heat pulse method, the measured quantity is the thermal diffusivity, 2.3-3

$$
\alpha=\frac{k}{C_{p} \rho}
$$

where

$$
\begin{aligned}
& \alpha=\text { thermal diffusivity }\left(\mathrm{m}^{2} / \mathrm{s}\right) \\
& k \quad=\text { thermal conductivity }(\mathrm{W} / \mathrm{m} \cdot \mathrm{K})
\end{aligned}
$$




\section{FTHCON}

$$
\begin{aligned}
& C_{p} \quad=\text { fuel specific heat at constant pressure }(\mathrm{J} / \mathrm{kg} \cdot \mathrm{K}) \\
& \rho \quad=\text { fuel density }\left(\mathrm{kg} / \mathrm{m}^{3}\right) .
\end{aligned}
$$

The available $\mathrm{UO}_{2}$ data are contained in References 2.3-11 to 2.3-27. Several of these sources were not used in the present analysis: Hedge 2.3-15 and Kingery2.3-16 used samples with densities between $70 \%$ and $75 \%$ theoretical density (TD)--far below those used in commercial fuel. Asamoto, 2.3-14 Reiswig, 2.3-23 Stora, 2.3-24 and Hetzler 2.3-17 employed radial heat flow methods in which the electrically heated center conductor may have been in contact with the oxide sample, so that Joule heating of the oxide could result and indicate anomalously high conductivity. The data of Hetzler and Asamoto also show unusually large scatter, probably because of cracking during the measurements. The data of Ferro2.3-25 show such large scatter that they were rejected for this reason alone. The temperature data of Lyons $2.3-22$ were derived from observation of postirradiation grain growth and restructuring, a method considered less reliable than that used by other investigators. The data of Van Craeynest and Stora, 2.3-11 and Lucks and Deem².3-20 showed anomalously low conductivity compared to data from fuels with similar density. The low conductivity was probably caused by cracking before the reported data were taken.

Christensen's data2.3-21 are the most suspect of those used. The apparatus used in his radial heat flow experiment is not well described. Possibly the sharp increase in thermal conductivity at high temperature reported by Christensen is due to electrical contact with the heating element. Because of this possibility and because the specimen composition changed from $\mathrm{UO}_{2.01}$ to $\mathrm{UO}_{1.99}$ during the test, Christensen's data for temperatures above $1800 \mathrm{~K}$ were not used. The data from Christensen that were used are listed in Table 2.3-1. 
Table 2.3-1. $\mathrm{UO}_{2}$ data from Christensen 2.3-21

\begin{tabular}{lll}
\hline $\begin{array}{c}\text { Temperature } \\
(\mathrm{K})\end{array}$ & $\begin{array}{c}\text { Density } \\
\text { (fraction of } \\
\text { theoretical) }\end{array}$ & $\begin{array}{c}\text { Thermal } \\
\text { Conductivity } \\
{[\mathrm{W} /(\mathrm{m} \cdot \mathrm{k})]}\end{array}$ \\
$.13120 \mathrm{E}+04$ & $.9400 \mathrm{E}+00$ & $.287000 \mathrm{E}+01$ \\
$.13890 \mathrm{E}+04$ & $.9400 \mathrm{E}+00$ & $.287000 \mathrm{E}+01$ \\
$.14320 \mathrm{E}+04$ & $.9400 \mathrm{E}+00$ & $.270000 \mathrm{E}+01$ \\
$.14960 \mathrm{E}+04$ & $.9400 \mathrm{E}+00$ & $.272000 \mathrm{E}+01$ \\
$.15520 \mathrm{E}+04$ & $.9400 \mathrm{E}+00$ & $.271000 \mathrm{E}+01$ \\
$.15870 \mathrm{E}+04$ & $.9400 \mathrm{E}+00$ & $.256000 \mathrm{E}+01$ \\
$.16120 \mathrm{E}+04$ & $.9400 \mathrm{E}+00$ & $.257000 \mathrm{E}+01$ \\
$.16560 \mathrm{E}+04$ & $.9400 \mathrm{E}+00$ & $.280000 \mathrm{E}+01$ \\
$.17470 \mathrm{E}+04$ & $.9400 \mathrm{E}+00$ & $.248000 \mathrm{E}+01$ \\
$.18380 \mathrm{E}+04$ & $.9400 \mathrm{E}+00$ & $.259000 \mathrm{E}+01$ \\
\hline
\end{tabular}




\section{FTHCON}

The data of Godfrey2.3-18 are the most reliable radial heat flow data reviewed in this section. Granular alumina insulation and careful positioning of the center heater were used to minimize electrical contact between the center heater and the sample. Runs which resulted in a change in the $0 / M$ ratio were reported as suspect and not used. Thermocouple errors were analyzed carefully, and runs at temperatures above $1373 \mathrm{~K}$ were identified as not valid because of thermocouple problems.

Unfortunately, Godfrey used only samples of $93.4 \%$ TD. Also, the data were corrected to TD by dividing by the fraction of theoretical density. The unsatisfactory nature of this correction would no doubt have become evident if samples of varying density had been used. This correction was removed before the data were used to develop the model described here.

The data with the density correction removed are listed in Table 2.3-2. Several runs are represented, and there is no systematic variation from run to run. Data at temperatures below $500 \mathrm{~K}$ are not included in Table 2.3-2 because the low-temperature data cannot be used with Equation (2.3-7). (The equation is valid only when temperatures are well above the Debye temperature.)

The remaining five sets of $\mathrm{UO}_{2}$ data used were all obtained with the heat pulse method. Bates 2.3-19 measured the thermal diffusivity of three samples, all with a density of $98.4 \%$ TD. Some data which correspond to runs taken when the samples had a metallic second phase at the grain boundaries were not used. Table 2.3-3 is a list of the values of thermal conductivity deduced from Bates' thermal diffusivity data, Equation (2.3-10), and the MATPRO expressions for fuel specific heat at constant pressure and for thermal expansion (see Sections 2.2 and 2.5). Systematic variation does not occur in the data either from run to run or sample to sample.

Gibby 2.3-27 reported the thermal diffusivity of a $\mathrm{UO}_{2}$ sample as part of a study on the effect of plutonium additions The sample had a density of 95.8\% TD. The thermal conductivity data calculated from Gibby's diffusivities are shown in Table 2.3-4. 
FTHCON

Table 2.3-2. $\mathrm{UO}_{2}$ data from Godfrey et a1 $2.3-18$

\begin{tabular}{|c|c|c|c|}
\hline $\begin{array}{c}\text { Temperature } \\
\text { (K) }\end{array}$ & $\begin{array}{l}\text { Density } \\
\text { (fraction of } \\
\text { theoretical) }\end{array}$ & $\begin{array}{l}\text { Therma? } \\
\text { Conduct ivity } \\
{[\mathrm{W} /(\mathrm{m} \cdot \mathrm{k})]}\end{array}$ & Run Number \\
\hline $\begin{array}{l}.57400 \mathrm{E}+03 \\
.67300 \mathrm{E}+03 \\
.76700 \mathrm{E}+03 \\
.87700 \mathrm{E}+03 \\
.97600 \mathrm{E}+03 \\
.10740 \mathrm{E}+04 \\
.67500 \mathrm{E}+03 \\
.87000 \mathrm{E}+03 \\
.86900 \mathrm{E}+03 \\
.97100 \mathrm{E}+03 \\
.10720 \mathrm{E}+04 \\
.11650 \mathrm{E}+04 \\
.11730 \mathrm{E}+04 \\
.12790 \mathrm{E}+04 \\
.12820 \mathrm{E}+04 \\
.57200 \mathrm{E}+03 \\
.87000 \mathrm{E}+03 \\
.87000 \mathrm{E}+03 \\
.87200 \mathrm{E}+03 \\
.11710 \mathrm{E}+04 \\
.11750 \mathrm{E}+04 \\
.57000 \mathrm{E}+03 \\
.57200 \mathrm{E}+03 \\
.67300 \mathrm{E}+03 \\
.67300 \mathrm{E}+03 \\
.77400 \mathrm{E}+03 \\
.77400 \mathrm{E}+03 \\
.87500 \mathrm{E}+03 \\
.87500 \mathrm{E}+03 \\
.97300 \mathrm{E}+03 \\
.97300 \mathrm{E}+03 \\
.10710 \mathrm{E}+04 \\
.10710 \mathrm{E}+04 \\
.11730 \mathrm{E}+04 \\
.12710 \mathrm{E}+04 \\
.13230 \mathrm{E}+04 \\
.57600 \mathrm{E}+03 \\
.57600 \mathrm{E}+03 \\
.67100 \mathrm{E}+03 \\
.67100 \mathrm{E}+03 \\
.67100 \mathrm{E}+03 \\
.87400 \mathrm{E}+03\end{array}$ & $\begin{array}{l}.9340 \mathrm{E}+00 \\
.9340 \mathrm{E}+00 \\
.9340 \mathrm{E}+00 \\
.9340 \mathrm{E}+00 \\
.9340 \mathrm{E}+00 \\
.9340 \mathrm{E}+00 \\
.9340 \mathrm{E}+00 \\
.9340 \mathrm{E}+00 \\
.9340 \mathrm{E}+00 \\
.9340 \mathrm{E}+00 \\
.9340 \mathrm{E}+00 \\
.9340 \mathrm{E}+00 \\
.9340 \mathrm{E}+00 \\
.9340 \mathrm{E}+00 \\
.9340 \mathrm{E}+00 \\
.9340 \mathrm{E}+00 \\
.9340 \mathrm{E}+00 \\
.9340 \mathrm{E}+00 \\
.9340 \mathrm{E}+00 \\
.9340 \mathrm{E}+00 \\
.9340 \mathrm{E}+00 \\
.9340 \mathrm{E}+00 \\
.9340 \mathrm{E}+00 \\
.9340 \mathrm{E}+00 \\
.9340 \mathrm{E}+00 \\
.9340 \mathrm{E}+00 \\
.9340 \mathrm{E}+00 \\
.9340 \mathrm{E}+00 \\
.9340 \mathrm{E}+00 \\
.9340 \mathrm{E}+00 \\
.9340 \mathrm{E}+00 \\
.9340 \mathrm{E}+00 \\
.9340 \mathrm{E}+00 \\
.9340 \mathrm{E}+00 \\
.9340 \mathrm{E}+00 \\
.9340 \mathrm{E}+00 \\
.9340 \mathrm{E}+00 \\
.9340 \mathrm{E}+00 \\
.9340 \mathrm{E}+00 \\
.9340 \mathrm{E}+00 \\
.9340 \mathrm{E}+00 \\
.9340 \mathrm{E}+00\end{array}$ & $\begin{array}{l}.540400 E+01 \\
.475400 E+01 \\
.432200 E+01 \\
.390200 E+01 \\
.355900 E+01 \\
.326500 E+01 \\
.461000 E+01 \\
.379400 E+01 \\
.383200 E+01 \\
.348700 E+01 \\
.318200 E+01 \\
.298500 E+01 \\
.297500 E+01 \\
.277400 E+01 \\
.275500 E+01 \\
.518700 E+01 \\
.373700 E+01 \\
.369000 E+01 \\
.368100 E+01 \\
.288800 E+01 \\
.287000 E+01 \\
.514000 E+01 \\
.511100 E+01 \\
.458900 E+01 \\
.455700 E+01 \\
.407700 E+01 \\
.409600 E+01 \\
.371100 E+01 \\
.373400 E+01 \\
.341600 E+01 \\
.341700 E+01 \\
.316900 E+01 \\
.316400 E+01 \\
.295000 E+01 \\
.275100 E+01 \\
.268200 E+01 \\
.523200 E+01 \\
.522900 E+01 \\
.469100 E+01 \\
.469100 E+01 \\
.470500 E+01 \\
.382100 E+01\end{array}$ & $\begin{array}{l}1 \\
3 \\
1 \\
1 \\
4 \\
1 \\
1 \\
5 \\
1\end{array}$ \\
\hline
\end{tabular}




\section{FTHCON}

Table 2.3-3. $\mathrm{UO}_{2}$ data from Bates ${ }^{2 \cdot 3-19}$ thermal diffusivity measurements

\begin{tabular}{|c|c|c|c|c|}
\hline $\begin{array}{c}\text { Temperature } \\
(\mathrm{K})\end{array}$ & $\begin{array}{l}\text { Density } \\
\text { (Fraction of } \\
\text { theoretical) }\end{array}$ & $\begin{array}{l}\text { Thermal } \\
\text { Conductivity } \\
{[\mathrm{W} /(\mathrm{m} \cdot \mathrm{k})]}\end{array}$ & Sample & $\begin{array}{l}\text { Cycle } \\
\text { Number }\end{array}$ \\
\hline $\begin{array}{l}.53900 E+03 \\
.53900 E+03 \\
.75600 E+03 \\
.76100 E+03 \\
.89500 E+03 \\
.89100 E+03 \\
.99400 E+03 \\
.99500 E+03 \\
.11800 E+04 \\
.11850 E+04 \\
.13250 E+04 \\
.13250 E+04 \\
.14890 E+04 \\
.14910 E+04 \\
.16660 E+04 \\
.16550 E+04 \\
.17780 E+04 \\
.17800 E+04 \\
.18630 E+04 \\
.18660 E+04 \\
.19770 E+04 \\
.19720 E+04 \\
.20930 E+04 \\
.21020 E+04 \\
.21740 E+04 \\
.21870 E+04 \\
.23730 E+04 \\
.23730 E+04 \\
.22800 E+04 \\
.22850 E+04 \\
.15990 E+04 \\
.16010 E+04 \\
.16090 E+04\end{array}$ & $\begin{array}{l}.9840 \mathrm{E}+00 \\
.9840 \mathrm{E}+00 \\
.9840 \mathrm{E}+00 \\
.9840 \mathrm{E}+00 \\
.9840 \mathrm{E}+00 \\
.9840 \mathrm{E}+00 \\
.9840 \mathrm{E}+00 \\
.9840 \mathrm{E}+00 \\
.9840 \mathrm{E}+00 \\
.9840 \mathrm{E}+00 \\
.9840 \mathrm{E}+00 \\
.9840 \mathrm{E}+00 \\
.9840 \mathrm{E}+00 \\
.9840 \mathrm{E}+00 \\
.9840 \mathrm{E}+00 \\
.9840 \mathrm{E}+00 \\
.9840 \mathrm{E}+00 \\
.9840 \mathrm{E}+00 \\
.9840 \mathrm{E}+00 \\
.9840 \mathrm{E}+00 \\
.9840 \mathrm{E}+00 \\
.9840 \mathrm{E}+00 \\
.9840 \mathrm{E}+00 \\
.9840 \mathrm{E}+00 \\
.9840 \mathrm{E}+00 \\
.9840 \mathrm{E}+00 \\
.9840 \mathrm{E}+00 \\
.9840 \mathrm{E}+00 \\
.9840 \mathrm{E}+00 \\
.9840 \mathrm{E}+00 \\
.9840 \mathrm{E}+00 \\
.9840 \mathrm{E}+00 \\
.9840 \mathrm{E}+00\end{array}$ & $\begin{array}{l}.650000 E+01 \\
.657000 E+01 \\
.482000 E+01 \\
.502000 E+01 \\
.411000 E+01 \\
.435000 E+01 \\
.383000 E+01 \\
.391000 E+01 \\
.328000 E+01 \\
.313000 E+01 \\
.285000 E+01 \\
.289000 E+01 \\
.251000 E+01 \\
.255000 E+01 \\
.240000 E+01 \\
.237000 E+01 \\
.224000 E+01 \\
.213000 E+01 \\
.219000 E+01 \\
.219000 E+01 \\
.210000 E+01 \\
.224000 E+01 \\
.232000 E+01 \\
.225000 E+01 \\
.226000 E+01 \\
.225000 E+01 \\
.249000 E+01 \\
.264000 E+01 \\
.229000 E+01 \\
.242000 E+01 \\
.237000 E+01 \\
.249000 E+01 \\
.232000 E+01\end{array}$ & RRI & \\
\hline $\begin{array}{l}.13600 E+04 \\
.14530 E+04 \\
.15620 E+04 \\
.16490 E+04 \\
.17500 E+04 \\
.19070 E+04 \\
.20050 E+04 \\
.20070 E+04\end{array}$ & $\begin{array}{l}.9840 E+00 \\
.9840 E+00 \\
.9840 E+00 \\
.9840 E+00 \\
.9840 E+00 \\
.9840 E+00 \\
.9840 E+00 \\
.9840 E+00\end{array}$ & $\begin{array}{l}.283000 E+01 \\
.242000 E+01 \\
.248000 E+01 \\
.237000 E+01 \\
.239000 E+01 \\
.213000 E+01 \\
.210000 E+01 \\
.231000 E+01\end{array}$ & RRI & 4 \\
\hline
\end{tabular}


FTHCON

Table 2.3-3. (continued)

\begin{tabular}{|c|c|c|c|c|}
\hline $\begin{array}{c}\text { Temperature } \\
\text { (K) }\end{array}$ & $\begin{array}{l}\text { Density } \\
\text { (Fraction of } \\
\text { theoretical) }\end{array}$ & $\begin{array}{l}\text { Thermal } \\
\text { Conductivity } \\
{[\mathrm{W} /(\mathrm{m} \cdot \mathrm{k})]}\end{array}$ & Sample & $\begin{array}{l}\text { Cycle } \\
\text { Number }\end{array}$ \\
\hline $\begin{array}{l}.21090 E+04 \\
.21040 E+04 \\
.21950 E+04 \\
.22950 E+04 \\
.23840 E+04\end{array}$ & $\begin{array}{l}.9840 E+00 \\
.9840 E+00 \\
.9840 E+00 \\
.9840 E+00 \\
.9840 E+00\end{array}$ & $\begin{array}{l}.219000 E+01 \\
.227000 E+01 \\
.235000 E+01 \\
.247000 E+01 \\
.242000 E+01\end{array}$ & 1 & $\downarrow$ \\
\hline $\begin{array}{l}.57100 E+03 \\
.57700 E+03 \\
.57700 E+03 \\
.66100 E+03 \\
.68200 E+03 \\
.78600 E+03 \\
.78400 E+03 \\
.78500 E+03 \\
.86600 E+03 \\
.86700 E+03 \\
.96100 E+03 \\
.96100 E+03 \\
.96100 E+03 \\
.10690 E+04 \\
.10710 E+04 \\
.10690 E+04 \\
.11710 E+04 \\
.11740 E+04 \\
.11730 E+04 \\
.12700 E+04 \\
.12690 E+04 \\
.12700 E+04 \\
.13610 E+04 \\
.13610 E+04 \\
.13610 E+04 \\
.13610 E+04 \\
.14710 E+04 \\
.14720 E+04 \\
.14690 E+04 \\
.15690 E+04 \\
.15710 E+04 \\
.15690 E+04 \\
.16830 E+04 \\
.16830 E+04 \\
.17580 E+04 \\
.17560 E+04 \\
.17600 E+04\end{array}$ & $\begin{array}{l}.9840 \mathrm{E}+00 \\
.9840 \mathrm{E}+00 \\
.9840 \mathrm{E}+00 \\
.9840 \mathrm{E}+00 \\
.9840 \mathrm{E}+00 \\
.9840 \mathrm{E}+00 \\
.9840 \mathrm{E}+00 \\
.9840 \mathrm{E}+00 \\
.9840 \mathrm{E}+00 \\
.9840 \mathrm{E}+00 \\
.9840 \mathrm{E}+00 \\
.9840 \mathrm{E}+00 \\
.9840 \mathrm{E}+00 \\
.9840 \mathrm{E}+00 \\
.9840 \mathrm{E}+00 \\
.9840 \mathrm{E}+00 \\
.9840 \mathrm{E}+00 \\
.9840 \mathrm{E}+00 \\
.9840 \mathrm{E}+00 \\
.9840 \mathrm{E}+00 \\
.9840 \mathrm{E}+00 \\
.9840 \mathrm{E}+00 \\
.9840 \mathrm{E}+00 \\
.9840 \mathrm{E}+00 \\
.9840 \mathrm{E}+00 \\
.9840 \mathrm{E}+00 \\
.9840 \mathrm{E}+00 \\
.9840 \mathrm{E}+00 \\
.9840 \mathrm{E}+00 \\
.9840 \mathrm{E}+00 \\
.9840 \mathrm{E}+00 \\
.9840 \mathrm{E}+00 \\
.9840 \mathrm{E}+00 \\
.9840 \mathrm{E}+00 \\
.9840 \mathrm{E}+00 \\
.9840 \mathrm{E}+00 \\
.9840 \mathrm{E}+00\end{array}$ & $\begin{array}{l}.572000 E+01 \\
.603000 E+01 \\
.616000 E+01 \\
.533000 E+01 \\
.541000 E+01 \\
.448000 E+01 \\
.445000 E+01 \\
.454000 E+01 \\
.415000 E+01 \\
.415000 E+01 \\
.373000 E+01 \\
.363000 E+01 \\
.396000 E+01 \\
.335000 E+01 \\
.331000 E+01 \\
.351000 E+01 \\
.304000 E+01 \\
.307000 E+01 \\
.324000 E+01 \\
.280000 E+01 \\
.287000 E+01 \\
.281000 E+01 \\
.255000 E+01 \\
.263000 E+01 \\
.259000 E+01 \\
.263000 E+01 \\
.254000 E+01 \\
.267000 E+01 \\
.226000 E+01 \\
.240000 E+01 \\
.241000 E+01 \\
.246000 E+01 \\
.233000 E+01 \\
.237000 E+01 \\
.230000 E+01 \\
.219000 E+01 \\
.228000 E+01\end{array}$ & RR2 & 2 \\
\hline
\end{tabular}




\section{FTHCON}

Table 2.3-3. (continued)

\begin{tabular}{|c|c|c|c|c|}
\hline $\begin{array}{c}\text { Temperature } \\
\text { (K) }\end{array}$ & $\begin{array}{c}\text { Density } \\
\text { (Fraction of } \\
\text { theoretical) } \\
\end{array}$ & $\begin{array}{l}\text { Thermal } \\
\text { Conduct ivity } \\
{[\mathrm{W} /(\mathrm{m} \cdot \mathrm{k})]}\end{array}$ & Sample & $\begin{array}{l}\text { Cycle } \\
\text { Number }\end{array}$ \\
\hline $\begin{array}{l}.67300 E+03 \\
.12830 E+04 \\
.67300 E+03\end{array}$ & $\begin{array}{l}.9840 E+00 \\
.9840 E+00 \\
.9840 E+00\end{array}$ & $\begin{array}{l}.553000 E+01 \\
.275000 E+01 \\
.542000 E+01\end{array}$ & RR2 & 3 \\
\hline $\begin{array}{l}.11000 E+04 \\
.10890 E+04 \\
.10900 E+04 \\
.10990 E+04 \\
.81300 E+03 \\
.79700 E+03 \\
.50700 E+03 \\
.58300 E+03 \\
.67600 E+03 \\
.67900 E+03 \\
.76300 E+03 \\
.76400 E+03 \\
.87300 E+03 \\
.87600 E+03 \\
.97900 E+03 \\
.98100 E+03\end{array}$ & $\begin{array}{l}.9840 \mathrm{E}+00 \\
.9840 \mathrm{E}+00 \\
.9840 \mathrm{E}+00 \\
.9840 \mathrm{E}+00 \\
.9840 \mathrm{E}+00 \\
.9840 \mathrm{E}+00 \\
.9840 \mathrm{E}+00 \\
.9840 \mathrm{E}+00 \\
.9840 \mathrm{E}+00 \\
.9840 \mathrm{E}+00 \\
.9840 \mathrm{E}+00 \\
.9840 \mathrm{E}+00 \\
.9840 \mathrm{E}+00 \\
.9840 \mathrm{E}+00 \\
.9840 \mathrm{E}+00 \\
.9840 \mathrm{E}+00\end{array}$ & $\begin{array}{l}.360000 E+01 \\
.340000 E+01 \\
.354000 E+01 \\
.341000 E+01 \\
.486000 E+01 \\
.480000 E+01 \\
.646000 E+01 \\
.640000 E+01 \\
.542000 E+01 \\
.551000 E+01 \\
.501000 E+01 \\
.513000 E+01 \\
.450000 E+01 \\
.429000 E+01 \\
.395000 E+01 \\
.396000 E+01\end{array}$ & RR3 & 1 \\
\hline $\begin{array}{l}.10650 E+04 \\
.10720 E+04 \\
.11880 E+04 \\
.11870 E+04 \\
.12770 E+04 \\
.12850 E+04 \\
.12840 E+04 \\
.10710 E+04 \\
.88000 E+03 \\
.87900 E+03 \\
.87900 E+03 \\
.67800 E+03\end{array}$ & $\begin{array}{l}.9840 E+00 \\
.9840 E+00 \\
.9840 E+00 \\
.9840 E+00 \\
.9840 E+00 \\
.9840 E+00 \\
.9840 E+00 \\
.9840 E+00 \\
.9840 E+00 \\
.9840 E+00 \\
.9840 E+00 \\
.9840 E+00\end{array}$ & $\begin{array}{l}.374000 E+01 \\
.369000 E+01 \\
.317000 E+01 \\
.336000 E+01 \\
.309000 E+01 \\
.319000 E+01 \\
.328000 E+01 \\
.370000 E+01 \\
.457000 E+01 \\
.452000 E+01 \\
.452000 E+01 \\
.534000 E+01\end{array}$ & & \\
\hline $\begin{array}{l}.57300 E+03 \\
.58300 E+03 \\
.68000 E+03 \\
.68100 E+03 \\
.67800 E+03 \\
.77600 E+03 \\
.77500 E+03 \\
.89100 E+03 \\
.89500 E+03\end{array}$ & $\begin{array}{l}.9840 E+00 \\
.9840 E+00 \\
.9840 E+00 \\
.9840 E+00 \\
.9840 E+00 \\
.9840 E+00 \\
.9840 E+00 \\
.9840 E+00 \\
.9840 E+00\end{array}$ & $\begin{array}{l}.618000 E+01 \\
.589000 E+01 \\
.536000 E+01 \\
.524000 E+01 \\
.533000 E+01 \\
.488000 E+01 \\
.496000 E+01 \\
.417000 E+01 \\
.430000 E+01\end{array}$ & RR3 & 3 \\
\hline
\end{tabular}


FTHCON

Table 2.3-3. (continued)

\begin{tabular}{|c|c|c|c|c|}
\hline $\begin{array}{c}\text { Temperature } \\
\text { (K) }\end{array}$ & $\begin{array}{l}\text { Density } \\
\text { (Fraction of } \\
\text { theoretical) }\end{array}$ & $\begin{array}{l}\text { Thermal } \\
\text { Conductivity } \\
{[\mathrm{W} /(\mathrm{m} \bullet \mathrm{k})]}\end{array}$ & Sample & $\begin{array}{l}\text { Cycle } \\
\text { Number }\end{array}$ \\
\hline $\begin{array}{l}.96800 E+03 \\
.97300 E+03 \\
.10870 E+04 \\
.10810 E+04 \\
.11720 E+04 \\
.11730 E+04 \\
.12920 E+04 \\
.12910 E+04 \\
.13770 E+04 \\
.13800 E+04 \\
.14730 E+04 \\
.14770 E+04 \\
.15780 E+04 \\
.15840 E+04 \\
.16730 E+04 \\
.16790 E+04 \\
.17690 E+04 \\
.17920 E+04 \\
.17860 E+04 \\
.15950 E+04 \\
.15960 E+04 \\
.14000 E+04 \\
.13990 E+04 \\
.11660 \mathrm{E}+04 \\
.10790 E+04 \\
.10850 E+04 \\
.84700 E+03 \\
.84700 E+03 \\
.57700 E+03 \\
.55300 E+03\end{array}$ & $\begin{array}{l}.9840 \mathrm{E}+00 \\
.9840 \mathrm{E}+00 \\
.9840 \mathrm{E}+00 \\
.9840 \mathrm{E}+00 \\
.9840 \mathrm{E}+00 \\
.9840 \mathrm{E}+00 \\
.9840 \mathrm{E}+00 \\
.9840 \mathrm{E}+00 \\
.9840 \mathrm{E}+00 \\
.9840 \mathrm{E}+00 \\
.9840 \mathrm{E}+00 \\
.9840 \mathrm{E}+00 \\
.9840 \mathrm{E}+00 \\
.9840 \mathrm{E}+00 \\
.9840 \mathrm{E}+00 \\
.9840 \mathrm{E}+00 \\
.9840 \mathrm{E}+00 \\
.9840 \mathrm{E}+00 \\
.9840 \mathrm{E}+00 \\
.9840 \mathrm{E}+00 \\
.9840 \mathrm{E}+00 \\
.9840 \mathrm{E}+00 \\
.9840 \mathrm{E}+00 \\
.9840 \mathrm{E}+00 \\
.9840 \mathrm{E}+00 \\
.9840 \mathrm{E}+00 \\
.9840 \mathrm{E}+00 \\
.9840 \mathrm{E}+00 \\
.9840 \mathrm{E}+00 \\
.9840 \mathrm{E}+00\end{array}$ & $\begin{array}{l}.388000 E+01 \\
.396000 E+01 \\
.345000 E+01 \\
.348000 E+01 \\
.328000 E+01 \\
.316000 E+01 \\
.285000 E+01 \\
.281000 E+01 \\
.265000 E+01 \\
.263000 E+01 \\
.254000 E+01 \\
.259000 E+01 \\
.230000 E+01 \\
.245000 E+01 \\
.223000 E+01 \\
.220000 E+01 \\
.209000 E+01 \\
.224000 E+01 \\
.219000 E+01 \\
.206000 E+01 \\
.241000 E+01 \\
.261000 E+01 \\
.256000 E+01 \\
.329000 E+01 \\
.344000 E+01 \\
.350000 E+01 \\
.443000 E+01 \\
.445000 E+01 \\
.598000 E+01 \\
.622000 E+01\end{array}$ & RR3 & 3 \\
\hline
\end{tabular}




\section{FTHCON}

Table 2.3-4. UO 2 data from Gibby's $s^{2.3-27}$ thermal diffusivity meassurements

\begin{tabular}{|c|c|c|}
\hline $\begin{array}{c}\text { Temperature } \\
\text { (K) }\end{array}$ & $\begin{array}{c}\text { Density } \\
\text { (fraction of } \\
\text { theoretical) }\end{array}$ & $\begin{array}{l}\text { Thermal } \\
\text { Conductivity } \\
{[\mathrm{W} /(\mathrm{m} \bullet \mathrm{k})]} \\
\end{array}$ \\
\hline $\begin{array}{l}.57500 E+03 \\
.57800 E+03 \\
.58600 E+03 \\
.58700 E+03 \\
.58800 E+03 \\
.66500 E+03 \\
.67500 E+03 \\
.67900 E+03 \\
.69000 E+03 \\
.84600 E+03 \\
.84600 E+03 \\
.85200 E+03 \\
.85300 E+03 \\
.86500 E+03 \\
.86500 E+03 \\
.89300 E+03 \\
.90800 E+03 \\
.90700 E+03 \\
.96400 E+03 \\
.96400 E+03 \\
.96900 E+03 \\
.96900 E+03 \\
.10000 E+04 \\
.10310 E+04 \\
.10310 E+04 \\
.10710 E+04 \\
.10800 E+04 \\
.10800 E+04 \\
.12040 E+04 \\
.12040 E+04 \\
.12800 E+04 \\
.12880 E+04 \\
.12880 E+04 \\
.12890 E+04 \\
.13230 E+04 \\
.13350 E+04 \\
.13840 E+04 \\
.13900 E+04 \\
.13950 E+04 \\
.13990 E+04 \\
.14120 E+04\end{array}$ & $\begin{array}{l}.9580 \mathrm{E}+00 \\
.9580 \mathrm{E}+00 \\
.9580 \mathrm{E}+00 \\
.9580 \mathrm{E}+00 \\
.9580 \mathrm{E}+00 \\
.9580 \mathrm{E}+00 \\
.9580 \mathrm{E}+00 \\
.9580 \mathrm{E}+00 \\
.9580 \mathrm{E}+00 \\
.9580 \mathrm{E}+00 \\
.9580 \mathrm{E}+00 \\
.9580 \mathrm{E}+00 \\
.9580 \mathrm{E}+00 \\
.9580 \mathrm{E}+00 \\
.9580 \mathrm{E}+00 \\
.9580 \mathrm{E}+00 \\
.9580 \mathrm{E}+00 \\
.9580 \mathrm{E}+00 \\
.9580 \mathrm{E}+00 \\
.9580 \mathrm{E}+00 \\
.9580 \mathrm{E}+00 \\
.9580 \mathrm{E}+00 \\
.9580 \mathrm{E}+00 \\
.9580 \mathrm{E}+00 \\
.9580 \mathrm{E}+00 \\
.9580 \mathrm{E}+00 \\
.9580 \mathrm{E}+00 \\
.9580 \mathrm{E}+00 \\
.9580 \mathrm{E}+00 \\
.9580 \mathrm{E}+00 \\
.9580 \mathrm{E}+00 \\
.9580 \mathrm{E}+00 \\
.9580 \mathrm{E}+00 \\
.9580 \mathrm{E}+00 \\
.9580 \mathrm{E}+00 \\
.9580 \mathrm{E}+00 \\
.9580 \mathrm{E}+00 \\
.9580 \mathrm{E}+00 \\
.9580 \mathrm{E}+00 \\
.9580 \mathrm{E}+00 \\
.9580 \mathrm{E}+00\end{array}$ & $\begin{array}{l}.624000 E+01 \\
.636000 E+01 \\
.628000 E+01 \\
.587000 E+01 \\
.563000 E+01 \\
.512000 E+01 \\
.520000 E+01 \\
.531000 E+01 \\
.512000 E+01 \\
.430000 E+01 \\
.440000 E+01 \\
.453000 E+01 \\
.465000 E+01 \\
.430000 E+01 \\
.440000 E+01 \\
.429000 E+01 \\
.429000 E+01 \\
.420000 E+01 \\
.384000 E+01 \\
.392000 E+01 \\
.402000 E+01 \\
.412000 E+01 \\
.370000 E+01 \\
.394000 E+01 \\
.384000 E+01 \\
.366000 E+01 \\
.347000 E+01 \\
.355000 E+01 \\
.324000 E+01 \\
.334000 E+01 \\
.313000 E+01 \\
.299000 E+01 \\
.292000 E+01 \\
.299000 E+01 \\
.301000 E+01 \\
.290000 E+01 \\
.292000 E+01 \\
.280000 E+01 \\
.270000 E+01 \\
.280000 E+01 \\
.295000 E+01\end{array}$ \\
\hline
\end{tabular}


Table 2.3-4. (continued)

\begin{tabular}{|c|c|c|}
\hline $\begin{array}{c}\text { Temperature } \\
\text { (K) }\end{array}$ & $\begin{array}{c}\text { Density } \\
\text { (fraction of } \\
\text { theoretical) }\end{array}$ & $\begin{array}{l}\text { Thermal } \\
\text { Conduct ivity } \\
{[\mathrm{W} /(\mathrm{m} \bullet \mathrm{k})]}\end{array}$ \\
\hline $\begin{array}{l}.14910 E+04 \\
.15020 E+04 \\
.15080 E+04 \\
.15100 E+04\end{array}$ & $\begin{array}{l}.9580 E+00 \\
.9580 E+00 \\
.9580 E+00 \\
.9580 E+00\end{array}$ & $\begin{array}{l}.278000 E+01 \\
.244000 E+01 \\
.262000 E+01 \\
.266000 E+01\end{array}$ \\
\hline
\end{tabular}




\section{FTHCON}

Weilbacher $2.3-26$ reported the thermal diffusivity of a $\mathrm{UO}_{2}$ sample as part of a study of the effect thorium additions. The sample had a density of $98.0 \%$ TD. These data are important because they include temperatures up to melting and because the low-temperature part of the data falls within the narrow scatter of the data reported by Bates for his samples of similar density. The close agreement of the Bates and Weilbacher data provide support for the idea that the thermal diffusivity data on uncracked samples are consistent. The thermal conductivity data calculated from Weilbacher's thermal diffusivity data using the same MATPRO expressions used with Bates' data are listed in Table 2.3-5.

The data of Goldsmith and Douglas $2.3-12$ provide more support for the idea that thermal diffusivity data on uncracked samples are consistent. When the MATPRO expressions for specific heat and thermal expansion are employed to convert the thermal diffusivity data of Goldsmith and Douglas to thermal conductivity, the resultant thermal conductivities fall within the scatter of the data of several authors who performed extensive measurements on a limited number of samples. The thermal conductivities obtained from Goldsmith and Douglas' data are presented in Table 2.3-6. The thermal conductivity data from $98.2 \%$ and $97.7 \%$ TD samples agree with the data of Bates and Weilbacher, the $95.1 \%$ and $95.8 \%$ dense sample data agree with the data of Gibby, the $95.2 \%$ and $94.7 \%$ dense sample data agree with the data of Hobson $2.3-13$ (which will be discussed in the next paragraph), and the $93.2 \%$ and $93.0 \%$ dense sample data agree with the data of Godfrey. ${ }^{a}$

The final set of $\mathrm{UO}_{2}$ data to be discussed are those of Hobson et al. 2.3-13 These authors have apparently measured the thermal diffusivity of a series of $\mathrm{UO}_{2}$ samples. However, they reported only data from a

a. The thermal conductivities determined from each author's data witl be compared with each other and the MATPRO model in a series of figures presented in Section 2.3.4. 
FTHCON

Table 2.3-5. $\mathrm{UO}_{2}$ data from Weilbacher's $\mathrm{s}^{2 \cdot 3-26}$ thermal diffusivity measurements

\begin{tabular}{|c|c|c|}
\hline $\begin{array}{c}\text { Temperature } \\
(\mathrm{K})\end{array}$ & $\begin{array}{l}\text { Density } \\
\text { (fraction of } \\
\text { theoretical) }\end{array}$ & $\begin{array}{l}\text { Thermal } \\
\text { Conduct ivity } \\
{[\mathrm{W} /(\mathrm{m} \bullet \mathrm{k})]}\end{array}$ \\
\hline $\begin{array}{l}.97400 E+03 \\
.97400 E+03 \\
.11710 E+04 \\
.11710 E+04 \\
.13770 E+04 \\
.13760 E+04 \\
.15750 E+04 \\
.15750 E+04 \\
.17780 E+04 \\
.17760 E+04 \\
.29790 E+04 \\
.19800 E+04 \\
.21800 E+04 \\
.21820 E+04 \\
.22810 E+04 \\
.22840 E+04 \\
.23790 E+04 \\
.23790 E+04 \\
.24840 E+04 \\
.24830 E+04 \\
.25770 E+04 \\
.25770 E+04 \\
.26740 E+04 \\
.26740 E+04 \\
.27730 E+04 \\
.27730 E+04 \\
.28750 E+04 \\
.28750 E+04 \\
.30250 E+04 \\
.30270 E+04\end{array}$ & $\begin{array}{l}.9800 E+00 \\
.9800 E+00 \\
.9800 E+00 \\
.9800 E+00 \\
.9800 E+00 \\
.9800 E+00 \\
.9800 E+00 \\
.9800 E+00 \\
.9800 E+00 \\
.9800 E+00 \\
.9800 E+00 \\
.9800 E+00 \\
.9800 E+00 \\
.9800 E+00 \\
.9800 E+00 \\
.9800 E+00 \\
.9800 E+00 \\
.9800 E+00 \\
.9800 E+00 \\
.9800 E+00 \\
.9800 E+00 \\
.9800 E+00 \\
.9800 E+00 \\
.9800 E+00 \\
.9800 E+00 \\
.9800 E+00 \\
.9800 E+00 \\
.9800 E+00 \\
.9800 E+00 \\
.9800 E+00\end{array}$ & $\begin{array}{l}.358000 E+01 \\
.381000 E+01 \\
.309000 E+01 \\
.325000 E+01 \\
.262000 E+01 \\
.285000 E+01 \\
.231000 E+01 \\
.251000 E+01 \\
.218000 E+01 \\
.239000 E+01 \\
.219000 E+01 \\
.233000 E+01 \\
.226000 E+01 \\
.239000 E+01 \\
.231000 E+01 \\
.245000 E+01 \\
.245000 E+01 \\
.254000 E+01 \\
.261000 E+01 \\
.273000 E+01 \\
.274000 E+01 \\
.286000 E+01 \\
.291000 E+01 \\
.302000 E+01 \\
.310000 E+01 \\
.321000 E+01 \\
.332000 E+01 \\
.344000 E+01 \\
.366000 E+01 \\
.383000 E+01\end{array}$ \\
\hline
\end{tabular}




\section{FTHCON}

Table 2.3-6. $\mathrm{UO}_{2}$ data from Goldsmith and Douglas'2.3-12 thermal diffusivity measurements

\begin{tabular}{|c|c|c|}
\hline $\begin{array}{c}\text { Temperature } \\
\text { (K) }\end{array}$ & $\begin{array}{l}\text { Density } \\
\text { (fraction of } \\
\text { theoretical) }\end{array}$ & $\begin{array}{l}\text { Thermal } \\
\text { Conduct ivity } \\
{[\mathrm{W} /(\mathrm{m} \bullet \mathrm{k})]}\end{array}$ \\
\hline $\begin{array}{l}.67000 E+03 \\
.67000 E+03 \\
.67000 E+03 \\
.67000 E+03 \\
.67000 E+03 \\
.67000 E+03 \\
.67000 E+03 \\
.67000 E+03 \\
.67000 E+03 \\
.67000 E+03 \\
.67000 E+03 \\
.67000 E+03 \\
.67000 E+03 \\
.87000 E+03 \\
.87000 E+03 \\
.87000 E+03 \\
.87000 E+03 \\
.87000 E+03 \\
.87000 E+03 \\
.87000 E+03 \\
.87000 E+03 \\
.87000 E+03 \\
.87000 E+03 \\
.87000 E+03 \\
.87000 E+03 \\
.87000 E+03 \\
.10700 E+04 \\
.10700 E+04 \\
.10700 E+04 \\
.10700 E+04 \\
.10700 E+04 \\
.10700 E+04 \\
.10700 E+04 \\
.10700 E+04 \\
.10700 E+04 \\
.10700 E+04 \\
.10700 E+04 \\
.10700 E+04 \\
.10700 E+04 \\
.12700 E+04 \\
.12700 E+04 \\
.12700 E+04 \\
.12700 E+04\end{array}$ & $\begin{array}{l}.960 E+00 \\
.9860 \mathrm{E}+00 \\
.9860 \mathrm{E}+00 \\
.9820 \mathrm{E}+00 \\
.9770 \mathrm{E}+00 \\
.9610 \mathrm{E}+00 \\
.9580 \mathrm{E}+00 \\
.9520 \mathrm{E}+00 \\
.9470 \mathrm{E}+00 \\
.9320 \mathrm{E}+00 \\
.9300 \mathrm{E}+00 \\
.9060 \mathrm{E}+00 \\
.9040 \mathrm{E}+00 \\
.9860 \mathrm{E}+00 \\
.9860 \mathrm{E}+00 \\
.9860 \mathrm{E}+00 \\
.9820 \mathrm{E}+00 \\
.9770 \mathrm{E}+00 \\
.9610 \mathrm{E}+00 \\
.9580 \mathrm{E}+00 \\
.9520 \mathrm{E}+00 \\
.9470 \mathrm{E}+00 \\
.9320 \mathrm{E}+00 \\
.9300 \mathrm{E}+00 \\
.9060 \mathrm{E}+00 \\
.9040 \mathrm{E}+00 \\
.9860 \mathrm{E}+00 \\
.9860 \mathrm{E}+00 \\
.9860 \mathrm{E}+00 \\
.9820 \mathrm{E}+00 \\
.9770 \mathrm{E}+00 \\
.9610 \mathrm{E}+00 \\
.9580 \mathrm{E}+00 \\
.9520 \mathrm{E}+00 \\
.9470 \mathrm{E}+00 \\
.9320 \mathrm{E}+00 \\
.9300 \mathrm{E}+00 \\
.9060 \mathrm{E}+00 \\
.9040 \mathrm{E}+00 \\
.9860 \mathrm{E}+00 \\
.9860 \mathrm{E}+00 \\
.9860 \mathrm{E}+00 \\
.9820 \mathrm{E}+00\end{array}$ & $\begin{array}{l}.557000 \mathrm{E}+01 \\
.553000 \mathrm{E}+01 \\
.559000 \mathrm{E}+01 \\
.531000 \mathrm{E}+01 \\
.543000 \mathrm{E}+01 \\
.519000 \mathrm{E}+01 \\
.498000 \mathrm{E}+01 \\
.485000 \mathrm{E}+01 \\
.508000 \mathrm{E}+01 \\
.455000 \mathrm{E}+01 \\
.461000 \mathrm{E}+01 \\
.440000 \mathrm{E}+01 \\
.420000 \mathrm{E}+01 \\
.468000 \mathrm{E}+01 \\
.467000 \mathrm{E}+01 \\
.470000 \mathrm{E}+01 \\
.444000 \mathrm{E}+01 \\
.460000 \mathrm{E}+01 \\
.438000 \mathrm{E}+01 \\
.410000 \mathrm{E}+01 \\
.416000 \mathrm{E}+01 \\
.426000 \mathrm{E}+01 \\
.380000 \mathrm{E}+01 \\
.388000 \mathrm{E}+01 \\
.369000 \mathrm{E}+01 \\
.349000 \mathrm{E}+01 \\
.396000 \mathrm{E}+01 \\
.394000 \mathrm{E}+01 \\
.394000 \mathrm{E}+01 \\
.375000 \mathrm{E}+01 \\
.387000 \mathrm{E}+01 \\
.370000 \mathrm{E}+01 \\
.356000 \mathrm{E}+01 \\
.346000 \mathrm{E}+01 \\
.361000 \mathrm{E}+01 \\
.324000 \mathrm{E}+01 \\
.330000 \mathrm{E}+01 \\
.310000 \mathrm{E}+01 \\
.291000 \mathrm{E}+01 \\
.327000 \mathrm{E}+01 \\
.326000 \mathrm{E}+01 \\
.332000 \mathrm{E}+01 \\
.316000 \mathrm{E}+01\end{array}$ \\
\hline
\end{tabular}


FTHCON

Table 2.3-6. (continued)

\begin{tabular}{cccc}
\hline $\begin{array}{c}\text { Temperature } \\
(\mathrm{K})\end{array}$ & $\begin{array}{c}\text { Density } \\
\text { (fraction of } \\
\text { theoretical) }\end{array}$ & $\begin{array}{c}\text { Thermal } \\
\text { Conductivity } \\
{[W /(m \cdot k)]}\end{array}$ \\
${+04} }$ & $.9770 \mathrm{E}+00$ & $.323000 \mathrm{E}+01$ \\
$.12700 \mathrm{E}+04$ & $.9610 \mathrm{E}+00$ & $.312000 \mathrm{E}+01$ \\
$.12700 \mathrm{E}+04$ & $.9580 \mathrm{E}+00$ & $.301000 \mathrm{E}+01$ \\
$.12700 \mathrm{E}+04$ & $.9520 \mathrm{E}+00$ & $.295000 \mathrm{E}+01$ \\
$.12700 \mathrm{E}+04$ & $.9470 \mathrm{E}+00$ & $.301000 \mathrm{E}+01$ \\
$.12700 \mathrm{E}+04$ & $.9320 \mathrm{E}+00$ & $.266000 \mathrm{E}+01$ \\
$.12700 \mathrm{E}+04$ & $.9300 \mathrm{E}+00$ & $.275000 \mathrm{E}+01$ \\
$.12700 \mathrm{E}+04$ & $.9060 \mathrm{E}+00$ & $.259000 \mathrm{E}+01$ \\
$.12700 \mathrm{E}+04$ & $.9040 \mathrm{E}+00$ & $.246000 \mathrm{E}+01$ \\
\hline
\end{tabular}




\section{FTHCON}

single sample with a density of $10.40 \times 10^{3} \mathrm{~kg} / \mathrm{m}^{3}(94.9 \% \mathrm{TD})$. Their thermal diffusivity data were converted to thermal conductivity and are listed in Table 2.3-7.

The data appropriate for modeling the thermal conductivity of mixed $(\mathrm{U}, \mathrm{Pu}) \mathrm{O}_{2 \pm \mathrm{x}}$ include the $(\mathrm{U}, \mathrm{Pu}) \mathrm{O}_{2}$ measurements that are available, 2.3-11,2.3-17,2.3-27 to 2.3-34 and $\mathrm{vO}_{2 \pm x}$ data with $x \neq 0.2 \cdot 3-12,2 \cdot 3-13,2 \cdot 3-17$ The $\mathrm{U0}_{2 \pm x}$ data are important because the effect of nonstoichiometry in mixed-oxide fuels is at least as important as the effect of variations in the weight fraction $\mathrm{PuO}_{2}$. Unfortunately, the resources available to produce the present model were too limited to allow for a careful review of the $(U, P u) 0_{2 \pm x}$ or the $U_{2 \pm x}$ data. For that reason, the stoichiometric data from References 2.3-27 to 2.3-30 and the model proposed by 01 ander $2.3-1$ for the effect of $0 / M$ ratio variations will be adopted without modification.

Kim et al 2.3-35 provided the data which allow a calculation of the thermal conductivity of liquid fuel $\left(\mathrm{UO}_{2}\right.$ or $\mathrm{UO}_{2}-\mathrm{PuO}_{2}$ mixtures). They measured the thermal diffusivity of 0.813 - and $1.219-\mathrm{mm}$ layers of molten $\mathrm{UO}_{2}$ in the temperature range of 3187 through $3315 \mathrm{~K}$. The diffusivity values obtained of $1.90 \times 10^{-6}$ to $3.23 \times 10^{-6} \mathrm{~m}^{2} / \mathrm{s}$ can be used with specific heat and density measurements to calculate the thermal conductivity of liquid fuel.

\subsubsection{Mode1 Development}

The development of the model for thermal conductivity of $(U, \mathrm{Pu}) \mathrm{O}_{2 \pm x}$ was based directly on the theory and data which have just been reviewed. The first step in producing the model was the determination of an expression for the effect of density. The $\mathrm{UO}_{2}$ data were grouped by density, with second-degree polynomials in temperature fit to the data in each group. 
FTHCON

Table 2.3-7. $\mathrm{UO}_{2}$ data from Hobson's $\mathrm{s}^{2 \cdot 3-13}$ thermal diffusivity measurements

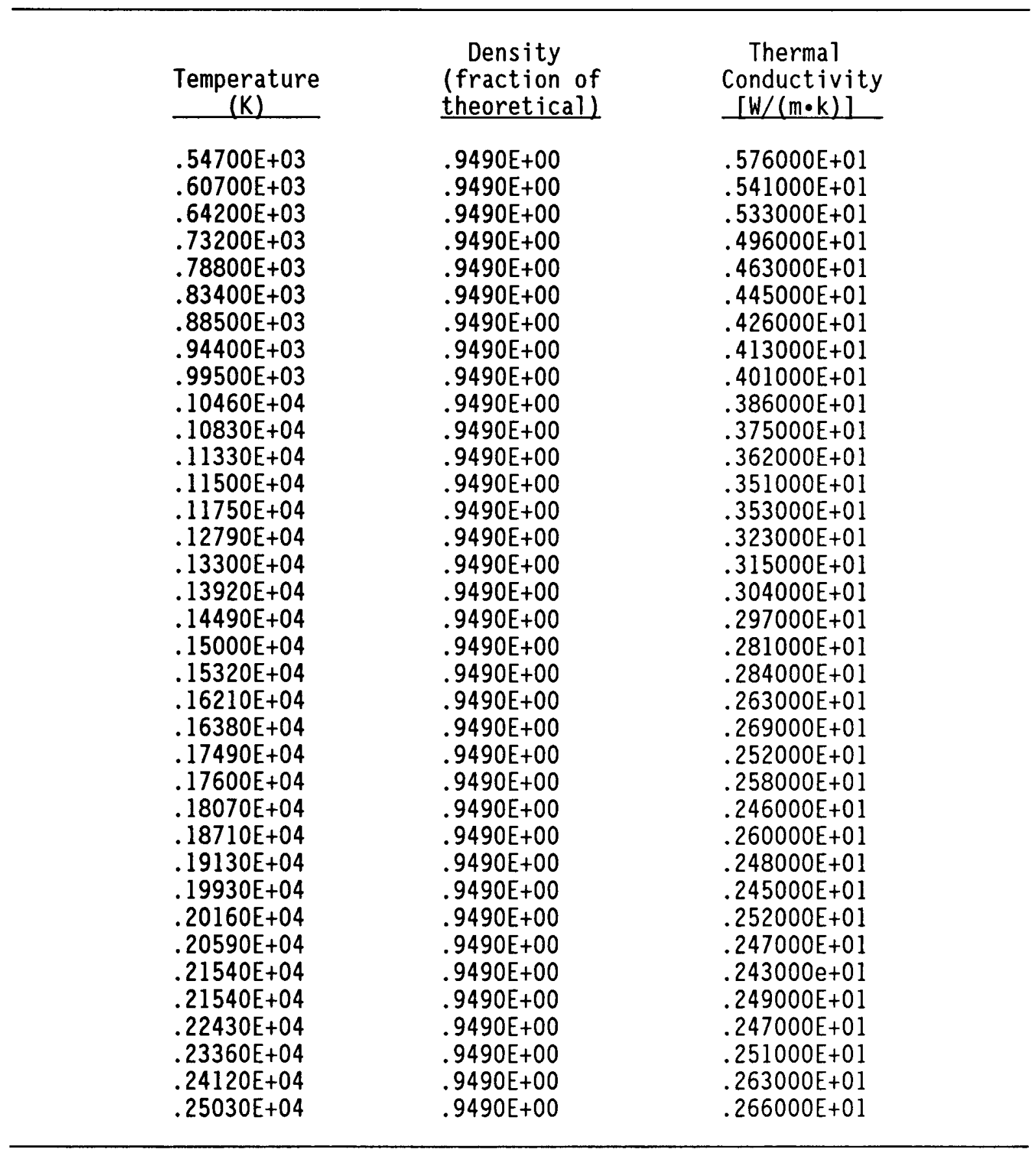




\section{FTHCON}

Inspection of the data ${ }^{a}$ revealed a regular pattern of decreasing thermal conductivity with decreasing density at low temperature but almost no density effect at high temperature. For this reason, the polynomials representing the thermal conductivity of the various groups were evaluated at 600 and $1000 \mathrm{~K}$ and the average thermal conductivities obtained were used with Equation (2.3-9) to obtain linear functions of the form

$\beta=\beta_{0}+\beta_{1}^{\top}$

corresponding to pairs of porosity groups. The resultant values of $\beta_{0}$ and $\beta_{1}$ are 1isted in Table 2.3-8.

The scatter in the values of $\beta_{0}$ and $\beta_{1}$ is caused by unknown variations of pore shape and content, as discussed in Section 2.3-2. In subsequent model development steps, all three sets of $\beta_{0}$ and $\beta_{1}$, as well as their average values, were tested to determine which produced the model with the smallest standard error. Since very little difference was found, the average values of $\beta_{0}$ and $\beta_{1}$ were adopted.

The second step in the development of the model was the determination of the constants $A$ and $B$ of Equation (2.3-7). This determination was done with a least-squares-fit technique and the $\mathrm{UO}_{2}$ thermal conductivity data for temperatures between 500 and $1000 \mathrm{~K} .{ }^{b}$ The data were normalized to $100 \%$ TD with Equation (2.3-9) before the fit was carried out.

The third step in developing the $\mathrm{UO}_{2}$ model was the determination of a value for the constant $f$ in Equation (2.3-6) through the use of the high-temperature data. Since Equation (2.3-6) models the electronic

a. The data and model predictions are illustrated in Section 2.3.4.

b. Data below $500 \mathrm{~K}$ were not used because Equation (2.3-7) is not valid near the Debye temperature. 
Table 2.3-8. Values of $\beta_{0}$ and $\beta_{1}$ from various density groups

\begin{tabular}{|c|c|c|}
\hline Group Compared ${ }^{\mathrm{a}}$ & $\underline{\beta_{0}}$ & $\beta_{1}$ \\
\hline 2 and 5 & 9.6 & -0.00946 \\
\hline 2 and 7 & 4.1 & -0.00281 \\
\hline 4 and 7 & 5.8 & -0.00181 \\
\hline AVERA & 6.5 & -0.00 \\
\hline
\end{tabular}

a. Group 2 contains densities between 0.975 and 0.985 of theoretical. Group 4 contains densities between 0.955 and 0.965 of theoretical. Group 5 contains densities between 0.945 and 0.955 of theoretical. Group 7 contains densities between 0.925 and 0.935 of theoretical. 


\section{FTHCON}

contribution to thermal conductivity, a value for $f$ was determined with a least-squares fit to the difference between the experimental thermal conductivities and the lattice vibration contribution predicted with Equation (2.3-7). The factor (A + BT) in Equation (2.3-7) was 1 imited to its value at $T=2050 \mathrm{~K}$ because the mean free path of the phonons is about equal to the interatomic distance at this temperature. ${ }^{2.3-1}$ No normalization for density was applied to the high-temperature data.

The final steps in the development of the $\mathrm{UO}_{2}$ model were a trivial smoothing of two discontinuities in the slope of the predicted thermal conductivities as a function of temperature and the provision of an estimate for liquid fuel. The discontinuities are caused by limiting $\beta$ in Equation (2.3-9) to values larger than -1 and limiting the phonon mean free path to at least the interatomic distance. Each discontinuity was removed by replacing temperature with an interpolated temperature in a range above the cutoff value and requiring the interpolated temperature to produce continuous functions and slopes at the ends of the range. For liquid fuel, the lattice vibration contribution to thermal conductivity was set equal to zero.

Several preliminary assumptions have been made to provide at least an approximate model for effects of variations in the plutonium content and the $0 / M$ ratio of ceramic fuels:

1. The effects of variations in density of mixed-oxide fuels have been assumed to be described by the porosity correction derived with $\mathrm{UO}_{2}$ data.

2. The high-temperature electronic contribution to thermal conductivity has been assumed to be the same for $\mathrm{PuO}_{2}, \mathrm{UO}_{2}$, and nonstoichiometric fuels.

3. Variations in plutonium content have been assumed to affect only the phonon-phonon scattering term in Equation (2.3-7). 


\section{FTHCON}

4. Variations in $0 / M$ ratio have been assumed to affect only the defect term of Equation (2.3-7).

The change in the phonon-phonon scattering term of Equation (2.3-7) was modeled by fitting reported thermal conductivities $2.3-27$ to $2.3-30,2.3-33$ of $(\mathrm{U}, \mathrm{Pu})_{2}$ to Equation $(2.3-7)$ with $\mathrm{B}$ replaced by

$\mathrm{B}^{\prime}=\mathrm{BUO}_{2}(1+b \cdot \mathrm{COMP})$

where

$B^{\prime}=$ coefficient of temperature in Equation (2.3-7) for mixed oxides

$\mathrm{BuO}_{2}=$ coefficient of temperature in Equation (2.3-7) for $\mathrm{UO}_{2}$

COMP $=\mathrm{PuO}_{2}$ content of the fuel (ratio of weight of $\mathrm{PuO}_{2}$ to total weight)

b $=$ constant to be determined.

The resultant value of $b$ was 0.6238 .

01 ander's expression $2.3-1$ for the effect of $0 / M$ ratio on the defect term of Equation (2.3-7) was adopted to provide a preliminary model for the effect of variations from stoichiometry. The fractional change in the defect term was estimated by 01 ander to be

$\frac{\Delta A}{A}=\frac{400 x}{A^{\prime}}$

where 


\section{FTHCON}

$x=$ absolute value of $(0 /$ M ratio -2.0$)$

$\mathrm{A}^{\prime}=$ defect term in 01 ander's version of Equation (2.3-7)

$\frac{\Delta A}{A}=$ fractional change in the defect term of Equation (2.3-1).

The expression for $A$ which resulted from this adaptation is given in Equation (2.3-1).

The thermal diffusivity values of $1.90 \times 10^{-6}$ through $3.23 \times 10^{-6} \mathrm{~m}^{2} / \mathrm{s}$ measured for the 0.813 and $1.219-\mathrm{mm}$ layers of molten $\mathrm{UO}_{2}$ in the temperature range of 3187 through $3315 \mathrm{~K}$ by $\mathrm{Kim}$ et a ${ }^{2.3-35}$ can be used with specific heat and density measurements to calculate the thermal conductivity of molten $\mathrm{UO}_{2}$ or $\mathrm{UO}_{2}-\mathrm{PuO}_{2}$ mixtures from the relation

$K=C_{p} \rho \alpha$

where

$\mathrm{K}=$ thermal conductivity of molten $\mathrm{UO}_{2}$ or $\mathrm{UO}_{2}-\mathrm{PuO}_{2}(\mathrm{~W} / \mathrm{m} \cdot \mathrm{K})$

$C_{p}=$ specific heat capacity $(\mathrm{J} / \mathrm{kg} \cdot \mathrm{K})$

$\rho=\operatorname{density}\left(\mathrm{kg} / \mathrm{m}^{3}\right)$

$\alpha=$ thermal diffusivity $\left(\mathrm{m}^{2} / \mathrm{s}\right)$

Substitution of the MATPRO values for $C_{p}$ and $\rho$ at melting into Equation (2.3-14) yields thermal conductivities in the range 8.5 to $14.5 \mathrm{~W} / \mathrm{m} \cdot \mathrm{K}$. These conductivities are an order of magnitude larger than the estimate used in MATPRO Revision 2. 
Kim et al. 2.3-35 interpret this unusually high conductivity as being due to internal infrared radiation heat transfer in the liquid $\mathrm{UO}_{2}$ that is not allowed in the solid because of the effect of scattering centers, such as grain boundaries or voids. Although they caution that radiative thermal diffusivity depends on the thickness of the material as well as on the emissivity of the boundary surfaces, the variations they estimate are only 0.10 to 0.30 times the measured value. The constant $11.5\left(\mathrm{~W} / \mathrm{m}^{2} \cdot \mathrm{s}\right)$ used for the thermal conductivity of liquid fuel $\left(\mathrm{UO}_{2}\right.$ or $\mathrm{UO}_{2}-\mathrm{PuO}_{2}$ mixtures) in the FTHCON subroutine is the average of a range of values calculated from the data of Kim et a1. An uncertainty of \pm 0.3 times the given liquid conductivity is estimated from the range of values measured.

\subsubsection{Model Uncertainty}

The standard error a ${ }^{2}$ of the FTHCON model for thermal conductivity with respect to its $\mathrm{UO}_{2}$ data base is $\pm 0.20 \mathrm{~W} / \mathrm{m} \cdot \mathrm{K}$. The standard error with respect to the $(\mathrm{U}, \mathrm{Pu})_{2}$ data base is $\pm 0.29 \mathrm{~W} / \mathrm{m} \cdot \mathrm{K}$. The first two terms of Equation (2.3-2), the expression of model uncertainty which has been added to the FTHCON subcode, were constructed to reproduce these uncertainties at $0 \%$ and $20 \% \mathrm{PuO}_{2}$ content. The third term of Equation (2.3-2) provides an engineering estimate of the increase in the error of the model for nonstoichiometric fuel.

Figures 2.3-1 to 2.3-4 illustrate the model predictions and the $\mathrm{UO}_{2}$ data base for several densities. Each figure shows data within \pm 0.005 of the fraction of theoretical density assumed for the model prediction. The $\mathrm{UO}_{2}$ data of each investigator show scatter nearly as large as the standard error of the model. This fact suggests that this part of the model is complete.

a. The standard error was estimated with the expression (sum of squared residuals/number of residuals minus the number of constants used to fit the data) 12 . Five constants were used for the $\mathrm{UO}_{2}$ data, and six were used for the $\mathrm{PuO}_{2}$ data. 


\section{FTHCON}

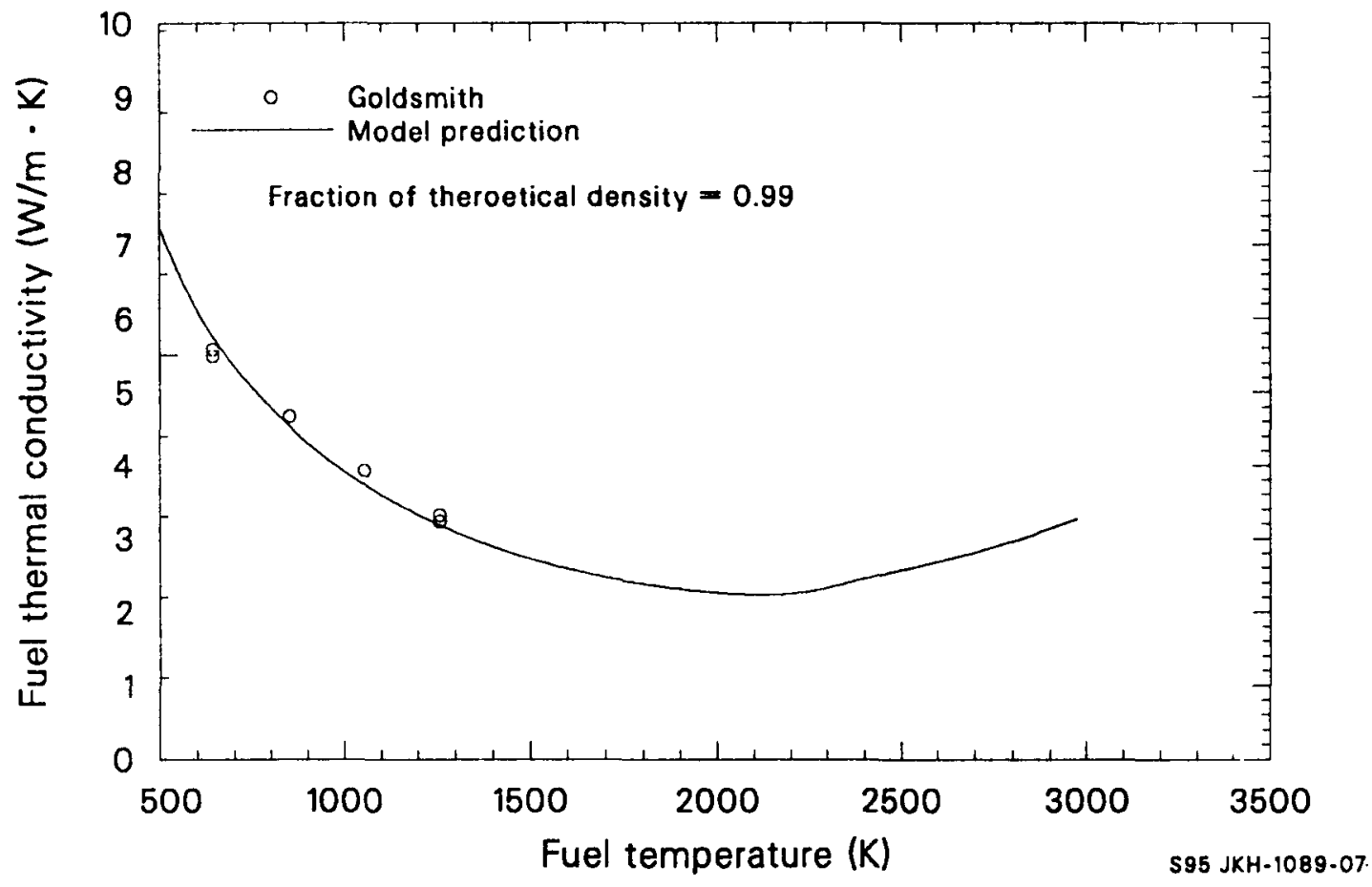

Figure 2.3-1. Model prediction for thermal conductivity of $0.99 \%$ TO $\mathrm{UO}_{2}$ compared to data from specimens with densities in the range $0.985 \%$ to $0.995 \%$ TD. 


\section{FTHCON}

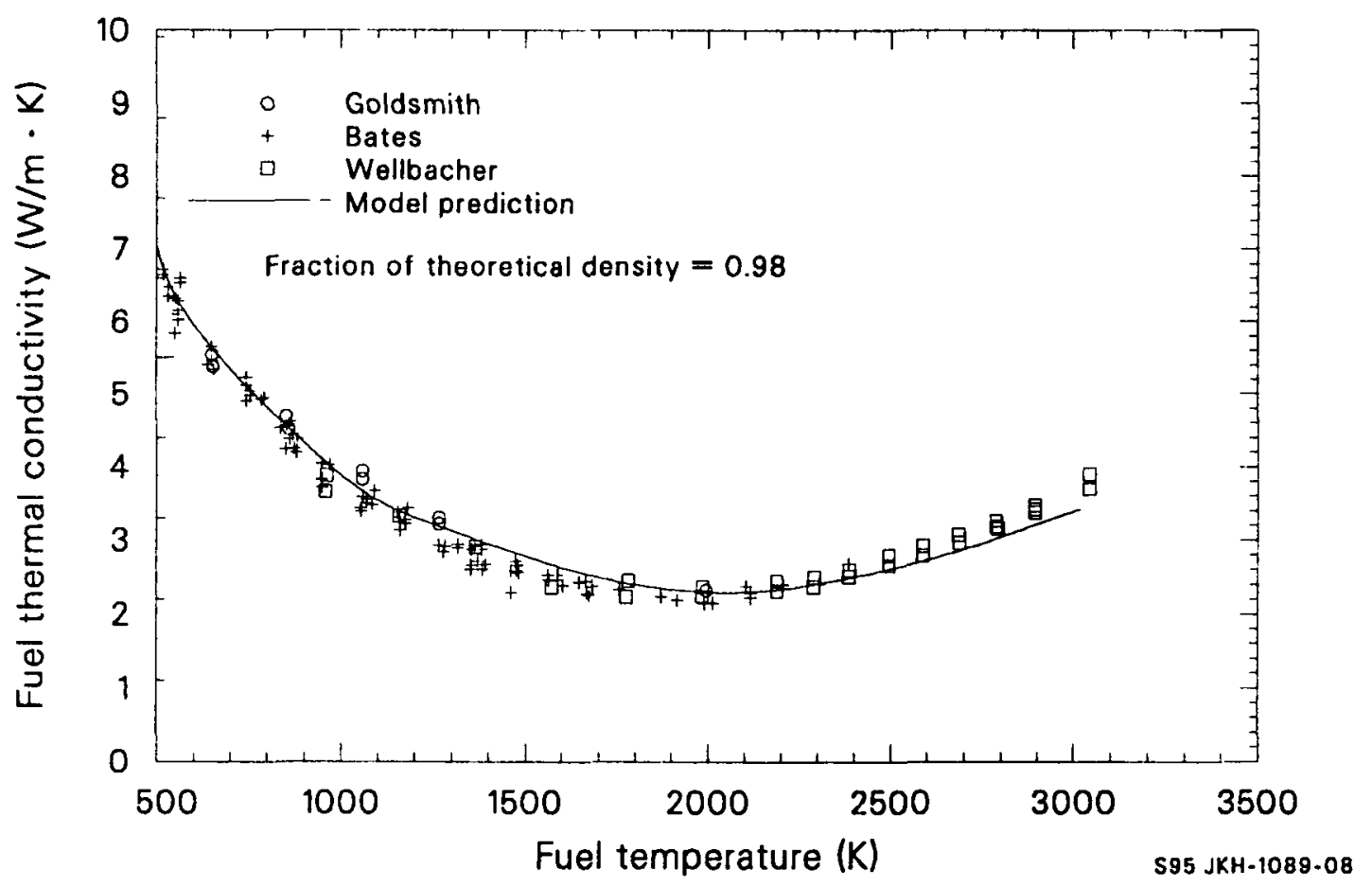

Figure 2.3-2. Model prediction for thermal conductivity of $0.98 \% \mathrm{TD} \mathrm{VO}_{2}$ compared to data from specimens with densities in the range $0.975 \%$ to $0.985 \%$ TD. 


\section{FTHCON}

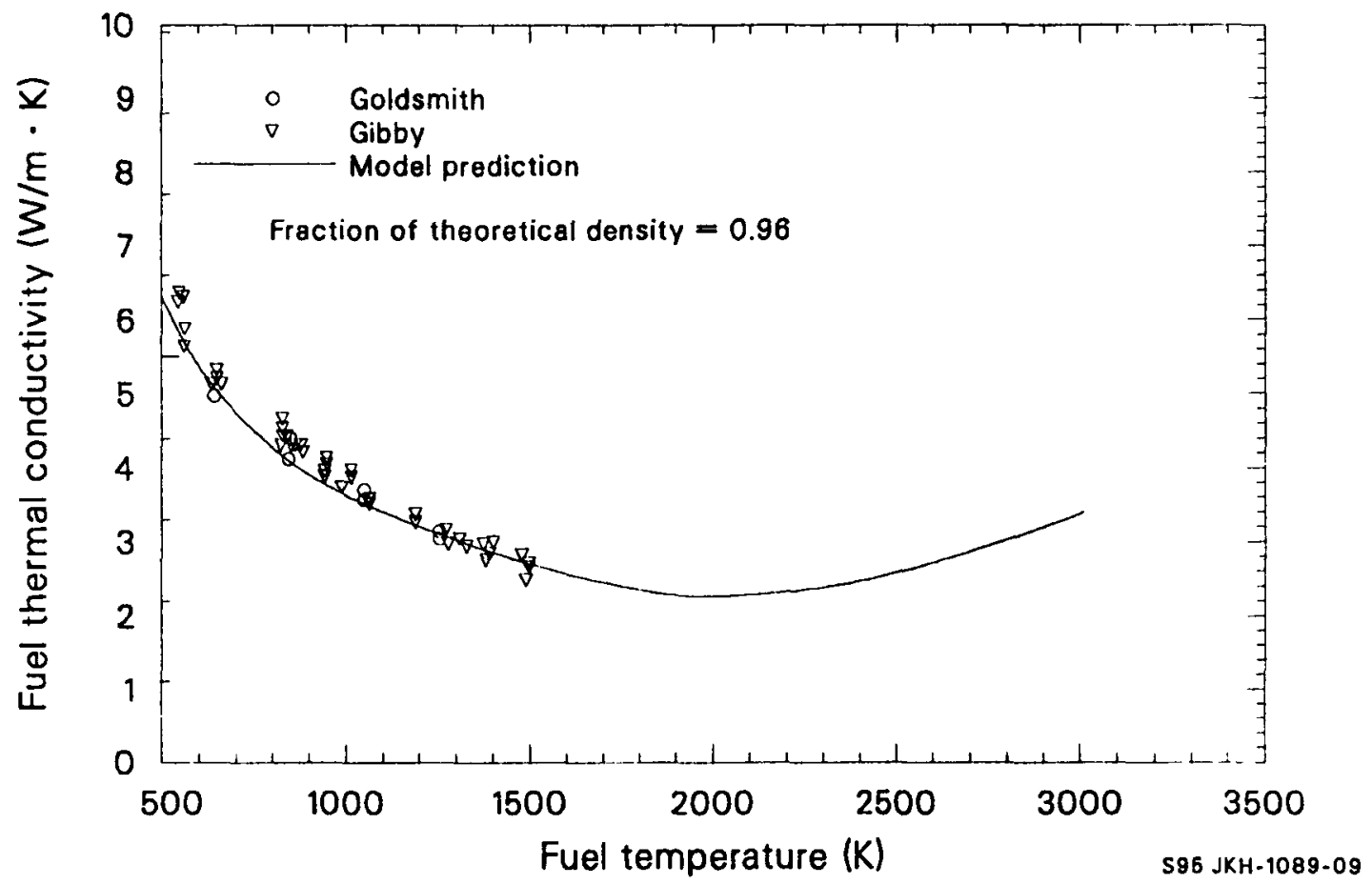

Figure 2.3-3. Model prediction for thermal conductivity of $0.96 \%$ TD $\mathrm{UO}_{2}$ compared to data from specimens with densities in the range $0.955 \%$ to $0.965 \%$ TD. 


\section{FTHCON}

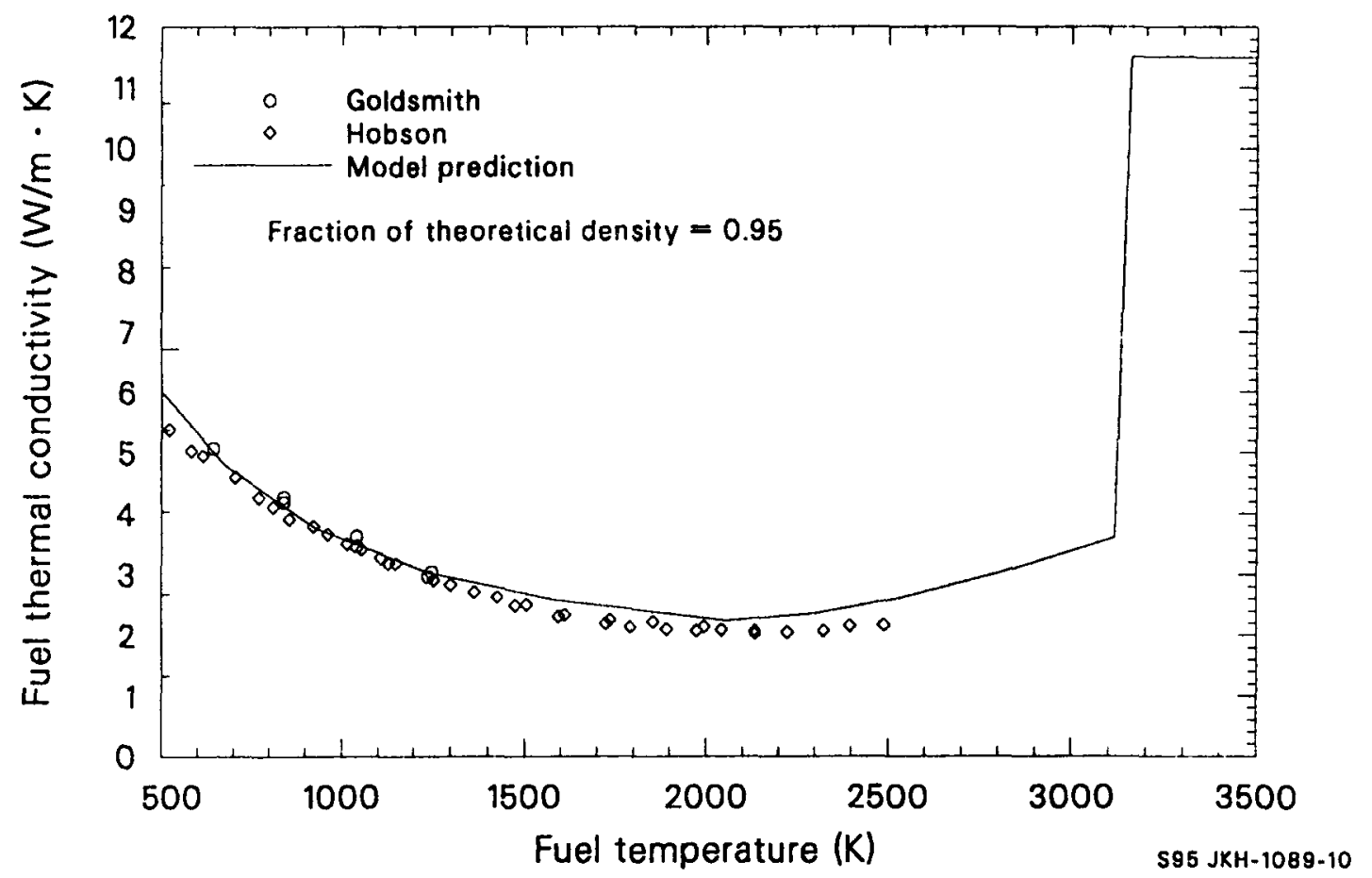

Figure 2.3-4. Model prediction for thermal conductivity of $0.95 \% \mathrm{TD} \mathrm{VO}_{2}$ compared to data from specimens with densities in the range $0.945 \%$ to $0.955 \%$ TD. 


\section{FTHCON}

Mixed-oxide data have not been compared to the current model because the part of the model that applies to mixed oxide (fuel) is preliminary.

\subsubsection{References}

2.3-1. D. R. 01 ander, Fundamental Aspects of Nuclear Reactor Fuel Elements, TID-26711-P1, 1976.

2.3-2. C. Kittel, Introduction to Solid State Physics, New York: John Wiley and Sons, Inc., 1956.

2.3-3. R. Berman, Thermal Conduction in Solids, 0xford: Clarendon Press, 1976.

2.3-4. H. J. Goldsmith, The Thermal Properties of Solids, New York: Dover Publications, Inc., 1965.

2.3-5. J. L. Bates, C. A. Hinman and T. Kawada, "Electrical Conductivity of Uranium Dioxide," Journal of the American Ceramic Society, 50, 1967, pp. 652-656.

2.3-6. G. P. Marino, "The Porosity Correction Factor for the Thermal Conductivity of Ceramic Fuels, " Journal of the American Ceramic Society, 38, 1970, pp. 178-190.

2.3-7. A. L. Loeb, "Thermal Conductivity: A Theory of Thermal Conductivity of Porous Materials," Journal of the American Ceramic Society, 37, 1954, pp. 96-99.

2.3-8. J. R. MacEwan, R. L. Stoute, and M. F. Notley, "Effect of Porosity on the Thermal Conductivity of $\mathrm{UO}_{2}$," Journal of Nuclear Materials, 24, 1967, pp.109-112.

2.3-9. A. Biancheria, "The Effect of Porosity on Thermal Conductivity of Ceramic Bodies," Transactions of the American Nuclear Society, 9, 1966, p. 15.

2.3-10. G. Ondracek and B. Schulz, "The Porosity Dependence of the Thermal Conductivity for Nuclear Fuels, " Journal of Nuclear Materials, 46, 1973, pp. 253-258.

2.3-11. J. C. Vancraeynest and J. P. Stora, "Effect de la Porosite sur la Variation de Conductubilite Thermique du Bioxyde d'Uranium en Fonction de la Temperature," Journal of Nuclear Materials, 37, 1970, pp. $153-158$. 
2.3-12. L. A. Goldsmith and J. A. M. Douglas, "Measurements of the Thermal Conductivity of Uranium Dioxide at 670-1270 K," Journal of Nuclear Materials, 47, 1973, pp. 31-42.

2.3-13. I. C. Hobson, R. Taylor, and J. B. Ainscough, "Effect of Porosity and Stoichiometry on the Thermal Conductivity of Uranium Dioxide," Journal of Physics Section D: Applied Physics, 7, 1974 pp. $1003-1015$.

2.3-14. R. R. Asamoto, F. L. Anselin, and A. E. Conti, "The Effect of Density on the Thermal conductivity of Uranium Dioxide, "Journal of Nuclear Materials, 29, 1969, pp. 67-81.

2.3-15. J. C. Hedge, Measurement of Thermal Conductivity of Uranium Dioxide, AECU-3881, September 20, 1956.

2.3-16. W. D. Kingery et al., "Thermal Conductivity X: Data for Several Pure 0xide Materials Corrected to Zero Porosity, "Journal of the American Ceramic Society, 37,1954, pp. 107-110.

2.3-17. F. J. Hetzler et al., The Thermal Conductivity of Uranium and Uranium-P7utonium Oxides, GEAP-4879, August 1967.

2.3-18. T. G. Godfrey et a1., Thermal Conductivity of Uranium Dioxide and Armco Iron by an Improved Radial Heat Flow Technique, ORNL-3556, June 1964 .

2.3-19. J. Lambert Bates, High Temperature Thermal Conductivity of "Round Robin" Uranium Dioxide, BNWL-1431, July 1970.

2.3-20. C. F. Lucks and H. W. Deem, "Thermal Conductivity and Electrical Conductivity of $\mathrm{UO}_{2}$," Progress Relating to Civilian Applications During June 1960, BMI-1448, July 1, 1960.

2.3-21. J. A. Christensen et a1., "Uranium Dioxide Thermal Conductivity," Transactions of the American Nuclear Society, 7,1964, pp. 391-392.

2.3-22. M. F. Lyons et al., $\mathrm{UO}_{2}$ Pellet Thermal Conductivity from Irradiations with Central Melting, GEAP-4624, July 1964.

2.3-23. R. D. Reiswig, "Thermal Conductivity of $\mathrm{UO}_{2}$ to $2100^{\circ} \mathrm{C}, "$ Journal of the American Ceramic Society, 44, 1961, pp. 48-49.

2.3-24. J. Stora et al., Thermal Conductivity of Sintered Uranium Oxide Under In-Pile Conditions, EURAEC 1095, CEA-R 2585, August 1964.

2.3-25. C. Ferro, C. Patimo, and C. Piconi, "Thermal Diffusivity of Mixed $\mathrm{TH}_{1-x}, U_{x}$ Oxides and Some Materials to be Used as Reference in the Range 650-2700 K," Journal of Nuclear Materials, 43, 1972 pp. $272-276$. 


\section{FTHCON}

2.3-26. J. C. Weilbacher, "Diffusivite Thermique de 1'Oxyde d'Uranium et de 1'Oxyde de Thorium a Haute Temperature," High Temperatures--High Pressure, 4, 1972, pp. 431-438.

2.3-27. R. L. Gibby, "The Effect of Plutonium Content on the Thermal Conductivity of $\left(\mathrm{U}, \mathrm{Pu} \mathrm{O}_{2}\right.$ Solid Solutions," Journal of Nuclear Materials, 38, 1971, pp. 163-177.

2.3-28. R. L. Gibby, The Thermal Diffusivity and Thermal Conductivity of Stoichiometric, $\left(U_{0.8} P_{0.2}\right)_{2}$, BNWL-704, May 1968.

2.3-29. R. L. Gibby, The Effect of Oxygen Stoichiometry on the Thermal Diffusivity and Conductivity of $U_{0.75} P u_{0.25} \mathrm{O}_{2-x}$, BNWL-927, January 1969.

2.3-30. L. A. Goldsmith and J. A. M. Douglas, "The Thermal Conductivity of Plutonium-Uranium Dioxide at Temperatures up to $1273 \mathrm{~K}$, "Journal of Nuclear Materials, 43, 1972, pp. 225-233.

2.3-31. M. Serizawa et a1., "Thermal Diffusivity and Thermal Conductivity of Uranium-Plutonium Dioxide, " Journal of Nuclear Materials, 34, 1970, pp. 224-226.

2.3-32. J. C. VanCraeynest and J. C. Weilbacher, "Etude de la Conductibility Thermique des Oxides Mixed d'Uranium et de Plutonium," Journal of Nuclear Materials, 26, 1968, pp. 132-136.

2.3-33. H. E. Schmidt, "Die Waermeleitfaehigkeit von Uran and Uran-Plutonium Dioxyd bei Hohen Temperaturen, " Forschung, Ingenieur-Wesen, 38, 1972, pp. 149-151.

2.3-34. H. E. Schmidt, "Die Waermeleitfaehigkeit von Uran and Uran-Plutonium Dioxyd bei Hohen Temperaturen," High Temperatures--High Pressure, 3, 1971, p. 345.

2.3-35. C. S. Kim et a1., "Measurement of Thermal Diffusivity of Molten $\mathrm{UO}_{2}, "$ Proceedings of the Seventh Symposium on Thermophysical Properties at the National Bureau of Standards, Gaithersberg, MD, May 10-12, 1977, CONF 770537-3, pp. 338-343. 
FEMISS

\subsection{EmisSIVITY (FEMISS)}

(R. E. Mason)

The fuel emissivity subcode FEMISS calculates total hemispherical $\mathrm{UO}_{2}$ emissivity (emissivity integrated over all wavelengths) as a function of temperature. Fuel emissivity is defined as the ratio of radiant energy emitted from a material to that emitted by a black body at the same temperature. The subcode is used to calculate radiant energy transfer from fuel to cladding in conjunction with thermal conduction. Radiant energy transfer can be a significant heat transfer mechanism, depending on the gap size, temperature gradient across the gap, and plenum gas.

\subsubsection{Summary}

According to the Stefan-Boltzmann law, the total radiant power per unit area emitted by a body at temperature $T$ is

$P=e \sigma T^{4}$

where

$P=$ radiant power per unit area $\left(\mathrm{W} / \mathrm{m}^{2}\right)$

e $\quad=$ total hemispherical emissivity (unitless)

$\sigma=$ the Stefan-Boltzmann constant $\left(5.672 \times 10^{-8} \mathrm{~W} / \mathrm{m}^{2} \cdot \mathrm{K}\right)$

$\mathrm{T}=$ temperature (K). 


\section{FEMISS}

The expression used in the FEMISS subcode to describe total emissivity is $e=0.7856+1.5263 \times 10^{-5} \mathrm{~T}$.

The standard error of estimate of Equation (2.4-2) with respect to its data base is $\pm 6.8 \%$. The emissivity data were measured at temperatures up to approximately $2400 \mathrm{~K}$, and use of FEMISS above this temperature is speculative because of possible high-temperature effects that are not modeled. At the time of model development, there were no data to develop a $(\mathrm{U}, \mathrm{Pu}) \mathrm{O}_{2}$ emissivity equation, so Equation (2.4-2) is also recommended for $(\mathrm{U}, \mathrm{Pu})_{2}$.

The data base for Equation (2.4-2) is discussed in Section 2.4.2. Model development is discussed in Section 2.4.3.

\subsubsection{Emissivity Data}

Emissivity data have been reported by Held and Wilder, 2.4-1 Cabannes, 2.4-2 Jones and Murchison, ${ }^{2.4-3}$ Claudson, 2.4-4 Belle, 2.4-5 and Ehlert and Margrave. 2.4-6

Held and Wilder reported hemispherical spectral (emissivity at one wavelength) emissivity data of $\mathrm{UO}_{2}$. These data are also documented by Touloukian and Dewitt. ${ }^{2.4-7}$ They determined the emissivity of $\mathrm{UO}_{2}$ having $0 / \mathrm{M}$ ratios between 1.95 and 2.29 and bulk densities between $8 \times 10^{3}$ and $10.6 \times 10^{3} \mathrm{~kg} / \mathrm{m}^{3}$. The measurements were taken at wavelengths of 0.656 and $0.7 \mu \mathrm{m}$ and at temperatures between 450 and $2400 \mathrm{~K}$. The data show no observable emissivity trend as a function of the fuel $0 / \mathrm{M}$ ratio or density, but scatter of the data is large $( \pm 10 \%)$ and may obscure trends. Their data indicate that emissivity increases with temperature between 450 and $2200 \mathrm{~K}$ and then drops a few percent at temperatures near $2400 \mathrm{~K}$. Whether or not the emissivity continues to drop at higher temperatures is uncertain because of lack of data. Since this decrease in emissivity at 


\section{FEMISS}

high temperatures is less than the scatter of the data, the trend cannot be considered to continue until more high-temperature data are obtained.

Cabannes measured reflectance (1.0--emissivity) of $\mathrm{UO}_{2}$ up to $2200 \mathrm{~K}$ as a function of wavelength and temperature. He found that the emissivity approaches 1.0 at wavelengths above $20 \mu \mathrm{m}$ but remains between 0.9 and 0.8 for wavelengths below $10 \mu \mathrm{m}$. He also found that emissivity did not change with thermal cycling. Since a polished surface normally deteriorates during thermal cycling, the study implies little sensitivity of emissivity data to the surface polish of the $\mathrm{UO}_{2}$ samples.

Jones and Murchison reported reflectivity of $\mathrm{UO}_{2}$ at wavelengths between 0.4 and $0.7 \mu \mathrm{m}$. The emissivity of the samples varied between 0.81 and 0.84 . They found emissivity to be smallest (0.81) at a wavelength of about $0.5 \mu \mathrm{m}$. It increased 1 to $3 \%$ for wavelengths other than $0.5 \mu \mathrm{m}$. Emissivity also varied less than $3 \%$ for $0 / M$ ratios between 2.003 and 2.203 .

Data reported by $\mathrm{Cl}$ audson and Belle indicate that emissivity decreases from 0.85 to 0.37 as temperature increases from 1000 to $2200 \mathrm{~K}$. This decrease with decreasing temperature is in direct contradiction to the Held and Wilder, Cabannes, and Jones and Murchison data. Cabannes has reviewed Claudson's data and concludes that the discrepancy is possibly due to an error in Claudson's measurement technique.

Ehlert and Margrave reported two data points from $\mathrm{UO}_{2}$ pellets. They measured the emissivity of $\mathrm{UO}_{2}$ at $2073 \mathrm{~K}$ and approximately $3000 \mathrm{~K}$ and found the emissivities to be 0.416 and 0.40 , respectively.

\subsubsection{Model Development}

The subcode FEMISS calculates total emissivity of fuel at a particular temperature. The hemispherical spectral data of Held and Wilder and the 


\section{FEMISS}

emissivity data of Cabannes and Jones and Murchison were used in developing the FEMISS model. Data of Claudson and Ehlert and Margrave were not used because of possible errors in measurement technique. ${ }^{2.4-2}$

Spectral emissivity data were also used to develop the total emissivity subcode FEMISS for the following reasons. Jones and Murchison indicate that spectral emissivities do not vary more than $2 \%$ or $3 \%$ at wavelengths between 0.4 and $0.7 \mu \mathrm{m}$, well within the uncertainty of the data. The Cabannes data show that $\mathrm{UO}_{2}$ emissivity is about 0.85 at all wavelengths below $10 \mu \mathrm{m}$. Since spectral data measured at wavelengths smaller than $10 \mu \mathrm{m}$ do not vary more than a few percent as wavelength varies, spectral data can be used to develop a total emissivity correlation. This assumption is valid in general for FEMISS calculations, since the radiation emitted from a black body or any material has maximum intensities at wavelengths smaller than $10 \mu \mathrm{m}$ at temperatures for which radiant energy transfer is important.

Besides the emitted wavelength, emissivity can be a function of material properties, such as density, porosity, surface finish, $0 / \mathrm{M}$ ratio, and temperature. Analysis of the data showed no dependence of emissivity on any of the above properties except temperature. The Held and Wilder data and the Cabannes data were used in a linear regression program to obtain Equation (2.4-2). A standard error of estimate of $\pm 6.8 \%$ was also determined using Equation (2.4-2) and the data base.

The emissivity data of Held and Wilder and Cabannes are shown in Figure 2.4-1 as a function of temperature. The emissivity predictions of FEMISS at temperatures between 300 and $3000 \mathrm{~K}$ are shown as a solid line in the figure. The dashed lines in the figure represent predicted $\pm 1 \sigma$ values. The decreasing emissivities of the Held and Wilder data at temperatures near $2400 \mathrm{~K}$ can be seen in Figure 2.4-1. There are no data past this temperature to determine whether the drop is a real effect or experimental error. If the trend is real, no data exist to indicate what 


\section{FEMISS}

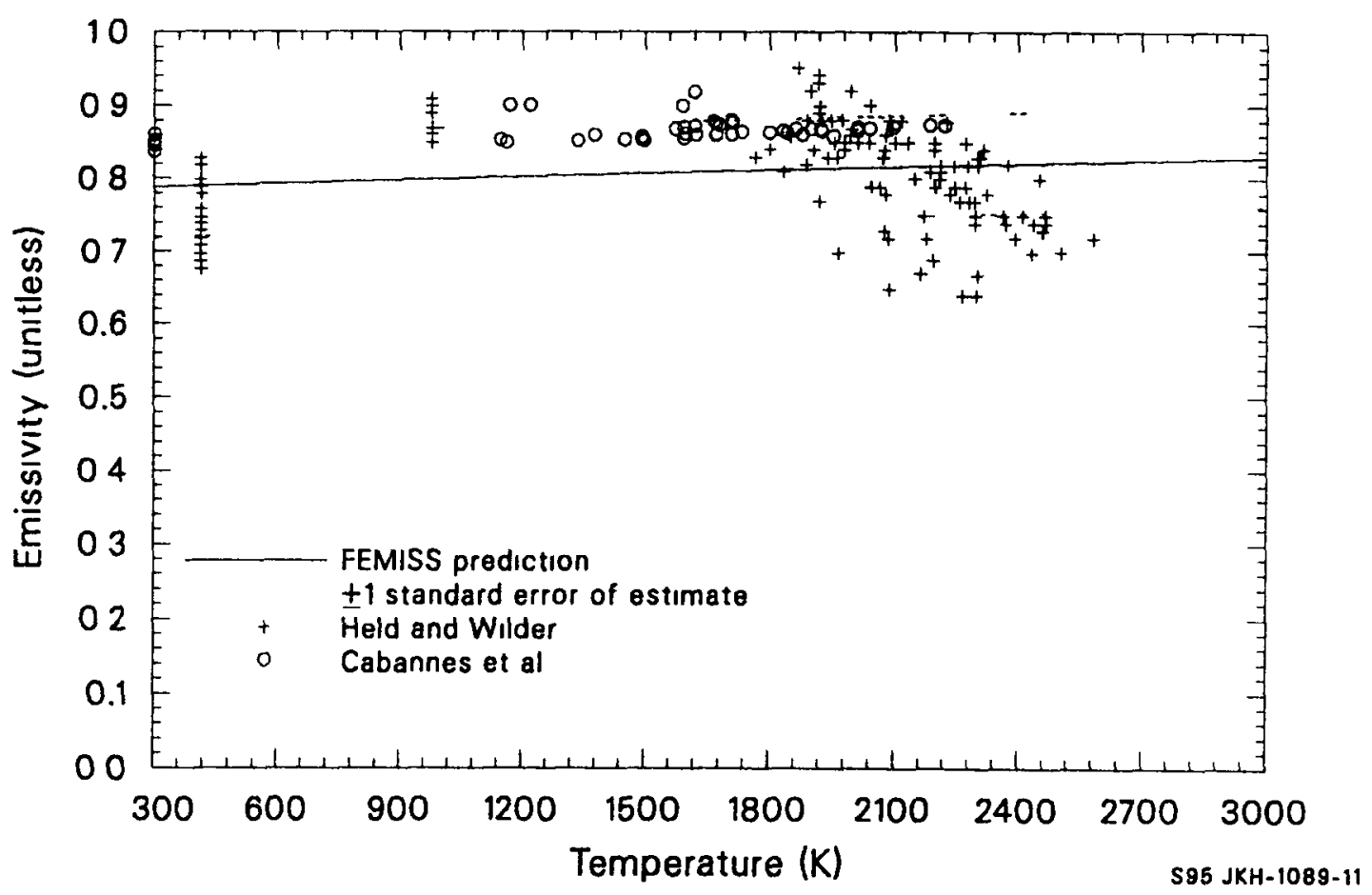

Figure 2.4-1. Emissivity data and corresponding FEMISS predictions. 


\section{FEMISS}

happens to the emissivity beyond $2400 \mathrm{~K}$; so until more data at higher temperatures are obtained, the drop of the Held and Wilder data near $2400 \mathrm{~K}$ is assumed to be experimental error.

\subsubsection{References}

2.4-1. P. C. Held and D. R. Wilder, "High Temperature Hemispherical Spectral Emittance of Uranium Oxides at 0.65 and $0.70 \mu \mathrm{m}, "$ Journal of the American Ceramic Society, 52, 1969.

2.4-2. M. M. F. Cabannes, J. P. Stora, and J. Tsakiris, "ORTIQUE-MOLECULAIRE-Fracteurs de re'flexion et d'e'mission de $\mathrm{UO}_{2}$ a' haute Temperature," C. R. Acad. Sc. Paris, t. 264, January 1967.

2.4-3. J. M. Jones and D. G. Murchison, "Optical Properties of Uranium Oxides," Nature, 205, 4972, 1965, pp. 663-665.

2.4-4. T. T. Claudson, Emissivity Data for Uranium Dioxides, HW-55414, November 5, 1958.

2.4-5. J. Belle, ed., Uranium Dioxide: Properties and Nuclear Applications, TID-7546, 1961.

2.4-6. T. C. Ehlert and J. L. Margrave, "Melting Point and Spectral Emissivity of Uranium Dioxide," Journal of the American Ceramic Society, 41, 1958, p. 330 .

2.4-7. Y. S. Touloukian and D. P. Dewitt, "Thermal Radiative Properties of Nonmetallic Solids," Thermophysical Properties of Materials, 8 , New York-Washington: IFI/Plemung, 1972. 
FTHEXP, FDEN

\subsection{Thermal Expansion and Density (fTHeXP, FDeN)}

(G. A. Reymann)

The FTHEXP function models dimensional changes in unirradiated fuel pellets caused by changes in temperature. It is capable of dealing with any combination of $\mathrm{UO}_{2}$ and $\mathrm{PuO}_{2}$ in solid, liquid, or solid-liquid states and includes expansion due to the solid-liquid phase change. The FDEN function determines the theoretical density of $\mathrm{UO}_{2}$ using room-temperature data and thermal expansion strains calculated by the FTHEXP subcode.

Fuel dimensional changes affect the pellet-to-cladding gap size, which is a major factor in determining gap heat transfer and thus the stored energy, an important quantity for safety analysis.

\subsubsection{Summary (FTHEXP)}

The function FTHEXP models fuel thermal expansion as a function of temperature, fraction of $\mathrm{PuO}_{2}$, and the fraction of fuel which is molten. The $0 / \mathrm{M}$ ratio is not included. When the departure from stoichiometry, $10 / M-2.0 \mid$, is greater than 0.2 , there is clearly an effect. 2.5-1,2.5-2,2.5-3 This effect is ignored in modeling thermal expansion, since typical reactor fuels only deviate about a tenth this much from the stoichiometric composition.

The equations for the thermal expansion of $\mathrm{UO}_{2}$ and $\mathrm{PuO}_{2}$ have the same form. In the solid phase, the equation is

$\Delta L / L_{0}=K_{1} T-K_{2}+K_{3} \exp \left(-E_{D} / k T\right)$ 


\section{FTHEXP，FDEN}

where

$$
\begin{aligned}
\Delta \mathrm{L} / \mathrm{L}_{0} & =\begin{array}{l}
\text { linear strain caused by thermal expansion (equal to zero } \\
\text { at } 300 \mathrm{~K}) \text { (unitless) }
\end{array} \\
\mathrm{T} & =\text { temperature }(\mathrm{K}) \\
\mathrm{E}_{\mathrm{D}} & =\text { energy of formation of a defect }(\mathrm{J}) \\
\mathrm{K} & =\text { Boltzmann's constant }\left(1.38 \times 10^{-23} \mathrm{~J} / \mathrm{K}\right)
\end{aligned}
$$

and $K_{1}, K_{2}$, and $K_{3}$ are constants to be determined. $K_{1}, K_{2}, K_{3}$, and $E_{D}$ are given in Table 2.5-1.

For mixed $\mathrm{UO}_{2}$ and $\mathrm{PuO}_{2}$, the thermal expansion of the solid is found by combining the contribution from each constituent in proportion to its weight fraction.

During melting, an expansion equal to a linear strain of 0.043 occurs. If the fuel is partially molten, the strain due to thermal expansion is given by

$\Delta L / L_{0}=\Delta L / L_{0}\left(T_{m}\right)+0.043 \cdot$ FACMOT

where

$$
\begin{aligned}
& \frac{\Delta L}{L_{0}}\left(T_{m}\right)=\quad \begin{array}{l}
\text { thermal expansion strain of solid fuel from Equation } \\
\text { with } T=T_{m}
\end{array} \\
& T_{m} \quad \text { melting temperature of the fuel }(K) \\
& \text { FACMOT = } \\
& \begin{array}{l}
\text { fraction of the fuel which is molten (unitless) } \\
\text { If FACMOT }=0.0, \text { the fuel is all solid; } \\
\text { If FACMOT }=1.0, \text { the fuel is all molten. }
\end{array}
\end{aligned}
$$




\section{FTHEXP，FDEN}

Table 2.5-1. Parameters used in $\mathrm{UO}_{2}$ and $\mathrm{PuO}_{2}$ solid-phase thermal expansion correlations

\begin{tabular}{|c|c|c|c|}
\hline Constant & $\mathrm{UO}_{2}$ & $\mathrm{PuO}_{2}$ & Units \\
\hline$K_{1}$ & $1.0 \times 10^{-5}$ & $9.0 \times 10^{-6}$ & $\mathrm{~K}^{-1}$ \\
\hline$k_{2}$ & $3.0 \times 10^{-3}$ & $2.7 \times 10^{-3}$ & Unitless \\
\hline$k_{3}$ & $4.0 \times 10^{-2}$ & $7.0 \times 10^{-2}$ & Unitless \\
\hline$E_{D}$ & $6.9 \times 10^{-20}$ & $7.0 \times 10^{-20}$ & $\mathrm{~J}$ \\
\hline
\end{tabular}




\section{FTHEXP, FDEN}

The correlation used to describe the expansion of entirely molten fuel is

$\Delta L / L_{0}=\Delta L / L_{0}\left(T_{m}\right)+0.043+3.6 \times 10^{-5}\left[T-\left(T_{m}+\Delta T_{m}\right)\right]$

The solid-to-liquid phase transition is isothermal only for pure $\mathrm{UO}_{2}$ or pure $\mathrm{PuO}_{2}$. For $(\mathrm{U}, \mathrm{Pu}) \mathrm{O}_{2}$, the transition occurs over a finite temperature range, denoted in Equation (2.5-3) by $\Delta \mathrm{T}_{\mathrm{m}}$.

The uncertainty of the pooled data was found to be temperature dependent, increasing approximately linearly with temperature. Therefore, a percentage error is given rather than a fixed number. The $\pm \sigma$ limits were found to be within $\pm 10 \%$ of the calculated value.

Section 2.5.2 contains a discussion and evaluation of the sources used. Section 2.5 .3 presents the development of the model. In Section 2.5.4, the model predictions are compared with data and an uncertainty estimate is given. Implementation of FTHEXP is described in Section 2.5.5. In Section 2.5.6, the subcode FDEN is described.

\subsubsection{Literature Review (FTHEXP)}

Data were taken from nine sources for $\mathrm{UO}_{2}, 2.5-1$ to 2.5-9 and two sources for $\mathrm{PuO}_{2} \cdot 2.5-3,2.5-10$ For $\mathrm{UO}_{2}$, the data cover a temperature range from 300 to $3400 \mathrm{~K}$; and for $\mathrm{PuO}_{2}$, the data cover a range from 300 to $1700 \mathrm{~K}$.

In four of the $\mathrm{UO}_{2}$ experiments, $2.5-1,2.5-2,2.5-8,2.5-9 x$-ray measuring techniques were used. This type of measurement gives the change in the lattice parameter rather than the bulk thermal expansion. Several investigators $2.5-2,2.5-11,2.5-12$ have noted that the change in the lattice parameter is appreciably smaller than the bulk thermal expansion measured using dilatometric or interferometric methods, especially at high (>1000 K) 
FTHEXP, FDEN

temperature. In general, the difference is attributed to the creation of Schottky defects. 2.5-2,2.5-11,2.5-12 Hock and Momin 2.5-9 obtained results where there was no discrepancy between their $X$-ray results and bulk results. However, the bulk of the data support the Schottky defect theory, since the $X$-ray data consistently fall below other data at high temperatures where defects begin to appear in large numbers. Therefore, $X$-ray data were used in the data base only at low temperatures $(<800 \mathrm{~K})$.

\subsubsection{Mode1 Development (FTHEXP)}

While most authors simply fit their data with a polynomial, in this report correlations based on more physical grounds are used.

2.5.3.1 Low-Temperature Thermal Expansion. The simplest theory of the linear expansion of a solid near room temperature is found in most elementary physics texts, such as Sears and Zemansky. 2.5-13

$\Delta L=L_{0} K_{1}\left(T-T_{0}\right)$

or

$$
\Delta L / L_{0}=K_{1} T-K_{1} T_{0}
$$

where

$$
\begin{aligned}
& \Delta L=\text { linear expansion }(\mathrm{m}) \\
& \mathrm{K}_{1}=\text { the average coefficient of linear expansion }\left(\mathrm{K}^{-1}\right) \\
& \mathrm{T}_{0}=\text { a reference temperature }(\mathrm{K}) \\
& \mathrm{L}_{0}=\text { length at reference temperature }(\mathrm{m})
\end{aligned}
$$




\section{FTHEXP, FDEN}

At the reference temperature, $\Delta L=0$ or, equivalently, $L=L_{0}$.

The low-temperature $(<800 \mathrm{~K})$ data were fit by the method of least-squares to a generalized form of Equation (2.5-5)

$$
\Delta L / L_{0}=K_{1} T-K_{2}
$$

This fit was done separately for $\mathrm{UO}_{2}$ and $\mathrm{PuO}_{2}$, and the coefficients $K_{1}$ and $K_{2}$ for each material are listed in Table 2.5-1. The numbers in the table have been rounded off to two significant figures. Comparison of Equations (2.5-5) and (2.5-6) shows that $T_{0}=K_{2} / K_{1}$, which for both fuels is $300 \mathrm{~K}$, a temperature typical of the reference temperatures where $\Delta \mathrm{L}=0$ in data bases. These correlations describe low-temperature thermal expansion within the data scatter.

2.5.3.2 High-Temperature Thermal Expansion. For both $\mathrm{UO}_{2}$ and $\mathrm{PuO}_{2}$, Equation (2.5-6) was inadequate at higher temperatures $(\mathrm{T}>1000 \mathrm{~K}$ ), most likely due to the formation of Schottky defects. Fenkel defects will also be present but should have no measurable effect on the thermal expansion. 2.5-2,2.5-9 The contribution from Schottky defects should be directly proportional to their concentration, which is given by 2.5-2,2.5-14

$$
N / N_{0}=K_{3} \exp \left(-E_{D} / k T\right)
$$

where

$$
\begin{aligned}
& N=\text { number of Schottky defects in the crystal } \\
& N_{0}=\text { number of atoms in the crystal } \\
& E_{D}=\text { energy of formation of a defect }(\mathrm{J}) \\
& k \quad=\text { Boltzmann's constant }\left(1.38 \times 10^{-23} \mathrm{~J} / \mathrm{K}\right)
\end{aligned}
$$


FTHEXP， FDEN

$K_{3}=$ constant to be determined (unitless).

The difference between the thermal strain calculated with Equation $(2.5-6)$ and each data point was found. These differences were assumed to be the defect contribution to the thermal expansion strain and were fit by the method of least squares to an equation of the form

$$
\left(\Delta L / L_{0}\right)_{D}=+K_{3} \exp \left(-E_{D} / k T\right)
$$

where $\left(\Delta L / L_{0}\right)_{D}$ is the defect contribution to the thermal expansion (unitiess).

The values for $K_{3}$ and $E_{D}$ resulting from these fits are given in Table 2.5-1.

Baldock 2.5-2 did a similar analysis using $\mathrm{UO}_{2}$ data and those data of Conway. 2.5-4 Both the preexponential factor, $K_{3}$, and the energy of formation, $E_{D}$, were larger than those listed in Table 2.5-1. The differences mean that Baldock's Schottky term is smaller than the one found here at low temperatures and larger at high temperatures. The magnitude of the Schottky term determined this way is strongly dependent on the low-temperature correlation used. Since Equation (2.5-6) has been found using a much broader data base than Baldock's, the values for $K_{3}$ and $E_{D}$ in Table 2.5-1 should be the more accurate and are the ones used in this model.

2.5.3.3 Mixed-0xide Thermal Expansion. When the fuel is composed of a mixture of $\mathrm{UO}_{2}$ and $\mathrm{PuO}_{2}$, the thermal expansion is found by taking a weighted average of the contributions from each component

$$
\left(\frac{\Delta L}{L_{0}}\right)_{(U, P u) 0_{2}}=\left(\frac{\Delta L}{L_{0}}\right) U_{2} \cdot(1-F C O M P)+\left(\frac{\Delta L}{L_{0}}\right) P_{2} \cdot F C O M P
$$

where FCOMP is the $\mathrm{PuO}_{2}$ weight fraction. 


\section{FTHEXP, FDEN}

2.5.3.4 Thermal Expansion of Partially Molten Fuel. Christensen $2.5-6$ has determined that $\mathrm{UO}_{2}$ experiences a linear thermal strain of 0.043 on melting. His measurements show considerable scatter but are the only data available. No comparable measurements exist for $\mathrm{PuO}_{2}$. The structure of the two fuels is similar enough, however, so that no serious error should be introduced by equating the $\mathrm{PuO}_{2}$ expansion on melting with that of $\mathrm{UO}_{2}$. For partially molten fuel, the thermal expansion strain is given by

$$
\Delta L / L_{0}=\Delta L / L_{0}\left(T_{m}\right)+0.043 \cdot F A C M O T
$$

The various terms of Equation (2.5-2) are defined in Section 2.5.1.

2.5.3.5 Thermal Expansion of Entirely Molten Fuel. The experiment of Christensen on $\mathrm{UO}_{2}$ again produced the only data available and must be used for all combinations of $(U, \mathrm{Pu}) \mathrm{O}_{2}$.

A least-squares-fit to his limited data yields

$$
\Delta L / L_{0}=\Delta L / L_{0}\left(T_{m}\right)+0.043+3.6 \times 10^{-5}\left[T-\left(T_{m}+\Delta T_{m}\right)\right]
$$

where all the variables have been defined previously in Section 2.5.1.

\subsubsection{Mode1-Data Comparison and Uncertainty (FTHEXP)}

Figure 2.5-1 compares the correlation for $\mathrm{UO}_{2}$ with its data base. The three very low points around $1500 \mathrm{~K}$ are all from Christensen. $2.5-6$ Other data from Christensen fit well to the curve, and there is no obvious reason for the large deviation of these points. At the highest temperatures, there are several data considerably above the curve. These are also from Christensen. (At these temperatures, the possibility exists that the fuel was melted in the sample.) The large expansion which occurs on melting could easily explain the deviation of these data from the solid $\mathrm{UO}_{2}$ data. 
FTHEXP, FDEN

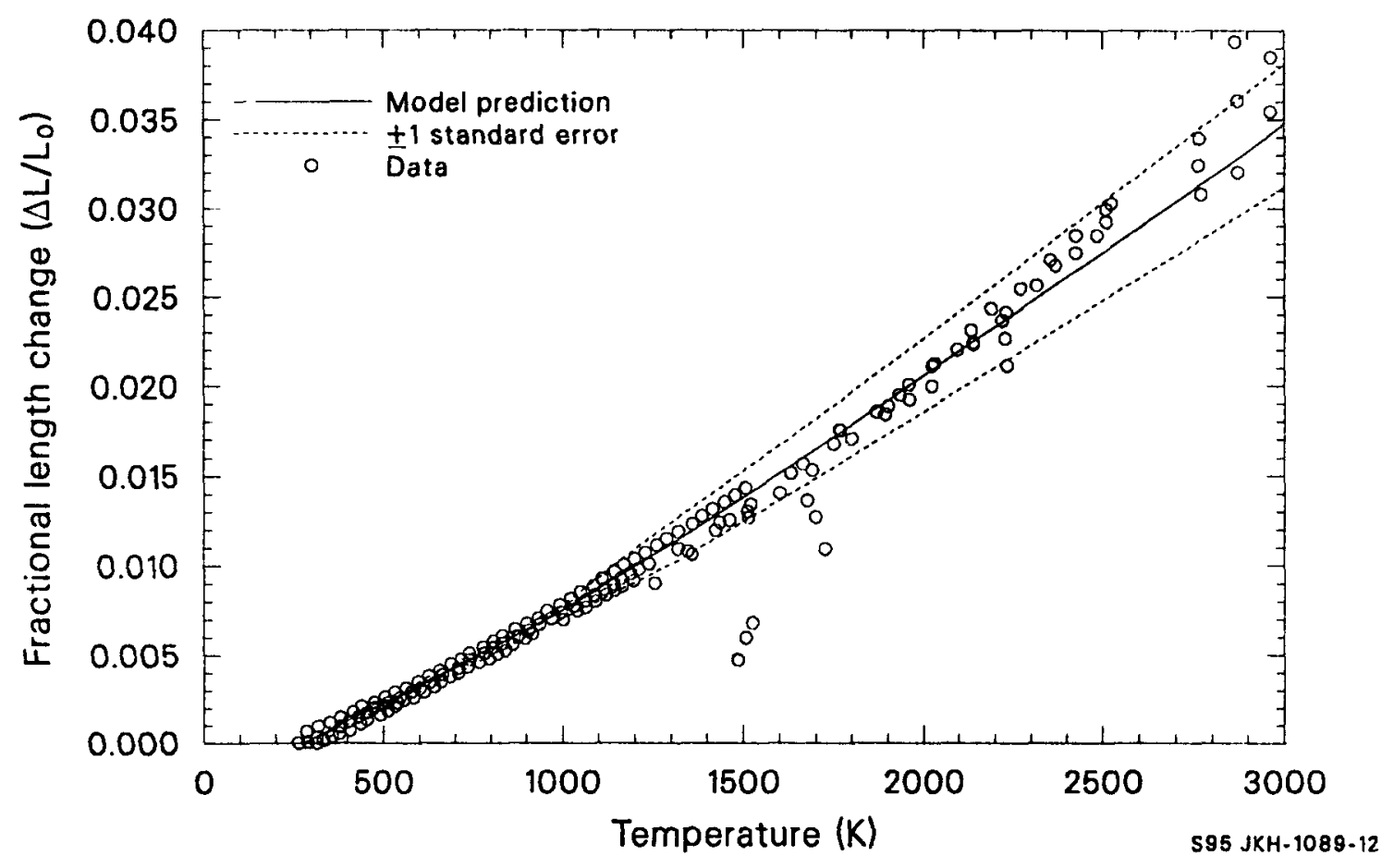

Figure 2.5-1. Correlation for the thermal expansion strain of $\mathrm{UO}_{2}$ compared with its data base. 


\section{FTHEXP， FDEN}

A similar comparison of the correlation and the data is shown in Figure 2.5-2 for $\mathrm{PuO}_{2}$. Figure 2.5-3 shows a comparison of the expansion curves for $\mathrm{UO}_{2}$ and $\mathrm{PuO}_{2}$ and $\left(\mathrm{U}_{0.8}, \mathrm{Pu}_{0.2}\right)_{2}$. No data are shown on this curve because thermal expansion data for mixed oxides are not available. The figures show that the thermal expansion behavior of the two materials differ, but only siightly.

Error bands, calculated from the sum of the squared residuals, are shown in Figure 2.5-1 and 2.5-2 as dotted lines. These reflect a standard error of $\pm 10 \%$ of the calculated value found from the $\mathrm{UO}_{2}$ data set. A percentage uncertainty is given because the error increases with temperature. A single-valued uncertainty can lead to a nonphysical possibility in this model. For example, the standard error for $\mathrm{UO}_{2}$ is \pm 0.0012 , which equals the thermal expansion strain at $420 \mathrm{~K}$. Thus, for any temperature less than $420 \mathrm{~K}$, the lower limit implied by the uncertainty would be negative, implying that as the fuel heats from 300 to $400 \mathrm{~K}$, it contracts. A percentage error automatically precludes this.

The error for $\mathrm{PuO}_{2}$ was somewhat smaller, probably due to the limited number of sources. The $\pm 10 \%$ error limit is also used for $\mathrm{PuO}_{2}$ to avoid assigning unrealistic accuracy to these data.

\subsubsection{Implementation (FTHEXP)}

The function FTHEXP is coded as described in the preceding sections to calculate the thermal expansion strains of $\mathrm{UO}_{2}$ and $\mathrm{PuO}_{2}$. As used in SCDAP/RELAP5, this function has the ability to calculate the thermal expansion strains with $\mathrm{PuO}_{2}$ disabled. ( $\mathrm{A} \mathrm{PuO}_{2}$ fractional composition of 0.0 , making the fuel pure $\mathrm{UO}_{2}$, is hardwired into the coding.) By inputting the $\mathrm{PuO}_{2}$ composition fraction by argument list or common block, the $\mathrm{PuO}_{2}$ thermal expansion strain can be restored. 
FTHEXP，FDEN

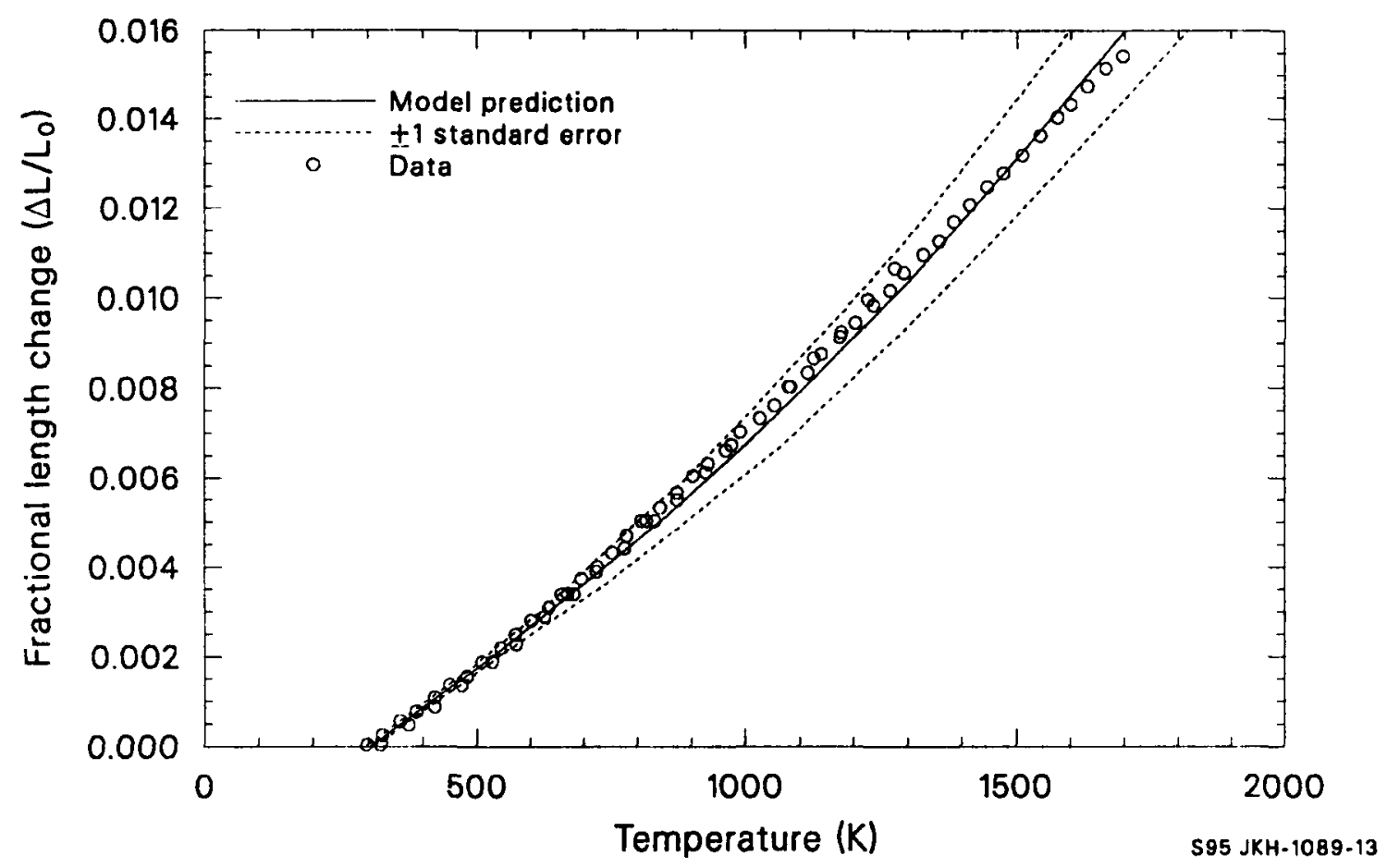

Figure 2.5-2. Correlation for the thermal expansion strain of $\mathrm{PuO}_{2}$ compared with its data base. 
FTHEXP， FDEN

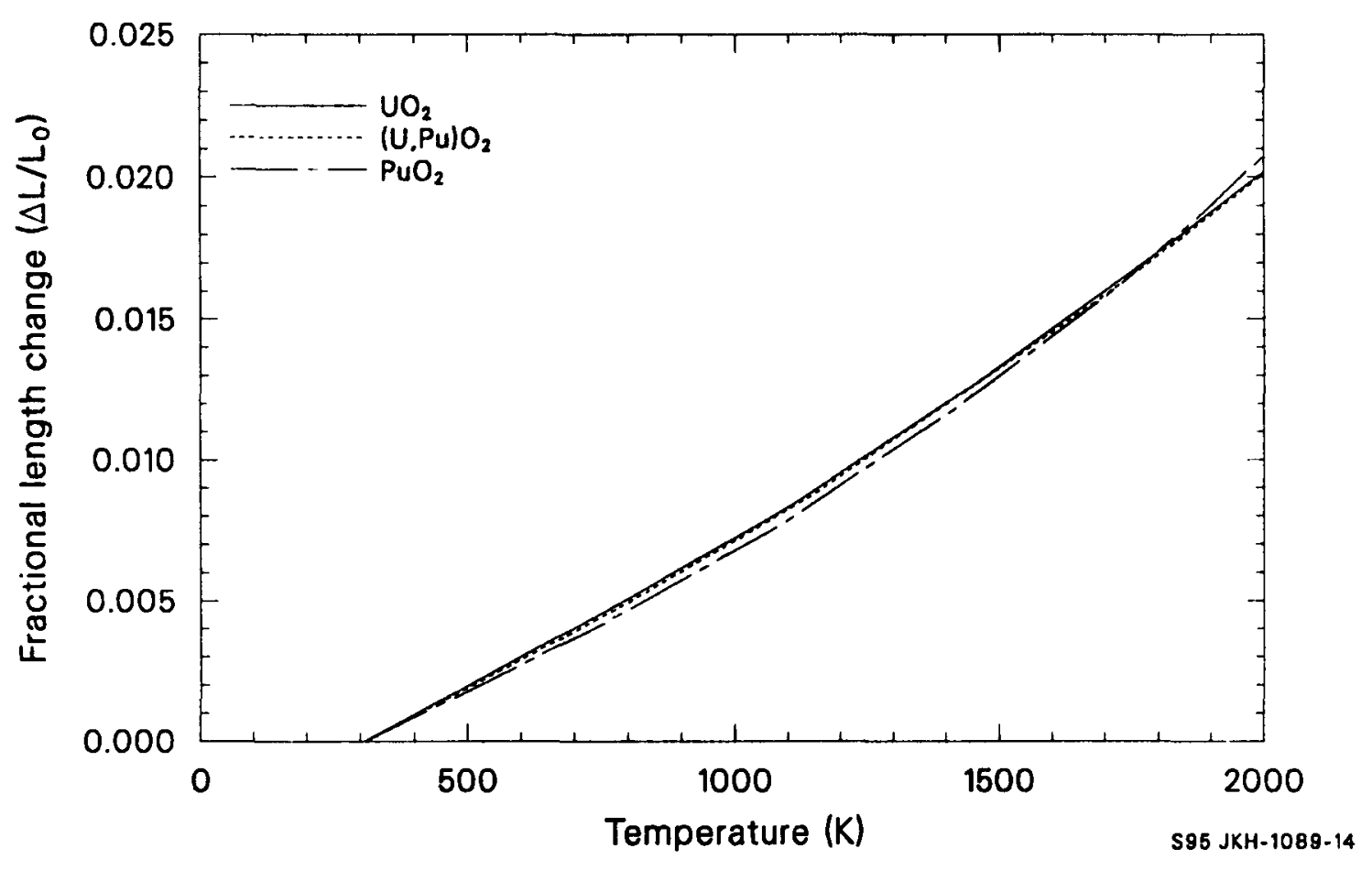

Figure 2.5-3. Comparisons of the $\mathrm{UO}_{2}, \mathrm{PuO}_{2}$, and $\left(\mathrm{U}_{0.8}, \mathrm{Pu}_{0.2}\right) \mathrm{O}_{2}$ correlations from 0 to $2000 \mathrm{~K}$. 
FTHEXP, FDEN

\subsubsection{Density (FDEN)}

The FDEN function determines the theoretical density of $\mathrm{UO}_{2}$ using room-temperature data and thermal expansion strains calculated by the FTHEXP subcode. The relation used is

$\rho=\rho_{0}\left(1-3 \epsilon_{U_{2}}\right)$

where

$$
\begin{aligned}
\rho= & \text { theoretical density of } \mathrm{UO}_{2}\left(\mathrm{~kg} / \mathrm{m}^{3}\right) \\
\rho_{\mathrm{O}}= & \text { room temperature density of } \mathrm{UO}_{2}=10,980\left(\mathrm{~kg} / \mathrm{m}^{3}\right) \\
\epsilon_{\mathrm{UO}_{2}=}= & 1 \text { inear thermal expansion strain calculated for } \\
& \mathrm{UO}_{2}, \text { using a reference (zero strain) temperature of } \\
& 300 \mathrm{~K}(\mathrm{~m} / \mathrm{m}) .
\end{aligned}
$$

The room-temperature density, $10,980 \mathrm{~kg} / \mathrm{m}^{3}$, was taken from 01 ander $2.5-15$ and is accurate to $\pm 20 \mathrm{~kg} / \mathrm{m}^{3}$. Figure $2.5-4$ shows the theoretical density of uranium dioxide as calculated by FDEN.

\subsubsection{References}

2.5-1. F. Gronvold, "High Temperature X-ray Study of Uranium Oxides in the $\mathrm{UO}_{2}-\mathrm{U}_{3} \mathrm{O}_{8}$ Region," Journal of Inorganic and Nuclear Chemistry, 1, 1955, pp. 357-370.

2.5-2. P. J. Baldock et a1., "The X-ray Thermal Expansion of Near-Stoichiometric $\mathrm{UO}_{2}$," Journal of Nuclear Materials, 18 , 1966, pp. 305-313.

2.5-3. N. H. Brett and L. E. Russel, "The Thermal Expansion of $\mathrm{PuO}_{2}$ and Some Other Actinide Oxides Between Room Temperature and $1000^{\circ} \mathrm{C}$," Proceedings of the Second International Conference on Plutonium Metallurgy, Grenoble, France, April 19-22, 1960, pp. 397-410. 


\section{FTHEXP，FDEN}

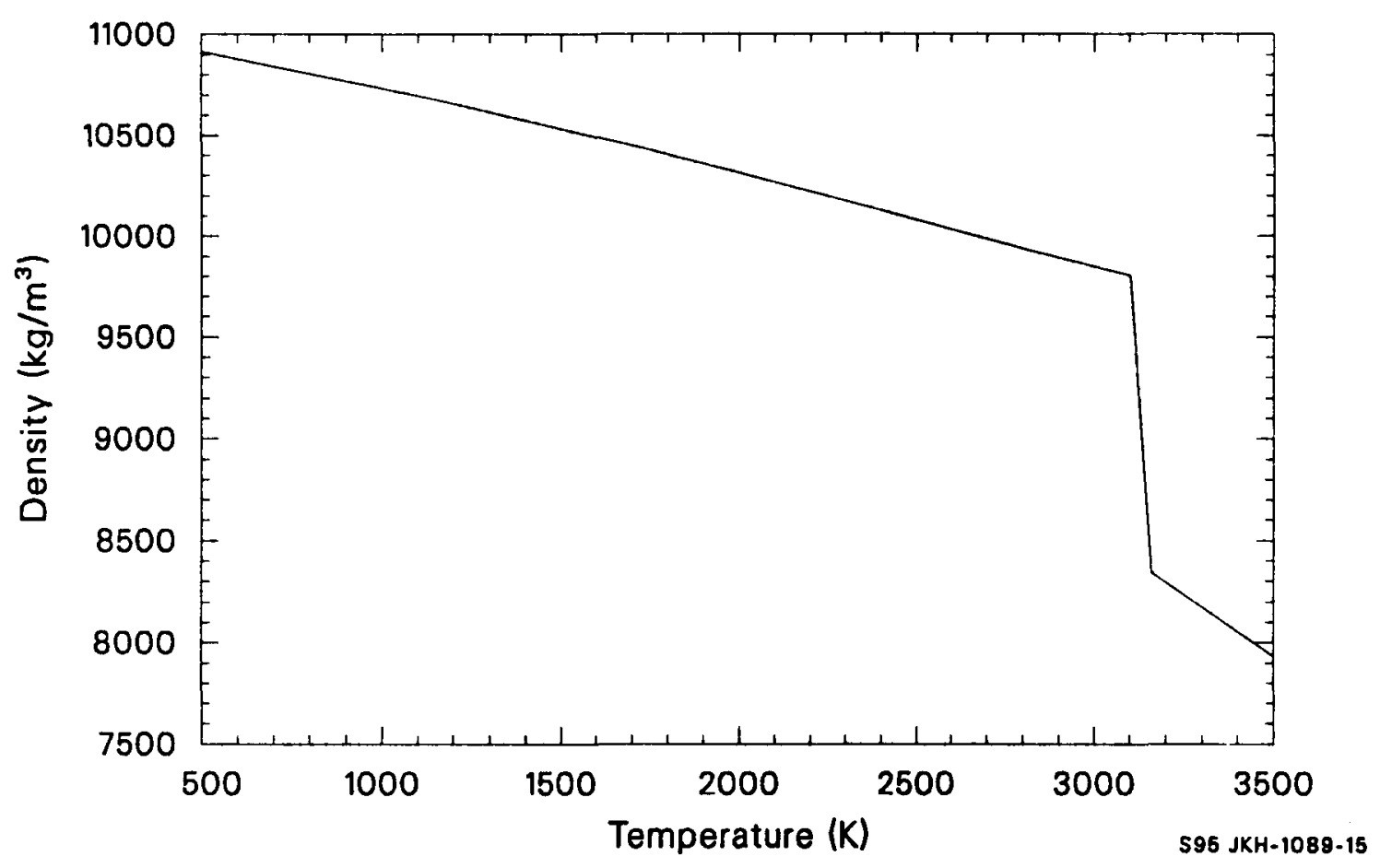

Figure 2.5-4. Theoretical density of $\mathrm{UO}_{2}$. 
2.5-4. J. B. Conway et al., The Thermal Expansion and Heat Capacity of $\mathrm{UO}_{2}$ to $2200^{\circ} \mathrm{C}, \mathrm{TM}-63-6-6,1963$.

2.5-5. M. D. Burdick and H. S. Parker, "Effect of Particle Size on Bulk Density and Strength Properties of Uranium Dioxide Specimens," Journal of the American Ceramic Society, 39, 1956, pp. 181-187.

2.5-6. J. A. Christensen, "Thermal Expansion and Change in Volume of Uranium Dioxide on Melting, "Journal of the American Ceramic Society, 46, 1963, pp. 607-608.

2.5-7. W. A. Lambertson and J. H. Handwerk, The Fabrication and Physical Properties of Urania Bodies, ANL-5053, 1956.

2.5-8. C. P. Kempter and R. E. Elliott, "Thermal Expansion of UN, $\mathrm{UO}_{2}$, $\mathrm{UO}_{2}-\mathrm{ThO}_{2}$, and $\mathrm{ThO}_{2}$, Journal of Chemical Physics, 30, 1958, pp. $1524-1526$.

2.5-9. M. Hoch and A. C. Momin, "High Temperature Thermal Expansion of $\mathrm{UO}_{2}$ and $\mathrm{ThO}_{2}$," High Temperature-High Pressures, 1, 1969, pp. 401-407.

2.5-10. M. Tokar and A. W. Nutt, "Thermal Expansion of $\mathrm{PuO}_{2}$ from 25 to $1420^{\circ} \mathrm{C}, "$ Transactions of the American Nuclear Society, 10 , June 1972, pp. 210-211.

2.5-11. M. Tokar et a7., "Linear Thermal Expansion of Plutonium Dioxide," Nuclear Technology, 17, 1973.

2.5-12. R. W. Siegel, "Vacancy Concentration in Metals," Journal of Nuclear Materials, 69 and 70, 1978, pp. 117-146

2.5-13. F. W. Sears and M. W. Zemansky, University Physics, 3rd Edition, Reading, Massachusetts: Addison-Wesley Publishing Company, 1967, p. 347 .

2.5-14. C. Kittel, Introduction to Solid State Physics, 3rd Edition, New York: John Wiley and Sons, Inc., 1966.

2.5-15. D. R. 01 ander, Fundamental Aspects of Nuclear Reactor Fuel Elements, TID-26711-P1, 1976, p. 114. 
$-$ 
FELMOD， FPOIR

\subsection{Elastic Moduli (FELMOD, FPOIR) \\ (D. L. Hagrman, E. T. Laats, and C. S. 01sen)}

The FELMOD subcode calculates values for Young's modulus for $\mathrm{UO}_{2}$ and $(U, \mathrm{Pu}) \mathrm{O}_{2}$. An estimate of the standard error expected with FELMOD is also calculated. FELMOD and FPOIR are intended for use with mechanical codes like FRACAS, ${ }^{2.6-1}$ which predict pellet deformation.

The FELMOD code is discussed in Sections 2.6.1 through 2.6.4, and the FPOIR code is discussed in Section 2.6.5.

\subsubsection{Summary (FELMOD)}

The Young's modulus of ceramic fuels is affected by the temperature, density, and, to a lesser extent, the oxygen-to-metal ratio $(0 / M)$ and burnup of the fuel. Although published $(U, \mathrm{Pu}) \mathrm{O}_{2}$ mixed-oxide data are very limited, several authors indicate that the addition of $\mathrm{PuO}_{2}$ to $\mathrm{UO}_{2}$ causes an increase in Young's modulus which is at least as large as the standard error of the $\mathrm{UO}_{2}$ correlation. The increase has therefore been included in the model.

The subcode was constructed by considering values of Young's modulus measured at high temperatures typical of normal and abnormal LWR operation. Extensive room-temperature data were available but were used only to help evaluate the uncertainty of the model.

The correlation developed to model Young's modulus for stoichiometric $\mathrm{UO}_{2}$ fuel below the melting temperature is

$$
E S=2.334 \times 10^{11}[1-2.752(1-D)]\left[1-1.0915 \times 10^{-4} \mathrm{~T}\right]
$$




\section{FELMOD， FPOIR}

where

$$
\begin{aligned}
E S & =\text { Young's modulus for stoichiometric } \mathrm{UO}_{2} \text { fuel }\left(\mathrm{N} / \mathrm{m}^{2}\right) \\
D & =\text { fuel density (fraction of the theoretical density) } \\
T & =\text { temperature }(\mathrm{K}) .
\end{aligned}
$$

For nonstoichiometric fuel or fuel which contains $\mathrm{PuO}_{2}$, the Young's modulus below melting temperature is

$$
E=E S \exp (-B x)[1+0.15 f]
$$

where

$E=$ Young's modulus $\left(\mathrm{N} / \mathrm{m}^{2}\right)$

$E S=$ Young's modulus for stoichiometric $\mathrm{UO}_{2}$ fuel $\left(\mathrm{N} / \mathrm{m}^{2}\right)$

$B=1.34$ for hyperstoichiometric fuel or 1.75 for hypostoichiometric fuel

$x=$ the magnitude of the deviation from stoichiometry in $\mathrm{MO}_{2 \pm X}$ fuel

$f=\mathrm{PuO}_{2}$ content of the fuel (weight fraction).

The estimated standard errora of FELMOD for stoichiometric fuel is

a. The standard error is estimated with a set of data by the expression (sum of squared residuals/number of residuals minus the number of constants used to fit the data) $1 / 2$. 
FELMOD, FPOIR

(1) for temperatures between 450 and $1600 \mathrm{~K}$,

$$
S_{E S}=0.06 \times 10^{11}
$$

(2) for temperatures between 1600 and $3113 \mathrm{~K}$,

$$
S_{E S}=0.06 \times 10^{11}+E S(T-1600) / 6052.6
$$

where $\mathrm{S}_{\mathrm{ES}}$ is the estimated standard error for stoichiometric $\mathrm{UO}_{2}$ fuel $\left(\mathrm{N} / \mathrm{m}^{2}\right)$ and $E S$ and $T$ were previously defined.

For nonstoichiometric fuel or fuel that contains $\mathrm{PuO}_{2}$, the estimated standard error is

$S_{E}=\left[\left(S_{E S}\right)^{2}+(E-E S)^{2}\right]^{1 / 2}$

where $S_{E}$ is the estimated standard error $\left(\mathrm{N} / \mathrm{m}^{2}\right)$ for nonstoichiometric fuel and E, ES, and $S_{E S}$ were previously defined.

The following subsection is a review of the available Young's modulus data for $\mathrm{UO}_{2}$ and $(U, \mathrm{Pu}) \mathrm{O}_{2}$ fuel. Section 2.6.3 describes the approach used to formulate the model, and Section 2.6.4 is a discussion of the uncertainty of the model.

\subsubsection{Survey of Available Data (FELMOD)}

Young's modulus for $\mathrm{UO}_{2}$ and $(U, \mathrm{Pu}) \mathrm{O}_{2}$ fuel has been measured by bending techniques $2.6-2,2.6-3$ and by resonant frequency methods. The bending techniques measure an isothermal Young's modulus that is more characteristic of reactor operating conditions than the adiabatic Young's modulus measured with resonant frequency methods. However, bending technique measurements are not as accurate as resonance frequency methods and will therefore not be used in the data base for this model. Also, the 


\section{FELMOD， FPOIR}

difference between adiabatic and isothermal Young's moduli is small, only about $0.1 \%$ of the measured value. $2.6-4$

\subsubsection{Stoichiometric Fuels at Reactor Operating Temperatures.}

Data from Padel and de Novion, 2.6-5 Belle and Lustman, 2.6-6 and Hal12.6-7 are most important because they include temperatures characteristic of reactors. Figure 2.6-1 illustrates values of Young's modulus for stoichiometric $\mathrm{UO}_{2}$ at several temperatures and densities. The modulus decreases with increasing temperature and decreasing density. Moreover, the temperature-dependence of the modulus at each density is nearly linear.

Padel and de Novion have reported measurements of mixed-oxide (with 20\% $\mathrm{PuO}_{2}$ ) moduli as a function of temperature and $0 / \mathrm{M}$ ratio, but their report includes only room-temperature data and curves representing the fractional decrease in Young's modulus with increasing temperature on $95 \%$ dense fuel. Room-temperature, mixed-oxide data from Padel and de Novion and from Boocock et a1., 2.6-8 as well as curves from Padel and de Novion, are shown in Figure 2.6-2. The effect of temperature on the $(U, \mathrm{Pu}) \mathrm{O}_{2}$ Young's modulus is similar to its effect on $\mathrm{UO}_{2}$, but the stoichiometric mixed-oxide samples have a larger Young's modulus than stoichiometric $\mathrm{UO}_{2}$ samples.

Boocock's results suggest that Padel and de Novion have exaggerated the increase of Young's modulus in mixed oxides. Boocock's measurements are supported by the following observations: (a) plutonium and uranium are transition elements with presumably similar atomic bonding; (b) more recent results that showed a $3 \%$ increase in Young's modulus due to the addition of $\mathrm{PuO}_{2}$ have been quoted el sewhere; $;^{2.6-9}$ and (c) Nutt et al ${ }^{2.6-10}$ have published a correlation for the effect of porosity on $(U, \mathrm{Pu}) \mathrm{O}_{2}$ oxides that agrees with Boocock's measurements. The $3 \%$ increase due to an addition of $20 \% \mathrm{PuO}_{2}$ to $\mathrm{UO}_{2}$ is probably the most reliable estimate, since it is based on the more recent data of de Novion. 2.6-11 
FELMOD， FPOIR

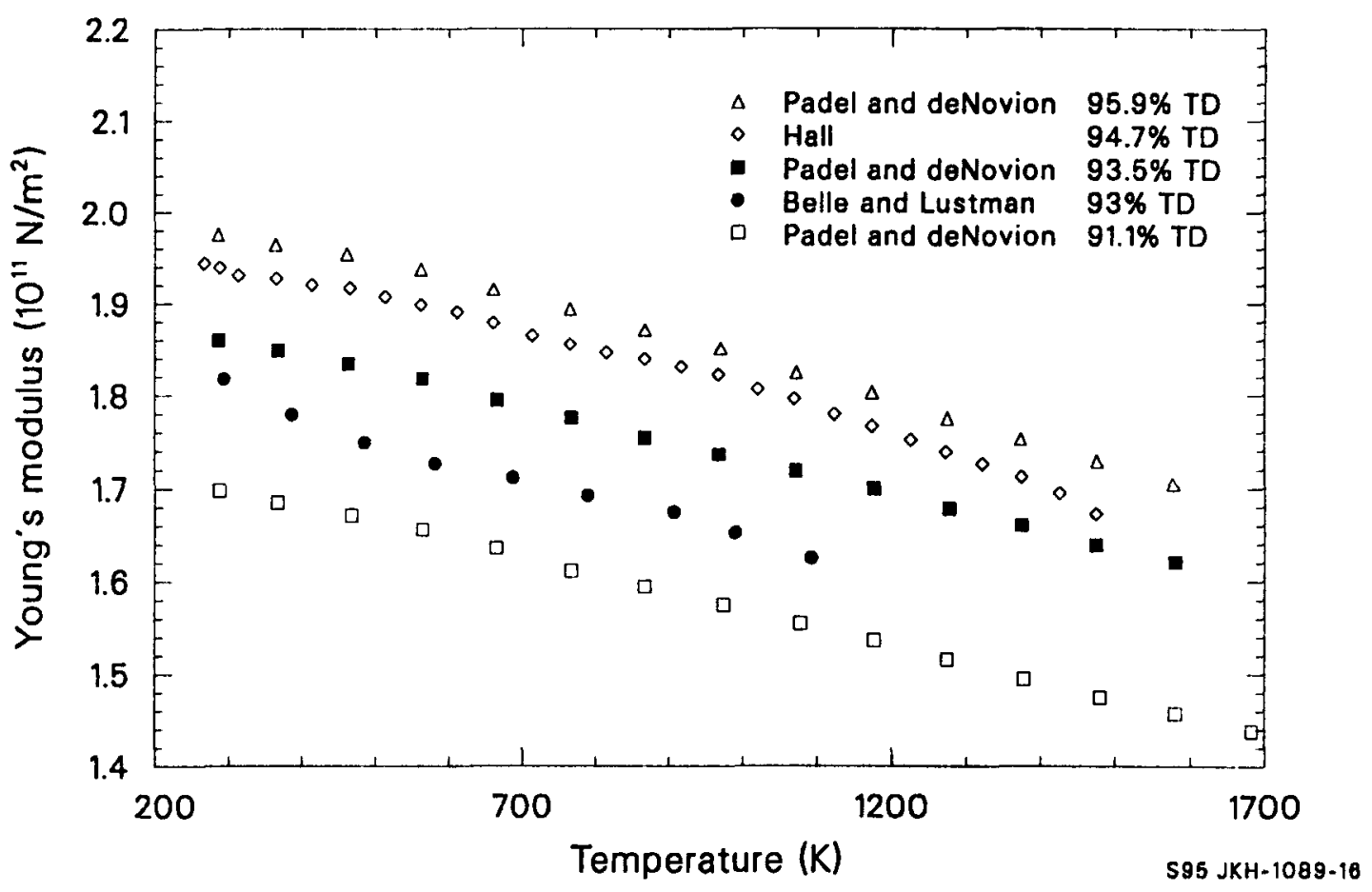

Figure 2.6-1. Young's modulus for stoichiometric $\mathrm{UO}_{2}$ fuel at several temperatures and fractions of theoretical density. 


\section{FELMOD，FPOIR}

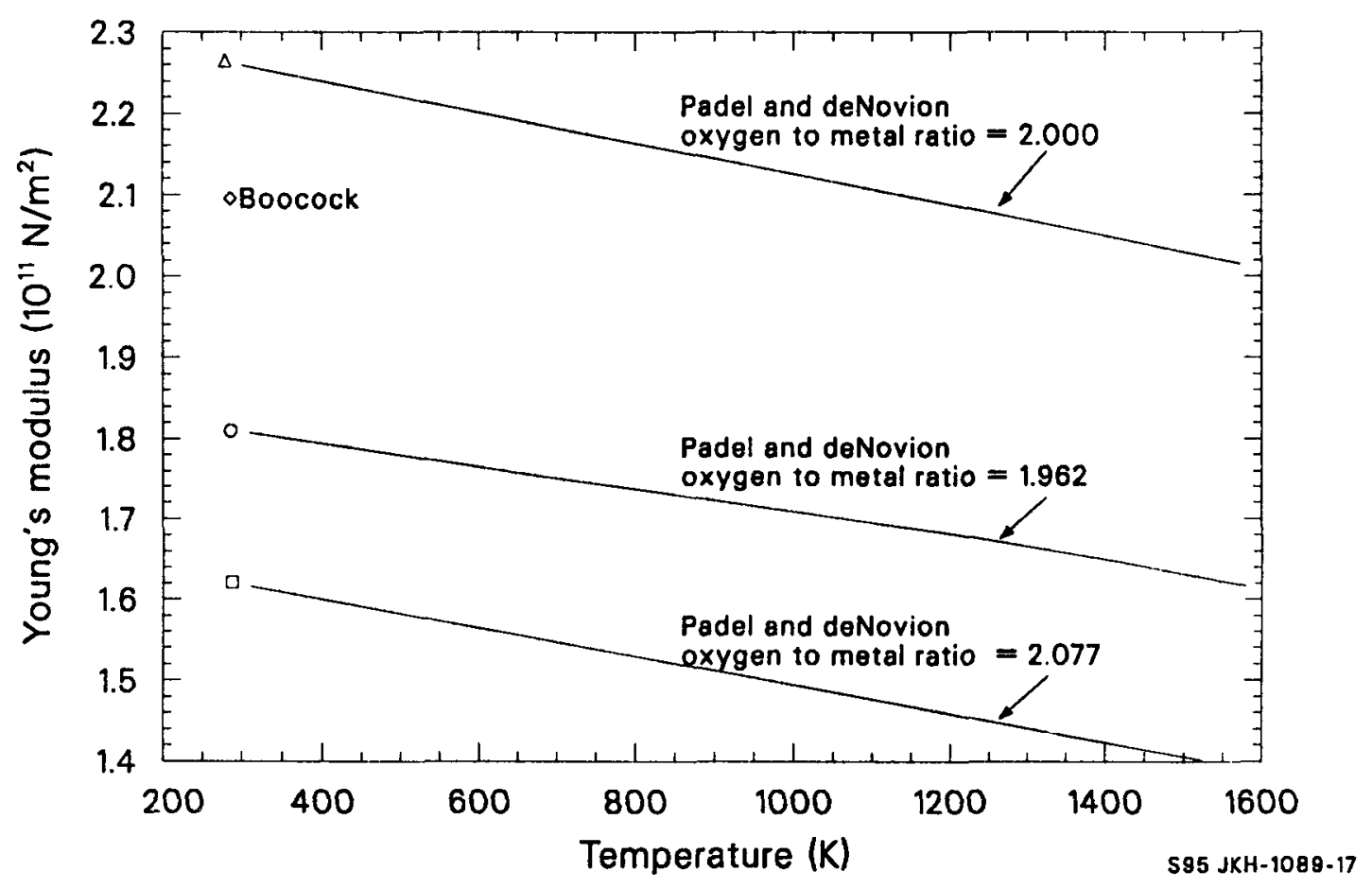

Figure 2.6-2. Young's modulus for $(U, \mathrm{Pu}) \mathrm{O}_{2}$ with various oxygen-to-metal ratios. 
In-reactor measurements of Young's modulus as a function of neutron fluence $2 \cdot 6-12$ have indicated that irradiation increases Young's modulus by about $2 \%$ at saturation. Since the effect is small and could be explained by in-reactor densification of the fuel, no separate model for such burnup-related changes as fission product accumulation and fuel lattice damage appears necessary at this time.

2.6.2.2 Room-Temperature Measurements of Young's Modulus. The effect of changes in fuel density shown in Figure 2.6-1 is confirmed by room-temperature measurements of Young's modulus as a function of density. Numerous data obtained with stoichiometric $\mathrm{UO}_{2}$ fuels between $90 \%$ and $100 \%$ of theoretical density2.6-5 to 2.6-8 and 2.6-13 to 2.6-15 are reproduced in Figure 2.6-3. The data are plotted both as a function of density and porosity ( 1 minus the density). The room-temperature data for porosities between 0 and 0.1 can be described with the least-squares regression line also shown in Figure 2.6-3. The equation represented by the line is

$E S=22.32 \times 10^{11}-56.3 \times 10^{11} \mathrm{P}$

where

$$
\begin{aligned}
& E S=\text { the Young's modulus for stoichiometric } \mathrm{UO}_{2} \text { fuel }\left(\mathrm{N} / \mathrm{m}^{2}\right) \\
& P=\text { porosity }(1-\mathrm{D}) .
\end{aligned}
$$

The standard deviation of this fit is $\pm 0.6 \times 10^{11} \mathrm{~N} / \mathrm{m}^{2}$.

2.6.2.3 Nonstoichiometric Fuels. The data available to describe the effect of variations in the $0 / M$ ratio on Young's modulus are difficult to interpret. For example, the significant variation of Young's modulus with changes in stoichiometry reported by Padel and de Novion (see Figure 2.6-2) is not seen in low-density fuel studies by Nutt et al.2.6-10 Data attributed to de Novion et al. by Matthews show an intermediate effect. 
FELMOD, FPOIR

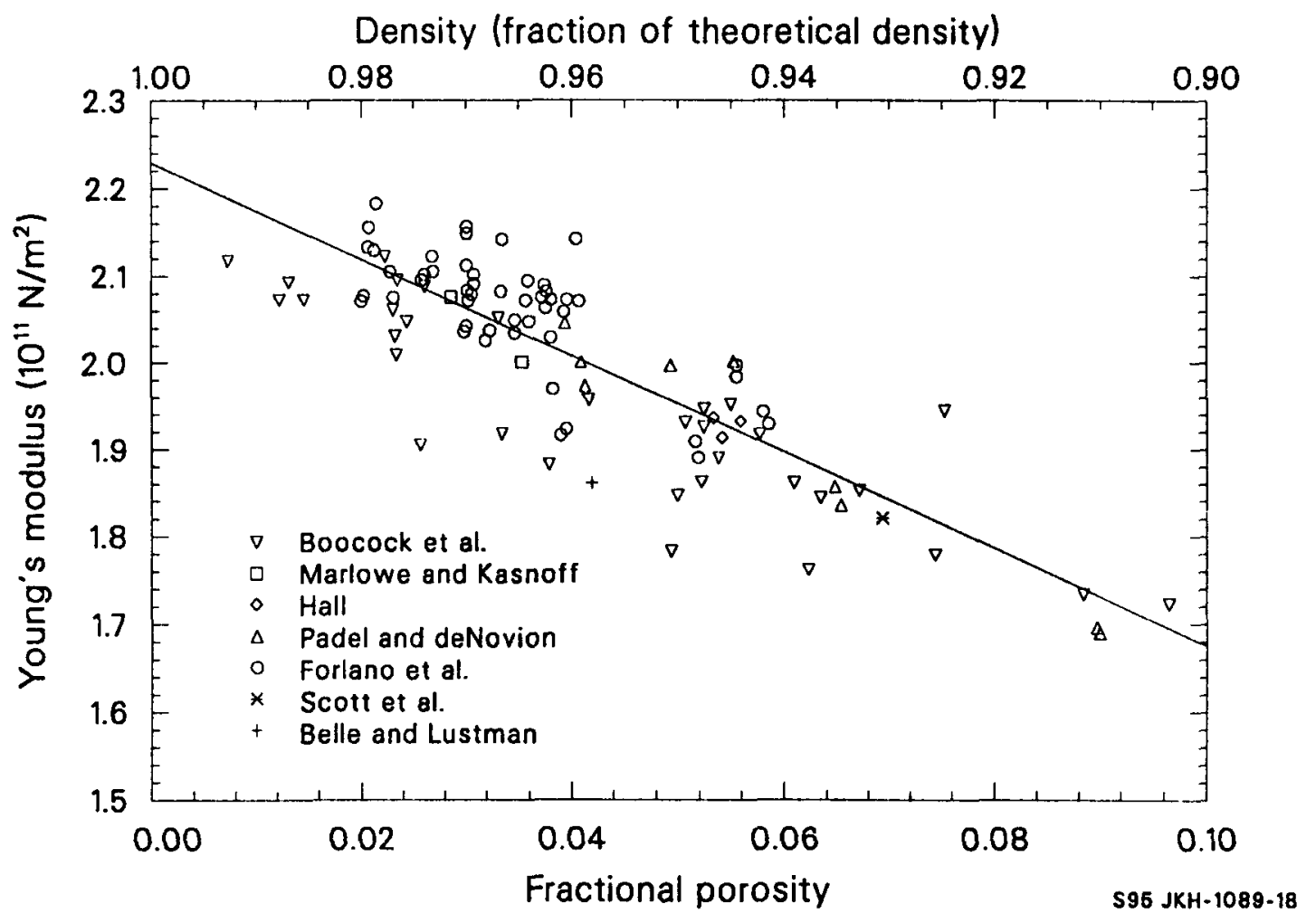

Figure 2.6-3. Young's modulus data and least-squares linear fit for stoichiometric $\mathrm{UO}_{2}$ fuel at room temperature and several different densities. 
FELMOD， FPOIR

Table 2.6-1 summarizes relevant nonstoichiometric fuel data taken at room temperature.

The ratio (Young's modulus in nonstoichiometric fuel/Young's modulus in stoichiometric fuel) is plotted as a function of the fuel's $0 / M$ ratio in Figure 2.6-4. Most of the points show a decrease in Young's modulus when the fuel is either hypo- or hyperstoichiometric, but there is little agreement about the magnitude of the decrease.

It is possible that the fabrication history of the fuel is more significant than the $0 / M$ ratio in determining the Young's modulus. However, the inconsistent data of Nutt et al. are from fuel of uncharacteristically low density $\left(9.5 \mathrm{~g} / \mathrm{cm}^{3}\right)$ and may not apply to more dense fuels. Therefore, the correlation selected for modeling the effects of nonstoichiometric fuel is that attributed to de Novion et al. by Matthews.

$E=E S \exp (-B x)$

where the terms of the equation were previously defined.

Since typical in-reactor values of the $0 / \mathrm{M}$ ratio are 1.96 to $2.04,2.6-16$ the effect of nonstoichiometry is a reduction of Young's modulus by 0 to $5 \%$.

\subsubsection{Model Development (FELMOD)}

The model for Young's modulus is based primarily on the available $\mathrm{UO}_{2}$ fuel data. A correlation for the Young's modulus of stoichiometric $\mathrm{UO}_{2}$ fuel in the temperature range 450 to $1600 \mathrm{~K}$ was developed first, then extrapolated to the approximate melting temperature and modified to predict a slight increase proportional to the weight fraction of $\mathrm{PuO}_{2}$. The rate of increase with $\mathrm{PuO}_{2}$ was set to reproduce the factor of 1.03 , which was estimated in Section 2.6.2 for $20 \% \mathrm{PuO}_{2}$. A second modification for the 


\section{FELMOD， FPOIR}

Table 2.6-1. Summary of Young's moduli measured in nonstoichiometric fuel at room temperature

\begin{tabular}{lllll}
\hline Composition & $\begin{array}{c}\text { Y/M } \\
\text { Ratio }\end{array}$ & Porosity & $\begin{array}{c}\text { Young's } \\
\text { Modulus } \\
\left(10^{11} \mathrm{~N} / \mathrm{m}^{2}\right)\end{array}$ & $\begin{array}{c}\text { Fraction of } \\
\text { Stoichiometric } \\
\text { Value }\end{array}$ \\
\hline
\end{tabular}

Padel and de Novion:

$\begin{array}{lllll}20 \% \mathrm{PuO}_{2 \pm X} & 1.962 & 0.051 & 1.808 & 0.798 \\ 20 \% \mathrm{PuO}_{2 \pm X} & 2.000 & 0.050 & 2.265 & 1.000 \\ 20 \% \mathrm{PuO}_{2 \pm X} & 2.077 & 0.050 & 1.620 & 0.715\end{array}$

Scott et al.:

$\begin{array}{lllll}\mathrm{UO}_{2 \pm X} & 2.000 & 0.042 & 1.860 & 1.000 \\ \mathrm{U0}_{2 \pm X} & 2.160 & 0.042 & 1.240 & 0.666\end{array}$

de Novion et al. as quoted by Matthews:

\begin{tabular}{|c|c|c|c|c|c|}
\hline $20 \% \mathrm{PuO}_{2 \pm X}$ & 2.000 & & -- & -- & 1.000 \\
\hline $20 \% \mathrm{PuO}_{2 \pm X}$ & 1.967 & -- & -- & 0.926 & \\
\hline $20 \% \mathrm{PuO}_{2 \pm X}$ & 1.963 & & -- & - & 0.919 \\
\hline $20 \% \mathrm{PuO}_{2 \pm X}$ & 1.926 & & -- & -- & 0.873 \\
\hline $20 \% \mathrm{PuO}_{2 \pm \mathrm{X}}$ & 1.911 & & -. & - & 0.848 \\
\hline $20 \% \mathrm{PuO}_{2 \pm \mathrm{X}}$ & 1.904 & & -- & - & 0.871 \\
\hline $20 \% \mathrm{PuO}_{2 \pm \mathrm{X}}$ & 1.900 & & - & -- & 0.876 \\
\hline $20 \% \mathrm{PuO}_{2 \pm X}$ & 2.022 & -- & -- & 0.960 & \\
\hline $20 \% \mathrm{PuO}_{2 \pm X}$ & 2.050 & & -- & -. & 0.929 \\
\hline $20 \% \mathrm{PuO}_{2 \pm X}$ & 2.052 & & -- & -- & 0.915 \\
\hline $20 \% \mathrm{PuO}_{2 \pm X}$ & 2.089 & & -- & -- & 0.903 \\
\hline $20 \% \mathrm{PuO}_{2 \pm X}$ & 2.111 & & -- & -- & 0.895 \\
\hline $20 \% \mathrm{PuO}_{2 \pm X}$ & 2.142 & & -- & - & 0.816 \\
\hline
\end{tabular}


FELMOD， FPOIR

Table 2.6-1. (continued)

\begin{tabular}{|c|c|c|c|c|}
\hline Composition & $\begin{array}{l}0 / M \\
\text { Ratio }\end{array}$ & Porosity & $\begin{array}{c}\text { Young's } \\
\text { Modulus } \\
\left(10^{11} \mathrm{~N} / \mathrm{m}^{2}\right)\end{array}$ & $\begin{array}{c}\text { Fraction of } \\
\text { Stoichiometric } \\
\text { Value }\end{array}$ \\
\hline \multicolumn{5}{|c|}{ de Novion et al. as quoted by Matthews: } \\
\hline $20 \% \mathrm{PuO}_{2 \pm X}$ & 2.168 & -- & -- & 0.812 \\
\hline \multicolumn{5}{|l|}{ Nutt et al.: } \\
\hline $20 \% \mathrm{PuO}_{2 \pm X}$ & 2.000 & -- & -- & 1.000 \\
\hline $20 \% \mathrm{PuO}_{2 \pm X}$ & 1.968 & -- & -- & 0.996 \\
\hline $20 \% \mathrm{PuO}_{2 \pm X}$ & 1.971 & -- & -- & 0.996 \\
\hline $20 \% \mathrm{PuO}_{2 \pm X}$ & 1.982 & - & - & 0.998 \\
\hline $20 \% \mathrm{PuO}_{2 \pm X}$ & 2.006 & -- & -- & 1.006 \\
\hline $20 \% \mathrm{PuO}_{2 \pm X}$ & 2.008 & -- & -. & 1.002 \\
\hline $20 \% \mathrm{PuO}_{2 \pm X}$ & 2.008 & -- & - & 1.005 \\
\hline
\end{tabular}




\section{FELMOD，FPOIR}

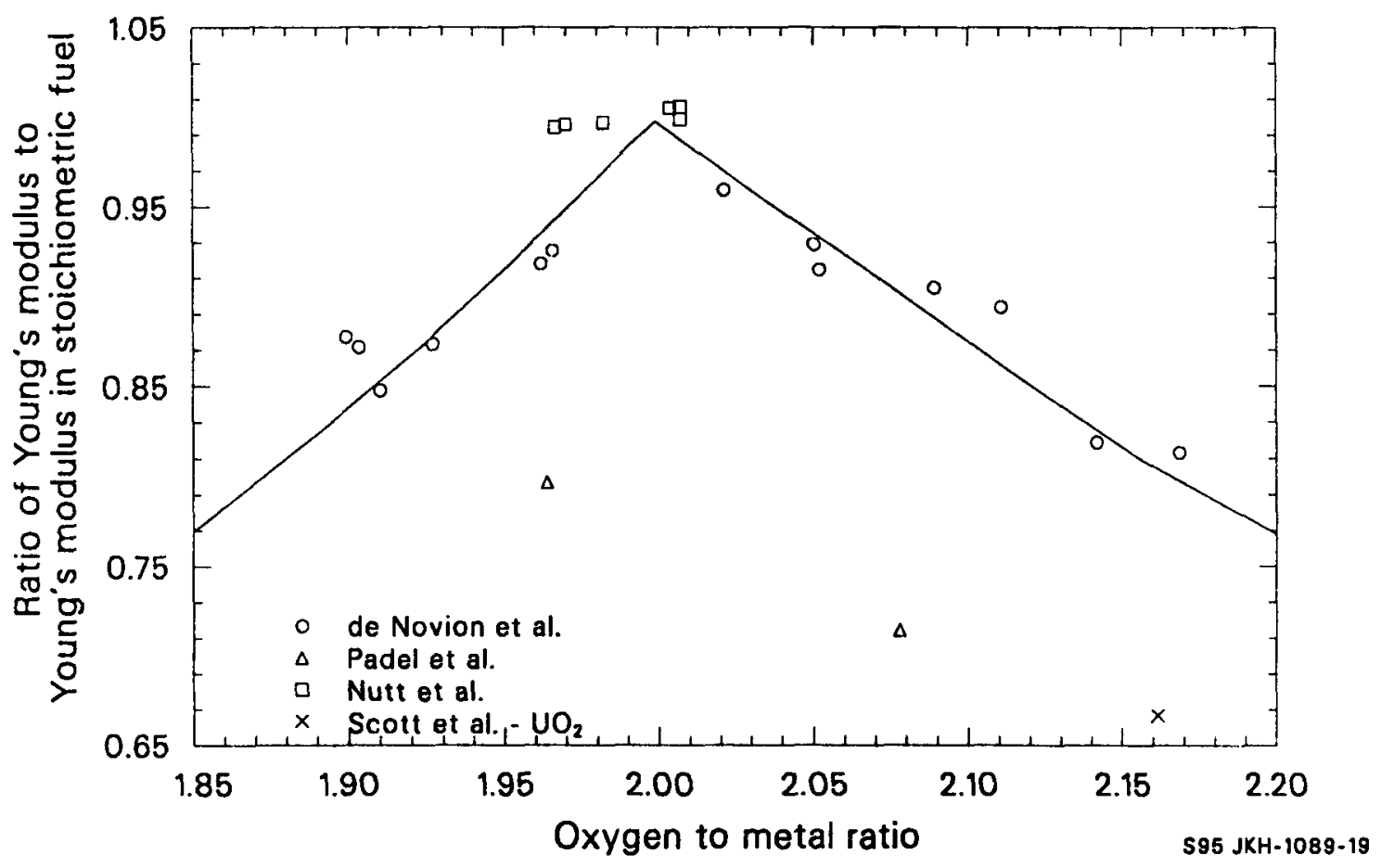

Figure 2.6-4. Ratio of Young's modulus for stoichiometric and nonstoichiometric fuels measured at room temperature compared to values predicted by de Novion's correlation. 


\section{FELMOD， FPOIR}

estimated effect of nonstoichiometric fuel was also included in the model. The section describes the development of the model for stoichiometric $\mathrm{UO}_{2}$ fuel.

The most realistic correlation for the effect of temperature on Young's modulus is the exponential form proposed by Wachtman et al.2.6-17 However, the data in the temperature range 300 to $1600 \mathrm{~K}$ shown in Figure 2.6-1 of Section 2.6.2 can be described with an expression of the form

$E=a(1+b T)$

where $a$ and $b$ are constants.

A similar approximation is possible to describe the effect of porosity on Young's modulus in the limited range of porosities of interest. The approximation is used because the information necessary to use detailed discussions of the effects of very large porosities $2.6-18,2.6-19$ and pore shape variation $2 \cdot 6-8,2 \cdot 6-20$ is most often not available. The room-temperature data of Figure 2.6-3 for porosities between 0 and 0.1 can be described with an expression of the form

$E=c(1+d P)$

where $c$ and $d$ are constants.

Equation (2.6-9) was used to describe the effect of porosity on Young's modulus at temperatures above $450 \mathrm{~K}$. However, the constants $c$ and $d$ were not evaluated with the room-temperature data because (a) sufficient high-temperature data exist to evaluate the effect of porosity in the temperature range of interest and (b) the room-temperature data exhibit considerable scatter. The expression used to correlate the combined effects of porosity and temperature on Young's modulus is 


\section{FELMOD， FPOIR}

$E=e(1+f T)(1+g P)$

where $E, T$, and $P$ have been defined previously and $e, f$, and $g$ are constants.

The constants $e, f$, and $g$ were evaluated using a two-step fitting procedure. In the first step, least-squares constants $a$ and $b$ of Equation (2.6-8) were determined for each $\mathrm{UO}_{2}$ fuel sample shown in Figure 2.6-1. The result of the fits is summarized in Table 2.6-2.

The constant $a$ is equivalent to the product of the factors e $(1+g P)$ in Equation (2.6-10) for each $\mathrm{UO}_{2}$ fuel sample, and the constant $b$ is equivalent to the constant $f$ in Equation (2.6-10). The second step of the fitting procedure was therefore the determination of a linear least-squares regression equation of constant $a$ on $P$ in order to find the best fit values of $e$ and $g$. The least-squares fit produced values of $e=23.34 \mathrm{x}$ $10^{10} \mathrm{~N} / \mathrm{m}^{2}$ and $\mathrm{g}=2.752$. These values were combined with the average of the values for $f=b$ from Table 2.6-2 to produce the correlation

$E=23.34 \times 10^{10}\left(1-1.0915 \times 10^{-4} \mathrm{~T}\right)(1-2.752 \mathrm{P})$

where the terms have been previously defined. The correlation is equivalent to Equation (2.6-1).

No data are available for solid $\mathrm{UO}_{2}$ fuel above $1500 \mathrm{~K}$. Equation (2.6-11) was simply extrapolated to estimate Young's modulus between $1600 \mathrm{~K}$ and the approximate melting temperature $(3113 \mathrm{~K})$.

\subsubsection{Model Uncertainty (FELMOD)}

The standard error of Equation (2.6-11) with respect to its own data base is $0.021 \times 10^{11} \mathrm{~N} / \mathrm{m}^{2}$ (about $1 \%$ of the predicted value), and the standard error of the equation with respect to the room-temperature data of 
FELMOD, FPOIR

Table 2.6-2. Least-squares constants for data of Figure 2.6-1

\begin{tabular}{|c|c|c|c|}
\hline Reference & $\begin{array}{c}\text { Fraction of } \\
\text { Theoretical } \\
\text { Density }\end{array}$ & $\stackrel{a}{\left(10^{10} \mathrm{~N} / \mathrm{m}^{2}\right)}$ & $\begin{array}{c}b \\
\left(10^{-4} / K\right)\end{array}$ \\
\hline Padel and de Novion & 0.911 & 17.605 & -1.1053 \\
\hline Padel and de Novion & 0.935 & 19.221 & -1.0056 \\
\hline Padel and de Novion & 0.959 & 20.549 & -1.0665 \\
\hline Belle and Lustman & 0.93 & 18.742 & -1.1957 \\
\hline Hall & 0.947 & 20.175 & -1.0843 \\
\hline
\end{tabular}




\section{FELMOD，FPOIR}

Figure $2.6-3$ is $0.073 \times 10^{11} \mathrm{~N} / \mathrm{m}^{2}$. ${ }^{a}$ These numbers represent lower and upper bounds for the standard error to be expected in applying the model to stoichiometric $\mathrm{UO}_{2}$ fuel in the range 450 to $1600 \mathrm{~K}$. The first number does not include possible variations to be expected with samples not in the data base, and the second number was obtained using data taken at a low temperature where the linear expression for the effect of temperature systematically overpredicts Young's modulus. The best estimate for the standard error to be expected with this model is the standard deviation of Equation (2.6-6). The value, $0.06 \times 10^{-11} \mathrm{~N} / \mathrm{m}^{2}$, includes the effect of sample-to-sample variation but does not include the artificial error due to the extrapolation of the temperature coefficient.

For temperatures above $1600 \mathrm{~K}$, there are no data and no rigorous ways to test the model. In Equation (2.6-4), the standard error estimate for 400 to $1600 \mathrm{~K}$ has been increased by an additive term, which is zero at $1600 \mathrm{~K}$ and increases to one fourth of the predicted value at the approximate melting temperature $(3113 \mathrm{~K})$.

The modifications to the basic $\mathrm{UO}_{2}$ fuel correlation to predict the effects of nonstoichiometry and $\mathrm{PuO}_{2}$ additions are based on limited data and are therefore uncertain. The standard error estimate expressed in Equation (2.6-5) assumes an independent error equal to the change produced by the models for nonstoichiometry and $\mathrm{PuO}_{2}$ addition. That is, the net estimated standard error is taken to be the square root of the sum of the square of the standard error of the prediction for the stoichiometric $\mathrm{UO}_{2}$ fuel elastic modulus and the square of the net change produced by the models for nonstoichiometric and $\mathrm{PuO}_{2}$ fuels.

a. Since three constants were used to fit the stoichiometric $\mathrm{UO}_{2}$ fuel data base, the number of degrees of freedom is equal to the number of measurements minus three. 
FELMOD， FPOIR

\subsubsection{Poisson's Ratio (FPOIR)}

Poisson's ratio for both $\mathrm{UO}_{2}$ and $(\mathrm{U}, \mathrm{Pu}) \mathrm{O}_{2}$ fuels is calculated by the routine FPOIR as a function of fuel temperature and composition.

Poisson's ratio can be related to Young's modulus and the shear modulus as follows: $2.6-21$

$\mu=E / 2 G-1$

where

$\mu=$ Poisson's ratio (unitless)

$E=$ Young's modulus $\left(\mathrm{N} / \mathrm{m}^{2}\right)$

$G \quad=\quad$ shear modulus $\left(\mathrm{N} / \mathrm{m}^{2}\right)$.

Wachtman et al ${ }^{2.6-22}$ report mean values for the Young's modulus and shear modulus of $\mathrm{UO}_{2}$ from two experiments as $E=2.30 \times 10^{11} \mathrm{~N} / \mathrm{m}^{2}$ and $\mathrm{G}=$ $0.874 \times 10^{11} \mathrm{~N} / \mathrm{m}^{2}$. Consequently, the value of Poisson's ratio is 0.316 and the routine FPOIR returns this value for $\mathrm{UO}_{2}$. The Wachtman et al. paper only considers single-crystal $\mathrm{UO}_{2}$ data at $25^{\circ} \mathrm{C}$. However, Padel and de Novion have reported values of 0.314 and 0.306 for the Poisson's ratio of polycrystalline $\mathrm{UO}_{2}$. These values are in reasonable agreement with Wachtman's value of 0.316 .

Nutt et al. determined Poisson's ratio for $\mathrm{U}_{0.8} \mathrm{Pu}_{0.2} \mathrm{O}_{2-\mathrm{x}}$ at room temperature by determining the Young's modulus and the shear modulus and calculating Poisson's ratio using Equation (2.6-12). Nutt and Allen's room-temperature Poisson's ratio for $(\mathrm{U}, \mathrm{Pu}) \mathrm{O}_{2}$ fuel of $0.276 \pm 0.094$ was found to be independent of density and is returned by FPOIR for mixed oxides. 


\section{FELMOD，FPOIR}

Poisson's ratio for the fuel is shown in Figure 2.6-5 as a function of temperature and fuel composition. As can be seen from the figure, any plutonia content is assumed to reduce Poisson's ratio, which is independent of temperature.

\subsubsection{References}

2.6-1. M. P. Bohn, FRACAS - A Subcode for the Analysis of Fuel Pellet-Cladding Mechanical Interaction, TREE-NUREG-1028, April 1977.

2.6-2. W. A. Lambertson and J. H. Handwerk, The Fabrication and Physical Properties of Urania Bodies, ANL-5053, February 1956.

2.6-3. J. T. A. Roberts and Y. Ueda, "Influence of Porosity and Deformation and Fracture of $\mathrm{UO}_{2}, "$ Journal of the American Ceramic Society, $55,1972, \mathrm{pp} .117-124$.

2.6-4. I. J. Fritz, "Elastic Properties of $\mathrm{UO}_{2}$ at High Pressure," Journal of Applied Physics, 47, 1976, pp. 4353-4358.

2.6-5. A. Padel and C. de Novion, "Constants Elastiques des Carbures, Nitures et Oxydes d'Uranium et de Plutonium, "Journal of Nuclear Materials, 33, 1969, pp. 40-51.

2.6-6. J. Belle and B. Lustman, "Properties of $\mathrm{UO}_{2}$, "Fuel Elements Conference, Paris, France, November 18-23, 1957, TID-7546, March 1958, pp. 480-481.

2.6-7. A. R. Hall, "Elastic Moduli and Internal Friction of Some Uranium Ceramics," Journal of Nuclear Materials, 37, 1970, pp. 314-323. Also AERE-R 5650, 1967.

2.6-8. J. Boocock, A. S. Furzer, J. R. Matthews, The Effect of Porosity on the Elastic Moduli of $\mathrm{UO}_{2}$ as Measured by an U7trasonic Technique, AERE-M 2565, September 1972.

2.6-9. J. R. Matthews, Mechanical Properties and Diffusion Data for Carbide and Oxide Fuels. Ceramics Data Manual Contribution, AERE-M 2643,1974 .

2.6-10. A. W. Nutt, Jr., A. W. Allen, J. H. Handwerk, "Elastic and Anelastic Response of Polycrystalline $\mathrm{UO}_{2}-\mathrm{PuO}_{2}$, "Journal of the American Ceramic Society, 53, 1970, p. 205.

2.6-11. A. de Novion et al., "Mechanical Properties of Uranium-Plutonium Based Ceramics," Nuclear Metallurgy, 17, 1970, pp. 509-517. 
FELMOD， FPOIR

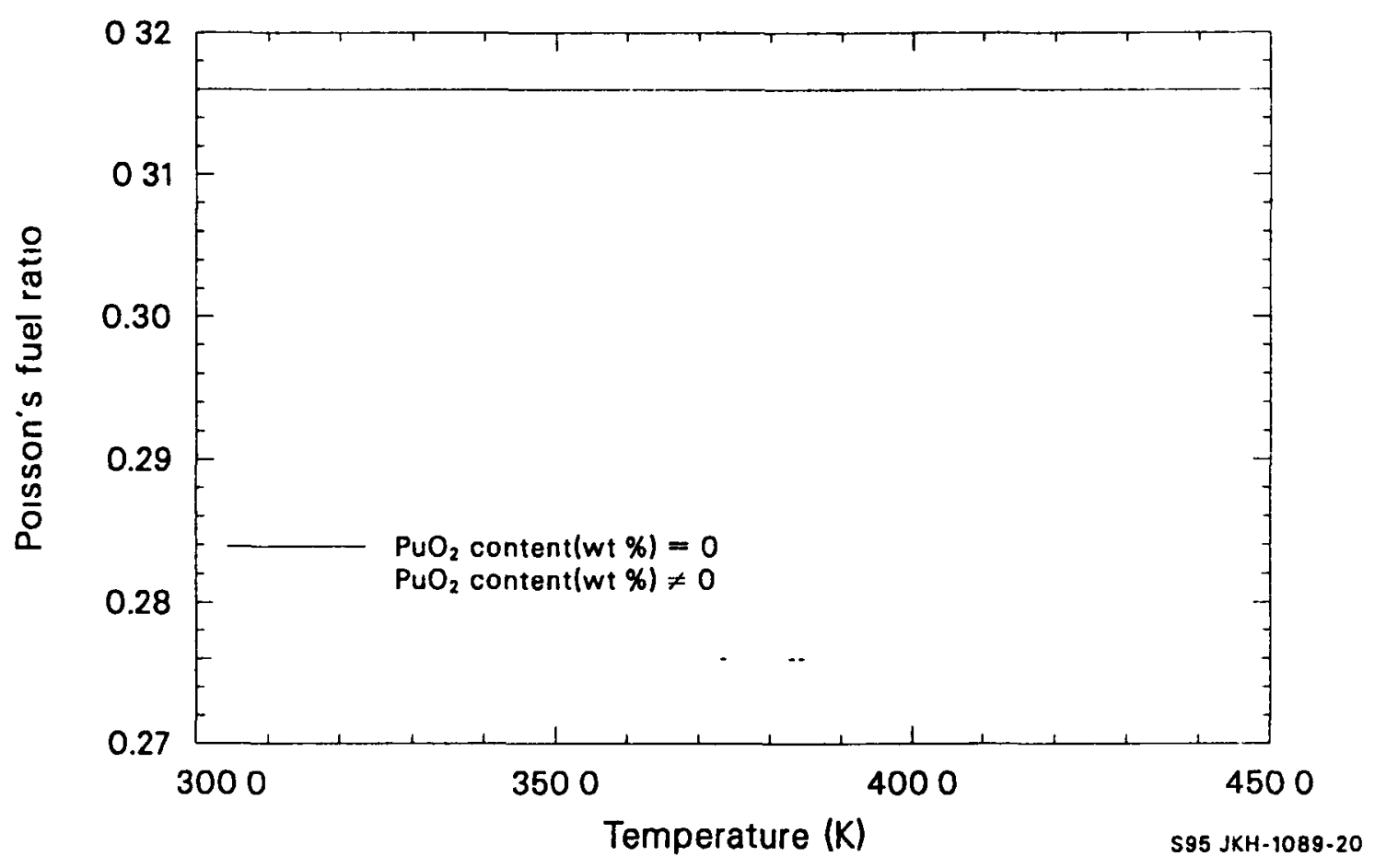

Figure 2.6-5. Poisson's ratio as a function of temperature. 


\section{FELMOD, FPOIR}

2.6-12. V. M. Baranov et a1., "In-Reactor Measurements of the Modulus of Elasticity of Uranium Dioxide," Soviet Atomic Energy, 40, 1976, pp. 37-39.

2.6-13. M. 0. Marlowe and A. I. Kaznoff, "Elastic Behavior of Uranium Dioxide," Journal of the American Ceramic Society, 53, 1970, pp. 90-99.

2.6-14. R. J. Forlano et al., "Elasticity and Anelasticity of Uranium Oxides at Room Temperature:I Stoichiometric Oxide," Journal of the American Ceramic Society, 50, 1967, pp. 92-96.

2.6-15. R. Scott et a1., "The Plastic Deformation of Uranium 0xides Above $800^{\circ} \mathrm{C}, "$ Journal of Nuclear Materials, 1, 1959, pp 39-48.

2.6-16. D. R. 01 ander, Fundamental Aspects of Nuclear Reactor Fuel Elements, TID-26711-P1, 1976, pp. 160-166.

2.6-17. J. B. Wachtman et al., "Exponential Temperature Dependence of Young's Modulus for Several 0xides," Physics Review, 122, 6, 1961, pp. $1754-1759$.

2.6-18. M. 0. Marlowe and D. R. Wilder, "Elasticity and Internal Friction of Polycrystalline Yttrium Oxide," Journal of the American Ceramic Society, 48, 1965, pp. 227-233.

2.6-19. N. Igata and K. Domoto, "Fracture Stress and Elastic Modulus of Uranium Dioxide Including Excess 0xygen," Journal of Nuclear Materials, 45, 1972/73, pp. 317-322.

2.6-20. D. P. H. Hasselman and R. M. Fulrath, "Effect of Cylindrical Porosity on Young's Modulus of Polycrystalline Brittle Materials," Journal of the American Ceramic Society, 48, 1965, p. 545.

2.6-21. I. S. Sokolnikoff and R. D. Specht, Mathematical Theory of Elasticity, 2nd Edition, New York: McGraw-Hill Book Company, Inc., 1956.

2.6-22. J. B. Wachtman, Jr., M. L. Wheat, H. J. Anderson, J. L. Bates, "Elastic Constants of Single Crystal $\mathrm{UO}_{2}$ at $25^{\circ} \mathrm{C}$, " Journal of Nuclear Materials, 16, 1, 1965, p. 39. 
FCREEP

\title{
2.7 CREeP (FCREEP)
}

\author{
(R. E. Mason)
}

The fuel creep model, FCREEP, calculates creep rate of $\mathrm{UO}_{2}$ and $(\mathrm{U}, \mathrm{Pu})_{2} \mathrm{O}_{2}$ fuels. Fuel creep affects the width of the gap between fuel pellets and cladding and hence the temperature gradient in the fuel rod. FCREEP was developed through use of both out-of-pile and in-pile data. The samples were high-density (generally above 95\% theoretically dense) and were irradiated to burnups too low for swelling to be a major factor. Therefore, the fuel dimensional changes calculated with the FCREEP subcode should simply be added to the dimensional changes calculated using other MATPRO correlations.

\subsubsection{Summary}

The FCREEP model calculates creep deformation of $\mathrm{UO}_{2}$ or mixed-oxide fuels. The model includes a time-dependent creep rate for $\mathrm{UO}_{2}$, valid for both steady-state and transient reactor conditions. Fuel creep is modeled as a function of time, temperature, grain size, density, fission rate, oxygen-to-metal (0/M) ratio, and external stress.

At a transition stress $\left(\sigma_{t}\right)$, the creep rate changes from a 1 inear stress dependence to a creep rate proportional to stress to a power $n$. The transition stress is defined by

$\sigma_{t}=1.6547 \times 10^{7} / \mathrm{G}^{0.5714}$

where 


\section{FCREEP}

$$
\begin{aligned}
& \sigma_{\mathrm{t}}=\text { transition stress }(\mathrm{Pa}) \\
& \mathrm{G} \quad=\quad \text { fuel grain size }(\mu) \mathrm{m} .
\end{aligned}
$$

The creep function is dependent on an Arrhenius-type activation energy. This energy is found to be a function of the fuel $0 / M$ ratio. Increasing the $0 / M$ ratio increases the creep rate, all other things being constant. The activation energy of $\mathrm{UO}_{2}$ below the transition stress is given by

$$
Q_{1}=17884.8\left\{\exp \left[\frac{-20}{\ln (x-2)}-8\right]+1\right\}^{-1}+72124.23
$$

where

$$
\begin{aligned}
& Q_{1}=\text { activation energy below the transition stress }(\mathrm{cal} / \mathrm{mol}) \\
& x=0 / M \text { ratio. }
\end{aligned}
$$

The activation energy of $\mathrm{UO}_{2}$ above the transition stress is

$$
Q_{2}=19872\left\{\exp \left[\frac{-20}{\ln (x-2)}-8\right]+1\right\}^{-1}+111543.5
$$

where $Q_{2}$ is the activation energy above the transition stress (cal/mol).

The steady-state creep rate of $\mathrm{UO}_{2}$ is determined using

$$
\dot{\epsilon}=\frac{\left(A_{1}+A_{2} \dot{F}\right) \sigma \exp \left(-Q_{1} / R T\right)}{\left(A_{3}+D\right) G^{2}}+\frac{\left(A_{4}+A_{8} \dot{F}\right) \sigma^{4.5} \exp \left(-Q_{2} / R T\right)}{A_{6}+D}
$$




\section{FCREEP}

$$
+A_{7} \sigma \dot{F} \exp \left(Q_{3} / R T\right)
$$

where

$$
\begin{aligned}
& \dot{\epsilon}_{s}=\text { steady-state creep rate }\left(s^{-1}\right) \\
& A_{1}=0.3919 \\
& A_{2}=1.3100 \times 10^{-19} \\
& A_{3}=-87.7 \\
& A_{4}=2.0391 \times 10^{-25} \\
& A_{6}=-90.5 \\
& A_{7}=3.72264 \times 10^{-35} \\
& A_{8}=0.0 \\
& \left.F=\text { fission rate (fissions } / \mathrm{m}^{3}\right) / \mathrm{s} \\
& \sigma=\operatorname{stress}(\mathrm{Pa}) \\
& R=\text { universal gas constant }(\mathrm{J} / \mathrm{mol} \cdot \mathrm{K}) \\
& \mathrm{T}=\text { temperature }(\mathrm{K}) \\
& D=\text { density (percent of theoretical density) } \\
& G=\text { grain size }(\mu \mathrm{m}) \\
& Q_{3}=2.6167 \times 10^{3}(\mathrm{~J} / \mathrm{mol})
\end{aligned}
$$




\section{FCREEP}

For mixed oxides, the steady-state creep rate is found using the equation

$$
\begin{aligned}
\dot{\epsilon}_{s} & =\frac{\left(B_{1}+B_{2} F\right) \sigma}{G^{2}} \exp \left[-Q_{3} / R T+B_{3}(1-D)+B_{4} C\right] \\
& +\left(B_{5}+B_{6} F\right) \sigma^{4 \cdot 5} \exp \left[-Q_{4} / R T+B_{7}(1-D)+B_{4} C\right]
\end{aligned}
$$

where

$$
\begin{aligned}
& B_{1}=0.1007 \\
& B_{2}=7.57 \times 10^{-20} \\
& B_{3}=33.3 \\
& B_{4}=3.56 \\
& B_{5}=6.469 \times 10^{-25} \\
& B_{6}=0.0 \\
& B_{7}=10.3 \\
& Q_{3}=55354.0 \\
& Q_{4}=70451.0 \\
& C \quad=\quad P u 0_{2} \text { concentration (weight percent) }
\end{aligned}
$$

and the other terms have been previously defined. 


\section{FCREEP}

When the applied stress $(\sigma)$ is less than the transition stress $\left(\sigma_{t}\right)$, the applied stress is used in the first term of Equation (2.7-4) or (2.7-5). For stresses greater than $\sigma_{t}$, the transition stress is used in the first term and the external stress is used in the second term of both equations.

When the fuel first experiences stress, usually during initial irradiation, or when a higher stress than in any other time step is applied, the strain rate is time-dependent and is calculated using the equation

$\dot{\epsilon}_{T}=\dot{\epsilon}_{S}\left[2.5 \exp \left(-1.40 \times 10^{-6} t\right)+1\right]$

where

$\dot{\epsilon}_{\mathrm{T}}=$ the total strain rate $\left(\mathrm{s}^{-1}\right)$

$\dot{\epsilon}_{\mathrm{S}}=$ steady-state strain rate defined by Equation $(2.7-4)\left(\mathrm{s}^{-1}\right)$

$t=$ time since the largest stress was applied $(s)$.

Equation (2.7-6) is the total creep rate function prescribed by the subcode FCREEP.

\subsubsection{Model Development}

Fuel deforms through a number of creep mechanisms depending on the stress, density, temperature, $0 / M$ ratio, irradiation level, and grain size. The FCREEP model is based on vacancy diffusion at low stress, dislocation climb at high stress, and a time-dependent creep rate at all stresses at times less than $300 \mathrm{~h}$ after a stress increase. The time-dependent creep increases the creep rate over' the steady-state value for times less than $300 \mathrm{~h}$ but contributes little at longer times. Only constant-volume creep is 


\section{FCREEP}

modeled in FCREEP, whereas hot-pressing processes are being considered separately.

This subcode incorporates the $\mathrm{UO}_{2}$ steady-state creep model proposed by Bohaboy, 2.7-1 with modifications suggested by Solomon ${ }^{2.7-2}$ for fission-enhanced and fission-induced creep. The subcode also incorporates the $(\mathrm{U}, \mathrm{Pu})_{2}$ creep equation proposed by Evans et al.$^{2.7-3}$ modified in a similar manner to include fission-enhanced creep. The constants proposed by Bohaboy and Solomon for $\mathrm{UO}_{2}$ creep and by Evans for $(\mathrm{U}, \mathrm{Pu})_{2}$ creep were fit to the data base.

2.7.2.1 Steady-State Creep. Steady-state creep for ceramic fuel can be modeled as a two-process phenomenon: (a) low-stress creep based on vacancy diffusion and (b) power law creep based on dislocation climb.

The theoretical model 2.7-4 to 2.7-6 for viscous creep is based upon diffusion of vacancies from grain boundaries in tension to grain boundaries in compression. This model results in a creep rate that is (a) proportional to the vacancy diffusion coefficient, (b) inversely proportional to the square of the grain size, and (c) proportional to stress. Low-stress creep can be written as

$\dot{\epsilon}_{s}=\left(A_{1} / G^{2}\right) \sigma \exp \left(-Q_{2} / R T\right)$

where the terms of the equation have been previously defined.

Equation (2.7-7) is based upon the assumption that volume diffusion controls the creep rate. Therefore, the creep rate is inversely proportional to the square of the grain size with an activation energy determined for volume diffusion. However, Coble $e^{2.7-7}$ has shown that if the diffusion path is along grain boundaries, the creep rate should be inversely proportional to the cube of the grain size with an associated 
activation energy that corresponds to grain boundary diffusion. Equation (2.7-7) is derived solely for diffusion of vacancies, but grain boundary sliding has been observed during low-stress creep deformation of $\mathrm{UO}_{2} \cdot 2.7-8,2.7-9$ Both grain boundary sliding and diffusional creep have the characteristics of linear stress dependence and an activation energy nearly that of self-diffusion. Therefore, it is not possible to distinguish between mechanisms of grain boundary sliding and diffusion. Regardless of which mechanism predominates, the form of Equation (2.7-7) is still applicable.

At high stresses, the movement of dislocations due to external shear stresses within the crystal structure results in a macroscopic movement of material. At high temperatures, dislocation climb can occur, which results in an increase in deformation rate by allowing dislocations to surmount barriers which normally would restrict movement. Weertman ${ }^{2.7-10}$ has proposed a model based upon dislocation climb which results in a creep rate proportional to stress raised to the 4.5 power. In this case, creep rate is not a function of grain size. This power law model for steady-state creep rate is

$\dot{\epsilon}_{\mathrm{S}}=\mathrm{A}_{2} \sigma^{4.5} \exp \left(-\mathrm{Q}_{2} / \mathrm{RT}\right)$

where the terms of the equation have been previously defined.

2.7.2.2 Irradiated Fuel Creep. Equations (2.7-3) and (2.7-4) were modified to model enhanced creep rate due to irradiation following the method suggested by Solomon. Solomon concluded that in-reactor creep of $\mathrm{UO}_{2}$ is composed of (a) an elevated temperature regime, in which normal thermal creep mechanisms are enhanced, and (b) a low-temperature regime, in which the fission process induces fuel creep. At temperatures less than $1173 \mathrm{~K}$, the creep rate is linearly proportional to fission rate and to stress. All the data appeared to lie within a broad scatter band that is insensitive to temperature. Evidence was insufficient to determine whether 


\section{FCREEP}

scatter is due primarily to variations of material properties (density, grain size, stoichiometry, and impurity concentration), or test conditions (temperature, stress, and fission rate).

Solomon consolidated the results of Perrin $2.7-11$ and used Bohaboy's equation to arrive at the following expression:

$\dot{\epsilon}_{s}=\frac{\left(A_{4}+A_{8} \dot{F}\right)}{\left(A_{6}+D\right)} \sigma^{4.5} \exp \left(Q_{2} / R T\right)+\frac{\left(A_{1}+A_{2} \dot{F}\right)}{\left(A_{3}+D\right) G^{2}} \sigma \exp \left(Q_{1} / R T\right)+A_{9} \sigma \dot{F}$

where $A_{1}, A_{2}, A_{3}, A_{4}, A_{6}, A_{8}, A_{9}$ are constants and the other terms of the equation have been previously defined. This equation assumes a fivefold increase in creep rate instead of the fourfold increase reported by Perrin at a fission rate of $1.2 \times 10^{19} \mathrm{fission} / \mathrm{m}^{3} / \mathrm{s}$. The fivefold increase is also assumed at higher stresses where dislocation creep occurs but where no experimental data are available.

Brucklacher et al. 2.7-12 reported an equation for the fission-induced creep up to $2.5 \%$ burnup of

$\dot{\epsilon}=5.6 \exp (-2616.8 / T) F$

where $\dot{\epsilon}$ is the creep rate $\left(s^{-1}\right)$.

Equation (2.7-10) is used in place of the last term of Equation (2.7-9), resulting in the final form of the $\mathrm{UO}_{2}$ steady-state creep Equation (2.7-4).

For the creep of mixed oxides, the equation suggested by Evans et al. is adopted with similar modification for fission-enhanced creep. The steady-state, mixed-oxide creep rate equation is 


$$
\begin{aligned}
\dot{\epsilon}_{s}= & \frac{\left(B_{1}+B_{2} \dot{F}\right)}{G^{2}} \sigma \exp \left[-Q_{1} / R T+B_{3}(1-D)+B_{4} C\right] \\
& +\left(B_{5}+B_{6} \dot{F}\right) \sigma^{4.5} \exp \left[-Q_{2} / R T+B_{7}(1-D)+B_{4} C\right]
\end{aligned}
$$

where $B_{1}, B_{2}, B_{3}, B_{4}, B_{5}, B_{6}, B_{7}$ are constants and the other terms of the equation have been previously defined.

2.7.2.3 Transition Stress. Wolfe and Kaufman 2.7-13 pointed out that the stress at which the transition from viscous creep to power law creep occurs is only mildly dependent upon temperature, but more strongly affected by grain size. Seltzer et al.2.7-14,2.7-15 performed an analysis of the transition stress that presents circumstantial evidence for a power law creep rate with a 4.5 stress coefficient and a viscous creep rate with an inverse dependence on the square of the grain size. At the transition, Equations (2.7-7) and (2.7-8) can be equated:

$$
\left(\frac{A_{1} \sigma}{G^{2}}\right) \exp \left(-Q_{1} / R T\right)=A_{2} \sigma^{4.5} \exp \left(-Q_{2} / R T\right)
$$

where the terms of the equation have been previously defined.

Solving Equation (2.7-12) for the stress at the transition $\left(\sigma_{t}\right)$ :

$$
\sigma_{t}=\left(\frac{A_{1}}{A_{2}}\right)^{1 / 3.5} G^{-0.57} \exp \left[\left(Q_{2}-Q_{1}\right) / 3.5 R T\right] .
$$

If the activation energies, $Q_{2}$ and $Q_{1}$, are about the same magnitude, then the temperature dependence of $\sigma_{t}$ should be minimal and the resulting transition stress is calculated using 


\section{FCREEP}

$\sigma_{\mathrm{t}}=A G^{-0.57}$

2.7.2.4 Time-Dependent Creep. The time-dependent creep rate is based on an anelastic creep equation and is used in FCREEP to calculate the creep rate of water reactor fuel during the first $300 \mathrm{~h}$ after the stress on the fuel has been increased. The strain resulting from the time-dependent stress can be a major portion of the total creep deformation.2.7-16 A number of time-dependent creep functions were compared with transient creep data. In particular, time to a power used by other authors to describe $\mathrm{UO}_{2}$ transient creep ${ }^{2.7-17}$ was tried; but the function found to best predict the transient creep data was the exponential function

$\dot{\epsilon}_{t}=2.5[1+\exp (-a t)]$

where

$$
\begin{aligned}
& \dot{\epsilon}_{\mathrm{t}}=\text { time-dependent creep rate }\left(\mathrm{s}^{-1}\right) \\
& \mathrm{a} \quad=\text { constant } \\
& \mathrm{t}=\operatorname{time}(\mathrm{s}) .
\end{aligned}
$$

Since this subcode is to be used to calculate both steady-state and transient reactor conditions, the anelastic form of time-dependent creep was used because it better predicted the creep data for all times. The anelastic equation is multiplied by the steady-state creep rate to obtain the total creep rate.

$$
\dot{\epsilon}_{\mathrm{T}}=[1+2.5 \exp (-\mathrm{at})] \epsilon_{\mathrm{S}}
$$

where $\dot{\epsilon}_{\mathrm{T}}$ is the total creep rate $\left(\mathrm{s}^{-1}\right)$ and the other terms of the equation have been previously defined. 


\subsubsection{Evaluation of Constants and Data Comparison}

Data selection for code development use was based on the following requirements:

1. The data results from compressive creep tests were considered.

2. The initial $0 / M$ ratio was measured and documented.

3. The temperature was measured and documented.

4. The grain size was measured and documented.

Requirement (2) prevented the use of some data in determining the constants of FCREEP. These data were used after the creep model was developed (with an assumed $0 / M$ ratio) as an extra data comparison, and no significant deviation was noted.

2.7.3.1 Evaluation of Steady-State Creep Constants. The basic form of the steady-state equation of Solomon and Evans et al. was retained, but some of the constants were refit to include the effect of the fuel $0 / M$ ratio. The activation energies of Equation (2.7-2) and (2.7-3) were determined by calculating the creep rate using the data reported by Burton and Reynolds, 2.7-18,2.7-19 Seltzer et al., 2.7-15 and Bohaboy et al. 2.7-1 These were data of $\mathrm{UO}_{2}$ under different stresses, temperatures, and $0 / M$ ratios. Fitting the equations to the available data gave effective activation energies, which changed less as the $0 / \mathrm{M}$ ratio increased than is reported in the literature. ${ }^{2.7-15}$

Other creep data considered while developing the subcode are Bohaboy and Asamoto, ${ }^{2.7-20}$ Speight, ${ }^{2.7-21}$ Brucklacher and Dienst, ${ }^{2.7-22}$ Solomon, ${ }^{2.7-23}$ Scott et al., 2.7-24 and Armstrong and Irvine. 2.7-25 


\section{FCREEP}

The activation energies found to give the best fit to the base data were

(1) for low stresses,

$$
Q_{1}=17884.8\left\{\exp \left[\frac{-20.0}{\log (x-2.0)}-8.0\right]+1.0\right\}^{-1}+72124.23
$$

(2) for high stresses,

$$
Q_{2}=19872.0\left\{\exp \left[\frac{-20.0}{\log (x-2.0)}-8.0\right]+1.0\right\}^{-1}+112142.4 \cdot(2.7-18)
$$

After the approximate activation energies were determined, the equations were further evaluated against the data of Bohaboy et al.2.7-1 to refine the constants. Figure 2.7-1 shows the calculated creep rates plotted against experimental data. Those data which did not have a documented $0 / \mathrm{M}$ ratio are shown, along with the data used to develop the code. Figure 2.7-2 shows the calculated creep rates for irradiated fuel compared to the experimental data base. The uncertainty of the FCREEP calculations was determined as the standard deviation of the $\log$ of the calculated creep rate compared with the $\log$ of the corresponding creep rate. The uncertainty range is shown as dashed lines in Figures 2.7-1 and 2.7-2. The uncertainty creep rates can be calculated using the equation:

$$
\dot{\epsilon}_{\mathrm{u}}=\dot{\epsilon} \cdot 10^{\mathrm{U}}
$$

where

$\dot{\epsilon}_{u}=$ upper and lower bounds of creep rate $\left(\mathrm{s}^{-1}\right)$

$\dot{\epsilon}=$ FCREEP calculated creep rate $\left(\mathrm{s}^{-1}\right)$

$\mathrm{U}= \pm 1.25$ 


\section{FCREEP}

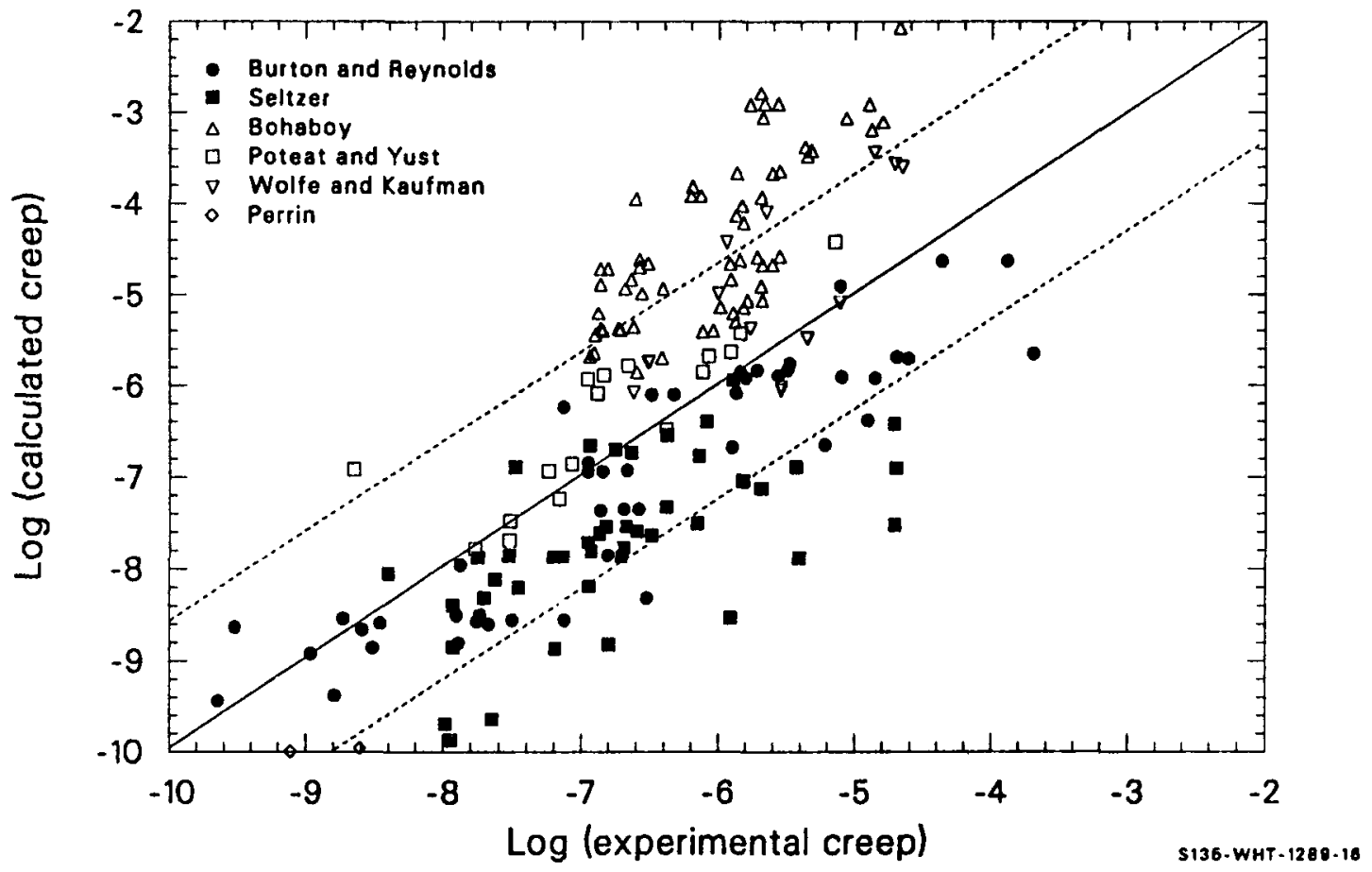

Figure 2.7-1. Comparison of unirradiated $\mathrm{UO}_{2}$ experimental data with corresponding calculated values from FCREEP. 


\section{FCREEP}

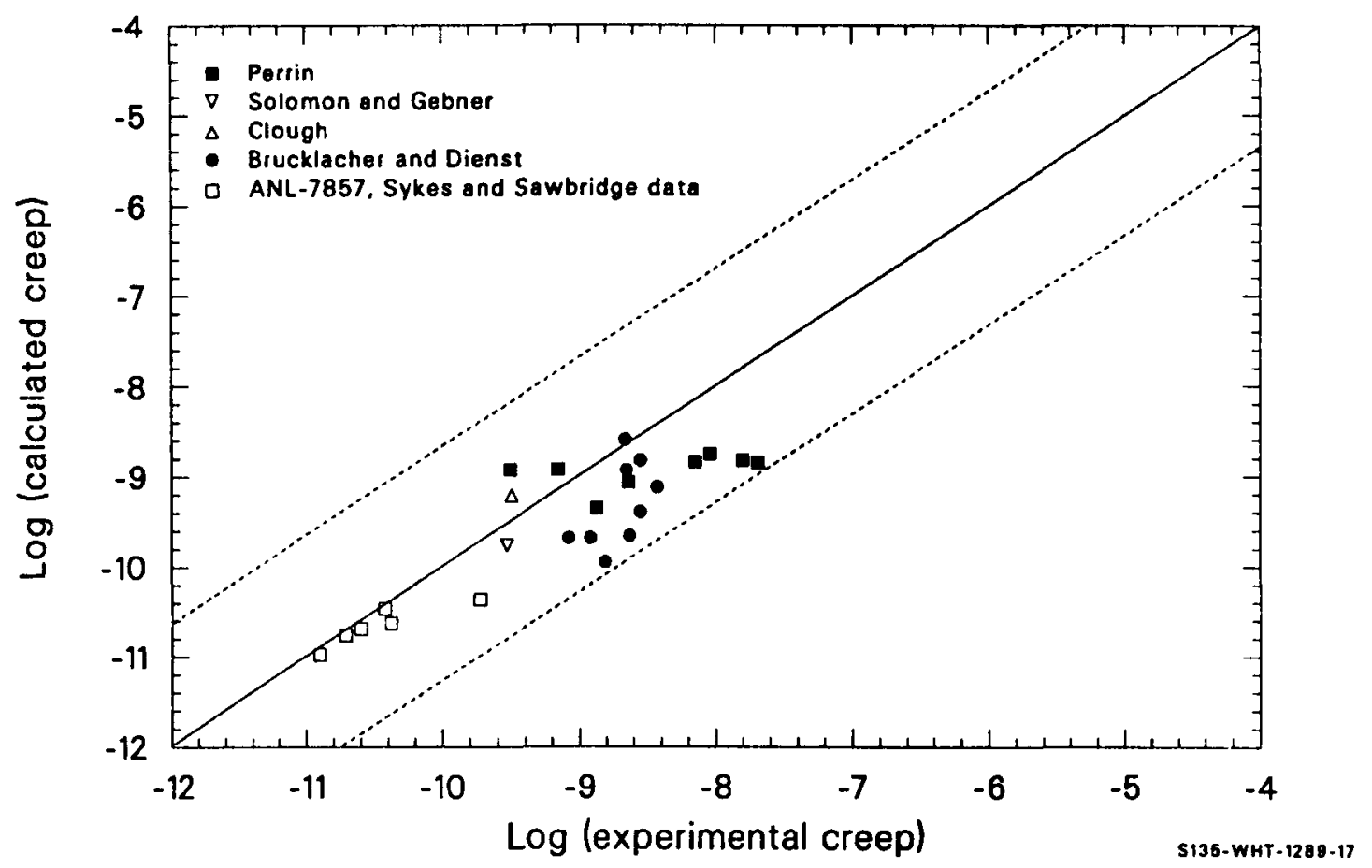

Figure 2.7-2. Comparison of irradiated $\mathrm{UO}_{2}$ experimental data with corresponding calculated values from FCREEP. 
2.7.3.2 Evaluation of Constants for Irradiation-Enhanced Creep. The data sources used to evaluate the constants for the last term of Equation (2.7-4) are the fission-induced creep tests of Sykes and Sawbridge, 2.7-26 Clough, 2.7-27 Brucklacher and Dienst, 2.7-28 and Solomon and Gebner $2.7-29$ and in-pile creep measurements of Perrin, 2.7-11 Vollath, 2.7-30 and Slagle. 2.7-31 These data were considered by Solomon, 2.7-2 who developed Equation (2.7-4) except for the last term, which was proposed by Brucklacher et al 2.7-12

In Figure 2.7-3, the predictions of FCREEP are compared with mixed-oxide creep data selected from compressive experiments with $0 / \mathrm{M}$ ratios between 1.95 and 1.98. This comparison includes data from Evans et al. , 2.7-3 Routbort et al., 2.7-32 and Perrin. 2.7-33 Good agreement is obtained for $0 / M$ ratios between 1.95 and 1.96 and grain sizes between 18 and

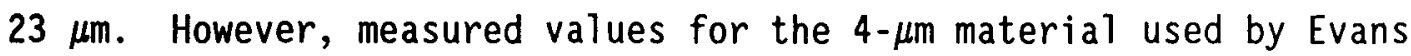
et al. 2.7-3 are one to two orders of magnitude higher than the corresponding values calculated by FCREEP. Also, the high-stress data of Routbort 2.7-32 (in the dislocation controlled creep regime) compare favorably with FCREEP calculations even though the $0 / M$ ratio is slightly higher than 1.95. The low-stress data lie about an order of magnitude higher than calculated by the FCREEP model, indicating the significance of the stoichiometry on the diffusion mechanism in the viscous creep regime. Perrin's 2.7-33 data were used to determine the constants for fission-enhanced creep in the linear stress creep of Equation (2.7-11). Reasonably good agreement is achieved for the irradiated material, but the calculated values for unirradiated material are about an order of magnitude less than experimental values. The solid line represents perfect agreement between experimental and calculated values.

2.7.3.3 Evaluation of Constants for Time-Dependent Creep. Much of the reported creep rate data do not include the time-dependent creep contribution, and the reported steady-state data probably include those contributions, making an accurate analysis difficult. Some excellent creep 


\section{FCREEP}

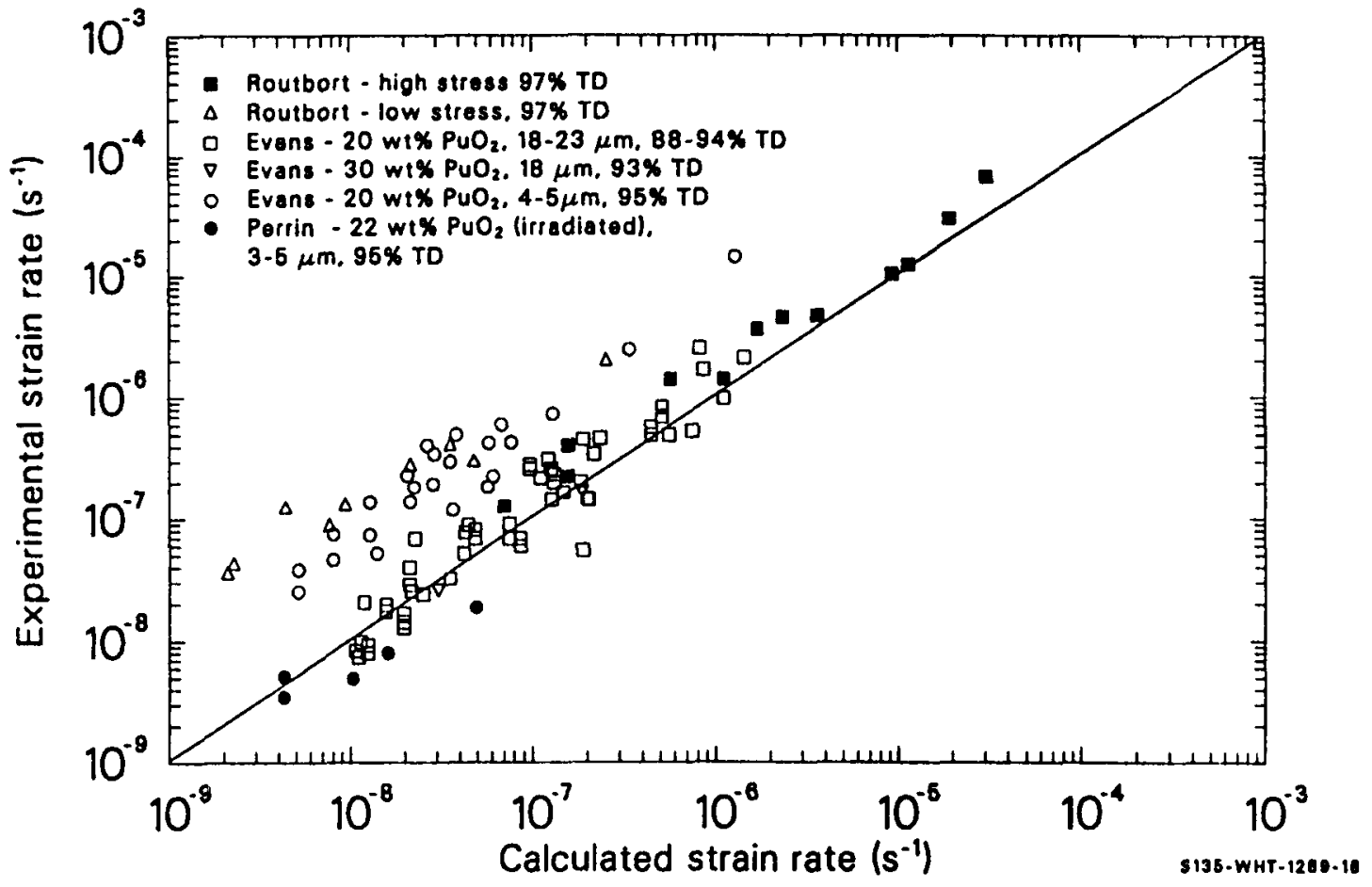

Figure 2.7-3. Comparison of $(U, \mathrm{Pu}) \mathrm{O}_{2}$ experimental data with corresponding calculated values from FCREEP. 
FCREEP

studies reporting both time-dependent and steady-state creep have been reported. A comprehensive study was conducted by Battelle Columbus Laboratories. 2.7-11,2.7-34,2.7-35 They evaluated creep of $\mathrm{UO}_{2}$ under both irradiated and unirradiated conditions. These data were used as the data base, along with the data reported by Solomon, 2.7-29,2.7-36 Clough, 2.7-37 Dienst, 2.7-38 and Brucklacher and Dienst. 2.7-22

Evaluation of the time-dependent creep equation was carried out, using the reported steady-state creep rate and then determining the appropriate function to follow the curve and have the appropriate magnitude after a number of iterations. The best-estimate equation is

$\dot{\epsilon}_{\mathrm{t}}=2.5 \exp \left(-1.4 \times 10^{\left.-\sigma_{\mathrm{t}}\right)} \dot{\epsilon}_{\mathrm{s}}\right.$

where the terms of the equation have been previously defined.

Examples of the strain determined using the final strain rate equation

$\dot{\epsilon}_{\mathrm{t}}=\left[2.5 \exp \left(-1.4 \times 10^{-6} \mathrm{t}\right)+1\right] \dot{\epsilon}_{\mathrm{s}}$

are shown in Figures 2.7-4 and 2.7-5. They show the FCREEP-calculated strain compared with the base data and show a reasonably good fit.

\subsubsection{References}

2.7-1. P. E. Bohaboy, R. R. Asamoto, A. E. Conti, Compressive Creep Characteristics of Stoichiometric Uranium Dioxide, GEAP-10054, May 1969.

2.7-2. A. A. Solomon, J. L. Routbort, J. C. Voglewede, Fission-Induced Creep of $\mathrm{UO}_{2}$ and Its Significance to Fue7-Element Performance, ANL-7857, September 1971 .

2.7-3. S. K. Evans, P. E. Bohaboy, R. A. Laskiewicz, Compressive Creep of Urania-Plutonia Fuels, GEAP-13732, August 1971. 


\section{FCREEP}

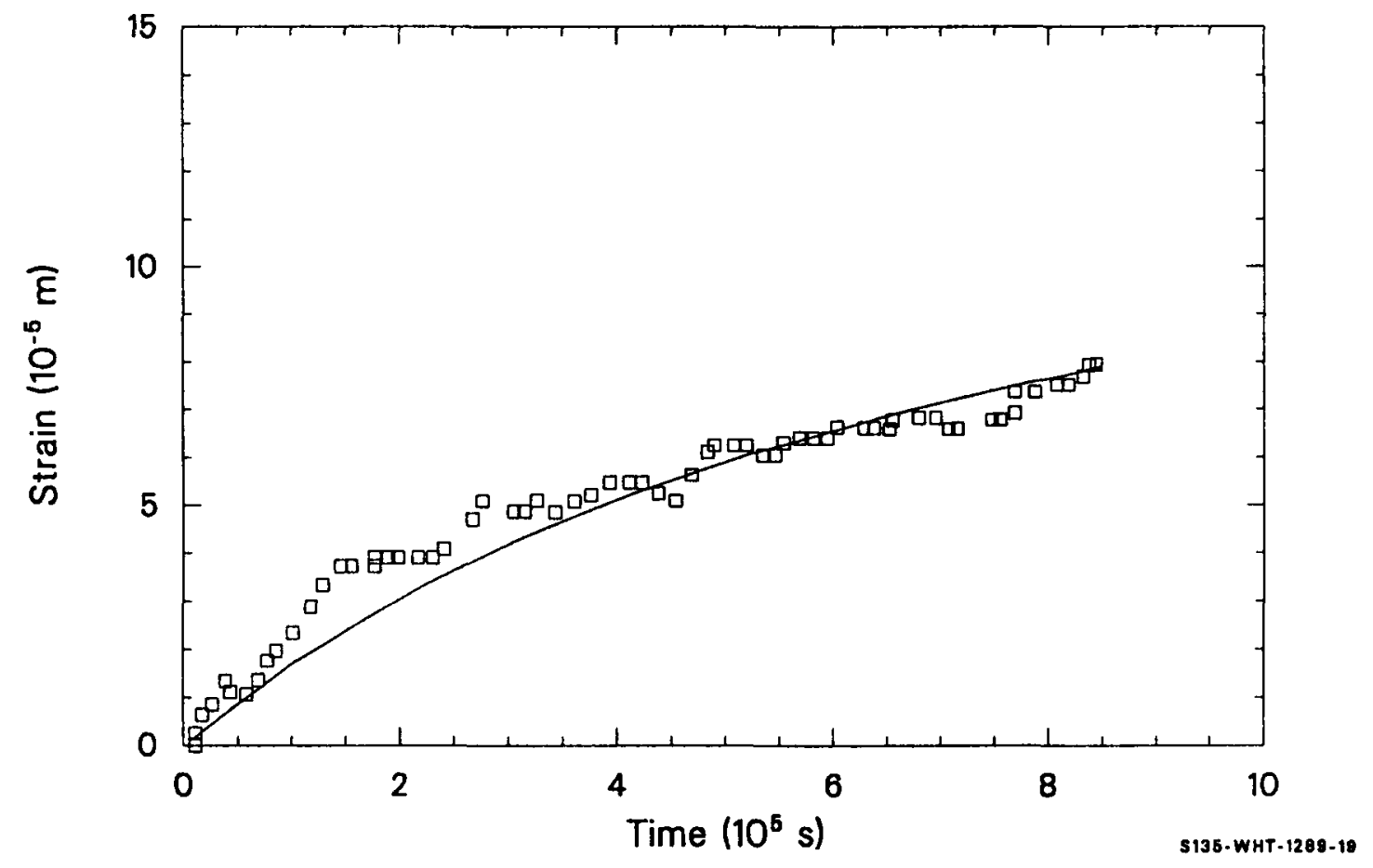

Figure 2.7-4. Comparison of $\mathrm{UO}_{2}$ strain data of Rod $3 \mathrm{C}$ with corresponding calculated values from FCREEP. 


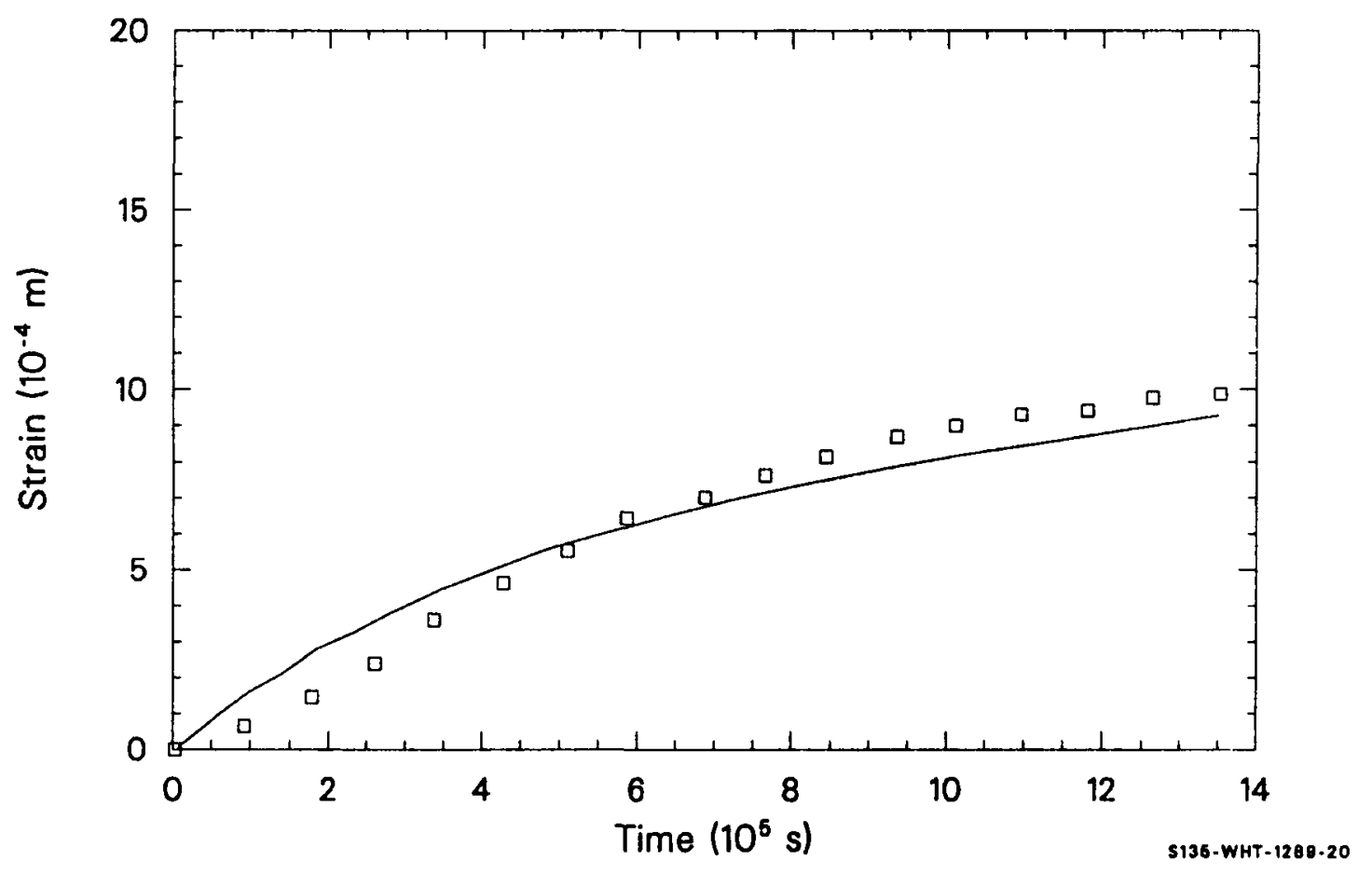

Figure 2.7-5. Comparison of $\mathrm{UO}_{2}$ strain data of Capsule 2 with corresponding calculated values from FCREEP. 


\section{FCREEP}

2.7-4. J. S. Perrin and W. R. D. Wilson, Effect of Irradiation on the Creep of Uranium Dioxide, BMI-1899, March 1971.

2.7-5. F. R. N. Nabarro, Report of a Conference on the Strength of Solids, Physical Society, London 1949, p. 75.

2.7-6. C. Herring, "Diffusional Viscosity of Poly-Crystalline Solid," Journal of Applied Physics, 21, 1950, p. 437.

2.7-7. R. L. Coble, "A Model for Boundary Diffusion Controlled Creep in Poly-Crystalline Materials," Journal of Applied Physics, 34, 1963, p. 1679 .

2.7-8. W. M. Armstrong, W. R. Irvine, R. H. Martinson, "Creep Deformation of Stoichiometric Uranium Dioxide," Journal of Nuclear Materials, 7, 2, 1962, pp. 133-141.

2.7-9. L. E. Poteat and C. S. Yust, Grain Boundary Reactions During Deformation, ORNL-P-2371, 1965.

2.7-10. J. Weertman, "Steady-State Creep Based Through Dislocation Climb," Journal of Applied Physics, 28, 1957, p. 362.

2.7-11. J. S. Perrin, "Irradiation-Induced Creep of Uranium Dioxide," Journal of Nuclear Materials, 39, 1971, pp. 175-182.

2.7-12. D. Brucklacher, W. Dienst, F. Thummler, Creep Behavior of Oxide Fuels Under Neutron Irradiation, Translated from German by J. L. Routbort, Argonne National Laboratory, ANL-Trans-942, May 1973.

2.7-13. R. A. Wolfe and S. F. Kaufman, Mechanical Properties of Oxide Fuels, WAPD-TM-587, October 1967.

2.7-14. M. S. Seltzer, A. H. Clauer, B. A. Wilcox, "The Stress Dependence for High Temperature Creep of Polycrystalline Uranium Dioxide," Journal of Nuclear Materials, 34, 1970, pp. 351-353.

2.7-15. M. S. Seltzer, J. S. Perrin, A. H. Clauer, B. A. Wilcox, "A Review of Creep Behavior of Ceramic Nuclear Fuels," Reactor Technology, 14,2 , January 1971, pp. 99-135.

2.7-16. J. R. Matthews, Mechanical Properties and Diffusion Data for Carbide and Oxide Fuels, AERE-M-2643, September 1974.

2.7-17. R. G. Sachs, Reactor Development Program Progress Report, ANL-RDP-16, April-May 1973.

2.7-18. B. Burton and G. L. Reynolds, "The Diffusional Creep of Uranium Dioxide: Its Limitation by Interfacial Processes," Acta Metallurgical, 21, August 1973, pp. 1073-1078. 
2.7-19. B. Burton and G. L. Reynolds, "The Influence of Deviations from Stoichiometric Composition on the Diffusional Creep of Uranium Dioxide," Acta Metallurgical, 21, December 1973, pp. 1641-1647.

2.7-20. P. E. Bohaboy and R. R. Asamoto, "Compressive Creep Characteristics of Ceramic Oxide Nuclear Fuels: Part I: Uranium Dioxide," Presented at American Ceramic Society Nuclear Division, Pittsburgh, Pennsylvania, October 6-8, 1968.

2.7-21. M. V. Speight, Enhancement of Diffusion Creep Under Irradiation, Central Electricity Generating Board, RD/B/N-2402, August 1972.

2.7-22. D. Brucklacher and W. Dienst, "Creep Behavior of Ceramic Nuclear Fuels Under Irradiation, "Journal of Nuclear Materials, 42, 1972, pp. 285-296.

2.7-23. A. A. Solomon, "Effect of $\gamma$-Radiation on the Deformation of $\mathrm{UO}_{2}, "$ Journal of Nuclear Materials, 47, 1973, pp. 345-346.

2.7-24. R. Scott, A. R. Hall, J. Williams, "The Plastic Deformation on Nonstoichiometric Uranium Dioxide," Journal of Nuclear Materials, 1 , 1959, pp. 39-48.

2.7-25. W. M. Armstrong and W. R. Irvine, "Creep Deformation on Nonstoichiometric Uranium Dioxide, "Journal of Nuclear Materials, $9,2,1963$, pp. 121-127.

2.7-26. E. C. Sykes and P. T. Sawbridge, The Irradiation Creep of Uranium Dioxide, Central Electricity Generating Board, RD/BN/1489, November 1969.

2.7-27. D. J. Clough, "Irradiation Induced Creep of Ceramic Fuels," Proceedings on Fast Reactor Fuel and Fuel Elements, GFK Karlsruhe, 1970 , p. 321.

2.7-28. D. Brucklacher and W. Dienst, "Kontinuierliche Messung Des Kriechens von $\mathrm{UO}_{2}$ Unter Bestrahlung, "Journal of Nuclear Materials, 36, 1970, pp. 244-247.

2.7-29. A. A. Solomon and R. H. Gebner, Instrumented Capsule for Measuring Fission-Induced Creep of Oxide Fuels, "Nuclear Technology, 13, February 1972, p. 177.

2.7-30. D. Vollath, "Thermisches Kriechen von Plutonium-Haltigen Oxidischen Kernbrennstoffen, " Reactor Meeting, Bonn, Germany, March 30, 1971, pp. 558-561.

2.7-31. 0. D. Slagle, High Temperature Creep of $\mathrm{UO}_{2}-20 \mathrm{wt} \% \mathrm{PuO}_{2}$, HEDL-TME-71-28, August 1971. 


\section{FCREEP}

2.7-32. J. L. Routbort, N. A. Javed, J. C. Voglewede, "Compressive Creep of Mixed-Oxide Fuel Pellets," Journal of Nuclear Materials, 44, 1972, pp. 247-259.

2.7-33. J. S. Perrin, "Effect of Irradiation on Creep of $\mathrm{UO}_{2}-\mathrm{PuO}_{2}$," Journal of Nuclear Materials, 42, 1972, pp. 101-104.

2.7-34. J. S. Wilson and R. D. William, Effect of Irradiation on the Creep of Uranium Dioxide, BMI-1899, March 1971.

2.7-35. W. R. D. Wilson and J. S. Perrin, "Anisothermal Effects During In-Pile Creep Testing of Uranium Dioxide, Nuclear Science and Engineering, 45, 1971.

2.7-36. A. A. Solomon, "Radiation-Induced Creep of $\mathrm{UO}_{2}$," Journal of the American Ceramic Society, 56, March 1973.

2.7-37. D. J. Clough, "Creep Properties of Oxide and Carbide Fuels Under Irradiation," Journal of Nuclear Materials, 65, 1977.

2.7-38. W. Dienst, "Irradiation Induced Creep of Ceramic Nuclear Fuels, " Journal of Nuclear Materials, 65, 1977. 


\subsection{DENSIfication (FUDENS)}

(R. E. Mason)

The subcode FUDENS calculates fuel dimensional changes due to irradiation-induced densification of $\mathrm{UO}_{2}$ and $(\mathrm{U}, \mathrm{Pu}) \mathrm{O}_{2}$ fuels during the first few thousand hours of water reactor operation. Densification is calculated as a function of fuel burnup, temperature, and initial density. This subcode is based on data of fuel that had small amounts of hydrostatic stress applied. Densification can result from hydrostatic stress on the fuel due to contact with the cladding, which is considered in Section 2.10. Both models describe the same physical process; the model which calculates the greater densification should be used.

The data used to develop FUDENS were taken from irradiated fuel which was also swelling. If fuel densification is much greater than swelling during the first $1000 \mathrm{~h}$ of irradiation, then, to a first approximation, swelling can be neglected during this period. That was done for the development of the FUDENS model. A suggested calculation procedure, combining calculations of models given in this section with pressure sintering and fuel swelling models, is discussed in Section 2.9.

\subsubsection{Summary}

The subcode FUDENS uses one of two methods to calculate the maximum density change during irradiation. The density change observed during a resintering test (1973 $\mathrm{K}$ for more than $24 \mathrm{~h}$ ) in a laboratory furnace is the preferred input for the calculation. If a resintering density change is not input, the code uses the initial unirradiated density of the fuel and the fuel fabrication sintering temperature for the calculations. These inputs 


\section{FUDENS}

are used in the following equations to calculate the maximum densification length change during irradiation.

If a nonzero value for the resintering density change is input,

$(\Delta \mathrm{L} / \mathrm{L})_{\mathrm{m}}=-(0.0015)$ RSNTR, when FTEMP $<1000 \mathrm{~K}$

$(\Delta L / L)_{m}=-(0.00285)$ RSNTR, when FTEMP $\geq 1000 \mathrm{~K}$

If zero is input for the resintering density change,

$(\Delta \mathrm{L} / \mathrm{L})_{\mathrm{m}}=\frac{-22.2(100-\text { DENS })}{(\text { TSINT }-1453)}$, when FTEMP $<1000 \mathrm{~K}$

$(\Delta \mathrm{L} / \mathrm{L})_{\mathrm{m}}=\frac{-66.6(100-\text { DENS })}{(\text { TSINT }-1453)}$, when FTEMP $\geq 1000 \mathrm{~K}$

where

$(\Delta \mathrm{L} / \mathrm{L})_{\mathrm{m}}=$ maximum possible dimension change of fuel due to irradiation (percent)

RSNTR = resintered fuel density change $\left(\mathrm{kg} / \mathrm{m}^{3}\right)$

FTEMP $=$ fuel temperature $(\mathrm{K})$

DENS = theoretical density (percent)

TSINT $=$ sintering temperature $(K)$.

Densification as a function of burnup is calculated using

$\Delta L / L=(\Delta L / L)_{m}+\exp [-3(F B U+B)+2.0 \exp [-35(F B U+B)]$

where 


\title{
FUDENS
}

\author{
$\Delta L / L=$ dimension change (percent) \\ $\mathrm{FBU}=$ fuel burnup (MWd/kgU) \\ $B=$ a constant determined by the subcode to fit the boundary \\ condition: $\Delta \mathrm{L} / \mathrm{L}=0$ when $\mathrm{FBU}=0$.
}

The FUDENS subcode uses Equation (2.8-5) to calculate total densification and then subtracts the densification from the previous time step to obtain the incremental densification. The incremental densification for the time step being considered is the output of the subcode FUDENS.

\subsubsection{Uranium Dioxide and Mixed-Oxide Densification Data and Models}

The sintering of cold-pressed $\mathrm{UO}_{2}$ powder may be divided usefully into three regimes: (a) the formation of necks between particles, (b) the decrease of interconnected porosity, and (c) the subsequent volume reduction of isolated pores. ${ }^{2.8-1}$ The last stage begins when $92 \%$ to $95 \%$ theoretical density (TD) is reached. Two types of porosities, open along grain edges and closed along grain boundaries, are present in low-density fuels, less than $92 \%$ TD, sintered at low temperatures. However, at higher sintering temperatures, accelerated grain growth occurs; and closed porosity may be found inside the grains even in low-density fuel pellets. ${ }^{2.8-2}$ In-reactor densification involves the third sintering regime in which fine, isolated, closed porosity (located either at grain boundaries or within the grains) is annihilated.

2.8.2.1 Uranium Dioxide and Mixed-oxide Densification Data. Edison Electric Institute/Electric Power Research Institute (EEI/EPRI) 2.8-3,2.8-4 performed a comprehensive study of $\mathrm{UO}_{2}$ fuel densification. The fuel was tested in the RAFT (Radially Adjustable Facility Tubes) of the General Electric Test Reactor (GETR), located in Pleasanton, CA. Pre- and postirradiation physical properties were reported on fuel subjected to 


\section{FUDENS}

burnups of up to $3.5 \mathrm{MWd} / \mathrm{kgU}$. It was concluded that irradiation-induced densification can be correlated with fuel microstructure, that is, the largest in-reactor density changes occurred for fuel types having a combination of the smallest pore size, the largest volume percent of porosity less than $1 \mu \mathrm{m}$ in diameter, the smallest initial grain size, and the lowest initial density. The volume fraction of porosity less than $1 \mu \mathrm{m}$ in diameter contributed significantly to densification of the fuel types studied; and density increases were accompanied by a significant decrease in volume fraction of pores in this size range. The volume fraction of pores ranging in diameter from 1 to $10 \mu \mathrm{m}$ initially increased with densification but decreased with continued densification. Significant density increases occurred during irradiation, with only minimal increases in grain size.

Analysis of the EPRI data also shows that pellets in low-burnup, low-fission-rate, and low-temperature regions densify less than pellets irradiated to the same burnup but in higher fission rate and temperature positions, as shown in Figure 2.8-1. At higher fission rates and temperatures, densification occurs rapidly, with pellets approaching maximum densities at a burnup of $1 \mathrm{MWd} / \mathrm{kgU}$. At lower fission rates, densification appears to be increasing with a fuel burnup of $2 \mathrm{MWd} / \mathrm{kgU}$.

Rolstad et al 2.8-5 measured the fuel stack length change of $\mathrm{UO}_{2}$ in the Halden HBWR reactor. Fuel densities (87\%, 92\%, and $95 \%$ TD), fabrication sintering temperatures, irradiation power levels, and fuel-cladding gap sizes were used to study irradiation-induced densification. Rolstad found that fuel sintered at the highest temperature densified the least (stable fuel) and fuel sintered at the lowest temperature densified the most (unstable fuel). The axial length change, measured during irradiation and as a function of burnup (Figure 2.8-2) for different power levels, did not depend on reactor power levels or fuel temperatures. Hanevik et al. 2.8-6 proposed that this may be attributed to the fact that temperatures of the outer edges (shoulders) of the pellet would be within 200 to $300 \mathrm{~K}$ of each 


\section{FUDENS}

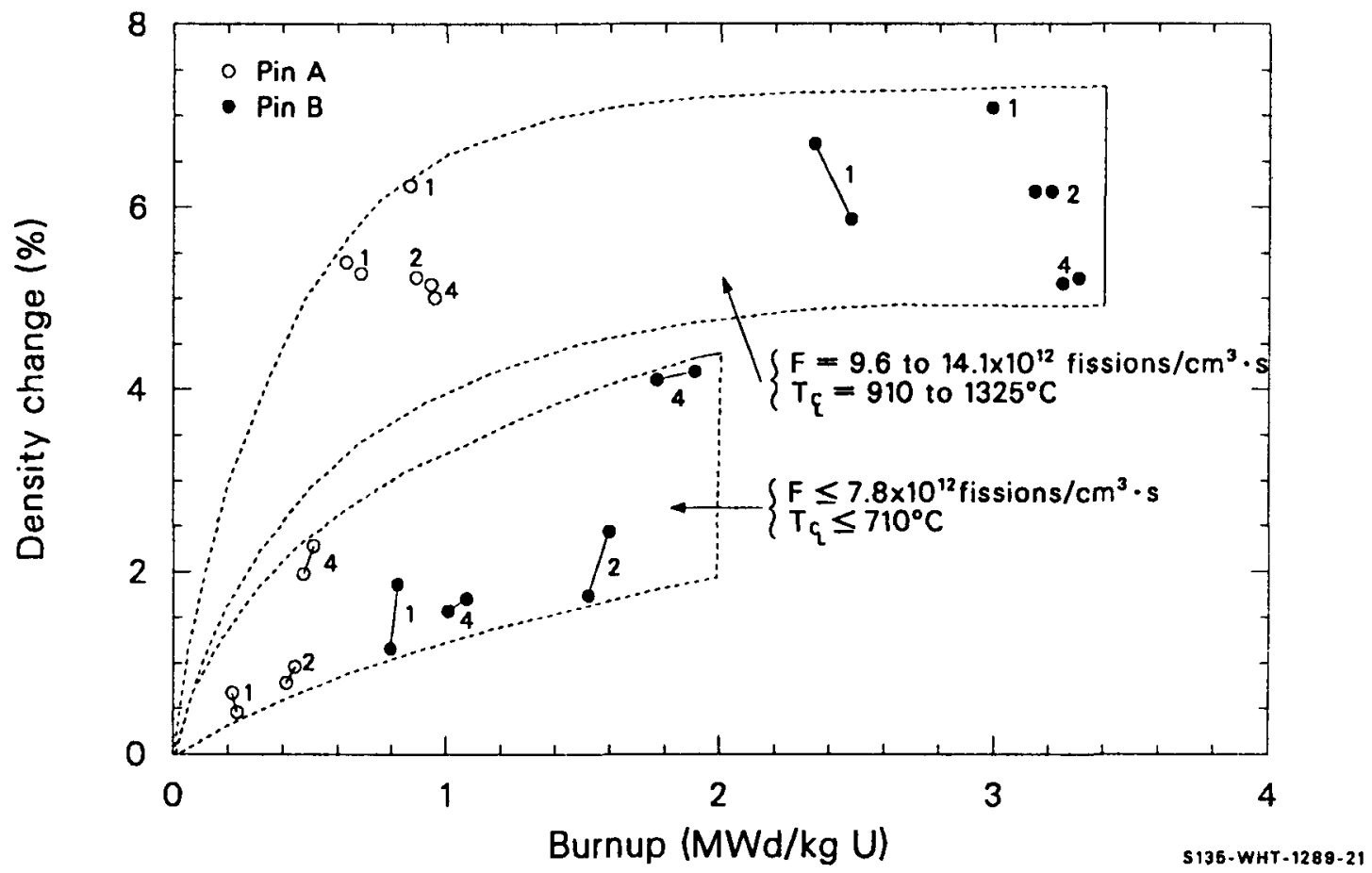

Figure 2.8-1. The effect of burnup and fission rate on the fuel density change for EPRI fuel types 1,2 , and 4 . 


\section{FUDENS}
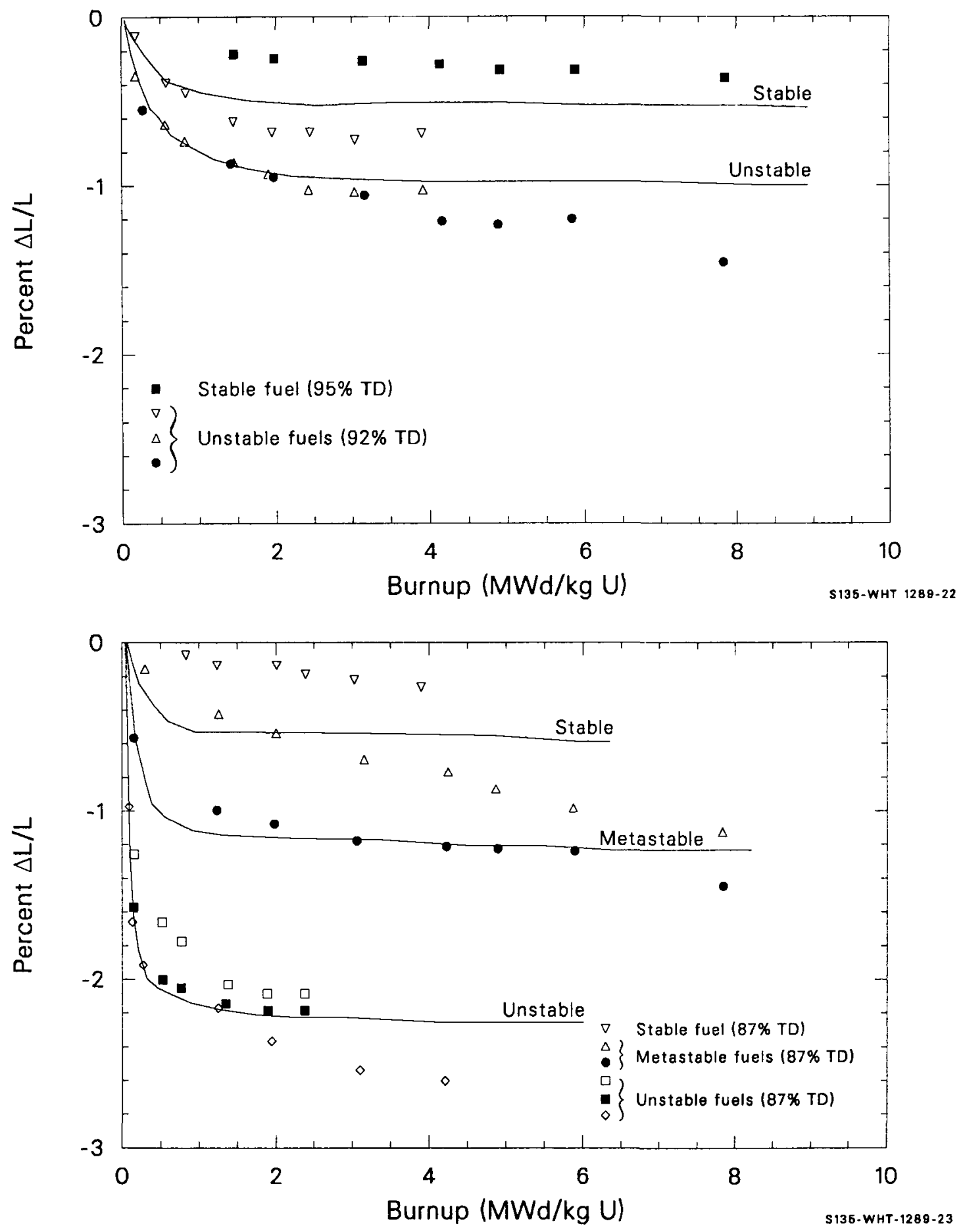

Figure 2.8-2. Change in fuel stack length of Halden fuel as a function of burnup. 
other at both power levels. Since the shoulders of the pellet are much colder than its center, the axial in-reactor length change measurements are probably a measurement of the shrinkage in these regions (low-temperature irradiation densification). The amount of fuel stack length change of the Halden fuel was found to depend on out-of-pile thermal fuel stability, initial density, and burnup.

Collins and Hargreaves ${ }^{2.8-7}$ compared measurements of out-of-pile sintering rates at temperatures greater than $1600 \mathrm{~K}$ with the sintering rates of fuel irradiated in the Windscale Advanced Gas-Cooled Reactor (WAGR). The observed out-of-pile densification was attributed to the sintering of grain boundary porosity and was characterized by an activation energy of $2.9 \times$ $10^{5} \mathrm{~J} / \mathrm{mol}$ for grain boundary diffusion. Extrapolation of these results to $1000 \mathrm{~K}$, the approximate temperature of the in-pile material, indicated that negligible thermal sintering would be expected after a few hundred hours at this temperature. In addition, no evidence of sintering was observed in out-of-pile annealing tests conducted at $1173 \mathrm{~K}$ and a pressure of $2.06 \mathrm{MPa}$. However, fuel irradiated to less than $0.3 \%$ burnup at temperatures between 1000 and $1100 \mathrm{~K}$ experienced significant reduction in diameter. This shrinkage was attributed to irradiation-induced sintering, which decreased the initial fuel porosity volume. Pores with diameters less than $3 \mu \mathrm{m}$ were reported by Collins and Hargreaves to be the major source of increased density. Pores with diameters greater than $10 \mu \mathrm{m}$ were reported stable during irradiation at temperatures below $1500 \mathrm{~K}$.

Ferrari et al. 2.8-8 measured $\mathrm{UO}_{2}$ fuel pellet densification in commercial reactors using both movable in-core flux detectors and postirradiation examination of selected test rods. The densification rate of the fuel was reported to occur rapidly during the early stages of irradiation and then slow or even stop after about 6 to $10 \mathrm{MWd} / \mathrm{kgU}$, as shown in Figure 2.8-3. These results are consistent with the measurements of Rolstad et al. For $92 \%$ TD, the extent of densification was reported to vary 


\section{FUDENS}

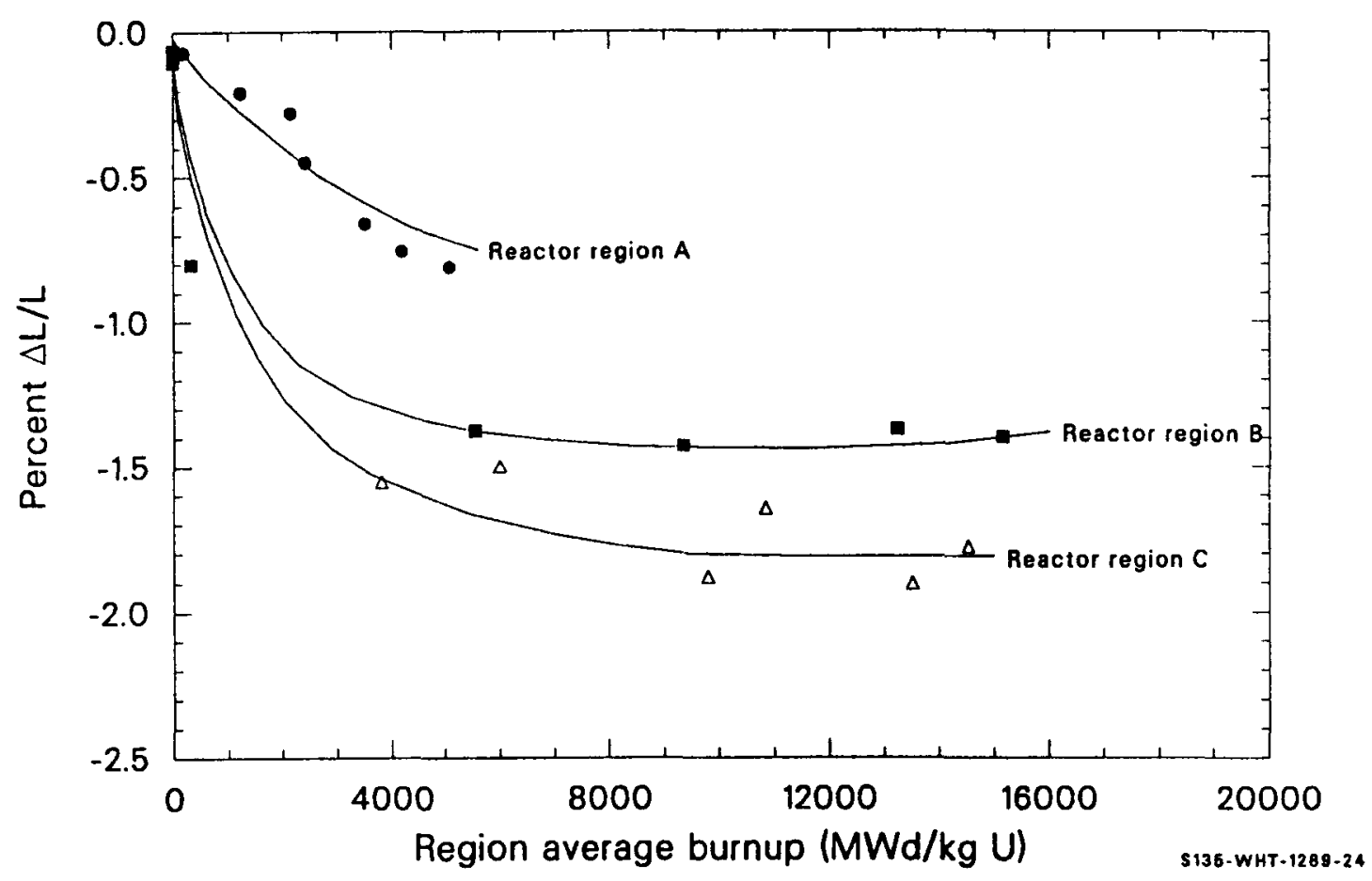

Figure 2.8-3. Fuel stack length changes for $92 \% \mathrm{TD} \mathrm{VO}_{2}$ processed by different techniques. 
significantly with microstructure, but no microstructure details were reported. Ferrari et al. reported that power levels between 4.9 and 55.8 $\mathrm{kW} / \mathrm{m}$ did not significantly affect densification. This result is in agreement with Rolstad et al. The axial shrinkage was suggested to be controlled by densification in the shoulder of the fuel pellets, a region of the fuel pellets where the temperature is generally below $1073 \mathrm{~K}$, a temperature too low for in-pile densification to be attributed to thermal mechanisms. Ferrari et al. proposed that the kinetics of densification are compatible with irradiation-enhanced diffusion processes.

Metallographic measurements on the fuel by Ferrari et al. indicated that the irradiation-enhanced densification was associated with the disappearance of fine pores and that pore shrinkage significantly decreased with increasing pore size. These results correspond to the EPRI findings. Ferrari et al. suggested that densification could be reduced through both microstructural control of the fuel pellet and a reduction of the fine porosity content. Both of these factors are influenced by the fabrication process, especially the sintering temperature and the use of so-called pore formers. Ferrari et al. reported that experimental fuel of $89 \%$ theoretical density has been made and demonstrated to be relatively stable in the Saxton reactor.

Heal et al.$^{2.8-9}$ reported that they have developed $\mathrm{UO}_{2}$ fuel which does not densify significantly by controlling the pore size. They assumed that shrinkage of the pores would continue until the internal pressure of trapped gas in the pores matched the surface tension forces. Their calculations show shrinkage in pores of diameters greater than $20 \mu \mathrm{m}$ and that pores of $10 \mu \mathrm{m}$ shrink only to 6 to $7 \mu \mathrm{m}$ before gas stabilization occurs, whereas voids of $1.0 \mu \mathrm{m}$ or less shrink to $0.2 \mu \mathrm{m}$ or less before gas stabilization occurs, causing considerable densification. Fuel pellets fabricated with porosity sizes greater than $25 \mu \mathrm{m}$ were irradiated by Heal et al. to $1.4 \times 10^{26}$ fissions $/ \mathrm{m}^{3}$ with center temperatures up to $1873 \mathrm{~K}$. Postirradiation examination of these pellets showed significantly less than $1 \%$ volume densification. 


\section{FUDENS}

Ross 2.8-10 has shown that fuel after an irradiation of $2 \times 10^{25} \mathrm{fission} / \mathrm{m}^{3}$ has lost most pores with radii less than 0.5 $\mu \mathrm{m}$. He found that fuels with burnups even as low as $2 \times 10^{24}$ fissions $/ \mathrm{m}^{3}$ had lost most pores with radii less than $0.3 \mu \mathrm{m}$.

Burton and Reynolds $2.8-11$ measured the shrinkage of three fuel pellets of $96.5 \% \mathrm{TD} \mathrm{UO}_{2}$ with isolated porosity at grain boundaries during the final stage of out-of-pile sintering. The densification rate was initially large but decreased with longer sintering times. (The shapes of these curves are very similar to those obtained for the in-pile densification of $\mathrm{UO}_{2}$; however, in-pile densification occurs at much lower temperatures.) This reduction in the densification rate with time can arise for several reasons: (a) grain boundaries may migrate away from cavities; (b) when significant entrapped gas is present, cavities may shrink until they become stabilized as the internal gas pressure becomes equal to the surface tension of the cavity, as proposed by Heal et al.; and/or (c) the number of cavities can progressively decrease as densification proceeds. The first and second reasons were rejected by Burton and Reynolds because the majority of the cavities in their samples remained on grain boundaries during sintering and smaller cavities centered to closure. Therefore, Burton and Reynolds suggested that the reduction in the densification rate with time is only due to the progressive reduction in the number of cavities.

The reported irradiation-induced densification data indicate that it is affected by porosity and pore size distribution, fuel density, and irradiation temperature. The lack of a temperature dependence of the fuel densification data reported by Ferrari et al. and Rolstad et al. is probably a result of the technique used to measure the length change in the low-temperature pellet edges.

2.8.2.2 Survey of Densification Models. Densification models proposed by Rolstad, Meyer, ${ }^{2.8-12}$ Collins and Hargreaves, Voglewede and 
FUDENS

Dochwat, 2.8-13 Stehle and Assmann, 2.8-14 Marlowe, 2.8-15 Hull and Rimmer, 2.8-16 and MacEwen and Hastings ${ }^{2.8-17}$ are reviewed in this section.

Rolstad et al 2.8-5 used two equations to correlate their data. In the first, the shortening $(\Delta L / L)_{m}$ is a function of the current theoretical density (DENS) and sintering temperature in degrees centigrade (TSINT) at a burnup of $5000 \mathrm{MWd} / \mathrm{tUO}_{2}$ :

$(\Delta L / L)_{m}=\frac{-22.2(100-\text { DENS })}{(\text { TSINT }-1453)}$

The effect of burnup was introduced through the use of a master curve created by shifting all curves vertically to agreement at $5000 \mathrm{MWd} / \mathrm{tU}$ and then horizontally to achieve the best agreement at the low-burnup portion of the curve. The master curve is

$\Delta L / L=-3.0+0.93 \exp (-B U)+2.07 \exp (-35 B U)$

where

$$
\begin{aligned}
& \Delta \mathrm{L} / \mathrm{L}=\text { the percent shrinkage of the fuel } \\
& \mathrm{BU}=\text { the burnup (MWd/kgU). }
\end{aligned}
$$

This equation results in a rapid length change at low burnups ( $<1.0 \mathrm{MWd} / \mathrm{kgU}$ ) and a small length change at higher burnup levels. Very little additional densification is calculated after a burnup greater than 5000 to $6000 \mathrm{MWd} / \mathrm{kgU}$.

Meyer developed a conservative model based on resintering of fuel at $1973 \mathrm{~K}$ for $24 \mathrm{~h}$. The change in density of fuel after resintering was used as an upper limit. Two equations were used to calculate densification, one for fuels that resintered less than $4 \%$ and one for fuels which resintered 


\section{FUDENS}

more than $4 \%$. Meyer's model was based on a log function of burnup and the resintering density change. Meyer reports that his model adequately bounds all in-reactor densification data at his disposal.

Collins and Hargreaves developed an empirical densification expression based on the initial porosity and an exponential burnup function. They suggested that a complete description of the densification rate of irradiated uranium dioxide demands a knowledge of the initial porosity size distribution of the as-manufactured $\mathrm{UO}_{2}$ fuel in addition to the total porosity volume because of the differing sintering rates associated with different pore sizes. However, the pore morphology of their fuel was not determined.

J. C. Voglewede and S. C. Dochwat developed an equation for final-stage densification of mixed-oxide fuels based on EBR-II reactor data. It is a semiempirical approach based on porosity, stress, and temperature.

Stehle and Assmann proposed a vacancy-controlled densification model as a function of initial fuel porosity, fission rate, initial pore radius, fuel temperature, and vacancy diffusion. Their equation considers pores of only one diameter; therefore, application of this equation to practical engineering problems requires that the equation be integrated over all pore sizes existing in the fuel. Their approach predicts that irradiation-induced densification is temperature-dependent because of the dependence of the volume diffusion coefficient, $D_{v}$, on temperature. The authors used approximate values for $D_{v}$ and found that the densification rate should change at approximately $1023 \mathrm{~K}$. This corresponds very well with the experiment results found in the EPRI densification study.

Marlowe proposed a model for diffusion-controlled densification and modified the model to include fuel swelling contributions to the density change, as well as an irradiation-induced diffusivity, which provides atomic mobility for grain growth densification. This model is based on 


\section{FUDENS}

densification and grain growth rate, which must be determined experimentally for any particular fuel. These rates strongly affect the predicted in-reactor densification behavior through grain-size modification. Because the model allows complete pore elimination and, in fact, densities greater than theoretical for the matrix material, an upper limit to the density must be calculated to limit the densification change.

Hul1 and Rimmer developed an empirical densification equation based on grain boundary diffusion and temperature. They report reasonably good agreement with the Burton and Reynolds data despite the approximations required to evaluate the equation and the errors in determining the porosity distribution of the samples. Both the shape of the predicted curve and the absolute magnitude of the values were reported to be in good agreement with experimental data, demonstrating that the decrease in sintering rate with time is associated only with the progressive reduction in the number of cavities. The calculation assumed a constant cavity spacing for each time step in changing from one volume size to the next. The similarity between out-of-pile and in-pile densification strongly suggests the importance of pore size distribution and volume for in-reactor densification.

MacEwen and Hastings developed a model describing the rate change of pore diameter based on the time-dependence of vacancy and interstitial concentrations, fission gas concentrations, and internal pore pressures. Two equations were used, one describing the diametral change of pores on the grain boundaries and the other describing intergranular pore shrinkage. Use of this model also requires vacancy jump frequencies. The model is thus difficult to use in engineering applications with the present in-reactor fuel data base.

Fuel densification models proposed in References 2.8-11 and 2.8-13 through 2.8-17 attempted to correlate fuel densification with fundamental material properties. These theoretical or semiempirical approaches will eventually be the preferred modeling techniques, but current versions of 


\section{FUDENS}

these models are based on estimates of material properties such as diffusion coefficients, void concentrations, and jump frequencies. These properties are not sufficiently defined to be used to predict in-reactor densification. As R. 0. Meyer pointed out in his review, the use of complicated theoretical approaches is not justified unless they can be supported with material property data, which allow significantly better predictions than fully empirical correlations. An empirical approach similar to the Meyer model is best for modeling densification.

\subsubsection{Mode1 Development}

The relation between densification and burnup suggested by Rolstad et a1. [Equation (2.8-7)] has been adopted for use in the FUDENS subcode. Densification is assumed to consist of a rapidly varying component, represented by the term $2.0 \exp [-35(F B U+B)]$ in Equation (2.8-5), and a slowly varying component, represented by the term $\exp [-3(F B U+B)]$ in Equation (2.8-5). The expression was adopted because it successfully describes the burnup dependence of both the original Rolstad et al. data and recent EPRI data.

The Rolstad et al. model, ${ }^{2.8-5}$ as originally proposed, is solved graphically, as indicated in Figure 2.8-4. The curves in Figure 2.8-4a are defined by Equation (2.8-6) for various sintering temperatures, and the curve in Figure 2.8-4b is defined by Equation (2.8-7).

The use of these equations to find the length change as a function of burnup is also shown in Figure 2.8-4. For an initial density of $91 \%$ TD and sintering temperature of $1500^{\circ} \mathrm{C}$, the left scale of Figure 2.8-4 shows that the eventual length change will be about $0.6 \%$. To determine the change as a function of burnup, new axes are drawn in Figure 2.8-4b, as shown by the dashed lines. With the $(x, y)$ origin of these new axes interpreted to be zero burnup and zero length change, the solid curve in Figure 2.8-4b then gives $\Delta L / L$ as a function of burnup. The $0.6 \%$ fractional length change is then seen to require about $5000 \mathrm{MWd} / \mathrm{tU}$ burnup. 


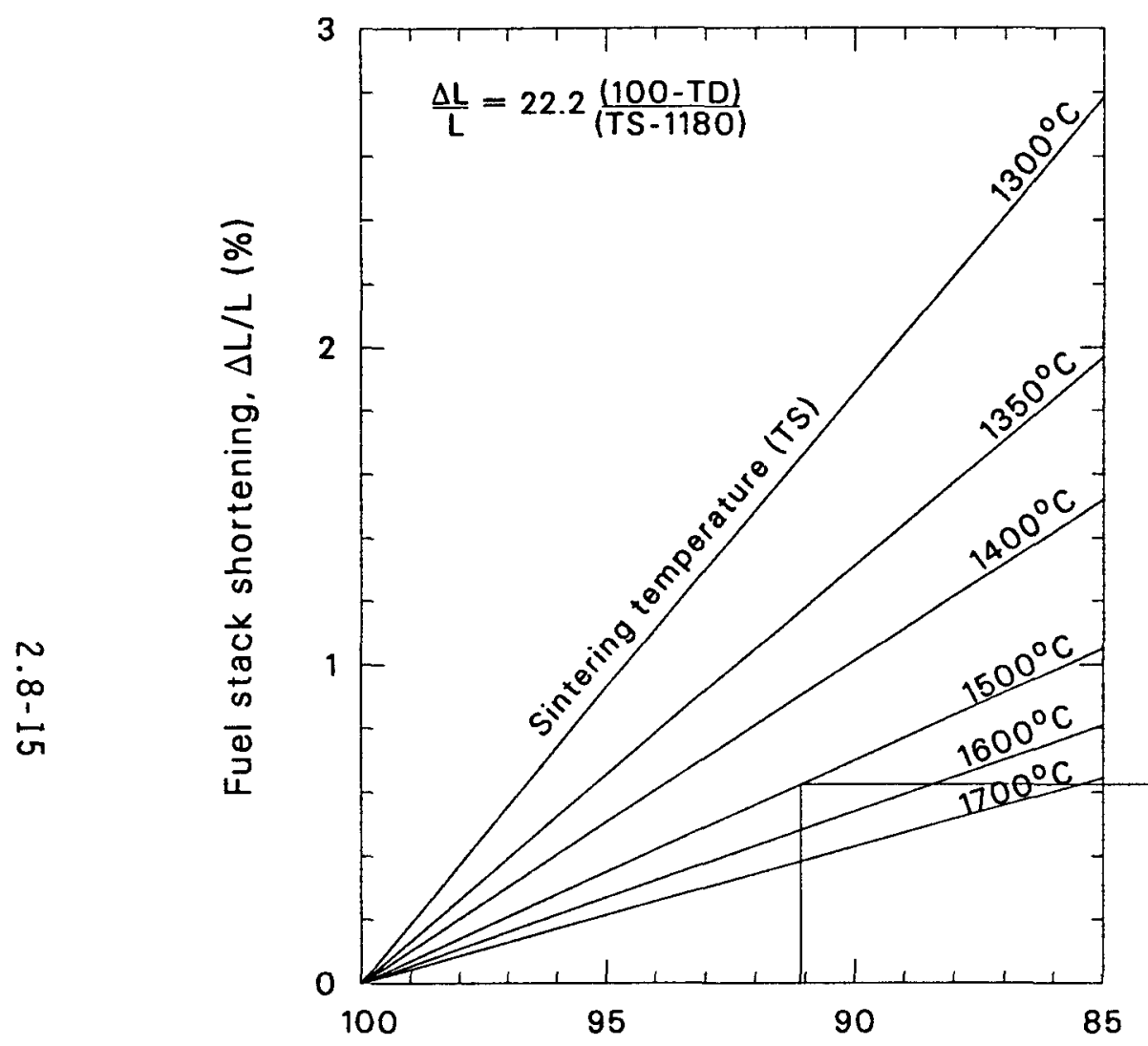

(a) Theoretical density, TD (\%)

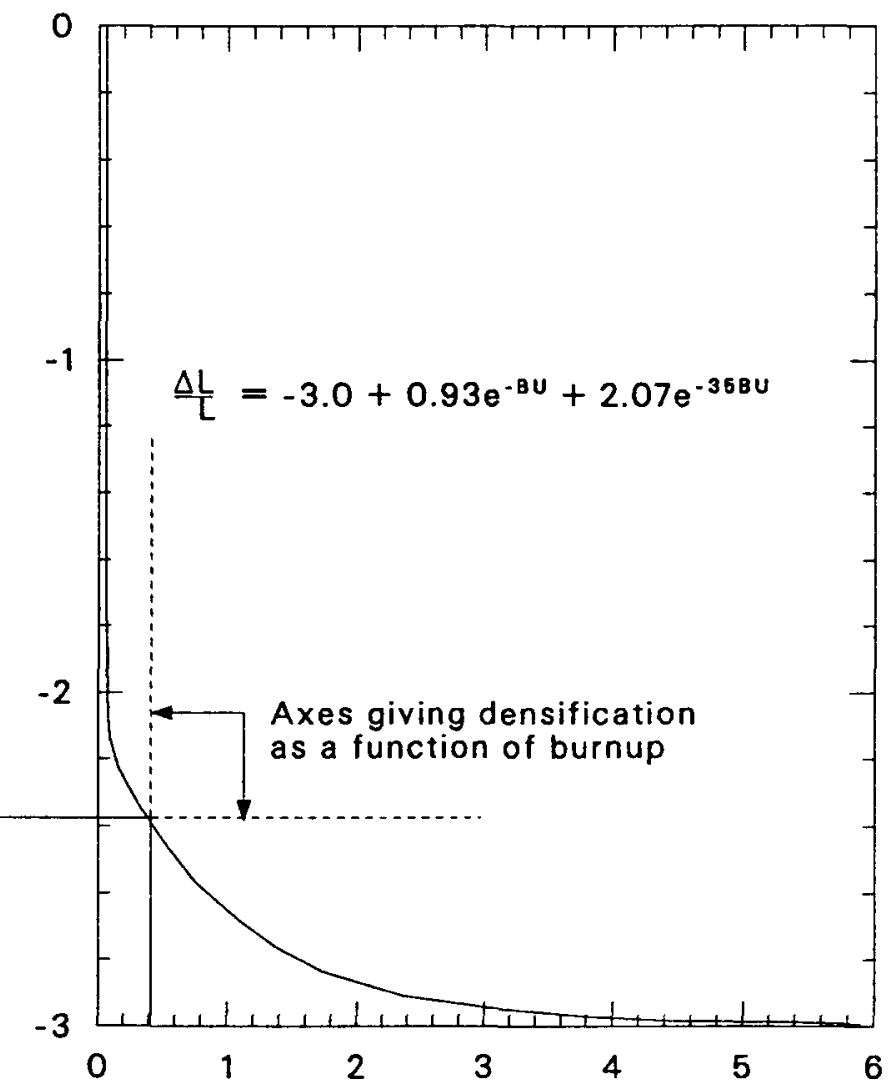

(b) Burnup, $\mathrm{BU}\left(\mathrm{MWd} / \mathrm{kg} \cup \mathrm{O}_{2}\right)$

S135-WHT-1289-25

Figure 2.8-4. Graphical solution of Rolstad's model, where TD is percent of theoretical density, TS is sintering temperature $\left({ }^{\circ} \mathrm{C}\right)$, and $\mathrm{BU}$ is burnup. 


\section{FUDENS}

The numerical equivalent to this graphical solution is incorporated into the subroutine FUDENS. Newton's method ${ }^{2.8-18}$ was selected for the iterative determination of the new origin because of its rapid convergence. Between four and ten iterations are typically required to determine the position of the new axes, with a $0.0002 \%$ convergence criterion defined by

$$
E=100\left(X-X_{1}\right) / X
$$

where

$\mathrm{E}=$ calculated convergence

$X=$ current value of burnup in Equation (2.8-8)

$X_{1}=$ preceding value of burnup in Equation (2.8-8).

The maximum densification term, $(\Delta L / L)_{m}$ in Equation (2.8-5), determines the in-reactor densification limit. Four different expressions, Equations (2.8-1) through (2.8-4), are used by the FUDENS code to determine a number for this term. When a measurement of fuel densification during a resintering test at $1973 \mathrm{~K}$ is available, this measurement is the basis of the model's prediction for the maximum in-pile shrinkage. The resintering density change found during a resintering test at $1973 \mathrm{~K}$ for at least $24 \mathrm{~h}$ is appropriate for use in calculating the maximum in-pile densification because in-pile densification and thermal resintering are both dependent on porosity removal. Meyer's assumption that the change in length during a resintering test is equal to the maximum in-pile densification is too conservative for a best-estimate code. Therefore, the maximum irradiation-induced densification calculated by FUDENS is a fraction of the density change found during a resintering test. If resintering test data are not available, the FUDENS model defaults to the expression suggested by Rolstad et al., Equation (2.8-3). This provides a reasonable estimate of in-pile densification but cannot account for variations in pore size distribution. 
Constants in the expressions used by FUDENS for maximum in-pile shrinkage were determined separately for high (>1000 K) and low temperatures. The separate expressions were used because a temperature dependence was found in the EPRI data and because of irregularities between the Halden and the EPRI high-temperature data sets. The Rolstad et al. model, which predicts the Halden data well, fits the EPRI low-temperature data but not the high-temperature EPRI data. Hanevik et al. suggested that the Halden data were probably measurements of the densification of fuel pellet edges, that is, the cooler regions of the pellet. The Rolstad et al. model is assumed by the FUDENS code to apply to low-temperature densification, and the high-temperature densification is assumed to be three times as large.

The constants in Equations (2.8-1) through (2.8-4) were determined by inspection to provide the best fit to the maximum density change of the EPRI data. Model predictions and the data base used are shown in Figures 2.8-2 and 2.8-5. Mixed-oxide fuel is assumed to densify in the same manner as $\mathrm{UO}_{2}$ due to lack of data to show otherwise.

\subsubsection{References}

2.8-1. W. Beere, "The Sintering and Morphology of Interconnected Porosity in $\mathrm{UO}_{2}$ Powder Compacts," Journal of Materials Science, 5, 1973, pp. 1717-1724.

2.8-2. W. M. Armstrong, W. R. Irvine, R. H. Martinson, "Creep Deformation of Stoichiometric Uranium Dioxide," Journal of Nuclear Materials, 7, 1962, pp. 133-141.

2.8-3. D. W. Brite et al., EEI/EPRI Fuel Densification Project, Research Project 131 Final Report, revised June 1975.

2.8-4. M. D. Freshley et a1., "The Effect of Pellet Characteristics and Irradiation Conditions on $\mathrm{UO}_{2}$ Fuel Densification, " ANS/CNA Topical Meeting on Commercial Nuclear Fuel-Current Technology, Toronto, Canada, April 1975.

2.8-5. E. Rolstad et al., "Measurements of the Length Changes of $\mathrm{UO}_{2}$ Fuel Pellets During Irradiation, "Enlarged HPG Meeting on Computer Control and Fuel Research, June 4-7, 1974. 

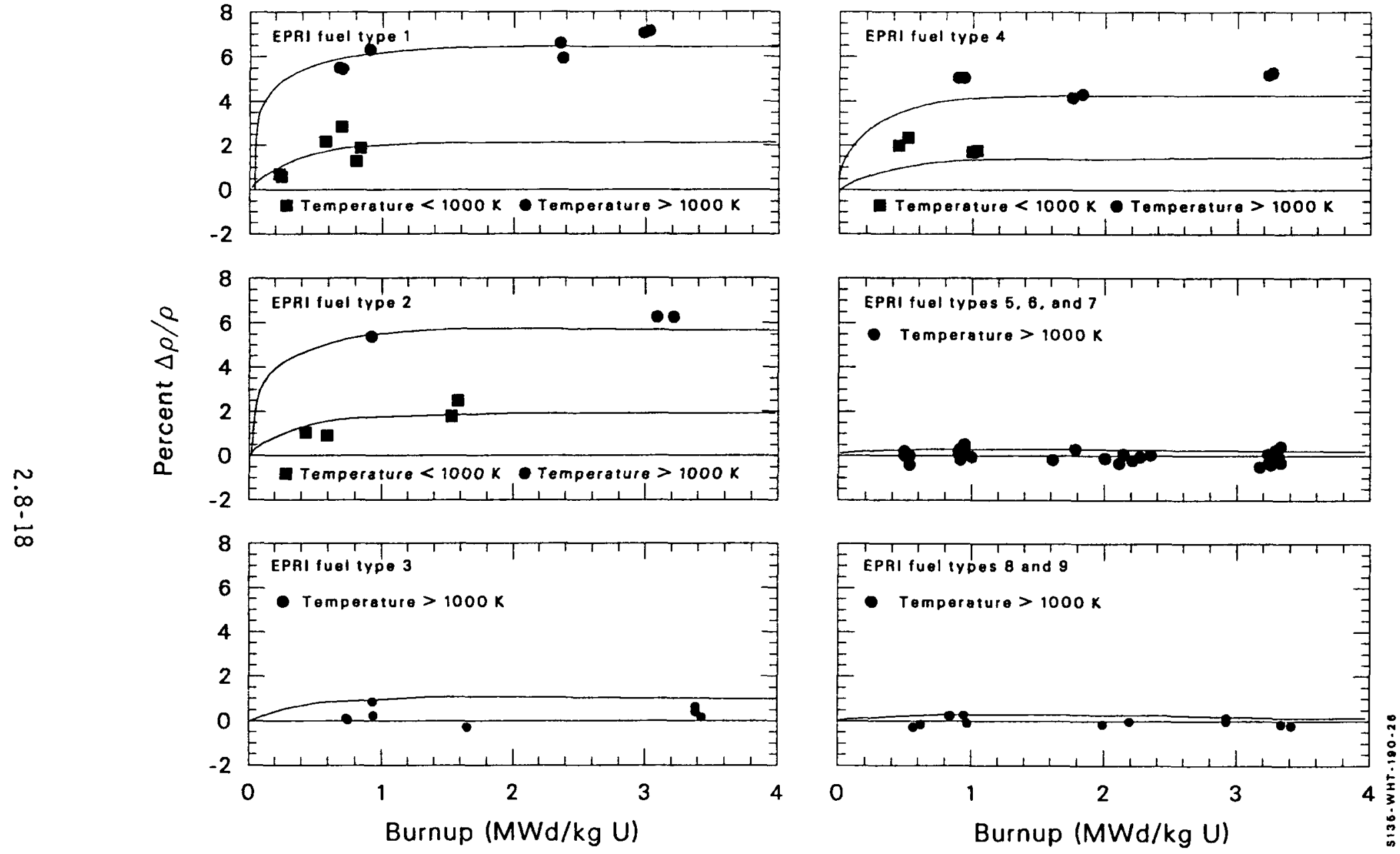

Figure 2.8-5. FUDENS calculations using EPRI fuel fabrication parameters and resintering values correlated with experimental EPRI in-pile data. 


\section{FUDENS}

2.8-6. A. Hanevik et al., "In-Reactor Measurements of Fuel Stack Shortening," BNES Nuclear Fuel Performance Conference, London, October 15-19, 1973, paper No. 89.

2.8-7. D. A. Collins and R. Hargreaves, "Performance-Limiting Phenomena in Irradiated $\mathrm{UO}_{2}$," BNES Nuclear Fuel Performance Conference, London, October 15-19, 1973, paper No. 50.

2.8-8. H. M. Ferrari et al., "Fuel Densification Experience in Westinghouse Pressurized Water Reactors," BNES Nuclear Fuel Performance Conference, London, October 15-19, 1973, paper No. 54.

2.8-9. T. J. Heal et al., "Development of Stable Density $\mathrm{UO}_{2}$ Fuel, " $B N E S$ Nuclear Fuel Performance conference, London, October $15-19,1973$, paper No. 52.

2.8-10. A. M. Ross, "Irradiation Behavior of Fission Gas Bubbles and Sintering Pores in $\mathrm{UO}_{2}, "$ Journal of Nuclear Materials, 30, April 1969, pp. 134-142.

2.8-11. B. Burton and G. L. Reynolds, "The Sintering of Grain Boundary Cavities in Uranium Dioxide," Journal of Nuclear Materials, 45, 1972/73, pp. 10-14.

2.8-12. R. 0. Meyer, The Analysis of Fuel Densification, NUREG-0085, July 1976.

2.8-13. J. C. Voglewede and S. C. Dochwat, Reactor Development Program Progress Report, ANL-RDP-33, December 1974, pp. 5-1 through 5-2.

2.8-14. H. Stehle and H. Assmann, "The Dependence of In-Reactor $\mathrm{UO}_{2}$ Densification on Temperature and Microstructure, "Journal of Nuclear Materials, 52, 1974, pp. 303-308.

2.8-15. M. 0. Marlowe, "Predicting In-Reactor Densification Behavior of $\mathrm{UO}_{2}, "$ Transactions of the American Nuclear Society, 17, November 1973, pp. 166-169.

2.8-16. D. Hull and D. E. Rimmer, "The Growth of Grain-Boundary Voids Under Stress," Philosophical Magazine, 4, 1959, p. 673.

2.8-17. S. R. MacEwen and I. J. Hasting, "A Model for In-Reactor Densification of $\mathrm{UO}_{2}$, "The Philosophical Magazine, 31, 1, January 1975, pp. 135-143.

2.8-18. R. W. Hamming, Introduction to Applied Numerical Analysis, New York: MaGraw-Hill Book Company, Inc., 1971. 



\subsection{SWeLLING (FSWELL)}
(R. E. Mason, K. A. McNei1)

The computer subcode FSWELL calculates fuel swelling, which is caused by the buildup of solid and gaseous fission products during irradiation. In order to calculate the overall fuel dimensional changes, fuel swelling (FSWELL) must be combined with the effects of creep-induced elongation (FCREEP) and densification due to pressure sintering (FHOTPS) and irradiation (FUDENS).

\subsubsection{Summary}

The expression used in FSWELL to calculate swelling due to solid fission products is

$$
S_{S}=2.5 \times 10^{-29} B_{S}
$$

where

$$
\begin{aligned}
& S_{S}=\quad \begin{array}{l}
\text { fractional volume change due to solid fission products }\left(\mathrm{m}^{3}\right. \\
\text { volume change } / \mathrm{m}^{3} \text { fuel) }
\end{array} \\
& \left.B_{S}=\text { burnup during a time step (fissions } / \mathrm{m}^{3}\right) .
\end{aligned}
$$

The correlation employed for swelling due to gaseous fission products when the temperature is below $2800 \mathrm{~K}$ is

$$
\begin{aligned}
S_{g} & =8.8 \times 10^{-56}(2800-T)^{11.73} \exp [-0.0162(2800-T)] \\
& \exp \left(-8.0 \times 10^{-27} \text { B) } B_{S}\right.
\end{aligned}
$$




\section{FSWELL}

where

$\mathrm{S}_{\mathrm{g}}=$ fractional volume change due to gas fission products (fissions $/ \mathrm{m}^{3}$ )

$\mathrm{T}=$ temperature $(\mathrm{K})$

B $=$ total burnup of fuel (fissions $/ \mathrm{m}^{3}$ ).

For temperatures greater than $2800 \mathrm{~K}, \mathrm{~S}_{\mathrm{g}}$ is zero because the gas that causes swelling is assumed to have been released.

\subsubsection{Solid Fission Product Swelling Model}

Volume changes caused by the buildup of nongaseous atoms are difficult to measure. However, a number of studies have been undertaken to determine the relative amounts of fission product elements and compounds, as well as their chemical states and locations within the fuel.2.9-1 to 2.9-15 The swelling rates proposed by these authors are summarized in Table 2.9-1.

Anselin 2.9-8 calculated swelling as a function of burnup using room-temperature data with an assumed fission product yield and chemical state for each element. He found a maximum solid fission product swelling rate of $0.13 \% \Delta V / V$ per $10^{26}$ fissions $/ \mathrm{m}^{3}$, if the fuel completely utilized the vacancies created during irradiation, and $0.54 \% \Delta V / V$ per $10^{26}$ fissions $/ \mathrm{m}^{3}$ if none of the vacancies are used. He proposed an average of $0.35 \% \Delta V / V$ per $10^{26}$ fissions $/ \mathrm{m}^{3}$ for all conditions but cautioned that there is no unique value for the swelling rate, since the irradiation conditions, fuel pin design, and fuel properties all contribute to swelling. 


\section{FSWELL}

Harrison and Davies $2.9-10$ calculated solid fission product swelling as a function of thermal neutron flux and concluded that the swelling rate decreases monotonically with increasing flux. They reported swelling rates of $0.45 \% \Delta V / V$ per $10^{26}$ fissions $/ \mathrm{m}^{3}$ and $0.39 \% \Delta V / V$ per $10^{26}$ fissions $/ \mathrm{m}^{3}$ for thermal neutron fluxes of $10^{18}$ and $10^{21} \mathrm{n} / \mathrm{m}^{2} \cdot \mathrm{s}$, respectively.

01 ander $2.9-16$ obtained a solid fission product swelling rate of $0.32 \%$ $\Delta V / V$ per atom percent burnup, which corresponds closely to Anselin's average value of $0.35 \% \Delta V / V$ per $10^{26}$ fissions $/ \mathrm{m}^{3}$. However, this calculation does not account for fission product migration and is influenced by uncertainties in the physical and chemical states of the fission products, leading to an error of $\pm 50 \%$ in the predicted value. 01 ander found a minimum swelling rate of $0.16 \% \Delta V / V$ per atom percent burnup for initially hypostoichiometric $U_{2}$ and a maximum of $0.48 \% \Delta V / V$ per atom percent burnup for initially hyperstoichiometric fuel or fuel irradiated to high burnups.

Rowland 2.9-17 conducted an extensive study of oxide fuel swelling and found the maximum total swelling due to both solid and gaseous fission products to be $0.4 \% \Delta V / V$ per $10^{26}$ fissions $/ \mathrm{m}^{3}$. Frost $2.9-18$ obtained $0.21 \% \Delta V / V$ per $10^{26}$ fissions $/ \mathrm{m}^{3}$, and Whapman and Sheldon $2.9-19$ obtained $0.20 \% \Delta V / V$ per $10^{26}$ fissions $/ \mathrm{m}^{3}$.

The FSWELL model was developed by choosing a swelling rate between Anselin's rate of swelling when vacancies are utilized and General Electric's maximum swelling rate due to both solid and gaseous fission products. The best solid fission product swelling rate at both low burnups and high burnups, where much of the fission gas is released and solid fission product swelling dominates, is $0.25 \% \Delta V / V$ per $10^{26}$ fissions $/ \mathrm{m}^{3}$. Thus, the correlation for swelling due to solid fission products is

$$
S_{S}=2.5 \times 10^{-29} B_{S}
$$




\section{FSWELL}

where the terms are previously defined. This equation has been modified in FSWELL, where burnup is given in terms of MW-s/kg-U. Tn make the proper conversion between units, the correlation must be

$$
\text { soldsw }=7.435 \times 10^{-13} \cdot \text { fdens }\left(b u-b u_{1}\right)
$$

where

$$
\begin{array}{ll}
\text { soldsw } & =\text { fractional volume change due to solid fission products } \\
\text { fdens } & =\text { initial input density of the fuel }\left(\mathrm{kg} / \mathrm{m}^{3}\right) \\
\text { bu } & =\text { input burnup to end of current time step }(\mathrm{MW}-\mathrm{s} / \mathrm{kg}-\mathrm{U}) \\
\mathrm{bu}_{1} & =\text { input burnup to end of last time step (MW-s/kg-U). }
\end{array}
$$

\subsubsection{Fission Gas Swelling Model}

Fuel swelling is primarily a result of the increase in fission gas bubbles within the fuel pellets. The physical mechanisms that cause the fuel to swell are complex and are not considered in detail in the FSWELL subcode. Swelling due to fission gas is modeled using a correlation for unrestrained swelling as a function of temperature and burnup. This correlation is based on the data reported by Battelle Columbus Laboratories, 2.9-20 to 2.9-24 Turnbul1, 2.9-25 to 2.9-27 Kuz'min and Lebedev, 2.9-28 and Grando et al. 2.9-29 for unrestrained swelling caused by the growth of intergranular gas bubbles and tunnels on the grain boundaries, edges, and corners at temperatures between 1373 and $1973 \mathrm{~K}$. The model considers two gross mechanisms, depending on the temperature of the fuel. Above $1573 \mathrm{~K}$, macropores begin to grow, causing a significant increase in fuel rod swelling. At very high temperatures (1973 $\mathrm{K}$ to the melting point), columnar grains form, fission gas is released, and swelling is reduced. 
FSWELL

The fuel volume changes listed by Chubb et al. 2.9-20 and Turnbul1 2.9-27 were used to correlate the unrestrained isothermal swelling rate. The fission gas swelling rate equation was determined by comparing the calculated swelling curve with the data and adjusting the equation until the predicted values matched the measured data. The shape of the unrestrained isothermal curve was determined by assuming that (a) at temperatures below $1000 \mathrm{~K}$, the gases remain in very small bubbles and/or as single atoms in the matrix so that little swelling occurs; (b) between 1000 and $2000 \mathrm{~K}$, bubbles grow at the grain boundaries, edges, and corners, creating volume changes; and (c) above $2000 \mathrm{~K}$, dense ( $98 \%$ of theoretical density) columnar grains form and gas is removed, making fission gas swelling insignificant compared to solid fission product swelling. The equation describing this process is

$$
F_{g}=8.8 \times 10^{-56}(2800-T)^{11.73} \exp [-0.0162(2800-T)]
$$

where

$$
\begin{aligned}
& \mathrm{F}_{\mathrm{g}}=\text { fractional volume change/burnup }\left(\mathrm{m}^{3} / \text { fission }\right) \\
& T \quad=\text { temperature }(\mathrm{K}) .
\end{aligned}
$$

The unrestrained fuel swelling predicted by Equation $(2.9-4)$ is shown in Figure 2.9-1. The values calculated by FSWELL are compared with the data of Turnbul1 and Chubb et a1. in Figure 2.9-2.

Fission gas swelling must also be modeled as a function of burnup. Data reported by Battelle Columbus Laboratories, Turnbul1, and Kuz'min and Lebedev indicate that fission gas swelling saturates at relatively low burnups ( $<10^{26}$ fissions $/ \mathrm{m}^{3}$ ). An exponential burnup function has been included in the FSWELL model to account for swelling saturation. The swelling dependence on burnup is 


\section{FSWELL}

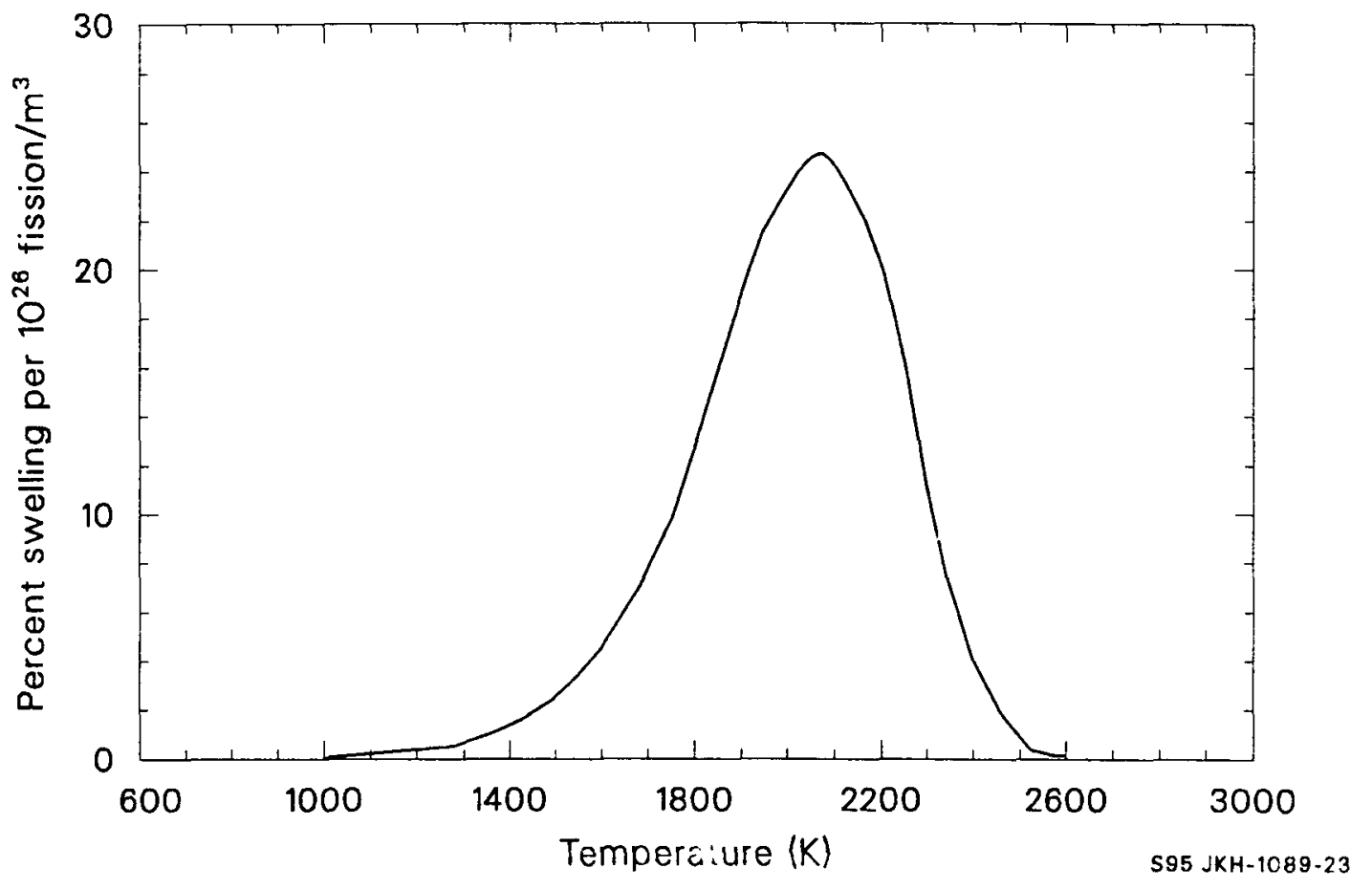

Figure 2.9-1. Unrestrained fission gas swelling. 
FSWELL

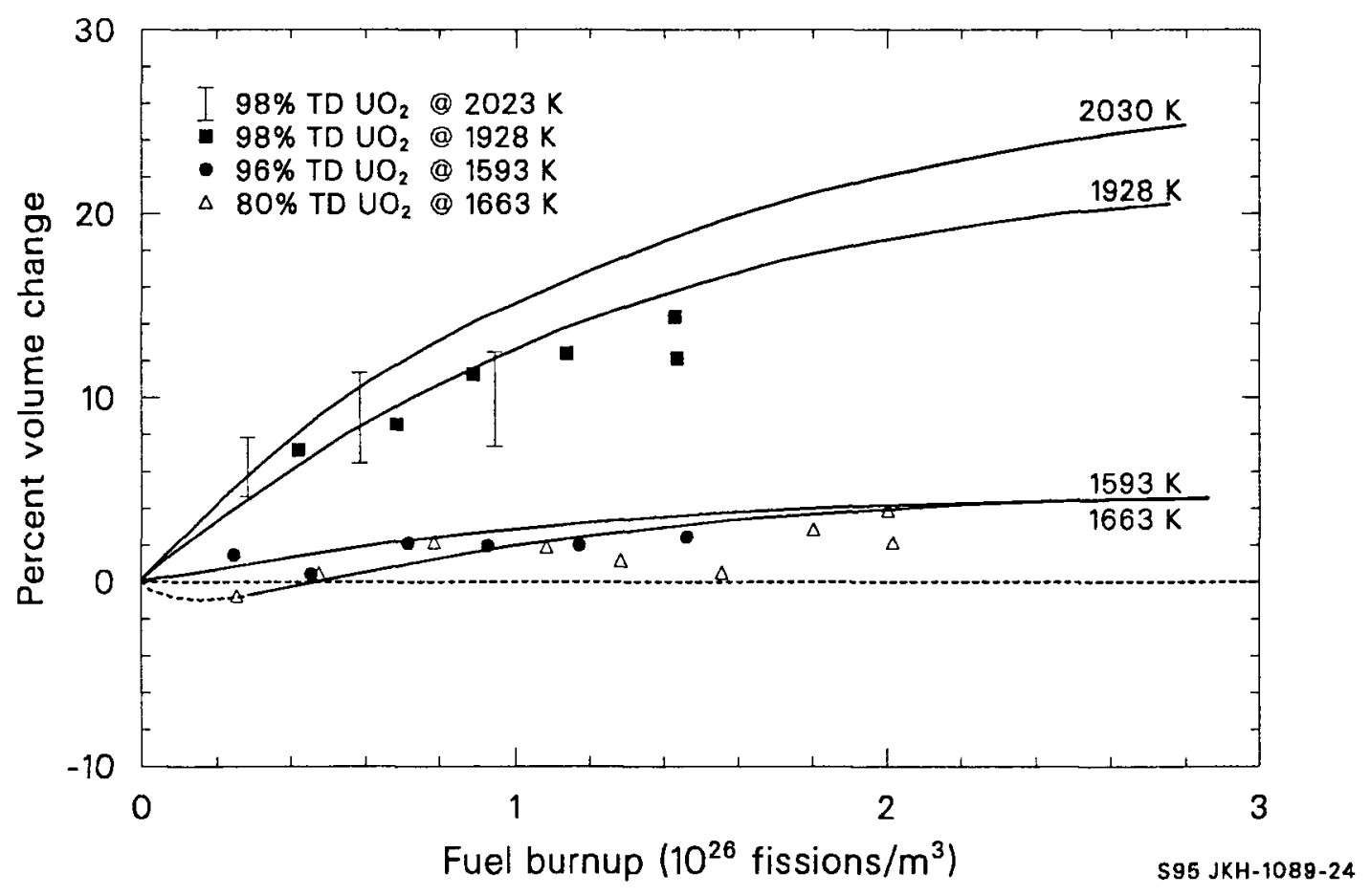

Figure 2.9-2. Fuel volume changes calculated by FSWELL compared with experimental fuel swelling data. 


\section{FSWELL}

$S_{g}=F_{g} B_{S} \exp \left(-8.0 \times 10^{-27} B\right) B_{S}$

where

$\mathrm{S}_{\mathrm{g}} \quad=$ fractional volume change due to gaseous fission products

$B=$ total burnup (fissions $/ \mathrm{m}^{3}$ ).

When Equation (2.9-4) is substituted into Equation (2.9-5), the correlation for swelling due to gaseous fission products becomes

$$
\begin{aligned}
S_{g}= & 8.8 \times 10^{-56}(2800-T)^{11.73} \exp [-0.0162(2800-T)] \\
& \exp \left(-8.0 \times 10^{-27} \text { B) } B_{S}\right.
\end{aligned}
$$

for $T<2800 \mathrm{~K}$, and

$S_{g}=0.0$

for $T \geq 2800 \mathrm{~K}$. Converting fissions $/ \mathrm{m}^{3}$ to $\mathrm{MW}-\mathrm{s} / \mathrm{kg}-\mathrm{U}$ gives

$$
\begin{aligned}
\text { gaswl }= & 2.617 \times 10^{-39} \cdot \text { fdens } \cdot\left(\text { bu }-b_{1}\right) \cdot(2800-T)^{11.73} \\
& \exp [-0.0162(2800-\mathrm{T})] \exp \left(-2.4 \times 10^{-10} \cdot \text { bu } \cdot \text { fdens }\right)
\end{aligned}
$$

where gaswl is the fractional volume change due to gaseous fission products.

\subsubsection{References}

2.9-1. B. T. Bradbury and B. R. T. Frost, Studies in Radiation Effects on Solids, New York: Gordon and Breach, 1967.

2.9-2. B. T. Bradbury, J. T. Demant, P. M. Martin, D. M. Poole, Journal of Nuclear Materials, 17, 1965. 
FSWELL

2.9-3. B. T. Bradbury, J. T. Demant, P. M. Martin, AERE-R-5149, 1966.

2.9-4. G. M. Jeffery, Journal of Nuclear Materials, 22, 1964.

2.9-5. J. L. Bates, Metallic Uranium in Irradiated $\mathrm{UO}_{2}$, HW-82263, 1964.

2.9-6. D. R. O'Boyle, F. L. Brown, J. E. Saneck, "Solid Fission Product Behavior in Uranium - Plutonium Oxide Fuel Irradiated in a Fast Neutron Flux," Journal of Nuclear Materials, 29, 1969, pp. 27-42.

2.9-7. I. J. Hastings, D. H. Rose, J. Barid, "Identification of Precipitates Associated with Intergranular Fission Gas Bubbles in Irradiated $\mathrm{UO}_{2}$ Fuel, " Journal of Nuclear Materials, 61, 1976, pp. 229-231.

2.9-8. F. Anselin, The Role of Fission Products in the Swelling of Irradiated $\mathrm{UO}_{2}$ and (U,PU)O $\mathrm{O}_{2}$ Fuel, GEAP-5583, January 1969.

2.9-9. F. Anselin and W. E. Baily, "The Role of Fission Products in the Swelling of Irradiated $\mathrm{UO}_{2}$ and (U,Pu) $0_{2}$ Fuels, "Transactions of the American Nuclear Society, 10, 1967.

2.9-10. J. W. Harrison and L. M. Davies, "The Variation of Solid Fission Product and Gas Swelling in Uranium Compounds with Thermal Neutron Dose Rate," Journal of Nuclear Materials, 27, 1968.

2.9-11. B. Lustman, Technical Progress Report, PWR Project, WAPD MRP 11, October 1964 - January 1965.

2.9-12. J. H. Davies, R. F. Boyle, D. Weidenbaum, J. Hanson, "On the Composition of Metallic Ingots Formed in High Performance Ceramic Fuel Elements," Transactions of the American Nuclear Society, 9, $63,1966$.

2.9-13. J. H. Davies, Some Considerations Regarding the Behavior of Fission Products in the Fast Ceramic Reactor, GEAP-4872.

2.9-14. M. L. Bleiberg, R. M. Berman, B. Lustman, Effect of High Burnup on Oxide Ceramic Fuels, WAPD-T-1455, 1962.

2.9-15. I. G. Lebedev, V. I. Kuz'min, A. S. Piskum, "Swelling of Hot Oxide Fuel, " Soviet Journal of Atomic Energy, 28, 1970.

2.9-16. D. R. 01ander, Fundamental Aspects of Nuclear Reactor Fuel Elements, TID-26711-P, 1967.

2.9-17. T. C. Rowland, M. O. Marlowe, R. B. Elkins, Fission Product Swelling BWR Fuels, NEDP-20702, November 1974. 


\section{FSWELL}

2.9-18. B. R. T. Frost, "Studies of Irradiation Effects in Ceramic Fuel at Harwell," Journal of the American Ceramic Society, 1969.

2.9-19. A. E. Whapham and B. E. Sheldion, Electron Microscope Observation of the Fission Gas Bubble Distribution in $\mathrm{UO}_{2}$, AERE-R-4970, April 1966.

2.9-20. W. Chubb, V. W. Storhok, D. L. Keller, "Observations Relating to the Mechanisms of Swelling and Gas Release in Uranium Dioxide of High Temperatures," Journal of Nuclear Materials, 44, 1972, pp. $136-152$.

2.9-21. W. Chubb, V. W. Storhok, D. L. Keller, "Factors Affecting the Swelling of Nuclear Fuel at High Temperatures, "Nuclear Technology, 18, June 1973, pp. 231-255.

2.9-22. W. Chubb and D. L. Keller, Implication of High Temperature Irradiation Data for Low Temperature Reactor Design, BMI-1918, July 1971, pp. B98-B112.

2.9-23. R. F. Hilbert, W. J. Zielenbach, D. E. Lozier, R. B. Clark, V. W. Storhok, Irradiation Behavior of Oxide Fuels at High Temperatures, BMI-1918, July 1971, pp. B2-B43.

2.9-24. R. F. Hilbert, V. W. Storhok, W. Chubb, D. L. Keller, "Mechanisms of Swelling and Gas Release in Uranium Dioxide," Journal of Nuclear Materials, 38, 1971, pp. 26-34.

2.9-25. 3. A. Turnbul1, "The Effect of Grain Size on the Swelling and Gas Release Properties of $\mathrm{UO}_{2}$ During Irradiation," Journal of Nuclear Materials, 50, 1974, pp. 62-68.

2.9-26. J. A. Turnbul1, "The Mobility of Intragranular Bubbles in Uranium Dioxide During Irradiation," Journal of Nuclear Materials, 62, 1976, pp. 325-328.

2.9-27. J. A. Turnbull and M. 0. Tucker, "Swelling in $\mathrm{UO}_{2}$ under Conditions of Gas Release," The Philosophical Magazine, 30, July 1974, pp. 47-64.

2.9-28. V. I. Kuz'min and I. G. Lebedev, "Effect of Temperature Distribution on the Swelling of $\mathrm{UO}_{2}$ and $\mathrm{UO}_{2}-\mathrm{PuO}_{2}$ Cores," Power Atomic Energy, 28, January 1975.

2.9-29. C. Grando, M. Montgomery, A. Strasser, "Unrestrained Swelling and Fission Gas Release of Fast Reactor Fuels, "Proceedings of the Conference on Fast Reactor Fuel Element Technology, New Orleans, LA, Apri1 13-15, 1971, Ruth Farmakes, ed., pp. 771-784. 


\section{FHOTPS}

\subsection{Pressure Sinterivg (FHOTPS)}

(R. E. Mason)

Urania or mixed-oxide fuel pellets densify when exposed to sufficiently high hydrostatic pressures (pressure sintering), high temperatures (thermal sintering), and irradiation. This report discusses a densification model based on published out-of-pile fuel pressure sintering data. The pressure sintering model complements the irradiation-dependent densification model described in Section 2.8 of this report.

A summary of the pressure sintering model, FHOTPS, is contained in Section 2.10.1. Section 2.10.2 describes pressure sintering theories and examines their applicability to modeling urania and mixed-oxide pressure sintering data. Section 2.10.3 describes the development of the FHOTPS mode1, provides standard error estimates, and compares FHOTPS calculated results with experimental data, and the references are given in Section 2.10.4.

\subsubsection{Summary}

Fuel densification in a reactor environment is a function of temperature, stress, and irradiation. Temperature and stress densification mechanisms are driven by a stress, $P$, expressed by

$P=P_{e}-P_{j}+2 \gamma / a$

where

$$
\mathrm{P}_{\mathrm{e}} \quad=\quad \text { external hydrostatic stress }(\mathrm{Pa})
$$




\section{FHOTPS}

$P_{j} \quad=\quad$ internal pore pressure $(\mathrm{Pa})$

$\gamma=$ surface energy per unit area $\left(\mathrm{J} / \mathrm{m}^{2}\right)$

$a=$ grain size $(m)$.

Pressure sintering is the dominant densification process if the stress $\left(P_{e}-P_{j}\right)$ is much larger than the surface energy stress, $2 \gamma / a$. If an external hydrostatic stress, $P_{e}$, is present, it will dominate the densification of in-pile fuel because the internal pore pressure, $P_{j}$, and the surface energy stress, $2 \gamma / \mathrm{a}$, are generally much smaller than the externally applied stress. Over an extended irradiation period and at zero $P_{e}$, the internal pore pressure, $P_{j}$, could cause fuel swelling and the surface energy stress could cause some fuel densification. However, these changes in fuel volume are small compared with densification caused by applied stress and are not considered in the development of the FHOTPS model.

Equation (2.10-1) does not include an irradiation-related driving stress. It is assumed that the irradiation densification driving stress would be added to the right side of Equation (2.10-1). Since the irradiation densification driving stress is a linear term, it is treated independently as a separate model (the FUDENS model, see Section 2.8). The values calculated with the FUDENS model should, therefore, be added to the FHOTPS model described in this section. The reader should, however, be cautioned that data used to develop the FUDENS model were in-pile data that may include some pressure sintering effects so that combining the two model outputs may be conservative. There are no in-pile data available that will allow separation of these effects.

A lattice diffusion creep equation was fit to the data of Solomon ${ }^{2 \cdot 10-1}$ to give the equation used for urania in the FHOTPS model 
FHOTPS

$\frac{1}{\rho} \frac{\mathrm{d} \rho}{\mathrm{dt}}=48939\left(\frac{1-\rho}{\rho}\right)^{2.7} \frac{\mathrm{p}}{\mathrm{TG}^{2}} \exp \left(Q_{\mathrm{u}} / \mathrm{RT}\right)$

where

$$
\begin{aligned}
& \rho=\text { fraction of theoretical density (unitless) } \\
& t=\text { time }(\mathrm{s}) \\
& P \quad=\text { hydrostatic pressure }(\mathrm{Pa}) \\
& T=\text { temperature }(\mathrm{K}) \\
& G \quad=\text { grain size }(\mu \mathrm{m}) \\
& Q_{U}=\operatorname{activation} \text { energy }(\mathrm{J} / \mathrm{mole}) \\
& R=8.314(\mathrm{~J} / \mathrm{mole} \cdot \mathrm{K}) .
\end{aligned}
$$

The activation energy of urania pressure sintering for Equation (2.10-2) is calculated with the oxygen-to-metal-dependent equation

$Q_{u}=R\left\{9000 \exp \left[\frac{20-8|\log (x-1.999)|}{|\log (x-1.999)|}+1.0\right]^{-1}+36294.4\right\}$

where $x$ is the oxygen-to-metal ratio.

The lattice diffusion creep equation was fit to the mixed-oxide data of Routbort ${ }^{2 \cdot 10-2}$ to give the mixed-oxide fuel pressure sintering equation

$\frac{1}{\rho} \frac{\mathrm{d} \rho}{\mathrm{dt}}=1.8 \times 10^{7}\left(\frac{1-\rho}{\rho}\right)^{2.25} \frac{\mathrm{P}}{\mathrm{TG}^{2}} \exp (-450000 / \mathrm{RT})$ 


\section{FHOTPS}

The estimated standard error of estimate for both equations is $\pm 0.5 \%$ of the calculated density.

Care must be exercised when using these models out of the 1600- to $1700-\mathrm{K}$ and 2- to 6-MPa data base range. Pressure sintering not represented in the data base may be controlled by a different creep densification mechanism, as discussed below. Pressure sintering rates would then be much different than those calculated by Equations (2.10-2) or (2.10-4).

\subsubsection{Pressure Sintering Process and Data}

Pressure sintering or volume creep consists of several modes of creep. One of these modes of creep mechanisms can dominate the others, depending on the fuel temperature, pressure, porosity, and grain size conditions, as will be discussed below. Equations representing each creep mechanism combined with the theoretical constants for $\mathrm{UO}_{2}$ were used by Routbort $2.10-2$ to determine the most probable dominating (contributes the highest densification rate) mechanism under reactor operating conditions. These equations, their use, and the published experimental data used to develop the FHOTPS model are described in this section.

2.10.2.1 Creep Densification. Several distinct mechanisms, such as lattice diffusion (Narbarro-Herring creep) or rate-independent plasticity (yielding or dislocation glide), contribute to fuel densification. ${ }^{2.10-3}$ Each mechanism imposes specific stress-porosity-temperature-dependent functions. One or any combination of these creep mechanisms can dominate densification, depending on the grain size and stress-porosity-temperature conditions. There is no single mechanism that will always dominate the densification process. Therefore, an equation representing each creep mechanism is presented so that all possible densification parameter dependencies are described.

Pressure sintering by grain boundary diffusion creep (grain boundary acting as a diffusion path) is usually dominant at temperatures less than 
one half the melting temperature. $2 \cdot 10-3,2 \cdot 10-4$ The densification rate by grain boundary creep is expressed by

$\frac{d \rho}{d t}=\frac{4.5 \delta D_{b} \Omega}{k T b^{3}} \frac{p}{1-(1-\rho)^{1 / 3}}$

where

$\delta \quad=$ grain boundary thickness
$\mathrm{D}_{\mathrm{b}} \quad=$ grain boundary diffusion coefficient
$\Omega \quad=$ atomic volume
$\mathrm{P} \quad=$ applied stress
$\mathrm{k} \quad=$ Boltzman's constant
$\mathrm{b} \quad=\quad$ grain size.

Pressure sintering by grain boundary diffusion creep can dominate only if the grain sizes remain small, so that the diffusion paths along the grain boundaries are small.

Pressure sintering by lattice diffusion creep often dominates at temperatures greater than half the melting temperature and before significant grain growth has occurred. Densification by lattice diffusion creep is expressed by

a. It was assumed here and in the following equations that the effective particle radius is the grain size. This is consistent with the model that is based on the assumption of about one pore to every grain in the compact. 


\section{FHOTPS}

$\frac{d \rho}{d t}=\frac{3 D v^{\Omega P}}{k T b^{2}}$

where $D_{v}$ is the lattice diffusion coefficient. This equation is used to calculate densification by vacancy flow from the surface of a pore to sinks on nearby grain boundaries. $2.10-3$

Pressure sintering by power law creep can dominate at high fuel temperatures or pressures. Densification by power law creep (dislocation creep) has been derived by Wilkinson and Ashby 2.10-4 and by Wolfe and Kaufman. $2 \cdot 10-5$ The densification rate equation is

$\frac{\mathrm{d} \rho}{\mathrm{dt}}=\frac{\mathrm{SA}}{\mathrm{T}} \exp \frac{0}{\mathrm{kT}}\left(\frac{\rho(1-\rho)}{\left[1-(1-\rho)^{1 / n}\right]^{n}}\right)\left(\frac{3|\rho|^{n}}{2 \mathrm{n}}\right)$

where

$$
\begin{aligned}
& S \quad=\text { sign of pressure } \\
& A \quad=\text { constant } \\
& Q \quad=\text { power law activation energy }(\mathrm{J} / \mathrm{mole}) \\
& \mathbf{n}=\text { stress and porosity exponent. }
\end{aligned}
$$

Equation (2.10-7) assumes steady-state creep and densification independent of the grain size and is valid even after extensive grain growth.

The fourth pressure sintering mechanism, plastic flow, operates at low temperatures or very high strain rates and is defined by the expression 


\section{FHOTPS}

$\frac{d q}{d t}=\left\{\begin{array}{l}0 \text { if } \rho \geq 1-\exp \left(\frac{-3 P}{2 \sigma_{y}}\right) \\ \infty \text { if } \rho<1-\exp \left(\frac{-3 P}{2 \sigma_{y}}\right)\end{array}\right.$

where $\sigma_{y}$ is the yield stress. Densification by the plastic flow mechanism is assumed to occur instantaneously.2.10-3

The stress-dependency of the above equations has been shown by Ross $i$ and Fulrath, ${ }^{2 \cdot 10-6}$ McCell and, ${ }^{2 \cdot 10-7}$ Fryer, ${ }^{2 \cdot 10-8}$ and Wolf ${ }^{2 \cdot 10-5}$ to be dependent on the applied stress and the fuel porosity. Porosity in fuel increases stress in the vicinity of the pores and results in a vacancy concentration difference between the pore surfaces and the grain boundaries. Various porosity-dependent functions have been proposed by the above authors, but the porosity-dependent function of Fryer ${ }^{2 \cdot 10-8}$ is the most generally accepted effective stress-porosity-dependent function. The form of Fryer's expression is

$P=\left(\frac{1-\rho}{\rho}\right)^{n}$

where

$$
\begin{aligned}
& P=\text { effective stress }(\mathrm{Pa}) \\
& \rho=\text { fractional density (unitless) } \\
& n=1.0 .
\end{aligned}
$$

Routbort ${ }^{2 \cdot 10-2}$ found that the porosity exponent, $n$, of Equation (2.10-9) was not constant for mixed oxides but varied with the pressure sintering temperature. Routbort mapped pressure sintering of mixed oxides 


\section{FHOTPS}

(determined the most dominant mechanism using theoretical material properties) using predominantly urania material constants. It was found that the lattice diffusion mechanism dominates under LWR conditions (fuel temperatures between 1100 and $3136 \mathrm{~K}$, pressures < $100 \mathrm{MPa}$, and fuel densities $>0.90 \%$ of theoretical density). This conclusion, however, must be exercised with caution because the densification rate equations depend on the grain size and the oxygen-to-metal ratio and neither were included in the pressure sintering map analysis. The oxygen-to-metal ratio has been shown by Seltzer $2 \cdot 10-9,2 \cdot 10-10,2 \cdot 10-11$ to strongly influence the activation energy and thereby drastically alter the densification rates predicated by Equations (2.10-5), (2.10-6), and (2.10-7).

The final pressure sintering mechanism is lattice diffusion modified to include an effective applied stress. The expression describing this mechanism is

$\frac{1}{\rho} \frac{\mathrm{d} \rho}{\mathrm{dt}}=A\left(\frac{1-\rho}{\rho}\right)^{n} \quad \frac{P}{T G^{2}} \exp (Q / R T)$

where
$A=$ constant
$Q=$ activation energy $(\mathrm{J} / \mathrm{mole})$.

2.10.2.2 Pressure Sintering Data. The models presented in Section 2.10.1 are based on data published in the open literature that deal with final-stage sintering of urania and mixed oxide fuels. These models are based on the urania pressure sintering data of Solomon $2 \cdot 10-1$ and the mixed-oxide pressure sintering data of Routbort.2.10-2 0ther data were used as comparison data, but fuel resintering data or final-stage sintering data are used because these data most closely resemble what is occurring in 


\section{FHOTPS}

a reactor. Measurement techniques and urania and mixed-oxide data published in the open literature are presented in this section.

2.10.2.2.1 Measurement Techniques--Immersion density and specimen length change measurements are used to obtain densification data. From the more accurate immersion density measurements, is the more accurate technique, but only the initial and final densities are obtained. Densities from specimen length changes provide time-density data and are calculated by

$\underline{\rho}_{\mathrm{f}}=\left(\frac{1 \mathrm{f}}{1}\right)^{3}$

where

$$
\begin{aligned}
& \rho=\text { initial fraction of theoretical density (unitless) } \\
& \rho_{f}=\text { final fraction of theoretical density (unitless) } \\
& 1_{f}=\text { final length }(\mathrm{mm}) \\
& 1=\text { initial length }(\mathrm{mm}) .
\end{aligned}
$$

Density changes determined from length change measurements have several inherent sources of error. The most critical error is the change in length during the initial densification of the test sample, caused by seating and alignment changes. This strain error affects only the initial $1 \%$ to $2 \%$ of sample densification. Creep (nonvolumetric strain) of the sample and loading column is another source of error. Routbort measured the final densities using both the immersion and length change techniques and found about a $5 \%$ difference. 


\section{FHOTPS}

2.10.2.2.2 Urania Densification Data--Pressure sintering data of $\mathrm{UO}_{2}$ fuel have been published by Solomon, 2.10-1 Kaufman, 2.10-12 Amato, ${ }^{2 \cdot 10-13}$ Hart, ${ }^{2 \cdot 10-14}$ Fryer, ${ }^{2 \cdot 10-8}$ and Warren and Chaklader. 2.10-15 Fuel resintering or final-stage sintering data from other sources were used only as comparison data.

Solomon ${ }^{2 \cdot 10-1}$ measured pressure sintering rates of $\mathrm{UO}_{2}$ fuel pellets with pretest theoretical densities between $92 \%$ and $94 \%$ at $1673 \mathrm{~K}$ for up to $136 \mathrm{~h}$. A summary of the experimental conditions used by Solomon is provided in Table 2.10-1. These pressure sintering tests indicate that (a) significant densification occurred prior to the application of pressure, (b) internal pore pressures were possible influences on the densification rate, (c) pressure sintering rates are approximately linear with applied stress $\left(\sigma^{1.03}\right.$ to $\left.\sigma^{1.2}\right)$, and (d) activation energy for specimens at different temperatures and constant density was $0.290 \mathrm{MJ} / \mathrm{g} \cdot \mathrm{mole}$. The activation energy of $0.480 \mathrm{MJ} / \mathrm{g} \cdot \mathrm{mole}$ obtained from two isothermal tests was reported to be more accurate. Pressure cycling tests showed that the specimens swelled after the applied pressure was removed and that the applied pressure-densification and released pressure-swelling rates were reversible.

Kaufman ${ }^{2 \cdot 10-12}$ reported experimental urania pressure and sintering data of fuel with initial theoretical densities of $80.7 \%$ to $83.7 \%$. Immersion densities were taken before and after pressure sintering with a $\pm 0.2 \%$ accuracy. These data are intermediate sintering data and can only be used to check the FHOTPS model densification rates. Kaufman observed in his experiments that no densification from heating occurred prior to the application of the load. From experimental results, Kaufman determined the stress exponent values for Equation (2.10-9) to be between 1 and 4.5.

Amato $^{2 \cdot 10-13}$ used a graphite die plunger lined with alumina to obtain hot pressing data in pressure sintering tests conducted in a vacuum of $10^{-5}$ torr. A summary of test conditions is given in Table 2.10-1. This 
FHOTPS

Table 2.10-1. Pressure sintering data

\begin{tabular}{|c|c|c|c|c|}
\hline & \multicolumn{3}{|c|}{ Urania } & \multirow{2}{*}{$\begin{array}{l}\text { Mixed-Oxide } \\
\text { Routbort } \\
\end{array}$} \\
\hline & Solomon & Kaufman & Amato & \\
\hline $0 / M$ ratio & $2.004+0.001$ & -- & 2.00 & $1.98+0.01^{a}$ \\
\hline \multicolumn{5}{|l|}{ Presintering-- } \\
\hline Temperature (K) & $1783 \pm 1$ & 2023 & -- & -. \\
\hline Time $(h)$ & 3 & 12 to 24 & -- & -- \\
\hline \multicolumn{5}{|c|}{ Pressure sintering-- } \\
\hline $\begin{array}{l}\text { Theoretical } \\
\text { density }(\%)\end{array}$ & 92 to 98 & 80 to 92 & 68 to 96 & 90 to 99 \\
\hline Temperature $(\mathrm{K})$ & $1673 \pm 1$ & 2123 & 1373 to 1473 & $1598 \leq T \leq 1823$ \\
\hline Time (s) & $0<t<5 \times 10^{5}$ & - & $900<t<3600$ & - \\
\hline Pressure (MPa) & -. & $\begin{array}{l}3.86 \text { to } \\
3.96 \times 10^{7}\end{array}$ & $\begin{array}{l}2.76 \text { to } \\
5.52 \times 10^{7}\end{array}$ & 7.6 to 76 \\
\hline Stress exponent & $1.03<n<1.2$ & -. & -- & 1.33 \\
\hline $\begin{array}{l}\text { Porosity } \\
\text { exponent }\end{array}$ & 2.7 & - & -- & 2.25 \\
\hline $\begin{array}{l}\text { Initial grain } \\
\text { size (mm) }\end{array}$ & 3.354 & 10 to 40 & -- & 8.0 \\
\hline $\begin{array}{l}\text { a. Mixed-oxide pe } \\
\text { enriched). }\end{array}$ & ets consiste & of $25 w t \%$ & and $75 \mathrm{wt} \% \mathrm{U}$ & $(20 \% 235 U$ \\
\hline
\end{tabular}




\section{FHOTPS}

intermediate and final-stage sintering data is used to check the densification rates and is not part of the FHOTPS data base.

The fabrication pressure sintering data reported by Hart $2 \cdot 10-14$ and Fryer, ${ }^{2 \cdot 10-8}$ which include initial, intermediate, and final-stage densification, and the chemical reaction sintering data reported by Warren and Chaklader were not useful in the MATPRO modeling effort, since the densification and chemical reaction rate equations change at each stage.

\subsection{Mixed-0xide Densification Data--The experimental} results of Routbort ${ }^{2 \cdot 10-2}$ and Voglewede $2 \cdot 10-16,2 \cdot 10-17$ were the only mixed-oxide pressure sintering data published in the open literature. The test conditions used by Routbort for his experiments are summarized in Table 2.10-1. Routbort determined a porosity exponent of from 1.5 at $1673 \mathrm{~K}$ to 2.25 at $1823 \mathrm{~K}$. His results also showed pressure sintering to be a nonlinear function of stress, with a stress exponent of 1.33 .

\subsubsection{Model Development and Uncertainties}

The pressure sintering model, FHOTPS, calculates the volume reduction rate of fuel under hydrostatic pressures and elevated temperatures. The model is based on the urania and plutonia data described above and the semiempirical equation suggested by Solomon, Routbort, and Voglewede. The model simulates the removal of closed porosity developed during fuel pellet fabrication and porosity created by released fission gases.

The appropriate pressure sintering mechanism to model reactor fuel behavior is best determined by comparing the densification rates calculated using the theoretical equations described in Section 2.10.2. The equation indicating the largest densification rate at expected reactor pressures and temperatures is the best model for in-reactor pressure sintering. Both Routbort, from his analysis of mixed oxides using mostly $\mathrm{UO}_{2}$ physical constants, and Solomon, from his analysis of urania densification rates, 


\section{FHOTPS}

determined lattice diffusion to be the controlling mechanism. The lattice diffusion equation is therefore used as the framework for the final FHOTPS model.

The constants used in Equation (2.10-2) were obtained from the general equation for lattice diffusion, Equation (2.10-10), and the data of Solomon. Determining constant A of Equation (2.10-10) constituted equation fitting to the data. Trial-and-error adjustments of $A$ were made until the standard error of estimate from Equation (2.10-10) and the data converged to the smallest error possible. The porosity exponent, $n$, for urania was obtained by using the average slope value of $1 / \rho(d \rho / d t)$ plotted versus $\ln [(1-\rho) / \rho]$. The average slope value was determined to be 2.7 .

The lattice diffusion equation, Equation (2.10-10), was fit to the Solomon data using a porosity exponent of 2.7 , an initial grain size of $3.5 \mu \mathrm{m}$, an assumed activation energy of $0.48 \mathrm{MJ} / \mathrm{mole}$, the reported hydrostatic pressure, and isothermal temperature. This fitted equation calculated a larger densification rate than indicated by the intermediate-stage sintering data of Amato. This was opposite to the expected results because intermediate sintering is usually faster than final-stage sintering. The lattice diffusion equation was then refit to the Solomon data, using an apparent activation energy closer to $0.290 \mathrm{MJ} / \mathrm{mole}$ (apparent activation energy obtained by Solomon from specimen data taken at different temperatures). The activation energy used in the urania pressure sintering model was calculated using Equation (2.10-3). This activation energy equation and the resulting activation energy were used to be consistent with the FCREEP model of the MATPRO package. With the oxygen-to-metal ratio of 2.004 , an apparent activation energy of $0.332 \mathrm{MJ} / \mathrm{mole}$ was calculated using Equation (2.10-3), which is relatively close to the lower Solomon activation energy. Using this activation energy, Equation (2.10-10) was fit by trial and error adjustments of constants to fit the Solomon data, with a final error estimation of $\pm 0.48 \%$.

Calculations using Equation (2.10-2) compared with the Solomon data are shown in Figure 2.10-1. 


\section{FHOTPS}

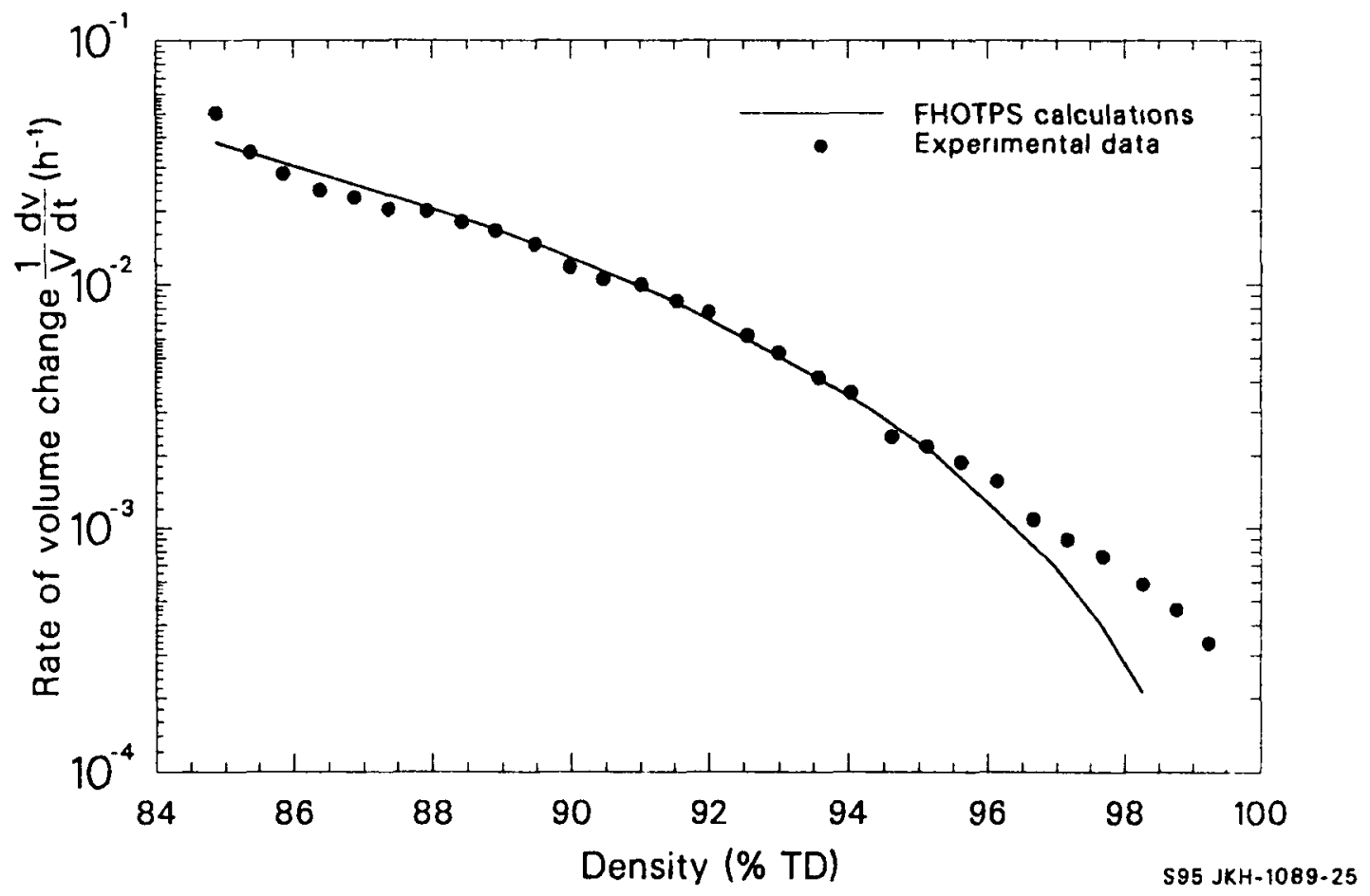

Figure 2.10-1. Urania pressure sintering rates calculated using the FHOTPS model compared with data. 


\section{FHOTPS}

The mixed-oxide pressure sintering rate equation suggested by Routbort was used as the FHOTPS mixed-oxide model except with the grain size dependence of the theoretical lattice-diffusion equation consistent with the urania mode1. The $0.4-\mathrm{MJ} / \mathrm{mole}$ activation energy for mixed oxides suggested by Routbort, with an oxygen-to-metal ratio of 1.98 , was used in the model. This activation energy is assumed not to vary with the oxygen-to-metal ratio because of a lack of data. The porosity exponent is also assumed constant at 2.25, the value determined by Routbort for samples tested at $1823 \mathrm{~K}$. Although Routbort observed a temperature dependence of the porosity exponent, a model for the dependence was not developed because data on which this conclusion was based were not included in the published report.

Equation (2.10-10) was fit to the Routbort data using an activation energy of $0.4 \mathrm{MJ} / \mathrm{g}$ mole, a porosity exponent of 2.25 , and an initial grain size of $9 \mu \mathrm{m}$. Constants were adjusted until the smallest standard error estimate was obtained. The final standard error of estimate is $0.5 \%$. Figure 2.10-2 shows a comparison of the mixed-oxide densification rates corresponding to the Routbort data and those calculated with the FHOTPS model.

The FHOTPS model calculates a density change rate. These calculations are easily modified to obtain strain rate by multiplying calculational results by $-1 / 3$. This is a result of the following analysis. Using a fuel mass, $g$, a change in density can be expressed.

$\frac{1}{\rho} \frac{\mathrm{d} \rho}{\mathrm{dt}}=\frac{\frac{\mathrm{g}}{\mathrm{V}}-\frac{\mathrm{g}}{\mathrm{V}_{0}}}{\frac{\mathrm{g}}{\mathrm{V}_{\mathrm{T}}}} \frac{1}{\Delta \mathrm{T}}$

where

$\mathrm{g}=$ fuel mass 


\section{FHOTPS}

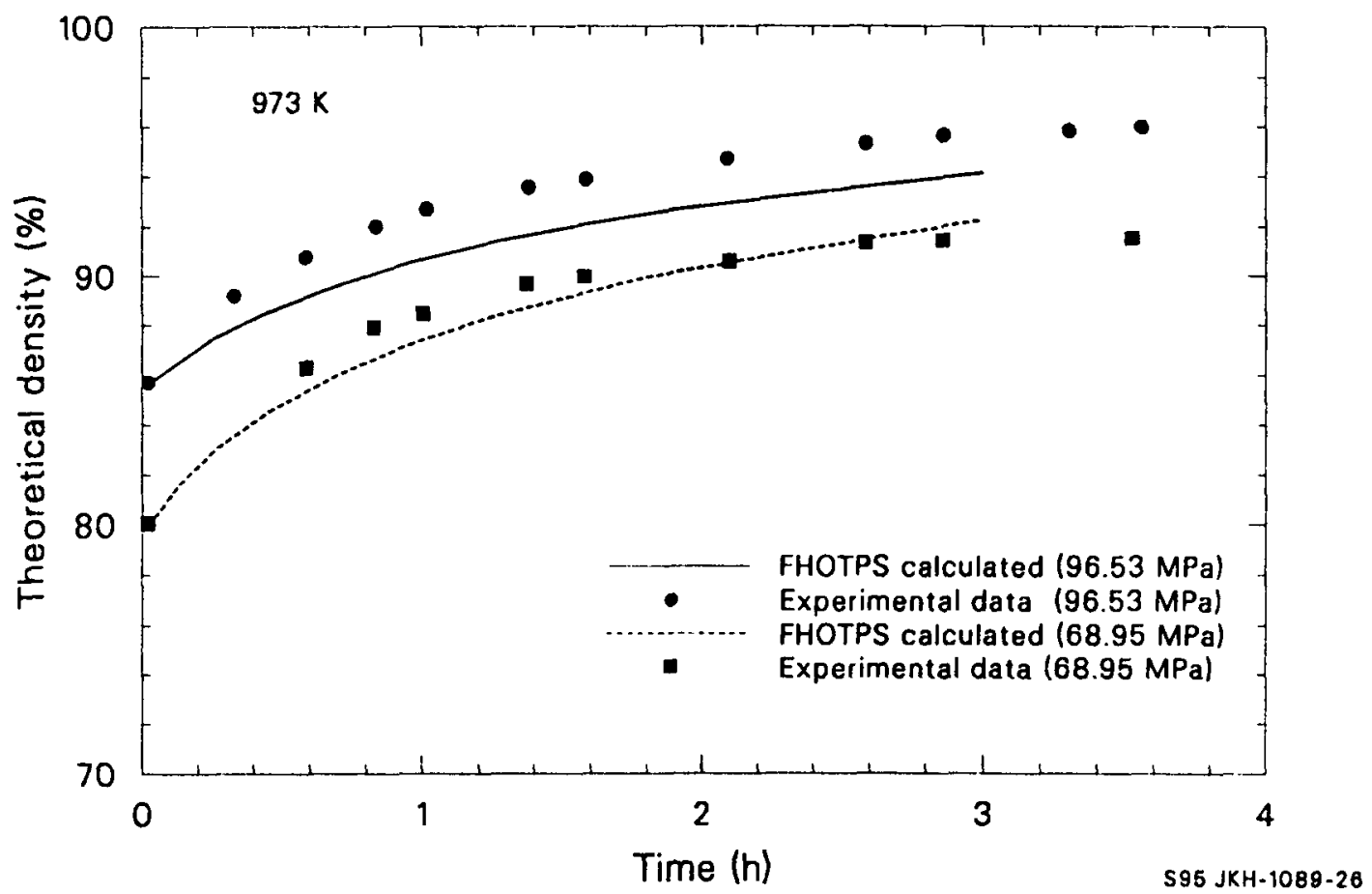

Figure 2.10-2. Mixed-oxide pressure sintering rates calculated using the FHOTPS model compared with data. 


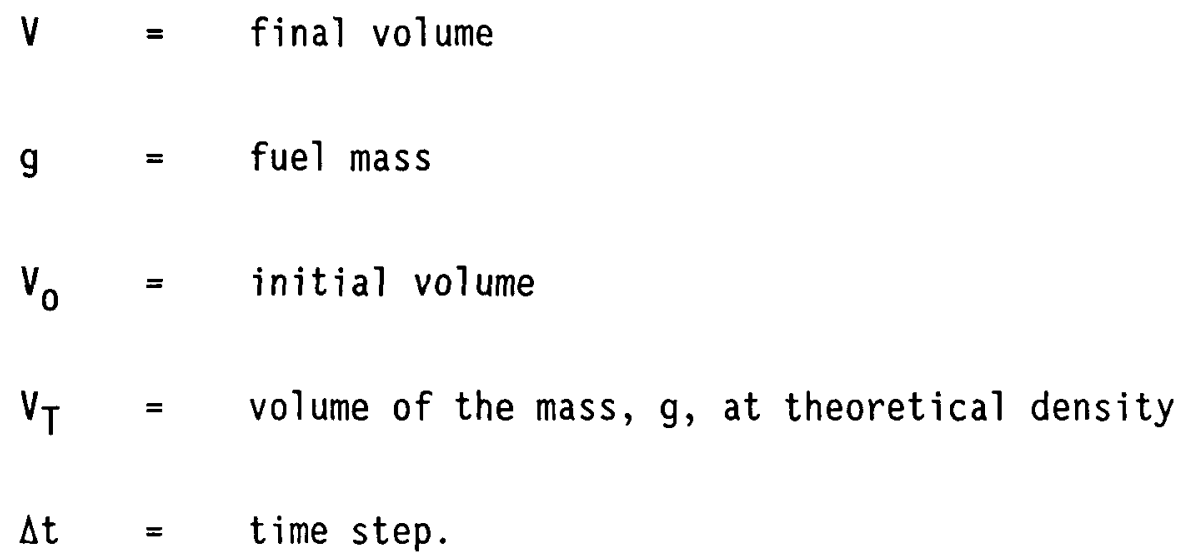

Eliminating $g$ and multiplying denominator and numerator by $V_{T}$ gives

$\frac{1}{\rho} \frac{\mathrm{d} \rho}{\mathrm{dt}}=\mathrm{V}_{\mathrm{T}}\left(\frac{V-V_{0}}{V V_{0}}\right) \frac{1}{\Delta \mathrm{T}}$

Assuming that $V_{T} \simeq V$, then Equation (2.10-13) relates a densification strain rate to a volume strain rate by

$\frac{1}{\rho} \frac{\mathrm{d} \rho}{\mathrm{dt}}=\left(\frac{V-V_{0}}{V_{0}}\right) \frac{1}{\Delta \mathrm{T}}$

This can be reduced to a linear strain rate by using the assumption that

$\frac{1}{3} \frac{\Delta V}{V_{0} \Delta T}=\frac{\Delta L}{L_{0}} \frac{1}{\Delta T}$

Equations (2.10-2) and (2.10-4) must be used with caution because the models are based on very 1 imited data. Both equations are based on one data set, and these data cover only a small portion of the temperatures, pressures, oxygen-to-metal ratios, and grain sizes possible in a reactor environment. An additional concern is that a significant change in any one of these parameters could result in a different creep mechanism. 
FHOTPS

\subsubsection{References}

2.10-1. A. A. Solomon, K. M. Cochran, J. H. Habermeyer, Modeling Hot-Pressing of $\mathrm{UO}_{2}$, NUREG/CR-PUR-2023, March 1981.

2.10-2. J. L. Routbort, J. C. Voglewede, D. S. Wilkinson, "Final-Stage Densification of Mixed Oxide Fuels, " Journal of Nuclear Materials, $80,1979, \mathrm{pp} .348-355$.

2.10-3. D. S. Wilkinson and M. F. Ashby, "The Development of Pressure Sintering Maps, "Proceedings of the Fourth International Conference on Sintering and Related Phenomena, May 26-28, 1975.

2.10-4. D. S. Wilkinson and M. F. Ashby, "Pressure Sintering by Power Law Creep," Acta Metallurgica, 23, November 1975.

2.10-5. R. A. Wolfe and S. F. Kaufman, Mechanical Properties of Oxide Fuels (LSBR/LWB) Development Program, WAPD-TM-58, October 1967.

2.10-6. R. C. Rossi and R. M. Fulrath, "Final Stage Densification in Vacuum Hot-Pressing of Alumina," Journal of the American Ceramic Society, 48,1965, pp. 558-564.

2.10-7. J. D. McCelland, Kinetics of Hot Pressing, NAA-SR-5591, 1961.

2.10-8. G. M. Fryer, "Hot Pressing of Alumina: A New Treatment of Final Densification," Transactions of the British Ceramics Society, 66, 1967, pp. 127-134.

2.10-9. M. S. Seltzer, A. H. Claver, B. A. Wilcox, "The Influence of Stoichiometry on Compression Creep of Uranium Dioxide Single Crystals," Journal of Nuclear Materials, 44, 1972, pp. 43-56.

2.10-10. M. S. Seltzer, et al., "A Review of Creep Behavior of Ceramic Nuclear Fuels," Reactor Technology, 14, 2, January 1971, pp. $99-135$.

2.10-11. M. S. Seltzer, A. H. Calver, B. A. Wilcox, "The Stress Dependence for High Temperature Creep of Polycrystalline Uranium Dioxide," Journal of Nuclear Materials, 34, 1970, pp. 351-353.

2.10-12. S. F. Kaufman, The Hot-Pressing Behavior of Sintered Low-Density Pellets of $\mathrm{UO}_{2}, \mathrm{ZRO}_{2}-\mathrm{UO}_{2}, \mathrm{THO}_{2}$ and $\mathrm{THO}_{2}-\mathrm{UO}_{2}$, WAPD-TM-751, May 1969.

2.10-13. I. Amato, R. L. Colombo, A. M. Petrucciolo Balzari, "Hot Pressing of Uranium Dioxide," Journal of Nuclear Materials, 20, 1966, pp. 210-214. 


\section{FHOTPS}

2.10-14. P. E. Hart, "Fabrication of High-Density $\mathrm{UO}_{2}$ and $\left(\mathrm{U}_{0}, 75\right.$ $\mathrm{Pu}_{2} \mathrm{25}_{2} \mathrm{O}_{2}$ by Hot Pressing, "Journal of Nuclear Materials, 51, 1974, pp. 199-202.

2.10-15. I. H. Warren and A. C. D. Chaklader, "Reactive Hot Pressing of Nonstoichiometric Uranium Dioxide, "Metallurgical Transactions, 1, 1970, pp. 199-205.

2.10-16. J. C. Voglewede, Reactor Development Program Progress Report, ANL-RDP-26, March 1974.

2.10-17. J. C. Voglewede, Reactor Development Program Progress Report, ANL-RDP-29, June 1974. 



\title{
FRESTR
}

\subsection{Restructuring (FRESTR)}

\author{
(R. E. Mason)
}

The morphology and structural integrity of oxide fuel changes while power is being produced in LWRs. These changes are a function of time, temperature, burnup, and energy density. These structural changes affect the effective fuel thermal conductivity, fuel swelling, fission gas release, and fuel creep. The structure of irradiated fuel can be grouped into four categories: as-fabricated unrestructured fuel, equiaxial grains which are enlarged fuel grains with all sides approximately the same length, columnar grains that have their long axes parallel to the radial temperature gradient, and shattered or desintered grains consisting of fuel grains which are fractured free of bonds to other grains during high-power transients. The physical processes which create restructured fuel and models to predict the modified fuel structures are discussed in the following sections.

\subsubsection{Summary}

The FRESTR subroutine is used to calculate equiaxial grain size, columnar grain size, and regions of fuel shattering during normal or transient reactor operation. Grain growth is driven by a potential difference across a curved grain boundary or by a temperature gradient, with the growth rate is controlled by the motion of impurities at the grain boundaries. Since impurities and migration mechanisms are probably the same in $\mathrm{UO}_{2}$ and $(\mathrm{U}, \mathrm{Pu}) \mathrm{O}_{2}$, the model described in the following paragraphs is assumed to apply for both fuel types.

The growth rate of equiaxial fuel grains is calculated using the expression 


\section{FRESTR}

$g=\left\{\frac{1.0269 \times 10^{-13} \mathrm{texp}(-35873.2 / T)}{\left(1.0+5.746 \times 10^{-6} B\right)^{2} T}+g_{0}^{4}\right\}^{1 / 4}$

where

$g=$ grain size at the end of a time interval (m)

$g_{0}=$ grain size at beginning of the time interval (m)

$\mathrm{t}=$ time interval(s)

$T=$ temperature $(K)$

$B=$ burnup (MWs $/ \mathrm{kg}$ ).

The standard error of Equation (2.11-1) with respect to its data base is $\pm 8.4 \times 10^{-6} \mathrm{~m}$.

Columnar grains form behind lenticular (large lens-shaped) pores, moving up the temperature gradient in the fuel at a rate given by the equation

$V=\frac{49.22 \nabla T \exp (-44980 / T)}{T^{2}}$

where

$$
\begin{aligned}
& V \quad=\quad \text { rate of pore movement }(\mathrm{M} / \mathrm{s}) \\
& \nabla T \quad=\text { temperature gradient }(\mathrm{K} / \mathrm{m}) \\
& T \quad=\text { temperature }(\mathrm{K}) .
\end{aligned}
$$


FRESTR

Columnar grain formation is characterized by a threshold temperature and temperature gradient. This threshold temperature is defined by the time, temperature, and temperature gradient combination required to move a grain boundary or bubble across one-tenth of the pellet diameter (approximately $0.0005 \mathrm{~m}$ ) during a time step. The long axis of a columnar grain is the smaller of the length of the pore migration during a time step or the distance to the center of the pellet.

Formation of shattered fuel is characterized in FRESTR by an integer switch, NSHATR, which is unity if the fuel is shattered and zero if the fuel is not shattered.

NSHATR $=1$ if $E \geq E_{0}$ and $T<T_{m}$ and columnar grains have not formed

NSHATR $=0$ if $E<E_{0}$ or $T>T_{m}$ or columnar grains have formed

where

$E=$ energy density deposited during a transient $\left(\mathrm{J} / \mathrm{m}^{3}\right)$

$E_{0}=$ energy density required to fracture the fuel at the grain boundaries $\left(\mathrm{J} / \mathrm{m}^{3}\right)$

$T_{m}=$ fuel melting temperature $(K)$

$T=$ fuel temperature $(K)$.

The energy density required to fracture the fuel at the grain boundaries is determined by the expression

$E_{0}=\frac{8.64 \times 10^{-14}}{g}(T-1673)$. 


\section{FRESTR}

The following paragraphs discuss restructuring data and the code development approach. Section 2.11.2 is a discussion of restructuring data. Section 2.11.3 describes the approach used to develop the FRESTR code. Section 2.11.4 is a list of references, and Section 2.11.5 is a bibliography of literature reviewed during code development but not referenced directly in text.

\subsubsection{Restructuring Data}

The FRESTR restructuring subcode is based on a fit of equation constants to data available in the literature. A complete data base requires both unirradiated isothermal and irradiated restructuring data, with accompanying well-documented temperature profiles. Unirradiated isothermal restructuring data are relatively easy to obtain, and a number of good data sets are available for the data base. Irradiated restructuring data with well-documented temperature and time histories, on the other hand, are difficult to obtain, especially at burnups above 20,000 MWd/t. The following paragraphs discuss data available in the open literature and the merits of those data for the FRESTR code data base.

The data of Ainscough, 2.11-1 Singh, 2.11-2 MacEwan, 2.11-3 Stehle, ${ }^{2.11-4}$ Brite, 2.11-5 and Freshley ${ }^{2.11-6}$ are useful for equiaxial grain growth model development. Data analysis published by Singh, Michels and Poeppe ${ }^{2.11-7}$ and 01dfield and Brown $2.11-8$ show surface diffusion as the mechanism controlling boundary migration; and data published by Gulden, 2.11-9 Williamson and Cornel1, 2.11-10 Brite, ${ }^{2.11-5}$ and Michels and Poeppel ${ }^{2.11-7}$ (for fission gas bubbles) show either volume diffusion or vapor transport as the controlling mechanism. Since no data unequivocally demonstrate which mechanism is controlling grain growth and since more available data indicate volume diffusion or vapor transport as the controlling mechanism, volume diffusion equations were used to develop the FRESTR code. A detailed discussion of the data sets used is contained in this section. 
Lenticular pore migration velocity data of Kawamata, 2.11-11 0ldfield and Brown, ${ }^{2.11-8}$ and Ronchi and Sari ${ }^{2.11-12}$ were used to develop the FRESTR columnar grain growth model. Other available data sets were used only qualitatively to determine specific mechanisms. These data sets are also discussed in this section. Lenticular pore migration data indicate that the probable diffusion mechanism controlling columnar grain growth rates is volume diffusion or vapor phase transport. Each mechanism results in a velocity migration rate equation of the form discussed in the model development section.

Ainscough ${ }^{2.11-1}$ conducted a thorough investigation of equiaxial grain growth in urania using samples with initial theoretical densities between $0.94 \%$ and $0.99 \%$, temperatures between 1273 and $1773 \mathrm{~K}$, and times up to 24 weeks $\left(1.45152 \times 10^{7} \mathrm{~s}\right)$. The densities and the $0 / \mathrm{M}$ ratios of the samples remained constant during testing and showed little grain growth at temperatures below $1500 \mathrm{~K}$. Above $1500 \mathrm{~K}$, the grain growth rate increased rapidly with increasing temperatures. Ainscough also reported some data from irradiated fuel that were received through personal communications. These data had burnup values approaching $14,000 \mathrm{MWd} / \mathrm{t}$ at temperatures representative of LWRs. Therefore, the Ainscough data were considered to be the best available for determining the effect of burnup or grain growth rates.

Singh 2.11-2 measured isothermal grain growth rates of urania at temperatures between 2073 and $2373 \mathrm{~K}$ for times up to $21 \mathrm{~h}(75600 \mathrm{~s})$. Equiaxial grains formed during their experiments, with no accompanying change in $0 / M$ ratio. Singh concluded from his data analys is that urania grain growth follows the cubic vapor transport law and determined pore sizes to be at equilibrium with the surface tension. He also observed test sample densities to decrease during the experiments. These observations suggest vapor-phase transport growth with a pore size-gas pressure equilibrium. 


\section{FRESTR}

MacEwan 2.11-3 measured grain growth of urania at constant temperatures between 1828 and $2713 \mathrm{~K}$ for times up to $700 \mathrm{~h}(2.52 \times$ $\left.10^{6} \mathrm{~s}\right)$. The MacEwan data are excellent for model development because of the long times and appropriate temperatures.

Stehle $\mathrm{e}^{2.11-4}$ reported grain growth measured at temperatures between 1823 and $2373 \mathrm{~K}$ and at times up to $120 \mathrm{~h}\left(4.32 \times 10^{5} \mathrm{~s}\right)$. These data are a) so an excellent source for the FRESTR data base.

Hausner ${ }^{2.11-13}$ studied grain growth while sintering green urania pellets (cold-pressed and unsintered) and grain growth in some presintered pellets. Grain-growth rates in presintered pellets were measured at temperatures between 2223 and $2853 \mathrm{~K}$. Sintering grain growth of green pellets is different than the grain growth being modeled in FRESTR, so the Hausner data were not used in the FRESTR data base.

Brite $2.11-5$ reported extensive $\mathrm{UO}_{2}$ densification, and Freshley2.11-6 reported mixed-oxide densification grain growth and porosity measurements in both isothermal and in-reactor environments. Although these data were useful for determining the effect of burnup on grain growth rate, they were less useful than desired because most of the data were obtained at temperatures where little grain growth occurs.

Eichenberg $2.11-14$ reported three grain growth data taken from samples at 2273, 2473 and $2573 \mathrm{~K}$ and annealed at these temperatures for $900 \mathrm{~s}$. These data were used as part of the FRESTR data base.

Runfors ${ }^{2.11-15}$ and Padden 2.11-16 measured grain growth in $\mathrm{UO}_{2}$ during sintering from green compacts. These data do not represent growth rates of final sintering or resintering pellets and are, therefore, of no value for FRESTR code development. 


\section{FRESTR}

Williamson and Corne112.11-10 observed bubble migration rates in single-crystal $\mathrm{UO}_{2}$. Although the FRESTR code does not consider pore velocities or rates for equiaxial grain growth, these observation are interesting in that they demonstrate possible migration mechanisms of pores or impurities that control the growth rate of equiaxial grains.

Data provided by Kawamata $2.11-11$ dealt with columnar grain formation. His results demonstrated that columnar grains are formed by pores migrating up a temperature gradient with migration velocities between $2.389 \times 10^{-9}$ and $4.0 \times 10^{-8} \mathrm{~m} / \mathrm{s}$.

Buescher and Meyer ${ }^{2.11-17}$ measured migration velocities of $3 \times 10^{-10} \mathrm{~m} / \mathrm{s}$ for helium gas bubbles in single-crystal urania. Their results were not useful for the FRESTR data base because intragranular bubbles do not control grain boundary movement.

0ldfield and Brown 2.11-8 published from experimental results lenticular pore migration velocities up to $1.5 \times 10^{-8} \mathrm{~m} / \mathrm{s}$ and columnar grain growth measurements. These data were used in the data base for the FRESTR grain growth model.

Michels and Poeppe $7^{2.11-7}$ measured migration velocities of fission gas bubbles and fission product inclusions in mixed oxides. The migration velocities of fission product inclusions were found to be dependent on the size of the inclusion. These data were used only to help define maximum and minimum migration rates.

Gulden ${ }^{2.11-9}$ measured bubble migration velocities at the equilibrium pressures of long-lived or stable fission gas species, using irradiated fuel with burnups of approximately $10^{26}$ fissions $/ \mathrm{m}^{3}\left(-3.0 \times 10^{25}\right.$ krypton and xenon atoms $/ \mathrm{m}^{3} \mathrm{UO}_{2}$ ). These data are interesting in that they show the probable bubble migration mechanism but were not useful for developing the detailed thermal gradient correlation for bubble migration contained in the FRESTR subcode. 


\section{FRESTR}

Ronchi and Sari2.11-12 measured lenticular pore migration rates and grain boundary migration rates at temperatures between 2200 and $3000 \mathrm{~K}$. These data were useful in developing the FRESTR subcode.

In-pile restructuring data from EG\&G Idaho, Inc. 2.11-18 to 2.11-20 and out-of-pile data from Argonne tests ${ }^{2.11-21}$ were all that are available on fuel shattering. These data were used to determine an approximate fuel shattering model in spite of the large uncertainty of the temperature.

\subsubsection{Mode1 Development}

An equiaxial grain growth and pore migration model based on theory and a fit of the data, was developed for use in the FRESTR subcode. Many of the material properties used in developing the theoretical equations are not well defined and are, therefore, included in the fitted constants. The theoretical derivation proves very beneficial in that the dependence of restructuring on temperature, time, power density, and impurity particle size can be determined.

The equiaxial and columnar grain growth equations are based on the equations developed in a paper by Shewman, 2.11-22 who considers three possible diffusion mechanisms: surface diffusion, volume diffusion, and vapor transport. These mechanisms describe the motion of impurities, bubbles, or inclusions on the grain boundaries that retard and control the motion of the grain boundaries. As discussed in the previous section, much of the data show volume diffusion as the controlling mechanism for grain boundary migration. The equation Shewman obtained for volume diffusion migration is

$V=\frac{\alpha D_{v} F_{a}}{T}$

where 


\section{FRESTR}

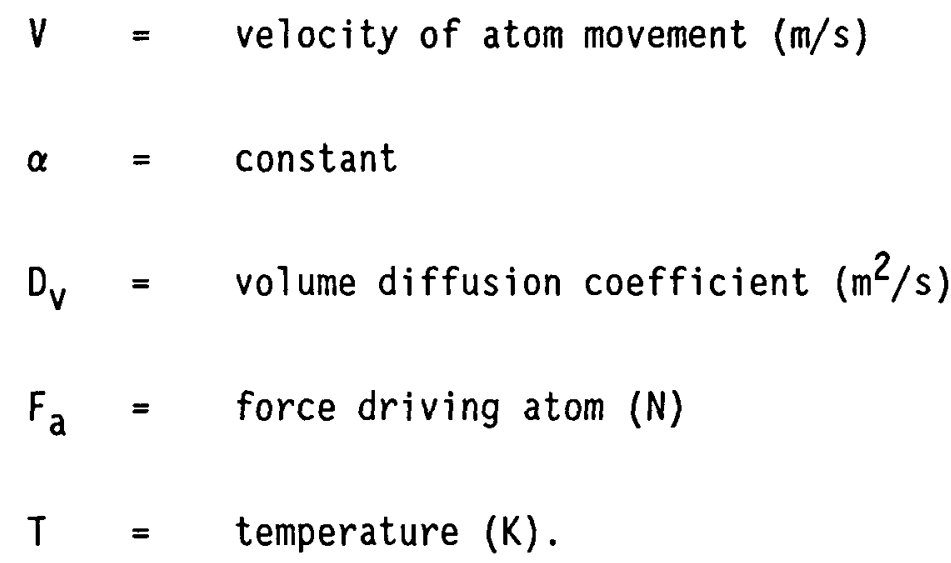

Equation (2.11-6) was used for columnar grain growth for the following reasons. The data discussed in Section 2.11.3 indicate volume diffusion or possibly vapor transport at constant pressure as the controlling mechanism for lenticular pores forming large columnar grains. Shewman 2.11-22 showed that an approach similar to that described previously for vapor transport produced an equation of the same form as Equation (2.11-6), thus making this equation proper assuming either mechanism.

The approach used by Nichols $\mathrm{s}^{2.11-23}$ and Shewman ${ }^{2.11-22}$ to relate the force on each atom to the force driving the entire bubble and grain boundary was used to further develop Equation (2.11-6) into a usable form, resulting in the following equation for equiaxial grain growth.

$$
\frac{d x}{d t}=\frac{\beta D_{v}}{r^{3} T}
$$

where

$$
\begin{aligned}
& x=\text { the migration distance }(\mathrm{m}) \\
& \mathrm{t}=\operatorname{time}(\mathrm{s}) \\
& \beta=\text { constant }
\end{aligned}
$$




\section{FRESTR}

$r=$ bubble radius $(m)$.

If the migration distance is assumed to be equal to the grain boundary migration distance and the particle radius is assumed to be proportional to the grain size and burnup, then

$r=\beta^{\prime}(1-\beta B) g$

where

$$
\begin{aligned}
\beta^{\prime}, \beta & =\text { constants } \\
B & =\text { burnup (MWs } / \mathrm{kg} \text { ) } \\
\mathrm{g} & =\text { grain size (m). }
\end{aligned}
$$

Substitution of Equation (2.11-8) into Equation (2.11-7) and use of a common temperature-dependent form for the volume diffusion constant results in the expression

$$
\frac{d g}{d t}=\frac{a D_{0} \exp (\theta / T)}{T(1-\beta B)^{2} g^{3}}
$$

where

$$
\begin{aligned}
& D_{0}=\text { diffusion coefficient }\left(\mathrm{m}^{2} / \mathrm{s}\right) \\
& \theta=\text { activation energy divided by the gas constant }(K) .
\end{aligned}
$$

Combining the equation constants and integrating gives the final form of the equiaxial grain growth equation

$$
g^{4}-g_{0}{ }^{4}=\frac{D \Delta t \exp (\theta / T)}{T(1-\beta B)^{2}}
$$


FRESTR

where

$$
\begin{aligned}
& g \quad=\text { final grain size }(m) \\
& g_{0}=\text { grain size at beginning of increment }(m) \\
& D=\text { constant. }
\end{aligned}
$$

The constants $D$ and $\theta$ of Equation (2.11-10) were determined by fitting the data of Singh, 2.11-2 MacEwan, 2.11-3 Stehle, 2.11-4 and Ainscough $2.11-1$ with $\beta=0$ (no irradiation). The constant $\beta$ was then determined by fitting the equation to the irradiation data of Ainscough. 2.11-1

The movement of columnar grains can be derived using Equation (2.11-6). For columnar grain growth, the grain boundary driving force is derived from a temperature gradient in the fuel. This analysis was done by Shewman, who obtained the following expression for the bubble velocity

$V=\frac{\operatorname{crT} \exp (\theta / T)}{T^{2}}$

where

$$
\begin{aligned}
& V=\text { pore migration velocity }(\mathrm{m} / \mathrm{s}) \\
& C=\text { constant } \\
& \nabla T=\text { temperature gradient }(\mathrm{K} / \mathrm{m}) .
\end{aligned}
$$

The constants in Equation (2.11-11) were then fit to the data of Ronchi and Sari,2.11-12 Michels and Poeppe12.11-7 (for upper and lower bounds), Buescher, 2.11-17 01dfield and Brown,2.11-8 and Kawamata.2.11-11 


\section{FRESTR}

Equation (2.11-11) was used to calculate the onset of columnar grain growth. An assumption, suggested by Nichols, ${ }^{2.11-24}$ that columnar grains form only if lenticular pores are able to migrate one-sixth of the pellet radius, was required to define columnar grain growth in the subcode. On the basis of this criterion, columnar grains form only if the migration distance per time step is greater than $0.0005 \mathrm{~m}$. If this criterion is not met, the grain size is determined by equiaxial grain size calculations and the columnar grain growth switch, NCOLGN, is set to zero. If columnar grains were formed in a previous time step, the preceding calculations are bypassed and NCOLGN remains unity. If columnar grains are formed, their length is the smaller of the migration distance during the time step or the distance from the ring edge to the center of the fuel pellet. Figure 2.11-1 shows typical columnar growth threshold as a function of time and temperature with an average temperature gradient of $4.0 \times 10^{5} \mathrm{~K} / \mathrm{m}$.

The model for fuel shattering is taken from a study of this effect by Cronenberg and Yackle, ${ }^{2.11-25}$ using data from the reactivity-initiated accident (RIA) tests by EG\&G Idaho and direct electrical heating tests by Argonne. They found the fuel shattered at the grain boundaries when the stress resulting from the deposited energy is greater than the fracture strength. Their expression for the energy density at fracture is

$$
E=\frac{8.64 \times 10^{-14}(T-1673)}{g}
$$

The FRESTR subcode uses Equation (2.11-12) to determine whether the fuel in the region of fuel being considered has fractured at the grain boundaries. If the input energy density is greater than $E$, the fuel temperature is less than melting, and columnar grains have not formed, the fuel is assumed to be shattered and the shattering parameter, NSHATR, is set to unity. 
FRESTR

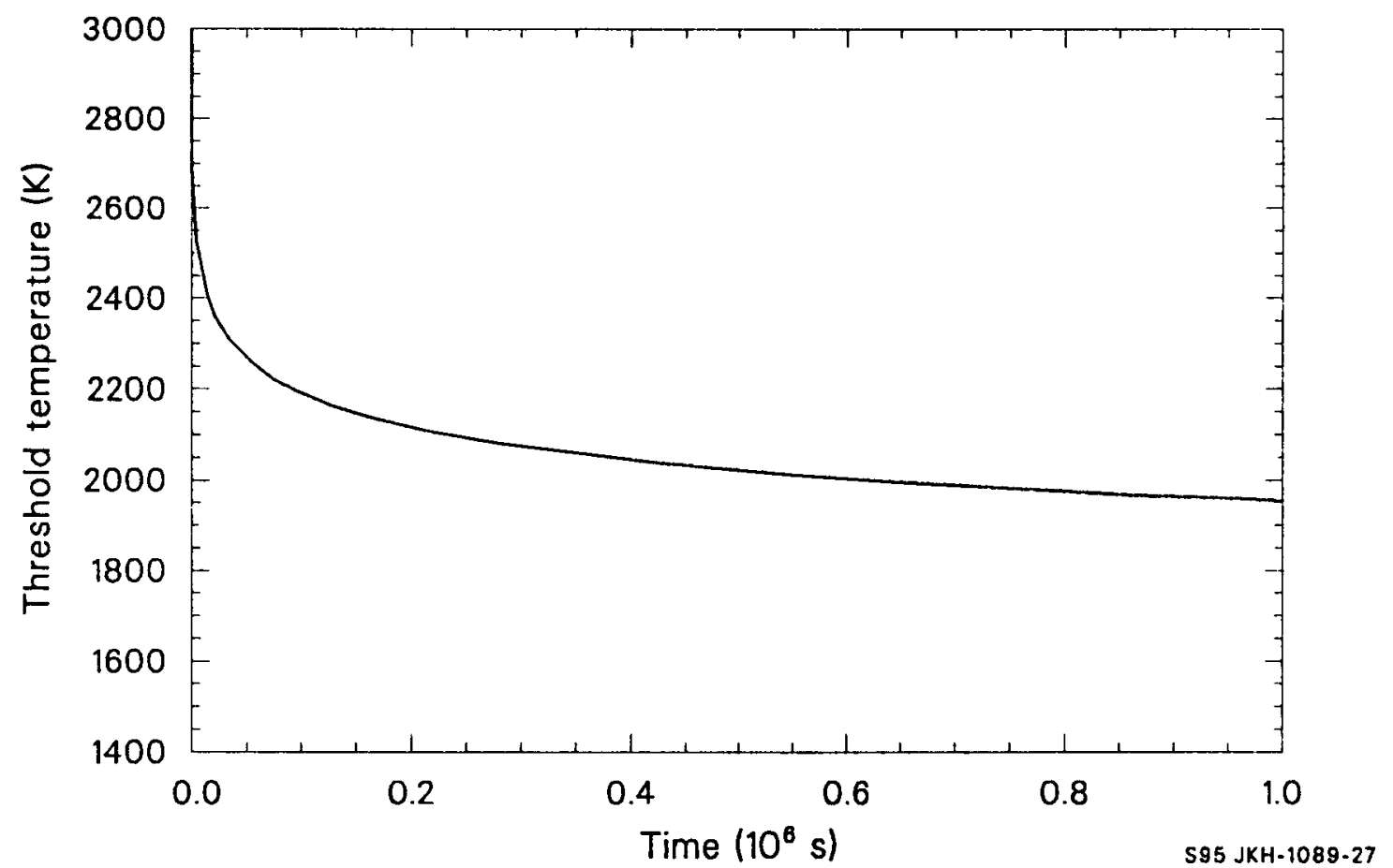

Figure 2.11-1. Threshold of columnar grain growth with temperature gradient of $4.0 \times 10^{5} \mathrm{~K} / \mathrm{m}$. 


\section{FRESTR}

\subsubsection{References}

2.11-1. J. B. Ainscough, B. W. 01dfield and J. 0. Ware, "Isothermal Grain Growth Kinetics in Sintered $\mathrm{UO}_{2}$ Pellets, "Journal of Nuclear Materials, 49, 1973/74, pp. 117-128.

2.11-2. R. N. Singh, "Isothermal Grain-Growth Kinetics in Sintered U0, Pellets," Journal of Nuclear Materials, 64, 1977, pp. 174-178.

2.11-3. J. R. MacEwan, Grain Growth in Sintered Uranium Dioxide, AECL-1184, 1961.

2.11-4. V. H. Stehle, "Kornwachstrum von $\mathrm{UO}_{2}, "$ Bericht der Deutschen Keramische Gesel7shaft, 1963, pp. 129-135.

2.11-5. D. W. Brite et al., EEI/EPRI Fuel Densification Project 131-Final Report, 1975.

2.11-6. M. D. Freshley et al., Plutonia Fuel Study, EPRI NP-637, 1978.

2.11-7. L. C. Michels and R. B. Poeppel, "In-Pile Migration of Fission Product Inclusions in Mixed-0xide Fuel," Journal of Applied Physics, 44, 1973.

2.11-8. W. 0ldfield and J. B. Brown, Jr., "Bubble Migration in $\mathrm{UO}_{2}-\mathrm{A}$ Study Using a Laser Image Furnace," Material Science and Engineering, 6, 1970, pp. 361-370.

2.11-9. M. E. Gulden, "Migration of Gas Bubbles in Irradiated Uranium Dioxide," Journal of Nuclear Materials, 23, 1967, pp. 30-36.

2.11-10. G. K. Williamson and R. M. Cornell, "The Behavior of Fission Product Gases in Uranium Dioxide," Journal of Nuclear Materials, 13, 1974, pp. 278-280.

2.11-11. H. Kawamata, H. Kaneko, H. Furuya, M. Koizumi, "Migration Rate of Lenticular Voids in $\mathrm{UO}^{2}$ Under the Influence of Temperature Gradient," Journal of Nuclear Materials, 68, 1977, pp. 48-53.

2.11-12. C. Ronchi and C. Sari, "Properties of Lenticular Pores in $\mathrm{UO}_{2}$, (U,Pu $\mathrm{O}_{2}$ " Journal of Nuclear Materials, 50, 1974, pp. 91-97.

2.11-13. H. Hausner, "UO, Grain Growth and Melting Studies," High Performance Quarterly Progress Reports, GEAP-3771-5, 3771-6, $3771-7,1962,1963$.

2.11-14. J. D. Eichenberg, Effects of Irradiation on Bulk $\mathrm{UO}_{2}$, WAPD-183, 1957. 
2.11-15. U. Runfors et al., "Sintering of Uranium Dioxide," Proceedings of 2nd International Conference on Peaceful Uses of Atomic Energy, 6, Paper P/142, September 1958, p. 605.

2.11-16. T. R. Padden, "Behavior of Uranium Oxide as a Reactor Fuel," Proceedings of 2nd International Conference on Peaceful uses of Atomic Energy, 6, Paper P/2404, September 1958, pp. 569-586.

2.11-17. B. J. Buescher and R. 0. Meyer, "Thermal Gradient Migration of Helium Bubbles in Uranium Dioxide," Journal of Nuclear Materials, 48,1973 , pp. 143-156.

2.11-18. P. E. MacDonald et al., Response of Unirradiated and Irradiated PWR Fuel rods Tested Under Power-Cooling-Mismatch Conditions, TREE-NUREG-1196, January 1978.

2.11-19. R. W. Garner et al., Gap Conductance Test Series-2, Test Results Report of Tests GC2-1, GC2-2, and GC2-3, NUREG/CR-0300, TREE-1268, 1978.

2.11-20. R. J. Buckland, C. E. White, and D. G. Abbott, Experimental Data Report for Test RIA 1-1 (Reactivity Initiated Accident Test Series), NUREG/CR-0516, TREE-1236, 1979.

2.11-21. R. G. Sachs and J. A. Kyger, Light-Water Reactor Safety Research Program: Quarterly Progress Report, ANL-77-59, Apri1-June 1977, pp. $76-111$.

2.11-22. P. G. Shewman, "The Movement of Small Inclusions in Solids by a Temperature Gradient," Transactions of the Metallurgical Society of AIME, 230, 1964.

2.11-23. F. A. Nichols, "Theory of Grain Growth in Porous Compacts," Journal of Applied Physics, 37, 1966, pp. 4599-4062.

2.11-24. F. A. Nichols, "Theory of Columnar Grain Growth and Central Void Formation in Oxide Fuel Rods, "Journal of Nuclear Materials, 22, 1977, pp. 214-222.

2.11-25. A. W. Cronenberg and T. R. Yackle, An Assessment of Intergranular Fracture Within Unrestructured $\mathrm{UO}_{2}$ Fuel Due to Film Boiling Operation, NUREG/CR-0595, TREE-1330, March 1979.

\subsubsection{Bibliography}

(1) W. L. Baldewicz, A. R. Wazzan, D. Okrent, "Grain Growth in Nuclear Fuels Containing Fission Gas," Transactions of the American Nuclear Society, 23, 1978. 
FRESTR

(2) P. F. Sens, "The Kinetics of Pore Movement in $\mathrm{UO}_{2}$ Fuel Rods," Journal of Nuclear Materials, 43, 1972, pp. 293-307.

(3) D. R. DeHalas and G. R. Horn, "Evolution of Uranium Dioxide Structure During Irradiation of Fuel Rods, "Journal of Nuclear Materials, 8, 1963, pp. 207-220.

(4) W. 0ldfield and A. J. Markworth, "Effects of Impurities on the Migration of Lenticular Pores in $\mathrm{UO}_{2}$," Scripta Metallurgica, 6, 1972, pp. 277-762.

(5) F. A. Nichols, "Pore Migration in Ceramic Fuel Elements, "Journal of Nuclear Materials, 27, 1968, pp. 137-146.

(6) F. A. Nichols, "Kinetics of Diffusional Motion of Pores in Solids," Journal of Nuclear Materials, 30, 1969, pp. 143-165.

(7) W. D. Whapman, "Electron Microscope Observation of the Fission Gas Bubble Distribution in $\mathrm{UO}_{2}$," Nuclear Applications, 2, 1966.

(8) W. Beere and G. L. Reynolds, "The Morphology and Growth of Interlinked Porosity in Irradiated $\mathrm{UO}_{2}, "$ Journal of Nuclear Materials, 47, 1973, pp. 51-57.

(9) M. V. Speight, "The Migration of Gas Bubbles in Materials Subject to a temperature Gradient, "Journal of Nuclear Materials, 13, 1964, pp. 207-209.

(10) F. A. Nichols, "Movement of Pores in Solids," Journal of Nuclear Materials, 19, 1969.

(11) J. R. MacEwan and V. B. Lawson, "Grain Growth in Sintered Uranium Dioxide: II, Columnar Grain Growth," Journal of the American Ceramic Society, 45, 1962.

(12) W. D. Kingery and B. Francois, "Grain Growth in Porous Compacts," Journal of the American Ceramic Society, 48, 1965.

(13) W. 0ldfield and A. J. Markworth, "The Theory of Bubble Migration Applied to Irradiated Materials, "Material Science and Engineering, 4, 1969, pp. 353-366.

(14) A. J. Markworth, "Growth Kinetics of Inert-Gas Bubbles in Polycrystalline Solids," Journal of Applied Physics, 43, 1972.

(15) D. R. DeHalas, "The Shape of Migrating Voids," Journal of Nuclear Materials, 23, 1967, pp. 118-120.

(16) J. A. Christensen, "In-Pile Void Migration in Uranium Dioxide," Transactions of the American Nuclear Society, 8, 1965, pp. 44-45. 


\section{FRESTR}

(17) J. A. Christensen, "Columnar Grain Growth in Oxide Fuels," Transactions of the American Nuclear Society, 15, 1972.

(18) M. F. Lyons, D. H. Coplin, B. Weidenbaum, Analysis of $\mathrm{UO}_{2}$ Grain Growth Data from "Out-of-Pile" Experiments, GEAP-4411, 1963.

(19) R. 0. Meyer and J. C. Voglewede, "Thermal Gradient Migration of Pores in $\mathrm{UO}_{2}, "$ Reactor Development Program Progress Report, ANL-7753, 1970.

(20) M. V. Speight and G. W. Greenwood, "Grain Boundary Mobility and Its Effect in Materials Containing Inert Gases," Philosophical Magazine, 9, 1964, pp. 683-688.

(21) J. A. Turnbul1, "The Mobility of Intragranular Bubbles in Uranium Dioxide During Irradiation, " Journal of Nuclear Materials, 62, 1976, pp. 325-328.

(22) K. Smidoda, W. Gottschalk, H. Gleifer, "Diffusion in Migrating Interfaces," Acta Metallurgica, 26, 1978, pp. 1833-1836. 

FFRACS

\subsection{Fracture Strength (fFracs)}

(C. S. 01 sen)

FFRACS calculates the $\mathrm{UO}_{2}$ fracture strength as a function of fuel temperature and fractional fuel density.

\subsubsection{Summary}

FFRACS calculates the fracture strength of $\mathrm{UO}_{2}$ as a function of fractional fuel density and temperature up to $1000 \mathrm{~K}$, the lowest temperature at which plasticity has been observed in-pile. For temperatures above $1000 \mathrm{~K}$, a constant value is used for the in-pile fracture strength of plastic $\mathrm{UO}_{2}$. The $\mathrm{UO}_{2}$ fracture model is given by the following equations:

For $273<\mathrm{T} \leq 1000 \mathrm{~K}$,

$\sigma_{\mathrm{F}}=1.7 \times 10^{8}[1-2.62(1-\mathrm{D})]^{1 / 2} \exp (-1590 / 8.314 \mathrm{~T})$

For $T>1000 \mathrm{~K}$,

$\sigma_{F}=\sigma_{F}(1000 \mathrm{~K})$

where

$\begin{aligned} \sigma_{f} & =\text { fracture strength }(\mathrm{Pa}) \\ D & =\text { fraction of theoretical density }\end{aligned}$ 


\section{FFRACS}

$\mathrm{T} \quad=$ temperature $(\mathrm{K})$

$\sigma_{\mathrm{F}}(1000 \mathrm{~K})=$ fracture strength found with $\mathrm{T}=1000 \mathrm{~K}$.

Equation (2.12-1) is based upon out-of-pile $\mathrm{UO}_{2}$ data and describes the behavior of brittle $\mathrm{UO}_{2}$. Because no in-pile measurements of fracture strength have been made, Equation (2.12-2) is based upon theoretical considerations and fragmentary out-of-pile data and applies to plastic $\mathrm{UO}_{2}$. The transition from brittle to ductile material is accompanied by a discontinuity in fracture strength and occurs at temperatures below the usual out-of-pile brittle-ductile transition temperature due to fission-induced plasticity. Equation $(2.12-1)$ has a standard deviation with respect to experimental data of $0.19 \times 10^{8} \mathrm{~Pa}$. The uncertainty in Equation (2.12-2) is not estimated because of lack of in-pile data.

\subsubsection{Out-of-Pile Uranium Dioxide Deformation}

The out-of-pile deformation of $\mathrm{UO}_{2}$ exhibits either elastic or elastic-plastic behavior. Elastic behavior is characterized by stress being linearly proportional to strain up to the fracture point. $2.12-1$ to 2.12-5 Elastic-plastic behavior is characterized by the stress-strain curve, which is initially elastic (to the elastic proportional limit) and which then exhibits plastic behavior. $2.12-1$ to $2.12-5$

2.12.2.1 Review of Out-of-Pile Uranium Dioxide Elastic Behavior Data and Theory. At temperatures below a ductile-brittle transition temperature, $\mathrm{T}_{\mathrm{c}}$, $\mathrm{UO}_{2}$ deforms elastically up to the fracture point. $2.12-1$ to 2.12-5 In such cases, the fracture strength, $\sigma_{F}$, is much less than the yield strength, $\sigma_{y}$, so that no yielding occurs prior to fracture. The fracture topography of near-theoretically dense $\mathrm{UO}_{2}$ exhibits the cleavage fracture mode of a brittle material. However, this fracture mode is affected by the amount of porosity and grain size, 


\section{FFRACS}

where, in general, the relative proportion of brittle-to-ductile fracture decreases with an increase in porosity and a decrease in grain size. ${ }^{2.12-6}$

The crack initiator $2.12-1,2.12-2,2.12-4,2.12-6$ has been suggested as the largest pore. The Griffith fracture theory $2.12-7$ can be applied to theoretically examine the parameters that affect the fracture strength. Griffith showed that the fracture stress or critical stress required to propagate an elliptical crack of length $2 c$ with an infinitely small radius of curvature is given by Equation (2.12-3):

$\sigma_{F}=\left(\frac{2 \mathrm{E} \gamma}{\pi c\left(1-\nu^{2}\right)}\right)^{1 / 2}$

where

$E=$ elastic modulus $(\mathrm{Pa})$

$\gamma \quad=\quad$ surface energy $\left(\mathrm{J} / \mathrm{m}^{2}\right)$

$c=$ crack length $(\mathrm{m})$

$\nu=$ Poisson's ratio (unitless) .

This equation applies to planar strain conditions and to an infinitely thick section of purely elastic material.

In Equation (2.12-3), the fracture strength is proportional to the square root of the elastic modulus, which, in turn, linearly decreases with porosity and temperature, as discussed in Section 2.6.1 of this report. Therefore, the fracture strength should decrease with increasing temperature. However, the fracture strength of $\mathrm{UO}_{2}$ has been observed to increase slightly with temperature. ${ }^{2} \cdot 12-2,2.12-4$ These measurements can be explained by the fact that $\gamma$ in Equation (2.12-3) probably increases 


\section{FFRACS}

with temperature ${ }^{2 \cdot 12-4}$ at a faster rate than the rate of decrease of $E$ with temperature.

Hasselman $2.12-8$ has shown that when a material contains numerous elliptical cracks of length $2 \mathrm{c}$ spaced a distance $2 \mathrm{~h}$ from each other, Equation (2.12-3) becomes for planar strain conditions

$\sigma_{F}=\left(\frac{E \gamma}{2\left(1-\nu^{2}\right) h}\right)^{1 / 2} \cot \left(\frac{\pi c}{2 h}\right)$

where the terms are previously defined.

Equation (2.12-4) and Equation (2.12-3) both predict a $\mathrm{UO}_{2}$ fracture strength that is dependent on porosity because of the effect of porosity on the elastic modulus. Equation (2.12-4) also predicts a crack spacing effect upon fracture strength, which, in turn, depends upon both the pore size and volume of porosity. A fracture strength dependence upon the pore morphology (size, shape, and distribution) has also been observed by Roberts and Ueda. $2.12-1$

2.12.2.2 Out-of-Pile Elastic Models. Experimental

$\operatorname{data}^{2} .12-1,2.12-2,2.12-6,2.12-9,2.12-10$ for fracture strength in the brittle region were fit to Equation (2.12-5) using a linear least-squares regression analysis [after reducing Equation (2.12-5) to a linear form] to determine the coefficients $A, m$, and $Q$

$\sigma_{F}=A[1-2.62(1-D)]^{1 / 2} G^{-m} \exp (-Q / R T)$

where

$G=$ grain size $(\mu \mathrm{m})$ 
$R=$ gas constant $(8.314 \mathrm{~J} / \mathrm{mol} \cdot \mathrm{K})$

and the other terms of the equation have been previously defined. The following values of $A, m$, and $Q$ were determined:

$$
\begin{aligned}
& A=1.70 \times 10^{8} \mathrm{~Pa} \\
& \mathrm{~m}=0.047 \\
& Q=1590 \mathrm{~J} / \mathrm{mol} .
\end{aligned}
$$

The expression $[1-2.62(1-D)]^{1 / 2}$ arises from the proportionality between $\sigma_{\mathrm{F}}$ and $\sqrt{ } \mathrm{E}$ in Equations (2.12-3) and (2.12-4) and the relation between $E$ and $D$ (see Section 2.6.1 of this report). The expression between fracture strength and grain size was based upon the suggestion of Orowan ${ }^{2} \cdot 12-11$ and Petch $2 \cdot 12-12$ and the data of Igata and Domoto, 2.12-13 which relate the strength of a material to $G^{-1 / 2}$. In general terms, this factor is written $G^{-m}$. The Boltzmann factor was selected to represent the temperature dependence. The effects of pore morphology have been ignored because of a lack of appropriate data. In Figure 2.12-1, Equation (2.12-5) is compared with experimental data normalized to a $10-\mu \mathrm{m}$ grain size and to $95 \%$ TD using Equation (2.12-5).

Knudsen ${ }^{2.12-14}$ proposed the following empirical equation relating fracture strength to grain size and porosity:

$\sigma_{F}=A G^{-m} \exp [-b(1-D)]$

where

$$
\begin{aligned}
1-D & =\text { porosity } \\
b & =\text { constant }
\end{aligned}
$$




\section{FFRACS}

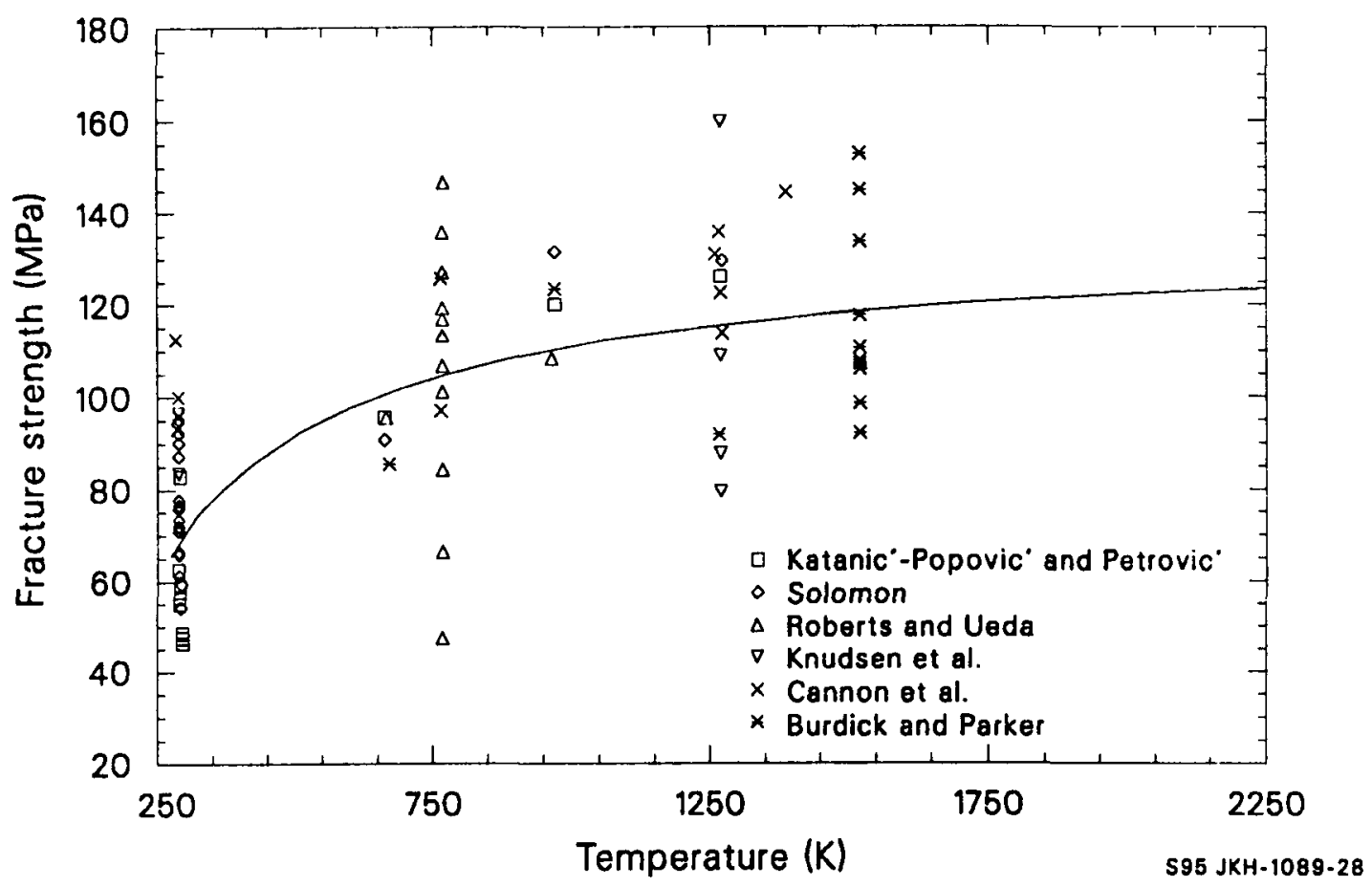

Figure 2.12-1. Comparison of Equation (2.12-5) in the elastic behavior regime with out-of-pile $\mathrm{UO}_{2}$ fracture strength data normalized to $10-\mu \mathrm{m}$ grain size and $95 \%$ TD. 


\section{FFRACS}

the other terms have been previously defined, and constants are given below.

Knudsen suggested that this relation describes the strength of chromium carbide and thoria reasonably well. This expression was fit to $\mathrm{UO}_{2}$ fracture strength data, except that the Arrhenius term from Equation (2.12-5) was added to provide a temperature-dependence. The resultant expression was reduced to a linear form; and a linear, multiple-variable regression analysis was used to determine the coefficients $A, m, b$, and $Q$. The results are:

$$
\begin{aligned}
& A=1.7108 \times 10^{8} \mathrm{~Pa} \\
& \mathrm{~m}=0.05136 \\
& \mathrm{~b}=2.412 \\
& Q=1649 \mathrm{~J} / \mathrm{mol} .
\end{aligned}
$$

Equation (2.12-6) is compared with experimental data in Figure 2.12-2.

Both Equations (2.12-5) and (2.12-6) indicate a very small effect of grain size upon the fracture strength. Values of $m$ on the order of 0.5 are expected theoretically; ${ }^{2} \cdot 12-11,2.12-12$ but values of 0.05 were obtained, indicating a very insignificant effect of grain size on $\mathrm{UO}_{2}$ fracture strength. Much scatter exists in the data with respect to Equations (2.12-5) and (2.12-6) and is attributed to differences in pore morphology not accounted for in these equations and al so not reported with the data.

In some cases, porosity has not been the initiator of cracks in $\mathrm{UO}_{2}$. Instead, silica or alumina2.12-15 precipitated at grain boundaries has considerably reduced the fracture strength, whereas small additions of titania increased the fracture strength of $\mathrm{UO}_{2} \cdot{ }^{2.12-9}$ These additions are not normally part of the fabrication process and were not considered in the $\mathrm{UO}_{2}$ fracture strength model. 


\section{FFRACS}

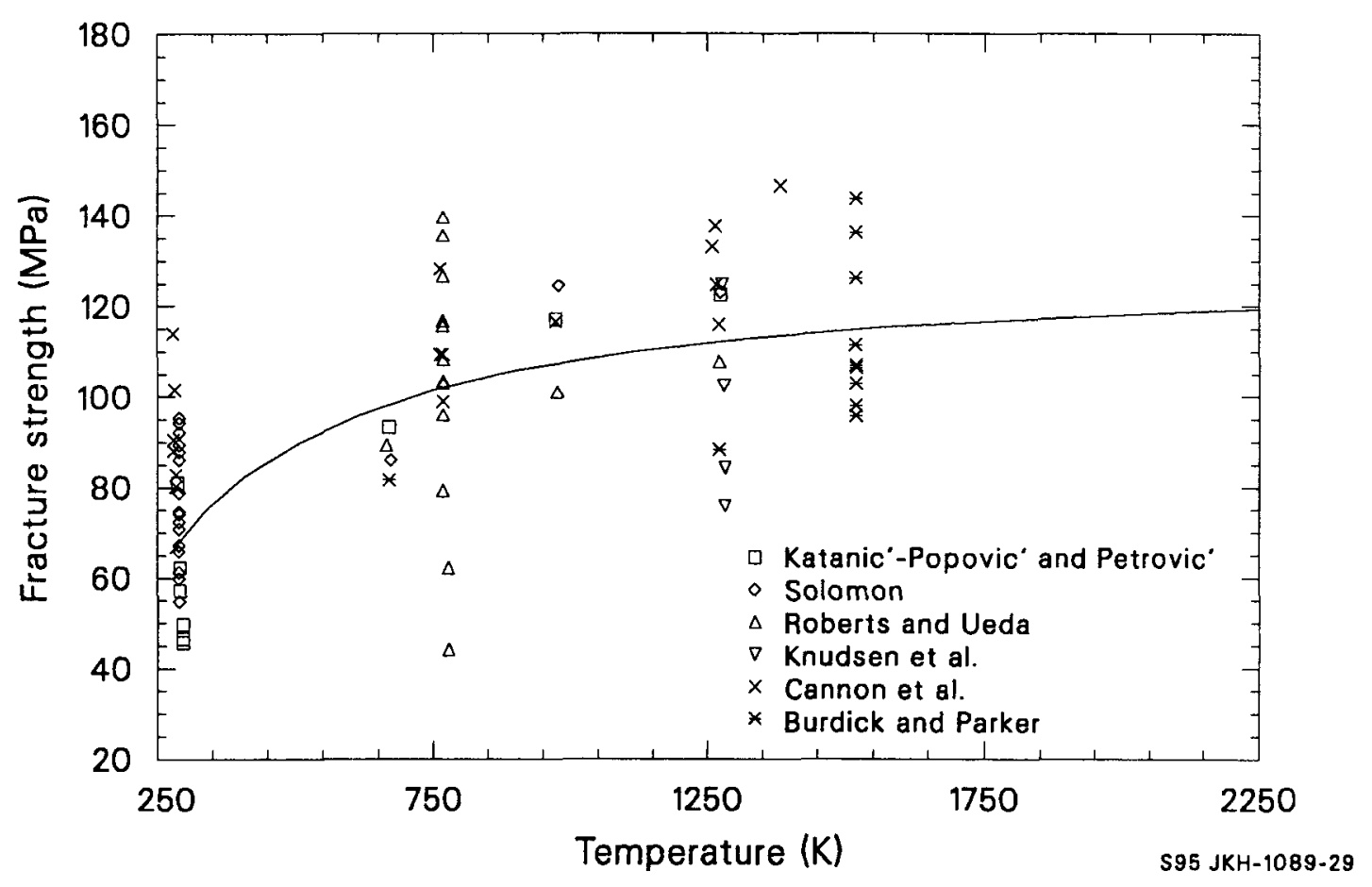

Figure 2.12-2. Comparison of Equation (2.12-6) in the elastic behavior regime with out-of-pile $\mathrm{UO}_{2}$ fracture strength data normalized to $10-\mu \mathrm{m}$ grain size and $95 \%$ TD. 
2.12.2.3 Out-of-Pile Transition Temperature. The transition temperature, $T_{c}$, is defined to be the temperature at which the stress-strain curve departs from (linear) elastic to plastic behavior. Density, grain size, and strain rate are expected to affect this transition temperature, but data are insufficient to obtain a precise relationship.

Cannon et al.2.12-2 reported out-of-pile transitions at 1100, 1375, and $1450^{\circ} \mathrm{C}$ for strain rates of $0.092,0.92$, and $9.2 / \mathrm{h}$, respectively, in material with an $8-\mu \mathrm{m}$ average grain size. Transitions at 1050 and $1100^{\circ} \mathrm{C}$ occurred for a strain rate of $0.092 / \mathrm{h}$ in material with $15-$ and 31- $\mu \mathrm{m}$ average grain sizes, respectively. Evans and Davidge $2.12-4$ reported transition temperatures of 1200 and $1300^{\circ} \mathrm{C}$ for $8-$ and $25-\mu \mathrm{m}$ materials. A transition temperature of $1250^{\circ} \mathrm{C}$ is assumed for FFRACS, since that is the midpoint of the $1050-$ to $-1450^{\circ} \mathrm{C}$ range.

2.12.2.4 Out-of-Pile Uranium Dioxide Elastic-Plastic Behavior. At temperatures above the transition temperature, the deformation of $\mathrm{UO}_{2}$ exhibits plastic behavior after some elastic deformation has occurred. The fracture mode is mostly intergranular, and a significant contribution to the deformation arises from grain boundary sliding. Figure 2.12-3 shows the fracture strength of $\mathrm{UO}_{2}$ as a function of temperature. At temperatures above $T_{c}$, the ultimate tensile strength decreases with increasing temperature. The effect of strain rate is significant, but the effect of grain size is negligible for grain sizes up to about $30 \mu \mathrm{m}$. Strain rate effects and grain boundary sliding strongly suggest that creep plays a dominant role at these temperatures. When the creep rate for a given temperature is nearly the same order of magnitude as the strain rate, stress relaxation reduces the fracture stress. This effect is shown in Figure 2.12-3 by the increase in fracture strength with the increase in strain rate. 


\section{FFRACS}

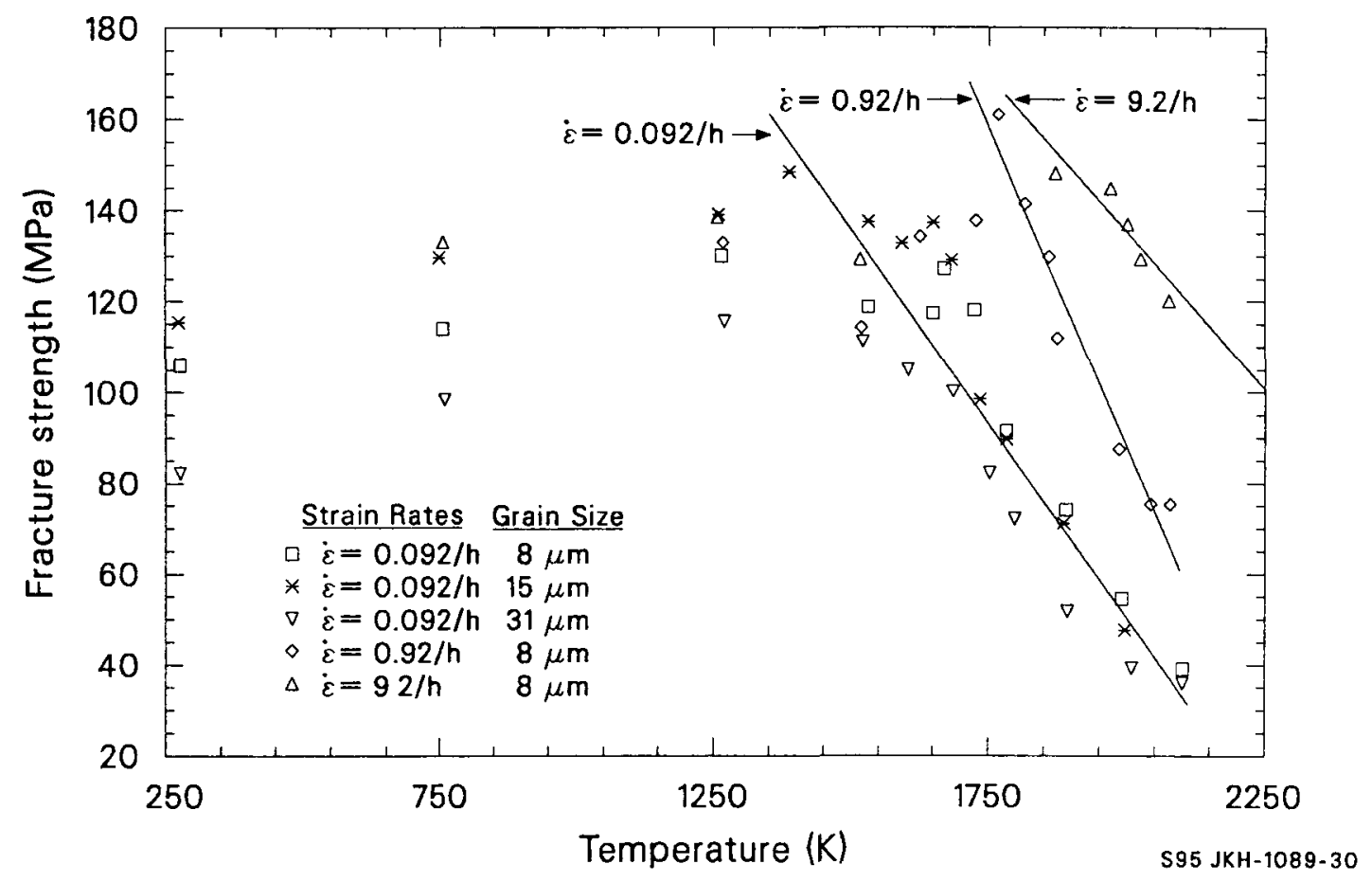

Figure 2.12-3. Least-squares regression fit of $\mathrm{UO}_{2}$ fracture strength in the elastic-plastic regime to out-of-pile data of Cannon et al. 


\section{FFRACS}

\subsubsection{Uranium Dioxide Fracture Strength Model}

Irradiation substantially reduces the ductile-brittle transition temperature. As discussed in Section 7 , in-pile creep measurements show that plasticity exists in $\mathrm{UO}_{2}$ at temperatures as $1 \mathrm{OW}$ as $1000 \mathrm{~K} . \mathrm{UO}_{2}$ is assumed to be brittle below this temperature, and Equation (2.12-5) (without the grain size term) is selected for the low-temperature fracture strength model for $\mathrm{VO}_{2}$. Equations (2.12-5) and (2.12-6), each with a standard deviation of about $1.9 \times 10^{7} \mathrm{~Pa}$, predict the experimental out-of-pile fracture strength about equally well; but Equation (2.12-5) has more theoretical foundation.

Above $1000 \mathrm{~K}$, irradiation and thermal effects enhance the plasticity of $\mathrm{UO}_{2}$ so that a decrease in fracture strength with increasing temperature may not occur. A strain rate effect may also exist, but the experimental data available are not sufficient to quantify a strain rate effect. Therefore, the in-pile fracture strength for plastic $\mathrm{UO}_{2}$ at temperatures higher than $1000 \mathrm{~K}$ is taken to be that found with the low-temperature correlation at $1000 \mathrm{~K}$. This ensures calculational continuity between the two correlations.

The in-pile $\mathrm{UO}_{2}$ fracture strength model is summarized by Equations $(2.12-1)$ and $(2.12-2)$.

Equation (2.12-1) can be used for temperatures up to about $1323 \mathrm{~K}$ for out-of-pile use. The predictions of FFRACS for two different fuel densities as a function of temperature are shown in Figure 2.12-4.

\subsubsection{References}

2.12-1. J. T. A. Roberts and Y. Ueda, "Influence of Porosity on Deformation and Fracture of $\mathrm{UO}_{2}$," Journal of the American Ceramic Society, $55,3,1972$, pp. $117-124$. 


\section{FFRACS}

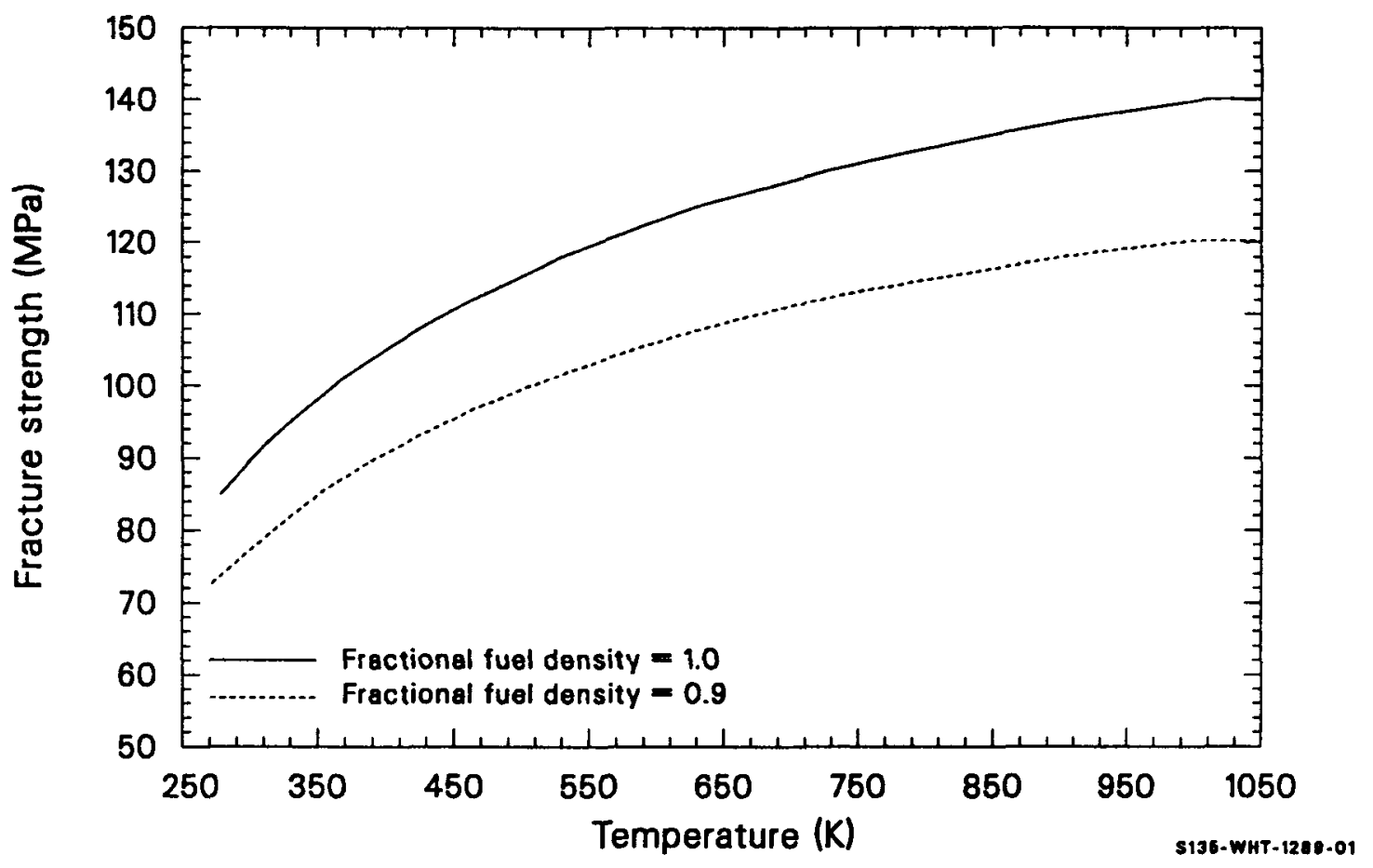

Figure 2.12-4. Calculated curves showing the predictions of FFRACS as a function of temperature for two fuel densities. 
2.12-2. R. F. Cannon, J. T. A. Roberts, R. J. Beals, "Deformation of $\mathrm{UO}_{2}$ at High Temperatures," Journal of the American Ceramic Society, 54, 1971, pp. 105-112.

2.12-3. Y. Guerin, "Etude par Compression a Hautes Temperatures de la Deformation Plastique du Bioxyde d'Uranium Polycristall in," Journal of Nuclear Materials, 56, 1975, pp. 61-75.

2.12-4. A. G. Evans and R. W. Davidge, "The Strength and Fracture of Stoichiometric Polycrystalline $\mathrm{UO}_{2}$," Journal of Nuclear Materials, 33, 1969, pp. 249-260.

2.12-5. C. R. Tottle, Mechanical Properties of Uranium Compounds, ANL-7070, November 1965.

2.12-6. J. Katanic'-Popovic' and V. Petrovic', "Strength Dependence on Microstructure Characteristics of Sintered $\mathrm{UO}_{2}$," Physics Sintering, 5, 2, 1973, pp. 95-105.

2.12-7. A. Tetelman and A. McEvily, Jr., Fracture of Structural Materials, New York: John Wiley and Sons, 1967, p. 53.

2.12-8. D. Hasselman, "Analysis of the Strain at Fracture of Brittle Solids with High Densities of Microcracks, "Journal of the American Ceramic Society, 52, 1969, pp. 458-459.

2.12-9. F. P. Knudsen, H. S. Parker, and M. D. Burdick, "Flexural Strength of Specimens Prepared from Several Uranium Dioxide Powders: Its Dependence on Porosity and Grain Size and the Influence of Additions of Titania," Journal of the American Ceramic Society, 43, 1960, pp. 641-647.

2.12-10. M. C. Burdick and H. S. Parker, "Effect of Particle Size on Bulk Density and Strength Properties of Uranium Dioxide Specimens," Journal of the American Ceramic Society, 39, 1956, pp. 181-187.

2.12-11. E. Orowan, "Die Erhohte Festigkeit Dunner Faden, die Joffe-Effekt, und Verwandte Erscheinungen vom Standpunkt der Griffithschen Bruchtheorie," Zeitschrift Fuer Physik, 3/4, pp. 195-213.

2.12-12. N. J. Petch, "Cleavage Strength of Polycrystals," Journal of the Iron Steel Institute, 174, Part I, 1953, pp. 25-28.

2.12-13. N. Igata and K. Domoto, "Fracture Stress and Elastic Modulus of Uranium Dioxide Including Excess Oxygen, "Journal of Nuclear Materials, 45, 1972/73, pp. 317-322.

2.12-14. F. P. Knudsen, "Dependence of Mechanical Strength of Brittle Polycrystalline Specimen on Porosity and Grain Size, "Journal of the American Ceramic Society, 42, 1959, pp. 376-387. 


\section{FFRACS}

2.12-15. A. A. Solomon, "Influence of Impurity Particles on the Fracture of $\mathrm{UO}_{2}$," Journal of the American Ceramic Society, 55, 1972, pp. $622-627$. 
FVISCO

\subsection{Viscosity (FVISCO) \\ (C. S. Watson and D. L. Hagrman)}

The function FVISCO calculates the dynamic viscosity of $\mathrm{UO}_{2}$. The viscosity is one of the parameters needed to model the motion of fuel during severe core damage.

The effects of departure from stoichiometry and the range of temperatures where liquid and solid $\mathrm{UO}_{2}$ can coexist are not modeled. Also, the model does not consider any possible contamination of the molten $\mathrm{UO}_{2}$. Uncertainty estimates are provided based on the data used in the model.

\subsubsection{Summary}

Viscosity of $\mathrm{UO}_{2}$ is modeled as a function of temperature, melting temperature (solidus), and the fraction of the fuel that has liquefied. Input arguments describing the oxygen-to-metal ratio and $\mathrm{PuO}_{2}$ content are not used in the current correlations for viscosity.

Viscosity is calculated by one of three equations, depending on whether the temperature is below the melting point for $\mathrm{UO}_{2}$, in the range of temperatures where liquid and solid $\mathrm{UO}_{2}$ can coexist, or above this range.

The equation used to model the viscosity of completely liquefied fuels is

$\eta_{e}=1.23 \times 10^{-2}-2.09 \times 10^{-6} \mathrm{~T}$ 


\section{FVISCO}

where

$$
\begin{aligned}
& \eta_{e}=\text { dynamic viscosity of the liquid }(\mathrm{Pa} \cdot \mathrm{s}) \\
& T \quad=\text { temperature }(\mathrm{K}) .
\end{aligned}
$$

For solid $\mathrm{UO}_{2}$, the viscosity is modeled with the expression

$$
\eta_{S}=1.38 \exp \left(4.942 \times 10^{4} / \mathrm{T}\right)
$$

where $\eta_{S}$ is the dynamic viscosity of the $\mathrm{UO}_{2}$ for temperatures below melting $(\mathrm{Pa} \cdot \mathrm{s})$.

In the temperature range where 1 iquid and solid $\mathrm{UO}_{2}$ phases can both exist, the viscosity is modeled with the expression

$$
\eta=\eta_{\mathrm{S}}(1-f)+\eta_{e} f
$$

where

$\eta=$ dynamic viscosity of the liquid-solid mixture $(\mathrm{Pa} \cdot \mathrm{s})$

$f=$ fuel fraction that is liquid (unitless).

The estimated uncertainty of the values computed with Equations (2.13-1) to (2.13-3) is computed with the FVISCO subcode but not returned as an output argument. The expressions used for this uncertainty are

$U=\eta A(1+|Y-2|)$

where

$$
U=\text { estimated uncertainty }(\mathrm{Pa} \cdot \mathrm{s})
$$


$A=0.33$ for temperatures above melting 0.67 for temperatures below melting

$Y=$ oxygen-to-metal ratio of the fuel (unitless).

Details of the development of the fuel viscosity model used in the FVISCO function are presented in the following sections. Section 2.13.2 is a review of the data, and Section 2.13.3 is a discussion of the model development.

\subsubsection{Fuel Viscosity Data}

Viscosities for solid $\mathrm{UO}_{2}, \mathrm{UO}_{2.06}$, and $\mathrm{UO}_{2.15}$ have been reported by Scott, Hall, and Williams.2.13-1 Viscosities for the nonstoichiometric oxides are lower than the viscosity of $\mathrm{UO}_{2}$ at corresponding temperatures and could be measured over a sufficient range to establish the following relation for nonstoichiometric $\mathrm{UO}_{2}$ :

$g_{S}=A \exp (-B / T)$

where $A$ and $B$ are material constants. The viscosity of $\mathrm{UO}_{2}$ was determined to be $2 \times 10^{11} \mathrm{~Pa} \cdot \mathrm{s}$ at $1923 \mathrm{~K}$ and to be in excess of $10^{17} \mathrm{~Pa} \cdot \mathrm{s}$ at $1273 \mathrm{~K}$.

Viscosity data at much higher temperatures were obtained by Nelson. 2.13-2,2.13-3 An early measurement (0.145 $\mathrm{Pa} \cdot \mathrm{s}$ at a temperature of $3028 \mathrm{~K}$ ) was reported to correspond to incomplete melting of the sample. Subsequent data $(0.045 \mathrm{~Pa} \cdot \mathrm{s}$ at $3028 \mathrm{~K}$ and 0.036 at $3068 \mathrm{~K})$ represent a viscous fluid at temperatures below the melt temperature used in this report. ${ }^{a}$ These data are not suitable for use in the viscosity model

a. The melt temperature for $\mathrm{UO}_{2}$ is given as $3113 \mathrm{~K}$ in the PHYPRP subcode of the MATPRO package. 


\section{FVISCO}

because all three measurements have indicated viscosities well above the more extensive viscosity measurements at temperatures where the $\mathrm{UO}_{2}$ is known to be completely liquefied.

Two useful sources of data with completely molten $\mathrm{UO}_{2}$ were available. Tsai and 01 ander $2.13-4$ published data from two samples, and Woodley2.13-5 published more extensive data from a single sample. The data are tabulated in Tables 2.13-1 and 2.13-2 and plotted in Figure 2.13-1. The precision of the data by Woodley is noticeably higher than the precision of the other data, but there is a larger difference between the two experiments than can be explained by random measurement error. This difference is discussed by Woodley, but no definite reason for it was found. The model developed in the next section therefore contains the assumption that the difference between the data of Tsai and 01 ander and the data of Woodley is caused by some material parameter that has not been considered (oxygen-to-metal ratio, for instance).

\subsubsection{Model Development and Uncertainty}

The correlation for the viscosity of $\mathrm{UO}_{2}$ below the melt temperature was obtained by solving Equation (2.13-5) for the values of the two material constants that reproduce the viscosity measured by Scott, Hall, and Williams at $1273 \mathrm{~K}$ and the minimum viscosity reported by these authors for $\mathrm{UO}_{2}$ at $1273 \mathrm{~K}$. The fact that this procedure produces only a crude engineering estimate of viscosity is expressed by assigning a large fractional uncertainty, two thirds, to the predicted viscosity of solid $\mathrm{NO}_{2}$.

Equation (2.13-1), the correlation for viscosity of liquid $\mathrm{UO}_{2}$, was obtained from the data of Tsai and 01 ander and the data of Woodley. The less precise data of Tsai and 01 ander were used because Woodley used only one sample and the viscosities measured by Tsai and 01 ander with their samples differ from Woodley's data by more than the scatter of their measurements. 
Table 2.13-1. $\mathrm{UO}_{2}$ viscosity data from Tsai and 0lander 2.13-4

\begin{tabular}{ccc}
\hline & $\begin{array}{c}\text { Temperature } \\
(\mathrm{K})\end{array}$ & $\begin{array}{c}\text { Viscosity } \\
(\mathrm{Pa} \cdot \mathrm{s})\end{array}$ \\
\cline { 2 - 3 } Sample 1 & 3153 & 0.00583 \\
& 3153 & 0.00739 \\
& 3153 & 0.00594 \\
& 2333 & 0.00514 \\
& 3113 & 0.00628 \\
& 3113 & 0.00686 \\
& 3173 & 0.00762 \\
& 3083 & 0.00921 \\
& 3188 & 0.00869 \\
& 3188 & 0.00771 \\
& 3138 & 0.00781 \\
& 3328 & 0.00602 \\
& 3328 & 0.00602 \\
& 3328 & 0.00765 \\
& 3248 & 0.00808 \\
& 3248 & 0.00682 \\
\hline
\end{tabular}




\section{FVISCO}

Table 2.13-2. $\mathrm{UO}_{2}$ viscosity data from Woodley $2.13-5$

\begin{tabular}{|c|c|}
\hline $\begin{array}{c}\text { Temperature } \\
\text { (K) }\end{array}$ & $\begin{array}{c}\text { Viscosity } \\
(\mathrm{Pa} \cdot \mathrm{s}) \\
\end{array}$ \\
\hline $\begin{array}{l}3143 \\
3148 \\
3148 \\
3193 \\
3193 \\
3193 \\
3258 \\
3258 \\
3258 \\
3213 \\
3213 \\
3218 \\
3178 \\
3183 \\
3183 \\
3163 \\
3163 \\
3163 \\
3158 \\
3158 \\
3163 \\
3198 \\
3208 \\
3198 \\
3263 \\
3263 \\
3263 \\
3298 \\
3298 \\
3303 \\
3273 \\
3273 \\
3273 \\
3218 \\
3213 \\
3218 \\
3178 \\
3178 \\
3178\end{array}$ & $\begin{array}{l}0.00425 \\
0.00365 \\
0.00326 \\
0.00441 \\
0.00434 \\
0.00444 \\
0.00420 \\
0.00417 \\
0.00415 \\
0.00426 \\
0.00428 \\
0.00427 \\
0.00432 \\
0.00436 \\
0.00434 \\
0.00424 \\
0.00420 \\
0.00423 \\
0.00418 \\
0.00428 \\
0.00425 \\
0.00417 \\
0.00418 \\
0.00419 \\
0.00399 \\
0.00405 \\
0.00402 \\
0.00398 \\
0.00395 \\
0.00394 \\
0.00399 \\
0.00398 \\
0.00397 \\
0.00409 \\
0.00406 \\
0.00404 \\
0.00412 \\
0.00406 \\
0.00413\end{array}$ \\
\hline
\end{tabular}


FVISCO

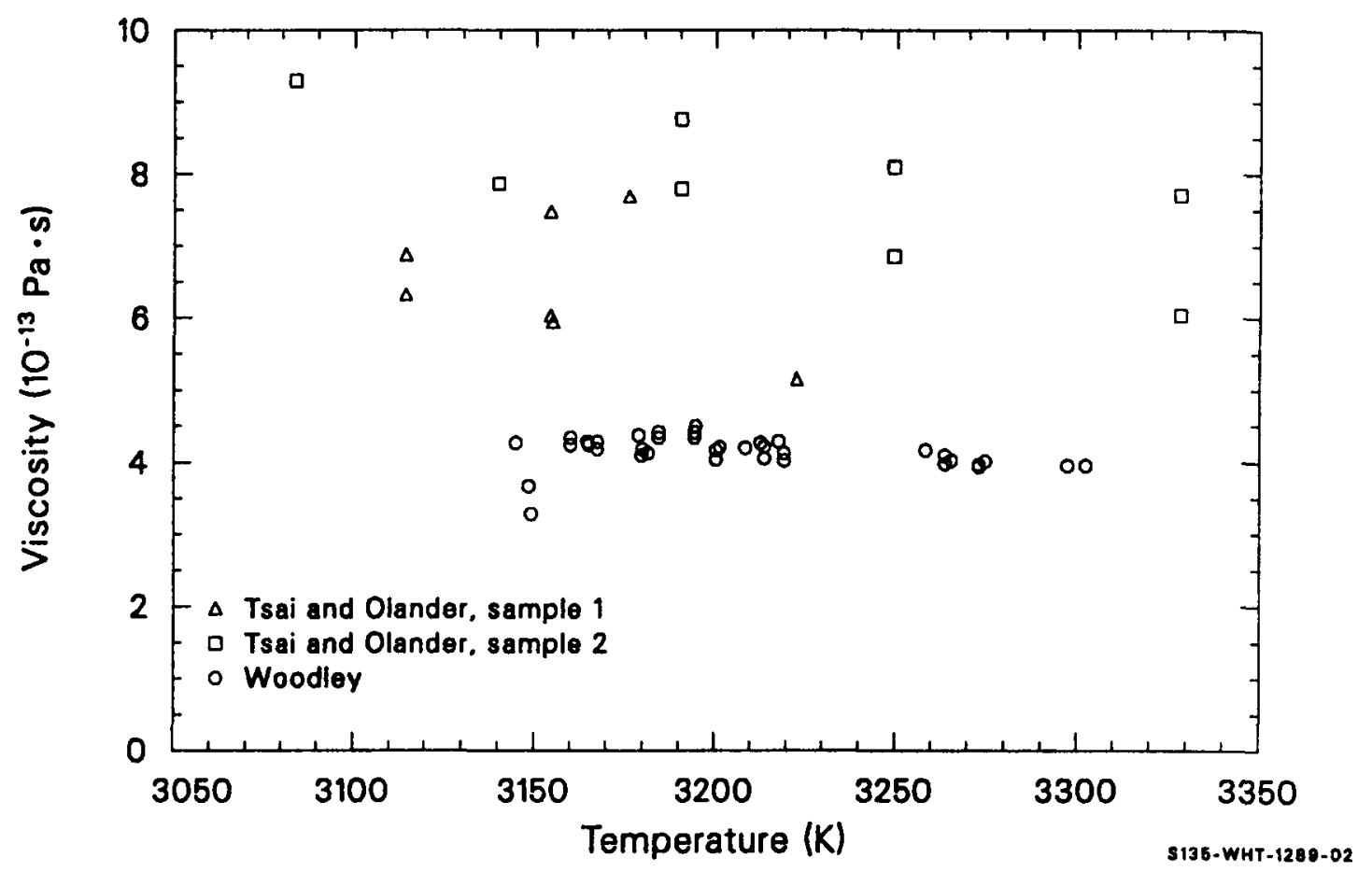

Figure 2.13-1. Uranium dioxide viscosities measured as a function of temperature. 


\section{FVISCO}

The traditional Arrhenius relation (Equation 2.13-5) was not used to correlate the liquid viscosities because a simpler linear expression fits the data as well as the exponential form. A linear least-squares fit to the data of Woodley (with the two anomalously low viscosities at $3148 \mathrm{~K}$ omitted) produced the equation

$\eta_{e}=1.09 \times 10^{-2}-2.09 \times 10^{-6} \mathrm{~T}$

The data of Tsai and 01 ander yielded the following correlation

$\eta_{e}=1.60 \times 10^{-2}-2.77 \times 10^{-6} \mathrm{~T}$

The viscosities predicted by Equations (2.13-6) and (2.13-7) are compared with the data in Figure 2.13-2. By inspection of this figure, it was concluded that the best mathematical description of the difference in the viscosities measured for the different lots of $\mathrm{UO}_{2}$ is to assume that the viscosities of the two different lots differ by an additive constant. ${ }^{a}$

In order to recognize the more precise measurements of Woodley, yet account for the probable lot-to-lot variation indicated by the data of both authors, the least-squares fit to the data of Tsai and 01 ander was repeated with the added constraint that the slope of the correlation match the slope obtained from the data of Woodley. The resultant correlation for the data of Tsai and 01 ander is

$\eta_{e}=1.38 \times 10^{-2}-2.09 \times 10^{-6} \mathrm{~T}$

a. The interpretation corresponds to the assumption mentioned at the end of Section 2.13.2; the difference in viscosities is caused by some unknown material parameter of the $\mathrm{UO}_{2}$. 


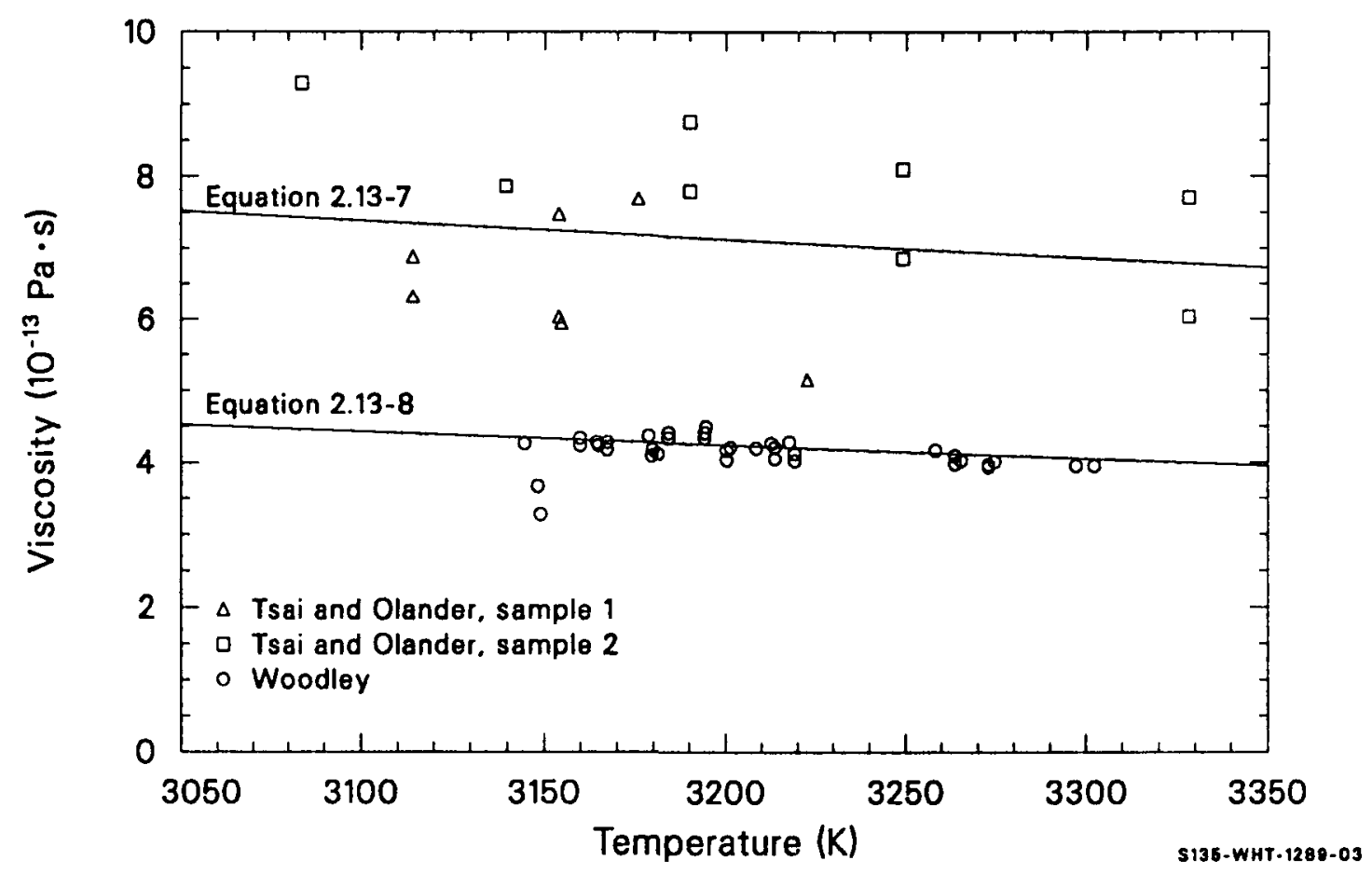

Figure 2.13-2. Data from uranium dioxide samples compared with least-squares fit. 


\section{FVISCO}

The final step in the derivation of Equation (2.13-1) was to average Equations (2.13-8) and (2.13-6). With a lot-to-lot variation present, this step assumes that each lot of $\mathrm{UO}_{2}$ is equally probable.

The estimated uncertainty of the values of viscosity computed with Equation (2.13-8) was determined using the assumption that the important difference in the measurements of the two references is the unknown difference in the two lots of $\mathrm{UO}_{2}$. The resultant standard deviation is

$\sigma=2 \times 10^{-3} \mathrm{~Pa} \cdot \mathrm{s}$

which is approximately one-third the predicted value of the viscosity. The increased uncertainty for nonstoichiometric $\mathrm{UO}_{2}$ shown in Equation (2.13-4) is simply an estimate that has been included to indicate that the model contains no dependence on the oxygen-to-metal ratio of the fuel.

Figure 2.13-3 illustrates the viscosities calculated with Equation (2.13-1) for liquid $\mathrm{UO}_{2}$. The dashed lines are the upper and lower uncertainty limits obtained by adding $\pm 1 / 3$ of the predicted viscosity and an assumed melt temperature of $3113 \mathrm{~K}$.

Equation (2.13-3), which is employed only in the temperature range where liquid and solid can both exist (for temperatures between the fuel melting temperature and the melt temperature plus the liquid-solid coexistence temperature range), is obtained from the assumption that the viscosity is the volume-weighted average of the solid and liquid viscosities in this temperature range.

\subsubsection{References}

2.13-1. R. Scott, A. R. Hall, J. Williams, "The Plastic Deformation of Uranium Oxides Above $800 \mathrm{~K}$, "Journal of Nuclear Materials, 1 , 1959, pp. 39-48. 
FVISCO

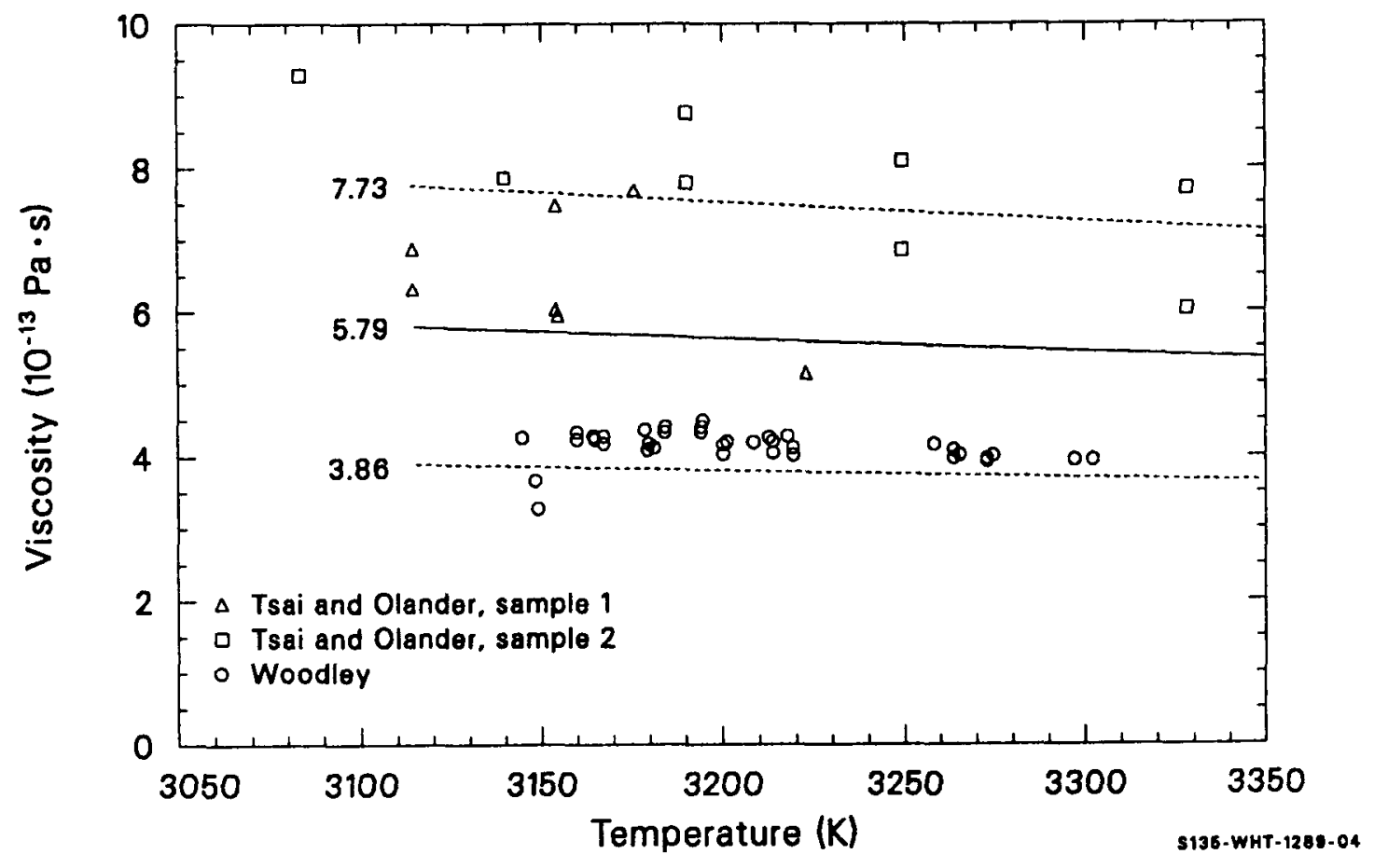

Figure 2.13-3. Viscosities calculated with Equation (5.13-1) (solid line) and upper and lower uncertainty estimates (dashed lines) compared with data. 


\section{FVISCO}

2.13-2. W. F. Sheely, ed., Quarterly Progress Report, July, August, September, 1969, Reactor Fuels and Materials Development Programs for Fuels and Materials Branch of USAEC Division of Reactor Development and Technology, BNWL-1223, November 1969.

2.13-3. W. F. Sheely, ed., Quarterly Progress Report, October, November, December, 1969, Reactor Fuels and Materials Development Programs for Fuels and Materials Branch of USAEC Division of Reactor Development and Technology, BNWL-1279, February 1970.

2.13-4. H. C. Tsai and D. R. 0lander, "The Viscosity of Molten Uranium Dioxide," Journal of Nuclear Materials, 44, 1972, pp. 83-86.

2.13-5. R. E. Woodley, "The Viscosity of Molten Uranium Dioxide," Journal of Nuclear Materials, 50, 1974, pp. 103-106. 
FVAPRS

\subsection{VAPOR PRESSURe (FVAPRS)}

(R. E. Mason)

During very high temperature excursions, evaporating reactor fuel (urania or plutonia-urania mixtures) can create pressures that equal or exceed plenum gas or fission gas pressures in the fuel rod. This pressure will influence the failure mechanism of the cladding and may cause the melted portion of the fuel to froth and swell. Significant volume changes of the fuel may also result from phase changes due to noncongruent evaporation (composition of the vapor phase being different than that of the fuel). A number of compounds are present in fuel vapors. These are actinide and actinide oxide vapors $\left(\mathrm{UO}_{2}, \mathrm{UO}_{3}, \mathrm{UO}_{4}, \mathrm{U}, \mathrm{PuO} \mathrm{O}_{2}, \mathrm{PuO}, \mathrm{Pu}\right)$ and oxygen vapors $\left(0\right.$ to $\mathrm{O}_{2}$ ). The total pressure (sum of all partial pressures) of the actinides and actinide oxides is calculated.

The vapor pressure equations described in this section are to be used in transient fuel codes, mechanistic gas release codes, or restructuring codes that require vapor pressures of calculate bubble migration by evaporation-condensation.

\subsubsection{Summary}

The FVAPRS model determines the saturated actinide vapor and oxygen vapor pressures over urania, plutonia, and mixed oxides as a function of fuel $0 / M$ ratio and temperature. Semiempirical equations based on the Clausius-Clapeyron equation are used. The standard error of estimate (SEOE) with respect to the $\log$ of the data base is given for each equation.

For urania, 


\section{FVAPRS}

$\log _{10}(P)=-11191 / T+9.9932 \ln (T)-0.00132 T-69.174$

and SEOE $\left(\log _{10} P\right)= \pm 0.206$

For plutonia,

$$
\begin{aligned}
\log _{10}(P)= & (-5404.1+6854.6 x) / T+18.166 \ln (T)-0.003389 T \\
& -130.65
\end{aligned}
$$

and SEOE $\left(\log _{10} P\right)= \pm 0.559$

where

$$
\begin{aligned}
& P \quad=\text { vapor pressure }(\mathrm{Pa}) \\
& \mathrm{X}=\text { deviation from stoichiometry (absolute value of } 0 / \mathrm{M}-2 \text { ) } \\
& T \quad=\text { temperature }(\mathrm{K}) .
\end{aligned}
$$

Equation (2.14-1) is used to calculate the vapor pressure of urania at al1 0/M ratios. Plutonia vapor pressures are calculated in the FVAPRS code for hypostoichiometric fuel using Equation (2.14-2). Because it is improbable that plutonia or mixed oxides will be hyperstoichiometric, the FVAPRS code uses a default value of 2.0 for all $0 / \mathrm{M}$ ratios greater than 2.0. Mixed-oxide vapor pressures are obtained by multiplying the plutonia and urania equations by the weight fraction of each material and adding the two resulting calculated pressures.

Similar equations are used for the oxygen vapor pressure $\left(\mathrm{P}_{2}\right.$ or $P_{0}$ ) over urania.

For $0 / M$ ratios $>2.004$, 
FVAPRS

$\log _{10}\left(P_{0_{2}}\right)=-14638.2 / T+21.7752 x+6.2062$

and SEOE $\left(\log _{10} P_{O_{2}}\right)= \pm 0.545$

For $0 / \mathrm{M}$ ratios $<1.999$,

$\log _{10}\left(P_{0}\right)=-(49535+1418.1 \ln x) / T+15.181$

and SEOE $\left(\log _{10} P_{0}\right)= \pm 0.801$.

For $0 / \mathrm{M}$ ratios $<2.004$ but $>1.999$,

$\log _{10}\left(P^{\prime}{ }_{0}\right)=-14638 / T+1.8036 \ln (x+0.004)+6.2933$

and SEOE $\left(\log _{10} P^{\prime} O_{2}\right)= \pm 9.0$

where $\mathrm{P}_{2}^{\prime} \mathrm{O}_{2}$ is the diatomic oxygen pressure for $1.999<0 / \mathrm{M}<2.004$.

The rapid decrease of the pressure predicted by Equation (2.14-5) as stoichiometric composition is approached is limited by imposing the following restrictions:

$$
\begin{gathered}
\text { If }-52708 / T+23.32 \geq \log _{10}\left(P_{0_{2}}^{\prime}\right), \\
\log _{10}\left(P_{0_{2}}\right)=-52708 / T+23.32 \\
\text { If }-52708 / T+23.32<\log _{10}\left(P^{\prime} 0_{2}\right),
\end{gathered}
$$

$\log _{10}\left(P_{0_{2}}\right)=\log _{10}\left(P^{\prime} 0_{2}\right)$

The following sections contain a discussion of the information and techniques used to develop Equations (2.14-1) through (2.14-7). Section 


\section{FVAPRS}

2.14.2 is a discussion of data described in the literature and methods used by each investigator to obtain those data. Section 2.14.3 is a discussion of vapor pressure theory, FVAPRS subcode development, and comparisons of the FVAPRS subcode with literature data. Section 2.14-5 contains a bibliography of references studied but not used to develop the FVAPRS subcode.

\subsubsection{Vapor Pressure Data}

Vapor pressure data for urania, plutonia, and mixed oxides are obtained, using a number of different experimental techniques, such as transpiration, effusion, Knudsen effusion, laser heating, electron beam heating, free evaporation, static testing, and boiling point pressures. of these techniques, transpiration, Knudsen effusion, static testing, and laser heating are most widely used. Reported vapor pressures are generally determined indirectly, calculated from measurements of sample weight loss, sample momentum, weight of deposit on a target, or by analysis of the ions in a gas stream. Techniques such as coulorimetric or X-ray analysis are used to determine vapor pressure when the $0 / M$ ratio of the sample is known. These measurement techniques are discussed in the following text in enough detail to indicate their advantages or disadvantages.

The transpiration technique is one of the techniques that can be used to measure vapor pressure in the presence of large concentrations of other gases. It is most accurate at temperatures where the confining material does not contribute significantly to the measured vapor pressure. Since it is not limited by the pressure of the gas being measured, a distinct advantage of this technique is that a carrier gas can be used to control the composition of the sample. Using this technique, the vapor pressure of a sample is determined from measurements of sample weight loss, weight of vapor condensed in a cold trap, or by monitoring molecular species in the carrier gas. A disadvantage of the technique is that vapor pressure is independent of the carrier gas flow rate in only a narrow band of flow rates which depend on other experimental conditions. 


\section{FVAPRS}

The Knudsen effusion technique $2.14-1$ and a similar technique, the Langmuir free-evaporation technique, are good measurement methods for vapor pressures below $15 \mathrm{~Pa}$. An advantage of the Knudsen technique to measure vapor pressure is that there are very small temperature gradients in the sample and its surroundings.

The application of lasers or electron beams to heat the surface of materials that melt at very high temperatures has provided an experimental method to study materials at temperatures above those that would melt the retaining crucibles. Vapor pressure data gathered when intense pulses of laser or electron beams impinge on the surface of the samples are derived from sample weight loss, evaporation depth, recoil momentum, torsion, or by mass spectrometry ion intensity measurements. These experiments must be analyzed with caution because equilibrium vapor pressure may not be the pressure measured.

2.14.2.1 Urania Vapor Pressure. The measurement techniques described previously have been used to measure urania vapor pressures discussed in the following paragraphs.

Szwarc and Latta2.14-2 reported total equilibrium vapor pressure data of hypostoichiometric urania, using the transpiration technique with the oxygen potential of the carrier gas controlled with $\mathrm{H}_{2} / \mathrm{H}_{2} \mathrm{O}$ mixtures. They found that the initial $0 / M$ ratios remained stable to within \pm 0.005 but that the vapor pressure changed an order of magnitude as the $0 / M$ ratio varied between 1.88 to 1.94 .

Bober 2.14-3 measured urania vapor pressure, using the laser heating technique to attain temperatures between 4100 and $4400 \mathrm{~K}$ and found vapor pressures between 0.608 and $1.01 \mathrm{MPa}$.

Reedy and Chasanov2.14-4 used the transpiration technique to obtain total vapor pressure data. They determined the $0 / M$ ratio of remaining 


\section{FVAPRS}

residues and found final $0 / M$ ratios to be dependent on the testing temperatures.

Ackermann ${ }^{2.14-5}$ determined the vapor pressure of hypostoichiometric urania between 1580 to $2400 \mathrm{~K}$, using effusion rate measurements, with an assumed vapor of U0. Mass spectrometric measurements on the system found the UO vapor pressure to be about 10 times greater than the $\mathrm{UO}_{2}$ and $U$ vapor pressures.

Tetenbaum and Hunt 2.14-6 measured total vapor pressure of hypostoichiometric and nearly stoichiometric urania, using the transpiration technique. The $0 / M$ ratio of their samples increased with increasing temperatures, and the fuel vapor pressure increased as the $0 / M$ ratio approached the hypostoichiometric phase boundary. Their reported vapor pressure data are in very good agreement with those of Szwarc and Latta for U $0_{1.88}$ but are approximately 1.5 to 2 times greater for $\mathrm{U}_{1.92}$ and $\mathrm{UO}_{1.94}$. They also reported an order of magnitude pressure change as the $0 / M$ ratio of the samples changed.

Benezech ${ }^{2.14-7}$ used the transpiration technique to obtain urania vapor pressure data at temperatures between 2200 and $2600 \mathrm{~K}$ with $0 / \mathrm{M}$ ratios varying between 2.0 and 2.15. He reported large temperature gradients in the crucible and found the dominant vapor species $\left(\mathrm{UO}_{2}\right.$ or $\left.\mathrm{UO}\right)$ to be dependent on the composition of the carrier gas.

Ohse $2.14-8,2.14-9$ reported vapor pressures of urania at temperatures up to $4710 \mathrm{~K}$, using the laser heating technique. These data are important because they were taken at temperatures above melting and show the vapor pressure at very high temperatures to increase with increasing temperature at a much slower rate than it does below the melting temperatures.

Alexander $2.14-10$ measured total vapor pressure and oxygen dissociation pressures of urania, thoria, zirconia, and combinations of the 
three, using the transpiration technique at temperatures between 2000 and $3000 \mathrm{~K}$. They reported vapor pressures of thoria-urania mixtures to be an order of magnitude less than urania vapor pressures.

Ackermann 2.14-11,2.14-12 reported vapor pressures for urania at temperatures between 1600 and $2800 \mathrm{~K}$, using the Knudsen effusion technique. These data were later revised and reported after the results of later experiments were analyzed. ${ }^{2.14-13}$ Their reported results, urania vapor pressure invariant to $2700 \mathrm{~K}$ and melting at $2678 \mathrm{~K}$, conflict with results previously discussed by other investigators. Their sample composition probably varied from pure urania, containing impurities that affected the measured vapor pressures and the melting point. However, the magnitude and the slope of the pressure as a function of temperature are within the data scatter bands of other investigators' data.

Chapman and Meadows 2.14-14,2.14-15 investigated nonstoichiometric urania of compositions between $\mathrm{UO}_{2.02}$ and $\mathrm{UO}_{2.63}$ in the $\mathrm{UO}_{2+x}$ and $\mathrm{U}_{3} \mathrm{O}_{8-\mathrm{x}}$ and $\mathrm{U}_{3} \mathrm{O}_{8-\mathrm{y}}$ phase regions at temperatures between 1273 and $1873 \mathrm{~K}$, using a thermogravimetric technique to obtain the vapor pressure data. They reported evidence of $\mathrm{UO}_{4}$ vapor instead of $\mathrm{UO}$ or $\mathrm{UO}_{2}$ and an equilibrium 0/M ratio, in a vacuum at temperatures above $1973 \mathrm{~K}$, to be less than the ratio 2.0 obtained by other investigators.

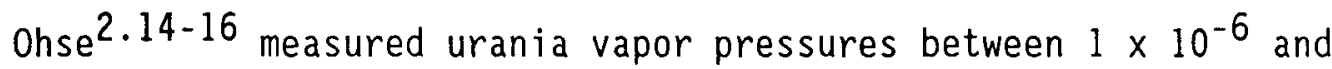
$3.4 \times 10^{-4} \mathrm{MPa}$ in an effusion cell at temperatures between 2278 and $2768 \mathrm{~K}$.

Benson 2.14-17 investigated vapor pressures of urania, using an electron beam to heat the samples to temperatures between 4500 and $7200 \mathrm{~K}$.

Babelot ${ }^{2.14-18}$ reported urania vapor pressure data obtained at temperatures between 3300 and $4700 \mathrm{~K}$, using a laser to heat the samples. The slope and magnitude of these data agree very well with those reported by Benson. 


\section{FVAPRS}

The literature data discussed in this section generally indicate that urania evaporates bivariantly as a function of $0 / M$ ratio and temperature. A composition change from stoichiometry can, at temperatures less than $2500 \mathrm{~K}$, cause the vapor pressure to increase 10 times or more as the urania becomes increasingly hypostoichiometric. The data are insufficient to determine how much effect deviation from stoichiometry has on vapor pressures in the hyperstoichiometric region. Tetenbaum and Hunt observed little effect of urania nonstoichiometry on the vapor pressure at temperatures near melting with hypostoichiometric fuel. Data at temperatures above melting and not having $0 / M$ ratios reported can therefore be used. There is no observed discontinuity of vapor pressure at the urania melting temperature, although the temperature-dependence does begin to decrease. The early data of Ackermann $2.14-12$ are considered in error by the authors $2.14-15$ and are therefore not useful for model development. Also, the Chapman and Meadows data are not applicable for model development because the scatter is large due to unreported $0 / \mathrm{M}$ ratios much greater than 2.0. All the rest of the data discussed are amenable to model development, al though some scatter between data sets occurs. Data discussed in this section are displayed in Figure 2.14-1. The urania vapor pressure as a function of temperature can be seen in each figure. The decreasing rate of change at temperature above $3000 \mathrm{~K}$ can also be seen.

2.14.2.2 Plutonia Vapor Pressure. Plutonia $\left(\mathrm{PuO}_{2}\right)$ is very similar to urania in many of its material properties. The plutonia vapor pressure data presently available in the literature are briefly discussed in the following paragraphs.

Ohse and Ciani ${ }^{2.14-19}$ reported vapor pressures of urania, at 1800 , 2000 , and $2200 \mathrm{~K}$, and plutonia, with $0 / \mathrm{M}$ ratios between 1.51 and 1.61 , based on effusion cell measurements. They found it very difficult to obtain good data with $0 / M$ ratios greater than 1.94 due to rapid change of fuel $0 / M$ ratios, or vapor $0 / M$ ratios, or both. 
FVAPRS
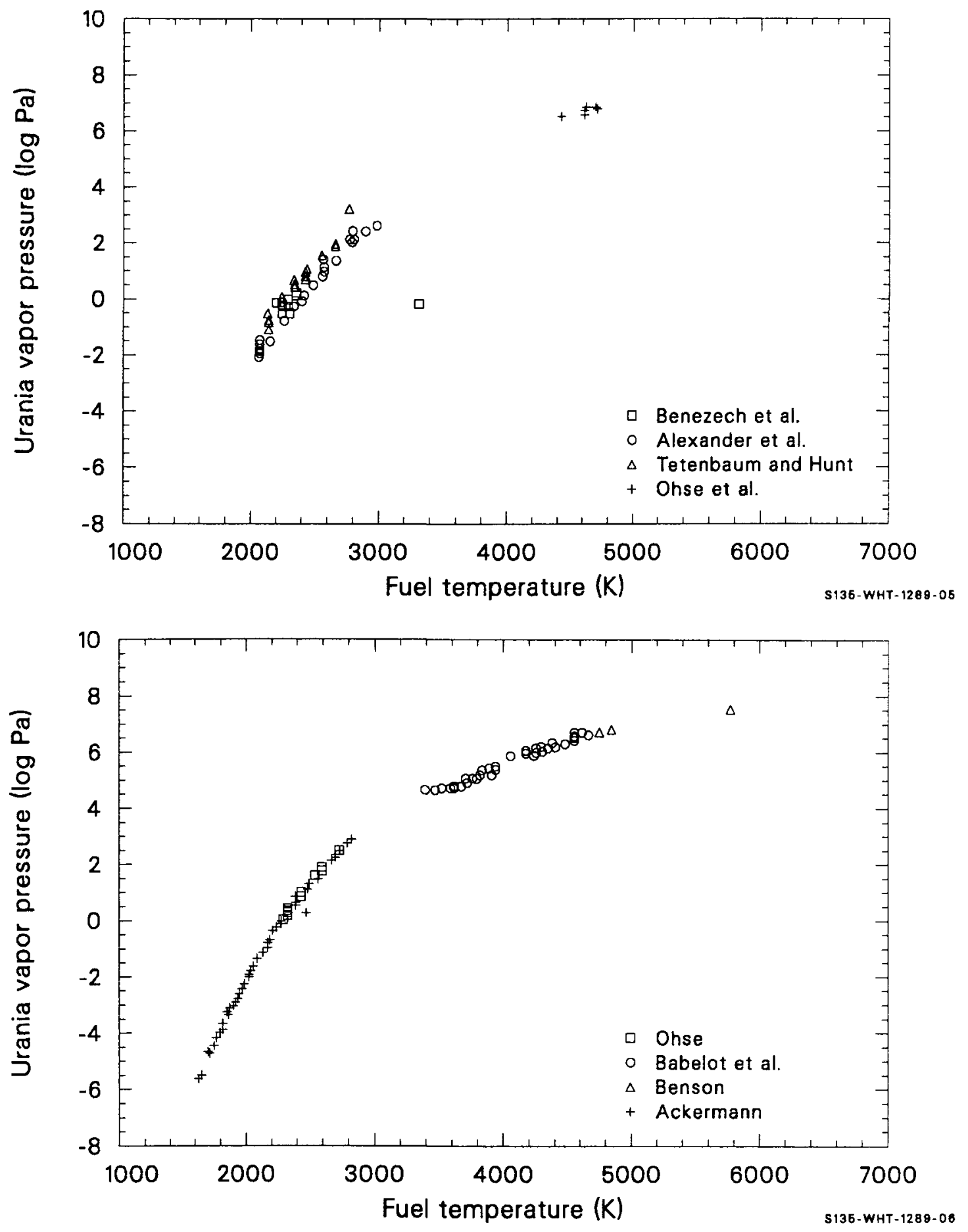

Figure 2.14-1. Urania vapor pressure data. 


\section{FVAPRS}

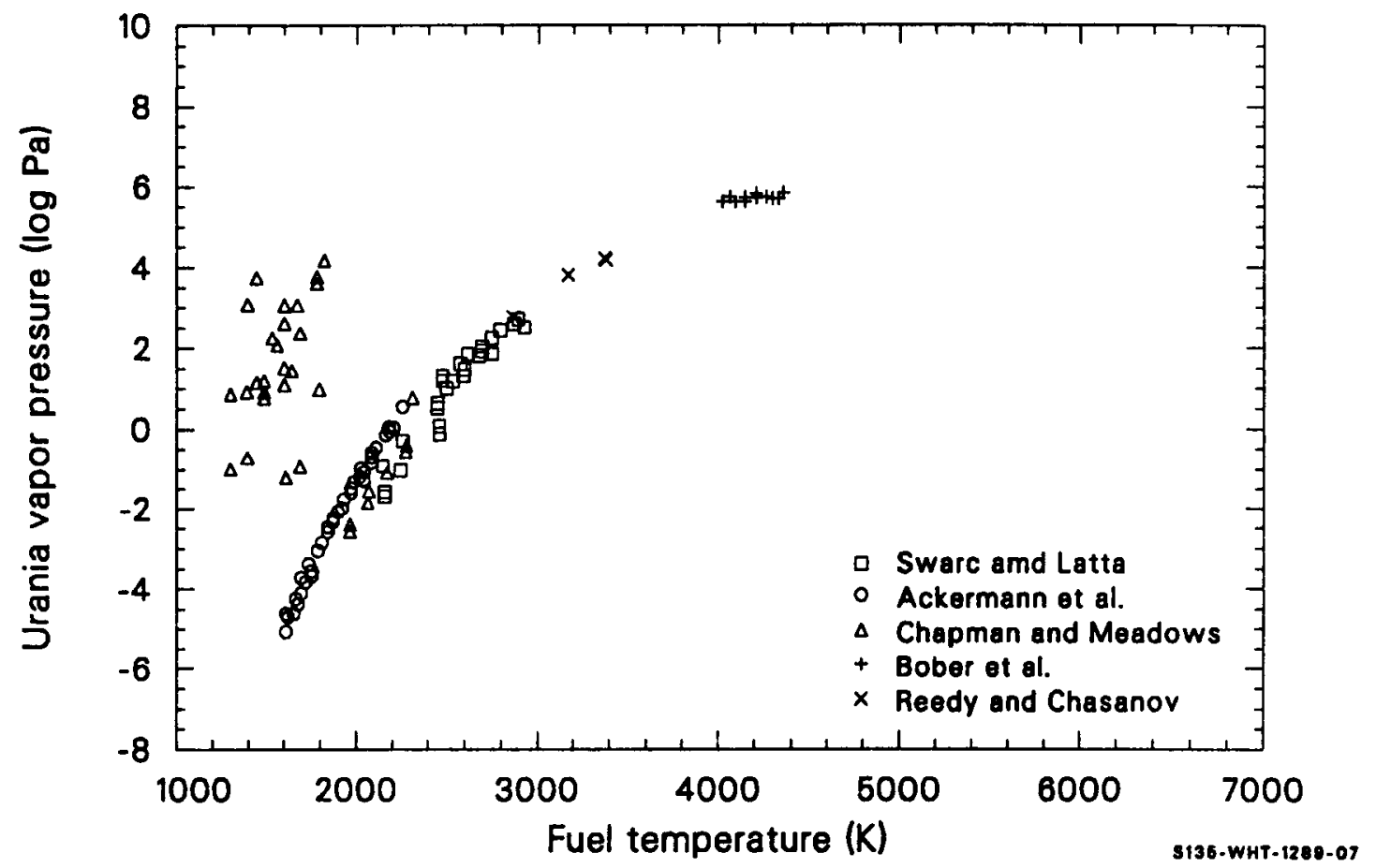

Figure 2.14-1. (continued) 


\section{FVAPRS}

Ackermann 2.14-20 measured plutonia vapor pressures of hypostoichiometric plutonia in effusion cells. Investigating the effects of both temperature and composition on the total vapor pressures, he found the evaporation rate to decrease more than 30\% from the initial rate after $8 \mathrm{~h}$ and found the composition to change with time. Chemical and $X$-ray analyses determined the $0 / \mathrm{M}$ ratios to be 1.923 to 1.916 and 1.90 to 1.93 , respectively.

Phipps2.14-21 used the Knudsen effusion method to measure vapor pressures between 1589 and $2060 \mathrm{~K}$. The vapor pressure data reported were derived from radiochemical analysis of the deposit on the effusion target. Phipps reported that oxygen reacted with the vapor flow and, therefore, had to be included in the vapor pressure calculations.

Pardue and Keller 2.14-22 measured the vapor pressure of plutonia in three atmospheres of air, argon, and oxygen at temperatures between 1723 and $2048 \mathrm{~K}$, using the transpiration technique to obtain their data.

Mulford and Lamar ${ }^{2.14-23}$ reported plutonia vapor pressure data measured at temperatures between 2000 and $2400 \mathrm{~K}$, using the Knudsen effusion technique, that were significantly different than those observed by Phipps.

The plutonia data reviewed include vapor pressures of plutonia between 1600 and $2500 \mathrm{~K}$ and $0 / \mathrm{M}$ ratios between 1.5 and 2.0. These data are shown in Figure 2.14-2. Vapor pressures of plutonia decrease as the hypostoichiometric phase boundary is approached. Vapor pressures were observed between $10^{-6}$ and $10 \mathrm{~Pa}$. Large scatter in the data can be seen in Figure 2.14-2, partially a result of $0 / M$ ratio effects not recorded by many of the investigators. Therefore, only the data of Ackermann 2.14-20 and Ohse and Ciani2.14-19 are used for model development.

2.14.2.3 Mixed-0xide Vapor Pressure. Some mixed-oxide data have appeared in the literature. These are discussed briefly. 
FVAPRS

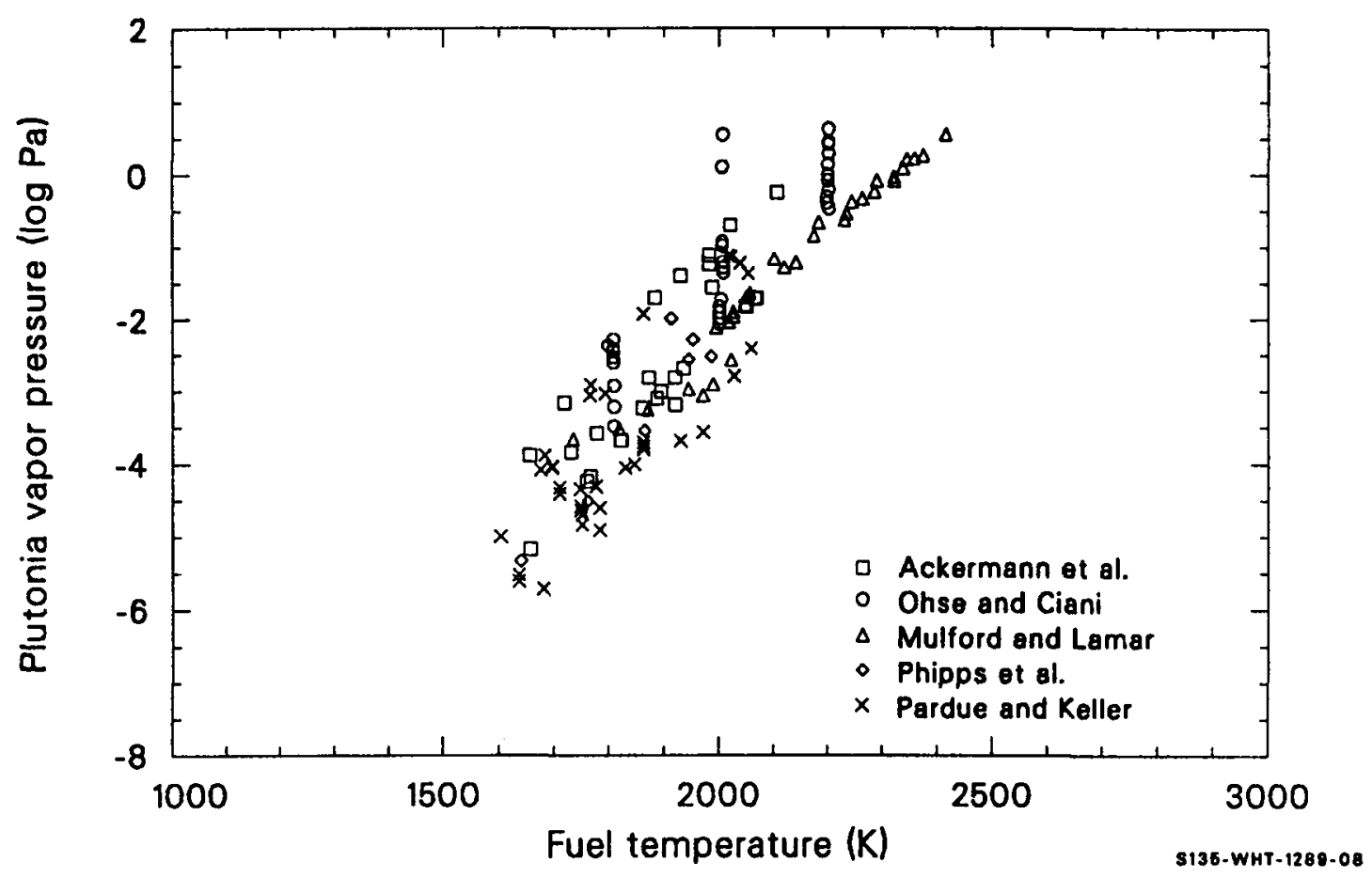

Figure 2.14-2. Plutonia vapor pressure data. 
FVAPRS

Tetenbaum 2.14-24 reported the results of an investigation of total vapor pressure of actinide-bearing species over the U-Pu-O system, using the transpiration technique. The data indicate that mixed oxides of composition $\left(U_{0.8}, \mathrm{Pu}_{0.2}\right) \mathrm{O}_{2-\mathrm{x}}$ have vapor pressures between 0.1 and $1 \mathrm{~Pa}$ at temperatures between 2150 and $2450 \mathrm{~K}$. Analysis of these data shows the urania vapor pressure to be approximately 0.85 of the total vapor pressure and plutonia is approximately 0.15 of the total.

Ohse and 01 son $^{2.14-25}$ reported the vapor pressures of coprecipitated mixed oxide with a composition of $\left(\mathrm{U}_{0.85} \mathrm{Pu}_{0.15}\right)_{2-x}$ obtained in a tungsten effusion cell heated by an electron beam. The measurements were taken at temperatures between 1800 and $2350 \mathrm{~K}$, with the $0 / \mathrm{M}$ ratios varying between 2.0 and 1.94. Ohse and 01 son observed urania vapor pressures to be about 10 times greater than for any of the other oxides present.

Battles $2.14-26$ reported vapor pressures of mechanically mixed urania and plutonia $\left(\mathrm{U}_{0.8} \mathrm{Pu}_{0.2}\right)_{2-x}$ with the $0 / \mathrm{M}$ ratio between 1.92 and 2.01 and the temperature approximately $2240 \mathrm{~K}$. They used the Knudsen effusion technique with a mass spectrometer to determine the vapor pressure. They reported the urania vapor pressure to be much greater than the plutonia vapor pressure.

Ohse $2.14-8,2.14-9$ reported mixed-oxide data measured at very high temperatures $(4000$ to $7000 \mathrm{~K}$ ), using the laser heating technique. These test samples were melted prior to laser heating and vapor pressure measurements.

The four data sets just reviewed all show the vapor pressure of urania to be on the order of 10 times greater than the pressure of other chemical species present. The $0 / \mathrm{M}$ ratios between 1.91 and 2.00 were investigated at temperatures between 2100 and $2500 \mathrm{~K}$. Vapor pressures ranged from approximately $0.01 \mathrm{~Pa}$ at $2150 \mathrm{~K}$ to approximately $12 \mathrm{MPa}$ at $7000 \mathrm{~K}$. Figure 2.14-3 shows the mixed-oxide data just discussed. The high-temperature data 


\section{FVAPRS}

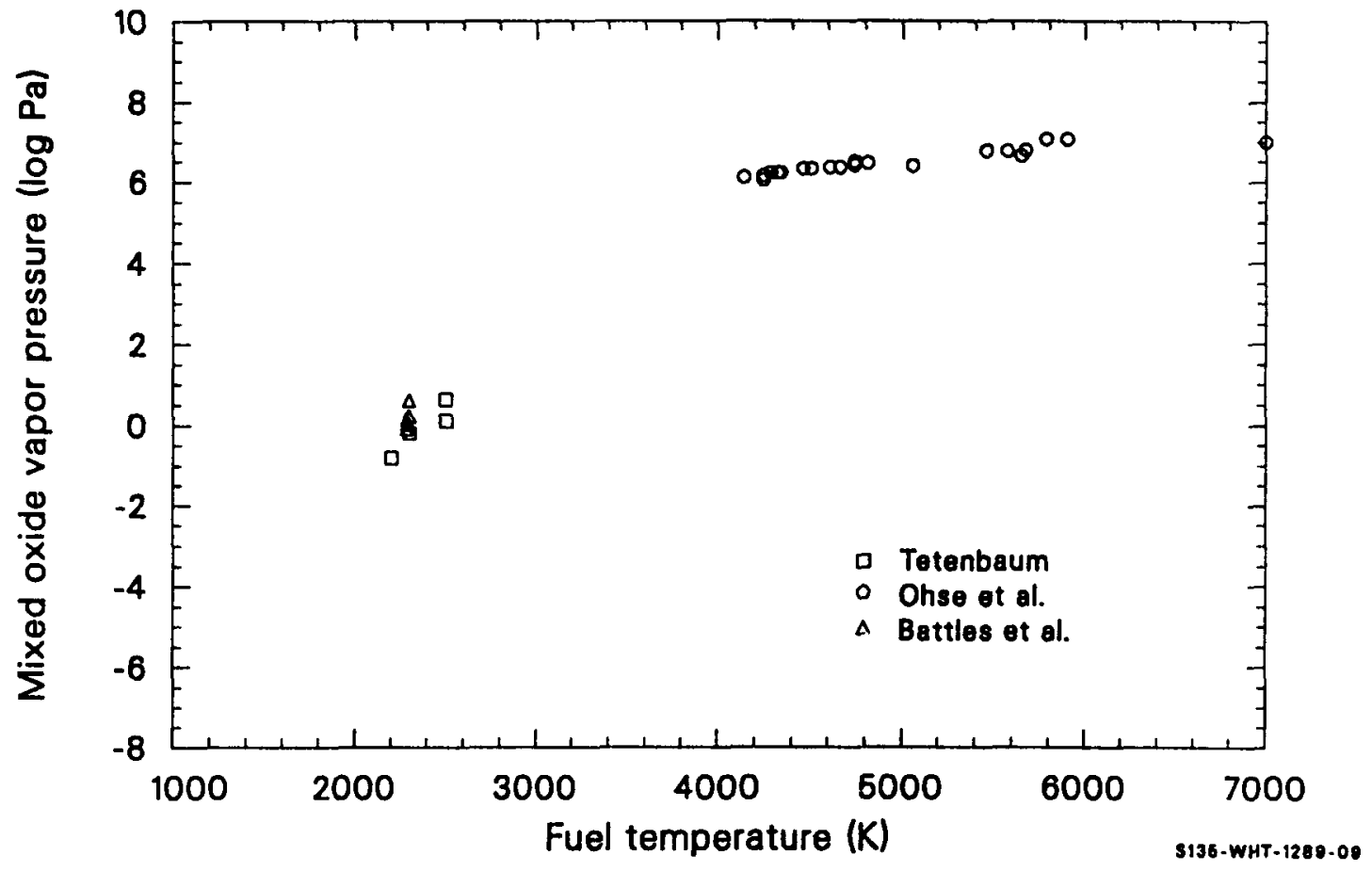

Figure 2.14-3. Mixed-oxide vapor pressure data. 


\section{FVAPRS}

show a significant decrease in the rate of vapor pressure increase. The data also show scatter bands of about an order of magnitude at temperatures below $3000 \mathrm{~K}$.

2.14.2.4 0xygen Vapor Pressure. Although actinide oxide vapors constitute the most prominent vapors evolving from reactor fuels, oxygen vapors $\left(0\right.$ and $\left.\mathrm{O}_{2}\right)$ do evaporate and thereby change the chemical composition of the fuel. A number of investigators have found metallic uranium in otherwise pure urania after heating above $2073 \mathrm{~K}$ in a vacuum. For example, Aitken 2.14-27 found both hypo- and hyperstoichiometric urania to change with time and temperature until an $0 / M$ ratio of 1.88 was reached. Vaporization of oxygen from the fuel not only changes the composition of the fuel but is directly related to the oxidation of the internal surfaces of the cladding. Oxygen vapor pressures have been determined for urania up to approximately $2900 \mathrm{~K}$. Most of this oxygen data is derived from measurement of moisture content of carrier gases, sample weight, or composition changes. Onty one set of oxygen vapor pressure data for plutonia2.14-28 was found. This data set was at temperatures too low (less than $1323 \mathrm{~K}$ ) and is inefficacious until more data are available. Modeling of plutonia oxygen pressures was therefore not attempted. Data reported for oxygen pressures over urania are described in the following paragraphs.

Tetenbaum and Hunt 2.14-29 used the transpiration technique to measure the oxygen partial pressure of hypostoichiometric urania. Monatomic oxygen pressures were determined up to $2700 \mathrm{~K}$. Vapor pressure measurements were determined for compositions ranging from $U_{2} 0_{2}$ to approximately $U_{1.86}$. Their data show oxygen vapor pressure to increase sharply near the stoichiometric composition at the lower temperatures measured. This pressure increase near the stoichiometric composition is not as steep at the higher temperatures.

Markin 2.14-30 used a unique method (sample composition measurements after equilibrium was reached) to obtain monatomic oxygen vapor pressure 


\section{FVAPRS}

data for hypostoichiometric and hyperstoichiometric urania. The $0 / \mathrm{M}$ ratios reported are accurate to within \pm 0.005 . Measurements were obtained for hypostoichiometric urania between 2000 and $2400 \mathrm{~K}$ and for hyperstoichiometric urania between 1600 and $1700 \mathrm{~K}$. Their data agree well with that of Tetenbaum and Hunt.

Wheeler 2.14-31 measured the monatomic oxygen vapor pressure of urania between 1800 and $2000 \mathrm{~K}$. He used a technique of equilibrating $\mathrm{UO}_{2-x}$ in an oxygen atmosphere controlled by the equilibrium reaction

$\mathrm{C}+\mathrm{O}_{2}=\mathrm{CO}_{2}$

Data were obtained from urania with $0 / M$ rations between 2.0 and 1.98 . These data agree well with both data sets just described.

Javed $^{2.14-32}$ reported diatomic oxygen vapor pressure data of urania, using the transpiration technique at temperatures between 1873 and $2173 \mathrm{~K}$. The $0 / M$ ratios were obtained from chemical, $X$-ray, and metallographic techniques. These oxygen vapor pressure data tend to be higher than those of Tetenbaum and Hunt, Marken, and Wheeler.

Aitken 2.14-27 used free evaporation and flowing gas transpiration techniques to obtain the oxygen pressure of urania between 2023 and $2223 \mathrm{~K}$. These data were reported as diatomic oxygen pressures. Aitken observed the $0 / M$ ratio of the urania to approach 1.88 for both hypo- and hyperstoichiometric urania when the samples were heated above $2000 \mathrm{~K}$. The oxygen vapor pressure implied by these data is approximately two to ten times that of the Tetenbaum and Hunt data. Tetenbaum and Hunt suggest that the discrepancy is a result of the Aitken data not having reached equilibrium pressures.

Roberts and Walter $2.14-33$ investigated diatomic oxygen equilibrium vapor pressure of urania with compositions between $\mathrm{UO}_{2.00}$ and $\mathrm{UO}_{2.3}$ and 
at temperatures between 1273 and $1723 \mathrm{~K}$. Temperature measurements were obtained, using a tensimetric technique (direct measurement of pressure). The technique is crude, and there was no control of the sample $0 / M$ ratio. The investigators found deposits of mixtures of the $\mathrm{U}_{4} \mathrm{O}_{9}$ and $\mathrm{UO}_{2.61}$ phases in cooler parts of the furnace, indicating that the $0 / \mathrm{M}$ ratio of the samples was changing. The authors also suggest that an equilibrium vapor pressure may not have been obtained. These data were therefore not used as part of the data base for model development.

Hagemark and Broli2.14-34 conducted an extensive investigation of diatomic oxygen pressures of urania with $0 / \mathrm{M}$ rations between 2.0 and 2.25 and at temperatures between 1173 and $1773 \mathrm{~K}$. Oxygen vapor pressure measurements were obtained from thermobalance measurements during testing.

Alexander $2 \cdot 14-10$ used the transpiration technique to determine the oxygen dissociation pressure of urania. They investigated oxygen vapor pressures of urania compositions of $\mathrm{UO}_{2.03}, \mathrm{UO}_{2} .0$, and $\mathrm{UO}_{1.97}$ with compositions accurate to \pm 0.01 units at temperatures between 1950 and $2720 \mathrm{~K}$.

Blackburn 2.14-35 used the Knudsen effusion technique to measure the diatomic oxygen vapor pressure of urania. He obtained oxygen vapor pressure data for $0 / \mathrm{M}$ ratios between 2.1 and 2.6 at temperatures between 1263 and $1400 \mathrm{~K}$. For purposes of the FVAPRS code and this report, only the data of $0 / M$ ratios less than 2.2 can be used. This is roughly the boundary of urania-oxygen solid solution at temperatures above $1273 \mathrm{~K}$. These data are in fair agreement with those reported by other investigators.

Aronson and Belle $e^{2 \cdot 14-36}$ used an electrochemical measurement technique (emf measurements on urania half-cells) to measure the diatomic oxygen vapor pressure of urania. Vapor pressures for urania compositions between $\mathrm{UO}_{2.0}$ and approximately $\mathrm{UO}_{2.5}$ at temperatures between 1150 and $1350 \mathrm{~K}$ were investigated. Oniy the urania data with $0 / \mathrm{M}$ ratios below 2.2 were considered for model development. 


\section{FVAPRS}

Kiukkola $a^{2 \cdot 14-37}$ used emf measurements from galvanic cells to obtain diatomic vapor pressures over urania. Vapor pressure measurements of urania at compositions of $\mathrm{UO}_{2.01}$ to $\mathrm{UO}_{2.67}$ were obtained at temperatures between 1073 and $1473 \mathrm{~K}$. Here again, only those data points with urania 0/M ratios less than $\mathrm{UO}_{2.0}$ were considered.

Markin and Bones ${ }^{2.14-38}$ used emf measurements of urania with $0 / M$ ratios between 2.00 and 2.003 in a high-temperature galvanic cel1. Diatomic oxygen pressures of urania between the temperatures of 973 and $1673 \mathrm{~K}$ were investigated. The $0 / M$ ratios were controlled and determined by coulorimetric titration of oxygen ions, using $\mathrm{NiO}$ as a source of oxygen. The main purpose of their investigations was to obtain thermodynamic functions and not oxygen vapor pressures, so there is very little discussion of the vapor pressure data. Their data indicate a steep slope (decrease in vapor pressure) as the composition of the urania approaches stoichiometry. This is consistent with other data in this composition range. These data are therefore useful in the modeling effort.

Aukrust ${ }^{2.14-39}$ determined equilibrium oxygen pressures over hyperstoichiometric urania. The $0 / M$ ratios were determined by a thermogravimetric method, and oxygen pressures were determined from known $\mathrm{CO}_{2} / \mathrm{CO}$ or $\mathrm{O}_{2} / \mathrm{Ar}$ gas mixtures and $0 / \mathrm{M}$ ratio measurements. Data were obtained at temperatures between 1373 and $1673 \mathrm{~K}$. They report $0 / \mathrm{M}$ ratios accurate to within +0.0002 and the $\log _{10} \mathrm{P}_{0_{2}}$ accurate to \pm 0.02 .

The data discussed in this section must be divided into two groups; hypostoichiometric and hyperstoichiometric. For hypostoichiometric fuel, the data of Tetenbaum and Hunt, Markin, Wheeler, and Alexander are the best available. The data of Javed and Atkins were probably measured under nonequilibrium conditions and should not be used. For hyperstoichiometric fuel and oxygen pressure, data of Hagemark and Broli are the most extensive and are the best. The rest are within an order of magnitude of these data and have been used. 


\section{FVAPRS}

\subsubsection{Mode1 Development}

The equations used in FVAPRS are based on thermodynamic equations fitted to the data. The following section is a discussion of thermodynamic and chemical theory and the technique used to develop the FVAPRS correlations.

2.14.3.1 Review of Basic Theory. Evaporation is a change in chemical state obeying the law of conservation of mass. Equations can therefore be used to show which elements or compounds could be expected to be present in the vapor phase above a fuel substrate. Possible reactions of urania are 2 14-12

$\mathrm{UO}_{2(\beta)} \rightarrow \mathrm{UO}(\mathrm{g})+(1-\alpha) / 2 \mathrm{O}_{2(\mathrm{~g})}+\alpha 0(\mathrm{~g})$

$\mathrm{UO}_{2(\beta)} \rightarrow 1 / 2 \mathrm{UO}_{2(\mathrm{~g})}+(2-3 \alpha) / 40_{2(g)}+3 \alpha / 20_{(g)}+1 / 2 U_{(\beta)}$

$\mathrm{UO}_{2(\beta)} \rightarrow 1 / 2 \mathrm{UO}(\mathrm{g})+1 / 2 \mathrm{UO}_{3}(\mathrm{~g})$

$\mathrm{UO}_{2(\beta)} \rightarrow 1 / 3 U_{(\mathrm{g})}+2 / 3 \mathrm{UO}_{3}(\mathrm{~g})$

$\mathrm{UO}_{2(\beta)}+\mathrm{UO}^{+} 2(\mathrm{~g})+\mathrm{e}^{-}(\mathrm{g})$

$\mathrm{UO}_{(\beta)} \rightarrow \mathrm{UO}_{(\mathrm{g})}$

$2 \mathrm{UO}_{2}(\beta) \rightarrow\left(\mathrm{UO}_{2}\right)_{2}(\mathrm{~g})$

where $\beta$ denotes that the material is in the solid or liquid phase and $\mathrm{g}$ denotes the gas phase. These equations apply only in the oxygen solid solution regions of solid and liquid urania. Of these possible compounds, one is usually much more prominent than the others. Analysis of the data indicates that for substrate temperatures $<2000 \mathrm{~K}$, the magnitude of the actinide oxide vapors follow the order, $\mathrm{P}_{\mathrm{UO}}>\mathrm{P}_{\mathrm{UO}_{2}}>\mathrm{PU}_{\mathrm{U}}>\mathrm{P}_{\mathrm{UO}_{3}}$, 


\section{FVAPRS}

where $P$ is the vapor pressure. At about $3000 \mathrm{~K}$, the order of partial pressures is $\mathrm{P}_{\mathrm{UO}_{2}} \approx \mathrm{P}_{\mathrm{UO}}>\mathrm{P}_{\mathrm{UO}_{3}}, \approx \mathrm{P}_{\mathrm{U}}$; and at temperatures $>3500 \mathrm{~K}$, the partial pressure order is $\mathrm{P}_{\mathrm{UO}_{2}}>\mathrm{P}_{\mathrm{UO}_{3}}>\mathrm{P}_{\mathrm{UO}}>\mathrm{P}_{\mathrm{U}}$. The oxygen partial pressure at all temperatures is generally much smaller than the combined vapor pressure of the actinide oxides.

For plutonia, the chemical reactions are similar to those of urania

$$
\begin{aligned}
& \mathrm{PuO}_{2(\beta)}+\mathrm{PuO}_{(g)}+(1-\alpha) / 2 \mathrm{O}_{2}(\mathrm{~g})+\alpha 0_{(\mathrm{g})} \\
& \mathrm{PuO}_{2(\beta)}+1 / 2 \mathrm{PuO}_{2(\mathrm{~g})}+(2-3 \alpha) / 40_{2}(\mathrm{~g})+3 \alpha / 2 \mathrm{O}_{(\mathrm{g})}+1 / 2 \mathrm{Pu}(\beta) \\
& \mathrm{PuO}_{2(\beta)} \rightarrow 1 / 2 \mathrm{PuO}_{(\mathrm{g})}+1 / 2 \mathrm{PuO}_{3}(\mathrm{~g}) \\
& \mathrm{PuO}_{2(\beta)}+1 / 3 \mathrm{Pu}_{(\mathrm{g})}+2 / 3 \mathrm{PuO}_{3}(\mathrm{~g}) \\
& \mathrm{PuO}_{2(\beta)}+\mathrm{PuO}_{2(\mathrm{~g})}+\mathrm{e}^{-}(\mathrm{g}) \\
& \mathrm{PuO}_{(\beta)} \rightarrow \mathrm{PuO}_{(\mathrm{g})} \\
& 2 \mathrm{PuO}_{2(\beta)}+\left(\mathrm{PuO}_{2}\right)_{2(\mathrm{~g})}
\end{aligned}
$$

It is experimentally determined that PuO is the prominent species of plutonia up to an $0 / \mathrm{M}$ ratio of approximately 1.99 , where $\mathrm{PuO}_{2}$ becomes more prominent.

Evaporation can be described by simple thermodynamic considerations of a first-order phase transition of a pure substance, solid to vapor or liquid to vapor, at constant temperature and pressure. At the phase transition

$$
d G_{\beta}=d G_{g}
$$


where

$$
\begin{aligned}
& d G_{\beta}=\text { change in Gibbs free energy for the solid or liquid } \\
& { }^{d G_{g}}=\text { change in Gibbs free energy for the gas. }
\end{aligned}
$$

Since the process is reversible for a first-order phase transition at constant temperature and pressure,

$$
\begin{aligned}
& d G_{\beta}=v_{\beta} d p-S_{\beta} d T \\
& d G_{g}=v_{g} d p-S_{g} d T
\end{aligned}
$$

where

$$
\begin{array}{ll}
V_{\beta} & =\text { molar volume of solid or liquid } \\
V_{g} & =\text { molar volume of gas } \\
p & =\text { pressure }(P a) \\
S_{\beta} & =\text { entropy of solid or liquid } \\
S_{g} & =\text { entropy of gas } \\
T & =\text { temperature }(K) .
\end{array}
$$

Combining Equations (2.14-23 through 2.14-25) and rearranging gives

$$
\left(S_{g}-S_{\beta}\right) d T=\left(V_{g}-V_{\beta}\right) d p
$$

Since $V_{g}$ is generally much greater than $V_{\beta}$, Equation $(2.14-26)$ can be reduced to 


\section{FVAPRS}

$\Delta S / V_{g}=d p / d T$

From the second law of thermodynamics, we know that

$\Delta S=\int_{\beta}^{g} d Q / T$

where $d Q$ is the differential of heat for a reversible phase transition proceeding at constant temperature and pressure.

The first law and the definition of system enthalpy can be used to relate dQ to enthalpy. From the first law,

$d U=d Q-p d V$

where $U$ is the internal energy and $V$ is the volume. The differential of the system enthalpy for a reversible process is

$d H=d U+p d V+V d p$

At constant pressure, Equations (2.14-29) and (2.14-30) imply

$d Q=d H$

The change of enthalpy can then be written as

$\Delta S=\int_{\beta}^{g} d H / T$

Integrating Equation (2.14-32) at constant temperature gives

$\Delta S=\Delta H / T$ 
FVAPRS

where $\Delta H$ is the enthalpy change of the phase transition.

Since the enthalpy change of the phase transition is a function of heat capacity, which is different for solids and gases at different temperatures, the temperature-dependence of $\Delta \mathrm{H}$ must be taken into account for the vapor pressure to be evaluated accurately. The temperature-dependence of $\Delta H$ can be approximated by the second-order empirical equation

$\Delta H=a+f(x)+b T+c T^{2}$

where

$$
\begin{aligned}
& f(x)=\text { a function of composition } \\
& a, b, c=\text { constants. }
\end{aligned}
$$

Substituting Equation (2.14-34) into Equation (2.14-33) and the resultant expression into Equation (2.14-27) gives

$\frac{d p}{d T}=\left\{\frac{[a+f(x)]}{T}+b+c T\right\} v_{g}^{-1}$

If the vapor behaves as an ideal gas,

$V_{g}=R T / p$

where $R$ is the universal gas constant $\left(m^{3} \mathrm{~Pa} / \mathrm{mole} \cdot \mathrm{K}\right)$. Equation (2.14-35) reduces to

$\frac{d p}{p}=\left\{\frac{[a+f(x)]}{T^{2}}+\frac{b}{T}+c\right\} R^{-1} d T$

and integrating gives 


\section{FVAPRS}

$\ln p=\left\{-\frac{[a+f(x)]}{T}+b \ln T+c T+D\right\} R^{-1}$

2.14.3.2 Evaluation of Constants. Constants used in Equation (2.14-1) were obtained from fitting of Equation (2.14-38) to literature data. Hyperstoichiometric and hypostoichiometric data were fit separately.

The urania model is based on the data discussed in Section 2.14.2.1 except for that of Chapman and Meadows2.14-14 and Ackermann, 2.14-12 for the reasons discussed in that section. The data of Tetenbaum and Hunt indicate the urania total pressure to be dependent on the urania $0 / M$ ratio, but this dependence diminishes near the melting temperature. Since many of the data have been obtained at temperatures where the $0 / M$ ratio seems to have 1 ittle effect and most of the data do not include the $0 / M$ ratio, the FVAPRS urania correlation was developed disregarding the vapor pressure dependence on the fuel composition. The low-temperature data of Ackermann, 2.14-5 Alexander, ${ }^{2.14-10}$ and Benezech ${ }^{2.14-7}$ were used, assuming that their test samples did not deviate greatly from stoichiometry. The best-fit correlations prediction (solid line) is shown in Figure 2.14-4 compared to the urania data in Section 2.14.2.1. The standard error of estimate of the FVAPRS equation and $\log$ of the data is \pm 0.206 .

Material constants of Equation (2.14-1) for hypostoichiometric plutonia were obtained by fitting the vapor pressure data of Ackermann 2.14-20 and Ohse and Ciani.2.14-19 The data of Mulford and Lamar, 2.14-23 Phipps, 2.14-21 and Pardue and Keller 2.14-22 were not used because these data did not include $0 / M$ ratios. As a result of the vapor pressure studies of mixed oxides at temperatures between 4000 and $7000 \mathrm{~K}$ (which indicate maximum pressures of $100 \mathrm{MPa}$ ), the data of ohse $2.14-8$ were modified and used to find the plutonia constants for temperatures above $4000 \mathrm{~K}$. The data of Ohse were modified by multiplying by the weight fraction of plutonia in the samples. This modification of observed vapor pressure approximates the 


\section{FVAPRS}

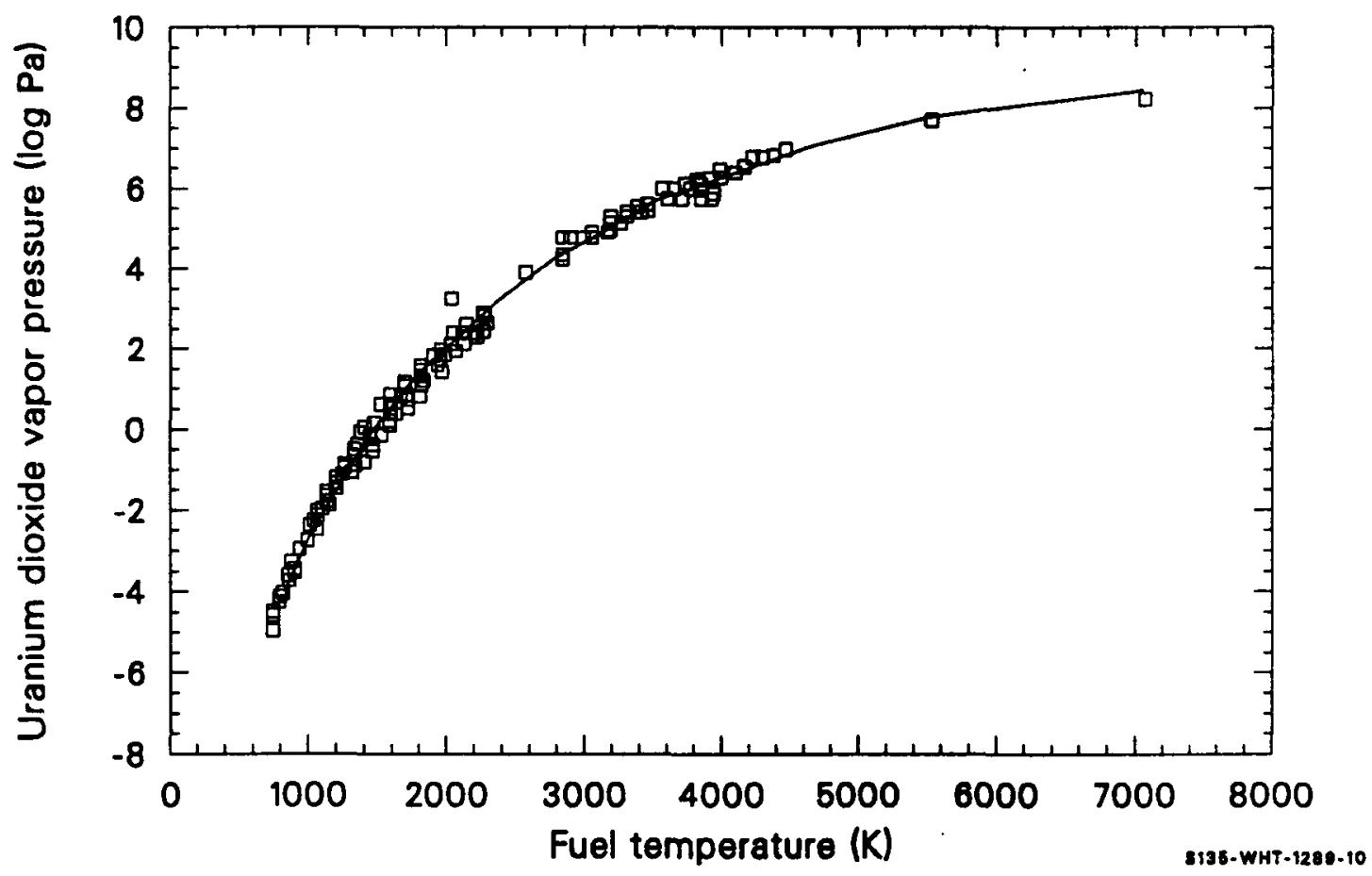

Figure 2.14-4. FVAPRS calculations (solid line) compared to urania data. 


\section{FVAPRS}

ratios of urania and plutonia vapor pressures over the mixed oxides observed in the Tetenbaum ${ }^{2.14-24}$ data. The fitting method followed this sequence. Data in a narrow $0 / M$ ratio band near stoichiometry were used to determine a normalization curve. The resulting equation was then used with all applicable data to normalize the data with respect to temperature, while a best-fit slope as a function of deviation from stoichiometry was determined. This $0 / M$-dependent function was then used to determine the final equation as a function of temperature and $0 / M$ ratio. Figure 2.14-5 shows FVAPRS plutonia subcode predictions, using $0 / M$ ratios of 2.0 (bottom curve) and 1.5 (top curve). The data with $0 / M$ ratio between 1.5 and 2.0 are seen to lie between the two lines.

The FVAPRS correlation for mixed-oxide vapor pressure was obtained by combining the equation calculations of urania and plutonia. This is accomplished by multiplying the weight fraction of urania and plutonia times the calculated vapor pressure of urania and plutonia, respectively. This approach was used rather than modeling the mixed-oxide directly because mixed oxide data at typical mixture ratios (< 10\%) have not been investigated and Tetenbaum's ${ }^{2 \cdot 14-24}$ plutonia pressures are roughly the same fraction $f$ the total pressure as the weight fraction. A comparison of the FVAPRS mixed-oxide predictions (VAPMIX) to data is shown in Figure 2.14-6. The fit is good at temperatures below $5000 \mathrm{~K}$ but becomes too 1 arge by about an order of magnitude at $6000 \mathrm{~K}$, well above the temperatures for which this subcode will usually be used.

FVAPRS oxygen vapor pressure calculations for hypostoichiometric urania are for monatomic oxygen up to $0 / \mathrm{M}$ ratios of 1.999 . Because of the scatter in the data, a simplified form of Equation (2.14-37) was used. The resultant expressions are Equations (2.14-3) through (2.14-7). The constants of the equations were obtained by a simple least-squares fit technique. A log function of the deviation from stoichiometry is reported to describe the oxygen vapor pressure for hypostoichiometric fuel. This was used in Equation (2.14-4) with good results. The fit procedure was to first 


\section{FVAPRS}

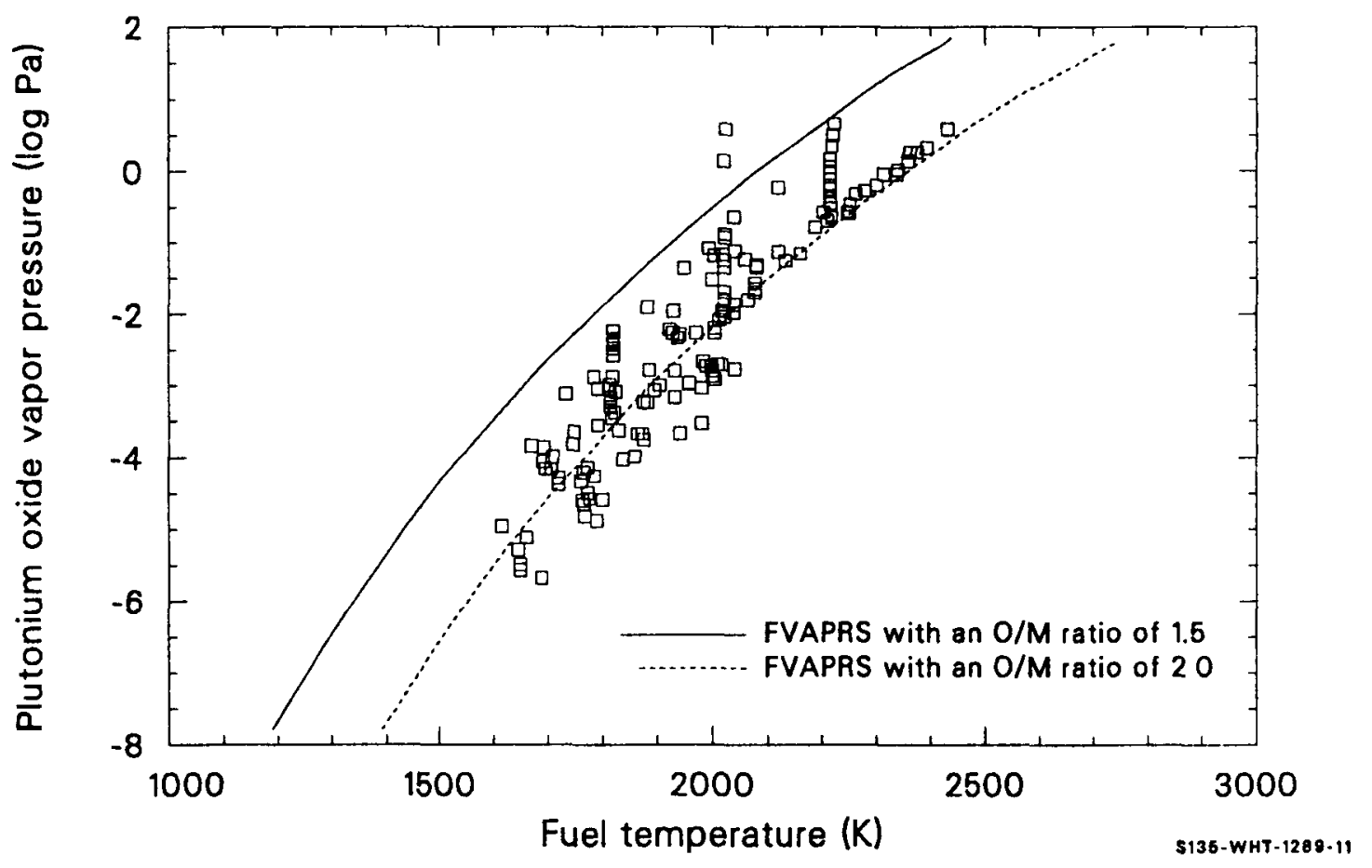

Figure 2.14-5. FVAPRS calculations (solid line) compared to plutonia data. 
FVAPRS

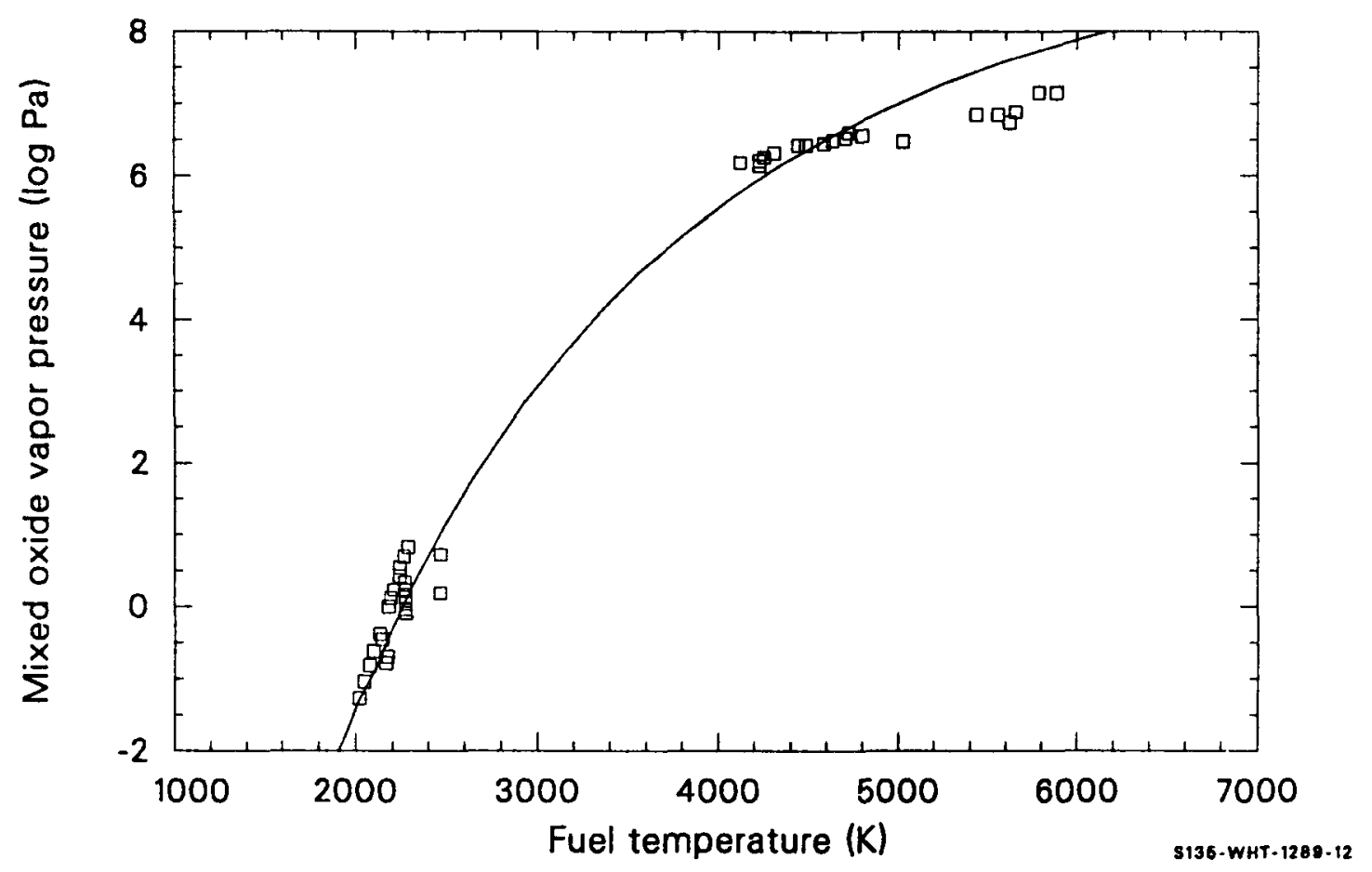

Figure 2.14-6. FVAPRS calculations (solid line) compared to mixed-oxide data. An oxygen-to-metal ratio of 2.0 was used in the FVAPRS calculations. 
FVAPRS

determine a composition normalization factor from a narrow range of temperature ( 1300 to $1400 \mathrm{~K}$ ). This was then used to normalize the data and develop the temperature-dependent function. The data of Tetenbaum and Hunt, 2.14-29 Markin, 2.14-30 Wheeler, ${ }^{2.14-31}$ and Alexander $2.14-10$ were used to develop the equation constants.

FVAPRS oxygen vapor pressure for hyperstoichiometric urania is defined in two composition regimes, 1.999 to 2.004 and 2.004 to 2.2. Data, especially those of Hagemark and Broli, 2.14-34 show an approximately linear increase in pressure as the $0 / M$ ratios increase from 2.004 to 2.2 ; they show an exponential increase as $0 / \mathrm{M}$ ratios increased from 1.999 to 2.004. Equations (2.14-3) and (2.14-5) were developed by determining a composition normalization factor, using the data of Hagemark and Broli.2.14-34 These normalization factors were then used in a least-squares-fit subroutine, using the data of Hagemark and Broli, Blackburn, 2.14-35 Aronson and Belle, ${ }^{2.14-36}$ and Markin and Bones $^{2.14-38}$ to obtain the final Equations (2.14-3) and (2.14-4).

To ensure that no discontinuity exists between the hyperstoichiometric and hypostoichiometric calculations, thermodynamic equations must be applied. At equilibrium, the reaction $\mathrm{O}_{2} * 20$ implies that

$2 \mu_{0}=\mu_{0_{2}}$

where

$$
\begin{aligned}
& \mu_{0}=\text { monatomic oxygen chemical potential } \\
& \mu_{0_{2}}=\text { diatomic oxygen chemical potential. }
\end{aligned}
$$

For ideal gases at equilibrium, the chemical potentials are

$$
\mu_{0}=\Delta G_{0}^{\circ}+R T \ln \left(P_{0}\right)
$$




\section{FVAPRS}

$\mu_{O_{2}}=\Delta G^{\circ}{ }_{2}+R T \ln \left(P_{0_{2}}\right)$

where

$$
\begin{aligned}
& \Delta G^{\circ}{ }_{0}=\text { heat of formation of monatomic oxygen (J) } \\
& \Delta G^{\circ} O_{2}=\text { heat of formation of diatomic oxygen (J) } \\
& R=\text { universal gas constant }(J / K) \\
& \mathrm{T}=\text { temperature }(\mathrm{K}) \\
& \mathrm{P}_{0} \quad=\quad \text { monatomic vapor pressure }(\mathrm{Pa}) \\
& \mathrm{P}_{2}=\text { diatomic vapor pressure }(\mathrm{Pa}) \text {. }
\end{aligned}
$$

Since $\Delta \mathrm{G}^{\circ} \mathrm{O}_{2}$ defined as zero, combining Equations (2.14-39)

through (2.14-41) and solving for $\log P_{0}$ gives

$1 / 2 \log P_{0_{2}}-\Delta G_{0}^{\circ}(2.303 R T)^{-1}=\log P_{0}$.

The heat of formation, or $\Delta G_{0}^{\circ}$, of Equation (2.14-42) has been reported by Markin2.14-30 and Breitung 2.14-40 among others. For the FVAPRS code, the Markin value was used

$\Delta G_{0}^{\circ}=61250-16.1 \mathrm{~T}$

which gives the following expression when substituted into Equation (2.14-41):

$\log P_{0_{2}}=2.0\left(\log P_{0}+13384.57 / T+3.52\right)$ 
Equation (2.14-44) is used with Equation (2.14-4) to find the diatomic pressure and limits the calculation of Equation (2.14-4) to the maximum calculated by Equation (2.14-3) at an 0/M ratio of 1.999. Equation (2.14-44) does not always produce reasonable results (especially at low temperatures) when used to compare different data sets. It should, therefore, be used with caution except in this case of defining continuity of equations.

Figure 2.14-7 shows the FVAPRS hypostoichiometric oxygen vapor pressure correlation (UOXVAP) predictions compared to the literature data. The FVAPRS predictions, using $0 / M$ ratios of 1.8 and 2.0 (solid lines) show fair agreement, and the correlation predictions bound vapor pressure data having $0 / \mathrm{M}$ ratios between 1.6 and 2.0. Figure 2.14-8 compares the FVAPRS hyperstoichiometric oxygen vapor pressure calculation (DIOVAP) at $0 / \mathrm{M}$ ratios of 2.004 and 2.2 to the 1 iterature data having $0 / \mathrm{M}$ ratios greater than 2.004. These calculations are also seen to yield pressures in the same range as the data. Because of the large scatter in the data, the standard error of estimate of the $\log$ of the data is large, \pm 0.545 in the case of hyperstoichiometric oxygen pressures and \pm 0.806 for hypostoichiometric oxygen pressures.

Correlations for urania (U02VAP), plutonia (PUOVAP), mixed oxide (VAPMIX), and monatomic oxygen (UOVAP) are compared in Figure 2.14-9. The calculated urania vapor pressures are the largest, with plutonia vapor pressures about an order of magnitude less and the oxygen vapor pressures (for $0 / \mathrm{M}$ ratios less than 2.0) even smaller. Oxygen vapor pressure calculations are probably not accurate above $4000 \mathrm{~K}$ (much above the data base temperatures), and the plutonia vapor pressure calculations are useful only to about $5500 \mathrm{~K}$.

\subsubsection{References}

2.14-1. T. E. Phipps, G. W. Sears, and 0. C. Simpson, "The Volatility of Plutonium Dioxide," Journal of Chemical Physics, 8, 1950. 


\section{FVAPRS}

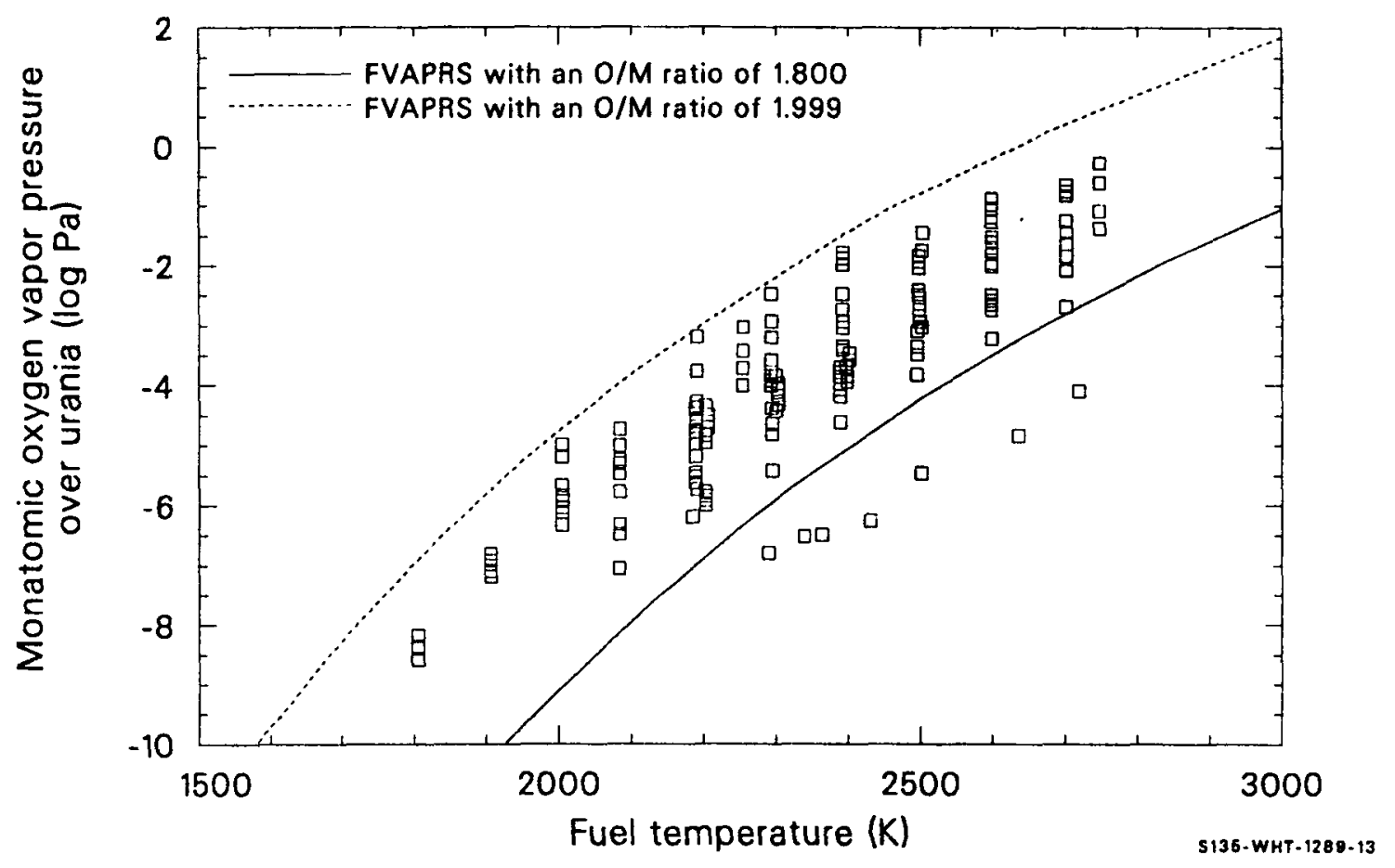

Figure 2.14-7. FVAPRS hypostoichiometric oxygen vapor pressure calculations (UOXVAP) compared to the data. 
FVAPRS

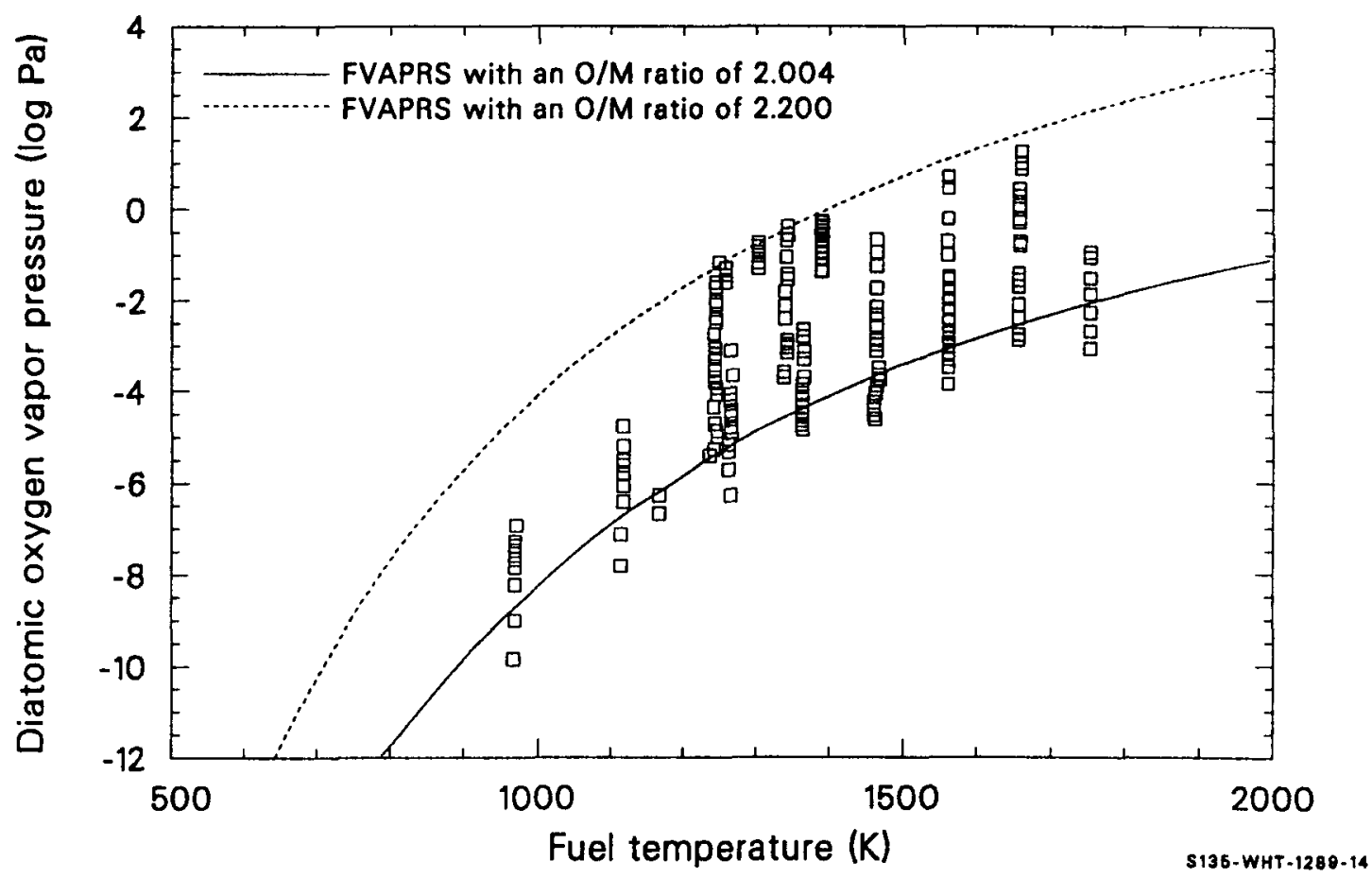

Figure 2.14-8. FVAPRS hyperstoichiometric oxygen vapor pressure calculations (DIOVAP) compared to the data. 
FVAPRS

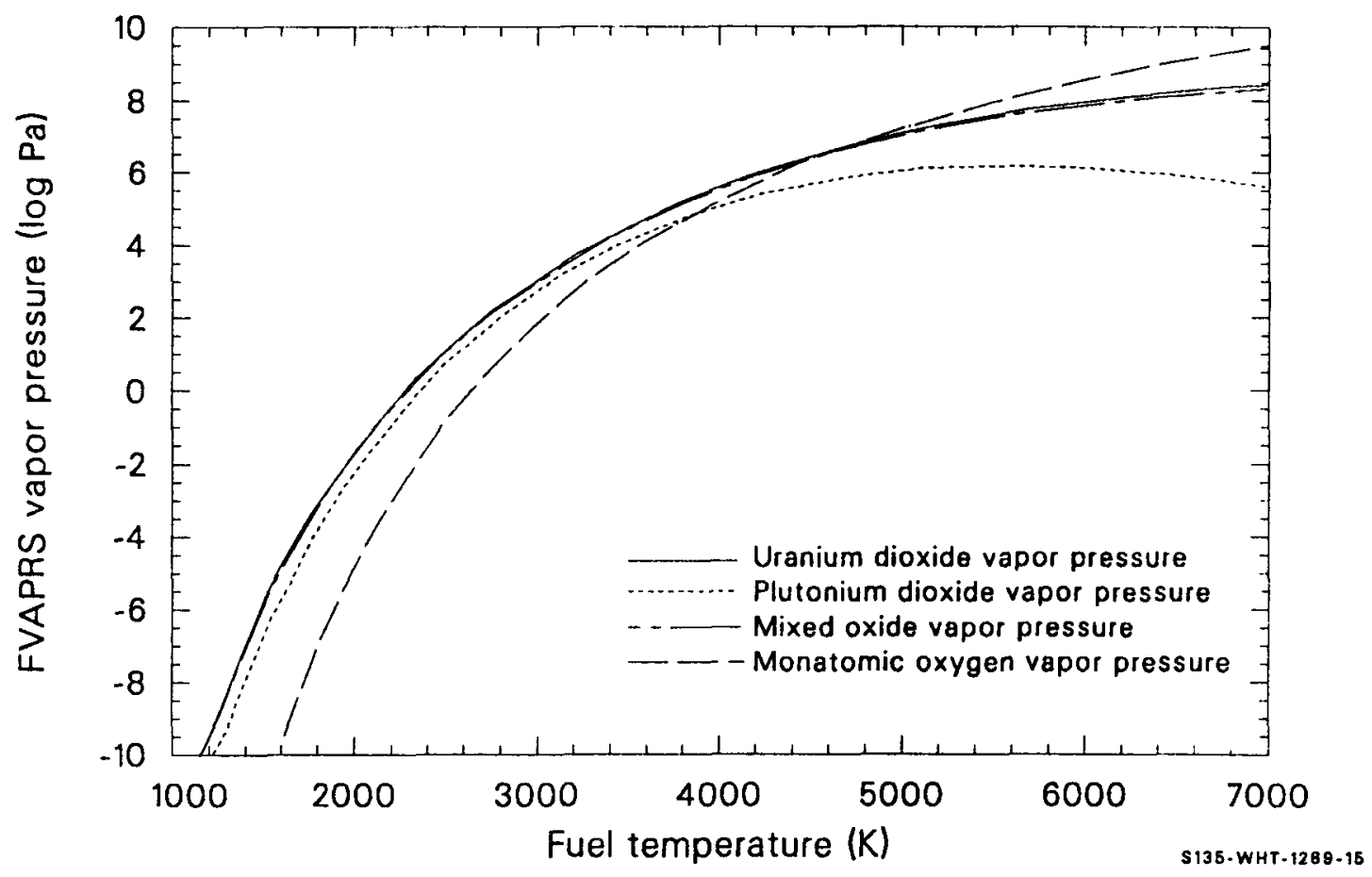

Figure 2.14-9. FVAPRS vapor pressure calculations of plutonia (PUOVAP), urania (U02VAP), mixed oxides (VAPMIX), and monatomic oxygen over urania (UOXVAP), using an oxygen-to-metal ratio of 2.0 . 
2.14-2. R. Szwarc and R. E. Latta, "Vapor Pressure of Hypostoichiometric Urania as a Function of Composition, " Journal of the American Ceramic Society, 51, 1968.

2.14-3. M. Bober, H. U. Karow and K. Schretzmann, "Vapor Pressure Measurements of Oxide Fuel Between 3000 and $5000 \mathrm{~K}$ Using Laser Heating," Nuclear Technology, 26, 1975.

2.14-4. G. T. Reedy and M. G. Chasanov, "Total Pressure of Uranium-Bearing Species Over Molten Urania," Journal of Nuclear Materials, 42, 1972, pp. 341-344.

2.14-5. R. J. Ackermann, E. G. Rauh, M. S. Chandrasekharaish, "A Thermodynamic Study of the Urania-Uranium System, "Journal of Physical Chemistry, 73, 1969, pp. 762-769.

2.14-6. M. Tetenbaum and P. D. Hunt, "Total Pressure of Urania-Bearing Species Over Oxygen-Deficient Urania," Journal of Nuclear Materials, 34, 1970, pp. 86-91.

2.14-7. G. Benezech, J. P. Coutures, and M. Fox, Transpiration Study of Uranium Dioxide Vaporization Processes Between $2200 \mathrm{~K}$ and $2600 \mathrm{~K}$, ANL-TRANS-972, 1974.

2.14-8. R. W. Ohse, P. G. Berrie, H. G. Bogensberger, E. A. Fischer, "Extension of Vapor Pressure Measurements of Nuclear Fuels $\left(\mathrm{U}, \mathrm{Pu} \mathrm{O}_{2}\right.$ and $\mathrm{UO}_{2}$ to $7000 \mathrm{~K}$ for Fast Reactor Safety Analysis," Journal of Nuclear Materials, 59, 1976, pp. 112-124.

2.14-9. R. W. Ohse, P. G. Berrie, H. G. Bogensberger, E. A. Fischer, "Measurement of Vapor Pressure of $(\mathrm{U}, \mathrm{Pu}) \mathrm{O}_{2}$ and $\mathrm{UO}_{2}$ to $5000 \mathrm{~K}$ for Fast Reactor Safety Analysis and the Contribution of the Radial Cs Distribution to Fuel Pin Failure, "Thermodynamics of Nuclear Materials, 1, IAEA-SM-190/8, Vienna 1975.

2.14-10. C. A. Alexander, J. S. Ogden, and G. W. Cunningham, Thermal Stability of Zirconia-and Thoria Based Fuels, BMI-1789, 1967.

2.14-11. R. J. Ackermann, The High Temperature, High Vacuum Vaporization and Thermodynamic Properties of Uranium Dioxide, ANL-5482, 1955.

2.14-12. R. J. Ackermann, P. W. Gilles and R. J. Thorn, "High-Temperature Thermodynamic Properties of Uranium Dioxide," Journal of Chemical Physics, 25, 1956.

2.14-13. Ackermann et al., Journal of Chemical Physics, 49, 1968) p. 4739.

2.14-14. A. T. Chapman and R. E. Meadows, "Volatility of $\mathrm{UO}_{2+x}$ and Phase Relations in the System Uranium-0xygen, "Journal of the American Ceramic Society, 47, 1964. 


\section{FVAPRS}

2.14-15. A. T. Chapman and R. E. Meadows, The Volatility of $\mathrm{VO}_{2+x}$ and Phase Relations in the Uranium-Oxygen System, ORNL-3587, 1964.

2.14-16. R. W. Ohse, "High-Temperature Vapor-Pressure Studies of $\mathrm{UO}_{2}$ by the Effusion Method and Its Thermodynamic Interpretation, "Journal of Chemical Physics, 44, 1966.

2.14-17. D. A. Benson, Application of Pulsed Electron Beam Vaporization to Studies of $\mathrm{UO}_{2}$, SAND-77-0429, 1977.

2.14-18. J. R. Babelot, G. D. Brumme, P. R. Kinsmann, and R. W. Ohse, "Vapor Pressure Measurement Over Liquid $\mathrm{UO}_{2}$ and $(U, \mathrm{PU}) \mathrm{O}_{2}$ by Laser Surface Heating up to $5000 \mathrm{~K}$, "Atomwirtschaft, 1977.

2.14-19. R. W. Ohse and C. Ciani, "Evaporation Behavior and High-Temperature Thermal Analysis of Substoichiometric Plutonium Oxide for $1.51<0 / \mathrm{Pu}<2.00, "$ Thermodynamics of Nuclear Materials, Vienna: IAEA, 1968.

2.14-20. R. J. Ackermann, R. L. Faircloth, M. H. Rand, "A Thermodynamic Study of the Vaporization Behavior of the Substoichiometric Plutonium Dioxide Phase," Journal of Physical Chemistry, 70, 1966.

2.14-21. T. E. Phipps, G. W. Sears, 0. C. Simpson, "The Volatility of Plutonium Dioxide," Journal of Chemical Physics, 8, 1950.

2.14-22. W. M. Pardue and D. L. Keller, "Volatility of Plutonium Dioxide, "Journal of Chemical Physics, 8, 1950.

2.14-23. R. N. R. Mulford and L. E. Lamar, "The Volatility of Plutonium 0xide (31)," Plutonium 1960--The Proceedings of the Second International Conference on Plutonium Metallurgy, Grenoble, France, 1960, pp. 411-429.

2.14-24. M. Tetenbaum, "Tota1 Pressures of Uranium and Plutonium-Bearing Species Above the U-Pu-O System," Transactions of the American Nuclear Society, 23, 1976.

2.14-25. R. W. Ohse and W. M. 01son, "Evaporation Behavior of Substoichiometric (U, Pu) $\mathrm{O}_{2}$, "Proceedings of the 4 th International Conference on Plutonium and other Actinides, Santa Fe, New Mexico, 1970.

2.14-26. J. E. Battles, W. A. Shinn, P. E. Blackburn, R. K. Edwards, "A Mass Spectrometric Investigation of the Volatization Behavior of $\left(U_{0.8}\right.$ $\left.\mathrm{Pu}_{0}{ }_{2}\right) \mathrm{O}_{2-\mathrm{x}}$, Proceedings of the 4 th International Conference on Plutonium and Other Actinides, Santa Fe, New Mexico, 1970. 
2.14-27. E. A. Aitken, H. C. Brassfield, and R. E. Fryxe11, "Thermodynamic Behavior of Hypostoichiometric $\mathrm{UO}_{2}$, "Thermodynamics, Vienna: IAEA, 1966.

2.14-28. T. L. Markin and M. H. Rand, "Thermodynamic Data for Plutonium Oxides," Thermodynamics, Vienna: IAEA, 1965, pp. 145-156.

2.14-29. M. Tetenbaum and P. D. Hunt, "High Temperature Thermodynamic Properties of Oxygen-Deficient Urania," Journal of Chemical Physics, 49, 1968.

2.14-30. T. L. Markin, V. J. Wheeler, and R. J. Bones, "High Temperature Thermodynamic Data for $\mathrm{UO}_{2+x}$, Journal of Inorganic Nuclear Chemistry, 30, 1968.

2.14-31. V. J. Wheeler, "High Temperature Thermodynamic data for $\mathrm{UO}_{2-\mathrm{x}}$," Journal of Nuclear Materials, 39, 1971, pp. 315-318.

2.14-32. N. A. Javed, "Thermodynamic Study of Hypostoichiometric Urania," Journal of Nuclear Materials, 43, 1972, pp. 219-224.

2.14-33. L. E. J. Roberts and A. J. Walter, "Equilibrium Pressures and Phase Relations in the Uranium Oxide System," Journal of Inorganic Nuclear Chemistry, 22, 1961, pp. 213-229.

2.14-34. K. Hagemark and M. Broli, "Equilibrium Oxygen Pressures Over Nonstoichiometric Uranium Oxides Between $\mathrm{UO}_{2+x}$ and $\mathrm{U}_{3} \mathrm{O}_{8-7}$ at Higher Temperatures, "Journal of Inorganic Nuclear Chemistry, 28, 1966.

2.14-35. P. E. Blackburn, "Oxygen Dissociation Pressures Over Uranium Oxides, "Journal of Physical Chemistry, 8, 1958, pp. 897-902.

2.14-36. S. Aronson and U. Belle, "Nonstoichiometry in Uranium Dioxide," Journal of Chemical Physics, 29, 1958.

2.14-37. K. Kiukkola, "High-Temperature Electrochemical Study of Uranium Oxides in the $\mathrm{U0}_{2-x}$ Region," Acta Chemical Scandinavica, 16, 1962, pp. 327-345.

2.14-38. T. L. Markin and R. J. Bones, The Determination of Some Thermodynamic Properties of Uranium Oxides with O/U Ratios Between 2.00 and 2.03 Using a High Temperature Galvanic Cell, AERE-R 4178, 1962.

2.14-39. E. Aukrust, T. Forland and K. Hagemark, "Equilibrium Measurements and Interpretation of Non-Stoichiometry in $\mathrm{UO}_{2+x}$ " Procedures of the IAEA Symposium on Thermodynamics of Nuclear Materials, Vienna, 1962 . 


\section{FVAPRS}

2.14-40. W. Breitung, Calculation of Vapor Pressures of Oxide Fuels up to $5000 \mathrm{~K}$ for Equilibrium and Non-Equilibrium Evaporation, KfK-2091, 1975.

\subsubsection{Bibliography}

The following list of reference material is pertinent to a literature review and was consulted by the FVAPRS code developer.

(1) J. Dorwart, A. Pattoret, S. Smoes, Procedure of the British Ceramic Society, 8, 1967, p. 67.

(2) G. H. Winslow, "An Examination of the Total Pressure Over Hypostoichiometric Uranium Dioxide," High Temperature Science, 7, 1975, pp. 81-102.

(3) P. A. Finn, A. Sheth, and L. Leibowitz," Equation of State of Uranium Dioxide," Journal of Nuclear Material, 79, 1979, pp. 14-19.

(4) R. A. Meyer and B. E. Wolfe, "High-Temperature Equation of State of Uranium Dioxide, Transactions of the American Nuclear Society, 7, 1964, pp. 14-17.

(5) R. K. Edwards, M. S. Chandrasekharaish, and P. M. Danielson, "The Congruently Evaporating Compositions of Urania," High Temperature Science, 1, 1969, pp. 98-113.

(6) R. A. Meyer and B. E. Wolfe, "High Temperature Equation of State of Uranium Dioxide," Transactions of the American Nuclear Society, 7, 1964.

(7) G. H. Winslow, "An Examination of the Oxygen Pressure Over Hypostoichiometric Uranium Dioxide," High Temperature Science, 5, 1973, pp. 176-191.

(8) J. L. Margrave, The Characterization of High-Temperature Vapors, New York: John Wiley and Sons, Inc., 1967.

(9) J. R. Thorn and G. H. Winslow, Journal of Chemical Physics, 44, 1966. 


\section{URANIUM ALLOYS}

As the need for uranium metal materials properties became apparent, correlations for the specific heat capacity (UCP), enthalpy (UENTHL), thermal conductivity (UTHCON), thermal expansion (UTHEXP), and density (UDEN) were developed for the MATPRO package of materials properties subcodes. Descriptions of these subcodes and required input are given in this section. 



\section{UCP， UENTHL}

\subsection{Specific Heat Capacity and Enthalpy (UCP, Uenthl)}

(J. K. Hohorst)

The function UCP calculates the specific heat capacity of uranium metal as a function of temperature. The function UENTHL calculates the enthalpy of uranium metal as a function of temperature and a reference temperature (for which the enthalpy change will be zero).

\subsubsection{Specific Heat Capacity (UCP)}

The function UCP calculates the specific heat capacity of uranium metal from equations derived from data reported by Touloukian $3.1-1$ and listed in Tables 3.1-1 through 3.1-3. Specific heat capacity data for the alpha phase $(300 \leq T<938 \mathrm{~K})$ were approximated using a least-squares fit to a second-degree polynomial. An average of the data for the beta $(938 \leq T<1049 \mathrm{~K})$ and gamma $(1049 \leq T<1405.6 \mathrm{~K})$ phases was used to determine a constant specific heat capacity for these phases because sample-to-sample variation was greater than variation with temperature. Since no data were found for the liquid specific heat capacity, the gamma-phase specific heat capacity was used as an estimate.

The following expressions were used to calculate the specific heat capacity of uranium metal:

For $T<938 \mathrm{~K}$,

$C_{p}=104.82+5.3686 \times 10^{-3} \mathrm{~T}+10.1823 \times 10^{-5} \mathrm{~T}^{2}$.

For $938 \leq \mathrm{T}<1049 \mathrm{~K}$, 
UCP， UENTHL

Table 3.1-1. Alpha-phase uranium specific heat capacity data

\begin{tabular}{l}
$\begin{array}{c}\text { Temperature } \\
(\mathrm{K})\end{array}$ \\
\hline 300.104 \\
307.465 \\
327.514 \\
337.489 \\
347.549 \\
304.95 \\
314.904 \\
323.15 \\
373.15 \\
573.15 \\
623.15 \\
673.15 \\
723.15 \\
773.15 \\
823.15 \\
873.15 \\
298. \\
300. \\
400. \\
500. \\
600. \\
700. \\
800. \\
900. \\
935. \\
373.15 \\
473.15 \\
573.15 \\
673.15 \\
773.15 \\
873.15 \\
933.15 \\
323.15 \\
373.15 \\
423.15 \\
473.15 \\
523.15 \\
573.15 \\
623.15 \\
673.15 \\
723.15 \\
773.15 \\
823.15 \\
\\
\hline
\end{tabular}

Specific Heat Capacity $(\mathrm{cal} / \mathrm{g} \cdot \mathrm{K})$

0.02779

0.02793

0.02834

0.02853

0.02868

0.02789

0.02806

0.0268

0.0284

0.0345

0.0362

0.0378

0.0394

0.041

0.0425

0.044

0.02758

0.0276

0.0295

0.0323

0.03543

0.03873

0.04212

0.0455

0.04676

0.0278

0.0296

0.0324

0.0353

0.0392

0.0437

0.0466

0.0283

0.02919

0.03022

0.03135

0.03257

0.03388

0.03529

0.03681

0.03846

0.04031

0.04253 
UCP， UENTHL

Table 3.1-1. (continued)

$\begin{array}{ll}\begin{array}{c}\text { Temperature } \\ (\mathrm{K})\end{array} & \begin{array}{l}\text { Specific Heat Capacity } \\ (\mathrm{cal} / \mathrm{g} \cdot \mathrm{K})\end{array} \\ & 0.04521 \\ 923.15 & 0.04818 \\ 941.15 & 0.0493\end{array}$

Table 3.1-2. Beta-phase uranium specific heat capacity data

$\begin{array}{cc}\begin{array}{c}\text { Temperature } \\ (\mathrm{K})\end{array} & \begin{array}{c}\text { Specific Heat Capacity } \\ (\mathrm{ca} / \mathrm{g} \cdot \mathrm{K})\end{array} \\ 935 & 0.0436 \\ 950 & 0.0436 \\ 1000 & 0.0436 \\ 1045 & 0.0436 \\ 953.15 & 0.0394 \\ 973.15 & 0.0396 \\ 1043.15 & 0.0397 \\ 1063.15 & 0.034 \\ 1073.15 & 0.034 \\ 941.15 & 0.04262 \\ 973.15 & 0.04262 \\ 1023.15 & 0.04262 \\ 1047.15 & 0.04262\end{array}$

Table 3.1-3. Gamma-phase uranium specific heat capacity data

\begin{tabular}{lc}
$\begin{array}{c}\text { Temperature } \\
(\mathrm{K})\end{array}$ & $\begin{array}{c}\text { Specific Heat Capacity } \\
\text { (cal/g・K) }\end{array}$ \\
\cline { 2 - 2 } 1045 & 0.03822 \\
1100 & 0.03822 \\
1200 & 0.03822 \\
1300 & 0.03822 \\
1047.15 & 0.03843 \\
1073.15 & 0.03843 \\
1123.15 & 0.03843 \\
1173.15 & 0.03843
\end{tabular}




\section{UCP， UENTHL}

$$
C_{p}=176.41311
$$

For $\mathrm{T} \geq 1049 \mathrm{~K}$,

$$
C_{p}=156.80756
$$

where

$$
\begin{aligned}
& C_{p}=\text { uranium metal specific heat capacity }(\mathrm{J} / \mathrm{kg} \cdot \mathrm{K}) \\
& T=\text { uranium metal temperature }(K) .
\end{aligned}
$$

The first three equations represent the alpha, beta, and gamma solid phases of uranium, while the fourth equation represents the liquid phase.

Figure 3.1-1 is a plot of the specific heat capacity for uranium metal calculated by the function UCP.

\subsubsection{Enthalpy (UENTHL)}

The function UENTHL calculates the change in enthalpy of the uranium metal during a constant pressure change from the reference temperature of $300 \mathrm{~K}$ to the temperature of the uranium metal. The uranium specific heat capacity equations calculated in UCP were integrated piecewise over the alpha, beta, and gamma temperature ranges to determine the uranium enthalpy. A constant of integration was determined to force an enthalpy of zero at $300 \mathrm{~K}$. (This number will not affect code calculations because the subroutine UENTHL uses a reference temperature of $300 \mathrm{~K}$ and subtracts the calculated enthalpy at this reference temperature from the calculated enthalpy at the temperature of interest.) Heats of transformation taken from Tipton $3 \cdot 1-2$ were: 
UCP, UENTHL
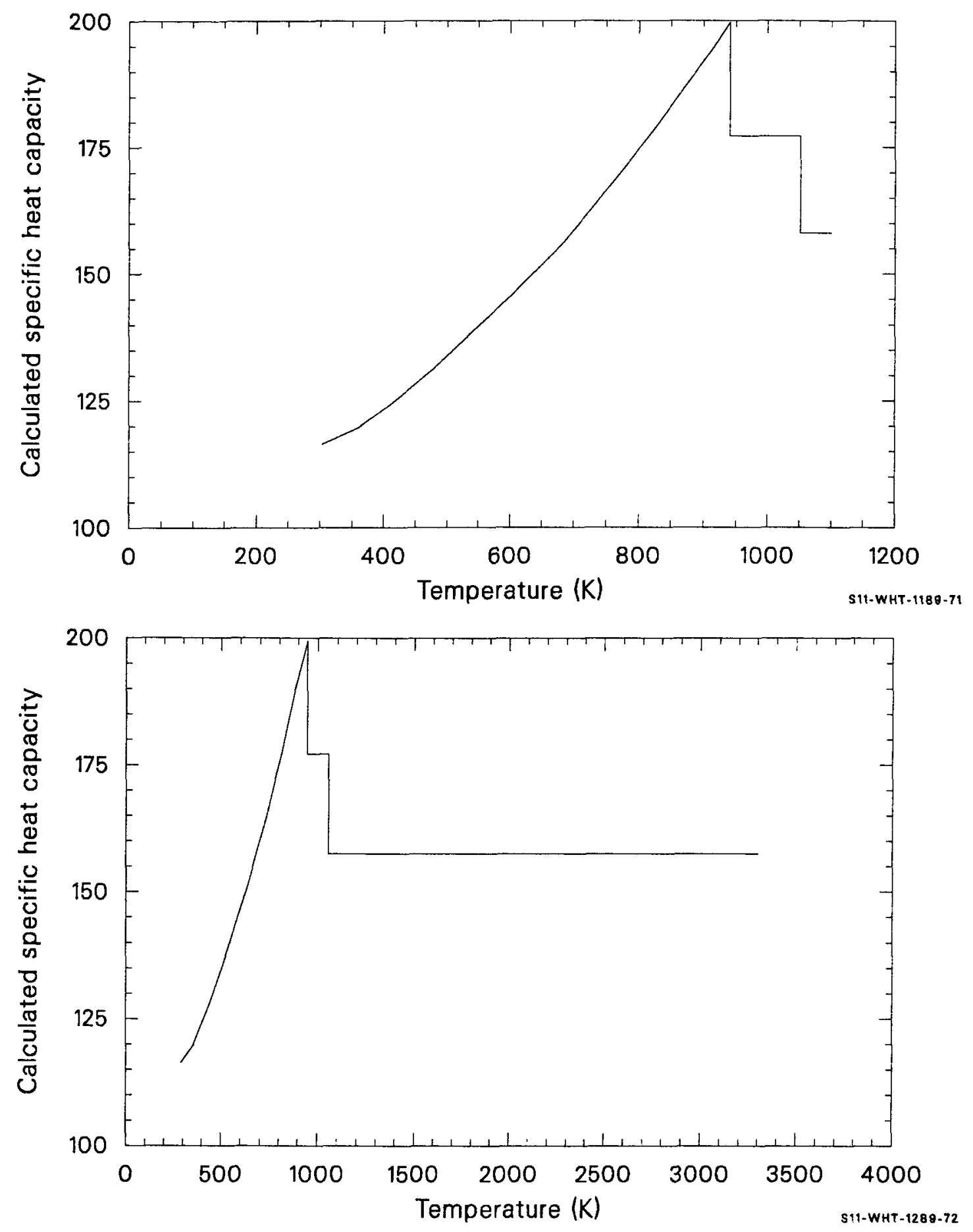

Figure 3.1-1. Specific heat capacity for uranium metal caiculated by UCP. 


\section{UCP， UENTHL}

$$
\begin{array}{ll}
\text { alpha-to-beta } & 12500 \mathrm{~J} / \mathrm{kg} \\
\text { beta-to-gamma } & 20060 \mathrm{~J} / \mathrm{kg} \\
\text { gamma-to-1 iquid } & 82350 \mathrm{~J} / \mathrm{kg}
\end{array}
$$

The expressions used to calculate the enthalpy of the uranium metal in this function are as follows:

For $300<T<938 \mathrm{~K}$,

$$
\begin{aligned}
H_{u}= & -3.255468 \times 10^{4}+T\left[1.0466 \times 10^{2}+T\left(2.685 \times 10^{-03}\right.\right. \\
& \left.\left.+3.389 \times 10^{-05} \mathrm{~T}\right)\right] . \\
& \text { For } 938 \leq \mathrm{T}<1049 \mathrm{~K}, \\
H_{u}= & -5.1876776 \times 10^{4}+1.7092 \times 10^{2} \mathrm{~T} .
\end{aligned}
$$

For $1049 \leq \mathrm{T}<1405.6 \mathrm{~K}$,

$$
H_{u}=-2.0567496 \times 10^{-4}+1.602 \times 10^{2} \mathrm{~T} .
$$

For $\mathrm{T} \geq 1405.6 \mathrm{~K}$,

$$
H_{u}=6.177850 \times 10^{5}+1.602 \times 10^{2} \mathrm{~T}
$$

where

$$
\begin{aligned}
& H_{U}=\text { uranium metal enthalpy }(\mathrm{J} / \mathrm{kg}) . \\
& T \quad=\text { uranium metal temperature }(\mathrm{K})
\end{aligned}
$$

The first three equations represent the alpha, beta, and gamma solid phases of uranium, while the fourth equation represents the liquid phase. 


\section{UCP， UENTHL}

Figure 3.1-2 is a plot of the enthalpy change for uranium metal returned by the function UENTHL.

\subsubsection{References}

3.1-1. Y. S. Touloukian, E. H. Buyco, Thermal Physical Properties of Matter, V4, Specific Heat - Metallic Elements and Alloys, New York: IFI/Plenum, 1970, p.270.

3.1-2. C. R. Tipton, Jr., Reactor Handbook, New York: Interscience Publishers, Inc., p. 113. 
UCP， UENTHL
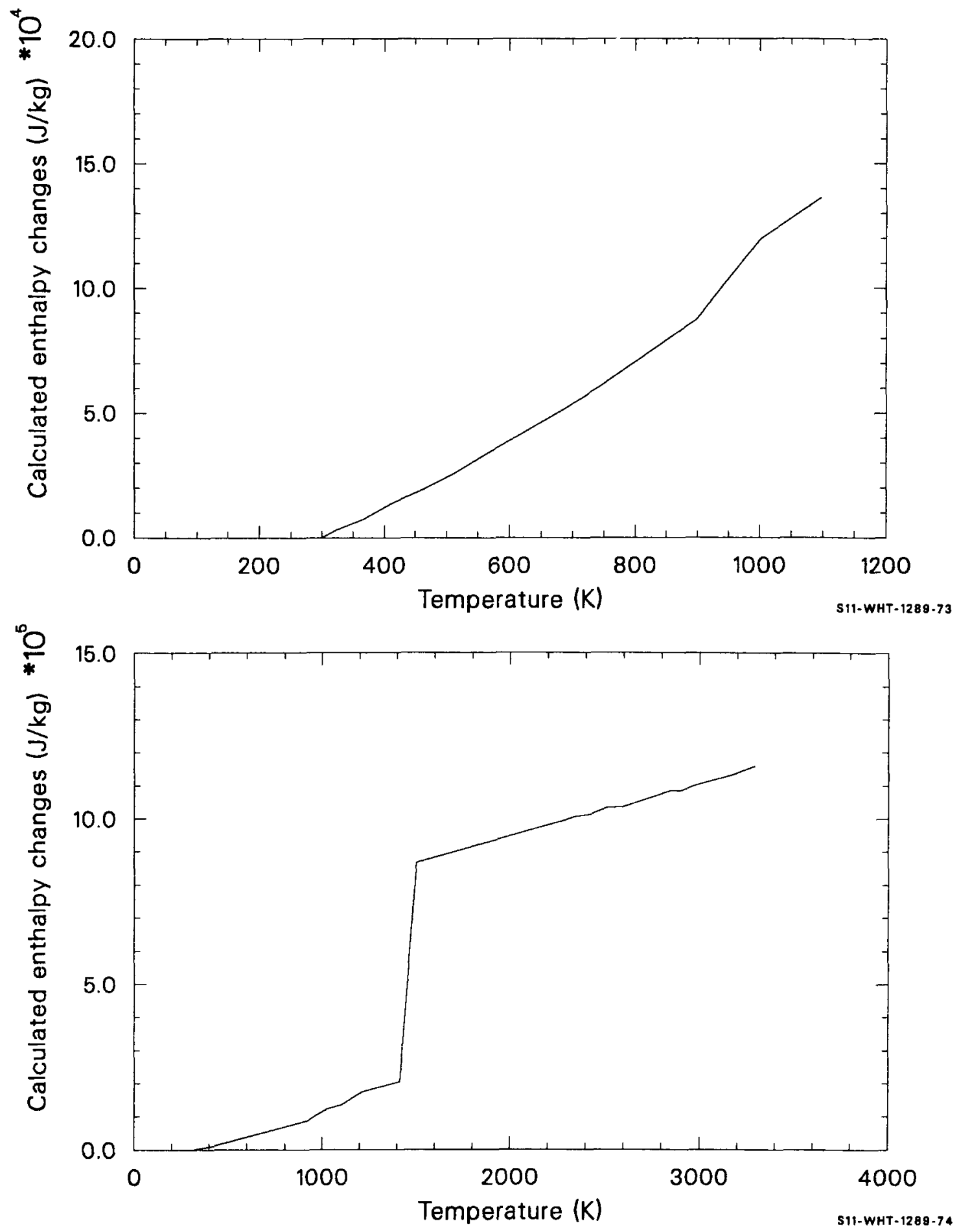

Figure 3.1-2. Enthalpy change for uranium metal calculated by UENTHL. 


\section{UTHCON}

\subsection{Thermal Conductivity (UTHCON)}

(J. K. Hohorst)

The thermal conductivity of uranium metal as a function of temperature is calculated by the function UTHCON. The only input required is the temperature of the uranium metal (UTEMP).

\subsubsection{Model Development}

Since the thermal conductivity of uranium metal is not significantly affected by the phase changes that take place during the heating of uranium metal, the single equation used to calculate the thermal conductivity of uranium metal for temperatures less than the melting point $(1405.6 \mathrm{~K})$ is obtained from a polynomial fit of the temperatures and thermal conductivity values obtained in Reference 3.2-1. These values are shown in Table 3.2-1. The correlation used to calculate the thermal conductivity is as follows:

$K_{S}=20.457+1.2047 \times 10^{-2} \mathrm{~T}-5.7368 \times 10^{-6} \mathrm{~T}^{2}$

where

$\mathrm{K}_{\mathrm{S}}=$ uranium metal thermal conductivity $(\mathrm{W} / \mathrm{m} \cdot \mathrm{K})$

$\mathrm{T}=$ uranium metal temperature (K).

The expected standard error of the predicted conductivities is \pm 0.2 times the calculated conductivity. A plot of the thermal conductivities calculated by UTHCON is shown in Figure 3.2-1. 


\section{UTHCON}

Table 3.2-1. Uranium metal thermal conductivity from Touloukian et al.

\begin{tabular}{|c|c|}
\hline $\begin{array}{c}\text { Temperature } \\
(\mathrm{K})\end{array}$ & $\begin{array}{c}\text { Thermal Conductivity } \\
(\mathrm{W} / \mathrm{m} \cdot \mathrm{K})\end{array}$ \\
\hline $\begin{array}{l}255.4 \\
255.4 \\
310.9 \\
310.9 \\
311.2 \\
318.2 \\
323.2 \\
353.2 \\
353.2 \\
358.2 \\
383.2 \\
398.2 \\
408.2 \\
422.1 \\
423.2 \\
458.2 \\
469.2 \\
473.2 \\
533.2 \\
548.2 \\
567.9 \\
573.2 \\
644.3 \\
673.3 \\
755.4 \\
773.2 \\
866.5 \\
873.2 \\
933.2 \\
949.9 \\
973.3 \\
977.6 \\
1002.6 \\
1005.4 \\
1033.2 \\
1073.2 \\
1173.2\end{array}$ & $\begin{array}{l}21.4 \\
22.6 \\
22.4 \\
23.5 \\
25.5 \\
25.5 \\
24.3 \\
26.4 \\
24.5 \\
25.9 \\
26.8 \\
28.5 \\
27.2 \\
24.4,25.4 \\
30.1 \\
29.3 \\
27.5 \\
28.6 \\
26.5,27.4 \\
34.7 \\
29.5 \\
30.9 \\
28.6,29.3 \\
33.1 \\
31.1,31.1 \\
35.4 \\
33.6,33.2 \\
37.3 \\
34.8 \\
35.9 \\
40.0 \\
36.9 \\
37.4 \\
37.9 \\
38.9 \\
42.3 \\
44.6 \\
2\end{array}$ \\
\hline
\end{tabular}




\section{UTHCON}

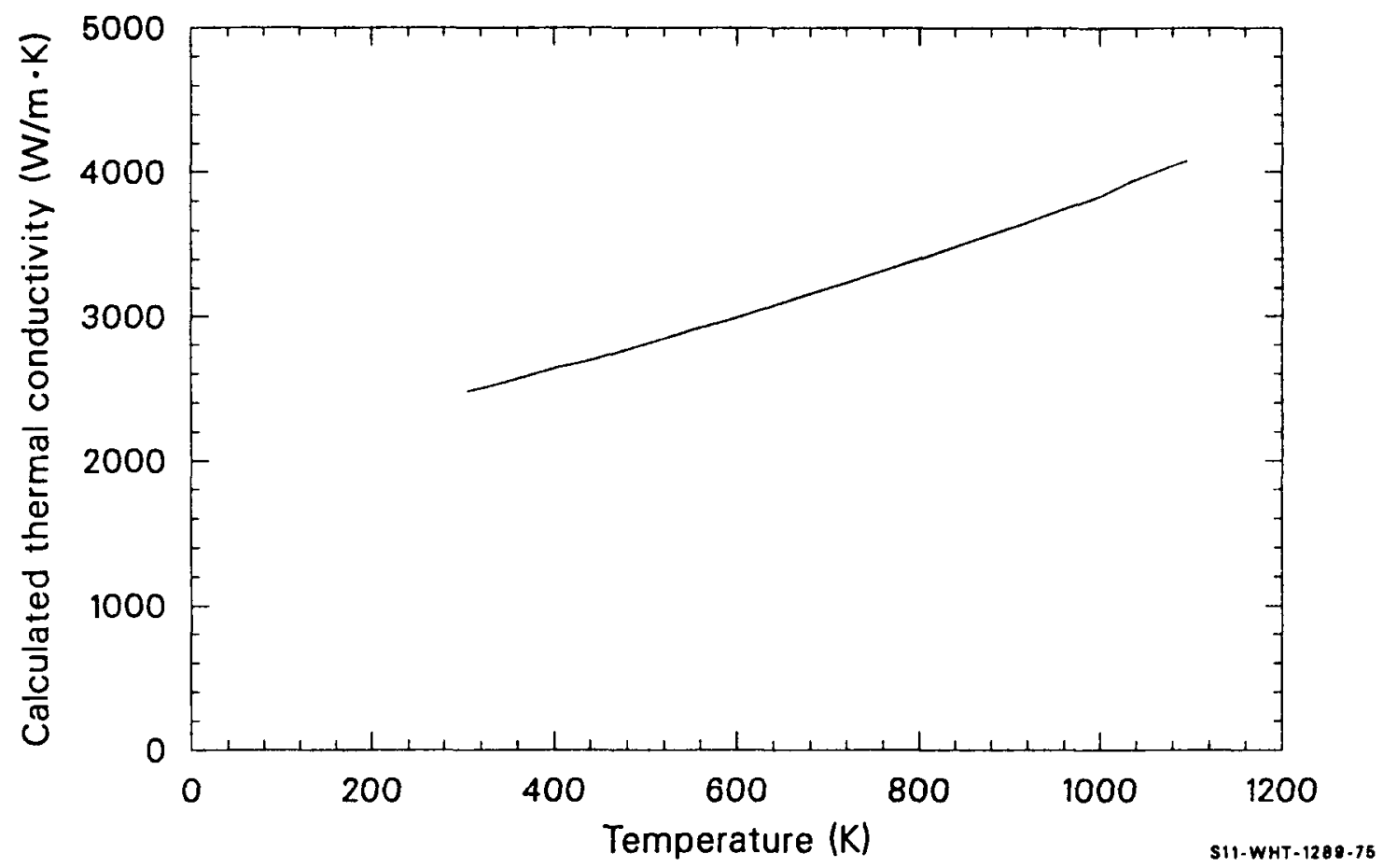

Figure 3.2-1. Thermal conductivities for uranium metal calculated by UTHCON. 


\section{UTHCON}

\subsubsection{References}

3.2-1. Y. S. Touloukian, R. W. Powell, C. Y. Ho, P. G. Klemens, Thermal Physical Properties of Matter, V1, Thermal Conductivity-Metallic Elements and Alloys, New York: IFI/Plenum, 1970, pp. 429-440. 


\section{UTHEXP，UDEN}

\subsection{Thermal Expansion and Density (UTHEXP, UDEN)}

(J. K. Hohorst)

The function UTHEXP calculates the polycrystalline uranium metal thermal expansion strain, and the function UDEN computes the density from $300 \mathrm{~K}$ to the melting point of the uranium metal, $1132.3 \mathrm{~K}$. Input values required for UTHEXP are the uranium metal temperature and a reference temperature (for which the thermal strain will be zero), while UDEN requires only the uranium metal temperature.

\subsubsection{Thermal Expansion (UTHEXP)}

The expressions used to calculate the uranium metal thermal expansion strains are:

For $300<T<942 \mathrm{~K}$,

$$
\epsilon_{\mathrm{u}}=\left[-0.30033+\mathrm{T}\left(7.1847 \times 10^{-4}+1.0498 \times 10^{-6} \mathrm{~T}\right)\right] / 100 .
$$

For $942 \leq T<1045 \mathrm{~K}$,

$$
\epsilon_{u}=\left(-0.28340+1.9809 \times 10^{-3} \mathrm{~T}\right) / 100 .
$$

For $1045 \leq T \leq 1132.3 \mathrm{~K}$,

$$
\epsilon_{u}=\left(-0.27120+2.2298 \times 10^{-3} \mathrm{~T}\right) / 100
$$

where 


\section{UTHEXP, UDEN}

$$
\begin{aligned}
& \epsilon_{\mathrm{u}}=\text { uranium metal thermal strain }(\mathrm{m} / \mathrm{m}) \\
& \mathrm{T}=\text { uranium metal temperature }(\mathrm{K})
\end{aligned}
$$

At the present time, the phase change to liquid is not modeled.

A polynomial fit of the thermal expansion data from Touloukian 3.3-1 shown in Table 3.3-1 yields an expression that can be integrated to produce Equation (3.3-1). Equations (3.3-2) and (3.3-3) are derived by using a linear fit of the thermal expansion rates given in Tables 3.3-2 and 3.3-3, respectively. The constant of integration is ignored because the quantity returned by UTHEXP is the strain calculated by Equations (3.3-1), (3.3-2), or (3.3-3) at the given temperature minus the strain calculated at the reference temperature $(300 \mathrm{~K})$.

Uranium metal goes through two phase changes, one at approximately $942 \mathrm{~K}$ and another at approximately $1045 \mathrm{~K}$. The discontinuous change in thermal strain at these phase changes is the reason three different equations are used to calculate $\epsilon_{u}$. Each equation calculates the thermal expansion strain of one phase. (The expected standard error for these curves is about 0.1 times the calculated value).

\subsubsection{Density (UDEN)}

The function UDEN uses the general relation between density and thermal strain, together with a reference density of $1.905 \times 10^{4} \mathrm{~kg} / \mathrm{m}^{3}$, the density of uranium at $300 \mathrm{~K} \cdot{ }^{3.3-2}$ The thermal expansion strain as a function of temperature calculated by UTHEXP using a reference temperature of $300 \mathrm{~K}$ is illustrated in Figure 3.3-1, and the density calculated by UDEN using the thermal strain calculated by UTHEXP is shown in Figure 3.3-2. 


\section{UTHEXP，UDEN}

Table 3.3-1. Uranium thermal expansion data from Touloukian et al.3.3-1 for temperature $<942 \mathrm{~K}$

\begin{tabular}{c} 
Temperature \\
$(\mathrm{K})$ \\
\hline 0 \\
20 \\
40 \\
60 \\
80 \\
100 \\
120 \\
140 \\
160 \\
180 \\
200 \\
220 \\
240 \\
260 \\
273 \\
280 \\
291 \\
293 \\
300 \\
373 \\
473 \\
573 \\
673 \\
773 \\
873
\end{tabular}

$$
\begin{aligned}
& \text { Thermal Strain } \\
& \left(10^{-3} \mathrm{~m} / \mathrm{m}\right) \\
& -.263,-.18 \\
& -.267,-.184,-.265 \\
& -.312,-.257 \\
& -.306,-.258,-.296 \\
& -.302,-.237,-.280 \\
& -.259,-.215,-.258 \\
& -.233,-.192,-.234 \\
& -.206,-.170,-.207 \\
& -.179,-.148,-.180 \\
& -.159,-.126,-.153 \\
& -.123,-.104,-.126 \\
& -.095,-.081,-.099 \\
& -.068,-.059,-.072 \\
& -.179,-, 148,-.180 \\
& -.022,-.022 \\
& -.013,-.015,-.018 \\
& -.0032 \\
& 0.00 \\
& .014, .009, .008 \\
& .127, .118 \\
& .306, \quad .268 \\
& .424, \quad .506 \\
& .728, \quad .594 \\
& .972, \quad .780 \\
& 1.238,1.000
\end{aligned}
$$




\section{UTHEXP， UDEN}

Table 3.3-2. Uranium thermal expansion data from Touloukian et a1.3.3-1 $942 \mathrm{~K} \leq \mathrm{T}<1045 \mathrm{~K}$

\begin{tabular}{cc}
$\begin{array}{c}\text { Temperature } \\
(\mathrm{K})\end{array}$ & $\begin{array}{c}\text { Therma1 Strain } \\
\left(10^{-3} \mathrm{~m} / \mathrm{m}\right)\end{array}$ \\
\hline 935 & 1.618 \\
942 & 1.515 \\
948 & 1.643 \\
973 & 1.577 \\
973 & 1.685 \\
998 & 1.731 \\
1000 & 1.629 \\
1023 & 1.743 \\
1045 & 1.813 \\
\hline
\end{tabular}

Table 3.3-3. Uranium thermal expansion data from Touloukian et a1.3.3-1 $\mathrm{T} \geq 1045 \mathrm{~K}$

Temperature

\begin{tabular}{c}
$(\mathrm{K})$ \\
\hline 1045 \\
1073 \\
1123
\end{tabular}

1173

1223

1273

1323

1373
Thermal Strain

$\left(10^{-3} \mathrm{~m} / \mathrm{m}\right)$

2.061

2.116

2.232

2.347

2.457

2.572

2.679

2.786 


\section{UTHEXP， UDEN}

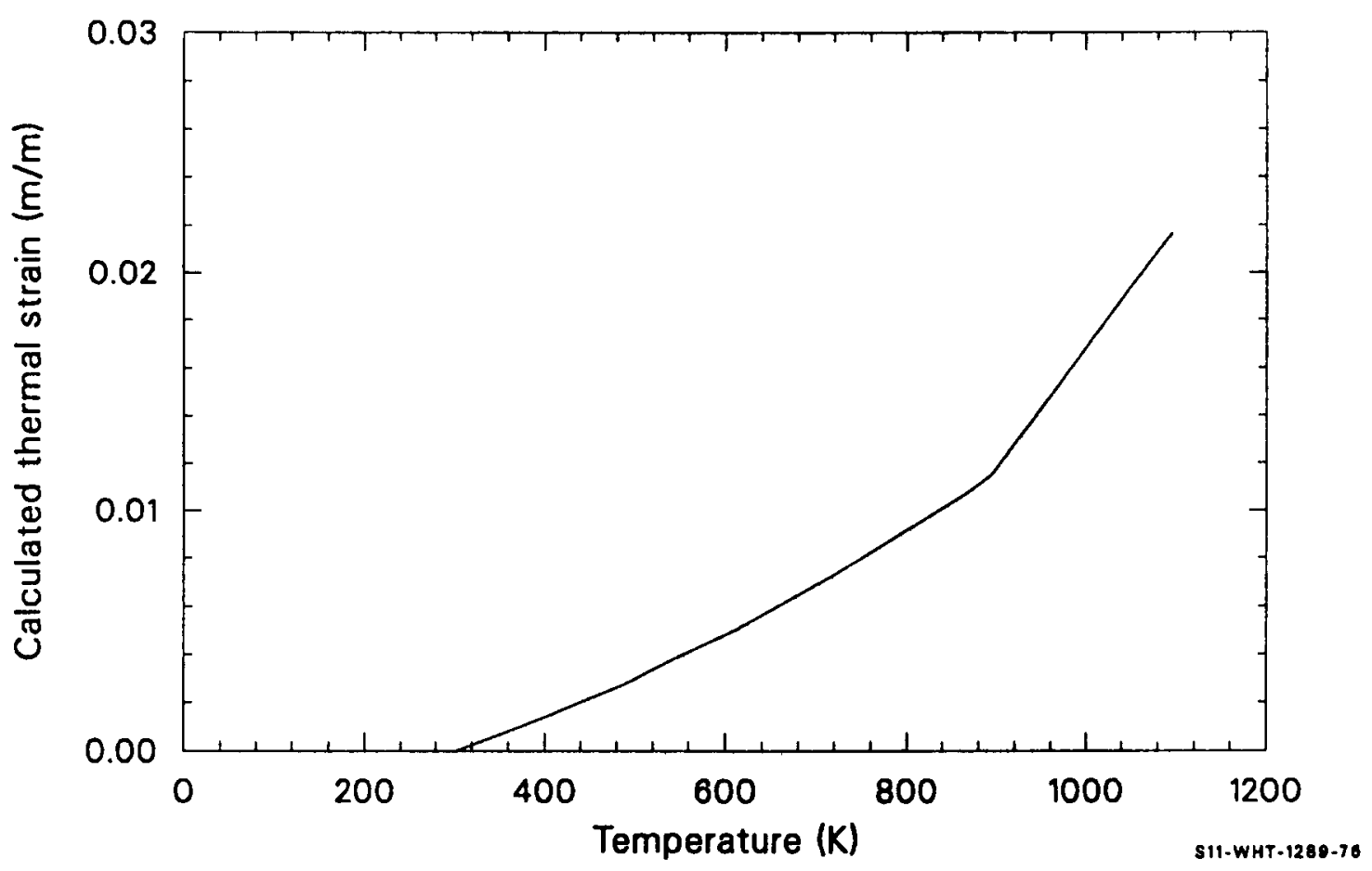

Figure 3.3-1. Thermal expansion strain as a function of temperature calculated by UTHEXP. 
UTHEXP, UDEN

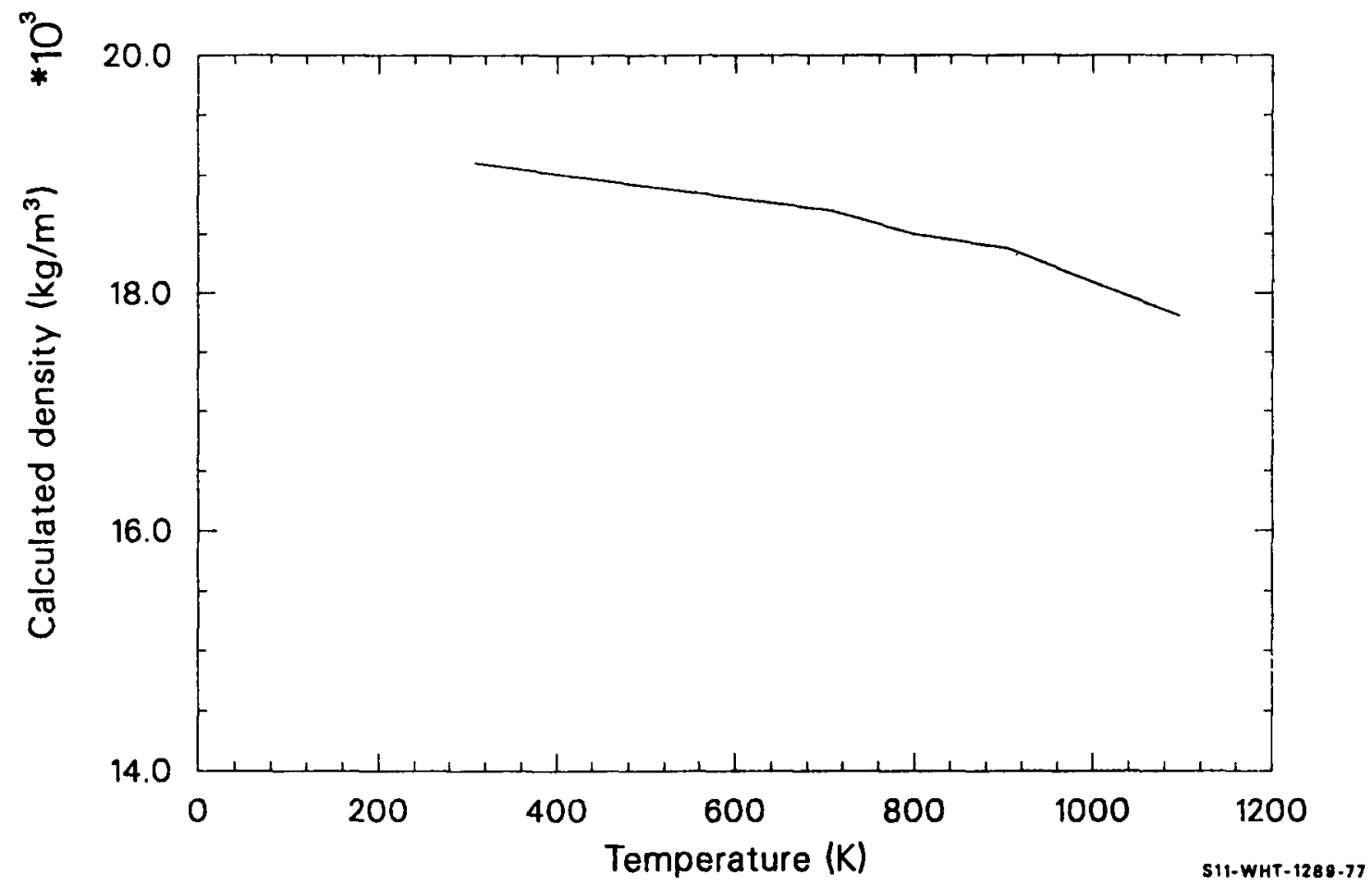

Figure 3.3-2. Density calculated by UDEN using the thermal strain calculated by UTHEXP. 


\section{UTHEXP， UDEN}

\subsubsection{References}

3.3-1. Y. S. Touloukian, R. K. Kirby, R. E. Taylor, P. D. Desai, Thermal Physical Properties of Matter, V12, Thermal Expansion - Metallic Elements and Alloys, New York: IFI/Plenum, 1970, pp. 336-372. 



\title{
UOXWTK
}

\subsection{Uranium Oxidation Parabolic Rate Constant (UOXWTK)}

\author{
(J. K. Hohorst)
}

\subsubsection{Model Development}

To calculate the oxidation rates for uranium, the parabolic rate constant is necessary. The subcode UOXWTK was developed from analytical data reported by R. E. Wilson et al.3.4-1 The parabolic rate constant for uranium at a given temperature is calculated using the following expression:

For $\mathrm{T}<1473 \mathrm{~K}$,

$K_{U 0}=1.3503 \exp (-25000 / 1.987$ UTEMP $)$.

For $T \geq 1473 \mathrm{~K}$,

$K_{U 0}=0.1656 \exp (-18600 / 1.987$ UTEMP $)$

where

$\mathrm{K}_{\mathrm{UO}}=$ the parabolic rate constant for the oxidation of uranium $\left(\mathrm{kg}^{2} / \mathrm{m}^{4} \cdot \mathrm{s}\right)$

UTEMP $=$ temperature $(K)$

\section{4-2 References}

3.4-1. R. E. Wilson et al., "Isothermal Reaction of Uranium with Steam between 400 and $1600^{\circ} \mathrm{C}$, "Nuclear Science and Engineering, 25, 1966 , pp. $109-115$. 



\section{ZIRCALOY}

Twenty-seven materials properties of LWR fuel rod cladding (zircaloy-2 or -4) have been modeled for inclusion in the SCDAP/RELAP5 materials properties subcode package. Modeling approaches range from a choice of experimental data with linear interpolation or extrapolation or both to a semiempirical expression suggested by theory.

Al1 27 properties are modeled as a function of the cladding temperature. In addition, such variables as fast neutron flux, fluence, cold work, stress, time, and impurity content are used as arguments. Some of the subcodes are interconnected, employing in part identical or very similar correlations (for example, strain versus stress, stress versus strain, and cladding ultimate strength). Some subcodes call upon others, such as the physical properties subcode, PHYPRO, but all of the information needed to run a given subcode is contained in this report. 



\section{CHYPRP}

\subsection{Melting and Phase Transformation Temperatures (Chyprp)}

To perform an accurate analysis of reactor behavior during an accident involving the core, it is necessary to know the melting and phase transformation temperatures of zircaloy. The subroutine CHYPRP calculates the zircaloy phase transition temperatures of interest for use in LWR analysis. The only input required in this subroutine is the excess weight fraction oxygen content of the zircaloy. From this input, the subroutine calculates the solidus (appearance of first liquid phase) temperature, the liquidus (melting of the last solid phase) temperature, the alpha-to-alpha + beta phase boundary, and the alpha + beta-to-beta phase boundary for zircaloy.

\subsubsection{Model Development}

Four parameters are often used to describe the oxygen concentration in zircaloy. Table 4.1-1 shows the relationship between the one used in CHYPRP and the others. The first column gives the excess weight fraction oxygen content. The second column gives the corresponding values for the total weight fraction oxygen, assuming an as-received oxygen concentration of 0.0012 by weight. The third column presents corresponding values for the atomic fraction of oxygen in the compound. The atomic fraction oxygen is related to the weight fraction oxygen in zirconium oxide by the equation

$$
x=\frac{W F O X}{W F O X+\frac{G M W T(0)}{\operatorname{GMWT}(Z r)}(1-W F O X)}
$$

where 


\section{CHYPRP}

Table 4.1-1. 0xygen content parameters for zircaloy

\begin{tabular}{|c|c|c|c|}
\hline $\begin{array}{l}\mathrm{kg} \text { Excess } \\
0 / \mathrm{kg} \operatorname{Zr}(0)\end{array}$ & $\begin{array}{l}\text { WFOX } \\
{[\mathrm{kg} 0 / \mathrm{kg} \operatorname{Zr}(0)]}\end{array}$ & $\begin{array}{l}\text { Number of Atoms } \\
\text { (0/atoms compound })\end{array}$ & $\begin{array}{c}\begin{array}{c}\text { Oxygen-to-Metal } \\
\text { Ratio }\end{array} \\
\end{array}$ \\
\hline $\begin{array}{l}0.0000 \\
0.0100 \\
0.0200 \\
0.0300 \\
0.0400 \\
0.0500 \\
0.0600 \\
0.0657\end{array}$ & $\begin{array}{l}0.0012 \\
0.0112 \\
0.0212 \\
0.0312 \\
0.0412 \\
0.0512 \\
0.0612 \\
0.0669\end{array}$ & $\begin{array}{l}0.007 \\
0.061 \\
0.110 \\
0.155 \\
0.197 \\
0.235 \\
0.271 \\
0.290\end{array}$ & $\begin{array}{l}0.007 \\
0.065 \\
0.124 \\
0.183 \\
0.245 \\
0.307 \\
0.372 \\
0.408\end{array}$ \\
\hline \multicolumn{4}{|c|}{ As-received zircaloy is presumed to have 0.0012 weight fraction oxygen. } \\
\hline
\end{tabular}




\begin{tabular}{|c|c|c|}
\hline$x$ & $=$ & $\begin{array}{l}\text { the atomic fraction of oxygen in zircaloy containing } \\
\text { oxygen (atoms of oxygen/atoms of compound) }\end{array}$ \\
\hline WFOX & $=$ & $\begin{array}{l}\text { weight fraction of oxygen in zircaloy containing } \\
\text { oxygen ( } \mathrm{kg} \text { oxygen } / \mathrm{kg} \text { compound) }\end{array}$ \\
\hline GMWT(0) & $=$ & molecular weight of an oxygen atom $[16 \mathrm{~kg}(0) / \mathrm{kg} \cdot \mathrm{mole}]$ \\
\hline GMWT $(Z r)$ & $=$ & $\begin{array}{l}\text { molecular weight of a zircaloy atom }[91.22 \mathrm{~kg} \\
(\mathrm{Zr}) / \mathrm{kg} \cdot \mathrm{mole}]\end{array}$ \\
\hline
\end{tabular}

The fourth column gives the corresponding values of the oxygen-to-metal ratio. This ratio is related to the atomic fraction oxygen by the following equation for zirconium oxide (which approximates zircaloy oxide):

$Y E=\frac{x}{1-x}$

where $Y E$ is the oxygen-to-metal ratio (atoms of oxygen/atoms of zirconium).

To convert the input excess weight fraction oxygen to an atomic fraction for oxygen in the zircaloy, the as-received oxygen weight fraction for the zircaloy is added to the input weight fraction oxygen prior to calculating the atomic fraction of the oxygen in the zircaloy. From the calculated atomic fraction oxygen, the melting and phase transformation temperatures are calculated using equations from the PYHPRP, PSOL, and PLIQ subcodes described in Section 11.1. To calculate the solidus temperature from the atomic fraction of oxygen in zircaloy, the following relationships are used:

For $x \leq 0.1$,

$T_{\text {SOl }}=2098+1150 x$. 


\section{CHYPRP}

$$
\begin{aligned}
& \text { For } 0.1<x \leq 0.18, \\
& T_{\text {sol }}=2213 . \\
& \text { For } 0.18<x \leq 0.29, \\
& T_{\text {sol }}=1389.5317+7640.0748 x-17029.172 x^{2} . \\
& \text { For } 0.29<x \leq 0.63, \\
& T_{\text {sol }}=2173 .
\end{aligned}
$$

For $0.63<x \leq 0.667$,

$$
\mathrm{T}_{\text {SO1 }}=-11572.454+21818.181 \times .
$$

For $x>0.667$,

$\mathrm{T}_{\text {SOl }}=-11572.454+x(1.334-x) 21818.181$.

where $T_{\text {sol }}$ is the solidus temperature $(K)$.

The liquidus temperatures are calculated using the following relationships:

For $x \leq 0.19$,

$$
\begin{aligned}
& T_{1 \mathrm{iq}}=2125 .+1632.1637 x-5321.6374 \mathrm{x}^{2} . \\
& \quad \text { For } 0.19<x \leq 0.41, \\
& T_{1 \mathrm{iq}}=2111.6553+1159.0909 x-2462.1212 \mathrm{x}^{2} .
\end{aligned}
$$


CHYPRP

For $0.41<x \leq 0.667$

$\mathrm{T}_{1 \mathrm{iq}}=895.07792+3116.8831 \times$.

For $x>0.667$

$T_{1 i q}=895.07792+(1.34-x) 3116.8831$.

where $T_{1 i q}$ is the liquidus temperature $(K)$.

The subcode CHYPRP also calculates the low and high temperature boundaries of the alpha + beta phase region as a function of the total weight fraction oxygen in the compound. If the compound weight fraction oxygen is less than 0.025 , then the low-temperature boundary of the two-phase region is calculated as follows:

ctranb $=1094 .+$ WFOX $\cdot\left(-1.289 \times 10^{3}+\right.$ WFOX $\left.\cdot 7.914 \times 10^{5}\right)$.

If the total weight fraction is greater than 0.025 , then the low-temperature boundary is calculated using the following equation:

ctranb $-1556.4+3.8281 \times 10^{4} \cdot($ WFOX -0.025$)$

where ctranb is the low-temperature boundary of the alpha + beta phase region $(K)$. If the lower alpha + beta transition temperature is equal to or larger than the calculated solidus temperature, then the alpha + beta lower-boundary phase temperature is set equal to the solidus temperature.

The high-temperature alpha + beta phase region boundary temperatures are calculated using the following relationships, which use the input oxygen content rather than weight fraction. With an input oxygen content less than $4.7308937 \times 10^{-3}$, the upper phase boundary temperature is calculated using the following correlation: 


\section{CHYPRP}

ctrane $=392.46 \cdot\left[(100 \cdot W F O X)^{2}+3.1417\right]$.

If the oxygen content is greater than $4.7308937 \times 10^{-03}$, then the equation used to calculate the upper alpha + beta phase boundary temperature is

ctrane $=(100 \cdot$ WFOX $) \cdot 491.157+1079.639$

where ctrane is the high-temperature boundary of the alpha + beta phase region ( $K)$. If the upper boundary temperature of the alpha + beta phase region is greater than the calculated solidus temperature, then the upper boundary alpha + beta phase temperature is set equal to the solidus temperature. The alpha + beta boundaries expressions are based on data from Chung and Kassner. ${ }^{4 \cdot 1-1}$

Figure 4.1-1 shows the calculated zircaloy solidus and liquidus temperatures and the calculated alpha + beta phase region boundaries.

\subsubsection{References}

4.1-1. H. M. Chung and T. F. Kassner, "Pseudobinary Zircaloy-0xygen Phase Diagram," Journal of Nuclear Materials, 84, 1979, pp. 327-339. 


\section{CHYPRP}

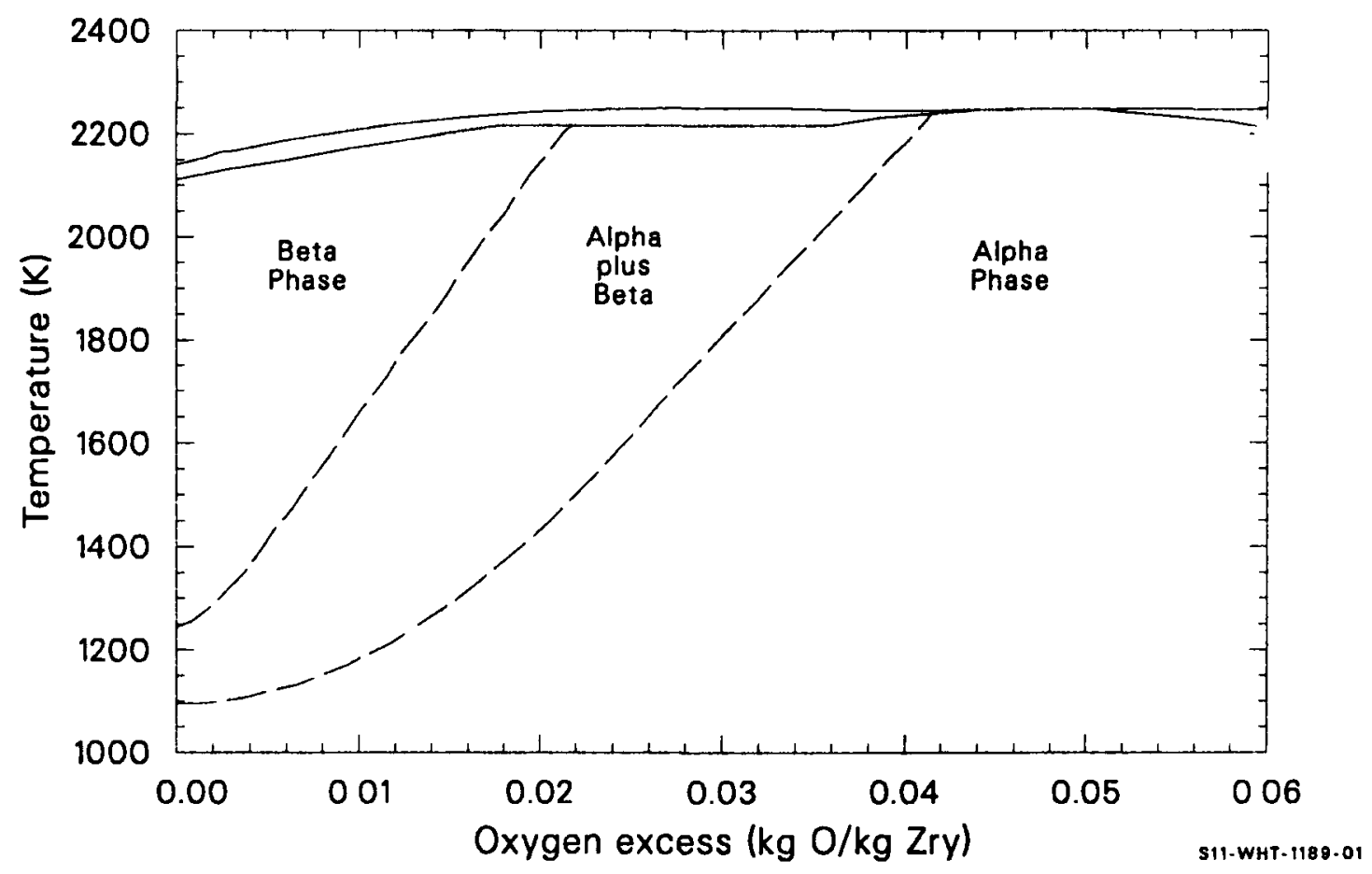

Figure 4.1.1. Zircaloy solidus and liquidus temperatures. 

CTSOL

\subsection{Temperature Required to Prevent Hydriding of}

\section{a Given Concentration of Hydrogen in Zircaloy (CTSOL)}

An estimate of the temperature at which hydride precipitates begin to form in zircaloy cladding is useful for estimating when hydriding will begin to embrittle the cladding. The function CTSOL calculates the minimum temperature for complete solution of a given concentration of hydrogen. The expression used for the calculation is

CTSOL $=\frac{4401 K}{\ln \frac{1.332 E+05}{H}}$

where

CTSOL = minimum temperature for complete solution of a concentration of hydrogen in zircaloy (K)

$\mathrm{H}=$ hydrogen concentration (parts per million by weight)

The development of this equation is discussed in Section 4.3 in conjunction with the derivation of the model for the effect of hydride solution on zircaloy cladding specific heat. 



\section{CCP, CHSCP, CENTHL}

\subsection{Cladding Specific Heat, the Effect of Hydride Solution on Cladding Specific Heat, AND ENTHALPY (CCP, CHSCP, CENTHL)}

(D. L. Hagrman)

Two function subcodes are used to describe the apparent specific heat of the zircaloys. The first, CCP, describes the true specific heat at constant pressures for the alloys. The second, CHSCP, describes the apparent addition to the specific heat because of energy used to dissolve the hydrides present in zircaloys. Uncertainty estimates have been determined and are returned by each function.

CCP requires only temperature as input, while CHSCP requires both temperature and the concentration of hydrogen. The hydrogen concentration may be supplied directly by the user or it may be calculated by the MATPRO function CHUPTK.

\subsubsection{Specific Heat (CCP)}

For the alpha phase of the zircaloys (temperature less than $1090 \mathrm{~K}$ ), CCP returns linear interpolations for the points listed in Table 4.3-1. (Linear interpolation is computed by the subcode POLATE described in Section 21.1.)

Table 4.3-1 is based on precise data taken by Brooks and

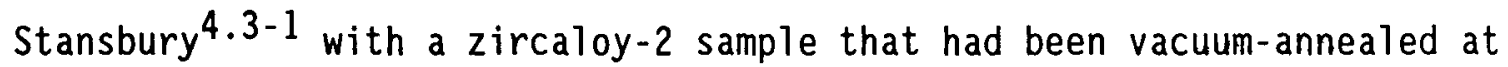
$1075 \mathrm{~K}$ to remove hydrogen. The standard error ${ }^{\mathrm{a}}$ of the CCP interpolation

a. The standard error is estimated for a data set by the expression: [sum of squared resjghals/(number of residuals minus number of constants used to fit the data)] ${ }^{1 / 2}$. 
CCP, CHSCP, CENTHL

Table 4.3-1. Zircaloy specific heat capacities for CCP

\begin{tabular}{cc}
\hline $\begin{array}{c}\text { Temperature } \\
(\mathrm{K})\end{array}$ & $\begin{array}{c}\text { Specific Heat Capacity } \\
(\mathrm{J} / \mathrm{Kq} \cdot \mathrm{K})\end{array}$ \\
\cline { 2 - 2 } 300 & 281 \\
400 & 302 \\
640 & 331 \\
1090 & 375 \\
1093 & 502 \\
1113 & \\
1133 & 590 \\
1153 & 615 \\
1173 & 719 \\
1193 & 816 \\
1213 & 770 \\
1233 & \\
1248 & 619 \\
2098 & 469 \\
2099 & 356 \\
& 356 \\
\hline
\end{tabular}




\section{CCP, CHSCP, CENTHL}

(that is, the precision of the fit to the data) was based on the 90 points in the data base and was found to be temperature-dependent. For the 57 data points between 300 and $800 \mathrm{~K}$, the standard error is $1.1 \mathrm{~J} / \mathrm{kg} \cdot \mathrm{K}$. Between 800 and $1090 \mathrm{~K}$, it is $2.8 \mathrm{~J} / \mathrm{kg} \cdot \mathrm{K}$.

For temperatures from 1090 to $1300 \mathrm{~K}$ (where Brooks and Stansbury do not report results), values of specific heat proposed by Deem and Eldridge $4.3-2$ are adopted by MATPRO. The Deem and Eldridge values, shown in Table 4.3-2, are based on measurements of enthalpy and temperature which provide considerably less precise specific heat data than the results of Brooks and Stansbury. $4.3-1$

The standard error as estimated by the Deem and Eldridge data in the region 1090 through $1310 \mathrm{~K}$ is $10.7 \mathrm{~J} / \mathrm{kg} \cdot \mathrm{K}$. Again, this standard error is a measure only of the precision of the fit, since only a single data source is employed.

The specific heat as calculated by CCP is shown in Figure 4.3-1. Figures 4.3-2 and 4.3-3 also show the CCP prediction, using an expanded scale at lower temperatures and illustrating the base data from Brooks and Stansbury as well as alpha phase (300 to $1090 \mathrm{~K}$ ) data from Deem and Eldridge that were not used in constructing CCP.

At temperatures up to $900 \mathrm{~K}$, the Brooks and Stansbury data agree with the Deem and Eldridge data within 3\%. Above the alpha + beta to beta transformation temperature (about $1250 \mathrm{~K}$ ) and up to about $1320 \mathrm{~K}$, a constant value of $355.7 \mathrm{~J} / \mathrm{kg} \cdot \mathrm{K}$ was reported by Deem and Eldridge. This value agrees well with a value of 365.3 reported by Coughl in and $\mathrm{King}^{4.3-3}$ for pure beta zirconium.

The estimated standard error of CCP for data consisting of a random sample from all zircaloy-2 and zircaloy-4 claddings is also shown in Figures 4.3-2 and 4.3-3. This standard error is discussed in Section 4.3.3 after the discussion of the effect of hydride solution. 


\section{CCP， CHSCP， CENTHL}

Table 4.3-2. Specific heat as a function of temperature--beta phase

\begin{tabular}{cc}
\hline $\begin{array}{c}\text { Temperature } \\
(\mathrm{K})\end{array}$ & $\begin{array}{c}\text { Specific Heat } \\
(\mathrm{J} / \mathrm{kg} \cdot \mathrm{K})\end{array}$ \\
& 502 \\
1113 & 590 \\
1133 & 615 \\
1153 & 719 \\
1173 & 816 \\
1193 & 770 \\
1213 & 619 \\
1233 & 469 \\
1248 & 356 \\
\hline
\end{tabular}


CCP， CHSCP， CENTHL

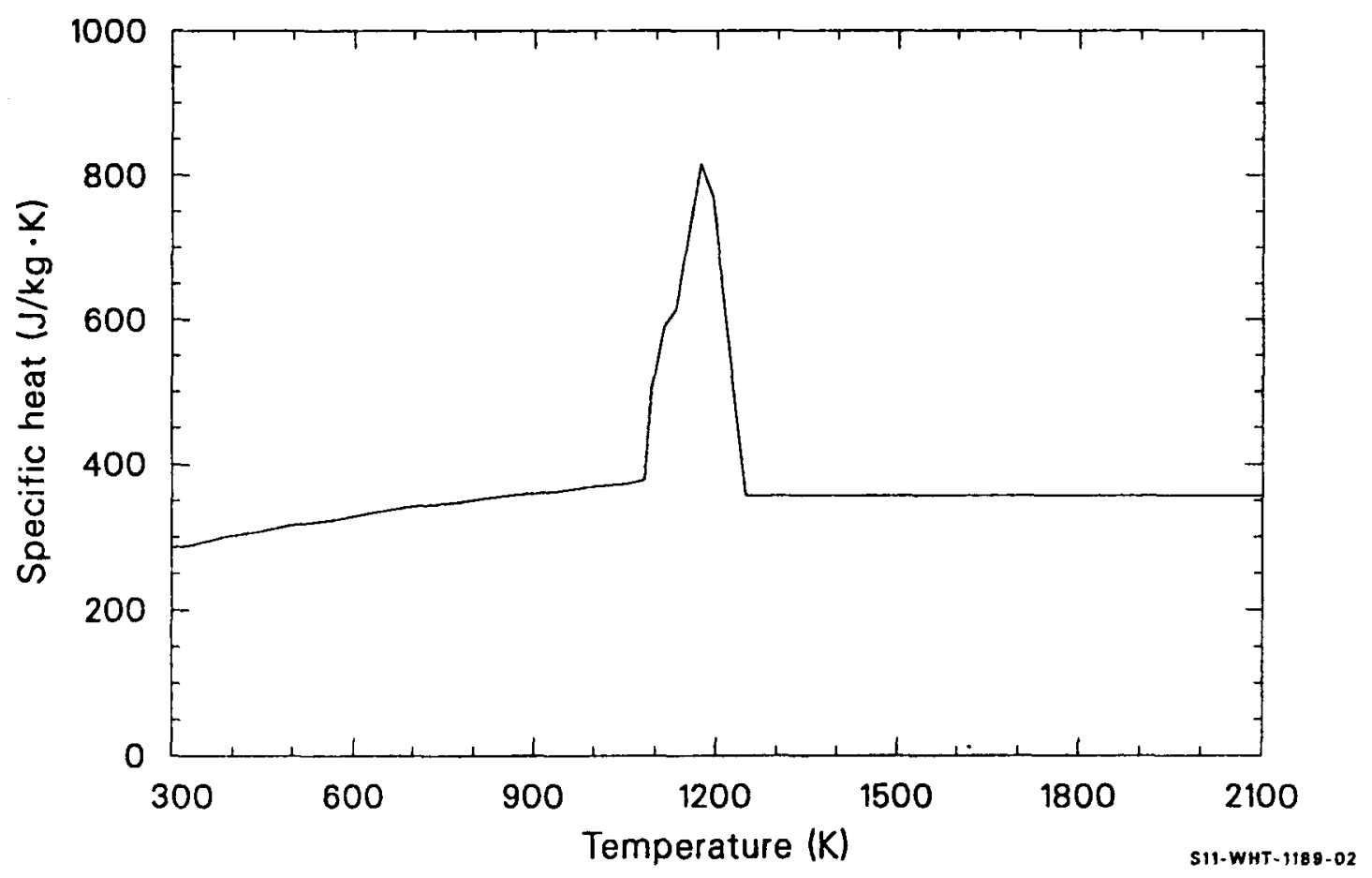

Figure 4.3-1. Specific heat of zircaloys as calculated by CCP for alloys without hydrides. 


\section{CCP, CHSCP, CENTHL}

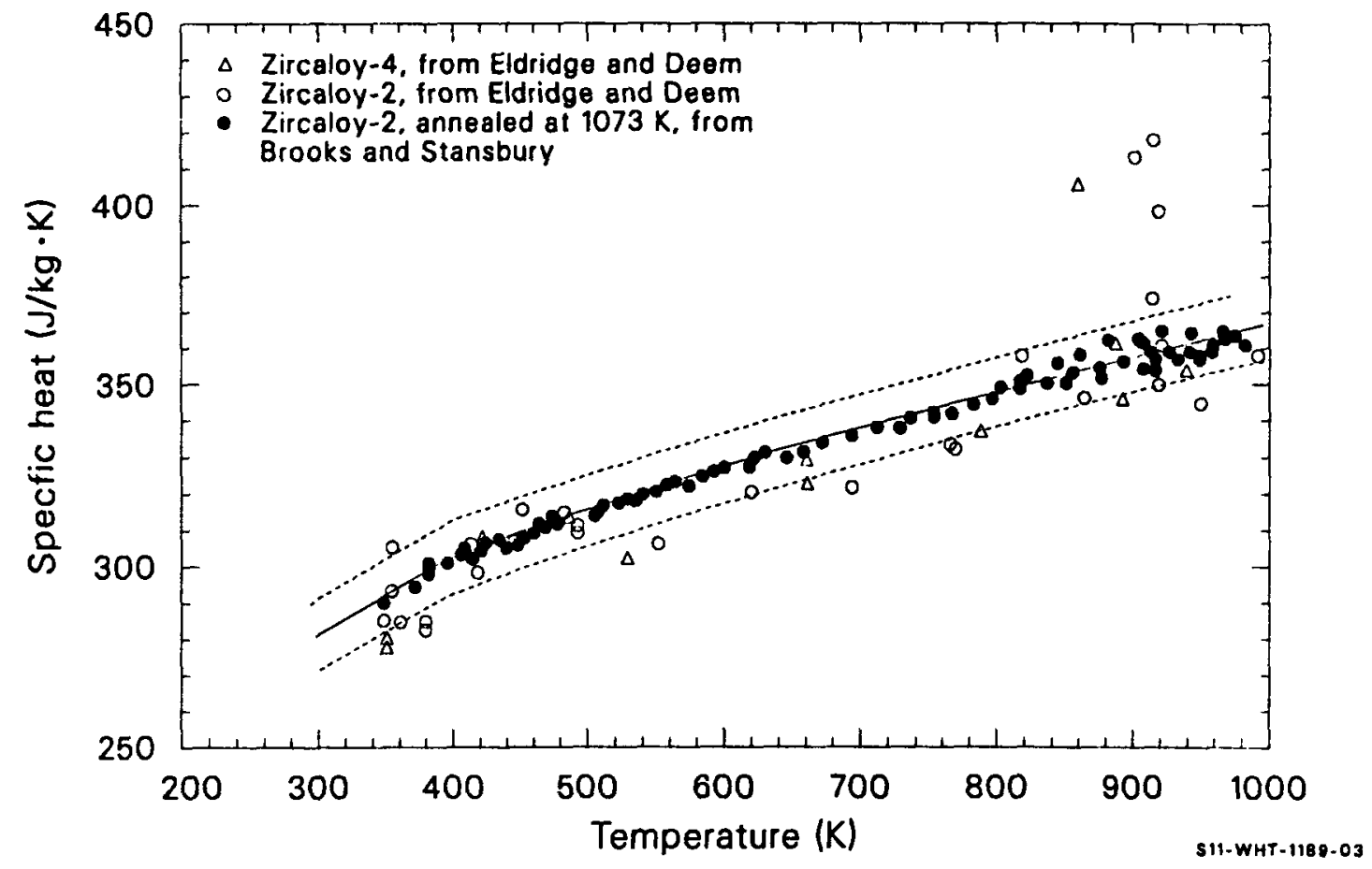

Figure 4.3-2. Available data, MATPRO expressions for specific heat, and estimated uncertainty of the MATPRO expression for temperatures from 300 to $1000 \mathrm{~K}$. 


\section{CCP, CHSCP, CENTHL}

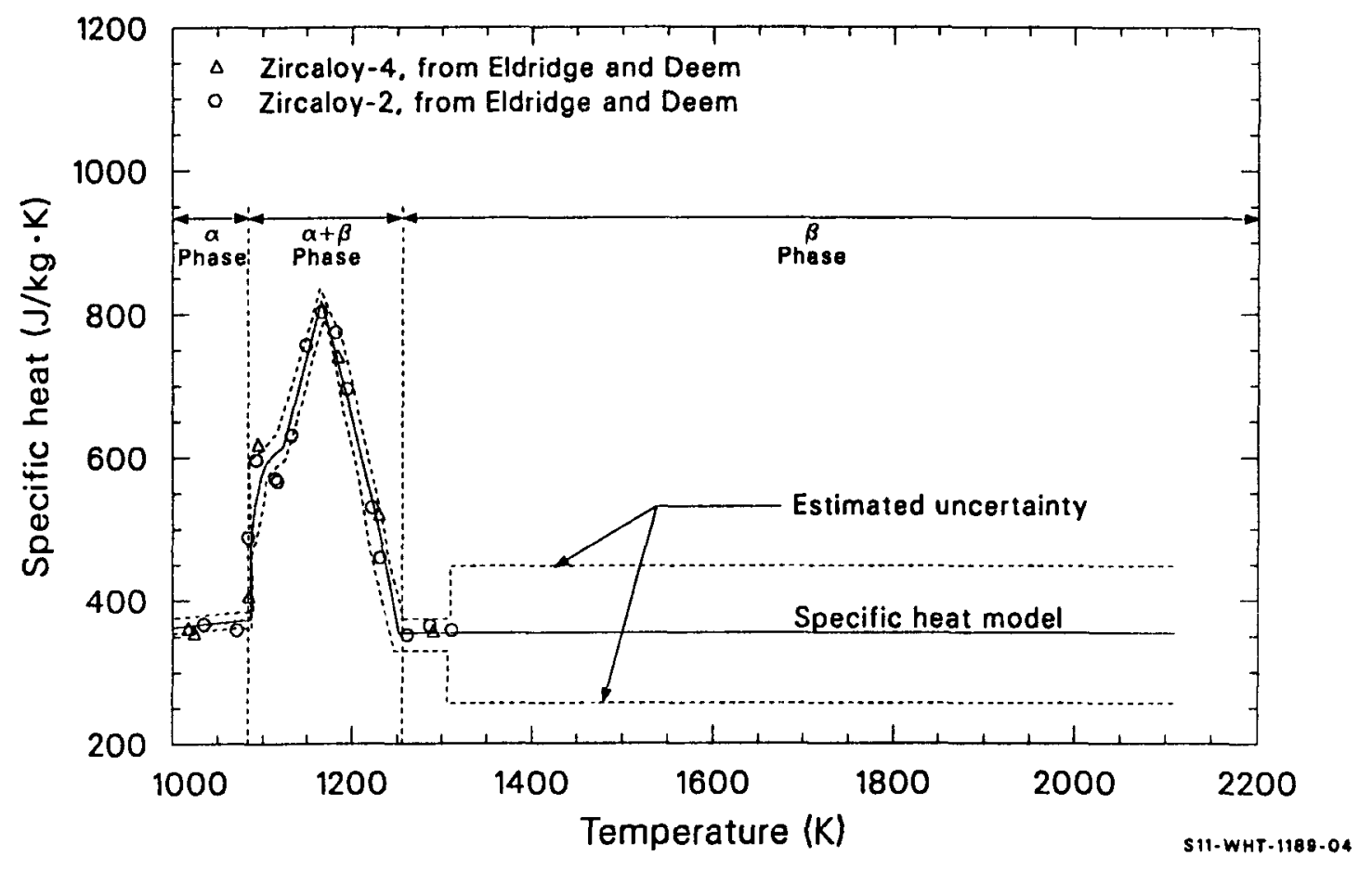

Figure 4.3-3. Available data, MATPRO expressions for specific heat, and estimated uncertainty of the MATPRO expression for temperatures from 1000 to $2000 \mathrm{~K}$. 


\section{CCP, CHSCP, CENTHL}

\subsubsection{Effect of Hydride Solution (CHSCP)}

Values returned by the function CHSCP for the addition to the specific heat due to energy used in solution of hydrides are:

$C H S C P=\frac{A B C}{T^{2}}\left[\exp \left(\frac{-B}{T}\right)\right]\left[\exp \left(\frac{T-T S O L}{0.02 T S O L}\right)+1\right]-1$

where

$$
\begin{aligned}
\text { CHSCP } & =\begin{array}{l}
\text { addition to true specific heat due to hydride solution } \\
(\mathrm{J} / \mathrm{kg} \cdot \mathrm{K})
\end{array} \\
T & =\text { cladding temperature }(\mathrm{K}) \\
\text { TSOL } & =\begin{array}{l}
\text { Minimum temperature for complete solution of the hydrogen } \\
\text { concentration, as determined with Equation }(4.3-2)(\mathrm{K})
\end{array} \\
\mathrm{A} & =1.332 \times 10^{5}(\mathrm{ppm} \text { hydrogen }) \\
\mathrm{B} & =4.401 \times 10^{3}(\mathrm{~K}) \\
\mathrm{C} & =45.70(\mathrm{~J} / \mathrm{kg} \cdot \mathrm{ppm} \text { hydrogen }) .
\end{aligned}
$$

TSOL, the minimum temperature required for complete solution of the hydrogen in the cladding, is determined from the expression

$$
\mathrm{TSOL}=\frac{\mathrm{B}}{\ln \left(\frac{\mathrm{A}}{\mathrm{H}}\right)}
$$

where 


\section{CCP, CHSCP, CENTHL}

$A$ and $B=$ constants given in conjunction with Equation (4.3-1)

$\mathrm{H}=$ hydrogen concentration (ppm by weight).

A value of $H$ can be determined with the function CHUPTK (Section 20.3).

Equations (4.3-1 and 4.3-2) are based on data reported by Scott $4.3-4$ for zirconium with and without intentional additions of hydrogen. For temperatures below $830 \mathrm{~K}$, Scott (Figure 16 of Reference 4.3-4) finds the logarithm of the terminal solubility of hydrogen in zirconium to be proportional to temperature. Below the temperature TSOL, when hydrides are not completely dissolved,

Energy to dissolve hydride $=$ constant $\times \exp \left(\frac{\text { negative constant }}{\text { temperature }}\right)$

It is assumed in this expression that the terminal solubility will be attained as long as undissolved hydrogen is present. The heat of solution per gram atom of hydrogen may be taken as the average of two values given by Scott (Table VII of Reference 4.3-4). Equation (4.3-1) results from differentiation of this expression with respect to temperature and multiplication by the empirical factor

$\left[\exp \left(\frac{\mathrm{T}-\mathrm{TSOL}}{0.02 \mathrm{TSOL}}\right)+1\right]^{-1}$

to express the fact that the data do not show an instant termination of hydride solution with increasing temperature.

Figure 4.3-4 illustrates Scott's data for two samples of zirconium iodide and a single sample of zirconium intentionally doped with approximately $300 \mathrm{ppm}$ of hydrogen. The two zirconium iodide samples apparently contained some hydrogen and were fit by the MATPRO correlation [Equation (4.3-2)], assuming they contained $28 \mathrm{ppm}$ hydrogen. Figure 4.3-4 


\section{CCP, CHSCP, CENTHL}

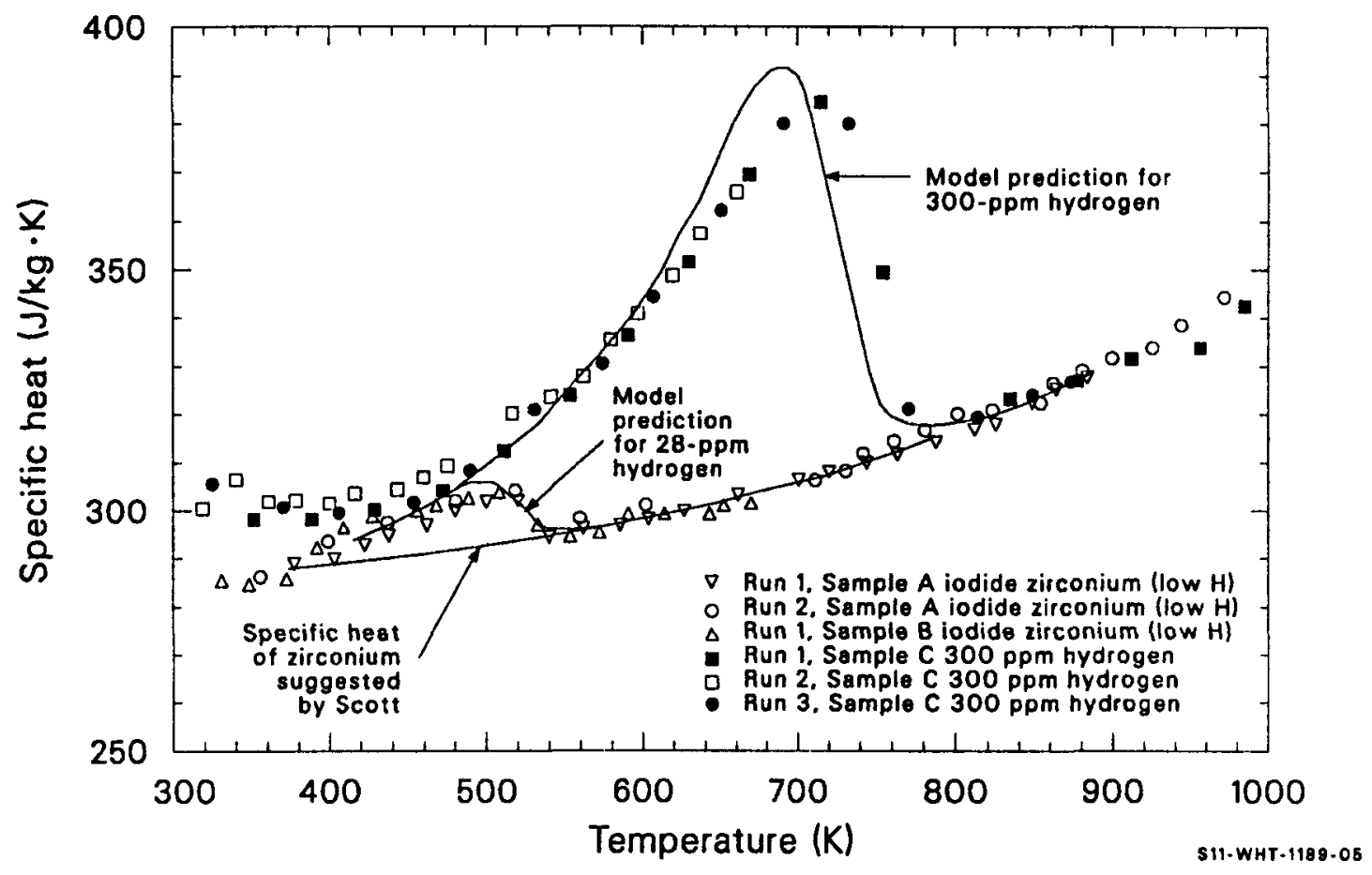

Figure 4.3-4. Data base for MATPRO prediction of the effect of hydride solution on specific heat, Scott's proposed curve for the specific heat of zirconium, and the MATPRO predictions for the effect of 28 and $300 \mathrm{ppm}$ of hydrogen on the specific heat curve. 


\section{CCP, CHSCP, CENTHL}

al so shows the MATPRO correlation assuming $300 \mathrm{ppm}$ hydrogen and the curve recommended by Scott for pure zirconium.

\subsubsection{Uncertainties in Specific Heat Predictions}

The systematic error (the estimated variation between values obtained with different samples) is larger than the imprecision in the base data of CCP and CHSCP.

The standard error of CCP, reflecting the systematic error for a random sample of cladding zircaloys, is estimated to be $\pm 10 \mathrm{~J} / \mathrm{kg} \cdot \mathrm{K}( \pm 3 \%)$ in the alpha phase. This value is based on the difference between values of specific heat estimated by Deem and Eldridge from their data 4.3 .2 and the more precise data from one sample of zircaloy-2 used by MATPRO. In the alpha-beta phase region and the beta region to $1300 \mathrm{~K}$, a roughly estimated standard error of $25 \mathrm{~J} / \mathrm{kg} \cdot \mathrm{K}$ is assigned to CCP, based on the decreased precision of the measurements and on the lack of confirming data in this temperature range. Above $1300 \mathrm{~K}$, the only basis for the assumed constant value of specific heat is the prediction of the Debye model of heat capacity for temperatures above the Debye temperature. Since no data are available, a standard error of $\pm 100 \mathrm{~J} / \mathrm{kg} \cdot \mathrm{K}$ is listed.

The basis for the estimate of the standard error of CHSCP over a random sample of cladding zircaloy is shown in Figure 4.3-5, which compares MATPRO predictions for several concentrations of hydrogen with a curve published by Brooks and Stansbury ${ }^{4.3-1}$ for the specific heat of zircaloy-2 tested without prior heat treatment. The unpublished data are reported to be within $1 \%$ of this curve, and the MATPRO prediction is as far as $3 \%$ $(10 \mathrm{~J} / \mathrm{kg} \cdot \mathrm{K})$ below the reported curve. Since the prediction of CCP in this temperature range is based on precise data $( \pm 1.1 \mathrm{~J} / \mathrm{kg} \cdot \mathrm{K})$ taken with vacuum-annealed samples of the same alloy, shown by a dashed line in Figure 4.3-5, most of the discrepancy (between the dashed line and the $28 \mathrm{ppm} \mathrm{H}$ solid line) is presumed to be due to errors inherent in the application by 


\section{CCP， CHSCP， CENTHL}

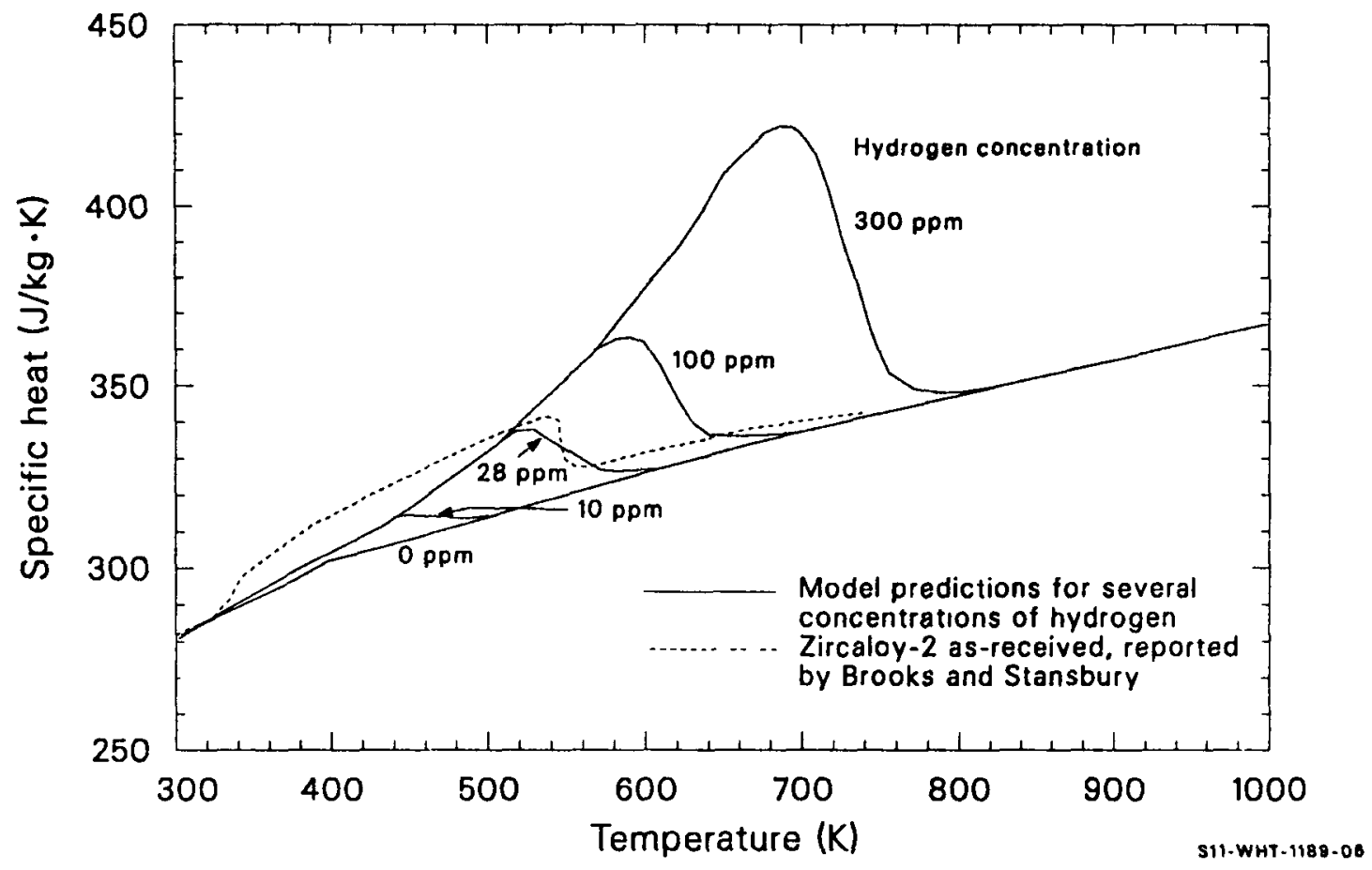

Figure 4.3-5. MATPRO predictions for apparent zircaloy specific heat for several hydrogen concentrations compared with the curve measured with as-received zircaloy-2. 


\section{CCP, CHSCP, CENTHL}

CHSCP to the zirconium data of Scott for zircaloy. A standard error of 50\% in the hydrogen-induced increment to apparent specific heat is, therefore, assigned to the model.

The uncertainties in CCP are summarized in Table 4.3-3.

\subsubsection{Zircaloy Enthalpy (CENTHL)}

The function CENTHL provides zircaloy enthalpy for temperatures above $300 \mathrm{~K}$. The CENTHL enthalpy subcode requires a temperature and a reference temperature for which the enthalpy will be set equal to zero.

Zircaloy enthalpy is modeled by integrating the expressions used in the cladding specific heat subcode, CCP. Since CCP utilizes linear interpolation on the set of points reproduced in Table 4.3-1, the CENTHL routine uses the expression

$H(T)-H(300)=\sum_{j=1}^{i} \Delta H_{j}+C_{p_{i}}\left(T-T_{j}\right)+\frac{\left(T-T_{j}\right)^{2}}{2\left(T_{i+1}-T_{j}\right)}\left(C_{p_{j+1}}-C_{p_{j}}\right)$

where

$H(T)=$ enthalpy of zircaloy at temperature $T(\mathrm{~J} / \mathrm{kg})$
$T_{i}=$ i-th temperature in Table $4.3-1(\mathrm{~K})$
$\mathrm{C}_{\mathrm{p}}=$ specific heat capacity at $\mathrm{T}_{\mathbf{i}}(\mathrm{J} / \mathrm{kg} \cdot \mathrm{K})$
$\Delta H_{i}=$ change in enthalpy of zircaloy between $T_{i-1}$ and
$T \quad T_{i}$
$T \quad=$ temperature (K)


CCP, CHSCP, CENTHL

Table 4.3-3. Uncertainties in specific heat of zircaloy

Temperature Range

$$
\begin{aligned}
300<T & <1090 \mathrm{~K} \\
1090<T & <1300 \mathrm{~K} \\
T & <1300 \mathrm{~K}
\end{aligned}
$$

Standard Error in CPP

$$
\begin{array}{r} 
\pm 10 \mathrm{~J} / \mathrm{kg} \cdot \mathrm{K} \\
\pm 25 \mathrm{~J} / \mathrm{kg} \cdot \mathrm{K} \\
\pm 100 \mathrm{~J} / \mathrm{kg} \cdot \mathrm{K}
\end{array}
$$




\section{CCP， CHSCP， CENTHL}

to find the enthalpy at a temperature greater than or equal to $T_{j}$, but less than $T_{i+1}$. Equation $(4.3-4)$ can be derived by inspection of Figure 4.3-6. The first term is the enthalpy between $T_{1}$ and $T_{j}$, that is the area under the line segments which connect $C_{p 1}$ to $C_{p i}$. The second term is the area of rectangle $B$, and the third term is the area of triangle $A$. The sum of these two areas is the enthalpy between $T_{j}$ and $T$. Table 4.3-4 lists values of

$$
\sum_{j+1}^{i} \Delta H
$$

corresponding to the values of $C_{p}$ in Table 4.3-1. The entries for 2098 and $2099 \mathrm{~K}$ incorporate the heat of fusion for melting zircaloy. The melt temperature and heat of fusion were taken from the MATPRO-11, Revision 2, PHYPRP subcode and do not include the effect of oxidation on these quantities.

For temperatures greater than $2099 \mathrm{~K}$, an enthalpy consistent with a constant specific heat capacity above $2099 \mathrm{~K}$ is calculated by omitting the third term on the right-hand side of Equation (4.3-4). Table 4.3-5 lists engineering estimates for the expected standard error of the enthalpy predicted by CENTHL with a reference temperature of $300 \mathrm{~K}$.

A code-generated plot of zircaloy enthalpy change as a function of temperature is presented in Figure 4.3-7.

\section{3-5 References}

4.3-1. C. R. Brooks and E. E. Stansbury, "The Specific Heat of Zircaloy-2 from 50 to $700^{\circ} \mathrm{C}, "$ Journal of Nuclear Materials, 18, 1966, p. 223.

4.3-2. H. W. Deem and E. A. Eldridge, Specific Heats and Heats of Transformation of Zircaloy-2 and Low Nickel Zircaloy-2. USAEC BM1-1803, May 31, 1967. 
CCP, CHSCP, CENTHL

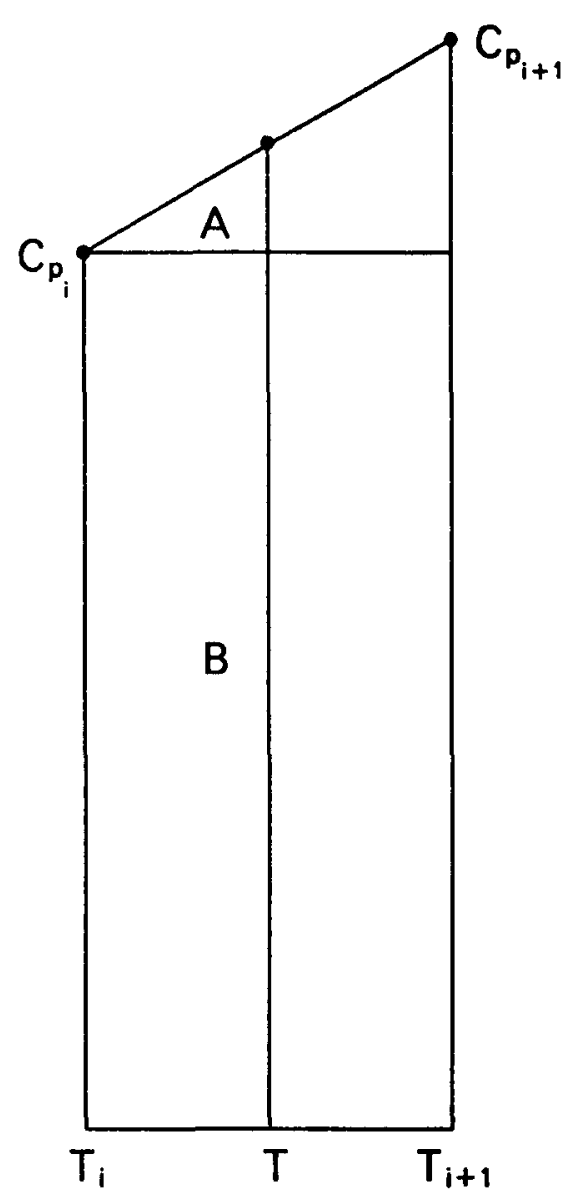

S11-WHT-1089-07

Figure 4.3-6. Derivation of Equation (4.3-4). 
CCP， CHSCP， CENTHL

Table 4.3-4. Values of $\sum_{j=1}^{i} \Delta H_{j}$ for zircaloy

\begin{tabular}{|c|c|}
\hline $\begin{array}{c}\text { Temperature, } \\
(\mathrm{K})\end{array}$ & $\begin{array}{l}\sum_{j=1}^{i-1} \Delta H_{j} \\
\left(10^{4} \mathrm{~J} / \mathrm{kg}\right)\end{array}$ \\
\hline 300 & 0.000 \\
\hline 400 & 2.915 \\
\hline 640 & 10.511 \\
\hline 1090 & 26.396 \\
\hline 1093 & 26.52755 \\
\hline 1113 & 27.61955 \\
\hline 1133 & 28.82455 \\
\hline 1153 & 30.15855 \\
\hline 1173 & 31.69355 \\
\hline 1193 & 33.27955 \\
\hline 1213 & 34.66855 \\
\hline 1233 & 35.67655 \\
\hline 1248 & 36.29530 \\
\hline 2098 & 66.5553 \\
\hline 2099 & 89.0909 \\
\hline
\end{tabular}




\section{CCP, CHSCP, CENTHL}

Table 4.3-5. Uncertainty of zircaloy enthalpy

\begin{tabular}{cc}
\hline $\begin{array}{c}\text { Temperature Range } \\
(\mathrm{K})\end{array}$ & $\begin{array}{c}\text { Expected Standard Error of CNTHL } \\
\text { (fraction of predicted value) }\end{array}$ \\
\hline $300 \leq T \leq 1090$ & 0.03 \\
$1090 \leq T \leq 2656.67$ & $3 \times 10^{-4}(T-1090)+0.03$ \\
$2656.67 \leq T$ & 0.5 \\
\hline
\end{tabular}




\section{CCP， CHSCP， CENTHL}

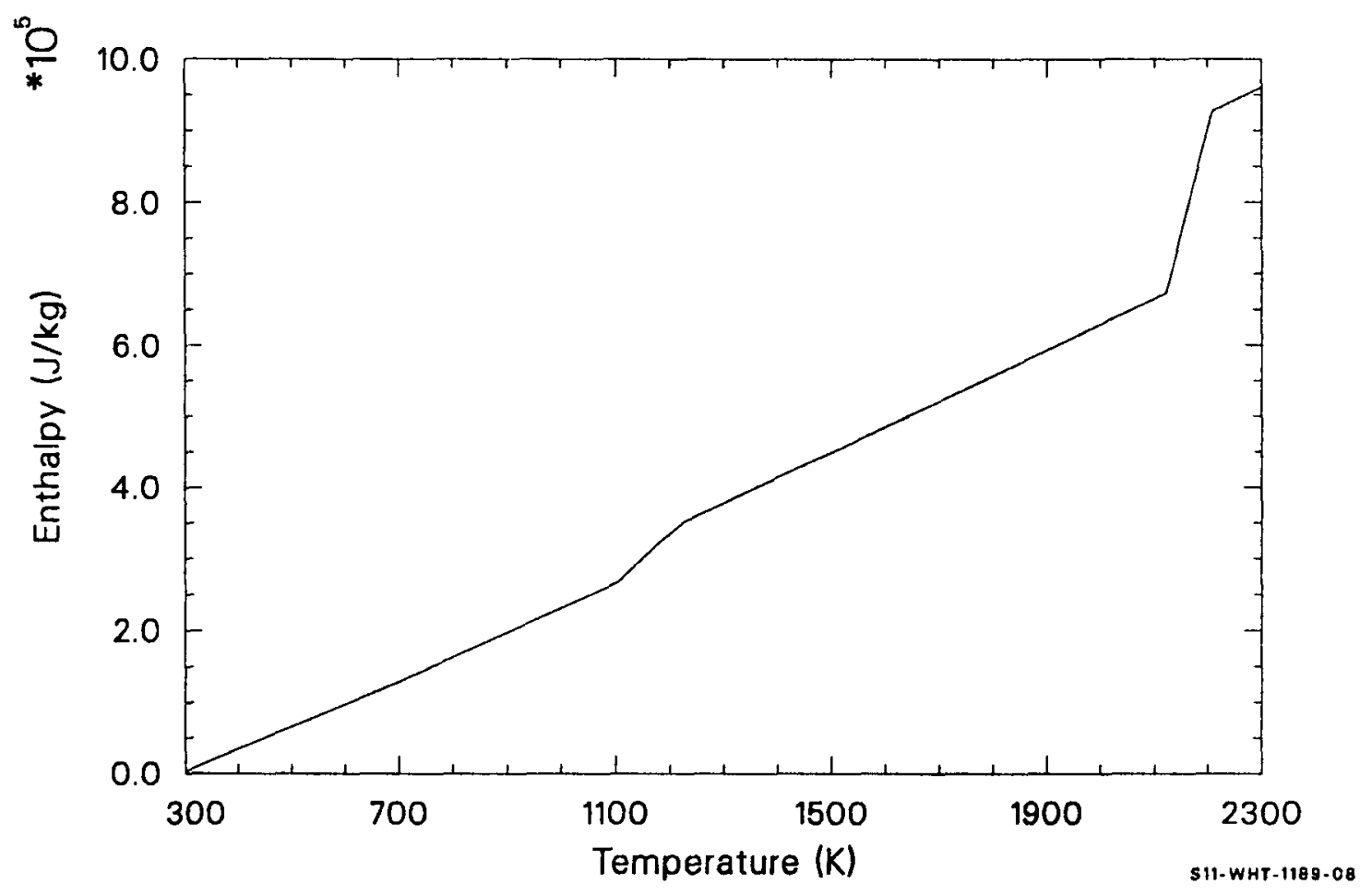

Figure 4.3-7. Zircaloy enthalpy as a function of temperature. 


\section{CCP， CHSCP， CENTHL}

4.3-3. J. P. Cought in and E. G. King, "High-Temperature Heat Contents of Some Zirconium-Containing Substances," Journal of the American Chemical Society, 72, 1950, p. 2262.

4.3-4. J. Scott, A Calorimetric Investigation of Zirconium, Titanium, and Zirconium Alloys from 60 to $960^{\circ} \mathrm{C}$, Ph.D. Thesis, University of Tennessee, 1957. 


\section{CTHCON}

\subsection{Thermal Conductivity (CTHCON)}

(R. L. Miller)

The transfer of heat from the fuel pellet to reactor coolant depends partly on the thermal conductivity of the cladding. Accurate predictions of fuel temperatures require knowledge of zircaloy thermal conductivities. An expression has been developed for the thermal conductivity of zircaloy-2 and -4 based on the pooled data from eight reports. This expression and the uncertainty in the correlation are presented in this section.

\subsubsection{Summary}

The thermal conductivity of alloys is primarily a function of temperature. Other characteristics, such as residual stress levels, crystal orientation, and minor composition differences (zircaloy-2 versus zircaloy-4, for example), may have a secondary influence on thermal conductivity. Considering only temperature as the defining parameter, the thermal conductivity of zircaloy for temperatures less than $2098 \mathrm{~K}$ and its uncertainty are found to be:

$k=7.51+2.09 \times 10^{-2} \mathrm{~T}-1.45 \times 10^{-5} \mathrm{~T}^{2}+7.67 \times 10^{-9} \mathrm{~T}^{3}$

$\sigma_{k}=1.01$.

For temperatures greater than or equal to $2098 \mathrm{~K}$, the thermal conductivity and uncertainty are:

$K=36$

$\sigma_{k}= \pm 5$

where

$k=$ thermal conductivity of zircaloy $(W / m \cdot K)$ 


\section{CTHCON}

$$
\begin{aligned}
& T=\text { temperature }(K) \\
& \sigma_{K}=\text { standard deviation }(W / m \cdot K) .
\end{aligned}
$$

This equation predicts $k$ very well from room temperature to the data limit of about $1800 \mathrm{~K}$ and may be extrapolated with some confidence to the melting point. The standard deviation $\left(\sigma_{k}\right)$ of the data with respect to this correlation appears to be temperature-independent over the data range (Figure 4.4-1). Least-squares regression analysis indicates that the standard deviation for each of the constants in Equation (4.4-1) is $20 \%$ to $30 \%$ of the value of the constant.

The correlations for zircaloy thermal conductivity at high temperatures required only consideration of the effect of melting on thermal conductivity. No data for liquid zircaloy thermal conductivity have been found; but Nazare, Ondracek, and Schulz $z^{4-1}$ have reported that the ratios of solid-state conductivities to liquid-state conductivities at the melting temperatures for metals like zircaloy with eight nearest neighbor atoms is $1.6 \pm 0.2 .^{2}$ Since the solid state conductivity predicted by the CTHCON function is $58 \mathrm{~W} / \mathrm{m} \cdot \mathrm{K}$, the liquid state conductivity should be about $36 \pm 5 \mathrm{~W} / \mathrm{m} \cdot \mathrm{K}$.

\subsubsection{Literature Review}

Anderson 4.4-2 reported thermal conductivity data for zircaloy-2 in the temperature range of 380 to $872 \mathrm{~K}$. Chirigos et al.$^{4.4-3}$ reported thermal conductivity data for zircaloy-4 between 370 and $1125 \mathrm{~K}$. Feith ${ }^{4-4-4}$ studied the thermal conductivity of zircaloy-4 between 640 and $1770 \mathrm{~K}$. Lucks and Deem ${ }^{4.4-5}$ measured the thermal conductivity of zircaloy-2 in the temperature range of 290 to $1075 \mathrm{~K}$. Powers 4.4-6

a. The body-centered cubic lattice of beta-phase zircaloy has eight nearest neighbors. 
CTHCON

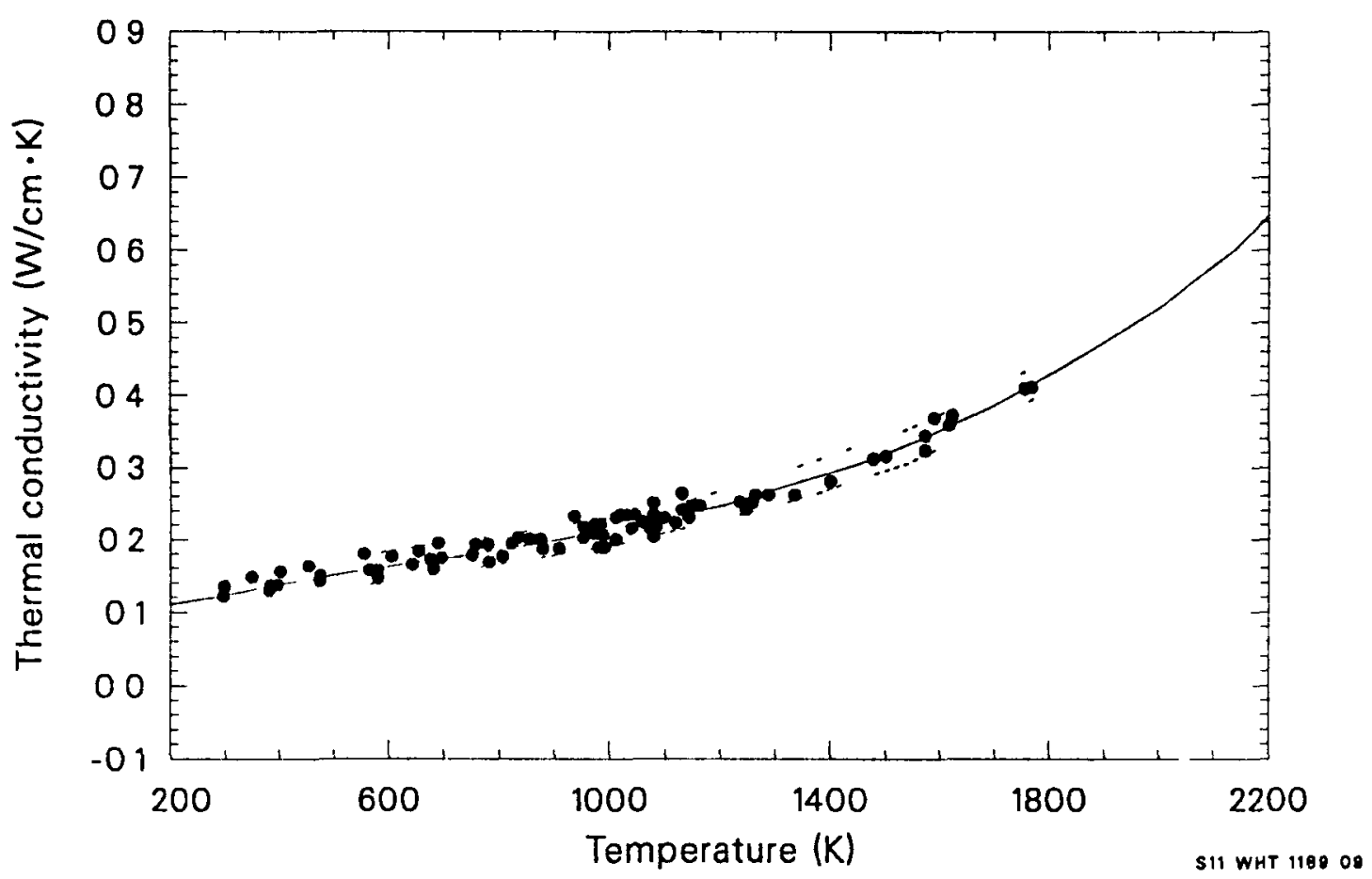

Figure 4.4-1. Thermal conductivity data, least-squares fit, and the two standard deviation limits. 


\section{CTHCON}

reported three sets of thermal conductivity data for zircaloy taken from Battelle Memorial Institute (BMI) letter reports. These data cover both zircaloy-2 and -4 over temperature ranges of approximately 300 to $1000 \mathrm{~K}$. Scott $4.4-7$ reported the thermal conductivity of zircaloy-4 between 400 and $1060 \mathrm{~K}$. Numerical values of his data were reported by Touloukian et a) 4.4-8 These data are presented in Table 4.4-1.

\subsubsection{Mode1 Development}

The data reported in Section 4.4 .2 refer to zircaloy-2 and zircaloy-4 having various textures and pretest histories. The alloy chemistry and heat transfer properties of zircaloy-2 and -4 are similar enough to consider them to be a single material. The differences in thermal conductivity between the materials appears to be of the same magnitude as the statistical scatter in the data.

Texture may have an effect in the alpha-phase temperature region. Zircaloy is crystallized in a hexagonal, close-packed configuration in the low-temperature alpha phase; and there may be some difference in the thermal conductivity along the prismatic and basal directions. At higher temperatures, the material is body-centered cubic and will not exhibit texture effects. In any case, contributions to the thermal conductivity due to texture are probably well within the scatter of the experimental data used to develop models for this property.

All of the available data for thermal conductivity of zircaloy-2 and -4 were combined and analyzed using a least-squares polynomial fit of the third degree. The equation is:

$k=7.51+2.09 \times 10^{-2} \mathrm{~T}-1.45 \times 10^{-5} \mathrm{~T}^{2}+7.67 \times 10^{-9} \mathrm{~T}^{3}$

where 


\section{CTHCON}

Table 4.4-1. Zircaloy thermal conductivity data base

\begin{tabular}{|c|c|c|c|c|c|}
\hline $\begin{array}{l}\text { Temperature } \\
(\mathrm{K})\end{array}$ & $\begin{array}{l}\text { Experimenta } 1 \\
\text { Thermal } \\
\text { Conduct ivity } \\
(\mathrm{W} / \mathrm{m} \bullet \mathrm{K}) \\
\end{array}$ & $\begin{array}{l}\text { Ca lcu lated } \\
\text { Thermal } \\
\text { Conduct ivity } \\
(\mathrm{W} / \mathrm{m} \cdot \mathrm{K}) \\
\end{array}$ & $\begin{array}{c}\text { Difference Between } \\
\text { Calculated and } \\
\text { Experimental Thermal } \\
\text { Conductivities } \\
\end{array}$ & Reference & Material \\
\hline 380.4 & 13.50 & 13.78 & -0.28 & W. K. Anderson et al. & Zircaloy-2 \\
\hline 469.3 & 14.43 & 14.92 & -0.49 & & \\
\hline 577.6 & 15.68 & 16.22 & -0.54 & & \\
\hline 685.9 & 17.10 & 17.50 & -0.40 & & \\
\hline 774.8 & 18.42 & 18.57 & -0.15 & & \\
\hline 872.0 & 19.91 & 19.80 & 0.11 & & \\
\hline 373.2 & 13.60 & 13.69 & -0.09 & J. N. Chirigos et al. & Zircaloy -4 \\
\hline 473.2 & 14.30 & 14.97 & -0.67 & & \\
\hline 573.2 & 15.20 & 16.17 & -0.97 & & \\
\hline 673.2 & 16.40 & 17.35 & -0.95 & & \\
\hline 773.2 & 18.00 & 18.55 & -0.55 & & \\
\hline 873.2 & 20.10 & 19.81 & 0.29 & & \\
\hline 973.2 & 22.50 & 21.19 & 1.31 & & \\
\hline 1073.2 & 25.20 & 22.72 & 2.48 & & \\
\hline 1123.2 & 26.60 & 23.56 & 3.04 & & \\
\hline 642.2 & 16.30 & 16.98 & -0.68 & A. D. Feith & Zircaloy-4 \\
\hline 678.2 & 16.10 & 17.41 & -1.31 & & \\
\hline 746.2 & 17.60 & 18.22 & -0.62 & & \\
\hline 780.2 & 18.40 & 18.63 & -0.23 & & \\
\hline 800.2 & 17.70 & 18.88 & -1.18 & & \\
\hline 819.2 & 19.80 & 19.12 & 0.68 & & \\
\hline 833.2 & 20.10 & 19.29 & 0.81 & & \\
\hline 847.2 & 19.60 & 19.47 & 0.13 & & \\
\hline
\end{tabular}




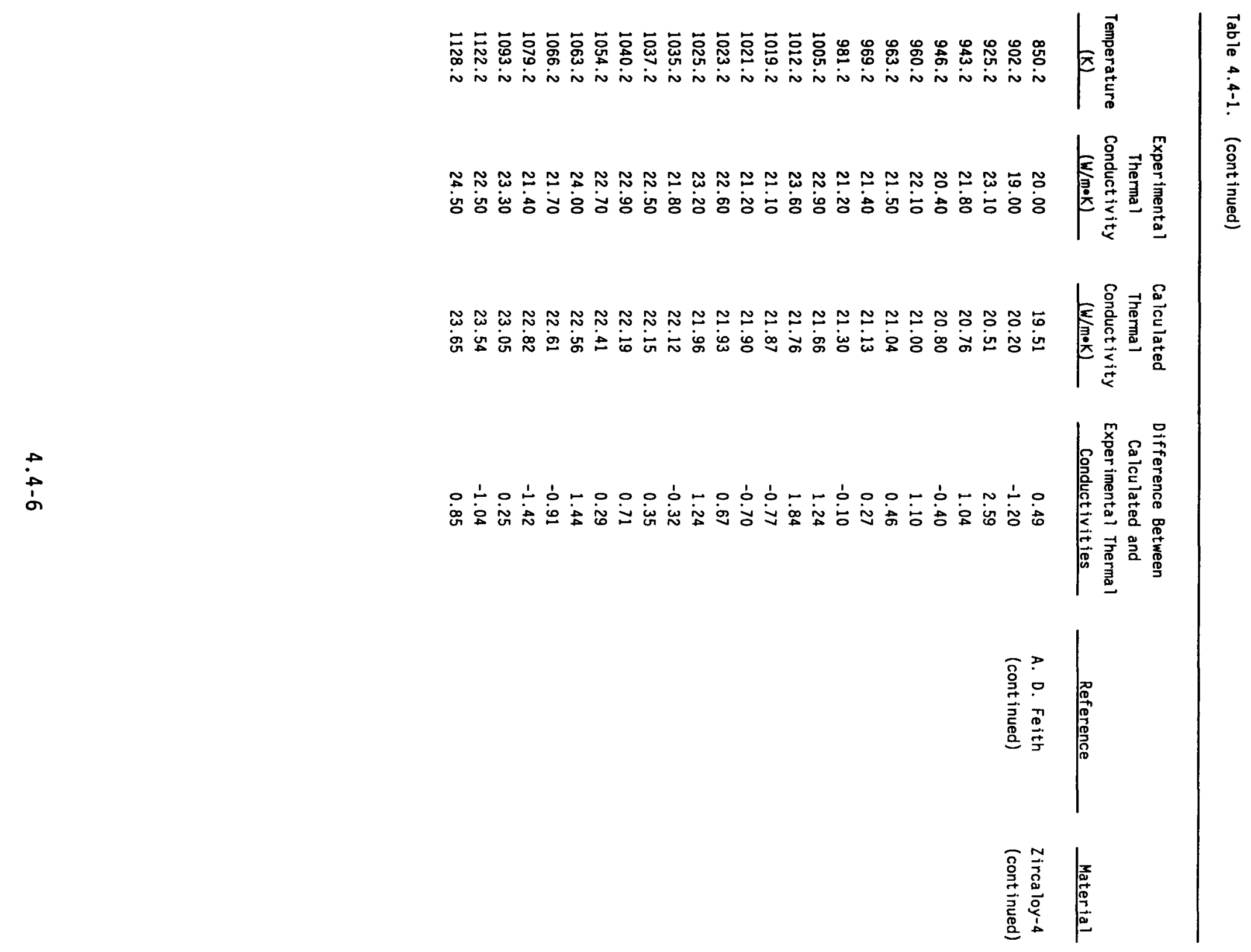




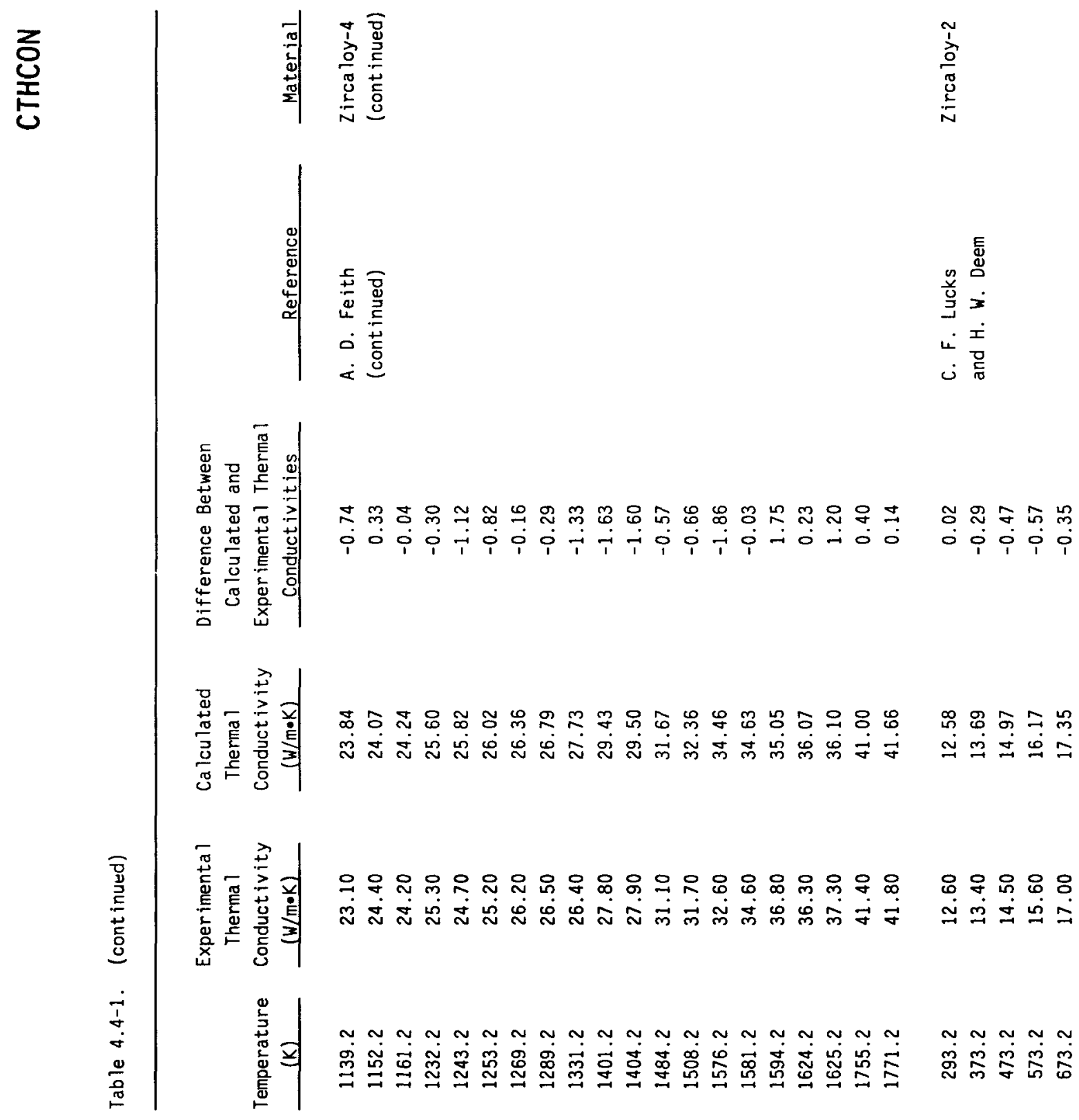




\section{CTHCON}

Table 4.4-1. (continued)

\begin{tabular}{|c|c|c|c|c|c|}
\hline $\begin{array}{l}\text { Temperature } \\
\text { (K) }\end{array}$ & $\begin{array}{l}\text { Experimenta } 1 \\
\text { Therma } 1 \\
\text { Conduct ivity } \\
(\mathrm{W} / \mathrm{m} \bullet \mathrm{K}) \\
\end{array}$ & $\begin{array}{l}\text { Calculated } \\
\text { Thermal } \\
\text { Conduct ivity } \\
(W / m \cdot K) \\
\end{array}$ & $\begin{array}{l}\text { Difference Between } \\
\text { Calculated and } \\
\text { Experimental Therma? } \\
\text { Conductivities } \\
\end{array}$ & Reference & Material \\
\hline 773.2 & 18.40 & 18.55 & -0.15 & C. F. Lucks & Zircaloy-2 \\
\hline 873.2 & 19.90 & 19.81 & 0.09 & and $H$. W. Deem & (cont inued) \\
\hline 973.2 & 21.50 & 21.19 & 0.31 & (cont inued) & \\
\hline 1073.2 & 23.10 & 22.72 & 0.38 & & \\
\hline 373.2 & 14.11 & 13.69 & 0.42 & A. E. Powers & Zircaloy-2 \\
\hline 473.2 & 14.80 & 14.97 & -0.17 & & \\
\hline 573.2 & 15.32 & 16.17 & -0.85 & & \\
\hline 673.2 & 16.01 & 17.35 & -1.34 & & \\
\hline 773.2 & 17.05 & 18.55 & -1.50 & & \\
\hline 873.2 & 1.18 & 19.81 & -1.63 & & \\
\hline 973.2 & 19.42 & 21.19 & -1.77 & & \\
\hline 1073.2 & 20.77 & 22.72 & -1.95 & & \\
\hline 293.2 & 12.55 & 12.58 & -0.03 & & \\
\hline 373.2 & 13.29 & 13.69 & -0.40 & & \\
\hline 473.2 & 14.37 & 14.97 & -0.60 & & \\
\hline 573.2 & 15.58 & 16.17 & -0.59 & & \\
\hline 673.2 & 16.88 & 17.35 & -0.47 & & \\
\hline 773.2 & 18.42 & 18.55 & -0.13 & & \\
\hline 873.2 & 19.91 & 19.81 & 0.10 & & \\
\hline 973.2 & 21.52 & 21.19 & -0.33 & & \\
\hline 1073.2 & 23.02 & 22.72 & 0.30 & & \\
\hline 293.2 & 13.42 & 12.58 & 0.84 & & \\
\hline 373.2 & 13.67 & 13.69 & -0.02 & & \\
\hline 473.2 & 14.16 & 14.97 & -0.81 & & \\
\hline 573.2 & 15.13 & 16.17 & -1.04 & & \\
\hline
\end{tabular}




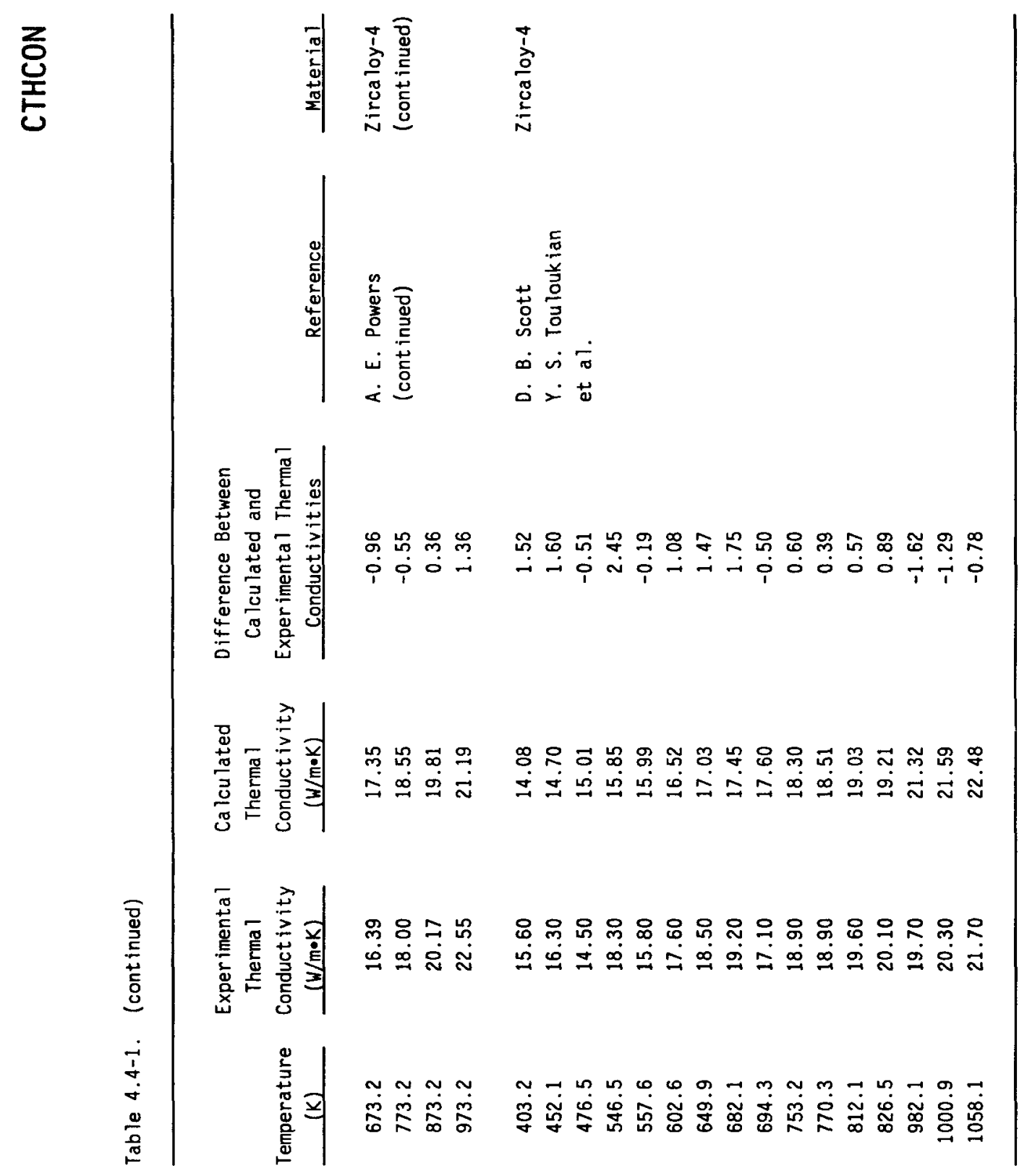




\section{CTHCON}

$k=$ zircaloy thermal conductivity $(\mathrm{W} / \mathrm{m} \cdot \mathrm{K})$

$\mathrm{T}=$ temperature of cladding $(K)$.

A comparison of calculated thermal conductivities and the data is shown in Figure 4.4-1.

The standard deviation of the data with respect to Equation (4.4-5) is $1.01 \mathrm{~W} / \mathrm{m} \cdot \mathrm{K}$. Thirty-two of the points fall outside $\pm 1 \sigma$ from the curve. Four points fal1 outside $\pm 2 \sigma$ (Figure 4.4-1). The standard deviations of the coefficients of Equation (4.4-5) are about 20\% to $30 \%$ of the absolute value of the coefficients.

The standard deviation is small enough so that the user may have considerable confidence in the model. Jensen ${ }^{4.4-9}$ performed a parametric analysis of several variables involved in estimation of fuel and cladding temperatures. Both steady-state and transient analyses showed that variations of $\pm 20 \%$ resulted in calculated cladding temperature variations of about $2.8 \mathrm{~K}$. Fuel centerline temperatures are more sensitive to cladding thermal conductivity and showed variations of $28 \mathrm{~K}$. Similar findings were reported by Korber and Unger. ${ }^{4.4-10}$

\subsubsection{References}

4.4-1 S. Nazare, G. Ondracek, and B. Schulz, "Properties of Light Water Reactor Core Melts, Nuclear Technology, 32, 1977, pp. 239-246.

4.4-2 W. K. Anderson, C. J. Beck, A. R. Kephart, and J. S. Theilacker "Zirconium Alloys, "Reactor Structural Materials: Engineering Properties as Affected by Nuclear Reactor Service, ASTM-STP-314, 1962, pp. $62-93$

4.4-3 J. N. Chirigos et al., "Development of Zircaloy-4," Fuel Element Fabrication, New York: Academic Press, 1961, pp. 19-55.

4.4-4 A. D. Feith, Thermal Conductivity and Electrical Resistivity of Zircaloy-4, GEMP-669, October 1966. 


\section{CTHCON}

4.4-5 C. F. Lucks and H. W. Deem, Progress Relating to Civilian Applications During June, 1958, R. W. Dayton and C. R. Tipton, Jr., (eds.), BMI-1273, 1958, pp. 7-9.

4.4-6 A. E. Powers, Application of the Ewing Equation for Calculating Thermal Conductivity from Electrical Conductivity, KAPL-2146, April 7, 1961.

4.4-7 D. B. Scott, Physical and Mechanical Properties of Zircaloy 2 and 4, WCAP-3269-41, May 1965, pp. 5, 9.

4.4-8 Y. S. Touloukian, R. W. Powe11, C. Y. Ho, P. G. Klemens, Thermophysical Properties of Matter, Volume 1, Thermal

Conductivity, New York: Plenum Press, 1970, pp. 888-889.

4.4-9 S. E. Jensen, Parametric Studies of Fuel Pin Temperature Response, ID0-17295, February 1969.

4.4-10 H. Korber and H. E. Unger, "Sensitivity Study on Core Heatup and Meltdown by Variation of Heat Conductivity and Thermal Emissivity," Transactions of the American Nuclear Society, 18, 1974, pp. 234-235. 
$-$ 


\title{
4.5 Thermal Expansion and its Relation to Texture AND DENSITY (CTHEXP, CDEN)
}

\author{
(G. A. Reymann)
}

The model described herein calculates components of the thermal expansion strain for single-crystal zircaloy. By use of pole figures to ascertain the average orientation of single crystals in a multicrystalline sample, such as zircaloy fuel rod cladding, these single-crystal values may be applied to find the thermal expansion strain of any sample.

Thermal expansion strain, especially in the diametral direction, is important in safety analyses because it is a major factor in determining the pellet-cladding gap, and thus the pellet temperature and its stored energy. Since zircaloy is an anisotropic solid, strains parallel and perpendicular to the basal pole direction of single-crystal grains are needed to find the diametral strain in a multicrystalline sample. The subcode CTHEXP treats this strain as a tensor and uses pole figures to calculate the thermal expansion strain.

The subroutine CDEN returns the density of zircaloy from room temperature data and thermal expansion strains calculated with the CTHEXP subcode.

\subsubsection{Summary (CTHEXP)}

A total of six correlations that are functions of temperature only are used to find single-crystal thermal strains. In addition, basal plane symmetry $\left(\epsilon_{11}=\epsilon_{22}\right)$ is assumed. The model was developed for as-fabricated zircaloy-4, but comparisons with zircaloy-2 and zirconium data al so show good agreement for these materials. 


\section{CTHEXP, CDEN}

The correlations for single-crystal thermal strains are:

For $300<T<1083 \mathrm{~K}$,

$\epsilon_{11}=4.95 \times 10^{-6} \mathrm{~T}-1.485 \times 10^{-3}$

$\epsilon_{33}=1.26 \times 10^{-5} \mathrm{~T}-3.78 \times 10^{-3}$

where

$$
\begin{aligned}
& \epsilon_{11}=\text { circumferential thermal expansion }(\mathrm{m} / \mathrm{m}) \\
& \epsilon_{33}=\text { axial thermal expansion }(\mathrm{m} / \mathrm{m}) \\
& T \quad=\quad \text { temperature }(\mathrm{K}) . \\
& \text { For } 1083 \leq \mathrm{T} \leq 1244 \mathrm{~K} \\
& \epsilon_{11}=\left[2.77763+1.09822 \cos \left(\frac{\mathrm{T}-1083}{161} \pi\right)\right] \cdot 10^{-3} \\
& \epsilon_{33}=\left[8.76758+1.09822 \cos \left(\frac{T-1083}{161} \pi\right)\right] \cdot 10^{-3}
\end{aligned}
$$

where the arguments of the cosines are in radians.

For $1244 \mathrm{~K} \leq \mathrm{T} \leq 2098 \mathrm{~K}$,

$$
\begin{aligned}
& \epsilon_{11}=9.7 \times 10^{-6} \mathrm{~T}-1.04 \times 10^{-2} \\
& \epsilon_{33}=9.7 \times 10^{-6} \mathrm{~T}-4.4 \times 10^{-3}
\end{aligned}
$$




\section{CTHEXP, CDEN}

For temperatures $>2098 \mathrm{~K}$, consideration of the volume change associated with melting is required. Since no data have been found, a typical $2 \%$ volume increase at melt is assumed. The expressions used for the thermal strain in 1iquid zirconium (temperatures $\geq 2098 \mathrm{~K}$ ) are thus

$\epsilon_{\mathrm{p}}=\frac{2}{3} \epsilon_{11}+\frac{1}{3} \epsilon_{33}+0.0067$

where

$$
\begin{aligned}
& \epsilon_{\mathrm{p}}=\text { thermal expansion strain in liquid zircaloy }(\mathrm{m} / \mathrm{m}) \\
& \epsilon_{11}=\begin{array}{l}
\text { circumferential thermal expansion strain of a single } \\
\text { crystal of zircaloy at } 2098 \mathrm{~K}(\mathrm{~m} / \mathrm{m})
\end{array} \\
& \epsilon_{33=} \text { axial thermal expansion strain of a single crystal of } \\
& \text { zircaloy at } 2098 \mathrm{~K}(\mathrm{~m} / \mathrm{m}) .
\end{aligned}
$$

Equations (4.5-3) and (4.5-4) are used to calculate $\epsilon_{11}$ and $\epsilon_{33}$.

To obtain cladding strains from these single-crystal strains, it is necessary to do a volume-weighted averaging over the entire cladding section. Such an averaging requires a pole figure and is described in Section 16.2. The results are

$$
\begin{aligned}
& \left\langle\epsilon^{\prime}{ }_{11}\right\rangle=\left\langle\sin ^{2} \phi\right\rangle \epsilon_{11}+\left\langle\cos ^{2} \theta \cos ^{2} \phi\right\rangle \epsilon_{22}+\left\langle\sin ^{2} \theta \cos ^{2} \phi\right\rangle \epsilon_{33} \\
& \left\langle\epsilon^{\prime}{ }_{22}\right\rangle=\left\langle\cos ^{2} \phi\right\rangle \epsilon_{11}+\left\langle\cos ^{2} \theta \sin ^{2} \phi\right\rangle \epsilon_{22}+\left\langle\sin ^{2} \theta \sin ^{2} \phi\right\rangle \epsilon_{33} \\
& \left\langle\epsilon^{\prime}{ }_{33}\right\rangle=\left\langle\sin ^{2} \theta\right\rangle \epsilon_{22}+\left\langle\cos ^{2} \theta\right\rangle \epsilon_{33}
\end{aligned}
$$

where primed strains refer to the laboratory system (cladding and unprimed strains to the single crystals), 


\section{CTHEXP, CDEN}

$\theta=$ angle between the radial direction of the cladding and the $c$ axis of the single crystals

$\phi \quad=\quad$ angle between the circumferential direction of the cladding and the projection of the $c$ axis at a grain onto the circumferential--axial plane at the cladding.

As an example, the strains for a typical LWR cladding tube (zircaloy-4) are, for $T<1083 \mathrm{~K}$

$$
\begin{aligned}
& \left\langle\epsilon^{\prime}{ }_{11}\right\rangle=6.48 \times 10^{-6} \mathrm{~T}-1.95 \times 10^{-3} \\
& \left\langle\epsilon^{\prime}{ }_{22}\right\rangle=5.63 \times 10^{-6} \mathrm{~T}-1.69 \times 10^{-3} \\
& \left\langle\epsilon^{\prime}{ }_{33}\right\rangle=1.04 \times 10^{-5} \mathrm{~T}-3.11 \times 10^{-3}
\end{aligned}
$$

Equations (4.5-11 to 4.5-13) are valid for $\left\langle\cos ^{2} \theta\right\rangle=0.71013$ and $\left\langle\sin ^{2} \phi\right\rangle=0.30822$.

Section 4.5.2 contains a review of the literature consulted. The model development is given in Section 4.5.3, and Section 4.5 .4 contains a model-data comparison with an uncertainty analysis.

\subsubsection{Literature Review (CTHEXP)}

The most important source is the model on cladding plastic deformation, Section 4.9, where the volume-weighted averages of the direction cosines for typical LWR cladding are given. These averages were used with thermal expansion data from an EPRI report by Bunne $17^{4.5-1}$ to make the basic model. Since Bunnell does not report data in the beta phase $(T>1244 \mathrm{~K}$ ) for circumferential expansion, the data can be used only for an alpha phase model. The EPRI data do not show $\epsilon_{11}$ or $\epsilon_{22}$ equal to zero at $300 \mathrm{~K}$, and therefore each point was shifted by an amount such that this 


\section{CTHEXP, CDEN}

requirement was met. To determine the validity of the resulting data, they were checked against the older data sources of Douglass, 4.5-2 Mehan and Wiesinger, 4.5-3 Scott, 4.5-4 and Kearns. 4.5-5 The correlations given here compare well with those of Douglass and Kearns, as shown in Figures 4.5-1 through 4.5-4. The Mehan and Wiesinger data are for plates. To be compared with Equations (4.5-1) and (4.5-2), these equations must be converted from single-crystal form to plate form. Since Mehan and Wiesinger give no detailed texture information, typical values for texture coefficients from Hann ${ }^{4-5}$ were used. The results are shown in Table 4.5-1.

The differences shown in Table 4.5-1 can be easily explained by the unknown texture differences between the samples from which the data sets were derived.

All data sets had to be adjusted to give $\Delta L=0$ at $300 \mathrm{~K}$. This was done by adding or subtracting the strain at $300 \mathrm{~K}$. This technique is not exact for engineering strains but results in negligible error when the strains are small, as in the case here.

These comparisons show that the Bunnell data are adequate in the alpha phase. Therefore, this data set is used as the data base in the low-temperature $(T<1083 \mathrm{~K}$ ) range.

In the transition region between the alpha and beta phases (1083 $\leq \mathrm{T} \leq$ $1244 \mathrm{~K}$ ), the volume strain was found using lattice constants for alpha zirconium from Douglass and for beta zirconium from Kittel. 4.5-7 This strain was divided by 3.0 to find an approximate linear strain, which was assumed to be equal in all three directions. A cosine function was fit to the strains to match the values at the end of the alpha phase and the beginning of the beta phase. For the beta phase, the coefficient of expansion for zirconium from Skinner and Johnston ${ }^{4-5-8}$ was used. 


\section{CTHEXP, CDEN}
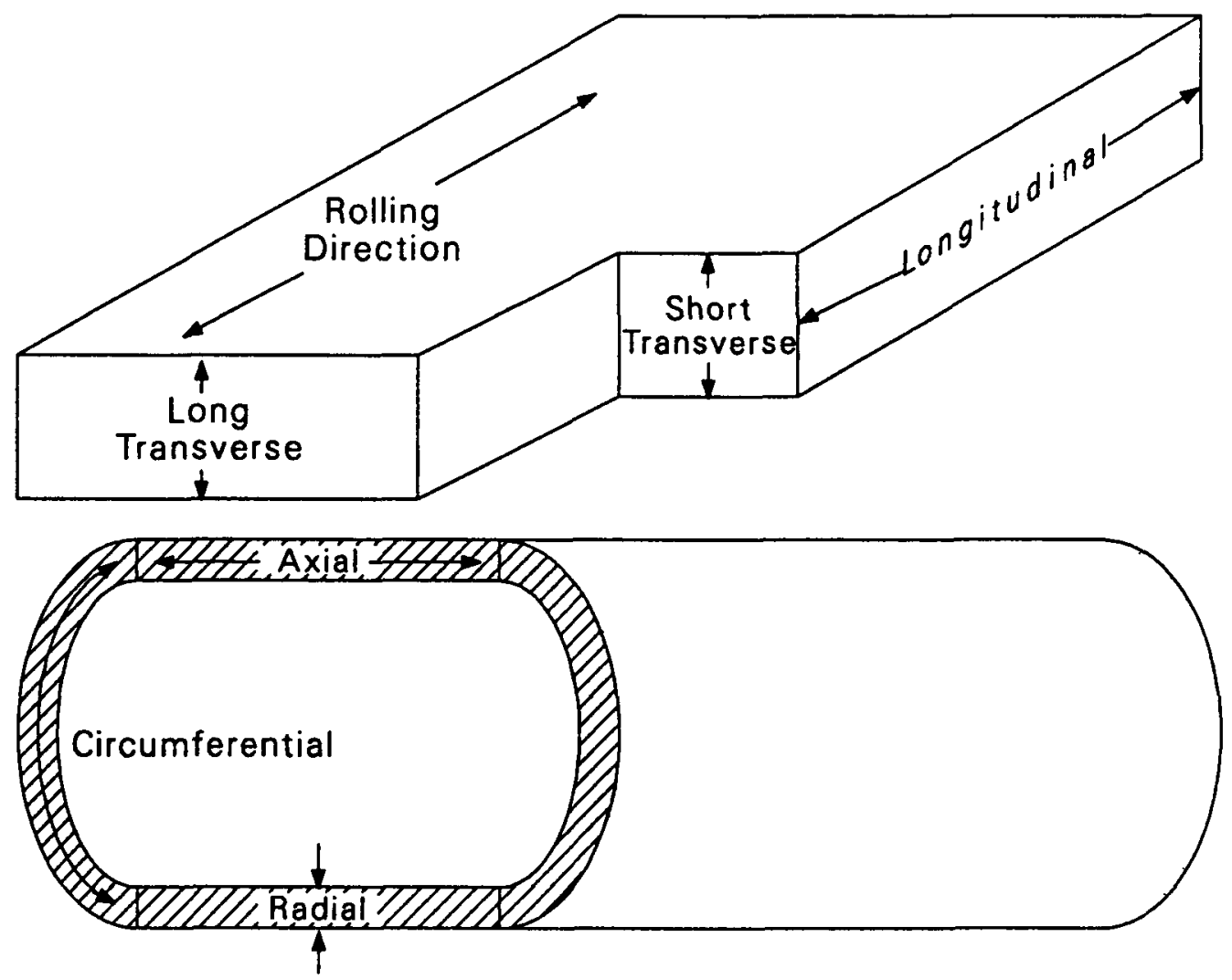

S11-WHT-1089-10

Figure 4.5-1. Comparison of CTHEXP prediction with Douglass' data in the axial direction. 


\section{CTHEXP， CDEN}

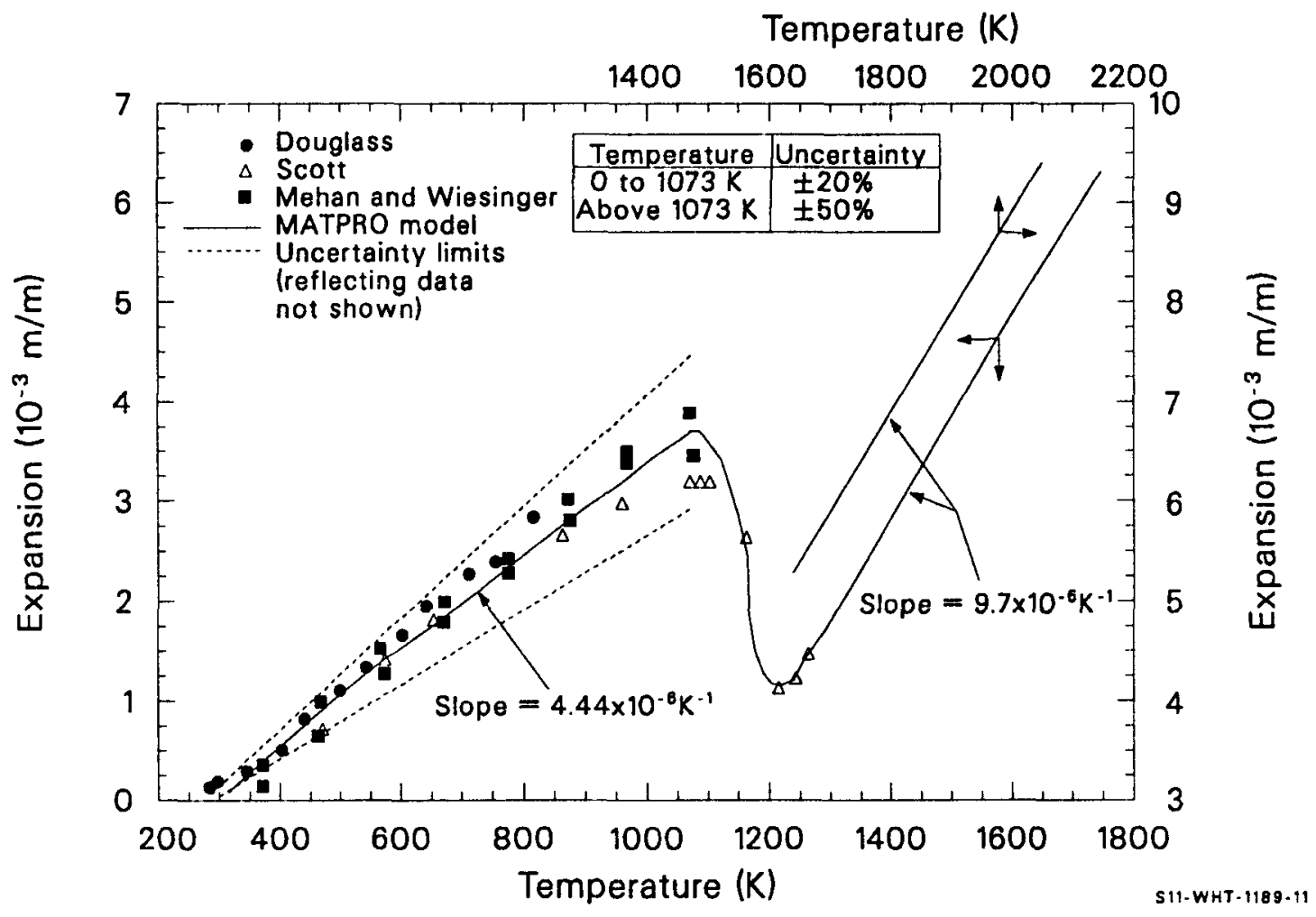

Figure 4.5-2. Comparison of CTHEXP prediction with Douglass' data in the circumferential direction. 


\section{CTHEXP, CDEN}

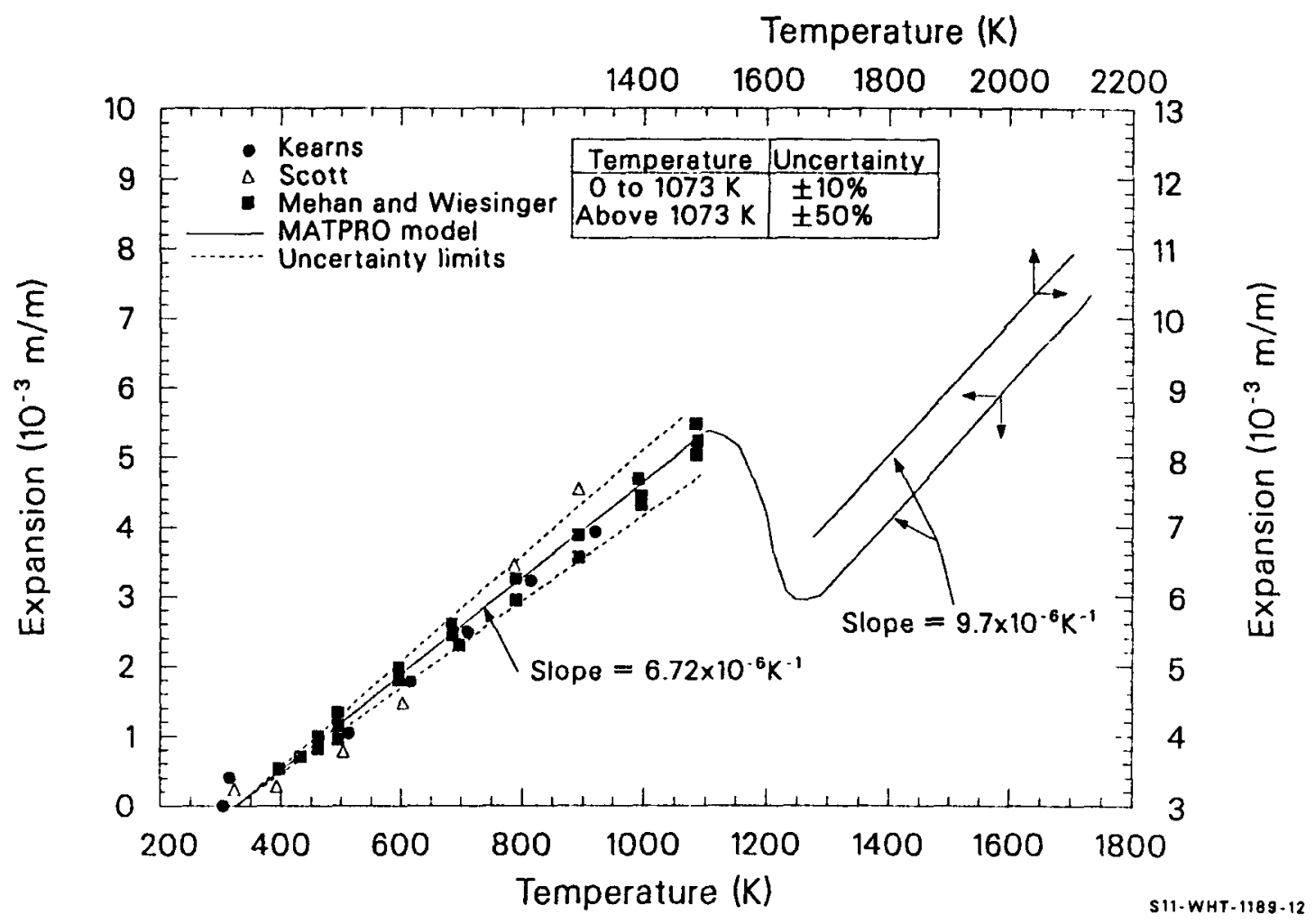

Figure 4.5-3. Comparison of CTHEXP prediction with Kearns' model in the axial direction. 


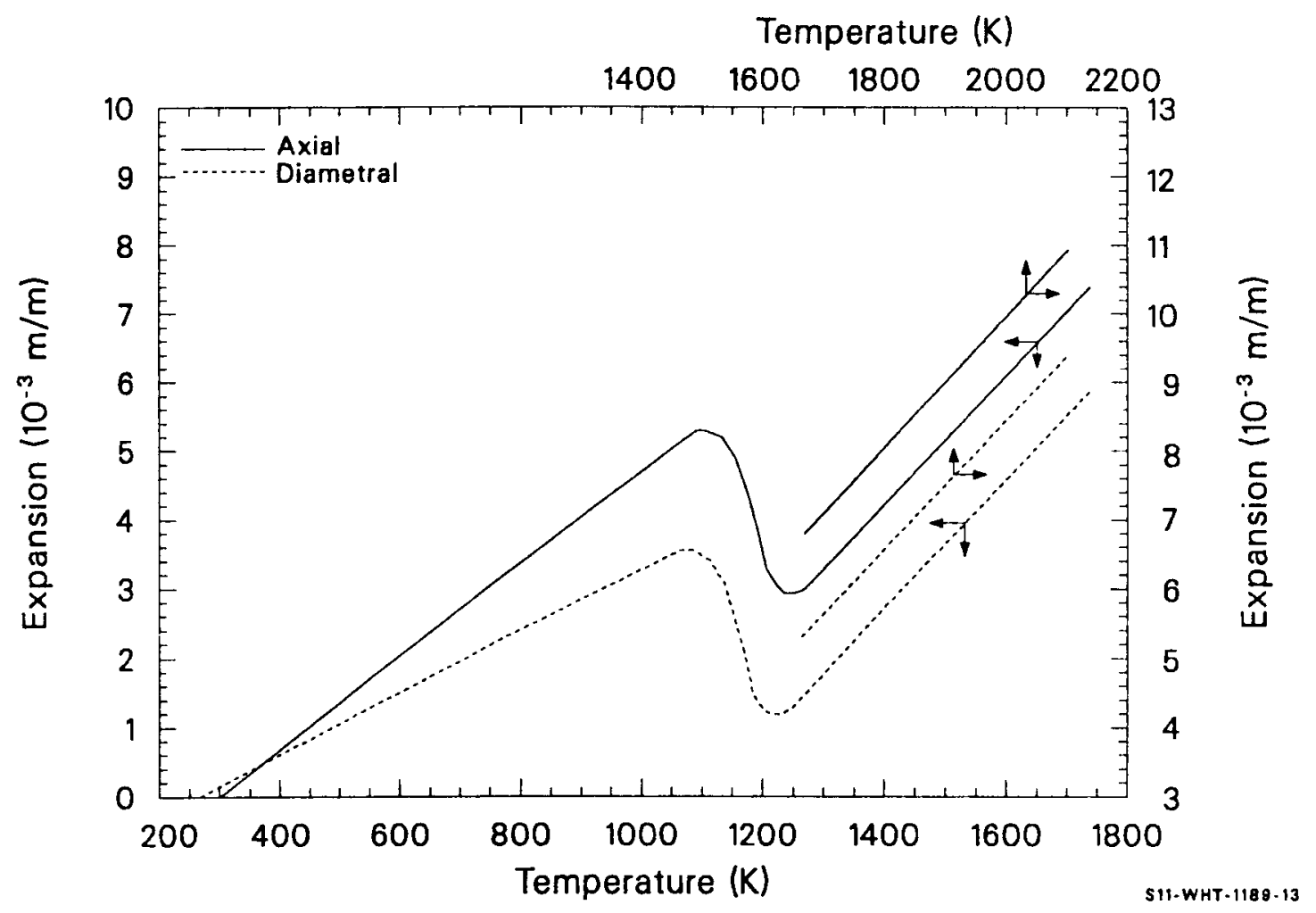

Figure 4.5-4. Comparison of CTHEXP prediction with Kearns' model in the circumferential direction. 


\section{CTHEXP， CDEN}

Table 4.5-1. Comparison of Mehan and Wiesinger plate expansion with MATPRO mode 1

\begin{tabular}{|c|c|c|c|}
\hline Direction & Mehan and Wiesinger & MATPRO Model & $\begin{array}{c}\text { Difference } \\
(\%)\end{array}$ \\
\hline Longitudinal & $4.62 \times 10^{-6}$ & $5.41 \times 10^{-6}$ & -14.60 \\
\hline Transverse & $6.58 \times 10^{-6}$ & $7.10 \times 10^{-6}$ & -7.32 \\
\hline
\end{tabular}


The correlations for $\mathrm{T}>1083 \mathrm{~K}$ are approximate. However, at these temperatures, the cladding is so soft that typical in-reactor stresses cause a significantly greater strain than the strain due to thermal expansion.

\subsubsection{Model Development (CTHEXP)}

The model development is divided into three sections, depending on the temperature: an alpha-phase region, a transition-phase region, and a beta-phase region.

4.5.3.1 Thermal Expansion in the Alpha Phase. The basic equations used to model thermal expansion in the alpha phase are tensor transformation equations relating cladding strain components to single-crystal strain components and parameters that describe the distribution of grain orientations in the cladding. The model is based on measured thermal strains in two directions for cladding with known texture. The inverse of the transformation is used to deduce single-crystal thermal expansions from data.

Since strain is a second-rank tensor, it is necessary to do a forma 7 rotation of axes to describe single crystal strains viewed from a laboratory system. The rotation is shown schematically in Figure 4.5-5, which was taken from Section 4.6. To derive the various tensors, first consider the transformation necessary to obtain the laboratory unit vectors expressed in terms of the single-crystal unit vectors. Since the single crystal is isotropic in planes perpendicular to the $c$ axis, assume for this transformation that the $y$ axis (single crystal) is in the same plane as the $c$ axis and the radial direction of the tube. Primed coordinates refer to those fixed in the laboratory system, and the unprimed coordinates refer to those fixed in the single crystals. The resulting transformation is

$$
\begin{aligned}
& \hat{x^{\prime}}=\sin \phi \hat{x}+\cos \theta \cos \phi \hat{y}+\sin \theta \cos \phi \hat{z} \\
& \hat{y}^{\prime}=-\cos \theta \hat{x}+\cos \theta \sin \phi \hat{y}+\sin \theta \sin \phi \hat{z}
\end{aligned}
$$




\section{CTHEXP, CDEN}

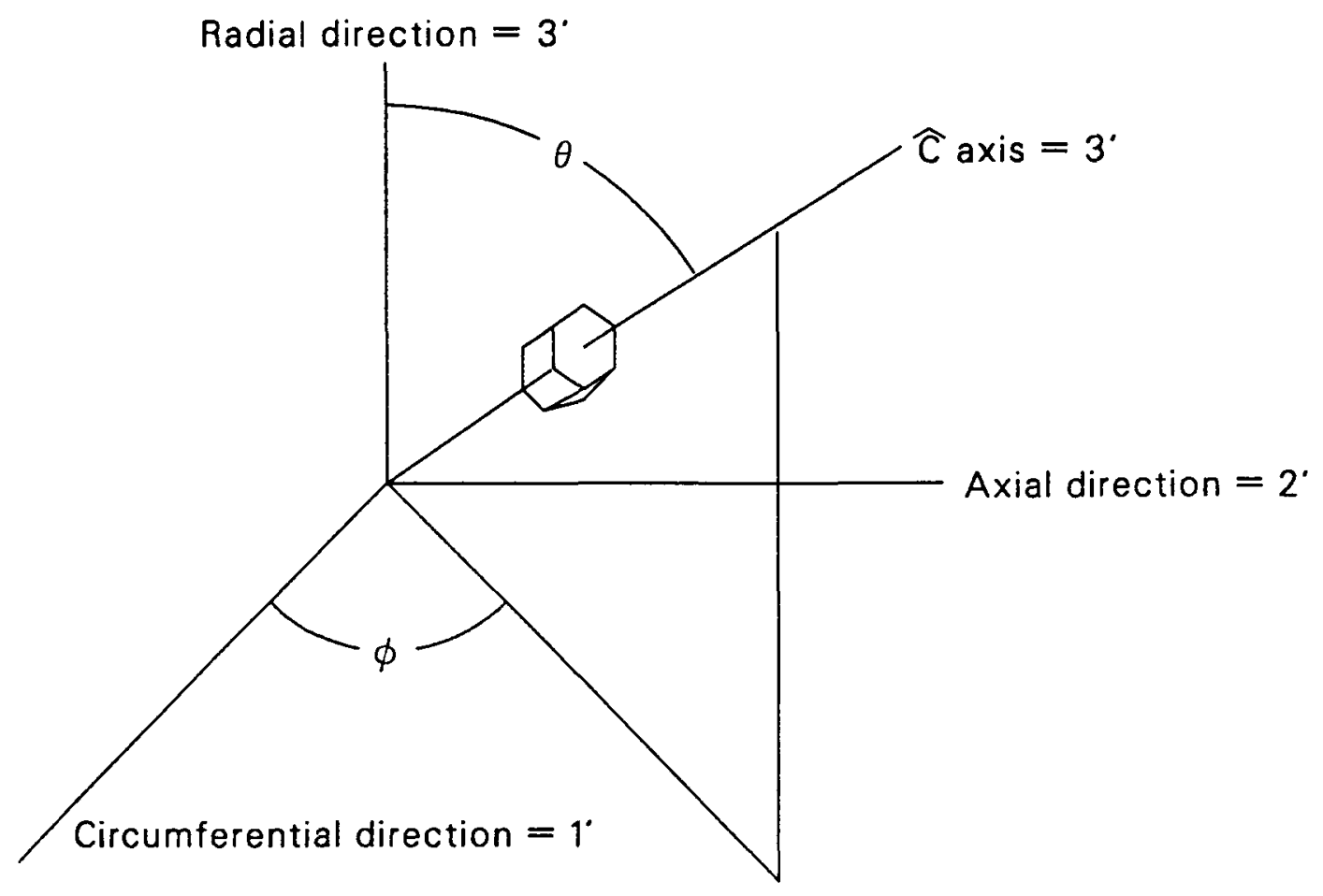

Primed coordinate

system is fixed in lab

S11-WHT-1089-14

Figure 4.5-5. Angles and orientation of the unit cell of zircaloy relative to a system of coordinates fixed in the lab frame of reference. 


\section{CTHEXP, CDEN}

$\hat{z}^{\prime}=-\sin \theta \hat{y}+\sin \theta \cos \theta \hat{z}$

where $\theta$ and $\phi$ are defined in Figure 4.5-5.

Equations (4.5-14) through (4.5-16) show a first-rank tensor transformation.

$\hat{x}_{i}^{i}=c_{i j} \hat{x}_{j}$

where $c_{i j}$ is the transformation coefficient.

The corresponding transformations for strains (2nd-rank tensors) are

$\epsilon_{i j}^{\prime}=\sum_{s=1}^{3} \sum_{t=1}^{3} c_{i s} c_{j t} \epsilon_{s t}$

where $C_{i s}$ is the coefficient from the first-order tensor transformation [Equations (4.5-14) to (4.5-16)]. For example, $C_{11}=\sin \phi$, $\mathrm{C}_{12}=\cos \theta \cos \phi$, and $\mathrm{C}_{13}=\sin \theta \cos \phi$.

Applying Equation (4.5-18) to find $\epsilon^{\prime}{ }_{11}$ gives

$$
\begin{aligned}
\epsilon_{11}^{\prime} & =\left(c_{11} c_{11} \epsilon_{11}+c_{12} c_{11} \epsilon_{21}+c_{13} c_{11} \epsilon_{31}\right) \\
& +\left(c_{11} c_{12} \epsilon_{12}+c_{12} c_{12} \epsilon_{22}+c_{13} c_{12} \epsilon_{32}\right) \\
& +\left(c_{11} c_{13} \epsilon_{13}+c_{12} c_{13} \epsilon_{23}+c_{13} c_{13} \epsilon_{33}\right)
\end{aligned}
$$

Substituting the appropriate $C_{i j} s$ into Equation (4.5-19) gives

$\epsilon_{11}^{\prime}=\sin ^{2} \phi \epsilon_{11}+\cos \theta \cos \phi \sin \phi \epsilon_{21}+\sin ^{2} \theta \cos \phi 3 \epsilon_{31}$ 


\section{CTHEXP， CDEN}

$$
\begin{aligned}
& +\sin \phi \cos \theta \cos \phi \epsilon_{12}+\cos ^{2} \theta \cos ^{2} \phi \epsilon_{22}+\sin \theta \cos ^{2} \phi \cos \theta \epsilon_{32} \\
& +\sin \phi \cos \phi \sin \theta \epsilon_{13}+\cos \theta \cos \phi \sin \theta \epsilon_{23}+\sin ^{2} \theta \cos ^{2} \phi \epsilon_{33} .
\end{aligned}
$$

The volume-weighted averages of the strain tensors are needed. These are given by

$\left\langle\epsilon^{\prime}{ }_{i j}\right\rangle=\int_{0}^{2 \pi} \int_{0}^{\pi} \epsilon^{\prime}{ }_{i j}(\theta, \phi) \rho(\theta, \phi) \sin \theta d \theta d \phi$

where

$$
\begin{aligned}
& \left\langle\epsilon^{\prime}{ }_{i j}\right\rangle=\text { volume fraction weighted average of } \epsilon_{i j}(\mathrm{~m} / \mathrm{m}) \\
& \epsilon_{i j}^{\prime}(\theta, \phi)=\text { thermal expansion strain }(\mathrm{m} / \mathrm{m}) \\
& \rho(\theta, \phi)=\text { volume fraction of grains with their } c \text { axes } \\
& \text { oriented in the region } \sin \theta \mathrm{d} \theta \mathrm{d} \phi \text { about } \\
& \theta \text { and } \phi \text {. }
\end{aligned}
$$

Putting Equation (4.5-20) into Equation (4.5-21) gives

$$
\begin{aligned}
\left\langle\epsilon^{\prime}{ }_{i j}\right\rangle & =\epsilon_{11} \int_{0}^{2 \pi} \int_{0}^{\pi} \sin ^{2} \phi \rho(\theta, \phi) \sin \theta \mathrm{d} \theta \mathrm{d} \phi \\
& +\epsilon_{21} \int_{0}^{2 \pi} \int_{0}^{\pi} \cos \theta \cos \phi \sin \phi \rho(\theta, \phi) \sin \theta \mathrm{d} \theta \mathrm{d} \phi \\
& +\epsilon_{31} \int_{0}^{2 \pi} \int_{0}^{\pi} \sin ^{2} \theta \cos \phi \rho(\theta, \phi) \sin \theta \mathrm{d} \theta \mathrm{d} \phi+\ldots
\end{aligned}
$$




\section{CTHEXP, CDEN}

The integral $\iint \sin ^{2} \theta \rho(\theta, \phi) \sin \theta \mathrm{d} \theta \mathrm{d} \phi=\left\langle\sin ^{2} \phi\right\rangle$, the volume-weighted average of $\sin ^{2} \phi$. Similarly, the integral

$\iint \sin ^{2} \theta \cos \phi \rho(\theta, \phi) \sin \theta \mathrm{d} \theta \mathrm{d} \phi=\left\langle\sin ^{2} \theta \cos \phi\right\rangle=\left\langle\sin ^{2} \theta\right\rangle\langle\cos \phi\rangle=0.0$

because averaged over the 0 to $2 \pi$ interval, $\cos \phi$ equals zero. In the same way, $\sin \phi, \sin \theta$, and $\cos \theta$ are zero. Only a squared function has a nonzero average. These averages may be found with the CTXTUR subcode of Section 16.2, using a pole figure for input texture information.

All nine of the tensor elements $\left\langle\epsilon_{i j}\right\rangle$ may be found using Equations (4.5-18) and (4.5-21). The only nonzero ones are listed in Equations (4.5-8) through (4.5-10).

$\left\langle\epsilon_{11}^{\prime}\right\rangle=\left\langle\sin ^{2} \phi\right\rangle \epsilon_{11}+\left\langle\cos ^{2} \theta \cos ^{2} \phi\right\rangle \epsilon_{22}+\left\langle\sin ^{2} \theta \cos ^{2} \phi\right\rangle \epsilon_{33}$

$\left\langle\epsilon_{22}^{\prime}\right\rangle=\left\langle\cos ^{2} \phi\right\rangle \epsilon_{11}+\left\langle\cos ^{2} \theta \sin ^{2} \phi\right\rangle \epsilon_{22}+\left\langle\sin ^{2} \theta \sin ^{2} \phi\right\rangle \epsilon_{33}$

$\left\langle\epsilon^{\prime}{ }_{33}\right\rangle=\left\langle\sin ^{2} \theta\right\rangle \epsilon_{22}+\left\langle\cos ^{2} \theta\right\rangle \epsilon_{33}$

From Section 4.9, the coefficients of the strains in Equations (4.5-8) to $(4.5-10)$ may be found for the cladding used by Bunnel1. Substituting these values into Equations $(4.5-8)$ to $(4.5-10)$, Equations $(4.5-24)$ to $(4.5-26)$ are obtained.

$$
\begin{aligned}
& \left\langle\epsilon_{11}^{\prime}\right\rangle=0.18 \epsilon_{11}+0.54 \epsilon_{22}+0.28 \epsilon_{33} \\
& \left\langle\epsilon_{22}^{\prime}\right\rangle=0.82 \epsilon_{11}+0.12 \epsilon_{22}+0.06 \epsilon_{33} \\
& \left\langle\epsilon_{33}^{\prime}\right\rangle=0.34 \epsilon_{22}+0.66 \epsilon_{33}
\end{aligned}
$$

In a single crystal, the circumferential strain, $\epsilon_{11}$, is equal to the diametral strain, $\epsilon_{22}$, so Equations $(4.5-24)$ to $(4.5-26)$ reduce to 


\section{CTHEXP, CDEN}

$\left\langle\epsilon_{11}^{\prime}\right\rangle=0.72 \epsilon_{11}+0.28 \epsilon_{33}$

$\left\langle\epsilon_{22}^{\prime}\right\rangle=0.94 \epsilon_{11}+0.06 \epsilon_{33}$

$\left\langle\epsilon_{33}^{\prime}\right\rangle=0.34 \epsilon_{22}+0.66 \epsilon_{33}$

Bunnel1's data were taken in the laboratory frame. Therefore, Equations $(4.5-26)$ to $(4.5-28)$ must be inverted to find the single-crystal strains in terms of the cladding strains

$$
\begin{aligned}
& \epsilon_{11}=-0.27\left\langle\epsilon^{\prime}{ }_{11}\right\rangle+1.27\left\langle\epsilon_{22}^{\prime}\right\rangle \\
& \epsilon_{33}=4.27\left\langle\epsilon^{\prime}{ }_{11}\right\rangle-3.27\left\langle\epsilon_{22}^{\prime}{ }_{22}\right\rangle \\
& \epsilon_{22}=\epsilon_{11}
\end{aligned}
$$

Bunnell's data, adjusted so the strain is zero at $300 \mathrm{~K}$, are given in Tables 4.5-2 and 4.5-3 for circumferential and axial thermal expansion, respectively.

Using the data listed in these tables, the next step is to find the single-crystal strains as a function of temperature. Since temperatures in the two tables do not always correspond, it was necessary to use Bunnell's correlations, which he used to fit those data, again adjusting them so the strains are zero at $300 \mathrm{~K}$. A least-squares fit was done, with the constraint that the strains are zero at $300 \mathrm{~K}$. The results are

$$
\begin{aligned}
& \epsilon_{11}=4.95 \times 10^{-6} \mathrm{~T}-1.485 \times 10^{-3} \\
& \epsilon_{33}=1.26 \times 10^{-5} \mathrm{~T}-3.78 \times 10^{-3}
\end{aligned}
$$

where $T$ is the temperature $(K)$. 
CTHEXP, CDEN

Table 4.5-2. Bunnell's circumferential thermal expansion data

\begin{tabular}{|c|c|c|c|}
\hline $\begin{array}{c}\text { Temperature } \\
(\mathrm{K})\end{array}$ & $\begin{array}{l}\epsilon_{11} \times 10^{-3} \\
\text { (unitless) } \\
\end{array}$ & $\begin{array}{c}\text { Temperature } \\
(\mathrm{K})\end{array}$ & $\begin{array}{l}\epsilon \text { l1 } \times 10^{-3} \\
\text { (unitless) }\end{array}$ \\
\hline $\begin{array}{l}394.15 \\
398.15 \\
401.15 \\
405.15\end{array}$ & $\begin{array}{l}1.806 \\
1.136 \\
1.266 \\
0.716\end{array}$ & $\begin{array}{l}616.15 \\
620.15 \\
625.15 \\
627.15\end{array}$ & $\begin{array}{l}2.326 \\
2.516 \\
1.916 \\
2.926\end{array}$ \\
\hline $\begin{array}{l}439.15 \\
444.15 \\
444.15 \\
447.15\end{array}$ & $\begin{array}{l}1.336 \\
1.516 \\
2.206 \\
0.926\end{array}$ & $\begin{array}{l}663.15 \\
667.15 \\
671.15 \\
673.15\end{array}$ & $\begin{array}{l}2.636 \\
2.826 \\
2.226 \\
3.396\end{array}$ \\
\hline $\begin{array}{l}481.15 \\
485.15 \\
488.15 \\
488.15\end{array}$ & $\begin{array}{l}1.616 \\
1.786 \\
1.196 \\
2.196\end{array}$ & $\begin{array}{l}708.15 \\
712.15 \\
716.15 \\
718.15\end{array}$ & $\begin{array}{l}2.986 \\
3.126 \\
2.516 \\
3.736\end{array}$ \\
\hline $\begin{array}{l}523.15 \\
528.15 \\
531.15 \\
532.15\end{array}$ & $\begin{array}{l}1.876 \\
2.016 \\
1.416 \\
2.516\end{array}$ & $\begin{array}{l}751.15 \\
755.15 \\
759.15 \\
761.15\end{array}$ & $\begin{array}{l}3.266 \\
3.456 \\
2.856 \\
3.916\end{array}$ \\
\hline $\begin{array}{l}568.15 \\
572.15 \\
577.15 \\
579.15\end{array}$ & $\begin{array}{l}2.096 \\
2.216 \\
1.626 \\
2.776\end{array}$ & $\begin{array}{l}794.15 \\
797.15 \\
802.15 \\
804.15\end{array}$ & $\begin{array}{l}3.646 \\
3.756 \\
3.166 \\
4.346\end{array}$ \\
\hline $\begin{array}{l}836.15 \\
840.15 \\
844.15 \\
846.15\end{array}$ & $\begin{array}{l}4.026 \\
4.096 \\
3.476 \\
4.396\end{array}$ & $\begin{array}{l}964.15 \\
969.15 \\
972.15 \\
975.15\end{array}$ & $\begin{array}{l}4.806 \\
5.026 \\
4.376 \\
4.676\end{array}$ \\
\hline $\begin{array}{l}878.15 \\
881.15 \\
885.15 \\
888.15\end{array}$ & $\begin{array}{l}4.086 \\
4.436 \\
3.786 \\
4.506\end{array}$ & $\begin{array}{l}1008.15 \\
1013.15 \\
1017.15 \\
1019.15\end{array}$ & $\begin{array}{l}5.006 \\
5.326 \\
4.656 \\
4.616\end{array}$ \\
\hline $\begin{array}{l}920.15 \\
925.15 \\
929.15 \\
931.15\end{array}$ & $\begin{array}{l}4.606 \\
4.716 \\
4.136 \\
4.706\end{array}$ & $\begin{array}{l}1044.15 \\
1044.15 \\
1044.15 \\
1044.15\end{array}$ & $\begin{array}{l}4.736 \\
4.876 \\
5.646 \\
5.406\end{array}$ \\
\hline
\end{tabular}




\section{CTHEXP, CDEN}

Table 4.5-3. Bunnell's axial thermal expansion data

\begin{tabular}{|c|c|c|c|}
\hline $\begin{array}{c}\text { Temperature } \\
(\mathrm{K})\end{array}$ & $\begin{array}{l}\epsilon_{11} \times 10^{-3} \\
\text { (unitless) } \\
\end{array}$ & $\begin{array}{c}\text { Temperature } \\
(\mathrm{K})\end{array}$ & $\begin{array}{l}\epsilon_{11} \times 10^{-3} \\
\text { (unitless) }\end{array}$ \\
\hline $\begin{array}{l}376.15 \\
380.15 \\
389.15 \\
396.15 \\
396.15\end{array}$ & $\begin{array}{l}0.461 \\
0.421 \\
0.531 \\
0.461 \\
0.611\end{array}$ & $\begin{array}{l}569.15 \\
569.15 \\
578.15 \\
579.15 \\
581.15\end{array}$ & $\begin{array}{l}1.321 \\
1.621 \\
1.311 \\
1.631 \\
1.401\end{array}$ \\
\hline $\begin{array}{l}398.15 \\
403.15 \\
406.15 \\
411.15 \\
421.15\end{array}$ & $\begin{array}{l}0.481 \\
0.561 \\
0.481 \\
0.581 \\
0.591\end{array}$ & $\begin{array}{l}588.15 \\
599.15 \\
604.15 \\
604.15 \\
613.15\end{array}$ & $\begin{array}{l}1.731 \\
1.451 \\
1.661 \\
1.811 \\
1.901\end{array}$ \\
\hline $\begin{array}{l}424.15 \\
428.15 \\
436.15 \\
441.15 \\
444.15\end{array}$ & $\begin{array}{l}0.661 \\
0.741 \\
2.061 \\
0.681 \\
0.811\end{array}$ & $\begin{array}{l}616.15 \\
620.15 \\
627.15 \\
629.15 \\
630.15\end{array}$ & $\begin{array}{l}1.571 \\
1.841 \\
1.551 \\
1.461 \\
1.921\end{array}$ \\
\hline $\begin{array}{l}445.15 \\
449.15 \\
456.15 \\
462.15 \\
466.15\end{array}$ & $\begin{array}{l}0.671 \\
0.691 \\
0.901 \\
0.941 \\
0.801\end{array}$ & $\begin{array}{l}646.15 \\
646.15 \\
651.15 \\
653.15 \\
663.15\end{array}$ & $\begin{array}{l}1.701 \\
2.031 \\
1.851 \\
2.111 \\
1.841\end{array}$ \\
\hline $\begin{array}{l}468.15 \\
477.15 \\
482.15 \\
489.15 \\
490.15\end{array}$ & $\begin{array}{l}0.901 \\
1.031 \\
0.901 \\
1.121 \\
0.911\end{array}$ & $\begin{array}{l}663.15 \\
671.15 \\
673.15 \\
675.15 \\
686.15\end{array}$ & $\begin{array}{l}2.031 \\
2.151 \\
1.831 \\
1.871 \\
2.221\end{array}$ \\
\hline $\begin{array}{l}496.15 \\
504.15 \\
506.15 \\
511.15 \\
512.15\end{array}$ & $\begin{array}{l}1.201 \\
1.201 \\
1.021 \\
1.181 \\
1.251\end{array}$ & $\begin{array}{l}691.15 \\
694.15 \\
697.15 \\
704.15 \\
707.15\end{array}$ & $\begin{array}{l}1.991 \\
2.271 \\
2.221 \\
2.061 \\
2.111\end{array}$ \\
\hline $\begin{array}{l}523.15 \\
524.15 \\
531.15 \\
532.15 \\
535.15\end{array}$ & $\begin{array}{l}1.111 \\
1.351 \\
1.451 \\
1.101 \\
1.131\end{array}$ & $\begin{array}{l}711.15 \\
718.15 \\
721.15 \\
726.15 \\
833.15\end{array}$ & $\begin{array}{l}2.351 \\
2.101 \\
2.111 \\
2.401 \\
2.511\end{array}$ \\
\hline
\end{tabular}


CTHEXP, CDEN

Table 4.5-3. (continued)

\begin{tabular}{|c|c|c|c|}
\hline $\begin{array}{c}\text { Temperature } \\
\text { (K) }\end{array}$ & $\begin{array}{l}\epsilon 11 \times 10^{-3} \\
\text { (unitless) }\end{array}$ & $\begin{array}{l}\text { Temperature } \\
\text { (K) }\end{array}$ & $\begin{array}{l}\epsilon 11 \times 10^{-3} \\
\text { (unitless) }\end{array}$ \\
\hline $\begin{array}{l}540.15 \\
548.15 \\
550.15 \\
557.15 \\
563.15\end{array}$ & $\begin{array}{l}1.141 \\
1.481 \\
1.211 \\
1.441 \\
1.581\end{array}$ & $\begin{array}{l}734.15 \\
738.15 \\
740.15 \\
749.15 \\
750.15\end{array}$ & $\begin{array}{l}2.251 \\
1.051 \\
2.481 \\
2.531 \\
2.381\end{array}$ \\
\hline $\begin{array}{l}760.15 \\
763.15 \\
764.15 \\
771.15 \\
776.15\end{array}$ & $\begin{array}{l}2.351 \\
2.321 \\
2.631 \\
2.691 \\
2.481\end{array}$ & $\begin{array}{l}930.15 \\
932.15 \\
932.15 \\
946.15 \\
948.15\end{array}$ & $\begin{array}{l}3.281 \\
3.221 \\
3.471 \\
3.431 \\
3.601\end{array}$ \\
\hline $\begin{array}{l}782.15 \\
790.15 \\
794.15 \\
804.15 \\
804.15\end{array}$ & $\begin{array}{l}2.721 \\
2.751 \\
2.591 \\
2.611 \\
2.811\end{array}$ & $\begin{array}{l}955.15 \\
961.15 \\
963.15 \\
964.15 \\
973.15\end{array}$ & $\begin{array}{l}3.661 \\
3.741 \\
3.521 \\
3.691 \\
3.541\end{array}$ \\
\hline $\begin{array}{l}806.15 \\
812.15 \\
819.15 \\
826.15 \\
828.15\end{array}$ & $\begin{array}{l}2.601 \\
2.851 \\
2.721 \\
2.961 \\
2.941\end{array}$ & $\begin{array}{l}973.15 \\
975.15 \\
991.15 \\
991.15 \\
998.15\end{array}$ & $\begin{array}{l}3.741 \\
3.451 \\
3.671 \\
3.801 \\
3.931\end{array}$ \\
\hline $\begin{array}{l}835.15 \\
843.15 \\
844.15 \\
848.15 \\
851.15\end{array}$ & $\begin{array}{l}2.781 \\
3.031 \\
2.821 \\
2.761 \\
3.081\end{array}$ & $\begin{array}{l}1003.15 \\
1007.15 \\
1007.15 \\
1015.15 \\
1017.15\end{array}$ & $\begin{array}{l}3.581 \\
3.781 \\
3.851 \\
3.941 \\
3.081\end{array}$ \\
\hline $\begin{array}{l}862.15 \\
868.15 \\
869.15 \\
877.15 \\
878.15\end{array}$ & $\begin{array}{l}2.961 \\
3.171 \\
3.191 \\
3.051 \\
3.181\end{array}$ & $\begin{array}{l}1021.15 \\
1032.15 \\
1035.15 \\
1042.15 \\
1044.15\end{array}$ & $\begin{array}{l}3.711 \\
3.901 \\
3.961 \\
4.181 \\
3.671\end{array}$ \\
\hline $\begin{array}{l}882.15 \\
886.15 \\
889.15 \\
890.15 \\
904.15\end{array}$ & $\begin{array}{l}3.261 \\
3.061 \\
2.941 \\
3.321 \\
3.181\end{array}$ & $\begin{array}{l}1047.15 \\
1048.15 \\
1052.15 \\
1052.15 \\
1052.15\end{array}$ & $\begin{array}{l}3.821 \\
4.041 \\
4.071 \\
4.421 \\
4.161\end{array}$ \\
\hline
\end{tabular}




\section{CTHEXP， CDEN}

Table 4.5-3. (continued)

\begin{tabular}{cccc}
$\begin{array}{c}\text { Temperature } \\
(\mathrm{K})\end{array}$ & $\begin{array}{c}\epsilon_{11 \times 10^{-3}} \\
\text { (unitless) }\end{array}$ & $\frac{\begin{array}{c}\text { Temperature } \\
(\mathrm{K})\end{array}}{2}$ & $\begin{array}{c}\epsilon_{11} \times 10^{-3} \\
\text { (unitless) }\end{array}$ \\
\cline { 1 - 2 } 908.15 & 3.401 & 1054.15 & 4.341 \\
910.15 & 3.401 & 1084.15 & 4.461 \\
919.15 & 3.291 & & \\
919.15 & 3.381 & & \\
923.15 & 3.461 & & \\
\hline
\end{tabular}




\section{CTHEXP, CDEN}

Equations (4.5-1) and (4.5-2) are the models for the alpha phase of zircaloy single crystals. If one has a pole figure for cladding, Equations $(4.5-21)$ to $(4.5-23)$ may be used to find the cladding thermal expansion, remembering that $\epsilon_{22}=\epsilon_{11}$.

\subsubsection{Thermal Expansion in the Transition Region. To obtain} single-crystal thermal expansion, both the axial and circumferential cladding thermal expansions are necessary. While axial data in the transition region are available, circumferential data are not. Due to this lack of data and the insignificance of thermal strain at these temperatures, an approximation was made.

For zirconium in the alpha phase at $1123 \mathrm{~K}$, the Douglass $4.5-2$ correlation gives the lattice constants as $c=5.193 \times 10^{-10} \mathrm{~m}$ and $a=3.245 \times 10^{-10} \mathrm{~m}$, giving a volume of $47.356 \times 10^{-30} \mathrm{~m}^{3}$.

Kitte ${ }^{4.5-7}$ gives the lattice constant for beta zirconium at the same temperature as $3.61 \times 10^{-10} \mathrm{~m}$, implying a unit cell volume of $47.046 \times$ $10^{-30} \mathrm{~m}^{3}$. This decrease in volume as the material changes from the alpha close-packed structure to the generally more open beta body-centered cubic is surprising, although it has been reported by many investigators. $4.5-2,4.5-4,4.5-8$ The volume strain is $-0.66 \%$, in good agreement with Skinner and Johnston. ${ }^{4.5-8}$ To model the transition region, it is assumed that each dimension contributes equally to this volume strain

$\frac{\Delta 1}{1_{0}}=\frac{1}{3} \frac{\Delta V}{V_{0}}=\frac{1}{3} \frac{3.1 \times 10^{-31}}{\left(3.61 \times 10^{-10}\right)^{3}}=2.196 \times 10^{-3}$

where

$\begin{array}{ll}\Delta 1 & =\text { change in length }(\mathrm{m}) \\ 1_{0} & =\text { reference length }(\mathrm{m})\end{array}$ 


\section{CTHEXP, CDEN}

$$
\begin{array}{ll}
\Delta V & =\text { change in volume }\left(\mathrm{m}^{3}\right) \\
V_{0} & =\text { reference volume }\left(\mathrm{m}^{3}\right)
\end{array}
$$

At the start of the transition $(T=1083 \mathrm{~K})$, from Equations $(4.5-1)$ and $(4.5-2), \epsilon_{11}=3.88 \times 10^{-3}$ and $\epsilon_{33}=9.87 \times 10^{-3}$; and at the end of the transition, $\epsilon_{11}=1.68 \times 10^{-3}$ and $\epsilon_{33}=7.67 \times$ $10^{-3}$. A simple pair of correlations fit these numbers.

$$
\begin{gathered}
\text { For } 1083 \leq T \leq 1244 \mathrm{~K}, \\
\epsilon_{11}=\left[2.77763+1.09822 \cos \left(\frac{T-1083}{161} \pi\right)\right] \cdot 10^{-3} \\
\epsilon_{33}=\left[8.76758+1.09822 \cos \left(\frac{T-1083}{161} \pi\right)\right] \cdot 10^{-3}
\end{gathered}
$$

where the arguments for the cosines are in radians. There are more significant constants in Equations (4.5-3) and (4.5-4) than in other parts of the model to avoid discontinuities, not to reflect more accurate data.

\subsubsection{Thermal Expansion in the Beta Region. For the transition} region, there are insufficient data to construct a detailed model for the thermal expansion in the beta region. However, the strain due to thermal expansion is relatively unimportant to the total strain at these high temperatures. The model for $T>1244 \mathrm{~K}$, based on the expansivity for zirconium reported by Skinner and Johnston, ${ }^{4.5-8}$ is

$$
\begin{aligned}
& \epsilon_{11}=9.7 \times 10^{-6} \mathrm{~T}-1.04 \times 10^{-2} \\
& \epsilon_{33}=9.7 \times 10^{-6} \mathrm{~T}-4.4 \times 10^{-3}
\end{aligned}
$$

\subsubsection{Mode1-Data Comparison and Uncertainty (CTHEXP)}




\section{CTHEXP, CDEN}

The only data to which the model is compared are from Bunnel1's correlations in the alpha phase. The predictions of the model using Equations (4.5-1) and (4.5-2) are compared with the data predictions in Tables 4.5-4 and 4.5-5 using Bunnel1's correlations and Equations (4.5-33) and (4.5-34). The first table is for circumferential strain, and the second is for axial strain; both tables are for a single crystal.

From these tables, the standard error of estimate is $\pm 12 \%$ for the circumferential direction and $\pm 8 \%$ for the axial direction. These uncertainties are somewhat artificial, since the model is compared to its own data base.

In the transition region and the beta phase, the uncertainty is expected to be much larger. An uncertainty of $\pm 50 \%$ was arbitrarily assigned to these regions until appropriate data are available for a better model.

\subsubsection{Density (CDEN)}

The CDEN function determines zirconium density from room temperature data and the thermal expansion strains calculated with the CTHEXP subroutine. By definition

$\rho=\frac{m}{V}$

where

$$
\begin{aligned}
& \rho=\text { density }\left(\mathrm{kg} / \mathrm{m}^{3}\right) \\
& m \quad=\text { mass of a sample of material }(\mathrm{kg}) \\
& V \quad=\quad \text { volume of the given mass of material }\left(\mathrm{m}^{3}\right) .
\end{aligned}
$$




\section{CTHEXP, CDEN}

Table 4.5-4. Comparison of model predictions and Bunnell's alpha phase data in the diametral direction

\begin{tabular}{|c|c|c|c|}
\hline $\begin{array}{c}\text { Temperature } \\
(\mathrm{K})\end{array}$ & $\begin{array}{l}\epsilon_{11}^{\prime} \times 10^{-3} \\
\text { (model) } \\
\text { (unitless) }\end{array}$ & $\begin{array}{l}\epsilon_{11^{\prime}}^{\prime} \times 10^{-3} \\
\text { (Bunne11) } \\
\text { (unitless) }\end{array}$ & $\begin{array}{c}\text { Bunnel } 1 \text {-Model } \\
\text { Model }\end{array}$ \\
\hline $\begin{array}{l}300 \\
400 \\
500 \\
600\end{array}$ & $\begin{array}{l}0 \\
0.0007 \\
0.0014 \\
0.0021\end{array}$ & $\begin{array}{l}0 \\
0.0009 \\
0.0016 \\
0.0022\end{array}$ & $\begin{array}{l}-. \\
0.28 \\
0.14 \\
0.05\end{array}$ \\
\hline $\begin{array}{r}700 \\
800 \\
900 \\
1000 \\
1100\end{array}$ & $\begin{array}{l}0.0028 \\
0.0035 \\
0.0043 \\
0.0050 \\
0.0057\end{array}$ & $\begin{array}{l}0.0028 \\
0.0035 \\
0.0043 \\
0.0050 \\
0.0055\end{array}$ & $\begin{array}{r}0.00 \\
0.00 \\
0.00 \\
0.00 \\
-0.04\end{array}$ \\
\hline
\end{tabular}

Table 4.5-5. Comparison of model predictions and Bunnel1's alpha phase data in the axial direction

\begin{tabular}{|c|c|c|c|}
\hline $\begin{array}{c}\text { Temperature } \\
(\mathrm{K})\end{array}$ & $\begin{array}{l}\epsilon_{11}^{\prime} \times 10^{-3} \\
\text { (mode1) } \\
\text { (unitless) } \\
\end{array}$ & $\begin{array}{l}\epsilon_{11}^{\prime} \times 10^{-3} \\
\text { (Bunne11) } \\
\text { (unitless) }\end{array}$ & $\begin{array}{c}\text { Bunnel 1-Model } \\
\text { Model }\end{array}$ \\
\hline $\begin{array}{l}300 \\
400 \\
500 \\
600\end{array}$ & $\begin{array}{l}0 \\
0.0005 \\
0.0011 \\
0.0016\end{array}$ & $\begin{array}{l}0 \\
0.0006 \\
0.0011 \\
0.0016\end{array}$ & $\begin{array}{l}0 . \\
0.20 \\
0.00 \\
0.00\end{array}$ \\
\hline $\begin{array}{r}700 \\
800 \\
900 \\
1000 \\
1100\end{array}$ & $\begin{array}{l}0.0022 \\
0.0027 \\
0.0032 \\
0.0038 \\
0.0042\end{array}$ & $\begin{array}{l}0.0021 \\
0.0027 \\
0.0032 \\
0.0038 \\
0.0045\end{array}$ & $\begin{array}{r}-0.05 \\
0.00 \\
0.00 \\
0.00 \\
-0.07\end{array}$ \\
\hline
\end{tabular}




\section{CTHEXP, CDEN}

Thermal expansion changes only the volume. The volume is related to a reference voiume by

$V=V_{0} \exp \epsilon_{x} \exp \epsilon_{y} \exp \epsilon_{z}$

where

$v_{0}=$ volume of the mass $m$ when strains are zero $\left(\mathrm{m}^{3}\right)$

$\epsilon_{x}, \epsilon_{y}, \epsilon_{z}=$ true strains for any orthogonal coordinate system $(m / m)$.

Substitution of Equation (4.5-34) into Equation (4.5.33) shows

$\rho=\rho_{0} \exp \left(-\epsilon_{x}\right) \exp \left(-\epsilon_{y}\right) \exp \left(-\epsilon_{z}\right)$

where $\rho_{0}$ is the density at any reference temperature $\left(\mathrm{kg} / \mathrm{m}^{3}\right)$.

Since thermal strains are always much less than one,

$\rho \approx \rho_{0}\left(1-\epsilon_{x}-\epsilon_{y}-\epsilon_{z}\right)$

The three orthogonal strains are provided by CTHEXP, and the reference density used is the value of $6.5510^{3} \mathrm{~kg} / \mathrm{m}^{3}$ at $300 \mathrm{~K}$ reported by Scott ${ }^{4.5-4}$ This value is consistent with the high-temperature value of $6490 \mathrm{~kg} / \mathrm{m}^{3}$ often used in material properties subcodes. The predicted zircaloy thermal strains are estimated in material properties subroutines to have an expected standard error near $10 \%$ of their predicted valves for temperatures below $1090 \mathrm{~K}$ and $50 \%$ for higher temperatures.

\subsubsection{References}

4.5-1. L. R. Bunnell et al., High Temperature Properties of Zircaloy-Oxygen A7loys, EPRI NP-524, March 1977. 


\section{CTHEXP, CDEN}

4.5-2. D. L. Douglass, "The Physical Metallurgy of Zirconium," Atomic Energy Review, 1, 4, December 1963, pp. 73-74.

4.5-3. R. L. Mehan and F. W. Wiesinger, Mechanical Properties of Zircaloy-2, KAPL-2110, February 1961.

4.5-4. P. B. Scott, Physical and Mechanical Properties of Zircaloy-2 and -4, WCAP-3269-41, May 1965.

4.5-5. J. J. Kearns, Thermal Expansion and Preferred Orientation in Zircaloy, WAPD-TM-472, November 1965, pp. 17-18.

4.5-6. C. R. Hann et a1., Transient Deformation Properties of Zircaloy for LOCA Simulation, NP-526, Volume 3, March 1978.

4.5-7. C. Kittel, Introduction to Solid State Physics, 3rd Edition, New York: John Wiley and Sons, Inc., 1966, p. 29.

4.5-8. G. B. Skinner and H. L. Johnston, "Thermal Expansion of Zirconium Between 298 and $1600 \mathrm{~K}, "$ Journal of Chemical Physics, 21, August 1953, pp. 1383-1384. 


\section{CELMOD， CSHEAR， CELAST}

\subsection{Elastic Moduli (CELMOD, CSHEAR, AND CELAST)}

(D. L. Hagrman)

Elastic moduli are required to relate stresses to strains. The elastic moduli are defined by the generalized form of Hooke's law as elements of the fourth-rank tensor that relates the second-rank stress and strain tensors below the yield point. In practice, cladding is frequently assumed to be an isotropic material. In such a case, only two independent elastic moduli are needed to describe the relation between elastic stress and strain. These two constants, the Young's modulus and the shear modulus, are calculated by the functions CELMOD and CSHEAR. Elements of the tensor necessary to describe anisotropic cladding are calculated by the subroutine CELAST.

\subsubsection{Summary}

Cladding elastic moduli are affected primarily by temperature and oxygen content. Fast neutron fluence, cold work, and texture effects are also included in the models described herein; but they are not as important as temperature and oxygen content for typical LWR fuel rod cladding. The models are based primarily on data published by Bunnell et al., ${ }^{4.6-1}$ Fisher and Renken, 4.6-2 Armstrong and Brown, ${ }^{4.6-3}$ and Padel and Groff, ${ }^{4.6-4}$ since these data include the best description of texture for the temperature range in which they were used. Data from several other sources $4.6-5$ to 4.6-11 are used to evaluate the expected standard error of the CELMOD and CSHEAR codes and to estimate the effect of fast neutron fluence. ${ }^{4.6-12}$ To calculate zircaloy elastic moduli at temperatures greater than the melting temperature of zircaloy $(2098 \mathrm{~K})$, the moduli are set to zero. (Actualiy, $1.0 \times 10^{-10}$ is used to avoid dividing by zero.) 


\section{CELMOD， CSHEAR， CELAST}

The expressions used in the CELMOD subcode to calculate the isotropic Young's modulus are:

a. In the alpha phase,

$$
Y=\left(1.088 \times 10^{11}-5.475 \times 10^{7} T+K_{1}+K_{2}\right) / K_{3}
$$

b. In the beta phase,

$$
Y=9.21 \times 10^{10}-4.05 \times 10^{7} \mathrm{~T}
$$

where

$Y=$ Young's modulus for zircaloy-2 and -4 with random texture $(\mathrm{Pa})$

$\mathrm{T}=$ cladding temperature $(\mathrm{K})$

$k_{1}=$ modification to account for the effect of oxidation ( $\mathrm{Pa}$ )

$K_{2}=$ modification to account for the effect of cold work (Pa)

$K_{3}=$ modification to account for the effect of fast neutron fluence (unitless).

In the alpha + beta phase, $Y$ is the value obtained by linear interpolation of values calculated at the alpha to alpha + beta and the alpha + beta to beta boundaries.

The expressions used to model the effects of oxidation, cold work, and fast neutron fluence are 


\section{CELMOD， CSHEAR， CELAST}

$K_{1}=\left(6.61 \times 10^{11}+5.912 \times 10^{8} \mathrm{~T}\right) \Delta$

$\mathrm{K}_{2}=-2.6 \times 10^{10} \mathrm{C}$

$K_{3}=0.88+0.12 \exp \left(-\Phi / 10^{25}\right)$

where

$\Delta=$ average oxygen concentration minus oxygen concentration of as-received cladding ( $\mathrm{kg}$ oxygen $/ \mathrm{kg}$ zircaloy). As-received oxygen concentrations are so small $(0.0012 \mathrm{~kg}$ oxygen $/ \mathrm{kg}$ zircaloy) that the exact magnitude of the as-received concentration will not affect the correlation predictions.

$C=$ cold work (unitless ratio of areas)

$\Phi=$ fast neutron fluence $\left(n / m^{2}\right)$.

The standard error of the CELMOD code is $6.4 \times 10^{9} \mathrm{~Pa}$.

The expressions used in the CSHEAR subcode to calculate the isotropic shear modulus are:

a. In the alpha phase,

$$
G=\left(4.04 \times 10^{10}-2.168 \times 10^{7} T+K_{1}+K_{2}\right) / K_{3}
$$

b. In the beta phase,

$$
G=3.49 \times 10^{10}-1.66 \times 10^{7} \mathrm{~T} \text {. }
$$

In the alpha + beta phase, $G$ is the value obtained by linear interpolation of values calcuiated at the alpha to alpha + beta and the alpha + beta to beta 


\section{CELMOD， CSHEAR， CELAST}

boundaries, where the other terms have been defined in conjunction with Equations (4.6-1) and (4.6-2).

The expression used to model the effect of oxidation for shear modulus is

$$
K_{1}=\left(7.07 \times 10^{11}-2.315 \times 10^{8} \mathrm{~T}\right) \Delta
$$

where the terms have been previously defined. The standard error of the CSHEAR code is $9 \times 10^{9} \mathrm{~Pa}$.

The subcode CELAST calculates elastic compliance constants for isotropic cladding. This subcode is discussed in the model development Section 4.6-3 because it is the basis for the much simpler CELMOD and CSHEAR codes. The elastic moduli predicted by CELAST for typical textures are reasonably close to the moduli for isotropic cladding. Figure 4.6-1 illustrates this. The solid lines represent the Young's and shear moduli for isotropic (random texture) material. The six broken lines represent reciprocal compliance constants corresponding to diagonal elements of the traditional $S$ matrix. Three of these quantities may be interpreted as the apparent Young's moduli for stresses in the direction indicated, and the other three may be interpreted as the apparent shear moduli for shears acting normal to the direction indicated. The only modulus which departs significantly from the isotropic moduli is the Young's modulus in the radial direction. It should be noted that this modulus was based on zirconium single-crystal data because appropriate zircaloy data are not available. The axial and circumferential Young's moduli are based on zircaloy-4 data, and they are very similar to the isotropic Young's modulus. The increased Young's modulus in the radial direction is not expected to affect code predictions, even if zircaloy data do confirm the difference shown by the zirconium data. 
CELMOD， CSHEAR， CELAST

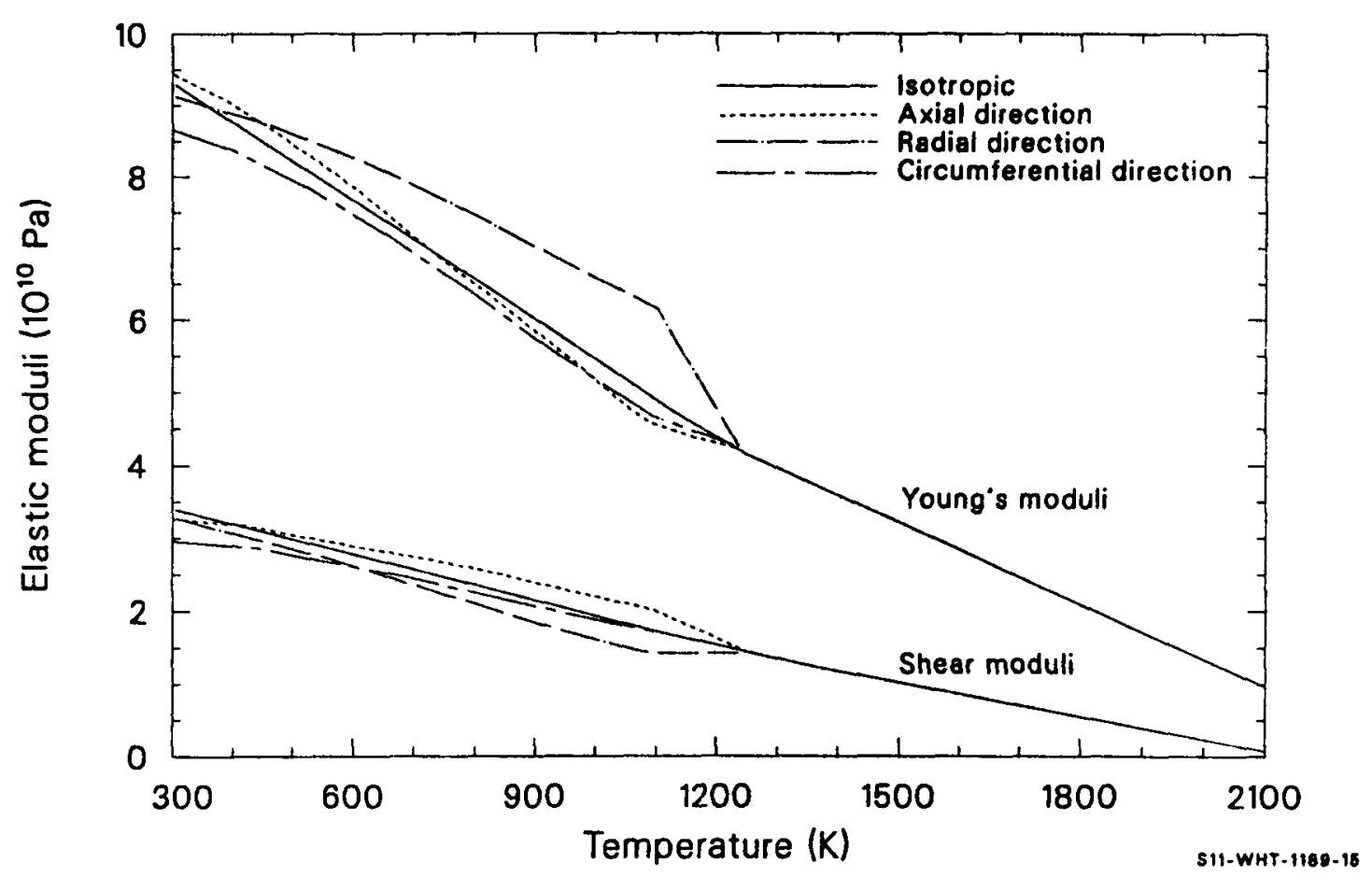

Figure 4.6-1. Elastic moduli for isotropic material compared to corresponding moduli for typical PWR cladding. 


\section{CELMOD， CSHEAR， CELAST}

Details of the elastic modulus models are presented in the following sections. Section 4.6 .2 is a review of available data, and Section 4.6.3 describes the model development. Section 4.6 .4 is a comparison of the model and its data base. Uncertainties are discussed in Section 4.6.5.

\subsubsection{Review of Available Data}

Elastic moduli measurements may be classified as either static or dynamic. The static moduli are based on measurements of stress and strain under conditions which can, in principle, be representative of in-reactor cladding. However, the accuracy of the static moduli are typically limited by the accuracy of the measurement of the strain. Dynamic measurements avoid this difficulty by vibrating a sample of known dimensions in a resonant mode and inferring the moduli from accurate measurements of resonant frequency. The advantage in accuracy of the dynamic measurements is somewhat compromised by the fact that these measurements are made with the small cyclic strains associated with resonant modes. To date, static measurements have not achieved sufficient accuracy to show significant discrepancies with the dynamic measurements, so the dynamic measurements are used as a basis for the models discussed herein.

The most complete set of applicable elastic moduli measurements available are the dynamic measurements of zirconium single-crystal moduli by Fisher and Renken. ${ }^{4.6-2}$ Measured values of the stiffness moduli,a $C_{11}, C_{33}, C_{44}, C_{13}$, and $C_{12}$, are reported at $50-K$ intervals from $4 \mathrm{~K}$ to the alpha + beta phase transition at $1135 \mathrm{~K}$. The $\mathrm{C}_{11}, \mathrm{C}_{33}$, $C_{44}$, and $C_{13}$ moduli vary almost linearly with temperature between 300 and $1135 \mathrm{~K}$, while the $C_{12}$ modulus is reported to increase in a nonlinear fashion with temperature. Least-squares polynomial fits to Fisher and

a. The definition of elastic stiffness moduli is reviewed in subsection 4.6.3 in conjunction with the development of the model for the effect of texture variations. 


\section{CELMOD， CSHEAR， CELAST}

Renken's data yield the following correlations when the data at $300 \mathrm{~K}$ or greater are used:

$$
\begin{aligned}
& c_{11}=1.562 \times 10^{11}-4.484 \times 10^{7} \mathrm{~T} \\
& c_{33}=1.746 \times 10^{11}-3.282 \times 10^{7} \mathrm{~T} \\
& c_{44}=3.565 \times 10^{10}-1.281 \times 10^{7} \mathrm{~T} \\
& c_{12}=6.448 \times 10^{10}+\left(3.1882 \times 10^{7}-1.2318 \times 10^{4} \mathrm{~T}\right) \mathrm{T} \\
& c_{13}=6.518 \times 10^{10}-6.817 \times 10^{5} \mathrm{~T}
\end{aligned}
$$

where $C_{i j}$ are the five independent stiffness moduli for a hexagonal crystal $(\mathrm{Pa})$. (The subscripts $1,2,3$ refer to orthogonal coordinate axes arranged with the direction labeled 3 parallel to the $c$ axis. By basal plane symmetry, the 1 and 2 axes are any orthogonal axes in the basal plane.)

Single-crystal constants have not been determined for the high-temperature beta phase, so measurements on polycrystalline materials of unknown texture are used. The models are based on dynamic measurement of the Young's modulusa of zirconium by Armstrong and Brown ${ }^{4.6-3}$ and by Padel and Groff. 4.6-4 The data from these two sources are reproduced in Tables 4.6-1 and 4.6-2. The measurements differ by less than $5 \%$ at corresponding temperatures. As discussed in Section 4.6-3, compliance constants (elements of the inverse of the stiffness matrix) are obtained by assuming that the beta phase is isotropic.

a. Young's modulus is defined as stress in a given direction divided by strain in the same direction. 


\section{CELMOD， CSHEAR， CELAST}

Table 4.6-1. Beta-phase zirconium Young's Modulus measured by Armstrong and Brown

\begin{tabular}{cc} 
Temperature & Young's Modulus \\
\hline$(\mathrm{K})$ & $\frac{\left(10^{10} \mathrm{~Pa}\right)}{}$ \\
1173 & 4.426 \\
1223 & 4.233 \\
1273 & 4.047 \\
1323 & 3.861 \\
1373 & 3.675 \\
1423 & 3.488 \\
1473 & 3.302 \\
\hline
\end{tabular}

Table 4.6-2. Beta-phase zirconium Young's Modulus measured by Padel and Groff

\begin{tabular}{cc} 
Temperature & Young's Modulus \\
\hline (K) & $\left(10^{10} \mathrm{~Pa}\right)$ \\
\cline { 2 - 2 } 1143 & 4.578 \\
1156 & 4.544 \\
1181 & 4.311 \\
1234 & 4.233 \\
1266 & 4.111 \\
1281 & 4.122 \\
1311 & 3.922 \\
1340 & 3.833 \\
1380 & 3.611 \\
1395 & 3.544 \\
1409 & 3.422 \\
1449 & 3.278 \\
1474 & 3.167 \\
\hline
\end{tabular}




\section{CELMOD， CSHEAR， CELAST}

The alpha-phase data of Fisher and Renken do not help one to address three of the effects which are under consideration in this report--the effects of zircaloy-alloying elements, of oxidation, and of variations in texture. These considerations are addressed with the help of Young's moduli measurements in the axial and circumferential direction by Bunnell et a). 4.6-1 Bunnell's data provide important additional information because (a) they were taken with zircaloy cladding, (b) the samples contained various amounts of oxygen, and (c) an estimate of the initial texture of the material is available. Unfortunately, the texture information is only available for the as-received samples and consists of a basal pole figure published by R. H. Chapman. 4.6-13

Bunnell's data were analyzed using the model for the effect of texture developed in Section 4.6.3. The axial and circumferential Young's modulus data are used to establish correlations for the effect of temperature and oxygen on two of the five independent compliance constants. The correlations for as-received and homogenized (annealed) cladding agree closely with the compliance constants obtained by inverting Equations (4.6-9) through (4.6-13) and lend confidence to the assumption that single-crystal zirconium data are a good approximation to zircaloy data when oxygen concentrations are on the order of 0.001 weight fraction. The latter assumption is necessary because the data from zircaloy cladding are not sufficient to determine all five independent compliance constants.

Data relevant to modeling the effect of irradiation and cold work are limited both in quantity and in completeness. The Saxton Core II Fuel Performance Evaluation ${ }^{4.6-12}$ reports elastic moduli at $630 \mathrm{~K}$ for irradiated cladding. The modul $i$ were measured with a static method in the axial direction, but no pole figure was provided so the effects of irradiation could not be separated from the effects of texture.

Data relevant to modeling the effect of cold work are contained (but not discussed as such) in the report by Bunnell et al. ${ }^{4.6-1}$ The 


\section{CELMOD， CSHEAR， CELAST}

as-received material was cold-worked to about 0.75 and stress-relieved for $4 \mathrm{~h}$ at $770 \mathrm{~K} \cdot{ }^{4.6-13}$ The homogenized material was completely annealed. Unfortunately, the effect of cold work suggested by Bunnell's dynamic measurements of Young's modulus is opposite to the trend reported by Shober et a1. 4.6-10 from static measurements. The dynamic measurements show a slight decrease in Young's modulus with cold work, and the static measurements show a slight increase in Young's modulus with cold work. Since neither source provides usable texture information, it is impossible to tell whether the change with cold work is due to associated changes in texture, to a separate effect associated with the cold work, or to a fundamental difference in the quantity that is being measured with the different techniques. The small decrease implied by Bunnell's data was tentatively included in the models for elastic moduli because of the greater precision of the dynamic data.

Several measurements of Young's and shear modul $i$ were not used in constructing the models for elastic moduli because texture information was not available. The data are useful, however, as an independent test of the two approximate models for isotropic cladding. Busby $4.6-5$ reported the axial Young's modulus for zircaloy-4 between 300 and $645 \mathrm{~K}$ for five combinations of cold work and heat treatment. Busby's data are reproduced in Table 4.6-3. Spasic et a7. 4.6-6 reported values of the static elastic modulus from room temperature to $675 \mathrm{~K}$. Their data are reproduced in Table 4.6-4. The material used by Spasic et al. was not characterized as to cold work or texture. It is assumed that unirradiated material in the annealed condition was used in these tests. Mehan 4.6-7 and Mehan and Wiesinger ${ }^{4-6-8}$ reported Young's modulus data from room temperature to $1090 \mathrm{~K}$. The data were taken with both static and dynamic techniques on unirradiated, vacuum-annealed zircaloy-2 plates. Table 4.6-5 is a summary of Mehan's measurement. Northwood et al.$^{4.6-9}$ reported Young's modulus and shear modulus data from 293 to $773 \mathrm{~K}$. The data were obtained with a resonance method and are accompanied by an excellent discussion of the effects of texture. The zircaloy-2 samples were machined from bar stock 


\section{CELMOD， CSHEAR， CELAST}

Table 4.6-3. Young's Modulus measurements by Busby

\begin{tabular}{|c|c|c|c|}
\hline Material & $(K)$ & $\begin{array}{l}\text { Young's Modulus } \\
-\left(10^{10} \mathrm{~Pa}\right)\end{array}$ & $\begin{array}{l}\text { Effective cold Work } \\
\text { Predicted by the } \\
\text { Subcode CANEAL }\end{array}$ \\
\hline $\begin{array}{l}78 \% \text { cold work } 922 \mathrm{~K} \\
\text { recrystallization for } \\
5 \mathrm{~h}\end{array}$ & 297 & 9.686 & $0 \%$ \\
\hline $\begin{array}{l}78 \% \text { cold work } 922 \mathrm{~K} \\
\text { recrystallization for } \\
5 \mathrm{~h}\end{array}$ & 516 & 8.018 & $0 \%$ \\
\hline $\begin{array}{l}78 \% \text { cold work } 922 \mathrm{~K} \\
\text { recrystallization for } \\
5 \mathrm{~h}\end{array}$ & 644 & 7.515 & $0 \%$ \\
\hline $\begin{array}{l}15-20 \% \text { cold work } \\
783 \mathrm{~K} \text { stress relief } \\
\text { for } 5 \mathrm{~h}\end{array}$ & 297 & 10.031 & $5 \%$ \\
\hline $\begin{array}{l}15-20 \% \text { cold work } \\
783 \mathrm{~K} \text { stress relief } \\
\text { for } 5 \mathrm{~h}\end{array}$ & 561 & 8.583 & $5 \%$ \\
\hline $\begin{array}{l}15-20 \% \text { cold work } \\
783 \mathrm{~K} \text { stress relief } \\
\text { for } 5 \mathrm{~h}\end{array}$ & 559 & 8.349 & $5 \%$ \\
\hline $\begin{array}{l}74 \% \text { cold work } 783 \mathrm{~K} \\
\text { stress relief for } \\
5 \mathrm{~h}\end{array}$ & 297 & 9.907 & $25 \%$ \\
\hline $\begin{array}{l}73 \% \text { cold work } 783 \mathrm{~K} \\
\text { stress relief for } \\
5 \mathrm{~h}\end{array}$ & 644 & 7.708 & $25 \%$ \\
\hline
\end{tabular}




\section{CELMOD， CSHEAR， CELAST}

Table 4.6-4. Young's Modulus measurements by Spasic et al.

\begin{tabular}{cc} 
Temperature & Young's Modulus \\
\hline$(K)$ & $\left(10^{10} \mathrm{~Pa}\right)$ \\
\hline 300 & 10.10 \\
373 & 9.25 \\
423 & 8.78 \\
473 & 8.52 \\
673 & 7.70 \\
673 & 7.40 \\
\hline
\end{tabular}


CELMOD， CSHEAR， CELAST

Table 4.6-5. Young's modulus measurement by Mehan

\begin{tabular}{|c|c|c|}
\hline $\begin{array}{c}\text { Temperature } \\
\text { (K) }\end{array}$ & $\begin{array}{l}\text { Young's Modulus } \\
\left(10^{10} \mathrm{~Pa}\right) \\
\end{array}$ & Method/Direction \\
\hline $\begin{array}{l}300 \\
300 \\
300 \\
300 \\
589 \\
589\end{array}$ & $\begin{array}{l}9.493 \\
9.473 \\
9.459 \\
9.500 \\
7.928 \\
7.790\end{array}$ & $\begin{array}{l}\text { Static/not reported } \\
\text { Static/not reported } \\
\text { Static/not reported } \\
\text { Static/not reported } \\
\text { Static/not reported } \\
\text { Static/not reported }\end{array}$ \\
\hline $\begin{array}{l}297 \\
427 \\
593 \\
704 \\
298 \\
422 \\
594 \\
711 \\
811 \\
300 \\
424 \\
598 \\
703 \\
809\end{array}$ & $\begin{array}{l}9.804 \\
9.142 \\
8.273 \\
7.715 \\
9.921 \\
9.238 \\
8.466 \\
7.784 \\
7.246 \\
9.893 \\
9.128 \\
8.294 \\
7.715 \\
7.852\end{array}$ & $\begin{array}{l}\text { Dynamic/transverse } \\
\text { Dynamic/transverse } \\
\text { Dynamic/transverse } \\
\text { Dynamic/transverse } \\
\text { Dynamic/transverse } \\
\text { Dynamic/transverse } \\
\text { Dynamic/transverse } \\
\text { Dynamic/transverse } \\
\text { Dynamic/transverse } \\
\text { Dynamic/transverse } \\
\text { Dynamic/transverse } \\
\text { Dynamic/transverse } \\
\text { Dynamic/transverse } \\
\text { Dynamic/transverse }\end{array}$ \\
\hline $\begin{array}{l}298 \\
428 \\
591 \\
703 \\
814 \\
298 \\
430 \\
593 \\
698 \\
814 \\
303 \\
422 \\
594 \\
707 \\
822\end{array}$ & $\begin{array}{l}9.452 \\
8.659 \\
7.535 \\
6.991 \\
6.356 \\
9.445 \\
8.597 \\
7.604 \\
6.908 \\
6.219 \\
9.445 \\
8.597 \\
7.535 \\
6.942 \\
6.253\end{array}$ & $\begin{array}{l}\text { Dynamic/longitudinal } \\
\text { Dynamic/longitudinal } \\
\text { Dynamic/longitudinal } \\
\text { Dynamic/longitudinal } \\
\text { Dynamic/longitudinal } \\
\text { Dynamic/longitudinal } \\
\text { Dynamic/longitudinal } \\
\text { Dynamic/longitudinal } \\
\text { Dynamic/longitudinal } \\
\text { Dynamic/longitudinal } \\
\text { Dynamic/longitudinal } \\
\text { Dynamic/longitudinal } \\
\text { Dynamic/longitudinal } \\
\text { Dynamic/longitudinal } \\
\text { Dynamic/longitudinal }\end{array}$ \\
\hline
\end{tabular}




\section{CELMOD， CSHEAR， CELAST}

that had been annealed for $1 \mathrm{~h}$ at $1061 \mathrm{~K}$. Table 4.6-6 is a summary of the zircaloy-2 data reported by Northwood et al.

\subsubsection{Mode1 Development}

The equations used in the CELMOD and CSHEAR subcodes are simplified forms of the more complex expressions used in the CELAST subcode. The quantities modeled by CELAST are elastic compliance coefficients. These coefficients, and the closely related elastic stiffness coefficients, are defined by the relations $4.6-14$

$$
\begin{aligned}
& \epsilon_{i}=S_{i j} \sigma_{j} \\
& \sigma_{i}=C_{i j} \epsilon_{j}
\end{aligned}
$$

where

$$
\begin{aligned}
\epsilon_{i} & =\text { strain components } \\
\sigma_{i} & =\text { stress components } \\
s_{i j} & =\text { compliance matrix elements } \\
c_{i j} & =\text { stiffness matrix elements. }
\end{aligned}
$$

Also, the usual tensor summation convention is assumed.

By inspection of Equations (4.6-14) and (4.6-15), it is clear that the compliance matrix is the reciprocal of the stiffness matrix. The author has elected to use compliance coefficients. 


\section{CELMOD， CSHEAR， CELAST}

Table 4.6-6. Elastic moduli measurements by Northwood et al.

\begin{tabular}{|c|c|c|c|}
\hline \multirow[b]{2}{*}{$\begin{array}{l}\text { Temperature } \\
\text { (K) }\end{array}$} & \multicolumn{2}{|c|}{ Young's Modulus } & Shear Modulus \\
\hline & $\begin{array}{l}\text { Longitudinal } \\
.\left(10^{10} \mathrm{~Pa}\right) \\
\end{array}$ & $\begin{array}{l}\text { Transverse } \\
\left(10^{10} \mathrm{~Pa}\right)\end{array}$ & $\begin{array}{l}\text { Torsional Resonant Mode } \\
\qquad\left(10^{10} \mathrm{~Pa}\right) \\
\end{array}$ \\
\hline $\begin{array}{l}293 \\
373 \\
473 \\
573 \\
673 \\
773\end{array}$ & $\begin{array}{l}9.67 \\
9.01 \\
8.64 \\
7.99 \\
7.38 \\
6.78\end{array}$ & $\begin{array}{l}9.61 \\
8.98 \\
8.60 \\
8.01 \\
7.34 \\
6.81\end{array}$ & $\begin{array}{l}3.48 \\
3.36 \\
3.18 \\
2.94 \\
2.79 \\
2.53\end{array}$ \\
\hline
\end{tabular}




\section{CELMOD， CSHEAR， CELAST}

4.6.3.1 Effect of Texture Variations. Texture effects are modeled using techniques which have become fairly standard. 4.6-9,4.6-15,4.6-16 Macroscopic compliance matrix elements for polycrystalline materials are computed as the average of corresponding single-crystal values, weighted by the volume fraction of grains at each orientation.

$\overline{S^{\prime}{ }_{i j}}=\iiint S^{\prime}{ }_{i j}(\theta, \phi) \rho(\theta, \phi) d v$

where

$$
\begin{aligned}
& \overline{S^{\prime}{ }_{i j}}=\text { macroscopic compliance constants }\left(\mathrm{Pa}^{-1}\right) \\
& S^{\prime}{ }_{i j}(\theta, \phi)=\text { single-crystal compliance constants defined relative to }
\end{aligned}
$$

The volume fraction of grains at angles $\theta$ and $\phi$ can be determined from $c$ axis pole figures.

$$
\rho(\theta, \phi)=\frac{I(\theta, \phi)}{\int_{0}^{2 \pi} \int_{0}^{\pi} I(\theta, \phi) \sin \theta d \theta d \phi}
$$

where $I(\theta, \phi)$ is the diffracted $X$-ray intensity of the basal planes as plotted in basal pole figures. 


\section{CELMOD， CSHEAR， CELAST}

Expressions for the various single-crystal compliance constants, referred to a fixed coordinate system $S^{\prime}{ }_{i j}(\theta, \phi)$ in Equation (4.6-16), are obtained by applying standard tensor rotation techniques ${ }^{4-6-17}$ to single-crystal compliances defined relative to a set of coordinates attached to each grain, $S_{i j} \cdot{ }^{a}$ The traditional matrix notation is converted to a formal fourth-rank tensor using the relations listed in Table 4.6-7.4.6-14 The coordinate system is rotated with the equation

$S_{i j k e}^{\prime}(\theta, \phi)=C_{i r} C_{j s} C_{k t} C_{e u} S_{r s t u}$

where

$$
\begin{aligned}
& S^{\prime}{ }_{i j k e}(\theta, \phi)=\text { single-crystal compliance tensor elements } \\
& \text { measured with respect to the fixed (primed) } \\
& \text { coordinate system shown in Figure 4.6-2 }\left(\mathrm{Pa}^{-1}\right) \\
& \mathrm{S}_{\text {rstu }}=\text { single-crystal compliance tensor elements } \\
& \text { measured with respect to a coordinate } \\
& \text { system attached to each grain }\left(\mathrm{Pa}^{-1}\right) \\
& c_{i j}=\text { elements of the rotation matrix } \\
& =\left(\begin{array}{lll}
\cos \alpha & \sin \alpha \cos \theta & +\sin \alpha \sin \theta \\
-\sin \alpha & \cos \alpha \cos \theta & +\cos \alpha \sin \theta \\
0 & -\sin \theta & \cos \theta
\end{array}\right)
\end{aligned}
$$

a. In this section, primed compliance constants are referred to a system of coordinates which are fixed. Unprimed compliance constants are referred to a system of coordinates which are determined by the orientation of each grain, as shown in Figure 4.6-2. 


\section{CELMOD, CSHEAR, CELAST}

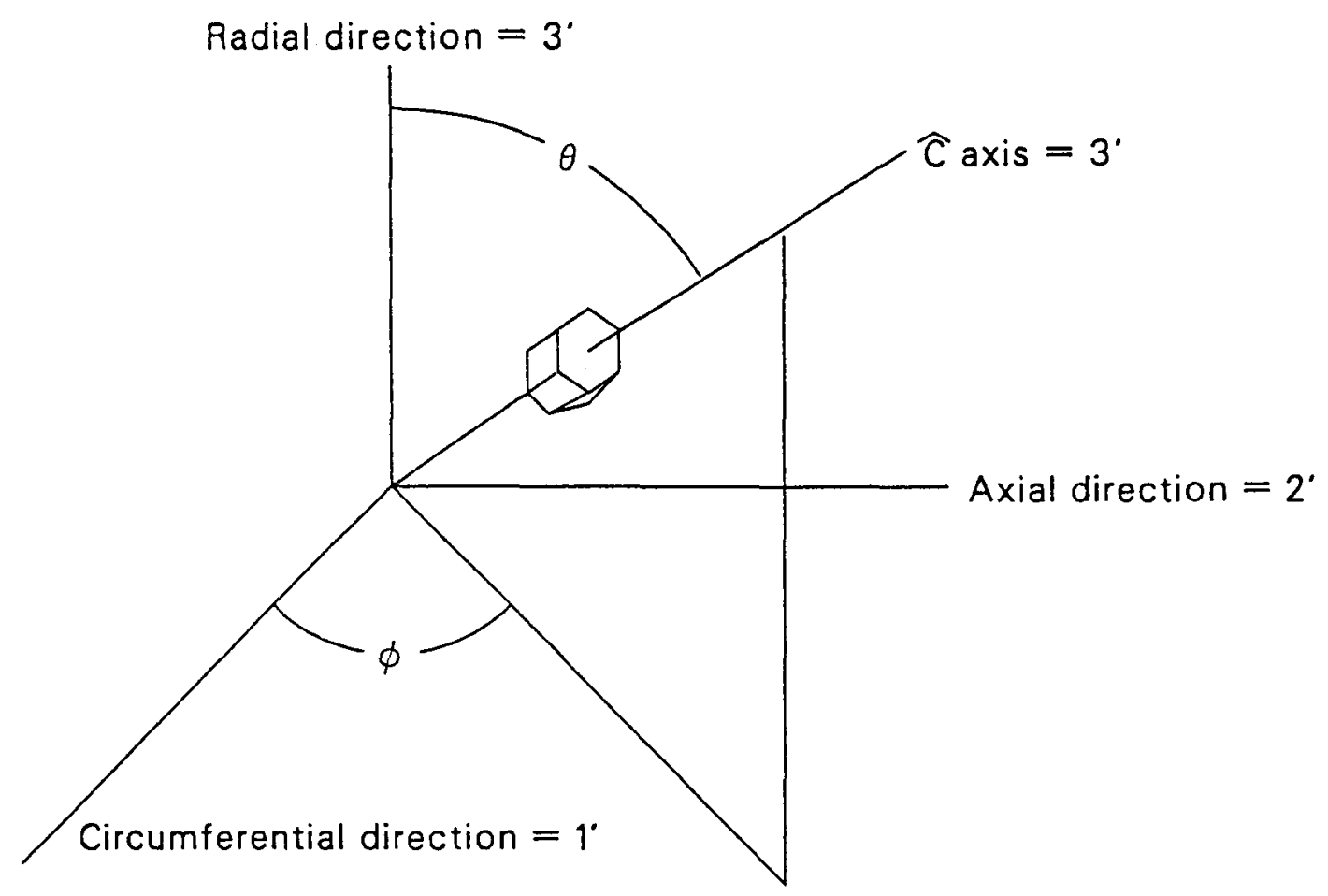

Primed coordinate

system is fixed in lab

S11-WHT-1089-14

Figure 4.6-2. Reference directions selected for CELMOD/CSHEAR/CELAST analysis. 
CELMOD， CSHEAR， CELAST

Table 4.6-7. Relations between fourth-rank tensor elements and traditional matrix elements.

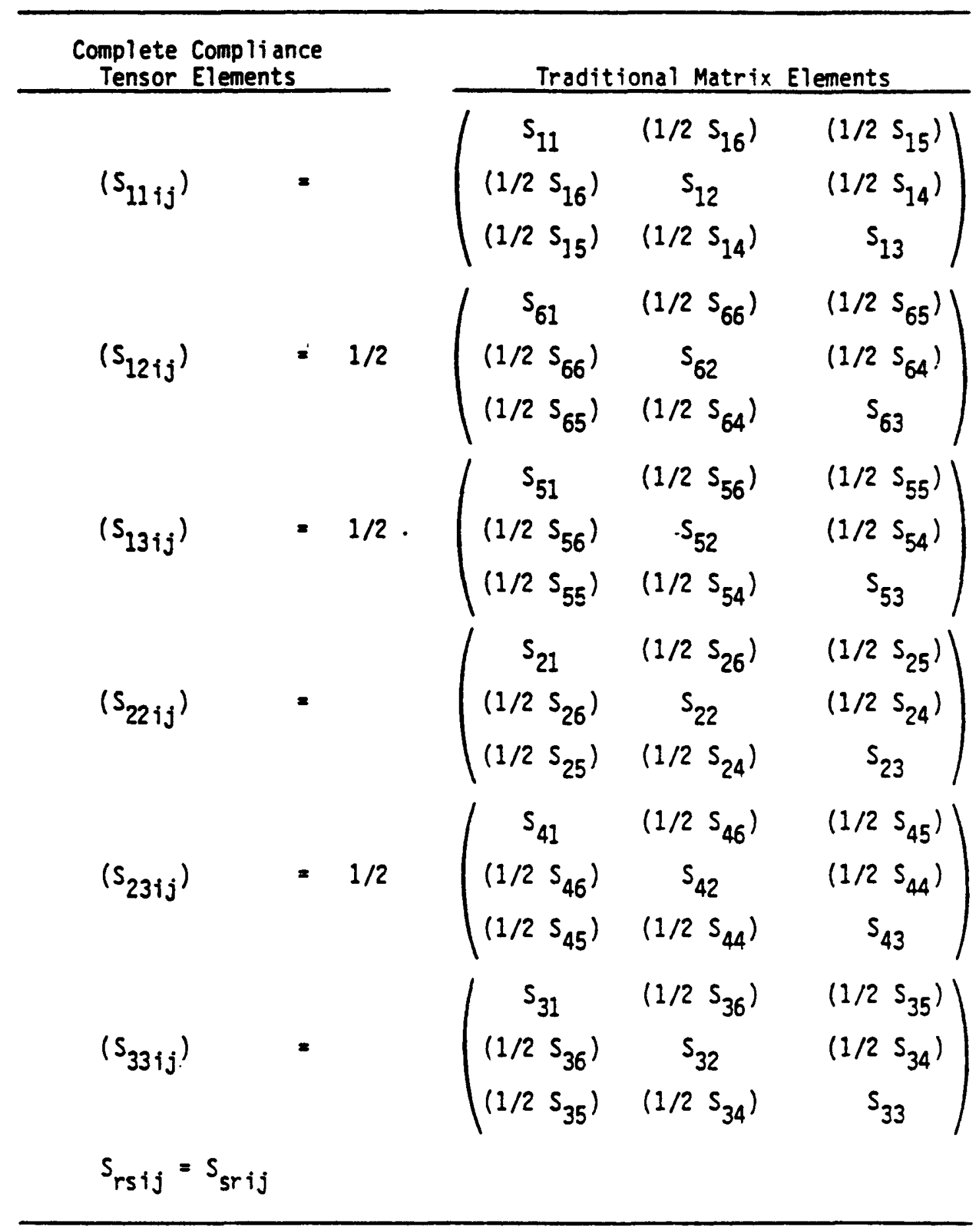




\section{CELMOD， CSHEAR， CELAST}

$$
\alpha \quad=\quad \text { complement of } \phi \text {. }
$$

The expressions that result from combining the relations in Table 4.6-7 and Equations (4.6-17) and (4.6-18) are available in the CELAST subcode listing. As an example, the equation relating the macroscopic elastic compliance constant $S_{33}$ to the single-crystal compliance constants is

$$
\begin{aligned}
\overline{S_{33}^{\prime}} & =\left(1-2\left\langle\cos ^{2} \theta\right\rangle+\left\langle\cos ^{4} \theta\right\rangle\right) S_{11} \\
& +\left(\left\langle\cos ^{2} \theta\right\rangle-\left\langle\cos ^{4} \theta\right\rangle\right)\left(2 S_{13}+S_{44}\right)+\left\langle\cos ^{4} \theta\right\rangle S_{33}
\end{aligned}
$$

where

$$
\begin{aligned}
& \overline{S^{\prime} 33}=\text { macroscopic elastic compliance constant } \\
& \text { relating radial stress to radial strain } \\
& \text { (Figure 4.6-2) }\left(\mathrm{Pa}^{-1}\right) \\
& \mathrm{S}_{11}, \mathrm{~S}_{13} \text {, = single-crystal compliance constants }\left(\mathrm{Pa}^{-1}\right) \\
& \mathrm{S}_{33}, \mathrm{~S}_{44} \\
& \left\langle\cos ^{2} \theta\right\rangle=\text { volume fraction weighted average of the } \\
& \text { squared cosine of the angle } \theta \text { (Figure 4.6-2) } \\
& \left\langle\cos ^{4} \theta\right\rangle=\text { volume fraction weighted average of the } \\
& \text { fourth power of the angle } \theta \text {. }
\end{aligned}
$$

4.6.3.2 Effect of Temperature. The effect of temperature on single-crystal elastic compliance constants is modeled separately for the a)pha and beta phases of zircaloy.

Correlations for two of the five independent elastic constants, $S_{11}$ and $S_{44}$, are developed from Bunnell's measurements of the axial and circumferential Young's modulus of unoxidized zircaloy-4.4.6-14 The other 


\section{CELMOD， CSHEAR， CELAST}

three single-crystal alpha phase constants, $S_{33}, S_{12}$, and $S_{13}$, are modeled by finding the matrix inverse of the stiffness moduli for zirconium [Equations (4.6-9) to (4.6-13)]. The expressions obtained from Bunnell's data are an improvement over the alternate expressions that could be obtained from the zirconium data because Bunnell's data were taken with zircaloy-4 cladding.

In order to use the zircaloy-4 data, the pole figure provided by $R . H$. Chapman is input to the MATPRO subcode CTXTUR to find the orientation angle averages relating single-crystal elastic compliance constants to $\overline{S_{11}{ }^{\prime}}$ and $\overline{\mathrm{S}_{22}{ }^{\prime}}$ for this cladding. The resultant expressions are:

$$
\begin{aligned}
& \overline{s_{11^{\prime}}}=0.65106 s_{11}+0.09210 s_{33}+(0.12842)\left(2 s_{13}+s_{44}\right) \\
& \overline{S_{22}}=0.88030 s_{11}+0.01900 s_{33}+(0.05035)\left(2 s_{13}+s_{44}\right)
\end{aligned}
$$

where $\overline{S_{11}}, \overline{S_{22}}$ are the macroscopic elastic compliance constants $\left(\mathrm{Pa}^{-1}\right)$.

Inspection of the defining relation for the elastic compliance constant [Equation (4.6-9)] and the reference direction conventions used in the report (Figure 4.6-2) shows that $\overline{S_{11}{ }^{\prime}}$ is the reciprocal of Young's modulus measured in the circumferential direction of the cladding and $\overline{\mathrm{S}_{22}}$ is the reciprocal of Young's modulus measured in the axial direction of the cladding. Thus, Equations (4.6-20) and (4.6-21) can be used with Bunnell's measurements of the circumferential and axial Young's modulus of this cladding and the inverse matrix values of $S_{33}$ and $S_{13}$ to find least-squares correlations for $S_{11}$ and $S_{44}$ as a function of temperature.

The correlations found from a least-squares fit to Bunnells's data are:

$$
S_{11}=0.1028 \times 10^{-10}+T\left(-0.5417 \times 10^{-14}+T 0.1476 \times 10^{-16}\right)
$$




\section{CELMOD， CSHEAR， CELAST}

$S_{44}=0.3904 \times 10^{-10}+T\left(-0.8118 \times 10^{-14}+T 0.2115 \times 10^{-16}\right)$

where the terms of the equations have been previously defined.

Equation (4.6-22) predicts values of $S_{11}$ which vary from zero to $10 \%$ below the value of $S_{11}$ predicted by the zirconium data of Fisher and Renken. ${ }^{4.6-2}$ Equation (4.6-23) predicts values of $\mathrm{S}_{44}$ which are about $20 \%$ above the value of $\mathrm{S}_{44}$ predicted by the zirconium data of Fisher and Renken. ${ }^{4.6-2}$

In the beta phase, ${ }^{\mathrm{a}}$ only two independent single-crystal compliance constants are employed. The independent constants are $S_{11}$ and $S_{44}$. By classical symmetry arguments, $s_{33}=s_{11}$ and $s_{23}=s_{13}=s_{12}$. A correlation for one of the constants is obtained from a least-squares fit to the beta phase zirconium Young's modulus data of Armstrong and Brown $4.6-3$ and Padel and Groff. ${ }^{4.6-4}$ The expression is

$S_{11}^{-1}=Y=9.21 \times 10^{10}-4.05 \times 10^{7} \mathrm{~T}$

where

$$
\begin{aligned}
& S_{11}=\text { elastic compliance constant for beta phase zircaloy }\left(\mathrm{Pa}^{-1}\right) \\
& Y=\text { Young's modulus for beta phase zircaloy }(\mathrm{Pa}) .
\end{aligned}
$$

Since no measurements of the shear modulus in beta phase zirconium are available, the second constant, $S_{44}$, is estimated by extrapolation of an approximate expression for the shear modulus of isotropic alpha phase zirconium to the higher temperatures of the beta phase.

a. The beta phase is body-centered cubic and has therefore been assumed isotropic. 


\section{CELMOD， CSHEAR， CELAST}

The phase boundaries of the alpha, alpha + beta, and beta phases are determined with correlations based on data from Figure III.33 of Reference 4.6-18. Compliance constants in the alpha + beta phase region are obtained by interpolating between these constants at the boundaries of this region.

\subsubsection{Effect of 0xygen. The only data available to model the} effect of oxygen on the single-crystal compliance constants are Bunnell's measurements of axial and circumferential Young's moduli as a function of oxygen concentration. 4.6-1 The effect of oxygen on the alpha phase compliance constants is modeled in much the same way that Bunnell's data were used to correlate changes in the single-crystal compliance constants $\mathrm{S}_{11}$ and $\mathrm{S}_{44}$ with temperature. The three-step procedure is outlined as follows:

a. Equation (4.6-21) is used with measured values of the axial Young's modulus $\left(1 / \overline{S^{\prime} 22}\right)$, approximate (zirconium) values of $\mathrm{S}_{33}, \mathrm{~S}_{13}$, and $\mathrm{S}_{44}$ in the small terms containing these factors and the measured values of oxygen concentration to find a least-squares fit correlation between $S_{11}$ and the oxygen concentration.

b. Equation (4.6-20) is used with measured values of the circumferential Young's modulus $\left(1 / \overline{S^{\prime}} 11\right)$, the expression for $S_{11}$ obtained in step (1), approximate (zirconium) values of $S_{33}$ and $S_{13}$, and the measured values of oxygen concentration to find a least-squares fit correlation for $S_{44}$ as a function of oxygen concentration. The correlations obtained are

$$
\begin{aligned}
& 1 / S_{11}=1 /\left(S_{11}\right)_{0}+\left(6.61 \times 10^{11}+5.912 \times 10^{8} \mathrm{~T}\right) \Delta \\
& 1 / S_{44}=1 /\left(S_{44}\right)_{0}+\left(7.07 \times 10^{11}+2.315 \times 10^{8} \mathrm{~T}\right) \Delta
\end{aligned}
$$

where 


\section{CELMOD， CSHEAR， CELAST}

$S_{11}, S_{44}=$ elastic compliance constants for oxidized zircaloy $\left(\mathrm{Pa}^{-1}\right)$

$\left.S_{11}\right)_{0}, \quad=\quad$ elastic compliance constants for as-received zircaloy $\left.\mathrm{S}_{44}\right)_{0} \quad\left(\mathrm{~Pa}^{-1}\right)$

$\Delta=$ average oxygen concentration minus oxygen concentration of as-received cladding ( $\mathrm{kg}$ oxygen $/ \mathrm{kg}$ zircaloy).

c. Equation (4.6-25) is assumed to apply to $S_{13}, S_{33}$, and $S_{12}$.

The effect of oxygen in the beta phase has been neglected because no relevant data are available and because an exact knowledge of elastic moduli at the high temperatures of the beta phase is not likely to be important to code applications.

4.6.3.4 Effect of Cold Work. Bunnell's measurements of the Young's modulus of cold-worked, stress-relieved cladding were compared to his Young's modulus measurements of homogenized (annealed) cladding to estimate cold-work effects. Measured values of the axial Young's modulus for the stress-relieved material are related to $S_{11}$ with Equation (4.6-21). The differences between $\left(S_{11}\right)^{-1}$ in the cold-worked material and $\left(S_{11}\right)$ computed for annealed material [Equation (4.6-22)] are assumed to be proportional to the cold work (assumed $=0.5$ ). The correlation resulting from an average of the six low-temperature data on as-received cladding is

$1 / S_{11}=1 /\left(S_{11}\right)_{0}-2.6 \times 10^{10} \mathrm{C}$

where

$S_{11}=$ elastic compliance constant for cold-worked zircaloy $\left(\mathrm{Pa}^{-1}\right)$ 


\section{CELMOD， CSHEAR， CELAST}

$\left(S_{11}\right)_{0}=$ elastic compliance constant for annealed zircaloy $\left(\mathrm{Pa}^{-1}\right)$

C = cold work (unitless ratio of areas).

No modification of $S_{44}$ was implied by Bunnell's measurements of the Young's modulus in the circumferential direction.

4.6.3.5 Effect of Irradiation. Data from the Saxton Core II Fuel Performance Evaluation ${ }^{4.6-12}$ are used to estimate fast neutron fluence effects on elastic compliance constants. Since no pole figures for this material were found, measured values of the axial Youngs's modulus for the irradiated material are related to $S_{11}, S_{33}, S_{13}$, and $S_{44}$ with

Equation (4.6-24). The four compliance constants are assumed to decrease by a single factor due to the fluence, and the factor is determined by comparing the measured values of Young's modulus to the values predicted for unirradiated material. The factor which results from the comparison is:

$s_{i j} /\left(s_{i j}\right)_{0}=0.88$

where

$$
\begin{aligned}
& S_{i j}=\begin{array}{l}
\text { each of the compliance constants for the irradiated } \\
\text { cladding }\left(\mathrm{Pa}^{-1}\right)
\end{array} \\
& \left(S_{i j}\right) 0=\begin{array}{l}
\text { each of the compliance constants predicted for } \\
\text { unirradiated cladding }\left(\mathrm{Pa}^{-1}\right) .
\end{array}
\end{aligned}
$$

Measured values of fast neutron fluences received by the Saxton rods varied from 2.2 to $3.410^{25} \mathrm{n} / \mathrm{m}^{2}$, and no correlation with the fluence was found. The fluence dependence is therefore modeled by replacing Equation (4.6-28) with an assumed fluence dependent expression 


\section{CELMOD， CSHEAR， CELAST}

$H=0.88+0.12 \exp \left(-\Phi / 10^{25}\right)$

where

$H=$ ratio of compliance constants for irradiated material to compliance constants for unirradiated material

$\Phi=$ fast neutron fluence $\left(n / m^{2}\right)$.

4.6.3.6 Derivation of the CELMOD and CSHEAR Codes from the CELAST Code. It has been mentioned in Section 4.6.3.2 that the compliance tensor contains only two independent constants for isotropic (random distribution of $C$ axes) cladding. Moreover, the definition of the compliance tensor implies that the constants may be interpreted as the reciprocals of Young's modulus and the shear modulus

${\overline{\left(S^{\prime}{ }_{i j}\right)_{i s o t r o p i c}}}_{\text {isot }}=\left(\begin{array}{llllll}Y^{-1} & a & a & 0 & 0 & 0 \\ a & Y^{-1} & a & 0 & 0 & 0 \\ 0 & 0 & Y^{-1} & 0 & 0 & 0 \\ 0 & 0 & 0 & G^{-1} & 0 & 0 \\ 0 & 0 & 0 & 0 & G^{-1} & 0 \\ 0 & 0 & 0 & 0 & 0 & G^{-1}\end{array}\right)$

where

$$
\begin{array}{ll}
\overline{\left(S^{\prime}{ }_{i j}\right)_{i s o t r o p i c}} & =\text { compliance matrix for isotropic cladding }\left(\mathrm{Pa}^{-1}\right) \\
Y & =\text { Young's modulus for isotropic cladding }(\mathrm{Pa}) \\
\mathrm{G} & =\text { shear modulus for isotropic cladding }(\mathrm{Pa}) \\
\text { a } & =1 / Y-1 / 2 \mathrm{G}\left(\mathrm{Pa}^{-1}\right)
\end{array}
$$


Expressions for the isotropic Young's modulus and shear modulus in the alpha phase are obtained by computing $\mathrm{S}_{11}$ and $\mathrm{S}_{44}$ for the isotropic case with the CELAST code. Isotropic values of the several averages required by the code are computed by taking $I(\theta, \phi)=1$ in Equation (4.6-17). The resultant values of the isotropic Young's and shear moduli decreased nearly linearly with temperature for temperatures above $450 \mathrm{~K}$. The isotropic alpha phase Young's and shear moduli are therefore modeled with simple linear correlations obtained by fitting straight lines to their values at 623 and $1023 \mathrm{~K}$. The resultant correlations are:

$$
\begin{aligned}
& Y=1.088 \times 10^{10}-5.475 \times 10^{7} \mathrm{~T} \\
& G=4.040 \times 10^{10}-2.168 \times 10^{7} \mathrm{~T}
\end{aligned}
$$

where the terms have been defined in Equation (4.6-28).

Equation (4.6-30) is extrapolated to the high temperatures of beta phase zircaloy because no high temperature shear modulus data are available. The expression used in CELMOD for the Young's modulus of isotropic cladding is identical to the expression used in the CELAST code [Equation (4.6-2)].

Expressions for the change in Young's and shear modul $i$ with increased oxygen, cold work, and fast neutron fluence are taken directly from the CELAST code. Expressions for the changes in the reciprocal of $S_{11}$ are applied to Young's modulus, and changes in the reciprocal of $S_{44}$ are applied to the shear modulus.

\subsubsection{Comparison of Models and Data Base}

Figures 4.6-3 and 4.6-4 compare predictions obtained with the CELAST code to the measurements of axial and circumferential Young's moduli by Bunne11. Predicted moduli increase with increasing oxygen and decrease with 


\section{CELMOD， CSHEAR， CELAST}

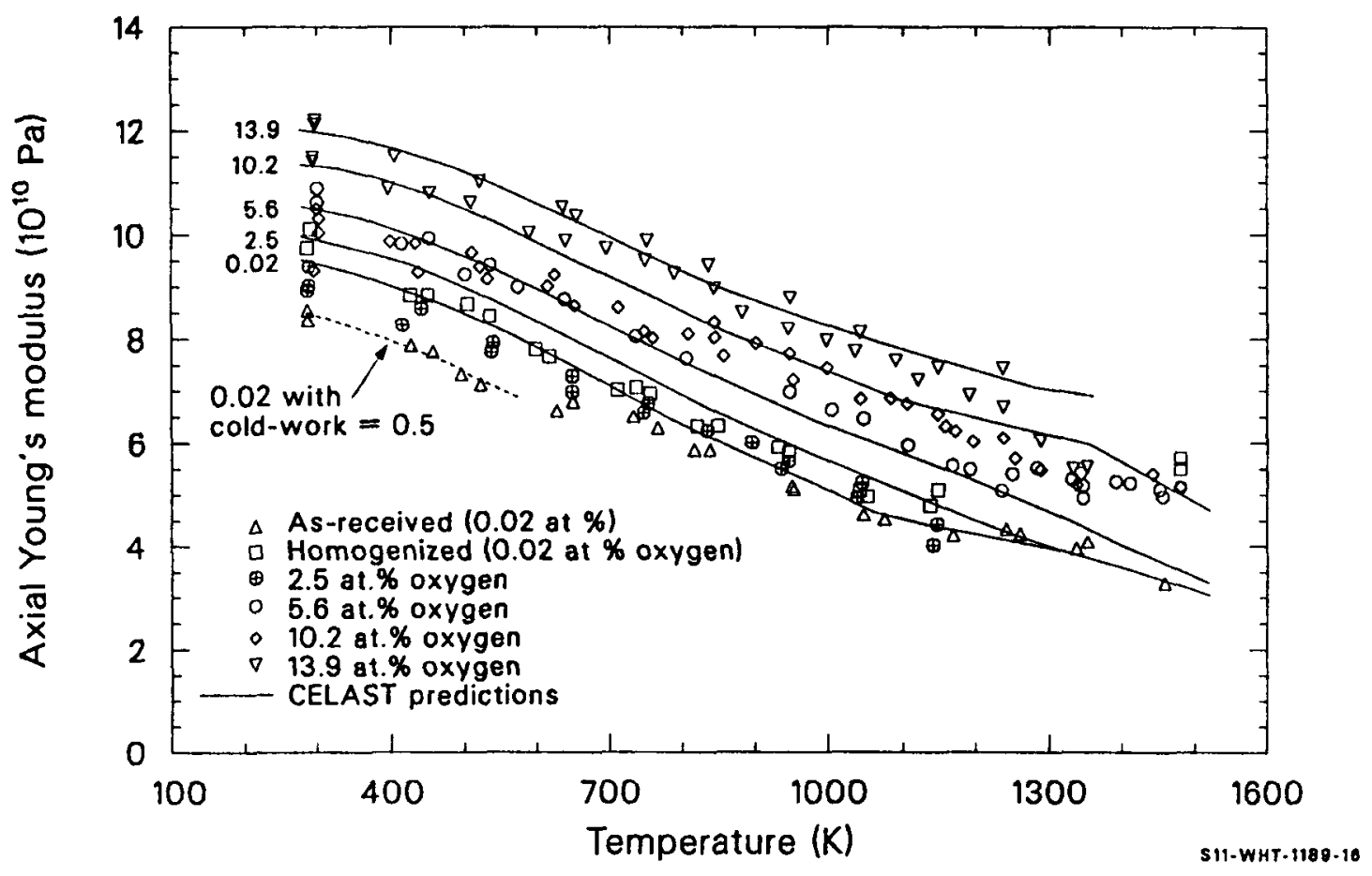

Figure 4.6-3. Measured values of axial Young's modulus compared to values predicted by the CELAST subcode for several oxygen concentrations and temperatures in the range of 300 to $1500 \mathrm{~K}$. 
CELMOD， CSHEAR， CELAST

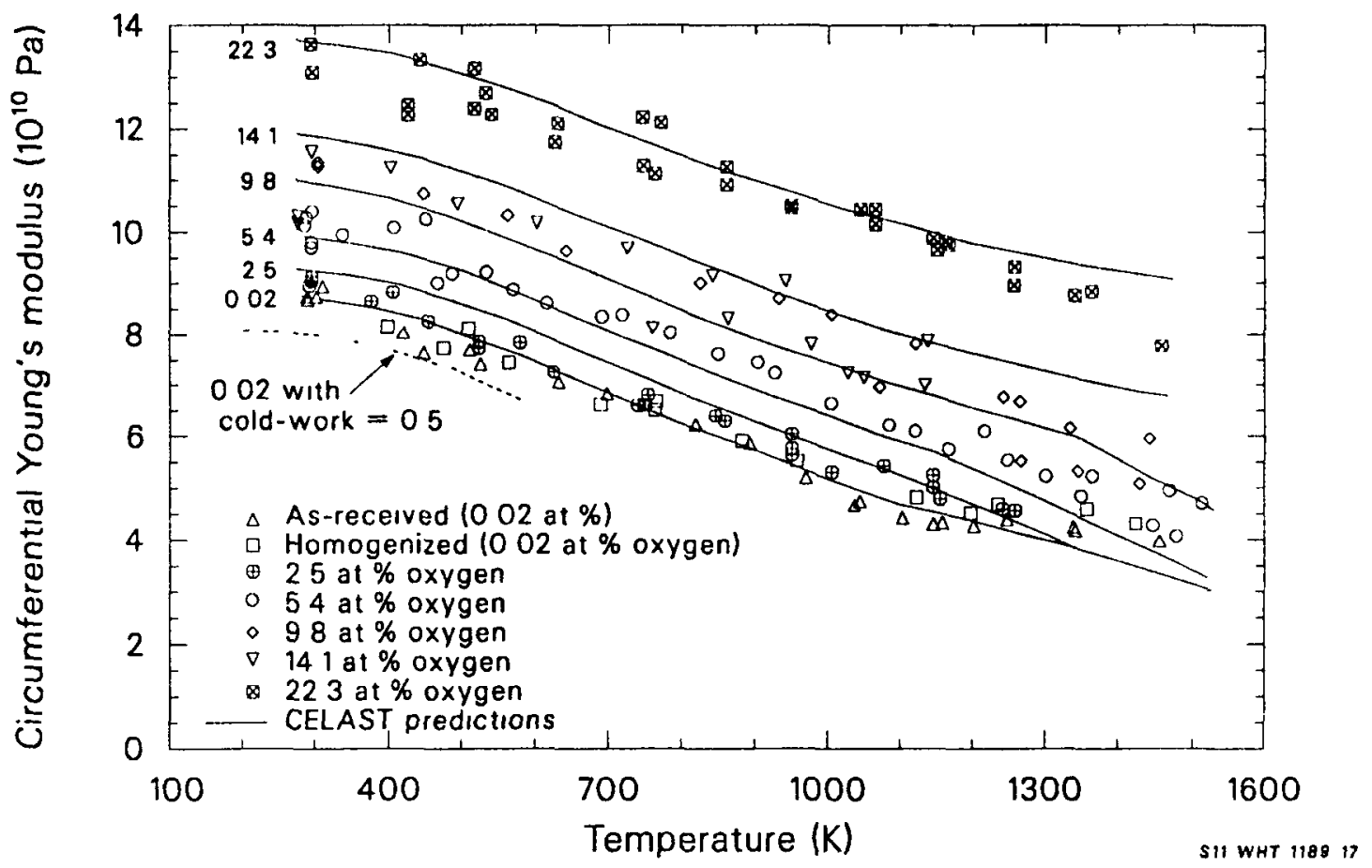

Figure 4.6-4. Measured values of circumferential Young's modulus compared to values predicted by the CELAST subcode for several oxygen concentrations and temperatures in the range of 300 to $1500 \mathrm{~K}$. 


\section{CELMOD， CSHEAR， CELAST}

increasing temperature. Both predicted and measured axial Young's moduli for homogenized (annealed) cladding at room temperature are larger than the corresponding circumferential Young's moduli, but the difference disappears at temperatures above $800 \mathrm{~K}$. Even at room temperature, the difference is only slightly larger than the standard error of the model predictions. However, the low value of the circumferential Young's modulus is consistent with a minimum in predicted Young's modulus versus $c$-axis direction reported by Northwood. ${ }^{4.6-9}$

Figure 4.6-5 is a comparison of the Young's modulus predicted using the CELAST code with the beta phase zirconium data of Armstrong and Brown $4.6-3$ and Padel and Groff. ${ }^{4.6-4}$ The data show very little scatter, but are based on measurements of the Young's modulus of zirconium. The CELAST code has introduced a slight discontinuity in slope at $1240 \mathrm{~K}$, the alpha + beta to beta phase boundary. For higher concentrations of oxygen, this discontinuity would appear at higher temperatures. The discontinuity is significant only in interpreting the physical meaning of the code predictions.

\subsubsection{Expected Standard Error of the CELMOD and CSHEAR Codes}

An estimate of the uncertainty of the CELMOD code is obtained by computing the standard error of the code with the data of Tables 4.6-3 to 4.6-6. For this calculation, the small effects of cold work are ignored. The standard error is $6.4 \times 10^{9} \mathrm{~Pa}$. Since (a) the data used to estimate standard error are not used in the data base of the mode 1 ; (b) the effects of texture, cold work, oxygen, and irradiation are not large compared to temperature effects; and (c) the residuals do not vary in any irregular

a. The standard error is estimated with a data set by the expression: [sum of squared residuals/(number of residuals - number of constants used to fit the data) $]^{1 / 2}$. 
CELMOD， CSHEAR， CELAST

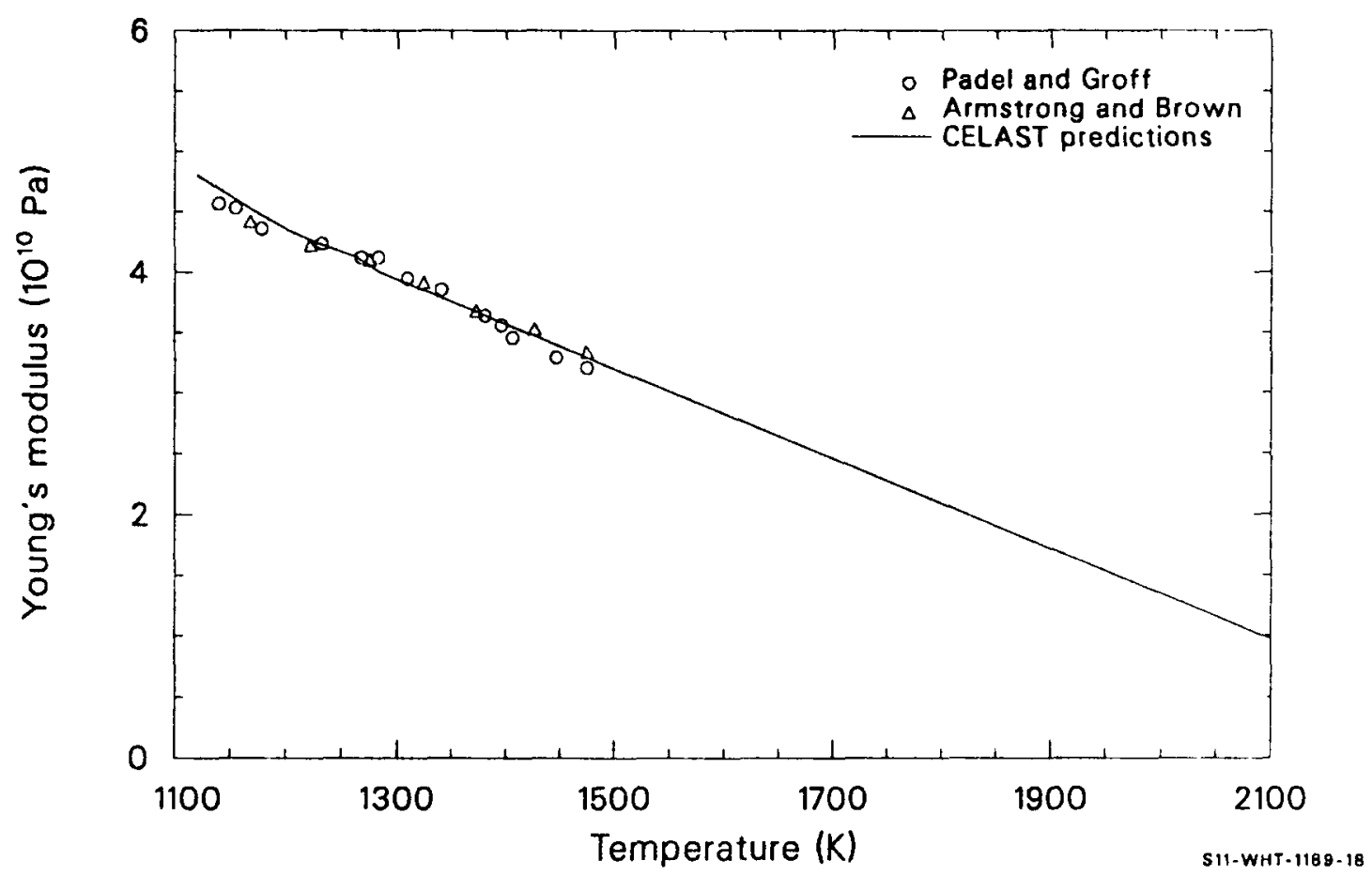

Figure 4.6-5. Comparison of the Young's modulus predicted with the CELAST code to the beta-phase zirconium data of Padel and Groff, and Armstrong and Brown. 


\section{CELMOD, CSHEAR, CELAST}

fashion with temperature, this number is assumed to be a reasonable estimate of the expected standard error of the CELMOD code for in-reactor problems. At normal LWR temperatures, this standard error is $10 \%$ of the predicted value.

The uncertainty of the CSHEAR code is estimated by computing the standard error of the code with a large block of data (214 measurements) reported by Bunne11.4.6-1 The data were not used in the development of the codes described here because the author was not able to interpret the effect of texture on the torsional wave used by Bunnell to measure shear modulus. The standard error, assuming the cladding was isotropic, is $9 \times 10^{9} \mathrm{~Pa}$. At normal LWR temperatures, the standard error of the isotropic shear is $30 \%$ of the predicted value.

\subsubsection{References}

4.6-1. L. R. Bunnell et al., High Temperature Properties of Zircaloy-Oxygen Alloys, EPRI NP-524, March 1977.

4.6-2. E. S. Fisher and C. J. Renken, "Single-Crystal Elastic Moduli and the HCP-BCC Transformation in Ti, Zr, and Hf, "Physical Review, 135 $2 A$, July 20, 1964, pp. A482-494.

4.6-3. P. E. Armstrong and H. L. Brown, "Dynamic Young's Modulus Measurements above $1000^{\circ} \mathrm{C}$ on Some Pure Polycrystalline Metals and Commercial Graphites," Transactions of the Metallurgical Society of AIME 230, August 1964, pp. 962-966.

4.6-4. A. Padel and A. Groff, "Variation du Module de Young du Zirconium $\beta$ en Function de la Temperature," Journal of Nuclear Materials 59,1976 , pp. 325-326.

4.6-5. C. C. Busby, Properties of Zircaloy-4 Tubing, WAPD-TM-585, December 1966, p. 65.

4.6-6. Z. Spasic et a7., Conference on the Use of Zirconium Alloys in Nuclear Reactors, Marlanske Lanze, Czechoslovakia, USAEC CONF-681086, 1968, pp. 277-284.

4.6-7. R. L. Mehan, Modulus of Elasticity of Zircaloy-2 Between Room Temperature and $1000^{\circ} \mathrm{F}$, KAPL-M-RLM-16, July 1958. 


\section{CELMOD， CSHEAR， CELAST}

4.6-8. R. L. Mehan and F. W. Wiesinger, Mechanical Properties of Zircaloy-2, KAPL-2110, February 1961, pp. 11-12.

4.6-9. D. 0. Northwood et al., "Elastic Constants of Zirconium Alloys," Journal of Nuclear Materials, 55, 1975, pp. 299-310.

4.6-10. F. B. Shober et al., The Mechanical Properties of Zirconium and Zircaloy-2, BMI-1168, 1957.

4.6-11. C. L. Whitmarsh, Review of Zircaloy-2 and Zircaloy-4 Properties Relevant to N. S. Savannah Reactor Design, ORNL-3281, 1962.

4.6-12. W. R. Smalley, Saxton Core II Fuel Performance Evaluation Part I: Materials, WCAP-3385-56, September 1971.

4.6-13. R. H. Chapman, Characterization of Zircaloy-4 Tubing Procured for Fuel Cladding Research Programs, ORNL/NUREG/TM-29, July 1976.

4.6-14. G. E. Dieter, Mechanical Metallurgy, McGraw-Hill Book Company, New York, 1976.

4.6-15. J. J. Kearns, Thermal Expansion and Preferred Orientation in Zircaloy, WAPD-TM-472, November 1965.

4.6-16. H. S. Rosenbaum and J. E. Lewis, "Use of Pole Figure Data to Compute Elasticity Coefficient of Zirconium Sheet," Journal of Nuclear Materials, 67, 1977, pp. 273-282.

4.6-17. R. B. Leighton, Principles of Modern Physics, New York: McGraw-Hil1 Book Company, Inc., New York, 1959.

4.6-18. H. M. Chung et al., "Mechanical Properties of Zircaloy Containing Oxygen," In Light-Water-Reactor Safety Research Program: Quarterly Progress Report January-March 1976, ANL-76-49. 


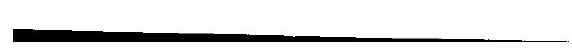




\section{CAGROW}

\subsection{AXIAL GROWTH (CAGROW)}

(D. L. Hagrman)

A model for calculating the fractional change in length of zircaloy tubes due to irradiation-induced growth is presented in this section. Effects of fast neutron fluence, tubing texture, cladding temperature, and cold work are included and apply equally well to zircaloy-2 and zircaloy-4. The change in length of commercial fuel rods due to irradiation growth is small; however, it can be a significant fraction of the clearance between the rod and the top and bottom assembly nozzles. Contact with the nozzles can cause rods to bow and possibly fail at points where rods contact each other.

\subsubsection{Summary}

The following equation has been developed to model the irradiation growth of zircaloy tubes at temperatures between 40 and $360^{\circ} \mathrm{C}$ (the normal range of cladding temperatures in (WRs).

$\Delta L / L=A[\exp (240.8 / T)](\phi t)^{1 / 2}\left(1-3 f_{Z}\right)(1+2.0 \mathrm{CW})$

where

$\Delta L / L=$ fractional change in length due to growth

$A=1.407 \times 10^{-16}\left(\mathrm{n} / \mathrm{m}^{2}\right)^{1 / 2}$

$\mathrm{T}=\mathrm{cladding}$ temperature $(\mathrm{K})$ 


\title{
CAGROW
}

\author{
$\phi \quad=\quad$ fast neutron flux $\left(n / \mathrm{m}^{2} \mathrm{~s}\right)(\mathrm{E}>1.0 \mathrm{MeV})$ \\ $t=\operatorname{time}(s)$ \\ $f_{Z}=$ texture factor ${ }^{a}$ for the tubing axis \\ $\mathrm{CW}=\operatorname{cold}$ work (fraction of cross-sectional area reduction).
}

Axial growth for temperatures below $40^{\circ} \mathrm{C}$ is approximated by using $\mathrm{T}=$ $40^{\circ} \mathrm{C}$ in Equation (4.7-1), and growth above $360^{\circ} \mathrm{C}$ is approximated by using $\mathrm{T}=360^{\circ} \mathrm{C}$.

A comparison of values calculated by the CAGROW subroutine for fully annealed material with experimental results is presented in Figure 4.7-1. Comparison with the data shown from cold-worked tubes was not possible because the exact amount of cold work was not reported.

\subsubsection{Background and Approach}

The irradiation growth of zircaloy cladding appears to be quite sensitive to texture; therefore, the effects of texture were considered first. The data were normalized to a standard texture $\left(f_{z}=0.05\right)$ before considering other effects on axial growth. The model was developed further by modeling the effects of fluence and irradiation temperature on the growth of annealed specimens. Finally, the effect of cold work was modeled after removing the effects of texture, fluence, and temperature from the cold-worked specimen data, using the model based on annealed specimens. (The data were normalized to a texture of 0.05 , a fluence of $2 \times 10^{25} \mathrm{n} / \mathrm{m}^{2}$, and a temperature of $300^{\circ} \mathrm{C}$.) It should be noted,

a. $f_{z}$ is the effective fraction of cells aligned with their $\langle 0001\rangle$ axis paraltel to the tubing axis, as gefermined by $x$-ray diffraction analysis. A value of $f_{z}=0.05$ is typical. $4.7-1$ 


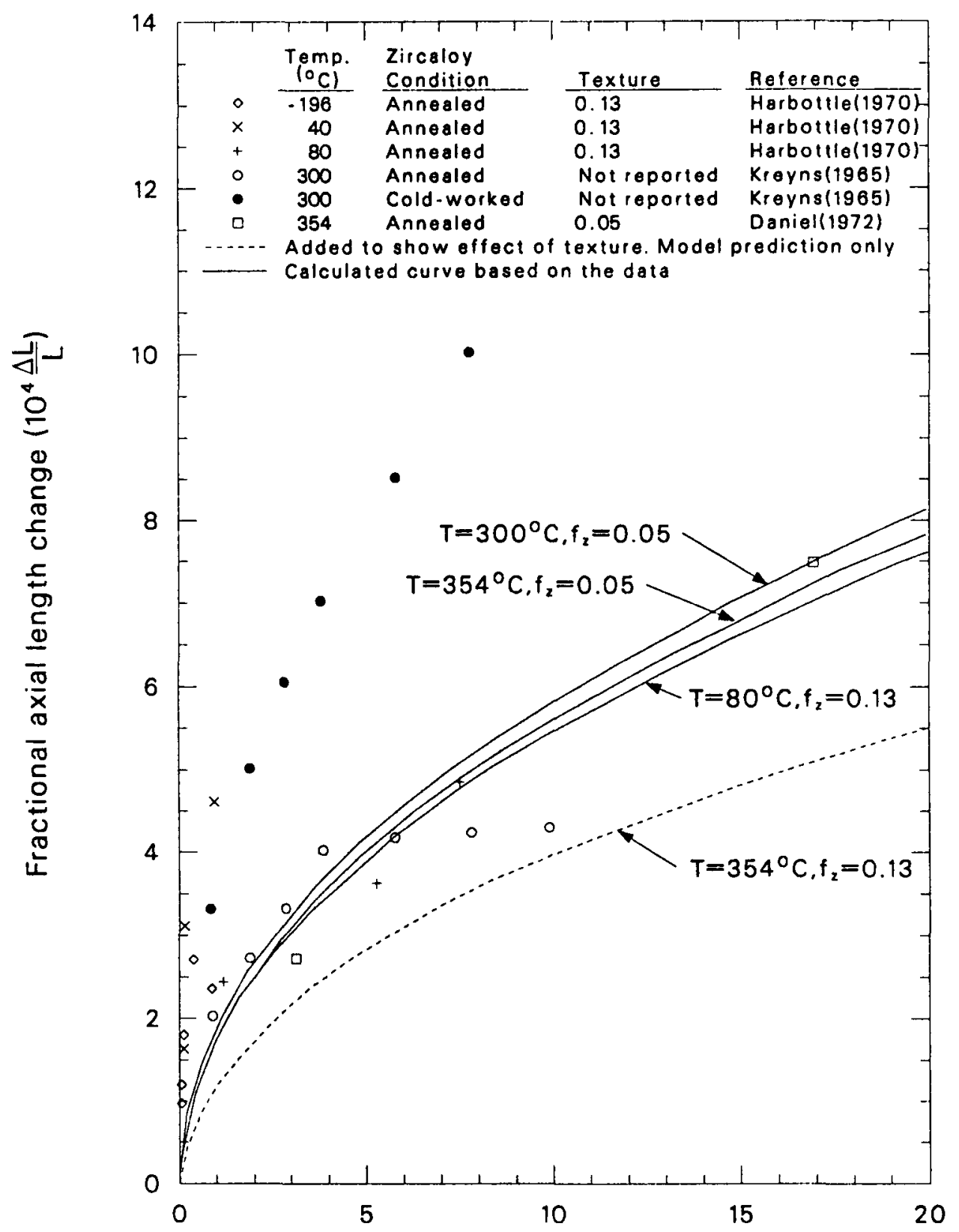

Fluence $\left(10^{24} \mathrm{n} / \mathrm{m}^{2}\right)$

S11-WHT-1189-19

Figure 4.7-1. Model predictions and measured values of zircaloy tube axial growth as a function of fast neutron fluence, irradiation temperature, cold work, and texture coefficient, $f_{z}$. 


\section{CAGROW}

the effect of cold work may not be treated completely, since the limited data base did not allow treatment of interactions between cold work and fluence, temperature, and texture.

In CAGROW, it is assumed that fast neutron flux and temperature both affect the growth rate by varying the concentration of interstitials which are free to migrate and cause growth. Since theoretical considerations imply a complex relation between temperature, fast neutron flux, time, and rate of growth, an empirical approach was used to approximate these effects. An empirical approach was also used to model the effect of cold work on zircaloy tube growth. The limited data were fit using an independent factor of the form $(1+$ constant $x$ cold work $)$, the least complex form consistent with the data available. The main conclusion is that cold work increases the rate of growth at low fluence. At higher fluences, the growth rate of annealed tubing may decrease rapidly. Cold-worked tubing continues to grow at higher fluences at nearly the rate established during early irradiation.

\subsubsection{Review of Experimental Data}

Samples of zirconium, zircaloy-2, and zircaloy-4 irradiated in a fast neutron flux $(E>1 \mathrm{MeV})$ to fluences of $10^{25} \mathrm{n} / \mathrm{m}^{2}$ show typical axial growth on the order of $0.1 \%$ of length or less. Since the effects of fuel-cladding mechanical interactions and pressure differentials across the cladding compete with the smaller effects of irradiation growth, the relatively plentiful data 4.7-2,4.7-3,4.7-4 are not directly useful in determining the change in cladding length due to irradiation growth. Data on thimble tubes or other structural elements relatively free of confounding effects would be useful. Table 4.7-1 summarizes the data used for development of the model.

Early data on irradiation-induced axial growth of zircaloy-4 tubing at $300^{\circ} \mathrm{C}$ were obtained by Kreyns..$^{4-5} \mathrm{His}$ experiments indicated that 
Table 4.7-1. Measurements of growth in zircaloy tubing

\section{$\Delta \mathrm{L} / \mathrm{L} \quad$ Differential ${ }^{\mathrm{a}} \begin{gathered}\text { Fast } \\ \text { Fluence }\end{gathered}$}

Source $\left(10^{-4}\right) \quad \Delta L / L\left(10^{-4}\right) \quad\left(10^{22} \mathrm{n} / \mathrm{m}^{2}\right)$ Material

$\begin{array}{ll}\text { Kreyns } & \\ (4.7-5) & 2.7 \\ & 3.3 \\ & 4.0 \\ & 4.15 \\ & 4.2 \\ & 4.3 \\ & 3.3 \\ & 5 \\ & 6 \\ & 7 \\ & 8.5 \\ & 10\end{array}$

100

200

300

400

600

800

1000

100

200

300

400

600

800
Cold-worked

zircaloy -4

(?)

300

(?)

300

310

1700

Annealed

12.5

354

(4.7-1,

2.7
7.5

zircaloy -4

$1.2 \pm 0.2$

$1.5 \pm 0.3$

$2.3 \pm 0.3$

4.9
9.7

Annealed

19

$3.5 \pm 0.5$

50

$3.0 \pm 0.1$

$2.1 \pm 0.2$

$4.0 \pm 0.2$

98

$5.6 \pm 0.4$

8.2

Annealed

$5.6 \pm 0.4 \quad 100$

zircaloy-2

$3.1 \pm 0.4 \quad 130$

$4.7 \pm 0.4 \quad 540$

Annealed

$6.3 \pm 1.0$

zircaloy-2
3
40
3 $-196$
12
80

770

a. Only the difference between longitudinal and transverse changes in length was reported. 


\section{CAGROW}

growth of cold-worked tubing is proportional to the square root of the fast neutron fluence up to its maximum fluence $\left(10^{25} \mathrm{n} / \mathrm{m}^{2}\right)$. Growth of annealed tubing appeared to saturate at a fluence of $4 \times 10^{24} \mathrm{n} / \mathrm{m}^{2}$ and a fractional length change of $4 \times 10^{-4}$. However, subsequent data taken by other investigators have indicated that saturation is not determined by fluence or net growth.

Harbottle $e^{4.7-6}$ reported the difference in growth strains of transverse and longitudinal strips cut from zircaloy-2 pressure tubes. The strips were annealed and then irradiated at $-196,40$, and $80^{\circ} \mathrm{C}$. The basal pole texture was found to be $13 \%$ in the direction of the tube axis and $36 \%$ in the circumferential direction, both before and after the cutting and annealing process. Harbottle's differential growth strains were converted to absolute values of axial growth strains by using the equation

$\frac{1-3 f_{z}}{1-3 f_{\theta}}=\frac{\text { growth strain in axial direction }}{\text { growth strain in circumferential direction }}$

where $f_{z}$ and $f_{\theta}$ are the texture factors in the axial and circumferential directions, respectively.

A somewhat different approach was taken by Danie $7^{4.7-1,4.7-7}$ in a series of experiments that measured both diameter and length changes of fuel rods. The effects of fuel-cladding interactions and pressure differentials across the cladding on measured changes in rod length could be separated from the effect of cladding growth, since no fuel-cladding mechanical interaction was present in one experiment series. The separation was achieved by noting that the expected ratio of length-to-diameter changes is very different for fuel-cladding interactions, creep due to pressure differentials across the rod, and irradiation-induced growth. In particular, the fractional change in diameter due to growth was predicted to be very small for typical cladding diameters and textures. Therefore, a plot of the measured change in length as a function of the measured change in diameter at a single fluence could be 


\section{CAGROW}

used to determine the change in length due to growth by simply extrapolating to zero changes in diameter with data that did not contain fuel-cladding mechanical interactions. Daniel determined the fractional change in length at two values of fluence. His results ${ }^{a}$ are particularly significant because they provide a measure of growth of annealed cladding at high fluence and do not show the saturation which Kreyns ${ }^{4-7-5}$ observed.

\subsubsection{The Effect of Texture on Axial and Circumferential Growth}

Single-crystal texture effects are related to polycrystalline growth. Growth is pictured simply as a reduction of the c-axis dimension of individual grains and an increase of the basal plane dimensions of the grains. The analysis is carried out with the help of an abstract picture of grains made up of schematic immobile unit cells, which decrease their c-axis length by a fraction $n$ and increase their $a_{1}, a_{2}$, and $a_{3}$ axis length by a fraction $m$. Although the picture of changing unit cell size does not represent atomic behavior within the grain, the growth of the grain is reproduced by the abstract picture.

Figure 4.7-2 illustrates the change in the axis lengths of the schematic unit cells. Growth of the three axes in the basal plane is assumed to be equal because of the symmetry of the lattice. The relation between the decrease of the c-axis dimension and the increase of the a axes is dependent on the details of the atomic model used to describe growth. For models that imply that the volume of the grain (and schematic unit cell) remains constant, $(1+m)=(1-n)^{-1 / 2}$. This value for $1+m$ will be assumed at the last stage of the derivation of the effect of texture. It should be noted that the assumption is not made on the basis of a detailed atomic model. The constant-volume assumption is made on the basis of experimental evidence, ${ }^{4.7-8,4.7-9}$ and this evidence has been somewhat contradictory.

a. $24^{A}$ growth component of strain equal to $3.5 \times 10^{-4}$ at a fluence of $17 \times$ $10^{24} \mathrm{n} / \mathrm{m}^{2}$ and a growth strain of $2.3 \times 10^{-4}$ at a fluence of $3.1 \mathrm{x}$
$10^{24} \mathrm{n} / \mathrm{m}^{2}$ were indicated by Daniel. $4.7,4.7-7$ a 


\section{CAGROW}
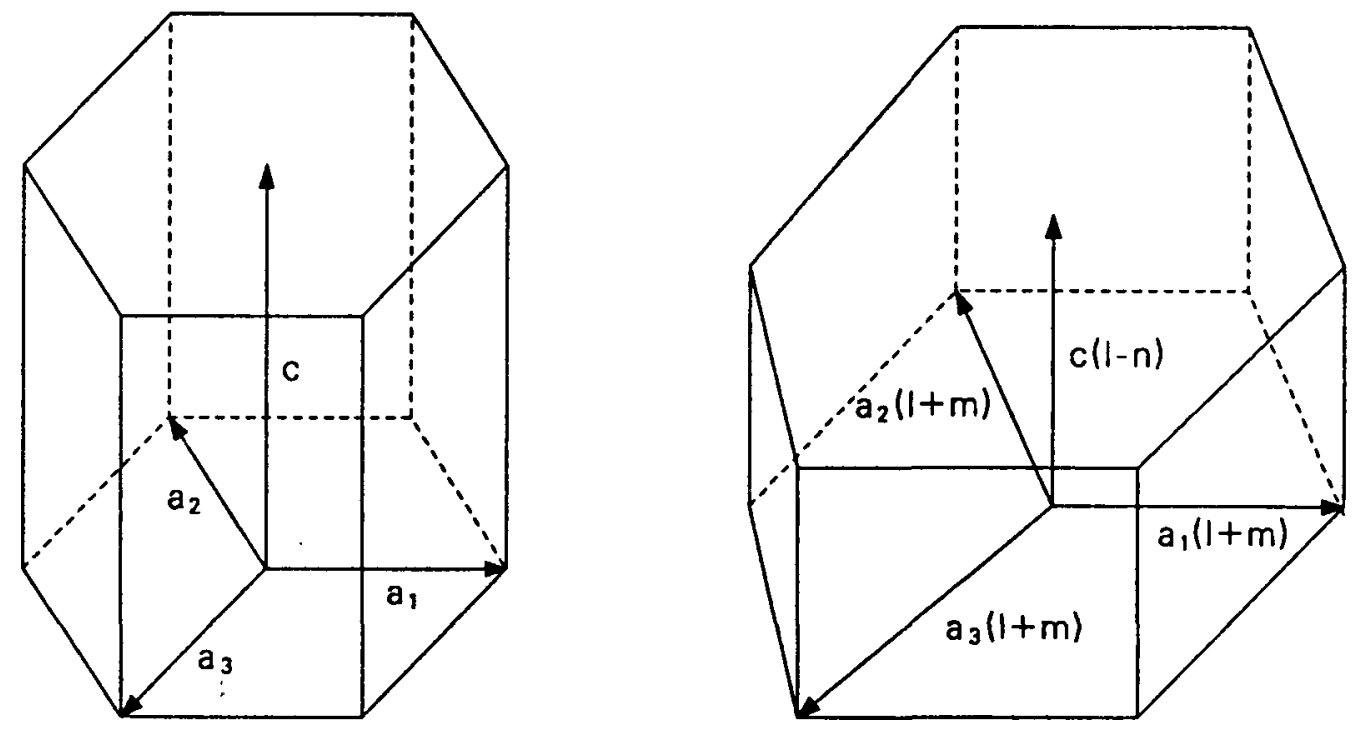

S11-WHT-1089-20

Figure 4.7-2. The growth of schematic unit cells in a grain. 


\section{CAGROW}

4.7.4.1 Use of the X-ray Diffraction Orientations Parameter to Relate Single-Crystal Models to Polycrystalline Results. The effective fraction of grains aligned with their $c$ axes parallel to a reference direction (axial, circumferential, or radial direction of the tube) is usually taken to be an orientation parameter ${ }^{4-10}$ determined from $X$-ray diffraction studies. This parameter is formally defined as the average of the squared cosine of the azimuthal angle between the $c$ axis of individual grains and the reference direction, weighted by the volume fraction, $v_{j}$, occupied by cells at a given azimuthal angle, $\theta_{j}$. That is,

$$
F=\frac{\sum_{i} v_{i} \cos ^{2} \theta_{i}}{\sum_{i} v_{j}}
$$

It is shown in Reference 4.7-10 that polycrystalline bulk properties in a reference direction can be expressed as

$$
P_{\text {ref }}=f P \|+(1-f) P_{\perp}
$$

if the property has the following characteristics:

$$
\text { a. } \quad P_{\eta}=P_{\|} \cos ^{2} \eta+P_{\perp} \sin ^{2} \eta
$$

where

$$
\begin{aligned}
& P_{\eta}=\text { the single-crystal property in a direction at an angle } \eta \\
& \text { to the axis } \\
& P_{\|}=\text {the single-crystal property along the c-axis } \\
& P_{\perp}=\text { the single-crystal property perpendicular to the c-axis }
\end{aligned}
$$

and 


\section{CAGROW}

b. The property in a reference direction of the polycrystalline sample is the volume-weighted summation of this property in its individual crystals.

A property of the schematic unit cells that satisfies condition (a) is the square of the distance between two points imbedded in the schematic unit cell. That is, if $(-x / 2,-y / 2,-z / 2)$ and $(x / 2, y / 2, z / 2)$ are coordinates of two points in the cell relative to an origin at the middle of the cell, the squared distance between the points is

$1^{2}=z^{2}+x^{2}+y^{2}$

or

$1^{2}=1_{0}^{2}(1-n)^{2} \cos ^{2} \theta+1_{0}^{2}(1+m)^{2} \sin ^{2} \theta$

where

$1_{0}=$ the distance between the points

$\mathrm{n}$ and $\mathrm{m}=$ parameters that describe cell change

$\theta=$ the angle between the $c$ axis and the line between the points

It is assumed here that condition (b) of the previous paragraph is also satisfied.

Equations (4.7-4) and (4.7-7) can be used to express the fractional change in the distance between two points of a polycrystalline sample. $P_{\|}$and $P_{\perp}$ of Equation (4.7-4) are identified as $1_{0}{ }^{2}(1-n)^{2}$ and $1_{0}{ }^{2}$ $(1+m)^{2}$ in Equation (4.7-7) so that $1^{2}$ (the square of the distance between points of a polycrystalline sample) is 


\section{CAGROW}

$$
1^{2}=f(1-n)^{2} 1_{0}^{2}+(1-f)(1+m)^{2} 1_{0}^{2} .
$$

The fractional change in length along the reference direction of a polycrystalline sample will then be

$$
\Delta 1 / 1_{0}=\left(1-1_{0}\right) / 1=\left[f(1-n)^{2}+(1-f)(1+m)^{2}\right]^{1 / 2}-1 .
$$

The parameters $n$ and $m$ represent the average fractional growth of single crystals along the $c$ and a axes. Since growth in zirconium alloys is typically less than $1 \%, n$ and $m$ are small numbers and a Taylor series expansion of the radical about $n=m=0$ is possible. The expansion yields

$$
\Delta 1 / 1_{0} \approx 1+m-(n+m) f+\text { terms of order } n^{2}, m^{2} \text {, and } n m .
$$

$$
\text { If }(1+m) \text { is taken equal to }(1-n)^{-1 / 2} \text { in order to impose the }
$$
restriction of a constant volume on the grain, the Taylor series expansion yields

$$
\Delta 1 / 1_{0} \approx n / 2(1-3 f)+\text { terms of order } n^{2} .
$$

The assumption of constant volume is made here in lieu of a successful atomic level model for kinetics of growth.

\subsubsection{Application of the Result of Section 4.7.4.1 to Measurements} of Growth in Different Directions. Equations (4.7-10) and (4.7-11) have been derived without reference to any particular direction. Thus, for the axial component of growth, $\Delta 1 / 1$ is measured along the tubing axis and $f$ is the axial orientation parameter, $f_{z}$. If a change in tubing circumference (or diameter of the tube since the diameter is $\pi-1$ times the circumference) is being considered, $\Delta 1 / 7$ is the fractional change in the tubing diameter or circumference and $f$ is $f_{\theta}$, the tangential orientation parameter. 


\section{CAGROW}

\subsubsection{Analysis of Irradiation-Induced Growth Factors Other than Texture}

The fast neutron flux (in addition to fluence) and the residual stress in the tubing may affect growth (References 4.7-6 and 4.7-11), but no attempt has been made to include these effects due to lack of data. Also, no significant difference in the growth rates of zirconium, zircaloy-2, and zircaloy-4 has been reported, so no distinction between their growth rates has been incorporated into the model. As mentioned in Section 4.7-2, the first step in developing the model was to account for differences in growth due to differences in texture. The factor (1 + 3f) of Equation (4.7-11) was used to adjust growth measured with arbitrary textures to values expected for $f=0.05$. The results are illustrated in Figure 4.7-3.

\subsubsection{The Effect of Fast Neutron Fluence on Irradiation-Induced} Growth. Many investigators have treated the effect of fast fluence by fitting in the empirical expression

Growth strain $=(\text { fluence })^{q}$

to the data, 4.7-6,4.7-8 with resultant values of $q$ in the range from 0.3 to 0.8. Although good agreement can be obtained by allowing $q$ to vary for each set of data, the results of such empirical fits are somewhat misleading. Hesketh ${ }^{4.7-12}$ has derived a dependence on the square root of fluence [ $q=0.5$ in Equation (4.7-12)], and data from individual irradiations have not demonstrated a clear departure (other than saturation effects) from this rule. This point is illustrated in Figure 4.7-4 by showing a plot of axial growth as a function of the square root of the fluence.

Departures from $q=0.5$ would be indicated by curvature of the data in Figure 4.7-4. Except for apparent saturation effects on annealed tubes at $300^{\circ} \mathrm{C}$, these departures are much less pronounced than differences due to different temperatures, fluences, and cold work. Moreover, there is a 


\section{CAGROW}

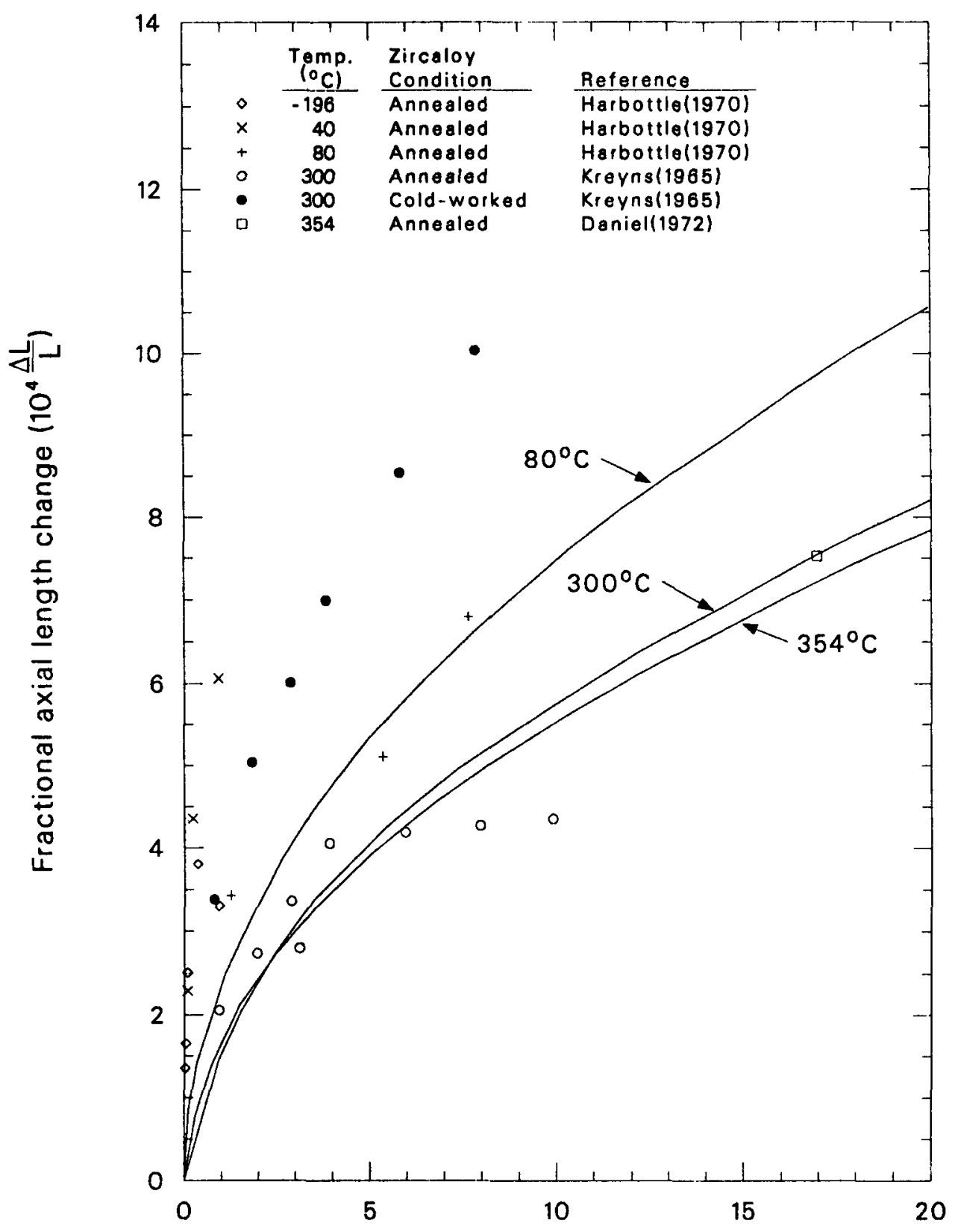

Fluence $\left(10^{24} \mathrm{n} / \mathrm{m}^{2}\right)$

S11-WHT-1189-21

Figure 4.7-3. Model predictions and measured values of the growth of zircaloy tubes adjusted to a common texture coefficient of $f_{z}=0.05$. 


\section{CAGROW}

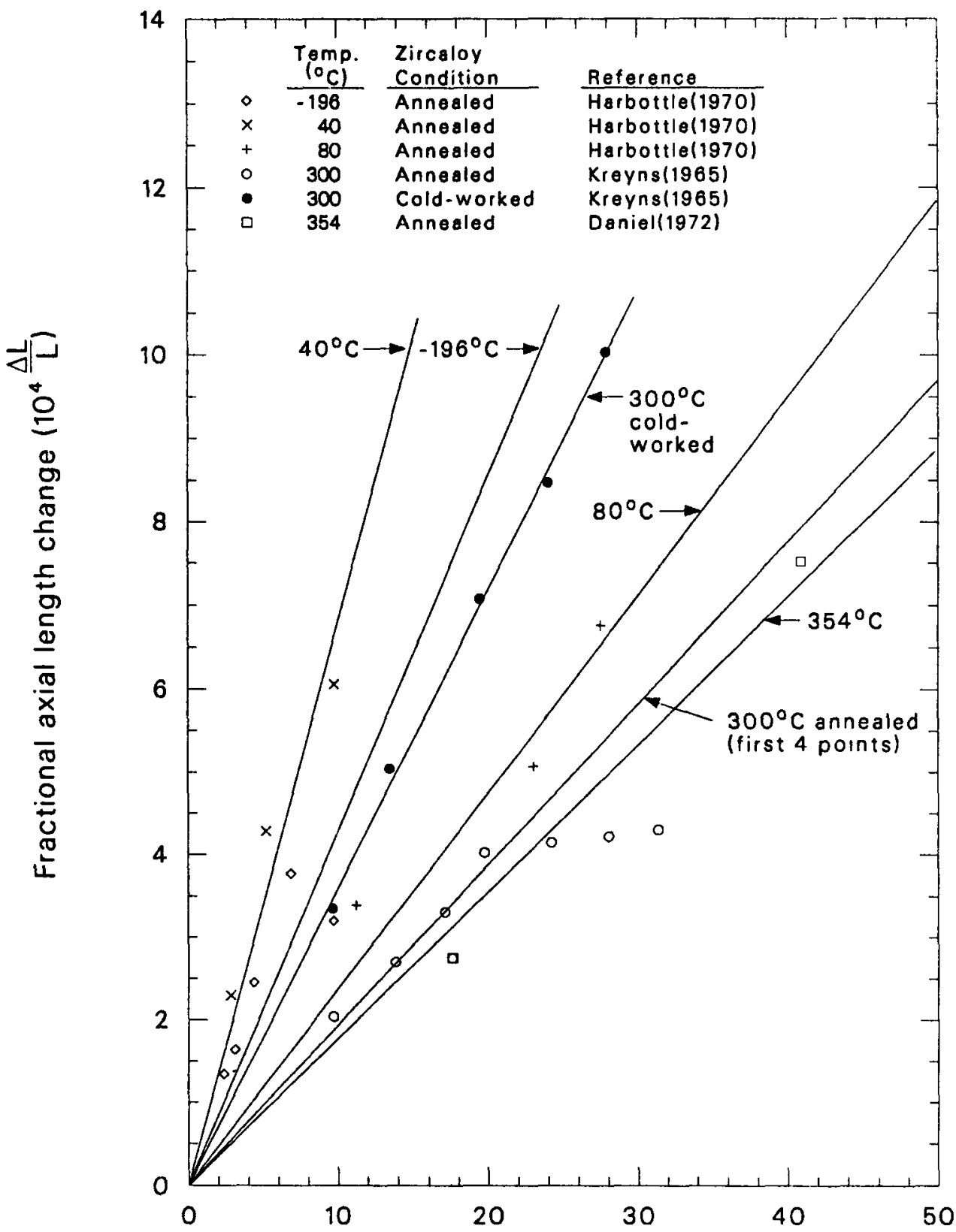

Square root of fluence $\left(10^{11} \sqrt{\mathrm{n} / \mathrm{m}^{2}}\right)$

S11-WHT-1189-22

Figure 4.7-4. Zircaloy growth versus square root of fast neutron fluence for data adjusted to a common tube texture coefficient of $f_{z}=0.05$ with linear least-squares fits superimposed. 


\section{CAGROW}

physical basis for expecting temperature and flux to modify the effect of given fluence. Therefore, the exponent in Equation (4.7-12) is fixed in the model at 0.5 .

4.7.5.2 The Effect of Temperature on Irradiation-Induced Growth. It has been suggested by Harbottle $e^{4.7-6}$ that growth is proportional to the instantaneous concentration of interstitials. This implies that growth should be directly proportional to the rate of interstitial production (which is proportional to neutron flux $\phi$ ) and inversely proportional to the rate of interstitial removal. Since interstitial removal is proportional to exp (-interstitial migration energy/RT), the following expression for growth should apply.

$\Delta L / L \propto \phi \exp \left(E_{M} / R T\right)$

where

$$
\begin{aligned}
& \mathrm{E}_{\mathrm{M}}=\text { interstitial migration energy } \\
& \mathrm{R}=\text { gas constant. }
\end{aligned}
$$

When Equation (4.7-13) is compared to data, $E_{M}$ varies with temperature as expected; but any simple variation of $E_{M}$ with temperature is not consistent with all experiments. A constant value for $E_{M}$ has been used in the model, due to these inconsistencies and because it has been suggested that the dependence of $E_{M}$ on temperature is too complex $4.7-13$ to evaluate with existing data. $E_{M}$ will actually change, in poorly defined steps, as the modes of interstitial migration change with increasing temperature. However, Figures 4.7-1, 4.7-3, and 4.7-4 indicate that there is a relatively small temperature dependence in the normal operating temperature range for LWRs. Use of a small and constant value for $E_{M}$ is therefore justified. A comparison of Equation (4.7-13) with the data shown in Figure 4.7-4 results in the following correlation: 


\section{CAGROW}

$\Delta \mathrm{L} / \mathrm{L} \propto \exp (240.8 / \mathrm{T})$

The fast flux factor of Equation (4.7-13) has been incorporated in the constant A of the full expression for growth, Equation (4.7-1).

The detailed data comparisons made while deriving Equation (4.7-14) provide justification for the functional dependence shown. When Harbottle $\mathrm{s}^{4.7-6}$ data for growth under fast fluxes differing by a factor of two (at 40 and $80^{\circ} \mathrm{C}$, see Table 4.7-1) are compared, they are consistent with a value of $E_{M}=0.3 \mathrm{eV}$. This value of $E$ is reasonable for atomic migration in that temperature range. When other data are examined, values of $E=0.075 \mathrm{eV}$ result at $-196^{\circ} \mathrm{C}$ and of $E=0.157 \mathrm{eV}$ at $354^{\circ} \mathrm{C}$. This range of values is also reasonable, 4.7-14 lending confidence to the functional dependence given by Equations (4.7-13) and $(4.7-14)$.

4.7.5.3 The Effect of Cold Work on Irradiation-Induced Growth. The observed effects of cold work have not been successfully explained in detail in the literature. For this model, general conclusions have been drawn from the available measurements and an empirical expression has been formed. The

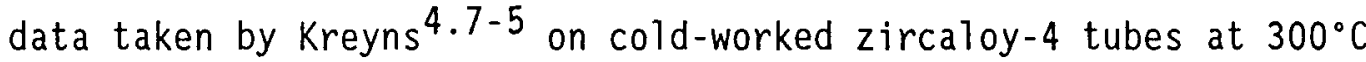
agree very well with a square root of fluence dependence, as shown in Figure 4.7-5. To compare these results with those for annealed tubes, the annealed data shown in Figure $4.7-4$ were normalized to $300^{\circ} \mathrm{C}$ using Equation (4.7-14). Figure 4.7-5 then indicates that the net effect of cold work is to increase the growth rate in the unsaturated range of fluence. Neither the dependence on the square root of the fluence nor the intercept at zero fluence are changed by cold work.

The only available data on the effect of varying the amount of cold work are reported in Figure 19 of Reference 4.7-8, which indicates the following approximate irradiation growth fractions in the longitudinal direction of zircaloy-4 plate specimens at $300^{\circ} \mathrm{C}$ (Table $4.7-2$ ). The 
CAGROW

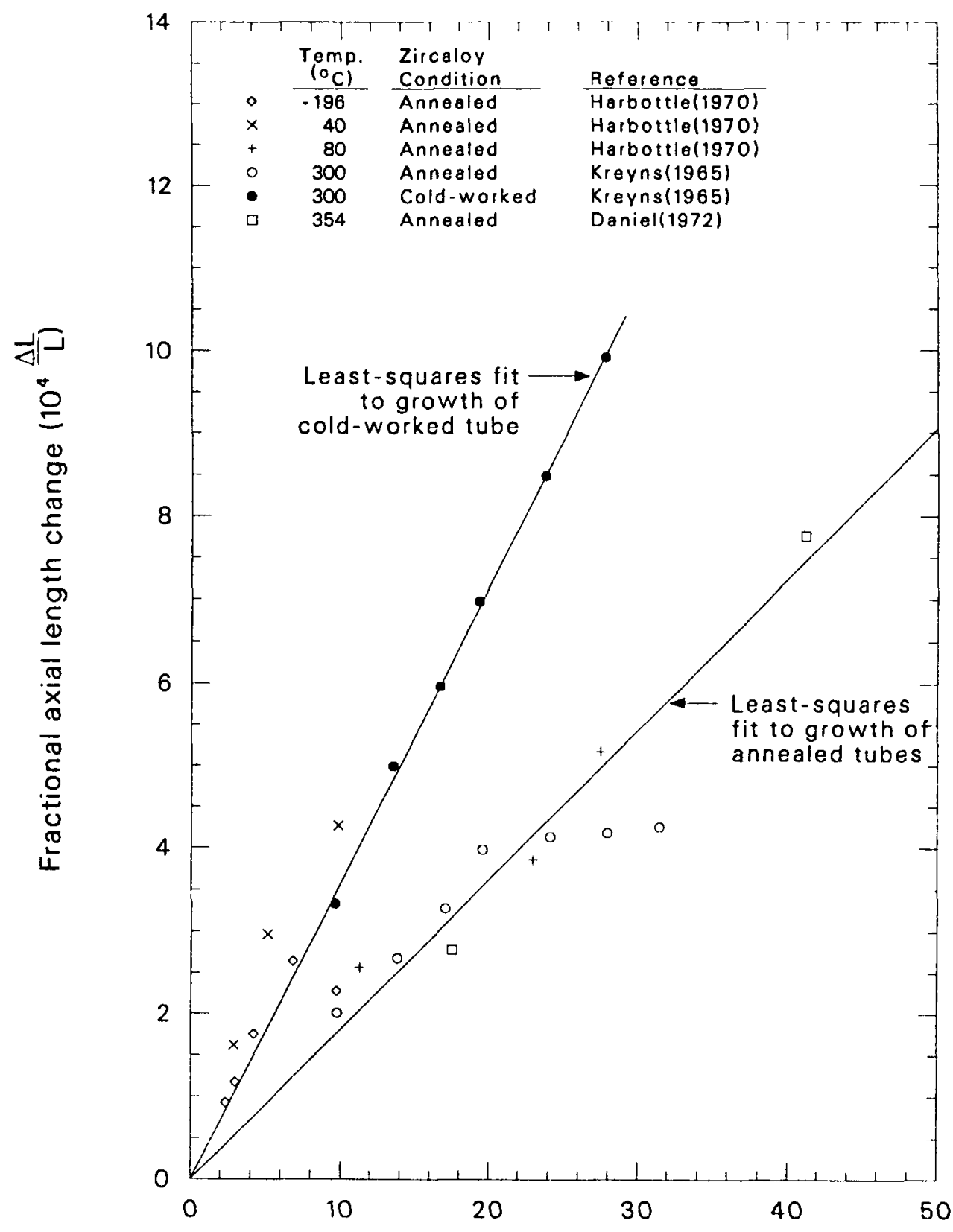

Square root of fluence $\left(10^{11} \sqrt{\mathrm{n} / \mathrm{m}^{2}}\right)$

S11-WHT-1189-23

Figure 4.7-5. Zircaloy growth versus square root of fast neutron fluence for data adjusted to a common tube texture coefficient of $f_{z}=0.05$ and to a common temperature of $300^{\circ} \mathrm{C}$ with linear least-squares fits superimposed. 


\section{CAGROW}

Table 4.7-2. Zircaloy growth data as a function of cold work and fluence

\begin{tabular}{cccc}
\multirow{2}{*}{$\begin{array}{c}\text { Fast } \\
\text { Fluence } \\
\left(10^{24} \mathrm{n} / \mathrm{m}\right)\end{array}$} & $\frac{0 \%}{2.4 \times 10^{-4}}$ & $\frac{20 \%}{7.8 \times 10^{-4}}$ & $\frac{78 \%}{17.4 \times 10^{-4}}$ \\
\cline { 2 - 4 } 14 & $8.2 \times 10^{-4}$ & $11.7 \times 10^{-4}$ & $24.4 \times 10^{-4}$ \\
20 & $9.2 \times 10^{-4}$ & $17.3 \times 10^{-4}$ & $35.7 .3 \times 10^{-4}$ \\
30 & & & \\
\hline
\end{tabular}




\section{CAGROW}

data are reasonably consistent with a linear relationship between growth and cold work and have been incorporated into the model by assuming a factor of the form $(1+D \times$ cold work). Values of $D$ determined from the data at three different fluences are listed in Table 4.7-3 where

$D=\frac{1}{\text { cold work }}\left[\frac{\text { growth with cold work }}{\text { growth without cold work }}-1\right]$.

The value $D=2.0$, given by the data at the lower fluences, is used in the model, since the measured growth with 0\% cold work (Table 4.7-2) shows gross saturation effects similar to the effects apparent in the high-fluence data of Kreyns. The model thus sacrifices a description of these gross saturation effects in order to fit the cold-work data and the majority of annealed tubing data.

\subsubsection{Evaluation of the Model and Its Uncertainty}

The normalization of all the annealed data to identical conditions (texture coefficient $f=0.05$, temperature at $300^{\circ} \mathrm{C}$ ), as shown in Figure 4.7-5, provides a test of the model. The model predicts irradiation-induced growth reasonably well except for data taken at fluences less than $10^{24} \mathrm{n} / \mathrm{m}^{2}$ and except for greater-than-normal saturation effect seen in some annealed samples. Figure 4.7-1 leads to the same conclusion and also indicates the relative effects of the temperature, texture, and fluence variables as predicted by the model. [The factor $A$ used in Equation (4.7-1) for these curves was derived from a linear least-squares fit to the data of Figure 4.7-5.]

Further refinement of the model to explain the relatively high growth measured at low fluence and to explain the gross saturation effects observed on some samples has not been attempted. In the low-fluence case, there are competing processes that may explain the high values sometimes found; and there is no way to distinguish between them without additional data. These effects are: 


\section{CAGROW}

Table 4.7-3. Determination of cold-work coefficient

\begin{tabular}{cc} 
Fast \\
Fluence \\
$\frac{\left(10^{24} \mathrm{n} / \mathrm{m}\right)}{14}$ & $\frac{D}{1.7}$ \\
14 & 2.0 \\
30 & 3.8 \\
\hline
\end{tabular}


1. Stress relief causing additional length changes (Reference 4.7-11)

2. Variation in fast flux causing different growth rates (Reference 4.7-6)

3. Variation in interstitial migration energy with temperature, causing error in the temperature model (as discussed in Section 4.7.5.2).

Similar problems exist with attempts to model the gross saturation effects observed in some experiments by Kreyns, using tubing, and Fidleris, ${ }^{4.7-8}$ using plate samples. There are sufficient data to indicate clearly that these saturation effects in growth are not simply a function of the fluence or the growth of the strain. However, few data are available to appraise correlations between saturation and other parameters.

An estimate of the uncertainty can be obtained by comparing predictions to the model with data not used in formulating the model. For example, the plate specimen data listed in Table 4.7-2 for $0 \%$ cold work (and $300^{\circ} \mathrm{C}$ ) were not used to formulate the predicted growth of annealed tubes. When these data are compared with the model predictions for annealed growth at $300^{\circ} \mathrm{C}$, a discrepancy of approximately $10 \%$ is found. This $10 \%$ discrepancy is consistent with the scatter of the data at fluences above $10^{24} \mathrm{n} / \mathrm{m}^{2}$ in Figure 4.7-5 and thus is a reasonable estimate of the model's uncertainty in the temperature range from 40 to $360^{\circ} \mathrm{C}$.

The uncertainty for temperatures outside of this range and for fluences less than $10^{24} \mathrm{n} / \mathrm{m}^{2}$ may be substantially greater than $10 \%$. In the low-fluence range, inspection of Figure 4.7-5 suggests uncertainties on the order of $100 \%$. Such large discrepancies may be due to stress relief effects. 4.7-11 For temperatures much outside the range 40 to $360^{\circ} \mathrm{C}$, increased error will be caused by the presence of different modes of interstitial or vacancy migration, causing different rates of zircaloy growth. 


\section{CAGROW}

\subsubsection{References}

4.7-1. R. C. Daniel, "In-Pile Dimensional Changes of Zircaloy-4 Tubing Having Stresses (Light Water Breeder Reactor Development Program)," Nuclear Technology, 14, May 1972, pp 171-186.

4.7-2. W. R. Smalley, Evaluation of Saxton Core III Fuel Materials Performance, WCAP 3385-87, 1974.

4.7-3. J. B. Melehan, Yankee Core Evaluation Program Quarterly Progress Report for the Period Ending September 30, 1969, WCAP-3017-6091, December 1969.

4.7-4. E. T. Laats and P. E. MacDonald, Halden Project Fuel Behavior Test Program - - Experimental Data Report for Test Assemblies IFA-226 and IFA-239, NRC-OECD, March 1975.

4.7-5. P. H. Kreyns, quoted by E. Duncombe et al., Comparisons with Experiment of Calculated Changes and Failure Analysis of Irradiated Bulk Oxide Fuel Test Rods Using the CYGRO-1 Computer Program, WAPD-TM-583, September 1966.

4.7-6. J. E. Harbottle, "The Temperature and Neutron Dose Dependence of Irradiation Growth in Zircaloy-2," Irradiation Effect on Structural Alloys for Nuclear Reactor Applications, ASTM-STP-485, 1970, pp. 287-299.

4.7-7. R. Daniel, In-Pile Dimensional Changes of Zircaloy-4 Tubing Having Low Hoop Stresses (LWBR Development Program), WAPD-TM-973, July 1971.

4.7-8. V. Fidleris, "Summary of Experimental Results on In-Reactor Creep and Irradiation Growth of Zirconium Alloys," Atomic Energy Review, 13, 1975, p. 51 .

4.7-9. S. N. Buckley, "Discussion at Institute of Metals Spring Meeting," Journal of the Institute of Metals, 97, 1969, p. 61.

4.7-10. J. J. Kearns, Thermal Expansion and Preferred Orientation in Zircaloy, WAPD-TM-472, November 1965.

4.7-11. V. Fidleris, "The Effect of Cold-Work and Stress-Relieving on the Irradiation Growth Behavior of Zirconium Alloys," Journal of Nuclear Materials, 46, 1973, pp. 356-360.

4.7-12. R. V. Hesketh, "Non-Linear Growth in Zircaloy-4," Journal of Nuclear Materials, 30, 1969, pp. 217-222. 


\section{CAGROW}

4.7-13. S. H. Bush, Irradiation Effects in Cladding and Structural Materials, New York: Rowman and Littlefield, 1965, p. 143.

4.7-14. A. Seeger and H. Mehren, "Analysis of Self-Diffusion and Equilibrium Measurements," Vacancies and Interstitials Metals, A. Seeger

(ed.), New York: American Elsevien Publishing Co., Inc., 1970, p. 892 . 



\subsection{Creep (CCSTRN, CCSTRS, CABTP, CTP)}

(D. L. Hagrman)

Cladding creep due to coolant pressure during steady-state operation is important in modeling the size of the fuel-cladding gap and initial stored energy at the start of transients. For fuel rods with low internal pressure, the creep may be sufficiently rapid to also affect fuel relocation and effective conductivity of fuel pellets. Subroutines for finding creep strain as a function of stress and stress required to produce a given creep strain are presented in this section. The model used in these subroutines is based primarily on surface displacement data from the HOBBIE-1 test conducted by the U.S. Nuclear Regulatory Commission and the Energieonderzock Centrum Nederl and.

\subsubsection{Summary}

The basic equation used in both the CCSTRN and CCSTRS subroutines is

$\dot{\epsilon}(t)=B A-\int_{0}^{t} B \exp \left[-\left(t-t^{\prime}\right)\left(\frac{\phi}{\Psi}+\frac{1}{\tau}\right)\right] \dot{\epsilon}\left(t^{\prime}\right) \phi t^{\prime}$

where

$\begin{aligned} \dot{\epsilon}(t) & =\text { tangential component of creep strain rate }\left(\mathrm{s}^{-1}\right) \\ \mathrm{t} & =\text { time since creep strain was zero }(\mathrm{s}) \\ \mathrm{t}^{\prime} & =\text { strain at prior time }(\mathrm{s}) \\ \mathrm{B} & =\text { rate constant }\left(\mathrm{s}^{-1}\right), \text { Equation }(4.8-3)\end{aligned}$




\section{CCSTRN, CCSTRS, CABTP, CTP}

A = ultimate strain for infinite correlation (unitless), Equation (4.8-2)

$\phi \quad=\quad$ fast neutron flux $\left[\mathrm{n} /\left(\mathrm{m}^{2} \cdot \mathrm{s}\right)\right], E>1 \mathrm{MeV}$

$\Psi=$ correlation fluence, Equation $(4.8-4)\left(\mathrm{n} / \mathrm{m}^{2}\right)$, E $>1 \mathrm{MeV}$

$\tau=$ zero flux correlation time, Equation $(4.8-5)(\mathrm{s})$

Correlations for the parameters $A$ and $B$ used in the CCSTRN and CCSTRS subroutines are contained in the CABTP and CTP subcodes. These correlations were obtained from out-of-pile creep-strain-versus-time data. CABTP is called from CCSTRN, and CTP is called from CCSTRS. Both CABTP and CTP use the following expressions to calculate the needed parameters:

$$
\begin{aligned}
A & =3.83 \times 10^{-19}|\sigma|^{r} \sigma /|\sigma| \\
B & =4.69 \times 10^{-6}|\sigma|^{r} \exp (-25100 / T), \text { for } T \geq 615 \mathrm{~K} \\
& =1.9519804 \times 10^{-16}|\sigma|^{r} \exp (-10400 / T \sigma), \text { for } T<615 \mathrm{~K}
\end{aligned}
$$

where

$$
\begin{aligned}
\sigma & =\text { tangential component of stress }(\mathrm{Pa}) \\
T & =\begin{array}{l}
\text { temperature }(\mathrm{K}) \text { (input temperatures are limited to the range } \\
450 \text { to } 750 \mathrm{~K} \text { ) }
\end{array}
\end{aligned}
$$

$r=2.0$ for stress between -0.2 and -0.75 times the strength coefficient of cladding

$=0.5$ for stress between 0 and -0.2 times the strength coefficient of cladding 
$=25.0$ for stress less than -0.75 times the strength coefficient of cladding. The strength coefficient is approximated by the linear expression $1.5 \times 10^{9}$ - $1.5 \times 10^{6} \mathrm{~T}$, and the constants in Equation (4.8-3) are modified when stress is outside the range -0.2 to -0.75 times the strength coefficient to guarantee continuity at the boundaries of this range.

Expressions for the correlation fluence, $\Psi$, and zero flux correlation time, $\tau$, were obtained from the slope of secondary creep rates versus temperature under tensile stress. These expressions are

$$
\begin{aligned}
\Psi & =2.9 \times 10^{6} \exp (25100 / T), \text { for } T \geq 615 \mathrm{~K} \\
& =6.967795 \times 10^{16} \exp (10400 / \mathrm{T}), \text { for } T<615 \mathrm{~K} \\
\tau & =8.6 \times 10^{-11} \exp (25100 / \mathrm{T}), \text { for } T \geq 615 \mathrm{~K} \\
& =2.0663116 \exp (10400 / \mathrm{T}), \text { for } T<615 \mathrm{~K}
\end{aligned}
$$

The CCSTRN subroutine calculates the tangential component of cladding creep strain at the end of a time step with constant cladding temperature, flux, and stress. For time-step intervals less than a time to steady state, the infinite-correlation approximation ${ }^{\mathrm{a}}$ is used to integrate Equation (4.8-1). The resultant expression for creep strain is

$$
\epsilon_{\text {final }}=\left[A-\epsilon_{\text {boundary }}\right][1-\exp (B \Delta t)]+\epsilon_{\text {initia }}
$$

where

a. The exponent in Equation (4.8-1) is approximated by a one. 


\section{CCSTRN, CCSTRS, CABTP, CTP}

$\begin{array}{ll}\epsilon_{\text {final }}= & \begin{array}{l}\text { tangential component of creep strain at the end of } \\ \text { the time step (unitless) }\end{array} \\ \epsilon_{\text {initial }}= & \begin{array}{l}\text { tangential component of creep strain at the start } \\ \text { of the time step (unitless) }\end{array} \\ \epsilon_{\text {boundary } \quad} \quad \begin{array}{l}\text { a boundary condition parameter used to force the } \\ \text { creep rate to be continuous at the time step } \\ \text { boundary when temperature and stress do not change } \\ \text { (unitless); this parameter is zero for the first }\end{array} \\ \text { time step and is determined by Equations (4.8-29) } \\ \text { and (4.8-30) for subsequent time steps }\end{array}$

For time-step durations longer than the time to steady state, the steady-state approximation $[\epsilon(t) \approx 0]$ is used to integrate Equation $(4.8-1)$. The resultant expression for creep strain is

$\epsilon_{\text {final }}=\left(A-\epsilon_{\text {boundary }}\right)\left[1-\exp \left(-B \Delta t_{S S}\right)\right]+\frac{B A\left(\Delta t-\Delta t_{S S}\right)}{1+\frac{\phi}{\Psi}+\frac{1}{\tau}}+\epsilon_{\text {initia }]}(4.8-7)$

where $\Delta t_{s s}$ is the time to steady state $(s)$. The time to steady state is defined to be the time when creep strain rates given by Equations (4.8-6) and $(4.8-7)$ are equal

$\Delta t_{S S}=-\frac{1}{B} \ln \left[\frac{A}{1+\frac{B}{\frac{\phi}{\Psi}+\frac{1}{\tau}}} \frac{1}{\left(A-\epsilon_{\text {boundary }}\right)}\right]$

or 


\section{CCSTRN, CCSTRS, CABTP, CTP}

0 if the argument of the $\log$ term is outside the range $0<$ argument $<1$.

Subroutine CCSTRS uses an interaction technique and trial assumptions to solve Equation (4.8-6) or (4.8-7) for stress when $\epsilon_{\text {final }}$, $\epsilon_{\text {initial }}$, and $\Delta t$ are known. The procedure begins by solving Equation (4.8-6) with the implied assumption that $\Delta t$ is $\left\langle\Delta t_{s s}\right.$. In this case, the possible range of stresses is bounded and the function is monotonic. The range is cut in half in each of several iterations by testing stress at the midpoint of the possible range. If substitution of the trial solution into Equation (4.8-8) yields a $\Delta t_{s s}$ that is $>\Delta t$, the trial solution is adopted.

A second trial solution is obtained by solving Equation (4.8-7) for $|\sigma|^{r}$ with the assumption that $\Delta t_{s s}$ is zero. If this trial solution yields $\Delta t_{s s}=0$ in Equation (4.8-8), it is adopted.

If neither of the two trial solutions are adopted, the technique used in CCSTRS employs the observation that the initial trial solution provides a maximum $|\sigma|^{r}$ and the second trial solution provides a minimum initial slope. The implied range of possible stress is then cut in half in each of several iterations by testing in Equations (4.8-8) and (4.8-7) with stress at the midpoint of the range.

Uncertainty estimates for creep strain and stress are provided by CCSTRN and CCSTRS. Both estimates are based on the observation that the onty creep data with compressive stresses are at a temperature of $644 \mathrm{~K}$ and stresses in the range -120 to $-140 \mathrm{MPa}$. The expression used to estimate the uncertainty of the strain calculated in CCSTRN is

$$
\begin{aligned}
& f_{\epsilon^{+}}=1+0.3\left(1+2\left|\frac{\sigma+130 \times 10^{6}}{130 \times 10^{6}}\right|+5\left|\frac{T-644}{644}\right|\right) \\
& f_{\epsilon^{-}}=0.4 /\left(1+2\left|\frac{\sigma+130 \times 10^{6}}{130 \times 10^{6}}\right|+5\left|\frac{T-644}{644}\right|\right)
\end{aligned}
$$




\section{CCSTRN, CCSTRS, CABTP, CTP}

where $f_{\epsilon} \pm$ are the upper and lower uncertainty estimates of the calculated creep strain increment magnitude.

The expression used to estimate the uncertainty of stress calculated in CCSTRS is

$$
\begin{aligned}
& f_{\sigma^{+}}=1+0.075\left(1+2\left|\frac{\sigma+130 \times 10^{6}}{130 \times 10^{6}}\right|+5\left|\frac{T-644}{644}\right|\right) \\
& f_{\sigma^{-}}=0.85 /\left(1+2\left|\frac{\sigma+130 \times 10^{6}}{130 \times 10^{6}}\right|+5\left|\frac{T-644}{644}\right|\right)
\end{aligned}
$$

where $f_{\sigma \pm}$ are the upper and lower uncertainty estimates of the calculated stress magnitude expressed as a function of the calculated stress magnitude.

The following subsections discuss available data and development of the model.

\subsubsection{Survey of Available Data}

Data that measure creep under tensile stress are being supplemented by data for creep with compressive stress in very limited ranges of temperature and stress. The available theories and data for creep under compressive stress are surveyed in this section. A bibliography of extensive literature on tensile creep experiments is provided in Section 4.8.6.

Currently, there are no theories directed specifically at compressive stress; but Dollins and Nichols, ${ }^{4.8-1}$ Piercy, 4.8-2 MacEwen, ${ }^{4.8-3}$ and Nichols $s^{4.8-4,4.8-5}$ have discussed similar physical models that explain the general features of in-pile creep of cladding under tensile stress. For the temperature range 523 to $623 \mathrm{~K}$, these authors believe the controlling mechanism for in-pile creep at stresses $<70$ to $100 \mathrm{MPa}$ is the preferred 


\section{CCSTRN， CCSTRS， CABTP， CTP}

alignment of irradiation-induced dislocation loops during nucleation. At higher stresses, the effective stress at dislocations is thought to be sufficiently large to allow dislocation glide between the neutron-produced depleted zones. The creep rate would then be controlled by combined rates of dislocation glide between depleted zones and climb out of these zones. Although some of Nichol's ideas have been challenged, 4.8-5, 4.8-6, 4.8-7 the predicted linear stress dependence of strain rate at low stress is supported by several authors $;^{4.8-8,4.8-9}$ and his prediction that the strain rate at high stress is proportional to approximately the one-hundredth power of stress in the 523- to 623-K temperature range is consistent with the MATPRO models for cladding plastic deformation at high stress. (see Section 4.9) Unfortunately, Nichols predicts a complex relation between strain rate and stress for intermediate stress. The dependence of strain rate on stress is expected to vary from the tenth power of stress to the first power and then to the fourth power as stress increases. The physical model proposed by Nichols has been consulted but not used directly because the cost associated with the use of such a detailed model is not justified until compressive creep data confirm the model.

A similar, but less physically founded, stress dependence is proposed by Fidleris in his review of experimental data. ${ }^{4.8-9}$ He reported that creep rate varies linearly with stress at temperatures around $570 \mathrm{~K}$ and stresses less than one-third the yield stress. With increasing stress, the strain rate is reported to be proportional to higher powers of stress, reaching a power of 100 at stresses of $600 \mathrm{MPa}$. The model for creepdown uses only the general features of the stress dependence reported by Fidleris because insufficient creepdown data exist to support detailed modeling.

The data referenced by Fidleris show that the in-reactor creep rate depends on material, flux temperature, and direction of testing, as well as stress. At temperatures below half the melting temperature $(1050 \mathrm{~K})$ and stresses lower than the yield stress, the in-reactor creep reaches a constant rate, while the out-of-reactor creep rate becomes negligibly small 


\section{CCSTRN, CCSTRS, CABTP, CTP}

with time. The steady-state creep rate is stated to be independent of test history or strain, at least for fast neutron fluences below $3 \times 10^{24} \mathrm{n} / \mathrm{m}^{2}(\mathrm{E}>1 \mathrm{MeV})$.

Below $450 \mathrm{~K}$, temperature is reported to have little effect and, for stresses below the yield stress, the strain is $<0.001$. The out-of-reactor creep data of Fidleris can be described by

$\epsilon=A \log t+B$

where

$$
\begin{aligned}
& \epsilon=\text { strain } \\
& t=\operatorname{time}(s) \\
& A, B=\text { constants. }
\end{aligned}
$$

In the range 450 to $800 \mathrm{~K}$, Fidleris reports that the out-of-reactor creep strain is often represented by equations of the type

$\epsilon=A t^{m}+B$

where $\epsilon, \mathrm{t}, \mathrm{A}$, and $\mathrm{B}$ were defined in conjunction with Equation (4.8-13) and $m$ is a constant between zero and one. Recovery of some of the strain is possible in this temperature range, and dynamic strain aging 4.8-10 frequently causes anomalously low creep strains and rates.

Equations (4.8-13) and (4.8-14) and other conclusions in Fidleris' review are based on his own extensive data for uniaxial, tensile creep of zirconium alloys, both in and out of reactor. ${ }^{4.8-11}$ From these data, Fidleris concluded that the in-reactor creep is approximately proportional to the fast neutron flux for all temperatures. Other investigators treat 


\section{CCSTRN, CCSTRS, CABTP, CTP}

the effect of fast neutron flux on creep in different ways. 4.8-12 A1 though most authors have treated in-reactor creep as the sum of the out-of-reactor creep and an additional irradiation-induced creep proportional to fast neutron flux to some power, a, there is disagreement about the magnitude of the exponent, a. Ross-Ross and Hunt ${ }^{4.8-8}$ report that creep rate is directly proportional to the fast flux, Wood $4.8-13,4.8-14$ uses $\mathrm{a}=0.85, \mathrm{Kohn}^{4.8-15}$ uses $\mathrm{a}=0.65$, and Gilbert ${ }^{4.8-16}$ finds $a=0.5$ for yielding creep at moderate stress levels. MacEwen 4.8-3 and Nichols $\mathrm{s}^{4-4}$ have resolved this apparent conflict by suggesting that the flux exponent can have values from 0 (Nichols) or 0.5 (MacEwen) to 1.0, depending on the flux and temperature.

The expressions for calculating creepdown models the effect of fast neutron flux on creep with an expression that is proportional to fast neutron flux for large fluxes but less dependent on flux for smaller fluxes. Equation (4.8-14), Fidleris' equation for creep strain versus time with tensile stress, has not been used because it is inconsistent with data obtained from tests with compressive stress.

The effects of grain size annealing and texture are addressed by several authors. Fidleris ${ }^{4.8}$ finds that the zircaloy-2 creep rate increases continuously with grain size at $573 \mathrm{~K}$. However, within the limited range of grain sizes formed in his recrystallized zircaloy-2 (6 to $20 \mu \mathrm{m})$, very $1 \mathrm{ittl}$ e variation is reported. Stehle $\mathrm{e}^{4.8-17}$ reports creep strains in cold-worked material that are more than twice as large as the creep strains in recrystallized cladding. He also reports that the short-time creep strain of stress-relieved tubes is larger than that of recrystallized tubes but that plots of creep strain versus time for stress-relieved and recrystallized cladding intersect at about 6,000 h. Kohn 4.8-15 reported that the biaxial creep rate of $Z r-2.5 \mathrm{Nb}$ fuel cladding is about 10 times higher than that of pressure-tube material under similar conditions. He states that texture differences between the materials and the overaged precipitate structure in the as-manufactured cladding can 


\section{CCSTRN， CCSTRS， CABTP， CTP}

explain the difference in creep rates. The importance of texture is disputed by Stehle, 4.8-17 who reported that mechanical anisotropy (especially in longtime creep) is surprisingly low compared to the anisotropy in short-time creep at room temperature. The effects of grain size, annealing, and texture have not been considered in the creepdown model because an explicit model for these effects on creepdown was premature at the time of model development.

Theories surveyed above may be misleading when applied to compressive creep because they are based primarily on tensile stress data.

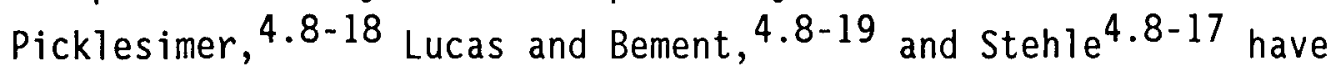
pointed out that deformation with compressive stress differs from tensile deformation. Stehle has obtained data showing that the magnitude of creep strain of tubes under external pressure can be as small as half the creep strain of tubes under internal pressure.

The biaxial compressive stress data available include out-of-reactor measurements at three stresses and one temperature. Results from a single in-reactor experiment are also available. All experiments except one were conducted by Hobson using tubes from a shipment of typical pressurized water reactor cladding purchased specifically for use in fuel cladding research programs sponsored by the NRC. 4.8-20

The only biaxial compressive strain data from a different lot of cladding were reported by Stehle. 4.8-17 His measurements of the tangential creep as a function of time for standard stress-relieved tubing fabricated according to $\mathrm{KwU}$ (Kraftwerke Union) specifications are reproduced in Figure 4.8-1. The tangential stress in this test was $140 \mathrm{MPa}$, and the temperature was $643 \mathrm{~K}$. The magnitudes of the measured creep strains are somewhat smaller than the out-of-pile strains computed from Hobson's out-of-pile data at the same temperature but are within the range of the scatter reported by Stehle for cladding with varying cold-work and stress-relief annealing histories. Since the details of the stress-relief 


\section{CCSTRN, CCSTRS, CABTP, CTP}

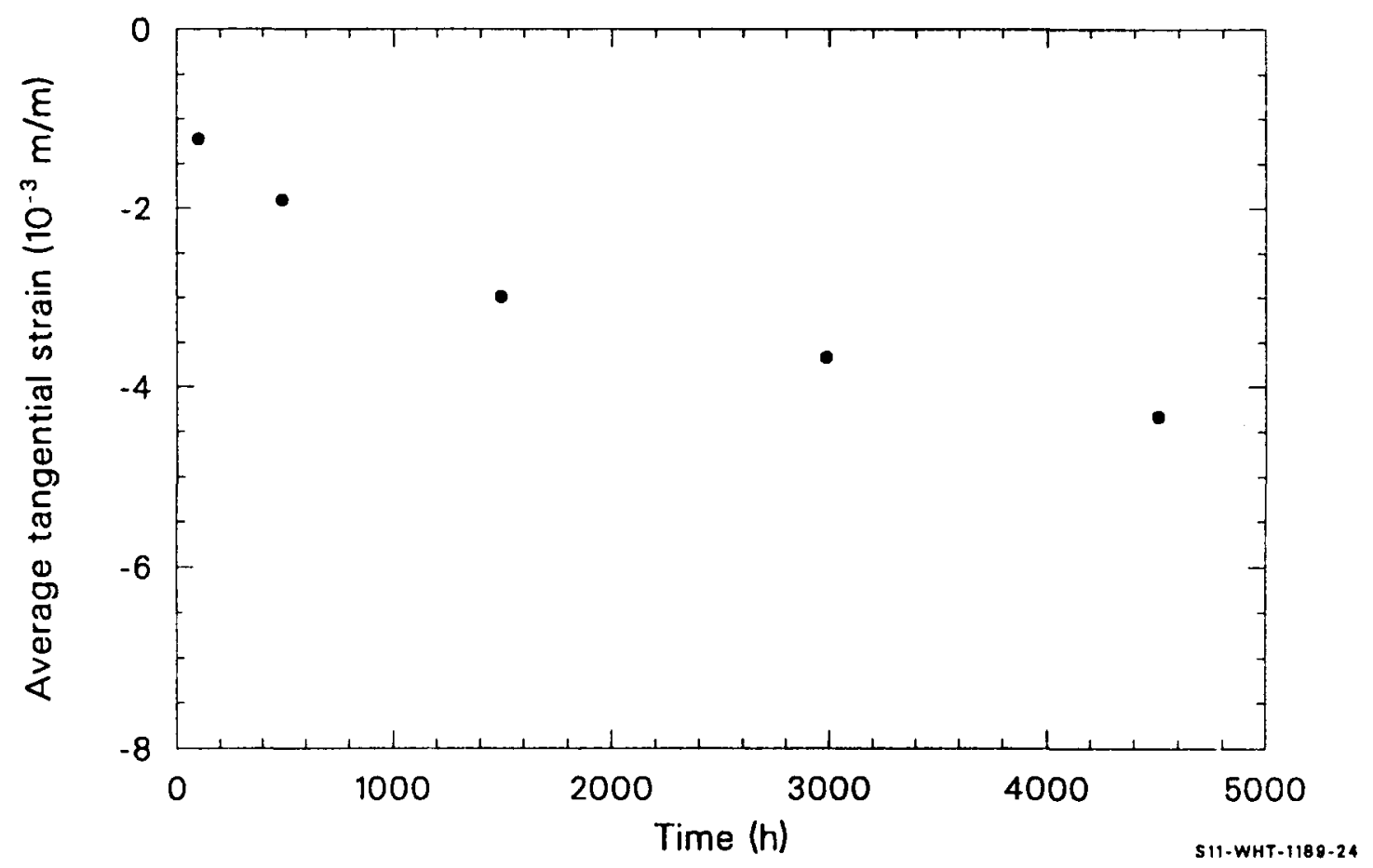

Figure 4.8-1. Average tangential creep strain as a function of time at $140 \mathrm{MPa}$ and $643 \mathrm{~K}$ reported by Stehle. 


\section{CCSTRN， CCSTRS， CABTP， CTP}

anneal on the lot of cladding used by Stehle are not reported, the data will be used only to assess the uncertainty of the creepdown model.

The data reported by Hobson 4.8-21 to 4.8-24 are radial displacements of the cladding surface at various azimuthal angles and axial positions ( $6.34 \mathrm{~mm}$ apart). The 20 probes used to measure the displacement were arranged in a double helix pattern over a 50.8-mm length of cladding, as shown by probe number in Table 4.8-1. This table is arranged so that the location of the probes may be visualized by thinking of the cladding surface as split along the cylinder axis and rolled out in the plane of the page. Hobson has pointed out ${ }^{4.8-23}$ that the exact shape of the cladding surface cannot be determined with point-by-point data from a few radial probes and that the exact stress state at any point in the sample is related to the geometry of the sample. In spite of these complications, the data can be analyzed to obtain the average tangential strain, as discussed in the next section of this report. Hobson data play a dominant role in the development of the creepdown model because the cladding is typical of LWR cladding, the stress is compressive, the cladding displacement is reported as a function of time at 2 -h intervals, and the temperature is typical of the cladding temperatures predicted by the FRAPCON-2 code. The only atypical feature of the data is the magnitude of the stresses employed by Hobson, 125 and 135 $\mathrm{MPa}$. These stresses are characteristic of low-pressure rods, so extrapolation to smaller stress magnitudes is necessary to model current fuel rod prepressurization levels.

\subsubsection{Mode1 Development}

It has been concluded that the most relevant data for modeling cladding creepdown under the compressive stress of steady-state LWR reactor conditions are the data of Hobson. Extensive theory and tensile creep data are useful only to provide a tentative extension of the model to stresses and temperatures where no creepdown data are available. 
CCSTRN, CCSTRS, CABTP, CTP

Table 4.8-1. Surface coordinates of probes which measure radial displacement

\begin{tabular}{|c|c|c|c|c|c|c|c|c|}
\hline \multirow{2}{*}{$\begin{array}{c}\text { Axial Position } \\
(\mathrm{mm})\end{array}$} & \multicolumn{8}{|c|}{$\begin{array}{c}\text { Azimuthal Angle } \\
\text { (degrees) }\end{array}$} \\
\hline & $\underline{0}$ & $\underline{45}$ & $\underline{90}$ & $\underline{135}$ & $\underline{180}$ & $\underline{225}$ & 270 & $\underline{315}$ \\
\hline 0.00 & 1 & -- & -- & -- & 13 & -- & -- & -. \\
\hline 6.35 & - & 4 & -- & -- & -- & 16 & -- & $\cdots$ \\
\hline 12.70 & -- & -- & 7 & -- & -- & -- & 19 & -- \\
\hline 19.05 & -- & -- & -- & 10 & -- & -- & -- & 22 \\
\hline 25.40 & 2 & -- & 8 & -- & 14 & -- & 20 & -- \\
\hline 31.75 & - & 5 & -- & -- & -- & 17 & -- & -- \\
\hline 38.10 & - & -- & 9 & -- & - & -- & 21 & -- \\
\hline 44.45 & -- & -- & -- & 11 & -- & -. & -- & 23 \\
\hline 50.80 & 3 & -- & -- & - & 15 & -. & -- & $\therefore$ \\
\hline
\end{tabular}




\section{CCSTRN, CCSTRS， CABTP， CTP}

The first step in the analysis of Hobson's data was to estimate the average tangential strain from radial displacements measured by probes at the locations shown in Table 4.8-1. This was done by inspecting plots of the radial displacement measured for each test. Table 4.8-2 and Figure 4.8-2 are examples of the results. The table was constructed from Hobson's data for Test 269-4 (14.48 $\mathrm{MPa}$ pressure) at $200 \mathrm{~h}$, and the figure is a polar plot of the radial displacement as a function of the azimuthal angle of the probe. The plot exaggerates the radial displacement by a factor of ten compared to the scale of the circle, which represents zero displacement. From an inspection of the figure, it can be seen that the radial displacements at $200 \mathrm{~h}$ in Test 269-4 are consistent with the assumption that the cladding surface was an ellipse, with major axis between 0 and 45 degrees and the center displaced slightly toward the 180- to 270-degree quadrant. There is some variation with axial position, as shown by the scatter in the displacements with common azimuthal angles and different axial positions.

The elliptical shape and gradual axial variations are also consistent with general descriptions of cladding surfaces after creepdown given by Stehle $e^{4.8-25}$ and Bauer. ${ }^{4.8-26}$ on the basis of several plots like Figure 4.8-2 and the general descriptions just mentioned, the author has concluded that (a) an ellipse is a reasonable approximation for the cladding surface at any given height prior to extensive fuel-cladding interaction and (b) the major and minor axes (length or orientation or both) vary slowly with axial position.

The assumption that the cladding surface at any axial position is an ellipse allows calculation of the average tangential strain, as outlined in the six steps below.

1. The circumference of the elliptical surface was related to the major and minor semi-axis lengths with the approximate expression 
CCSTRN， CCSTRS， CABTP， CTP

Table 4.8-2. Radiąl displacements At $200 \mathrm{~h}$ in Hobson's Test 269-4
$\left(10^{-3} \mathrm{~mm}\right)$

\begin{tabular}{|c|c|c|c|c|c|c|c|c|}
\hline \multirow{2}{*}{$\begin{array}{c}\text { Axial Position } \\
(\mathrm{mm}) \\
\end{array}$} & \multicolumn{8}{|c|}{$\begin{array}{c}\text { Azimuthal Angle } \\
\text { (degrees) }\end{array}$} \\
\hline & $\underline{0}$ & $\underline{45}$ & $\underline{90}$ & $\underline{135}$ & $\underline{180}$ & $\underline{225}$ & $\underline{270}$ & $\underline{315}$ \\
\hline 0.00 & 4 & -- & -. & -- & 12 & -- & -. & -- \\
\hline 6.35 & -- & 6 & -- & - & - & 12 & -- & -- \\
\hline 12.70 & -. & -. & 48 & - & - & - & 12 & - - \\
\hline 19.05 & -. & -- & -. & -19 & - & -- & -- & -29 \\
\hline 25.40 & 31 & -. & -63 & -- & 40 & -. & -58 & -- \\
\hline 31.75 & - & 3 & -- & -. & - & 31 & -- & - - \\
\hline 38.10 & - & -- & -77 & - & -- & -- & -60 & - - \\
\hline 44.45 & - & - - & -- & -36 & -- & -. & -- & -38 \\
\hline 50.80 & 31 & -- & -- & -- & 32 & -- & - - & - - \\
\hline
\end{tabular}
a. $14.88-\mathrm{MPa}$ pressure differential and $0.2127-\mathrm{mm}$ pellet-cladding
gap. 
CCSTRN, CCSTRS, CABTP, CTP

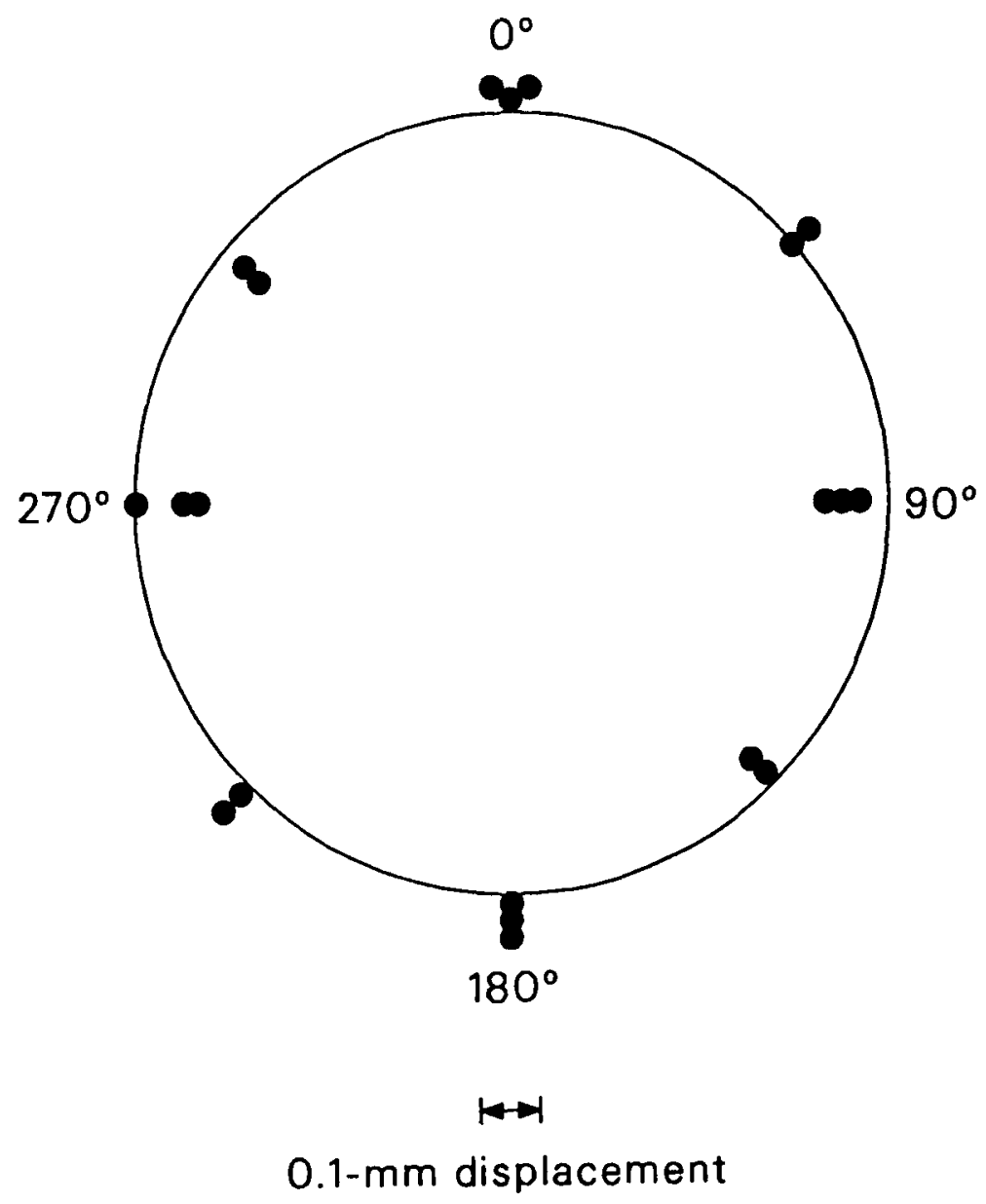

S11-WHT-1089-25

Figure 4.8-2. Radial displacement of cladding surface at $200 \mathrm{~h}$ in Hobson's test 269-4. 


\section{CCSTRN， CCSTRS， CABTP， CTP}

$c=2 \pi\left[\left(a^{2}+b^{2}\right) / 2\right]^{1 / 2}$

where

$$
\begin{aligned}
& c=\text { circumference }(m) \\
& a, b=\text { semi-axis lengths }(m) .
\end{aligned}
$$

2. The average tangential strain was defined as

$$
\epsilon_{\theta}=\int_{\text {circumference }}^{\mathrm{ds} / \mathrm{s}} \simeq \frac{\mathrm{c}_{\text {final }}-\mathrm{c}_{\text {initial }}}{\mathrm{c}_{\text {initial }}}
$$

where

$$
\begin{array}{ll}
\epsilon_{\theta} & =\text { average tangential strain (unitless) } \\
s & =\text { arc length } \\
c_{\text {initial }} & =\text { initial circumference }(m) \\
c_{\text {final }} & =\text { final circumference }(m) .
\end{array}
$$

3. Equations (4.8-15) and (4.8-16) were combined to obtain

$$
\epsilon_{\theta} \simeq\left(\frac{a_{\text {final }}^{2}+b_{\text {final }}^{2}}{a_{\text {initial }}^{2}+b_{\text {initial }}^{2}}\right)^{1 / 2}-1 .
$$

4. $a_{\text {initial }}$ and $b_{\text {initial }}$ were assumed equal to $r_{0}$, and $a_{\text {final }}$ and $b_{\text {final }}$ were set equal to the initial values plus $\Delta a$ and $\Delta b$. 


\section{CCSTRN, CCSTRS, CABTP, CTP}

5. A Taylor series expansion to order $\Delta a / r_{0}$ and $\Delta b / r_{0}$ was used with Equation (4.8-17) and Step 4 above to find

$$
\epsilon_{\theta} \equiv \frac{1}{2}\left(\Delta a+\Delta b / r_{0}\right)
$$

where

$$
\begin{aligned}
& r_{0}=\quad \begin{array}{l}
\text { initial radius of the outside (circular) } \\
\text { surface of the cladding }(m)
\end{array} \\
& \Delta a, \Delta b=\begin{array}{l}
\text { change of the major and minor } \\
\text { semi-axes lengths }(m) .
\end{array}
\end{aligned}
$$

6. Measurements of the radial displacements at one axial position $(25.4 \mathrm{~mm})$ and azimuthal angles of $0,90,180$, and 270 degrees are available from Hobson's data. If these four measurements happen to occur along the major and minor axes of the ellipse, Equation (4.8-18) is sufficient to convert the data to an expression for the average circumferential component of the strain. When the radial displacements at $25.4 \mathrm{~mm}$ are not measured along the major and minor axes of the ellipse, the derivation is more complex; but the result (to order $\Delta a / r_{r}$ in the Taylor series expansion) is an equation of the same form as Equation (4.8-18), with $\Delta a$ and $\Delta b$ replaced by the average radial displacements along any two axes at right angles to each other and at any angle to the major and minor axes of the ellipse. The expression then becomes

$$
\epsilon_{\theta} \equiv \frac{1}{2}\left(\Delta a^{\prime}+\Delta b^{\prime} / r_{0}\right)
$$

where $\Delta a^{\prime}$ and $\Delta b^{\prime}$ are the change of the cladding radius measured along any mutually perpendicular axes at one axial position (m). 
The second part of the analysis of Hobson's data was to describe the average tangential strains obtained from the data and Equation (4.8-19). Figure 4.8-3 displays the calculated average tangential strain from two out-of-pile tests at $15.86-\mathrm{MPa}$ differential pressure. During the first $600 \mathrm{~h}$, the strains are remarkably consistent. During the last $400 \mathrm{~h}$ of the tests, the strain in Test 269-27 was noticeably larger than that of Test 269-8. Test 269-27 had a large simulated axial gap centered about the axial position of the four probes used to determine the strain. Test 269-8 had only a small axial gap. The difference in strain at long times is probably due to the effect of the different contact times with the simulated fuel.

Figure 4.8-4 illustrates the strain versus time results obtained from the 14.48-MPa out-of-pile test. The magnitude of the strain at any time is significantly smaller than the strains obtained with the $15.86-\mathrm{MPa}$ tests.

In an effort to describe the strain-versus-time data shown in Figures 4.8-3 and 4.8-4, the constants in Equations (4.8-13) and (4.8-14) for tensile creep were fit to selected strain-time pairs. Each equation was then tested by extrapolating to longer or shorter times and comparing the predicted strains to strain-time pairs not used in determining the constants $A$ and $B$. Neither equation passed this test. Equation (4.8-13) consistently had too much curvature, ${ }^{a}$ and Equation (4.8-14) had too little curvature.

The equation finally adopted for short-time out-of-pile tests was

$$
\epsilon_{\theta}=A[1-\exp (-B t)]
$$

where

a. $\left(d^{2} \epsilon_{\theta}\right) / d t^{2}$ too large. 
CCSTRN， CCSTRS， CABTP， CTP

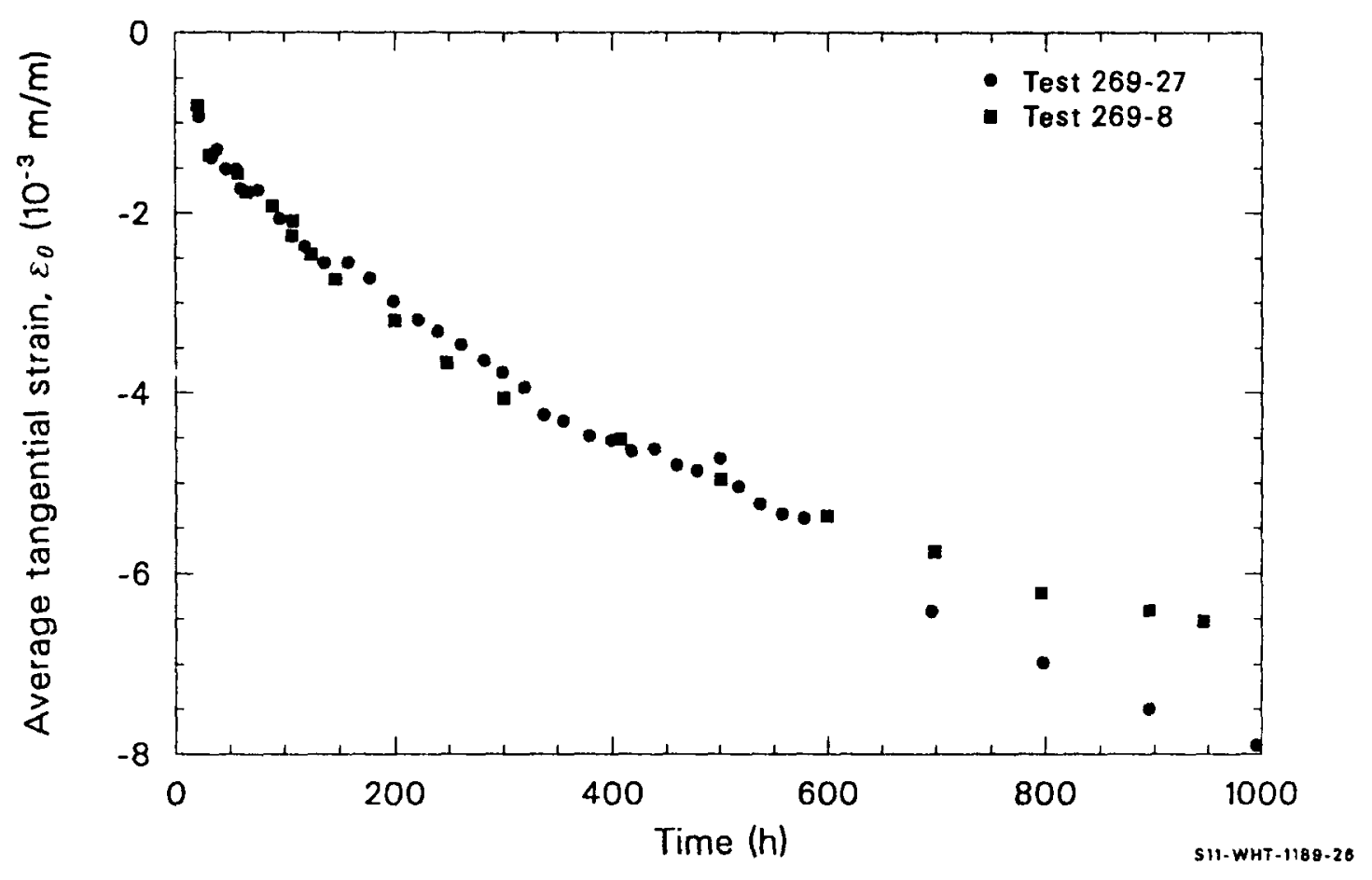

Figure 4.8-3. Average tangential creep strain as a function of time at $15.86-\mathrm{MPa}$ differential pressure. 
CCSTRN, CCSTRS, CABTP, CTP

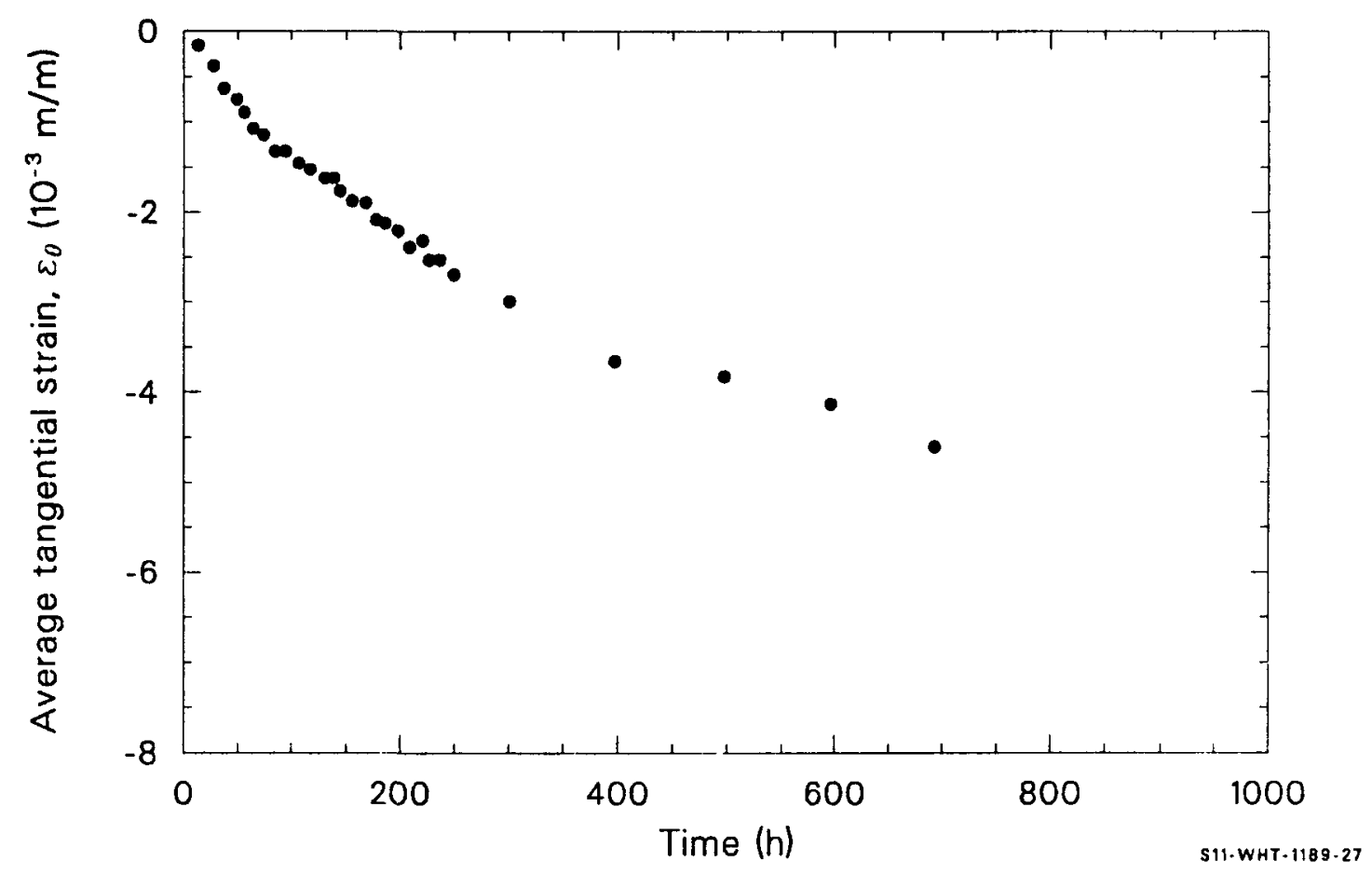

Figure 4.8-4. Average tangential creep strain as a function of time at 14.48-MPa differential pressure. 


\section{CCSTRN, CCSTRS, CABTP, CTP}

$$
\begin{aligned}
& \epsilon_{\theta}=\text { average tangential strain }(\mathrm{m} / \mathrm{m}) \\
& t=\text { time }(\mathrm{s}) \\
& A, B=\text { functions of stress and temperature. }
\end{aligned}
$$

For the $14.48-\mathrm{MPa}$ test, $A=-5.32 \times 10^{-3}$ and $B=7.64 \times 10^{-7} \mathrm{~s}$. For the $15.86-\mathrm{MPa}$ tests, $A=-6.32 \times 10^{-3}$ and $B=9.17 \times 10^{-7} \mathrm{~s}$. The values of $A$ and $B$ for each stress were determined with a two-step process:

1. A value of $B$ was guessed and one strain-time pair $\left(\epsilon_{0}, t_{0}\right)$ was selected as a reference. Other strain-time pairs $\left(\epsilon_{j}, t_{j}\right)$ were then used to find an improved guess for $B$ according to the relation

$$
B_{j}=\ln \left\{1-\frac{\epsilon_{j}\left[1-\exp \left(-B_{\text {guessed }} t_{0}\right)\right]}{\epsilon_{0}}\right\} \text {. }
$$

2. Once a single value of $B$ that worked for several strain-time pairs was determined, a least-squares fit was carried out to determine A.

The two sets of values for $A$ and $B$ were used to estimate the effect of change in stress. $A$ and $B$ were assumed to be dependent on stress to some power, $n$; and $n$ was calculated from $A$ and $B$ at the two stresses where they are known

$$
\begin{aligned}
& n=\frac{\ln (A \text { at } 15.86 \mathrm{MPa} / \mathrm{A} \text { at } 14.48 \mathrm{MPa})}{\ln (15.86 / 14.48)}=1.89 \\
& n=\frac{\ln (\mathrm{B} \text { at } 15.86 \mathrm{MPa} / \mathrm{B} \text { at } 14.48 \mathrm{MPa})}{\ln (15.86 / 14.48)}=2.01 .
\end{aligned}
$$


In view of the limited number of tests, both values of $n$ were assumed to be 2. This result implies a strain rate proportional to the fourth power of stress, ${ }^{a}$ a conclusion that agrees with one of the intermediate stress regions suggested by Dollins and Nichols ${ }^{4.8-1}$ in Section 4.8.2.

The resultant expressions for the stress-dependence of $A$ and $B$ near $125 \mathrm{MPa}$ and at a temperature of $644 \mathrm{~K}$ are

$$
\begin{aligned}
& A=-5.32 \times 10^{-3}\left\{0^{2} /\left[\left(1.245 \times 10^{8}\right)^{2}\right]\right\} \\
& B=7.64 \times 10^{-7}\left\{0^{2} /\left[\left(1.245 \times 10^{8}\right)^{2}\right]\right\}
\end{aligned}
$$

where $\sigma$ is the tangential component of stress.

The data from Hobson's in-reactor experiment were converted to average tangential strains with the same technique used for the out-of-reactor experiment. Figure 4.8-5 displays the resultant average tangential strains as a function of time, along with the predicted out-of-reactor average strain from Equations $(4.8-20),(4.8-24)$, and (4.8-25). The temperature during the in-reactor experiment was approximately the same as the temperature of Hobson's out-of-reactor experiments, but pressure varied from 13 to $13.5 \mathrm{MPa}$, so the tangential stress $(-116 \mathrm{MPa})$ was smaller in magnitude than stresses of the out-of-pile experiments.

Interpretation of the in-reactor data is complicated by absence of data for the first $80 \mathrm{~h}$, by reactor shutdown from $540 \mathrm{~h}$ to $610 \mathrm{~h}$, and by the apparent positive average tangential strains from 80 to $200 \mathrm{~h}$. Hobson $4.8-24$ has discussed the apparent positive average strains during the early part of the experiment and suggests that the positive readings come from the effects of a reactor scram at $50 \mathrm{~h}$ on the experiment electronics.

a. The time derivative of Equation (4.8-20) is proportional to $A \times B$. 
CCSTRN, CCSTRS, CABTP, CTP

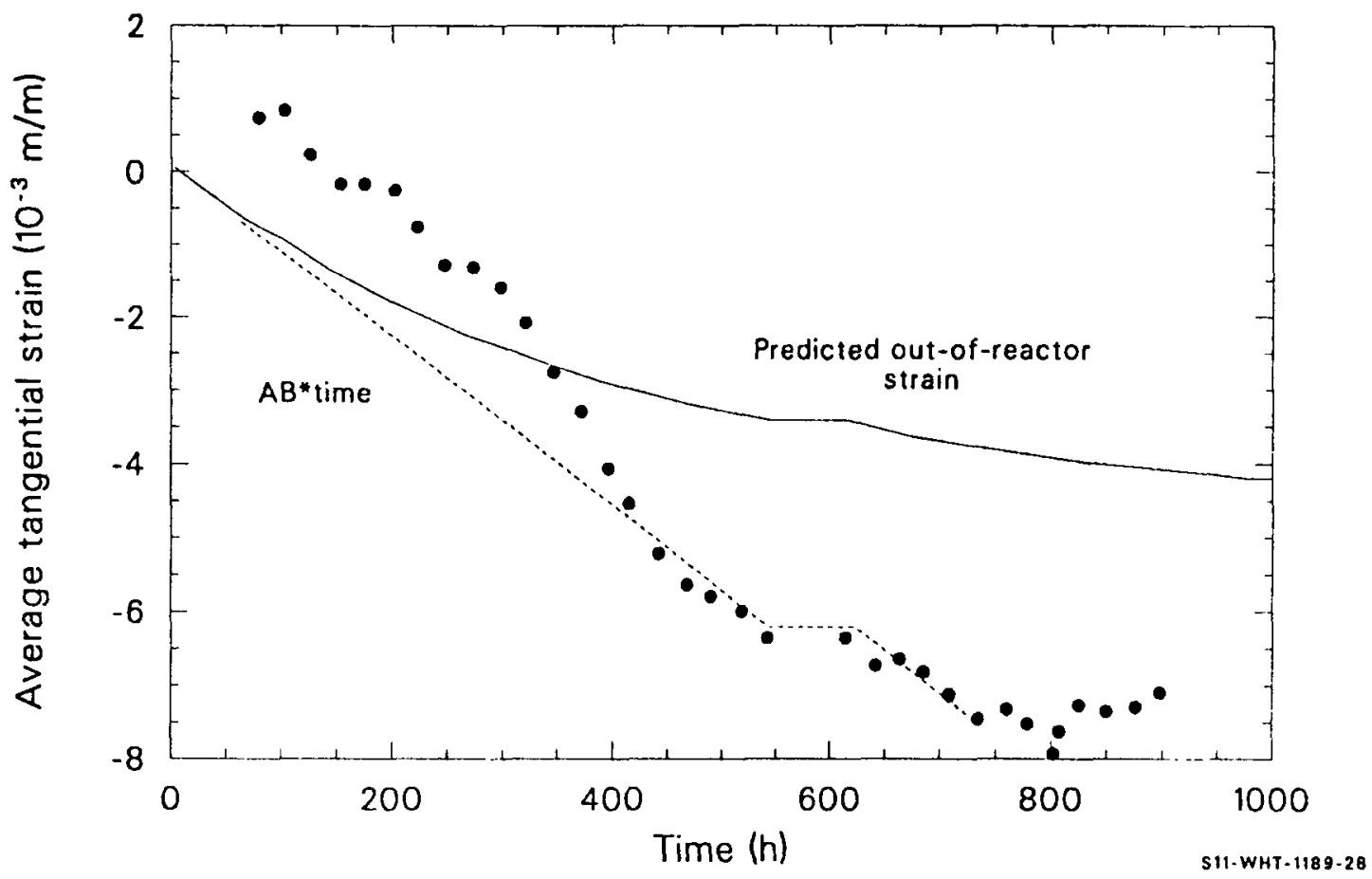

Figure 4.8-5. Average tangential creep strain as a function of time from Hobson's in-reactor experiment at $13-$ to $13.5-\mathrm{MPa}$ differential pressure and $5.4 \times 10^{17}$ fast neutrons $\left(\mathrm{m}^{2} / \mathrm{s}\right)$. 


\section{CCSTRN， CCSTRS， CABTP， CTP}

The in-reactor strains shown in Figure 4.8-5 are consistent with a simple relation between the out-of-reactor strains and the in-reactor strains [for fast neutron flux $\approx 5.4 \times 10^{17} \mathrm{n} / \mathrm{m}^{2} \cdot \mathrm{s}$ ). The dashed line of the figure is the strain predicted by assuming that the initial out-of-reactor strain rate, $A B$, is maintained throughout the in-reactor experiment. The strains are described to within the experimental uncertainty by this line.

If this simple relation between initial out-of-reactor creep rates and in-reactor creep is confirmed by subsequent experiments with compressive stress, the implications for model development are significant. The result implies that irradiation-induced creep for compressive stress is not an independent additional creep (as virtually all the models based on tensile deformation data have assumed) but simply the result of destruction of some effect associated with prior creep strain that impedes further creep strain. In the absence of any data other than those from Hobson's experiments, the assumption must be made that either (a) the in-reactor creep rate is related to the initial out-of-reactor creep rate for compressive stress at temperatures near $644 \mathrm{~K}$ or (b) the fast neutron flux, stress magnitude, and temperature are coincidentally at values that make the independent irradiation-induced creep rate equal to the initial out-of-reactor creep rate. The author has selected assumption (a) and has developed a model for cladding creepdown that is consistent with this assumption.

To be consistent with the assumption that some effect associated with prior creep strain impedes further creep strain, the independent variable in Equation (4.8-20) was changed from time to prior strain. The equation was then differentiated with respect to time, and the differentiated expression was used with Equation (4.8-20) to eliminate time, resulting in the expression

$\epsilon_{\theta}=B\left(A-\epsilon_{\theta}\right)$ 


\section{CCSTRN, CCSTRS, CABTP, CTP}

where $\epsilon_{\theta}$ is the time derivative of the tangential $\operatorname{strain}\left(s^{-1}\right)$.

If fast neutron flux destroys some effect associated with prior creep strain, the appropriate modification of Equation (4.8-26) to describe in-reactor creep will reduce or eliminate the term, $-B \in \theta$, when a fast neutron flux is present. This was accomplished by adapting the idea of an auto-correlation function from statistical mechanics. ${ }^{4.8-27}$ The total strain in Equation (4.8-26) is replaced by the integral of the strain increment at a prior time, $t^{\prime}$, times a correlation function that approximates the rate of destruction of the effect of prior strain on the current strain rate. In the absence of detailed information, the correlation function is represented by an exponential. The resultant generalization of Equation (4.8-26) is

$\dot{\epsilon}_{\theta}=B\left\{A-\int_{0}^{t} \exp \left[-\left(t-t^{\prime}\right)\left(\frac{\phi}{\Psi}+\frac{1}{\tau}\right)\right] d \epsilon\left(t^{\prime}\right)\right\}$

where

$$
\begin{array}{lll}
\phi \quad & \text { fast neutron flux }\left(\mathrm{n} / \mathrm{m}^{2} \cdot \mathrm{s}\right) \\
\Psi \quad & \text { correlation fluence }\left(\mathrm{n} / \mathrm{m}^{2}\right) \\
\tau= & \text { zero flux correlation time (s) }
\end{array}
$$

and other symbols have been previously defined.

New parameters introduced in Equation (4.8-27) can be given a physical interpretation without defining a detailed mechanistic model. The correlation fluence, $\Psi$, is the amount of radiation damage required to destroy most of the effect of prior strain on current strain rate; and the zero flux correlation time, $\tau$, is the time at the temperature required to anneal most of the effect of prior strain in zero flux. Since Equation 


\section{CCSTRN， CCSTRS， CABTP， CTP}

(4.8-1) is an alternate form of Equation (4.8-27), the same interpretation can be applied to Equation (4.8-1).

CCSTRN Equations (4.8-6) and (4.8-7) are approximations derived from Equation (4.8-1). Equation (4.8-6) is obtained from Equation (4.8-1) by assuming

$t(\phi / \Psi+1 / \tau)<<1$

and integrating Equation (4.8-1) from an initial to a final time, $t$. Equation (4.8-7) uses the steady-state approximation to Equation (4.8-1), derived by setting the time derivative of Equation (4.8-1) equal to zero and solving for the steady-state creep rate. If the creep rate at the given final time of a time step interval is greater than or equal to the steady-state creep rate, Equation (4.8-6) is employed for the entire time interval. If the creep rate at the given final time of a time step interval is less than the steady-state creep rate, the time to steady state is calculated with Equation (4.8-8) and Equation (4.8-7) is used to calculate the final strain from the assumption that the creep rate after the time interval given by Equation (4.8-8) has passed. The time interval to steady state is found by solving the time derivative of Equation (4.8-6) for the time when the creep rate is equal to the steady-state creep rate.

Equations (4.8-6) and (4.8-7) contain a term, $\epsilon_{\text {boundary, which is }}$ the initial creep strain for any time step in which the temperature and stress are the same as the previous time step. For time steps in which the temperature, stress, or fast neutron flux has changed, Equation (4.8-1) implies that the creep rate should respond immediately to changes in the product $A B$ (a function of stress and temperature); but the response of the creep rate to changes in the factor, $\phi / \Psi+1 / \tau$ (a function of flux and temperature) should be more gradual. A boundary condition is therefore required to make the initial creep rate of Equation (4.8-6) equal to the creep rate at the end of the prior step. The appropriate condition is: 


\section{CCSTRN， CCSTRS， CABTP， CTP}

For prior steps not in steady state,

$\epsilon_{\text {boundary }}=A P \exp (-B P \Delta t p)+\epsilon \mathrm{P}_{\text {boundary }}[1-\exp (-B P \Delta t p)]$

For prior steps in steady state,

$\epsilon_{\text {boundary }}=\frac{A B B P}{\frac{\phi P}{\Psi P}+\frac{1}{\tau P}+B P}$

where $A P, B P, \Delta t p, \epsilon P_{\text {boundary }}, \phi P, \Psi P$, and $\tau P$ are equal to $A, B, \Delta t$, $\epsilon_{\text {boundary }}, \phi, \Psi$, and $\tau$ during the previous time step.

Values for the parameters $A$ and $B$ at $644 \mathrm{~K}$ and stresses near $125 \mathrm{MPa}$ have been determined from Hobson's out-of-reactor data. These data can also be used in conjunction with the modeling ideas just developed to find a minimum value for the zero flux correlation time, $\tau$, at $644 \mathrm{~K}$. The strains shown in Figure 4.8-3 show that a steady-state creep rate (a straight-7ine plot for strain versus time) did not occur prior to $600 \mathrm{~h}$ in either of the out-of-reactor experiments represented in the figure. Equation (4.8-8), with $\phi=0$ and $\Delta \mathrm{t}_{\text {ss }}$ at least as large as $600 \mathrm{~h}$, implies a $\tau$ of at least $6.8 \times 10^{6} \mathrm{~s}$. This value was adopted as an interim estimate for $\tau$ at $644 \mathrm{~K}$, since the strains calculated from Test 269-27 (test that simulated an axial gap in the fuel pellets) are consistent with steady-state creep after $600 \mathrm{~h}$.

The temperature-dependent factors in Equations (4.8-3), (4.8-4), and (4.8-5) are interim estimates because they are based on the temperature-dependence of tensile creep data. The data from Fidleris' tests, R-6 and Rx-14, 4.8-11 were selected to estimate the temperature dependence of $B, \tau$, and $\Psi$ because these tests were carried out at stress magnitude that closely approximates the magnitude of the stress in Hobson's experiments. 


\section{CCSTRN， CCSTRS， CABTP， CTP}

Figure 4.8-6 117 ustrates the steady-state creep rates reported by Fidleris for a stress of $138 \mathrm{MPa}$ at several temperatures. The in-reactor data are at fast neutron fluxes of $6.8 \times 10^{16}$ or $6.0 \times 10^{16} \mathrm{n} / \mathrm{m}^{2} \cdot \mathrm{s}$. The range of steady-state creep rates predicted by the model for creepdown at $644 \mathrm{~K}$ is also represented. A solid square is used to represent the steady-state creep rate seen in Hobson's experiment at a fast neutron flux of $5.4 \times 10^{17} \mathrm{n} / \mathrm{m}^{2} \cdot \mathrm{s}$. The slope of the tensile stress data at temperatures $>614 \mathrm{~K}\left(1 / \mathrm{T}<1.626 \times 10^{-3}\right)$ corresponds to a temperature-dependent factor of the form $\exp (-25,100 / T)$. The in-reactor data $<615 \mathrm{~K}$ correspond to a temperature-dependent factor of the form $\exp (-10,400 / T)$. The temperature-dependent factors in Equations (4.8-3), (4.8-4), and (4.8-5) are the most convenient way of forcing the steady-state creep rate implied by Equation (4.8-7) to correspond to the temperature dependence shown by the Fidleris equation.

The constants $2.9 \times 10^{6}$ and $6.967795 \times 10^{16}$ in Equation (4.8-4) are the result of a least-squares fit to the steady-state creep rate data of Fidleris. As expected from the previous discussion, the resultant prediction of the steady-state creep rate for Hobson's in-reactor creep rate at $5.4 \times 10^{17} \mathrm{n} / \mathrm{m}^{2}$. $\mathrm{s}$ with a compressive stress is slightly too high. The predicted rate, $s^{-1}$, is shown in Figure $4.8-6$ by the dashed 1 ine.

\subsubsection{Model Uncertainty}

Lack of an extensive data base for creep under compressive stress makes the assignment of uncertainty limits very tentative. The data of Stehle (illustrated in Figure 4.8-1) are the only other compressive stress data available. These data show creep strains of about half the magnitude of the model-predicted strains. Since these are the only appropriate data not used in developing the model, they were used to estimate fractional error of -0.6 and +0.3 in strain at $644 \mathrm{~K}$ and $-130 \mathrm{MPa}$ stress. The remaining terms of the uncertainty estimate for the strain predicted by CCSTRN [Equations (4.8-9) and $(4.8-10)$ ] are simply engineering judgments that estimate $100 \%$ error when 
CCSTRN, CCSTRS, CABTP, CTP

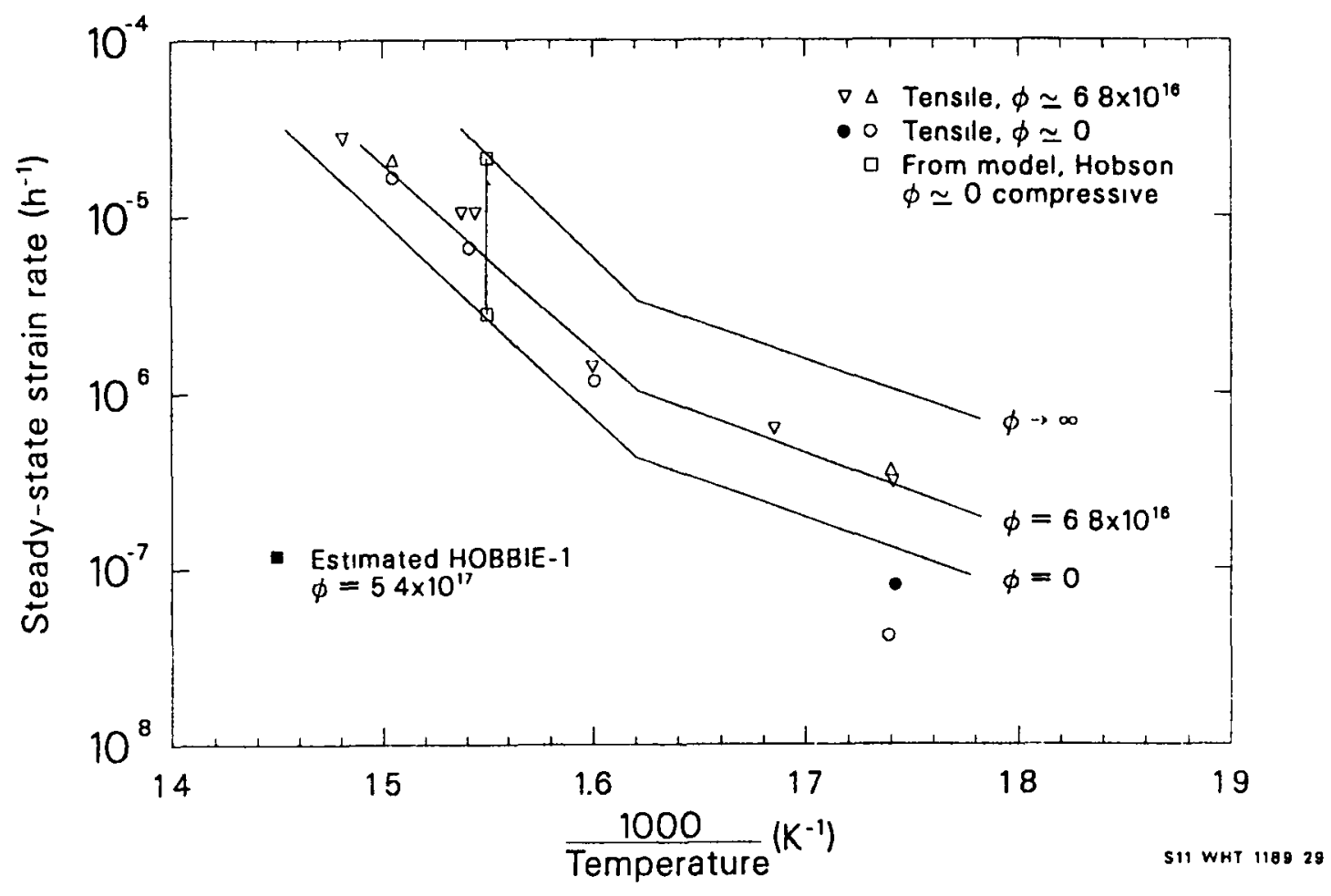

Figure 4.8-6. Steady-state creep rates reported by Fidleris for Tests R- 6 and $R x-14$ compared to model predictions for steady-state creepdown rates derived from these data. 


\section{CCSTRN, CCSTRS, CABTP, CTP}

the stress differs from -130 MPa by more then $65 \mathrm{MPa}$ or the temperature differs from $644 \mathrm{~K}$ by more than $60 \mathrm{~K}$.

Equations (4.8-11) and (4.8-12), the expressions for the uncertainty of the stress calculated by CCSTRS, were derived from Equations (4.8-9) and (4.8-10) and the observation that the predicted strain is usually proportional to the fourth power of stress. The resultant uncertainty in stress expressed as a fraction of stress is one-fourth the fractional uncertainty in strain.

\subsubsection{References}

4.8-1. C. C. Dollins and F. A. Nichols, "Mechanisms of Irradiation Creep in Zirconium-Base Alloys," Zirconium in Nuclear Applications, ASTM-STP-551, 1974, pp. 229-248.

4.8-2. G. R. Piercy, "Mechanisms for the In-Reactor Creep of Zirconium Alloys," Journal of Nuclear Materials, 2, 1968, pp. 18-50.

4.8-3. J. R. MacEwen, "The Effect of Neutron Flux on Dislocation Climb," Journal of Nuclear Materials, 54, 1974, pp. 85-96.

4.8-4. F. A. Nichols, "Point Defects and the Creep of Metals, "Journal of Nuclear Materials, 69 and 70, 1978, pp. 451-464.

4.8-5. F. A. Nichols, "On the SIPA Contribution to Irradiation Creep," Journal of Nuclear Materials, 84, 1979, pp. 207-221.

4.8-6. D. 0. Northwood, "Comments on In-Pile Dimensional Changes in Neutron Irradiated Zirconium Base Alloys," Journal of Nuclear Materials, 64, 1977, pp. 316-319.

4.8-7. E. F. Ibrahim, "In-Reactor Creep of Zirconium Alloys by Thermal Spikes," Journal of Nuclear Materials, 58, 1975, pp. 302-310.

4.8-8. P. A. Ross-Ross and C. E. L. Hunt, "The In-Reactor Creep of Cold-Worked Zircaloy-2 and Zirconium-2.5 wt Niobium Pressure Tubes," Journal of Nuclear Materials, 26, 1968, pp. 2-17.

4.8-9. V. Fidleris, "Summary of Experimental Results on In-Reactor Creep and Irradiation Growth of Zirconium Alloys," Atomic Energy Review, 13, 1976, pp. 51-80. 


\section{CCSTRN, CCSTRS, CABTP, CTP}

4.8-10. R. D. Warda, V. Fidleris, E. Teghtsoonian, "Dynamic Strain Aging During Creep of $\alpha-Z r$," Metallurgical Transactions, 4, 1972/1973, pp. 302-316.

4.8-11 V. Fidleris, "Uniaxial In-Reactor Creep of Zirconium Alloys," Journal of Nuclear Materials, 26, 1968, pp. 51-76.

4.8-12. W. J. Duffin and F. A. Nichols, "The Effect of Irradiation on Diffusion-Controlled Creep Processes, "Journal of Nuclear Materials, 45, 1972/1973, pp. 302-316.

4.8-13. D. S. Wood, "Dose Dependence of Irradiation Creep of Zircaloy-2," Properties of Reactor Structural Alloys After Neutron or Particle Irradiation, ASTM-STP-570, 1975, pp. 207-217.

4.8-14. D. S. Wood and B. Watkins, "A Creep Limit Approach to the Design of Zircaloy-2 Reactor Pressure Tubes at $275^{\circ} \mathrm{C}, "$ Journal of Nuclear Materials, 41, 1971, pp. 327-340.

4.8-15. E. Kohn, "In-Reactor Creep of $\mathrm{Zr}-2.5 \mathrm{Nb}$ Fuel Cladding, "Zirconium in the Nuclear Industry, ASTM-STP-633, 1977, pp. 402-417.

4.8-16. E. R. Gilbert, "In-Reactor Creep of Reactor Materials, "Reactor Technology, 14, Fal1 1971, pp. 258-285.

4.8-17. H. Stehle et al., "Mechanical Properties of Anisotropy and Microstructure of Zircaloy Canning Tubes, "Zirconium in the Nuclear Industry, ASTM-STP-633, American Society for Testing and Materials, December 1977, pp. 486-507.

4.8-18. M. L. Picklesimer, "Deformation, Creep, and Fracture in Alpha-Zirconium Alloys," Electrochemical Technology, 4, 1966, pp. 289-300.

4.8-19. G. E. Lucas and A. L. Bement, "Temperature Dependence of the Zircaloy-4 Strength Differential," Journal of Nuclear Materials, 48,1975 , pp. 163-170.

4.8-20. R. H. Chapman, Characterization of Zircaloy-4 Tubing Procured for Fuel-Cladding Research Programs, ORNL/NUREG/TM-29, 1976.

4.8-21. D. 0. Hobson and C. V. Dodd, Interim Report on the Creepdown of Zry Fuel Cladding, ORNL/NUREG/TM-103, May 1977.

4.8-22. D. 0. Hobson, Quarterly Progress Report on the Creepdown and Collapse of Zircaloy Fuel Cladding for January 1977-March 1977, ORNL/NUREG/TM-125, July 1977.

4.8-23. D. 0. Hobson, Creepdown of Zircaloy Fuel Cladding--Initial Tests, ORNL/NUREG/TM-181, Apri1 1978. 


\section{CCSTRN, CCSTRS, CABTP, CTP}

4.8-24. D. 0. Hobson, Preliminary Analysis of Surface Displacement Results in the Creepdown Irradiation Experiment HOBBIE-1, NUREG/CR-0810 and ORNL/NUREG/TM-310, June 1979.

4.8-25. H. Stehle et al., "Uranium Dioxide Properties for LWR Fuel Rods," Nuclear Engineering and Design, 33, 1975, pp. 230-260.

4.8-26. A. A. Bauer et al., Progress on Evaluating Strength and Ductility of Irradiated Zircaloy During July through September 1975, BMI-1938, September 1975.

4.8-27. C. Kittle, Elementary Statistical Physics, New York: John Wiley and Sons, Inc., 1958.

\subsubsection{Bibliography}

This section is a list of additional references from the extensive literature on creep experiments. The list is reported here because one of the objectives of this report is to provide lists of available literature for future studies of material behavior. In most cases, the additional references were not used in the development of the model for creepdown because literature for the different case of creep under compressive stress has become available.

(1) G. Dressler et a1., "Determination of Complete Plane Stress Yield of Zircaloy Tubing," Zirconium in Nuclear Applications, ASTM-STP-551, 1974, pp. 72-103.

(2) D. G. Franklin and W. A. Franz, "Numerical Model for the Anisotropic Creep of Zircaloy, "Zirconium in the Nuclear Industry, ASTM-STP-633, 1977, pp. 365-384.

(3) P. J. Pankaskie, Irradiation Effects on the Mechanical Properties of Zirconium and Dilute Zirconium Alloys--A Review, BN-SA-618, July 1976, updated November 1976.

(4) C. E. Coleman, "Tertiary Creep in Cold-Worked Zircaloy-2, "Journal of Nuclear Materials, 43, 1971, pp. 180-190.

(5) C. C. Busby and L. S. White, Some High Temperature Mechanical Properties of Internally Pressurized Zircaloy-4, WAPD-TM-1243, February 1976.

(6) M. Gartner and H. Stehle, In-Pile Creep Behavior of Zircaloy-4 Cladding Tubes at 400C, Siemens Aktiengesellschaft Reaktortechnik, September 1972. 


\section{CCSTRN, CCSTRS, CABTP, CTP}

(7) M. Bernstein, "Diffusion Creep in Zirconium and Certain Zirconium Alloys," Transactions of the Metallurgical Society of AIME,329, 1969, pp. 1518-1522.

(8) F. A. Nichols, "On the Mechanisms of Irradiation Creep in Zirconium-Base Alloys," Journal of Nuclear Materials, 26, 1967, pp. 51-76.

(9) H. P. Kreyns and M. W. Burkart, "Radiation-Enhanced Relaxation in Zircaloy-4 and Zr/2.5wt Nb/0.5wt Cu Alloys," Journal of Nuclear Materials, 26, 1968, pp. 87-104.

(10) F. L. Yagee and A. Purohit, "Biaxial Creep Characteristics of GCFR Cladding at $650^{\circ}$ and 32.4-ksi Hoop Stress," Transactions of the American Nuclear Society, 22, November 1975, p.182.

(11) E. F. Ibrahim and C. E. Coleman, "Effect of Stress Sensitivity on Stress-Rupture Ductility of Zircaloy-2 and $\mathrm{Zr}-2.5$ wt\%Nb, "Canadian Metallurgical Quarterly, 12, 3, 1973, pp. 285-287.

(12) V. Fidleris, "The Effect of Texture and Strain Aging on Creep of Zircaloy-2," Applications of Related Phenomena for Zirconium and Its A17oys, ASTM-STP-458, 1969, pp. 1-17.

(13) F. J. Azzarto et al., "Unirradiated In-Pile and Postirradiation Low Strain Rate Tensile Properties of Zircaloy-4," Journal of Nuclear Materials, 30, 1969, pp. 208-218.

(14) W. R. Smalley, Saxton Plutonium Program: Semi Annual Progress Report for the Period Ending June 30, 1969, WCAP-3385-20, October 1969.

(15) T. E. Caye and W. R. Smalley, Saxton Plutonium Project: Quarterly Progress Report for the Period Ending December 31, 1970, WCAP-3385-26, March 1971.

(16) E. F. Ibrahim, "In-Reactor Tubular Creep of Zircaloy-2 at $260^{\circ} \mathrm{C}$ and $300^{\circ} \mathrm{C}, "$ Journal of Nuclear Materials, 46, 1973, pp. 196-182.

(17) H. Conrad, "Experimental Evaluation of Creep and Stress Rupture," Mechanical Behavior of Materials at Elevated Temperatures, New York: McGraw-Hi11 Book Company, Inc., 1961, p. 149.

(18) F. A. Nichols, "Theory of the Creep of Zircaloy During Neutron Irradiation," Journal of Nuclear Materials, 30, 1969, pp. 249-270.

(19) V. Fidleris and C. D. Williams, "Influence of Neutron Irradiation of Zircaloy-2 at $300^{\circ} \mathrm{C}$, "Journal of Electrochemical Technology, 4, May-June 1966, pp. 258-267.

(20) E. F. Ibranim, "In-Reactor Creep of Zirconium-2.5 Nb Tubes at $570 \mathrm{~K} . "$ Zirconium in Nuclear Industry, ASTM-STP-551, 1974, pp. 249-262. 
(21) C. E. Ells and V. Fidleris, "Effect of Neutron Irradiation on Tensile Properties of the Zirconium-2.5 Weight Percent Niobium Alloy, "Journal of Electrochemical Technology, 4, May-June 1966, pp. 268-274.

(22) E. R. Gilbert, "In-Reactor Creep of $2 r-2.5 \mathrm{wt} \mathrm{Nb,"} \mathrm{Journal} \mathrm{of} \mathrm{Nuclear}$ Materials, 26, 1968, pp. 105-111.

(23) W. J. Langford and L. E. J. Mooder, "Metallurgical Properties of Irradiated Cold-Worked of Zr2.5 wt\% Nb Pressure Tubes, "Journal of Nuclear Materials, 30, 1969, pp. 292-302.

(24) E. F. Ibrahim, "In Reactor Creep of Zirconium-Alloy Tubes and Its Correlation with Uniaxial Data," Applications-Related Phenomena for Zircaloy and Its Alloys, ASTM-STP-458, 1969, pp. 18-36.

(25) T. M. Frenkel and M. Weisz, "Effect of the Annealing Temperature on the Creep Strength of Cold-Worked Zircaloy-4 Cladding, " Zirconium in Nuclear Applications, ASTM-STP-551, 1974, pp. 140-144.

(26) K. Kallstrom et a1., "Creep Strength of Zircaloy Tubing at $400^{\circ} \mathrm{C}$ as Dependent on Metallurgical Structure and Texture, "Zirconium in Nuclear Applications, ASTM-STP-551, 1974, pp. 160-168.

(27) C. R. Woods, ed., Properties of Zircaloy-4, WAPD-TM-585, December 1966.

(28) 0. D. Sherby and A. K. Miller, Development of the Materials Code, MATMOD (Constitutive Equations for Zircaloy), NP-567, December 1977.

(29) D. G. Franklin and H. D. Fisher, "Requirements for In-Reactor Zircaloy Creep Measurements for Application in the Design of PWR Fuel, "Journal of Nuclear Materials, 65, 1977, pp. 192-199.

(30) W. R. Smalley, Saxton Core II Fuel Performance Evaluation Part I: Materials, WCAP-3385-56, September 1971.

(31) W. R. Smalley, Evaluation of Saxton Core III Fuel Materials Performance, WCAP-3385-57, July 1974.

(32) A. A. Bauer et al., Evaluating Strength and Ductility of Irradiated Zircaloy, Quarterly Progress Report, January through March 1977, BMI-NUREG-1971, April 1977. 



\section{CSTRES，CSTRAN， CSTRNI， CANISO， CKMN}

\subsection{Plastic Deformation (CSTRES, CSTRAN, CStRni, CANiso, CKMN)}

(D. L. Hagrman and G. A. Reymann)

This section is a description of materials properties subcodes for cladding stress and plastic deformation. The subroutine CSTRES calculates instantaneous cladding stress as a function of plastic strain, strain rate, temperature, cold work, fast neutron fluence, and average oxygen concentration. The subroutine CSTRAN calculates instantaneous cladding strain as a function of strain rate, stress, temperature, cold work, fast neutron fluence, and average oxygen concentration. CSTRNI calculates the cladding strain at the end of a time step of specified length as a function of the initial strain, average stress during the time step, temperature, cold work, fast neutron fluence, and average oxygen concentration.

The stresses and strains used with CSTRES, CSTRAN, and CSTRNI are effective stresses and strains. The subcode CANISO provides coefficients of anisotropy for converting given stress and plastic strain components to effective stresses and strains. CANISO includes a preliminary model for the change in texture with deformation. The subcode CKMN provides the parameters for the cladding equation of state as a function of temperature, average oxygen concentration, fast neutron fluence, and cold work. 


\section{CSTRES， CSTRAN， CSTRNI， CANISO， CKMN}

\subsubsection{Summary}

A11 input strain or stress components are assumed by MATPRO mechanical property routines to be true strain or true stress. ${ }^{a}$ The basic equation used to relate stress and plastic strain is

$\sigma=K \epsilon^{\mathrm{n}}\left(\dot{\epsilon} / 10^{-3}\right)^{\mathrm{m}}$

where

$$
\begin{array}{ll}
\sigma & =\text { true effective stress }(\mathrm{Pa}) \\
\epsilon \quad & \text { true effective plastic strain (unitless) } \\
\dot{\epsilon} & =\text { rate of change of true effective plastic strain }\left(\mathrm{s}^{-1}\right) \\
K, \mathrm{n}, \mathrm{m} \quad & =\begin{array}{l}
\text { parameters which describe the metallurgical state of the } \\
\text { cladding. }
\end{array}
\end{array}
$$

Equation (4.9-1) is the expression used in CSTRES to calculate effective stress.

The strain returned by CSTRAN is obtained from the solution of Equation (4.9-1) for strain. The strain returned by CSTRNI is obtained from the time integral of the strain-dependent factors of Equation (4.9-1), assuming stress is constant during the time interval

a. True strain equals the change in length divided by the length at the instant of change integrated from the original to the final length. True stress equals the force per unit cross-sectional area determined at the instant of measurement of the force. 


\section{CSTRES, CSTRAN, CSTRNI, CANISO, CKMN}

$\epsilon_{f}=\left[\left(\frac{n}{m}+1\right)^{10^{-3}}\left(\frac{\sigma}{k}\right)^{1 / m} \Delta t+\epsilon_{i}^{(n / m+1)}\right]^{\frac{m}{n+m}}$

where

$\epsilon_{f} \quad=\quad$ true effective strain at the end of a time interval (unitless)

$\epsilon_{\mathbf{i}}=$ true effective strain at the start of a time interval (unitless)

$\Delta \mathrm{t}=$ duration of the time interval (s).

Effective stress for use with the CSTRAN and CSTRNI subroutines is obtained from stress components and the equation

$\sigma=\left[A 1 S\left(\sigma_{1}-\sigma_{2}\right)^{2}+\operatorname{A} 2 S\left(\sigma_{2}-\sigma_{3}\right)^{2}+A 3 S\left(\sigma_{3}-\sigma_{1}\right)^{2}\right]^{1 / 2}$

where

$\sigma \quad=\quad$ effective stress $(\mathrm{Pa})$

$\sigma 1, \sigma 2, \sigma 3=$ principal axis stress components $(\mathrm{Pa})$

A1S, A2S, A3S = coefficients of anisotropy provided by the CANISO subcode.

Effective strain for use with the CSTRES code is obtained from strain components with the equation

$$
\begin{aligned}
d \epsilon= & {\left[\frac{1}{A 1 E A 2 E+A 2 E A 3 E+A 3 E A 1 E}\right]\left[A 1 E\left(A 2 E d \epsilon_{1}-A 3 E d \epsilon_{2}\right)^{2}\right.} \\
& \left.+A 2 E\left(A 3 E d \epsilon_{2}-A 1 E d \epsilon_{3}\right)^{2}+A 3 E\left(A 1 E d \epsilon_{3}-A 2 E d \epsilon_{1}\right)^{2}\right]^{1 / 2}
\end{aligned}
$$




\section{CSTRES, CSTRAN, CSTRNI, CANISO, CKMN}

where

de $\quad=$ effective plastic strain increment

$d \epsilon_{1}, d \epsilon_{2}, d \epsilon_{3}=$ axial, circumferential, and radial strain component increments

AlE, $A 2 E, A 3 E=$ coefficients of anisotropy provided by the CANISO subroutine.

Once effective stress and strain are known, along with the input values of either strain or stress components, the unknown components of either stress or strain can be obtained from the Prandt1-Reuss flow rule $e^{4-9-1}$

$$
\begin{aligned}
& d \epsilon_{1}=\frac{d \epsilon}{\sigma}\left[\sigma_{1}(A 1 E+A 3 E)-\sigma_{2} A 1 E-\sigma_{3} A 3 E\right] \\
& d \epsilon_{2}=\frac{d \epsilon}{\sigma}\left[-\sigma_{1} A 1 E+\sigma_{2}(A 2 E+A 1 E)-\sigma_{3} A 2 E\right] \\
& d \epsilon_{3}=\frac{d \epsilon_{1}}{\sigma}\left[-\sigma_{1} A 3 E-\sigma_{2} A 2 E+\sigma_{3}(A 3 E+A 2 E)\right]
\end{aligned}
$$

where all the terms have been previously defined.

As mentioned in conjunction with Equations (4.9-3) and 4.9-4), coefficients of anisotropy are provided by the CANISO subroutine. The information required by this subroutine is the temperature, the three principal components of plastic strain during a time interval, three constants related to the cladding basal pole distribution at the start of the time interval, and three constants related to the deformation history of the cladding prior to the time interval. For each time step, the subroutine updates the six constants required and provides the six coefficients of anisotropy required by Equations (4.9-3) through (4.9-7). Initial (no plastic deformation) values of the pole figure and deformation history 


\section{CSTRES, CSTRAN, CSTRNI, CANISO, CKMN}

constants will be discussed in conjunction with the following summary of the equations used in the CANISO subcode.

For undeformed cladding, with $\sigma_{1}, \sigma_{2}, \sigma_{3}$ of Equation (4.9-3) defined to be the axial, circumferential, and radial components of stress, the expressions used to find the stress anisotropy constants are

$$
\begin{aligned}
& \text { A1S }=\left(1.5 f_{r}-0.5\right) g(T)+0.5 \\
& \text { A2S }=\left(1.5 f_{z}-0.5\right) g(T)+0.5 \\
& \text { A3S }=\left(1.5 f_{\theta}-0.5\right) g(T)+0.5
\end{aligned}
$$

where

$$
\begin{aligned}
g(T)= & \text { a function which is } 1.0 \text { for temperatures }<1090 \mathrm{~K}, 0 \\
& \text { for temperatures }>1255 \mathrm{~K} \text {, and found by } 1 \text { inear } \\
& \text { interpolation for temperatures between } 1090 \text { and } \\
& 1255 \mathrm{~K} . \\
\mathrm{f}_{r}, \mathrm{f}_{\mathrm{Z}}, \mathrm{f}_{\theta}= & \text { average of the squared cosine between the c axis } \\
& \text { of grains in the cladding and the radial, axial, and } \\
& \text { tangential reference directions, respectively, } \\
& \text { weighted by the volume fraction of grains at each } \\
& \text { orientation. These averages can be obtained from a } \\
& \text { pole figure and the CTXTUR subroutine described in } \\
& \text { Section } 21.2 \text { ( } f_{r}=\text { COSTH2, } f_{z}=\text { COSF12 - CT2CF2, } \\
& \text { and } f_{\theta}=1-\text { COSTH2 - COSFI2 }+ \text { CT2CF2 in the } \\
& \text { notation of the CTXTUR subroutine). Values of } f_{r}, \\
& f_{z}, \text { and } f_{\theta} \text { for typical cladding textures are } \\
& f_{r}=0.66, f_{z}=0.06, \text { and } f_{\theta}=0.28 .4 .9-2
\end{aligned}
$$




\section{CSTRES，CSTRAN， CSTRNI， CANISO， CKMN}

The change of the factors, $f_{r}, f_{\theta}$, and $f_{z}$, of Equations (4.9-8) through (4.9-10) due to deformation is modeled with the following correlations

$$
\begin{aligned}
\Delta f^{\prime}{ }_{r} & =-d \epsilon_{3}\left[\begin{array}{ll}
-1.404 & T(0.00895)
\end{array}\right] \\
\Delta f^{\prime}{ }_{\theta} & =-d \epsilon_{1}\left[\begin{array}{ll}
-1.404 & T(0.00895)
\end{array}\right] \\
\Delta f^{\prime}{ }_{Z} & =-d \epsilon_{2}\left[\begin{array}{ll}
-1.404 & T(0.00895)
\end{array}\right]
\end{aligned}
$$

where

$$
\begin{array}{rl}
\Delta \mathrm{f}_{\sigma}, \Delta \mathrm{f}_{\mathrm{Z}}, \Delta \mathrm{f}_{\theta}= & \text { change in } \mathrm{f}_{r}, \mathrm{f}_{\mathrm{Z}} \text {, and } \mathrm{f}_{\theta} \text { due to deformation } \\
\mathrm{T} & 644 \mathrm{~K}, \text { for temperature }<644 \mathrm{~K} \text {, the temperature for } \\
& \leq 644 \text { temperature } \leq 1090 \mathrm{~K}, 1090 \mathrm{~K} \text { for temperature } \\
& >1090 \mathrm{~K} .
\end{array}
$$

The strain anisotropy coefficients $A 1 E, A 2 E$, and $A 3 E$ are given by Equations (4.9-8) through (4.9.13), with A1S, A2S, and A3S replaced by AlE, $\mathrm{A} 2 \mathrm{E}$, and $\mathrm{A} 3 \mathrm{E}$ when the cladding temperature is below $650 \mathrm{~K}$. However, limited data at temperatures above $800 \mathrm{~K}$ suggest initial strain anisotropy coefficients of 0.5 (the isotropic values). The description of high-temperature strain anisotropy thus requires a separate set of $f$ values, set initially at the isotropic values and changed during each time step by an amount given by Equations (4.9-11) through (4.9.13). The expressions for A1E, A2E, and A3E which are used to model this rather complex switching from texture-dependent to deformation-dependent strain anisotropy are

$$
\begin{aligned}
& A 1 E=\frac{A 1 S+\left[\left(1.5 f^{\prime}{ }_{r}-0.5\right) g(T)+0.5\right] \exp [(T-725) / 18]}{\exp [(T-725) / 18]+1} \\
& A 2 E=\frac{A 2 S+\left[\left(1.5 f^{\prime}{ }_{z}-0.5\right) g(T)+0.5\right] \exp [(T-725) / 18]}{\exp [(T-725) / 18]+1}
\end{aligned}
$$




\section{CSTRES， CSTRAN， CSTRNI， CANISO， CKMN}

$A 3 E=\frac{A 3 S+\left[\left(1.5 f^{\prime}{ }_{\theta}-0.5\right) g(T)+0.5\right] \exp [(T-725) / 18]}{\exp [(T-725) / 18]+1}$

where $f^{\prime}{ }_{r}, f^{\prime}{ }_{z}$, and $f^{\prime}{ }_{\theta}$ are deformation-dependent parameters set equal to $1 / 3$ at zero deformation and changed like the parameters $f_{r}, f_{Z}$, and $f_{\theta}$ in Equations (4.9-11) through (4.9.13).

Effects of cladding temperature, cold work, irradiation, in-reactor annealing, and oxidation on mechanical properties are expressed as changes in the strength coefficient, $K$; the strain hardening exponent, $n$; and the strain rate sensitivity exponent, $m$; of Equations (4.9-1) and (4.9-2). For fully annealed isotropic zircaloy-2 or zircaloy-4 cladding, the temperature and strain rate dependent values of $m, n$, and $K$ are as shown below.

(1) Values of the strain rate sensitivity exponent, $\mathrm{m}^{2}$ For $\mathrm{T} \leq 730 \mathrm{~K}$,

$\mathrm{m}=0.02$.

For $730<T<900 \mathrm{~K}$,

$\begin{aligned} m= & 2.063172161 \times 10^{1}+T\left\{-7.704552983 \times 10^{-2}\right. \\ & \left.+T\left[9.504843067 \times 10^{-5}+T\left(-3.860960716 \times 10^{-8}\right)\right]\right\} .\end{aligned}$

For $900 \leq T<1090 \mathrm{~K}$,

$\mathrm{m}=-6.47 \times 10^{-2}+2.203 \times 10^{-4} \mathrm{~T}$.

a. Eight to ten significant figures are used in these expressions to minimize discontinuities. 


\section{CSTRES， CSTRAN， CSTRNI， CANISO， CKMN}

$$
\begin{aligned}
\text { For } 1090 \leq \mathrm{T} \leq 1172.5 \mathrm{~K} \\
\mathrm{~m}=-6.47 \times 10^{-2}+2.203 \times 10^{-4} \mathrm{~T}, \dot{\epsilon} \geq 6.34 \times 10^{-3} / \mathrm{s} \\
\mathrm{m}=-6.47 \times 10^{-2}+2.203 \times 10^{-4} \mathrm{~T} \\
+6.78 \times 10^{-2}\left(\frac{\mathrm{I}-1090}{82.6}\right) \ln \left(\frac{6.34 \times 10^{-3}}{\epsilon}\right) \dot{\epsilon}<6.34 \times 10^{-3} / \mathrm{s}
\end{aligned}
$$

For $1172.5<T<12551255 \mathrm{~K}$,

$\mathrm{m}=-6.47 \times 10^{-2}+2.203 \times 10^{-4} \mathrm{~T}, \dot{\epsilon} \geq 6.34 \times 10^{-3} / \mathrm{s}$

$m=-6.47 \times 10^{-2}+2.203 \times 10^{-4} \mathrm{~T}$

$+6.78 \times 10^{-2}\left(\frac{1255-\mathrm{T}}{82.6}\right) \ln \left(\frac{6.34 \times 10^{-3}}{\dot{\epsilon}}\right) \dot{\epsilon}<6.34 \times 10^{-3} / \mathrm{s}$

For $1255 \leq T \leq 2100 \mathrm{~K}$,

$\mathrm{m}=-6.47 \times 10^{-2}+2.203 \times 10^{-4} \mathrm{~T}$.

(2) Values of the strain hardening exponent, $n$

For $T<1099.0772 \mathrm{~K}$,

$$
\begin{aligned}
n= & -9.490 \times 10^{-2}+T\left[1.165 \times 10^{-3}+T\left(-1.992 \times 10^{-6}\right.\right. \\
& \left.\left.+T 9.588 \times 10^{-10}\right)\right] .
\end{aligned}
$$

For $1099.0722 \leq \mathrm{T}<1600 \mathrm{~K}$,

$n=-0.22655119+2.5 \times 10^{-4} \mathrm{~T}$. 


\section{CSTRES, CSTRAN, CSTRNI, CANISO, CKMN}

$$
\begin{aligned}
& \text { For } T \geq 1600 \mathrm{~K}, \\
& n=-0.17344880
\end{aligned}
$$

When the strain is $<n /(1+m)$, the strain-hardening exponent is modified to a larger value than the one given by Equations (4.9-23) through (4.9-25). The expression used to modify $n$ for strains $<n /(1+m)$ is

$n^{\prime}=$ the smaller of ANL or $n^{2} /[(1+m) \cdot \epsilon]$

where

$$
\begin{aligned}
\text { ANL } & =0.17 \text { for } T \leq 730 \mathrm{~K} \\
& =0.056 \mathrm{~T}-11.218 \text { for } 730<\mathrm{T}<780 \mathrm{~K} \\
& =0.95 \text { for } T \geq 780 \mathrm{~K} \\
n & =\text { the number given by Equations }(4.9-23) \text { through }(4.9 .25) \\
n^{\prime} & =\text { the revised number to be used with Equation }(4.9-1) \text { or } 4.9-2) \\
& \text { in place of } n .
\end{aligned}
$$

(3) Values of the strength coefficient, $K$

$$
\begin{aligned}
& \text { For } T<750 \mathrm{~K}, \\
& K=1.17628 \times 10^{9}+T\left\{4.54859 \times 10^{5}+T\left[-3.28185 \times 10^{3}\right.\right. \\
& +T(1.72752)]\} . \\
& \text { For } 750 \leq T<1090 \mathrm{~K}, \\
& K=2.522488 \times 10^{6} \exp \left(2.8500027 \times 10^{6} / \mathrm{T}^{2}\right) .
\end{aligned}
$$




\section{CSTRES， CSTRAN， CSTRNI， CANISO， CKMN}

$$
\begin{aligned}
& \text { For } 1090 \leq T<1255 \mathrm{~K}, \\
K= & 1.841376039 \times 10^{8}-\mathrm{T} 1.4345448 \times 10^{5} \\
& \text { For } 1255 \leq T \leq 2100 \mathrm{~K} \\
K= & 4.3302 \times 10^{7}+\mathrm{T}\left[-6.685 \times 10^{4}+\mathrm{T}\left(3.7579 \times 10^{1}\right.\right. \\
& \left.\left.-\mathrm{T} 7.33 \times 10^{-3}\right)\right] .
\end{aligned}
$$

The changes in form of Equations (4.9-17) through (4.9-30) in various temperature ranges are caused by changes in the physical mechanism of the plastic deformation. At 700 to $900 \mathrm{~K}$, the deformation becomes significantly strain-rate-dependent, the strength of the material begins to decrease rapidly with temperature, and strain hardening becomes relatively unimportant. This change is generally attributed to thermal creep at high temperature, but the specific deformation system change has not been identified. The $1090-$ to $1255-\mathrm{K}$ region is the $\alpha+\beta$ phase region for zircaloy, and the region above $1255 \mathrm{~K}$ is the $\beta$ phase region for this material.

The change in the strain hardening exponent due to irradiation and cold-working of cladding is described by multiplying the value of $n$ given in Equations (4.9-23) through (4.9-25) by

$$
\begin{aligned}
R I C= & {\left[0.847 \exp (-39.2 \operatorname{COLDW})+0.153+\operatorname{coLDW}\left(-9.16 \times 10^{-2}+0.229 \operatorname{coLDW}\right)\right] } \\
& \exp \left(\frac{-\Phi^{1 / 3}}{3.73 \times 10^{7}+2 \times 10^{6} \operatorname{CoLDW}}\right)
\end{aligned}
$$

where 


\section{CSTRES， CSTRAN， CSTRNI， CANISO， CKMN}
RIC = strain hardening exponent for irradiated and cold-worked material divided by the expression in Equations (4.9-23) through (4.9-25)
COLDW = effective cold work for strain hardening exponent (unitless ratio of areas). (Changes in the effective cold work as a function of time and temperature are modeled by the CANEAL subroutine discussed in Section 4.10.)
$\Phi=$ effective fast neutron fluence (neutrons > 1.0 $\mathrm{MeV} / \mathrm{m}^{2}$ ). (Changes in the effective fast neutron fluence are modeled by the CANEAL subroutine discussed in Section 4.10.)

The change in the strength coefficient due to irradiation and cold-working of the cladding is modeled with the expression

$D K=\left(0.546\right.$ COLDW $\left.+9.76 \times 10^{-27} \Phi\right) K$

where DK is the strength coefficient for irradiated and cold-worked material minus the expression in Equations (4.9-27) through (4.9-30) (Pa). The strain rate sensitivity exponent does not change as a function of irradiation or cold work.

Correlations for the changes in the strain hardening exponent, strength coefficient, and strain rate sensitivity exponent due to the oxidation of the cladding are

$$
\begin{aligned}
& \text { RNO }=1+\left[1250-\frac{1250}{\exp [(T-1380) / 20]+1}\right] Y \\
& \text { RNO }=1+\left[1120-\frac{990}{\exp [(T-1300) / 61]+1}\right] Y
\end{aligned}
$$




\section{CSTRES， CSTRAN， CSTRNI， CANISO， CKMN}

and

$R M O=\exp (-69 Y)$

where

$$
\begin{aligned}
& \text { RNO = strain hardening exponent for oxidized cladding divided by } \\
& \text { strain hardening exponent for as-fabricated cladding } \\
& \text { RKO = strength coefficient for oxidized cladding divided by } \\
& \text { strength coefficient for as-fabricated cladding } \\
& \text { RMO = strain rate sensitivity exponent for oxidized cladding } \\
& \text { divided by strain rate sensitivity exponent for as-fabricated } \\
& \text { cladding } \\
& \mathrm{T}=\text { temperature }(\mathrm{K}) \\
& Y=\text { average oxygen concentration increase }(\mathrm{kg} \text { oxygen } / \mathrm{kg} \\
& \text { zircaloy). (Changes in oxygen concentration are modeled by } \\
& \text { the COBILD subroutine discussed in Section 20.2.) }
\end{aligned}
$$

Estimates have been made for the expected error of the strength coefficient, strain hardening exponent, and strain rate sensitivity exponent. The expressions for these uncertainties are

$$
\begin{aligned}
& \text { UK }=\left\{\begin{array}{l}
77 \times 10^{6} \text { for } T<700 \mathrm{~K} \\
110.43693 \times 10^{6}-T 4.7767045 \times 10^{4} \text { for } 700 \leq T \leq 800 \mathrm{~K} \\
\text { (strength coefficient) } / 3 \text { for } T>800 \mathrm{~K}
\end{array}\right. \\
& \text { Un }=\left\{\begin{array}{l}
0.017 \text { for } T<700 \mathrm{~K} \\
-2.8405405 \times 10^{-2}+1.64864864 \times 10^{-5} \mathrm{~T} \text { for } 700 \leq T \leq 1255 \mathrm{~K} \\
0.053 \text { for } T>800 \mathrm{~K}
\end{array}\right.
\end{aligned}
$$




\section{CSTRES, CSTRAN, CSTRNI, CANISO, CKMN}

$U m=\left\{\begin{array}{l}0.01 \text { for } T<700 \mathrm{~K} \\ -2.97992 \times 10^{-2}+5.6856 \times 10^{-5} \mathrm{~T} \text { for } 700 \leq T \leq 1255 \mathrm{~K} \\ 0.16 \text { (strain rate sensitivity exponent) for } T>800 \mathrm{~K} .\end{array}\right.$

where

UK = expected error of the strength coefficient (fraction of value)

$U_{n}=$ expected error of the strain hardening exponent (fraction of value)

Um = expected error of the strain rate sensitivity exponent (fraction of value).

The following section is a review of the data used to derive the expressions summarized in this section. Section 4.9.3 describes the development of the plastic deformation models, and Section 4.9.4 is a comparison of model predictions to data not used to develop the models. Uncertainties are discussed in Section 4.9.5.

\subsubsection{Available Data}

A number of references which discuss zircaloy plastic deformation are available. 4.9-2 to 4.9-37 However, many of the data are from uniaxial load elongation tests on poorly characterized material. Also, the basic data used to construct models are often not published. The critical data for analysis of cladding deformation stress and strain versus time in tests with biaxial stress using well characterized cladding are sparse. This section is a review of the theoretical results and data available for use in cladding plastic deformation models. The general features of zircaloy plastic deformation are reviewed first, followed by reviews of uniaxial and biaxial test data. 


\section{CSTRES， CSTRAN， CSTRNI， CANISO， CKMN}

4.9.2.1 Modes of Deformation. Zircaloy has a hexagonal, close-packed crystal structure at temperatures in the range from 300 to $1090 \mathrm{~K}$. At temperatures of 1255 to $2100 \mathrm{~K}$, the alloy has a body-centered cubic structure. Since the structure changes, significant changes in the plastic deformation must also be expected in the temperature range 1090 to $1255 \mathrm{~K}$. Moreover, the alpha (hexagonal), alpha + beta, and beta (body-centered cubic) phase boundaries change with increasing oxygen content. Thus, the temperatures at which one expects discontinuities in cladding plastic deformation change with oxygen content.

The alpha phase (at least in unirradiated zircaloy) is anisotropic. This means the texture (orientation of individual grains) of the material is important at temperatures below $1090 \mathrm{~K}$. Theories exist to deal with anisotropic plastic deformation 4.9-30,4.9-38 under varying stress states, but they rely on the assumption that the physical process responsible for plastic deformation does not change significantly as a function of the stress state. That is, a single plastic potential ${ }^{4.9-38}$ or a single stress-strain 1aw4.9-29 is assumed at each temperature. There is evidence that indicates that this is an oversimplification.4.9-3, 4.9-31 Both slip and twinning systems are expected to operate in zircaloy, and the operable system is related to the orientation of grains with respect to the applied stress. As multiaxial stress-versus-strain data become available, it is likely that different stress-strain laws (equations of state) will be developed for each mode of deformation, along with conditions for specifying when each mode is active. There is not enough detailed biaxial data to develop equations of state for separate modes of deformation; therefore, an equation of state has been developed based on existing uniaxial data and compared to limited biaxial data to see if discrepancies exist. Analysis discussed in Section 4.9 .3 of this report indicates that the discrepancies may be significant.

Modeling zircaloy plastic deformation is further complicated by the fact that deformation is caused by true stress, which is not measured in any 


\section{CSTRES, CSTRAN, CSTRNI, CANISO, CKMN}

of the tests reported because none of the investigators measured the minimum cross-sectional area of the sample during deformation. The problem was addressed by other experiments, 4.9-37 but zircaloy data from these tests were not included in the model.

4.9.2.2 Uniaxial Test Data. The low-temperature part of the equation of state used in MATPRO for fully annealed cladding, Equation (4.9-1), in conjunction with Equations (4.9-23) through (4.9-30), is based primarily on data in Section VI of a review by Woods. ${ }^{4.9-5}$ He reports strength coefficients and strain hardening exponents derived from load elongation tests at temperatures from 300 to $783 \mathrm{~K}$. Strain rates of $1.25 \times$ $10^{-2}$ and $5 \times 10^{-4} / \mathrm{s}$ were used in the tests, and cladding samples with several different annealing histories were studied. Reciprocal pole figures were provided to specify the texture of each cladding group, but these figures are not sufficiently detailed to allow an accurate characterization of the texture. Considerable scatter has no doubt been introduced into the data base because the details of the material texture are not accurately known and because models for cold-work effects had to be used to try to account for the different annealing histories of the samples.

U1timate strength data from Bauer 4-9-27 have been used to supplement the data from Woods for the low-temperature equation of state. These data were from we11-characterized cladding, 4.9-39 but the full stress-strain curve was not published. In order to use these data, a stress-strain law of the form of Equation (4.9-1) had to be assumed.

Since neither Woods nor Bauer reported strain rate sensitivities, data from tests on zircaloy sheet specimens were used for the low-temperature correlation for the strain rate sensitivity exponent, Equation (4.9-17). The values of $m$ obtained with zircaloy-2 plate by Mehan and Wiesinger $4.9-6$ and those reported for zircaloy-4 plate in the transverse direction by Lee and Backofen ${ }^{4-9}$-9 were employed. 


\section{CSTRES, CSTRAN，CSTRNI， CANISO， CKMN}

With two important exceptions, which will be discussed in the next subsection, all of the correlations for plastic deformation above $783 \mathrm{~K}$ are based on ultimate strength, uniform elongation, and strain rate sensitivity measurements by Chung, Garde, and Kassner 4-9-20 and on ultimate strength data reported by Brassfield. 4.9-7 Such data are not satisfactory for deriving an equation of state because (a) the form of the equation of state must be assumed to use the data and (b) even if the assumed form of the equation of state is correct, the parameters obtained from those data in the alpha phase may apply to a mode of deformation not active when biaxial stress is applied. The high-temperature data just discussed were used in MATPRO because there have been so few publications on biaxial isothermal measurements of stress and strain versus time at high temperature.

Equations (4.9-31) and (4.9-32) for the effects of cold work and irradiation on plastic deformation are based primarily on a study by Bement. 4.9-8 The study was conducted with well characterized zircaloy-2 plates irradiated to fast neutron fluences of $10^{25}$ fast $\mathrm{n} / \mathrm{m}^{2}$. The entire load-elongation curve was used to deduce values of the strength coefficient and strain hardening exponent. Unfortunately, specimen irradiation was conducted at $333 \mathrm{~K}$ and testing was at room temperature. It is, therefore, possible that irradiation at reactor operating temperature produces different results. 4.9-40 For that reason, the data from this study were compared with 1 imited and less we11-characterized data from Cowan and Langford 4-9-12 and Howe and Thomas. 4.9-10 The latter data were obtained from material irradiated at reactor operating temperatures. The load-elongation tests of References 4.9-10 and 4.9-12 were conducted at room temperature and $573 \mathrm{~K}$.

The most applicable data for modeling the effect of irradiation and cold work are the measurements of ultimate strengths, yield strengths, and uniform elongation reported by Bauer. 4.9-26,4.9-28 His measurements were taken with cladding irradiated in the Carolina Power and Light $H$. B. Robinson reactor to fast neutron fluences of $4 \times 10^{25} \mathrm{n} / \mathrm{m}^{2}$. Testing was 


\section{CSTRES， CSTRAN， CSTRNI， CANISO， CKMN}

performed at $644 \mathrm{~K}$. Unfortunately, Bauer was unable to test unirradiated samples from the lot of tubing they used. Use of this data must therefore rely on nominal preirradiated values of ultimate strength. ${ }^{4.9-28}$

The models for the effect of $\mathrm{cladding}$ oxidation on plastic deformation are based on ultimate strength data from Rubenstein ${ }^{4-9-11}$ and additional work by Chung, Garde, and Kassner. ${ }^{4.9-23}$ The tensile strength data by Rubenstein were measured at temperatures in the range 300 to $644 \mathrm{~K}$ and oxygen concentrations up to $6330 \mathrm{ppm}$. Unfortunately, neither load-elongation curves nor values of uniform elongation were published.

Chung, Garde, and Kassner ${ }^{4.9-23}$ published constants based on a fit of stress-strain data. The temperature range (1123 to $1673 \mathrm{~K}$ ) and oxygen concentrations ( 0.46 to $1.10 \mathrm{wt} \%$ oxygen) make the data unique. An approximate model was developed by reformulating correlations so that they could be used in the MATPRO package.

4.9.2.3 Biaxial Test Data. Tube burst tests provide strain-versus-time data that are usable for stress-versus-strain modeling of multiaxial stress states. These experiments are important because it is possible that a change in the deformation mode under multiaxial stress will lead to a completely different equation of state for relating stress and strain under biaxial stress.

The earliest attempt at providing data for a biaxial stress-strain law is the work of Hardy. ${ }^{4.9-34}$ Zircaloy-4 cladding tubes were heated in an inert environment, and both temperature and internal pressure were recorded. The important feature of these tests is that tests with similar initial pressures and heating rates were stopped by venting internal pressure before burst temperature occurred. The posttest diameter measurements from tests with the same input conditions provide a reasonable measure of strain during a typical test. Only the diametral expansion was reported, so only one component of strain can be obtained from these tests. 


\section{CSTRES, CSTRAN, CSTRNI, CANISO, CKMN}

Their primary value is for checking predicted diametral strain versus time. At least two components of strain are needed to construct an (effective stress)-(effective strain) expression.

Similar biaxial data have been provided by Chung $4.9-23,4.9-24$ using a laser and high-speed camera. In most cases, only diameter versus time was reported; but the data are a valuable supplement to Hardy's measurements of diametral strain versus time. In a few cases, $4.9-24$ both diameter and length versus time were reported. Unfortunately, those cases include only preoxidized cladding; and it has been shown ${ }^{4.9-23}$ that the presence of an oxide changes the properties of the composite specimen considerably.

The most useful data available to date are measurements of cladding diameter and length versus time by Hann. 4.9-2 The cladding is well characterized, and experimental details are discussed. The principal difficulty with using these data are possible local-effects variations in temperatures and cladding wall thickness, which will cause the measured strain to be an average of local strains. The published data from two of the tests described in Reference 4.9-2 have been analyzed and are discussed in Section 4.9.3.

\subsubsection{Model Development}

The equation of state used in MATPRO to provide a description of zircaloy cladding plastic deformation under tensile stress is based on the Holloman relation

$$
\sigma=K \epsilon^{n}
$$

where

$$
\sigma=\text { true effective stress (Pa) }
$$




\title{
CSTRES， CSTRAN， CSTRNI， CANISO， CKMN
}

\author{
$K=$ strength coefficient $(\mathrm{Pa})$ \\ $n=$ strain hardening exponent (unitless) \\ $\epsilon=$ true effective strain (unitless).
}

Holloman's equation was modified to include the effect of strain rate because this parameter was found to be more important than strain in high-temperature, uniaxial stress tests. The resultant form of the equation of state is

$\sigma=K \epsilon^{\mathrm{n}}\left(\dot{\epsilon} / 10^{-3}\right)^{\mathrm{m}}$

where

$$
\begin{aligned}
& \dot{\epsilon}=\text { rate of change of true effective strain }\left(s^{-1}\right) \\
& m \quad=\text { strain rate sensitivity exponent (unitless). }
\end{aligned}
$$

Several more complex relations between stress and strain have been proposed, 4.9-18,4.9-20,4.9-30 and a few highly simplified equations have been successfully employed in limited temperature ranges. 4.9-32,4.9-33 Equation (4.9-1) was selected because it is efficient for code use and consistent with available data.

The following subsections discuss the development of equations for the coefficients of anisotropy used to determine effective stress and strain from their components. Equations (4.9-17) to (4.9-30) for $m, n$, and $k$ as a function of temperature are developed in Subsection 4.9.3.2. Subsection 4.9.3.3 discusses Equation (4.9-31) and (4.9-32) for the change in $n$ and $k$ with cold-work and irradiation. Finally, Equations (4.9-33) to (4.9-35) for the effect of oxidation on the equation of state are developed in Subsection 4.9 .3 .4 . 


\section{CSTRES, CSTRAN, CSTRNI, CANISO, CKMN}

4.9.3.1 Coefficients of Anisotropy. The model for the effects of texture is based on Hill's quadratic expression for plastic potential 4.9-38 [for principal axes, Equation (4.9-3)]. As Hill and several others have pointed out, the expression implies that the effect of tensile stress is the same as compressive stress. Since compressive and tensile stress of equal magnitude produce different strains in zircaloy, ${ }^{4.9-3}$ Hill's theory is not sufficient to model plastic strain for all states of stress. The theory has been used because (a) it is compatible with the mechanics package of the FRAPCON and FRAP-T codes $4.9-1$ and (b) there are not enough data to modify Hill's theory in the temperature range from 500 to $1255 \mathrm{~K}$.

The constants A1S, A2S, and A3S in Equation (4.9-3) have been assumed to be proportional to the texture factors defined in conjunction with Equations (4.9-8) through $(4.9-10)$ and to correspond to isotropic material in the beta phase. The assumption is ad hoc and intended to reflect the general observation that effective stress is smaller when stress is applied in directions with heavy concentrations of basal poles. Its justification is that it reduces the scatter in measured values of cladding strength for material with different textures, as discussed in Subsection 4.9.3.2.

The appropriate texture factor to use to estimate each anisotropy constant was determined simply by considering uniaxial tests. For example, in a test with $\sigma_{2}=\sigma_{3}=0$ and $\sigma_{1}=$ axial stress, Equation (4.9-3) becomes

$$
\begin{aligned}
\sigma & =(A 1 S+A 3 S)^{1 / 2} \sigma_{z} \\
& =\left[3 / 2\left(f_{r}+f_{\theta}\right)\right]^{1 / 2} \sigma_{z} \\
& =\left[3 / 2\left(1-f_{z}\right)\right]^{1 / 2} \sigma_{z}
\end{aligned}
$$




\section{CSTRES， CSTRAN， CSTRNI， CANISO， CKMN}

where the symbols have been defined previously. For a texture with basal poles strongly concentrated in the axial direction, $f_{z}$ could be nearly 1.0 and the effective stress small. For the small values of $f_{z}$ more characteristic of cladding, the effective stress would be relatively large.

For a perfect crystal, the empirical constants A1S, A2S, and A3S would imply that there is no deformation at all in the basal pole direction. Since twinning is known to occur and allow deformation along the basal pole direction, the estimated values of A1S, A2S, and A3S can be expected to overestimate the effect of texture when the largest stress differences in the expression for effective stress

$\sigma=\left[1.5 f_{r}\left(\sigma_{z}-\sigma_{\theta}\right)^{2}+1.5 f_{z}\left(\sigma_{\theta}-\sigma_{r}\right)^{2}+1.5 f_{\theta}\left(\sigma_{r}-\sigma_{z}\right)^{2}\right]^{1 / 2}$

multiply small texture factors.

The uniaxial stress tests by Busby 4.9-18 agree well with both the effective stress predicted by Equation (4.9-41) and with the strain ratios predicted when A1E, A2E, and A3E in Equations (4.9-5) through (4.9-7) are presumed to be equal to the anisotropy coefficients just discussed for effective stress. However, an analysis of recent experimental data at 811 and $1089 \mathrm{~K}$ has indicated that the anisotropy coefficients given in Equation (4.9-41) are not appropriate for a closed-tube burst test in the temperature range 800 to $1090 \mathrm{~K}$. For these tests, strain anisotropy coefficients derived from the data are characteristic of isotropic material for small strain but change rapidly with increasing strain. A similar result has been reported by Stehle. $4.9-35$

It is likely that the change in the strain anisotropy is due to a change in the physical mechanism of plastic deformation that is, in turn, caused either by increased temperature or the biaxial stress state of the data. The data that could be used to tell whether the important difference between Busby's tests and later tests is the temperature or the stress state 


\section{CSTRES, CSTRAN, CSTRNI, CANISO, CKMN}

were not published at the time of model development. If the stress state changes the mechanism of plastic deformation, a second equation of state and a second set of anisotropy coefficients would be required to describe this second mode of deformation.

An attempt has been made to include the second mode of deformation by defining experimentally determined strain anisotropy coefficients that are different than the texture-related stress anisotropy coefficients previously discussed. The experimental data used to define the high-temperature strain anisotropy coefficients are measurements of length, diameter, and internal pressure versus time for isothermal cladding burst tests at 810 and $1089 \mathrm{~K}$ by Hann. 4.9-2 With the incompressibility assumption, the data can be used to calculate the three components of strain as a function of the stress components. With the additional assumption that the deformation of these samples was symmetric, at least during the early part of the test, plastic strain components were calculated and compared to the predictions of Equations (4.9-5) through (4.9-7) using the texture-determined values for $A 1 E, A 2 E$, and A3E. These predicted results were totally inconsistent with the measured strain components. However, consistent results were obtained by assuming that the constants A1E, A2E, and A3E were all initially 0.5. Moreover, if the anisotropy coefficients are interpreted as texture coefficients, the change in the anisotropy coefficients with deformation was consistent with the general rule suggested by Busby (Reference 4.9-18), i.e., that "the basal planes of zircaloy tend to become aligned parallel to the direction of positive (tensile) strain and perpendicular to negative (compressive) strain."

Unfortunately, a direct solution for A1E, A2E, and A3E from the measured strain components and Equations (4.9-5) through (4.9-7) is not possible. The equations are not independent, since the sum of the strain increments is zero. However, the assumption that the coefficients of anisotropy are proportional to the volume average of some texture coefficients gives another independent equation 


\section{CSTRES, CSTRAN, CSTRNI， CANISO， CKMN}

$A 1 E+A 2 E+A 3 E=1.5$.

With this relation, it is possible, in principle, to solve two of Equations (4.9-5) through (4.9-7) and Equation (4.9-42) in terms of stress and strain components. However, the expressions for $d \epsilon$ and $\sigma$ are complicated functions, so an alternate approach, taking $d \epsilon / \sigma$ as a fourth unknown, was used. With this approach, the expressions for two of the three unknowns AIE, A2E, and A3E in terms of a third and measured stress and strain components are Equation (4.9-42) and

$\frac{\mathrm{de}_{\theta}}{\mathrm{de}_{z}}=\frac{\operatorname{A1E}\left(\sigma_{\theta}-\sigma_{z}\right)+\operatorname{A2E}\left(\sigma_{\theta}-\sigma_{r}\right)}{\operatorname{A3E}\left(\sigma_{z}-\sigma_{r}\right)+\operatorname{AlE}\left(\sigma_{z}-\sigma_{\theta}\right)}$

The idea that the basal poles of zircaloy should tend to become aligned in the direction of compressive strain leads to the conclusion that A2E, the coefficient proportional to the axial concentration of basal poles, should change very little because the axial strain observed in closed-tube burst tests is small. With this assumption and using Equation (4.9-42), the increase in $\mathrm{AlE}$ and the decrease in $\mathrm{ABE}$ are of equal magnitude. Substitution of

$A l E=1 / 2+\delta$

$A 2 E=1 / 2$

$A 3 E=1 / 2-\delta$

into Equation (4.9-43) allows $\delta$ (and thus A1E, A2E, and A3E) to be determined from measured quantities.

Figure 4.9-1 shows the results obtained for the two tests from Reference 4.9-2 at 810 and $1089 \mathrm{~K}$. The increase in the anisotropy coefficient that has been assumed proportional to the effective 


\section{CSTRES, CSTRAN, CSTRNI, CANISO, CKMN}

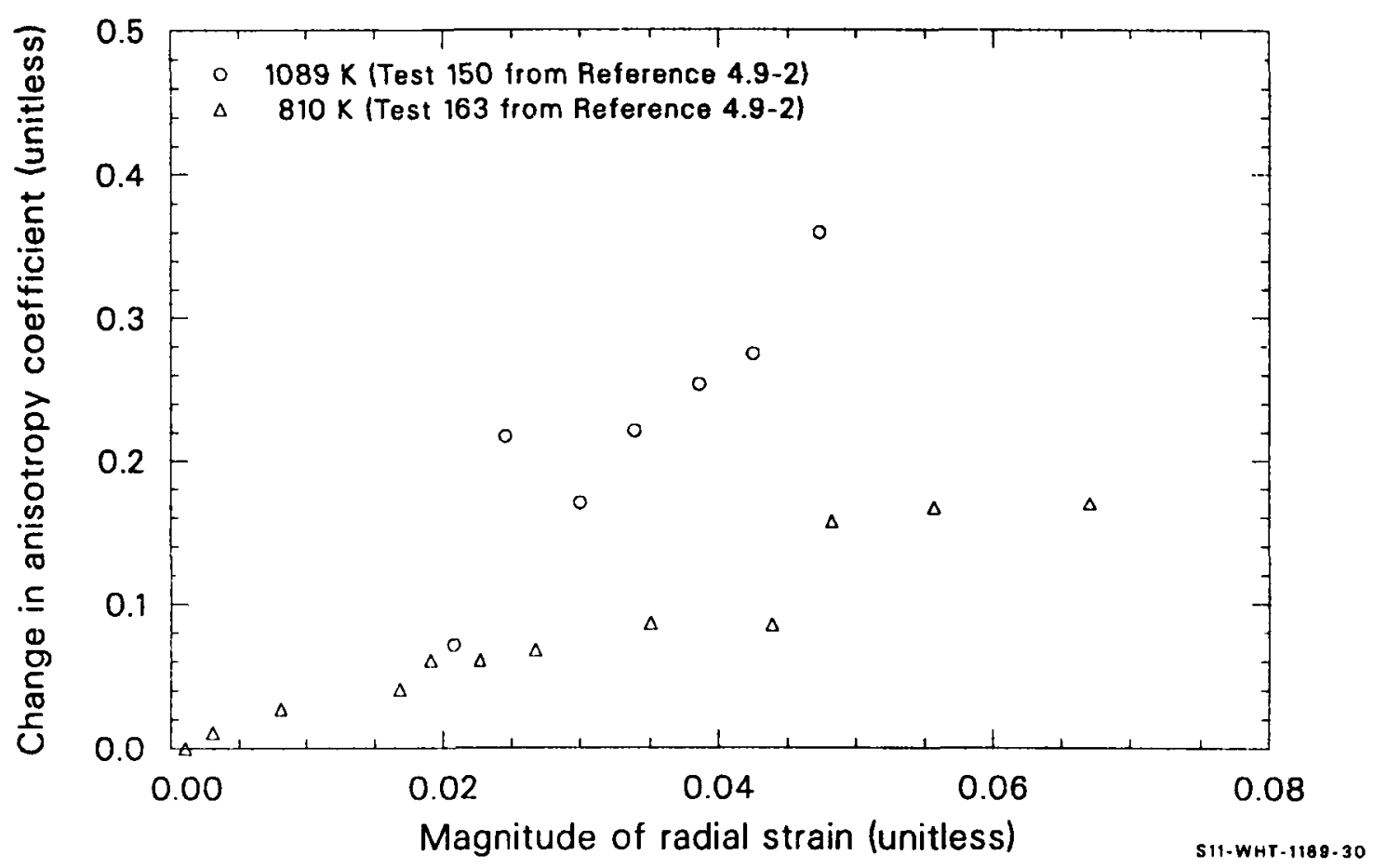

Figure 4.9-1. Increase of the strain anisotropy constant AlE as a function of radial compressive strain in two tests. 


\section{CSTRES， CSTRAN， CSTRNI， CANISO， CKMN}

concentration of basal poles in the radial direction (AIE) is approximately proportional to the radial compressive strain in each test. The rate of change appears to increase with temperature. The expressions for the change of anisotropy coefficients with compressive strain, Equations (4.9-11) through (4.9-13), were obtained by least-squares fits to the two sets of data shown in Figure 4.9-1, assuming a linear temperature dependence. Extrapolation of this correlation to $644 \mathrm{~K}$ predicts no significant departure of the coefficients A1E, A2E, and A3E from their initial values until strains of about 0.15 are produced. This is the approximate strain for which Busby reported significant departure in his tests.

4.9.3.2 Plastic Deformation Parameters $m, n$, and $K$ as Functions of Temperature. The strain rate sensitivity constant, $m$, of zircaloy-2 and zircaloy-4 was evaluated with data obtained from References 4.9-5, 4.9-20, 4.9-6, 4.9-9, and 4.9-16. The data are plotted in Figure 4.9-2. Most of the values of $\mathrm{m}$ at temperatures higher than $900 \mathrm{~K}$ were given in Reference 4.9-20 as a function of engineering strain for strain rate changes centered around $10^{-3} / \mathrm{s}$. No significant dependence on strain was indicated, so $m$ is modeled without strain dependence. Outside the $\alpha-\beta$ phase transition region (taken as from 1090 to $1255 \mathrm{~K}$ ), significant dependence of $m$ on strain rate again was not observed. Within the $\alpha-\beta$ transition region and at strain rates below $6.34 \times 10^{-3}$, $m$ was a strong function of the strain rate.

In the MATPRO plastic deformation models, values of $m$ from data taken at temperatures below $730 \mathrm{~K}$ are approximated with a constant $(\mathrm{m}=0.02)$, while data for temperatures above $900 \mathrm{~K}$ and outside the $\alpha-\beta$ phase transition region are modeled as a linear function of temperature. The value of $\mathrm{m}$ in the region from 730 to $900 \mathrm{~K}$ is modeled by a third-degree polynomial in temperature with the constants determined so that the values and slopes of the polynomial match the values and slopes of the expressions for $\mathrm{m}$ outside the boundaries of the 730-to-900-K region. The values of $\mathrm{m}$ predicted by Equations (4.9-17) to (4.9-22) are illustrated in Figure 4.9-2, 
CSTRES, CSTRAN, CSTRNI, CANISO, CKMN

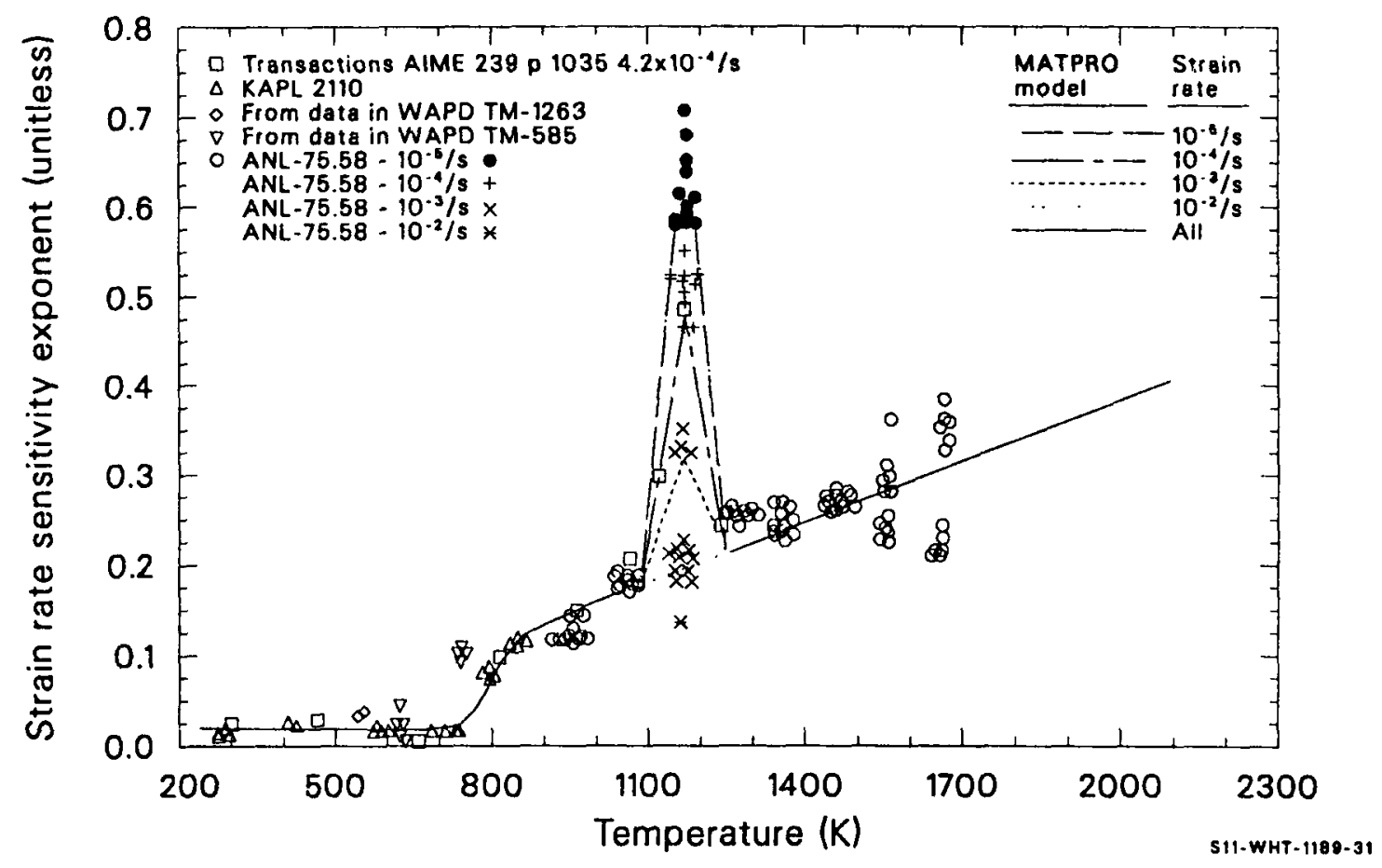

Figure 4.9-2. Strain rate sensitivity exponent as a function of temperature and strain rate. 


\section{CSTRES， CSTRAN， CSTRNI， CANISO， CKMN}

along with the data. The two points at $561 \mathrm{~K}$ are particularly interesting because they are estimates based on high-strain-rate (4/s) tests with irradiated material. They do not appear to be significantly different from the values of $m$ obtained at lower strain rates with unirradiated material.

Most of the values of $m$ in the $\alpha-\beta$ transition region were also obtained from data presented in Reference 4.9-20. The strain-rate-dependent values measured at $1173 \mathrm{~K}$ were assumed to reflect an additive increase in $\mathrm{m}$ due to the mixed phases. When the increase is plotted against the logarithm of the strain rate, the effect of varying strain rates on $m$ can be closely approximated by a straight line of the form

$\Delta \mathrm{m}=0.1253+0.1562 \log _{10}\left(10^{-3} \mathrm{~s}^{-1} /\right.$ STRAIN RATE $)$

which was obtained by a least-squares fit to the data. The fit is illustrated in Figure 4.9-3. For strain rates outside the range $10^{-5} / \mathrm{s}$ to $6.34 \times 10^{-3} / \mathrm{s}$, the change in $\mathrm{m}$ is taken to be equal to its value at the nearest point of this range.

In this model, it is assumed that $m$ increases linearly from its value at the edges of the $\alpha-\beta$ transition region to a maximum at $1172.5 \mathrm{~K}$ in the center of the region, as shown in Figure 4.9-2. Additional data on values of $m$ as a function of temperature and strain rate in the $\alpha-\beta$ transition region will be required if this approximation is to be refined. However, the need for such refinement is questionable, at least until biaxial data confirm a similar effect.

Values of the strain hardening exponent, $n$, as a function of temperature from room temperature to $755 \mathrm{~K}$ are based on data from tensile tests on zircaloy-4 tubes. 4.9-5 The data and the values of $n$ predicted by the MATPRO correlation Equations (4.9-23) through (4.9-25) are shown in Figure 4.9-4. At temperatures above $850 \mathrm{~K}$, the only datum from a full stress-strain curve is the point from EPRI NP 526.4.9-2 This value was 


\section{CSTRES， CSTRAN， CSTRNI， CANISO， CKMN}

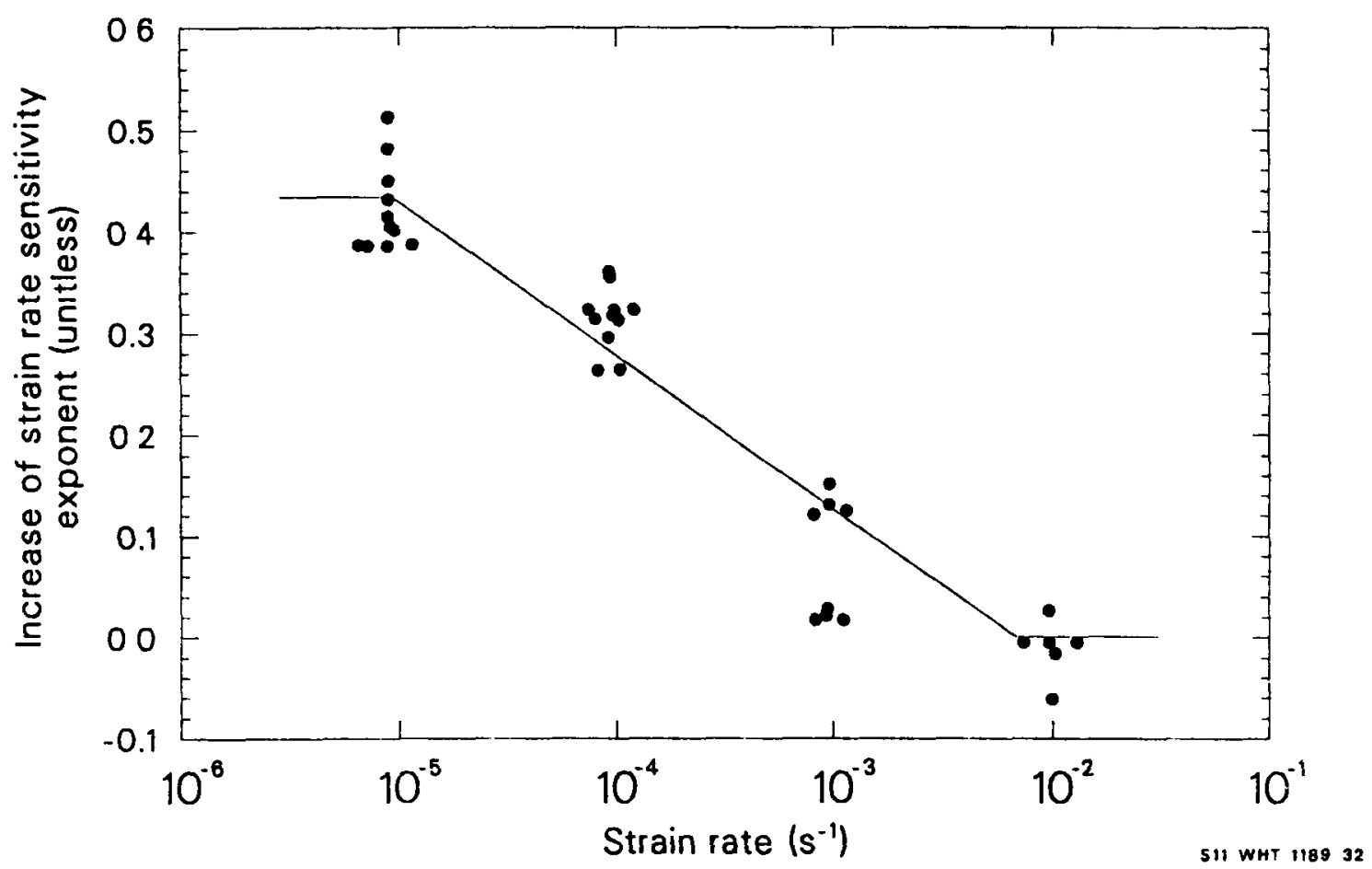

Figure 4.9-3. Increase of the strain rate sensitivity exponent at $1173 \mathrm{~K}$ as a function of strain rate based on Chung, Garde, and Kassner's data. 


\section{CSTRES， CSTRAN， CSTRNI， CANISO， CKMN}

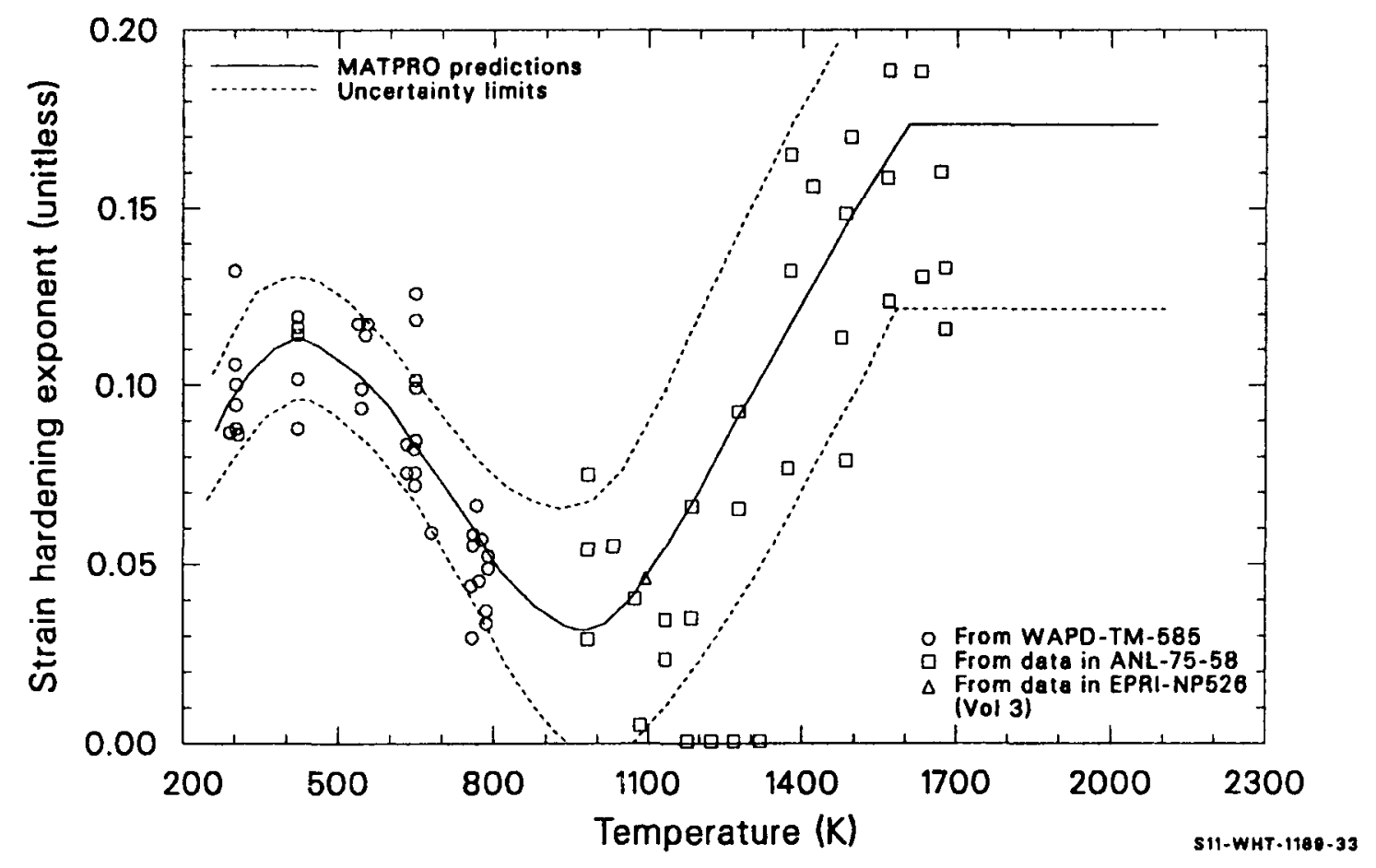

Figure 4.9-4. Base data, MATPRO prediction, and uncertainty estimate for strain hardening exponent of annealed tubes. 


\section{CSTRES, CSTRAN, CSTRNI, CANISO, CKMN}

obtained by a double regression fit to data derived from EPRI Test 150 . The majority of the estimates for the high-temperature strain hardening exponent are simply the values of uniform strain reported by Garde. ${ }^{4.9-20}$ Use of the uniform strain as an estimate is based on the theoretical result that the maximum force in a uniaxial test on a material which obeys Equation (4.9-1) will occur at a strain of $n /(1+m)$.

The very large value of $n$ at $811 \mathrm{~K}$ was obtained from a double regression analysis of EPRI Test 163, which will be discussed in more detail later in this subsection. The large value of $n$ is either due to an unfortunate feature of the double-regression fitting technique or an indication that the stress-strain law for cladding plastic deformation is significantly different when biaxial (closed-tube burst tests) rather than uniaxial stress drives the deformation.

Equations (4.9-27) through (4.9-30) for the strength coefficients, $K$, of fulty annealed, isotropic cladding are based on uniaxial tests of cladding, ${ }^{4.9-5,4.9-27}$ on a uniaxial plate test, ${ }^{4.9-20}$ and on two closed-tube burst tests. ${ }^{4.9-2}$ For the low-temperature data, the effects of varying amounts of cold work and stress relief in the tubing tested were removed prior to including the measured values of $K$ in the data base. This was done by using the cladding annealing model discussed in Section 5.10 and the models for the effects of irradiation and cold work, which will be described in the next subsection. The effects of different strain rates were similarly removed with the model discussed in previous paragraphs of this section. ${ }^{a}$

a. Strain rate effects and annealing effects yefe removed from $K$ by redefining $K^{\prime}$ (from the expression $\left.\sigma=K^{\prime} \epsilon^{n}\right)^{4.9-5}$ as

$K^{\prime}=K\left[\dot{\epsilon} /\left(10^{-3} / s\right)\right]^{m}$

Then, the fractional change in $K$ expected from varying amounts of cold work and annealing was romoved to give values for the $K$ of annealed tubing consistent with the model for the effects of cold work and annealing. 


\section{CSTRES， CSTRAN， CSTRNI， CANISO， CKMN}

The strength coefficients based on uniaxial tests of cladding were modified to apply to isotropic cladding using the empirical anisotropy coefficients discussed in the previous subsection. This was done by substituting values of effective stress from Equation (4.9-3) and values of effective strain from Equation (4.9-5) into the equation of state, Equation (4.9-1) to obtain

$\sigma_{z}=\left[\frac{k}{\left(1.5 f_{r}+1.5 f_{\theta}\right)^{(1+m+n) / 2}}\right] \epsilon_{n}^{z}\left[\frac{\dot{\epsilon}_{z}}{10^{-3}}\right] m$

Thus, the isotropic strength coefficient is related to the strength coefficient determined in a uniaxial test by the expression

$K=K_{\text {axial test }}\left(1.5 f_{r}+1.5 f_{\theta}\right)^{1+m+n / 2}$

This approach is different than the usual practice of taking the uniaxial test as the equation of state. ${ }^{4.9-41}$ The new approach reduces the scatter in values of $K$ because the texture of the material being tested is considered.

Unfortunately, values of $f_{r}$ and $f_{h}$ were not given in Reference 4.9-5, so estimated values based on the texture factors were employed. The approximation that worked best to reduce the scatter in values of the strength coefficient was

$f_{r}+f_{\theta}=1-[$ axial (002) texture coefficient $] / 4$

The factor of $1 / 4$ was determined by requiring the sum of the axial, tangential, and radial (002) texture coefficients of Reference 4.9-5 to be approximately 1.5 ( $f$ factors sum to 1 ). 


\section{CSTRES， CSTRAN， CSTRNI， CANISO， CKMN}

The base data and the values of the strength coefficient predicted by the MATPRO correlation of the strength coefficient Equations (4.9-27) through (4.9-30) are shown in Figure 4.9-5. Discontinuities in the slope of the predicted strength coefficient as a function of temperature occur at 750,1090 , and $1255 \mathrm{~K}$.

Values of the strength coefficient from BMI-NUREG-1961, 4.9-27 GEMP-482, 4.9-7 and ANL-75-584.9-20 were calculated from ultimate tensile strengths (presumed equal to maximum engineering strength at constant engineering strain rate). In order to estimate $K_{a x i a l}$ test, the axial stress and strain rate are converted to their engineering equivalents, ${ }^{a}$ the true strain at maximum engineering stress is found, ${ }^{b}$ and this true strain is substituted into Equation (4.9-1) to find

$K_{\text {axial test }}=\frac{S_{\max } \exp (n / 1+m)}{\left(\frac{n}{1+m}\right)^{m}\left[\frac{\dot{e} \exp (-n / 1+m)}{10^{-3}}\right]^{m}}$

where

$$
\begin{array}{ll}
S_{\max } & =\text { maximum engineering stress }(\mathrm{Pa}) \\
\dot{\mathrm{e}} & =\text { engineering strain rate }\left(\mathrm{s}^{-1}\right)
\end{array}
$$

This approach is not very satisfactory because it neglects possible necking of the test sample. It is used because true-stress/true-strain curves were not available.

a. Engineering stress $=$ true stress $x$ exp(-true strain) inside the exp of the first equation, true strain rate $=$ engineering strain rate $\times \exp (-$ true strain).

b. The true strain at maximum engineering stress with constant engineering strain rate is $1=m / n$. 

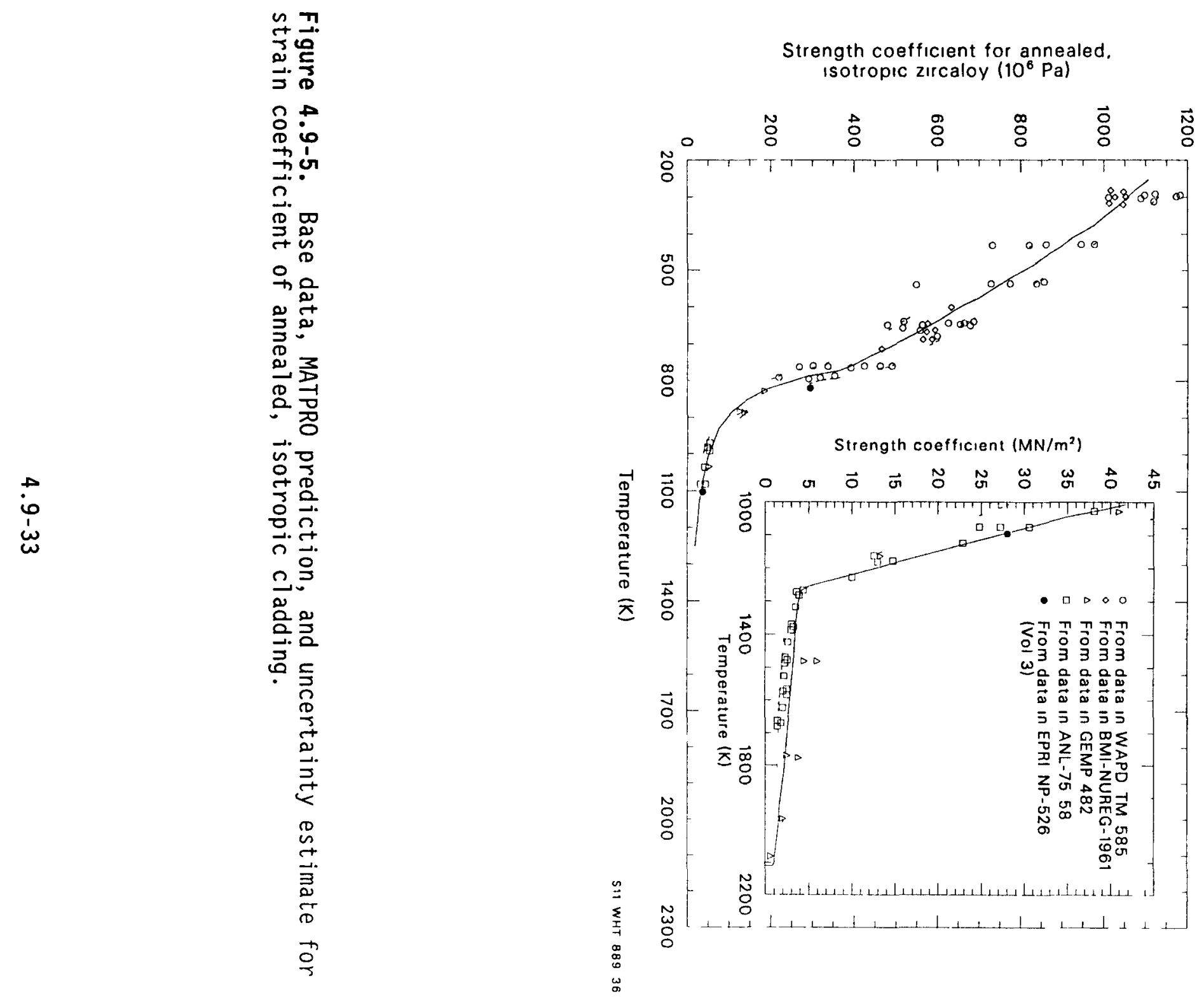

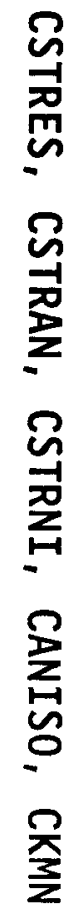




\section{CSTRES, CSTRAN, CSTRNI, CANISO, CKMN}

The most important strength coefficient data shown in Figure 4.9-5 are the two values determined from data in EPRI NP-526 (Vo1. 3).4.9-2 These strength coefficients were determined with a least-squares regression technique that found the values of $K, n$, and $m$ of Equation (4.9-1) that best fit the measured values of the stress and plastic strain. ${ }^{a}$

As previously discussed, the anisotropy coefficients calculated from strain components did not agree with the anisotropy coefficients determined from the materials texture. An effort was made to construct a plastic deformation equation of state by assuming that the experimentally determined strain anisotropy coefficients were also the stress anisotropy coefficients. This approach leads to strength coefficients of $469 \mathrm{MPa}$ at $810 \mathrm{~K}$ and $32.9 \mathrm{MPa}$ at $1089 \mathrm{~K}$--results that differ from the uniaxial strength coefficients significantly. With this approach, a second equation of state is required; but there were only two tests available and no useful model could be produced. The approach was, therefore, abandoned; and it was assumed that stress anisotropy coefficients are different than strain anisotropy coefficients at high temperatures. The anisotropy coefficients determined from material texture were used for stress, and the experimentally determined strain anisotropy coefficients were retained for strain only. The corresponding values of strength coefficients were $360 \mathrm{MPa}$ at $810 \mathrm{~K}$ and $27.9 \mathrm{MPa}$ at $1089 \mathrm{~K}$--results that are consistent with the uniaxial strength coefficients.

The most plausible explanation of these results is that the kind of deformation assumed in Equation (4.9-41) does not occur because some other mode is activated first. The physical arguments for this explanation have been advanced by Picklesimer. ${ }^{4.9-3}$ If the empirical anisotropy coefficients in Equation (4.9-41) are considered acceptable, then Picklesimer's ideas are confirmed by the fact that (a) the largest shear

a. Elastic strains were calculated with the CELAST model and subtracted from the total strain components. 


\section{CSTRES, CSTRAN, CSTRNI， CANISO， CKMN}

stress for $\sigma_{\theta} \approx 2 \sigma_{z}$ and $\sigma \approx 0$ in Equation (4.9-41) is multiplied by a very small texture coefficient, $f_{z}$, and (b) the strength coefficients found when experimentally determined anisotropy coefficients are used to calculate effective stress are larger than those calculated for basal plane slip. The first fact means that basal plane slip is not likely in the EPRI tests because of the relationship between the applied stress and the material texture. The second fact means that the second mode of deformation will be seen only when the effective stress for basal plane slip is low, because the second mode produces much less strain than the basal plane slip when the effective stresses for the two modes are equal.

Unfortunately, this interpretation cannot yet be exploited because the two sets of values for $k, n, m$, and the anisotropy coefficients are also the only values available to use to construct an equation of state for the second mode of deformation in the temperature range from 600 to $1255 \mathrm{~K}$. The values of $K$ obtained with effective stresses calculated from Equation (4.9-41) have thus been incorporated into the data base for MATPRO (after the 810-K value was corrected for cold-work effects) to help force reasonable predictions even though the model is probably incomplete.

\subsubsection{Irradiation and Cold-Work Effects. Irradiation and} cold-work effects on cladding plastic deformation have been incorporated into the equation of state for plastic deformation by repeating the analysis discussed in Section 4.9.3.2 for uniaxial tests and noting the changes in the strain rate sensitivity exponent $(m)$, the strain hardening exponent $(n)$, and the strength coefficient $(K)$ with varying amounts of cold work and irradiation. No change in the strain rate sensitivity exponent with irradiation or cold work was found, but the other two parameters did vary with both cold work and irradiation. The effect of cold work on $K$ and $n$ will be discussed first, followed by the effect of irradiation.

Strength coefficients from Reference 4.9-8 are plotted in Figure 4.9-6. Although texture effects are evident in annealed material and 


\section{CSTRES， CSTRAN， CSTRNI， CANISO， CKMN}

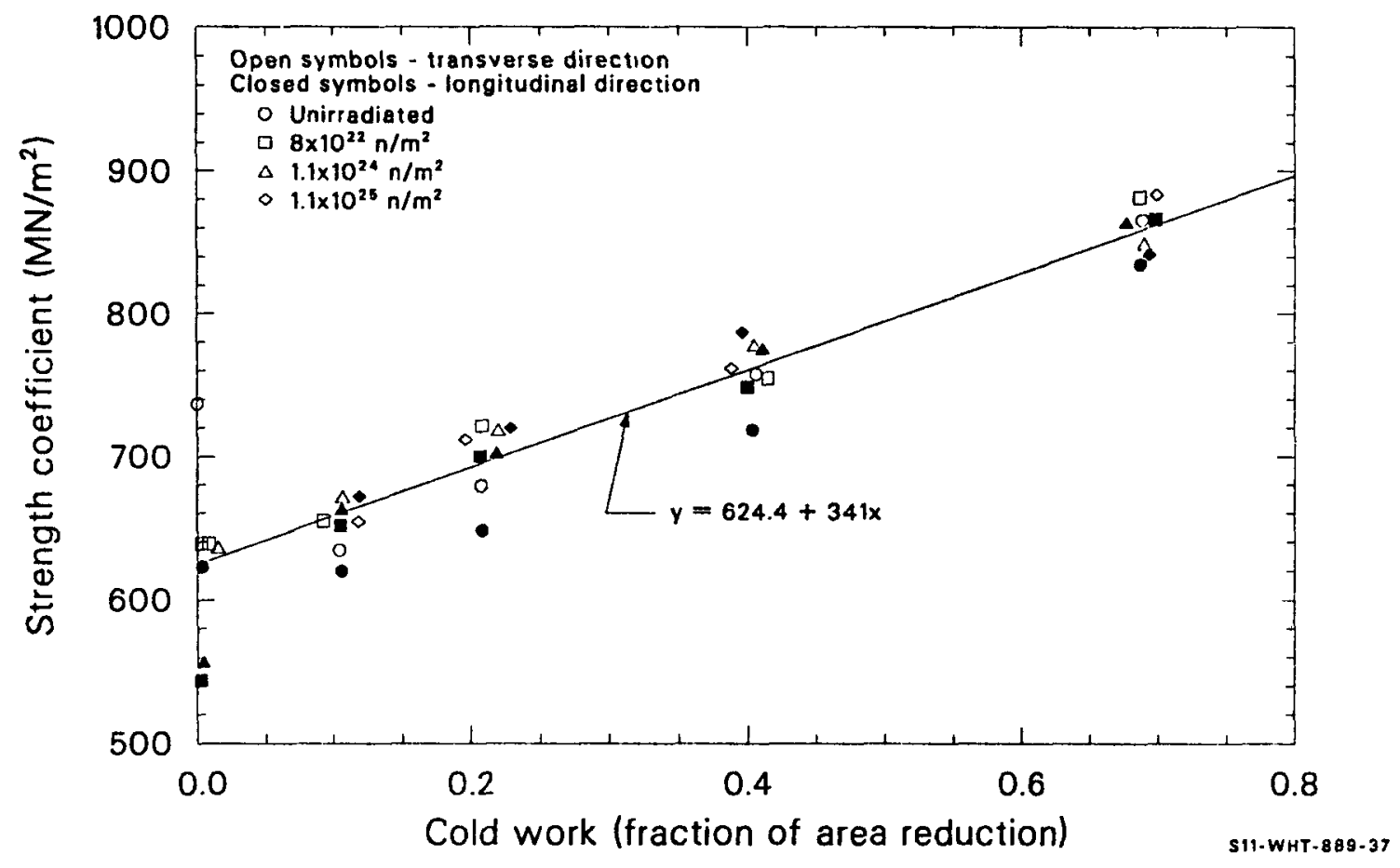

Figure 4.9-6. Data and least-squares fit to strength coefficients as a function of cold work and irradiation at room temperature. 


\section{CSTRES, CSTRAN, CSTRNI, CANISO, CKMN}

irradiation does tend to increase the strength coefficient slightly, the dominant correlation is a linear increase in the strength coefficient with cold work. A linear least-squares fit yields the room-temperature correlation

$K^{\prime}=624.4+341 \mathrm{CWK}=624.4(1+0.546 \mathrm{CWK})$

where

CWK $=$ the cold work for strength coefficient

$K^{\prime}=$ strength coefficient at room temperature $\left(\mathrm{MN} / \mathrm{m}^{2}\right)$.

To estimate the effect of temperature on this correlation, values of the strength coefficient determined from the limited data from References 4.9-12 and 4.9-10 at temperatures of 553 and $573 \mathrm{~K}$ were also fit to a straight line, with the resultant correlation

$K^{\prime}=373+238 C W K=373(1+0.64)$ CWK.

Comparison of the two results show that they are consistent with a temperature-dependent expression of the form

$K^{\prime}=K(T)[1+$ constant $C W K]$

where $K(T)$ is the the temperature-dependent function describing the behavior of the strength coefficient of annealed zircaloy [Equations (4.9-27) to 4.9-30)]. The form of Equation (4.9-54) has, therefore, been assumed. The constant coefficient of the cold work is taken to be 0.546 , as determined at room temperature, because the room temperature data exhibit much less scatter then the high-temperature data taken from several different sources.

Figure 4.9-7 illustrates the effect of cold work and irradiation on the strain hardening exponent, $n$, as determined at room temperature in Reference 4.9-37 
CSTRES, CSTRAN, CSTRNI, CANISO, CKMN

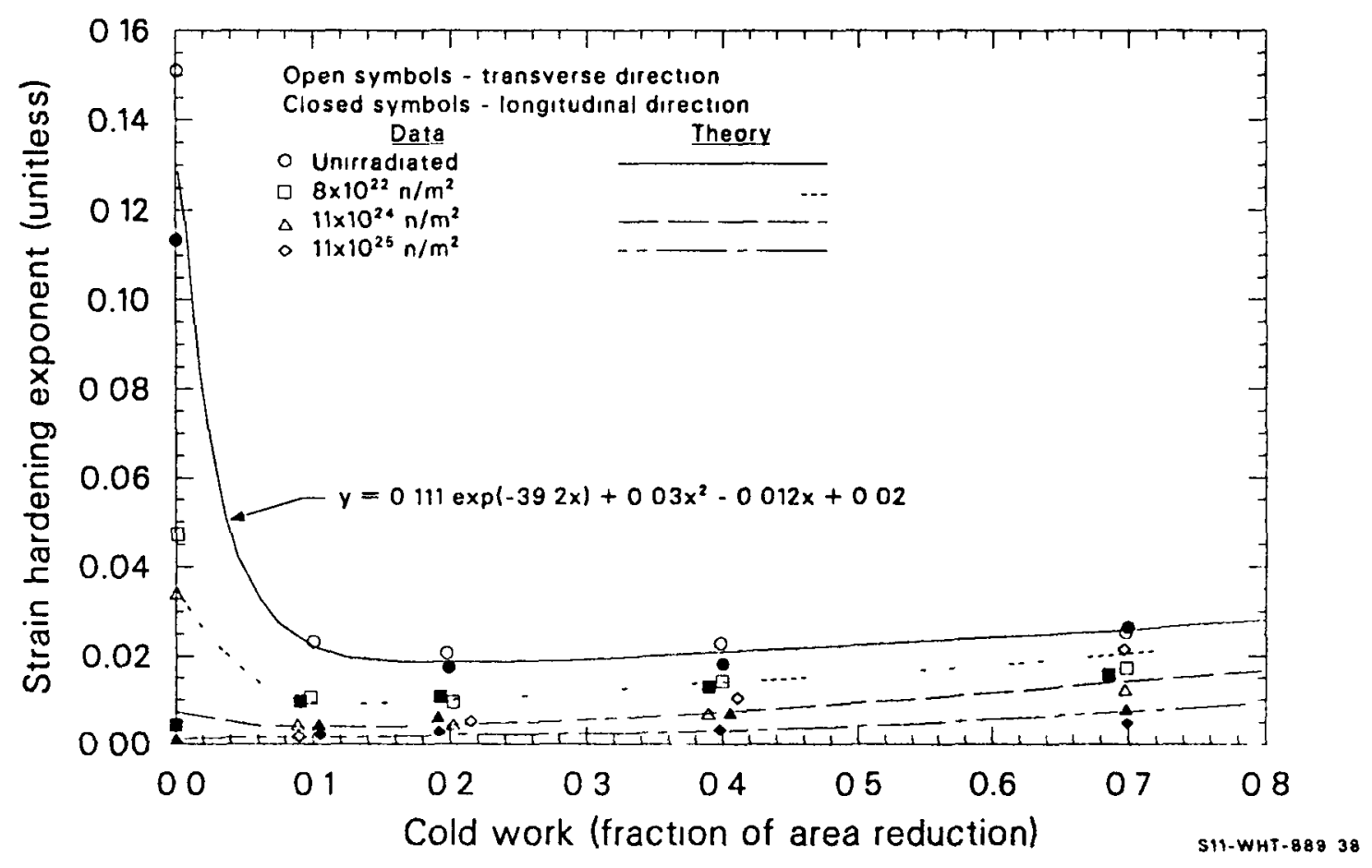

Figure 4.9-7. Data and analytical functions for strain hardening coefficient as a function of cold work and irradiation at room temperature. 


\section{CSTRES, CSTRAN, CSTRNI, CANISO, CKMN}

4.9-8. The strain hardening exponent of unirradiated material shown in Figure 4.9-7 can be described by the empirical relation

$n=0.11 \exp \left(-39.2(W N)+0.03(C W N)^{2}-0.12(C W N)+0.021\right.$

where CWN is the effective cold work for the strain hardening exponent. This expression is essentially a decreasing exponential function for small values of cold work and a slowly increasing parabola for large values of cold work.

At higher temperatures, trends exhibited by the limited and scattered values of $n$ (which have been obtained at 553 4.9-12 and $573 \mathrm{k}^{4.9-10}$ ) are consistent with the assumption that the fractional changes in $n$ with cold work are similar to the fractional changes in $n$ at room temperature. The following functional relationship is assumed in the present model

$n(T$, cold work $)=n(T) \frac{n(\text { cold work })}{n(\text { at } 0 \text { cold work })}$

When the expression for $n$ as a function of cold work given by Equation (4.9-55) is substituted into Equation (4.9-56), the following expression is obtained:

$n=n(T) \frac{0.11 \exp [-39.2(C W N)]+0.03(C W N)^{2}-0.012(C W N)+0.021}{0.132}$

where $n(T)$ is given by Equations (4.9-23) through (4.9-25).

The data from Reference 4.9-8 plotted in Figure 4.9-6 show little effect of irradiation on the strength coefficient. However, the irradiation of these samples were conducted at $333 \mathrm{~K}$, and it is probable that irradiation at reactor operating temperature produces different results. ${ }^{4-9-40}$ 


\section{CSTRES，CSTRAN， CSTRNI，CANISO，CKMN}

The most applicable data for modeling the effect of irradiation on cladding are the measurements of ultimate strength and uniform elongation reported by Bauer. 4.9-26,4.9-28 Their measurements were taken with cladding irradiated in the Carolina Power and Light H. B. Robinson Reactor to fast neutron fluences of $4 \times 10^{25}$ fast $\mathrm{n} / \mathrm{m}^{2}$. Testing was performed at $644 \mathrm{~K}$. Unfortunately, they were unable to test unirradiated samples from the lot of tubing they used, so use of their data must rely on nominal preirradiated ultimate strengths. ${ }^{4.9-28}$

Bauer's data are most representative of in-reactor irradiation damage and are, therefore, used instead of the data from Reference 4.9-8 to find an expression for the effect of irradiation on temperature. Strength coefficients for irradiated cladding at $644 \mathrm{~K}$ were determined with Equation (4.9-51) and tensile test results given in Table $I$ of Reference 4.9-26 (samples P8-20, P8-34, and P8-46). Equations (4.9-27) and (4.9-54) were then used to estimate the strength coefficient for annealed cladding and the cold-work contribution to the strength coefficient (for typical cold work of $0.5)$ at $644 \mathrm{~K}$. The difference between the strength coefficient of the irradiated material and the predicted strength coefficient of cold-worked material is presumed to be due to irradiation effects. Furthermore, the effect of irradiation is assumed to be proportional to the fast neutron fluence. The second term of Equation (4.9-32) resulted from these assumptions .

At present, the best evidence in support of a linear dependence of $k$ on fast neutron fluence is the fact that the small effect of irradiation on the samples of Reference 4.9-8 is not inconsistent with the predictions of Equation (4.9-32) for the relatively low fluences reported in that reference.

The effect of irradiation on the strain hardening exponent, $n$, is complex. Figure 4.9-7 shows that the fractional change in $n$ due to irradiation at $333 \mathrm{~K}$ is large in annealed material and somewhat less in 


\section{CSTRES， CSTRAN， CSTRNI， CANISO， CKMN}

material that has been heavily cold-worked. Furthermore, the effect of irradiation is highly nonlinear. Increasing amounts of irradiation produce continually decreasing changes in $n$.

These features are described empirically in the irradiation model by expressing the ratio of the value of $n$ after irradiation to the value of $n$ before irradiation as an exponential multiplier with a moderating cold-work dependent term in the argument of the exponent. The strain hardening exponent of irradiated material is then

$n=n$ (unirradiated) $\exp \left[-(\text { fluence })^{1 / 3} /(A+B C W N)\right]$

where

$$
\begin{aligned}
& A=3.73 \times 10^{7}\left(\mathrm{n} / \mathrm{m}^{2}\right)^{1 / 3} \\
& B=2.0 \times 10^{8}\left(/ \mathrm{m}^{2}\right)^{1 / 3}
\end{aligned}
$$

and $n$ (unirradiated) is defined in Equation (4.9-57).

4.9.3.4 Effects of 0xygen. The effects of oxygen on cladding plastic deformation have been incorporated into the equation of state for plastic deformation by developing correlations for the changes in the strength coefficient, the strain hardening exponent, and the strain rate sensitivity exponent with increasing oxygen content. The derivation of the expressions for the change in the strength coefficient is presented first, followed by a discussion of the effects of oxygen on the strain hardening exponent and the strain rate sensitivity exponent.

\subsection{Effect of Oxygen Concentration on the Strength} Coefficient--There are no data that may be used directly to find the influence of oxygen on the strength coefficient. However, data do exist 


\section{CSTRES， CSTRAN， CSTRNI， CANISO， CKMN}

that may be manipulated to yield this information. Because different types of data are available for high and low temperatures, different analytical techniques were used for these temperature ranges and the analyses are presented separately.

\section{(1) Low-Temperature Strength Coefficient Data. In the} range 300 to $650 \mathrm{~K}$, which includes typical LWR operating temperatures, the effect of oxygen concentration may be obtained from measurements of the change in the ultimate tensile strength (UTS) of zircaloy as a function of oxygen content. The true strain at maximum engineering stress, that is, the engineering stress at the onset of plastic instability in a tensile test on sheet specimens at constant strain rate, is given by Equation (4.9-51), which is rewritten here for convenience

$K=\frac{S_{\max } \exp (n / 1+m)}{\left(\frac{n}{1+m}\right)^{m}\left(\frac{\dot{\epsilon}}{10^{-3}}\right)^{m}}$

where $S_{\max }$ is the ultimate tensile strength in a tensile test $(\mathrm{Pa})$. When $\epsilon$ was specified in the data, it was $10^{-3} / \mathrm{s}$. Since $10^{-3} / \mathrm{s}$ is a typical value for $\epsilon$ in tensile tests, this value was assumed when not specified. In this case, Equation (4.9-59) reduces to

$K=S_{\max }\left[\frac{\exp (n / m+1)}{(n / m+1)^{n}}\right]$

A paper by Rubenstein ${ }^{4.9-11}$ gives values for the UTS as a function of oxygen concentration for temperatures ranging from about 300 to $650 \mathrm{~K}$. For this range, MATPRO estimates an $m$ of 0.02 for as-received zircaloy. Therefore, $m$ has very little effect on the value of $K$ calculated with Equation (4.9-59) and can be neglected. The value for $n$ predicted by MATPRO varies from 0.119 to 0.144 in this temperature range, causing the term 


\section{CSTRES， CSTRAN，CSTRNI，CANISO，CKMN}

$\exp (n) / \mathrm{n}^{n}$ of Equation (4.9-60) (with $m=0$ ) to vary from 1.45 to 1.53 . If this term is replaced by 1.49 for all temperatures, the maximum error introduced is smaller than $3 \%$, which is substantially less than the scatter in the data. Therefore, the strength coefficient in this temperature range has been calculated by simply multiplying the UTS by 1.49. Strength coefficients calculated in this way using data taken from Rubenstein are presented in Table 4.9-1. The lowest concentration for each temperature ( 9 $\times 10^{-3}$ weight fraction) was assumed to be the concentration of the as-fabricated zircaloy. With this information, the ratio $\mathrm{K} / \mathrm{K}_{0}$, where $\mathrm{K}_{0}$ is the strength coefficient of as-received zircaloy, may be calculated; and these data are also shown in the table.

(2) High-Temperature Strength Coefficient Data. All of the information used to model the effects of oxygen concentration on the high-temperature plastic deformation of zircaloy was taken from a report by Chung, Garde, and Kassner, ${ }^{4 \cdot 9-23}$ of Argonne National Laboratory. Rather than reporting the stress associated with a given strain, however, the Argonne group made a computer fit of their data to a flow curve equation known as the Ludwik equation, ${ }^{4.9-41}$

$\sigma=K \epsilon^{n}+\sigma_{0}$

and reported only the parameters $K, \mathrm{n}$, and $\sigma_{0}$ for many different strain intervals and oxygen concentrations. The additional variable, $\sigma_{0}$, will cause the stress, $\sigma$, resulting from Equation (4.9-61) for a given $\epsilon$ to differ from that of Equation (4.9-3) for the same $K$ and $n$.

The Argonne curves generally start at strains of 0.0004 , and their data are fit accurately to the Ludwik equation by dividing the flow curve into two or three strain intervals with different values of $k, n$, and $\sigma_{0}$ for each interval. There are scattered examples in the Argonne results, indicating that this approach may be inappropriate for small strains. In several of these cases, $\sigma<0$. Since $\sigma_{0}$ can be interpreted as the yield stress, ${ }^{4.9-41}$ a negative value indicates a physical inconsistency. 


\section{CSTRES， CSTRAN， CSTRNI， CANISO， CKMN}

Table 4.9-1. Strength coefficient calculated with data of L. S. Rubenstein

\begin{tabular}{ccccc}
\hline $\begin{array}{c}\text { Temperature } \\
(\mathrm{K})\end{array}$ & $\begin{array}{c}\text { Ultimate } \\
\text { 0xygen Content } \\
\text { (weight fraction) }\end{array}$ & $\begin{array}{c}\text { Tensile } \\
\text { Strength } \\
\text { (MPa) }\end{array}$ & $\begin{array}{c}\text { Calculated K } \\
(\mathrm{MPa})\end{array}$ & $\mathrm{K} / \mathrm{K}_{0}$ \\
\hline 297 & 0.0009 & 524 & 781 & 1.00 \\
297 & 0.0018 & 616 & 918 & 1.18 \\
297 & 0.0034 & 785 & 1170 & 1.50 \\
297 & 0.0063 & 949 & 1414 & 1.81 \\
422 & 0.0009 & & & \\
422 & 0.0034 & 354 & 527 & 1.00 \\
422 & 0.0063 & 544 & 811 & 1.54 \\
533 & 0.0009 & 680 & 1013 & 1.92 \\
533 & 0.0018 & 266 & 396 & 1.00 \\
533 & 0.0034 & 298 & 444 & 1.12 \\
533 & 0.0063 & 361 & 538 & 1.36 \\
644 & 0.0009 & 462 & 688 & 1.74 \\
644 & 0.0018 & 227 & & \\
644 & 0.0034 & 241 & 338 & 1.00 \\
644 & 0.0063 & 283 & 359 & 1.06 \\
& & 373 & 422 & 1.25 \\
\hline
\end{tabular}




\section{CSTRES， CSTRAN， CSTRNI， CANISO，CKMN}

To avoid these problems, the Argonne correlations were used only for strains greater than an arbitrarily chosen minimum of 0.002 .

To get a base for a model, data were generated using Equation (4.9-61) and fit to Equation (4.9-3) (the Holloman equation). The strain interval (from 0.002 to the maximum reported strain) was divided into 20 equally spaced intervals for each temperature-oxygen content combination. The Ludwik equations were then used to find a stress associated with each strain, and the resulting stress-strain pairs were fit by the method of least-squares to the Holloman equation. Only those tests where $\epsilon=$ $10^{-3} / \mathrm{s}$ were used. This included 82 equations describing 60 different samples. The fluctuations in the resulting strength coefficient and the strain hardening exponent were much smaller for the Holloman equation than they were for the Ludwik equation.

For these derived data, the ratio $\left(K / K_{0}\right)$ was calculated, as was done with the low-temperature data. As with the Rubenstein data, $\left(K / K_{0}\right)$ increases with oxygen concentration for all temperatures.

(3) Correlation for the Effect of Oxygen Concentration on the Strength Coefficient. Because little is known about the physical mechanism causing the strength coefficient of zircaloy to change with oxygen concentration, a model based on theory is not possible. An empirical fit to the data is, therefore, the approach chosen. In addition to fitting the data, the correlation should satisfy the obvious condition that $\left(K / K_{0}\right)=1$ when $C=C_{0}$. A quite simple correlation that does this is

$K / K_{0}=1+a\left(C-C_{0}\right)$

where

$C=$ oxygen concentration (weight fraction) 


\title{
CSTRES，CSTRAN， CSTRNI， CANISO， CKMN
}

\author{
$\mathrm{C}_{0}=$ oxygen concentration of as-received zircaloy (weight \\ fraction) \\ $\mathrm{a}=\mathrm{a}$ function of temperature to be determined (weight \\ fraction $)^{-1}$.
}

An equation of the form of Equation (4.9-62) for each temperature was generated by a least-squares-fit technique using the data. The results are presented in Table 4.9-2.

The ratio $\left(K / K_{0}\right)$ derived from Equation (4.9-62) is plotted as a function of oxygen concentration for all temperatures used in Figure 4.9-8. The data from Table 4.9-2 are shown in the same figure. The six lowest temperatures are represented by a single line with $a=130$ because they are too close together to be distinguishable.

The general characteristics of the temperature-dependence of a are that it is relatively constant until about $1200 \mathrm{~K}$, rises rapidly between 1200 and $1400 \mathrm{~K}$, and then begins to level off. The leveling off is based on only the data point at the highest temperature. However, there are too few data to justify a sophisticated correlation. A single function can be found which fits the data with acceptable accuracy over the entire temperature range, thus having the advantages of automatically avoiding discontinuities and fitting compactly into a computer routine. For $300<\mathrm{T}<1673 \mathrm{~K}$, the function is

$a=1120-\frac{990}{\exp [(T-1301.5) / 61]+1}$

Equation (4.9-63) is plotted as the function of temperature in Figure 4.9-9, where it is compared with the data from Table 4.9-2.

A comparison of the values of $\left(K / K_{0}\right)$ predicted by Equations (4.9-62) and (4.9-63) with the data shows that the average percentage error is $12 \%$. All the points except those at 1123 and $1173 \mathrm{~K}$ have percentage errors of $4.9-46$ 


\section{CSTRES，CSTRAN， CSTRNI， CANISO， CKMN}

Table 4.9-2. Rate of change of $K / K_{0}$ with oxygen content

\begin{tabular}{cc}
$\begin{array}{c}\text { Temperature } \\
(\mathrm{K})\end{array}$ & $\mathrm{a}$ \\
\cline { 2 - 2 } 297 & \\
422 & 160 \\
533 & 178 \\
644 & 137 \\
1123 & 115 \\
1173 & 89 \\
& 95 \\
1223 & \\
1273 & 343 \\
1323 & 541 \\
1373 & 676 \\
1673 & 891 \\
& 1116
\end{tabular}


CSTRES， CSTRAN， CSTRNI， CANISO， CKMN

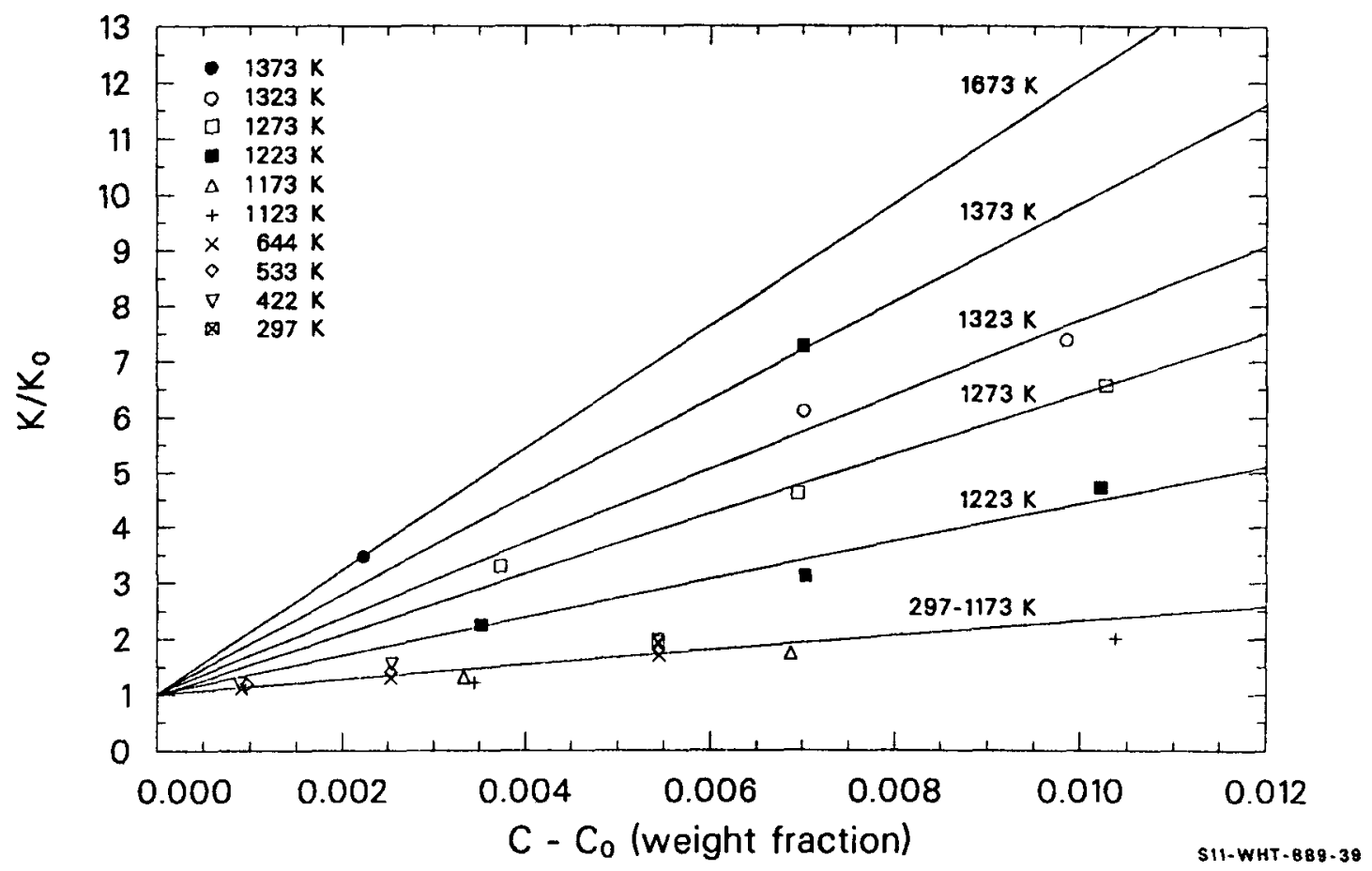

Figure 4.9-8. Calculated ratios of the strength coefficients of zircaloy, containing oxygen $(K)$ and the strength coefficients of as-fabricated zircaloy $\left(K_{0}\right)$ as a function of oxygen concentration for several temperatures. 
CSTRES， CSTRAN， CSTRNI， CANISO， CKMN

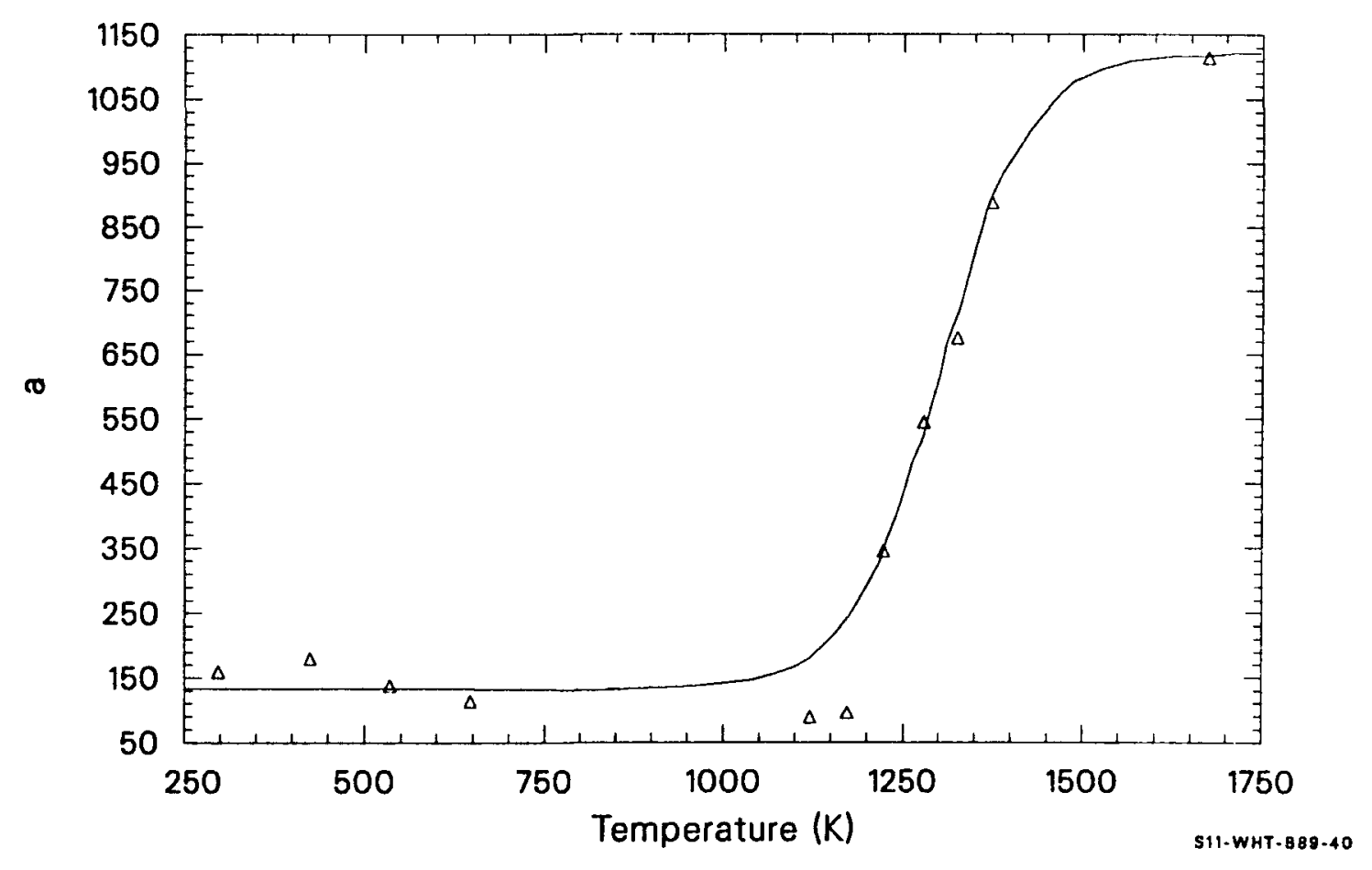

Figure 4.9-9. Calculated curve and data showing the rate of change of the zircaloy strength coefficient with oxygen content as a function of temperature. 


\section{CSTRES, CSTRAN, CSTRNI， CANISO， CKMN}

this size or less. At these two temperatures, the average percentage error is $45 \%$. These uncertainties can serve only as a rough guide in assessing the accuracy of the model, since they were calculated by comparing the correlation to its own data base.

\subsection{Effect of Oxygen Concentration on the Strain}

Hardening--The methods of development and the form of the equations used to correlate oxygen content with changes in the strain hardening exponent, $n$, are identical to those used for the analogous changes in the strength coefficient.

(1) High-Temperature Strain Hardening Exponent Data. The only data available are those from Chung, which were all taken at high temperature.

(2) Correlation for the Effect of Oxygen Concentration on the Strain Hardening Exponent. The ratio $\left(n / n_{0}\right)$ is modeled using the equation

$n / n_{0}=1+b\left(c-c_{0}\right)$

where $b$ is a function of temperature to be determined. A fit of Equation (4.9-64) to the data gives the value for b listed in Table 4.9-3.

The lines given by Equation (4.9-64) using the values of $b$ listed in Table 4.9-3 are plotted in Figure 4.9-10 with their data bases.

The data presented in Table 4.9-3 and Figure 4.9-10 show considerable scatter. It is possible that this is a reflection of actual physical processes. Systematic oscillations in such things as the total strain at failure and the strain at maximum engineering stress have been repeatedly documented in the Argonne Quarterly Reports, 4.9-22,4.9-23 to 4.9-26 and these oscillations may be due in part to variations in the strain hardening 


\section{CSTRES, CSTRAN， CSTRNI， CANISO，CKMN}

Table 4.9-3. Rate of change of $n / n_{0}$ with oxygen content

\begin{tabular}{cr}
$\begin{array}{c}\text { Temperature } \\
(\mathrm{K})\end{array}$ & \multicolumn{1}{c}{$\mathrm{b}$} \\
\cline { 2 - 2 } 1123 & -19.0 \\
1173 & 4.9 \\
1223 & -12.7 \\
1273 & -11.1 \\
1323 & 340.0 \\
1373 & 244.3 \\
1673 & 1245.0
\end{tabular}




\section{CSTRES， CSTRAN， CSTRNI， CANISO， CKMN}

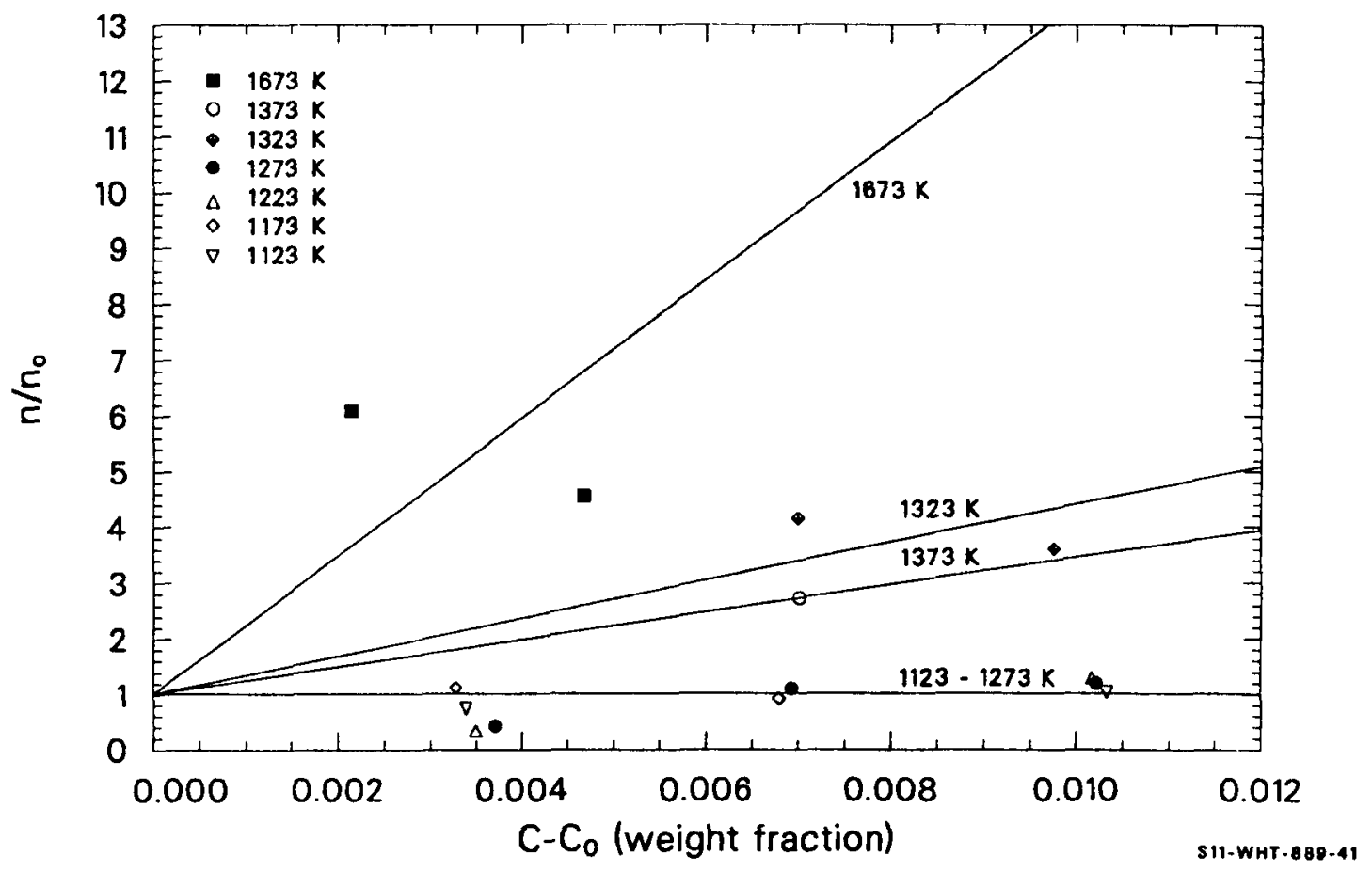

Figure 4.9-10. Calculated ratios of the strain hardening exponents of zircaloy containing oxygen ( $n$ ) and the strain hardening exponents of as-fabricated zircaloy $\left(n_{0}\right)$ as a function of oxygen concentration for several temperatures. 
CSTRES, CSTRAN, CSTRNI, CANISO, CKMN

exponent. More data are needed to accurately quantify these variations. Therefore, only the general features of the coefficient $b$ in Equation (4.9-64) are treated in the model. It is small below about $1300 \mathrm{~K}$, rises rapidly between 1300 and $1400 \mathrm{~K}$. and then levels off about $1500 \mathrm{~K}$. The function used is

$b=1250-\frac{1250}{\exp [(T-1380) / 20]+1}$

for $1123<T<1673 \mathrm{~K}$.

Equation (4.9-65) is plotted in Figure 4.9-11, where it is compared with the data from Table 4.9-3.

At temperatures below $1100 \mathrm{~K}$, b calculated with Equation (4.9-65) is negligibly small, so that $\left(n / n_{0}\right)=1$. This means that the strain hardening exponent is unchanged by the presence of oxygen. Therefore, the lower limit of the model may be extended down to operating temperatures without affecting the stress-strain laws now in MATPRO.

The uncertainty in the predictions of Equations (4.9-64) and (4.9-65) when compared with the data base is quite large. The one standard deviation limits are $\pm 42 \%$. There are two data which are in error by more than $100 \%$; but since the data indicate that the strain hardening exponent changes by a factor of five or more in some cases, the model is certainly better than entirely neglecting oxygen effects.

\subsection{Effect of 0xygen Concentration on the Strain Rate}

Sensitivity Exponent--As with the strength coefficient and the strain hardening exponent, the data used for determining the effect of oxygen concentration on the strain rate sensitivity exponent $m$ of Equation (4.9-3) are taken from Chung. In this case, however, the data may be used directly, since they are consistent with the Holloman equation, Equation (4.9-3), as will be shown in the next subsection. 
CSTRES, CSTRAN, CSTRNI, CANISO, CKMN

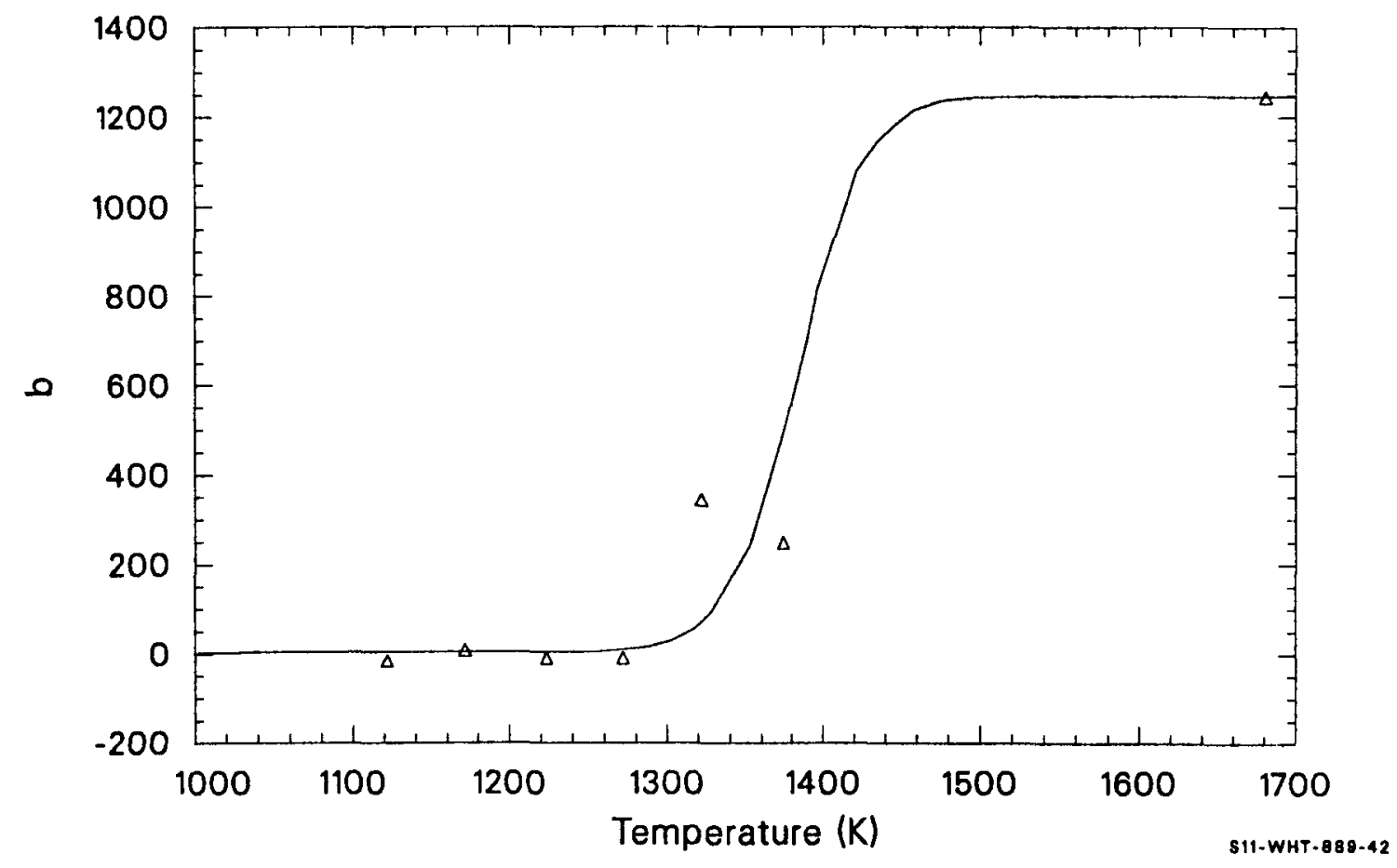

Figure 4.9-11. Calculated curve and data showing the rate of change of the zircaloy strain hardening exponent as a function of temperature. 


\section{CSTRES, CSTRAN, CSTRNI, CANISO, CKMN}

(1) Experimental Technique. Chung ${ }^{4 \cdot 9-19}$ measured m by quickly changing the strain rate during a stress-strain test, causing a change in the stress, $\sigma$. If the change occurs rapidly, the strain itself does not change significantly during the transient, and $m$ may be found from the equation

$$
\left(\sigma_{1} / \sigma_{2}\right)=\left(\dot{\epsilon}_{1} / \dot{\epsilon}_{2}\right)^{m}
$$

or

$m=\ln \left(\sigma_{1} / \sigma_{2}\right) / \ln \left(\dot{\epsilon}_{1} / \dot{\epsilon}_{2}\right)$

where

$$
\begin{aligned}
& \sigma_{1}=\text { stress immediately before the transient }(\mathrm{Pa}) \\
& \sigma_{2}=\text { stress immediately after the transient }(\mathrm{Pa}) \\
& \dot{\epsilon}_{1}=\text { strain rate before the transient }\left(\mathrm{s}^{-1}\right) \\
& \dot{\epsilon}_{2}=\text { strain rate after the transient }\left(\mathrm{s}^{-1}\right) .
\end{aligned}
$$

Taking the logarithm of both sides of Equation (4.9-1) for two cases with different stresses and strain rates, but the same strain,

$$
\begin{aligned}
& \ln \left(\sigma_{1}\right)=\ln (K)+n[\ln (\epsilon)]+m\left[\ln \left(\epsilon_{1}\right)\right]-m\left[\ln \left(10^{-3}\right)\right] \\
& \ln \left(\sigma_{2}\right)=\ln (K)+n[\ln (\epsilon)]+m\left[\ln \left(\epsilon_{2}\right)\right]-m\left[\ln \left(10^{-3}\right)\right]
\end{aligned}
$$

Subtracting Equation (4.9-69) from Equation (4.9-68) yields Equation (4.9-67), so the strain rate sensitivity exponents measured by Chung may be used directly in Equation (4.9-1). 


\section{CSTRES, CSTRAN, CSTRNI, CANISO, CKMN}

\section{(2) High-Temperature Strain Rate Sensitivity Exponent}

Data. The data were taken from two Argonne Quarterly Reports $4.9-22,4.9-23$ and, as with the strain hardening exponent, cover the temperature range from 1123 to $1673 \mathrm{~K}$. These data are shown in Figure 4.9-12, where $m$ is plotted as a function of oxygen concentration for seven temperatures. The change in $m$ is plotted as a function of oxygen concentration for seven temperatures. The changes in $\mathrm{m}$ with temperature reflect the changes predicted by MATPRO. The 1173-K curve is anomalous because the as-received zircaloy is in the alpha + beta transition phase region at this temperature. ${ }^{a}$ It is evident that $m$ decreases with increasing $C$ in a11 cases; and each curve resembles an exponential decay, although the scatter in the data precludes quantification of the temperature dependence.

Only the ratio $\left(\mathrm{m} / \mathrm{m}_{0}\right)$ as a function of concentration was modeled, as shown in Figure 4.9-13. The equation used was

$m / m_{0}=\exp \left[-69\left(C-C_{0}\right)\right]$

where $m_{0}$ is the strain rate sensitivity constant for as-received material. The number 69 in the argument of the exponent in Equation (4.9-70) was obtained by a least-squares fit of the data to the equation.

The quality of the fit of Equation (4.9-70) using Chung's values for $m_{0}$ can be seen in Figure 4.9-13. Although a quantitative statement cannot be made at this time, the scatter may be partly the result of phase transitions which can occur even isothermally with changes in oxygen content (Figure 4.9-14). For example, at $1123 \mathrm{~K}, \mathrm{~m}_{0}$ is measured using material

a. This explanation will not suffice to explain the low values of $m$ at $1473 \mathrm{~K}$, where the material remains in the beta region over the entire range of oxygen cgncentrations reported, as may be seen in the phase diagram taken from Chung. 
CSTRES， CSTRAN， CSTRNI， CANISO， CKMN

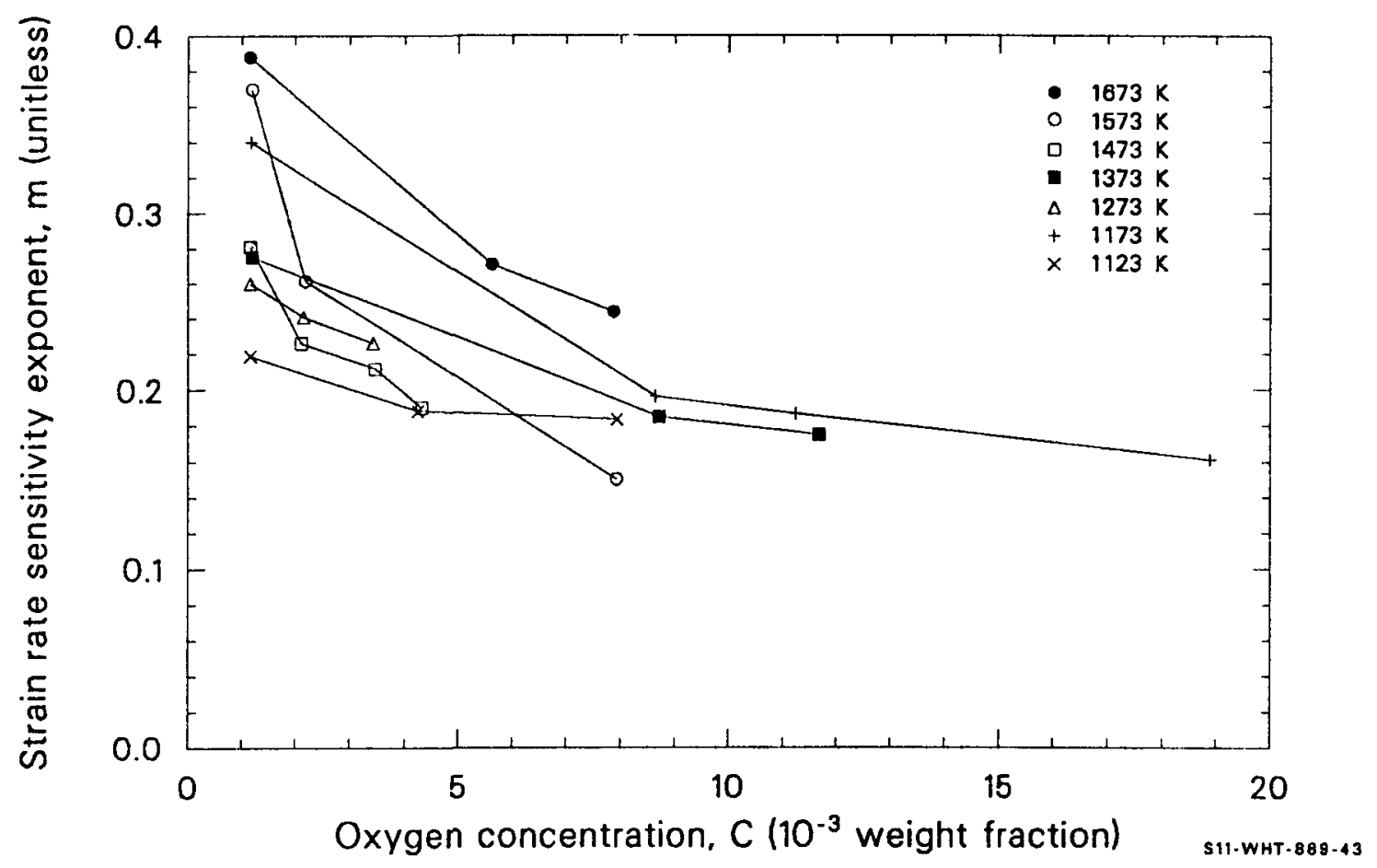

Figure 4.9-12. Strain rate sensitivity exponent, $m$, data as a function of oxygen concentration from Chung. 
CSTRES， CSTRAN， CSTRNI， CANISO， CKMN

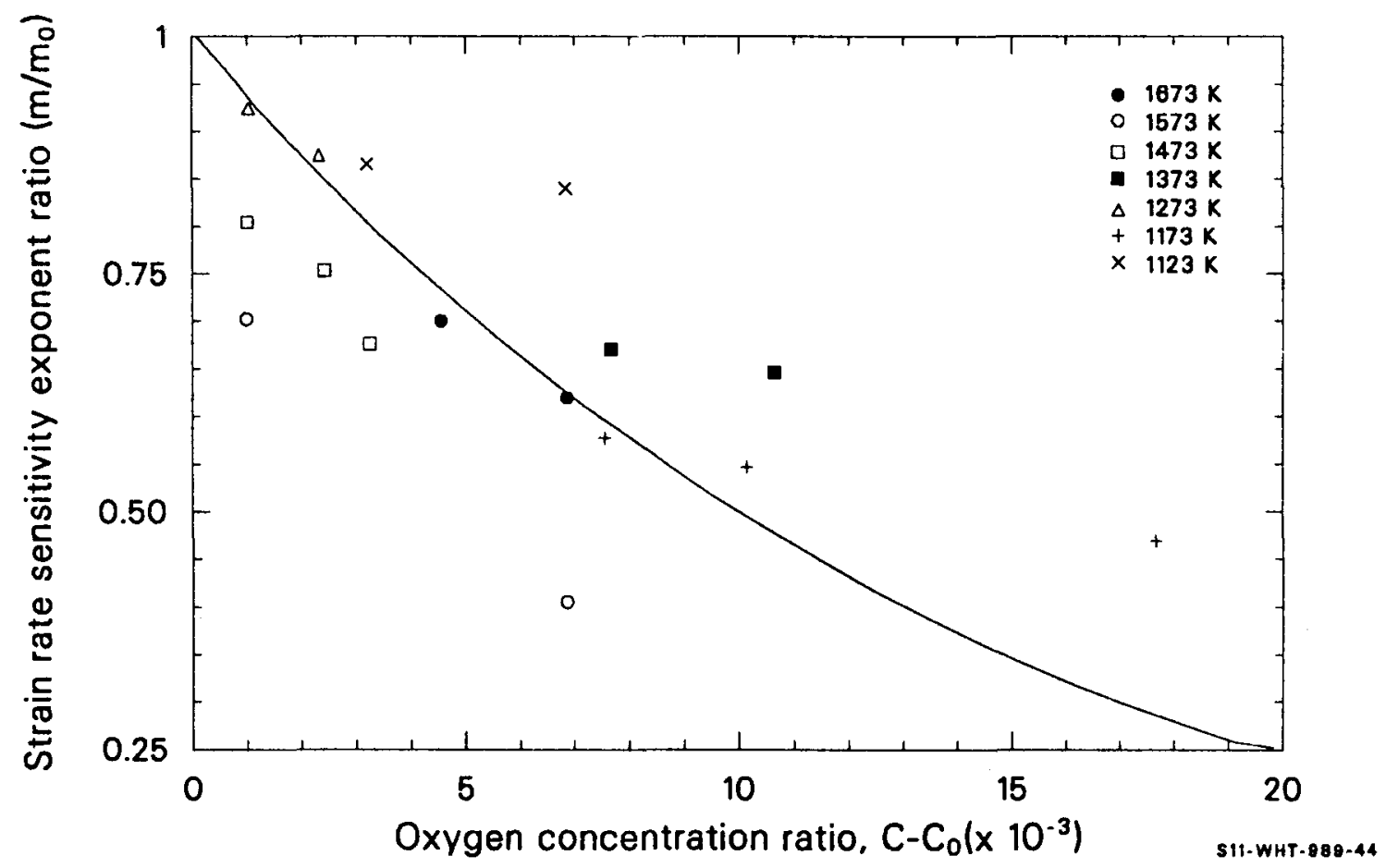

Figure 4.9-13. The ratio $\mathrm{m} / \mathrm{m}_{0}$ as a function of oxygen concentration showing Chung data and the line used to fit these data. 
CSTRES， CSTRAN， CSTRNI， CANISO， CKMN

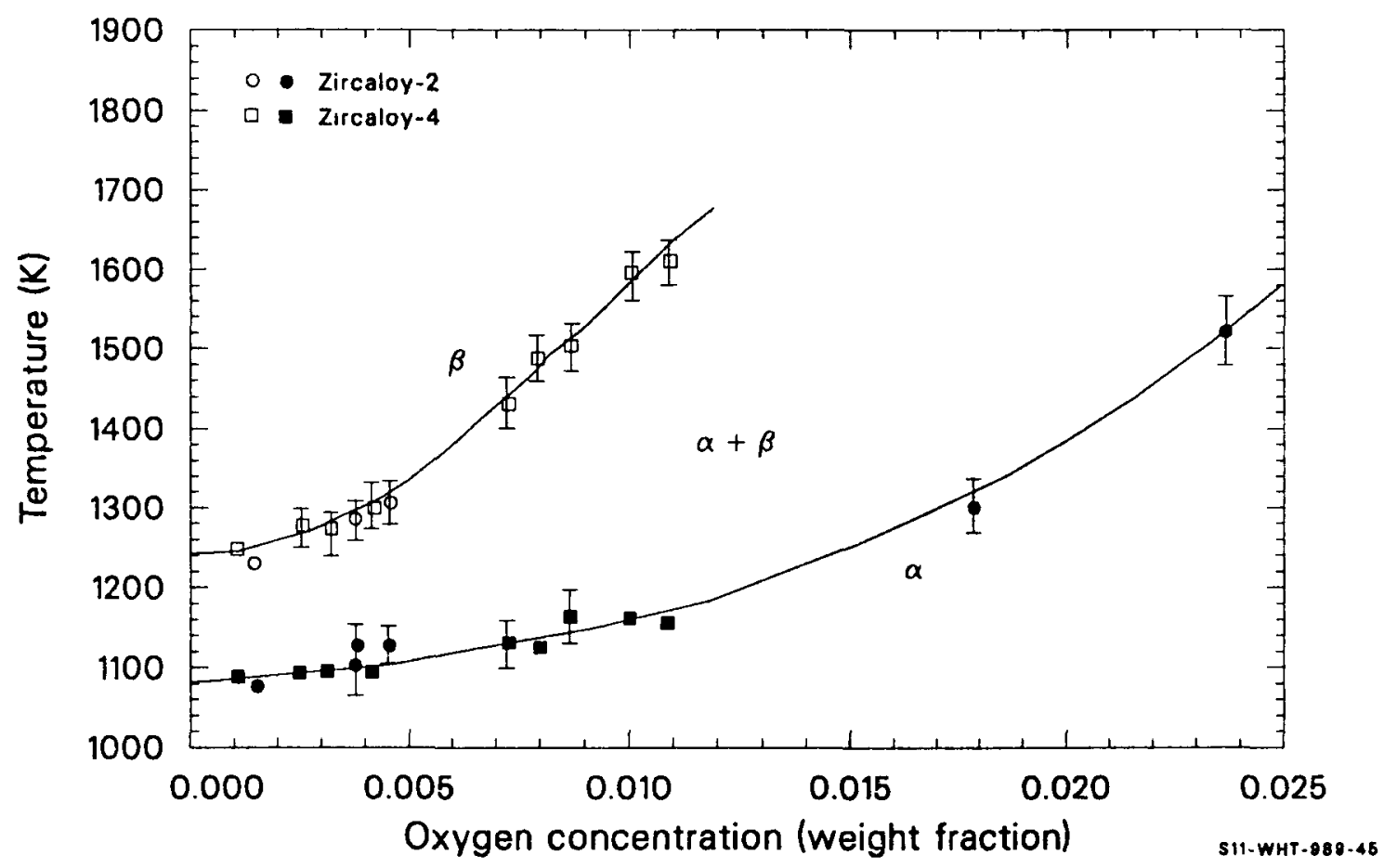

Figure 4.9-14. Zircaloy-oxygen phase diagram, taken from Chung. 


\section{CSTRES， CSTRAN， CSTRNI， CANISO， CKMN}

which is midway through the alpha + beta transition phase; while the material at the highest oxygen concentration point at $1123 \mathrm{~K}$ is oxygen-stabilized, alpha-phase zircaloy. The fact that this point is quite far from the calculated curve may be a reflection of the failure to consider the effects of the phase transition.

To include the $68 \%$ of the data that should fall within one standard deviation from the calculated 1ine, the coefficient 69 of Equation (4.9-70) must be given quite large uncertainty limits, \pm 40 . The data lying below the calculated line in Figure 4.9-13, especially those for which $\left(C-C_{0}\right)=10^{-3}$, contribute much to the uncertainty because they require particularly large values to make the curve drop abruptly enough from its starting point to pass through them.

\subsection{Flow Curves Showing the Effect of 0xygen}

Concentration--Three figures are presented in this section to show how oxygen concentration affects the plastic deformation portion of the stress-strain curves predicted by MATPRO. Equations (4.9-62) to (4.9-65) and Equation (4.9-70) were used in conjunction with the MATPRO subroutines to generate these plots. All plots show two curves, one for as-fabricated zircaloy $\left(C-C_{0}=0\right)$ and one for zircaloy containing a total of about five times the as-fabricated oxygen level $\left(C-C_{0}=0.005\right.$ weight fraction). Unless otherwise specified, the as-fabricated oxygen content, $\mathrm{C}_{0}$, was assumed to be 0.0012 weight fraction.

Figure 4.9-15 shows the flow curves at $600 \mathrm{~K}$, a temperature typical of PWR normal operation. The strain rate was taken as $10^{-3} / \mathrm{s}$, so that the strain rate dependence on oxygen content was not a factor. At this temperature, Equations (4.9-64) and (4.9-65) predict a completely negligible change in $n$, the strain hardening exponent. The entire difference between the curves thus results from the change in $K$ which, for these conditions, increases by a factor of 1.65 . 
CSTRES， CSTRAN， CSTRNI， CANISO， CKMN

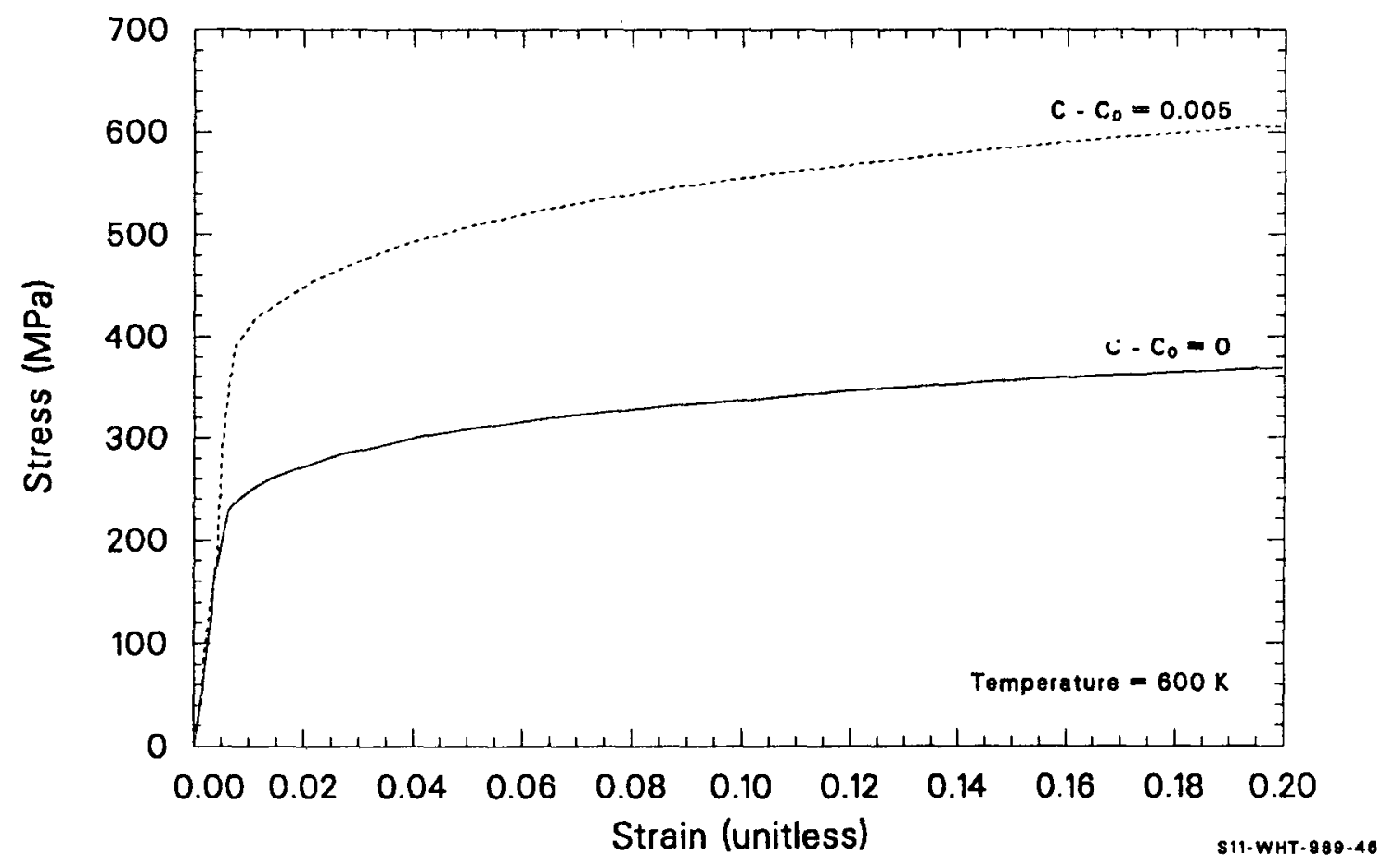

Figure 4.9-15. Stress as a function of strain at a strain rate of $10^{-3} / \mathrm{s}$ for two oxygen concentrations at $600 \mathrm{~K}$. 


\section{CSTRES， CSTRAN， CSTRNI， CANISO， CKMN}

Figure 4.9-16 shows flow curves for conditions the same as those of Figure 4.9-15 except that the temperature is $1400 \mathrm{~K}$, which is characteristic of the temperature postulated for reactor transients, such as a loss-of-coolant or a power-cooling-mismatch. At this temperature, $K$ increases by a factor of 5.8 and $n$ by a factor of 5.6. Since the curve with $C=C_{0}=0$ is nearly flat except at very small strains, the increasing slope of the curve for $C-C_{0} \neq 0$ is largely due to the change in $n$ caused by the extra oxygen.

Figure 4.9-17 shows the stress required to cause a strain of 0.1 at various strain rates. This figure is included to illustrate the effect of oxygen concentration on the strain rate exponent. Nearly all of the difference between the oxidized and unoxidized cladding is caused by the change in the strength coefficient. Careful examination of the curves will show a slightly increasing separation between them as the strain rate increases. The separation of the curves increases by only $2.5 \%$ as the strain rate changes from $10^{-4}$ to $10^{-2}$. However, under these conditions, if $m$ were unchanged by oxygen concentration but $K$ were affected, the increase would be $9.3 \%$. In general, the effect of oxygen concentration on $m$ is to increase $d \sigma / d \epsilon$ for $\epsilon<10^{-3} / \mathrm{s}$ and to decrease $d \sigma / d \epsilon$ for $\epsilon$ $>10^{-3} / \mathrm{s}$. For the strain rate range of Figure $4.9-17$, approximately nine-tenths of the strain rates are greater than $10^{-3} / \mathrm{s}$; therefore, the net effect is a slope smaller than would be found if $m$ were not a function of oxygen concentration. These observations must still be regarded as tentative, since Equation (4.9-39) was derived from data taken at strain rates close to $10^{-3} / \mathrm{s}$, and these data included large scatter.

\subsubsection{Comparison to Burst Test Data}

The transient temperature tests by Hardy 4.9-34 discussed in Section 4.9.2 offer an opportunity to test the model at temperatures in the range 900 to $1400 \mathrm{~K}$. Figure 4.9-18 is a comparison of predicted-versus-measured strains for four of Hardy's tests at a heating rate of $25 \mathrm{~K} / \mathrm{s}$ and initial 
CSTRES, CSTRAN， CSTRNI， CANISO, CKMN

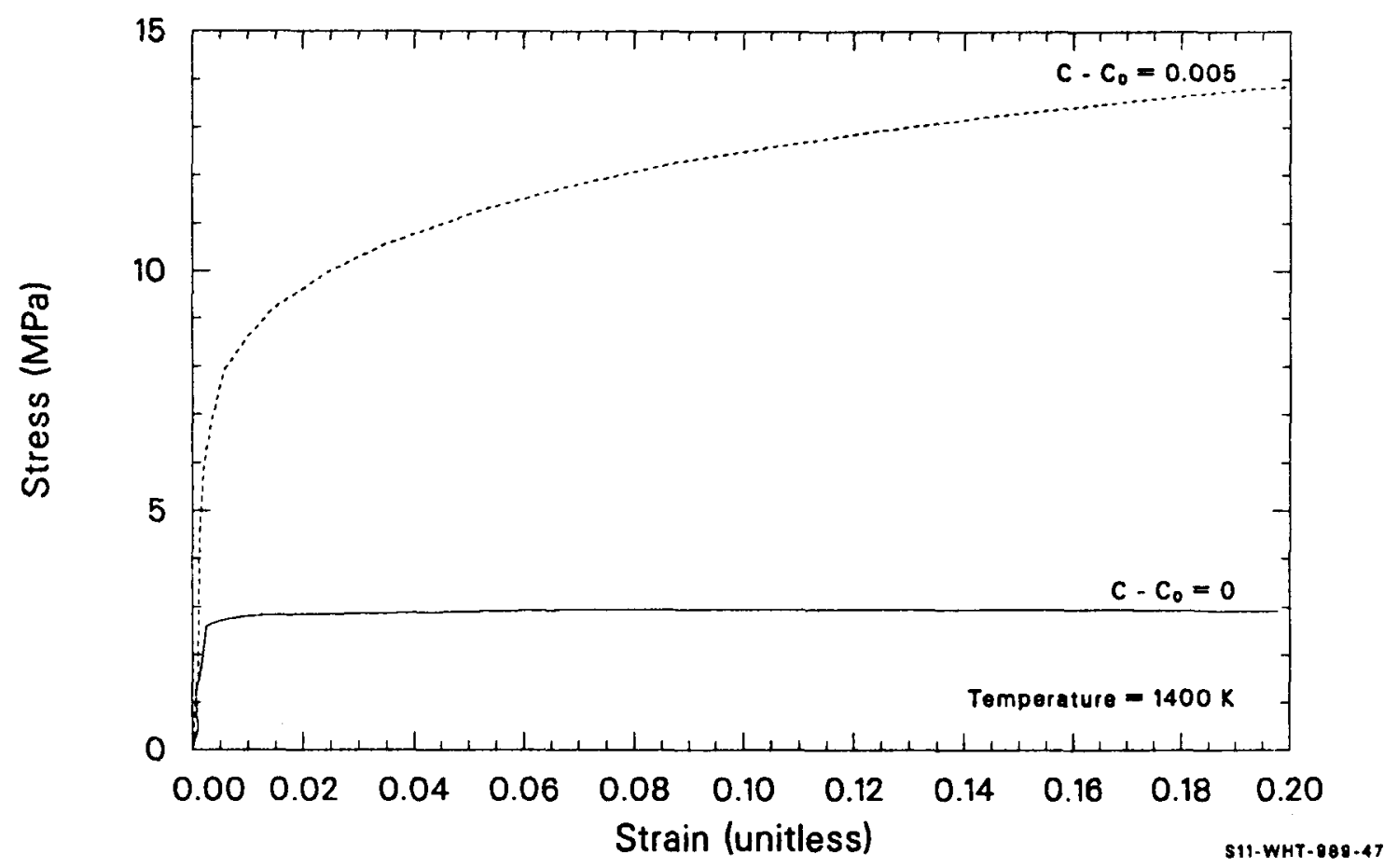

Figure 4.9-16. Stress as a function of strain at a strain rate of $10^{-3} / \mathrm{s}$ for two oxygen concentrations at $1400 \mathrm{~K}$. 


\section{CSTRES, CSTRAN, CSTRNI, CANISO, CKMN}

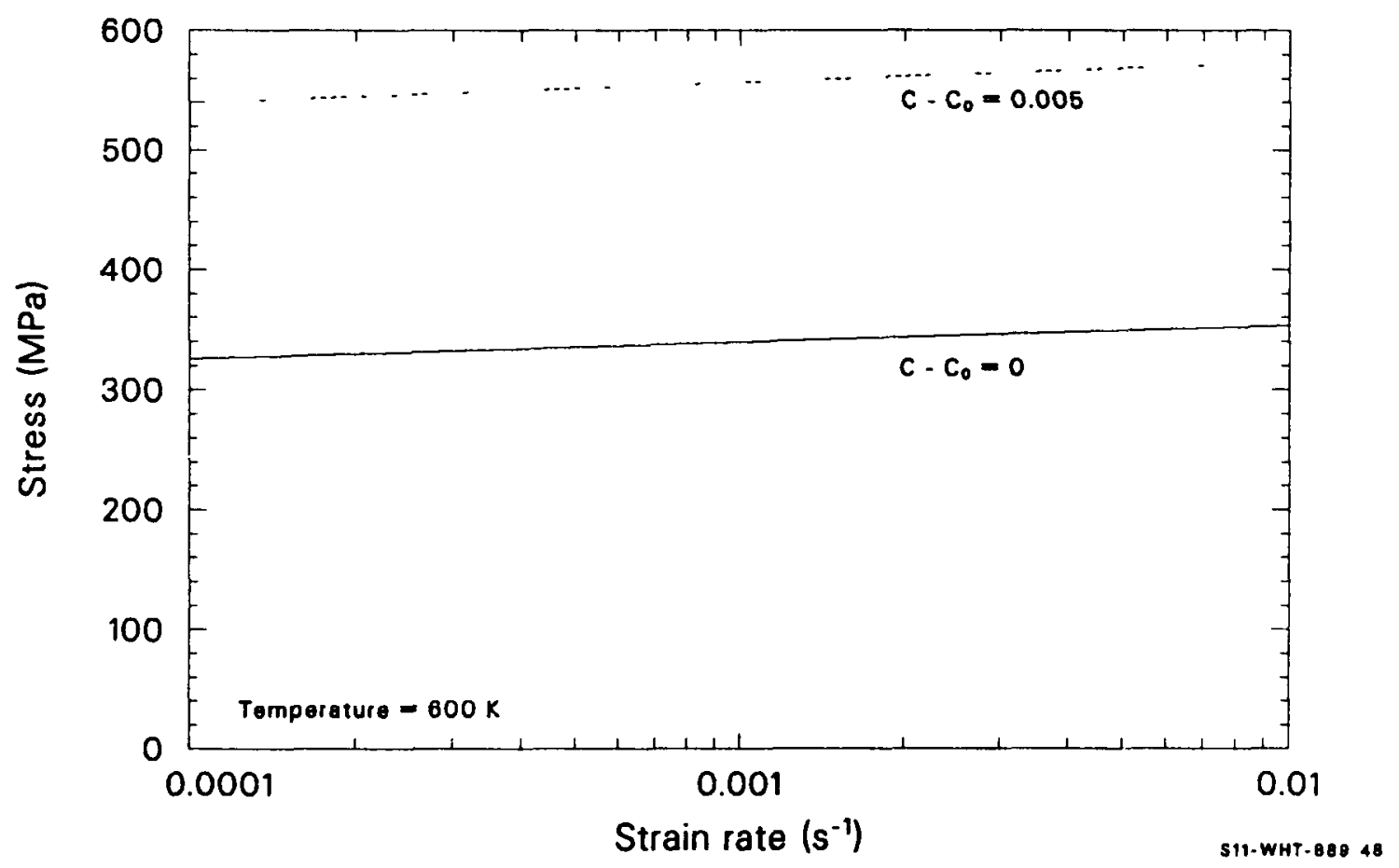

Figure 4.9-17. Stress as a function of strain at a strain rate of 0.1 for two oxygen concentrations at $600 \mathrm{~K}$. 


\section{CSTRES，CSTRAN， CSTRNI，CANISO，CKMN}

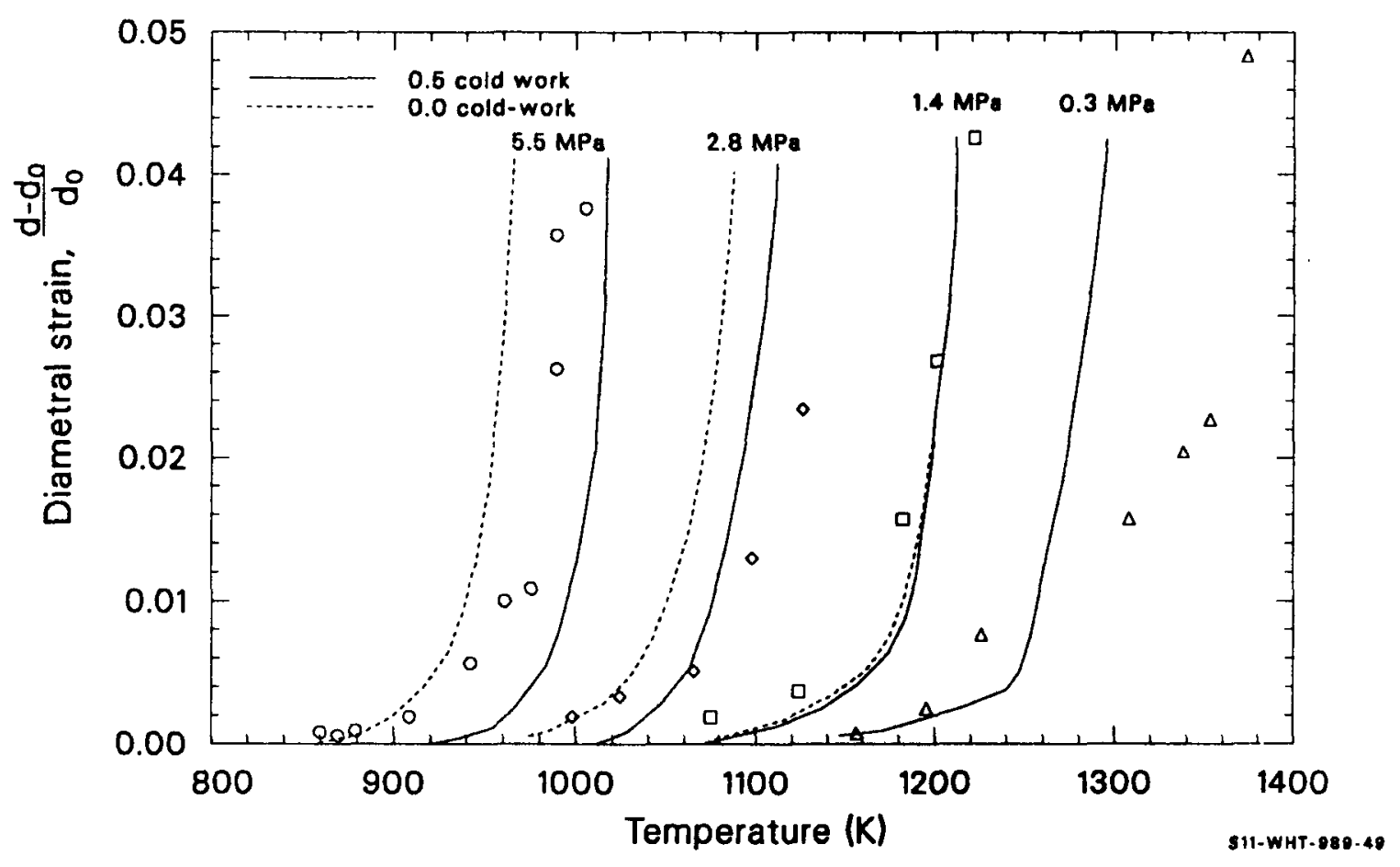

Figure 4.9-18. Measured diametral strain versus MATPRO predictions for two initial values of cold work in tests conducted by Hardy at heating rates of $25 \mathrm{~K} / \mathrm{s}$. 


\section{CSTRES, CSTRAN, CSTRNI, CANISO, CKMN}

pressures of $5.5,2.8,1.4$, and $0.3 \mathrm{MPa}$. Since Hardy did not report the cladding texture, typical values were assumed $\left(f_{r}=0.66, f_{z}=0.06\right.$, and $\left.f_{\theta}=0.28\right)$.

Details of the stress relief were also not reported, so two predicted strains are shown for each series--one for fully annealed material and one for a very light stress relief. With the exception of the highest temperature data (where slight oxidation due to residual water vapor in the vacuum chamber may have affected the experiment), the predictions are within $\pm 25 \mathrm{~K}$ of the experimental value.

It is somewhat surprising that a model based on uniaxial deformation and empirical texture coefficients stays within about $25 \mathrm{~K}$ of these biaxial data. Apparently, the temperature dependence of the strength coefficient for the second mode of deformation is similar to the temperature dependence of the mode observed with uniaxial tests. Inspection of the predicted strain curves and Hardy's data seems to confirm the different (large) strain hardening exponent found with the biaxial test by Hann. Strains are systematically underpredicted when they are small and tend to be overpredicted when they are large. It is also possible that the relatively large initial strain is caused by an as-yet-unmodeled annealistic deformation.

A more sensitive test is provided by a stress rupture experiment reported by $\mathrm{H}$. M. Chung. ${ }^{4.9-24}$ In this test, temperature and pressure were set at $1023 \mathrm{~K}$ and $5.2 \mathrm{MPa}$. Chung's data and the MATPRO model predictions for 1023 and $1048 \mathrm{~K}$ are shown in Figure 4.9-19. The model overpredicts cladding strength at $1023 \mathrm{~K}$, but the prediction at $1048 \mathrm{~K}$ approximates Chung's data fairly well out to strains of 0.2 , where ballooning becomes important. 
CSTRES， CSTRAN， CSTRNI， CANISO， CKMN

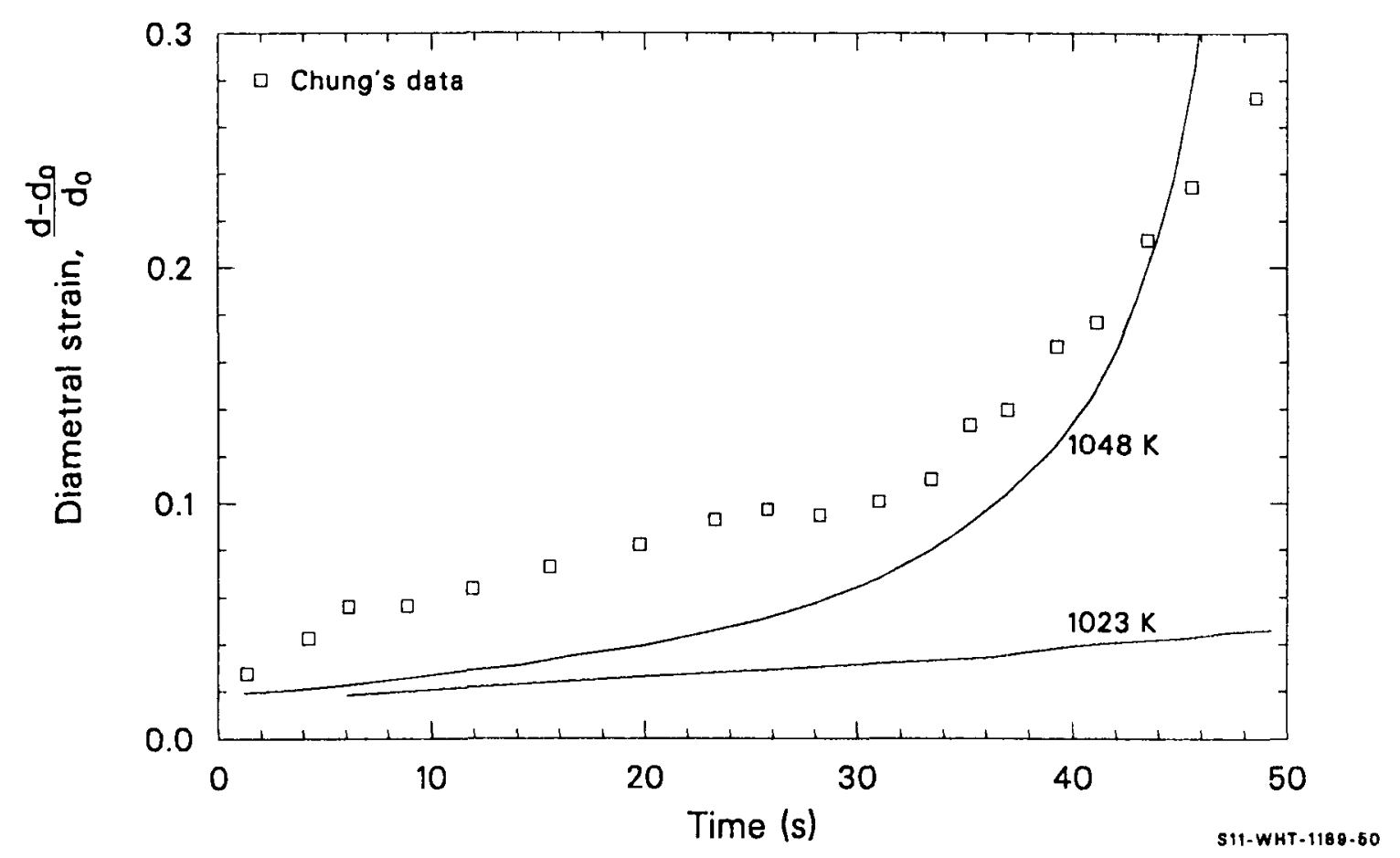

Figure 4.9-19. Measured diametral strain versus MATPRO predictions for Chung's test at $1023 \mathrm{~K}$ and $5.2 \mathrm{MPa}$. 


\section{CSTRES, CSTRAN, CSTRNI， CANISO， CKMN}

\subsubsection{Uncertainties}

Equations (4.9-36) to (4.9-38) for the expected error of the constants $K, n$, and $m$ were obtained by comparing values predicted by Equations (4.9-17) to (4.9-30) with their own data base. Two points should be emphasized for users of these expressions: (a) they are not standard errors, and (b) they do not apply to irradiated or oxidized material. Standard error was not used as a measure of uncertainty because the scatter in the data is a function of temperature. Use of a single standard error would lead to nonphysical predictions, such as negative strengths at high temperatures, and there are not enough data to define a more reasonable distribution than the Gaussian distribution of the usual standard error definition. The error estimates of Equations (4.9-27) through (4.9-30) seem to be consistent with the comparison to burst tests that were discussed in the previous section. That is, the error from Equations (4.9-27) through (4.9-30) (strength coefficient/3.0) is approximately equivalent to an error of $25 \mathrm{~K}$. The limited burst test data also were found to be in error by $25 \mathrm{~K}$.

\subsubsection{References}

4.9-1. L. J. Siefken, M. P. Bohn, S. O. Peck, and J. A. Dearien, FRAP-T5 A Computer Code for the Transient Analysis of Oxide Fuel Rods, NUREG/CR-0840, TREE-1281, June 1979.

4.9-2. C. R. Hann et al., Transient Deformation Properties of Zircaloy for LOCA Simulation, NP-526, Volume 3, March 1978.

4.9-3. M. L. Picklesimer, "Deformation, Creep and Fracture in Alpha-Zirconium Alloys, " Journal of Electrochemical Technology, 4, July-August 1966, pp. 289-300.

4.9-4. P. L. Rittenhouse and M. L. Picklesimer, "Research on the Mechanical Anisotropy of Zircaloy-2," Journal of Electrochemical Technology, 4, July-August 1966, pp. 322-329.

4.9-5. C. R. Woods (ed.), Properties of Zircaloy-4 Tubing, WAPD-TM-585, December 1966. 


\section{CSTRES, CSTRAN, CSTRNI, CANISO, CKMN}

4.9-6. R. L. Mehan and F. W. Wiesinger, Mechanical Properties of Zircaloy-2, KAPL 2110, February 1, 1961.

4.9-7. H. C. Brassfield, J. F. White, L. Sjodah1, J. T. Bittel, Recommended Property and Reaction Kinetics Data for Use in Evaluating a Light-Water Cooled Reactor Loss-of-Coolant Incident Involving Zircaloy-4 or 304-SS-Clad U0 2 , GEMP-482, April 1968.

4.9-8. A. L. Bement, Jr., Effects of Cold-Work and Neutron Irradiation on the Tensile Properties of Zircaloy-2, HW-74955, April 1963.

4.9-9. D. Lee and W. A. Backofen, "Superplasticity in Some Titanium and Zirconium Alloys, "Transactions of the Metallurgical Society of AIME, 239, July 1967, pp. 1034-1040.

4.9-10. L. M. Howe and W. R. Thomas, "The Effects of Neutron Irradiation on the Tensile Properties of Zircaloy-2," Journal of Nuclear Materials, 2, 1960, pp. 248-260.

4.9-11. L. S. Rubenstein et a1., "Effect of Oxygen on the Properties of Zircaloy-2," Transactions of the American Society for Metals, 54, 1961, pp. 20-30.

4.9-12. A. Cowan and W. J. Langford, "Effects of Hydrogen and Neutron Irradiation on the Failure of Flawed Zircaloy-2 Pressure Tubes," Journal of Nuclear Materials, 30, 1969, pp. 271-281.

4.9-13. C. C. Busby and K. B. Marsh, High Temperature Deformation and Burst Characteristics of Recrystallized Zircaloy-4 Tubing, WAPD-TM-900, January 1970.

4.9-14. D. 0. Pickman, "Properties of Zircaloy Cladding," Nuclear Engineering and Design, 21, 1972, pp. 212-236.

4.9-15. G. F. Fieger and D. Lee, "Strength and Ductility of Neutron Irradiated and Textured Zircaloy-2, "Zirconium in Nuclear Applications, ASTM-STP-551, 1973, pp. 355-369.

4.9-16. P. J. Crescimanno, High Strain Rate Tensile Tests of Zircaloy at $550^{\circ} \mathrm{F}$ (LWBR Development Program), WAPD-TM-1263, February 1976.

4.9-17. Y. Miyamoto, Y. Komatsu, N. Nagai, "Mechanical Behavior of Zircaloy-2 Tubing Under Biaxial Stresses, "Journal of Nuclear Materials, 61, 1976, pp. 53-65.

4.9-18. C. C. Busby and K. B. Marsh, High Temperature, Time-Dependent Deformation in Internally Pressurized Zircaloy-4 Tubing, WAPD-TM-1043, October 1974. 


\section{CSTRES， CSTRAN， CSTRNI， CANISO， CKMN}

4.9-19. H. M. Chung, A. M. Garde, T. F. Kassner, Light-Water-Reactor Safety Research Program: Quarterly Progress Report, January-March 1975, ANL-75-28, June 12, 1975.

4.9-20. H. M. Chung, A. M. Garde, T. F. Kassner, Light-Water-Reactor Safety Research Program: Quarterly Progress Report, April-June 1975, ANL-75-58, June 13, 1975.

4.9-21. H. M. Chung, A. M. Garde, T. F. Kassner, Light-Water-Reactor Safety Research Program: Quarterly Progress Report, July-September 1975, ANL-75-72, no date.

4.9-22. H. M. Chung, A. M. Garde, T. F. Kassner, Light-Water-Reactor Safety Research Program: Quarterly Progress Report, October-December 1975, ANL-76-15, no date.

4.9-23. H. M. Chung, A. M. Garde, T. F. Kassner, Light-Water-Reactor Safety Research Program: Quarterly Progress Report, January-March 1976, ANL-76-49, no date.

4.9-24. H. M. Chung, A. M. Garde, T. F. Kassner, Light-Water-Reactor Safety Research Program: Quarterly Progress Report, July-September 1976, ANL-76-121, no date.

4.9-25. H. M. Chung, A. M. Garde, T. F. Kassner, Light-Water-Reactor Safety Research Program: Quarterly Progress Report, January-March 1977, ANL-77-34, no date.

4.9-26. A. A. Bauer, L. M. Lowry, and J. S. Perrin, Evaluating Strength and Ductility of Irradiated Zircaloy: Quarterly Progress Report April-June 1976, BMI-NUREG-1956, JuTy 1976.

4.9-27. A. A. Bauer, L. M. Lowry, and J. S. Perrin, Evaluating Strength and Ductility of Irradiated Zircaloy: Quarterly Progress Report Ju7y-September 1976, BMI-NUREG-1961, October 1976.

4.9-28. A. A Bauer, L. M. Lowry, and J. S. Perrin, Evaluating Strength and Ductility of Irradiated Zircaloy: Quarterly Progress Report October-December 1976, BMI-NUREG-1967, January 1977.

4.9-29. D. Lee et al., Plasticity Theories and Structural Analysis of Anisotropic Metals--Zircaloys, NP-500, May 1977.

4.9-30. 0. D. Sherby and A. K. Miller, Development of the Materials Code, MATMOD (Constitutive Equations of Zircaloy), NP-567, December 1977.

4.9-31. E. Tenckhoff, "Operable Deformation Systems and Mechanical Behavior of Textured Zircaloy Tubing," Zirconium in Nuclear Applications, ASTM STP 551, 1974, pp. 179-200. 


\section{CSTRES， CSTRAN， CSTRNI，CANISO，CKMN}

4.9-32. B. D. Clay and G. B. Redding, "Creep Rupture Properties of Alpha-Phase Zircaloy Cladding Relevant to the Loss-of-Coolant Accident," J. Br. Nucl. Energy Soc., 15, 1976, pp. 253-256.

4.9-33. J. R. Stanbridge and B. A. Keen, "Strain in the Zircaloy Clad of Fuel Pins in Loss-of-Coolant Accidents," J. Br. Nucl. Energy Soc., 16, 1977, pp. 341-346.

4.9-34. D. G. Hardy, "High Temperature Expansion and Rupture Behavior of Zircaloy Tubing, "Topical Meeting on Water Reactor Safety, Salt Lake City, UT, March 26-28, 1973, CONF-730304.

4.9-35. H. Stehle, H. Steinberg, and E. Tenckhoff, "Mechanical Properties Anisotropy and Microstructure of Zircaloy Canning Tubes," Zirconium in the Nuclear Industry, ASTM STP 663, pp. 486-507.

4.9-36. K. H. Matucha and G. Dressler, "Yield and Fracture of Biaxially Stressed Zircaloy-4 Cladding Tubes at Room Temperature and at $400^{\circ} \mathrm{C}, "$ Zirconium in the Nuclear Industry, ASTM STP 663, pp. 508-522.

4.9-37. C. S. Hartley, "Properties of Reactor Materials at Constant True Strain Rates," Progress Report July 1, 1977--June 30, 1978, NUREG/CR-0235, August 1978.

4.9-38. R. Hill, "A Theory of the Yielding and Plastic Flow of Anisotropic Metals, "Proceedings of the Royal Society of London, Series A, Mathematical and Physical Sciences, 193, 1948, pp. 281-297.

4.9-39. R. H. Chapman, Characterization of Zircaloy-4 Tubing Procured for Fuel Cladding Research Programs, ORNL/NUREG/TM-29, July 1976.

4.9-40. D. R. 01ander, Fundamental Aspects of Nuclear Reactor Fuel Elements, TID-26711-P1, 1976.

4.9-41. G. E. Dieter, Mechanical Metallurgy, New York: McGraw-Hill Book Company, Inc., 1976, pp. 28-32.

4.9-42. J. G. Merkle, An Engineering Approach to Multiaxial Plasticity, ORNL-4138, July 1967. 

CANEAL

\subsection{Annealing (CANeAL)}

(D. L. Hagrman)

The equation of state for cladding plastic deformation described in Section 4.9 contains terms which are dependent on cold work and fast neutron fluence. This section is a description of a subcode that determines the thermal annealing of cold work and fast neutron fluence. The annealing is modeled with empirical rate equations, which are used to keep track of the remaining effective cold work and fast neutron fluence for use in the equation of state for cladding plastic deformation.

\subsubsection{Summary}

The CANEAL subcode requires input values of temperature at the start of a time step, an estimate of the rate of change of temperature during the time step, time step size, fast neutron flux, and start-of-step values of cold work and fast neutron fluence.

The expression used to find the ratio of effective cold work for the strength coefficient at the end of a time step divided by effective cold work at the beginning of an isothermal time step with temperature $<1255 \mathrm{~K}$ is

$F K=\exp \left[-1.504\left(1+2.2 \times 10^{-25} \phi_{K O}\right)(t) \exp \left(-2.33 \times 10^{18} / T^{6}\right)\right]$

where

$\mathrm{FK}=$ effective cold work for the strength coefficient at the end of a time step divided by effective cold work at the start of the time step 


\section{CANEAL}

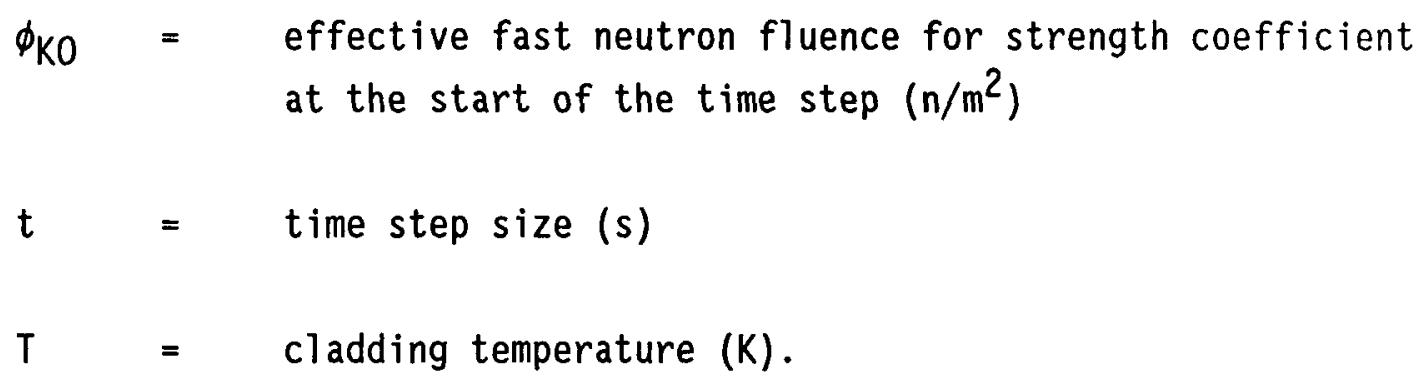

The effective fast neutron fluence for calculating the strength coefficient after an isothermal time step with temperature $<1255 \mathrm{~K}$ is computed with the expression

$\frac{10^{20}}{\phi_{K}}=2.49 \times 10^{-6}(t) \exp \left(\frac{-5.35 \times 10^{23}}{T^{8}}\right)+\frac{10^{20}}{\phi_{K O}}$

where $\phi_{K}$ is the effective fast neutron fluence for the strength coefficient at the end of a time step $\left(\mathrm{n} / \mathrm{m}^{2}\right)$.

For temperatures $<1255 \mathrm{~K}$, the expression used to find the ratio of effective cold work for the strain hardening exponent at the end of an isothermal time step to the effective cold work for strain hardening at the start of the time step is

$F N=\exp \left[-12.032\left(1+2.2 \times 10^{-25} \phi_{N O}\right)(t) \exp \left(\frac{-2.23 \times 10^{18}}{T^{6}}\right)\right]$

where 


\section{CANEAL}
$\mathrm{FN} \quad=$
effective cold work for strain hardening exponent at the end of a time step divided by effective cold work for strain hardening exponent at the start of the time step
$\phi_{\mathrm{NO}}=$ effective fast neutron fluence for the strain hardening exponent at the start of the time step $\left(n / m^{2}\right)$.

For temperatures < $1255 \mathrm{~K}$, the effective fast neutron fluence for calculating the strain hardening exponent after an isothermal time step is computed with the expression

$$
\frac{10^{20}}{\phi_{N}}=2.49 \times 10^{-6}(t) \exp \left(\frac{-5.35 \times 10^{23}}{T^{8}}\right)+\frac{10^{20}}{\phi_{N O}}
$$

where $\phi_{N}$ is the effective fast neutron fluence for the strain hardening exponent at the end of a time step $\left(n / m^{2}\right)$.

If the time step is not isothermal, Equations (4.10-1) through (4.10-4) must be modified to include the effect of varying temperature. The modification used is

$\exp \left(\frac{-0}{T^{m}}\right)-\exp \left(\frac{-0}{T 0^{m}}\right)\left[\frac{\exp \left[Q\left(\frac{d T}{d t}\right) t\left(\frac{m}{T 0^{m+1}}\right)\right]-1}{Q\left(\frac{d T}{d t}\right) t\left(\frac{m}{T 0^{m+1}}\right)}\right]$

where

$Q, m=$ the constants that appear in the isothermal expression

TO = temperature at the start of the time step (K)

$\mathrm{dT} / \mathrm{dt}=$ average rate of change of temperature expected during the time step $(\mathrm{K} / \mathrm{s})$. 


\section{CANEAL}

Expression (4.10-5) is exact for a constant rate of temperature change and is only an approximation for nonlinear temperature changes.

If the temperature during the time step is as high as $1255 \mathrm{~K}$, the effective cold works and fast neutron fluences are set equal to zero.

The following section is a discussion of the data that were available to use to develop annealing rate equations. The model development itself is presented in Section 4.10.3.

\subsubsection{Available Data}

Howe and Thomas ${ }^{4 \cdot 10-1}$ reported postirradiation annealing studies on annealed, $13.1 \%$ cold-worked, and tempered $25.5 \%$ cold-worked zircaloy-2 irradiated at 493 and $553 \mathrm{~K}$ with integrated fast neutron fluences of $3.6 \times 10^{23} \mathrm{n} / \mathrm{m}^{2}$ and $2.7 \times 10^{24} \mathrm{n} / \mathrm{m}^{2}$. Specimens were given $1-\mathrm{h}$ anneals in vacuum at various temperatures. The nominal room temperature ultimate stresses measured with these samples are listed in Table 4.10-1.

The data from irradiated annealed zircaloy-2 show that irradiation-induced hardening in this material is completely annealed out after $1 \mathrm{~h}$ at temperatures above $775 \mathrm{~K}$ and that most of the recovery occurs in the temperature range from 575 to $675 \mathrm{~K}$. From their recovery data with $25.5 \%$ cold-worked zircaloy-2, Howe and Thomas concluded that:

1. The recovery occurring in the temperature range 550 to $725 \mathrm{~K}$ is the annealing out of irradiation damage rather than cold work.

2. The irradiation damage in cold-worked material is completely annealed out after $1 \mathrm{~h}$ at approximately $725 \mathrm{~K}$. 
Table 4:10-1. Room temperature ultimate strengths of cladding annealed for $1 \mathrm{~h}$ from Howe and Thomas

\begin{tabular}{clcc}
\hline Cold Work & $\begin{array}{l}\text { Neutron } \\
\text { Fluence }\end{array}$ & $\begin{array}{c}\text { Annealing } \\
\text { Temperature }\end{array}$ & $\begin{array}{c}\text { Ultimate } \\
\text { Strength }\end{array}$ \\
$\begin{array}{c}(\%) \\
0\end{array}$ & $\frac{\left(\mathrm{n} / \mathrm{m}^{2}\right)}{(\mathrm{K})}$ & $(\mathrm{MPa})$ \\
0 & $3.6 \times 10^{23}$ & 555 & 634 \\
0 & $3.6 \times 10^{23}$ & 625 & 588 \\
0 & $3.6 \times 10^{23}$ & 675 & 513 \\
0 & $3.6 \times 10^{23}$ & 725 & 513 \\
0 & $3.6 \times 10^{23}$ & 775 & 500 \\
0 & $3.6 \times 10^{23}$ & 875 & 500 \\
25.5 & $3.6 \times 10^{23}$ & 975 & 499 \\
25.5 & 0 & 555 & 619 \\
25.5 & 0 & 675 & 614 \\
25.5 & 0 & 775 & 603 \\
25.5 & 0 & 875 & 530 \\
25.5 & 0 & 975 & 512 \\
25.5 & $2.7 \times 10^{24}$ & 555 & 728 \\
25.5 & $2.7 \times 10^{24}$ & 625 & 672 \\
25.5 & $2.7 \times 10^{24}$ & 675 & 626 \\
25.5 & $2.7 \times 10^{24}$ & 725 & 579 \\
25.5 & $2.7 \times 10^{24}$ & 775 & 504 \\
25.5 & $2.7 \times 10^{24}$ & 875 & 486 \\
\hline
\end{tabular}




\section{CANEAL}

3. The recovery from 725 to $973 \mathrm{~K}$ for irradiated material is fairly similar to that for unirradiated material. However, there is an indication that the irradiated material recovers slightly faster.

Since the 1-h anneals of Howe and Thomas represent times which are long compared to loss-of-coolant accident blowdown and refill times, the data were used only for general guidance and verification of the models developed from shorter annealing times reported by Bauer. In particular, the data support the ideas that (a) irradiation damage anneals before cold work and (b) irradiation damage affects the rate of annealing of cold work.

Bauer reported yield strengths, ultimate strength, uniform elongations (engineering strain at maximum load), and total elongations from annealing studies of both cold-worked and irradiated cold-worked zircaloy cladding material. 4.10-2,4.10-3 The unirradiated cold-worked cladding was from a standard lot of tubing which has been characterized by Chapman. ${ }^{4 \cdot 10-4}$ The irradiated cladding was obtained from spent fuel rods irradiated in the Carolina Power and Light $\mathrm{H}$. B. Robinson Plant to a fast neutron fluence of approximately $4.4 \times 10^{25} \mathrm{n} / \mathrm{m}^{2}$.

Ultimate strengths and uniform elongations obtained at $644 \mathrm{~K}$ and a strain rate of $0.025 / \mathrm{min}$ with the unirradiated cladding are listed in Table 4.10-2. With a heating rate of $5.6 \mathrm{k} / \mathrm{s}$, most of the recovery of both strength and uniform elongation occurs between temperatures of 894 and $978 \mathrm{~K}$. However, the recovery has barely started at $978 \mathrm{~K}$ when the heating rate is $27.8 \mathrm{~K} / \mathrm{s}$. Since the annealing times at temperature are short, the maximum temperature required to anneal these samples is considerably higher than the temperatures reported by Howe and Thomas.

Tables 4.10-3 and 4.10-4 are a summary of Bauer's measurements of ultimate strengths and uniform elongations of annealed irradiated tubing. The measurements were performed at $644 \mathrm{~K}$ and a strain rate of $0.025 / \mathrm{min}$. The results in Tabla 4.10-3 were obtained with transient anneals similar to 
CANEAL

Table 4.10-2. $\begin{aligned} & \text { 644-K test } \\ & \text { cladding }\end{aligned}$

\begin{tabular}{|c|c|c|c|c|}
\hline Specimen Number $^{a}$ & $\begin{array}{l}\text { Heating } \\
\text { Rate } \\
(\mathrm{K} / \mathrm{s}) \\
\end{array}$ & $\begin{array}{c}\text { Maximum } \\
\text { Temperature } \\
\text { (K) }\end{array}$ & $\begin{array}{l}\text { Ultimate } \\
\text { Strength } \\
(\mathrm{MPa}) \\
\end{array}$ & $\begin{array}{c}\text { Uniform } \\
\text { Elongation } \\
(\%)\end{array}$ \\
\hline $\begin{array}{l}\text { As-received } \\
0781-8 \\
0781-7 \\
0781-6 \\
0781-5 \\
0781-4 \\
0781-3 \\
0781-2 \\
0781-1\end{array}$ & $\begin{array}{r}-- \\
5.6 \\
5.6 \\
5.6 \\
5.6 \\
27.8 \\
27.8 \\
27.8 \\
27.8\end{array}$ & $\begin{array}{l}644 \\
811 \\
866 \\
894 \\
978 \\
811 \\
866 \\
894 \\
978\end{array}$ & $\begin{array}{l}434.5 \\
434 \\
432 \\
409 \\
252 \\
434 \\
438 \\
432 \\
422\end{array}$ & $\begin{array}{r}4.1 \\
4.1 \\
4.1 \\
4.8 \\
24.3 \\
3.6 \\
3.3 \\
3.6 \\
4.6\end{array}$ \\
\hline
\end{tabular}

a. The number 0781 is the rod number. 


\section{CANEAL}

Table 4.10-3. $\begin{aligned} & \text { 644-K test } \mathrm{t} \text { essults For irradiated transient annealed } \\ & \text { cladding }\end{aligned}$

\begin{tabular}{|c|c|c|c|c|}
\hline$\underline{S p e c i m e n ~ N u m b e r}^{\mathrm{a}}$ & $\begin{array}{l}\text { Heating } \\
\text { Rate } \\
(\mathrm{K} / \mathrm{s}) \\
\end{array}$ & $\begin{array}{c}\text { Maximum } \\
\text { Temperature } \\
(\mathrm{K}) \\
\end{array}$ & $\begin{array}{c}\text { U1timate } \\
\text { Strength } \\
\text { (MPa) }\end{array}$ & $\begin{array}{c}\text { Uniform } \\
\text { Elongation } \\
(\%) \\
\end{array}$ \\
\hline $\begin{array}{l}P B-20 \\
P B-34 \\
P B-46 \\
H 10-20\end{array}$ & $\begin{array}{l}-- \\
-- \\
-- \\
--\end{array}$ & $\begin{array}{l}644 \\
644 \\
644 \\
644\end{array}$ & $\begin{array}{l}622.8 \\
650.3 \\
660.9 \\
694.0\end{array}$ & $\begin{array}{l}4.10 \\
4.00 \\
2.80 \\
3.80\end{array}$ \\
\hline $\begin{array}{l}\mathrm{P} 4-50-55 \\
\mathrm{P} 4-55-60 \\
\mathrm{P} 4-89-1 / 2-94-1 / 2 \\
\mathrm{P} 4-94-1 / 2-99-1 / 2 \\
\mathrm{Pr}-89-1 / 2-104-1 / 2\end{array}$ & $\begin{array}{l}0.6 \\
0.6 \\
0.6 \\
0.6 \\
0.6\end{array}$ & $\begin{array}{l}700 \\
755 \\
811 \\
894 \\
978\end{array}$ & $\begin{array}{l}674.0 \\
633.0 \\
574.5 \\
286.1 \\
268.9\end{array}$ & $\begin{array}{l}2.10 \\
2.70 \\
2.30 \\
9.57 \\
9.21\end{array}$ \\
\hline $\begin{array}{l}\mathrm{P} 4-111-116 \\
\mathrm{P} 4-45-50 \\
\mathrm{P} 4-35-3 / 4-46-3 / 4 \\
\mathrm{Pr}-70-3 / 4-75-3 / 4 \\
\mathrm{Pr}-75-3 / 4-80-3 / 4 \\
\mathrm{Pr}-80-1 / 2-89-1 / 2\end{array}$ & $\begin{array}{l}5.6 \\
5.6 \\
5.6 \\
5.6 \\
5.6 \\
5.6\end{array}$ & $\begin{array}{l}700 \\
755 \\
811 \\
866 \\
894 \\
978\end{array}$ & $\begin{array}{l}653.0 \\
676.0 \\
595.2 \\
349.3 \\
313.7 \\
287.3\end{array}$ & $\begin{array}{r}2.00 \\
2.40 \\
2.35 \\
2.94 \\
4.77 \\
10.56\end{array}$ \\
\hline $\begin{array}{l}014-106-1 / 2-111-1 / 2 \\
\text { A8-120-3/4-125-3/4 } \\
\text { P4-16-1/2-21-1/2 } \\
\text { P4-21-1/2-26-1/2 } \\
\text { P4-26-1/2-31-1/2 }\end{array}$ & $\begin{array}{l}13.9 \\
13.9 \\
13.9 \\
13.9 \\
13.9\end{array}$ & $\begin{array}{l}755 \\
811 \\
866 \\
894 \\
978\end{array}$ & $\begin{array}{l}717.0 \\
652.7 \\
577.9 \\
456.2 \\
304.5\end{array}$ & $\begin{array}{l}2.40 \\
2.27 \\
2.50 \\
2.16 \\
5.74\end{array}$ \\
\hline $\begin{array}{l}\text { P4-65-70 } \\
\text { A1-29-1/2-34-1/2 } \\
\text { A8-105-3/4-110-3/4 } \\
\text { A8-110-3/4-115-3/4 } \\
\text { A8-115-3/4-120-3/4 } \\
\text { P4-116-21 } \\
014-111-1 / 2-116-1 / 2 \\
014-37-42\end{array}$ & $\begin{array}{l}27.8 \\
27.8 \\
27.8 \\
27.8 \\
27.8 \\
27.8 \\
27.8 \\
27.8\end{array}$ & $\begin{array}{r}755 \\
811 \\
866 \\
894 \\
978 \\
1033 \\
1144 \\
1255\end{array}$ & $\begin{array}{l}671.0 \\
721.6 \\
671.0 \\
597.5 \\
348.2 \\
329.0 \\
338.0 \\
340.0\end{array}$ & $\begin{array}{r}2.10 \\
2.70 \\
2.70 \\
2.06 \\
3.49 \\
4.70 \\
8.60 \\
10.50\end{array}$ \\
\hline
\end{tabular}

a. The letter and number, letter, or number before the first hyphen identifies the rod number; that is Rod P8, Rod P4-9, Rod 014, etc. 


\section{CANEAL}

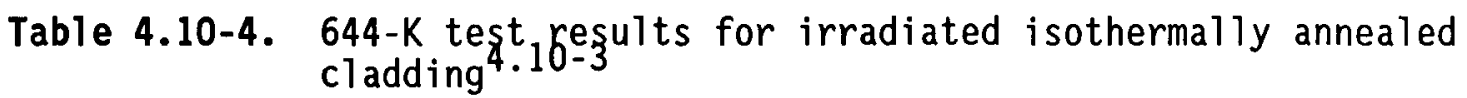

\begin{tabular}{|c|c|c|c|c|}
\hline$\underline{S p e c i m e n ~ N u m b e r}^{\mathrm{a}}$ & $\begin{array}{c}\text { Temperature } \\
(\mathrm{K} / \mathrm{s})\end{array}$ & $\begin{array}{l}\text { Time at } \\
\text { Temperature } \\
\text { (min) }\end{array}$ & $\begin{array}{l}\text { Ultimate } \\
\text { Strength } \\
\text { (MPa) }\end{array}$ & $\begin{array}{l}\text { Uniform } \\
\text { Elongation } \\
(\%)\end{array}$ \\
\hline $\begin{array}{l}\text { P8-20 } \\
\text { P8-34 } \\
\text { P8-46 } \\
\text { H1O-20 }\end{array}$ & $\begin{array}{l}644 \\
644 \\
644 \\
644\end{array}$ & $\begin{array}{l}-- \\
-- \\
--\end{array}$ & $\begin{array}{l}622.8 \\
650.3 \\
660.9 \\
694.0\end{array}$ & $\begin{array}{l}4.10 \\
4.00 \\
2.80 \\
3.80\end{array}$ \\
\hline $\begin{array}{l}H 10-5 \\
H 10-41 \\
H 10-17\end{array}$ & $\begin{array}{l}700 \\
755 \\
755\end{array}$ & $\begin{array}{l}60 \\
10 \\
60\end{array}$ & $\begin{array}{l}615.9 \\
590.6 \\
556.2\end{array}$ & $\begin{array}{l}3.35 \\
2.85 \\
3.06\end{array}$ \\
\hline $\begin{array}{l}\text { P4-60-65 } \\
\text { A1-24-1/2-29-1/2 } \\
\text { H10-18 }\end{array}$ & $\begin{array}{l}811 \\
811 \\
811\end{array}$ & $\begin{array}{r}1 \\
10 \\
30\end{array}$ & $\begin{array}{l}560 \\
363.1 \\
371.1\end{array}$ & $\begin{array}{l}2.90 \\
3.20 \\
5.10\end{array}$ \\
\hline $\begin{array}{l}\text { Al-105-3/4-110-3/4 } \\
\text { Al-99-104 } \\
\text { H10-3 }\end{array}$ & $\begin{array}{l}866 \\
866 \\
866\end{array}$ & $\begin{array}{r}1 \\
5 \\
30\end{array}$ & $\begin{array}{l}332.1 \\
311.4 \\
321.7\end{array}$ & $\begin{array}{r}4.52 \\
8.03 \\
10.10\end{array}$ \\
\hline $\begin{array}{l}\text { Al-110-3/4-115-3/4 } \\
\text { H10-4 }\end{array}$ & $\begin{array}{l}894 \\
894\end{array}$ & $\begin{array}{r}1 \\
30\end{array}$ & $\begin{array}{l}308.9 \\
319.4\end{array}$ & $\begin{array}{r}7.90 \\
13.93\end{array}$ \\
\hline $\begin{array}{l}A 1-116-1 / 2-121-1 / 2 \\
\mathrm{H} 10-16\end{array}$ & $\begin{array}{l}978 \\
978\end{array}$ & $\begin{array}{r}1 \\
30\end{array}$ & $\begin{array}{l}305.6 \\
311.4\end{array}$ & $\begin{array}{r}7.67 \\
11.80\end{array}$ \\
\hline
\end{tabular}

a. The letter and number before the first hyphen identifies the rod number; that is, Rod P8, Rod H10, and Rod Al. 


\section{CANEAL}

those used with the unirradiated tubing. Table 4.10-4 summarizes results from isothermal anneals similar to the anneals carried out by Howe and Thomas.

The annealing behavior of the irradiated cladding is different than the behavior of the unirradiated material. Ultimate strengths obtained with irradiated material which had little or no annealing are substantially higher than the ultimate strengths of the unirradiated material. However, transient anneals that begin to affect the strength of cold-worked material $(5.6 \mathrm{~K} / \mathrm{s}$ to 866 and $894 \mathrm{~K}$ or $27.8 \mathrm{~K} / \mathrm{s}$ to $978 \mathrm{~K})$ leave the irradiated material with strengths below the strengths of the unirradiated material after corresponding anneals. It is possible that these differences are due to the fact that the tubing does not come from the same lot, but a similar trend has been shown by the studies of Howe and Thomas on material from one 10t. It has thus been concluded that irradiation for long times at reactor operating temperatures causes a significant increase in the strength of zircaloy cladding and enhances the annealing of the strength increase due to cold work.

Comparison of uniform elongation measurements with the unirradiated cladding (Tables 4.10-2 and 4.10-3) shows that the effect of irradiation on this parameter is different than its effect on ultimate strength. The uniform elongation of the unannealed irradiated material is less than the uniform elongation of the unannealed unirradiated material, but there is no obvious increase in the rate of recovery from cold-work effects because of the irradiation. Therefore, models that describe annealing by keeping track of effective cold work and effective fluence should be set up to use different values of these parameters for predicting strength and elongation.

The isothermal annealing effects reproduced in Table 4.10-4 are similar to those of Table 4.10-3 in that recovery of ultimate strength precedes recovery of uniform elongation. However, several additional features of the annealing of cold-worked and irradiated zircaloy cladding become apparent from the isothermal data. 
CANEAL

1. The four tests at $644 \mathrm{~K}$ show that approximately $10 \%$ sample-to-sample scatter should be expected in the measured values of strength. In particular, rod H10 shows consistently high strength. Variation on the order of a percent seems to be present in the uniform elongation data. Models for annealing will therefore have to emphasize general trends and avoid exact fits to individual measurements.

2. Irradiation effects on the strength of zircaloy cladding do not seem to saturate at the low fluences used by Howe and Thomas. The two 60 -min anneals show strengths at $644 \mathrm{~K}$ similar to the room temperature strengths measured after similar anneals by Howe and Thomas. If the tensile test data had been taken at similar temperatures, the cladding measured by Bauer would show considerably greater strength.

3. Time at temperature during annealing is less important for the irradiated material than for the unirradiated material. The exponential dependence on time of the model developed in Section 4.10-3 for annealing of the effect of cold work on strength predicts that the $\log$ of the departure of strength parameters from their annealed values for two isothermal anneals that differ only in the time at temperature should be proportional to the reciprocal ratio of the annealing times. The major component of the increase of the strengths in Table 4.10-4 is much less dependent on time at temperature than this relation would imply. ${ }^{\mathrm{a}}$

a. For example, the 10 - and 60 -min anneals at $775 \mathrm{~K}$ have ultimate strengths that are 279.2 and $244.8 \mathrm{MPa}$ above the fully annealed ultimate strength of sample H10-16. An equation with the exponential time dependence of Equation (4.10-1) would imply that the ratio of the logs of the two strengths should be $1 / 6$, or 0.17 . The ratio is 0.98 . 


\section{CANEAL}

The net impression left by the data of Tables 4.10-1 to 4.10-4 is that at least two different processes are important in the annealing of cold-worked and irradiated cladding and that the annealing of the irradiation-caused component follows a rate equation that is different than the rate equation for the cold-work component. Data that could be used to model these separate processes (for example, annealing studies with one lot of material irradiated to several different fluences) were not available for use in the development of the annealing model for MATPRO. Therefore, the model developed in the next section is a strictly empirical attempt to reproduce the available data with a reasonably concise set of correlations. Also, there were no data for annealing rates at temperatures corresponding to the beta phase (temperature $>1255 \mathrm{~K}$ ).

\subsubsection{Model Development}

The approach used to develop the annealing models presented here was to develop a model for the annealing of cold-worked cladding and modify it to fit data from cold-worked and irradiated material in the alpha and alpha + beta phase temperature range. The model for recovery kinetics in cold-worked cladding is based on a result reported by Byrne. ${ }^{4 \cdot 10-5} \mathrm{He}$ found that recovery ${ }^{a}$ data frequently conform to the assumption that the rate of recovery of a property from its cold-worked value is proportional to the instantaneous value of the property. If the property is the strength coefficient, ${ }^{b}$ the rate equation for recovery is

$d K / d t=-f_{T}\left(K-K_{A}\right)$

a. A separate model for recrystallization kinetics was developed but not used because only limited recrystallization data were available.

b. Since the change in the strength coefficient is modeled as a linear function of cold work, one can use cold work instead of the strength coefficient in this equation. 
where

$K=$ strength coefficient of cold-worked cladding (MPa)

$t=\operatorname{time}(s)$

$f_{T}=a$ temperature-dependent factor

$K_{A}=$ strength coefficient of annealed cladding (MPa).

Since isothermal annealing data with unirradiated cold-worked tubing are not available, the effect of temperature on the factor $f_{T}$ in Equation (4.10-6) had to be determined from the limited transient annealing data of Table 4.10-2. The method used to do this is outlined as follows:

(1) The change of the factor $f_{T}$ in Equation (4.10-6) is assumed to be represented by the expression

$f_{T}=B \exp \left(-Q / T^{m}\right)$

where

$$
\begin{aligned}
B, Q, m & =\text { positive constants } \\
T & =\text { temperature }(K) .
\end{aligned}
$$

(2) Equation (4.10-6) is integrated over a very short (approximately isothermal) time interval to produce a differential expression for the change in strength coefficient

$$
\frac{K_{\text {final }}-K_{A}}{K_{\text {initial }}-K_{A}}=\exp \left[-B\left(t_{\text {final }}-t_{\text {initial }}\right) \exp \left(\frac{-0}{T^{m}}\right)\right] \text {. }
$$




\section{CANEAL}

(3) The long interval beginning at a temperature $T_{j}$, and ending at a temperature $T_{f}$ is divided into $\eta$ small intervals, and the temperature during any small interval is assumed constant. The net change in $K$ is the product of $\eta$ terms like Equation (4.10-8) for each interval

$$
\begin{aligned}
\frac{K_{\text {final }}-K_{A}}{K_{\text {initial }}-K_{A}} & =\prod_{j=1}^{\eta} \exp \left[-B\left(\frac{t_{\text {final }}-t_{\text {initial }}}{\eta}\right) \exp \left(\frac{-0}{T_{j}^{m}}\right)\right] \\
& =\exp \left[-B\left(\frac{t_{\text {final }}-t_{\text {initial }}}{\eta}\right) \sum_{j=1}^{\eta} \exp \left(\frac{-Q}{T_{j}^{m}}\right)\right](4.10-9)
\end{aligned}
$$

where $T_{j}$ is the temperature during the $j$-th interval.

(4) When the temperature change is a linear function of time, $T_{j}$ in Equation (4.10-9) can be obtained by interpolation between the initial and final temperatures. The linear interpolation, ${ }^{\mathrm{a}} \mathrm{a}$ Taylor series expansion, and a power series summation yield

$$
\sum_{j=1}^{\eta} \exp \left(\frac{-0}{T_{j}^{m}}\right)=\sum_{j=1}^{\eta} \exp \left\{\frac{-0}{\left[T_{f}-\left(\frac{T_{f}-T_{i}}{2 \eta}\right)-(\eta-j)\left(\frac{T_{f}-T_{i}}{\eta}\right)\right]^{m}}\right\}
$$

a. The interpolation may start with the final temperature as is done here

$T_{j}=T_{f}-\left(\frac{T_{f}-T_{i}}{2 \eta}\right)-(\eta-j)\left(\frac{T_{f}-T_{i}}{\eta}\right)$

or it may start with the initial temperature so that

$T_{j}=T_{i}+\left(\frac{T_{f}-T_{i}}{2 \eta}\right)+j\left(\frac{T_{f}-T_{i}}{\eta}\right)$

The second form was used for coding the annealing model because it yields a result in terms of the initial temperature. 
CANEAL

$$
\begin{aligned}
& =\sum_{j=1}^{n} \exp \left\{\frac{-Q}{\left[T_{f}-\left(\frac{T_{f}-T_{i}}{2 \eta}\right)\right]^{m}}\left[1+\frac{m(\eta-j) \frac{T_{f}-T_{i}}{\eta}}{T_{f}-\frac{T_{f}-T_{i}}{2 \eta}}+. .\right]\right\} \\
& =\exp \frac{-0}{T_{f}-\frac{T_{f}-T_{i}}{2 \eta} m}\left\{\frac{1-\exp \left\{\frac{-m\left(T_{f}-T_{i}\right) Q}{\left[T_{f}-\left(\frac{T_{f}-T_{i}}{2 \eta}\right)\right]^{m+1}}\right\}}{1-\exp \left\{\frac{-m\left(T_{f}-T_{i}\right) Q}{\left[\eta\left[T_{f}-\left(\frac{T_{f}-T_{i}}{2 \eta}\right)\right]^{m+1}\right.}\right\}}\right\}
\end{aligned}
$$

(5) Equation (4.10-10) is substituted into Equation (4.10-9), and the limit as the number of short intervals approaches infinity $(n \rightarrow \infty)$ is determined. The resultant expression is

$$
\frac{K_{f}-K_{A}}{K_{j} K_{A}}=\exp \left\{-B\left[\exp \left(\frac{-Q}{T_{f}^{m}}\right)\right]\left[\frac{1-\exp \left(\frac{-Q\left(T_{f}-T_{j}\right)^{m}}{T_{f}^{m+1}}\right)}{\frac{Q\left(T_{f}-T_{i}\right)^{m}}{T_{f}^{m+1}}}\right]\left(t_{f}-t_{j}\right)\right\}
$$

(6) Ultimate strengths and uniform elongations from Table 4.10-2 are used to determine the strength coefficient after the various anneals described in this table.

(7) The strength coefficients of Step (6) are used to determine Q, B, and $m$. For the current MATPRO version, the values of $K_{f}$ after 


\section{CANEAL}

the anneals to 866 and $978 \mathrm{~K}$ at $5.6 \mathrm{~K} / \mathrm{s}$ were used with the value of $K_{i}$ from the as-received material and Equation (4.10-11) to determine $B$ and $Q$ with assumed trial values of $K_{A}$ between 364 and $442 \mathrm{MPa}$ and assumed trial integral values of $\mathrm{m}$ between 1 and 9. Finally, the values of $Q, B, K_{j}, K_{A}$, and $m$ for each trial were used in Equation (4.10-11) to predict $K_{f}$ for the six anneals that were not already considered. The predictions were compared with the data. The trial values of $K_{A}$ and $m$ that most successfully predicted both the postanneal data and the as-received strength coefficient (using the stress relief annealing schedule provided in Reference 4.10-4) were $K_{A}=406 \mathrm{MPa}$ and $m=6$. The value $m=6$ and the values of $Q$ and $B$ which produced the successful predictions $\left(Q=2.33 \times 10^{18}\right.$ and $B=1.504$ ) were therefore adopted for the model.

A procedure similar to the one described in the previous seven steps could be used to develop a model for the effect of cold-work annealing on the strain hardening exponent. However, the complex form of the expression relating cold work and the strain hardening exponent would complicate the solution considerably. For the time being, the rate of annealing of effective cold work for the strain hardening exponent is assumed to be proportional to the rate of the effective cold work for the strength coefficient. The best fit was obtained with a value of $B$ which is eight times as large as the $B$ used for the strength coefficient.

The rest of this section describes the development of models for the annealing of cold-worked and irradiated cladding. It was concluded in Section 4.10.2 that the principal features of the annealing data with irradiated cladding are:

1. Fast neutron fluence increases the rate of recovery from cold-work effects. 
CANEAL

2. The annealing kinetics of the irradiation-caused increase in strength do not have the exponential time-dependence that characterizes the recovery from cold-work effects.

Based on these conclusions, the first step in producing the model for the effect of annealing on the strength coefficient of irradiated cladding was to modify the model for cold-work annealing to include the irradiation-caused enhancement of the recovery of the strength coefficient from cold-work effects. The modification of the cold-work annealing model was based on the information in Table 4.10-5. ${ }^{a}$ The first two columns identify the annealing tests, and the third column lists the strength coefficients calculated from the ultimate strengths and uniform elongations of Bauer's isothermal annealing tests (Table 4.10-4). The column entitled "Residual Strength Coefficient" is the strength coefficient minus the sum of the strength coefficient for annealed cladding and the contribution of cold work calculated with the unmodified model for cold-work annealing. The column entitled $\mathrm{CW} / \mathrm{CW}_{0}$ is the initial cold work divided into the postanneal cold work predicted by the unmodified cold-work annealing model. Comparison of the residual strengths and the column titled $\mathrm{CW} / \mathrm{CW}_{0}$ shows that the residual strength coefficient is negative whenever the cold work is predicted to be partly annealed $\left(\mathrm{CW} / \mathrm{CW}_{0}\right.$ in the range 0.4 to 0.8$)$. The most reasonable interpretation of this feature is to assume that the irradiation enhances the rate of annealing of the cold work. The change required to model this effect is to replace the constant $B$ in Equation (4.10-11) by a function which increases with increasing fluence. The expression adopted for the strength coefficient annealing model was

$$
B=1.504\left[1+2.22 \times 10^{-25}\right] \phi
$$

a. A similar table was constructed from Bauer's transient annealing data. The transient data gave no new information. 


\section{CANEAL}

Table 4.10-5. Strength and residual strength coefficients after isothermal anneals

\begin{tabular}{|c|c|c|c|c|}
\hline $\begin{array}{c}\text { Temperature } \\
(\mathrm{K})\end{array}$ & $\begin{array}{c}\begin{array}{c}\text { Time at } \\
\text { Temperature } \\
\text { (min) }\end{array} \\
\end{array}$ & $\begin{array}{l}\text { Strength } \\
\text { Coefficient } \\
(\mathrm{MPa}) \\
\end{array}$ & $\begin{array}{c}\text { Residual } \\
\text { Strength } \\
\text { Coefficient } \\
(\mathrm{MPa}) \\
\end{array}$ & $\underline{\mathrm{CW} / \mathrm{CW}_{0}}$ \\
\hline $\begin{array}{l}644 \\
644 \\
644 \\
644\end{array}$ & $\begin{array}{l}\text { As-received } \\
\text { as-received } \\
\text { as-received } \\
\text { as-received }\end{array}$ & $\begin{array}{l}750.7 \\
781.5 \\
763.4 \\
828.9\end{array}$ & $\begin{array}{l}191.7 \\
222.5 \\
204.4 \\
205.9\end{array}$ & $\begin{array}{l}1 \\
1 \\
1 \\
1\end{array}$ \\
\hline 700 & 60 & 724.8 & 101.8 & 1 \\
\hline $\begin{array}{l}755 \\
755\end{array}$ & $\begin{array}{l}10 \\
60\end{array}$ & $\begin{array}{l}683.5 \\
648.2\end{array}$ & $\begin{array}{l}61.0 \\
28.3\end{array}$ & $\begin{array}{l}0.997 \\
0.982\end{array}$ \\
\hline $\begin{array}{l}811 \\
811 \\
811\end{array}$ & $\begin{array}{r}1 \\
10 \\
30\end{array}$ & $\begin{array}{l}649.7 \\
425.2 \\
460.8\end{array}$ & $\begin{array}{r}94.5 \\
-100.1 \\
-72.6\end{array}$ & $\begin{array}{l}0.975 \\
0.780 \\
0.475\end{array}$ \\
\hline $\begin{array}{l}866 \\
866 \\
866\end{array}$ & $\begin{array}{r}1 \\
5 \\
30\end{array}$ & $\begin{array}{l}387.9 \\
417.2 \\
451.6\end{array}$ & $\begin{array}{r}-125.1 \\
-14.3 \\
-0.9\end{array}$ & $\begin{array}{l}0.700 \\
0.167 \\
0.000\end{array}$ \\
\hline $\begin{array}{l}894 \\
894\end{array}$ & $\begin{array}{r}1 \\
30\end{array}$ & $\begin{array}{l}411.3 \\
483.2\end{array}$ & $\begin{array}{l}-54.7 \\
-30.7\end{array}$ & $\begin{array}{l}0.392 \\
0.000\end{array}$ \\
\hline $\begin{array}{l}978 \\
978\end{array}$ & $\begin{array}{r}1 \\
30\end{array}$ & $\begin{array}{l}406.0 \\
452.5\end{array}$ & $\begin{array}{l}0 \\
0\end{array}$ & $\begin{array}{l}0.002 \\
0.000\end{array}$ \\
\hline
\end{tabular}


where

$B=$ the rate constant in Equation (4.10-11)

$\phi=$ fast neutron fluence $\left(n / m^{2}\right)$.

Table 4.10-6 lists the information of Table 4.10-5 using the revised rate constant of Equation (4.10-12). The residual strength coefficients are close to zero for temperatures above $866 \mathrm{~K}$ and for the two long isothermal anneals at $811 \mathrm{~K}$.

The second step in producing a model for the effect of annealing on the strength coefficient of irradiated cladding was the derivation of expressions to describe the annealing of the residual strength coefficient. The expressions for the annealing of the residual strength coefficient are based on the values of this parameter presented in Table 4.10-6 and on residual strengths obtained with the transient test data of Table 4.10-3.

Tables 4.10-7 and 4.10-8 are summaries of the strength coefficient and residual strength coefficients obtained with the transient test data. Table 4.10-7 groups the tests with equal maximum temperature together, and Tabie 4.10-8 groups tests with equal heating rates together. Several trends used to develop the model for the annealing of the residual strength coefficient are apparent from an inspection of Tables 4.10-7 and 4.10-8.

Inspection of the data in Table 4.10-8 shows that the residual strength coefficient does not anneal significantly in any of the tests with a maximum temperature of $755 \mathrm{~K}$ or less. All of the tests with maximum temperature of $978 \mathrm{~K}$ show essentially complete annealing. The tests with maximum temperatures of $811 \mathrm{~K}$ show varying amounts of annealing, but the effect of different heating rates (or, said another way, different times at temperature) on the residual strength coefficient is much less than one would expect from an expression with an exponential time dependence like 


\section{CANEAL}

Table 4.10-6. Strength and residual strength coefficients with modified cold-work annealing model

\begin{tabular}{|c|c|c|c|c|}
\hline $\begin{array}{c}\text { Temperature } \\
\text { (K) }\end{array}$ & $\begin{array}{c}\text { Time at } \\
\text { Temperature } \\
\text { (min) }\end{array}$ & $\begin{array}{l}\text { Strength } \\
\text { Coefficient } \\
\begin{array}{c}(\mathrm{MPa}) \\
\end{array}\end{array}$ & $\begin{array}{c}\text { Residual } \\
\text { Strength } \\
\text { Coefficient } \\
(\mathrm{MPa}) \\
\end{array}$ & $\mathrm{CW} / \mathrm{CW}_{0}$ \\
\hline $\begin{array}{l}644 \\
644 \\
644 \\
644\end{array}$ & $\begin{array}{l}\text { As-received } \\
\text { As-received } \\
\text { As-received } \\
\text { As-received }\end{array}$ & $\begin{array}{l}750.7 \\
781.5 \\
763.4 \\
828.9\end{array}$ & $\begin{array}{l}191.7 \\
222.5 \\
204.4 \\
205.9\end{array}$ & $\begin{array}{l}1 \\
1 \\
1 \\
1\end{array}$ \\
\hline 700 & 60 & 724.8 & 101.8 & 1 \\
\hline $\begin{array}{l}755 \\
755\end{array}$ & $\begin{array}{l}10 \\
60\end{array}$ & $\begin{array}{l}683.5 \\
648.2\end{array}$ & $\begin{array}{l}65.8 \\
54.7\end{array}$ & $\begin{array}{l}0.969 \\
0.827\end{array}$ \\
\hline $\begin{array}{l}811 \\
811 \\
811\end{array}$ & $\begin{array}{r}1 \\
10 \\
30\end{array}$ & $\begin{array}{l}649.7 \\
425.2 \\
460.8\end{array}$ & $\begin{array}{r}239.9 \\
19.2 \\
8.3\end{array}$ & $\begin{array}{l}0.025 \\
0.000 \\
0.000\end{array}$ \\
\hline $\begin{array}{l}866 \\
866 \\
866\end{array}$ & $\begin{array}{r}1 \\
5 \\
30\end{array}$ & $\begin{array}{l}387.9 \\
417.2 \\
451.6\end{array}$ & $\begin{array}{r}-18.1 \\
11.2 \\
-0.9\end{array}$ & $\begin{array}{l}0.000 \\
0.000 \\
0.000\end{array}$ \\
\hline $\begin{array}{l}894 \\
894\end{array}$ & $\begin{array}{r}1 \\
30\end{array}$ & $\begin{array}{l}411.3 \\
483.2\end{array}$ & $\begin{array}{r}5.3 \\
30.7\end{array}$ & $\begin{array}{l}0.000 \\
0.000\end{array}$ \\
\hline $\begin{array}{l}978 \\
978\end{array}$ & $\begin{array}{r}1 \\
30\end{array}$ & $\begin{array}{l}406.0 \\
452.5\end{array}$ & $\begin{array}{l}0 \\
0\end{array}$ & $\begin{array}{l}0.000 \\
0.000\end{array}$ \\
\hline
\end{tabular}


CANEAL

Table 4:10-7. Strength and residual strength coefficients after transient anneals (tests with equal maximum temperature)

\begin{tabular}{|c|c|c|c|c|}
\hline $\begin{array}{l}\text { Heating } \\
\text { Rate } \\
(\mathrm{K} / \mathrm{s}) \\
\end{array}$ & $\begin{array}{c}\text { Maximum } \\
\text { Temperature } \\
(\mathrm{K}) \\
\end{array}$ & $\begin{array}{l}\text { Strength } \\
\text { Coefficient } \\
(\mathrm{MPa}) \\
\end{array}$ & $\begin{array}{c}\text { Residual } \\
\text { Strength } \\
\text { Coefficient } \\
(\mathrm{MPa}) \\
\end{array}$ & $\mathrm{CWCW}_{0}$ \\
\hline $\begin{array}{l}\text { As-received } \\
\text { As-received } \\
\text { As-received } \\
\text { As-received }\end{array}$ & $\begin{array}{l}644 \\
644 \\
644 \\
644\end{array}$ & $\begin{array}{l}750.7 \\
781.5 \\
763.4 \\
828.9\end{array}$ & $\begin{array}{l}191.7 \\
222.5 \\
204.4 \\
205.9\end{array}$ & $\begin{array}{l}1 \\
1 \\
1 \\
1\end{array}$ \\
\hline $\begin{array}{l}0.6 \\
5.6\end{array}$ & $\begin{array}{l}700 \\
700\end{array}$ & $\begin{array}{l}758.5 \\
732.4\end{array}$ & $\begin{array}{l}199.5 \\
173.4\end{array}$ & $\begin{array}{l}1 \\
1\end{array}$ \\
\hline $\begin{array}{r}0.6 \\
5.6 \\
13.9 \\
27.8\end{array}$ & $\begin{array}{l}755 \\
755 \\
755 \\
755\end{array}$ & $\begin{array}{l}728.8 \\
769.4 \\
816.5 \\
755.4\end{array}$ & $\begin{array}{l}169.7 \\
210.4 \\
257.5 \\
196.4\end{array}$ & $\begin{array}{l}0.999 \\
1.0 \\
1.0 \\
1.0\end{array}$ \\
\hline $\begin{array}{r}0.6 \\
5.6 \\
13.9 \\
27.8\end{array}$ & $\begin{array}{l}811 \\
811 \\
811 \\
811\end{array}$ & $\begin{array}{l}651.8 \\
676.5 \\
739.7 \\
830.7\end{array}$ & $\begin{array}{l}111.0 \\
119.5 \\
181.5 \\
272.1\end{array}$ & $\begin{array}{l}0.881 \\
0.987 \\
0.995 \\
0.997\end{array}$ \\
\hline $\begin{array}{r}5.6 \\
13.9 \\
27.8\end{array}$ & $\begin{array}{l}866 \\
866 \\
866\end{array}$ & $\begin{array}{l}405.5 \\
660.5 \\
772.4\end{array}$ & $\begin{array}{r}-115.0 \\
118.2 \\
220.0\end{array}$ & $\begin{array}{l}0.749 \\
0.891 \\
0.944\end{array}$ \\
\hline $\begin{array}{r}0.6 \\
5.6 \\
13.9 \\
27.8\end{array}$ & $\begin{array}{l}894 \\
894 \\
894 \\
894\end{array}$ & $\begin{array}{l}397.0 \\
385.8 \\
514.9 \\
681.8\end{array}$ & $\begin{array}{r}-9.0 \\
-79.7 \\
4.0 \\
149.2\end{array}$ & $\begin{array}{l}0.000 \\
0.389 \\
0.685 \\
0.828\end{array}$ \\
\hline $\begin{array}{r}0.6 \\
5.6 \\
13.9 \\
27.8\end{array}$ & $\begin{array}{l}978 \\
978 \\
978 \\
978\end{array}$ & $\begin{array}{l}370.1 \\
407.1 \\
384.9 \\
411.6\end{array}$ & $\begin{array}{r}-35.9 \\
1.1 \\
-22.4 \\
-8.7\end{array}$ & $\begin{array}{l}0.000 \\
0.000 \\
0.009 \\
0.932\end{array}$ \\
\hline 27.8 & 1033 & 403.6 & -2.4 & 0.001 \\
\hline $\begin{array}{l}27.8 \\
27.8\end{array}$ & $\begin{array}{l}1144 \\
1255\end{array}$ & $\begin{array}{l}458.7 \\
481.1\end{array}$ & $\begin{array}{l}52.7 \\
75.1\end{array}$ & $\begin{array}{l}0.000 \\
0.000\end{array}$ \\
\hline
\end{tabular}




\section{CANEAL}

Table 4.10-8. Strength and residual strength coefficients after transient anneals (test with equal heating rates)

\begin{tabular}{|c|c|c|}
\hline $\begin{array}{l}\text { Heating } \\
\text { Rate } \\
(\mathrm{K} / \mathrm{s}) \\
\end{array}$ & $\begin{array}{l}\text { Maximum } \\
\text { Temperature } \\
\text { (K) }\end{array}$ & $\begin{array}{c}\text { Residual Strength } \\
\text { Coefficient } \\
(\mathrm{MPa}) \\
\end{array}$ \\
\hline $\begin{array}{l}\text { As-received } \\
\text { As-received } \\
\text { As-received } \\
\text { As-received }\end{array}$ & $\begin{array}{l}644 \\
644 \\
644 \\
644\end{array}$ & $\begin{array}{l}191.7 \\
222.5 \\
204.4 \\
205.4\end{array}$ \\
\hline $\begin{array}{l}0.6 \\
0.6 \\
0.6 \\
0.6 \\
0.6\end{array}$ & $\begin{array}{l}700 \\
755 \\
811 \\
894 \\
978\end{array}$ & $\begin{array}{r}199.5 \\
169.7 \\
111.0 \\
-9.0 \\
-35.9\end{array}$ \\
\hline $\begin{array}{l}5.6 \\
5.6 \\
5.6 \\
5.6 \\
5.6 \\
5.6\end{array}$ & $\begin{array}{l}700 \\
755 \\
811 \\
866 \\
894 \\
978\end{array}$ & $\begin{array}{r}173.4 \\
210.4 \\
119.5 \\
-115.0 \\
-79.7\end{array}$ \\
\hline $\begin{array}{l}13.9 \\
13.9 \\
13.9 \\
13.9 \\
13.9\end{array}$ & $\begin{array}{l}755 \\
811 \\
866 \\
894 \\
978\end{array}$ & $\begin{array}{r}257.5 \\
181.5 \\
118.2 \\
4.0 \\
-22.4\end{array}$ \\
\hline $\begin{array}{l}27.8 \\
27.8 \\
27.8 \\
27.8 \\
27.8 \\
27.8 \\
27.8 \\
27.8\end{array}$ & $\begin{array}{r}755 \\
811 \\
866 \\
894 \\
978 \\
1033 \\
1144 \\
1255\end{array}$ & $\begin{array}{r}196.4 \\
272.1 \\
222.0 \\
149.2 \\
-8.7 \\
-2.4 \\
52.7 \\
75.1\end{array}$ \\
\hline
\end{tabular}


Equation (4.10-11). If an equation of the form of equation (4.10-11) were used to model the annealing of the residual strength coefficient, the ratio of the logs of the measured residual strength coefficients after two anneals to the same maximum temperature would be predicted to be proportional to the heating rates. The four residual strengths measured after anneals with a maximum temperature of $811 \mathrm{~K}$ (where annealing changes are greater than the scatter of the data) show significantly less dependence on heating rate. This observation is supported by the isothermal annealing data of Table 4.10-6, which also show relatively little dependence on the time at a given temperature.

When the transient data are grouped with equal heating rates together, (Table 4.10-8), a very strong dependence of residual strength on maximum temperature is apparent. For all of the heating rates, the annealing of the residual strength occurs over a range of maximum temperatures only about $75 \mathrm{~K}$ wide. Moreover, the center of this $75-\mathrm{K}$ band is increased by only about $100 \mathrm{~K}$ when the heating rate is increased by a factor of 50 .

The approach used to model the annealing of the residual strength coefficient was to assume that this component is not subject to the rate equation used for the annealing of cold-work effects. The assumption is logical, not only because of the information in Tables 4.10-6 and 4.10-7 but also because the probable cause of the residual strength coefficient is radiation damage--vacancies, interstitials, and dislocation loops--rather than cold-work effects. To describe the annealing of the residual strength coefficient, an empirical rate equation which is a generalized form of Equations (4.10-6) and (4.10-7) was written ${ }^{2}$

$d v / d t=-B \exp \left(-Q / T^{m}\right) y^{P}$

a. Since the change in the strength coefficient due to irradiation is modeled as a linear function of fast neutron fluence [Equation (5.9-32)] of Section 4.9, one could use the fast neutron fluence in place of the variable $y$ in this equation. The net effect would be a change of the constant $B$. 


\section{CANEAL}

where

$$
\begin{aligned}
y & =\text { irradiation contribution to the strength coefficient (MPa) } \\
\mathrm{T} & =\text { temperature }(K) \\
\mathrm{t} & =\operatorname{time}(\mathrm{s})
\end{aligned}
$$

and $B, Q, m$, and $P$ are positive constants to be evaluated by comparison to the residual strength coefficient data of Tables 4.10-6 to 4.10-8. The procedure used with the rate equation for the annealing of cold-work effects [Steps (2) to (5) after Equation (4.10-7)] was repeated with Equation (4.10-13) to produce a differential expression for the change in $y$ during a time interval with a linear change in temperature. The differential expression is

$$
\frac{1}{y_{f}^{p-1}}=\left[\begin{array}{ll}
p-1
\end{array}\right] B \exp \left(\frac{-Q}{T_{f}^{m}}\right)\left\{\frac{1-\exp \left[\frac{-Q\left(T_{f}-T_{i}\right)^{m}}{T_{f}^{m+1}}\right]}{\frac{Q\left(T_{f}-T_{j}\right)^{m}}{T_{f}^{m+1}}}\right\}\left(t_{f}-t_{i}\right)+\frac{1}{y_{i}^{p-1}}
$$

where terms with subscripts $i$ refer to initial values and terms with subscripts $f$ refer to final values of the terms in Equation (4.10-13).

No completely analytical method to obtain a best fit of Equation $(4.10-13)$ to the data has been found. However, several observations aided in finding values of $B, Q, m$, and $P$ that provide a fit that is within the scatter of the data.

(1) The factor 


$$
\frac{1-\exp \left[\frac{-Q\left(T_{f}-T_{i}\right)^{m}}{T_{f}^{m+1}}\right]}{\frac{Q\left(T_{f}-T_{j}\right)^{m}}{T_{f}^{m+1}}}
$$

can be viewed as a correction for the fact that the temperature did not remain at $T_{f}$ throughout the anneal. It is not relevant to the fundamental annealing properties of the cladding.

(2) Increasing $m$ increases the effect of temperature on the change in $y$ because the factor $\exp \left[-Q /\left(T_{f}\right)^{m}\right]$ is more sensitive to temperature when $m$ is larger.

(3) Increasing $P$ decreases the sensitivity of the change in $y$ to the time span $t_{f}-t_{i}$. This is most easily seen by noting that for large $y_{i}, y_{f}$ is proportional to $\left(t_{f}-t_{j}\right)-1 /(P-1)$. For large values of $P$, the $1 /(P-1)$-th root of $t_{f}-t_{i}$ is relatively insensitive to $t_{f}-t_{j}$.

The residual strength data of Tables 4.10-6 and 4.10-8 were fit by trying integral values of $m$ and $P$ and using pairs of residual strengths from Table 4.10-8 in conjunction with the average value of the as-received residual strength (206 $\mathrm{MPa}$ ) and Equation (4.10-14) to solve for trial values of $Q$ and $B$. Predictions of Equation (4.10-14) with each trial set of $m, P$, $Q$, and $B$ were then compared to all the residual strengths in Tables 4.10-6 and 4.10-7. The best fit to the residual strength data was obtained with $\mathrm{m}$ $=8, P=2, Q=5.35 \times 10^{23}$, and $B=4.50 \times 10^{-3}$. $^{\mathrm{a}}$

a. The $13.9-\mathrm{K} / \mathrm{s}$ anneals to 811 and $866 \mathrm{~K}$ were used to find these values of $Q$ and $B$. 


\section{CANEAL}

Two trivial steps were required to convert Equation (4.10-14) to the form actually used in MATPRO subcodes.

1. The equation was transformed to an equivalent expression in terms of the initial temperature and heating rate. This transformation allows all the required input information to be parameters at the beginning of a time step. The transformation was carried out by using an alternate linear interpolation for temperature, as noted in conjunction with Equation (4.10-10).

2. The equation was modified to express the change in residual strength in terms of an effective fluence for use in Equation (4.9-32) of Section 4.9.

The expression for the rate of annealing of the effective fast neutron fluence for strain hardening [Equation (4.10-4)] was obtained by assuming that the rate of annealing of the effective fast neutron fluence for the strain hardening exponent is proportional to the rate of annealing of the effective fluence for the strength coefficient. The model development was complicated by the fact that the cladding used to construct the model experienced three periods at high temperature in addition to the actual annealing test.

1. The stress relief anneal

2. The two-year in-reactor life of the rod

3. The normal thermal transients during postirradiation handling of the rods. 4.10-6

The effective fast neutron fluence for the strain hardening exponent at the start of the actual annealing test can be estimated from Bauer's 
as-received data (Table 4.10-3 or 4.10-4), and Equations (4.9-23) and (4.9-31) of Section 4.9. A maximum effective fluence of $8.4 \times 10^{22} \mathrm{n} / \mathrm{m}^{2}$ (for zero effective cold work) was found. Since the measured fast neutron fluence was $4.3 \times 10^{25} \mathrm{n} / \mathrm{m}^{2}$, considerable annealing of the radiation damage component that determines the strain hardening exponent must be assumed either in-reactor or during postirradiation handling of the rods.

The constants used in Equation (4.10-4) were obtained by (a) assuming as-received effective fast neutron fluences in the range $1 \times 10^{21}$ to $8 \times$ $10^{22} \mathrm{n} / \mathrm{m}^{2}$; (b) determining a constant of proportionality between the annealing rates of effective fast neutron fluences for strength and strain hardening that yields a prediction consistent with the annealing data; and (c) checking the first two steps by applying the annealing model to the in-reactor history to see if the assumed as-received effective fast neutron fluence and annealing rate are consistent. Self-consistent results were obtained with an as-received effective fast neutron fluence for strain hardening of $2 \times 10^{22} \mathrm{n} / \mathrm{m}^{2}$ and a constant of proportionality of 1000 .

Since no data are available for beta-phase annealing, an approximation is necessary. The effective cold works and fast neutron fluences are set equal to zero whenever the temperature is as high as $1255 \mathrm{~K}$, the approximate equilibrium phase boundary for beta zircaloy.

\subsubsection{Comparison of Annealing Models to Data}

Tables 4.10-9 through 4.10-11 are comparisons of the predicted strength coefficients and strain hardening exponents to the data base used to construct the annealing models. The limited data for unirradiated cladding appear in Table 4.10-9. The cladding used in these tests had been $70 \%$ cold-worked, then stress relieved according to schedules published by R. H. Chapman. ${ }^{4 \cdot 10-4}$ Equations $(4.10-1)$ and (4.10-3) predict an effective cold work of $50 \%$ for the strength coefficient and $4 \%$ for the strain hardening exponent after the stress relief anneal. Both strength coefficient and strain hardening exponent are well predicted by the model. 
CANEAL

Table 4.10-9. Comparison of model predictions of $K$ and $n$ with data base for unirradiated cladding

\begin{tabular}{|c|c|c|c|c|c|}
\hline \multirow{2}{*}{$\begin{array}{c}\text { Heating } \\
\text { Rate } \\
(\mathrm{K} / \mathrm{s}) \\
\end{array}$} & \multirow{2}{*}{$\begin{array}{c}\text { Maximum } \\
\text { Temperature } \\
(\mathrm{K}) \\
\end{array}$} & \multicolumn{2}{|c|}{$\begin{array}{l}\text { Strength Coefficient } \\
(\mathrm{MPa})\end{array}$} & \multicolumn{2}{|c|}{$\begin{array}{c}\text { Strain Hardening } \\
\text { Exponent }\end{array}$} \\
\hline & & From Data & Predicted & From Data & Predicted \\
\hline $\begin{array}{c}\text { As-received } \\
5.6 \\
5.6 \\
5.6 \\
5.6 \\
27.8 \\
27.8 \\
27.8 \\
27.8\end{array}$ & $\begin{array}{l}644 \\
811 \\
866 \\
894 \\
978 \\
811 \\
866 \\
894 \\
978\end{array}$ & $\begin{array}{l}524 \\
524 \\
520 \\
503 \\
444 \\
515 \\
514 \\
513 \\
516\end{array}$ & $\begin{array}{l}524 \\
524 \\
521 \\
515 \\
457 \\
524 \\
524 \\
522 \\
505\end{array}$ & $\begin{array}{l}0.040 \\
0.040 \\
0.040 \\
0.047 \\
0.218 \\
0.035 \\
0.033 \\
0.035 \\
0.045\end{array}$ & $\begin{array}{l}0.040 \\
0.040 \\
0.047 \\
0.062 \\
0.119 \\
0.040 \\
0.041 \\
0.044 \\
0.087\end{array}$ \\
\hline
\end{tabular}


CANEAL

Table 4.10-10. Comparison of model predictions of $K$ and $n$ with data base for transient anneals of irradiated cladding

\begin{tabular}{|c|c|c|c|c|c|}
\hline \multirow{2}{*}{$\begin{array}{l}\text { Heating } \\
\text { Rate } \\
(\mathrm{K} / \mathrm{s}) \\
\end{array}$} & \multirow{2}{*}{$\begin{array}{c}\text { Maximum } \\
\text { Temperature } \\
(\mathrm{K}) \\
\end{array}$} & \multicolumn{2}{|c|}{$\begin{array}{c}\text { Strength Coefficient } \\
(\mathrm{MPa})\end{array}$} & \multicolumn{2}{|c|}{$\begin{array}{c}\text { Strain Hardening } \\
\text { Exponent }\end{array}$} \\
\hline & & From Data & Predicted & From Data & Predicted \\
\hline $\begin{array}{l}\text { As-received } \\
\text { As-received } \\
\text { As-received } \\
\text { As-received }\end{array}$ & $\begin{array}{l}644 \\
644 \\
644 \\
644\end{array}$ & $\begin{array}{l}750.7 \\
781.5 \\
763.4 \\
828.9\end{array}$ & $\begin{array}{l}765.1 \\
765.1 \\
765.1 \\
765.1\end{array}$ & $\begin{array}{l}0.040 \\
0.039 \\
0.028 \\
0.037\end{array}$ & $\begin{array}{l}0.024 \\
0.024 \\
0.024 \\
0.024\end{array}$ \\
\hline $\begin{array}{l}0.6 \\
0.6 \\
0.6 \\
0.6 \\
0.6\end{array}$ & $\begin{array}{l}700 \\
755 \\
811 \\
894 \\
978\end{array}$ & $\begin{array}{l}758.5 \\
728.5 \\
651.8 \\
397.0 \\
370.1\end{array}$ & $\begin{array}{l}764.6 \\
721.3 \\
574.1 \\
442.7 \\
409.9\end{array}$ & $\begin{array}{l}0.021 \\
0.027 \\
0.023 \\
0.091 \\
0.088\end{array}$ & $\begin{array}{l}0.024 \\
0.024 \\
0.029 \\
0.092 \\
0.100\end{array}$ \\
\hline $\begin{array}{l}5.6 \\
5.6 \\
5.6 \\
5.6 \\
5.6 \\
5.6\end{array}$ & $\begin{array}{l}700 \\
755 \\
811 \\
866 \\
894 \\
978\end{array}$ & $\begin{array}{l}732.4 \\
769.4 \\
676.5 \\
405.5 \\
385.8 \\
407.1\end{array}$ & $\begin{array}{l}765.1 \\
759.9 \\
706.2 \\
598.7 \\
547.0 \\
441.0\end{array}$ & $\begin{array}{l}0.020 \\
0.024 \\
0.023 \\
0.029 \\
0.047 \\
0.100\end{array}$ & $\begin{array}{l}0.024 \\
0.024 \\
0.025 \\
0.030 \\
0.041 \\
0.083\end{array}$ \\
\hline $\begin{array}{l}13.9 \\
13.9 \\
13.9 \\
13.9 \\
13.9\end{array}$ & $\begin{array}{l}755 \\
811 \\
866 \\
894 \\
978\end{array}$ & $\begin{array}{l}816.5 \\
739.7 \\
680.5 \\
514.9 \\
384.9\end{array}$ & $\begin{array}{l}762.9 \\
736.9 \\
660.5 \\
511.6 \\
482.9\end{array}$ & $\begin{array}{l}0.024 \\
0.022 \\
0.025 \\
0.021 \\
0.056\end{array}$ & $\begin{array}{l}0.024 \\
0.024 \\
0.026 \\
0.031 \\
0.071\end{array}$ \\
\hline $\begin{array}{l}27.8 \\
27.8 \\
27.8 \\
27.8 \\
27.8 \\
27.8 \\
27.8 \\
27.8\end{array}$ & $\begin{array}{l}755 \\
811 \\
866 \\
894 \\
978 \\
1033 \\
1144 \\
1255\end{array}$ & $\begin{array}{l}755.4 \\
830.7 \\
772.4 \\
681.8 \\
411.6 \\
403.6 \\
458.7 \\
481.1\end{array}$ & $\begin{array}{l}764.0 \\
750.2 \\
700.6 \\
662.1 \\
532.3 \\
476.4 \\
439.7 \\
428.7\end{array}$ & $\begin{array}{l}0.021 \\
0.027 \\
0.027 \\
0.026 \\
0.034 \\
0.046 \\
0.083 \\
0.100\end{array}$ & $\begin{array}{l}0.024 \\
0.024 \\
0.025 \\
0.027 \\
0.054 \\
0.074 \\
0.081 \\
0.084\end{array}$ \\
\hline
\end{tabular}




\section{CANEAL}

Table 4.10-11. Comparison of model predictions of $K$ and $N$ with data base for isothermal anneals of irradiated cladding

\begin{tabular}{|c|c|c|c|c|c|}
\hline \multirow{2}{*}{$\begin{array}{l}\text { Heating } \\
\text { Rate } \\
(\mathrm{K} / \mathrm{s}) \\
\end{array}$} & \multirow{2}{*}{$\begin{array}{c}\text { Maximum } \\
\text { Temperature } \\
(\mathrm{K}) \\
\end{array}$} & \multicolumn{2}{|c|}{$\begin{array}{c}\text { Strength Coefficient } \\
(\mathrm{MPa})\end{array}$} & \multicolumn{2}{|c|}{$\begin{array}{l}\text { Strain Hardening } \\
\text { Exponent }\end{array}$} \\
\hline & & From Data & Predicted & From Data & Predicted \\
\hline $\begin{array}{l}644 \\
644 \\
644 \\
644\end{array}$ & $\begin{array}{l}\text { As-received } \\
\text { As-received } \\
\text { As-received } \\
\text { As-received }\end{array}$ & $\begin{array}{l}750.7 \\
781.5 \\
763.4 \\
828.9\end{array}$ & $\begin{array}{l}765.1 \\
765.1 \\
765.1 \\
765.1\end{array}$ & $\begin{array}{l}0.040 \\
0.039 \\
0.028 \\
0.037\end{array}$ & $\begin{array}{l}0.024 \\
9.024 \\
0.024 \\
0.024\end{array}$ \\
\hline 700 & 60 & 724.8 & 700.8 & 0.033 & 0.024 \\
\hline $\begin{array}{l}755 \\
755\end{array}$ & $\begin{array}{l}10 \\
60\end{array}$ & $\begin{array}{l}683.5 \\
648.2\end{array}$ & $\begin{array}{l}567.7 \\
512.7\end{array}$ & $\begin{array}{l}0.028 \\
0.030\end{array}$ & $\begin{array}{l}0.028 \\
0.036\end{array}$ \\
\hline $\begin{array}{l}811 \\
811 \\
811\end{array}$ & $\begin{array}{r}1 \\
10 \\
30\end{array}$ & $\begin{array}{l}649.7 \\
425.2 \\
460.8\end{array}$ & $\begin{array}{l}547.9 \\
421.9 \\
409.5\end{array}$ & $\begin{array}{l}0.029 \\
0.031 \\
0.050\end{array}$ & $\begin{array}{l}0.032 \\
0.080 \\
0.100\end{array}$ \\
\hline $\begin{array}{l}866 \\
866 \\
866\end{array}$ & $\begin{array}{r}1 \\
5 \\
30\end{array}$ & $\begin{array}{l}387.9 \\
417.2 \\
451.6\end{array}$ & $\begin{array}{l}428.5 \\
411.3 \\
408.0\end{array}$ & $\begin{array}{l}0.044 \\
0.077 \\
0.096\end{array}$ & $\begin{array}{l}0.080 \\
0.097 \\
0.106\end{array}$ \\
\hline $\begin{array}{l}894 \\
894\end{array}$ & $\begin{array}{r}1 \\
30\end{array}$ & $\begin{array}{l}411.3 \\
483.2\end{array}$ & $\begin{array}{l}420.4 \\
407.8\end{array}$ & $\begin{array}{l}0.076 \\
0.130\end{array}$ & $\begin{array}{l}0.088 \\
0.108\end{array}$ \\
\hline $\begin{array}{l}978 \\
978\end{array}$ & $\begin{array}{r}1 \\
30\end{array}$ & $\begin{array}{l}406.0 \\
452.5\end{array}$ & $\begin{array}{l}414.2 \\
407.6\end{array}$ & $\begin{array}{l}0.074 \\
0.112\end{array}$ & $\begin{array}{l}0.093 \\
0.110\end{array}$ \\
\hline
\end{tabular}


CANEAL

Tables 4.10-10 and 4.10-11 compare model predictions for strength coefficients and strain hardening exponents with corresponding values derived from Bauer's measurements with cold-worked and irradiated cladding. No annealing schedule has been published for this material, but published nominal preirradiation values ${ }^{4 \cdot 10-7}$ are consistent with the assumption that the annealing schedule was similar to the unirradiated cladding. Therefore, the effective cold works of $50 \%$ and $4 \%$ were also used to describe the irradiated cladding.

\subsubsection{References}

4.10-1. L. M. Howe and W. R. Thomas, "The Effect of Neutron Irradiation on the Tensile Properties of Zircaloy-2," Journal of Nuclear Materials, 2, 1960, pp. 248-260.

4.10-2. A. A. Bauer, L. M. Lowry, J. S. Perrin, Evaluating Strength and Ductility of Irradiated Zircaloy: Quarterly Progress Report, JuTy--September 1976, BMI-NUREG-1961, October 1976.

4.10-3. A. A. Bauer, L. M. Lowry, J. S. Perrin, Evaluating Strength and Ductility of Irradiated Zircaloy: Quarterly Progress Report, Apri7--June 1976, BMI-NUREG-1956, July 1976.

4.10-4. R. H. Chapman, Characterization of Zircaloy-4 Tubing Procured for Research Programs, ORNL/NUREG/TM-29, July 1976.

4.10-5. J. G. Byrne, Recovery, Recrystallization and Grain Growth, New York: The Macmillan Company, 1965.

4.10-6. A. A. Bauer, L. M. Lowry, J. S. Perrin, Progress on Evaluating Strength and Ductility of Irradiated Zircaloy During Ju7y--September 1975, BMI-NUREG-1938, September 1975.

4.10-7. A. A. Bauer, L. M. Lowry, J. S. Perrin, Evaluating Strength and Ductility of Irradiated Zircaloy: Quarterly Progress Report, October--December 1976, BMI-NUREG-1967, January 1977. 


\title{
CMLIMT， CBRTTL
}

\subsection{Mechanical Limits and Embrittlement (CMLIMt, CBRTtL)}

\author{
(D. L. Hagrman and G. A. Reymann)
}

Cladding deformation and failure under stress is characterized by several boundaries that define important changes in the physical response of the cladding to stress. This section is a description of these boundaries and the two subcodes used to model them. The first subcode, CMLIMT, defines the elastic-plastic transition and cladding failure under tensile stress. The second subcode, CBRTTL, defines the amount of oxygen the cladding can absorb without becoming brittle.

\subsubsection{Summary (CMLIMT)}

Cladding mechanical limits are important to code predictions of both the number and shape of failed rods. This section describes expressions used to determine the most important limits, the elastic-plastic transition (yield) and cladding failure under tensile stress, as well as the ultimate engineering strength and the uniform elongation under uniaxial stress.

Failure expressions are related to the amount of detail the user chooses to consider in mechanical models. The fundamental failure criterion is derived for codes that model cladding plastic deformation without assuming azimuthally symmetric deformation. Alternate expressions are presented for less sophisticated codes that assume symmetric deformation, and one simplified correlation is presented for users who do not model plastic deformation at alt.

The input parameters for the CMLIMT subcode are temperature, cold work, fast neutron fluences ( $>1 \mathrm{MeV}$ ), average oxygen concentration, and strain rate. The equations used are 


\section{CMLIMT, CBRTTL}

true strain at yield $=\left[\frac{K}{E}\left(\frac{\dot{\epsilon}}{10^{-3}}\right)^{\mathrm{m}}\right]^{1 /(1-n)}$

true yield strength $=\left[\frac{K}{E^{n}}\left(\frac{\dot{\epsilon}}{10^{-3}}\right)^{m}\right]^{1 /(1-n)}$

true strain at maximum load $=\frac{n}{1+m}$

true ultimate strength $=\frac{K}{E}\left(\frac{\dot{\epsilon}}{10^{-3}}\right)^{m}\left(\frac{n}{1+m}\right)^{n}$

where

$K=$ strength coefficient $\langle\mathrm{Pa}\rangle$

$E=$ Youngs's modulus $(\mathrm{Pa})$

$\dot{\epsilon}=$ true strain rate $\left(\mathrm{s}^{-1}\right)$

$\mathrm{n}=$ strain hardening exponent (unitless)

$m=$ strain rate sensitivity constant (unitless).

$K, n$, and $m$ are calculated with the subcode CKMN discussed in the description of CSTRES (Section 4.9), E is obtained by calling the function CELMOD (Section 4.6), and $\epsilon$ is required input information.

Arguments are presented in Section 4.11.3 that demonstrate that cladding failure should be predicted by comparing the tangential component of true stress to the burst stress. Heating rate and strain rate do not affect this criterion, but irradiation and cold work increase it somewhat. 
CMLIMT, CBRTTL

The burst stress as a function of temperature is given by the following equations:

$$
\begin{aligned}
& \text { For } T \leq 750 \mathrm{~K}, \\
\sigma_{\theta B}= & 1.36 \mathrm{~K} \\
& \text { For } 750<T \leq 1050 \mathrm{~K}, \\
\sigma_{\theta B}= & 46.861429 \mathrm{~K} \exp -\left(1.9901087 \times 10^{6} / \mathrm{T}^{2}\right) \\
& \text { For } \mathrm{T}>1050 \mathrm{~K}, \\
\sigma_{\theta B}= & 7.7 \mathrm{~K}
\end{aligned}
$$

where

$$
\begin{aligned}
\sigma_{\theta B} & =\text { tangential component of true stress at burst }(\mathrm{Pa}) \\
K_{A} & =\begin{array}{l}
\text { strength coefficient for annealed cladding as determined } \\
\text { with the MATPRO CKMN subcode }(\mathrm{Pa})
\end{array} \\
T & =\text { temperature }(\mathrm{K}) .
\end{aligned}
$$

For cold-worked or irradiated cladding, the burst stress is increased by four tenths of the increase of the strength coefficient due to irradiation and cold work.

The standard error a ${ }^{2}$ of Equations (4.11-5) through (4.11-7) is

$$
\begin{aligned}
& \text { a. The standard error of a model is estimated with a set of data by the } \\
& \text { expression: (sum of squared residuals s/number of residuals minus the number } \\
& \text { of constants used to fit the data) } 192 \text {. }
\end{aligned}
$$

$$
4.11-3
$$




\section{CMLIMT, CBRTTL}

$U \sigma_{\theta \mathrm{B}}=0.1 \sigma_{\sigma_{\theta \mathrm{B}}}$

where $U \sigma_{\theta \mathrm{B}}$ is the standard error of $\sigma_{\theta \mathrm{B}}$.

Section 4.11 .2 is a review of the available data. Equations (4.11-1) through (4.11-6) are derived in Section 4.11.3, and alternate methods of applying Equation (4.11-5) are derived in Section 4.11.4.

\subsubsection{Available Data}

The data reported as yield points, strain at maximum load (uniform strain), and ultimate strength have been reviewed in conjunction with the description of the CSTRES code (Section 4.9). This subsection will review only the data used in development of the CMLIMT subcode failure criterion. The number of these data has been severely restricted by the requirement that they be sufficiently complete to allow an estimate of local stresses and strains at failure.

The most useful data have been produced by the Multirod Burst Test Program sponsored by the NRC. All of these data were obtained with internal heaters and an external steam environment. Heating rates varied from 0 to $28 \mathrm{k} / \mathrm{s}$. Estimated burst temperatures, burst pressures, and burst strains (average circumferential elongation) have been published for a number of single rod tests. ${ }^{4.11-1,4.11-2}$ In addition, calibrated photographs of cross sections through the burst regions of some of the tests have been published. ${ }^{4} 11-2,4.11-3,4.11-4,4.11-5$ These cross sections were needed to estimate wall thickness at burst ${ }^{a}$ for the calculation of local stress at failure. The other required information for the local stress analysis developed in Section 4.11 .3 is an estimate of the axial radius of curvature

a. Most burst edges displayed one or more cleavage-like lines approximately 45 degrees from the radial direction. The wall thickness was measured adjacent to this line or, if the line could not be distinguished, $0.25 \mathrm{~mm}$ from the burst tear. 


\section{CMLIMT， CBRTTL}

at burst. This information was not published but could be estimated from side view photographs of the burst tubes. 4.11-6,4.11-7,4.11-8 Table 4.11-1 is a summary of the Multirod Burst Test Program Data used.

Data from tests by Hobson and Rittenhouse $4.11-9$ were also employed. The Hobson-Rittenhouse tests were conducted using a radiant heating furnace on BWR cladding in an argon environment with heating rates from 5.6 to $56 \mathrm{~K} / \mathrm{s}$. There was no significant difference in the local failure stress predicted from the Hobson-Rittenhouse tests conducted in argon and that predicted from the tests in a steam environment. It is possible that longtime tests in steam will show a difference in local stress at failure. However, it is also possible that specimens that accumulate thick, oxygen-rich layers before significant deformation occurs will show that the oxygen-rich layers of the cladding rupture before the oxygen-poor layers. In the latter case, oxidation would have a significant effect on the early (small strain) deformation but little effect on the stress at failure.

Table 4.11-2 is a summary of the data that were used from the tests of Hobson and Rittenhouse. Burst temperatures, wall thickness measurements, and the average circumferential elongation were obtained from figures in Reference 4.11-9. Burst pressures were obtained by private communication from $R$. H. Chapman, and axial radii of curvature were estimated from samples sent by $D$. 0 . Hobson.

Table 4.11-3 is a summary of data obtained by Chung and Kassner 4.11-10 that were used in the development of the CMLIMT code. The burst temperature, differential pressure at burst, average circumferential strain, and axial radius of curvature were obtained from Reference 4.11-10. The wall thickness at burst was obtained from photographs of cross sections from Chung by private communication. An important factor is that all of the samples in Table 4.11-3 were constrained by an internal mandrel, which applied an unknown axial stress to the cladding. 
CMLIMT, CBRTTL

Table 4.11-1. Summary of Multirod Burst Test data employed in CMLIMT

\begin{tabular}{|c|c|c|c|c|c|}
\hline $\begin{array}{c}\text { Test } \\
\text { No. }\end{array}$ & $\begin{array}{c}\text { Burst } \\
\text { Temperature } \\
(K) \\
\end{array}$ & $\begin{array}{c}\text { Differential } \\
\text { Pressure at } \\
\text { Burst } \\
\text { (MPa) } \\
\end{array}$ & $\begin{array}{c}\text { Average } \\
\text { Circumferential } \\
\text { Strain } \\
(\mathrm{m} / \mathrm{m}) \\
\end{array}$ & $\begin{array}{l}\text { Wall } \\
\text { Thickness } \\
\text { at Burst } \\
\text { (mm) }\end{array}$ & $\begin{array}{l}\text { Axial } \\
\text { Radius of } \\
\text { Curvature } \\
(\mathrm{cm})\end{array}$ \\
\hline $\begin{array}{l}\text { PS }-10 \\
\text { PS-17 } \\
\text { PS }-18 \\
\text { PS-19 } \\
\text { SR-23 } \\
\text { SR-25 } \\
\text { SR }-34 \\
\text { SR-35 } \\
\text { SR }-37 \\
\text { SR }-41 \\
\text { SR-43 }\end{array}$ & $\begin{array}{l}1174^{a} \\
1051^{a} \\
1444^{a} \\
1232^{a} \\
1350^{a} \\
1365^{a} \\
1039 \\
1048^{b} \\
1033^{b} \\
1030^{b} \\
1046^{b}\end{array}$ & $\begin{array}{r}6.000^{\mathrm{a}} \\
12.130^{\mathrm{a}} \\
0.772^{\mathrm{a}} \\
2.590^{\mathrm{a}} \\
0.960^{\mathrm{a}} \\
0.960^{\mathrm{a}} \\
5.820^{\mathrm{b}} \\
4.470^{\mathrm{b}} \\
13.560^{\mathrm{b}} \\
9.765^{\mathrm{b}} \\
7.620^{\mathrm{b}}\end{array}$ & $\begin{array}{l}0.20^{\mathrm{a}} \\
0.25^{\mathrm{a}} \\
0.24^{\mathrm{a}} \\
0.28^{\mathrm{a}} \\
0.35^{\mathrm{a}} \\
0.78^{\mathrm{a}} \\
0.316^{\mathrm{b}} \\
0.290^{\mathrm{b}} \\
0.231 \mathrm{~b} \\
0.274^{\mathrm{b}} \\
0.290^{\mathrm{b}}\end{array}$ & $\begin{array}{l}0.079^{c} \\
0.176^{c} \\
0.111^{d} \\
0.079^{c} \\
0.164^{e} \\
0.077^{e} \\
0.109^{b} \\
0.073^{f} \\
0.263^{f} \\
0.199^{b} \\
0.179^{b}\end{array}$ & $\begin{array}{l}2.1^{\mathrm{c}} \\
1.2^{\mathrm{c}} \\
0.9^{\mathrm{g}} \\
0.6^{\mathrm{c}} \\
1.1^{\mathrm{h}} \\
0.6^{\mathrm{i}} \\
1.6^{\mathrm{C}} \\
3.1^{\mathrm{c}} \\
3.7^{\mathrm{c}} \\
2.7^{\mathrm{C}} \\
3.5^{\mathrm{c}}\end{array}$ \\
\hline
\end{tabular}
a. Reference 4.11-1.
b. Reference 4.11-2.
c. From photographs sent by R. H. Chapman.
d. Reference 4.11-3.
e. Reference 4.11-4.
f. Reference 4.11-5.
g. Reference 4.11-6.
h. Reference 4.11-7.
i. Reference 4.11-8. 
CMLIMT, CBRTTL

Table 4.11-2. Summary of data from the Hobson-Rittenhouse tests

\begin{tabular}{|c|c|c|c|c|c|}
\hline $\begin{array}{c}\text { Test } \\
\text { No. }\end{array}$ & $\begin{array}{c}\text { Burst } \\
\text { Temperature } \\
(\mathrm{K}) \\
\end{array}$ & $\begin{array}{c}\text { Differential } \\
\text { Pressure at } \\
\text { Burst } \\
(\mathrm{MPa}) \\
\end{array}$ & $\begin{array}{c}\text { Average } \\
\text { Circumferential } \\
\text { Strain } \\
(\mathrm{m} / \mathrm{m}) \\
\end{array}$ & $\begin{array}{l}\text { Wall } \\
\text { Thickness } \\
\text { at Burst } \\
\text { (mm) } \\
\end{array}$ & $\begin{array}{l}\text { Axial } \\
\text { Radius of } \\
\text { Curvature } \\
\text { (cm) }\end{array}$ \\
\hline $\begin{array}{r}35 \\
34 \\
40 \\
18 \\
17 \\
19 \\
21 \\
8 \\
16 \\
5 \\
5 \\
26 a \\
27 \\
15 \\
37 \\
26 \\
9 \\
28 \\
28 \\
11 \\
32 \\
29 \\
36 \\
4\end{array}$ & $\begin{array}{l}1061 \\
1081 \\
1111 \\
1145 \\
1158 \\
1160 \\
1171 \\
1179 \\
1195 \\
1196 \\
1205 \\
1213 \\
1214 \\
1215 \\
1220 \\
1235 \\
1253 \\
1299 \\
1302 \\
1432 \\
1440 \\
1472 \\
1487\end{array}$ & $\begin{array}{l}6.170 \\
7.584 \\
4.654 \\
4.826 \\
4.205 \\
4.895 \\
3.102 \\
3.826 \\
3.999 \\
3.757 \\
3.068 \\
2.241 \\
2.275 \\
2.344 \\
3.033 \\
1.448 \\
1.413 \\
1.434 \\
0.745 \\
0.676 \\
0.827 \\
0.689 \\
0.662\end{array}$ & $\begin{array}{l}0.63 \\
0.58 \\
0.79 \\
1.25 \\
0.57 \\
0.51 \\
0.30 \\
0.22 \\
0.42 \\
0.44 \\
0.27 \\
0.55 \\
0.41 \\
0.40 \\
0.53 \\
0.43 \\
0.85 \\
0.68 \\
0.93 \\
0.92 \\
0.50 \\
1.11 \\
0.74\end{array}$ & $\begin{array}{l}0.25 \\
0.23 \\
0.18 \\
0.18 \\
0.20 \\
0.23 \\
0.18 \\
0.20 \\
0.25 \\
0.20 \\
0.28 \\
0.15 \\
0.18 \\
0.18 \\
0.13 \\
0.20 \\
0.18 \\
0.25 \\
0.25 \\
0.23 \\
0.23 \\
0.20 \\
0.25\end{array}$ & $\begin{array}{l}2.9 \\
1.8 \\
1.8 \\
3.0 \\
2.5 \\
1.8 \\
1.7 \\
1.3 \\
1.7 \\
1.0 \\
1.8 \\
1.1 \\
1.1 \\
1.4 \\
1.5 \\
2.7 \\
2.8 \\
1.5 \\
2.1 \\
2.5 \\
1.5 \\
2.5 \\
1.5\end{array}$ \\
\hline
\end{tabular}




\section{CMLIMT, CBRTTL}

Table 4.11-3. Summary of data from the Chung-Kassner tests

\begin{tabular}{|c|c|c|c|c|c|}
\hline $\begin{array}{l}\text { Test } \\
\text { No. } \\
\end{array}$ & $\begin{array}{c}\text { Burst } \\
\text { Temperature } \\
\text { (K) } \\
\end{array}$ & $\begin{array}{c}\text { Differential } \\
\text { Pressure at } \\
\text { Burst } \\
\text { (MPa) } \\
\end{array}$ & $\begin{array}{c}\text { Average } \\
\text { Circumferential } \\
\text { Strain } \\
(\mathrm{m} / \mathrm{m}) \\
\end{array}$ & $\begin{array}{l}\text { Wall } \\
\text { Thickness } \\
\text { at Burst } \\
(\mathrm{mm}) \\
\end{array}$ & $\begin{array}{l}\text { Axial } \\
\text { Radius of } \\
\text { Curvature } \\
\quad(\mathrm{cm}) \\
\end{array}$ \\
\hline$A S-40$ & 1089 & 5.302 & 1.01 & 0.39 & 2.9 \\
\hline AS-36 & 1310 & 0.558 & 1.11 & 0.26 & 2.9 \\
\hline AS -9 & 1329 & 1.282 & 1.24 & 0.12 & 3.2 \\
\hline AS -5 & 1348 & 1.334 & 1.02 & 0.42 & 1.6 \\
\hline
\end{tabular}


None of the data mentioned so far were obtained from irradiated cladding or at temperatures below $1000 \mathrm{~K}$. The only available low-temperature data with irradiated cladding were obtained from studies by Bauer, Lowry, Gallagher, Markworth and Perrin 4.11-11,4.11-12,4.11-13 on cladding obtained from the $H$. B. Robinson reactor. The data from Bauer's tests which have been used in the development of CMLIMT are presented in Table 4.11-4. Tests M12-16, M-12-4, and M12-15 were conducted on as-received cladding; while Tests D9-7, D9-8, D9-13, and D9-14 were conducted on cladding that had been annealed. Wall thicknesses adjacent to the burst were obtained from unpublished photographs similar to Figure 7 of Reference 4.11-11. The axial radii of curvature in these tests have not been reported.

Two sources of in-reactor data were employed. One is the irradiation effects Test IE-5, conducted in the Power Burst Facility at EG\&G Idaho, Inc. 4.11-14,4.11-15 The measured (Rod IE-19) internal pressure in this test was reported to be $5.2 \mathrm{MPa}$ in excess of the coolant pressure, and the cladding temperature was estimated from microstructure studies to be near $1100 \mathrm{~K}$. The average circumferential elongation was reported to be 25\%.4.11-15 The wall thickness at burst was estimated to be $0.09 \mathrm{~mm}$, using figures from the postirradiation examination results report; $4.11-15$ and the axial radius of curvature was estimated to be approximately four times the rod diameter from the posttest side view in Reference 4.11-15.

The second source of in-reactor data is a series of tests in the FR2 reactor in Germany. ${ }^{4.11-16}$ Complete data from three tests (A2.3, B1.2, and $B 1.3$ ) were presented, but two of the cladding cross sections showed evidence of contact with the shroud (burst edges rolled in). For that reason, only data from Test $B 1.2$ were used. The average circumferential elongation, axial radius of curvature, burst pressure, and temperature for this test were taken from Reference 4.11-16 (0.249, $1.5 \mathrm{~cm}, 4.52 \mathrm{MPa}$, and $1188 \mathrm{~K})$. The coolant pressure was assumed to be the typical value of $0.3 \mathrm{MPa}$ quoted in Reference 4.11-16. 
Table 4.11-4. Summary of data from the Bauer tests

\begin{tabular}{|c|c|c|c|c|}
\hline $\begin{array}{c}\text { Test } \\
\text { No. } \\
\end{array}$ & $\begin{array}{c}\text { Burst } \\
\text { Temperature } \\
\text { (K) }\end{array}$ & $\begin{array}{l}\text { Burst } \\
\text { Strength } \\
\text { (MPa) } \\
\end{array}$ & $\begin{array}{c}\text { Average } \\
\text { Circumferential } \\
\text { Strain } \\
(\mathrm{m} / \mathrm{m}) \\
\end{array}$ & $\begin{array}{l}\text { Wall } \\
\text { Thickness } \\
\text { at Burst } \\
\quad(\mathrm{mm}) \\
\end{array}$ \\
\hline $\begin{array}{l}\text { M12-16 } \\
\text { M12-4 } \\
\text { M12-15 } \\
\text { D9-7 } \\
\text { D9-8 } \\
\text { D9-13 } \\
\text { D9-14 }\end{array}$ & $\begin{array}{l}477 \\
644 \\
644 \\
644 \\
644 \\
644 \\
644\end{array}$ & $\begin{array}{l}749.4 \\
659.1 \\
684.6 \\
356.4 \\
350.9 \\
372.3 \\
367.5\end{array}$ & $\begin{array}{l}0.026 \\
0.052 \\
0.028 \\
0.212 \\
0.204 \\
0.225 \\
0.292\end{array}$ & $\begin{array}{l}0.57 \\
0.60 \\
0.61 \\
0.45 \\
0.46 \\
0.51 \\
0.48\end{array}$ \\
\hline \multicolumn{5}{|c|}{ rom Reference 4.11-12. } \\
\hline b. & raphs & A. A. & and L. W. Lowry & \\
\hline
\end{tabular}




\section{CMLIMT， CBRTTL}

One out-of-pile test result from Germany $4.11-17$ was used in developing the CMLIMT failure model. The test was performed in air (one atmosphere) with an internal heater. The burst temperature, internal pressure at burst, average circumferential strain, and wall thickness at burst $(1114 \mathrm{~K}, 7.1 \mathrm{MPa}, 0.37$, and $0.215 \mathrm{~mm})$ were taken from Reference 4.11-17. The axial radius of curvature was estimated to be approximately three times the cladding radius at burst by inspection of $X$-ray photos of similar tests just prior to burst.

\subsubsection{Model Development}

The expressions used to describe the elastic-plastic transition (yield) do not correspond to the usual definition of yield (stress at $0.2 \%$ strain). In order to provide expressions that are consistent with code requirements for continuous stress-strain expressions, the yield point is taken to be the nonzero intersection of the stress-strain curves given by Hooke's law for the elastic region

$\sigma=E \epsilon$

and by the modified power law used in CSTRES and CSTRAN for the plastic region

$\sigma=K \epsilon^{n}(\dot{\epsilon} / 10-3) m$

where

$$
\begin{aligned}
& \sigma \quad=\text { true stress }(\mathrm{Pa}) \\
& \mathrm{E} \quad=\quad \text { Young's modulus }(\mathrm{Pa}) \\
& \epsilon \quad=\text { true strain (unitless) }
\end{aligned}
$$




\section{CMLIMT, CBRTTL}

$K=$ strength coefficient $(\mathrm{Pa})$

$n=$ strain hardening exponent (unitiess)

$\dot{\epsilon}=$ true strain rate $\left(\mathrm{s}^{-1}\right)$

$\mathbf{m}=$ strain rate sensitivity exponent (unitless)

Solution of these simultaneous equations gives the yield strain and yield strength described by Equations (4.11-1) and (4.11-2), respectively.

The point of maximum load in a one-dimensional stress test at constant engineering strain rate is found by converting the true stress and true strain rate in Equation (4.11-10) to their engineering equivalents

$\sigma=S \exp (\epsilon)$

$\dot{\epsilon}=\dot{e} / \exp (\epsilon)$

where

$S=$ engineering stress $(\mathrm{Pa})$

$\dot{\mathrm{e}}=$ engineering strain rate $\left(s^{-1}\right)$.

The derivative of $S$ with respect to $\epsilon$ is zero at the true strain given by Equation (4.11-3), and the true stress at this strain is given by Equation (4.11-4).

The development of Equation (4.11-7) was preceded by a review of several different cladding failure criteria in use. Two previously used criteria, average circumferential elongation and engineering hoop stress, were rejected because they ignore the effect of local wall thinning and 


\section{CMLIMT, CBRTTL}

because this effect is now realized to vary considerably from test to test. 4.11-4,4.11-10,4.11-16 Two other possible criteria, strain rate at failure and strain-fraction rules (strain increment/strain at failure), were considered and rejected because these criteria would require a considerable collection of strain-versus-time data. Such a collection did not exist in the publicly available literature at the time the model was developed. The remaining criteria, local strain at failure and local stress at failure, were investigated with the data presented in Section 4.11.2.

Local strain at failure was determined using the measured wall thickness adjacent to the burst ${ }^{a}$

$$
\epsilon_{r}=\ln \left(t_{B} / t_{0}\right)
$$

where

$$
\begin{aligned}
& \epsilon_{r}=\text { true radial strain at burst } \\
& t_{0}=\text { initial cladding wall thickness } \\
& t_{B}=\text { cladding wall thickness adjacent to burst. }
\end{aligned}
$$

Figure $4.11-1$ is a plot of the local radial strains at burst versus temperature. The relevant observations are:

1. The scatter of the local strains at failure is much smaller than the scatter of the average circumferential strains at failure for these tests. The average strains are shown in Figure 4.11-2.

a. Since the material is not compressible, the sum of the axial and circumferential strains is $\epsilon_{r}$. 


\section{CMLIMT, CBRTTL}

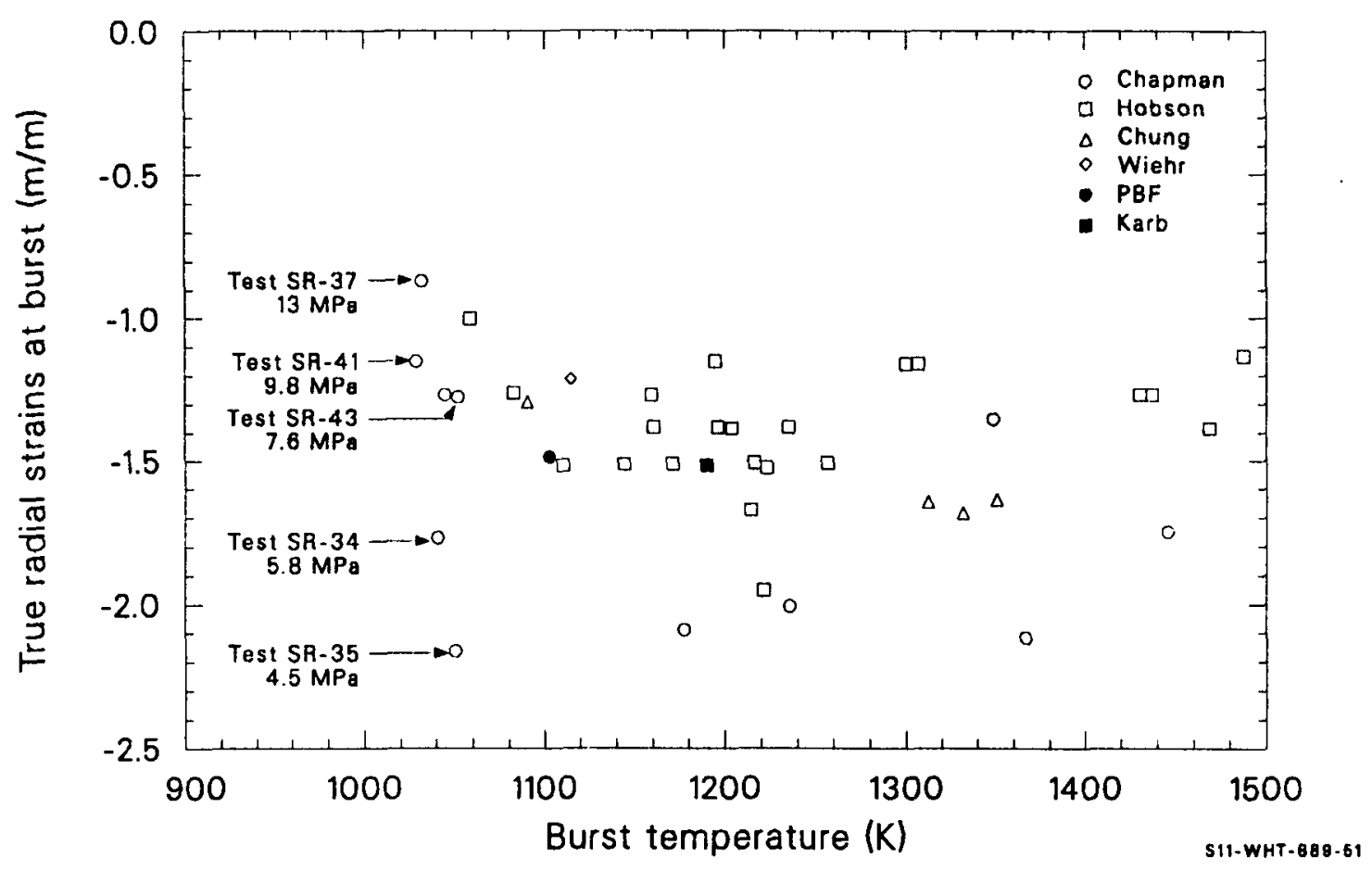

Figure 4.11-1. Local radial strains at burst versus temperature. 
CMLIMT, CBRTTL

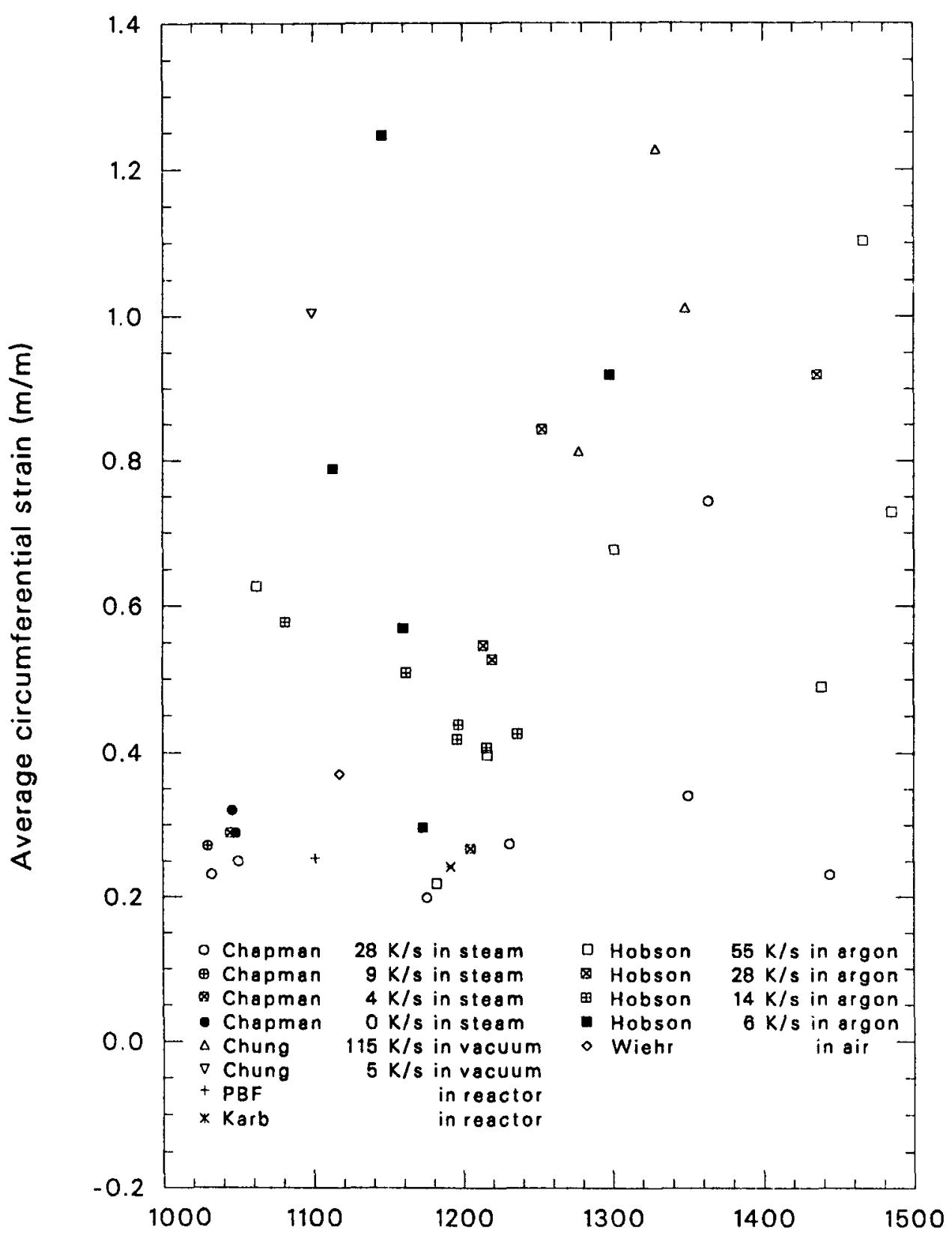

Burst temperature (K)

S11-WHT-1089-52

Figure 4.11-2. Average circumferential strains at failure versus temperature. 


\section{CMLIMT, CBRTTL}

2. An important series of tests by Chapman (SR-37, SR-41, SR-34, and SR-35), with decreasing pressures and heating rates but similar heaters, burst temperatures, and average circumferential elongations, show a regularly decreasing wall thickness (more negative radial strain) with decreasing pressure. The Chapman data are identified by test number and burst pressure in Figure 4.11-1.

These observations suggest that the local stress is the common parameter of cladding about to burst. The data in the plot of local strains at failure versus temperature are scattered by neglected variations in circumferential radii of curvature, axial radii of curvature, and burst pressure; and the data in the plot of average circumferential strains at failure are scattered further by circumferential variations in strain. More evidence for using stress as the failure criterion is provided by the observations that (a) failure cross sections usually show a fracture surface or surfaces at $45^{\circ}$ to the tangential direction and in the direction of maximum shear stress and (b) the fracture line is usually longitudinal. In cases where the fracture line is circumferential, there is good reason to suspect large axial stress components (Reference 4.11-10).

Local stresses at failure were estimated from the data presented in Section 4.11.2 and the equilibrium equation for a membrane element at the moment of failure $4.11-18$

$$
\frac{\sigma_{\mathrm{ZB}}}{r_{\mathrm{Z}}}+\frac{\sigma_{\theta \mathrm{B}}}{r_{\theta}}=\frac{\mathrm{P}_{\mathrm{B}}}{\mathrm{t}_{\mathrm{B}}}
$$

where

$$
\begin{array}{ll}
\sigma_{\mathrm{ZB}} & =\text { axial stress at burst }(\mathrm{Pa}) \\
\sigma_{\theta \mathrm{B}} & =\text { tangential stress at burst }(\mathrm{Pa})
\end{array}
$$




$\begin{array}{ll}P_{B} & =\begin{array}{l}\text { difference between gas pressure and coolant pressure at } \\ \text { burst }(\mathrm{Pa})\end{array} \\ r_{Z} & =\text { axial radius of curvature at burst }(\mathrm{m}) \\ r_{\theta} & =\text { circumferential radius of curvature at burst }(\mathrm{m}) \\ t_{B} & =\text { cladding thickness at burst }(\mathrm{m}) .\end{array}$

Two approximations are needed to deduce $\sigma_{\theta \mathrm{B}}$ from Equation (4.11-14) and the data presented in Section 4.11.2. The first approximation is that the azimuthal cross section shortly before burst is approximately circular

$r_{\theta}=$ undeformed radius $(1+$ average circumferential strain $)$.

The second approximation is needed to estimate $\sigma_{Z B}$. The range of possible values for $\sigma_{Z B}$ is severely 1 imited by physical considerations. It must have been greater than the yield stress for significant ballooning to occur, ${ }^{4.11-18}$ and it must have been less than $\sigma_{\theta B}$ for the failure to occur along an axial line. Since $r_{Z}$ is typically several times $r_{\theta}$, the first term of Equation (4.11-14) is smal1; and any value of $\sigma_{Z B}$ in the range between the yield stress and $\sigma_{\theta B}$ will estimate the first term of the equation with an uncertainty that is less than the uncertainty in the terms containing $r_{\theta}$ and $t_{B}$. The CMLIMT expression for failure stress was developed with the assumption that the axial and tangential stresses are nearly equal to burst because that assumption tends to underpredict $\sigma_{\theta \mathrm{B}}$, while the assumption of Equation (4.11-15) tends to overpredict $\sigma_{\theta B} \cdot{ }^{a}$ The resultant expression for the tangential stress at burst is

a. Local ballooning will cause the actual value of $r_{\theta}$ to be less than the value predicted with Equation (4.11-13). 


\section{CMLIMT, CBRTTL}

$$
\sigma_{\theta B}=\frac{P_{B}}{t_{B}}\left(\frac{1}{\frac{1}{r_{z}}+\frac{1}{r_{\theta}}}\right)
$$

Figure 4.11-3 is a plot of the local tangential failure stress obtained from Equation (4.11-16) and the data reviewed in Section 4.11-2. Approximate heating rates during burst are indicated to show that there is no systematic variation with heating rate. Comparison of the burst stresses obtained from Hobson's tests with both Chapman's tests and the two in-reactor data show that there is no significant effect of oxide films or alpha layers on the burst stress, at least at heating rates used in these tests. The most probable interpretation of this observation is the suggestion that the relatively thin oxide and alpha layers are cracked before the burst stress of the underlying beta layers is achieved.

Most of the burst stresses shown in Figure 4.11-3 are located near a curve that looks very similar to the plot of the strength coefficient for plastic deformation, which was obtained in Figure 4.9-5 of Section 4.9.3.2. The exceptions are not scattered randomly about the curve. They a11 lie above the curve. Upon closer inspection, it was noticed that the tests that yielded unusually high tangential burst stresses had some feature which caused one of the assumptions used in calculating tangential burst stress to be questionable. These features are discussed, test by test, in the next several paragraphs. The exceptional data are individually labeled in Figure 4.11-3.

In the PBF Test IE-5 (Rod IE-19), the maximum temperature of the cladding burst region was determined by metallography to be approximately $1100 \mathrm{~K}$. Postirradiation examination results $4.11-15$ show that the maximum temperature of the fracture area was less than the maximum cladding temperature at other azimuthal locations in the axial plane of the fracture. The interpretation given to this information in the postirradiation examination results report is that $1100 \mathrm{~K}$ was also the burst 


\section{CMLIMT, CBRTTL}

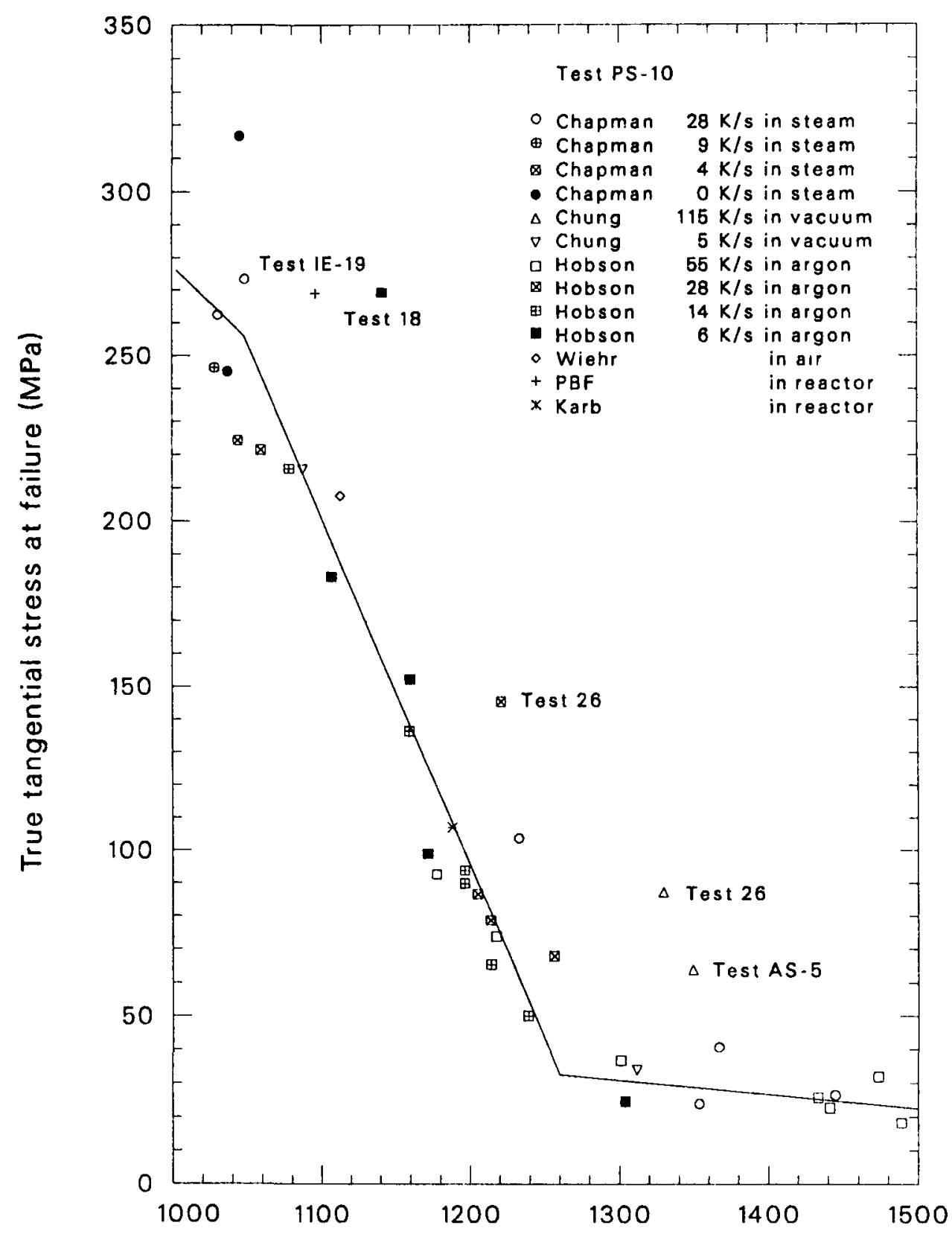

Burst temperature (K)

S11-WHT-1089-53

Figure 4.11-3. Local tangential stress at failure versus temperature. 


\section{CMLIMT, CBRTTL}

temperature because no increase in temperature could have occurred on the protruding fracture tips. This conclusion may be slightly overstated. The Test Results Report ${ }^{4.11-19}$ shows that the adjacent $45^{\circ}$ thermocouple, which also protruded, experienced a $50-K$ temperature rise after the initial increase. It is therefore probably more realistic to estimate the burst temperature of the cladding in Rod IE-19 at 1000 to $1050 \mathrm{~K}$.

Test PS-10 from Chapman's studies was performed with a heater which had an unusually large circumferential variation in temperature. ${ }^{4.11-20}$ In this case, very local ballooning is likely; and Equation (4.11-15) is probably a poor approximation for the circumferential radius of curvature near burst. Because of the questionable validity of Equation (4.11-15) for this test and because of the large difference between the calculated burst stress of this test and several other data obtained at similar burst temperatures, this test was omitted from the CMLIMT failure analysis.

Test 18 from the Hobson-Rittenhouse series burst at a thermocouple temperature of $1145 \mathrm{~K}$, yet had an average circumferential strain characteristic of temperatures in the alpha phase. Moreover, the axial profile of this test is almost triangular (Reference 4.11-9). In all probability, the axial radius of curvature in Table 4.11-2 (estimated from the bottom half of the sample) is much too large. The test was therefore el iminated from the CMLIMT data base.

Test 26 from the Hobson-Rittenhouse series is the only sample in the entire test series that did not exhibit approximate mirror symmetry of wal1 thickness about a plane through the burst area and the cladding centerline. In this test, one half of the cross section is essentially undeformed, and one half is uniformly thin. Thus, both the axial and circumferential radii of curvature estimated for this test are questionable; and the test was removed from the CMLIMT data base. 


\section{CMLIMT, CBRTTL}

Tests AS-9 and AS-5 by Chung are the most difficult of all the data shown in Figure 4.11-3 to understand. One might assume that the constraining mandrel used in these tests caused a large axial stress that somehow perturbed the test; however, the argument given in conjunction with Equation (4.11-16) shows that the local axial stress near the failure area was between the yield and the burst stresses. Moreover, Test AS-36, which differed only in heating rate from AS-5 and AS-9, does not differ from the Hobson or Chapman tests that burst at similar temperatures. Tests AS-5 and AS-9 were tentatively removed from the CMLIMT data base solely because they differ markedly from the two tests by Chapman that were conducted in steam with an internal heater, two features that are believed to make Chapman's tests more representative of in-reactor cladding failure.

The remaining data shown in Figure 4.11-3 and reviewed in Section 4.11.2 were used to find an expression for the tangential burst stress at failure above $1000 \mathrm{~K}$. The failure stress was divided by the strength coefficient used with Equation (4.11-10), and the quotients were averaged. For the alpha-phase data with burst temperatures above $1000 \mathrm{~K}$, the average quotient is $7.48 \pm 0.91$; for the alpha \pm beta region, it is $7.54 \pm 1.03$; and for the beta phase, it is $8.14 \pm 1.84$. Since there is no significant variation of the quotient, the average obtained for the entire temperature range above $1000 \mathrm{~K}, 7.70 \pm 1.29$, was used to produce Equations (4.11-7) and (4.11-8).

Equations (4.11-15) and $(4.11-16)^{\mathrm{a}}$ were also used with the low-temperature data of Table 4.11-4 in an attempt to find low-temperature failure stresses. In this case, the ratios of failure stress to strength coefficient obtained were much smaller than those of the high-temperature data- $-0.84 \pm 0.03$ for the annealed cladding and $0.80 \pm 0.06$ for the irradiated cladding. These ratios were not used for the CMLIMT failure

\footnotetext{
a. The axial radius of curvature was assumed to be three times the circumferential radii of annealed cladding and infinite for the irradiated cladding.
} 


\section{CMLIMT, CBRTTL}

stress correlation because the axial radii of curvature used to calculate them were assumed. Instead, the measured failure strains were used with Equation (4.11-10), an assumed strain rate sensitivity exponent of zero, and typical anisotropy coefficients ${ }^{a}$ to calculate failure stresses consistent with Equation (4.11-8) and the measured strain. The approximation is more reasonable than guessing axial radii of curvature at low temperature because (a) the unknown strain rate at failure is unimportant at low temperature and

(b) the stress-strain curve at low temperature is very flat; i.e., small uncertainties in stress are equivalent to large uncertainties in strain. The factor of 1.36 for annealed cladding and an increase of burst strength equal to four-tenths of the increase in the strength coefficient due to cold work or irradiation in Equation (4.11-5) reproduce the failure strains 1isted in Table 4.11-4. Equation (4.11-6) is simply an assumption contrived to extrapolate between the two regions where data are available without producing unreasonable predictions for failure strain in the temperature range where it is used.

\subsubsection{Application of the Failure Criterion to Determine Cladding Shape After Burst}

Equations (4.11-5) through (4.11-7) are sufficient to provide a complete description of both the time of cladding failure and the shape of failed cladding if they are used with an equation of state for plastic deformation and a mechanical code that models circumferential and axial variations in strain as a function of applied stress and time. The expressions derived in this section are intended as consistent alternatives to the direct use of Equations (4.11-5) through (4.11-7). They a) so illustrate the effect of deformation history on cladding shape after burst.

a. The irradiated cladding was assumed to be isotropic when effective stress and strains were ca? culated, but the annealed cladding was assumed to have the typical anisotropy coefficients given in Section 4.10. 
The first alternate expression is intended for use with codes like the FRAP-T5 ballooning subcode, ${ }^{4.11-18}$ which treat asymmetric deformation but do not calculate local stress. The recommended test for failure is a comparison of wall thickness to the minimum wall thickness given by the following approximate expressions for the strain at failure in a azimuthally symmetric test:

$\epsilon_{r}=\epsilon_{\theta S Y M}$

and

$\epsilon_{\theta S Y M}=\ln \left[\frac{\sigma_{Z B} t_{0}}{2 P_{B} r_{Z}}+\left(\frac{t_{0} \sigma_{h B}}{P_{B} r_{0}}\right)^{1 / 2}+\frac{1}{2}\left(\frac{\sigma_{Z B} t_{0}}{P_{B} r_{Z}}\right)^{2}\right]$

where

\begin{tabular}{|c|c|c|}
\hline$\epsilon_{r}$ & $=$ & local true radial strain at failure $(\mathrm{m} / \mathrm{m})$ \\
\hline SYM & $=$ & $\begin{array}{l}\text { true tangential strain at failure for azimuthally } \\
\text { symmetric deformation }(\mathrm{m} / \mathrm{m})\end{array}$ \\
\hline $\mathrm{B}$ & $=$ & axial component of true stress at burst $(\mathrm{Pa})$ \\
\hline & $=$ & initial cladding wall thickness (m) \\
\hline & $=$ & pressure differential across cladding at burst $(\mathrm{Pa})$ \\
\hline & $=$ & axial radius of curvature at burst (m). \\
\hline & $=$ & $\begin{array}{l}\text { tangential component of true stress at burst }(\mathrm{Pa}) \\
\text { given by Equation }(4.11-5) \text { through }(4.11-7)\end{array}$ \\
\hline & $=$ & initial cladding radius ( $\mathrm{m}$ ) \\
\hline
\end{tabular}




\section{CMLIMT, CBRTTL}

If ballooning is neglected $\left(r_{z}=\infty\right)$, Equation $(4.11-18)$ reduces to

$\epsilon_{\theta S Y M}=\ln \left(\frac{r_{\theta B}}{S_{\theta B}}\right)^{1 / 2}$

where $S_{\theta B}$ is the tangential component of engineering stress at burst

$(\mathrm{Pa})$. An outline of the derivation of Equation (4.11-18) follows:

1. Following Reference 4.11-21, the cladding deformation is considered to be composed of the strain for cylindrical deformation plus a perturbation due to ballooning. Axial strains for isotropic, closed-tube, cylindrical deformation are zero; and it is shown in Reference 4.11-21 that the change in axial strain due to a balloon with negligible tangential displacement is also zero. It is, therefore, reasonable to assume that the axial strain for typical bursts is small compared to the radial and tangential strains.

2. From the incompressibility relation (true strains sum to zero) and Step 1, the true radial strain equals the negative of the true tangential strain in an azimuthally symmetric burst test.

3. For an azimuthally symmetric burst test, the circumferential radius of curvature and the cladding thickness at burst are related to their initial values through the tangential strain

$$
\begin{aligned}
& r_{\theta}=r_{0} \exp \left(\epsilon_{\theta S Y M}\right) \\
& t_{B}=t_{0} \exp \left(-\epsilon_{\theta S Y M}\right)
\end{aligned}
$$

4. Substitution of Equations (4.11-20) and (4.11-21) into Equation (4.11-14) and a Taylor series expansion with 


$$
\frac{\sigma_{\mathrm{ZB}}}{r_{\mathrm{Z}}} \ll \frac{\sigma_{\theta \mathrm{B}}}{r_{\theta}}
$$

yields Equation (4.11-18) for $\epsilon_{\theta S Y M}$.

5. If the burst test does not have azimuthal symmetry, Equation (4.11-20) will overpredict the circumferential radius of curvature $^{4.11-18}$ and Equation (4.11-21) will overpredict the cladding wall thickness at failure. However, this is not a serious fault because the local deformation near failure is very rapid. The average strains, and thus the average elongation, will be only slightly underpredicted by using Equations (4.11-20) and (4.11-18) to predict strain at failure.

The second alternate set of expressions for determining cladding shape after failure and burst stress at failure are intended for codes that assume azimuthally symmetric cladding plastic deformation in spite of known temperature differences during the burst. An approximate expression for the effect of temperature variation on circumferential elongation was obtained by correlating to data taken at temperatures near $1050 \mathrm{~K} .4 .11-10,4.11-22$ The data and least-squares correlation used to describe them are shown in Figure 4.11-4. The least-squares expression obtained by fitting an exponential function to the data is

$$
\bar{\epsilon}_{\theta}=0.94 \exp (-0.01 \Delta \mathrm{T})
$$

where

$$
\begin{aligned}
\bar{\epsilon}_{\theta} & =\frac{\text { Lcircumferential at burst--initial circumference }}{\text { initial circumference }} \\
\Delta T & =\text { approximate temperature difference during burst }(K)
\end{aligned}
$$


CIIIIT, CBRTTL

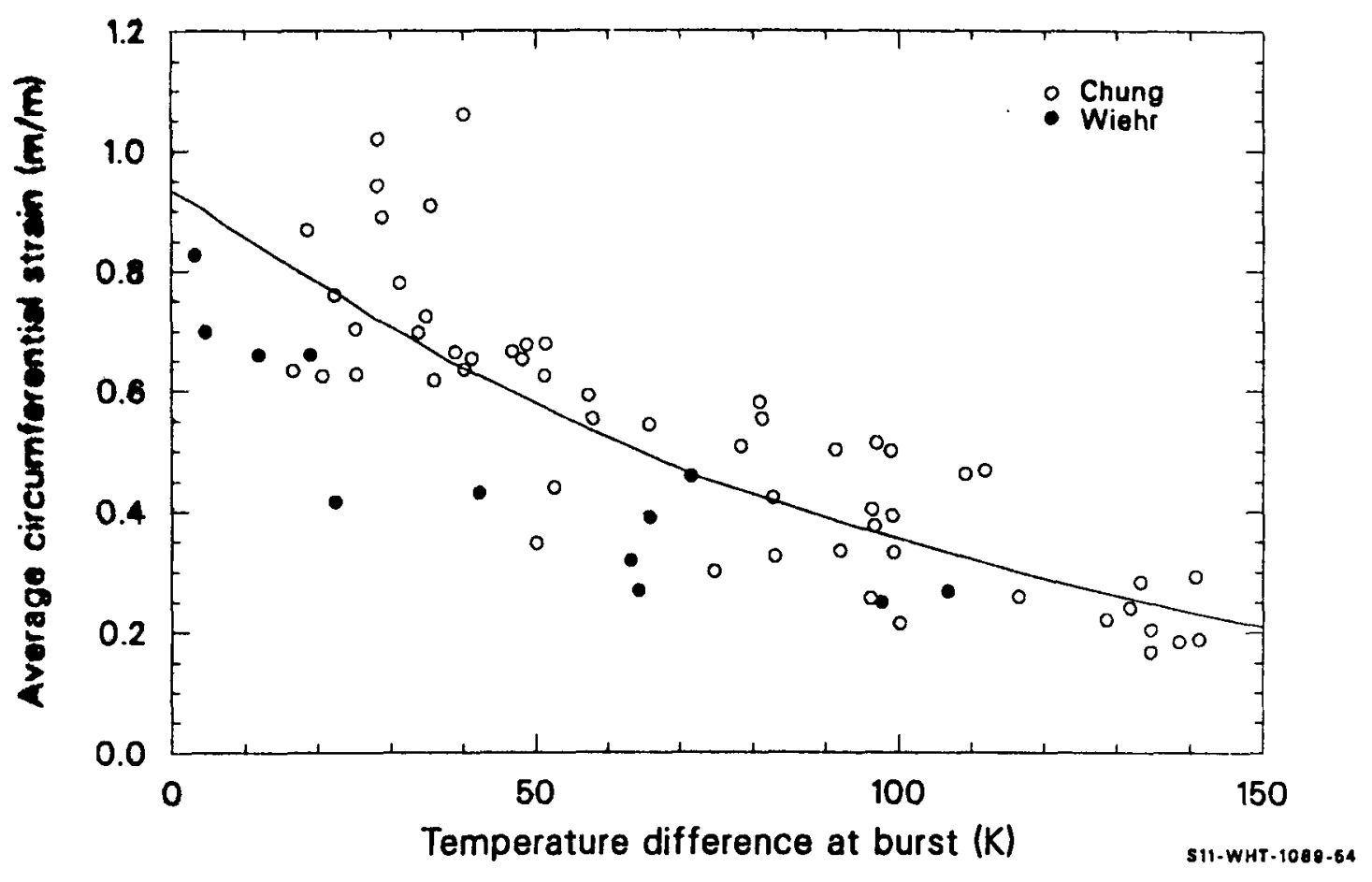

Figure 4.11-4. Base data and MATPRO correlation for effect of temperature variation on average circumferential elongation. 
CMLIMT, CBRTTL

If the 0.94 of Equation (4.11-22) is replaced by the more general expression of Equation (4.11-19), the resultant expression for the average circumferential elongation in a typical burst test near $1050 \mathrm{~K}$ is

$\bar{\epsilon}_{\theta}=\left[\left(\frac{t_{0} \sigma_{\theta B}}{P_{B} r_{0}}\right)^{1 / 2}-1\right] \exp (-0.01 \Delta T)$

where $\Delta T$ is the estimated temperature variation around the circumference during burst $(K)$ and the other symbols have been defined previously.

A mechanical model that assumes azimuthal symmetry cannot independently calculate the average circumference and the maximum stress of asymmetric deformation. However, it is possible to define an effective stress that is consistent with Equations (4.11-23) and (4.11-5). This effective burst stress is derived by considering the three cross sections shown in Figure 4.11-5.

Figure 4.11-5A represents the actual asymmetric cladding with local thinning at a hot spot and relatively little deformation elsewhere. Figure 4.11-5B represents an idealized symmetric deformation modeled by analytical codes that do not consider asymmetric deformation. The circumferences of Figures 4.11-5A and 4.11-5B are equal. Figure 4.11-5C represents a symmetrically deformed cladding with true stress equal to the maximum hoop stress of the actual asymmetric cladding.

The maximum tangential component of true stress of the asymmetric deformation is approximately

$\sigma_{\theta B}=P_{B} r_{a} / t_{B}$

where $r_{a}$ is the radius of the cladding ( $m$ ) and other symbols have been defined previously. The circumferential stress which will be used to predict the idealized deformation is 


\section{CMLIMT, CBRTTL}

A. Asymmetric deformation

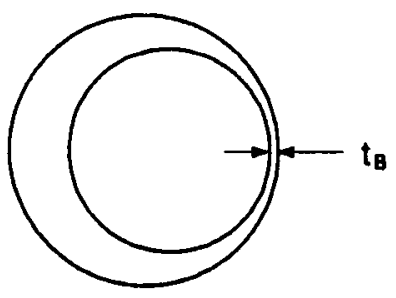

B. Idealized deformation

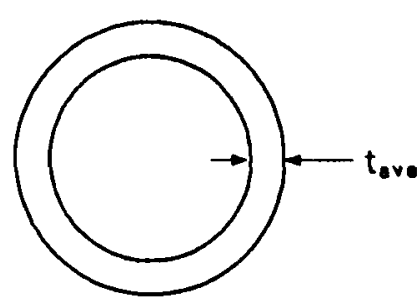

C. Symmetric deformation

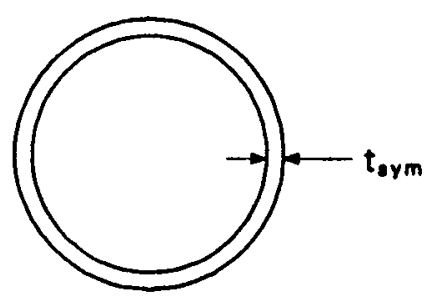

511-WHT-989-68

Figure 4.11-5. Schematic cross sections of cladding at burst. 
$\sigma_{\theta B}=P_{B} r_{a} / t_{a v e}$

where $t_{a v e}$ is the wall thickness of the cladding predicted with idealized symmetric deformation (m). From Equations (4.11-24) and (4.11-25), the tangential stress at failure calculated with idealized deformation is related to the true burst stress by the equation

$\sigma_{\theta B}=\sigma_{\theta B}\left(t_{B} / t_{a v e}\right)$.

The ratio $t_{B} / t_{\text {ave }}$ in Equation (4.11-26) is related to the reduction in circumferential elongation at failure. Since the maximum true local stress of asymmetric deformation and the circumferential stress of symmetric deformation are both equal to the burst stresses,

$$
P_{B} r_{a} / t_{B}=P_{B} r_{S Y M} / t_{S Y M}
$$

where

$$
\begin{aligned}
& r_{\text {SYM }}=\text { radius of symmetrically deformed cladding }(\mathrm{m}) \\
& \mathrm{t}_{\text {SYM }}=\text { wall thickness of symmetrically deformed cladding }(\mathrm{m})
\end{aligned}
$$

and the other terms were defined previously.

The incompressibility relations with the simplifying assumption that axial strain is less than radial or circumferential strain imply that the areas of the idealized and symmetrically deformed cladding are equal. This in turn implies

$r_{a} t_{\text {ave }}=r_{\text {SYM }} t_{S Y M}$.

Equations (4.11-27) and 4.11-28) can be combined to show 


\section{CMLIMT, CBRTTL}

$t_{B} / t_{a v e}=\left(r_{a} / r_{S Y M}\right)^{2}$.

The radii $r_{a}$ and $r_{S Y M}$ are related to the circumferential elongation of $A$ and $C$, (Figure 4.11-5)

$$
\begin{aligned}
r_{a} & =r_{0}\left(1.0+\epsilon_{\theta}\right) \\
r_{S Y M} & =r_{0}\left(1.0+\epsilon_{\theta S Y M}\right) \\
& =r_{0} \exp \left(\epsilon_{\theta S Y M}\right)
\end{aligned}
$$

where $r_{0}$ is the initial radius of the cladding.

Substitution of Equation (4.11-19) into Equation (4.11-31), Equations (4.11-30) and (4.11-31) into Equation (4.11-29), and the resultant expression into Equation (4.11-26) yields the following result for effective burst stress

$$
\sigma_{\theta B}=S_{\theta B}\left(1+\epsilon_{\theta}\right)^{2}
$$

where $\sigma_{\theta \mathrm{B}}$ is the effective burst stress to be used when azimuthally symmetric deformation is assumed in spite of known circumferential temperature differences.

The instability strain returned by CMLIMT is also determined with the correlation for typical strain distribution. The expression used in the CMLIMT subcode for instability strain is

$$
\bar{\epsilon}_{\theta 1}=\max \left\{\begin{array}{l}
0.05 \\
0 r \\
\left(\frac{1.15 \mathrm{Kt}}{10^{2 \mathrm{~m}_{\mathrm{p}} r_{0}}}\right)^{1 / 2}-1
\end{array}\right\} \exp \left(\frac{-\Delta \mathrm{T}}{100}\right)
$$




\section{CMLIMT, CBRTTL}

where

$$
\begin{aligned}
& \bar{\epsilon}_{\theta 1}=\frac{\text { circumference at instability--initial circumference }}{\text { initial circumference }} \\
& P=\text { pressure differential across cladding }\left(P_{a}\right) \\
& K=\text { strength coefficient }(P a) .
\end{aligned}
$$

Equation (4.11-33) was derived by setting the true strain rate in Equation (4.11-10) equal to $10^{-1} / \mathrm{s}$ and employing the following simplifying assumptions:

1. isotropic texture coefficients and closed tube stress radios were assumed $\left(\sigma=0.866 \sigma_{\theta}\right.$ and $\epsilon=$ $\left.\epsilon_{\theta} / 0.866\right)$

2. $\sigma_{\theta}=S_{\theta} \exp \left(2 \epsilon_{\theta}\right)$

3. Equation (4.11-22) relates average strain to symmetric strain at instability as well as at burst.

The third alternate expression for describing cladding failure is intended for users who choose to ignore all the details of the deformation history of the cladding. The quantity returned is a typical engineering burst stress obtained by correlating tests without regard for either the distribution of strain during the tests or the variation of pressure and temperature with time during the test. If the user is willing to accept the uncertainty associated with using typical burst stresses (pressure) for a given temperature, he can use this relation with all of the previous relations to determine typical average circumferential elongations as a function of burst temperature and the circumferential temperature variation during burst. The correlation used for typical engineering burst stresses is 


\section{CMLIMT, CBRTTL}

$\log _{10}(S)=8.42+T\left[2.78 \times 10^{-3}+T\left(-4.87 \times 10^{-6}+T 1.49 \times 10^{-9}\right)\right](4.11-34)$

where

$S=$ typical engineering hoop stress at burst $(\mathrm{Pa})$

$T=$ temperature at rupture $(K)$.

Equation (4.11-34) was obtained by correlating engineering burst stress to burst temperature using data obtained from several

sources. 4.11-9,4.11-23 to 4.11-29 Since all information about the local stress and strain has been ignored in producing this correlation, it provides only a typical engineering burst stress as a function of temperature.

Figure 4.11-6 shows typical average tangential strains as a function of temperature obtained by substituting typical engineering burst stresses from Equation (4.11-34), true stress at burst from Equation (4.11-5), and several assumed temperature differences during burst into Equation (4.11-23).

\subsubsection{Summary (CBRTTL)}

Cladding may fail because of embrittlement by oxygen. In embrittled cladding, failure occurs at low temperatures with no plastic strain. Several hypothetical reactor transients can cause cladding to reach the high temperature necessary for extensive oxygen diffusion. These transients include power-cooling-mismatch, reactivity insertion, and loss of coolant. In the cooling following these transients, the cladding will be subjected to thermal stresses that may cause its fragmentation. Therefore, oxygen embrittlement is an important safety consideration.

A model is presented in this report defining limits for the amount of oxygen that may diffuse into zircaloy without causing it to become embrittled. This model is restricted to outside oxidation. 
CMLIMT, CBRTTL

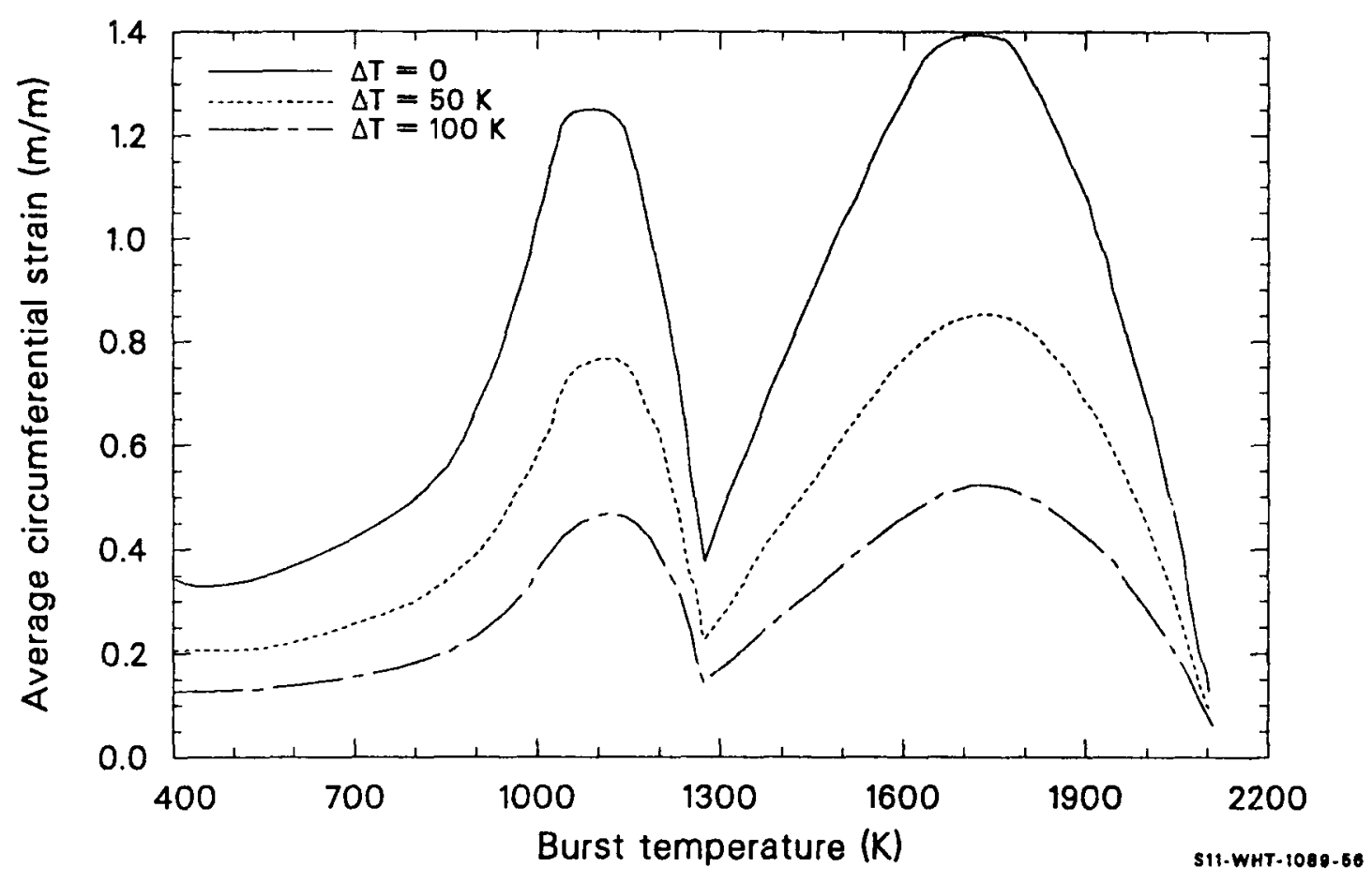

Figure 4.11-6. Typical average circumferential strains predicted by the MATPRO correlations for typical engineering burst stress, true burst stress, and typical strain distributions at three different temperature differences. 


\section{CMLIMT, CBRTTL}

The model deals with cladding that has reached a temperature of at least $1244 \mathrm{~K}$ at least once in its 1 ifetime. At this point, zircaloy has completed a phase transition from its low-temperature, hexagonal, close-packed structure, called the alpha phase, to a body-centered cubic structure called the beta phase. This threshold is chosen because oxygen uptake increases exponentially with temperature and, for typical postulated transients, not enough oxygen to cause embrittlement will diffuse into the cladding until beta temperatures are reached. However, for transients lasting more than about one half hour at around $1300 \mathrm{~K}$, the model is not adequate. The model is divided into two parts to account for both fast and slow cooling rates.

For fast cooling rates $(>100 \mathrm{~K} / \mathrm{s})$ such as are found following $\mathrm{film}$ boiling, the cladding is characterized as embrittled if:

1. The oxygen concentration in the beta phase is greater than $90 \%$ of the saturation concentration at the beginning of the fast quench,

2. The average oxygen concentration in the beta phase exceeds 0.65 percent by weight, or

3. The maximum temperature exceeds $1700 \mathrm{~K}$.

The first two of these restrictions are of the type proposed by Pawel, of Oak Ridge National Laboratory (ORNL). ${ }^{4 \cdot 11-30}$ The last is based on data obtained at EG\&G Idaho, Inc. ${ }^{4.11-31}$

During a LOCA transient, there are two cladding cooling rates. One is a rather slow rate during refill, and the other is a rapid rate due to quench. If the slow decrease brings the cladding below the temperature of the beta phase, it is this rate that is important for embrittlement. In these cases, the cladding is characterized as embrittled if $0.3 \mathrm{~mm}$ or more of the beta phase contains more than 1 wt\% oxygen. This criterion is similar to one proposed by Chung, Garde, and Kassner. ${ }^{4.11-32}$ 


\section{CMLIMT, CBRTTL}

The inputs required by the model are the temperature and oxygen profiles in the beta-phase zircaloy. At EG\&G Idaho, Inc., these are found with the FRAP codes, $4.11-18,4.11-33$ in conjunction with the COBILD high-temperature oxidation subcode (see Section 15.2). When the oxygen concentration exceeds the limits defined above, the model indicates that the cladding is critically embrittled.

Section 4.11 .6 contains a discussion of the literature reviewed. The model development is presented in Section 4.11.7, along with model data comparisons and a discussion of the uncertainty.

\subsubsection{Literature Review}

The paper by Pawe ${ }^{4.11-30}$ is the basis for the part of CBRTTL describing fast-cooled cladding. The criteria presented by Pawel are modified based on in-pile data taken at EG\&G Idaho, Inc. ${ }^{4.11-31}$ The embrittlement criterion for slow-cooled cladding is based on data taken from a recent series of reports from ANL. 4.11-32,4.11-34,4.11-35 These data sets are described in the following subsections.

4.11.6.1 Data for Fast Cooling. Data taken in-pile at the Power Burst Facility (PBF) reactor of EG\&G Idaho, Inc., are extensively documented. ${ }^{4.11-31}$ In this reactor, fuel rods about $3 \mathrm{ft}$ in length but otherwise of typical PWR dimensions are brought into film boiling. The rods are externally pressurized with a pressure differential of at least $10 \mathrm{MPa}$. The oxidizing agent is steam, since data were taken from areas experiencing film boiling. The rods were oxidized under nonisothermal conditions. In some cases, the cladding temperature varied by as much as $800 \mathrm{~K}$ during a single experiment. An important feature of the PBF tests is that the source of heat was actual fuel pellets, which can relocate causing pellet-cladding thermal and mechanical interactions. 


\section{CMLIMT， CBRTTL}

A major disadvantage of the PBF data base is that it is quite sma11. Competing embrittlement effects, such as chemical reactions at the inside surface from pellet-cladding interaction and aggressive fission products, present another difficulty. The fact that the PBF data conform well to Pawel's criteria developed from data taken out-of-pile, ${ }^{4.11-36}$ where such competing effects are absent, suggests that this latter disadvantage may not be important and that oxygen uptake is the dominant embrittlement process.

\subsubsection{Data for Slow Cooling. Many out-of-pile data were taken} from recent reports by Chung, Garde, and Kassner. 4.11-32,4.11-34,4.11-35 The samples were $30-\mathrm{cm}$ zircaloy tubes with inner and outer diameters typical of LWR cladding. About one-half of the tube length was filled with alumina $\left(\mathrm{Al}_{2} \mathrm{O}_{3}\right)$ pellets to simulate the fuel. The experimental procedure was to heat the sample by induction heating to the test temperature from room temperature at $10 \mathrm{k} / \mathrm{s}$. This temperature was held for the desired time period, after which the sample was cooled at $5 \mathrm{~K} / \mathrm{s}$ to approximately $810 \mathrm{~K}$ and then rapidly quenched by bottom flooding with water. The tubes ruptured during the heating phase due to an initial internal pressure, typically about $7 \mathrm{MPa}$. During the entire experiment, a steam generator circulated steam at about $0.15-\mathrm{MPa}$ pressure past the specimen. After each experiment, the tubes were examined and classified in one of three ways:

a. Tubes that failed during the quench,

b. Tubes that survived quench but failed in normal handling required to remove them from the experimental apparatus, and

c. Tubes that remained intact.

The ANL experiments provide a good test of the ability of zircaloy cladding, embrittled by nearly isothermal oxidation, to withstand the thermal shock of reflood after a hypothetical LOCA. The principal disadvantage of these tests is that the experiment environment may not apply the same stresses as cracked and relocated fuel. 


\subsubsection{Model Development}

Ideally, a model for embrittlement by oxygen uptake would specify a maximum acceptable stress as a function of oxygen content in the cladding. The available data, however, are not amenable to such an approach because neither the stress nor the strain at failure are measured. For some cases, the stress or strain could be calculated; but this is clearly not possible for those rods which failed during normal handling at the ANL. Therefore, a more empirical process is used, wherein several commonly used embrittlement criteria are tested against the data and the most appropriate ones are subjected to sensitivity studies to determine the best boundary conditions.

Several embrittlement criteria are now in use or have been proposed. In this subsection, the more prominent ones are compared to the data. The COBILD code was used to calculate oxide layer thicknesses, oxygen uptake, and oxygen profiles in the beta phase.

4.11.7.1 Presently Used Acceptance Criteria. For reactor licensing purposes, the present oxidation limits for an acceptable emergency core cooling system are defined in the Code of Federal Regulations, Title 10, Section 50. The code specifies:

(a) That the peak cladding temperature must not exceed $2200^{\circ} \mathrm{F}$ $(1477.5 \mathrm{~K})$ and

(b) That the oxide thickness that would result if all oxygen uptake produced $\mathrm{ZrO}_{2}$ (called the equivalent cladding reacted) must not exceed $17 \%$ of the original cladding wall thickness.

Both of these criteria have been shown to be conservative for out-of-pile tests $4.11-32,4.11-34$ and inconsistent for in-pile tests. ${ }^{4.11-31}$ 


\section{CMLIMT， CBRTTL}

\subsubsection{Fraction of Wall Thickness That is Beta Phase Criterion.}

Scatena ${ }^{411-37}$ suggested an embrittlement criterion based on the quantity $F_{W}$, where

$F_{W}=\frac{\text { remaining beta phase thickness }}{\text { original unoxidized wall thickness }}$.

If $F_{W} \leq 0.5$, the material is considered embrittled. This criterion was not found to work well for either the out-of-pile or in-pile data, being conservative in both cases.

4.11.7.3 Argonne Impact Energy Criterion. In these tests, the tubes were treated as described in Section 4.11.6. In an effort to quantify the embrittlement, those rods that emerged intact from quenching and handling were subject to impact testing with a pendulum device. Impact energies of 0.03 and $0.30 \mathrm{~J}$ were used, causing additional rods to fail. However, unless an allowable impact energy is specified, classification of tubes shattered by impact as failed is not useful. If such energy is specified, an embrittlement model based on these data will become attractive.

4.11.7.4 ORNL Correlation of Embrittlement with 0xygen Content in the Beta Phase. Using data from a report by Hobson and Rittenhouse, 4.11-36 Pawe 1 411-30 arrived at two embrittlement criteria for zircaloy. He considered the cladding embrittled if the oxygen content of the beta phase exceeded $95 \%$ of the saturation content, or 0.7 wt\%. This model, slightly modified, is used for fast-cooled cladding in this section. The saturation oxygen concentration is determined from a zircaloy-oxygen phase diagram published by Chung. 4.11-38

4.11.7.5 Argonne Correlation of Embrittlement with 0xygen Content in the Beta Phase. Using a computer code developed at ANL, Chung ${ }^{411-32}$ found an embrittlement criterion that fits their data very well. Their criterion states that the cladding will not be embrittled if there is at least $0.1 \mathrm{~mm}$ of beta with less than 1.0 wt\% oxygen. The limits set by the 


\section{CMLIMT, CBRTTL}

ANL group are consistent with the conclusions of a more qualitative study by A. Sawatzky, 4.11-39 who states that the maximum temperature and total oxygen content have lictle or no effect on the tensile properties of zircaloy-4. Sawatzky used a maximum cooling rate of $160 \mathrm{~K} / \mathrm{s}$ for about $10 \%$ of his samples; but the other $90 \%$ were cooled at rates of $21 \mathrm{~K} / \mathrm{s}$ or less, so his conclusions apply primarily to slow-cooled cladding. The ANL model is also modified and used for slow-cooled cladding in this section.

\subsubsection{Model for Fast-Cooled Cladding}

The Pawel criteria, slightly modified and with the additional limit that the peak cladding temperature must not exceed $1700 \mathrm{~K}$, are adopted for the fast-cooled cladding model. Physically, a percent saturation limit makes sense, at least qualitatively, because as the oxygen content of the beta phase approaches saturation, any local oxygen excess is relieved by the formation of brittle oxygen-stablized alpha precipitates, often in the form of incursions originating in the normal alpha-phase layer and extending into the beta phase. The presence of these oxygen-rich alpha incursions is always associated with a loss of ductility. They may also form during cooling because as the temperature decreases, so does the oxygen solubility, often making the beta phase super-saturated with oxygen.

The criterion specifying a maximum oxygen weight fraction is needed because the diffusivity of oxygen also decreases with temperature. If the cooling rate is high enough, there will not be sufficient time for incursions to form during cooling and only those formed at high temperature will be present. Since the ductility of zircaloy decreases even without incursions as its oxygen content increases, there must be a critical oxygen concentration that causes embrittlement. The $1700-\mathrm{K} 1 \mathrm{imit}$, although in contradiction to the conclusions of Sawatzsky, ${ }^{4.11-39}$ was necessary to fit the data. 


\section{CMLIMT, CBRTTL}

Pawel's limits of $95 \%$ saturation and $0.70 \mathrm{wt} \%$ oxygen were subjected to a brief sensitivity analysis to examine the effect of varying these limits. Combinations that were tried included 0.70 and $0.65 \mathrm{wt} \%$ and saturations of 90 and $95 \%$. The results are shown in Figure 4.11-7, along with data from the Hobson-Rittenhouse experiment. The plot shows little to be gained by changing the limits. These criteria do not specify a single thickness for the beta layer necessary to retain ductility. However, for a given original wall thickness, it is possible to find a critical beta thickness as a function of temperature corresponding to the limits of this model. This thickness is usually expressed as a ratio

$\left(F_{w}\right)_{c r i t}=\frac{\text { critical thickness of beta layer }}{\text { original unoxidized wall thickness }}$.

An $\left(F_{W}\right)_{c r i t}$ criterion corresponding to limits such as those specified by Pawel is particularly useful because it contains no explicit reference to time and may therefore be generalized to more realistic situations where the rod temperature changes. Time is still a necessary parameter to make the calculations; but, in the evaluation of the ductility, only the oxygen content and the temperature at a time are required. For this part of the model, the time and temperature used are those at the end of the last time-temperature segment when the cladding was entirely in the beta phase. In Figure 4.11-8, $\left(F_{W}\right)_{c r i t}$ is plotted as a function of temperature. The solid lines are for $0.7 \mathrm{wt} \%$ and $95 \%$ filled, and the dashed lines are for 0.65 wt\% and $90 \%$ filled. Also shown in the figure are data from the Hobson-Rittenhouse out-of-pile isothermal tests and the in-pile PBF nonisothermal tests. All the points, as well as the limiting lines, were calculated with the COBILD subcode. As with Figure 4.11-7, the data apply for a specific wall thickness, chosen here to be $0.60 \mathrm{~mm}$ to correspond to the PBF data. However, COBILD runs show that the limiting lines in Figure 4.11-8 move less than $1 \%$ when the wall thickness changes by as much as $40 \%$ from $0.60 \mathrm{~mm}$. 
CMLIMT, CBRTTL

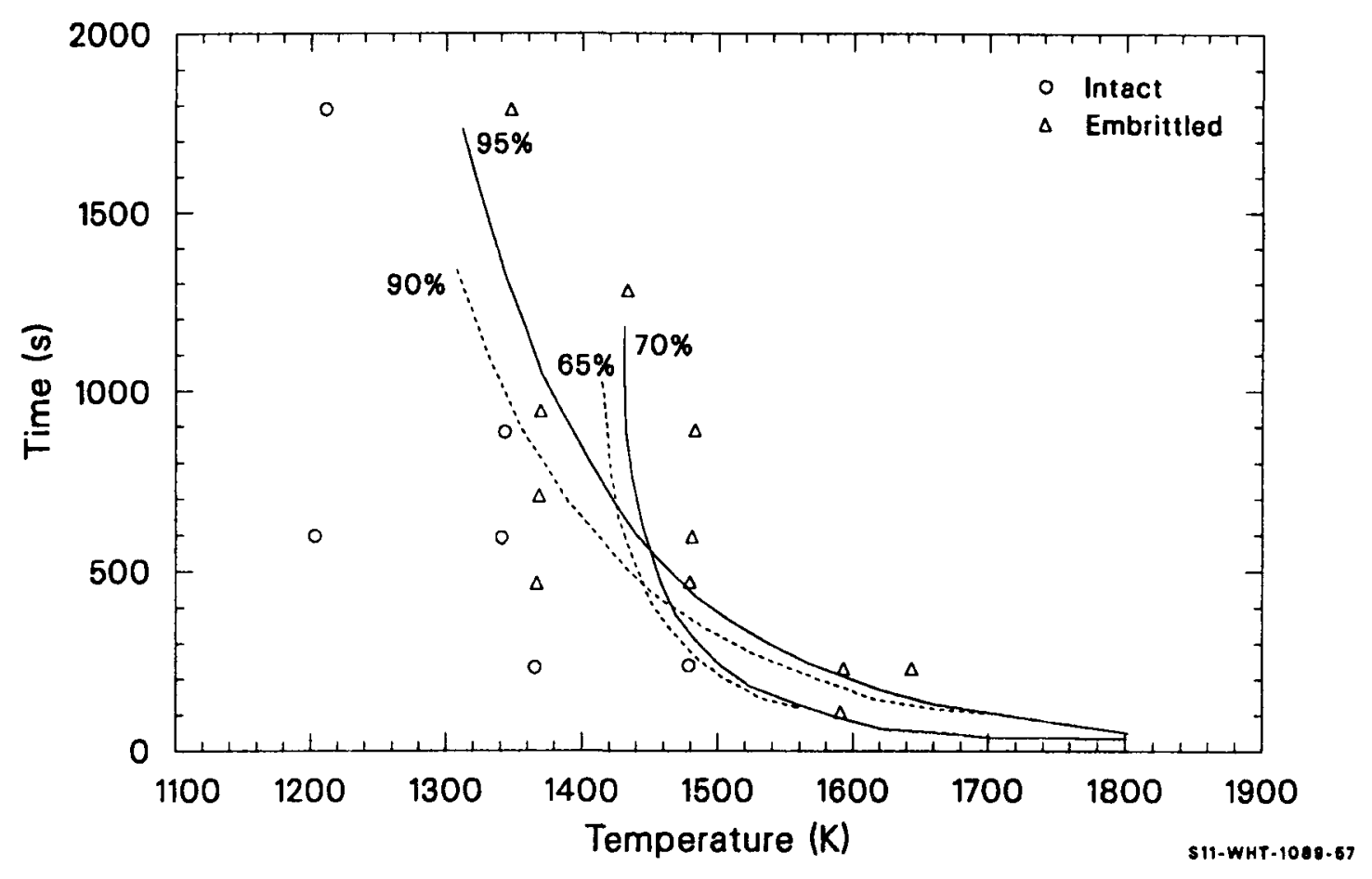

Figure 4.11-7. Hobson-Rittenhouse isothermal data for fast-cooled cladding compared with the 0.65 and $0.70 \mathrm{wt} \%$ and the $90 \%$ and $95 \%$ filled criteria. 


\section{CMLIMT, CBRTTL}

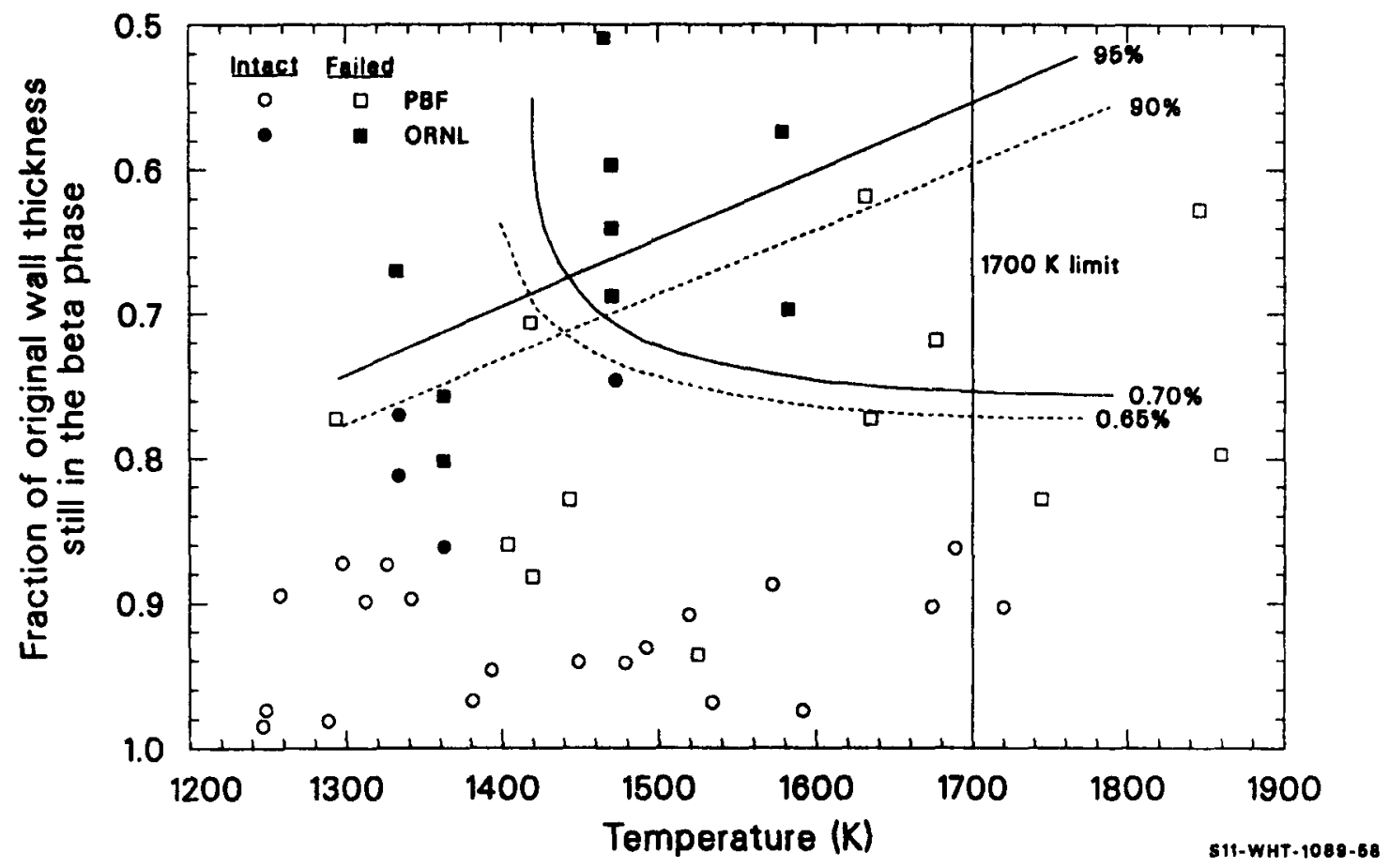

Figure 4.11-8. Hobson-Rittenhouse and PBF data for fast-cooled rods compared with the critical fractional wall thickness as calculated from the 0.65 and 0.70 wt\% and the $90 \%$ and $95 \%$ filled criteria. 


\section{CMLIMT, CBRTTL}

An obvious feature of these figures is that three in-pile rods failed when they apparently should not have. These rods were at temperatures of 1405,1418 , and $1523 \mathrm{~K}$. Postirradiation examination of the inner surface oxidation showed that these rods had a wall defect in the vicinity of the failure, allowing steam to enter. Hot zircaloy exposed to stagnant steam will absorb an abnormally large amount of hydrogen, $4.11-40$ and the failures of these three rods show evidence of hydride influence. 4.11-31 These rods are therefore not deemed suitable examples of the simple failure by oxygen embrittlement.

It is clear from Figure 4.11-8 that the 1ower 1imits of $90 \%$ saturation and 0.65 wt\% oxygen include more of the failed rods than do Pawel's original limits. Consequently, the model for fast-cooled cladding is considered embrittled if the oxygen content of the beta phase exceeds (a) $90 \%$ of the saturation content or (b) $0.65 \%$ of weight. A third criterion limiting the maximum cladding temperature to $<1700 \mathrm{~K}$ is added to fit the highest temperature data.

The data are still too limited to consider this model final; however, the accuracy is encouraging, especially considering the differences in the experiments. The Hobson-Rittenhouse samples were oxidized on both sides, out of pile, and quenched rapidly, while the PBF samples were oxidized primarily on the outside, in pile, and quenched slowly.

\subsubsection{Model for Slow-Cooled Cladding}

Designation of this part of the model as being applicable to slow-cooled cladding is slightly misleading; it is meant to apply during the prequench of a LOCA. As described in Section 4.11.2.2 of this report, Chung, Garde, and Kassner 4.11-32,4.11-34,4.11-35 have completed many out-of-pile tests of this sort and have developed an embrittlement criterion requiring at least $0.1 \mathrm{~mm}$ of cladding thickness with $<1$ wt\% oxygen. When the criterion was checked using COBILD, it was found that at least $0.3 \mathrm{~mm}$ 


\section{CMLIMT, CBRTTL}

with $<1$ wt\% oxygen are required to avoid failure by thermal shock. No reason for the difference between this and the ANL minimum thickness of $0.1 \mathrm{~mm}$ has been found. It possibly lies in the mechanics of the two codes. Until a comparison of the ANL code and COBILD can be performed, the criterion established with COBILD is recommended for use with the MATPRO package.

In Figure 4.11-9, this criterion is compared with the data. Only temperatures $>1244 \mathrm{~K}$ are considered, since this is the lower range of validity for COBILD. Not all of the data are shown in the figure because many are coincident, or nearly so. of the 146 intact rods, 16 (or $11 \%$ ) are predicted to fail; and of the 57 failed rods, 4 (or $7 \%$ ) are predicted to remain intact. In the entire data set, $<10 \%$ of the predictions are incorrect. Given the scatter in the data, this is considered acceptable accuracy.

Since all the tubes tested at ANL had a wall thickness of $0.635 \mathrm{~mm}$, it is impossible to conclude whether $0.30 \mathrm{~mm}$ is the actual minimum thickness required to retain ductility or if there is some minimum $F_{W}$. The former is more reasonable on physical grounds because it seems logical that there should be a minimum thickness of ductile material necessary for ductility.

If the embrittlement criteria for fast-cooled rods are compared with the slow-cooled data, failure would be predicted in most cases, contrary to experimental observation. Similarly, the criterion used for the slow-cooled rods almost never predicts a failure when compared to the fast-cooled data. These facts underscore the importance and complexity of cooling rate on the ductility of zircaloy at high temperature and further emphasize the importance of clearly specifying the cooling rate. 
CMLIMT, CBRTTL

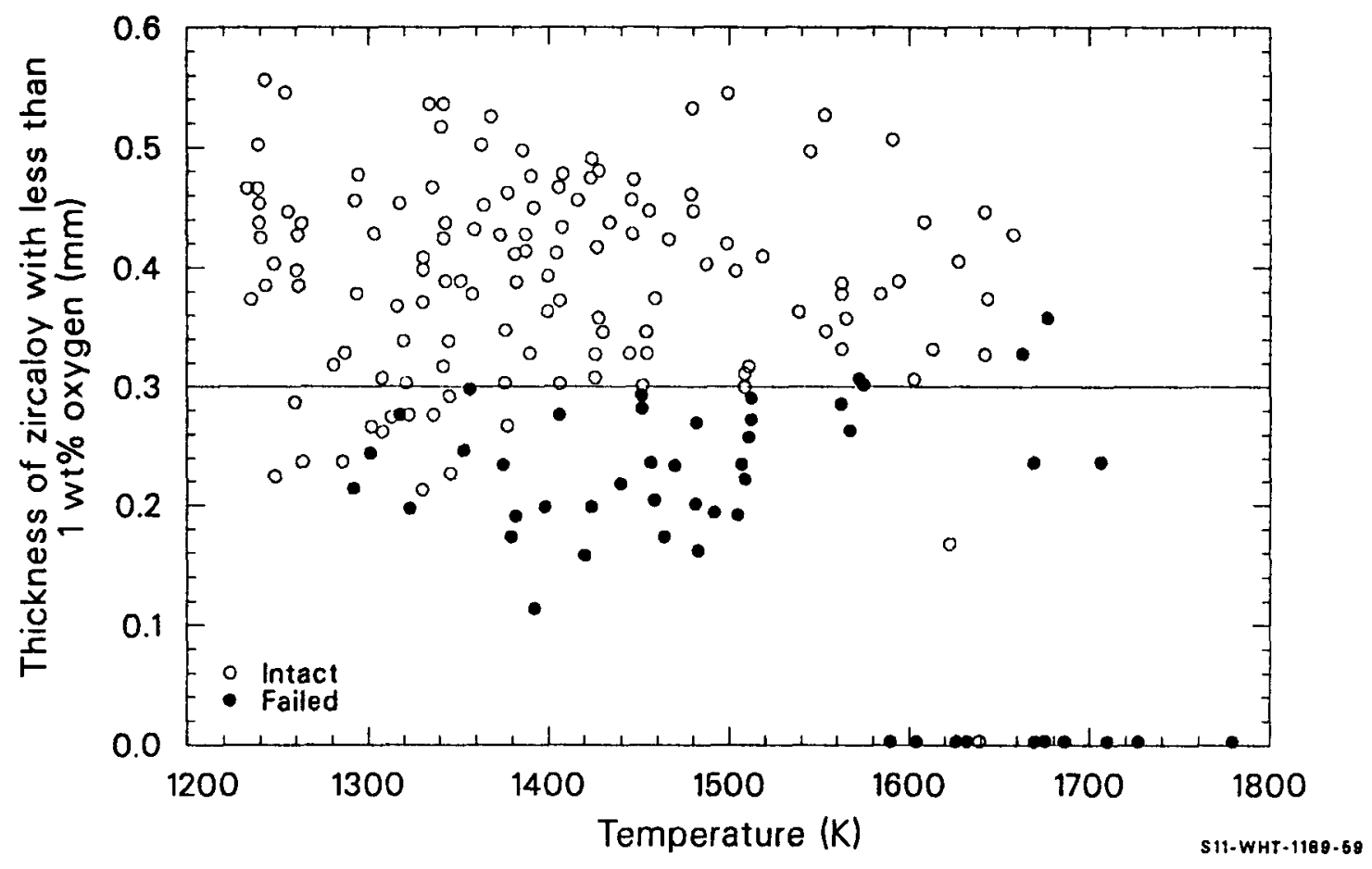

Figure 4.11-9. Comparison of the Argonne data for slow-cooled cladding with the criterion that at least $0.3 \mathrm{~mm}$ of zircaloy with less than 1 wt\% oxygen is required to survive thermal shock. 


\section{CMLIMT, CBRTTL}

\subsubsection{Mode1 Uncertainties}

A primary source of uncertainty for both models is in temperature measurement. For the Hobson-Rittenhouse data set, the temperature uncertainty is estimated by comparing the temperature reported for a given layer thickness with that calculated using isothermal oxidation kinetics published by Cathcart $4.11-41$ for the same thickness. From this analysis, the root mean square of the temperature difference is about $50 \mathrm{~K}$. A similar technique was used for the PBF and ANL data. Seiffert and Hobbins 4.11-31 also arrived at an uncertainty of about $50 \mathrm{~K}$, while Chung $4.11-34$ found an 85-K uncertainty. This technique should give a reasonable estimate because Cathcart's correlations are based on a careful analysis of his own data. This analysis shows the data to have a high degree of consistency, and the major error in measurement should be the temperature, the layer thickness being much easier to obtain with accuracy.

There is another potentially important source of systematic error in the ANL data. They were presented in graphical rather than tabular form. A digitizer was used to obtain numerical values. The data were generally plotted as the logarithm of the time versus reciprocal temperature, so larger errors result for long times or high temperatures. By repeating the digitizing from the same plots, the uncertainties listed in Table 4.11-5 were found.

An idea of the effect of errors for fast-cooled cladding may be obtained by examining Figure 4.11-6. For slow-cooled cladding, a sensitivity analysis is required to find what change in beta-phase thickness with less than $1 \%$ oxygen content would result from the given uncertainties. Such an analysis has not been carried out.

\subsubsection{References}

4.11-1. R. H. Chapman, Multirod Burst Test Program Quarterly Progress Report for April - June 1977, ORNL/NUREG/TM-135, December 1977. 
CMLIMT, CBRTTL

Table 4.11-5. Uncertainties in digitized Argonne data

\begin{tabular}{cccc}
$\begin{array}{c}\text { Temperature } \\
(\mathrm{K})\end{array}$ & $\begin{array}{c}\Delta \text { Temp } \\
(\mathrm{K})\end{array}$ & $\begin{array}{l}\text { Time } \\
(\mathrm{s})\end{array}$ & $\begin{array}{c}\Delta \text { Time } \\
(\mathrm{s})\end{array}$ \\
\cline { 4 - 5 } 1250 & 16 & $10^{2}$ & 2.50 \\
1650 & 28 & $10^{4}$ & 2.50 \\
\hline
\end{tabular}




\section{CMLIMT, CBRTTL}

4.11-2. R. H. Chapman, J. L. Crowley, A. W. Longest and E. G. Sewe11, Effect of Creep Time and Heating Rate on Deformation of Zircaloy-4 Tubes Tested in Steam With Internal Heaters, ORNL/NUREG/TM-245 and NUREG/TM-74, October 1978.

4.11-3. R. H. Chapman, Multirod Burst Test Program Quarterly Progress Report for April - June 1976, ORNL/NUREG/TM-74, January 1977.

4.11-4. R. H. Chapman, Multirod Burst Test Progress Report for July December 1977, ORNL/NUREG/CR-0103, June 1978.

4.11-5. R. H. Chapman, Multirod Burst Test Progress Report for January March 1978, NUREG/CR-0225, ORNL/NUREG/TM-217, August 1978.

4.11-6. R. H. Chapman, Multirod Burst Test Program Quarterly Progress Report for January - March 1976, ORNL/NUREG/TM-36, September 1976 .

4.11-7. R. H. Chapman, Multirod Burst Test Program Quarterly Progress Report for October-December 1976, ORNL/NUREG/TM-95, Apri1 1977.

4.11-8. R. H. Chapman, Multirod Burst Test Program Quarterly Progress Report for January-March 1977, ORNL/NUREG/TM-108, May 1977.

4.11-9. D. 0. Hobson and P. L. Rittenhouse, Deformation and Rupture Behavior of Light-Water Reactor Fuel Cladding, ORNL-4727, October 1971 .

4.11-10. H. M. Chung and T. F. Kassner, Deformation Characteristics of Zircaloy Cladding in Vacuum and Steam Under Transient-Heating Conditions: Summary Report, NUREG/CR-0344, ANL-77-31, July 1978.

4.11-11. A. A. Bauer, L. M. Lowry, J. S. Perrin, Evaluating Strength and Ductility of Irradiated Zircaloy: Quarterly Progress Report for January through March 1976, BMI-NUREG-1948, March 1976.

4.11-12. A. A. Bauer, W. J. Gallagher, L. M. Lowry and A. J. Markworth, Evaluating Strength and Ductility of Irradiated Zircaloy: Quarterly Progress Report July through September 1977 , BMI - NUREG-1985, October 1977.

4.11-13. A. A. Bauer, W. J. Gallagher, L. M. Lowry and A. J. Markworth, Evaluating Strength and Ductility of Irradiated Zircaloy: Quarterly Progress Report October through December 1977 , NUREG/CR-0026, BMI-1992, January 1978.

4.11-14. D. W. Croucher, Behavior of Defective PWR Fuel Rods During Power Ramp and Film Boiling Operation, NUREG/CR-0283, TREE-1267, February 1979. 
4.11-15. T. F. Cook, S. A. Ploger and R. R. Hobbins, Postirradiation Examination Results for the Irradiation Effects Test IE-5, TREE-NUREG-1201, March 1978.

4.11-16. E. H. Karb, "Results of the FR-2 Nuclear Tests on the Behavior of Zircaloy Clad Fuel Rods," 6th NRC Water Reactor Safety Research Information Meeting, Gaithersburg, MD, November 7, 1978.

4.11-17. K. Wiehr, H. Schmidt, Out-of-Pile Versuche zum Aufblahvorgang von Zirkaloy-Hullen Ergenbnisse aus Vorversuchen mit verkurzten Brennstabsimulatoren, KfK 2345, October 1977.

4.11-18. L. J. Siefken, M. P. Bohn, S. 0. Peck, J. A. Dearien, FRAP-T5: A Computer Code for the Transient Analysis of Oxide Fuel Rods, TREE-1281, NUREG-CR-0840, June 1979.

4.11-19. D. W. Croucher, T. R. Yackle, C. M. Allison, and S. A. Ploger, Irradiation Effects Test Series IE-5 Test Results Report, TREE-NUREG-1130, January 1978.

4.11-20. R. H. Chapman, Multirod Burst Test Program Quarterly Progress Report for October-December 1975, ORNL/NUREG/TM-10, May 1976.

4.11-21. J. M. Kramer and L. W. Deitrich, Cladding Failure by Local Plastic Instability, ANL-77-95, December 1977.

4.11-22. K. Wiehr et a1., Jahreskolloquim 1977 des Projekts Nukleare Sicherheit.

4.11-23. C. C. Busby and K. B. Marsh, High Temperature Deformation and Burst Characteristics of Recrystallized Zircaloy-4 Tubing, WAPD-T-900, January 1970.

4.11-24. D. G. Hardy, "Burst Testing of Zircaloy $\mathrm{Cladding}$ from Irradiated Pickering-Type Fuel Bundles, " Symposium on the Effects of Radiation on Substructure and Mechanical Properties of Metal and Alloys, Los Angeles, June 25-30, 1972, ASTM-STP-529, 1973, pp. 415-435.

4.11-25. M. F. Osborne and G. W. Parker, The Effect of Irradiation on the Failure of Zircaloy-Clad Fuel Rods, ORNL-3626, January 1972.

4.11-26. D. 0. Hobson, M. F. Osborne, G. W. Parker, "Comparison of Rupture Data from Irradiated Fuel Rods and Unirradiated Cladding," Nuclear Technology, II, August 1971. 


\section{CMLIMT, CBRTTL}

4.11-27. D. G. Hardy, "The Effect of Neutron Irradiation on the Mechanical Properties of Zirconium Alloy Fuel Cladding in Uniaxial and Biaxial Tests," Symposium on Irradiation Effects on Structural Alloys for Nuclear Reactor Applications, Niagara Falls, Canada, June 29-July 1, 1970, ASTM-STP 484, 1971, pp. 215-216.

4.11-28. W. J. Landford, "Metallurgical Properties of Cold-Worked Zircaloy-2 Pressure Tubes Irradiated Under CANDU-PHW Power Reactor Conditions," Symposium on Irradiation Effects on Structural Alloys for Nuclear Reactor Applications, Niagara Falls, Canada, June 29-July 1, 1970, ASTM-STP 484, 1971, pp. 259-286.

4.11-29. W. R. Smalley, Saxton Core II Fuel Performance Evaluation Material WCAP-3385-56, September 1971, pp. 4-84, 4-65;

W. R. Smalley, Evaluation of Saxton Core III Fuel Materials Performance, WCAP-3385-57, July 1974, pp. 3-69, 3-132, 3-134.

4.11-30. R. E. Pawe1, "Oxygen diffusion in Beta Zircaloy During Steam Oxidation," Journal of Nuclear Materials, 50, 1974, pp. 247-258.

4.11-31. S. L. Seiffert and R. R. Hobbins, Oxidation and Embrittlement of Zircaloy-4 Cladding from High Temperature Film Boiling Operation, TFBP-TR-292, October 1978.

4.11-32. H. M. Chung, A. M. Garde, and T. F. Kassner, Light-Water Reactor Safety Research Program: Quarterly Progress Report, January-March 1978, ANL-78-49, p. 56.

4.11-33. G. A. Berna et al., FRAPCON-1: A Code for the Steady-State Analysis of Oxide Fuel Rods, CDAP-TR-78-032-R1, , November 1978.

4.11-34. H. M. Chung, A. M. Garde, and T. F. Kassner, Light-Water Reactor Safety Research Program: Quarterly Progress Report, July-September 1977, ANL-78-3, January 1978, pp. 47-75.

4.11-35. H. M. Chung, A. M. Garde, and T. F. Kassner, Light-Water Reactor Safety Research Program: Quarterly Progress Report, October-December 1977. ANL-78-25, May 1978, pp. 31-44.

4.11-36. D. 0. Hobson and P. L. Rittenhouse, Embrittlement of Zircaloy-Clad Fuel Rods by Steam During LOCA Transients, ORNL-4758, January 1972.

4.11-37. C. J. Scatena, Fuel Cladding Embrittlement During a Loss-of-Coolant Accident, NEDO-10674, General Electric, October 1972.

4.11-38. H. M. Chung, A. M. Garde, and T. F. Kassner, Light-Water Reactor Safety Research Program: Quarterly Progress Report, January-March 1976, ANL-76-49. 
4.11-39. A. Sawatzsky, "Oxygen Embrittlement of Zircaloy-4 Fuel C1adding," Sixth Water Reactor Safety Research Information Meeting, Gaithersburg, Maryland, November 6, 1978.

4.11-40. C. Roy, "An Experiment to Clarify the Effect of Dissolved 0xygen on the Terminal Solubility of Hydrogen in Zirconium," Journal of Nuclear Materials, 13, 1964.

4.11-41. J. V. Cathcart et al., Zirconium Metal Water Oxidation Kinetics VI Reaction Rate Studies, ORNL/NUREG-17, August 1977. 

CFATIG

\subsection{Cyclic fatigue (CFAtig)}

(D. L. Hagrman)

The subcode CFATIG provides preliminary estimates of material constants in a format compatible with the use of fracture mechanics to model the effect of cyclic fatigue as described in the following equations.

\subsubsection{Summary}

High-cycle (nominally elastic strain) fatigue uses material constants in an equation of the following form:

For $\Delta K \geq 9.5 \times 10^{6} \mathrm{MN} / \mathrm{m}^{1.5}$,

$\mathrm{d} l / \mathrm{dN}=\mathrm{B}(\Delta \mathrm{K})^{\mathrm{m}}$

and for $\Delta K<9.5 \times 10^{6} \mathrm{MN} / \mathrm{m}^{1.5}$,

$\mathrm{dl} / \mathrm{dN}=0$

where

$\mathrm{dl} / \mathrm{dN}=$ the change in crack length per cycle $(\mathrm{m} / \mathrm{cycle})$

$\Delta K=$ the stress intensity range $\left(\mathrm{MN} / \mathrm{m}^{1.5}\right)$

$B, m=$ material parameters returned by the CFATIG code.

The exponent $\mathrm{m}$ is 


\section{CFATIG}

$m=15-12 \exp \left(-\Phi / 10^{24}\right)$

where $\Phi$ is the fast neutron fluence $\left(n / m^{2}\right)$.

The parameter $B$ in Equation (4.12-1) is computed from the following expressions for fast neutron fluences less than $10^{25} \mathrm{n} / \mathrm{m}^{2}$ :

$B=2 \times 10^{-11}\left\{15.531432^{12}\left[\exp \left(-\Phi / 10^{24}\right)-1\right]\right\}$.

For fast neutron fluences of $10^{25} \mathrm{n} / \mathrm{m}^{2}$ or more,

$B=1.0165786 \times 10^{-25}$.

Low-cycle (plastic strain) fatigue uses material constants intended for use in the equation proposed by Tomkins. ${ }^{4.12-1}$

$\mathrm{d} 1 / \mathrm{dN}=\mathrm{K}(\Delta \epsilon)^{1 / \alpha} 1$

where

$$
\begin{aligned}
\Delta \epsilon & =\text { plastic strain amplitude (unitless) } \\
1 & =\text { crack length }(\mathrm{m}) \\
\alpha, \mathrm{K} & =\text { material parameters. }
\end{aligned}
$$

The value returned by CFATIG for the dimensionless material parameter $\mathrm{K}$ is 10.7 , and the value for $\alpha$ is 0.6 .

\subsubsection{Basis for High-Cycle Fatigue Material Constants}

Constants for the description of high-cycle crack propagation are based on data taken by Rao ${ }^{4 \cdot 12-2}$ and preliminary measurements by Walker and 
Kass. 4.12-3 S-N (stress versus number of cycles to failure) data reported by $0^{\prime}$ Donne 11 and Langer ${ }^{4.12-4}$ are not incorporated into the model because the effect of varying initial crack sizes is not known.

Rao's measurements of crack growth rates as a function of stress intensity (from Figure 4 of Reference 4.12-2) are reproduced in Table 4.12-1. The parameter $m$ in Equation (4.12-1) is equal to the slope of a plot of $\log \mathrm{dl} / \mathrm{dN}$ against $\log \Delta \mathrm{K}$. The value of $\mathrm{m}$ obtained from a least-squares fit to a plot of the data of Table 4.12-1 is 3.3.

The preliminary data of Walker and Kass (Figure 9 of Reference 4.12-2) were analyzed with the same approach used for the data of Rao. The straight line used by Walker and Kass to summarize data from unirradiated samples is equivalent to a value of $m=2.8$ in Equation (4.12-1).

Walker and Kass also reported crack growth rates from eleven samples which received fast neutron fluences from 5 to $19 \times 10^{24} \mathrm{n} / \mathrm{m}^{2}$. A linear least-squares fit to a $[\log$ (stress intensity) versus $\log$ (crack growth rate)] plot of these measurements suggests that a value of $m=15.7$ in Equation (4.12-1) would yield the best description of irradiated zircaloy.

The exponential form of Equation (4.12-3) is an estimate relating the values of $m=3$ for unirradiated zircaloy and $m=15$ for zircaloy irradiated to a fast neutron fluence of $10^{25} \mathrm{n} / \mathrm{m}^{2}$. A decreasing exponential is typical of the change of material constants with fluence.

Value of the parameter B for unirradiated zircaloy were determined by substituting measurements of crack growth rate and stress intensity range into Equation (4.12-1) with $m=3$. Values of $B$ determined from the two sets of data shown in Table 4.12-1 were averaged to obtain 12.7 and $6 \times 10^{-30}$ for stress intensities in $\mathrm{N} / \mathrm{m}^{1.5}$. Two additional estimates for $B$ were obtained by repeating the solution of Equations (4.12-4) and (4.12-5) with Rao's measurements of crack growth rates at constant stress intensity 


\section{CFATIG}

Table 4.12-1. Crack growth rate versus stress intensity range from Rao

\begin{tabular}{cc} 
Stress Intensity Range & Crack Growth Rate \\
$\left(M N / \mathrm{m}^{1.5}\right)$ & $\left(10^{-8} \mathrm{~m} / \mathrm{cycle}\right)$ \\
20.5 & 4.0 \\
25.5 & 11.3 \\
31.6 & 22.1 \\
37.4 & 37.8 \\
45.3 & 69.2 \\
54.9 & 134.5 \\
20.5 & 9.4 \\
25.5 & 22.4 \\
31.6 & 42.5 \\
37.4 & 71.4 \\
45.3 & 116.7 \\
54.9 & 203.8 \\
\hline
\end{tabular}


(Figure 9 of Reference 4.12-2). Analysis of data from these two samples yielded $B=19.3 \times 10^{-30}$ and $B=16 \times 10^{-30}$. A fifth estimate for $B$ in unirradiated zircaloy was obtained using the Walker and Kass summary of their data with unirradiated material. Their straight-line fit corresponds to a value of $B=48 \times 10^{-30}$.

The only data used to find B for irradiated zircaloy are the eleven measurements of crack growth rate and stress intensity factor range by Walker and Kass discussed earlier in this section. The average value of $B$ from these data and Equation (4.12-1) with $\mathrm{m}=15$ was $\mathrm{B}=10^{-25}$.

The expression used to mode $1 B$ [Equation $(4.12-4)$ ] is a fit to the average of the five estimates for $B$ at zero fast neutron fluence and the one value of $B$ at fluences on the order of $10^{25} \mathrm{n} / \mathrm{m}^{2}$. The functional dependence of $B$ on fast neutron fluence is an estimate based on the data at zero and $10^{25} \mathrm{n} / \mathrm{m}^{2}$. The value of $B$ for fluences between $10^{24}$ and $10^{25} \mathrm{n} / \mathrm{m}^{2}$ has been determined to cause the predicted value of crack growth rate to remain constant at stress intensity factors of $15.531432 \mathrm{MN} / \mathrm{m}^{1.5}$.

The value $\Delta K_{\min }=9.5 \mathrm{MN} / \mathrm{m}^{1.5}$ in Equation $(4.12-1)$ is based on a test by Rao at this stress intensity range. No change in crack length was observed in this test.

\subsubsection{Basis for Low-Cycle Fatigue Material Constants}

The values returned for the material parameters in Equation (4.12-6) are based on the data and analysis of Pettersson. 4.12-5 Pettersson has shown that Equation (4.12-6) can be integrated and expressed in the form of the Coffin-Manson relationship

$\Delta E=C N_{f}^{-\alpha}$ 


\section{CFATIG}

where

$$
\begin{aligned}
& \Delta \epsilon=\text { plastic strain range } \\
& N_{f}=\text { number of cycles to failure } \\
& C, \alpha=\text { material parameters. }
\end{aligned}
$$

The constant $\alpha$ in Equation (4.12-7) is the same material parameter as the constant $\alpha$ in Equation (4.12-6). Pettersson shows that the constant $C$ in Equation (4.12-7) is related to the material constant $K$ of Equation $(4.12-6)$ by the following expressions

for uniaxial straining,

$c^{1 / \alpha}=\ln \left(1_{f} / 1_{0}\right) / K=4.83 / K$

for bend tests,

$c^{1 / \alpha}=\frac{1}{k} \int_{1_{0} / t}^{1 / t} \frac{d X}{x(1-x)^{1 / \alpha}}=\frac{6.26}{k}$

where

$$
\begin{aligned}
& I_{0}=\text { the initial crack length }(\mathrm{m}) \\
& I_{f}=\text { the final crack length }(\mathrm{m}) \\
& t=\text { the specimen thickness }(\mathrm{m}) .
\end{aligned}
$$

The constants $\alpha$ and $\log C$, which Pettersson reports from fits to his data, are listed in Table 4.12-2, along with the constant $K$ obtained from Equation (4.12-9). 
CFATIG

Table 4.12-2. Low-cycle fatigue material parameters

\begin{tabular}{lccc}
\hline Fast Fluence & $\begin{array}{c}\text { Material } \\
\text { Parameter, } \alpha \\
\text { (unitless) }\end{array}$ & $\begin{array}{c}\text { log } C \\
\text { (unitless) }\end{array}$ & $\begin{array}{c}\text { Material } \\
\text { Parameter, K } \\
\text { (unitless) }\end{array}$ \\
\cline { 2 - 3 } & 0.60 & 1.87 & 10.3 \\
$1.3 \times 10^{24}$ & 0.64 & 1.96 & 11.7 \\
$2.6 \times 10^{24}$ & 0.56 & 1.75 & 10.1 \\
Average & 0.6 & -- & 10.7 \\
\hline
\end{tabular}




\section{CFATIG}

\subsubsection{References}

4.12-1. B. Tomkins, "Fatigue Crack Propagation - An Analysis," Philosophical, 18, 1968, p. 1041.

4.12-2. V. S. Rao, High Cycle Fatigue Crack Growth of Two Zirconium Alloys, AE-486, March 1974.

4.12-3. T. J. Walker and J. N. Kass, "Variation of Zircaloy Fracture Toughness in Irradiation, "Zirconium in Nuclear Applications, ASTM-STP-551, 1974, pp. 328-254.

4.12-4 W. J. 0'Donnell and B. F. Langer, "Fatigue Design Basis for Zircaloy Components," Nuclear Science and Engineering, 20, 1, 1964

4.12-5 K. Pettersson, "Low Cycle Fatigue Properties of Zircaloy Cladding," Journal of Nuclear Materials, 56, 1975, pp. 91-102. 


\section{CCLAPS}

\subsection{Collapse Pressure (CCLaps)}

(D. L. Hagrman)

The subcode CCLAPS was produced to aid in the prediction of cladding collapse into axial gaps between fuel pellets. It is based on a correlation developed by Hobson, 4.13-1 which predicts collapse pressure for temperatures between 590 and $700 \mathrm{~K}$. This version of the subcode does not apply to the description of high-temperature $(900 \mathrm{~K})$ collapse or waisting of cladding into pellet-to-pellet gaps, which has been observed during power-cooling-mismatch (PCM) accident tests. ${ }^{4.13-2}$

\subsubsection{Model Development}

The required input parameters for the function CCLAPS are cladding temperature $(K)$, the largest pellet-to-pellet gap in the node considered $(\mathrm{m})$, and the room-temperature midwall diamond-pyramid hardness number (DPH) of the cladding. An additional input argument, pellet-to-cladding gap size ( $m$ ) is not used by this version of the model but is included in the argument list to allow for future improvement of the model. The function returns the pressure at which collapse is predicted by Hobson's correlation.

When measured values of hardness for the particular lot of tubing under consideration are not available, it is suggested that the user input Hobson's measured values. These were reported $4.13-3$ as follows: for $80 \%$ cold-worked and $775 \mathrm{~K}$ stress-relieved material, hardness equals $238 \mathrm{DPH}$; for fully recrystallized material, hardness equals $180 \mathrm{DPH}$.

The expression for collapse pressure derived by Hobson $4 \cdot 13-1$ is 
CCLAPS

$$
\begin{aligned}
P=6895[15,660 & +\frac{G}{2.17 \times 10^{-4} G-4.57 \times 10^{-7}}-183 H \\
& \left.+0.729 H^{2}-7.40 \times 10^{-4} H^{3}-3.762 \mathrm{~T}\right]
\end{aligned}
$$

where

$$
\begin{aligned}
P \quad & \text { collapse pressure }(\mathrm{Pa}) \\
\mathrm{G} & =\text { pellet-to-pellet gap }(\mathrm{m}) \\
H \quad & =\text { room-temperature midwall hardness }(\mathrm{DPH}) \\
\mathrm{T} & =\text { test temperature }(\mathrm{K}) .
\end{aligned}
$$

Hobson's correlation is based on out-of-pile tests with unirradiated cladding and pellet-to-cladding gaps of $0.20 \mathrm{~mm}(0.008 \mathrm{in.})$. Some tests were conducted with other pellet-to-cladding gaps sizes $4.13-3$ but were not included in the data base of the correlation.

\subsubsection{References}

4.13-1. D. 0. Hobson, Quarterly Progress Report on the Creepdown and Collapse of Zircaloy Fuel Cladding Program Sponsored by the NRC Division of Reactor Safety Research for Apri7-June 1976, ORNL/NUREG/TM-52, October 1976.

4.13-2. J. B. Ferguson (ed.), Quarterly Technical Progress Report on Water Reactor Safety Programs Sponsored by the Nuclear Regulatory Commission's Division of Reactor Safety Research October-December 1976, TREE-NUREG-1070, Apri1 1977, p. 37.

4.13-3. D. 0. Hobson, Quarterly Progress Report on the Creepdown and Collapse of Zircaloy Fuel Cladding Program Sponsored by the NRC Division of Reactor Safety Research for January-March 1976, ORNL/NUREG/TM-51, October 1976. 
CMHARD

\subsection{Meyer Hardness (CMHARD)}

(M. A. Morgan)

The routine CMHARD calculates Meyer hardness as a function of cladding temperature.

\subsubsection{Mode1 Development}

One of the parameters required for calculating fuel-to-cladding contact conductance is hardness. As the contact pressure between the two surfaces increases, the points of contact enlarge due to localized plastic deformation and the solid-to-solid thermal conductance is improved. The Meyer hardness is used by Ross and Stoute ${ }^{4 \cdot 14-1}$ in their heat transfer correlation as an indication of the hardness of resistance to deformation of the softer (zircaloy) material.

The Meyer hardness number is a measure of indentation hardness and is defined in conjunction with Meyer's law,

$L=a d^{n}$

where

$L \quad=$ load

$d=$ the diameter of impression at the surface of a specimen in a static ball test

$\mathrm{n}=$ the Meyer work hardening coefficient 


\section{CMHARD}

a $=$ a material constant.

The Meyer hardness number $(M H)$ is defined as $4 \mathrm{~L} / \pi \mathrm{d}^{2}$. Other hardness numbers are available (Brinell, Rockwel1, etc.), and conversion from one to another is possible. However, the routine CMHARD was created to provide information required by the Ross and Stoute gap conductance model.

Meyer hardness numbers for temperatures from 298 to $877 \mathrm{~K}$ were taken from Peggs and Godin. 4.14-2 A regression analysis of the reciprocal of the Meyer hardness values versus the log of temperature was used to obtain the analytical expression used in CMHARD. The correlation used is given by Equation (4.14-2).

$$
\begin{aligned}
M H & =\exp \left\{2.6034 \times 10^{1}+T\left\{-2.6394 \times 10^{-2}+T\left[4.3504 \times 10^{-5}\right.\right.\right. \\
& \left.\left.+T\left(2.5621 \times 10^{-8}\right)\right]\right\}
\end{aligned}
$$

where

$$
\begin{aligned}
M H & =\text { Meyer hardness }\left(\mathrm{N} / \mathrm{m}^{2}\right) \\
T & =\text { temperature }(\mathrm{K}) .
\end{aligned}
$$

Figure 4.14-1 illustrates the correlation and its data base. The Meyer hardness decreases rapidly with increasing temperature, beginning at $2 \times 10^{9} \mathrm{MPa}$ at room temperature and decreasing to $2 \times 10^{8} \mathrm{MPa}$ at $875 \mathrm{~K}$. The hardness is presumed to continue its rapid rate of decrease at temperatures above $875 \mathrm{~K}$. The minimum Meyer hardness number of zircaloy cladding is $1.0 \times 10^{5} \mathrm{~N} / \mathrm{m}^{2}$. 
CMHARD

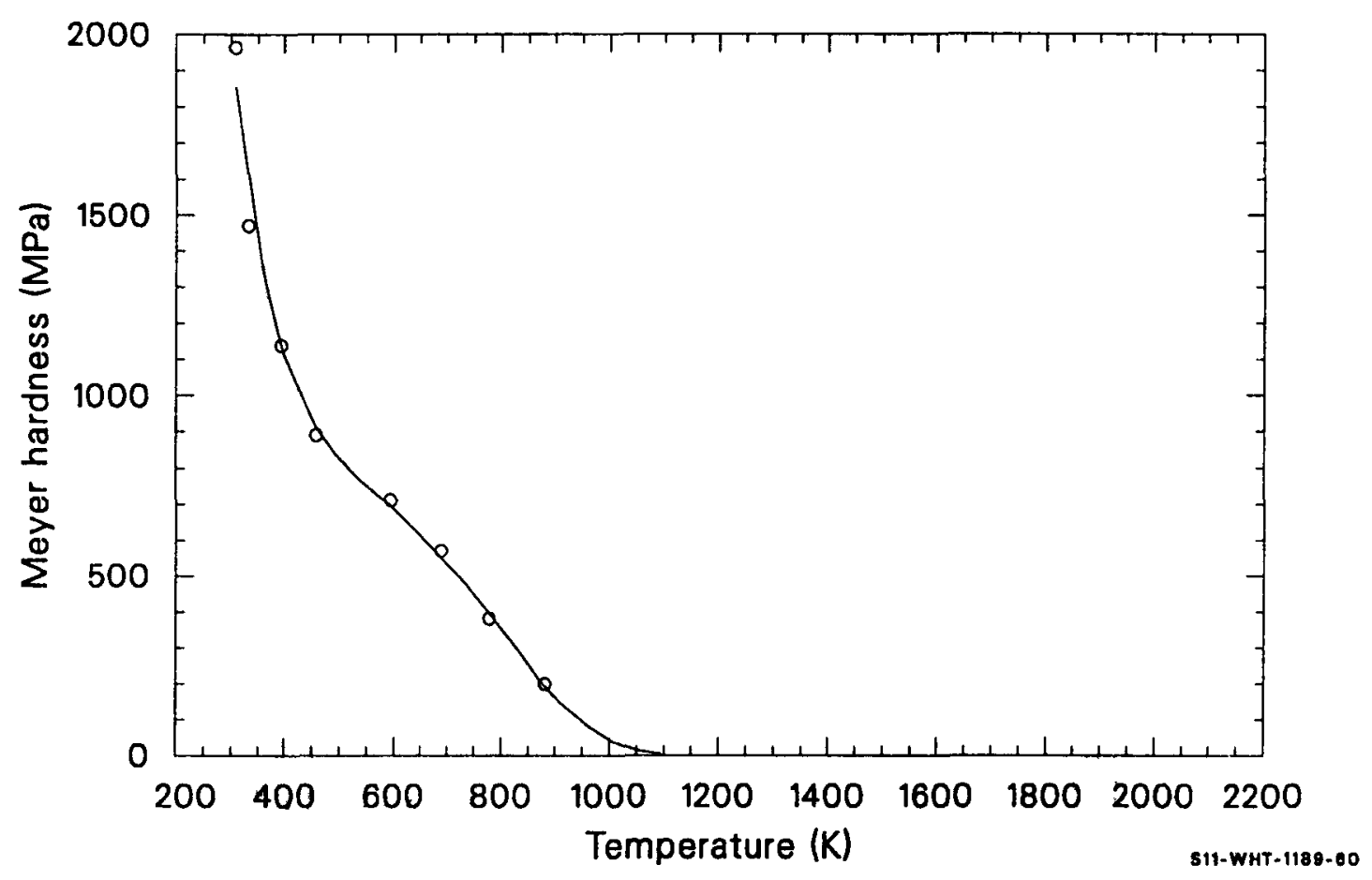

Figure 4.14.1. Values of the CMHARD correlation and its data base. 


\section{CMHARD}

\subsubsection{References}

4-14.1. A. M. Ross and R. L. Stoute, Heat Transfer Coefficient Between $\mathrm{UO}_{2}$ and Zircaloy-2, AECL-1552, June 1962.

4-14.2. I. D. Peggs and D. P. Godin, "The Yield Strength -- Hot Hardness Relationship of Zircaloy-4," Journal of Nuclear Materials, 57, 1975, pp. 246-248. 


\section{ZIRCALOY OXIDES}

The materials properties correlations needed for the oxides of the zircaloy fuel cladding formed at high temperatures were developed and are described in this section. The subcodes described in this section are for melting temperature (ZOPRP), specific heat capacity (ZOCP), enthalpy (ZONTHL), thermal conductivity (ZOTCON), thermal expansion (ZOTEXP), density (ZODEN), emissivity (ZOEMIS), elastic moduli (ZOEMOD, ZOPOIR), and mechanical limits and embrittlement (ZORUP). 


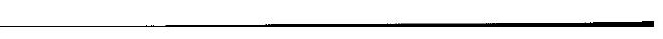




\subsection{Melting and Phase transformation Temperatures (ZOPRP)}

(D. L. Hagrman)

The subcode ZOPRP calculates the transition temperatures between the monoclinic, tetragonal, cubic, and liquid phases of zircaloy oxide. The oxygen-to-metal ratio of the oxide is the only required input to the subroutine. The monoclinic-to-tetragonal and tetragonal-to-cubic transition temperatures are constants that have been reported for $\mathrm{ZrO}_{2}$ (1478 and 2558 K).$^{5.1-1}$ These temperatures are assumed to apply to zircaloy oxide, in spite of the fact that the oxide is slightly substoichiometric and may be under stress.

\subsubsection{Model Development}

Since atomic fraction oxygen in the zircaloy oxide compound is used as a basis to determine the solidus (appearance of the first liquid phase) and the liquidus (melting of the last solid phase) temperatures of the zircaloy oxide, the input oxygen-to-metal ratio is converted to atomic fraction using the following relationship:

$x=\frac{Y E}{(1+Y E)}$

where

$\begin{aligned} X= & \text { atomic fraction oxygen (atoms of oxygen/atoms of compound) } \\ Y E= & \begin{array}{l}\text { oxygen-to-metal ratio in compound (atoms of oxygen/atoms of } \\ \text { zirconium. }\end{array}\end{aligned}$




\section{ZOPRP}

With a known atomic fraction oxygen for the zirconium oxide, the correlations developed for the PSOL and PLIQ subroutines described in Subsection 11.1 were used to calculate the solidus temperatures. These correlations are as follows:

For $x \leq 0.1$,

$\mathrm{T}_{\text {SO }}=2098+1150$.

For $0.1<x \leq 0.18$

$\mathrm{T}_{\text {SOl }}=2213$.

For $0.18<x \leq 0.29$,

$T_{\text {sol }}=1389.5317+7640.0748 x-17029.172 x^{2}$.

For $0.29<x \leq 0.63$,

$\mathrm{T}_{\text {SOl }}=2173$.

For $0.63<x \leq 0.667$,

$T_{\text {Sol }}=-11572.454+21818.181 \times$.

For $x>0.667$,

$T_{\text {Sol }}=-11572.454+x(1.334-x) 21818.181$

where $T_{\text {sol }}$ is the solidus temperature $(K)$.

The liquidus temperatures are calculated using the following relationships: 
For $x \leq 0.19$,

$T_{1 \mathrm{iq}}=2125+16321637 x-53216374 x^{2}$

For $0.19<x \leq 0.41$,

$T_{1 i q}=2111.6553+1159.0909 x-2462.1212 x^{2}$

For $0.41<x \leq 0.667$

$T_{1 i q}=895.07792+3116.8831 x$

For $x>0.667$,

$T_{7 i q}=895.07792+(1.34-x) 3116.8831 x$.

where $T_{1 i q}$ is the liquidus temperature $(K)$.

Figure 5.1-1 shows the zircaloy oxide solidus and liquidus temperatures as calculated by the subroutine.

\subsubsection{References}

5.1-1. R. R. Hammer, Zircaloy-4, Uranium Dioxide and Materials Formed By Their Interaction. A Literature Review with Extrapolation of Physical Properties to High Temperatures, IN-1093, September, 1967. 


\section{ZOPRP}

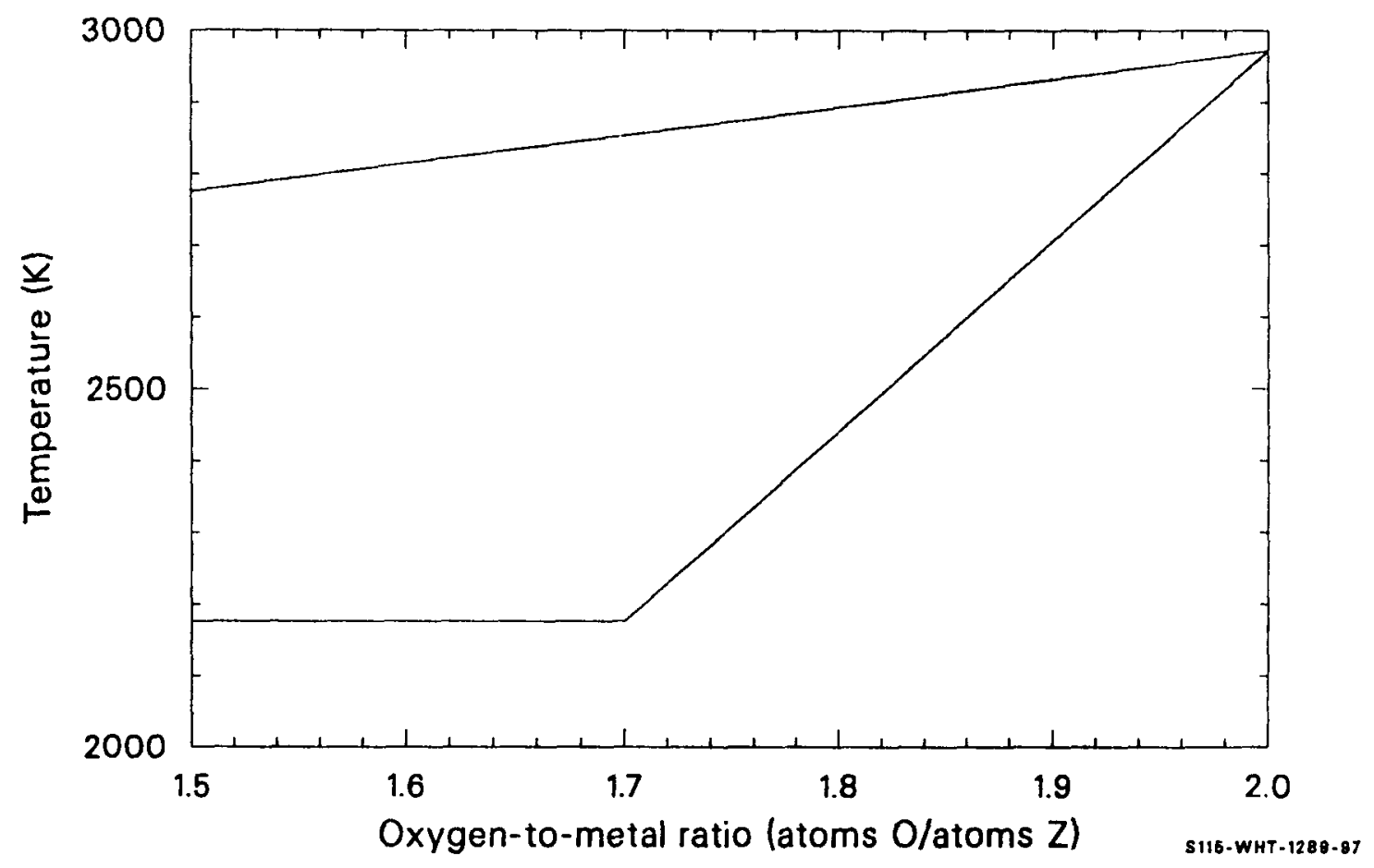

Figure 5.1-1. Zircaloy oxide solidus and liquidus temperatures. 


\subsection{Specific Heat Capacity and Enthalpy (ZOCP, ZONTHL)}

The functions ZOCP and ZONTHL return zircaloy oxide specific heat capacity and enthalpy. ZOCP requires only temperature as input, while the two enthalpy subcodes require temperature and a reference temperature for which the enthalpy will be set equal to zero.

\subsubsection{Specific Heat (ZOCP)}

Zircaloy oxide specific heat is modeled by the ZOCP function with the following expressions, which were taken from Reference 5.2-1:

For $300<\mathrm{T}<1478 \mathrm{~K}$ (monoclinic $\mathrm{ZrO}_{2}$ ),

$C_{p}^{0}=565+6.11 \times 10^{-2} \mathrm{~T}-1.14 \times 10^{+7} \mathrm{~T}^{-2}$.

For $1478 \leq \mathrm{T} \leq 2000 \mathrm{~K}$ (tetragonal $\mathrm{ZrO}_{2}$ ),

$c_{p}^{0}=604.5$

For $2000<T<2973 \mathrm{~K}$ (tetragonal and cubic $\mathrm{ZrO}_{2}$ ),

$c_{p}^{0}=171.7+0.2164 \mathrm{~T}$.

For $T \geq 2973 \mathrm{~K}$ (liquid $\mathrm{ZrO}_{2}$ ),

$C_{p}^{0}=815 \mathrm{~J} / \mathrm{kg} \cdot \mathrm{K}$. 


\section{ZOCP， ZONTHL}

where

$$
\begin{aligned}
C_{p}^{0} & =\text { specific heat of zircaloy oxide }(\mathrm{J} / \mathrm{kg} \cdot \mathrm{K}) \\
T & =\text { temperature }(\mathrm{K}) .
\end{aligned}
$$

The several equations correspond to the several phases of $\mathrm{ZrO}_{2}$.

\subsubsection{Enthalpy (ZONTHL)}

Zircaloy oxide enthalpy is modeled in the ZONTHL function with the integrated version of Equations (5.2-2) to (5.2-4), estimates of the changes of enthalpies at the phase changes and an estimate of the heat of fusion of $\mathrm{ZrO}_{2} \cdot \mathrm{a}$

For $300<\mathrm{T}<1478 \mathrm{~K}$ (monoclinic $\mathrm{ZrO}_{2}$ ):

$$
\begin{aligned}
H^{0}(T) & -H^{0}(300)=565 \mathrm{~T}+3.055 \times 10^{-2} \mathrm{~T}^{2} \\
& +1.14 \times 10^{+7} \mathrm{~T}^{-1}-2.102495 \times 10^{5} .
\end{aligned}
$$

For $1478 \leq \mathrm{T} \leq 2000 \mathrm{~K}^{\mathrm{a}}$ (tetragonal $\mathrm{ZrO}_{2}$ ),

$H^{0}(T)-H^{0}(300)=604.5 T-1.46 \times 10^{5}$.

For $2000<T<2558 \mathrm{~K}$ (tetragonal and cubic $\mathrm{ZrO}_{2}$ ),

$H^{0}(T)-H^{0}(300)=171.7 T+0.1082 T^{2}+2.868 \times 10^{5}$.

For $2558 \leq T<2973 \mathrm{~K}$,

a. Monoclinic to tetragonal transition $\Delta \mathrm{H}=48,200 \mathrm{~J} / \mathrm{kg}$; tetragonal to cubic transition $\Delta H=102,000 \mathrm{~J} / \mathrm{kg}$; heat of fusion $=706,000 \mathrm{~J} / \mathrm{kg}$. 


\section{ZOCP， ZONTHL}

$H^{0}(T)-H^{0}(300)=171.7 T+0.1082 \mathrm{~T}^{2}+3.888 \times 10^{5}$.

For $\mathrm{T} \geq 2973 \mathrm{~K}$ (1 iquid $\mathrm{ZrO}_{2}$ ),

$H^{0}(T)-H^{0}(300)=815 T+1.39 \times 10^{5}$

where

$H^{0}(T)=$ enthalpy of zircaloy oxide at temperature $T(\mathrm{~J} / \mathrm{kg})$.
$T \quad=\quad$ oxide temperature $(\mathrm{K})$.

The principal contribution to the expected standard error of the enthalpy and specific heat capacity predictions for cladding oxide is not the uncertainty of the correlations for $\mathrm{ZrO}_{2}$ because $C_{\mathrm{p}}$ measurements are typically accurate to several percent. It is the probability that the oxide film that appears on cladding differs significantly from the $\mathrm{ZrO}_{2}$ used to produce the correlations. The oxide is substoichiometric and has enough stress from the volume expansion during oxidation to cause significant changes of the phase transition temperatures. ${ }^{5.2-2}$ Therefore, a relatively large expected standard error of \pm 0.2 times the given values is suggested for both the predicted specific heat capacity and enthalpy of zircaloy oxide.

The specific heat capacity predicted with the ZOCP function is shown in Figure 5.2-2. Comparison of the predicted specific heat capacity with data reported by Gilchrest, ${ }^{5.2-3}$ which are reproduced in Table 5.2-1, suggests an expected standard error of $\pm 150 \mathrm{~J} / \mathrm{kg} \cdot \mathrm{K}$. Figure $5.2-3$ is a plot of the zircaloy oxide enthalpy predicted with the ZONTHL function. The numerous steps are heats of transitions for the several phase changes of zircaloy dioxide. 


\section{ZOCP， ZONTHL}

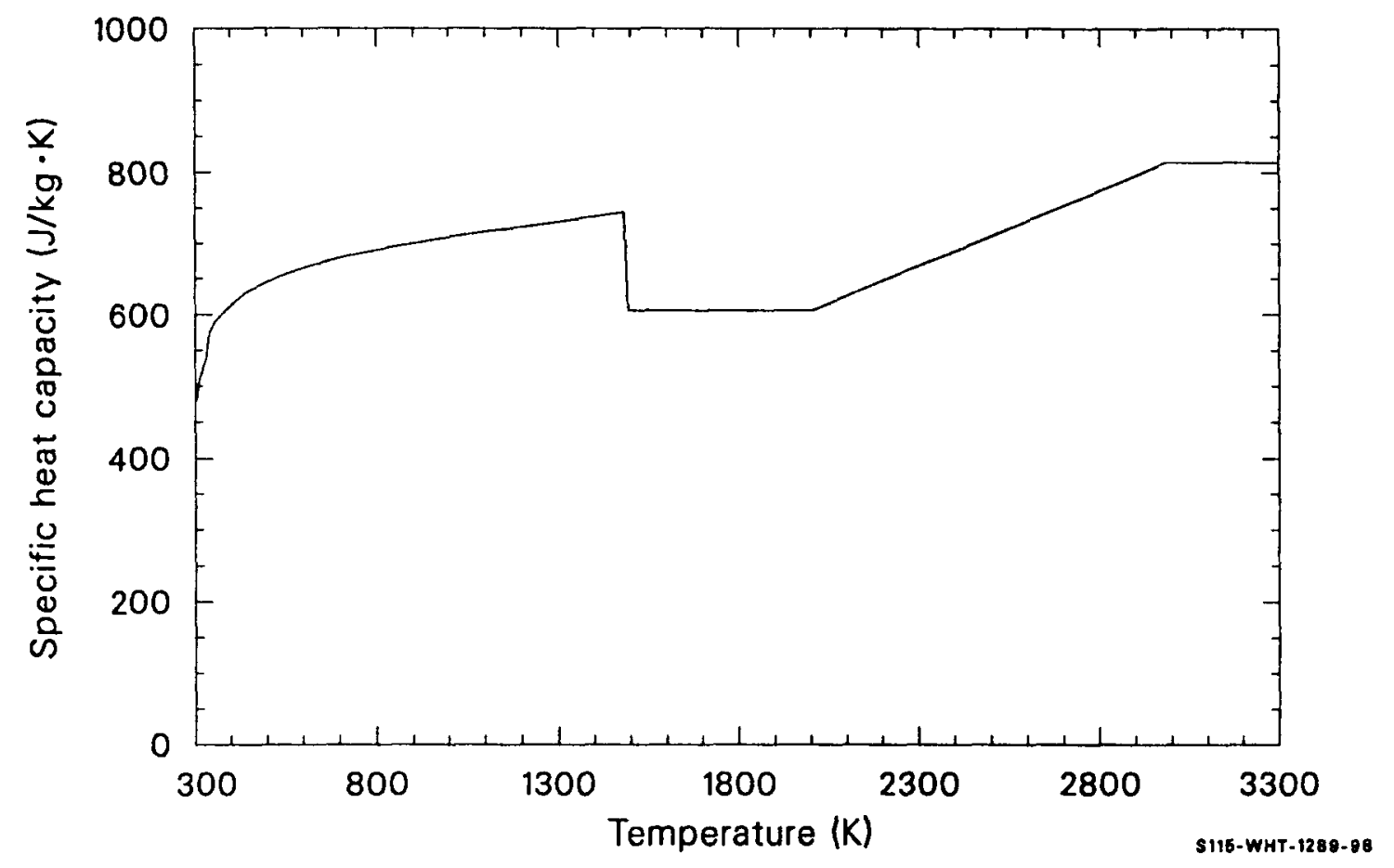

Figure 5.2-1. Zircaloy oxide specific heat capacity as a function of temperature. 
Table 5.2-1. Zircaloy cladding oxide specific heat capacity data from

\begin{tabular}{|c|c|c|}
\hline $\begin{array}{c}\text { Temperature } \\
(\mathrm{K})\end{array}$ & $\begin{array}{c}\text { Specific Heat Capacity } \\
(\mathrm{J} / \mathrm{kg} \cdot \mathrm{K})\end{array}$ & Comment \\
\hline 324 & 462 & Measured by Gilchrist \\
\hline 348 & 481 & Measured by Gilchrist \\
\hline 377 & 486 & Measured by Gilchrist \\
\hline 422 & 402 & Measured by Gilchrist \\
\hline 462 & 510 & Measured by Gilchrist \\
\hline 500 & 523 & Measured by Gilchrist \\
\hline 598 & 543 & Measured by Gilchrist \\
\hline 698 & 566 & Measured by Gilchrist \\
\hline 801 & 569 & Measured by Gilchrist \\
\hline 899 & 592 & Measured by Gilchrist \\
\hline 945 & 598 & Measured by Gilchrist \\
\hline 975 & 601 & Measured by Gilchrist \\
\hline 1004 & 603 & Measured by Gilchrist \\
\hline 772 & 563 & Measured by Smithe $11 \mathrm{~s}$ \\
\hline 373 & 437 & Measured by Washburn \\
\hline 774 & 525 & Measured by Washburn \\
\hline 1272 & 631 & Measured by Washburn \\
\hline 325 & 442 & $\begin{array}{l}\text { Reported by Gilchrist } \\
\text { as data from "Ther- } \\
\text { mophysical Properties } \\
\text { of Solid Material" }\end{array}$ \\
\hline 399 & 486 & $\begin{array}{l}\text { Reported by Gilchrist } \\
\text { as data from "Ther- } \\
\text { mophysical Properties } \\
\text { of Solid Material" }\end{array}$ \\
\hline
\end{tabular}


ZOCP， ZONTHL

Table 5.2-1. (continued)

\begin{tabular}{|c|c|c|}
\hline $\begin{array}{c}\text { Temperature } \\
(\mathrm{K})\end{array}$ & $\begin{array}{c}\text { Specific Heat Capacity } \\
(\mathrm{J} / \mathrm{kg} \cdot \mathrm{K})\end{array}$ & Comment \\
\hline 494 & 510 & $\begin{array}{l}\text { Reported by Gilchrist } \\
\text { as data from "Ther- } \\
\text { mophysical Properties } \\
\text { of Solid Material" }\end{array}$ \\
\hline 598 & 535 & $\begin{array}{l}\text { Reported by Gilchrist } \\
\text { as data from "Ther- } \\
\text { mophysical Properties } \\
\text { of Sol id Material" }\end{array}$ \\
\hline 692 & 555 & $\begin{array}{l}\text { Reported by Gilchrist } \\
\text { as data from "Ther- } \\
\text { mophysical Properties } \\
\text { of Solid Material" }\end{array}$ \\
\hline 790 & 576 & $\begin{array}{l}\text { Reported by Gilchrist } \\
\text { as data from "Ther- } \\
\text { mophysical Properties } \\
\text { of Solid Material" }\end{array}$ \\
\hline 1198 & 606 & $\begin{array}{l}\text { Reported by Gilchrist } \\
\text { as data from "Ther- } \\
\text { mophysical Properties } \\
\text { of Solid Material" }\end{array}$ \\
\hline 1398 & 612 & $\begin{array}{l}\text { Reported by Gilchrist } \\
\text { as data from "Ther- } \\
\text { mophysical Properties } \\
\text { of Solid Material" }\end{array}$ \\
\hline
\end{tabular}




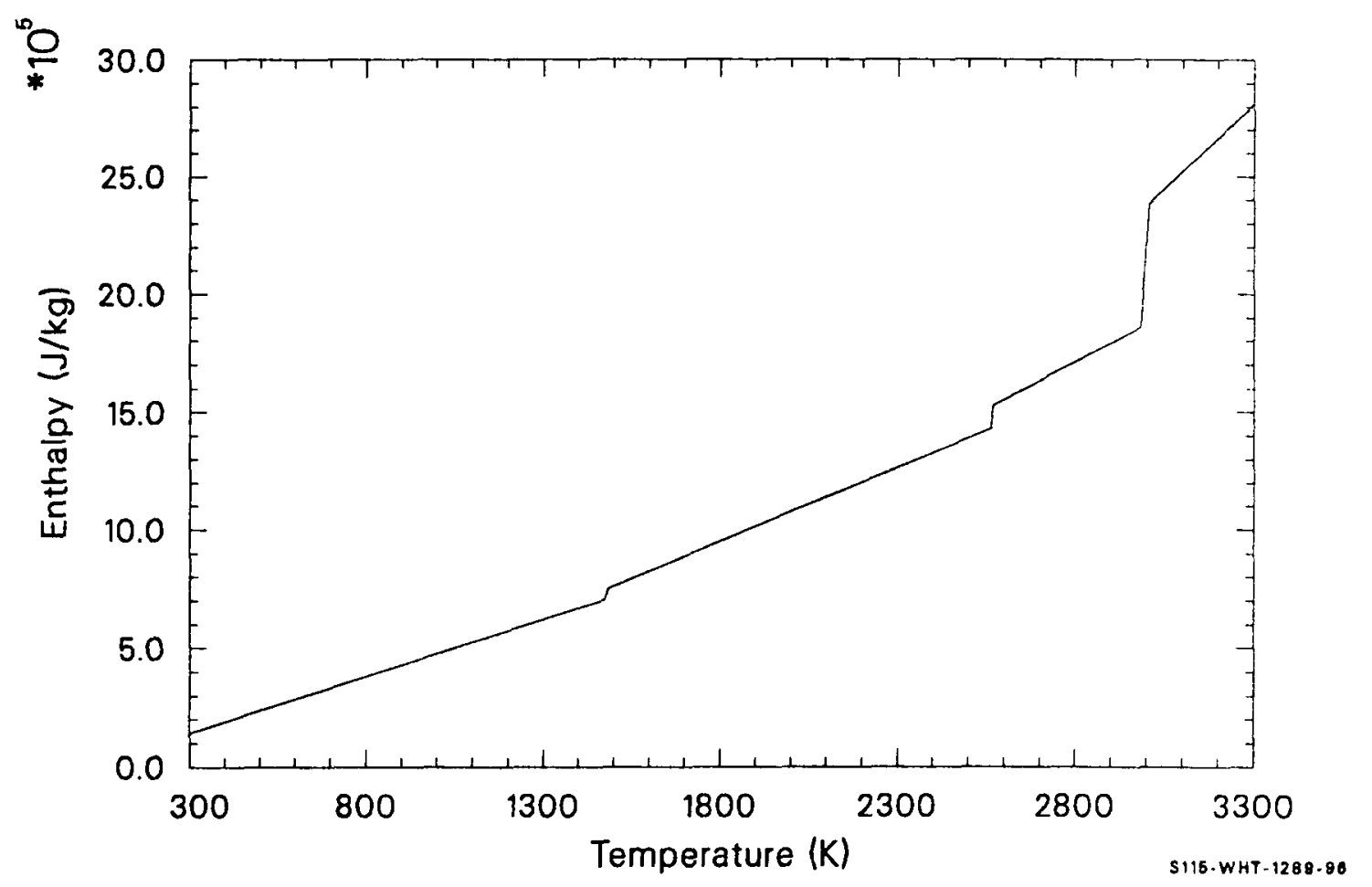

Figure 5.2-2. Zircaloy oxide enthalpy as a function of temperature. 


\section{ZOCP，ZONTHL}

\subsubsection{References}

5.2-1. R. R. Hammer, Zircaloy-4, Uranium Dioxide, and Materials Formed by Their Interaction. A Literative Review with Extrapolation of Physical Properties to High Temperatures, IN-1093, September 1967.

5.2-2. R. E. Pawe 1, J. V. Cathcart, J. J. Campbe11, and S. H. Jury, Zirconium Metal-Water Oxidation Kinetics. V. Oxidation of Zircaloy in High Pressure Steam, ORNL/NUREG-31, December 1977.

5.2-3. K. E. Gilchrist, "Thermal Property Measurements on Zircaloy-2 and Associated Oxide Layers," Journal of Nuclear Materials, 62, 1976, pp. 257-264. 
ZOTCON

\subsection{Thermal Conductivity (ZOTCON)}

(D. L. Hagrman)

The function ZOTCON returns zircaloy oxide thermal conductivity. The only input information required is the temperature of the material.

\subsubsection{Model Development}

To obtain an accurate value of zircaloy oxide thermal conductivity, accurate calculations of the peak cladding temperature during the rapid heating of cladding due to oxidation that occurs at high temperature are important. Data from the one sample that Adams reports ${ }^{5.3-1}$ are presented in Table 5.3-1. Additional sources of data are Maki, 5.3-2 Lapshov and Bashkatov, ${ }^{5.3-3}$ and Gilchrist. $5.3-4$

Data of Maki ${ }^{5.3-2}$ from two samples oxidized in steam are reproduced in Table 5.3-2. The data cover a small temperature range and show a sharp increase in conductivity between 400 and $500 \mathrm{~K}$. The principal recommendation for the data is that they were taken with black oxide from zircaloy tubes. Two sets of data attributed to Waldman by Maki are also shown in the table.

The data of Lapshov and Bashkatov ${ }^{5.3-3}$ are presented in Table 5.3-3. These data are from films formed by plasma sputtering of zirconium dioxide on tungsten substrates. Since sputtered coatings are quite porous, not of the same oxygen-to-metal ratio as cladding oxide, and may not be very adherent to the substrate, these data may not be representative of zircaloy cladding oxide conductivity.

Table 5.3-4 presents the data of Gilchrist. 5.3-4 Two types of oxide films were employed, one nodular oxide and the other a black oxide 


\section{ZOTCON}

Table 5.3-1. Stabilized zircaloy dioxide thermal conductivity data from

\begin{tabular}{|c|c|c|}
\hline $\begin{array}{l}\text { Temperature } \\
\text { (K) }\end{array}$ & $\begin{array}{l}\text { Thermal Conductivity } \\
(\mathrm{W} / \mathrm{m} \bullet \mathrm{K})\end{array}$ & $\begin{array}{c}\text { Thermal Conductivity } \\
\text { Corrected to } 5820 \mathrm{~kg} / \mathrm{m}^{3} \\
(\mathrm{~W} / \mathrm{m} \cdot \mathrm{K})\end{array}$ \\
\hline $\begin{array}{l}370 \\
460 \\
547 \\
641 \\
698\end{array}$ & $\begin{array}{l}1.69 \\
1.69 \\
1.70 \\
1.78 \\
1.73\end{array}$ & $\begin{array}{l}1.88 \\
1.88 \\
1.89 \\
1.98 \\
1.91\end{array}$ \\
\hline $\begin{array}{l}743 \\
817 \\
882 \\
945 \\
993\end{array}$ & $\begin{array}{l}1.74 \\
1.74 \\
1.74 \\
1.76 \\
1.79\end{array}$ & $\begin{array}{l}1.93 \\
1.93 \\
1.93 \\
1.95 \\
1.98\end{array}$ \\
\hline $\begin{array}{l}1059 \\
1123 \\
1187 \\
1245 \\
1285\end{array}$ & $\begin{array}{l}1.78 \\
1.79 \\
1.86 \\
1.89 \\
1.95\end{array}$ & $\begin{array}{l}1.97 \\
1.98 \\
2.06 \\
2.09 \\
2.16\end{array}$ \\
\hline $\begin{array}{l}1305 \\
1329 \\
1338 \\
1354 \\
1390\end{array}$ & $\begin{array}{l}1.92 \\
1.93 \\
1.94 \\
1.96 \\
1.96\end{array}$ & $\begin{array}{l}2.13 \\
2.14 \\
2.15 \\
2.17 \\
2.18\end{array}$ \\
\hline $\begin{array}{l}1405 \\
1427 \\
1440 \\
1448 \\
1480\end{array}$ & $\begin{array}{l}1.99 \\
1.98 \\
2.02 \\
2.08 \\
2.01\end{array}$ & $\begin{array}{l}2.20 \\
2.19 \\
2.24 \\
2.31 \\
2.23\end{array}$ \\
\hline $\begin{array}{l}1485 \\
1505 \\
1554 \\
1566 \\
1583\end{array}$ & $\begin{array}{l}2.03 \\
2.01 \\
2.01 \\
2.02 \\
2.01\end{array}$ & $\begin{array}{l}2.25 \\
2.23 \\
2.23 \\
2.24 \\
2.23\end{array}$ \\
\hline
\end{tabular}



Table 5.3-2. Zircal $\operatorname{Maki}_{5}$ oxide thermal conductivity data reported by

\begin{tabular}{|c|c|c|}
\hline $\begin{array}{c}\text { Average of Inside and } \\
\text { Outside Temperature } \\
(\mathrm{K})\end{array}$ & $\begin{array}{l}\text { Thermal Conductivity } \\
(\mathrm{W} / \mathrm{m} \cdot \mathrm{K})\end{array}$ & Comment \\
\hline 401 & 0.70 & Sample 4 \\
\hline 434 & 4.78 & Sample 4 \\
\hline 488 & 6.35 & Sample 4 \\
\hline 536 & 5.41 & Sample 4 \\
\hline 588 & 5.45 & Sample 4 \\
\hline 400 & 1.07 & Sample 5 \\
\hline 437 & 4.50 & Sample 5 \\
\hline 490 & 5.76 & Sample 5 \\
\hline 536 & 6.11 & Sample 5 \\
\hline 589 & 6.27 & Sample 5 \\
\hline 373 & 0.90 & Data from Waldman \\
\hline 373 & 1.35 & Data from Waldman \\
\hline
\end{tabular}




\section{ZOTCON}

Table 5.3-3. Zircaloy digxjde thermal conductivity data of Lapshov and

Temperature

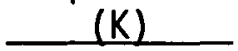

571

618

642

654

664

684

721

739

755

771

802

817

827

855

882

929

969

984

999

1006

1050

1071

1088

1097

1104

1162

1189

1201

1220

1250

1302

1354

1366

1380

1491
Thermal Conductivity

$(\mathrm{W} / \mathrm{m} \cdot \mathrm{K})$

0.509

0.636

0.508

0.627

0.715

0.474

0.652

0.448

0.441

0.558

0.430

0.512

0.605

0.456

0.522

0.477

0.506

0.509

0.509

0.472

0.509

0.522

0.493

0.587

0.527

0.563

0.636

0.577

0.555

0.623

0.623

0.577

0.661

0.663

0.708 
Table 5.3-3. (continued)

\begin{tabular}{cc}
$\begin{array}{c}\text { Temperature } \\
(\mathrm{K})\end{array}$ & $\frac{\begin{array}{c}\text { Therma1 Conductivity } \\
(\mathrm{W} / \mathrm{m} \bullet \mathrm{K})\end{array}}{1527}$ \\
1558 & 0.656 \\
1626 & 0.717 \\
1638 & 0.801 \\
1685 & 0.776 \\
1735 & 0.788 \\
& 0.854 \\
\hline
\end{tabular}




\section{ZOTCON}

Table 5.3-4. Zircaloy oxide thermal conductivity data of Gilchrist5.3-4

\begin{tabular}{|c|c|c|}
\hline $\begin{array}{c}\text { Temperature } \\
\text { (K) }\end{array}$ & $\begin{array}{c}\text { Thermal Conductivity } \\
(\mathrm{W} / \mathrm{m} \bullet \mathrm{K})\end{array}$ & Comment \\
\hline $\begin{array}{l}297 \\
668 \\
712 \\
806 \\
854\end{array}$ & $\begin{array}{l}1.354 \\
0.955 \\
0.958 \\
1.048 \\
1.060\end{array}$ & $\begin{array}{l}\text { Black oxide } \\
\text { Black oxide } \\
\text { Black oxide } \\
\text { Black oxide } \\
\text { Black oxide }\end{array}$ \\
\hline $\begin{array}{r}916 \\
983 \\
1043 \\
1193 \\
1260\end{array}$ & $\begin{array}{l}1.090 \\
1.163 \\
1.242 \\
1.443 \\
1.407\end{array}$ & $\begin{array}{l}\text { Black oxide } \\
\text { Black oxide } \\
\text { Black oxide } \\
\text { Black oxide } \\
\text { Black oxide }\end{array}$ \\
\hline $\begin{array}{r}1327 \\
1386 \\
1450 \\
299 \\
659\end{array}$ & $\begin{array}{l}1.393 \\
1.487 \\
1.586 \\
0.324 \\
0.137\end{array}$ & $\begin{array}{l}\text { Black oxide } \\
\text { Black oxide } \\
\text { Black oxide } \\
\text { Nodular oxide } \\
\text { Nodular oxide }\end{array}$ \\
\hline $\begin{array}{r}733 \\
806 \\
867 \\
944 \\
1018\end{array}$ & $\begin{array}{l}0.160 \\
0.192 \\
0.219 \\
0.271 \\
0.410\end{array}$ & $\begin{array}{l}\text { Nodular oxide } \\
\text { Nodular oxide } \\
\text { Nodular oxide } \\
\text { Nodular oxide } \\
\text { Nodular oxide }\end{array}$ \\
\hline $\begin{array}{l}1141 \\
1222 \\
1246 \\
1326 \\
1425\end{array}$ & $\begin{array}{l}0.606 \\
0.825 \\
0.864 \\
0.743 \\
0.700\end{array}$ & $\begin{array}{l}\text { Nodular oxide } \\
\text { Nodular oxide } \\
\text { Nodular oxide } \\
\text { Nodular oxide } \\
\text { Nodular oxide }\end{array}$ \\
\hline
\end{tabular}


characteristic of the kinds of layers usually reported in high-temperature tests with cladding. The black oxide thermal conductivities are much lower than the nodular oxide thermal conductivities, and both kinds of oxide have conductivities that are significantly lower than the stabilized zircaloy dioxide conductivities reported by Adams. Considerable uncertainty is reported by Gilchrist because of difficulty in measuring oxide film thickness.

Figure 5.3-1 is a plot of the data in Tables 5.3-1 to 5.3-4. The plot shows that, with the exception of the anomalously high data of Maki, the principal uncertainty in thermal conductivity is caused by sample-to-sample variations. Measurement inaccuracies with any one sample are much smaller than sample-to-sample variations. It is also clear from an inspection of Figure 5.3-1 that the slopes of the measurements on individual samples are quite consistent. The difference between the various samples is essentially a displacement of a line with a constant slope.

The slope of the thermal conductivity of a given sample was determined with a least-squares linear fit to the data of Adams. These data were used because they extend over a large temperature range and were made with the most accurate experimental technique. The equation which results from this fit is

$\mathrm{K}_{\mathrm{ZrO}_{2}}=1.67+3.62 \times 10^{-4} \mathrm{~T}$

where $\mathrm{K}_{\mathrm{ZrO}_{2}}$ is zircaloy dioxide thermal conductivity $(\mathrm{W} / \mathrm{m} \bullet \mathrm{K})$.

Since the black oxide data of Gilchrist are the most representative of the oxide found on cladding, Equation (5.3-1) is modified for zircaloy oxide by dividing the right hand side by two. The resultant expression is

$K_{0}=0.835+1.81 \times 10^{-4} \mathrm{~T}$ 


\section{ZOTCON}

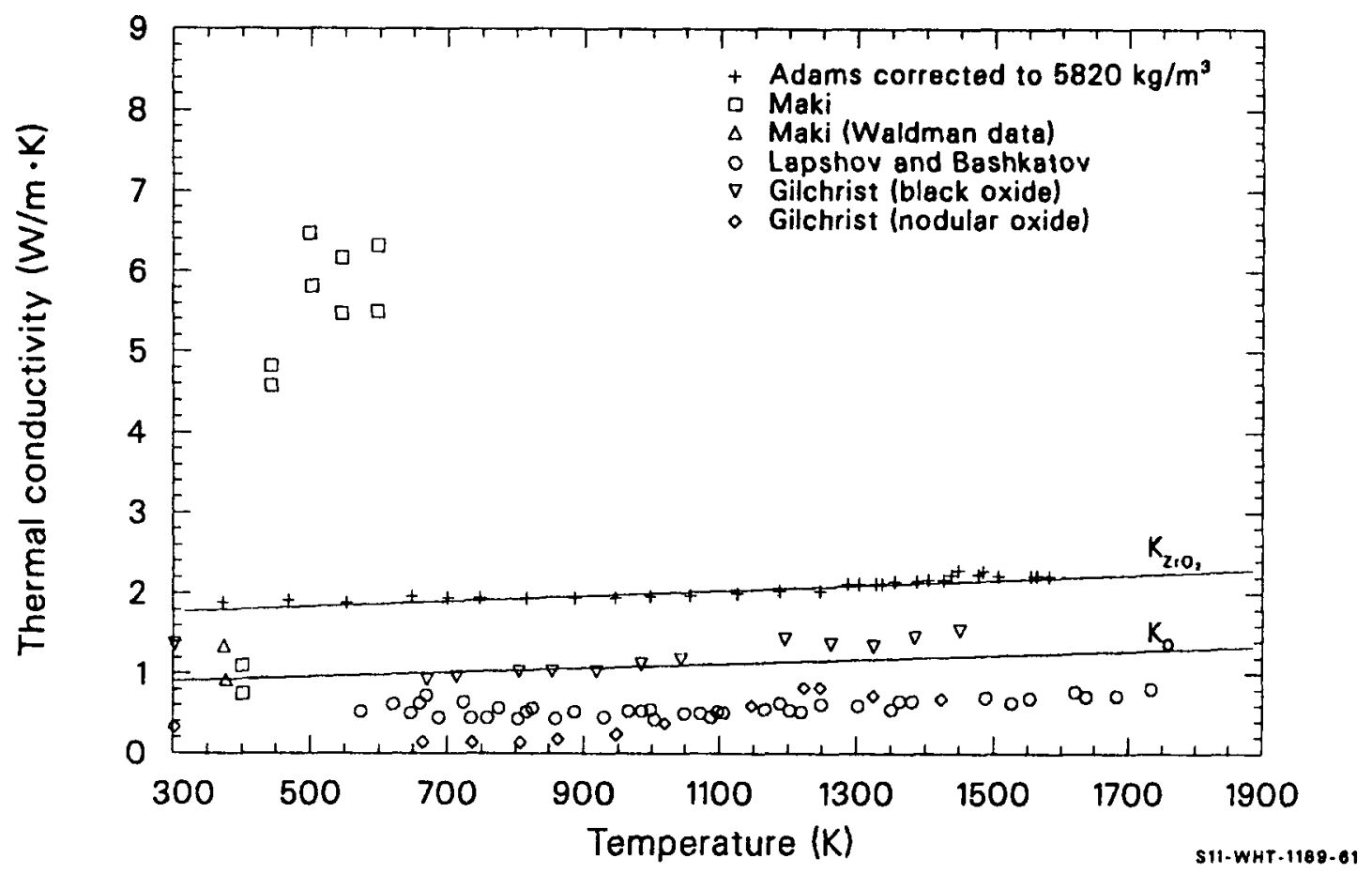

Figure 5.3-1. Zircaloy oxide thermal conductivity data and correlations. 
where $K_{0}$ is zircaloy cladding oxide thermal conductivity $(\mathrm{W} / \mathrm{m} \cdot \mathrm{K})$.

Values of $\mathrm{K}_{\mathrm{ZrO}_{2}}$ and $\mathrm{K}_{0}$ calculated with Equations (5.3-1) and (5.3-2) are shown with the data in Figure 5.3-1. Inspection of the figure suggests an expected standard error of \pm 0.75 of the measured value for $\mathrm{K}_{0}$. For material that is known to be $\mathrm{ZrO}_{2}$, the expected standard error is much less, approximately $10 \%$ of the value of $\mathrm{K}_{\mathrm{ZrO}_{2}}$.

For liquid zircaloy oxide (temperature $>2973 \mathrm{~K}$ ), the conductivity is assumed to be approximately the value of $K_{0}$ at the melting temperature of $\mathrm{ZrO}_{2}$ :

$\mathrm{K}_{0_{1 \text { iquid }}}=1.4 \mathrm{~W} / \mathrm{m} \cdot \mathrm{K}$.

This number is a compromise between the decrease in conductivity at melt due to the loss of the phonon contribution and the increase in conductivity at melt due to the loss of porosity.

Figure 5.3-2 is a plot of the thermal conductivity predicted by the function ZOTCON as a function of temperature.

\subsubsection{References}

5.3-1. M. Adams, Thermal Conductivity: III, Prolate Spheroidal Envelope Method," Journal of the American Ceramic Society, 37, 1954, pp. 74-79.

5.3-2. H. Maki, "Heat Transfer Characteristics of Zircaloy-2 Oxide Film," Journal of Nuclear Science and Technology, 10, 1973, pp. 107-175.

5.3-3. V. N. Lapshov and A. V. Bashkatov, "Thermal Conductivity of Coatings of Zirconium Dioxide Applied by the Plasma Sputtering Method," Heat Transfer, Soviet Research, 5, 1973, pp. 19-22.

5.3-4. K. E. Gilchrist, "Thermal Property Measurements on Zircaloy-2 and Associated Oxide Layers, Journal of Nuclear Materials, 62, 1976, pp. 257-264. 


\section{ZOTCON}

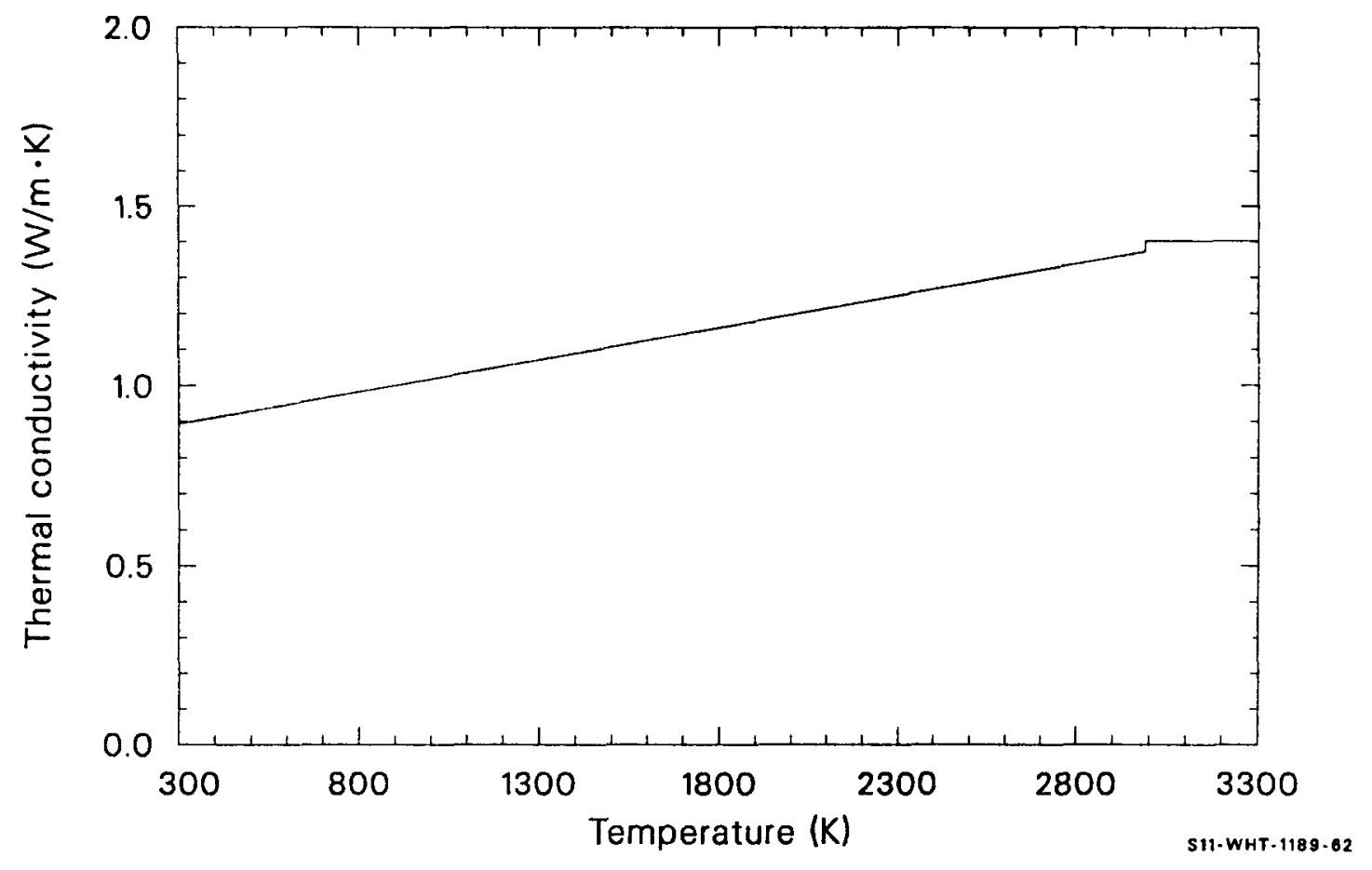

Figure 5.3-2. Zircaloy oxide thermal conductivity as a function of temperature. 
ZOEMIS

\subsection{Surface Emissivity (ZOEMIS)}

(D. L. Hagrman)

One of the important modes of heat transfer to and from cladding surfaces during an abnormal transient is radiant heat transfer. Since the energy radiated is directly proportional to the emissivity of the inner and outer cladding surfaces, surface emissivity is important in descriptions of abnormal transients.

\subsubsection{Summary}

Surface emissivities are significantly affected by surface layers on the cladding. For cladding with thin oxide coatings, the oxide surface thickness is only a few wavelengths of near infrared radiation and is partly transparent. Oxide thickness is an important parameter for these thin coatings. Thicker oxide layers are opaque, so the oxide thickness is not as important as the nature of the outer oxide surface, which is affected by temperature and by chemical environment. The effect of temperature has been modeled, but variations in crud on the external cladding surface and chemical reaction products on the inside surface are not modeled explicitly.

The model for emissivity was constructed by considering measured emissivities reported by several investigators. 5.4-1,5.4-2,5.4-3 Expressions used to predict the emissivity of zircaloy cladding surfaces are summarized below.

When the cladding surface temperature has not exceeded $1500 \mathrm{~K}$, emissivities are modeled by Equations (5.4-1) and (5.4-2). For oxide layer thicknesses less than $3.88 \times 10^{-6} \mathrm{~m}$, 


\section{ZOEMIS}

$\epsilon_{1}=0.325+0.1246 \times 10^{6} d$

For oxide layer thicknesses of $3.88 \times 10^{-6} \mathrm{~m}$ or greater,

$\epsilon_{1}=0.808642-50.0 \mathrm{~d}^{\mathrm{a}}$

where

$$
\begin{aligned}
& \epsilon_{1}=\text { hemispherical emissivity (unitless) } \\
& d=\text { oxide layer thickness }(\mathrm{m}) .
\end{aligned}
$$

When the maximum cladding temperature has exceeded $1500 \mathrm{~K}$, emissivity is taken to be the larger of 0.325 and

$$
\epsilon_{2}=\epsilon_{1} \exp [(1500-T) / 300]
$$

where

$$
\begin{aligned}
& \epsilon_{1}=\text { value for emissivity obtained from Equation (5.4-1) } \\
& T=\text { maximum cladding temperature }(K) .
\end{aligned}
$$

The standard error expected from the use of Equation (5.4-1) to predict emissivity in a reactor when cladding surface temperature has never exceeded $1500 \mathrm{~K}$ is

$$
\sigma_{1}= \pm 0.1
$$

a. The use of six significant figures in Equation (5.4-2) ensures an exact match of the values of $\epsilon_{1}$ at $d=3.88 \times 10^{-6} \mathrm{~m}$. 
When cladding temperature has exceeded $1500 \mathrm{~K}$, the expected standard error is estimated by $\sigma_{2}$ in the expression

$\sigma_{2}= \pm 0.1 \exp [(T-1500 / 300)]$

If Equations (5.4-3) and (5.4-5) predict values of $\epsilon_{2} \pm \sigma_{2}$ that fall inside the range of physicaliy possible values of emissivity $(0.0-1.0)$, the value $\sigma_{2}$ is returned as the expected standard error. If the prediction $\epsilon_{2}+\sigma_{2}$ is greater than 1 or if $\epsilon_{2}-\sigma_{2}$ is less than 0 , the standard error of Equation (5.4-5) is modified to Timit $\epsilon_{2}+\sigma_{2}$ at 1 and/or $\epsilon_{2}-\sigma_{2}$ at 0 .

The following subsection is a review of the available data on cladding emissivity. The approach used to formulate the model for emissivity is described in Section 5.4.3, and Section 5.4.4 is a discussion of the uncertainty of the model for cladding emissivity.

\subsubsection{Literature Review}

Measurements of zircaloy-2 emissivities as a function of temperature and dissolved oxygen content were reported by Lemmon. ${ }^{5.4-1}$ The measurements utilized the hole-in-tube method and were carried out in vacuum. Data from samples with an oxide film were reported, but the nonoxidizing environment of the sample during emissivity measurements caused the emissivity to change with time. Moreover, the thicknesses of the oxide films were not reported. The Lemmon data were not used in formulating the ZOEMIS subcode because the unknown oxide thickness probably influenced the emissivity and because of complications caused by the vacuum environment.

The emissivity of zircaloy-4 was reported by Juenke and Sjodaht $7^{5.4-2}$ from measurements on oxidized zircaloy in vacuum and from measurements in steam during the isothermal growth of oxide films. These authors reported a decrease in the emissivity measured in vacuum, which they attributed to the 


\section{ZOEMIS}

formation of a metallic phase in the oxide. This metallic phase did not form in the presence of steam. The data taken in steam were used in constructing ZOEMIS because the steam environment is similar to an abnormal reactor environment.

Figure 5.4-1 is a reproduction of the Juenke and Sjodahl steam data. The data suggest that emissivity decreases when oxide films become very thick (long times or high temperatures). In fact, Juenke and Sjodahl expect the total emissivity of very thick films to approach 0.3 or 0.4 , which is characteristic of pure $\mathrm{ZrO}_{2}$. However, the decrease in emissivity at temperatures greater than about $1200^{\circ} \mathrm{C}$ is greater than one would predict from oxide layer thickness alone. The correlation of this emissivity data with oxide layer thickness is discussed in Section 5.4.3.

Juenke and Sjodahl do not include very thin oxide films but do report that the total emittance rises almost instantaneously from about 0.2 to 0.7 with the introduction of steam. Data relevant to thin films are discussed below.

The emissivity of oxide films measured in air at temperatures in the range 100 to $400^{\circ} \mathrm{C}$ were reported by Murphy and Havelock $5.4-3$ and are reproduced in Table 5.4-1. The emissivities are not strongly dependent on temperature but do increase rapidly with oxide thickness for the thin oxide layers measured. The one value of emissivity measured with an oxide thickness of $94 \times 10^{-6} \mathrm{~m}$ is important because the oxide was approximately thirty times the thickness associated with the transition from black oxide layers to white oxide layers. The emissivity of this oxide, described as white by the authors, has a measured emissivity characteristic of surfaces which are black in the infrared region of the spectrum. Since (a) the Murphy and Havelock data were taken in an oxidizing environment and (b) the emissivity of the $94 \times 10^{-6}$-m oxide film agrees with the emissivity of films measured in steam, all of the Murphy and Havelock data were used in the formulation of ZOEMIS. 


\section{ZOEMIS}

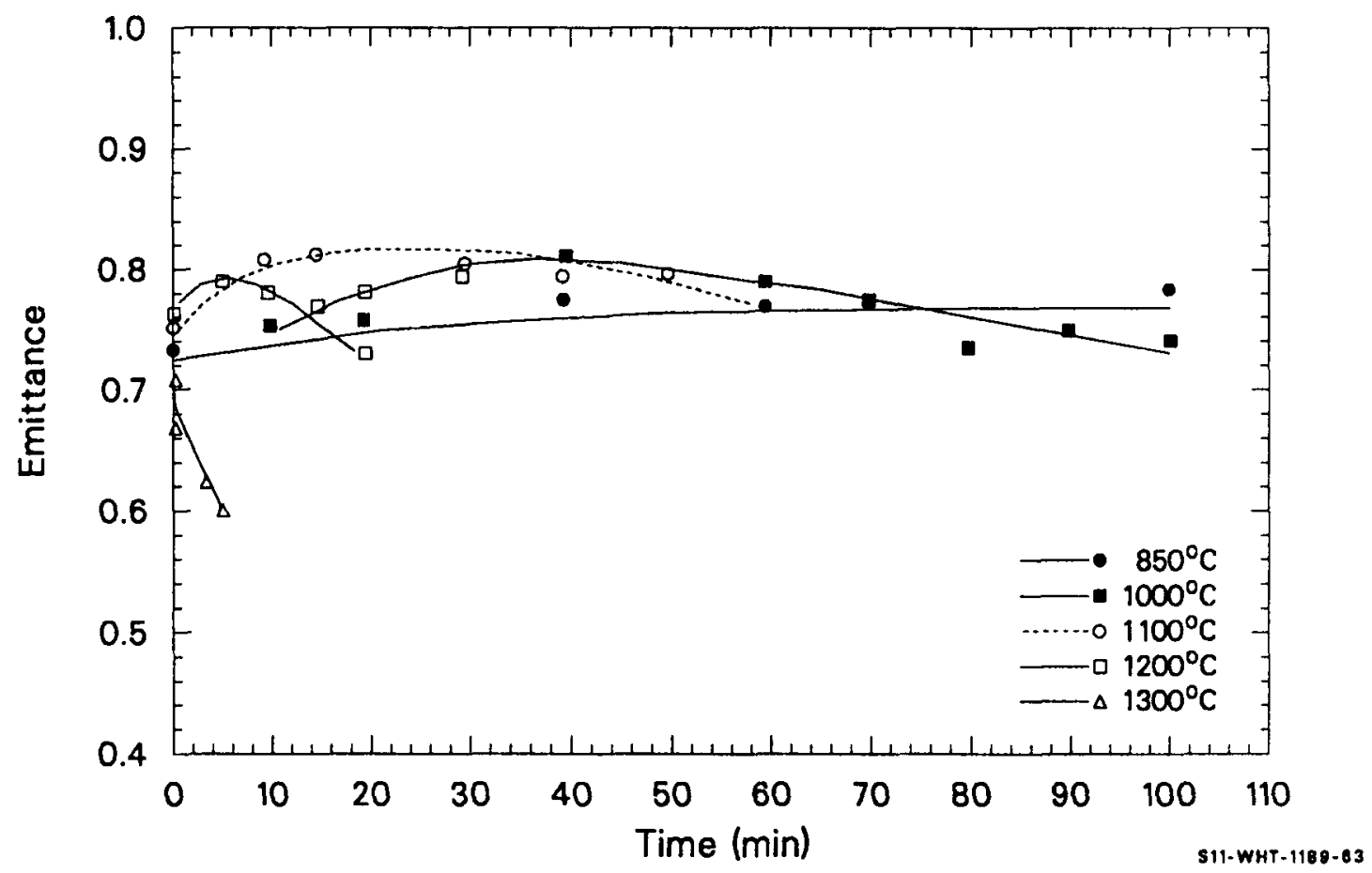

Figure 5.4-1. Total hemispherical emittance of zircaloy-4 versus time at temperature in steam. 


\section{ZOEMIS}

Table 5.4-1. Emissivity of thin oxide films as reported by Murphy and Havelock

\begin{tabular}{|c|c|c|c|c|c|c|}
\hline \multirow[b]{2}{*}{ Surface Condition } & \multirow{2}{*}{$\begin{array}{c}\text { Oxide- } \\
\text { Thickness } \\
(\mu \mathrm{m}) \\
\end{array}$} & \multicolumn{5}{|c|}{ Emissivity } \\
\hline & & $100^{\circ} \mathrm{C}$ & $\underline{150^{\circ} \mathrm{C}}$ & $200^{\circ} \mathrm{C}$ & $300^{\circ} \mathrm{C}$ & $400^{\circ} \mathrm{C}$ \\
\hline $\begin{array}{l}\text { Pickled }+2 \text { days } \\
\text { in air at } 400^{\circ} \mathrm{C}\end{array}$ & 0.9 & 0.424 & 0.414 & 0.416 & 0.434 & 0.433 \\
\hline $\begin{array}{l}\text { Pickled }+10 \text { days } \\
\text { in air at } 400^{\circ} \mathrm{C}\end{array}$ & 1.48 & 0.521 & 0.542 & 0.557 & 0.588 & - \\
\hline $\begin{array}{l}\text { Pickled }+55 \text { days } \\
\text { in } 400^{\circ} \mathrm{C} \text { steam } \\
\text { under a pressure } \\
\text { of } 10.4 \mathrm{MPa}\end{array}$ & 2.3 & -- & 0.582 & 0.599 & 0.620 & -- \\
\hline $\begin{array}{l}\text { Pickled }+30 \text { days } \\
\text { in air at } 400^{\circ} \mathrm{C} \\
+73 \text { days in air } \\
\text { at } 500^{\circ} \mathrm{C}\end{array}$ & 94 & -- & 0.748 & -- & -- & - \\
\hline
\end{tabular}


Additional data were reported by T. B. Burgoyne and A. Garlick at the OECD-CSNI meeting on the Behavior of Water Reactor Fuel Elements under Accident Conditions in Spinad, Norway, on September 13-16, 1976. Using a hot-filament calorimeter, these authors measured the emissivity of zircaloy-2 cladding surfaces coated with uniform oxide, nodular oxide, and crud. The emissivities were measured in vacuum. However, the following arguments are presented in favor of including some of these data in the data base of ZOEMIS: (a) a significant decrease in emissivity was not noticed with initial oxide thicknesses greater than $10^{-5} \mathrm{~m}$ until the samples were heated above approximately $800^{\circ} \mathrm{C}$ (the alpha-beta phase transition of zircaloy); and (b) the low-temperature values of emissivity data taken with nodular and crud-coated surfaces are representative of in-reactor surfaces not represented in other data. Data from Burgoyne and Garlick that did not show the sudden decrease in emissivity characteristic of the change caused by a vacuum environment were used in ZOEMIS. Table 5.4-2 is a summary of the measurements used.

\subsubsection{Mode1 Development}

Near infrared radiation has a wavelength of $1 \times 10^{-6} \mathrm{~m}$. Oxide films up to a few wavelengths thick should be partly transparent to infrared radiation and should therefore have emissivities strongly dependent on oxide thickness. The emissivity-versus-oxide-thickness data of Murphy and Havelock ${ }^{5-3}$ were fit with standard least-squares residual analysis to deduce Equation (5.4-1).

The equation for the emissivity of oxide films thicker than $4 \times 10^{-6} \mathrm{~m}$ is based on the data of Burgoyne and Garlick, Juenke and Sjodahl, 5.4-2 and one measurement from Murphy and Havelock, ${ }^{5.4-3}$ as discussed in Section 5.4.2. Oxide thicknesses were calculated from the time and temperatures reported by Juenke and Sjodahl using the correlation published by Cathcart. $5.4-4$ 


\section{ZOEMIS}

Table 5.4-2. Emissivity data From Burgoyne and Garlick

\begin{tabular}{|c|c|c|c|}
\hline Cladding Surface & $\begin{array}{l}\text { Surface Layer } \\
\text { Thickness }(\mu \mathrm{m})\end{array}$ & $\begin{array}{c}\text { Measurement } \\
\text { Temperature } \\
\text { (K) }\end{array}$ & $\begin{array}{l}\text { Emissivity } \\
\text { (unitless) }\end{array}$ \\
\hline Uniform oxide & $\begin{array}{l}10 \\
10 \\
10 \\
10 \\
10 \\
10 \\
10\end{array}$ & $\begin{array}{r}735 \\
805 \\
876 \\
885 \\
978 \\
986 \\
1072\end{array}$ & $\begin{array}{l}0.748 \\
0.770 \\
0.773 \\
0.773 \\
0.774 \\
0.767 \\
0.791\end{array}$ \\
\hline Uniform oxide & $\begin{array}{l}28 \\
28 \\
28 \\
28\end{array}$ & $\begin{array}{r}784 \\
884 \\
987 \\
1080\end{array}$ & $\begin{array}{l}0.834 \\
0.818 \\
0.832 \\
0.829\end{array}$ \\
\hline Nodular oxide & $\begin{array}{l}130 \\
130 \\
130 \\
130 \\
130 \\
130 \\
130 \\
130 \\
130\end{array}$ & $\begin{array}{r}654 \\
769 \\
775 \\
868 \\
885 \\
965 \\
975 \\
1066 \\
1149\end{array}$ & $\begin{array}{l}0.860 \\
0.845 \\
0.857 \\
0.849 \\
0.850 \\
0.849 \\
0.837 \\
0.866 \\
0.841\end{array}$ \\
\hline Crud & $\begin{array}{l}35 \\
35 \\
35 \\
35 \\
35 \\
35 \\
35 \\
35\end{array}$ & $\begin{array}{l}677 \\
683 \\
769 \\
777 \\
870 \\
876 \\
966 \\
977\end{array}$ & $\begin{array}{l}0.918 \\
0.930 \\
0.890 \\
0.888 \\
0.899 \\
0.888 \\
0.913 \\
0.903\end{array}$ \\
\hline
\end{tabular}


$X=\left[2.25 \times 10^{-6} \exp (-18,063 / T) t\right]^{1 / 2}$

where

$X=$ the oxide layer thickness $(m)$

$\mathrm{T}=$ temperature $(\mathrm{K})$

$t=$ time at temperature $(s)$.

Table 5.4-3 lists the emissivity, time, and temperature reported by Juenke and Sjodahl, together with the oxide thickness predicted using Equation (5.4-6). Values of emissivity and oxide layer thickness from Tables 5.4-1, 5.4-2, and 5.4-3 were used to establish Equation (5.4-2).

Figure 5.4-2 is a comparison of the curves generated by Equations (5.4-1) and (5.4-2) with the data base used to derive these equations. Predicted values of emissivity increase rapidly until the surface oxide layer thickness is $3.88 \times 10^{-6} \mathrm{~m}$, then decrease very slowly with increasing surface layer thickness.

The values of emissivity measured by Juenke and Sjodahl at $1575 \mathrm{~K}(0.62$ and 0.60 ) are significantly below the measured emissivities at lower temperatures. Since thicker oxide films were formed at lower temperatures, the low emissivity is not due to the thickness of the oxide film. Moreover, the low values of emissivities measured by Juenke and Sjodahl at high temperature are supported by posttest observations of cladding surfaces that have been at high temperatures. ${ }^{5.4-5}$ Cladding surfaces that experienced film boiling, and therefore high temperatures, showed spalled oxide and somewhat whiter oxide surfaces in the region of the film boiling. The observations reported (Reference 5.4-5) and the trend toward lower values of emissivity at higher temperatures reported by Juenke and Sjodahl at 1475 and $1575 \mathrm{~K}$ imply that lower cladding surface emissivities are likely at 


\section{ZOEMIS}

Table 5.4-3. Emissivity versus oxide thickness from Juenke and Sjodahl's data

\begin{tabular}{|c|c|c|c|}
\hline $\begin{array}{c}\text { Temperature } \\
\text { (K) }\end{array}$ & $\begin{array}{l}\text { Time } \\
(\mathrm{s})\end{array}$ & $\begin{array}{c}\text { Calculated } \\
\text { Oxide } \\
\text { Thickness } \\
(\mu \mathrm{m}) \\
\end{array}$ & $\begin{array}{l}\text { Measured } \\
\text { Emissivity } \\
\text { (unitless) }\end{array}$ \\
\hline $\begin{array}{l}1125 \\
1125 \\
1125 \\
1275 \\
1275 \\
1275 \\
1275 \\
1275 \\
1275 \\
1275 \\
1275 \\
1375 \\
1375 \\
1375 \\
1375 \\
1375 \\
1475 \\
1475 \\
1475 \\
1475 \\
1575 \\
1575\end{array}$ & $\begin{array}{r}1200 \\
2400 \\
6000 \\
600 \\
1200 \\
1800 \\
3600 \\
4200 \\
4800 \\
5400 \\
6000 \\
600 \\
900 \\
1200 \\
3000 \\
3600 \\
300 \\
600 \\
900 \\
1200 \\
210 \\
300\end{array}$ & $\begin{array}{r}17 \\
24 \\
38 \\
31 \\
43 \\
53 \\
75 \\
81 \\
86 \\
92 \\
96 \\
51 \\
63 \\
72 \\
114 \\
125 \\
57 \\
80 \\
98 \\
113 \\
70 \\
83\end{array}$ & $\begin{array}{l}0.755 \\
0.755 \\
0.785 \\
0.750 \\
0.773 \\
0.795 \\
0.790 \\
0.775 \\
0.738 \\
0.755 \\
0.740 \\
0.808 \\
0.815 \\
0.780 \\
0.798 \\
0.775 \\
0.795 \\
0.780 \\
0.775 \\
0.722 \\
0.620 \\
0.600\end{array}$ \\
\hline
\end{tabular}




\section{ZOEMIS}

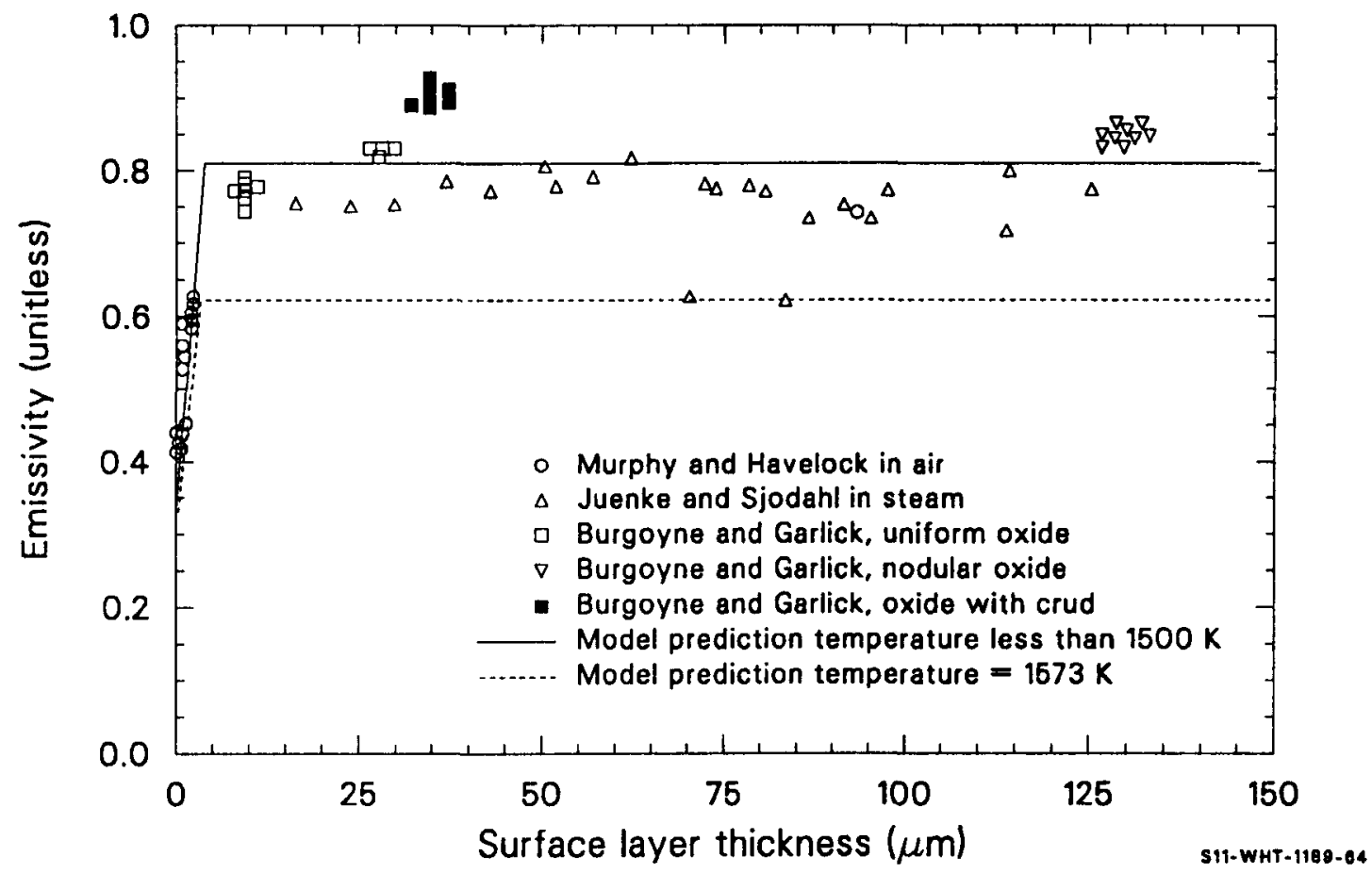

Figure 5.4-2. ZOEMIS calculations compared with the data base of the model. 


\section{ZOEMIS}

temperatures above approximately $1500 \mathrm{~K}$. This trend in the limited data has been included in ZOEMIS by (a) adding a multiplicative factor to the expression for emissivity,

$\exp [(1500-T) / 300]$

where $T$ is the greater of $1500 \mathrm{~K}$ and the maximum cladding temperature, and (b) limiting the minimum emissivity to 0.325 , the value predicted by the model for zero oxide thickness.

\subsubsection{Uncertainty}

The standard errors obtained with Equations (5.4-1) and (5.4-2) and the data base used to develop these equations are listed in Table 5.4-4.

Standard errors shown in Table 5.4-4 for oxide layers without the complicating features of nodular oxides or surface crud are consistent with measurement errors of $\pm 3 \%$ estimated by Lemmon. ${ }^{5.4-1}$ However, the model is intended to predict the emissivity of cladding surfaces with crud or $\mathrm{UO}_{2}$ fission products as well as the oxide layer. The data from Burgoyne and Garlick (illustrated in Figure 5.4-2) suggest that crud layers introduce a systematic error of approximately \pm 0.1 . The value of \pm 0.1 is therefore included in ZOEMIS as the best estimate for the standard error of the mode 1 prediction for emissivity during abnormal reactor operation at temperatures below $1500 \mathrm{~K}$.

The uncertainty of the prediction for emissivities above $1500 \mathrm{~K}$ is difficult to estimate. Equation (5.4-5) was selected as a reasonable expression for the expected standard error of Equation (5.4-3), simply because the expression $\pm 0.1 \exp \{-(1500$ - maximum cladding temperature $) / 300]$ predicts a standard error approximately equal to the change in emissivity caused by the empirical multiplicative factor of Equation (5.4-7). 
Table 5.4-4. Standard errors of ZOEMIS predictions

\begin{tabular}{|c|c|}
\hline Surface Description & $\begin{array}{c}\text { Emissivity } \\
\text { Standard Error }\end{array}$ \\
\hline Oxide films $<3.88 \times 10^{-6} \mathrm{~m}$ & \pm 0.04 \\
\hline Pure oxide films $>3.88 \times 10^{-6} \mathrm{~m}$ & \pm 0.05 \\
\hline $\begin{array}{l}\text { Oxide films including samples with } \\
\text { nodular oxides and crud }\end{array}$ & \pm 0.07 \\
\hline
\end{tabular}




\section{ZOEMIS}

In Figure 5.4-3, the data base and model predictions shown in Figure 5.4-2 are repeated. The standard error expected with ZOEMIS for temperatures below $1500 \mathrm{~K}$ is shown by the cross-hatched area centered on the solid line. The cross-hatched area centered on the dashed line shows the standard error estimated for temperatures of $1573 \mathrm{~K}$.

\subsubsection{References}

5.4-1. A. W. Lemmon, Jr., Studies Relating to the Reaction Between Zirconium and Water at High Temperatures, BMI-1154, January 1957.

5.4-2. E. F. Juenke and L. H. Sjodah1, "Physical and Mechanical Properties: Emittance Measurements," AEC Fuels and Materials Development Program, GEMP-1008, 1968, pp. 239-242.

5.4-3. E. V. Murphy and F. Havelock, "Emissivity of Zirconium Alloys in Air in the Temperature Range $100-400^{\circ} \mathrm{C}$, " Journal of Nuclear Materials, 60, 1976, pp. 167-176.

5.4-4 J. V. Cathcart, Quarterly Progress Report on the Zirconium Metal-Water Oxidation Kinetics Program Sponsored by the NRC Division of Reactor Safety Research for Apri7-June 1976, ORNL/NUREG-TM-41, August 1976.

5.4-5 Quarterly Technical Progress Report on Water Reactor Safety Programs Sponsored by the Nuclear Regulatory Commission's Division of Reactor Safety Research. October-December 1975, ANCR-NUREG-1301, May 1976, p. 67. 


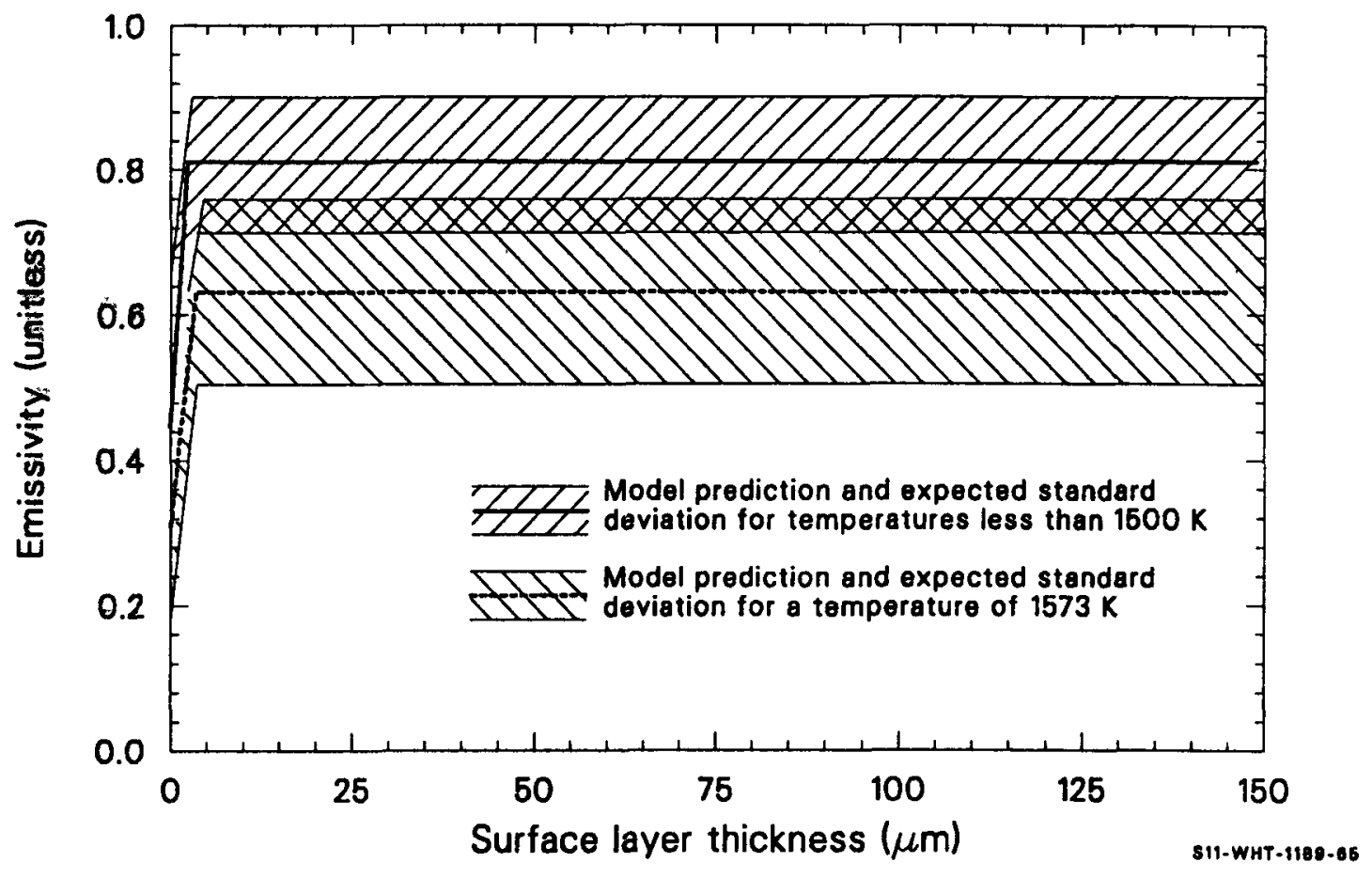

Figure 5.4-3. Expected standard errors of emissivity for temperatures below $1500 \mathrm{~K}$ and at $1573 \mathrm{~K}$. 
ZOTEXP， ZODEN

\title{
5.5 Thermal Expansion and Density (ZOTEXP, ZODEN)
}

\author{
(D. L. Hagrman)
}

The subroutine Z0TEXP calculates the zircaloy oxide thermal strain, using a reference temperature for which the thermal strain will be zero and the zircaloy oxide temperature. The subroutine ZODEN calculates the zircaloy oxide density from the zircaloy oxide temperature.

\subsubsection{Thermal Expansion (ZOTEXP)}

Expressions used in 20TEXP to calculate the thermal strains of solid zirconium oxide are taken from Hammer: ${ }^{5.5-1}$

For $300<\mathrm{T}<1478 \mathrm{~K}$ (monoclinic $\mathrm{ZrO}_{2}$ ),

$\epsilon_{0}=7.8 \times 10^{-6} \mathrm{~T}-2.34 \times 10^{-3}$

and for $1478 \leq \mathrm{T}<2973 \mathrm{~K}$ (tetragonal and cubic $\mathrm{ZrO}_{2}$ ),

$\epsilon_{0}=1.302 \times 10^{-5} \mathrm{~T}-3.338 \times 10^{-2}$

where $\epsilon_{0}$ is the linear thermal strain of zircaloy oxide $(\mathrm{m} / \mathrm{m})$. These expressions show a $7.7 \%$ decrease in volume at the monoclinic-tetragonal phase change (1478 K).

For liquid zirconium oxide, a $5 \%$ reduction in volume is assumed when the oxide melts. This assumption corresponds to the assumption that the $5 \%$ porosity of the oxide is removed when it melts. The resultant expression is 


\section{ZOTEXP，ZODEN}

$\epsilon_{0}=-1.1 \times 10^{-2}$

for $T \geq 2973 \mathrm{~K}$.

\subsubsection{Density (ZODEN)}

Thermal expansion equations (5.5-1) to (5.5-3) are used in ZODEN to calculate the density of zircaloy oxide. The relation employed is

$\rho_{\mathrm{X}}=\rho_{\mathrm{X0}}\left(1-3 \epsilon_{0}\right)$

where

$$
\begin{aligned}
& \rho_{x}=\text { zirconium oxide density at the given temperature }\left(\mathrm{kg} / \mathrm{m}^{3}\right) \\
& \rho_{x 0}=\text { zirconium oxide density at } 300 \mathrm{~K}\left(\mathrm{~kg} / \mathrm{m}^{3}\right) .
\end{aligned}
$$

The value of $\rho_{x o}$ used is the density of black oxide reported by Gilchrist, $5.5-25800 \mathrm{~kg} / \mathrm{m}^{3}$.

The expected standard error of Equations (5.5-1) and (5.5-2) is large, the greater of half the predicted value or $\pm 5 \times 10^{-3}$, because the equations are based on zircaloy dioxide data. The cladding oxide is not only substoichiometric but is formed under large stress because of the different densities of the oxide and the zircaloy on which it is formed.

The zircaloy dioxide thermal strains predicted by ZOTEXP are shown in Figure 5.5-1, and the density of the oxide predicted by ZODEN is illustrated in Figure 5.5-2. $\mathrm{ZrO}_{2}$ thermal expansion data by Fulkerson $5 \cdot 5-3$ and from pages 17 and 70 of Brassfield et al .5.5-4 are listed in Tables 5.5-1 and 5.5-2 and included in Figure 5.5-3 so that they may be compared with code predictions. 
ZOTEXP， ZODEN

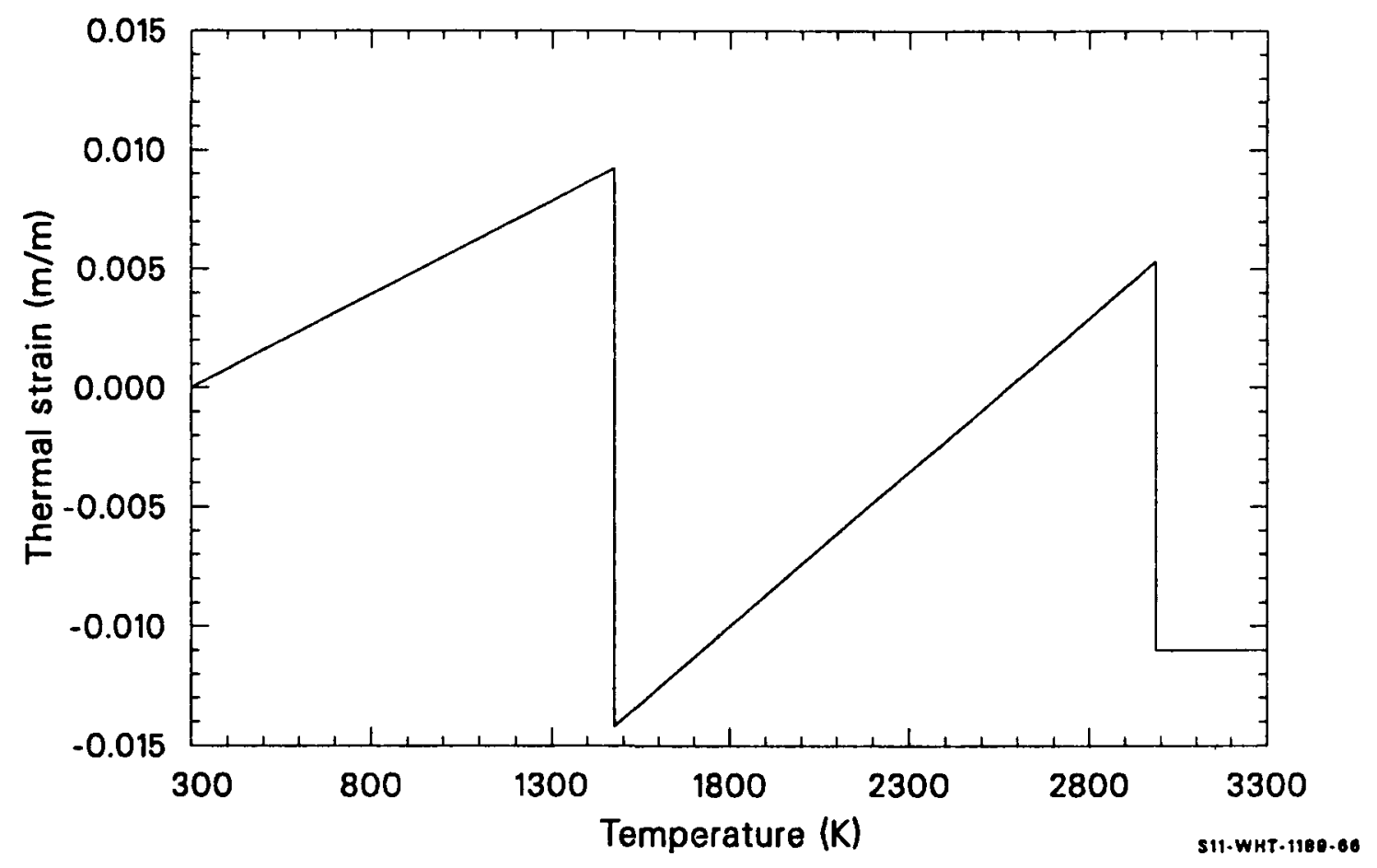

Figure 5.5-1. Zircaloy oxide thermal strain. 


\section{ZOTEXP， ZODEN}

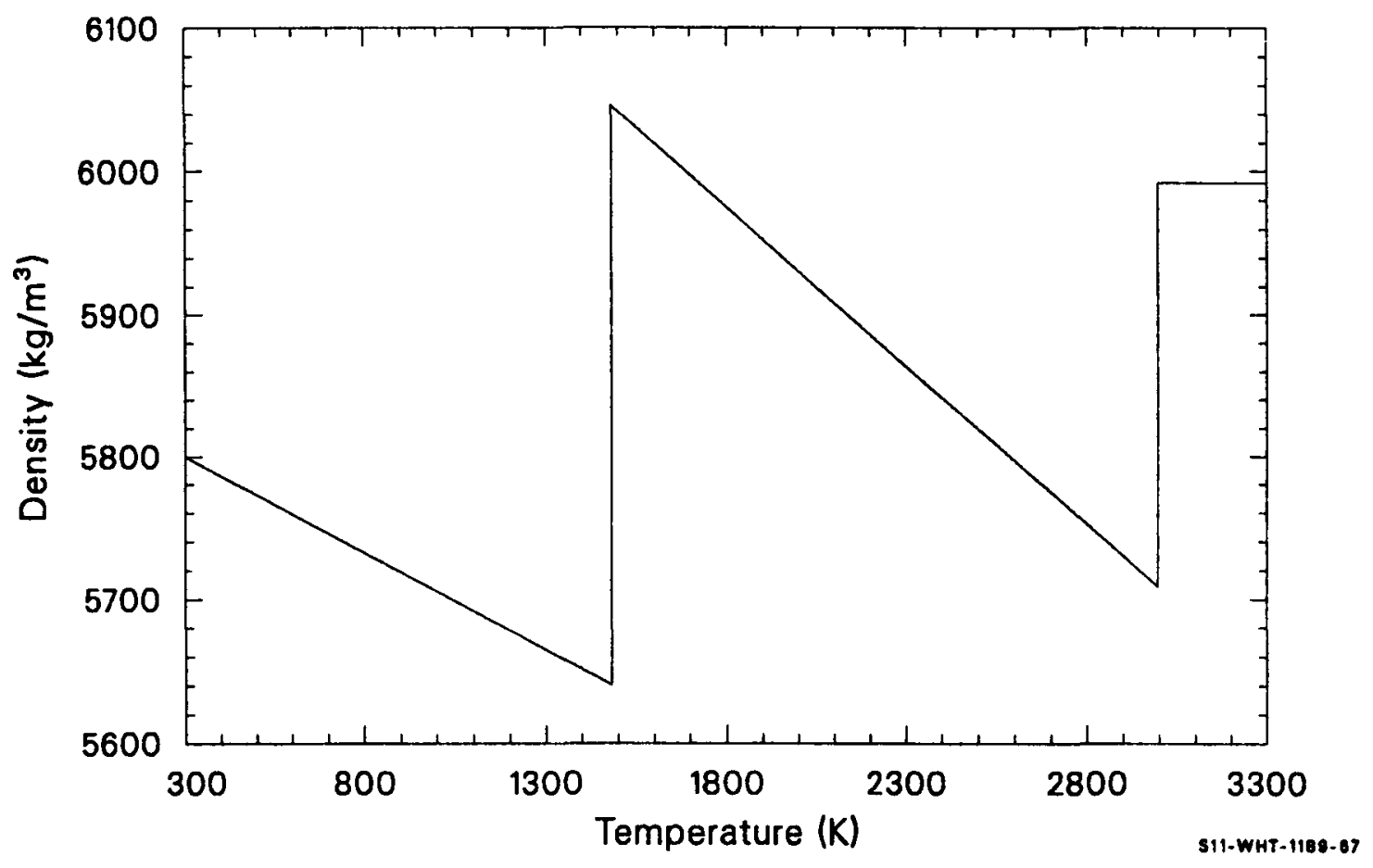

Figure 5.5-2. Zircaloy oxide density as a function of temperature. 
Table 5.5-1. Zircaloy dioxide thermal expansion data by Fulkerson ${ }^{5.5-3}$

\begin{tabular}{|c|c|}
\hline $\begin{array}{c}\text { Temperature } \\
(\mathrm{K})\end{array}$ & $\begin{array}{l}\text { Thermal Strain } \\
\left(10^{-3} \mathrm{~m} / \mathrm{m}\right)\end{array}$ \\
\hline $\begin{array}{l}289 \\
473 \\
571 \\
673 \\
773\end{array}$ & $\begin{array}{l}0 \\
1.34 \\
2.05 \\
2.82 \\
3.64\end{array}$ \\
\hline $\begin{array}{r}818 \\
922 \\
1019 \\
1119 \\
1222\end{array}$ & $\begin{array}{l}4.02 \\
4.78 \\
5.61 \\
6.63 \\
7.51\end{array}$ \\
\hline $\begin{array}{l}1308 \\
1330 \\
1349 \\
1369 \\
1390 \\
1430\end{array}$ & $\begin{array}{l}8.06 \\
8.25 \\
8.33 \\
8.38 \\
8.34 \\
7.63\end{array}$ \\
\hline $\begin{array}{l}1450 \\
1466 \\
1487 \\
1508 \\
1529 \\
1550 \\
1571\end{array}$ & $\begin{array}{r}6.10 \\
3.27 \\
1.16 \\
0.17 \\
-0.38 \\
-0.82 \\
-1.05\end{array}$ \\
\hline
\end{tabular}




\section{ZOTEXP， ZODEN}

Table 5.5-2. Zircaloy dioxide thermal expansion data from Brassfield et al. 5.5-4

\begin{tabular}{cc}
\hline $\begin{array}{c}\text { Temperature } \\
(\mathrm{K})\end{array}$ & $\begin{array}{c}\text { Thermal Strain } \\
\left(10^{-3} \mathrm{~m} / \mathrm{m}\right)\end{array}$ \\
300 & 0 \\
537 & 2.1 \\
778 & 3.7 \\
1031 & 5.05 \\
1238 & 7.35 \\
1383 & 9.10 \\
1488 & -1.8 \\
\hline
\end{tabular}


ZOTEXP， ZODEN

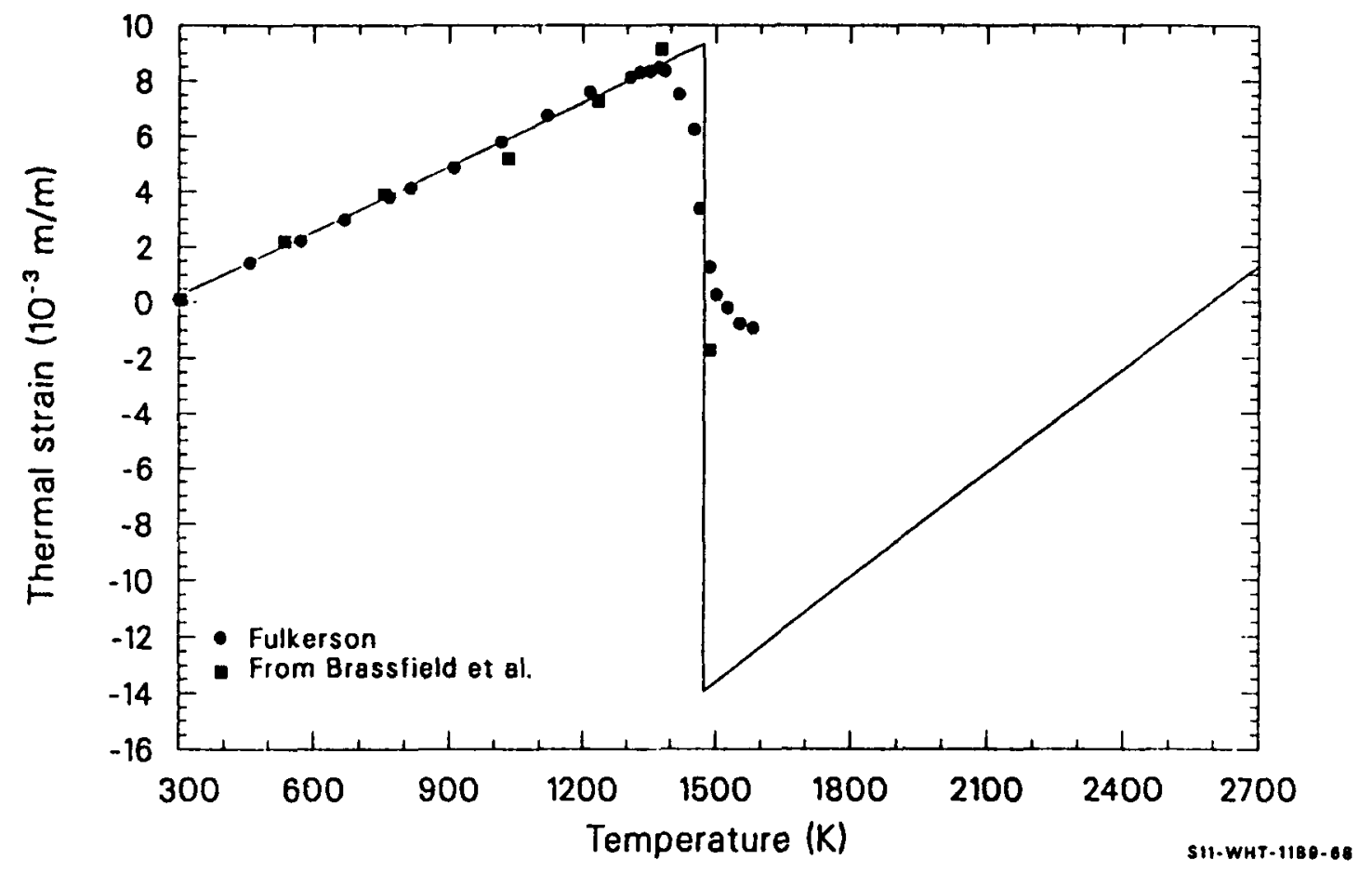

Figure 5.5-3. Zircaloy oxide thermal strain data compared to code prediction 


\section{ZOTEXP，ZODEN}

\subsubsection{References}

5.5-1. R. R. Hammer, Zircaloy-4, Uranium Dioxide and Materials formed by their Interaction. A Literature Review with Extrapolation of Physical Properties to High Temperatures, IN-1093, September 1967.

5.5-2. K. E. Gilchrist, "Thermal Property Measurements on Zircaloy-2 and Associated 0xide Layers, " Journal of Nuclear Materials, 62, 1976, pp. 257-264.

5.5-3. S. D. Fulkerson, Apparatus for Determining Linear Thermal Expansions of Materials in Vacuum or Controlled Atmosphere, ORNL-2856, 1960, p. 20.

5.5-4. H. C. Brassfield, J. F. White, L. Sjodahl, and J. T. Bittel, Recommended Property and Reaction Kinetics Data for Use in Evaluating a Light-Water-Cooled Reactor Loss-of-Coolant Incident Involving Zircaloy-4 or 304-SS Clad $\mathrm{UO}_{2}$, GEMP 482, 1968. 


\subsection{Elastic MOdUli (ZOEMOD, ZOPOIR)}

(D. L. Hagrman)

The function ZOEMOD calculates Young's modulus for zircaloy oxide from the zircaloy oxide temperature and oxygen-to-metal ratio. The function ZOPOIR calculates the Poisson's ratio for liquid and solid zircaloy oxide.

\subsubsection{Young's Modulus (ZOEMOD)}

Young's modulus for zircaloy oxide is returned by the ZOEMOD function. oxide temperature and oxide oxygen-to-metal ratio are the only required inputs. The function uses the following correlation to calculate the modulus for $300<T<1478 \mathrm{~K}$ (monoclinic phase):

$$
Y_{0}=-3.77 \times 10^{7} T+1.637 \times 10^{11} .
$$

For $1478 \leq T<T_{\text {SOL }}$ (tetragonal and cubic phase),

$$
Y_{0}=-8.024 \times 10^{7} \mathrm{~T}+2.255 \times 10^{11}
$$

$$
\text { For } \mathrm{T} \geq \mathrm{T}_{\mathrm{SOL}} \text {, }
$$

$$
Y_{0}=1
$$

where

$$
\begin{aligned}
Y_{0} & =\text { zircaloy oxide Young's modulus }(\mathrm{Pa}) \\
T & =\text { oxide temperature }(\mathrm{K})
\end{aligned}
$$




\section{ZOEMOD，ZOPOIR}

$\mathrm{T}_{\text {SOL }}=$ zircaloy oxide solidus temperature $(\mathrm{K})$ (obtained from the ZOPRP subroutine).

The equations are least-squares fits to data from Brassfield et a) . 5.6-1 Table 5.6-1 reproduces the data, and Figure 5.6-1 shows the data and values of $Y_{0}$ calculated with the ZOEMOD function. The function sets $Y_{0}=1 \mathrm{~Pa}$ for temperatures above $2810 \mathrm{~K}$ where Equation (5.6-2) would predict a negative modulus. Since so few data are available, a large expected standard error of \pm 0.2 times the predicted value is recommended.

\subsubsection{Poisson's Ratio (ZOPOIR)}

ZOPOIR returns constant values of 0.3 and 0.5 for the Poisson's ratios of solid and liquid zircaloy oxide, respectively. No data for these ratios have been found. The number 0.3 is merely typical of many solid materials, and 0.5 is the constant-volume, isotropic material value of Poisson's ratio. The expected standard error is therefore large, \pm 0.2

\subsubsection{References}

5.6-1. H. C. Brassfield, J. F. White, L. Sjodah1, and J. T. Bittel, Recommended Property and Reaction Kinetics Data for Use in Evaluating a Light-Water-Cooled Reactor Loss-of-Coolant Incident Involving Zircaloy-4 or 304-SS Clad UO 2 , GEMP 482, 1968, p. 89. 


\section{ZOEMOD，ZOPOIR}

Table 5.6-1. Zircaloy dioxide modulus of elasticity data from Brassfield et a1. ${ }^{5}$

Temperature

(K)

1323

1453

1498

1563

1633

\section{Elastic Modulus}

$\left(10^{10} \mathrm{~Pa}\right)$

11.38

10.89

10.48

10.10

9.41
Comment

Monoclinic phase

Monoclinic phase

Tetragonal phase

Tetragonal phase

Tetragonal phase 
ZOEMOD，ZOPOIR

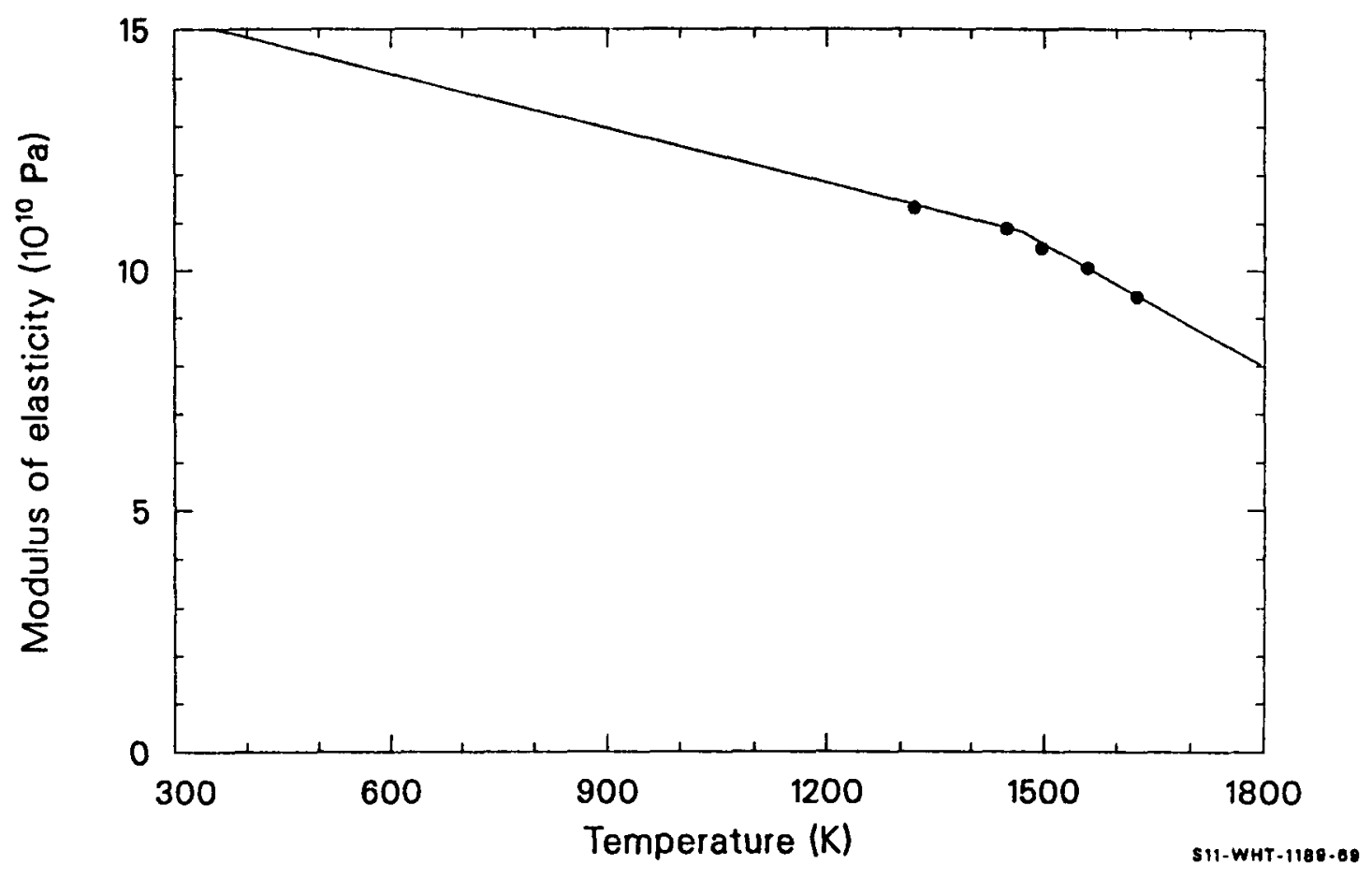

Figure 5.6-1. Data and calculated values of Young's modulus for zircaloy oxide. 
ZORUP

\subsection{Mechanical Limits and Embrittlement (ZORUP)}

(D. L. Hagrman)

The function ZORUP returns zircaloy oxide failure stress as a function of temperature. The correlations used in the function ZORUP to calculate the oxide failure stress are listed below.

\subsubsection{Model Development}

For $300 \leq T \leq 1200 \mathrm{~K}$ (monoclinic phase of $\mathrm{ZrO}_{2}$ ),

$S_{B}=96.28 \times 10^{6}$.

For $1200<\mathrm{T}<1478 \mathrm{~K}$ (monoclinic phase of $\mathrm{ZrO}_{2}$ ),

$S_{B}=-5.06 \times 10^{4} \mathrm{~T}+1.57 \times 10^{8}$.

For $1478 \leq \mathrm{T}<1869.4 \mathrm{~K}$ (tetragonal and cubic phases of $\mathrm{ZrO}_{2}$ ),

$S_{B}=-2.075 \times 10^{5} \mathrm{~T}+3.889 \times 10^{8}$.

For $1869.4 \leq T \leq T_{S O L}$,

$S_{B}=10^{6}$

For $\mathrm{T}>\mathrm{T}_{\mathrm{SOL}}$,

$S_{B}=0$. 


\section{ZORUP}

where

$$
\begin{aligned}
& S_{B}=\begin{array}{l}
\text { circumferential or axial stress on the oxide at failure } \\
(\mathrm{Pa})
\end{array} \\
& \mathrm{T}=\text { oxide temperature }(\mathrm{K}) \\
& \mathrm{T}_{\mathrm{SOL}}=\begin{array}{l}
\text { zircaloy oxide solidus temperature }(\mathrm{K}) \text { (Obtained from the } \\
\text { ZOPRP subroutine). }
\end{array}
\end{aligned}
$$

These correlations are fits to the three $\mathrm{ZrO}_{2}$ tensile strength data sets reported by Brassfield et al 5.7-1 The data are shown in Table 5.7-1 and are compared with the correlation values in Figure 5.7-1.

The values and shape of the curve are similar to the values and shape of the more extensive data for $\mathrm{UO}_{2}$ failure. In the temperature range of the data, the oxide failure stress is about three times the failure stress of zircaloy. In spite of these similarities, the very limited data used to construct the expressions for oxide failure stress suggest a large expected standard error for the correlation, \pm 0.7 times the predicted value.

Figure 5.7-2 is a plot of the failure stresses returned by the function.

\subsubsection{References}

5.7.1 H. C. Brassfield, J. F. White, L. Sjodahl, and J. L. Bittel, Recommended Property and Reaction Kinetics Data for Use in Evaluating a Light-Water-Cooled Reactor Loss-of-Coolant Incident Involving Zircaloy-4 or 304-SS Clad U0 2 , GEMP 482, 1968, p. 89. 
Table 5.7-1. Zircaloy dioxide tegsjile strength data from Brassfield et al. 5.7-1

\begin{tabular}{cc}
\hline $\begin{array}{c}\text { Temperature } \\
(\mathrm{K})\end{array}$ & $\begin{array}{c}\text { Tomsile strength } \\
\left.1300^{6} \mathrm{~Pa}\right)\end{array}$ \\
1473 & 91.2 \\
1813 & 82.6 \\
\hline
\end{tabular}




\section{ZORUP}

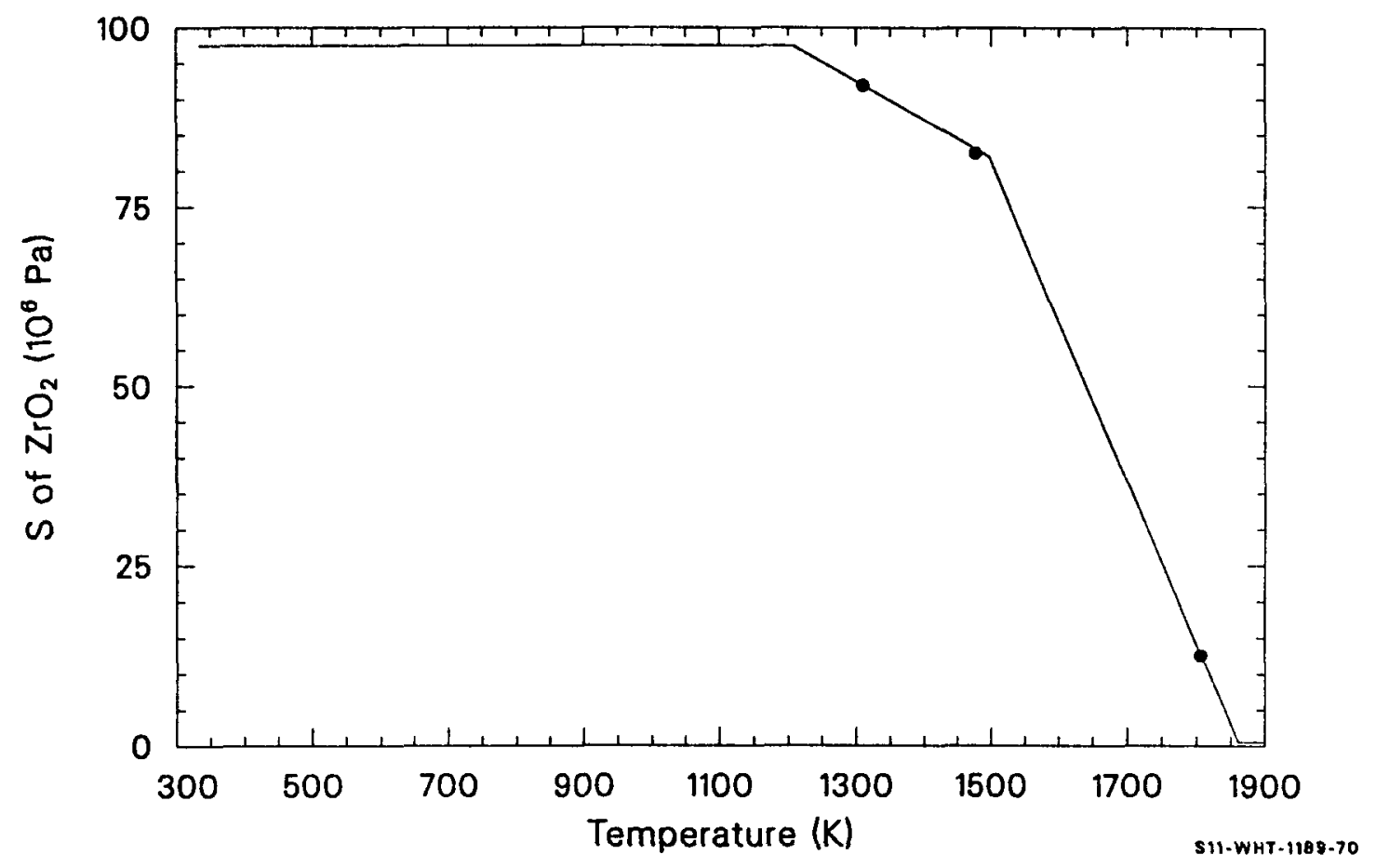

Figure 5.7-1. Zircaloy oxide failure stress data and correlations versus temperature. 


\section{ZORUP}

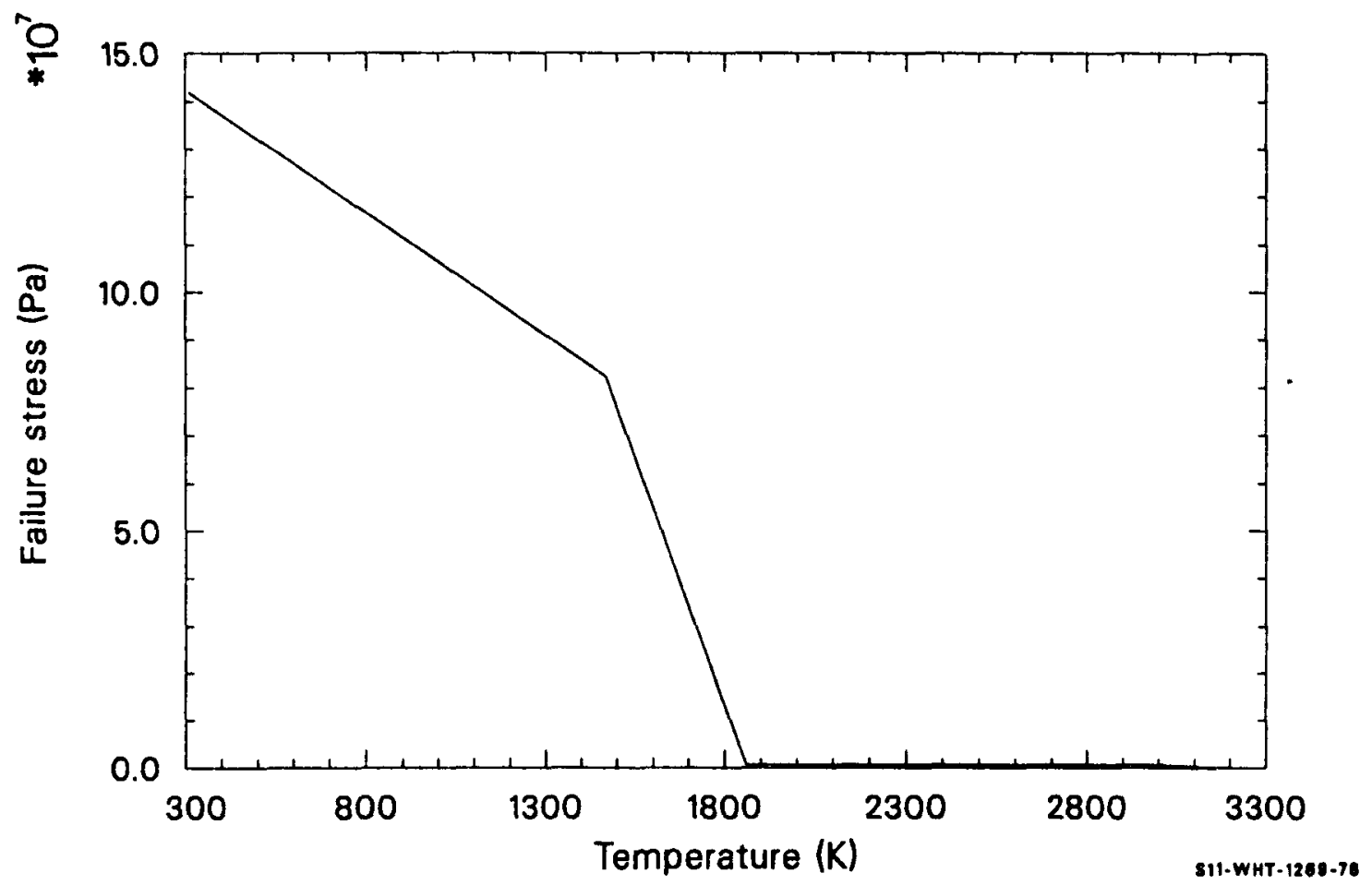

Figure 5.7-2. Zircaloy oxide failure stress calculated with the ZORUP function. 


\section{CONTROL ROD CLADDING}

A collection of properties of 304 stainless steel has been prepared to allow modeling of temperature-dependent phenomena and possible failure by melting or oxidation of stainless steel control rod cladding. Properties included are melting temperatures (SHYPRP), specific heat capacity (SCP), enthalpy (SENTHL), thermal conductivity (STHCON), thermal expansion (STHEXP), and density (SDEN). 


\subsection{Melting Temperatures (ShYPRP)}

(D. L. Hagrman)

The subroutine SHYPRP provides 304 stainless steel melting temperatures. There is no required input.

\subsubsection{Mode1 Development}

For this alloy, page 19-3 of Reference 6.1-1 reports a melting range of 1671 to $1727 \mathrm{~K}$. These numbers are used for the solidus (first liquid phase appears) and liquidus (last solid phase melts) temperatures of control rod cladding.

\subsubsection{References}

6.1-1. D. Peckner and I. M. Bernstein (eds.), Handbook of Stainless Stee 7, New York: McGraw-Hi11 Book Company, 1977. 


\title{
6.2 Specific Heat Capacity and Enthalpy (SCP, Senthl)
}

\author{
(M. L. McComas, D. L. Hagrman)
}

The function SCP returns the specific heat capacity of 304 stainless steel as a function of temperature. SENTHL uses the specific heat capacity to calculate the enthalpy change of the cladding as a function of temperature and a reference temperature for which the enthalpy change will be zero. The reference temperature used is $300 \mathrm{~K}$.

\subsubsection{Model Development}

For specific heat capacity, two expressions are used. The first [Equation (6.2-1)] is a fit to the specific heat capacity values of $398 \mathrm{~J} / \mathrm{kg} \cdot \mathrm{K}$ at $263 \mathrm{~K}, 488 \mathrm{~J} / \mathrm{kg} \cdot \mathrm{K}$ at $700 \mathrm{~K}$, and $540 \mathrm{~J} / \mathrm{kg} \cdot \mathrm{K}$ at $1119 \mathrm{~K}$. These values were obtained from a curve by Peckner and Bernstein.6.2-1 The curve reaches a maximum between 1558 and $1559 \mathrm{~K}$, and Equation (6.2-2) uses the maximum value of $558.228 \mathrm{~J} / \mathrm{kg} \cdot \mathrm{K}$ for temperatures above $1558 \mathrm{~K}$.

For $300 \leq T<1558 \mathrm{~K}$,

$C_{p s}=326+0.298 \mathrm{~T}-9.56 \times 10^{-5} \mathrm{~T}^{2}$.

For $T \geq 1558 \mathrm{~K}$,

$C_{p s}=558.228$

where

$C_{p s}=$ control rod cladding specific heat capacity $(\mathrm{J} / \mathrm{kg} \cdot \mathrm{K})$ 


\section{SCP， SENTHL}

$\mathrm{T}=\mathrm{cladding}$ temperature $(\mathrm{K})$.

SENTHL returns the enthalpy change of 304 stainless steel as a function of temperature. For temperatures below $1671 \mathrm{~K}$, at which 304 stainless steel begins to melt, the integrals of Equations (6.2-1) and (6.2-2) with respect to temperature are used [Equations (6.2-3) and (6.2-4)]. From 1671 to $1727 \mathrm{~K}$, the melting range for 304 stainless steel given in Reference 6.2-1, a heat of fusion is included in the specific heat capacity. The heat of fusion of $2.8 \times 10^{5}$ was added linearly over the melting range, and this is responsible for the additional $5000 \mathrm{~J} / \mathrm{kg} \cdot \mathrm{K}$ in Equation (6.2-5). This heat of fusion was calculated from the heats of fusion for chromium, iron, and nickel given by Brassfield et a1.6.2-2 and the composition of 304 stainless steel given by Murfin et al. 6.2-3 The heat of fusion for the alloy was assumed to be the atomic fraction of each element times its elemental heat of fusion. Equation (6.2-6) is a continuation of Equation (6.2-4) used to estimate the enthalpy change of the liquidus.

For $300<T \leq 1558 \mathrm{~K}$,

$h_{s}=326 \mathrm{~T}+0.149 \mathrm{~T}^{2}-3.187 \times 10^{-5} \mathrm{~T}^{3}$.

For $1558<\mathrm{T}<1671 \mathrm{~K}$,

$h_{S}=-1.206610 \times 10^{5}+558.228 \mathrm{~T}$.

For $1671 \leq \mathrm{T} \leq 1727 \mathrm{~K}$,

$h_{S}=-8.475661 \times 10^{6}+5558.228 \mathrm{~T}$.

For $\mathrm{T}>1727 \mathrm{~K}$,

$h_{S}=1.593390 \times 10^{5}+558.228 \mathrm{~T}$

where 
$h_{s}=$ control rod cladding enthalpy $(\mathrm{J} / \mathrm{kg})$

$T=$ control rod cladding temperature $(K)$.

The expected standard error of Equations (6.2-1) to (6.2-6) is \pm 0.10 of the predicted values. Figures 6.2-1 and 6.2-2 illustrate the calculated values of specific heat capacity and enthalpy change (relative to a reference temperature of $300 \mathrm{~K}$ ) over temperature.

\subsubsection{References}

6.2-1. D. Peckner and I. M. Bernstein (eds.), Handbook of Stainless Steel, New York: McGraw-Hill Book Company, 1977, pp. 19-3, $19-26$.

6.2-2. H. C. Brassfield, J. F. White, L. Sjodahl, and J. T. Bittel, Recommended Property and Reaction Kinetics Data for Use in Evaluating a Light-Water-Cooled Reactor Loss-of-Coolant Incident Involving Zircaloy-4 of $304 \mathrm{SS} \mathrm{Clad} \mathrm{UO}_{2}$, GEMP 482, 1968, p. 89.

6.2-3. W. B. Murfin et al., Core-Meltdown Experimental Review, SAND74-0382, NUREG-0205, 1977, p. 4-8. 


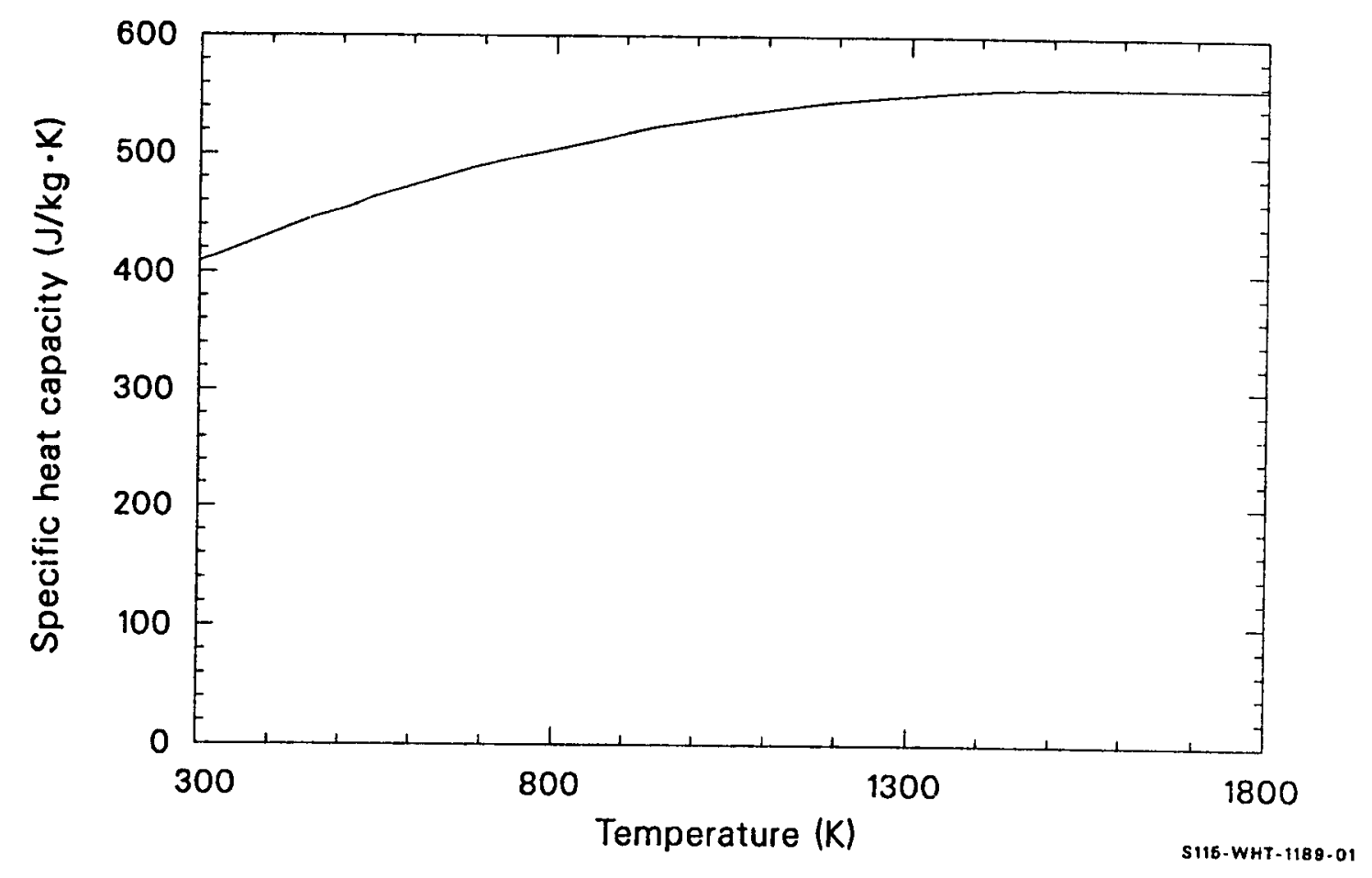

Figure 6.2-1. Stainless steel specific heat capacity at constant pressure. 


\section{SCP， SENTHL}

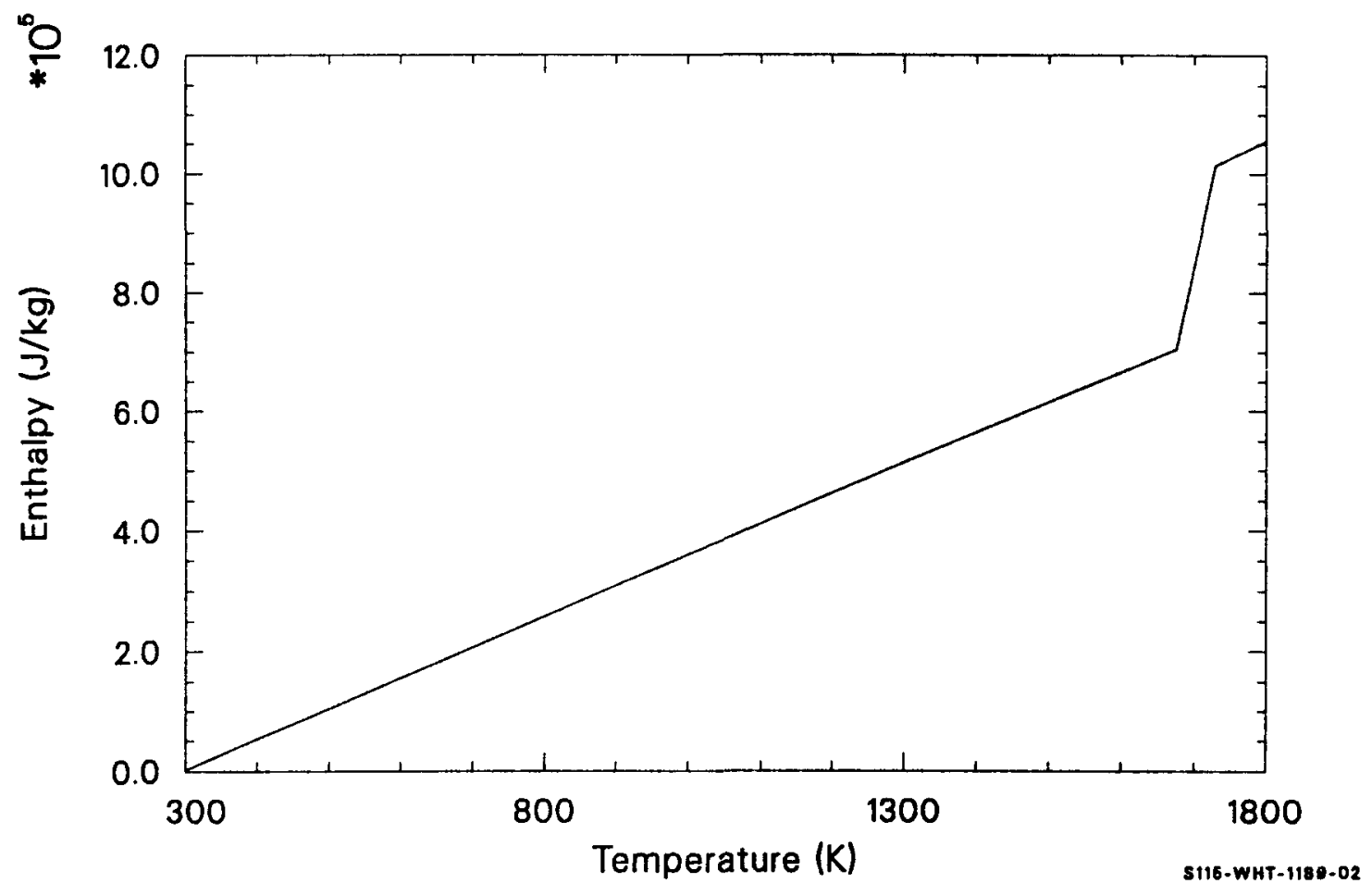

Figure 6.2-2. Stainless steel enthalpy change at constant pressure. 


\section{STHCON}

\subsection{Thermal Conductivity (STHCON)}

(M. L. McComas, D. L. Hagrman)

\subsubsection{Model Development}

The thermal conductivity of 304 stainless steel as a function of temperature is calculated by the STHCON function. Equation (6.3-1) is a fit to the values of $14.65 \mathrm{~W} / \mathrm{m} \cdot \mathrm{K}$ at $374 \mathrm{~K}$ and $25.83 \mathrm{~W} / \mathrm{m} \cdot \mathrm{K}$ at $965 \mathrm{~K}$ obtained from page 19-18 of Reference 6.3-1. Equation (6.3-3) is an approximation of the thermal conductivity at the lowest temperature for which the steel is completely melted. To obtain this approximation, Equation (6.3-1) was evaluated at $1727 \mathrm{~K}$ and then reduced by $50 \%$, noting that the thermal conductivity of a metal with a face-centered cubic structure like 304 stainless steel is reduced by half when melted. ${ }^{6.3-2}$ Equation (6.3-2) interpolates between the result of Equation (6.3-1) predicted at $1671 \mathrm{~K}$ and the value predicted by Equation (6.3-3) at and above $1727 \mathrm{~K}$.

For $300 \leq T<1671 \mathrm{~K}$,

$K_{S}=7.58+0.0189 \mathrm{~T}$.

For $1671 \leq T<1727 \mathrm{~K}$,

$K_{S}=610.9393-0.3421767 \mathrm{~T}$.

For $\mathrm{T} \geq 1727 \mathrm{~K}$,

$K_{s}=20$ 


\section{STHCON}

where

$$
\begin{aligned}
& \mathrm{K}_{\mathrm{S}}=\text { control rod cladding thermal conductivity }(\mathrm{W} / \mathrm{m} \cdot \mathrm{K}) \\
& \mathrm{T}=\text { control rod cladding temperature }(\mathrm{K}) .
\end{aligned}
$$

The expected standard error of the predicted conductivities is \pm 0.02 of the predicted conductivity. The predicted thermal conductivity as a function of temperature is shown in Figure 6.3-1.

\subsubsection{References}

6.3-1. D. Peckner and I. M. Bernstein (eds.), Handbook of Stainless Steel, New York: McGraw-Hill Book Company, 1977.

6.3-2. S. Nazare, G. Ondracek, and B. Schulz, "Properties of Light Water Reactor Core Melts," Nuclear Technology, 32, 1977, pp. 239-246. 
STHCON

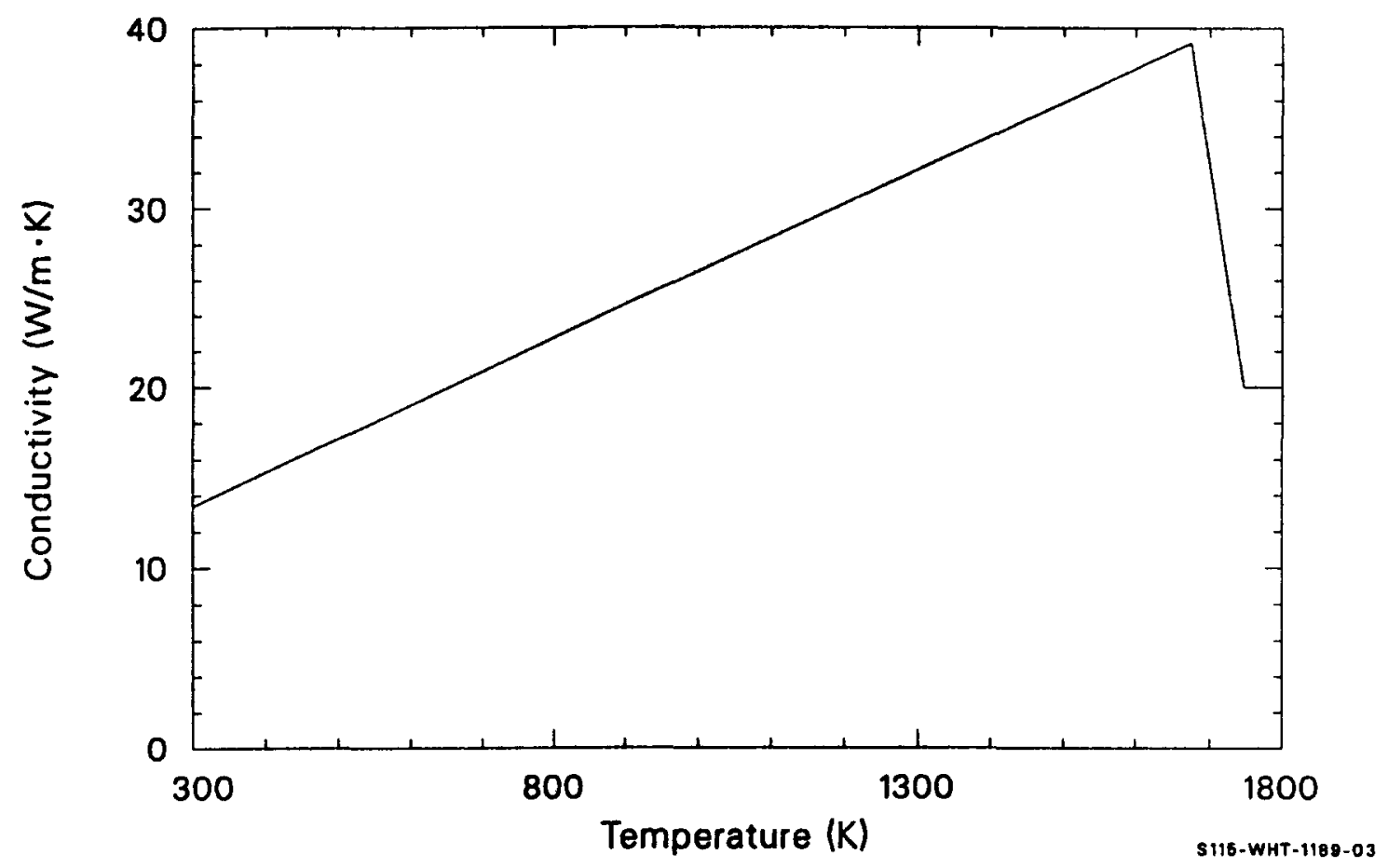

Figure 6.3-1. Stainless steel thermal conductivity. 


\section{STHEXP， SDEN}

\subsection{Thermal Expansion and Density (STHEXP, SDEN)}

(M. L. McComas, D. L. Hagrman)

The function STHEXP calculates 304 stainless steel thermal expansion strain, and SDEN computes the density of this material. STHEXP requires the control rod cladding temperature and a reference temperature (for which thermal strain will be zero), while SDEN requires only the temperature.

\subsubsection{Model Development}

The expressions used to calculate thermal expansion strains are

For $300 \leq T<1671 \mathrm{~K}$,

$\epsilon_{\mathrm{S}}=1.57 \times 10^{-5} \times \mathrm{T}+1.69 \times 10^{-9} \times \mathrm{T}^{2}$.

For $1671 \leq \mathrm{T}<1727 \mathrm{~K}$,

$\epsilon_{\mathrm{S}}=-2.986634 \times 10^{-1}+1.972573 \times 10^{-4} \times \mathrm{T}$.

For $T \geq 1727 \mathrm{~K}$,

$\epsilon_{S}=4.2 \times 10^{-2}$

where

$\epsilon_{\mathrm{S}}=$ control rod cladding thermal strain $(\mathrm{m} / \mathrm{m})$ 


\section{STHEXP， SDEN}

$\mathrm{T}=$ control rod cladding temperature $(\mathrm{K})$.

Equation (6.4-1) is derived from thermal expansion rates of $17.2 \times$ $10^{-6}$ and $18.9 \times 10^{-6} \mathrm{~m} / \mathrm{m} \cdot \mathrm{K}$ at 455 and $959 \mathrm{~K}$. These values were taken from a curve on page 197 of Reference 6.4-1. A linear fit to the thermal expansion rates yields an expression which can be integrated to produce Equation (6.4-1). The constant of integration is ignored because the quantity returned by STHEXP is the strain predicted by Equations (6.4-1) to $(6.4-3)$ at the given temperature minus the strain predicted at the reference temperature. Equation (6.4-3) is the strain predicted by Equation (6.4-1) at the lowest temperature for which the steel is completely melted, $1727 \mathrm{~K}$, plus an assumed additional expansion of $1 \%$ ( $3 \%$ volume increase) because of the melting. Equation (6.4-2) is a linear interpolation of the values predicted by Equation (6.4-1) at $1671 \mathrm{~K}$ and Equation (6.4-3) at $1727 \mathrm{~K}$. The expected standard error of these expressions is about 0.10 of the predicted value.

The function SDEN uses the general relation between density and thermal strain, together with a reference density of $7.9 \times 10^{3} \mathrm{~kg} / \mathrm{m}^{2}$ at $300 \mathrm{~K}$ obtained from page 87 of Reference 6.4-2. The expected standard error of this density is the uncertainty of reference density, $\pm 50 \mathrm{~kg} / \mathrm{m}^{3}$.

The thermal expansion strain returned by STHEXP for a reference temperature of $300 \mathrm{~K}$ is illustrated in Figure 6.4-1, and the density calculated with the SDEN function is shown in Figure 6.4-2.

\subsection{References}

6.4-1. D. Peckner and I. M. Bernstein (eds.), Handbook of Stainless Steel, New York: McGraw-Hill Book Company, 1977.

6.4-2. H. C. Brassfield, J. F. White, L. Sjodahl, and J. T. Bittel, Recommended Property and Reaction Kinetics Data for Use in Evaluating a Light-Water-Cooled Reactor Loss-of-Coolant Incident Involving Zircaloy-4 of $304 \mathrm{SS} \mathrm{Clad} \mathrm{UO}_{2}$, GEMP 482, 1968. 
STHEXP， SDEN

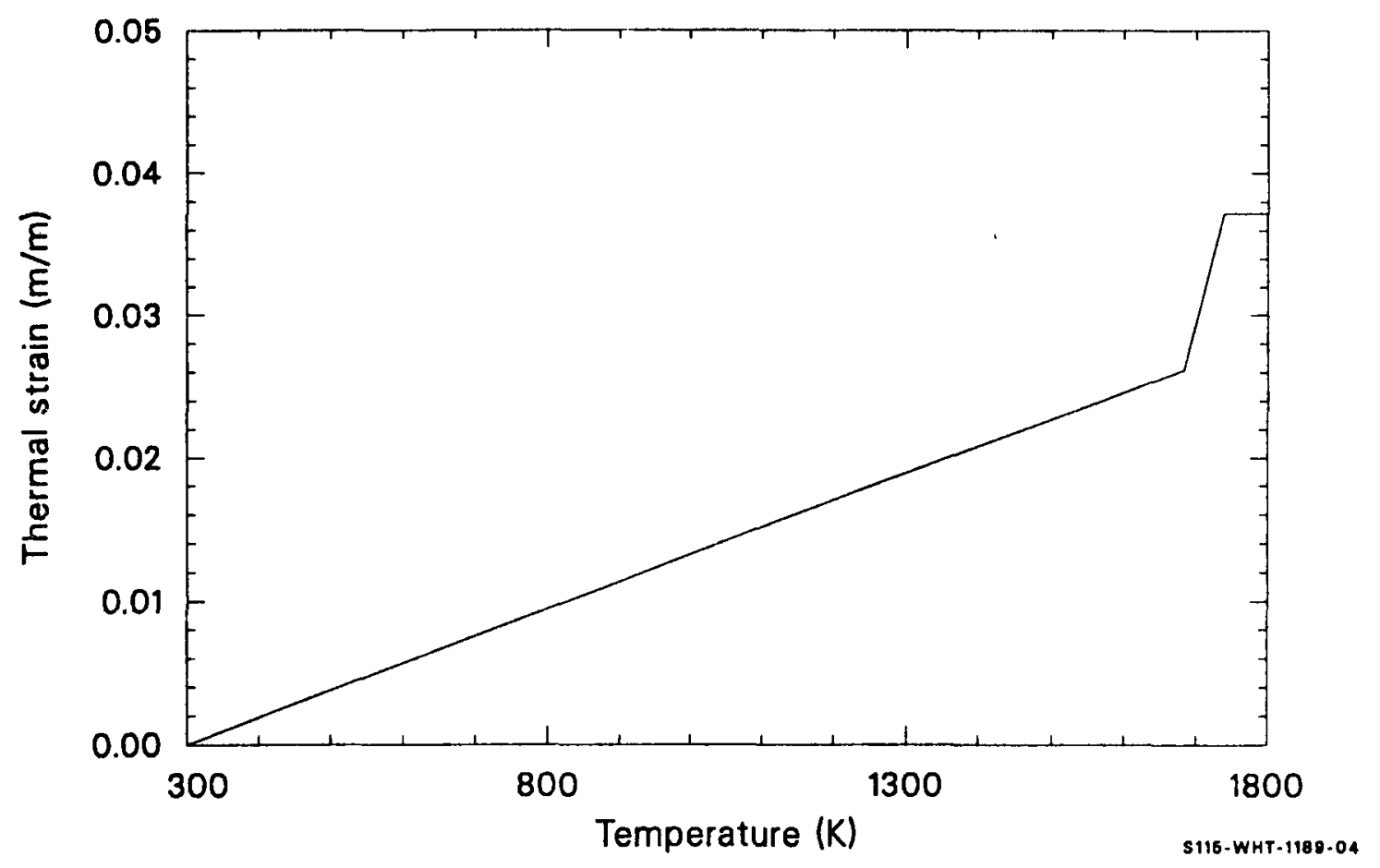

Figure 6.4-1. Stainless steel thermal expansion strain. 


\section{STHEXP， SDEN}

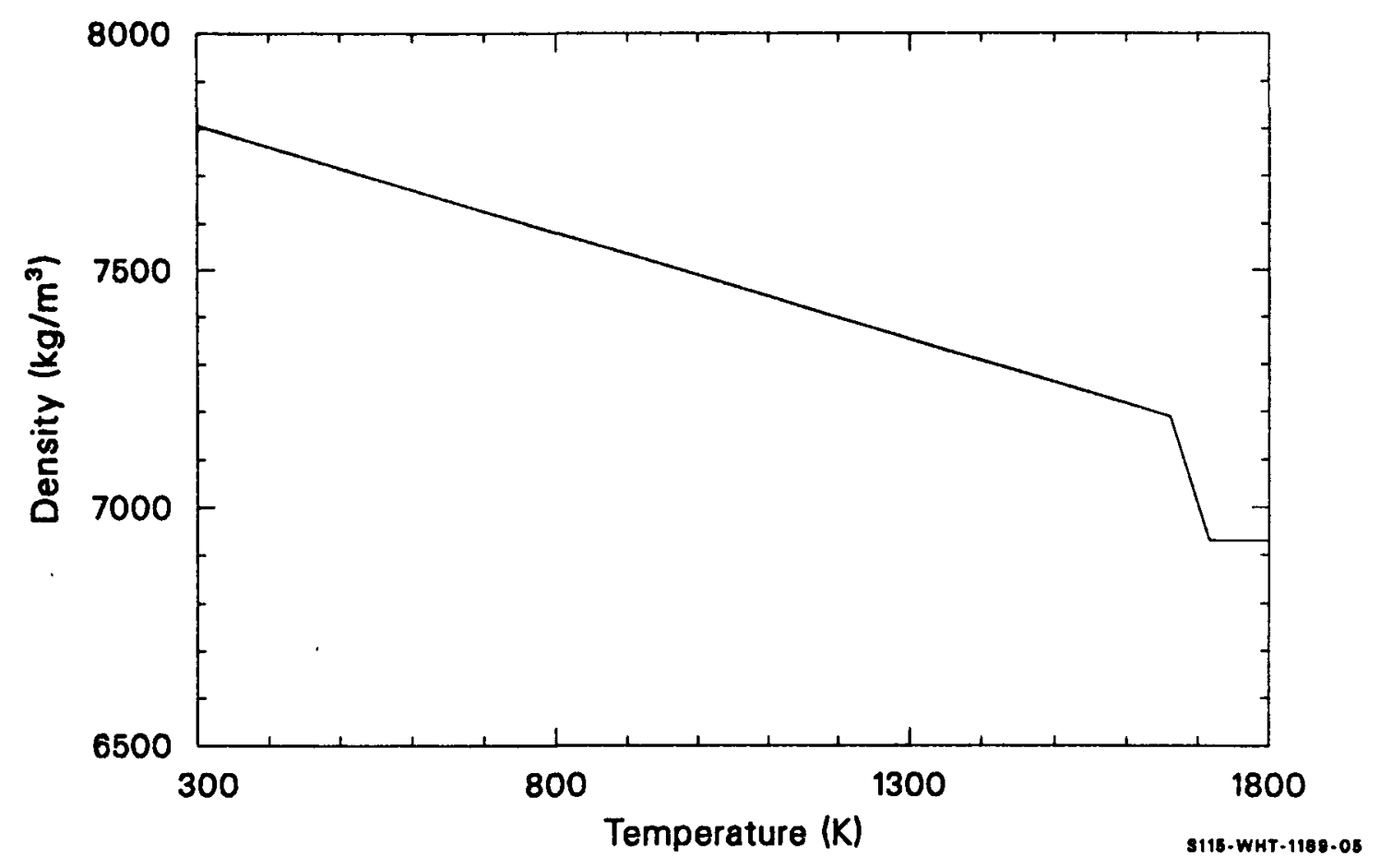

Figure 6.4-2. Stainless steel density. 


\section{STAINLESS STEEL OXIDES}

With the expansion of severe accident analysis computer codes to include boiling water reactors (BWR) using stainless steel control blades, it became apparent that materials properties information was needed for the stainless steel oxides formed at high temperatures. Correlations were developed to calculate specific heat capacity (SOCP), enthalpy (SONTHL), thermal conductivity (SOTCON), thermal expansion (SOTEXP), and density (SODEN). 
SOCP, SONTHL

\subsection{Specific Heat Capacity and Enthalpy (SOCP, SONTHL)}

(J. K. Hohorst)

The function SOCP calculates the specific heat capacity for stainless steel oxide at constant pressure as a function of temperature. The function SONTHL calculates the enthalpy change for stainless steel oxide at constant pressure as a function of temperature and a reference temperature, for which the enthalpy change will be zero.

\subsubsection{Specific Heat Capacity (SOCP)}

The function SOCP returns the specific heat capacity at constant pressure for a mixture of the iron oxides, $\mathrm{FeO}, \mathrm{Fe}_{2} \mathrm{O}_{3}$, and $\mathrm{Fe}_{3} \mathrm{O}_{4}$, as a function of temperature. These iron oxides are presumed to be the major components of stainless steel oxide. The expressions used to calculate specific heat capacity are:

Fe0:

For $300<T \leq 1642 K$ (solid phase),

$C_{p}=676.2+0.1432 \mathrm{~T}$.

For $\mathrm{T}>1642 \mathrm{~K}$ (1 iquid phase),

$C_{p}=989$.

$\mathrm{Fe}_{2} \mathrm{O}_{3}:$

For $300<T \leq 950 \mathrm{~K}$ (alpha phase), 
SOCP, SONTHL

$$
\begin{aligned}
C_{p}= & 337.6+T\left(1.099-2.372 \times 10^{-05} \mathrm{~T}\right) . \\
& \text { For } 950<T \leq 1050 \mathrm{~K} \text { (beta phase), } \\
C_{p}= & 1248 .
\end{aligned}
$$

For $1050<\mathrm{T} \leq 1838 \mathrm{~K}$ (gamma phase),

$$
C_{p}=829.9+4.26 \times 10^{-02} \mathrm{~T} .
$$

For $\mathrm{T}>1838 \mathrm{~K}$ ( 1 iquid phase),

$$
C_{p}=829.9+4.26 \times 10^{-02} \mathrm{~T} \text {. }
$$

$$
\mathrm{Fe}_{3} \mathrm{O}_{4}
$$

For $300<\mathrm{T} \leq 1000 \mathrm{~K}$ (alpha phase),

$$
C_{p}=394.9+T\left(0.8705-4.976 \times 10^{-07} \mathrm{~T}\right) .
$$

For $1000<\mathrm{T} \leq 1864 \mathrm{~K}$ (beta phase),

$$
C_{p}=866.5 \text {. }
$$

For $T>1864 \mathrm{~K}$ (1iquid phase),

$$
c_{p}=866.5
$$

Since no data were found for the liquid phase specific heat capacity, the specific heat capacity at the melting point of each oxide was used as an estimate. The final specific heat capacity for stainless steel oxide calculated by the SOCP subroutine is a simple average of the calculated specific heat capacities of each oxide of iron. 


$$
\operatorname{SOCP}_{F}=\left[\left(\mathrm{SOCP}_{(\mathrm{FeO})}+\operatorname{SOCP}\left(\mathrm{Fe}_{2} \mathrm{O}_{3}\right)+\operatorname{SOCP}\left(\mathrm{Fe}_{3} \mathrm{O}_{4}\right)\right] / 3\right.
$$

Figure 7.1-1 shows the calculated specific heat capacity for stainless steel oxide as a function of temperature. Tables 7.1-1 to 7.1-3 contain the specific heat capacity data from Touloukian $7.1-1$ that were used to derive the equations used in the calculation.

\subsubsection{Enthalpy (SONTHL)}

The function SONTHL calculates the enthalpy change for stainless steel oxide as a function of temperature and a reference temperature of $300 \mathrm{~K}$. At $300 \mathrm{~K}$, the enthalpy change is zero. The expressions used to calculated the enthalpy of stainless steel oxide are:

For $300<\mathrm{T}<950 \mathrm{~K}$,

$$
h_{S}=-1.7264166 \times 10^{5}+T\left[469.6+T\left(0.3521-2.691 \times 10^{-06} T\right)\right] .
$$

For $950 \leq \mathrm{T}<1000 \mathrm{~K}$,

$$
h_{s}=-2.9379084 \times 10^{5}+T\left[773.0+T\left(0.1690-5.53 \times 10^{-07} T\right)\right] \text {. }
$$

For $1000 \leq T<1050 \mathrm{~K}$,

$$
h_{S}=-3.530784 \times 10^{5}+T\left(930.2+2.387 \times 10^{-02} \mathrm{~T}\right) \text {. }
$$

For $1050 \leq T \leq 1642 \mathrm{~K}$,

$$
h_{S}=-1.6657291 \times 10^{5}+T\left(790.0+3.07 \times 10^{-02} \mathrm{~T}\right) \text {. }
$$

For $\mathrm{T}>1642 \mathrm{~K}$,

$$
h_{s}=-2.7403984 \times 10^{5}+T\left(895.1+7.1 \times 10^{-03} \mathrm{~T}\right) \text {. }
$$


SOCP, SONTHL

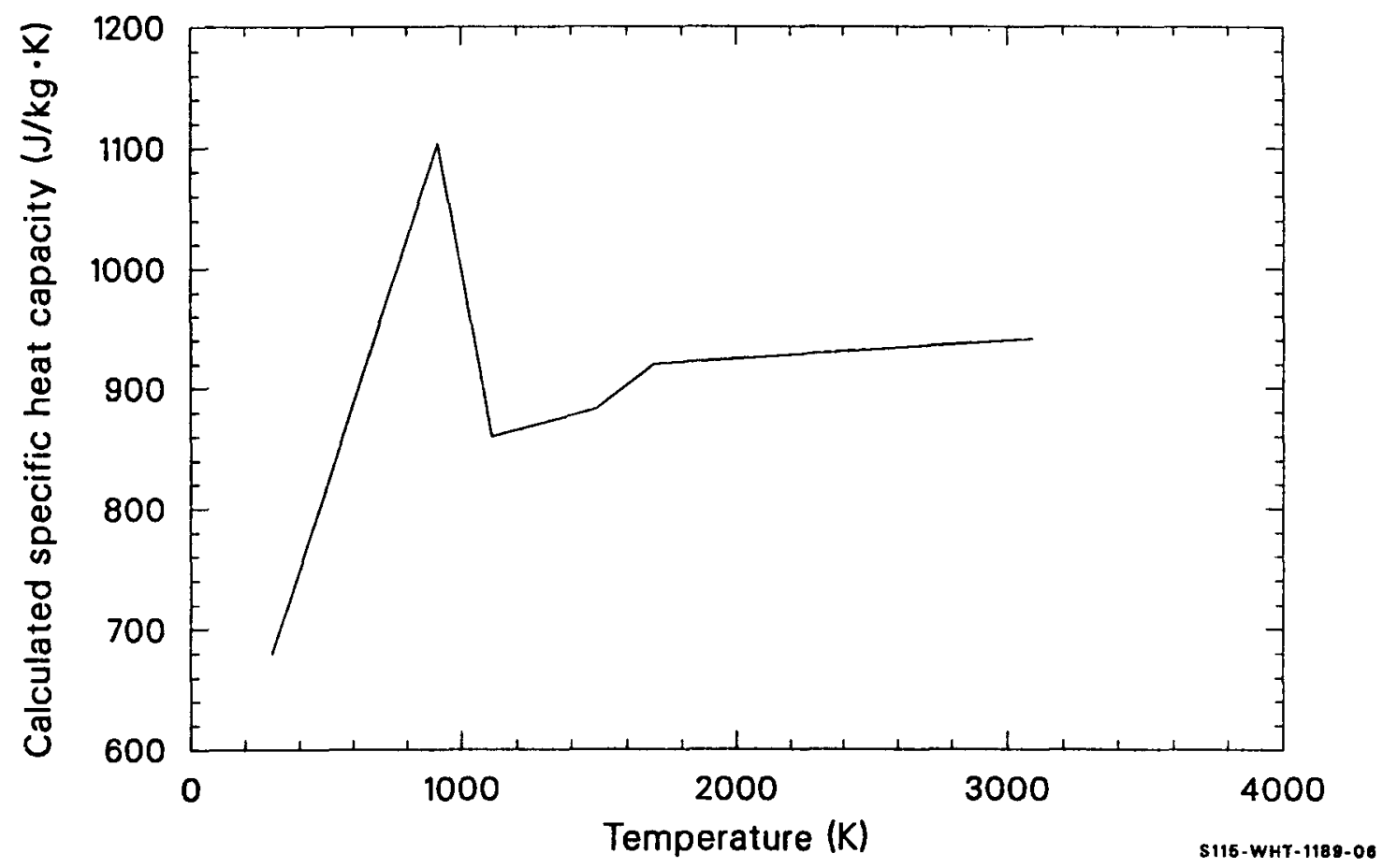

Figure 7.1-1. Specific heat capacity for stainless steel oxide calculated by SOCP. 
SOCP, SONTHL

Table 7.1-1. Fe0 specific heat capacity data

Temperature

(K)

Solid phase:

300

400

500

600

700

800

900

1000

1100

1200

1300

1400

1500

1600

1650
Specific Heat Capacity

(cal $/ \mathrm{g} \cdot \mathrm{K}$ )
0.1672
0.1747
0.1789
0.184
0.1876
0.191
0.1942
0.1973
0.2004
0.2034
0.2064
0.2094
0.2123
0.2153
0.2168

Liquid phase: 
SOCP， SONTHL

Table 7.1-2. $\mathrm{Fe}_{2} \mathrm{O}_{3}$ specific heat capacity data

Temperature

(K)

Alpha phase:
Specific Heat Capacity (cal/g.K)

$\begin{array}{ll}391 . & 0.182 \\ 393.5 & 0.184 \\ 414 . & 0.186 \\ 450.5 & 0.197 \\ 490.5 & 0.204 \\ 493 . & 0.207 \\ 508 . & 0.207 \\ 533 . & 0.217 \\ 419.2 & 0.187 \\ 435 . & 0.189 \\ 463 . & 0.211 \\ 479.5 & 0.217 \\ 483.7 & 0.206 \\ 505.5 & 0.214 \\ 535 . & 0.222 \\ 567 . & 0.22 \\ 592.5 & 0.223 \\ 626.5 & 0.238 \\ 654.5 & 0.264 \\ 682 . & 0.272 \\ 685.5 & 0.273 \\ 701.5 & 0.27 \\ 715.5 & 0.287 \\ 737.5 & 0.271 \\ 763 . & 0.288 \\ 799 . & 0.291 \\ 823 . & 0.298 \\ 840 . & 0.314 \\ 880 . & 0.335 \\ 904 . & 0.342 \\ 864 . & 0.326 \\ 870.5 & 0.32 \\ 889 . & 0.322 \\ 936 . & 0.328 \\ 941 . & 0.358 \\ 301.23 & 0.1563 \\ 310.2 & 0.1592 \\ 319.04 & 0.1616 \\ 327.77 & 0.164 \\ 336.53 & 0.1664 \\ 345.42 & 0.1687 \\ & \\ 753 & \end{array}$


SOCP， SONTHL

Table 7.1-2. (continued)

\begin{tabular}{|c|c|c|}
\hline & $\begin{array}{c}\text { Temperature } \\
(\mathrm{K})\end{array}$ & $\begin{array}{l}\text { Specific Heat Capacity } \\
(\mathrm{cal} / \mathrm{g} \cdot \mathrm{K})\end{array}$ \\
\hline 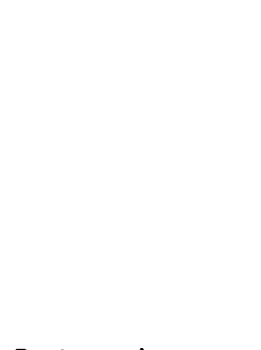 & $\begin{array}{l}300 . \\
400 . \\
500 . \\
600 . \\
700 . \\
800 . \\
900 . \\
950 .\end{array}$ & $\begin{array}{l}0.1796 \\
0.1922 \\
0.2044 \\
0.2163 \\
0.2281 \\
0.2399 \\
0.2516 \\
0.2575\end{array}$ \\
\hline & $\begin{array}{l}973 . \\
991.5\end{array}$ & $\begin{array}{l}0.367 \\
0.376\end{array}$ \\
\hline & $\begin{array}{l}950 \\
1000 \\
1050\end{array}$ & $\begin{array}{l}0.2254 \\
0.2254 \\
0.2254\end{array}$ \\
\hline \multicolumn{3}{|l|}{ Gamma phase: } \\
\hline & $\begin{array}{l}1050 . \\
1100 . \\
1200 . \\
1300 . \\
1400 . \\
1500 . \\
1600 . \\
1700 . \\
1750 .\end{array}$ & $\begin{array}{l}0.2101 \\
0.2106 \\
0.2118 \\
0.2128 \\
0.214 \\
0.2154 \\
0.2162 \\
0.2172 \\
0.2178\end{array}$ \\
\hline
\end{tabular}


SOCP， SONTHL

Table 7.1-3. $\mathrm{Fe}_{3} \mathrm{O}_{4}$ specific heat capacity data

Temperature

(K)

Alpha phase:

300 .

400.

500 .

600.

700.

800.

900 .
Specific Heat Capacity (cal $/ \mathrm{g} \cdot \mathrm{K}$ )

Beta phase:

1100 .

1200 .

1300 .

1400 .

1500 .

1600 .

0.1569

0.1778

0.1986

0.2193

0.2402

0.261

0.2818

1700 .

1800 .

0.2073

0.2073

0.2073

0.2073

0.2073

0.2073

0.2073

0.2073 
SOCP， SONTHL

where

$$
\begin{aligned}
& h_{S}=\text { the enthalpy change for stainless steel oxide }(\mathrm{J} / \mathrm{kg}) \\
& T \quad=\text { the stainless steel oxide temperature }(\mathrm{K})
\end{aligned}
$$

The above enthalpy expressions were obtained by averaging at each temperature range the enthalpies of $\mathrm{FeO}, \mathrm{Fe}_{2} \mathrm{O}_{3}$, and $\mathrm{Fe}_{3} \mathrm{O}_{4}$, the main components presumed to be present in the oxide of stainless steel. For each iron oxide, the enthalpies that were averaged were obtained by integrating the polynomials obtained from fitting the specific heat capacity data from Touloukian et al.7.1-1 The specific heat capacity data used to obtain the polynomials are presented in Tables 7.1-1 through 7.1-3.

Figure 7.1-2 is a plot of the enthalpy change for stainless steel oxide calculated by the subroutine SONTHL.

\subsubsection{References}

7.1-1 Y. S. Touloukian, E. H. Buyco, Thermal Physical Properties of Matter, V5, Specific Heat - Nonmetallic Solids, New York:

IFI/Plenum, 1970, p. 107-117. 
SOCP, SONTHL
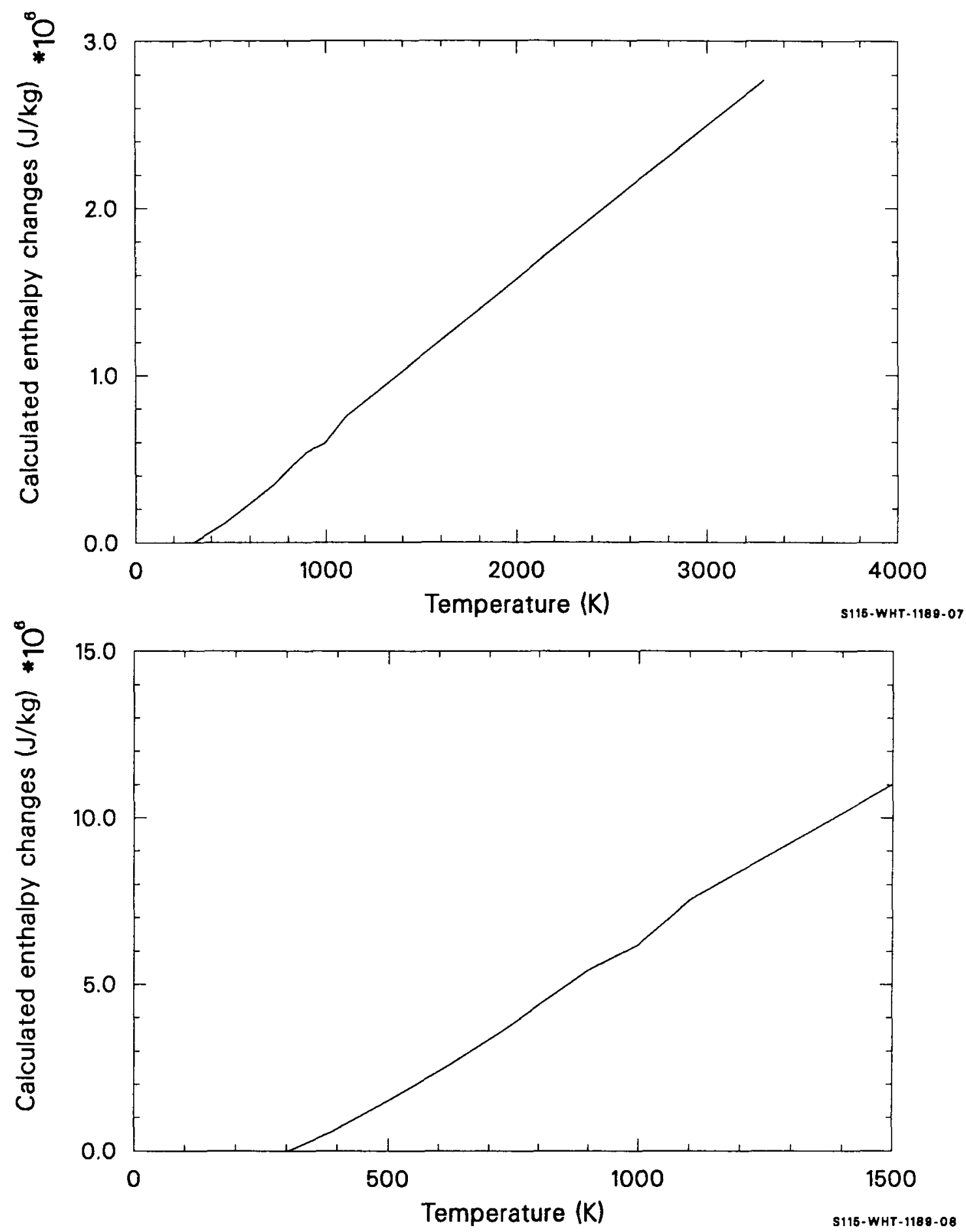

Figure 7.1-2. Enthalpy change for stainless steel oxide calculated by SONTHL. 


\subsection{Thermal CONductivity (SOTCON)}

(J. K. Hohorst)

The thermal conductivity of stainless steel oxide as a function of temperature is calculated by the function SOTCON. The only input required is the temperature of the stainless steel oxide (SOTEMP).

\subsubsection{Mode1 Development}

The correlation used to calculate the thermal conductivity is derived from a polynomial fit of data (Table 7.2-1) from Reference 7.2-1. Due to lack of available date, the calculation was truncated at a temperature of $800 \mathrm{~K}$. The equation used to calculate the thermal conductivity is:

$K_{S}=4.6851+100 \mathrm{~T}\left(-3.3292 \times 10^{-07}-2.5618 \times 10^{-08} \mathrm{~T}\right) \cdot$

where

$\mathrm{K}_{\mathrm{S}}=$ the stainless steel oxide thermal conductivity $(\mathrm{W} /(\mathrm{m} \cdot \mathrm{K})$

$\mathrm{T}=$ the stainless steel oxide temperature $(K)$

The expected standard error of the predicted conductivities is \pm 0.2 times the calculated conductivity for temperatures in the range from 300 to $800 \mathrm{~K}$. For temperatures greater than $800 \mathrm{~K}$, the uncertainty of the calculation increases. A plot of the thermal conductivities calculated by the function SOTCON is shown in Figure 7.2-1. 
Table 7.2-1. Stainless steel oxide thermal conductivity from Touloukian

Temperature

(K)

317.1

335.7

353.9

385.6

453.2
Thermal Conductivity

$(W / m \cdot K \times 100)$

.0444

.0435

.0435

.0431

.0414 


\section{SOTCON}

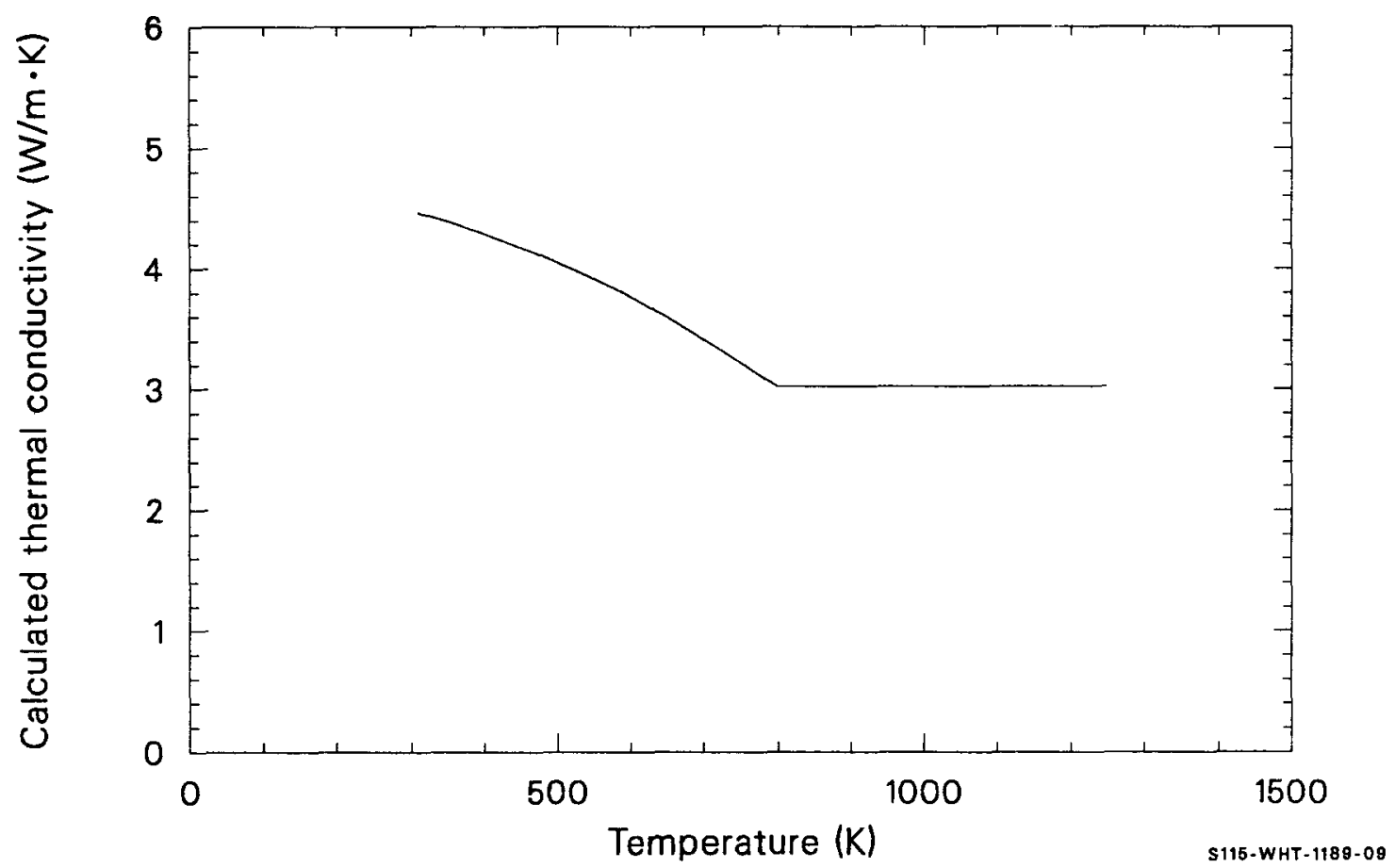

Figure 7.2-1. Thermal conductivities for stainless steel oxide calculated by SOTCON. 


\section{SOTCON}

\subsubsection{References}

7.2-1. S. Touloukian, R. W. Powel1, C. Y. Ho, P. G. Klemens, Thermal Physical Properties of Matter, V2, Thermal Conductivity Non-Metallic Solids, New York: IFI/Plenum, 1970, pp. 154-156. 
SOTHEX, SODEN

\subsection{Thermal Expansion and Density (SOTHEX, SODEN)}

(J. K. Hohorst)

The subcode SOTHEX calculates the stainless steel oxide thermal expansion strain, and the subcode SODEN computes the density from room temperature to the oxide melting point. SOTHEX requires the temperature of the stainless steel oxide and a reference temperature (for which the thermal strain will be zero), while SODEN requires only the temperature of the stainless steel oxide.

\subsubsection{Thermal Expansion (SOTHEX)}

The thermal expansion value calculated for stainless steel oxide was obtained by taking an average of the calculated thermal expansion of $\mathrm{Fe} 0$, $\mathrm{Fe}_{2} \mathrm{O}_{3}$, and $\mathrm{Fe}_{3} \mathrm{O}_{4}$. The equations used were obtained from Reference 7.3-1 and are as follows:

$$
\begin{aligned}
\epsilon_{\mathrm{S}(\mathrm{Fe} 0)=} & -0.409+1.602 \times 10^{-03} \mathrm{~T}-7.913 \times 10^{-07} \mathrm{~T}^{2} \\
& +5.348 \times 10^{-10} \mathrm{~T}^{3}
\end{aligned}
$$

$\begin{aligned} \epsilon_{\mathrm{S}}\left(\mathrm{Fe}_{2} \mathrm{O}_{3}\right)= & -2.537+7.30 \times 10^{-04} \mathrm{~T}+4.964 \times 10^{-07} \mathrm{~T}^{2} \\ & -1.140 \times 10^{-10} \mathrm{~T}^{3}\end{aligned}$

$\begin{aligned} \epsilon_{\mathrm{S}}\left(\mathrm{Fe}_{3} \mathrm{O}_{4}\right)= & -0.214+6.929 \times 10^{-04} \mathrm{~T}-1.107 \times 10^{-07} \mathrm{~T}^{2} \\ & +8.078 \times 10^{-10} \mathrm{~T}^{3}\end{aligned}$

$\epsilon_{s(\text { average })}=\left[\epsilon_{s}(\mathrm{Fe} 0)+\epsilon_{s}\left(\mathrm{Fe}_{2} \mathrm{O}_{3}\right)+\epsilon_{s}\left(\mathrm{Fe}_{3} \mathrm{O}_{4}\right)\right] / 3$ 


\section{SOTHEX， SODEN}

where

$$
\begin{aligned}
& \epsilon_{S}(\mathrm{Fe} 0)=\text { the thermal expansion strain for } \mathrm{Fe} 0(\mathrm{~m} / \mathrm{m}) \\
& \epsilon_{\mathrm{S}}\left(\mathrm{Fe}_{2} \mathrm{O}_{3}\right)=\text { the thermal expansion strain for } \\
& \mathrm{Fe}_{2} \mathrm{O}_{3}(\mathrm{~m} / \mathrm{m}) \\
& \epsilon_{s}\left(\mathrm{Fe}_{3} \mathrm{O}_{4}\right)=\text { the thermal expansion strain for } \\
& \mathrm{Fe}_{3} \mathrm{O}_{4}(\mathrm{~m} / \mathrm{m})
\end{aligned}
$$

T = the temperature of the stainless steel oxide $(K)$.

The calculated thermal expansion strain for stainless steel oxide was obtained by averaging the thermal expansion strains calculated for each oxide of iron. This average strain value was used as an approximation for the thermal expansion strain of stainless steel oxide because no data for the thermal expansion strain of the oxide mixture found on oxidized stainless steel surfaces are available.

The thermal expansion strains computed by the function SOTHEX for stainless steel oxide using a reference temperature of $300 \mathrm{~K}$ is illustrated in Figure 7.3-1.

\subsubsection{Density (SODEN)}

The function SODEN uses the general relation between density and thermal expansion strain to calculate the density of stainless steel oxide. A density of $5.2 \times 10^{3} \mathrm{~kg} / \mathrm{m}^{3}$ at $300 \mathrm{~K}^{7.3-2}$ is used as a reference density. The expected standard error of $\pm 0.5 \mathrm{~kg} / \mathrm{m}^{3}$ for the density of 


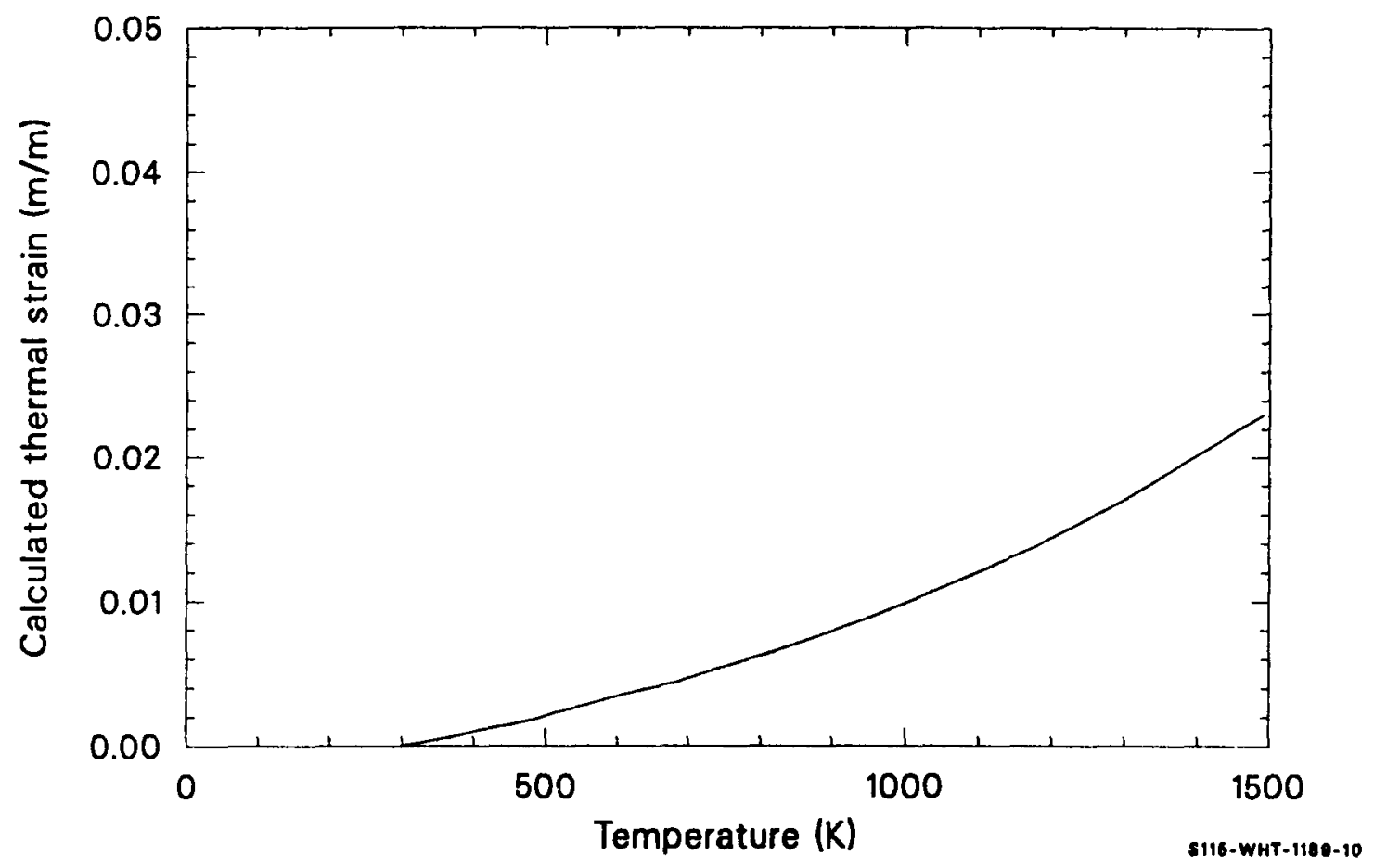

Figure 7.3-1. Thermal expansion strain as a function of temperature calculated by SOTHEX. 


\section{SOTHEX, SODEN}

stainless steel oxide is due to the uncertainty of the reference density. Figure 7.3-2 shows the density of stainless steel oxide calculated by the function SODEN using the thermal expansion strains calculated in SOTHEX.

\subsubsection{References}

7.3-1. Y. S. Touloukian, R. K. Kirby, R. E, Taylor, P. D. Desai, Thermal Physical Properties of Matter, V12, Thermal Expansion - Metallic Elements and Alloys, New York: IFI/Plenum, 1970, pp. 366-372.

7.3-2. Handbook of Chemistry and Physics, The Chemical Rubber Company, 50th Edition, 1969-1970. 
SOTHEX， SODEN

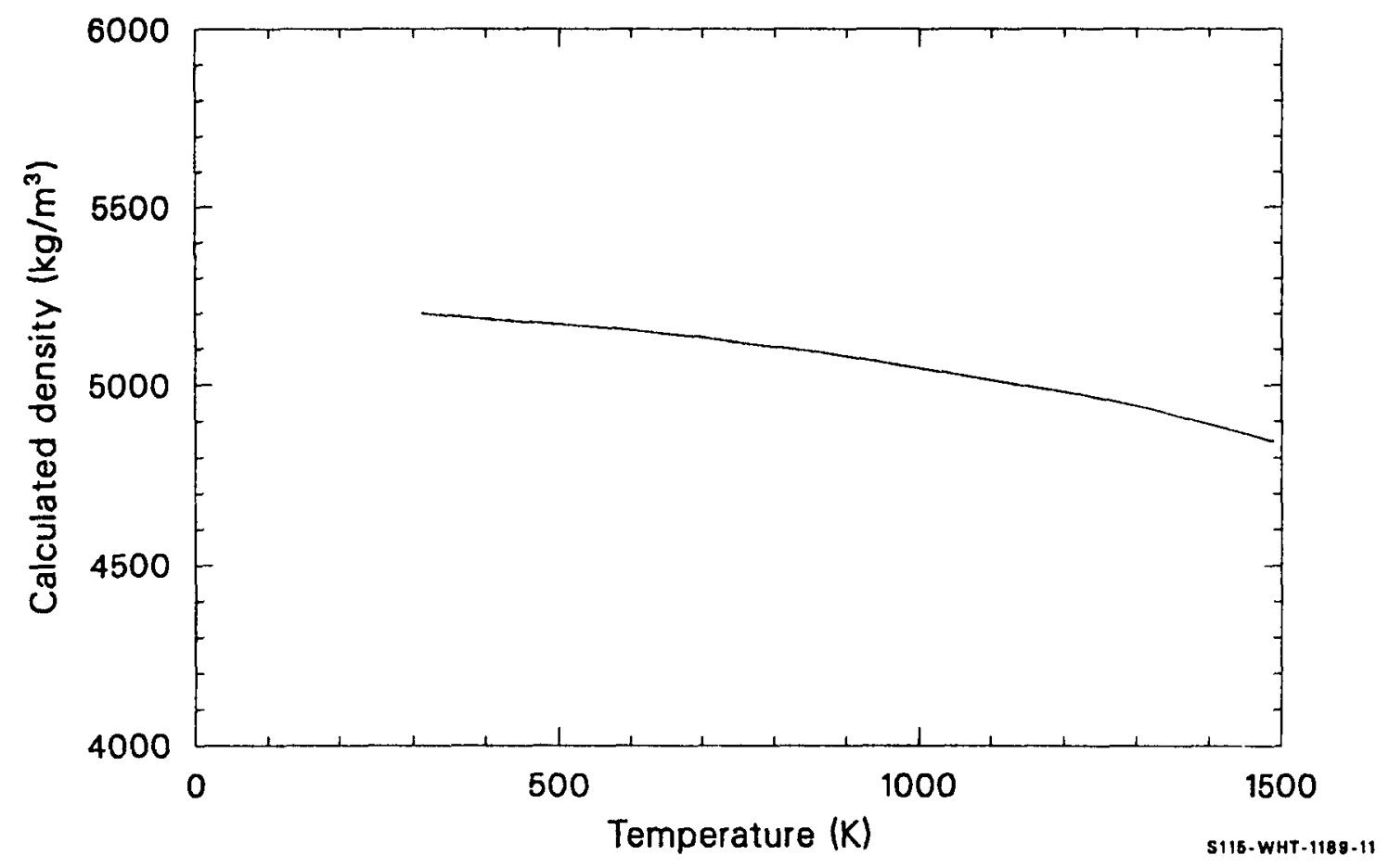

Figure 7.3-2. Density calculated by SODEN using the thermal strain calculated by SOTHEX. 


\title{
8.1 Melting Temperature (AhyprP)
}

\author{
(D. L. Hagrman)
}

The subroutine AHYPRP provides absorber solidus (appearance of the first liquid phase) and liquidus (melting of the last solid phase) temperatures. There is no required input other than a parameter to identify which absorber material is used.

\subsubsection{Model Development}

For the typical Ag-In-Cd alloy, Reference 8.1-1 reports an approximate melting range of 1073 to $1123 \mathrm{~K}$. These numbers are thus used for the solidus and liquidus temperatures of the alloy.

The melting temperature of $2743 \mathrm{~K}$ reported on page 541 of Reference 8.1-2 is used for the solidus and liquidus temperature of $B_{4} C$.

\subsubsection{References}

8.1-1. D. A. Petti, Silver-Indium-Cadmium Control Rod Behavior and Aerosol Formation in Severe Reactor Accidents, NUREG/CR-4876, EGG-2501, April 1987.

8.1-2. Chase et a1., JANAF Thermochemical Tables, 1986, pp. 541-543. 


\section{NEUTRON ABSORBERS (SILVER-INDIUM-CADMIUM CONTROL RODS AND BORON (ARBIDE CONTROL BLADES)}

A set of control rod neutron absorber properties for silver-indium-cadmium ( $\mathrm{Ag}-\mathrm{In}-\mathrm{Cd}$ ) alloys $(80 \% \mathrm{Ag}, 15 \% \mathrm{In}, 5 \% \mathrm{Cd}$ by weight) and boron carbide $\left(B_{4} C\right)$ has been prepared to allow modeling of the possible flow and freezing of these materials during a severe core disruption. Properties for both substances have been included in each subcode. An input argument, ICTYPE, is used to determine which substance properties are returned. (ICTYPE $=1$ for the Ag-In-Cd control rod properties, and ICTYPE $=2$ for the BWR $\mathrm{B}_{4} \mathrm{C}$ control rod properties.)

No models have been provided for mixtures of neutron absorbers and their stainless steel cladding because it has been reported $^{8-1}$ that Ag-In-Cd alloy is insoluble in stainless steel and because the very different melting temperatures of stainless steel $(1700 \mathrm{~K})$ and $\mathrm{B}_{4} \mathrm{C}$ $(2700 \mathrm{~K})^{8-2}$ make it likely that the stainless steel will oxidize or melt and run away from hot regions before $\mathrm{B}_{4} \mathrm{C}$ and stainless steel mix.

\section{References}

8-1. W. B. Murfin et a1., Core-Meltdown Experimental Review, SAND74-0382, NUREG-0205, 1977, p. 4-38.

8-2. Chase et a1., JANAF Thermochemical Tables, 1986, pp. 541-543. 
ACP, AENTHL

\title{
8.2 Specific Heat Capacity and Enthalpy (ACP, Aenthl)
}

\author{
(D. L. Hagrman, M. L. McComas)
}

The function ACP provides absorber-specific heat capacities as a function of temperature. AENTHL returns the absorber enthalpies as a function of temperature and a reference temperature for which the enthalpy will be zero.

\subsubsection{Specific Heat Capacity of Ag-In-Cd (ACP)}

The expressions used for the specific heat capacity of Ag-In-Cd are atomic fraction weighted averages of the specific heat capacities of silver, indium, and cadmium

$c_{p}=\frac{0.808 C_{p m_{A g}}+0.143 C_{p m}+0.049 C_{p m_{C d}}}{0.109 \mathrm{~kg} / \text { mole alloy }}$

where

$$
\begin{aligned}
& C_{p}=\text { alloy specific heat capacity }(\mathrm{J} / \mathrm{kg} \cdot \mathrm{K}) \\
& \mathrm{C}_{\mathrm{pm}}=\text { molar heat capacity of silver }(\mathrm{J} / \mathrm{mole} \cdot \mathrm{K}) \\
& C_{\mathrm{pm}}=\text { molar heat capacity of indium }(\mathrm{J} / \mathrm{mole} \cdot \mathrm{K}) \\
& \mathrm{C}_{\mathrm{pm}}=\text { molar heat capacity of cadmium }(\mathrm{J} / \mathrm{mole} \cdot \mathrm{K}) .
\end{aligned}
$$

Expressions for the silver, indium, and cadmium molar heat capacities up to the beginning of melting, $1073 \mathrm{~K}$, were taken from Table 2-24 of Reference 8.2-1. All are correlations of the form 


\section{ACP, AENTHL}

$c_{p m}=a+b \times 10^{-3} \mathrm{~T}+d \times 10^{5} \mathrm{~T}^{-2}$

where

$$
\begin{aligned}
\mathrm{C}_{\mathrm{pm}} & =\text { molar heat capacity }(\mathrm{J} / \text { mole } \cdot \mathrm{K}) \\
\mathrm{T} & =\text { temperature }(\mathrm{K})
\end{aligned}
$$

and the constants $a, b$, and $d$ are listed in Table 8.2-1. For temperatures above $1073 \mathrm{~K}, C_{p}$ is assumed to be equal to its value at $1073 \mathrm{~K}$. Figure 8.2-1 shows the heat capacity of Ag-In-Cd calculated by ACP. A standard error of $10 \%$ of the calculated value is predicted.

\subsubsection{Specific Heat Capacity for Boron Carbide (ACP)}

The expressions used for the specific heat capacity of $B_{4} C$ are 1 isted below:

For $T<2700 \mathrm{~K}$,

$c_{p}=563+T\left(1.54-\mathrm{T} 2.94 \times 10^{-4}\right)$.

For $T \geq 2700 \mathrm{~K}$,

$C_{p}=2577.740$.

Equations (8.2-3) and (8.2-4) were developed from a curve given on page 588 of Reference 8.2-2. Figure 8.2-2 shows the heat capacity of boron carbide as calculated by the function ACP. The prediction has a standard error near 0.10 of its value. 


\section{ACP, AENTHL}

Table 8.2-1. Molar heat capacity constants for Equation (8.2-1) from Reference 8.2-1

\begin{tabular}{|c|c|c|c|}
\hline Metal & $\begin{array}{c}a \\
(\mathrm{~J} / \mathrm{mole} \cdot \mathrm{K})\end{array}$ & $\begin{array}{c}b \\
\left(\mathrm{~J} / \mathrm{mole} \cdot \mathrm{K}^{2}\right)\end{array}$ & $\begin{array}{c}d \\
(J \cdot K / m o l e)\end{array}$ \\
\hline Silver & 21.3 & 4.27 & 1.51 \\
\hline Indium & 24.3 & 10.5 & 0 \\
\hline Cadmium & 22.2 & 12.3 & 0 \\
\hline
\end{tabular}




\section{ACP, AENTHL}

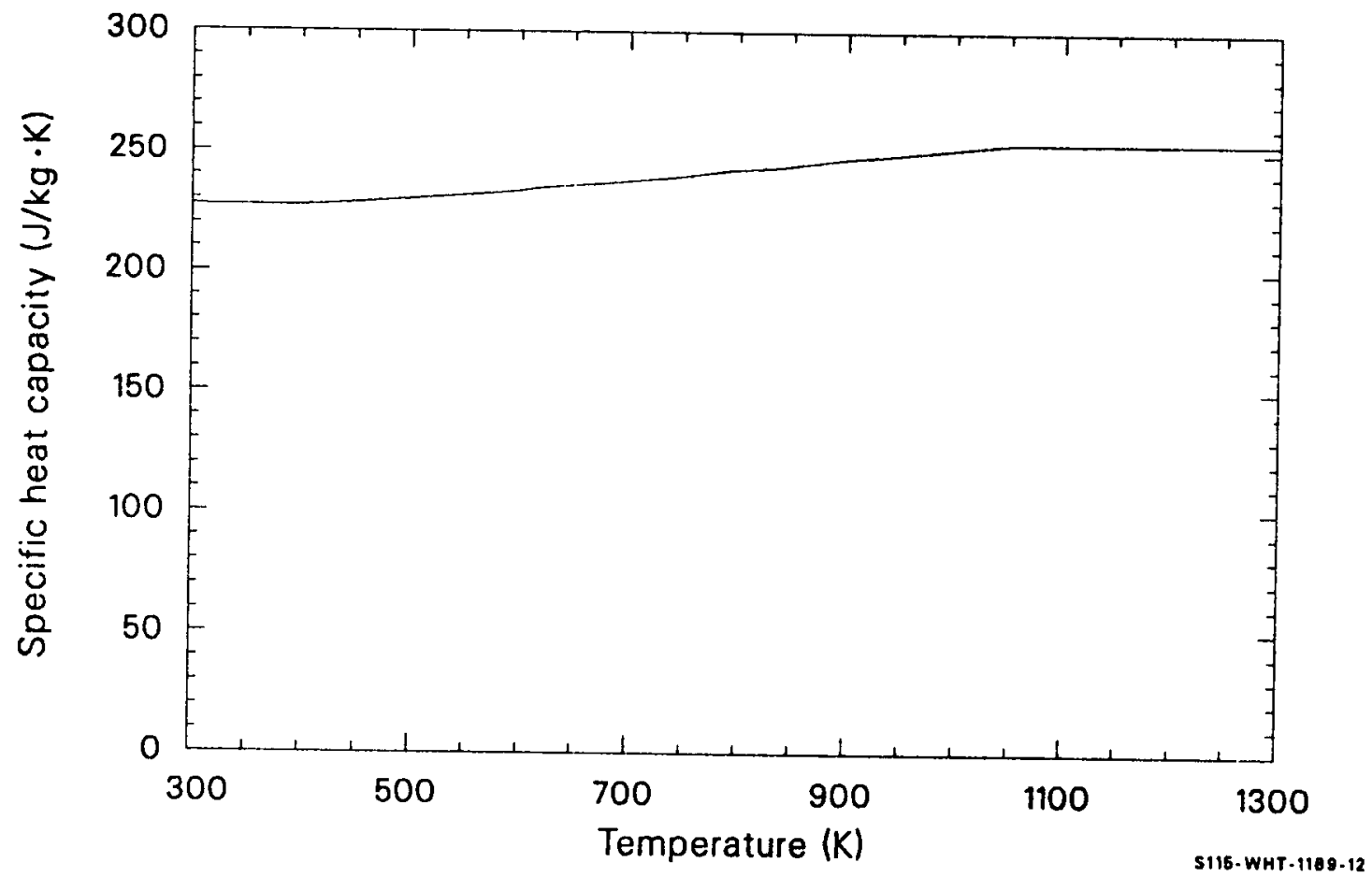

Figure 8.2-1. Silver-indium-cadmium absorber heat capacity. 
ACP, AENTHL

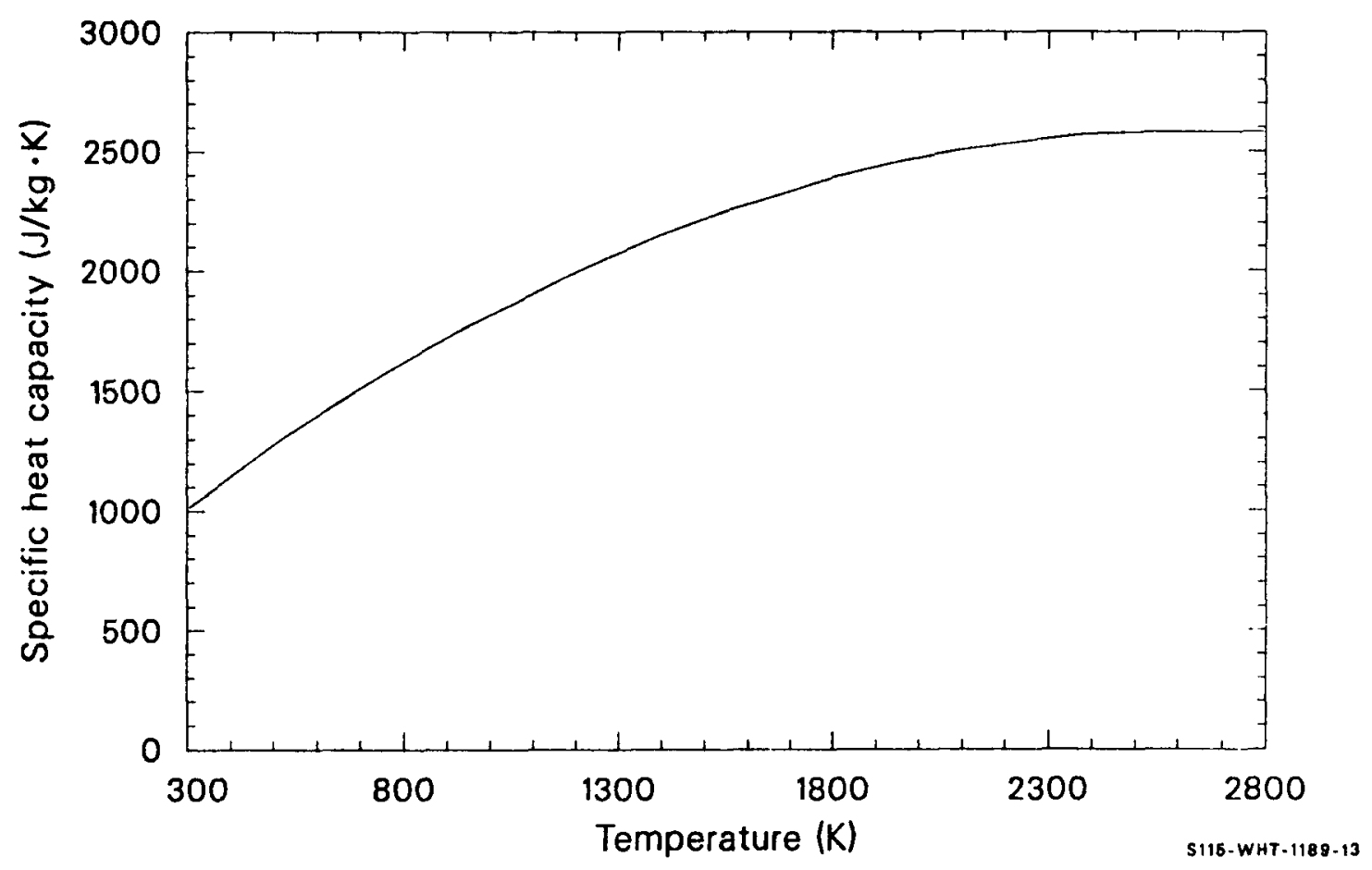

Figure 8.2-2. Boron carbide absorber heat capacity. 


\section{ACP, AENTHL}

\subsubsection{Enthalpy of Ag-In-Cd (AENTHL)}

Integrals of Equation (8.2-2), (8.2-3), or (8.2-4) are used to compute enthalpy changes in the AENTHL function for the Ag-In-Cd absorber (ICTYPE = 1). The heat of fusion which is included in the AENTHL function is an estimate. The Ag-In-Cd heat of fusion, $9.5610^{4} \mathrm{~J} / \mathrm{kg}$, was estimated by multiplying the molar heats of fusion of silver, indium, and cadmium by the atomic fraction of each element in the alloy; summing the calculated fractional heats of fusion; and dividing the sum by 0.109 , the weight of a $g$-mole of the alloy in kilograms. The elemental heats of fusion were obtained from Tables 2 through 24 of Reference 8.2-1. Figure 8.2-3 shows the enthalpy changes calculated for Ag-In-Cd by AENTHL. The prediction has a standard error near 0.10 of its value.

\subsubsection{Enthalpy of Boron Carbide (AENTHL)}

An integral of Equation (8.2-3) is used to compute enthalpy changes in the AENTHL function for the $B_{4} C$ absorber (ICTYPE $=2$ ). The estimated heat of fusion for $\mathrm{B}_{4} \mathrm{C}$ was taken to be that of $\mathrm{UO}_{2}, 2.74 \times 10^{5} \mathrm{~J} / \mathrm{kg}$.

Figure 8.2-4 shows the enthalpy changes calculated for $B_{4} C$ by AENTHL. The prediction has a standard error near 0.10 of its value.

\subsubsection{References}

8.2.1. C. T. Lynch (ed.), Handbook of Materials Science, II: Metals, Composites and Refractory Materials, Cleveland: CRC Press, Inc.

8.2-2. Aerojet Nuclear Company, Materials Properties Data Book, AGC2275, 1970 . 
ACP, AENTHL

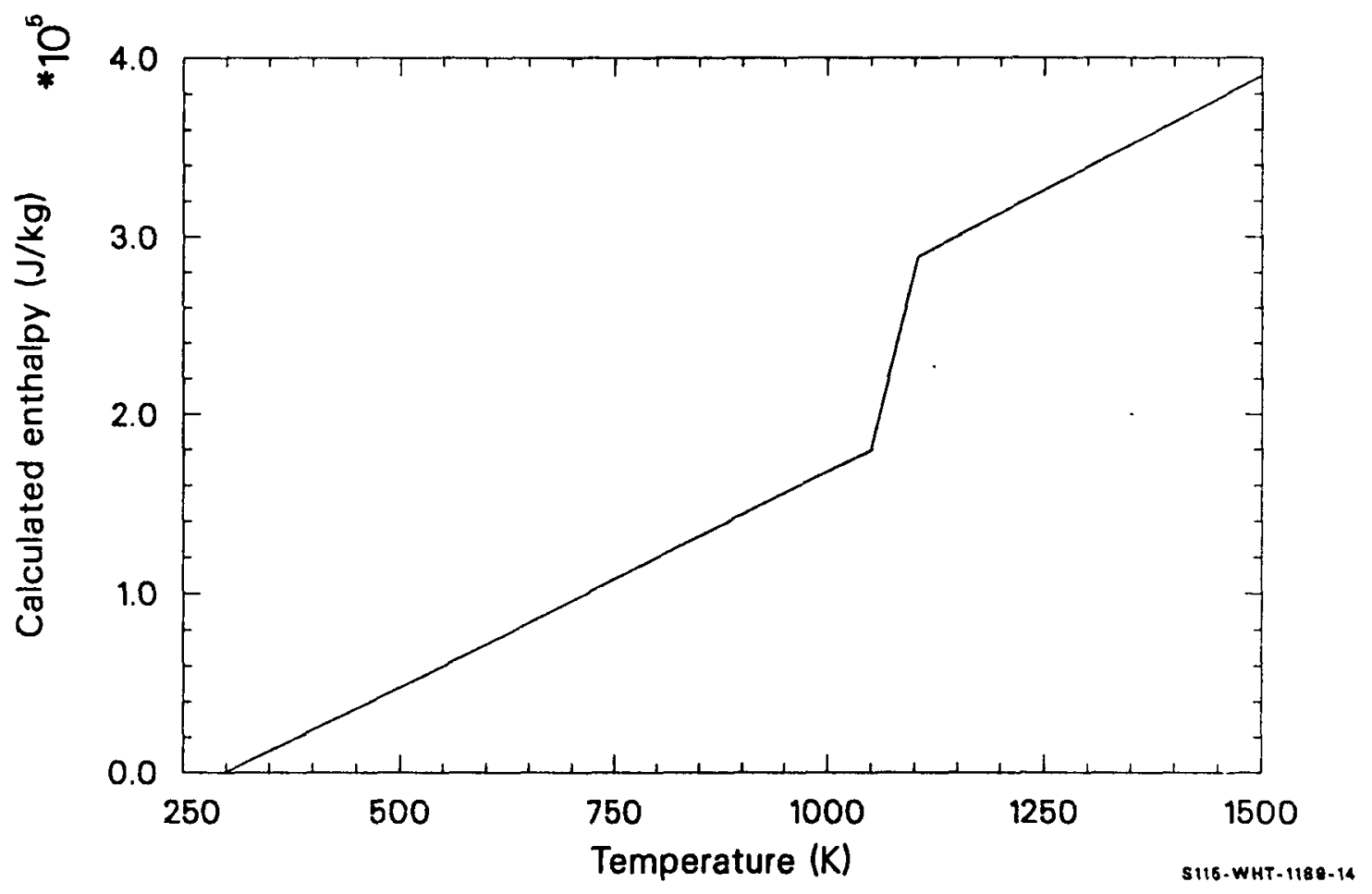

Figure 8.2-3. Silver-indium-cadmium absorber enthalpy. 
ACP, AENTHL

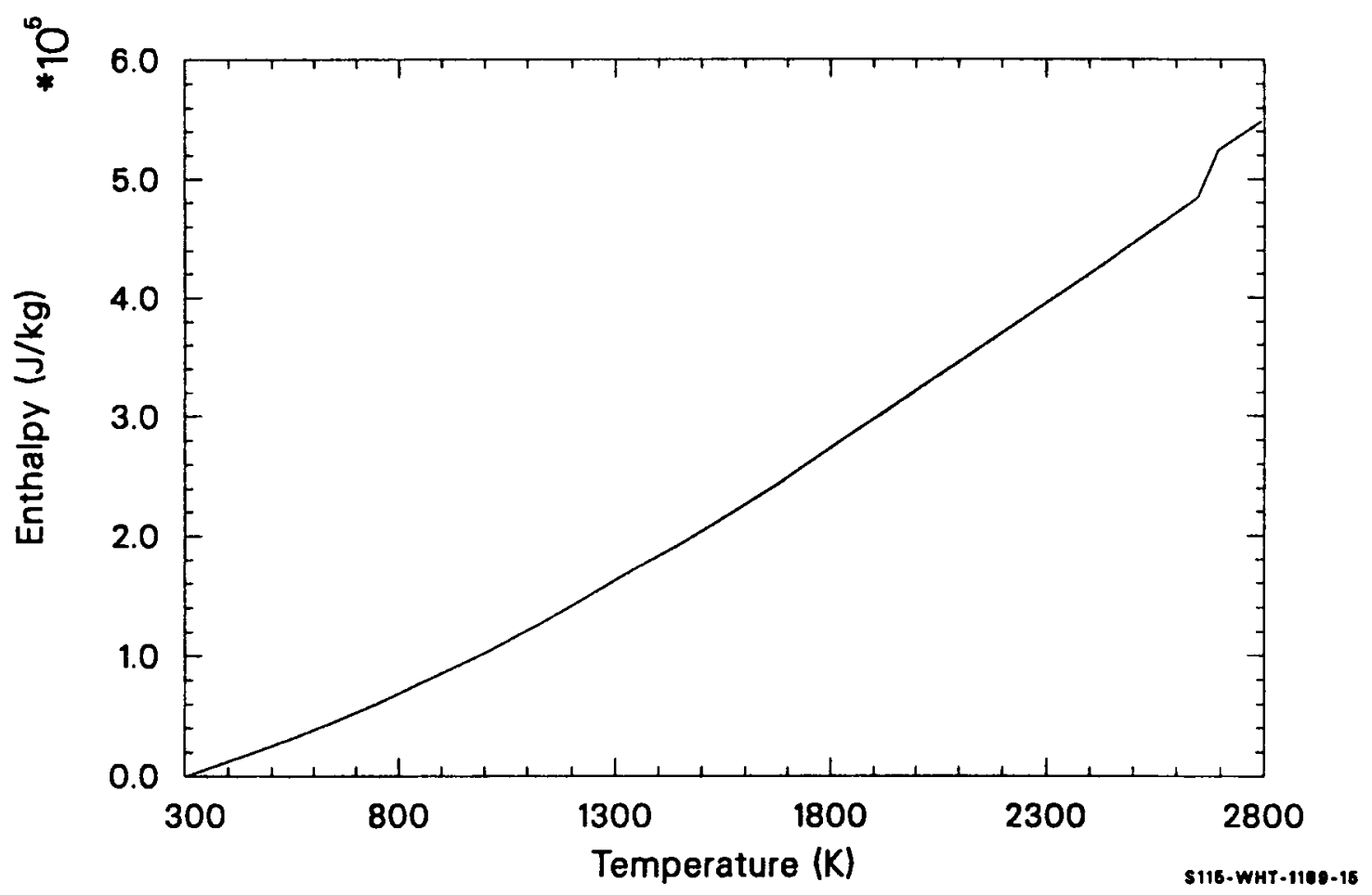

Figure 8.2-4. Boron carbide absorber enthalpy. 


\section{ATHCON}

\subsection{Thermal Conductivity (ATHCON)}

(D. L. Hagrman)

The only input required by ATHCON to calculate the thermal conductivity of $\mathrm{Ag}-\mathrm{In}-\mathrm{Cd}$ or $\mathrm{B}_{4} \mathrm{C}$ is the absorber temperature.

\subsubsection{Thermal Conductivity of Ag-In-Cd (ATHCON)}

The expressions used for $\mathrm{Ag}-\mathrm{In}-\mathrm{Cd}$ are listed below:

For $300 \leq T<1073 \mathrm{~K}$,

$K_{a}=2.805 \times 10^{1}+T\left(1.101 \times 10^{-1}-4.436 \times 10^{-5} \mathrm{~T}\right)$

For $1073 \leq \mathrm{T}<1123 \mathrm{~K}$,

$K_{a}=1.119736 \times 10^{3}-0.954592 \mathrm{~T}$.

For $T \geq 1123 \mathrm{~K}$,

$K_{a}=47.730$

where

$K_{a}=$ absorber thermal conductivity $(W / m \cdot K)$

$T=$ absorber temperature (K). 


\section{ATHCON}

The correlation (8.3-1) was derived by fitting a second-degree polynomial to the first, fourth, and seventh entries of a table of properties provided by Reference 8.3-1. The table is reproduced as Table 8.3-1. Equation (8.3-3) was derived by dividing the conductivity predicted by Equation (8.3-1) for $1098 \mathrm{~K}$ (the middle of the melting range) by two to estimate the conductivity when this face-centered cubic solid $8.3-1$ melts. The method for estimating liquid conductivities follows recommendations by Nazare et al.8.3-2 Equation (8.3-2) is simply a linear interpolation between the conductivity predicted by Equation (8.3-1) at the beginning of melting ( $1073 \mathrm{~K})$ and Equation (8.3-3) when melting is complete. Figure 8.3-1 is a comparison of the predictions of Equations (8.3-1) to (8.3-3) with the recommended values of Table 8.3-1. Figure 8.3-2 shows the thermal conductivity of the Ag-In-Cd absorber calculated by ATHCON. An expected standard error of 0.20 is recommended.

\subsubsection{Thermal Conductivity of Boron Carbide (ATHCON)}

For $\mathrm{B}_{4} \mathrm{C}$, thermal conductivity, the following expressions are used:

For $\mathrm{T}<1700 \mathrm{~K}$,

$K_{a}=\frac{1}{1.79 \times 10^{-2}+4.98 \times 10^{-5} \mathrm{~T}}$.

For $\mathrm{T} \geq 1700 \mathrm{~K}$

$K_{a}=9.750390$

The expression is a fit to values of 23.37 and $13.76 \mathrm{~W} / \mathrm{m} \cdot \mathrm{K}$ at 500 and $1100 \mathrm{~K}$, respectively, obtained from the $150-1 \mathrm{bm} / \mathrm{ft}^{3}$ curve presented on page 947 of Reference 8.3-3. An expected standard deviation of $50 \%$ is recommended because of the significant effect of density of the material. Figure 8.3-3 shows the predicted values for the thermal conductivity of $\mathrm{B}_{4} \mathrm{C}$. 


\section{ATHCON}

Table 8.3-1. Thermal condyctifity values for $\mathrm{Ag}-\mathrm{In}-\mathrm{Cd}$ recommended by Cohen et al.8.3-1

\begin{tabular}{cc}
$\begin{array}{c}\text { Temperature } \\
(\mathrm{K})\end{array}$ & $\begin{array}{c}\text { Thermal Conductivity } \\
(\mathrm{W} / \mathrm{m} \cdot \mathrm{K})\end{array}$ \\
\cline { 2 - 2 } 323 & 59.0 \\
373 & 62.8 \\
473 & 70.3 \\
573 & 76.6 \\
673 & 82.0 \\
773 & 86.6 \\
873 & 90.4
\end{tabular}




\section{ATHCON}

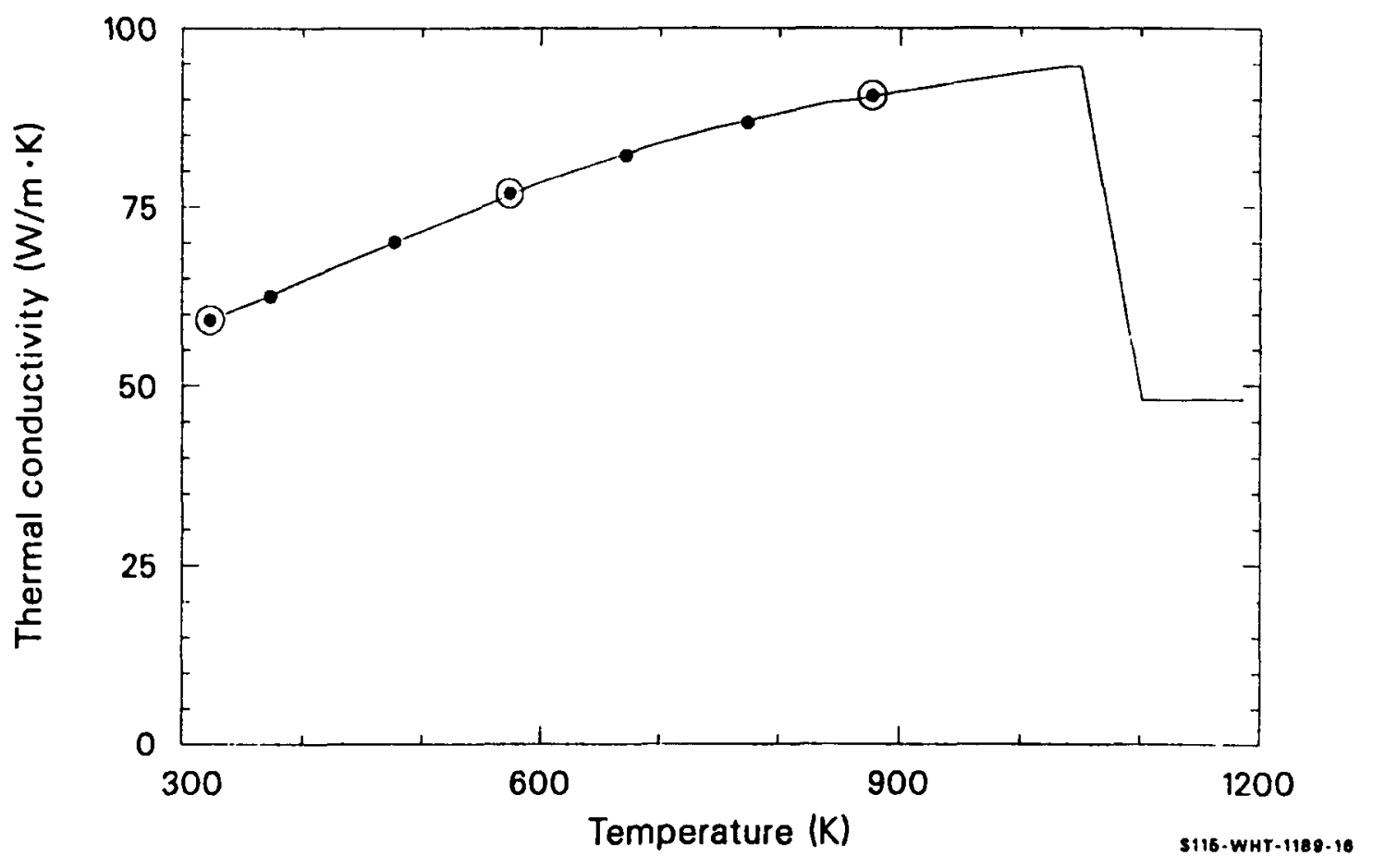

Figure 8.3-1. Thermal conductivity of silver-indium-cadmium alloy. 


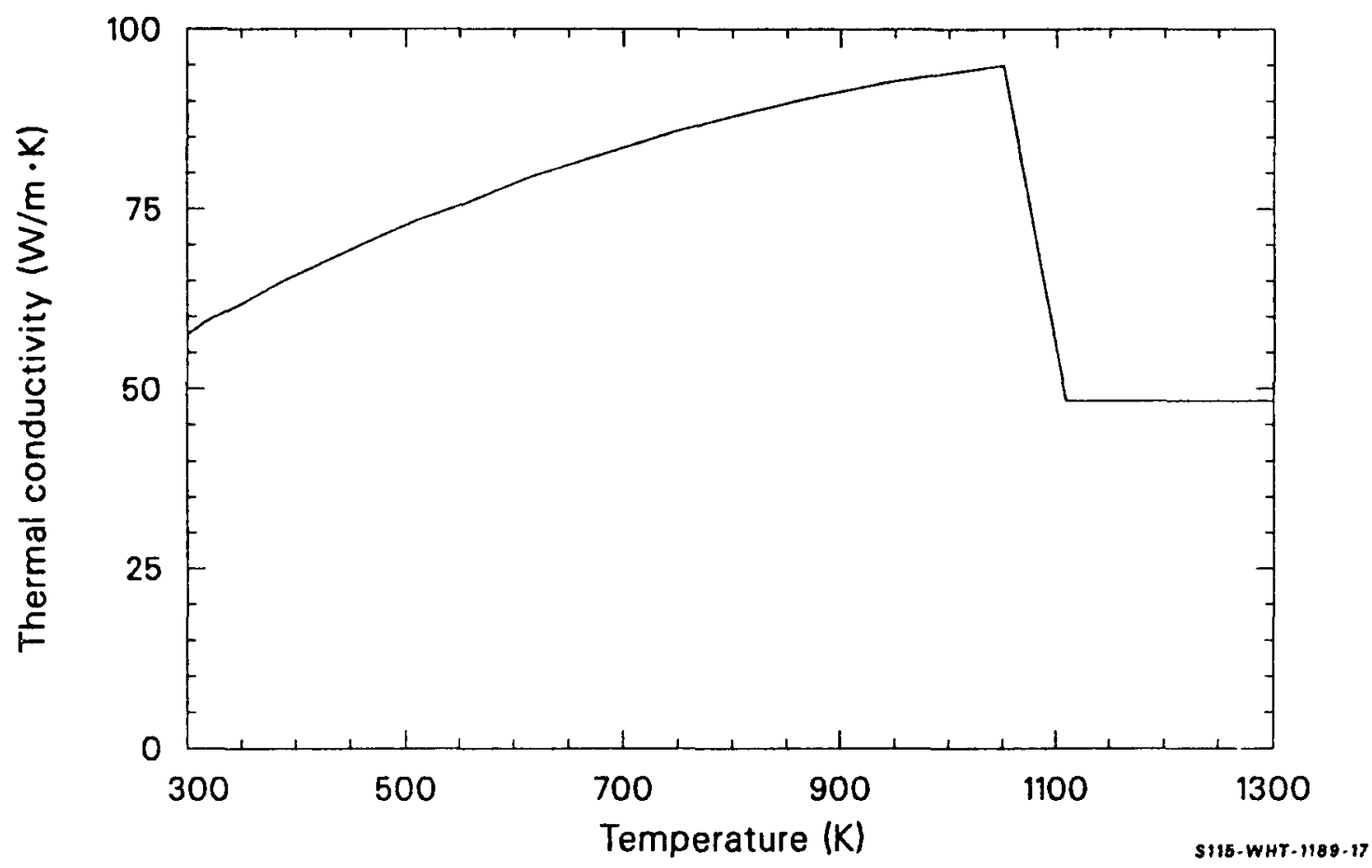

Figure 8.3-2. Thermal conductivity of silver-indium-cadmium absorber. 


\section{ATHCON}

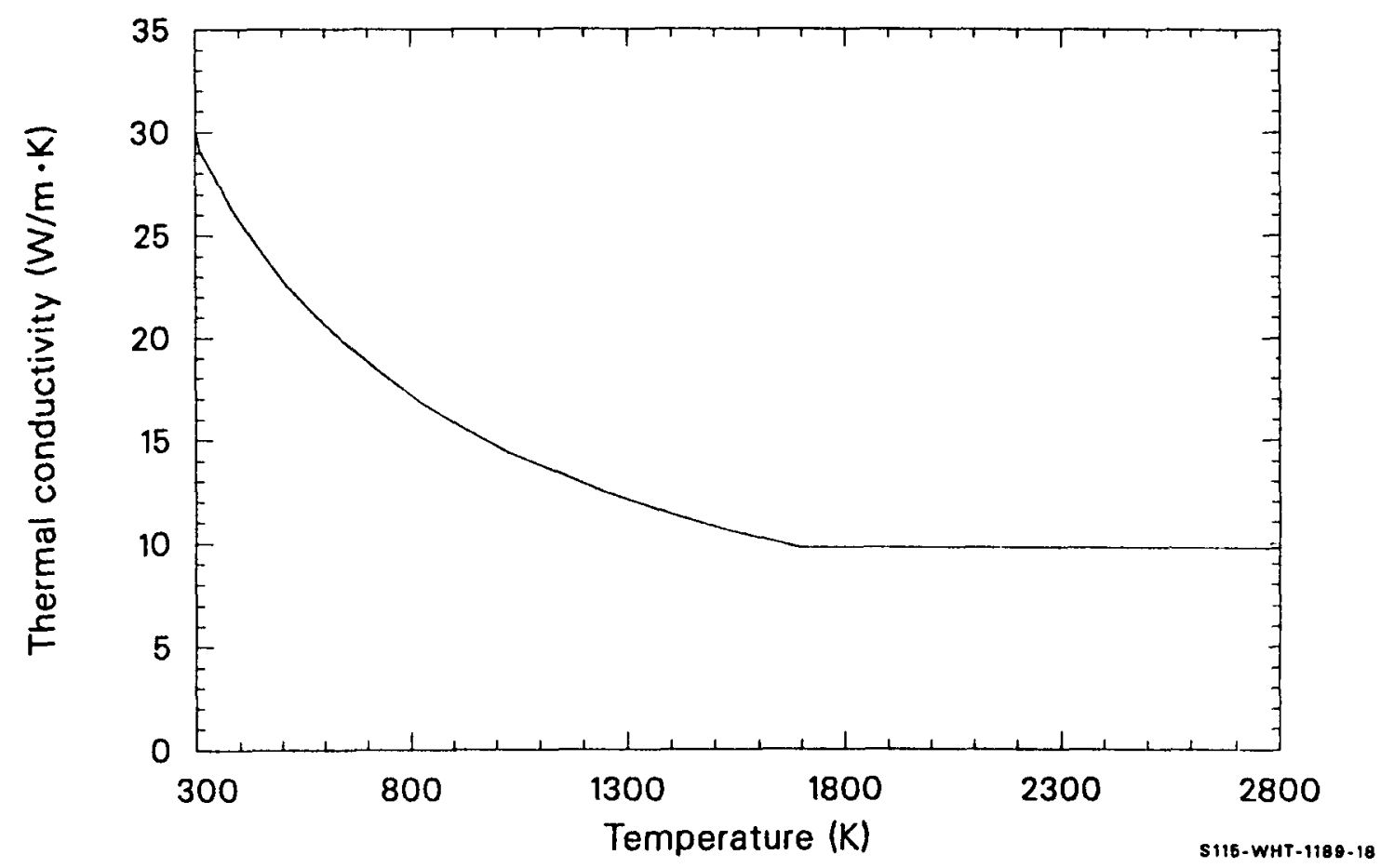

Figure 8.3-3. Thermal conductivity of boron carbide absorber. 


\subsubsection{References}

8.3-1. I. Cohen, E. F. Losco, and J. D. Eichenberg, "Metallurgical Design and Properties of Silver-Indium-Cadmium Alloys for PWR Control Rods," Bettis Technical Review, 1958.

8.3-2. S. Nazare, G. Ondracek, and B. Schulz, "Properties of Light Water Reactor Core Melts," Nuclear Technology, 32, 1977, pp. 239-246.

8.3-3. A. Goldsmith, T. E. Waterman, and H. J. Hirschhorn, Handbook of Thermophysical Properties of Solid Materials, Revised Edition, Volume III: Ceramics, New York: The MacMillan Company, 1961. 


\section{ATHEXP, ADEN}

\subsection{Thermal Expansion and Density (ATHEXP, ADEN)}

(D. L. Hagrman)

The function ATHEXP calculates absorber thermal expansion strain, while ADEN is designed to use this information to calculate absorber densities. ATHEXP requires input values of the materials temperature and a reference temperature (for which strain will be taken as zero). ADEN requires only temperature.

\subsubsection{Thermal Expansion Strain of Ag-In-Cd}

The expressions used for the thermal expansion strain of Ag-In-Cd absorbers are listed below:

For $300 \leq T<1073 \mathrm{~K}$,

$\epsilon_{a}=2.25 \times 10^{-5}(T-300)$.

For $1073 \leq T<1123 \mathrm{~K}$,

$\epsilon_{\mathrm{a}}=-0.25875+2.625 \times 10^{-4} \times \mathrm{T}$.

For $T \geq 1123 \mathrm{~K}$,

$\epsilon_{a}=3.0 \times 10^{-2}$

where

$\epsilon_{\mathrm{a}}=$ absorber thermal expansion strain $(\mathrm{m} / \mathrm{m})$ 


\section{ATHEXP, ADEN}

$T=$ absorber temperature $(K)$.

Equation (8.4-1) is taken from Table $V$ of Reference 8.4-1. Equation (8.4-3) was obtained by modifying the prediction of Equation (8.4-1) to allow for an increase of 0.038 in volume (0.013 in length) at the center of the melting range of 1073 to $1123 \mathrm{~K}$ because page 186 of Reference 8.4-2 reports this value for the change in volume of silver, the major component of the alloy, during melting. Equation (8.4-2) is a linear interpolation between the predictions of Equations (8.4-1) and (8.4-3) for the beginning and end of the melting range. The expected standard error of Equations (8.4-1) to (8.4-3), \pm 0.10 of the predicted strain, is small because the data cover most of the range of the correlations. Figure 8.4-1 shows the predicted thermal expansion strain for Ag-In-Cd.

\subsubsection{Thermal Expansion Strain of Boron Carbide}

The expression used to calculate thermal expansion strains of $B_{4} C$ is

$$
\epsilon_{\mathrm{a}}=-1.10 \times 10^{-3}+\mathrm{T}\left(3.09 \times 10^{-6}+1.88 \times 10^{-9} \mathrm{~T}\right)
$$

This correlation is a fit to values of $0,2.58 \times 10^{-3}$, and $5.32 \times$ $10^{-3}$ at 300,800 and $1200 \mathrm{~K}$, respectively, obtained from a curve presented on page 949 of Reference 8.4-3. The expected standard error is \pm 0.2 of the predicted strain. Figure 8.4-2 shows the predicted thermal expansion strain for $B_{4} C$.

\subsubsection{Density Calculations for Ag-In-Cd and Boron Carbide}

The function ADEN uses the general relation between density and thermal strain, together with reference densities of $10.17 \times 10^{3} \mathrm{~kg} / \mathrm{m}^{3}$ at $300 \mathrm{~K}$ for Ag-In-Cd (Reference 8.4-1, Table V) and $2.5 \times 10^{3} \mathrm{~kg} / \mathrm{m}^{3}$ at $300 \mathrm{~K}$ for $\mathrm{B}_{4} \mathrm{C}$ (page 943 of Reference 8.4-3). For $\mathrm{Ag}-\mathrm{In}-\mathrm{Cd}$, the expected standard 


\section{ATHEXP, ADEN}

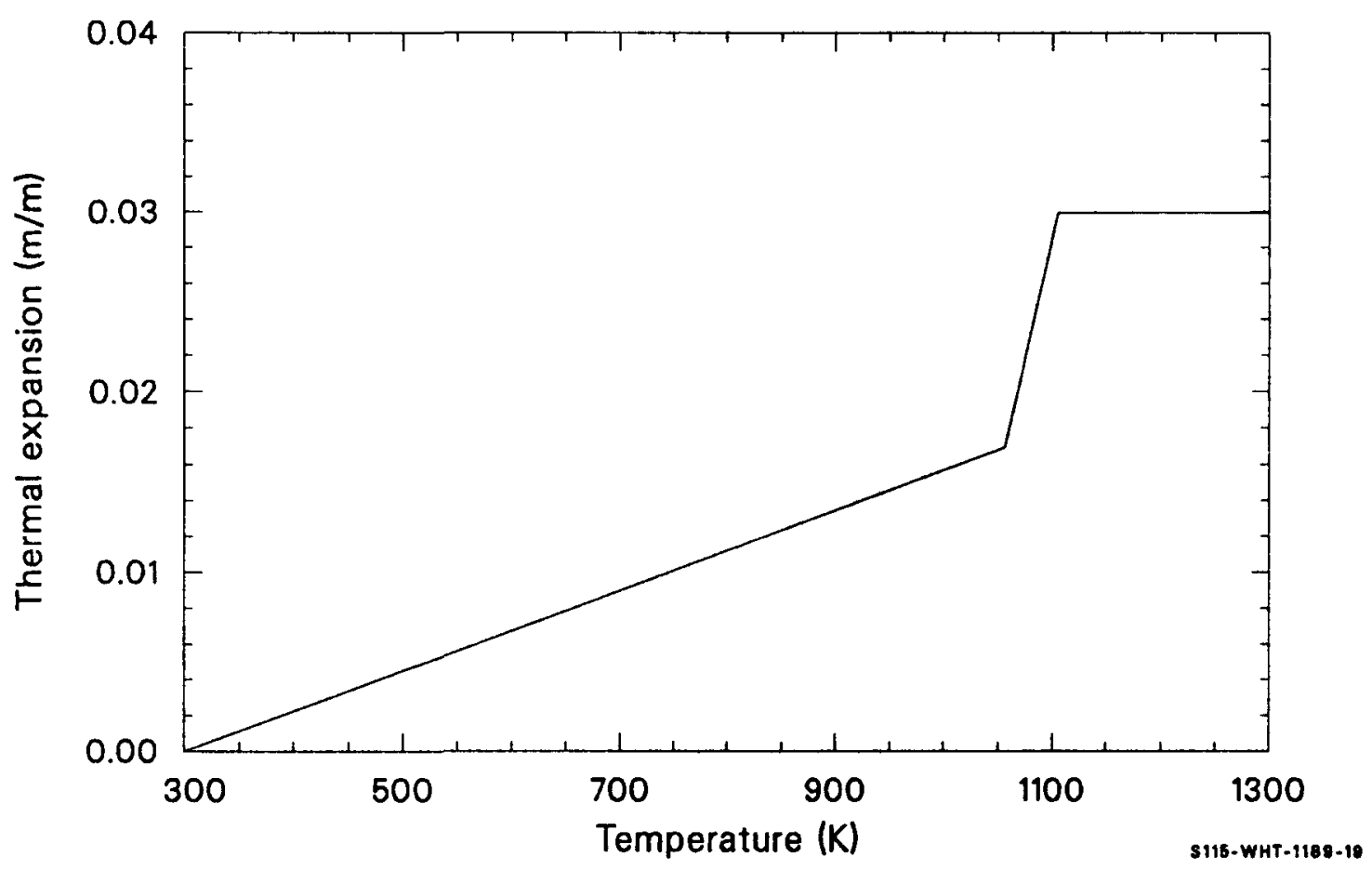

Figure 8.4-1. Thermal expansion strain of silver-indium-cadmium absorber. 


\section{ATHEXP, ADEN}

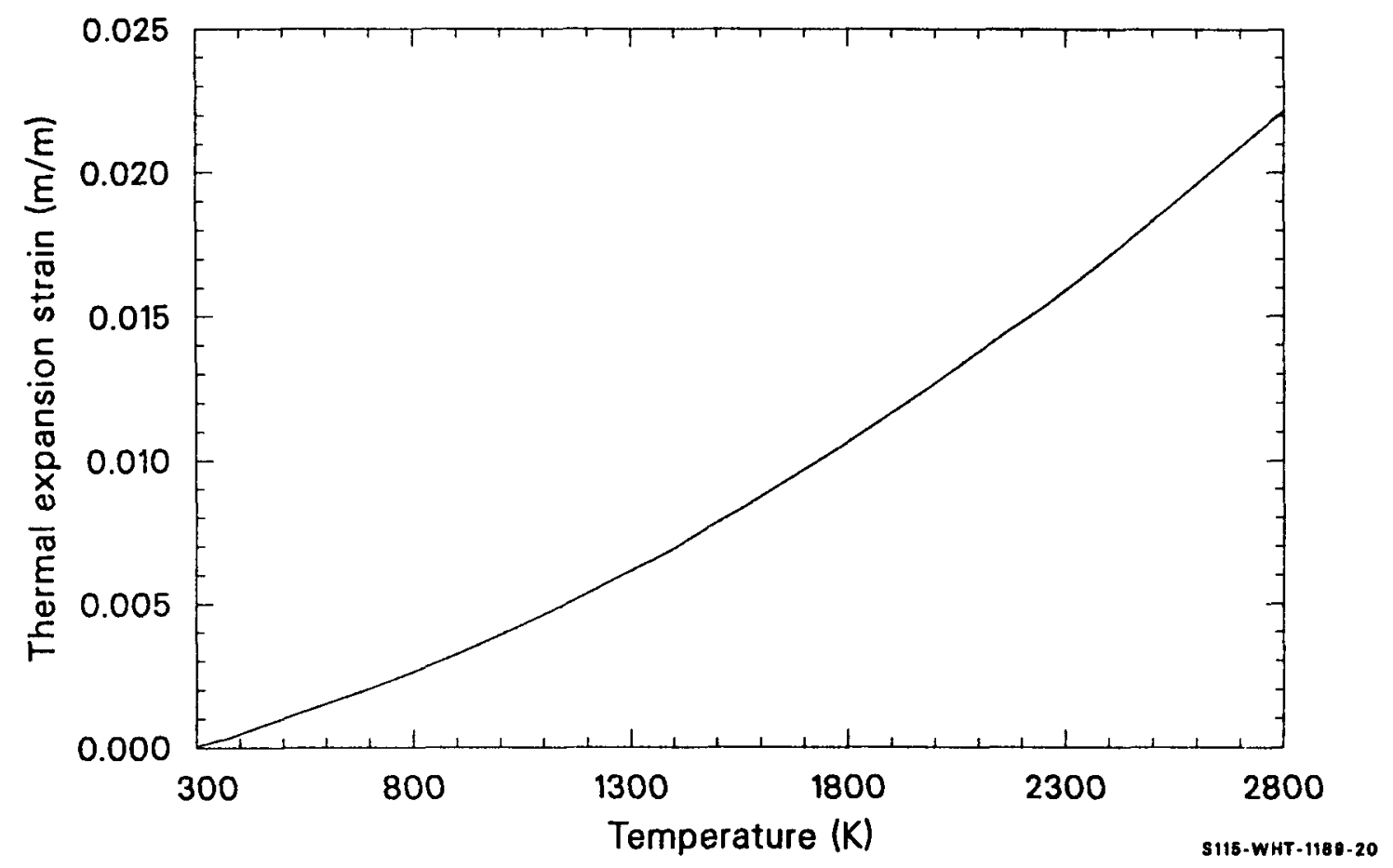

Figure 8.4-2. Thermal expansion strain of boron carbide absorber. 
error is only 0.02 of the predicted density; but for $B_{4} C$, it is \pm 0.30 of the predicted density.

The prediction for $\mathrm{Ag}-\mathrm{In}-\mathrm{Cd}$ and $\mathrm{B}_{4} \mathrm{C}$ versus temperature given by the function are shown in Figures 8.4-3 and 8.4-4.

\subsubsection{References}

8.4-1. I. Cohen, E. F. Losco and J. D. Eichenberg, "Metallurgical Design and Properties of Silver-Indium-Cadmium Alloys for PWR Control Rods," Bettis Technical Review, 1958.

8.4-2. C. J. Smithells and E. A. Brandes (eds.), Metals Reference Book, London and Boston: Butterworths, 1956.

8.4-3. A. Goldsmith, T. E. Waterman, and H. J. Hirschhorn, Handbook of Thermophysical Properties of Solid Materials. Revised Edition Volume III: Ceramics, New York: The MacMillan Company, 1961. 


\section{ATHEXP, ADEN}

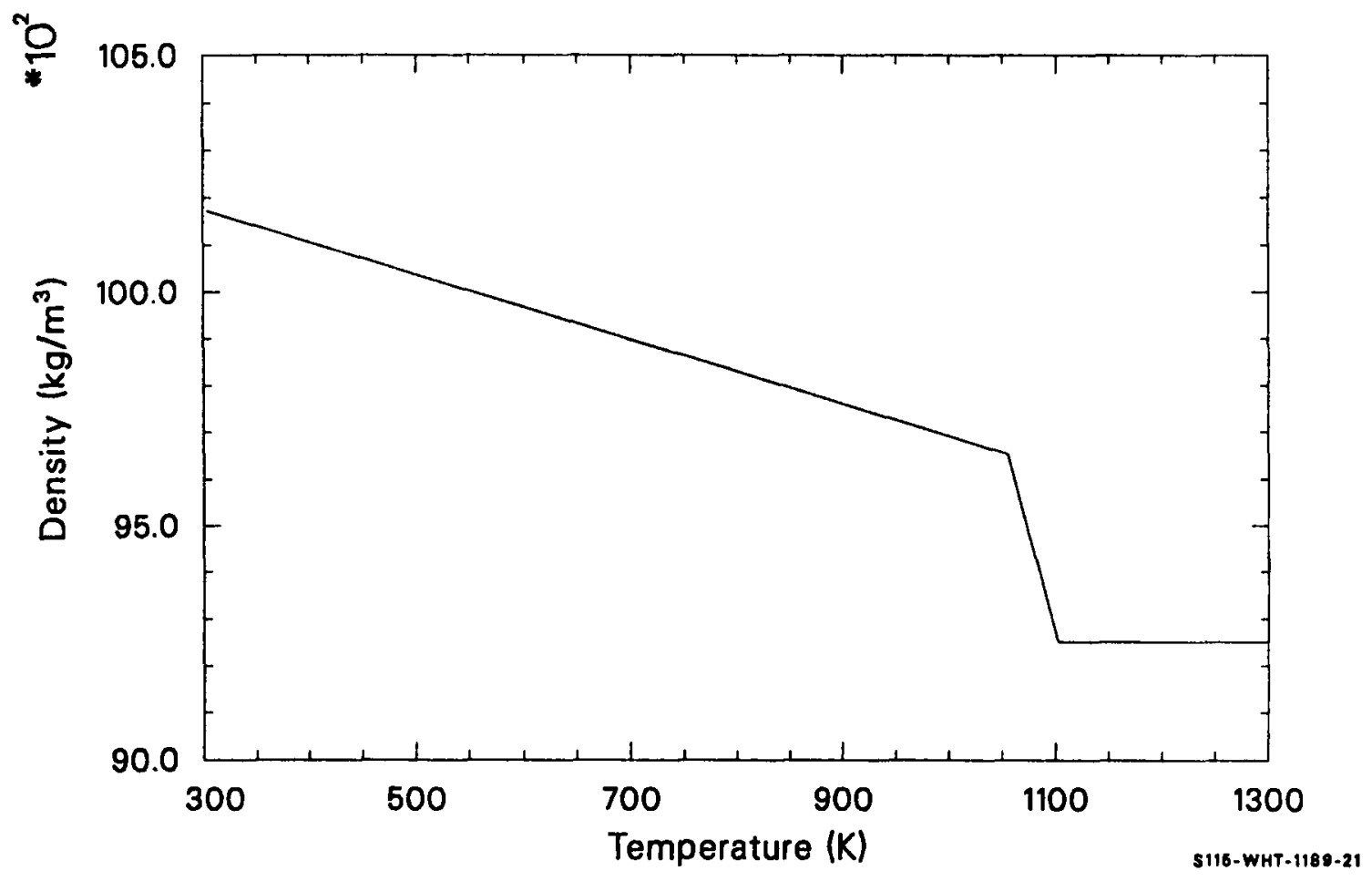

Figure 8.4-3. Density of silver-indium-cadmium absorber. 
ATHEXP, ADEN

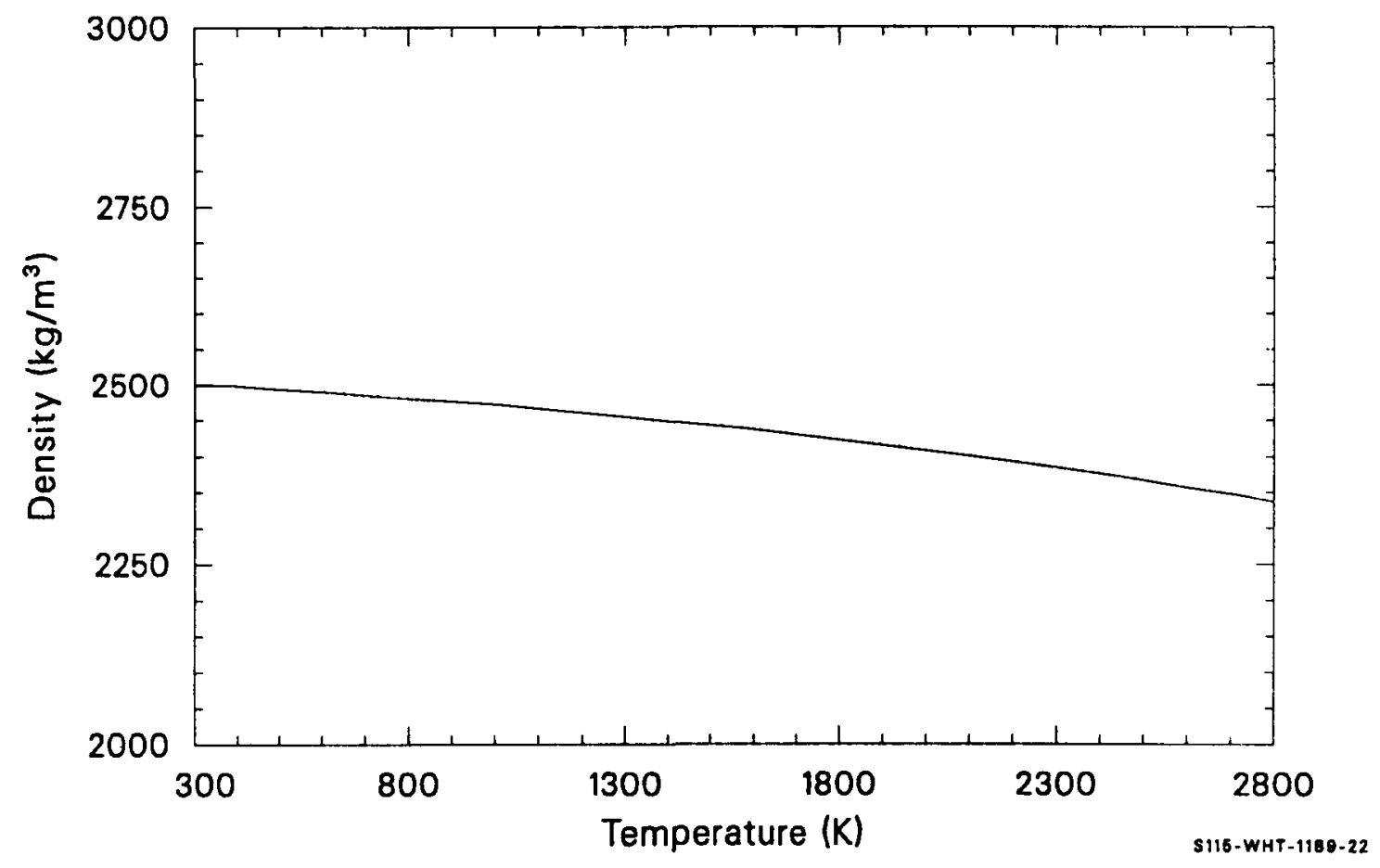

Figure 8.4-4. Density of boron carbide absorber. 


\title{
8.5 Surface Tension (ASTEN)
}

\author{
(D. L. Hagrman)
}

\subsubsection{Model Development}

The function ASTEN returns the interfacial surface tension of absorber material on stainless steel cladding. The value used for both the Ag-In-Cd and $\mathrm{B}_{4} \mathrm{C}$ absorbers is

$S T=0.3$

where ST is the interfacial surface tension $(\mathrm{N} / \mathrm{m})$.

The number used is an engineering estimate based on the relative magnitudes of zirconium and silver liquid surface tensions given by Allen ${ }^{8.5-1}$ and the interfacial surface tension for zircaloy and zirconiumuranium-oxygen compounds given in the ZUSTEN function of Section 11.6. The expected error of this number is $+2.0,-0.2$.

\subsubsection{References}

8.5-1. B. C. Allen, "The Surface Tension of Liquid Transition Metals at Their Melting Points, "Transactions of the Metallurgical Society of AIME, 227, 1963, pp. 1175-1183. 


\subsection{VIScosity (AVISC)}

(D. L. Hagrman)

The function AVISC returns an estimate of the viscosity of $\mathrm{Ag}-\mathrm{In}-\mathrm{Cd}$ or $\mathrm{B}_{4} \mathrm{C}$ neutron absorbers as a function of temperature.

\subsubsection{Viscosity of Ag-In-Cd}

For Ag-In-Cd, a viscosity of $10^{10} \mathrm{~Pa} \cdot \mathrm{s}$ is returned for temperatures below $1050 \mathrm{~K}$. When the temperature is above $1100 \mathrm{~K}$, a mole fraction weighted average of the alloy component viscosities is used.

$\eta_{1}=f_{A g} \eta_{A g}+f_{I n} \eta_{I n}+f_{C d} \eta_{C d}$

where

$$
\begin{aligned}
& \eta_{1}=\text { viscosity of liquid absorber }(\mathrm{Pa} \cdot \mathrm{s}) \\
& f_{A g}=\text { mole fraction of silver in the alloy, } 0.808 \\
& \eta_{A g}=\text { viscosity of silver }(\mathrm{Pa} \cdot \mathrm{s}) \\
& f_{I n}=\text { mole fraction of indium in the alloy, } 0.143 \\
& \eta_{\text {In }}=\text { viscosity of indium }(\mathrm{Pa} \cdot \mathrm{s}) \\
& \mathrm{f}_{\mathrm{Cd}}=\text { mole fraction of cadmium in the alloy, } 0.049 \\
& \eta_{\mathrm{cd}}=\text { viscosity of cadmium }(\mathrm{Pa} \cdot \mathrm{s}) .
\end{aligned}
$$




\section{AVISC}

The component viscosities are calculated with expressions obtained from procedures recommended by Nazare, Ondracek, and Schulz. ${ }^{8.6-1}$

$\eta_{A g}=2.95 \times 10^{-4} \exp \left(\frac{3187}{T}\right)$

$\eta_{\text {In }}=3.18 \times 10^{-4} \exp \left(\frac{768}{T}\right)$

$\eta_{C d}=3.19 \times 10^{-4} \exp \left(\frac{1190}{T}\right)$

where $T$ is the absorber temperature $(K)$.

When the temperature is between 1050 and $1100 \mathrm{~K}$, an interpolation scheme is used

$\eta=\frac{\eta_{1}(T-1050)+10^{10}(1100-T)}{50}$

where $\eta$ is the viscosity of the absorber in the two-phase temperature range, 1050 to $1100 \mathrm{~K}(\mathrm{~Pa} \cdot \mathrm{s})$. Figure $8.6-1$ is a plot showing the calculated liquid phase viscosity of Ag-In-Cd. The expected standard error is \pm 0.8 of the predicted value because there are no data to support the model.

\subsubsection{Viscosity of Boron Carbide}

For $\mathrm{B}_{4} \mathrm{C}$ absorbers, a viscosity of $10^{10} \mathrm{~Pa} \cdot \mathrm{s}$ is returned for temperatures less than $2700 \mathrm{~K}$. When the temperature is at or above $2700 \mathrm{~K}$, the expression used is 
AVISC

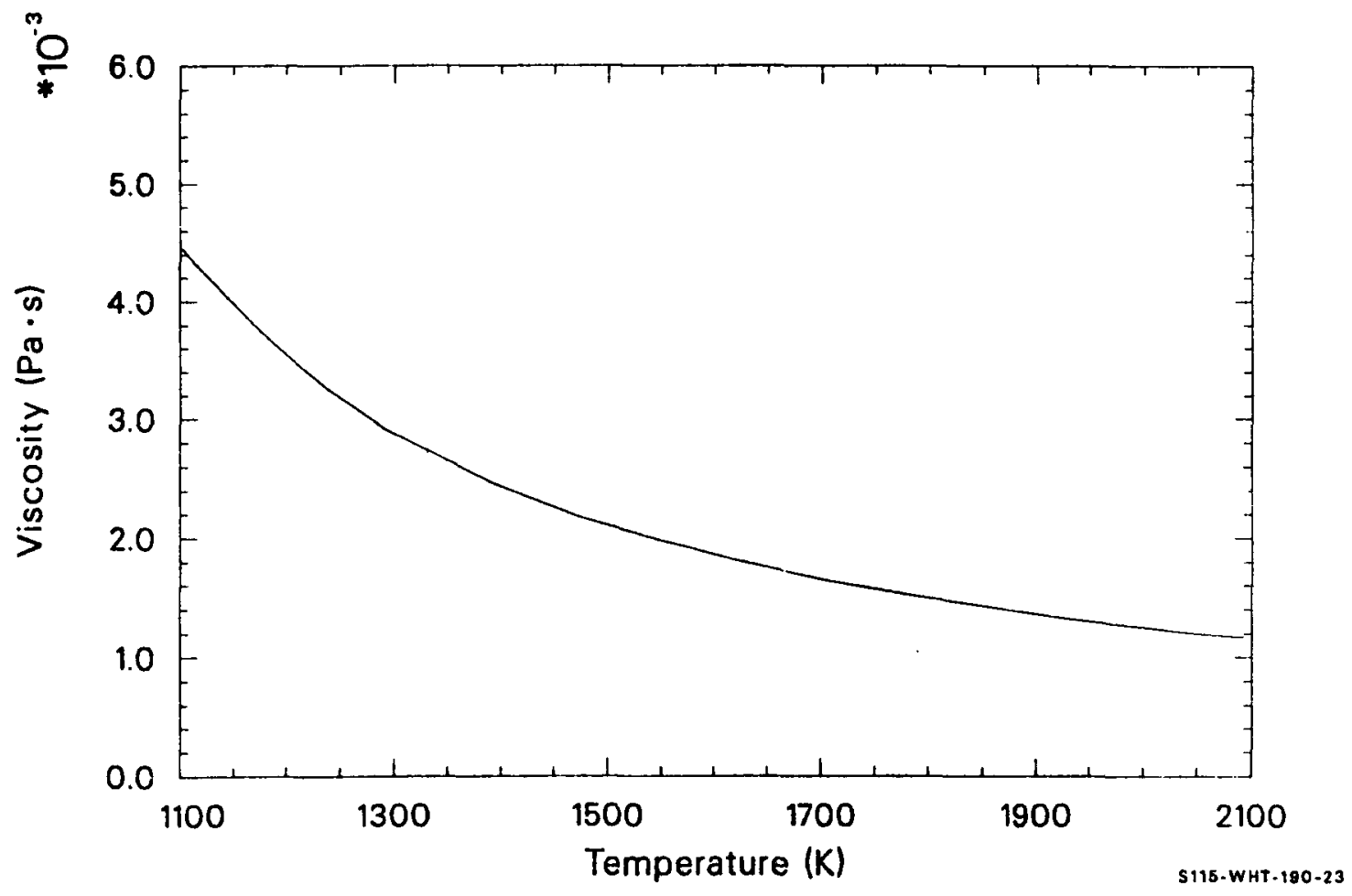

Figure 8.6-1. Viscosity of silver-indium-cadmium absorber. 


\section{AVISC}

$\eta_{B_{4} C}=1.21 \times 10^{-4} \exp \left(\frac{9158}{T}\right)$

where $\eta_{B_{4} C}$ is the viscosity of liquid $B_{4} C$ absorber (Pa.s).

Figure $8.6-2$ is a plot showing the calculated liquid phase viscosity of $B_{4} C$. The expected error of the $B_{4} C$ viscosity models is \pm 0.8 of the predicted value because there are no data in support of the model.

\subsubsection{References}

8.6-1. S. Nazare, G. Ondracek, and B. Schulz, "Properties of Light Water Reactor Core Melts," Nuclear Technology, 32, 1977, pp. 239-246. 


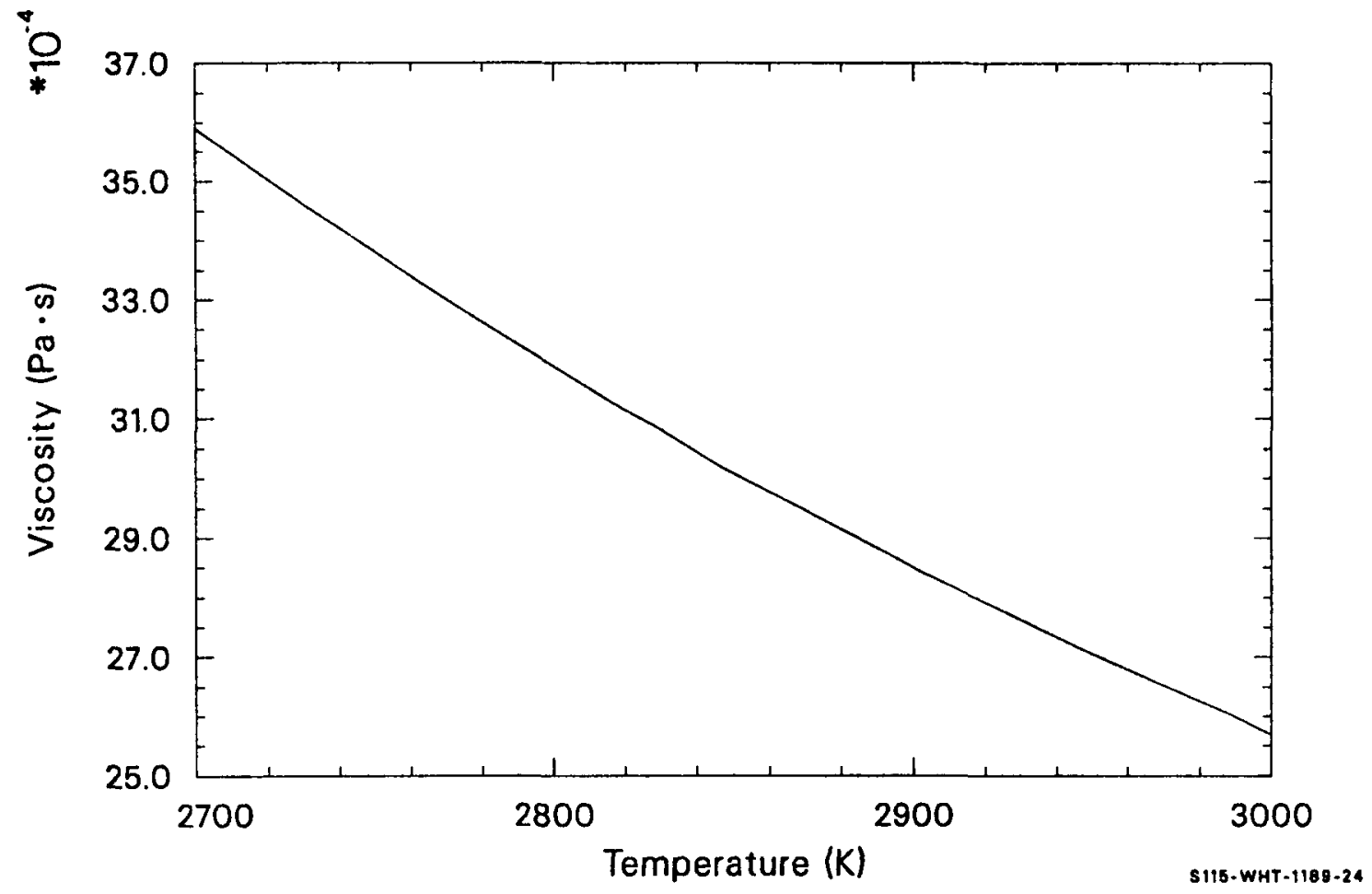

Figure 8.6-2. Viscosity of boron carbide absorber. 


\section{CORE COMPONENTS (ZIRCONIUM, URANIUM, ZIRCONIUM DIOXIDE, URANIUM DIOXIDE, STAINLESS STEEL, STAINLESS STEEL OXIDE, AND AG-IN-CD AND/OR BORON (ARBIDE)}

Extension of the MATPRO materials properties package to high temperatures requires consideration of mixtures and compounds that are not formed until zircaloy cladding melts. One approach to providing the properties of molten mixtures of core material has been to define standard compounds of core materials--Corium A, Corium E, Corium AX1, Corium EX1, Corium EX2, Corium EX3, etc. 11-1 This approach has been avoided here because deciding when to switch from properties of one kind of melt to another would needlessly complicate serious efforts to model severe core damage. The six different types of corium listed above are replaced with a single class of material whose properties vary with zirconium, uranium, and oxygen concentration in the subroutines originally supplied with MATPRO and with zirconium, uranium, stainless steel, oxygen, $\mathrm{Ag}-\mathrm{In}-\mathrm{Cd}$, and/or $\mathrm{B}_{4} \mathrm{C}$ in newer versions of the subcodes described in this section.

In the older versions of the subcodes, concentrations of iron, chrome, nickel, silver, indium, cadmium, and other low-melting components have been ignored because compounds rich in these components will probably migrate to cooler regions of the core before the melting temperature of zircaloy is attained. In the newer versions of the subcodes, only the concentrations of chrome, nickel, and a few other low-melting components have been ignored. Since both versions are supplied, a discussion of each subcode version will be included in this section.

Data for all the properties modeled in this section are very scarce, so most of the subcodes use interpolations of materials properties that are available--the properties of $\mathrm{UO}_{2}, \mathrm{ZrO}_{2}$, and zircaloy in the original version and these core component elements plus $\mathrm{FeO}, \mathrm{Fe}_{2} \mathrm{O}_{3}, \mathrm{Fe}_{3} \mathrm{O}_{4}$, silver, and $B_{4} C$ in the newer version. These materials are used as a basis 
for interpolation rather than the properties of elemental uranium, zirconium, and oxygen because $\mathrm{UO}_{2}, \mathrm{ZrO}_{2}$ and zircaloy more closely approximate the compositions of interest.

For Zr-U-0 compounds, a Gibbs triangle plot ${ }^{11-2}$ of the compositions of $\mathrm{Zr}-\mathrm{U}-\mathrm{O}$ compounds (as shown in Figure 11-1) illustrates this point. It can be shown that the composition of a mixture of any two ternary $\mathrm{Zr}-\mathrm{U}-0$ alloys will lie on a straight line joining the points representing the original compositions on a Gibbs plot. Severe core damage will melt zircaloy (represented here as mostly zirconium) that has been previously oxidized to some state between oxygen-stabilized zircaloy, $\operatorname{Zr}(0)$, and $\mathrm{ZrO}_{2}$. This melt will dissolve and mix with $\mathrm{UO}_{2}$. The gross compositions of interest are thus most likely to lie in the shaded region of the plot. (Some uranium-rich phases, which could melt and flow out of the hot region, are the only known exceptions to this general observation.)

When interpolated properties are used, the atomic fraction of each core material in the corium compound is input and is converted to a mole fraction using the following relation:

$$
m f c_{i}=\frac{a f_{i}}{\sum_{i=1}^{n} a f_{i}}
$$

where

$$
\begin{aligned}
& \mathrm{mfc}_{i}=\text { mole fraction of the } i \text {-th core component in the compound } \\
& \mathrm{af}_{i} \quad=\text { atomic fraction of the } i \text {-th core component in the compound } \\
& \mathrm{n} \quad=\text { number of core components in the compound. }
\end{aligned}
$$

An inspection of Equation (11-1) reveals several limitations: 


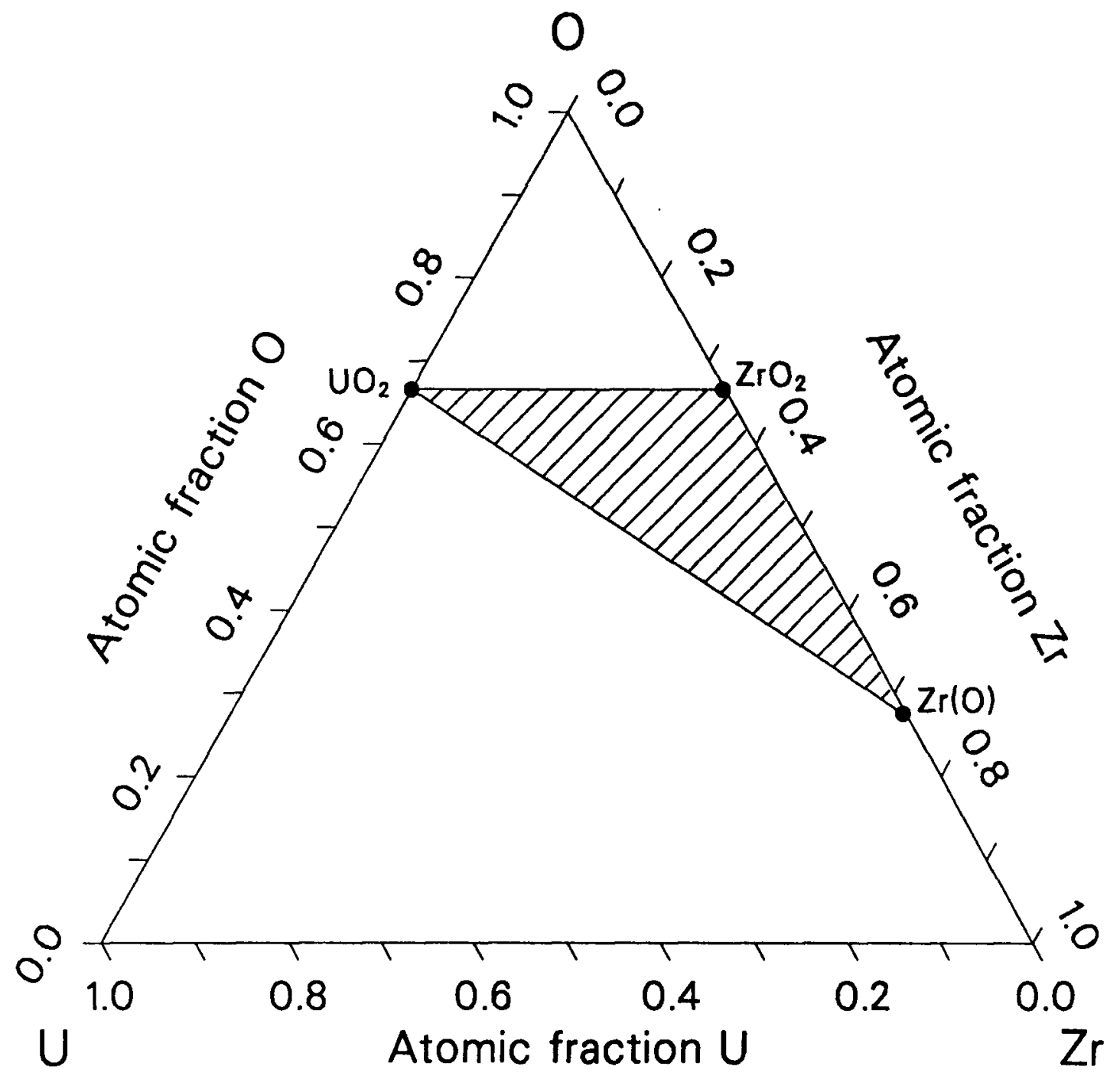

S115-WHT-1189-25

Figure 11-1. Compositions of $Z r-U-0$ compounds on a Gibbs triangle plot. 
First,

$1=\sum_{j=1}^{n} a f_{i}$

and thus all but one of the three atomic fractions must be input. Also, the atomic fraction of oxygen must lie in the range

$a f_{u} \leq \underbrace{n}_{j=1} a f_{i}-\sum_{j=1}^{m} a f o_{j} \leq \sum_{j=1}^{m} a f o_{j}$

where

$$
\begin{aligned}
& \mathrm{af}_{\mathbf{i}} \quad=\text { atomic fraction of the } i \text {-th component in the compound } \\
& \mathrm{afo}_{j}=\begin{array}{l}
\text { atomic fraction of the } j \text {-th component that reacts with } \\
\text { oxygen in the compound }
\end{array} \\
& \mathrm{af}_{\mathrm{u}} \quad=\text { atomic fraction of uranium in the compound } \\
& \mathrm{n} \quad=\text { number of core components in the compound } \\
& \quad=\text { number of core components that react with oxygen in the }
\end{aligned}
$$

if Equation (11-1) is to return physically meaningful positive fractions. The right-hand inequality means that the compound must not be oxidized beyond a metal dioxide, and the left-hand inequality requires that at least enough oxygen must be present to oxidize the uranium to $\mathrm{UO}_{2}$. With uranium and zirconium as the only components in the core compound that react with oxygen, Figure 11-1 shows that the right-hand inequality requires the compound to lie below the line drawn between the points labeled $\mathrm{UO}_{2}$ and 
$\mathrm{ZrO}_{2}$. The left-hand inequality requires that the compound 1 ie above a line from the point labeled $\mathrm{UO}_{2}$ to the point labeled $\mathrm{Zr}$. In this case, all of the shaded triangle lies within this region; so all compounds formed out of $\mathrm{UO}_{2}$ and zircaloy oxidized as far as $\mathrm{ZrO}_{2}$ will be in the acceptable range.

All subcodes which use Equation (11-1) check for acceptable ranges of oxygen concentration and raise or lower the presumed oxygen content to force it to fall within the range given by Equation (11-3). An error message is printed when the range is exceeded.

In the older, more limited versions of the MATPRO core materials properties subroutines, for input values of af $f_{u}$ and a $\mathrm{f}_{\mathrm{Zr}}$ that imply that $\left(1-a f_{u}-a f_{Z r}\right) / 2$ is greater than $a f_{u}+a f_{Z r}$, the input values of $a f_{u}$ and $a f_{Z r}$ are replaced by

$$
\begin{aligned}
& a f_{u 1}=\frac{a f_{u}}{3\left(a f_{u}+a f_{Z r}\right)} \\
& a f_{Z r 1}=\frac{a f_{Z r}}{3\left(a f_{u}+a f_{Z r}\right)}
\end{aligned}
$$

where

$$
\begin{aligned}
& \mathrm{af}_{\mathrm{u}} \quad=\text { atomic fraction of uranium in the compound } \\
& \mathrm{af}_{\mathrm{Zr}}=\text { atomic fraction zirconium in the compound } \\
& \mathrm{af} f_{\mathrm{ul}}=\text { revised atomic fraction of uranium in the compound } \\
& \mathrm{af}_{\mathrm{Zr} 1}=\text { revised atomic fraction of zirconium in the compound. }
\end{aligned}
$$


Inspection of Equations (11-2), (11-4), and (11-5) shows that the transformation preserves the uranium-to-zircaloy ratio but decreases (1 $\left.a f_{u 1}-a f_{Z r 1}\right) / 2$ to $a f_{u 1}+a f_{Z r 1}$.

For input values of $a f_{u}$ and $a f_{Z r}$ that imply that $\left(1-a f_{u}\right.$ $\left.a f_{Z r}\right) / 2$ is less than $a f_{u}$, input values of $a_{f u}$ and $a f_{Z r}$ are replaced by

$a f_{u 1}=\frac{a f_{u}}{3 a f_{u}+a f_{Z r}}$

$a f_{Z r 1}=\frac{a f_{Z r}}{3 a f_{u}+a f_{Z r}}$.

Inspection of Equations (11-2), (11-6), and (11-7) shows that this transformation preserves the uranium-to-zircaloy ratio but increases (1 $\left.a f_{u l}-a f_{Z r l}\right) / 2$ to $a f_{u l}$.

The above described transformations are not used in the later version of the core materials properties subroutines. However, since the older versions of these subroutines are contained in the MATPRO package along with the newer versions, where applicable, descriptions of both routines are included in this document.

\section{References}

11-1. S. Nazare, G. Ondracek, and B. Schulz, "Properties of Light Water Reactor Core Melts," Nuclear Technology, 32, 1977, pp. 239-246.

11-2. F. Rhines, Phase Diagrams in Metallurgy and Their Development and Application, New York: McGraw-Hill Book Company, 1956, pp. 110-113. 
PSOL, PLIO, ZUSOLV, COEF

\subsection{Zirconium-Uranium-0xygen Compound Melting, Solution, and Precipitation (PSOL, PLIQ, ZUSOLV, COEF)}

(D. L. Hagrman)

\subsubsection{Introduction}

Mechanistic modeling of severe core damage processes in LWRs requires models to describe the melting of core materials and the solution of $\mathrm{UO}_{2}$ fuel by liquid zircaloy. In particular, the temperature at which a liquid phase first appears during the heating of a $\mathrm{Zr}-\mathrm{U}-0$ compound, the solidus temperature, is required to model the structural failure of reactor core material. The temperature at which the last solid phase disappears during heating, the liquidus temperature, is required to determine the amount of solid core material that can be dissolved by molten zircaloy.

Three subcodes were developed to model the melting and solution properties of $\mathrm{Zr}-\mathrm{U}-\mathrm{O}$ compounds. The solidus temperature as a function of the atomic fraction zircaloy and the atomic fraction oxygen is modeled in the PSOL subcode. The PLIQ subcode returns the liquidus temperature using the same fractions that are required by PSOL.

The ZUSOLV subcode models solution behavior. Given the temperature, the solvent composition, and the solute composition, it determines whether or not the solvent, usually zircaloy with some oxygen, is supersaturated. If the solvent is supersaturated, the fraction that will freeze and the equilibrium composition of the solid and liquid phases is calculated. If the solvent is not supersaturated at the given temperature, the saturation composition of the liquid phase and the atomic fraction of the solute, usually uranium dioxide, is calculated. 


\section{PSOL, PLIQ, ZUSOLV, COEF}

The subcode COEF calculates the coefficients $a$ and $b$ of the equation $a x+b$, the equation of a line, and the intersection coordinates of two lines. The coordinates of two points on a line are input into the subcode if the equation of the line is to be calculated, and the constant and dependent variable for each line is input if the intersection of two lines is to be calculated. This subcode is used exclusively with ZUSOLV to calculate positions on isopleths in determining the composition of $\mathrm{Zr}-\mathrm{U}-\mathrm{O}$ mixtures.

A11 three subcodes are based on analytical expressions for the liquidus and solidus phase boundary compositions in the ternary $\mathrm{Zr}-\mathrm{U}-0$ system. These expressions, which are given in the model development section, were produced by interpolating the liquidus and solidus compositions determined as a function of temperature for the several available binary systems or isopleths for which liquidus and/or solidus temperatures as a function of composition are known. The analytical expressions are used with standard metallurgical techniques, the lever rule and the mixing rule, to calculate the solution parameters given by ZUSOLV. PSOL and PLIQ employ a matrix that provides an approximate inversion of the analytical expressions for composition as a function of temperature. The matrix uses a grid of 100 positions to represent the range of possible compositions and assigns a fixed temperature to each grid position.

\subsubsection{Data for the $\mathrm{Zr}-\mathrm{U}-0$ System}

The equations for the solidus and liquidus surfaces were obtained from numerous temperature-composition phase diagrams, which are available in the literature. In this section, all of these diagrams have been re-drawn to a common scale and units of atomic fraction so that they might be easily compared and checked for consistency.

11.1.2.1 Binary Systems. Solidus and liquidus temperatures of zirconium-oxygen mixtures have been published by Domagala and 
PSOL, PLIO, ZUSOLV, COEF

McPherson $11.1-1$ and modified by Ruh and Garrett.11.1-2 Figure 11.1-1 shows a phase diagram drawn from these references. The diagram of Domagala and McPherson was converted from weight fraction to atomic fraction using the expression

$f_{0}=\frac{f_{0}^{\text {mass }} / 16}{f_{0}^{\text {mass }} / 16+\left(1-f_{0}^{\text {mass }}\right) / 91.22}$

where

$$
\begin{aligned}
& f_{0}=\text { atomic fraction of oxygen in a } Z r-0 \text { compound } \\
& f_{0}^{\text {mass }}=\text { mass fraction of oxygen in a } Z r-0 \text { compound. }
\end{aligned}
$$

The solidus curve is made up of several segments, one above the beta phase, one above the alpha phase, and one above the cubic $\mathrm{ZrO}_{2}$ phase. The liquidus is composed of the two segments under the liquid region.

Figure 11.1-2 is a temperature-composition plot for the U-0 binary system, taken from Roth et al.11.1-3 Their diagram was converted to atomic fraction oxygen using the relation

$$
f_{0}=\frac{R}{1+R}
$$

where $R$ is the oxygen-to-metal ratio (atoms oxygen/atoms uranium).

The figure shows four solidus segments enclosing the $\mathrm{UO}_{2}$ region, two liquidus segments under the $L_{1}$ phase, and another two liquidus segments under the $L_{2}$ phase. Latta and Fryxe1111.1-4 have published detailed solidus and liquidus temperature data for the curves above $2700 \mathrm{~K}$ in Figure 11.1-2. Their data are shown in Figure 11.1-3 and reproduced in Table 11.1-1. 
PSOL, PLIQ, ZUSOLV, COEF

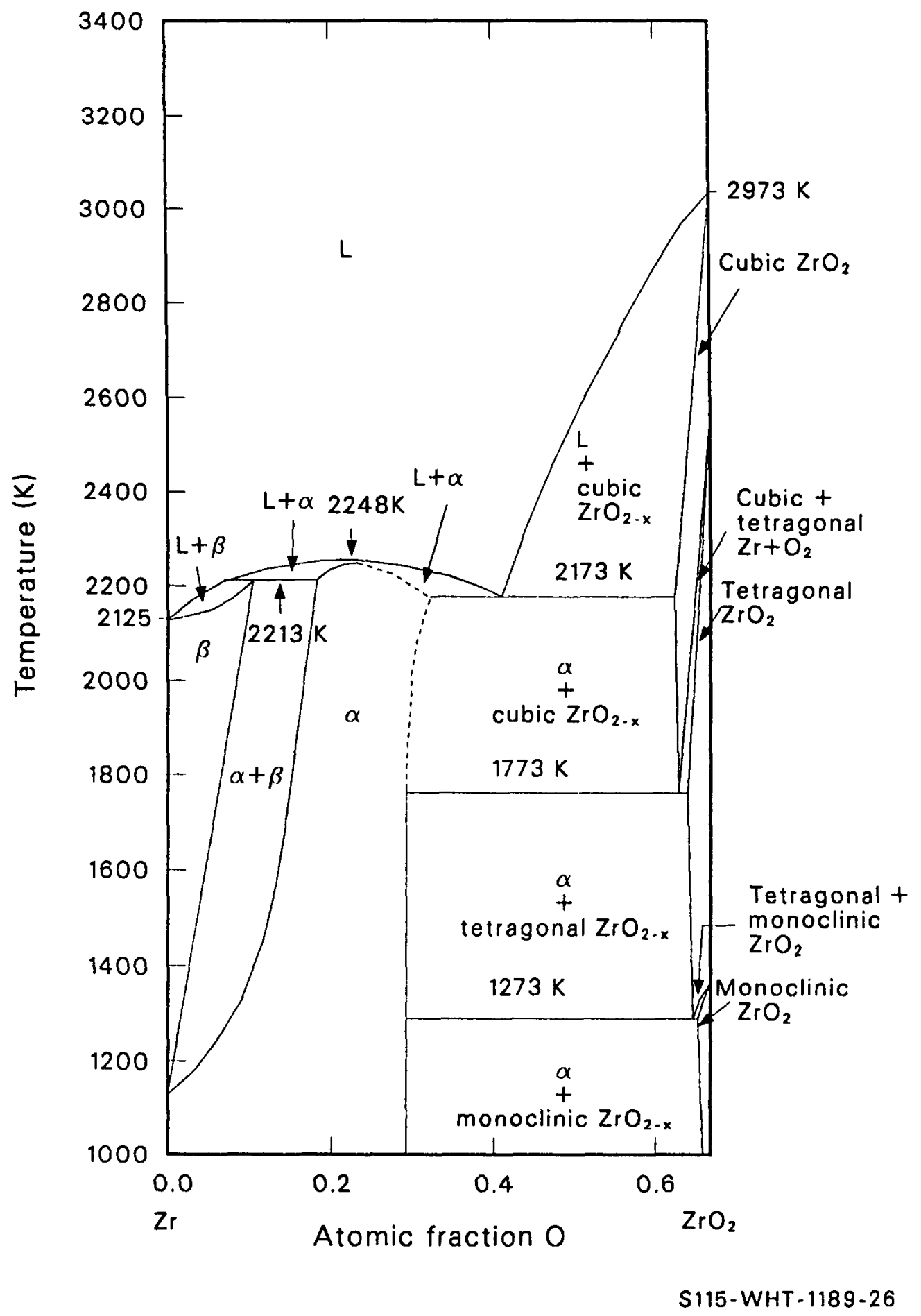

Figure 11.1-1. Zirconium-zirconium dioxide phase diagram. 
PSOL, PLIO， ZUSOLV， COEF

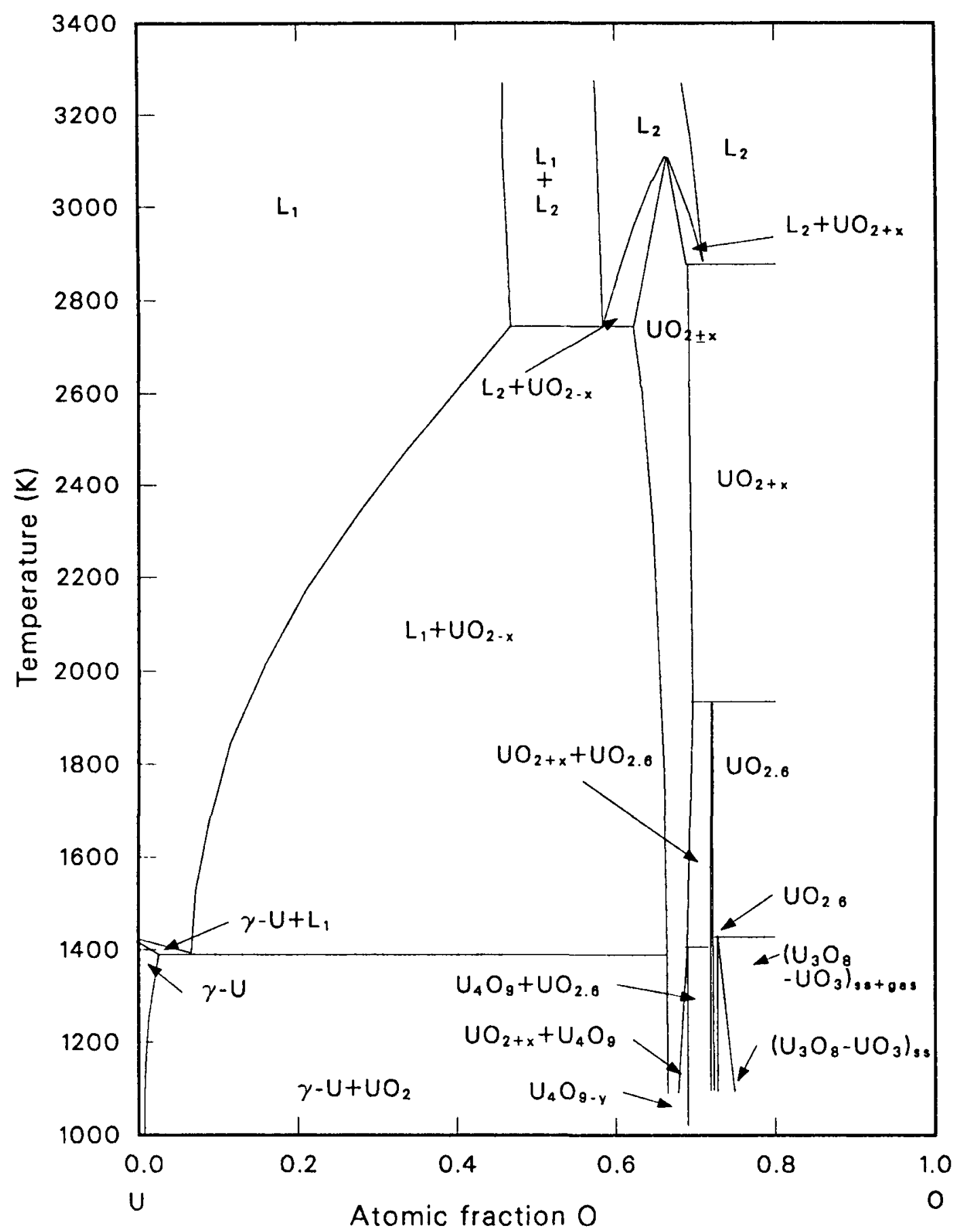

S115-WHT-1189-27

Figure 11.1-2. Uranium-oxygen phase diagram. 
PSOL, PLIO, ZUSOLV, COEF

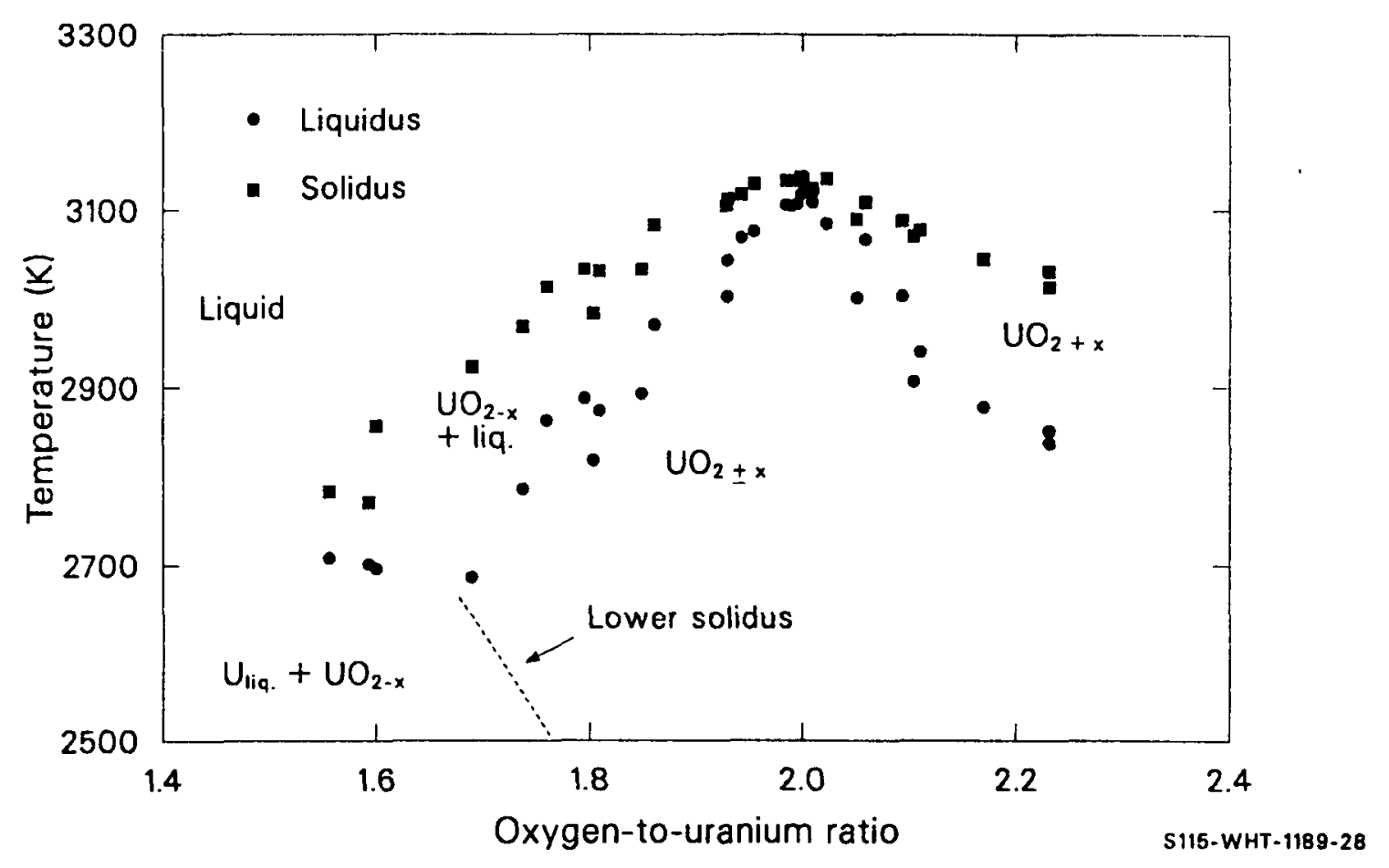

Figure 11.1-3. Solidus and liquidus temperatures of uranium oxides according to Latta and Fryxell. 
PSOL， PLIO， ZUSOLV， COEF

Table 11.1-1. Solidus and liquidus temperatures of $\mathrm{U0}_{2+x}$ from Latta and Fryxel1

\begin{tabular}{|c|c|c|c|c|}
\hline Sample No. & Pretest $0 / U$ & Post-Test $0 / U$ & $\begin{array}{l}\text { Sol idus } \\
(\mathrm{K}) \\
\end{array}$ & $\begin{array}{l}\text { Liquidus } \\
\text { (K) }\end{array}$ \\
\hline $\begin{array}{l}221 \\
217 \\
188 \\
201 \\
192 \\
303 \\
208 \\
172 \\
204 \\
193 \\
212 \\
190 \\
194 \\
209 \\
189 \\
146 \\
153 \\
138 \\
184 \\
150 \\
154 \\
177 \\
156 \\
159 \\
129 \\
104 \\
164 \\
166 \\
222 \\
168 \\
207\end{array}$ & $\begin{array}{l}2.23 \\
2.23 \\
2.184 \\
2.13 \\
2.12 \\
2.095 \\
2.095 \\
2.058 \\
1 . \\
2.019 \\
1.998 \\
1.997 \\
1.997 \\
1.993 \\
1.980 \\
1.980 \\
1.956 \\
1.943 \\
1.920 \\
1.890 \\
1.856 \\
1.809 \\
1.803 \\
1.793 \\
1.75 \\
1.790 \\
1.736 \\
1.662 \\
1.60 \\
1.556 \\
1.50\end{array}$ & $\begin{array}{c}- \\
2.169 \\
2.109 \\
2.103 \\
2.092 \\
2.050 \\
2.058 \\
2.022 \\
2.009 \\
1.998 \\
2.008 \\
2.000 \\
1.995 \\
1.990 \\
1.985 \\
1.955 \\
1.943 \\
1.930 \\
1.929 \\
1.861 \\
1.795 \\
1.849 \\
1.809 \\
1.803 \\
1.759 \\
1.736 \\
1.689 \\
-1 \\
1.593\end{array}$ & $\begin{array}{l}2837 \\
2851 \\
2878 \\
2940 \\
2907 \\
3003 \\
3001 \\
3067 \\
3085 \\
3109 \\
3118 \\
3118 \\
3120 \\
3107 \\
3105 \\
3106 \\
3076 \\
3069 \\
3043 \\
3002 \\
2970 \\
2888 \\
2893 \\
2874 \\
2818 \\
2863 \\
2786 \\
2686 \\
2696 \\
2708 \\
2701\end{array}$ & $\begin{array}{l}3031 \\
3013 \\
3045 \\
3078 \\
3071 \\
3088 \\
3090 \\
3109 \\
3136 \\
3125 \\
3138 \\
2138 \\
3135 \\
3133 \\
3133 \\
3133 \\
3130 \\
3118 \\
3113 \\
3105 \\
3083 \\
3033 \\
3033 \\
3031 \\
2983 \\
3013 \\
2968 \\
2923 \\
2857 \\
2783 \\
2771\end{array}$ \\
\hline
\end{tabular}




\section{PSOL, PLIO, ZUSOLV, COEF}

Figure 11.1-4 shows an isopleth extending from $\mathrm{Zr}_{0.70^{0}} 0.3$ (approximately the composition of alpha-phase zirconium saturated with oxygen) to $U_{0.33^{0}} 0.67$ (the composition of uranium dioxide written in atomic fraction units). The isopleth was presented as a quasi-binary section by Skokan.11.1-5 This presentation is in conflict with the phase diagram reproduced as Figure 11.1-1, which shows non-congruent melting of the alpha phase (the liquid-plus-alpha region between the alpha phase and liquid regions near 0.3 atomic fraction oxygen in Figure 11.1-1).

The $\mathrm{UO}_{2}-\mathrm{ZrO}_{2}$ quasi-binary system according to Romberger et a1.11.1-6 is shown in Figure 11.1-5. The liquidus and solidus exhibit a minimum at a 0.5-0.5 mix of the two components, and the liquidus dips sharply to touch the solidus at this minimum. Recent data presented by Hofmann ${ }^{11.1-7}$ suggest that the $U_{0.33} 0_{0.67}$-rich solidus does not rise as fast as shown in Figure 11.1-5. Hofmann finds a solidus temperature in the range 2793 to $2893 \mathrm{~K}$ for 0.1 mole fraction $\mathrm{ZrO}_{2}(0.1$ atomic fraction

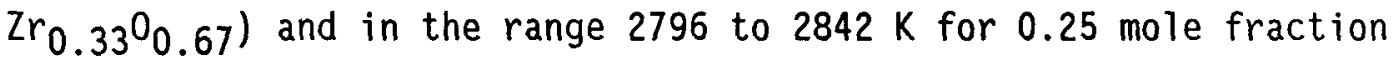
$\mathrm{ZrO}_{2}$.

Figure 11.1-6 is a reproduction of the liquidus and solidus curves of the U-Zr binary system. ${ }^{a}$ The components are mutually soluble for temperatures above $1136 \mathrm{~K}$, so the solidus and liquidus form the classic lens-shaped, two-phase region for such systems.

11.1.2.2 Ternary System Data. The only $\mathrm{Zr}-\mathrm{U}-\mathrm{O}$ system data in the temperature range from 1400 to $3100 \mathrm{~K}$ are the temperature composition plots published by Hofmann and Politis11.1-8 and extended by Skokan.11.1-5 Ternary temperature-composition plot sections from these authors are reproduced as Figures 11.1-7 through 11.1-13. The figures are all plotted on a Gibbs coordinate system, which is an equilateral triangle with each

a. P. Hofmann, private communication, EG\&G Idaho, Inc., 1985. 
PSOL, PLIQ，ZUSOLV， COEF

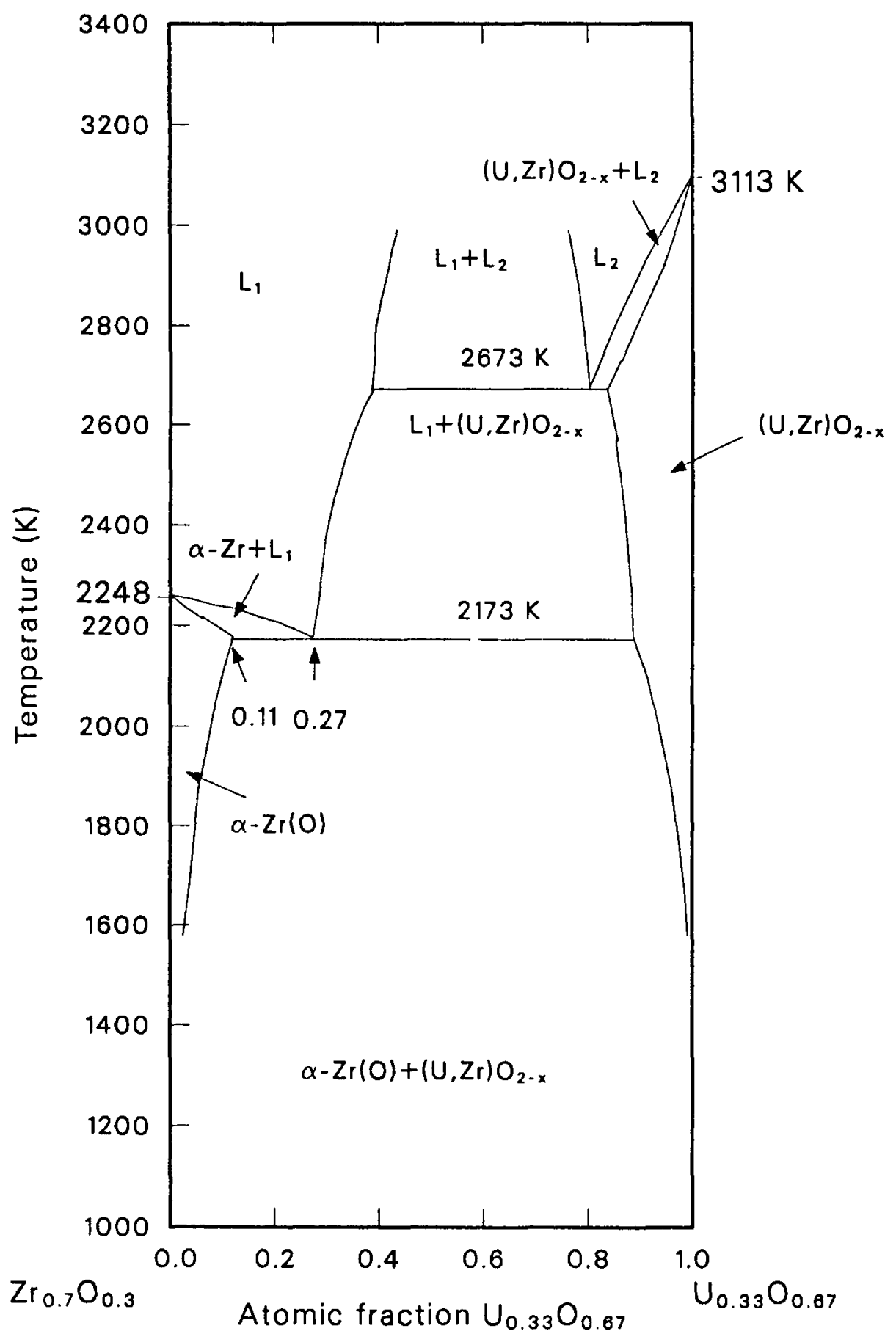

S115-WHT-1189-29

Figure 11.1-4. 0xygen-saturated, alpha-phase zirconium-uranium dioxide isopleth. 
PSOL，PLIO，ZUSOLV， COEF

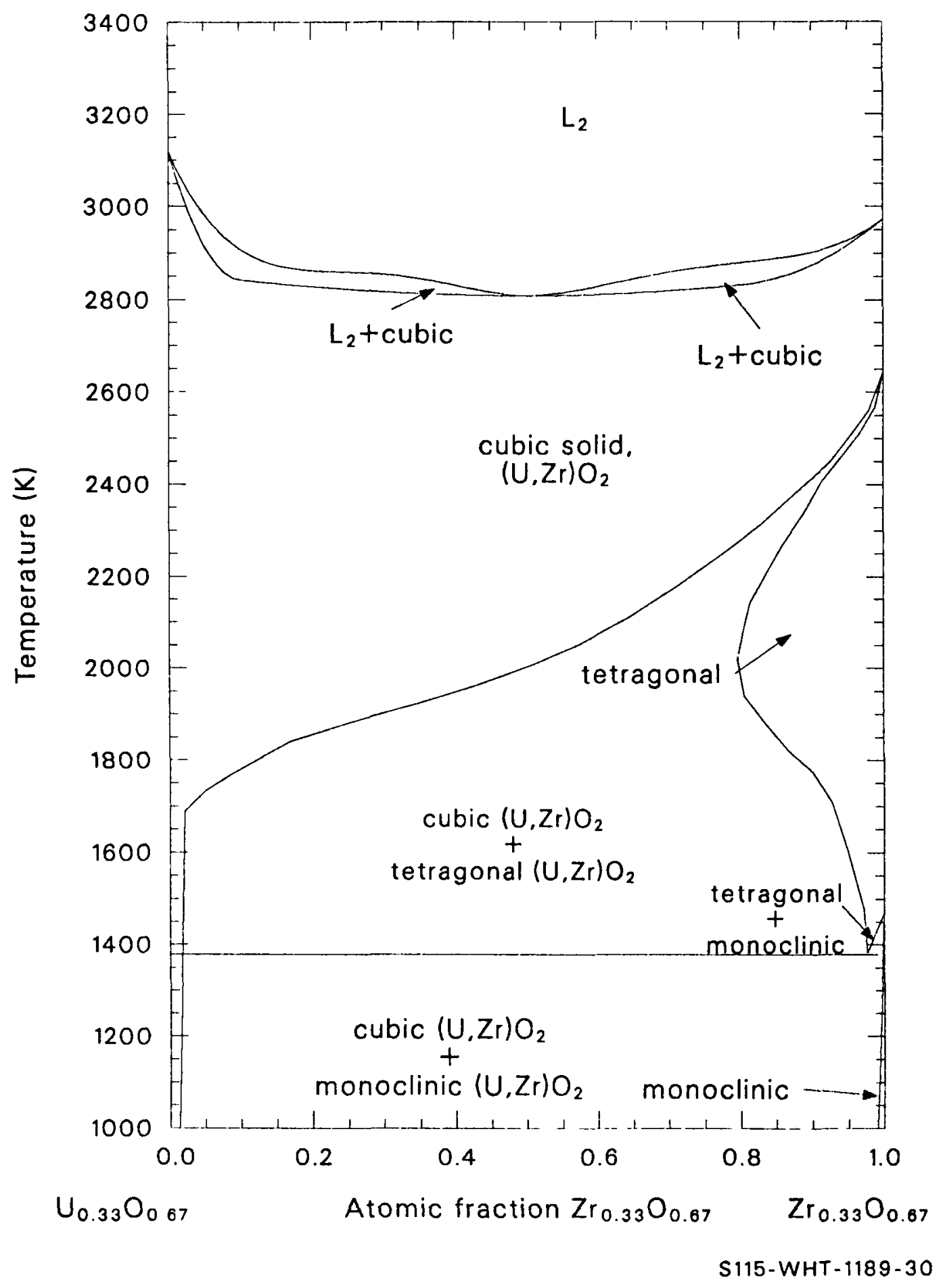

Figure 11.1-5. Uranium dioxide-zirconium dioxide quasi-binary phase diagram. 
PSOL, PLIO, ZUSOLV, COEF

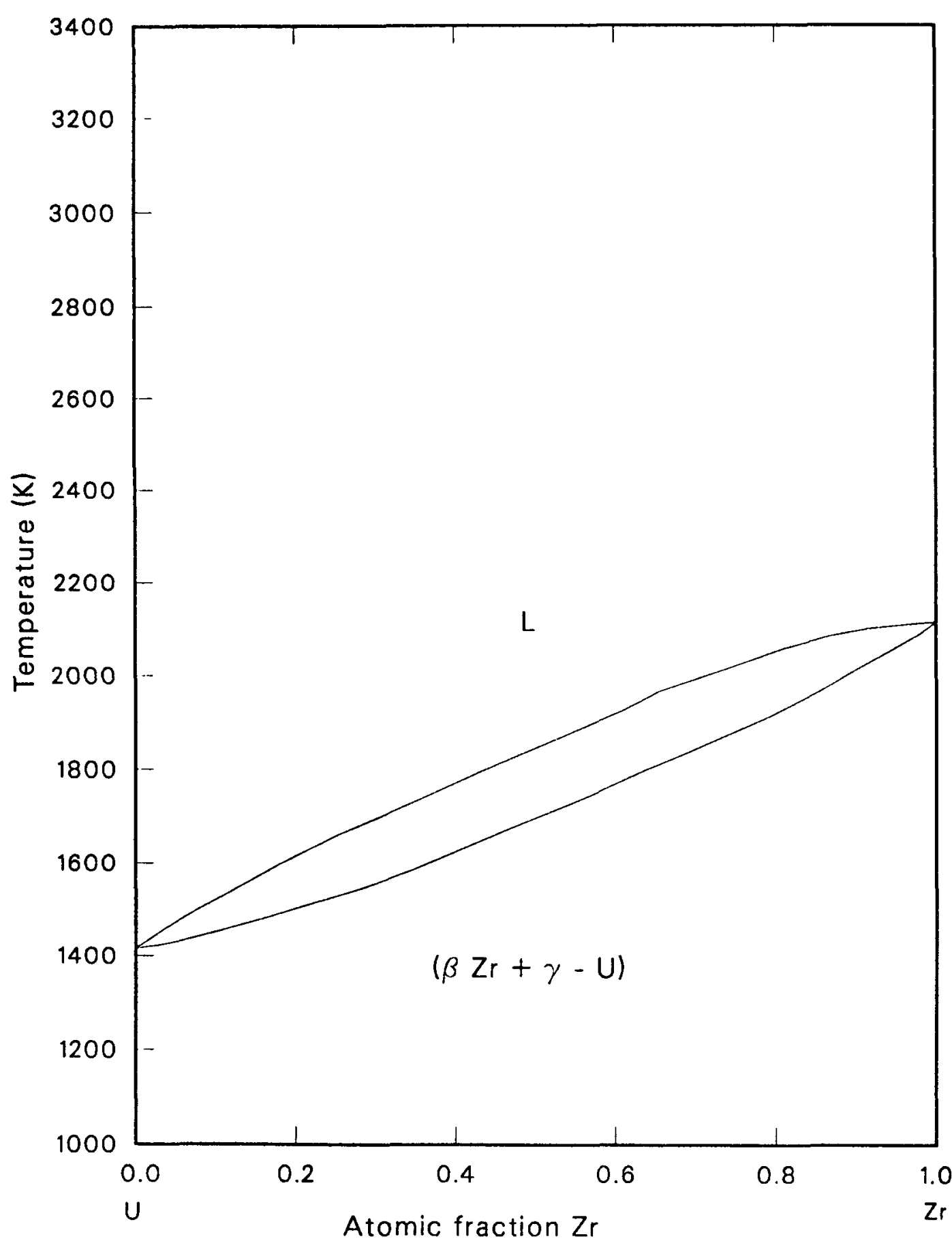

S:15-WHT-1189-31

Figure 11.1-6. Uranium-zirconium system liquidus and solidus. 
PSOL, PLIO, ZUSOLV, COEF

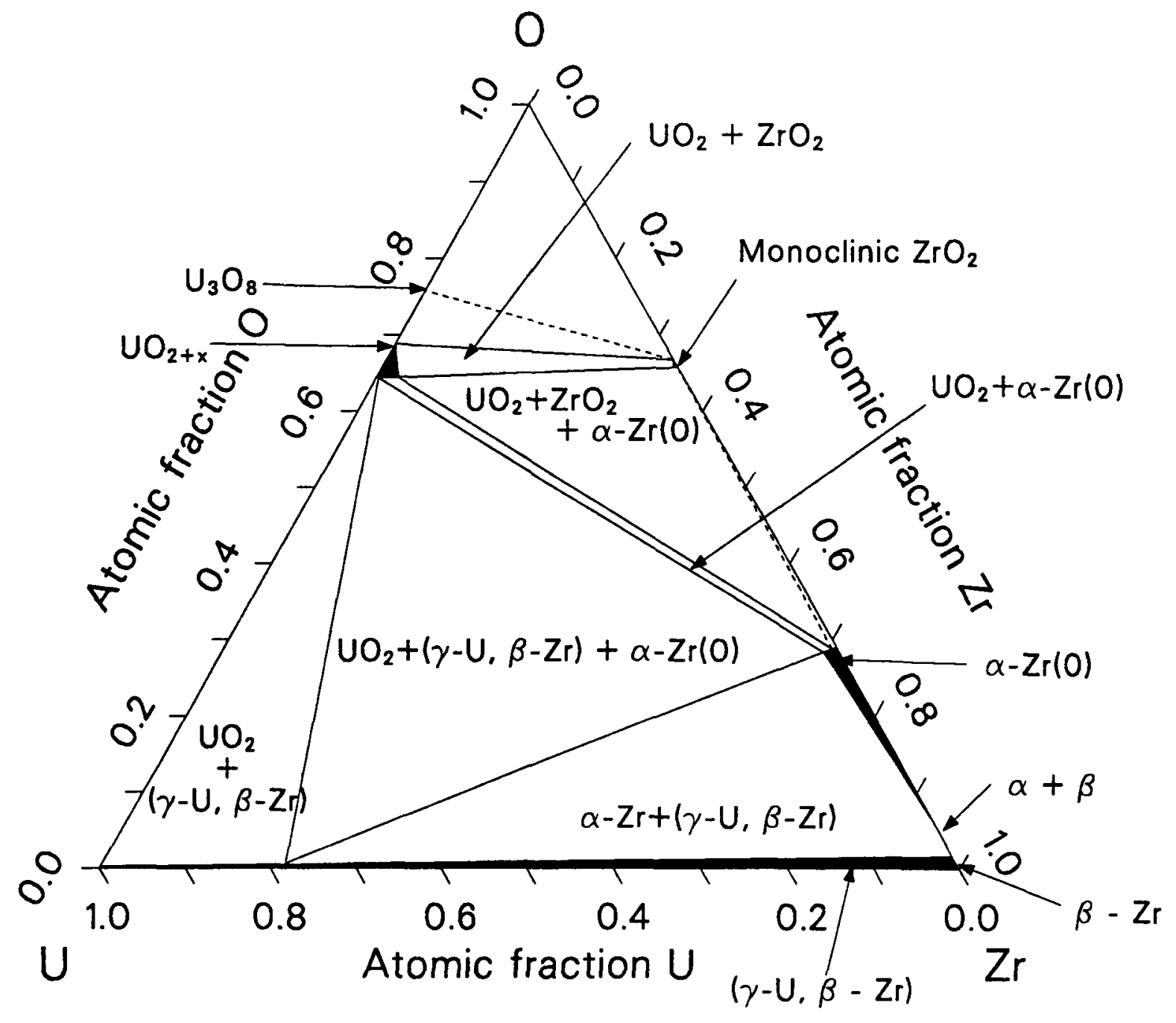

S115-WHT-1189-32

Figure 11.1-7. Phases of the $\mathrm{Zr}-\mathrm{U}-0$ system at $1273 \mathrm{~K}$. 
PSOL，PLIQ，ZUSOLV， COEF

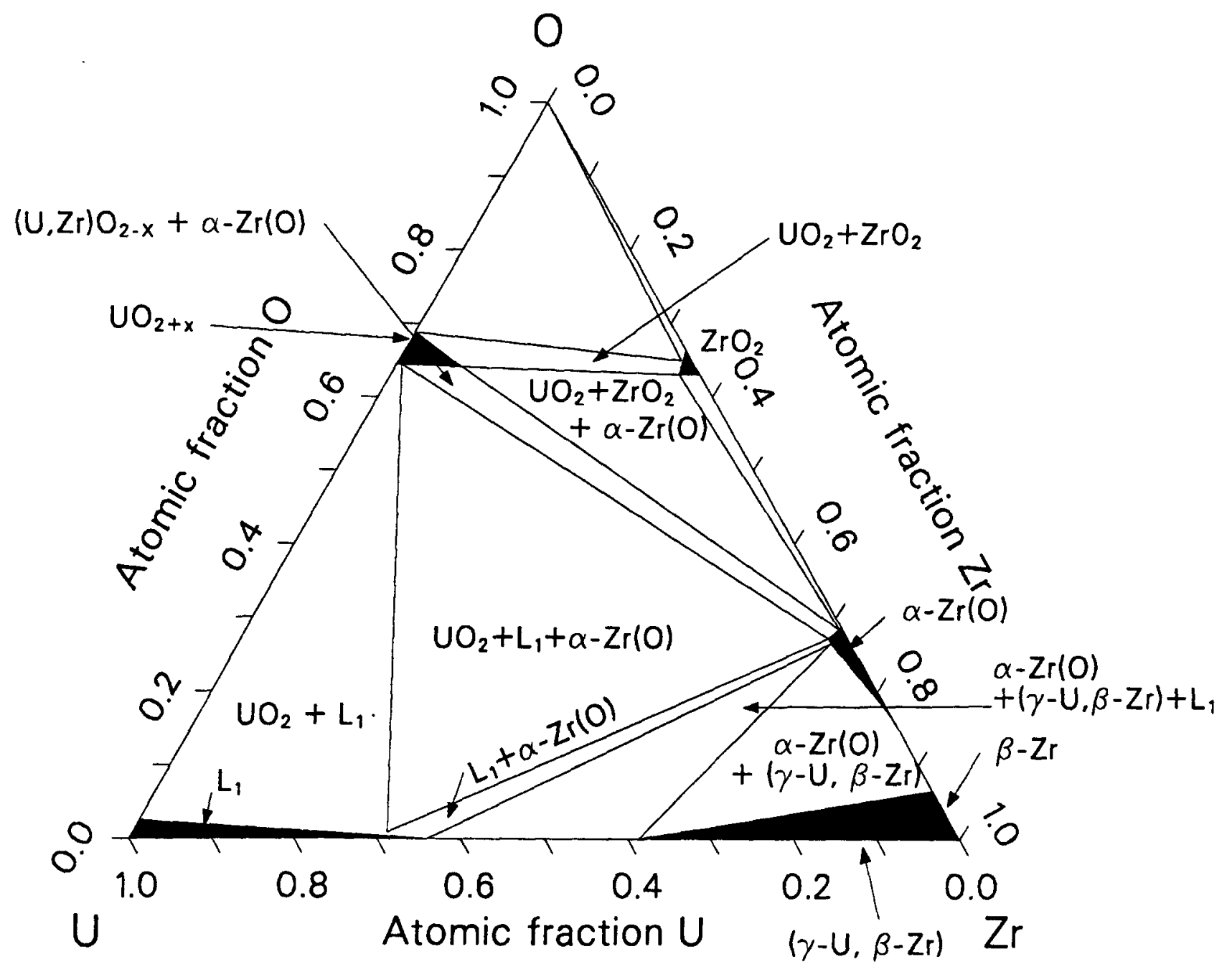

S115-WHT- $1189-33$

Figure 11.1-8. Phases of the $\mathrm{Zr-U}-0$ system at $1773 \mathrm{~K}$. 
PSOL, PLIQ，ZUSOLV, COEF

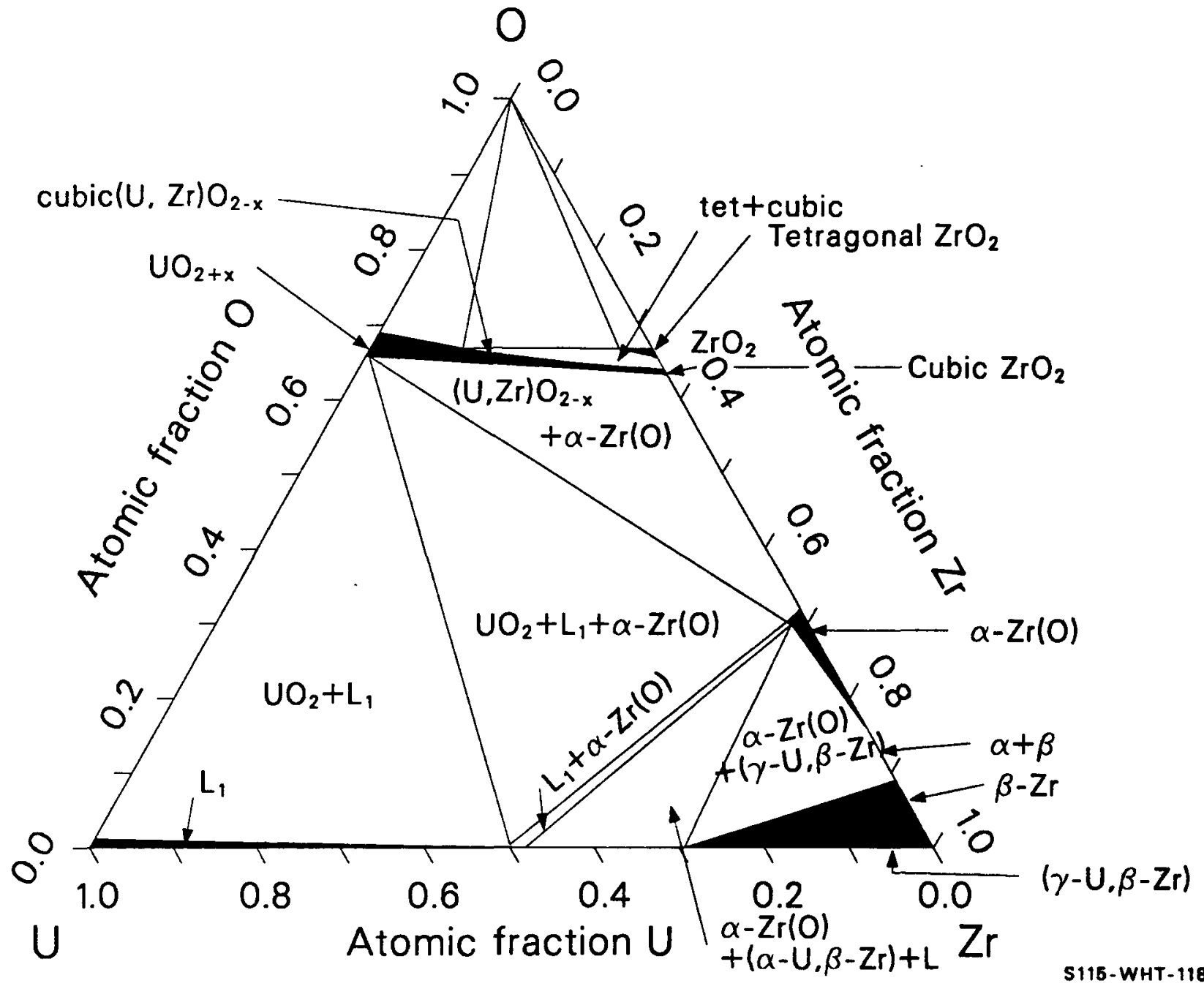

Figure 11.1-9. Phases of the $\mathrm{Zr}-\mathrm{U}-0$ system at $1873 \mathrm{~K}$. 
PSOL，PLIO，ZUSOLV， COEF

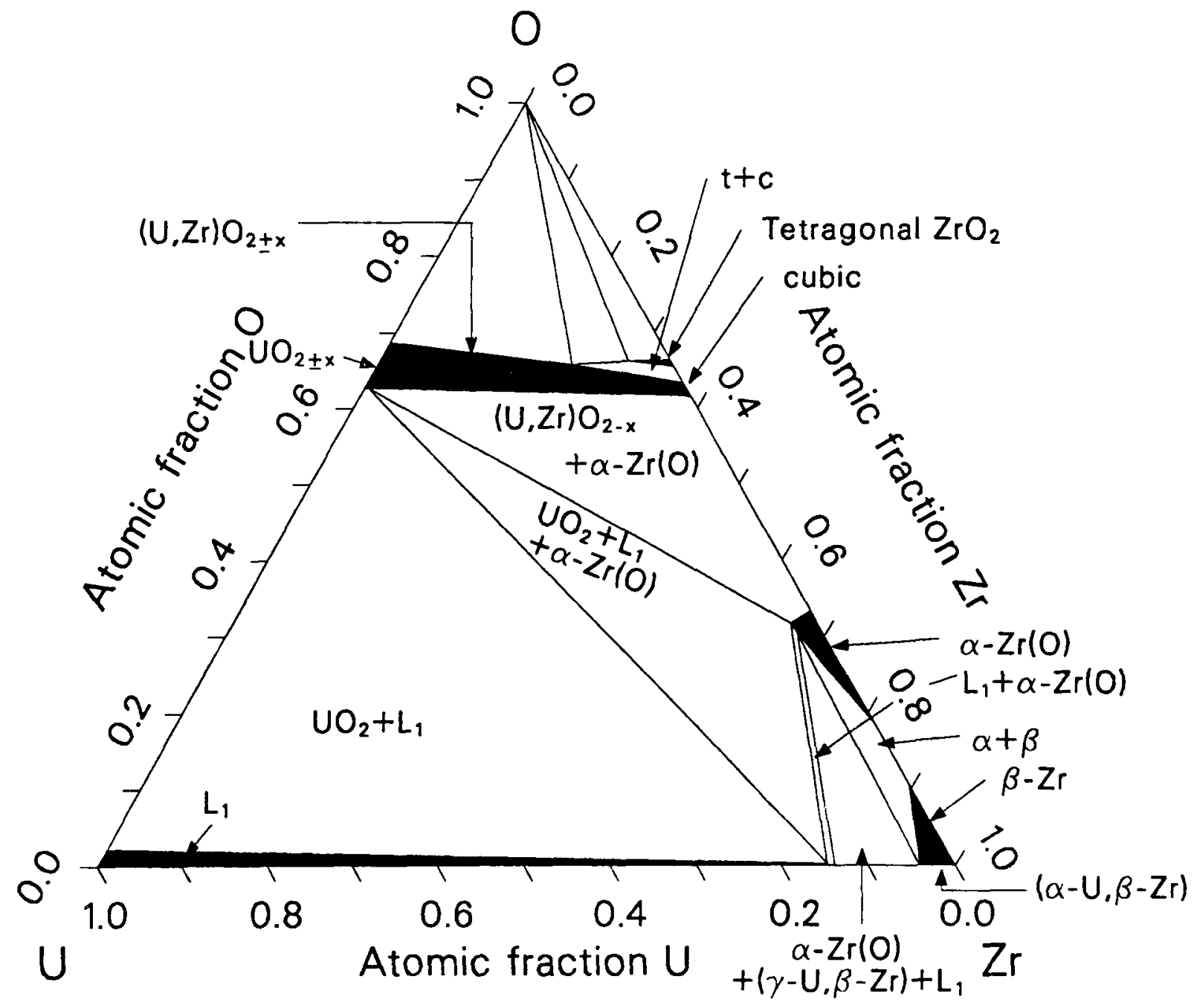

S116-WHT-1189-35

Figure 11.1-10. Phases of the $\mathrm{Zr}-\mathrm{U}-0$ system at $2073 \mathrm{~K}$. 
PSOL，PLIO，ZUSOLV, COEF

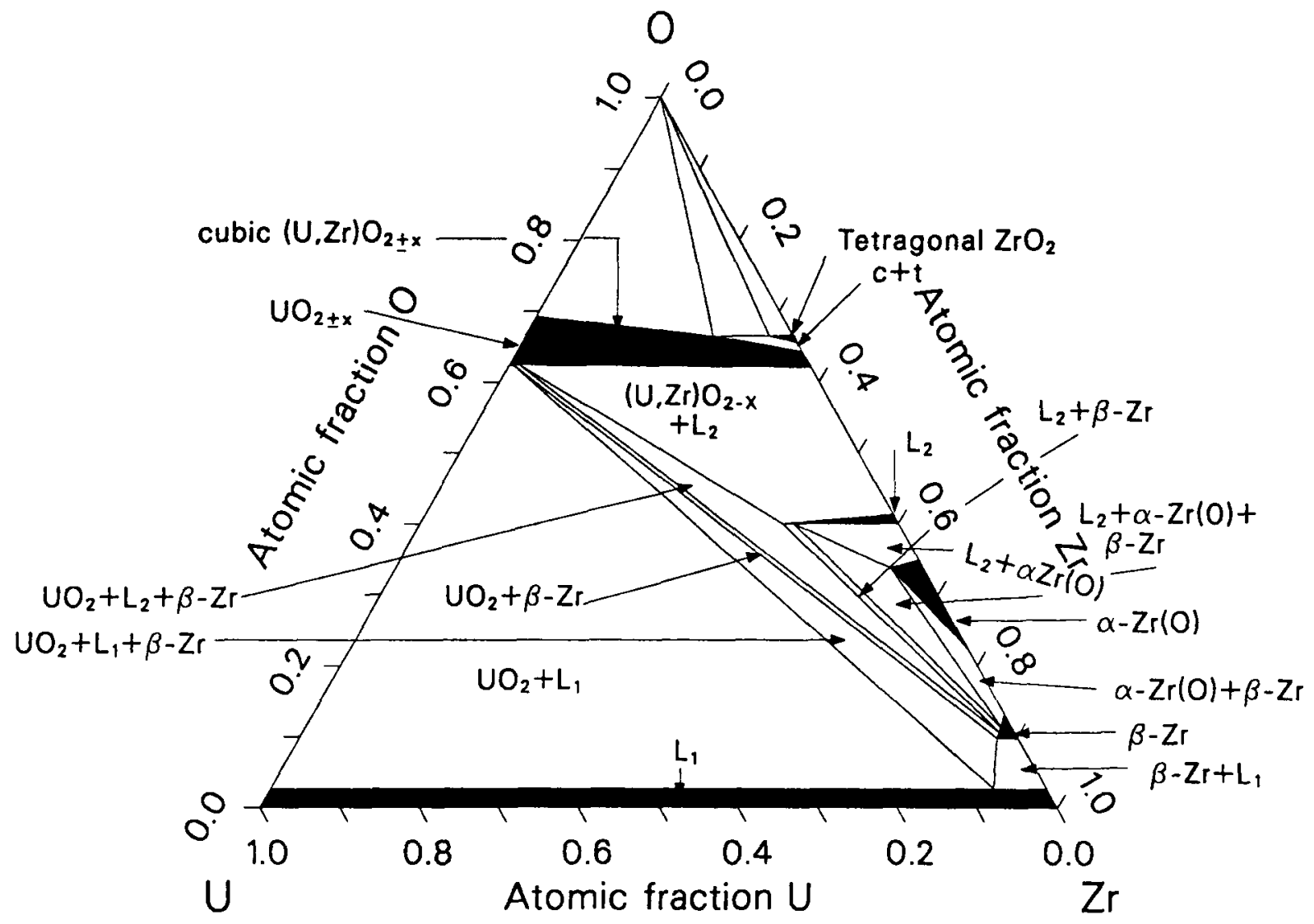

S116-WHT-1189-38

Figure 11.1-11. Phases of the $\mathrm{Zr}-\mathrm{U}-0$ system at $2178 \mathrm{~K}$. 
PSOL, PLIO，ZUSOLV, COEF

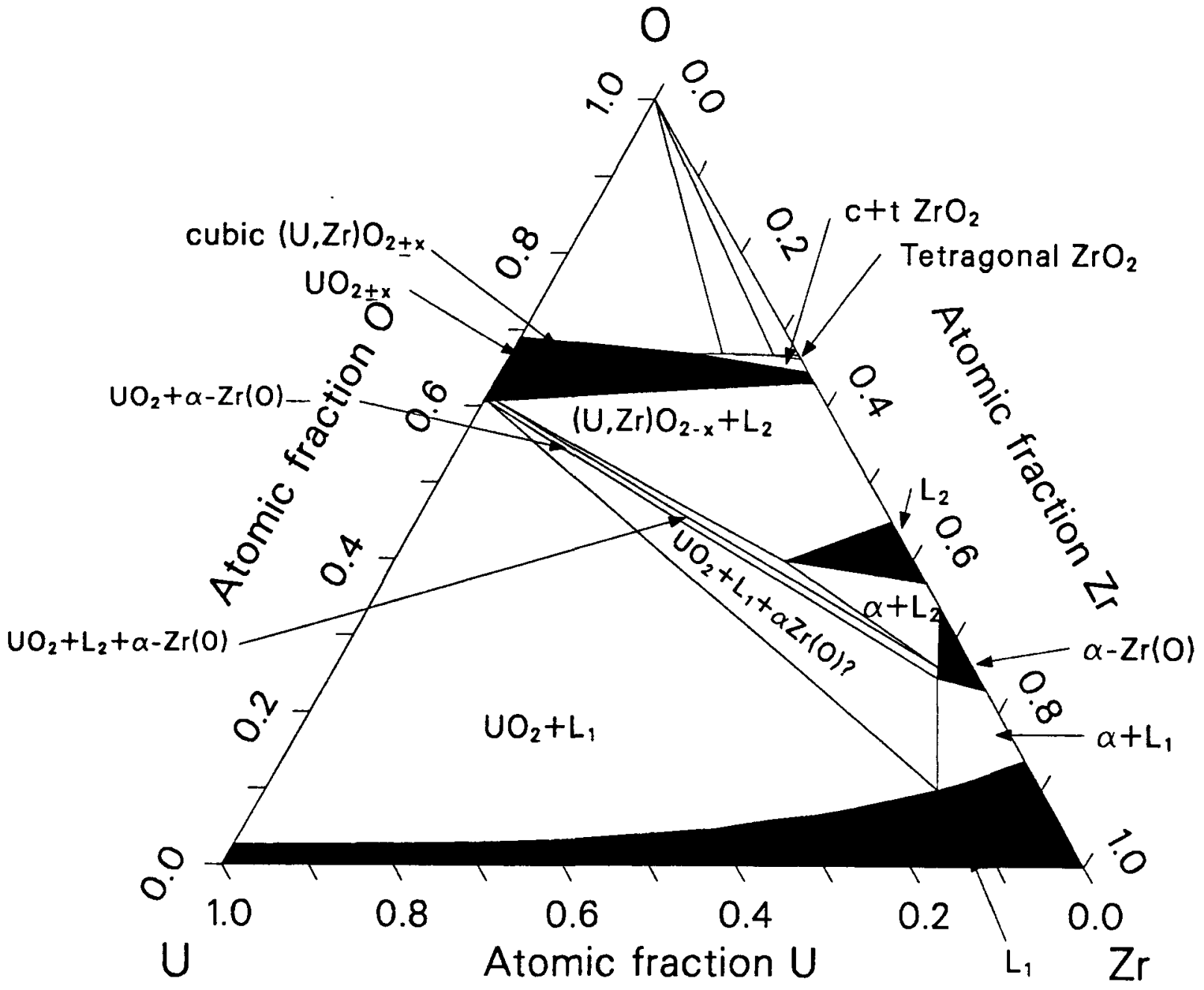

S115-WHT-1189-37

Figure 11.1-12. Phases of the $\mathrm{Zr}-\mathrm{U}-0$ system at $2223 \mathrm{~K}$. 
PSOL, PLIO， ZUSOLV, COEF

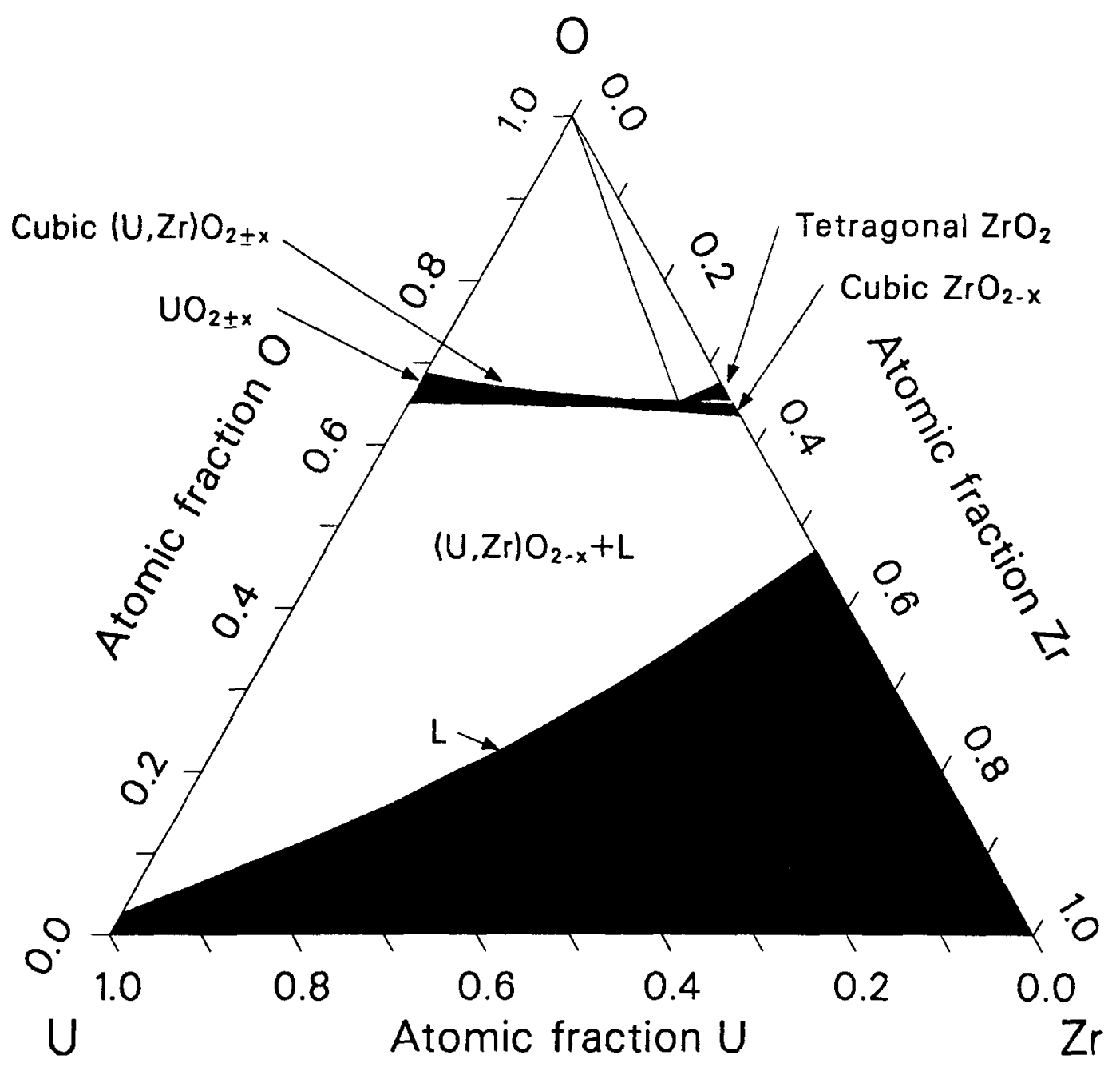

S115-WHT-1189-38

Figure 11.1-13. Phases of the $\mathrm{Zr}-\mathrm{U}-0$ system at $2273 \mathrm{~K}$. 
PSOL, PLIO, ZUSOLV, COEF

vertex representing one of the three components. The fraction of each component is proportional to the distance from the side opposite the component's vertex. The system is used because it ensures that the sum of the fraction of each component is one for any gross composition plotted.

Figure 11.1-7, the phase diagram at $1273 \mathrm{~K}, 11.1-8$ shows no liquid phase and very 1 imited single-phase regions along the $\mathrm{U}-0, \mathrm{Zr}-0$, and $\mathrm{U}-\mathrm{Zr}$ sides. A large, three-phase region connecting $\alpha-\operatorname{Zr}(0),(\gamma-U$, $\beta-\mathrm{Zr}$ ) with about $0.8 \mathrm{U}$, and $\mathrm{UO}_{2}$ dominates the diagram.

The 1773-K system ${ }^{11.1-8}$ (Figure 11.1-8) shows a liquid phase in the lower left-hand side of the diagram, the U-rich and 0 -poor region. The phase is in equilibrium with $\mathrm{UO}_{2}$ via tie lines in the $\mathrm{UO}_{2}+\mathrm{L}$ region, with $\alpha-\operatorname{Zr}(0)$ via tie lines in the narrow $L+\alpha-\operatorname{Zr}(0)$ region, and with $\mathrm{UO}_{2}$ and $\alpha-\operatorname{Zr}(0)$ via the large, three-phase triangle that dominates the center of the phase diagram. The locations of the tie lines are not known, so the tie lines are not shown. Although most authors show the top of the $\mathrm{UO}_{2}+\mathrm{L}$ region as a point, it is drawn in Figure 11.1-8 as a short segment because the several liquid compositions at the bottom of the $\mathrm{UO}_{2}+\mathrm{L}$ region must connect to more than one composition at the edge of the one-phase region near the $\mathrm{UO}_{2}$ composition. The presence of the large, three-phase region in the center, $\mathrm{UO}_{2}+\mathrm{L}+\alpha-\operatorname{Zr}(0)$, suggests that compositions enclosed in the triangle will experience some melting when the liquid phase passes the lowest vertex of the three-phase triangle, i.e., near $1600 \mathrm{~K}$.

Figure 11.1-9 shows the phase diagram at $1873 \mathrm{~K} .11 .1-5$ The right-hand vertex of the $L$ region has moved toward the $Z r$ vertex of the Gibbs coordinates, in excellent agreement with the liquidus temperature shown in Figure 11.1-6. The right vertex of the $(\gamma-U, \beta-Z r)$ phase is in excellent agreement with the U-Zr binary system solidus, too. A similar agreement is evident between the right-hand side of Figure 11.1-9 and the $\mathrm{Zr}_{-}-\mathrm{ZrO}_{2}$ binary system shown in Figure 11.1-1. However, the 


\section{PSOL, PLIQ，ZUSOLV， COEF}

Teft-hand side of Figure 11.1-9 disagrees with the liquidus shown for the U-0 binary in Figure 11.1-2. According to Figure 11.1-2, the liquidus should be above 0.1 atomic fraction 0 at $1773 \mathrm{~K}$. It is shown at about 0.02 fraction 0 in Figure 11.1-9. The two phase $\alpha-\operatorname{Zr}(0)+L$ region was added to Skokan's figure to avoid showing a common boundary between three phase regions. $11.1-8$

Figure 11.1-10, the phase diagram at $2073 \mathrm{~K}, 11.1-5$ shows behavior similar to Figure 11.1-9. The $U-\mathrm{Zr}$ and $\mathrm{Zr}-\mathrm{ZrO}_{2}$ binaries are in excellent agreement with the figure, but the U-0 binary would place the top left vertex of the $L$ region considerably higher than it is shown on the ternary diagram. One should note that Figure 11.1-10 is an important addition to the binary systems data because it provides points like the left-hand extreme of the $\alpha-\operatorname{Zr}(0)$ region that are not available on any binary isopleth. The two-phase $\alpha-\operatorname{Zr}(0)+\mathrm{L}$ region was added to Skokan's figure for $2073 \mathrm{~K}$ for the same reason the region was added to Figure 11.1-9.11.1-8

Figures 11.1-11 and 11.1-1211.1-5 show the complex behavior caused by the appearance of the oxygen-rich liquid phase, $L_{1}{ }^{\prime}$, that corresponds to the liquidus minimum at about 0.4 atomic fraction oxygen in Figure 11.1-1. The tentative diagrams presented by Skokan for 2178 and $2223 \mathrm{~K}$ were modified to include narrow two-phase regions between the $\mathrm{UO}_{2}+\mathrm{L}_{1}^{\prime}+\beta-\mathrm{Zr}$ and $\mathrm{UO}_{2}+\mathrm{L}_{1}+\beta-\mathrm{Zr}$ three-phase regions proposed by Skokan.

Figure 11.1-13, the relatively simple phase diagram at $2273 \mathrm{~K}, 11.1-9$ shows that the $L_{1}{ }^{\prime}$ phase region no longer exists as a separate liquid when temperature increases $50 \mathrm{~K}$ above the temperature of Figure 11.1-12. The fairly simple system shown in Figure 11.1-13 is probably characteristic of the $\mathrm{Zr}-\mathrm{U}-\mathrm{O}$ system until temperatures near $2673 \mathrm{~K}$, when another oxygen-rich phase, $L_{2}$ in Figures 11.1-2, 4 and 5, appears. 


\section{PSOL, PLIO, ZUSOLV, COEF}

Unfortunately, no ternary system phase diagrams have been published for temperatures above $2273 \mathrm{~K}$. Data for these temperatures must be interpolated from binary phase diagrams.

\subsubsection{Model Development}

The expressions used in the PSOL, PLIQ, and ZUSOLV codes were developed by constructing polynomial expressions for the solidus and liquidus temperatures as a function of composition of the various binary systems, inverting these expressions to produce correlations for composition as a function of temperature, and connecting the resulting liquidus and solidus compositions with straight- 7 ine segments on the ternary phase diagram. Where additional correlations could be obtained from the ternary systems published, they were also employed.

Figure 11.1-14 shows the points that are connected to form the ternary liquidus, and Table 11.1-2 provides the analytical expressions for the compositions represented by the points. Figure 11.1-15 shows the points that are connected to form the ternary solidus, and Table 11.1-3 provides the analytical expressions for the compositions represented by the points. Dashed lines in Figure 11.1-15 represent tie lines across multiple-phase regions and are therefore not a section through a solidus surface in the three-dimensional, temperature-composition phase diagram.

Table 11.1-4 lists the liquidus equation number as identified in Table 11.1-2, the data that were used to construct the equation, and any appropriate comments about the derivation of the equation. The rather complex definition of point 17 given in Table 11.1-2 is caused by the fact that points 15 of the liquidus 1 ines and point 19 of the solidus lines form a three-phase region connecting $L_{1}, L_{2}$, and the $\mathrm{ZrO}_{2}$ cubic phase. Point 17 is the $L_{1}$ vertex of the three-phase region and was located as described to allow tie lines between $\mathrm{ZrO}_{2}$ and $\mathrm{L}_{1}$ on the right side of point 17 . 
PSOL，PLIO，ZUSOLV， COEF

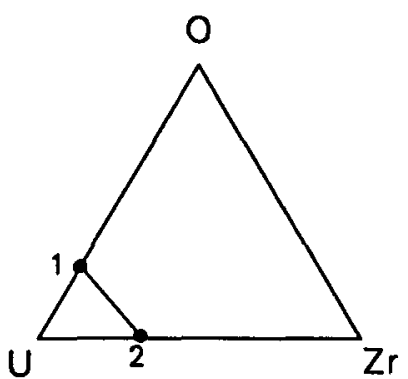

$1406 \leq \mathrm{T}<2125$

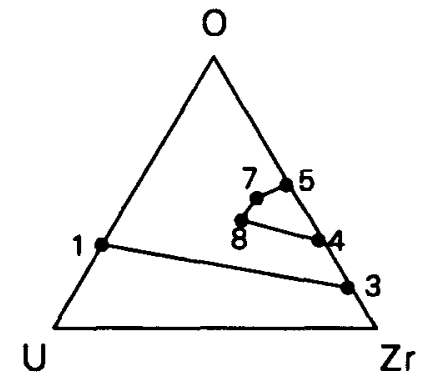

$2240.747 \leq \mathrm{T}<2248$

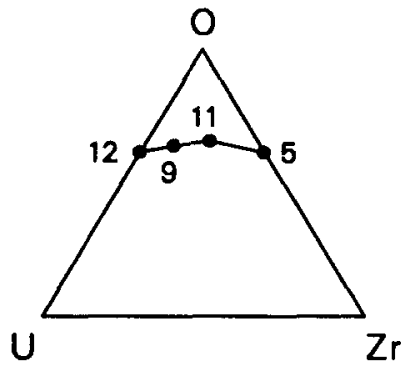

$2700 \leq T<2809$

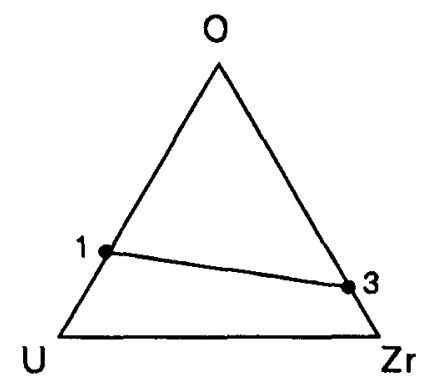

$2125 \leq T<2173$

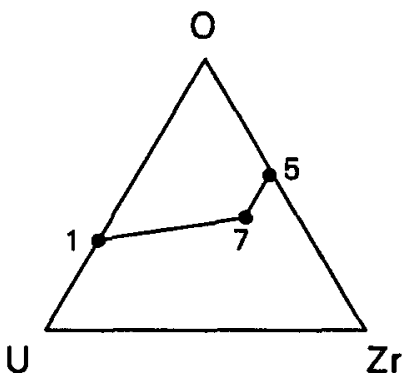

$2248 \leq T<2673$

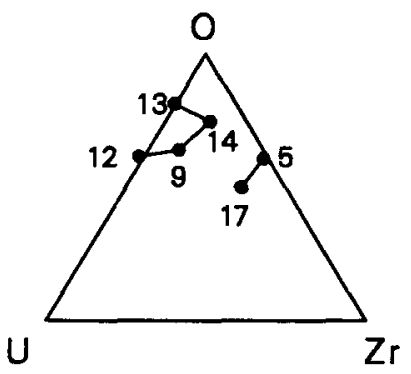

$2809 \leq T<2973$

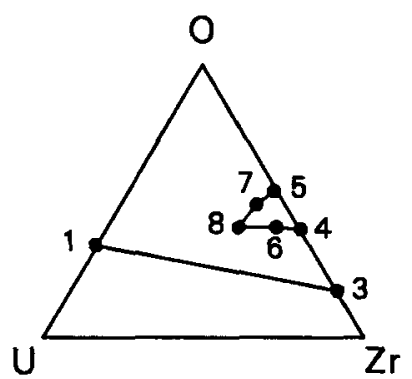

$2173 \leq T<2240.747$

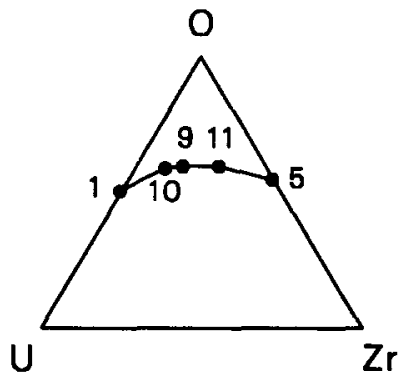

$2673 \leq T<2700$

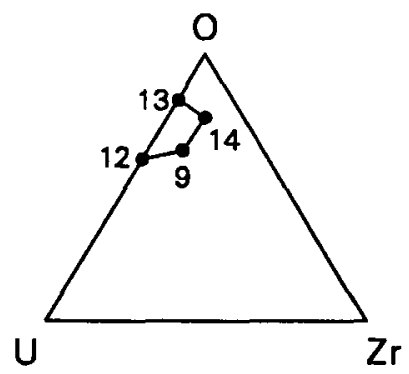

$2973 \leq \mathrm{T}<3119$

$T=$ temperature $(K)$

S115-WHT-1189-39

Figure 11.1-14. Points that are connected to form the ternary $\mathrm{Zr}-0-\mathrm{U}$ system liquidus lines. 
PSOL, PLIO, ZUSOLV, COEF

Table 11.1-2. Correlations for liquidus compositions

1. $L_{1}$ boundary, U-0 binary system

$f_{0}=\frac{2940.587-2940.587^{2}+4833.744(1026.259-T)}{4833.744}$

2. $\mathrm{L}_{1}$ boundary, $\mathrm{U}-\mathrm{Zr}$ binary system

$f_{Z r}=\frac{478.5-478.5^{2}+238(1406-T)}{238}$

3. Zr-rich $\mathrm{L}_{1}$ boundary, $Z r-\mathrm{ZrO}_{2}$ binary system

For $2125 \leq T \leq 2213 \mathrm{~K}$

$f_{0}=\frac{1114.952-1114.952^{2}+13704.72(2125-T)}{13704.72}$

For $2213<\mathrm{T} \leq 2248 \mathrm{~K}$

$f_{0}=\frac{263.9718-263.9718^{2}+1060.128(2182.271-T)}{1060.128}$

4. $\mathrm{Zr}$-rich $\mathrm{L}_{1}^{\prime}$ boundary, $\mathrm{Zr}-\mathrm{ZrO}_{2}$ binary system

$f_{0}=\frac{694.3412-694.3412^{2}+2788.519(2075.109-T)}{2788.519}$

5. 0 -rich $L_{1}$ and $L_{1}^{\prime}$ boundary, $Z r-Z r O_{2}$ binary system

$f_{0}=\frac{1785.754-1785.754^{2}+390.6488(764.6003-T)}{390.6488}$

6. Zr-rich $L_{1}$ boundary, $Z r_{0.7} 0.3^{-} U_{0.33^{0} 0.67}$ isopleth

$f_{U_{0.33} 0_{0.67}}=\frac{-13.40961+13.40961^{2}+829.9846(2240.747-T)}{829.9846}$ 


\section{PSOL, PLIO, ZUSOLV, COEF}

Table 11.1-2. (continued)

7. 0 -rich $L_{1}$ boundary, $\operatorname{Zr}_{0.7} 7^{0} 0.3^{-U_{0}} 0.33^{0} 0.76$ isopleth $f_{U_{0.33^{0} 0.67}}=\frac{11234.85-11234.85^{2}-27575.76(1883.545+T)}{27575.76}$

8. Forced to lie on the line from solidus point 11 to solidus point 5

9. 0 -rich $L_{2}$ boundary, $Z r_{0.7} 0_{0.3}-U_{0.33} 0_{0.67}$ isopleth

$f_{U_{0.33} 0_{0.67}}=\frac{4930-4930^{2}-6000(311+T)}{3000}$

10. Linear interpolation between point 9 's location at the given temperature and point 12 at $2700 \mathrm{~K}$ :

$$
\text { location of } \begin{aligned}
10= & {[\text { location of } 12 \text { at } 2700 \mathrm{~K}(T-2673)} \\
& + \text { location of } 9 \text { at } T(2700-T)] / 27
\end{aligned}
$$

11. Linear interpolation between point 9 's location at the given temperature and point 14 at $2809 \mathrm{~K}$ :

$$
\text { location of } \begin{aligned}
11= & {[\text { [ } \text { ocation of } 14 \text { at } 2809 \mathrm{~K}(T-2673)} \\
& + \text { location of } 9 \text { at } T(2809-T)] / 136
\end{aligned}
$$

12. O-rich substoichiometric boundary of $L_{2}, U-0$ binary system

$$
f_{0}=\frac{2-\frac{3119-T}{1610}}{3-\frac{3119-T}{1610}}
$$

13. U-rich hyperstoichiometric boundary of $L_{2}, U-0$ binary system

$$
f_{0}=\frac{2+\frac{3119-T}{1610}}{3+\frac{3119-T}{1610}}
$$


PSOL， PLIQ，ZUSOLV， COEF

Table 11.1-2. (continued)

14. $U_{0.33} 0_{0.67}-$ rich $L_{2}$ boundary, $U_{0.33} 0_{0.67}-0_{0.67}$ system

For $3119 \geq T \geq 2989$

$f_{Z r_{0.33} 0.67}=\frac{3119-T}{433.3333}$

For $2989>T \geq 2832$

$f_{Z r_{0.33} 0_{0.67}}=\frac{443.0286+443.0286^{2}+2194.367(2920.676-T)}{2194.367}$

For $2832>\mathrm{T} \geq 2809$

$f_{Z r_{0.33} 0.67}=0.5-0.25-\frac{(35809.46-T)}{132001.8}$

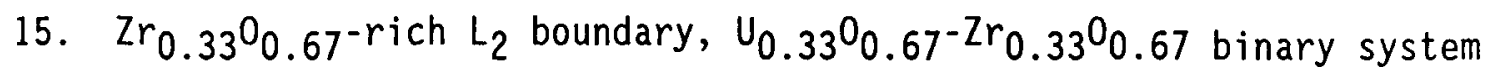
For $2809 \leq T \leq 2821$

$f_{Z r_{0.33} 0_{0.67}}=0.5+0.25-\frac{(5794.401-T)}{11941.6}$

For $2821<T \leq 2851.341$

$f_{Z r_{0.33^{0} 0.67}}=\frac{4162.934-4162.934^{2}+6838.223(327.3354-T)}{6838.223}$

For $2851.341<T \leq 2862$

$f_{Z r_{0.33} 0_{0.67}}=\frac{T-2817.588}{59.2158}$

For $2862<T \leq 2973$

$f_{Z r_{0.33} 0.67}=\frac{793+793^{2}-1160(3399-T)}{1160}$ 


\section{PSOL, PLIO, ZUSOLV, COEF}

Table 11.1-2. (continued)

16. Point 15 with $y$ coordinate increased 0.01

17. Intersection of 1 ines from $0.7 \mathrm{Zr}, 0.30$ to point 15 and point 5 to the $L_{1} / L_{1}+L_{2}$ boundary location is given by

$$
f_{U_{0.33^{0} 0.67}}=\frac{41641.97-41641.97^{2}-94995.94(15257.48-T)}{94995.94}
$$

a. $f_{A}$ denotes the faction of binary component $A$. These fractions must be converted to $f_{Z r}$ and $f_{0}$ or $x$ and $y$ using Equations (11.1-3) and $(11.1-4)$. 
PSOL，PLIO，ZUSOLV， COEF
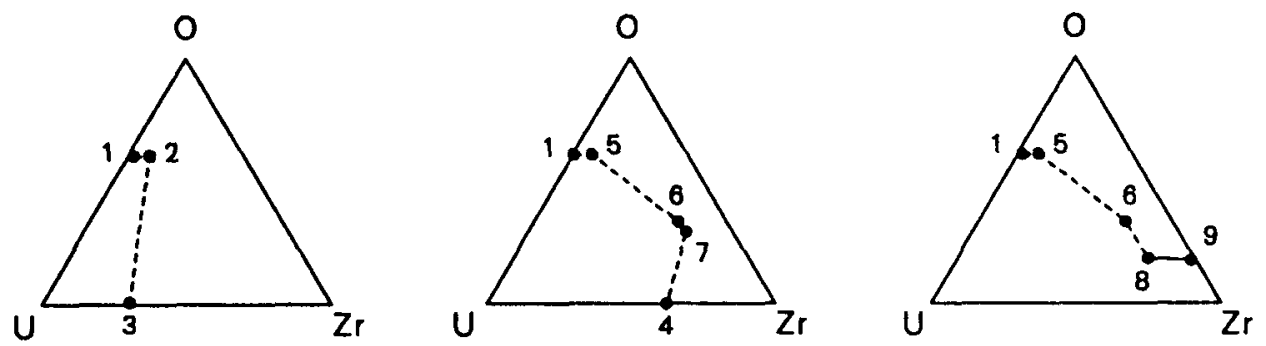

$1406 \leq \mathrm{T} \leq 1587.277 \quad 1587.277<\mathrm{T}<2125$

$$
2125 \leq \mathrm{T}<2173
$$
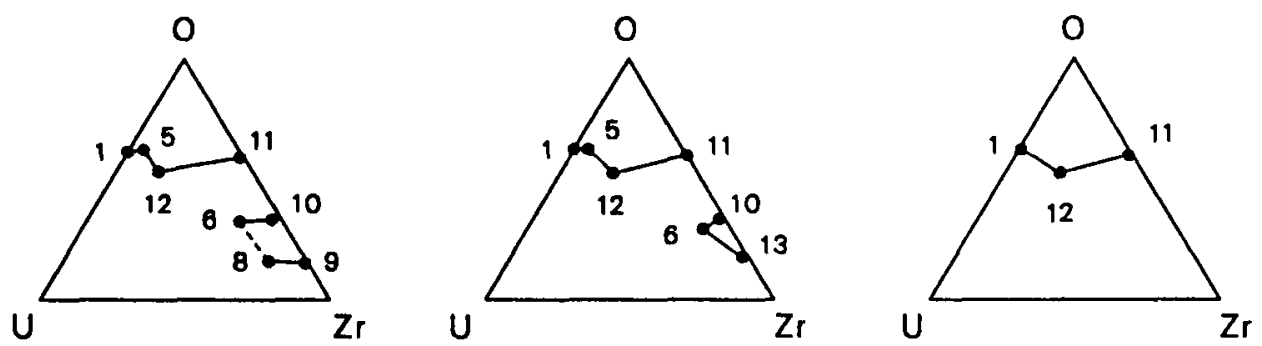

$2173 \leq T \leq 2213$

$$
2213<\mathrm{T} \leq 2248
$$

$$
2248<T<2673
$$

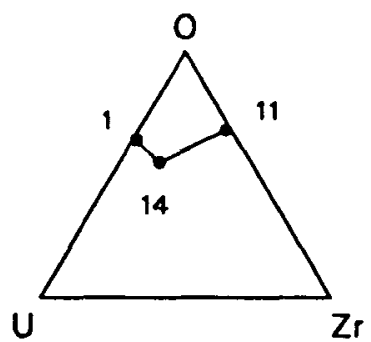

$2673 \leq T<2700$

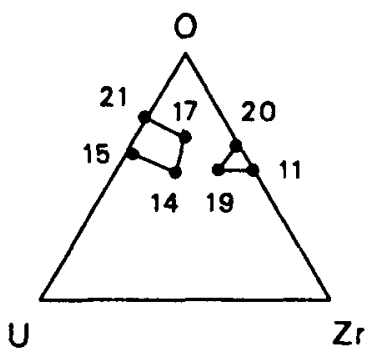

$2873<T \leq 2973$

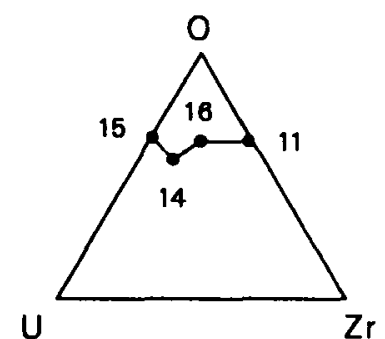

$2700 \leq T<2809$

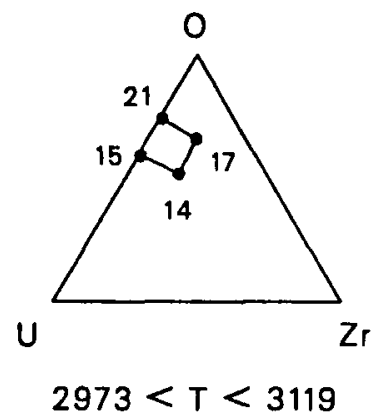

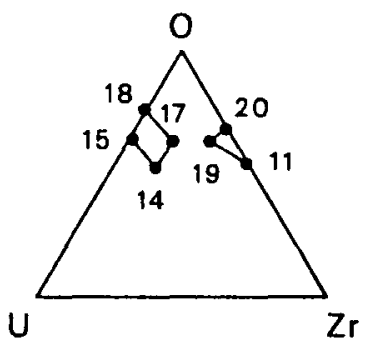

$2809 \leq T \leq 2873$

S115-WHT-1189-40

Figure 11.1-15. Points that are connected to form the ternary $Z r-0-U$ system solidus lines. 


\section{PSOL, PLIO, ZUSOLV, COEF}

Table 11.1-3. Correlations for solidus compositions

1. U-rich solid $\mathrm{UO}_{2-\mathrm{x}}$ boundary for $\mathrm{T}<2700 \mathrm{~K}, \mathrm{U}-0$ binary system $f_{0}=\frac{473984.9+473984.9^{2}-763564.9(291499.1+T)}{763564.9}$

2. Point 1 with $x$ coordinate increased 0.01 times the ratio of the $\mathrm{Zr}$ content of the U-Zr binary system liquidus / 0.1993

3. The U-Zr binary system liquidus, point 2 of Table 11.1-1.

4. $\beta-Z r, \gamma-U$ phase boundary, U-Zr binary system

$$
f_{Z r}=\frac{-208.5+208.5^{2}-302(1406-T)}{302}
$$

5. Point 1 with $\times$ coordinate increased 0.01

6. U-rich, 0-rich extriem of the alpha zircaloy phase region.

For $1587.277 \leq T<2223$

$$
x=0.6248868+\mathrm{T}(2.938827 \mathrm{E}-4+\mathrm{T}(-9.967758 \mathrm{E}-8))
$$

For $2223 \leq \mathrm{T} \leq 2248$

$$
\mathrm{X}=-7.207558+\mathrm{T} 3.595666 \mathrm{E}-3
$$

For $1587.277 \leq T, 2178$

$$
y=0.5935931+T(-4.90869 E-4+T 1.629741 E-7)
$$

For $2178 \leq T \leq 2248$

$$
y=2.848266-\mathrm{T} 1.171115 \mathrm{E}-3
$$

7. Point 7 displaced 0.01 parallel to the $0-\mathrm{Zr}$ side of the Gibbs triangle

8. U-rich, 0-poor extriem of the beta-phase zircaloy region

$$
\begin{aligned}
& x=32.99604+T(-2.993934 E-2+T 6.984916 E-6) \\
& y=-27.11131+T(2.472659 E-2+T(-5.619063 E-6))
\end{aligned}
$$


PSOL, PLIQ，ZUSOLV, COEF

Table 11.1-3. (continued)

9. Zr-rich boundary of the beta phase, $Z r-Z r_{2}$ binary system

$$
f_{0}=\frac{-131.723+131.723^{2}-5602.96(2125-T)}{5602.96}
$$

10. 0-rich part of the alpha-phase boundary, which is in equilibrium with 1 iquid $\mathrm{L}_{1}{ }^{\prime}, \mathrm{Zr}-\mathrm{ZrO}_{2}$ binary system

$$
f_{0}=\frac{10100.05+10100.05^{2}-40562.47(266.9135+\mathrm{T})}{40562.47}
$$

11. Zr-rich boundary of the cubic $\mathrm{ZrO}_{2}$ phase, which is in equilibrium with $\mathrm{liquid}, \mathrm{Zr}-\mathrm{ZrO}_{2}$ binary system

$$
f_{0}=\frac{52252.48+52252.48^{2}-9551941(30182.27-T)}{95519.41}
$$

12. $\operatorname{Zr}_{9} 7^{0} 0.3^{-r i c h}$ boundary of cubic $(U, Z r) 0_{2-x}$ phase for $2173 \leq T \leq$ $2693,2 \dot{r}_{0.7}^{3} 0.3^{-U_{0}} 0.33^{0} 0.67$ isopleth

$f_{U_{0.33} 0.67}=\frac{105794.3+105794.3^{2}-128402.4(84438.99+T)}{128462.5}$

13. Zr-rich part of the alpha-phase boundary, which is in equilibrium with liquid $L_{1}, Z r-Z_{2} O_{2}$ binary system

$$
f_{0}=\frac{1941.412-1941.412^{2}+7796.837(1764.588-T)}{7796.837}
$$

14. $\operatorname{Zr}_{9} 7^{0} 0.3^{-r i c h}$ boundary of cubic $(U, Z r) 0_{2-x}$ phase for $2673 \leq T \leq$ $3119 \mathrm{~K}, 2 r_{0.7} 0_{0.3}-U_{0.33^{0}} 0.67$ isopleth

$$
f_{U_{0.33^{0}} 0.67}=\frac{2489.661+2489.661^{2}-4179.972(3918-T)}{4179.972}
$$




\section{PSOL, PLIO, ZUSOLV, COEF}

Table 11.1-3. (continued)

15. U-rich solid $\mathrm{UO}_{2-\mathrm{x}}$ boundary for $2700 \leq T \leq 3119$, U-0 binary system

$$
f_{0}=\frac{2-\frac{418.85^{2}+1469(3119-T)-418.85}{1469}}{3-\frac{418.85^{2}+1469(3119-T)-418.85}{1469}}
$$

16. Linear interpolation between point $14^{\prime}$ 's location at the given temperature and point 17 at $2809 \mathrm{~K}$

$$
\begin{aligned}
& \text { location of } 16= \text { [location of } 17 \text { at } 2809(T-2673)+ \\
&\text { location of } 14 \text { at } T(2809-T)] / 136
\end{aligned}
$$

17. $U_{0.33} 0_{0.67}$-rich cubic phase boundary, $U_{0.33} 0.67^{-Z r_{0}} 0.33^{0} 0.67$ binary system

For $3119 \geq T \geq 2843$

$$
f_{Z r_{0.33} 0.67}=\frac{107-107^{2}-41.44(3119-T)}{1036}
$$

For $2843>T>=2809$

$$
f_{Z r_{0.33}{ }^{0} 0.67}=\frac{0.5-0.25-(2862.125-T)}{212.5}
$$

18. 0 -rich solid $\mathrm{UO}_{2+\mathrm{x}}$ boundary for $2809 \leq \mathrm{T} \leq 2873$, U-0 binary

$$
f_{0}=\frac{478156.7-478156.7^{2}-67587(3383979-\mathrm{T})}{675870}
$$

19. Zro.3300.67-rich cubic phase boundary,

$\mathrm{U}_{0.33^{0} 0.67^{-}-\mathrm{rr}_{0.33^{0}} 0.67 \text { binary system }}$

For $2809 \leq T \leq 2832$

$$
f_{Z r_{0.33}{ }^{0} 0.67}=0.5+\frac{0.25-(2872.889-T)}{255.5556}
$$

For $2832<T \leq 2973$ 
PSOL, PLIQ, ZUSOLV, COEF

Table 11.1-3. (continued)

$$
f_{Z r_{0.33} 0.67}=\frac{2212.5+2212.5^{2}-2850(4548-T)}{2850}
$$

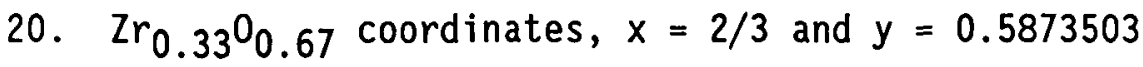

21. 0 -rich solid $U_{2+x}$ boundary for $2873 \leq T \leq 3119$, U-0 binary system

$$
f_{0}=\frac{37574.67-37574.67^{2}-48052.59(31862.23-T)}{48052.59}
$$

a. $f_{A}$ denotes the fraction of binary component $A$. These fractions must be converted to $f_{Z r}$ and $f_{0}$ or $x$ and $y$ using Equations (11.1-3) and $(11.1-4)$. 
PSOL, PLIO, ZUSOLV, COEF

Table 11.1-4. Data used to produce liquidus correlations

Equation

Number

1. (0.0655 atomic fraction $0,1391 \mathrm{~K})$

$(0.347$ atomic fraction $0,2485 \mathrm{~K}$ )

( 0.454 atomic fraction $0,2700 \mathrm{~K}$ )

2. (0 atomic fraction $\mathrm{Zr}, 1406 \mathrm{~K})$

$(0.5$ atomic fraction $\mathrm{Zr}, 1825 \mathrm{~K}$ )

(1 atomic fraction $\mathrm{Zr}, 2125 \mathrm{~K}$ )

3. a. $2213<\mathrm{T} \leq 2248 \mathrm{~K}$

(0.0673 atomic fraction $0,2213 \mathrm{~K}$ )

( 0.249 atomic fraction $0,2248 \mathrm{~K}$ )

b. $2125 \leq T \leq 2213 \mathrm{~K}$

( 0 atomic fraction $0,2125 \mathrm{~K}$ )

(0.0673 atomic fraction $0,2213 \mathrm{~K}$ )

4. (0.249 atomic fraction $0,2248 \mathrm{~K})$

(0.413 atomic fraction $0,2173 \mathrm{~K}$ )

5. (0.413 atomic fraction $0,2173 \mathrm{~K})$

(0.538 atomic fraction $0,2573 \mathrm{~K}$ )

(0.667 atomic fraction $0,2973 \mathrm{~K}$ )

6. (O atomic fr. $\left.U_{0} .33^{0} 0.67,2240.747 \mathrm{~K}\right)$

$\left(0.135\right.$ atomic fr: $\left.{ }_{0.33} 0_{0.67}, 2222 \mathrm{~K}\right)$

(0.27 atomic $\mathrm{fr} . \mathrm{U}_{0} .33 \mathrm{O}_{0.67}, 2173 \mathrm{~K}$ )

7. $\quad\left(0.27\right.$ atomic fr. $\left.U_{0} .33^{0} 0.67,2173 \mathrm{~K}\right)$

(0.32 atomic fr. $\left.U_{0.33} 0.67,2222 \mathrm{~K}\right)$

$\left(0.38\right.$ atomic $\left.\mathrm{fr} . \mathrm{U}_{0} .33^{0} 0.67,2673 \mathrm{~K}\right)$

9. (0.8 atomic fr. $\left.U_{0.330_{0}} 0.67,2673 \mathrm{~K}\right)$

(0.9 atomic fr. $U_{0} .33^{0} 0.67,2911 \mathrm{~K}$ )

(1 atomic $\mathrm{fr} . \mathrm{U}_{0.33} \mathrm{O}_{0.67}^{3}, 3119 \mathrm{~K}$ )

12. See Table 11.1-3
Comments

$\mathrm{L}_{1}$ boundary, $\mathrm{U}-0$

binary system,

Figure 11.1-2

Figure 11.1-6

The point at $2248 \mathrm{~K}$ was required to be a minimum. Figure 11.1-1

The slope at $2213 \mathrm{~K}$ was required to equal the slope of the correlation of $3 a$.

Figure 11.1-1

The point at $2248 \mathrm{~K}$ was required to be a maximum. Figure 11.1-1

0 -rich $L_{1}$ and $L_{1}$ boundary, $\mathrm{Zr}-\mathrm{ZrO}_{2}$

Figure 11.1-1

Zr-rich $\mathrm{L}_{1}$ boundary,

Figure 11.1-4.

0-rich $L_{1}$ boundary, Figure 11.1-4.

0 -rich $L_{2}$ boundary, Figure 1\}.1-4.

Least-squared deviation fit to the data of Latta and Fryxel1 
PSOL，PLIO，ZUSOLV， COEF

Table 11.1-4. (continued)

Equation

Number

13. See comments

14. a. $3119>\mathrm{T} \geq 2989 \mathrm{~K}$

(0 atomic fr. $\mathrm{Zr}_{\left.0.33^{0} 0,67,3119 \mathrm{~K}\right)}$

( 0.3 atomic fr. $2 \dot{r}_{0.33} 0_{0.67}, 2989 \mathrm{~K}$ )

b. $2989>\mathrm{T} \geq 2832 \mathrm{~K}$

(0.3 atomic fr. $\left.Z r_{0} 0.33^{0} 0.67,2989 \mathrm{~K}\right)$

$\left(0.4\right.$ atomic $\mathrm{fr}$. $\left.2 r_{0} .3300 .67,2924 \mathrm{~K}\right)$

(0.4868 at. fr. $\operatorname{Zr}_{0.33} 0_{0.67}, 2832 \mathrm{~K}$ )

c. $2832>T \geq 2809 \mathrm{~K}$

$\left(0.4868\right.$ at. fr. $\left.Z r_{0} .3300 .67,2832 \mathrm{~K}\right)$

(0.5 atomic fr. $\mathrm{Zr}_{0} .3300 .67,2809 \mathrm{~K}$ )

15. a. $2809 \geq T \geq 2821 \mathrm{~K}$

$\left(0.5\right.$ atomic fr. $\left.2 r_{0} 0.33^{0} 0.67,2809 \mathrm{~K}\right)$

(0.5317 at. fr. $2 r_{0} .3300 .67,2821 \mathrm{~K}$ )

b. $2821>T \geq 2851.341 \mathrm{~K}$

(0.5317 at. fr. $\left.Z r_{0} .33^{0} 0.67,2821 \mathrm{~K}\right)$

(0.55 at. fr. $2 r_{0} .3300 .67,2838 \mathrm{~K}$ )

$\left(0.65\right.$ at. fr. $\operatorname{Zr}_{0} 3300.67,2850 \mathrm{~K}$ )

c. $2851.341>T \geq 2862 \mathrm{~K}$

(0.57 at. fr. $2 r_{0} .33^{0} 0.67$,

$2851.341156 \mathrm{~K})$

$\left(0.75\right.$ at. fr. $2 r_{0.33^{0} 0.67}, 2862 \mathrm{~K}$ )

d. $2862>T \geq 2973 \mathrm{~K}$

(0.75 at. fr. $\mathrm{Zr}_{\left.0.33^{0} 0.67,2862 \mathrm{~K}\right)}$

( 0.85 at. fr. $\left.Z r_{0} .3300 .67,2889 \mathrm{~K}\right)$

(1.00 at. fr. $\operatorname{Zr}_{0.33} 00.67,2973 \mathrm{~K}$ )

17. $\left(0.38\right.$ at. $\left.f r . ~ Z r_{0} .33^{0} 067,2673 \mathrm{~K}\right)$

$\left(0.4023\right.$ at. fr. $\left.2 \dot{r}_{0} 3300.6 \mathrm{~J}, 2873 \mathrm{~K}\right)$

$\left(0.65\right.$ at $\left.\mathrm{fr} . \mathrm{Zr}_{0.33} 0_{0.67}^{33}, 2821 \mathrm{~K}\right)$
Comments

As sumed symmetry

about the $\mathrm{UO}_{2}$

composition in

Figure 11.1-2.

$\mathrm{U}_{0.33} \mathrm{O}_{0.67^{-r i c h}}$

$\mathrm{L}_{2}$ boundary

Figure 11.1-5.
The point at 2809 was required to be a minimum.

$2 r_{0} .33^{0} 0.67^{-r i c h}$ boundary. Figure 11.1-5. The point at $2809 \mathrm{~K}$ was required to be a minimum. Section b's range was reduced because it contained a local maximum that is not physically possible. The offending section was replaced with a linear fit, Section $c$.

The coordinates given are for the $\mathrm{L}_{1} / \mathrm{L}_{1}+\mathrm{L}_{2}$ Figure 11.1-7. 


\section{PSOL, PLIO，ZUSOLV， COEF}

Table 11.1-5 lists the solidus equation number as identified in Table 11.1-3, the data that were used to construct the equation, and any appropriate comments about the derivation of the equation.

The equations of Tables 11.1-2 and 11.1-3 are expressions for the compositions at boundaries of the single liquid-and solid-phase regions as a function of temperature. In order to use these expressions with the lever rule and the mixing rule $11.1-9$ to calculate fractions dissolved or precipitated, the distance between the boundaries of solid and liquid phases that are in equilibrium must be calculated. This is done by converting the composition to Cartesian coordinates centered on the lower left-hand side vertex of the Gibbs coordinate system with the transformation

$$
\begin{aligned}
& X=f_{0} \cos 60+f_{Z r} \\
& Y=f_{0} \sin 60
\end{aligned}
$$

where

$$
\begin{aligned}
& X, Y=\text { Cartesian coordinates } \\
& f_{0}=\text { atomic fraction oxygen } \\
& f_{Z r}=\text { atomic fraction zircaloy. }
\end{aligned}
$$

In addition to the distances between compositions, calculations of the fractions dissolved or precipitated require knowledge of the tie lines connecting interacting solid and liquid phases. Since no data for tie lines are available, tie lines are assumed to progress between the limits of the two-phase regions they cross in fan-shaped patterns. This is the simplest pattern that correctly joins to the binary systems at the edges and avoids the error of tie line crossing. 
PSOL, PLIO, ZUSOLV, COEF

Table 11.1-5. Data used to produce solidus correlations

Equation

Number

Coordinations

1. (0.6626 atomic fraction $0,1391 \mathrm{~K})$

(0.6375 atomic fraction $0,2514 \mathrm{~K}$ )

(0.626825706 at. fr. $0,2700 \mathrm{~K}$ )

4. (0 atomic fraction $\mathrm{Zr}, 1406 \mathrm{~K})$

(0.5 atomic fraction $\mathrm{Zr}, 1690 \mathrm{~K}$ )

( 1 atomic fraction $\mathrm{Zr}, 2125 \mathrm{~K}$ )

6. a. For $1587.277 \geq \mathrm{T}>2223 \mathrm{~K}, \mathrm{x}$ coordinate $(1273 \mathrm{~K}, 0.837 \overline{4})$

(1773 K,0.8364)

(1873 K,0.8113)

$(2073 \mathrm{~K}, 0.8113)$

(2178 K,0.7896)

b. For $2223 \mathrm{~K} \geq \mathrm{T}>2223 \mathrm{~K}, \mathrm{x}$ coordinate

(2223 K,0.785608339)

(2248 K,0.8755)

c. For $1587.227 \geq \mathrm{T} \geq 2178 \mathrm{~K}$, y coordinate

(1273 K,0.2339)

$(1773 \mathrm{~K}, 0.2213)$

$(1873 \mathrm{~K}, 0.2616)$

(2073 K,0.2767)

$(2178 \mathrm{~K}, 0.2948)$

d. For $2178 \geq T \geq 2248$

(2178 K,0.297578048)

$(2248 K, 0.2156)$

8. a. For the $x$ coordinate

(2073 K,0.948278264)

(2178 K,0.9224)

(2213K,0.948)
Comments

U-rich solid $\mathrm{UO}_{2-x}$

boundary for

$\mathrm{T}>2700 \mathrm{~K}$

Figure 11.1-2.

Figure 11.2-6.

Ternary phase

diagrams were used

to provide a

correlation for the $x$ and $y$ coordinates. The point does not appear on any available binary system.

The first point of the set for $b$ was generated by requiring continuity with $a$.

Ternary phase

diagrams were used.

The point $2073 \mathrm{~K}$

was calculated to

fit the binary

correlation. 


\section{PSOL， PLIO，ZUSOLV， COEF}

Table 11.1-5. (continued)

Equation

Number

Coordinations

b. For the $y$ coordinate

$(2073 \mathrm{~K}, 0)$

(2178 K,0.0882)

(2213 K, 0.090066642)

9. (0 atomic fraction $0,2125 \mathrm{~K})$

$(0.0545$ atomic fraction $0,2156 \mathrm{~K})$

(0.104 atomic fraction $0,2213 \mathrm{~K}$ )

10. (0.249 atomic fraction $0,2248 \mathrm{~K})$ (0.292 atomic fraction $0,2173 \mathrm{~K}$ )

11. (0.6246 atomic fraction $0,2173 \mathrm{~K})$ (0.65 atomic fraction $0,2611 \mathrm{~K}$ )

(0.667 atomic fraction $0,2973 \mathrm{~K}$ )

12. (0.834 at. fr. $\left.\mathrm{U}_{0} .33^{0} 0.67,2673 \mathrm{~K}\right)$

$\left(0.8681\right.$ at. fr. $\left.0.330_{0.67}, 2432 \mathrm{~K}\right)$

(0.8868 at. fr. $\left.U_{0.33} 0.67,2173 \mathrm{~K}\right)$
Comments

Zr-rich boundary of the beta phase, $\mathrm{Zr}-\mathrm{ZrO}_{2}$ system.

Figure 1. The data of Domagala and were converted from weight fractions.

0 -rich part of the alpha phase boundary which is in equilibrium with liquid $L_{1}{ }^{\prime}$, $\mathrm{Zr}-\mathrm{ZrO}_{2}$ binary phase system. Figure 1. The point at $2248 \mathrm{~K}$ was required to be a $\max$.

Zr-rich boundary of the cubic $\mathrm{ZrO}_{2}$ phase which is in equilibrium with liquid, $\mathrm{Zr}-\mathrm{ZrO}_{2}$ binary phase system. Figure 11.1-1.

$\mathrm{Zr}_{0} 7^{0} 0_{0.3-}$ rich boundary of cubic (U, $\mathrm{Zr}$ ) $\mathrm{O}_{2-\mathrm{X}}$ phase for $2173^{-x} \geq T$ $\geq 2673 \mathrm{~K}$, ${ }^{2} r_{0} .7^{0} O_{3} U_{0.33^{0}} 0.67$ isopleth.

Figure 11.1-7. 
PSOL，PLIO， ZUSOLV， COEF

Table 11.1-5. (continued)

Equation

Number

13. (0.249 atomic fraction $0,2248 \mathrm{~K})$

(0.182 atomic fraction $0,2213 \mathrm{~K}$ )

Coordinations
Comments

Zr-rich part of the alpha phase boundary which is in equilibrium with

liquid $\mathrm{L}_{1}$,

$\mathrm{Zr}-\mathrm{ZrO}_{2}$ binary

system.

Figure 11.1-1.

The point at $2248 \mathrm{~K}$ was required to be a maximum.

14. (0.834 at. fr. $\left.U_{0.33} 0_{0} 67,2673 \mathrm{~K}\right)$

$(0.91915$ at. fr. $03330.67,2873 \mathrm{~K})$

(1 atomic fr. $U_{0.33} 0_{0.67}, 3119 \mathrm{~K}$ )

$\mathrm{Zr}_{0.7^{0} 0.3^{-r i c h}}$ boundary of cubic $(U, \mathrm{Zr}) \mathrm{O}_{2-x}$ phase for $2673 \geq T \geq$ $3119 \mathrm{~K} \mathrm{Zr_{0 }} .7^{0} 0.3^{0} 0.67$ isopleth.

Figure 11.1-4.

15. See Table 11.1-3

Least squared deviation fit to the data of Latta and Fryxe11

17. a. For $3119 \geq \mathrm{T} \geq 2843 \mathrm{~K}$ ( 0 atomic $\mathrm{fr} .2 \mathrm{Zr}_{0.33} \mathrm{O}_{0.67}, 3119 \mathrm{~K}$ ) (0.1 at. fr. $2 r_{0} .330 .67,2843 \mathrm{~K}$ )

b. For $2843>\mathrm{T} \geq 2809 \mathrm{~K}$ ) (0.1 at. fr. $2 r_{0} 0.33^{0} 0.67,2843 \mathrm{k}$ ) (0.5 at. $\mathrm{fr} .2 r_{0} .33^{0} 0.67,2809 \mathrm{~K}$ )
$\mathrm{U}_{0} 33^{0} 0$
cubic phase boundary, $\mathrm{U}_{0.33} \mathrm{O}_{0.67} \mathrm{Zr}$ 0.330 .67 binary system. Figure 11.1-8. The equation for a was required to match the slope of the equation for $2843>$ $T \geq 2809 \mathrm{~K}$ at $2843 \mathrm{~K}$ and 0.1 atomic fraction. Equation 6 was required to have a min at $2809 \mathrm{~K}$. Datum at $2843 \mathrm{~K}$ is from Hofmann. 
PSOL， PLIO，ZUSOLV， COEF

Table 11.1-5. (continued)

Equation

Number

18. (0.6969 atomic fraction $0,1926 \mathrm{~K})$

$(0.6947$ atomic fraction $0,2273 \mathrm{~K}$ )

$(0.6919$ atomic fraction $0,2873 \mathrm{~K})$

19. a. For $2809 \geq T \geq 2832 \mathrm{~K}$

$\left(0.5\right.$ at. fr. $\left.2 r_{0} 0.330_{0} 0.67,2809 \mathrm{~K}\right)$

(0.3 at. fr. $2 r_{0} .3300 .67,2832 \mathrm{~K}$ )

b. For $2832>T \geq 2973 \mathrm{~K}$ )

(0.8 at. fr. $Z r_{0} 0.33^{0} 0.67,2832 \mathrm{~K}$ )

$\left(0.9\right.$ at. fr. $\left.\mathrm{Zr}_{0} .3300 .67,2874 \mathrm{~K}\right)$

(1.0 at. fr. $2 r_{0.3300 .67}, 2973 \mathrm{~K}$ )

21. (0.6916 atomic fraction $0,2873 \mathrm{~K})$

(0.6786 atomic fraction $0,2994 \mathrm{~K}$ )

$(0.667$ atomic fraction $0,3119 \mathrm{~K}$ )
Comments

0 -rich solid boundary for $2809 \geq T \geq$ $2873 \bar{K}$ U $-\overline{0}$ binary. Figure 11.1-2.

$\operatorname{Zr}_{0.33^{0}} 0.67^{-r i c h}$ cubic phàse boundary, $U_{0} .33^{0} 8.67^{-}$ Zr. ${ }_{0} 30_{0} .67$ binary system. Figure 11.1-5 The equation for a was required to have a minimum at $2809 \mathrm{~K}$.

0 -rich solid $\mathrm{UO}_{2}$ boundary for $2873^{x} \leq$ $\mathrm{T} \leq 3119 \mathrm{~K}, \mathrm{U}-0$ binary system.

Figure 11.1-2. 
Calculation of the fractions dissolved or precipitated proceeds with a tedious but direct geometric approach to find the lengths and intersections required by metallurgical techniques once the tie lines are modeled. The location of the point representing the solvent composition is compared to the liquidus and solidus lines expressed in Cartesian coordinates to determine whether the solvent lies between the liquidus and solidus lines (supersaturated) or in the liquid-phase region (subsaturated). If the solvent is supersaturated, tie lines or tie triangles and the lever rule are used to calculate the fraction of the solvent that will freeze. If the solvent is subsaturated, the mixing rule is used to determine the amount of solute that must be dissolved to bring the solvent composition to the liquidus line where dissolution will stop (because additional mixing of the solute would move the gross composition into the multiple-phase region between the liquidus and solidus where formation of a solid phase would take place).

Figure 11.1-16 is an example showing how a calculation of the amount of $\mathrm{UO}_{2}$ dissolved by two solvents at $2500 \mathrm{~K}$ proceeds. Solvent $\mathrm{A}$ has 0.6 atomic fraction $Z r$ and 0.4 atomic fraction 0 , while solvent $B$ has 0.9 atomic fraction $Z r$ and 0.1 atomic fraction 0 . The mixing rule shows that the solution formed when solvent $A$ attacks $\mathrm{UO}_{2}$ at $2500 \mathrm{~K}$ contains only about $20 \% \mathrm{UO}_{2}$ (the distance from $A$ to the liquidus along the $\mathrm{A}-\mathrm{UO}_{2}$ line divided by the distance from $A$ to the point marked $\mathrm{UO}_{2}$ on the plot). When solvent $B$ attacks the $\mathrm{UO}_{2}, 55 \%$ of the solute will be contained in the solution at equilibrium. The tie lines shown as dashed lines in the figure would be used to calculate freezing from the solvent if the solvent composition had placed it in the two-phase region between the solid and liquid phase boundaries.

\subsubsection{References}

11.1-1. R. F. Domagala and D. J. McPherson, "System Zirconium-0xygen," Journal of Metals, 6, Transactions AIME 200, 1954, pp. 238-246. 
PSOL, PLIO， ZUSOLV， COEF

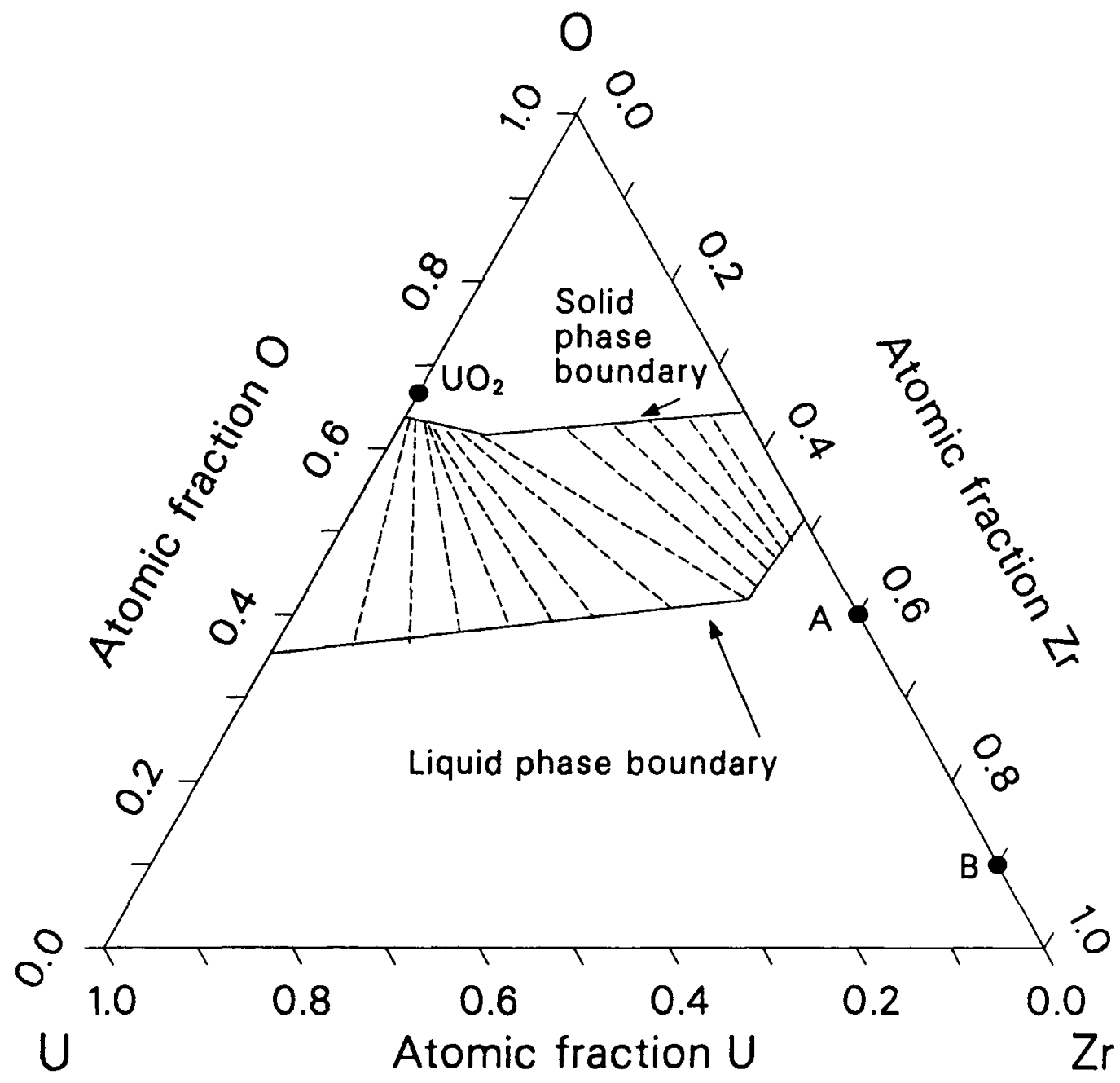

S115-WHT-1189-41

Figure 11.1-16. Solid and liquid phase boundaries with tie lines connecting compositions on the boundaries as they are represented for $2500 \mathrm{~K}$ in the ZUSOLV code. 
11.1-2. R. Ruh and H. J. Garrett, "Nonstoichiometry of $\mathrm{ZrO}_{2}$ and its Relation to Tetragonal-Cubic Inversion in $\mathrm{ZrO}_{2}$, Journal of the American Ceramic Society, 50, 1966, pp. 257-261.

11.1-3. Robert S. Roth, Taki Negas, and Lawrence P. Cook, Phase Diagrams for Ceramists Volume IV, The American Ceramic Society, 1981.

11.1-4. R. E Latta and R. E Fryxe11, "Determination of Solidus-Liquidus Temperatures in the $\mathrm{UO}_{2}$ system $(\leq 0.50 \times<0.2)$, "Journal of Nuclear Materials, 35, 1970, pp. 195-201.

11.1-5. A. Skokan, "High Temperature Phase Relations in the U-Zr-O System," Fifth International Meeting on Thermal Nuclear Reactor Safety, Karlsruhe, German Federal Republic, September 9-13, 1984, KfK 388011, December 1984, pp. 1035-1042.

11.1-6. K. A. Romberger, C. F. Bates, Jr., H. H. Stone, "Phase Equilibrium Studies in the $\mathrm{UO}_{2}-\mathrm{ZrO}_{2}$ System," Journal of Inorganic and Nuclear Chemistry, 29, 1966, pp. 1619-1630.

11.1-7. P. Hofmann, "SFD Singe Effects Laboratory Experiments, " Severe Fuel Damage and Source Term Research Program Review Meeting, Idaho Fal7s, Idaho, April 16-19, 1985.

11.1-8. P. Hofmann and C. Politis, "The Kinetics of the Uranium Dioxide-Zircaloy Reactions at High Temperatures, "Journal of Nuclear Materials, 87, 1975, pp. 375-397.

11.1-9. Fredick N. Rhines, Phase Diagrams in Metallurgy, Their Development and Application, New York: McGraw-Hill Book Company, Inc., 1956. 


\section{ZUCP, ZUNTHL, ZUCP1，ZUNTH1}

\subsection{Specific Heat Capacity and Enthalpy (ZUCP, ZUNTHL, ZUCP1, ZUNTH1) \\ (D. L. Hagrman, J. K. Hohorst)}

The function ZUCP provides the specific heat capacity of $\mathrm{Zr}-\mathrm{U}-0$ compounds as a function of component concentrations and the compound temperature. ZUNTHL returns the $\mathrm{Zr}-\mathrm{U}-0$ compound enthalpy as a function of component concentrations, the compound temperature, and a reference temperature for which the enthalpy will be zero. Functions ZUCP1 and ZUNTHI provide the same information for core components.

\subsubsection{Zirconium-Uranium-0xygen Compounds}

The expression used to calculate the specific heat capacity is an atomic-fraction-weighted average of the molar heat capacities of $\mathrm{UO}_{2}$, $\mathrm{ZrO}_{2}$, and zircaloy

$c_{p_{c}}=\frac{c_{p_{U_{2}}} 0.270 f_{U_{2}}+c_{p_{Z_{0} O_{2}}} 0.123 f_{Z O_{2}}+c_{p_{Z r}} 0.091 f_{Z r}}{0.270 f_{U_{2}}+0.123 f_{Z_{2} O_{2}}+0.091 f_{Z r}}$

where

$C_{P_{c}}=$ specific heat capacity of the compound $(\mathrm{J} / \mathrm{kg} \cdot \mathrm{K})$

$C_{\mathrm{PUO}_{2}}=\begin{aligned} & \text { specific heat capacity of } \mathrm{UO}_{2} \text { obtained from the } \mathrm{FCP} \\ & \text { subcode }(\mathrm{J} / \mathrm{kg} \cdot \mathrm{K})\end{aligned}$

$\mathrm{C}_{\mathrm{P}_{\mathrm{ZrO}_{2}}=} \begin{aligned} & \text { specific heat capacity of } \mathrm{ZrO}_{2} \text { obtained from the } \mathrm{ZOCP} \\ & \text { subcode }(\mathrm{J} / \mathrm{kg} \cdot \mathrm{K})\end{aligned}$ 


\section{ZUCP, ZUNTHL, ZUCP1, ZUNTH1}

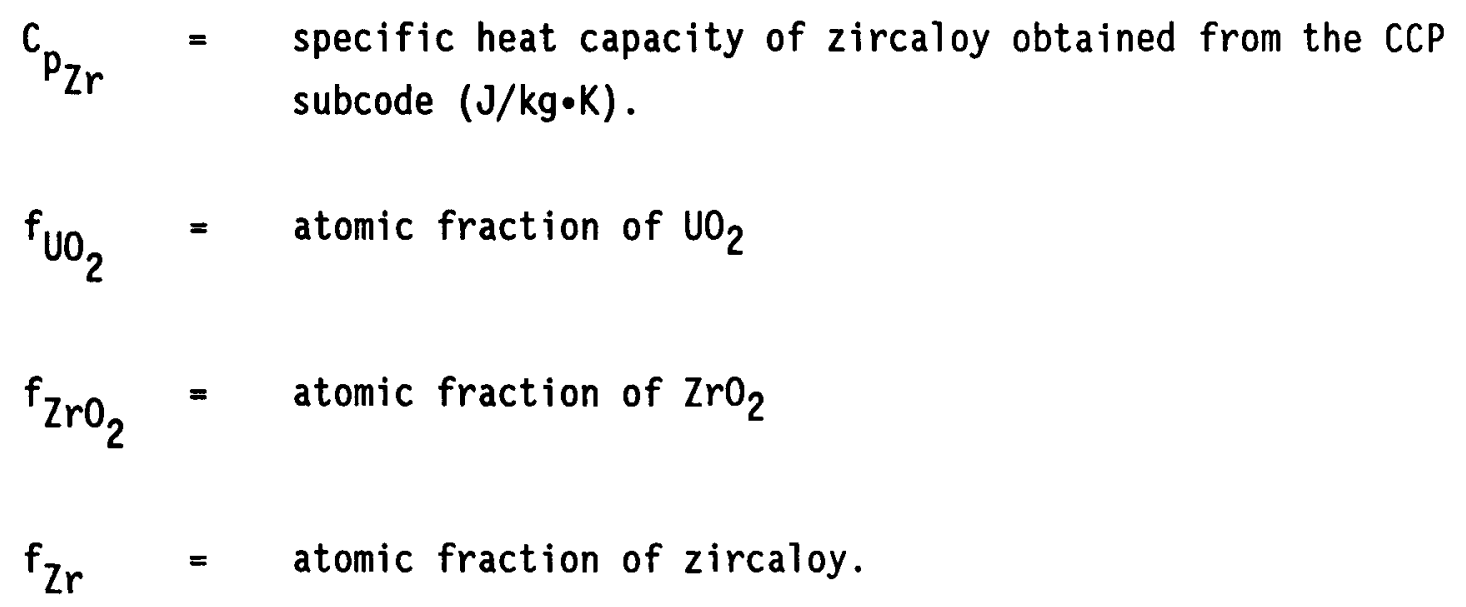

An analogous weighted average is used in ZUNTHL to calculate compound enthalpies. This technique has the advantage that the proper enthalpies are obtained for the limiting cases of $\mathrm{UO}_{2}, \mathrm{ZrO}_{2}$, or zircaloy, but the disadvantage that the heats of fusion are not constrained to appear between the solidus and liquidus temperatures of the compound.

Plots of the calculated specific heat capacity and enthalpy of a compound made up of 0.2 weight fraction $\mathrm{UO}_{2}$ and 0.8 weight fraction $\mathrm{ZrO}_{2}$ are shown in Figures 11.2-1 and 11.2-2.

Calculations with ZUNTHL are compared with enthalpies observed by Deem ${ }^{11.2-1}$ for several $\mathrm{UO}_{2}-\mathrm{ZrO}_{2}$ compounds in Tables $11.2-1$ to 11.2-4. (Deem's data are presented in Tables 14 to 17 of Reference 11.2-1.) The standard error of these predictions, $2 \times 10^{4} \mathrm{~J} / \mathrm{kg}$ or about 0.1 of the predicted value, is the expected standard error of the ZUNTHL function.

A similar expected standard error, 0.1 of the predicted specific heat capacity, is adopted for ZUCP. 
ZUCP, ZUNTHL, ZUCP1，ZUNTH1

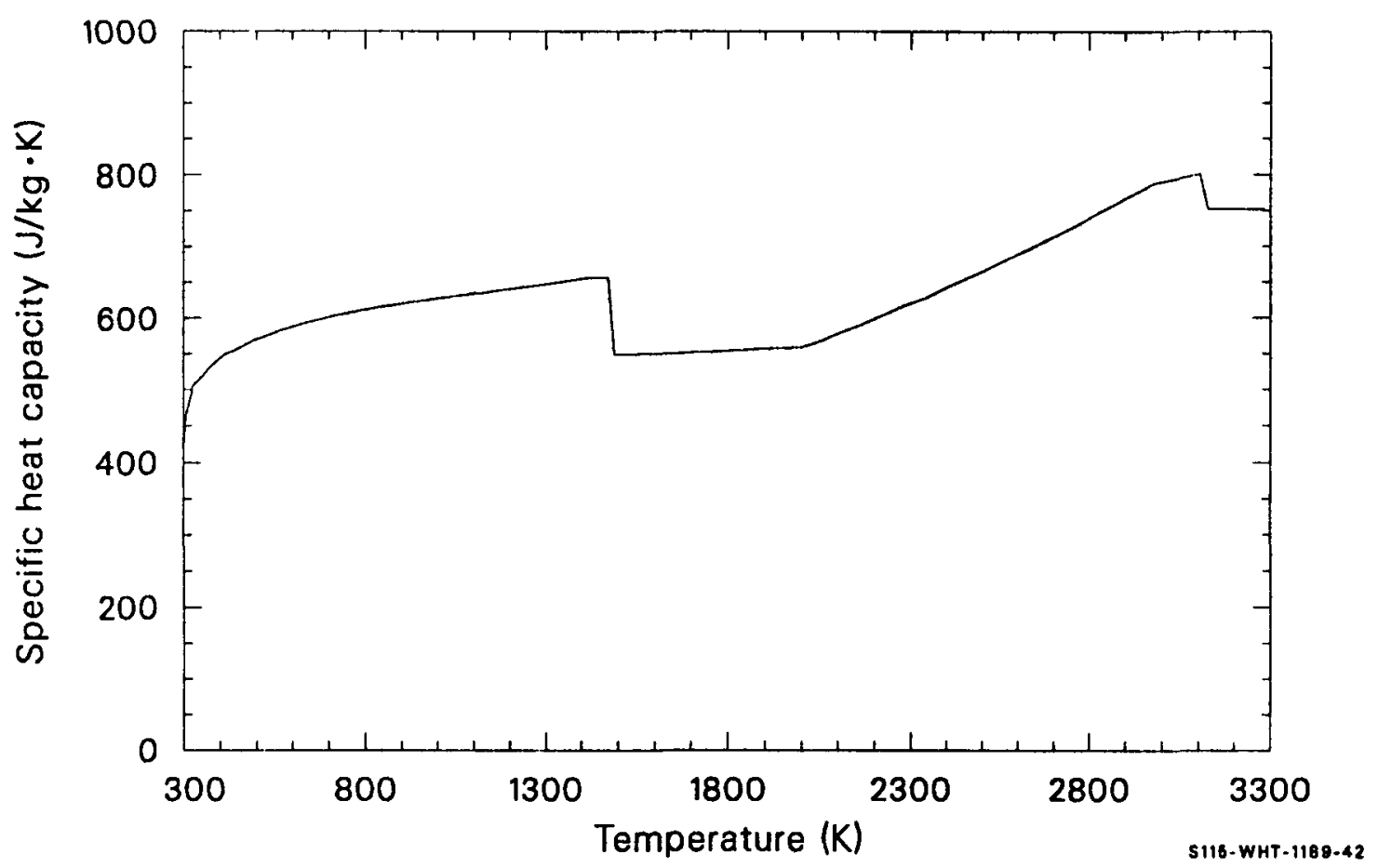

Figure 11.2-1. Specific heat capacity calculated for a $0.2 \mathrm{UO}_{2}-0.8$ $\mathrm{ZrO}_{2}$ weight fraction compound. 
ZUCP, ZUNTHL, ZUCP1, ZUNTH1

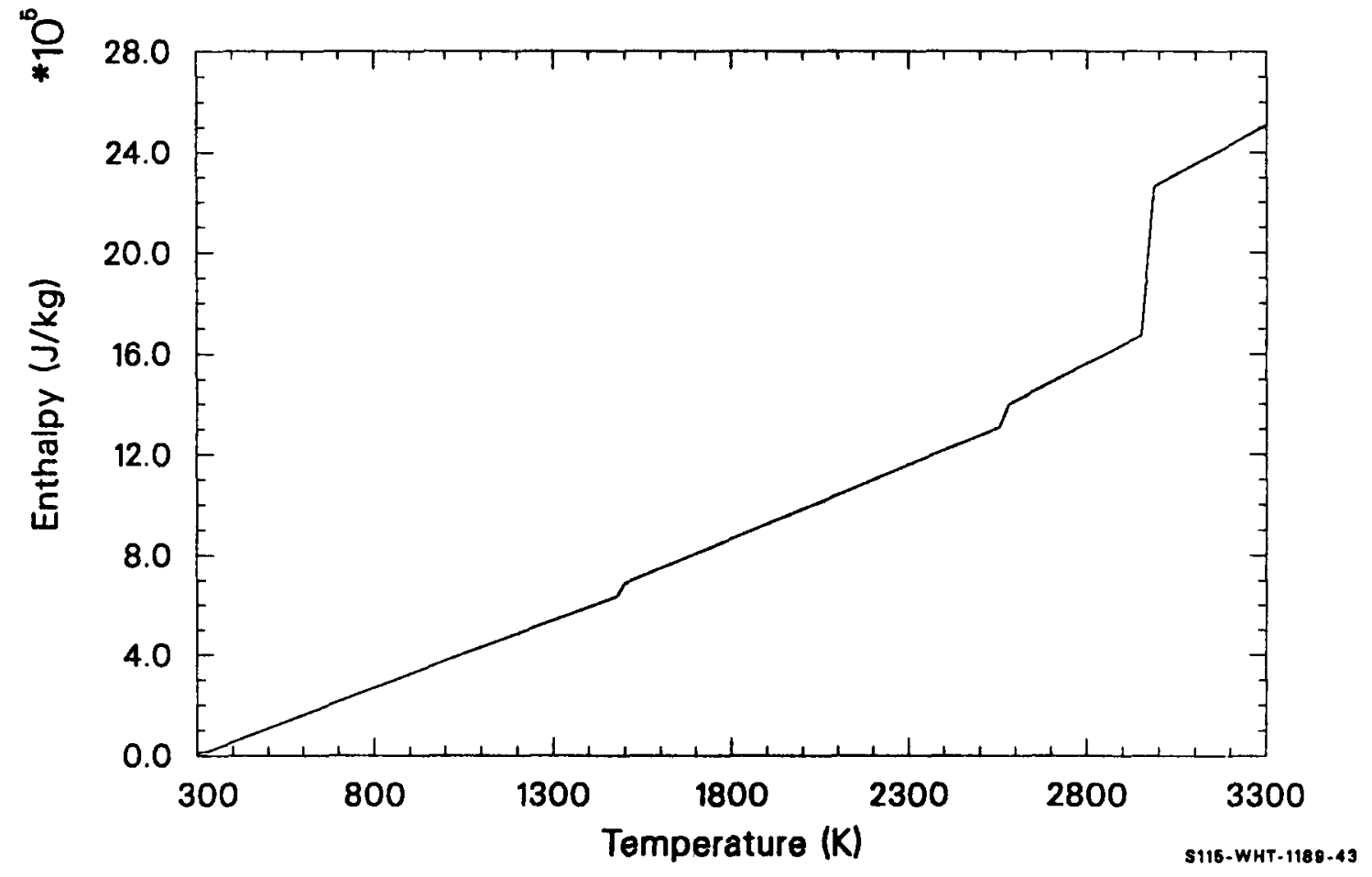

Figure 11.2-2. Enthalpy calculated for a $0.2 \mathrm{UO}_{2}-0.8 \mathrm{ZrO}_{2}$ weight fraction compound. 
ZUCP， ZUNTHL，ZUCP1，ZUNTH1

Table 11.2-1. ZUNTHL calculations and Deem's data11.2-1 for a $0.2 \mathrm{UO}_{2}-0.8 \mathrm{ZrO}_{2}$ weight fraction compound

\begin{tabular}{ccc}
$\begin{array}{c}\text { Temperature } \\
(\mathrm{K})\end{array}$ & $\begin{array}{c}\text { Observed Enthalpy } \\
\left(10^{4} \mathrm{~J} / \mathrm{kg}\right)\end{array}$ & $\begin{array}{c}\text { Calculated Enthalpy } \\
\left(10^{4} \mathrm{~J} / \mathrm{kg}\right)\end{array}$ \\
273 & 0.00 & 0.00 \\
370 & 4.23 & 4.16 \\
370 & 4.31 & 4.16 \\
378 & 4.64 & 4.53 \\
469 & 9.16 & 8.85 \\
& & \\
596 & 15.69 & 15.24 \\
596 & 15.56 & 15.24 \\
727 & 23.05 & 22.08 \\
868 & 30.92 & 29.66 \\
870 & 31.00 & 29.77 \\
1095 & & \\
1257 & 42.59 & 42.22 \\
1479 & 52.05 & 51.40 \\
1750 & 63.97 & 68.11 \\
2108 & 79.50 & 83.05 \\
2256 & 101.0 & 103.10 \\
& 112.0 & 111.92 \\
\hline
\end{tabular}


Table 11.2-2. ZUNTHL calculations and Deem's data11.2-1 for a $0.32 \mathrm{UO}_{2}-0.68 \mathrm{ZrO}_{2}$ weight fraction compound

\begin{tabular}{|c|c|c|}
\hline $\begin{array}{c}\text { Temperature } \\
(\mathrm{K})\end{array}$ & $\begin{array}{l}\text { Observed Enthalpy } \\
\left(10^{4} \mathrm{~J} / \mathrm{kg}\right) \\
\end{array}$ & $\begin{array}{l}\text { Calculated Enthalpy } \\
\left(10^{4} \mathrm{~J} / \mathrm{kg}\right)\end{array}$ \\
\hline $\begin{array}{l}273 \\
348 \\
349 \\
371 \\
372\end{array}$ & $\begin{array}{l}0.00 \\
2.93 \\
2.96 \\
3.95 \\
3.96\end{array}$ & $\begin{array}{l}0.00 \\
2.97 \\
3.01 \\
3.93 \\
3.98\end{array}$ \\
\hline $\begin{array}{l}390 \\
390 \\
408 \\
408 \\
541\end{array}$ & $\begin{array}{r}4.74 \\
4.77 \\
5.57 \\
5.61 \\
11.97\end{array}$ & $\begin{array}{r}4.75 \\
4.75 \\
5.54 \\
5.54 \\
11.63\end{array}$ \\
\hline $\begin{array}{l}543 \\
690 \\
691 \\
829 \\
829\end{array}$ & $\begin{array}{l}11.95 \\
19.20 \\
19.36 \\
26.21 \\
26.22\end{array}$ & $\begin{array}{l}11.72 \\
18.82 \\
18.87 \\
25.76 \\
25.76\end{array}$ \\
\hline $\begin{array}{r}947 \\
951 \\
1069 \\
1292 \\
1480\end{array}$ & $\begin{array}{l}32.30 \\
32.56 \\
37.24 \\
49.71 \\
60.84\end{array}$ & $\begin{array}{l}31.78 \\
31.99 \\
38.11 \\
49.94 \\
63.41\end{array}$ \\
\hline $\begin{array}{l}1678 \\
1797 \\
1878 \\
1919 \\
1976\end{array}$ & $\begin{array}{l}70.54 \\
75.94 \\
81.17 \\
82.26 \\
86.06\end{array}$ & $\begin{array}{l}73.68 \\
79.89 \\
84.14 \\
86.30 \\
89.32\end{array}$ \\
\hline $\begin{array}{l}2096 \\
2175 \\
2276 \\
2385 \\
2487\end{array}$ & $\begin{array}{r}93.55 \\
100.96 \\
107.19 \\
119.50 \\
125.98\end{array}$ & $\begin{array}{r}95.78 \\
100.19 \\
106.02 \\
112.57 \\
118.96\end{array}$ \\
\hline
\end{tabular}




\section{ZUCP，ZUNTHL, ZUCP1， ZUNTH1}

Table 11.2-3. ZUNTHL calculations and Deem's data11.2-1 for a $0.5 \mathrm{UO}_{2}-0.5 \mathrm{ZrO}_{2}$ weight fraction compound

\begin{tabular}{|c|c|c|}
\hline $\begin{array}{c}\text { Temperature } \\
(\mathrm{K})\end{array}$ & $\begin{array}{l}\text { Observed Enthalpy } \\
\frac{\left(10^{4} \mathrm{~J} / \mathrm{kg}\right)}{}\end{array}$ & $\begin{array}{l}\text { Calculated Enthalpy } \\
\left(10^{4} \mathrm{~J} / \mathrm{kg}\right)\end{array}$ \\
\hline $\begin{array}{l}273 \\
339 \\
339 \\
367 \\
367\end{array}$ & $\begin{array}{l}0.00 \\
2.33 \\
2.37 \\
3.41 \\
3.44\end{array}$ & $\begin{array}{l}0.00 \\
2.32 \\
2.32 \\
3.37 \\
3.37\end{array}$ \\
\hline $\begin{array}{l}383 \\
385 \\
401 \\
543 \\
547\end{array}$ & $\begin{array}{r}4.02 \\
3.97 \\
4.76 \\
10.63 \\
10.83\end{array}$ & $\begin{array}{r}3.99 \\
4.06 \\
4.69 \\
10.50 \\
10.67\end{array}$ \\
\hline $\begin{array}{l}702 \\
702 \\
877 \\
878 \\
978\end{array}$ & $\begin{array}{l}17.60 \\
17.62 \\
25.81 \\
25.66 \\
30.44\end{array}$ & $\begin{array}{l}17.40 \\
17.40 \\
25.27 \\
25.31 \\
29.91\end{array}$ \\
\hline $\begin{array}{r}979 \\
1102 \\
1243 \\
1273 \\
1484\end{array}$ & $\begin{array}{l}29.96 \\
34.98 \\
42.05 \\
43.43 \\
53.39\end{array}$ & $\begin{array}{l}29.96 \\
35.70 \\
42.38 \\
43.82 \\
56.46\end{array}$ \\
\hline $\begin{array}{l}1521 \\
1796 \\
1889 \\
1995\end{array}$ & $\begin{array}{l}63.64 \\
67.66 \\
72.17 \\
77.74\end{array}$ & $\begin{array}{l}58.19 \\
71.20 \\
75.66 \\
80.82\end{array}$ \\
\hline $\begin{array}{l}2086 \\
2188 \\
2297 \\
2430\end{array}$ & $\begin{array}{r}84.60 \\
89.66 \\
99.33 \\
105.94\end{array}$ & $\begin{array}{r}85.34 \\
90.60 \\
96.47 \\
104.01\end{array}$ \\
\hline
\end{tabular}


Table 11.2-4. ZUNTHL calculations and Deem's datall.2-1 for a $0.94 \mathrm{UO}_{2}-0.06 \mathrm{ZrO}_{2}$ weight fraction compound

\begin{tabular}{|c|c|c|}
\hline $\begin{array}{c}\text { Temperature } \\
(\mathrm{K})\end{array}$ & $\begin{array}{l}\text { Observed Enthalpy } \\
-\left(10^{4} \mathrm{~J} / \mathrm{kg}\right)\end{array}$ & $\begin{array}{l}\text { Calculated Enthalpy } \\
\frac{\left(10^{4} \mathrm{~J} / \mathrm{kg}\right)}{}\end{array}$ \\
\hline 273 & 0 & 0 \\
\hline 372 & 2.36 & 2.55 \\
\hline 372 & 2.55 & 2.55 \\
\hline 474 & 5.58 & 5.46 \\
\hline 596 & 9.25 & 9.15 \\
\hline 597 & 9.26 & 9.18 \\
\hline 728 & 13.41 & 13.29 \\
\hline 729 & 13.44 & 13.32 \\
\hline 870 & 17.96 & 17.87 \\
\hline 872 & 18.02 & 17.94 \\
\hline 1030 & 23.32 & 23.15 \\
\hline 1108 & 25.15 & 25.76 \\
\hline 1314 & 32.72 & 32.77 \\
\hline 1492 & 37.11 & 39.24 \\
\hline 1816 & 48.45 & 50.81 \\
\hline 2071 & 59.66 & 60.56 \\
\hline 2265 & 68.58 & 68.68 \\
\hline
\end{tabular}


ZUCP, ZUNTHL, ZUCP1, ZUNTH1

\subsubsection{Core Component Compounds}

The expression used to calculate the specific heat capacity is an atomic-fraction-weighted average of the molar heat capacities of all components of the materials in the core.

$$
c_{p_{c}}=\frac{\sum_{i=1}^{n} \quad c_{p_{i}} a f_{i}}{\sum_{i=1}^{n} \frac{M w_{i}}{100} a f_{i}}
$$

where

$$
\begin{aligned}
& c_{p_{c}}=\text { specific heat capacity of the compound }(\mathrm{J} / \mathrm{kg} \cdot \mathrm{K})
\end{aligned}
$$

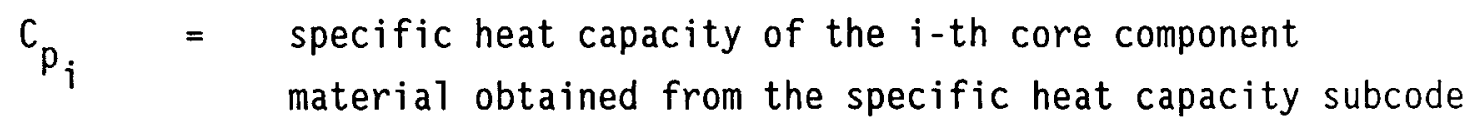

$$
\begin{aligned}
& \text { for that material }(\mathrm{J} / \mathrm{kg} \cdot \mathrm{K}) \\
& \mathrm{af}_{\mathrm{i}}=\text { atomic fraction of the } i \text {-th core component material } \\
& M W_{i}=\text { molecular weight of the } i \text {-th core component material }
\end{aligned}
$$

An analogous weighted average is used in ZUNTHL to calculate compound enthalpies. This technique has the advantage that the proper enthalpies are obtained for each core component material but the disadvantage that the heats of fusion are not constrained to appear between the solidus and liquidus temperatures of the compound.

The newer versions of the subcodes, ZUCP1 and ZUNTH1, were tested by inputting identical weight fractions to those used to test ZUCP and ZUNTHL, 


\section{ZUCP, ZUNTHL, ZUCP1, ZUNTH1}

with all other components in the core input as zero, and comparing the results. The results were identical to those shown in Figures 11.2-1 and 11.2-2. A comparison of the results obtained for several $\mathrm{UO}_{2}-\mathrm{ZrO}_{2}$ compounds using the later versions, ZUCP1 and ZUNTH1, and those obtained using ZUCP and ZUNTHL with enthalpies reported by Deem $11.2-1$ showed that the results were identical. The standard error of these predictions, $2 \times$ $10^{4} \mathrm{~J} / \mathrm{kg}$, or about 0.1 of the predicted value, is the standard error of the ZUNTH1 function. A similar standard error of 0.1 of the predicted specific heat capacity is used in ZUCP1.

Calculations with ZUNTHI were compared with enthalpies observed by Deem ${ }^{11.2-1}$ for several $\mathrm{UO}_{2}-\mathrm{ZrO}_{2}$ compounds in Tables 11.2-1 to 11.2-4. (Deem's data are presented in Tables 14 to 17 of Reference 11.2-1.) The standard error of these predictions, $2 \times 10^{4} \mathrm{~J} / \mathrm{kg}$ or about 0.1 of the predicted value, is the expected standard error of the ZUNTHI function.

A similar expected standard error, 0.1 of the predicted specific heat capacity, is adopted for ZUCP1.

\subsubsection{References}

11.2-1. H. W. Deem, Fabrication, Characterization, and Thermal-Property Measurements of $\mathrm{ZrO}_{2}$-Base Fuels, BMI-1775, June 1966. 


\title{
ZUTCON，ZUTCO1
}

\subsection{Thermal Conductivity (ZUTCON, ZUTCO1)}

\author{
(D. L. Hagrman, J. K. Hohorst)
}

\subsubsection{Zirconium-Uranium-0xygen Compounds}

Required inputs to ZUTCON to calculate compound thermal conductivities are the component concentrations and compound temperature. The expression used for the compound conductivity is the smaller of $k_{\mathrm{Zr}}$ and

$$
\begin{aligned}
k_{c}= & f_{U_{2}} k_{U_{2}}+f_{Z_{2} O_{2}} k_{\mathrm{ZrO}_{2}}+f_{Z r} k_{Z r}-0.4 f_{U_{2}} f_{Z_{2} O_{2}} \\
& +7.8 f_{U_{2}} f_{Z r}+7.8 f_{Z O_{2}} f_{Z r}
\end{aligned}
$$

where

$$
\begin{aligned}
& k_{c}=\text { compound thermal conductivity }(\mathrm{W} / \mathrm{m} \cdot \mathrm{K}) \\
& \mathrm{k}_{\mathrm{UO}_{2}}=\mathrm{UO}_{2} \text { thermal conductivity obtained from the FTHCON } \\
& \text { subcode }(W / m \cdot K) \\
& \mathrm{k}_{\mathrm{ZrO}_{2}}=\begin{array}{l}
\mathrm{ZrO}_{2} \text { thermal conductivity obtained from the ZOTCON } \\
\text { subcode }(\mathrm{W} / \mathrm{m} \cdot \mathrm{K})
\end{array} \\
& \mathrm{k}_{\mathrm{Zr}}=\text { zircaloy thermal conductivity obtained from the CTHCON } \\
& \text { subcode }(W / m \cdot K) \text {. } \\
& \mathrm{f}_{\mathrm{UO}_{2}}=\text { atomic fraction of } \mathrm{UO}_{2}
\end{aligned}
$$




\section{ZUTCON，ZUTCO1}

$$
\begin{aligned}
& \mathrm{fZrO}_{2}=\text { atomic fraction of } \mathrm{ZrO}_{2} \\
& \mathrm{f}_{\mathrm{Zr}}=\text { atomic fraction of zircaloy. }
\end{aligned}
$$

Equation (11.3-1) is an atomic-fraction-weighted average of the thermal conductivities of $\mathrm{UO}_{2}, \mathrm{ZrO}_{2}$, and zircaloy modified to include cross-products. The modification was added to reproduce the parabolic shape typically seen in plots of conduction versus composition in binary mixtures. ${ }^{11.3-1,11.3-2}$

The coefficient of the $\mathrm{UO}_{2}-\mathrm{ZrO}_{2}$ cross-product was obtained by requiring Equation (11.3-1) to reproduce a thermal conductivity of $1.44 \mathrm{~W} / \mathrm{m} \cdot \mathrm{K}$ at $2073 \mathrm{~K}$ for a composition of $0.315 \mathrm{~mole}$ fraction $\mathrm{UO}_{2}$ and 0.685 mole fraction $\mathrm{ZrO}_{2}\left(0.5 \mathrm{UO}_{2}-0.5 \mathrm{ZrO}_{2}\right.$ by weight). The thermal conductivity was obtained from a curve published as Figure 56 in Reference 11.3-3. A similar approach was used to determine the coefficient of the $\mathrm{Zr}-\mathrm{UO}_{2}$ cross product. A measurement from Rauch, ${ }^{11.3-4} 11.09 \mathrm{~W} / \mathrm{m} \cdot \mathrm{K}$ at $343 \mathrm{~K}$ for a composition of 0.80 weight fraction $\mathrm{UO}_{2}$ and 0.20 weight fraction zircaloy, was employed. No data were found to evaluate the $\mathrm{Zr}-\mathrm{ZrO}_{2}$ cross-product coefficient, so the $\mathrm{Zr}-\mathrm{UO}_{2}$ cross-product coefficient was used as an estimate.

A plot of the calculated thermal conductivity of a compound made up of 0.2 weight fraction $\mathrm{UO}_{2}$ and 0.8 weight fraction $\mathrm{ZrO}_{2}$ is shown in Figure 11.3-1.

Model predictions are compared to thermal conductivities calculated by Deem (Table 26 of Reference 11.3-3) from his data for several $\mathrm{UO}_{2}-\mathrm{ZrO}_{2}$ compounds in Tables 11.3-1 through 11.3-5. The standard error of the ZUTCON calculations is $\pm 1 \mathrm{~W} / \mathrm{m}$, most of which is caused by serious overprediction at low temperature and high $\mathrm{VO}_{2}$ content. 


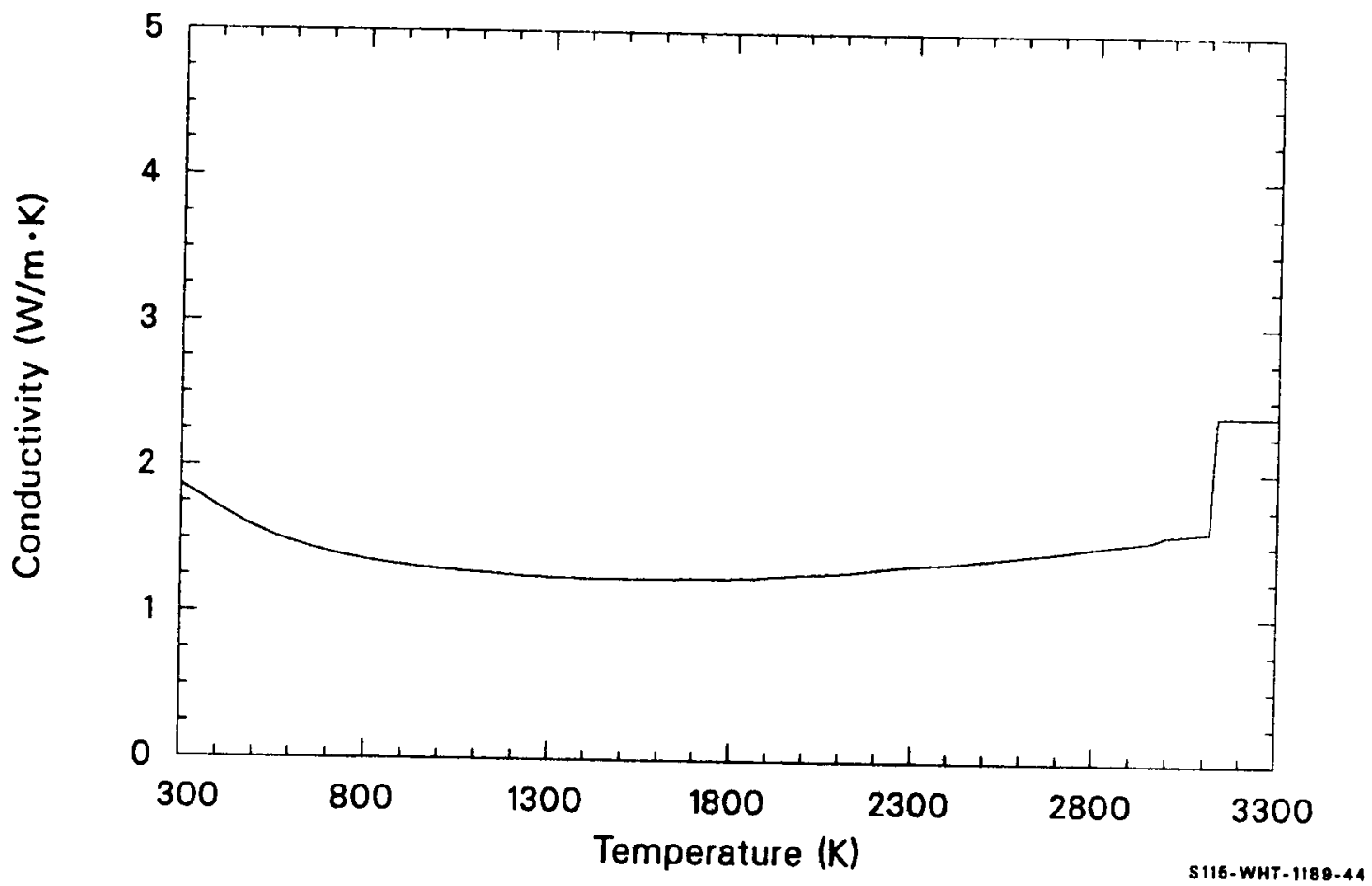

Figure 11.3-1. Thermal conductivity calculated for a $0.2 \mathrm{UO}_{2}-0.8 \mathrm{ZrO}_{2}$ weight fraction compound. 


\section{ZUTCON，ZUTCO1}

Table 11.3-1. ZUTCON calculations and Deem's results $11.3-3$ for a $0.2 \mathrm{UO}_{2}-0.8 \mathrm{ZrO}_{2}$ weight fraction compound

\begin{tabular}{ccc}
$\begin{array}{c}\text { Temperature } \\
(\mathrm{K})\end{array}$ & $\begin{array}{c}\text { Deem's Conductivity } \\
(\mathrm{W} / \mathrm{m} \cdot \mathrm{K})\end{array}$ & $\frac{C^{\text {Calculated Conductivity }}}{(\mathrm{W} / \mathrm{m} \cdot \mathrm{K})}$ \\
\hline 423 & 2.8 & 1.7 \\
473 & 2.6 & 1.6 \\
573 & 2.30 & 1.51 \\
673 & 2.42 & 1.43 \\
873 & 2.12 & 1.33 \\
1073 & 1.94 & 1.28 \\
1273 & 1.82 & 1.25 \\
1473 & 1.78 & 1.24 \\
1673 & 1.77 & 1.24 \\
1873 & 1.78 & 1.25 \\
2073 & 1.72 & 1.28 \\
2173 & 1.66 & 1.30 \\
2273 & 1.62 & 1.32 \\
\hline
\end{tabular}




\section{ZUTCON，ZUTC01}

Table 11.3-2. ZUTCON Calculations and Deem's Results $11.3-3$ for a $0.32 \mathrm{UO}_{2}-0.68 \mathrm{ZrO}_{2}$ weight fraction compound

\begin{tabular}{ccc}
$\begin{array}{c}\text { Temperature } \\
(\mathrm{K})\end{array}$ & $\begin{array}{c}\text { Deem's Conductivity } \\
(\mathrm{W} / \mathrm{m} \cdot \mathrm{K})\end{array}$ & $\begin{array}{c}\text { Calculated Conductivity } \\
(\mathrm{W} / \mathrm{m} \cdot \mathrm{K})\end{array}$ \\
\hline 423 & 2.5 & 2.2 \\
473 & 2.3 & 2.1 \\
573 & 2.1 & 1.9 \\
673 & 2.04 & 1.79 \\
873 & 2.00 & 1.59 \\
1073 & 2.00 & 1.47 \\
1285 & 1.97 & 1.39 \\
1480 & 1.46 & 1.34 \\
1673 & 1.59 & 1.32 \\
1873 & 1.73 & 1.31 \\
1943 & 1.58 & 1.32 \\
2073 & 1.76 & 1.33 \\
2273 & 1.87 & 1.38 \\
\hline
\end{tabular}




\section{ZUTCON，ZUTCO1}

Table 11.3-3. ZUTCON calculations and Deem's results $11.3-3$ for a $0.5 \mathrm{UO}_{2}-0.5 \mathrm{ZrO}_{2}$ weight fraction compound

\begin{tabular}{ccc}
$\begin{array}{c}\text { Temperature } \\
(\mathrm{K})\end{array}$ & $\begin{array}{c}\text { Deem's Conductivity } \\
(\mathrm{W} / \mathrm{m} \cdot \mathrm{K})\end{array}$ & $\frac{1}{\text { Calculated Conductivity }}(\mathrm{W} / \mathrm{m} \cdot \mathrm{K})$ \\
423 & 2.2 & 3.3 \\
473 & 2.0 & 3.1 \\
573 & 1.8 & 2.7 \\
673 & 1.75 & 2.44 \\
873 & 1.71 & 2.06 \\
1073 & 1.69 & 1.82 \\
1273 & 1.67 & 1.66 \\
1473 & 1.64 & 1.55 \\
1673 & 1.60 & 1.48 \\
1873 & 1.54 & 1.44 \\
2073 & 1.44 & 1.45 \\
2183 & 1.41 & 1.47 \\
2293 & 1.79 & 1.51 \\
2373 & 1.54 & 1.54 \\
\hline
\end{tabular}


Table 11.3-4. ZUTCON calculations and Deem's results11.3-3 for a low-density $0.32 \mathrm{UO}_{2}-0.68 \mathrm{ZrO}_{2}$ weight fraction compound

\begin{tabular}{|c|c|c|}
\hline $\begin{array}{l}\text { Temperature } \\
\text { (K) }\end{array}$ & $\begin{array}{c}\text { Deem's Conductivity } \\
(\mathrm{W} / \mathrm{m} \bullet \mathrm{K})\end{array}$ & $\begin{array}{c}\text { Calculated Conductivity } \\
(\mathrm{W} / \mathrm{m} \bullet \mathrm{K})\end{array}$ \\
\hline 423 & 2.2 & 2.2 \\
\hline 473 & 2.1 & 2.1 \\
\hline 573 & 1.8 & 1.9 \\
\hline 673 & 1.55 & 1.79 \\
\hline 873 & 1.53 & 1.59 \\
\hline 1073 & 1.53 & 1.47 \\
\hline 1273 & 1.53 & 1.39 \\
\hline 1473 & 1.17 & 1.34 \\
\hline 1673 & 1.28 & 1.32 \\
\hline 1873 & 1.36 & 1.31 \\
\hline 2073 & 1.40 & 1.33 \\
\hline 2173 & 1.30 & 1.35 \\
\hline
\end{tabular}




\section{ZUTCON, ZUTCO1}

Table 11.3-5. ZUTCON calculations and Deem's results $11 \cdot 3-3$ for a $0.94 \mathrm{VO}_{2}-0.06 \mathrm{ZrO}_{2}$ weight fraction compound

\begin{tabular}{|c|c|c|}
\hline $\begin{array}{l}\text { Temperature } \\
(\mathrm{K}) \\
\end{array}$ & $\begin{array}{c}\text { Deem's Conductivity } \\
(\mathrm{W} / \mathrm{m} \bullet \mathrm{K})\end{array}$ & $\begin{array}{l}\text { Calculated Conductivity } \\
(\mathrm{W} / \mathrm{m} \bullet \mathrm{K})\end{array}$ \\
\hline 423 & 3.8 & 7.8 \\
\hline 473 & 3.6 & 7.2 \\
\hline 573 & 2.8 & 6.1 \\
\hline 673 & 2.41 & 5.32 \\
\hline 873 & 2.32 & 4.19 \\
\hline 1073 & 2.19 & 3.45 \\
\hline 1273 & 2.05 & 2.93 \\
\hline 1473 & 1.99 & 2.55 \\
\hline 1673 & 1.93 & 2.28 \\
\hline 1873 & 1.87 & 2.11 \\
\hline 2073 & 1.84 & 2.07 \\
\hline 2173 & 1.82 & 2.10 \\
\hline
\end{tabular}

$11.3-8$ 


\subsubsection{Core Component Compounds}

Required inputs to ZUTCO1 to calculate compound thermal conductivities are the component concentrations and compound temperature. The expression used for the compound conductivity is the smaller of $\mathrm{k}_{\mathrm{Zr}}$ and

$$
k_{c}=\sum_{i=1}^{n} f_{c i} k_{c i}
$$

where

$$
\begin{aligned}
& k_{c}=\text { compound thermal conductivity }(W / m \cdot k) \\
& f_{c i}=\text { atomic fraction of the } i \text {-th core component } \\
& k_{c i}=\text { thermal conductivity of the } i \text {-th core component obtained } \\
& \text { from its thermal conductivity subcode } \\
& \quad=\text { the number of individual core components. }
\end{aligned}
$$

Equation (11.3-2) is an atomic-fraction-weighted average of the thermal conductivities of all core components. Where all core materials were considered, cross products were not used to obtain the total thermal conductivity of the core materials.

Model predictions using ZUTCO1 were compared to thermal conductivities calculated by Deem (Table 26 of Reference 11.3-3) from his data for several $\mathrm{UO}_{2}-\mathrm{ZrO}_{2}$ compounds in Tables 11.3-1 through 11.3-5. The standard error of the ZUTCO1 calculations is $\pm 1 \mathrm{~W} / \mathrm{m}$, most of which is caused by serious overprediction at low temperature and high $\mathrm{UO}_{2}$ content. 


\section{ZUTCON, ZUTCO1}

\subsubsection{References}

11.3-1. F. Rhines, Phase Diagrams in Metallurgy and Their Development and Application, New York: McGraw-Hill Book Company, 1956, pp. 110-113.

11.3-2. B. Abeles, "Lattice Thermal Conductivity of Disordered Semiconductor Alloys at High Temperatures," Physical Review, 131, 1963, pp. 1906-1911.

11.3-3. H. W. Deem, Fabrication, Characterization, and Thermal-Property Measurements of $\mathrm{ZrO}_{2}$-Base Fuels, BMI-1775, June 1966.

11.3-4. W. G. Rauch, Uranium-Zirconium Cermets, ANL-5268, 1954. 


\section{ZUTEXP，ZUDEN，ZUTEX1，ZUDEN1}

\subsection{Thermal Expansion and Density (ZUTEXP，ZUDEN，ZUTEX1，ZUDEN1)}

(D. L. Hagrman, J. K. Hohorst)

\subsubsection{Zirconium-Uranium-0xygen Compounds}

The function ZUTEXP calculates the thermal expansion strain of Zr-U-0 compounds as a function of composition, temperature, and a reference temperature for which the thermal expansion strain will be zero. ZUDEN returns the compound density as a function of composition and density.

The expression used to calculate thermal expansion strains in ZUTEXP is

$\epsilon_{c}=\frac{2.46 f_{\mathrm{UO}_{2}} \epsilon_{\mathrm{UO}_{2}}+2.12 f_{\mathrm{ZrO}_{2}} \epsilon_{\mathrm{ZrO}_{2}}+1.39 \mathrm{f}_{\mathrm{Zr}} \epsilon_{\mathrm{Zr}}}{2.46 \mathrm{f}_{\mathrm{UO}_{2}}+2.12 \mathrm{f}_{\mathrm{ZrO}_{2}}+1.39 \mathrm{f}_{\mathrm{Zr}}}$

where

$\epsilon_{\mathrm{c}}=$ compound thermal strain $(\mathrm{m} / \mathrm{m})$

$\epsilon_{\mathrm{UO}_{2}}=\mathrm{UO}_{2}$ thermal strain obtained from the FTHEXP subcode $(\mathrm{m} / \mathrm{m})$

$\epsilon_{\mathrm{ZrO}_{2}}=\quad \mathrm{ZrO}_{2}$ thermal strain obtained from the ZOTEXP subcode $(\mathrm{m} / \mathrm{m})$

$\epsilon_{Z r}=$ isotropic $Z r$ thermal strain obtained from the CTHEXP subcode with $\operatorname{COSTH} 2=1 / 3$ and $\operatorname{COSFI} 2=1 / 2(\mathrm{~m} / \mathrm{m})$ 


\section{ZUTEXP，ZUDEN，ZUTEX1，ZUDEN1}

$$
\begin{aligned}
& \mathrm{f}_{\mathrm{UO}_{2}}=\text { atomic fraction of } \mathrm{UO}_{2} \\
& \mathrm{frO}_{2}=\text { atomic fraction of } \mathrm{ZrO}_{2} \\
& f_{\mathrm{Zr}}=\text { atomic fraction of zircaloy. }
\end{aligned}
$$

This expression is a component-volume-fraction weighted average of the component strains. The volume fraction of each component is

$$
f_{v_{i}}=\frac{\frac{f_{i} m_{i}}{\rho_{i}}}{\sum_{j=1}^{3} \frac{f_{j} m_{j}}{\rho_{j}}}
$$

where

$$
\begin{aligned}
& f_{V_{i}}=\text { volume fraction of } i \text {-th component }\left(\mathrm{m}^{3} / \mathrm{m}^{3}\right) \\
& f_{j}=\text { mole fraction of } i \text {-th component } \\
& m_{j}=\text { mole weight of } i \text {-th component }(\mathrm{kg} / \mathrm{g} \cdot \mathrm{mole}) \\
& \left(0.270 \text { for } \mathrm{UO}_{2}, 0.123 \text { for } \mathrm{ZrO}_{2} \text {, and } 0.091 \text { for } \mathrm{Zr}\right. \text { ) } \\
& \rho_{i}=\text { density of } i \text {-th component }\left(\mathrm{kg} / \mathrm{m}^{3}\right) \\
& \left(10,980 \text { for } \mathrm{UO}_{2}, 5,800 \text { for } \mathrm{ZrO}_{2} \text {, and } 6,550 \text { for } \mathrm{Zr}\right) \text {. }
\end{aligned}
$$

Expression (11.4-1) is derived by assuming that the compound is made up of components which produce independent thermal strains. The initial volume is thus 


\section{ZUTEXP，ZUDEN，ZUTEX1，ZUDEN1}

$$
\begin{aligned}
v_{0} & =v_{\mathrm{UO}_{2}}+v_{\mathrm{ZrO}_{2}}+v_{\mathrm{Zr}} \\
& =f_{\mathrm{vO}_{2}} v_{0}+f_{\mathrm{ZrO}_{2}} v_{0}+f_{\mathrm{Zr}} v_{0}
\end{aligned}
$$

where

$\mathrm{V}_{\mathrm{UO}_{0}}, \mathrm{~V}_{\mathrm{ZrO}_{2}}$, and $\mathrm{V}_{\mathrm{Zr}_{0}}=$ initial component volumes $\left(\mathrm{m}^{3}\right)$

$\mathrm{f}_{\mathrm{UO}_{2}}, \mathrm{f}_{\mathrm{ZrO}_{2}}$, and $\mathrm{f}_{\mathrm{Zr}_{\mathrm{Z}}}=$ component volume fractions $\left(\mathrm{m}^{3} / \mathrm{m}^{3}\right)$.

The component volume after some thermal strain is

$$
V=V_{\mathrm{UO}_{2}} \exp \left(3 \epsilon_{\mathrm{UO}_{2}}\right)+\mathrm{V}_{\mathrm{ZrO}_{2}} \exp \left(3 \epsilon_{\mathrm{Zr}_{2}}\right)+\mathrm{V}_{\mathrm{Zr}_{0}} \exp \left(3 \epsilon_{\mathrm{Zr}}\right)
$$

or

$\mathrm{V} \approx \mathrm{V}_{\mathrm{UO}_{2}}\left(1+3 \epsilon_{\mathrm{UO}_{2}}\right)+\mathrm{V}_{\mathrm{ZrO}_{2}}\left(1+3 \epsilon_{\mathrm{ZrO}_{2}}\right)+\mathrm{V}_{\mathrm{Zr}_{0}}\left(1+3 \epsilon_{\mathrm{Zr}}\right)$.

The compound volume strain, $\epsilon_{\mathrm{c}_{v}}$, is

$$
\begin{aligned}
& \epsilon_{c_{v}}=\frac{V-v_{0}}{v_{0}}
\end{aligned}
$$

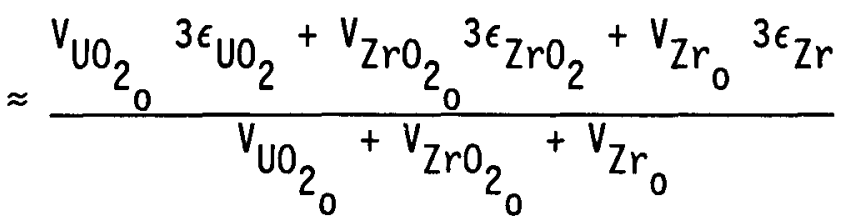




\section{ZUTEXP，ZUDEN，ZUTEX1，ZUDEN1}

$=\mathrm{f}_{\mathrm{V}_{\mathrm{UO}_{2}}} 3 \epsilon_{\mathrm{UO}_{2}}+\mathrm{f}_{\mathrm{ZrO}_{2}} 3 \epsilon_{\mathrm{ZrO}_{2}}+\mathrm{fv}_{\mathrm{Zr}} 3 \epsilon_{\mathrm{Zr}}$.

Replacement of the compound volume strain by three times the compound 7 inear strain and substitution using Equation (11.4-2) completes the derivation of Equation (11.4-1).

The expression used in ZUDEN to calculate compound densities is

$$
\rho_{\mathrm{c}}=\frac{0.270 \mathrm{f}_{\mathrm{UO}_{2}}+0.123 \mathrm{f}_{\mathrm{ZrO}_{2}}+0.091 \mathrm{f}_{\mathrm{Zr}}}{\frac{0.270 \mathrm{f}_{\mathrm{UO}_{2}}}{\rho_{\mathrm{UO}_{2}}}+\frac{0.123 \mathrm{f}_{\mathrm{ZrO}}}{\rho_{\mathrm{ZrO}_{2}}}+\frac{0.091 \mathrm{f}_{\mathrm{Zr}}}{\rho_{\mathrm{Zr}}}}
$$

where

$\rho_{\mathrm{C}} \quad=$ compound density $\left(\mathrm{kg} / \mathrm{m}^{3}\right)$

$\rho_{\mathrm{UO}_{2}}=\mathrm{UO}_{2}$ density obtained from the FDEN subcode $\left(\mathrm{kg} / \mathrm{m}^{3}\right)$

$\rho_{\mathrm{ZrO}_{2}}=\mathrm{ZrO}_{2}$ density obtained from the ZODEN subcode $\left(\mathrm{kg} / \mathrm{m}^{3}\right)$

$\rho_{Z r}=$ zircaloy density obtained from the CDEN subcode $\left(\mathrm{kg} / \mathrm{m}^{3}\right)$.

Equation (11.4-10) is derived by assuming that each compound component contributes a volume equal to the volume the component would have as a free substance. The compound density is thus the total mass divided by the total volume 


\section{ZUTEXP，ZUDEN，ZUTEX1，ZUDEN1}

$\rho_{c}=\frac{\sum_{i=1}^{3} N f_{i} m_{i}}{\sum_{i=1}^{3} \frac{N f_{j} m_{i}}{\rho_{i}}}$

where $\mathrm{N}$ is the number of moles present in the compound. Cancellation of the common factor $N$ and substitution of the component mole weights in Equation (11.4-11) yields Equation (11.4-10).

Plots of the calculated thermal expansion strain and density of a compound made up of 0.2 weight fraction $\mathrm{UO}_{2}$ and 0.8 weight fraction $\mathrm{ZrO}_{2}$ are shown in Figures 11.4-1 and 11.4-2.

Model predictions are compared with thermal expansion strains and densities measured at $293 \mathrm{~K}$ by Deem (Table 12 of Reference 11.4-1) for several $\mathrm{UO}_{2}-\mathrm{ZrO}_{2}$ compounds in Tables 11.4-1 to 11.4-5. The standard error of the ZUTEXP function calculations is $\pm 1.0 \times 10^{-2}$, and the standard error of the ZUDEN function calculations is $\pm 3 \times 10^{2}$. These standard errors are recommended as the expected standard errors of the ZUTEXP and ZUDEN function calculations.

\subsubsection{Core Component Compounds}

The function ZUTEX1 calculates the thermal expansion strain of core component compounds as a function of composition, temperature, and a reference temperature for which the thermal expansion strain will be zero. ZUDEN1 returns the compound density as a function of composition and density.

The expression used to calculate thermal expansion strains in ZUTEXI is 
ZUTEXP，ZUDEN，ZUTEX1，ZUDEN1

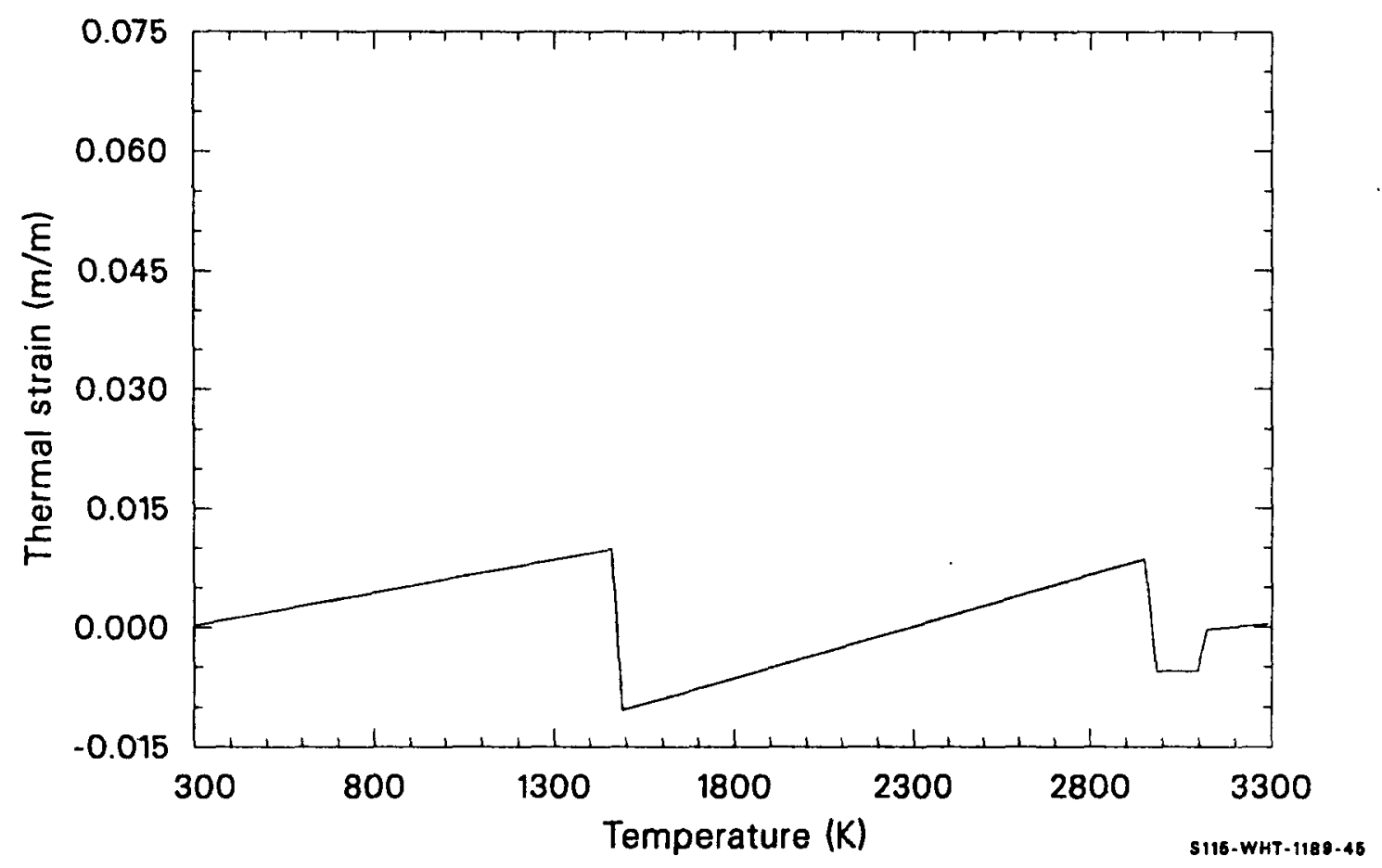

Figure 11.4-1. Thermal strain calculated for a $0.2 \mathrm{UO}_{2}-0.8 \mathrm{ZrO}_{2}$ weight fraction compound. 


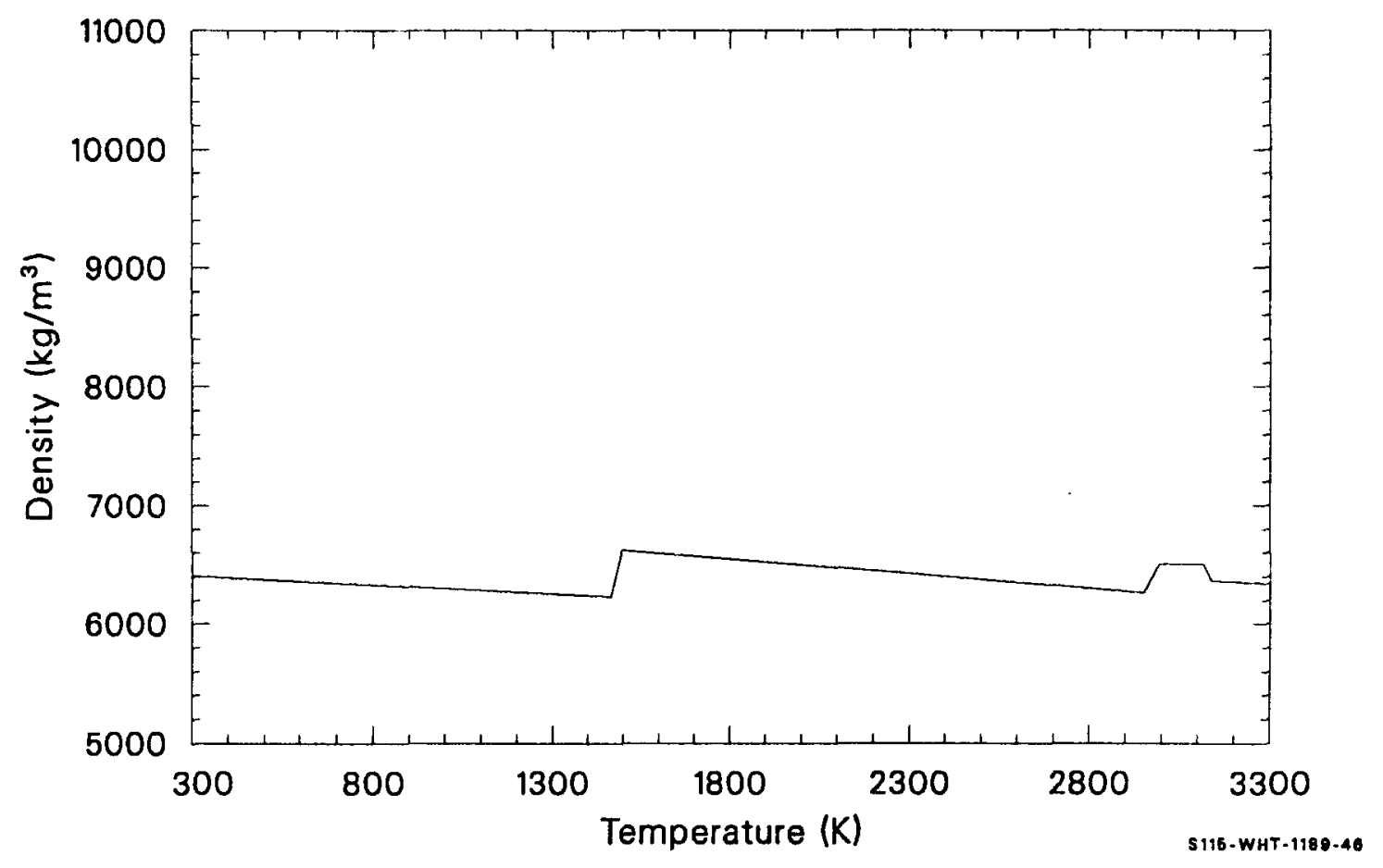

Figure 11.4-2. Density calculated for a $0.2 \mathrm{UO}_{2}-0.8 \mathrm{ZrO}_{2}$ weight fraction compound. 


\section{ZUTEXP，ZUDEN，ZUTEX1，ZUDEN1}

Table 11.4-1. ZUTEXP calculations and Deem's data11.4-1 for a $0.2 \mathrm{UO}_{2}-0.8 \mathrm{ZrO}_{2}$ weight fraction compound

\begin{tabular}{|c|c|c|}
\hline $\begin{array}{c}\text { Temperature } \\
(\mathrm{K})\end{array}$ & $\begin{array}{l}\text { Observed Strain } \\
\left(10^{-2} \mathrm{~m} / \mathrm{m}\right)\end{array}$ & $\begin{array}{l}\text { Calculated Strain } \\
\left(10^{-2} \mathrm{~m} / \mathrm{m}\right)\end{array}$ \\
\hline 293 & 0 & 0 \\
\hline 373 & 0.03 & 0.06 \\
\hline 473 & 0.09 & 0.15 \\
\hline 573 & 0.18 & 0.23 \\
\hline 598 & 0.20 & 0.24 \\
\hline 636 & 0.00 & 0.27 \\
\hline 673 & -0.33 & 0.31 \\
\hline 873 & -0.08 & 0.47 \\
\hline 1073 & 0.15 & 0.63 \\
\hline 1273 & 0.38 & 0.80 \\
\hline 1473 & 0.59 & 0.97 \\
\hline 1673 & 0.81 & -0.84 \\
\hline 1873 & 1.04 & -0.57 \\
\hline 2073 & 1.28 & -0.31 \\
\hline 2273 & 1.58 & -0.05 \\
\hline
\end{tabular}




\section{ZUTEXP，ZUDEN，ZUTEX1，ZUDEN1}

Table 11.4-2. ZUTEXP calculations and Deem's data11.4-1 for a $0.32 \mathrm{UO}_{2}-0.68 \mathrm{ZrO}_{2}$ weight fraction compound

\section{Temperature}

(K)

293

473

673

873

1073

1273

1473

1673

1873

2073

2273
Observed Strain

$\frac{\left(10^{-2} \mathrm{~m} / \mathrm{m}\right)}{0}$

0.17

0.40

0.65

0.88

1.11

1.35

1.57

1.81

2.05

2.33
Calculated Strain

$\frac{\left(10^{-2} \mathrm{~m} / \mathrm{m}\right)}{0}$

0.07

0.31

0.48

0.65

0.82

1.00

$-0.61$

$-0.35$

$-0.08$

0.18 
ZUTEXP，ZUDEN，ZUTEX1，ZUDEN1

Table 11.4-3. ZUTEXP calculations and Deem's data11.4-1 for a $0.5 \mathrm{UO}_{2}-0.5 \mathrm{ZrO}_{2}$ weight fraction compound

\begin{tabular}{ccc}
\hline $\begin{array}{c}\text { Temperature } \\
(\mathrm{K})\end{array}$ & $\begin{array}{c}\text { Observed Strain } \\
\left(10^{-2} \mathrm{~m} / \mathrm{m}\right)\end{array}$ & $\begin{array}{c}\text { Calculated Strain } \\
\left(10^{-2} \mathrm{~m} / \mathrm{m}\right)\end{array}$ \\
\hline 293 & 0 & 0 \\
473 & 0.16 & 0.15 \\
673 & 0.37 & 0.32 \\
873 & 0.61 & 0.50 \\
1073 & 0.84 & 0.68 \\
1273 & 1.08 & 0.87 \\
1473 & 1.32 & 1.06 \\
1673 & 1.56 & -0.21 \\
1873 & 1.80 & 0.05 \\
2073 & 2.08 & 0.33 \\
2273 & 2.46 & 0.59 \\
\hline
\end{tabular}




\section{ZUTEXP，ZUDEN，ZUTEX1，ZUDEN1}

Table 11.4-4. ZUTEXP calculations and Deem's data11.4-1 for a $0.94 \mathrm{UO}_{2}-0.06 \mathrm{ZrO}_{2}$ weight fraction compound

\begin{tabular}{ccc}
\hline $\begin{array}{c}\text { Temperature } \\
(\mathrm{K})\end{array}$ & $\begin{array}{c}\text { Observed Strain } \\
\left(10^{-2} \mathrm{~m} / \mathrm{m}\right)\end{array}$ & $\begin{array}{c}\text { Calculated Strain } \\
\left(10^{-2} \mathrm{~m} / \mathrm{m}\right)\end{array}$ \\
\hline 293 & 0 & 0 \\
473 & 0.17 & 0.18 \\
673 & 0.39 & 0.37 \\
873 & 0.63 & 0.58 \\
1073 & 0.87 & 0.80 \\
1273 & 1.13 & 1.03 \\
1473 & 1.41 & 1.27 \\
1673 & 1.67 & 1.29 \\
1873 & 1.94 & 1.56 \\
2073 & 2.22 & 1.84 \\
2273 & 2.54 & 2.12 \\
\hline
\end{tabular}




\section{ZUTEXP，ZUDEN，ZUTEX1，ZUDEN1}

Table 11.4-5. ZUDEN calculations and Deem's compound density data11.4-1

\begin{tabular}{lcc}
\hline $\begin{array}{c}\text { Composition } \\
\text { (weight fractions) }\end{array}$ & $\begin{array}{c}\text { Observed Density } \\
\left(10^{3} \mathrm{~kg} / \mathrm{m}\right)\end{array}$ & $\begin{array}{c}\text { Calculated Density } \\
\left(10^{3} \mathrm{~kg} / \mathrm{m}\right)\end{array}$ \\
$0.2 \mathrm{UO}_{2}-0.06 \mathrm{ZrO}_{2}$ & 6.26 & 6.40 \\
$0.32 \mathrm{UO}_{2}-0.8 \mathrm{ZrO}_{2}$ & 6.81 & 6.83 \\
$0.5 \mathrm{UO}_{2}-0.5 \mathrm{ZrO}_{2}$ & 7.62 & 7.59 \\
Low density & 6.46 & 6.83 \\
$0.32 \mathrm{UO}_{2}-0.68 \mathrm{ZrO}_{2}$ & & 10.04 \\
$0.94 \mathrm{UO}_{2}-0.06 \mathrm{ZrO}_{2}$ & 9.92 & \\
\hline
\end{tabular}




\section{ZUTEXP，ZUDEN，ZUTEX1，ZUDEN1}

$\epsilon_{c}=\frac{\sum_{i=1}^{n} A \text { af }}{\sum_{i=1}^{n} A \text { a } \epsilon_{i}}$

where

$\epsilon_{\mathrm{c}}=$ compound thermal strain $(\mathrm{m} / \mathrm{m})$

$\epsilon_{i}=i$-th core component thermal strain obtained from its individual thermal strain subcode $(\mathrm{m} / \mathrm{m})$

$\mathrm{n}=$ number of core components in the compound

$a_{f i}=$ atomic fraction of the $i$-th core component in compound

A = constant for each core component (Table 11.4-6).

This expression is a component-volume-fraction weighted average of the component strains. The volume fraction of each component is

$f_{V_{i}}=\frac{\frac{f_{i} m_{i}}{\rho_{i}}}{\sum_{j=1}^{n} \frac{f_{j} m_{j}}{\rho_{j}}}$

where

$f_{V i}=$ volume fraction of $i$-th core component $\left(\mathrm{m}^{3} / \mathrm{m}^{3}\right)$

$f_{i}=$ mole fraction of $i$-th core component 
ZUTEXP，ZUDEN，ZUTEX1，ZUDEN1

Table 11.4-6. Constants for thermal expansion strain

\begin{tabular}{ll}
\multicolumn{1}{c}{ Component } & $\mathrm{A}$ \\
Uranium & 1.28 \\
Zirconium & 1.46 \\
Stainless steel & 0.771 \\
Uranium dioxide & 2.46 \\
Zirconium dioxide & 2.12 \\
Silver-indium-cadmium & 1.07 \\
Boron carbide & 2.554 \\
Stainless steel oxide & 2.97
\end{tabular}




\section{ZUTEXP，ZUDEN，ZUTEX1，ZUDEN1}

$$
\begin{aligned}
& m_{i} \quad=\text { mole weight of } i \text {-th core component }(\mathrm{kg} / \mathrm{g} \cdot \mathrm{mole}) \\
& \mathrm{n} \quad=\text { number of core components in compound } \\
& \rho_{i} \quad=\text { density of } i-\text { th component }\left(\mathrm{kg} / \mathrm{m}^{3}\right) .
\end{aligned}
$$

Expression (11.4-12) is derived by assuming that the compound is made up of components which produce independent thermal strains. The initial volume is thus

$$
\begin{aligned}
& v_{0}=\sum_{i=1}^{n} v_{0_{i}} \\
& v_{0}=\sum_{i=1}^{n} f_{V_{i}} v_{0}
\end{aligned}
$$

where

$v_{0}=$ initial volume of the core components

$f_{V_{i}}=$ volume fraction of the $i-$ th core component

$n=$ number of core components in the compound.

The component volume after some thermal strain is

$$
\begin{aligned}
& v_{0}=\sum_{i=1}^{n} v_{0_{i}} \exp \left(3 \epsilon_{i}\right) \\
& \text { or } \\
& v_{0} \approx \sum_{i=1}^{n} v_{0_{i}} \exp \left(1+3 \epsilon_{i}\right)
\end{aligned}
$$




\section{ZUTEXP， ZUDEN，ZUTEX1，ZUDEN1}

where

$V=$ component volume strain

$\epsilon_{i}=$ thermal expansion strain of the $i$-th core component.

The compound volume strain, $\epsilon_{c_{v}}$, is

$\epsilon_{c_{V}}=\frac{V-V_{0}}{V_{0}}$

or

$v_{0} \approx \sum_{i=1}^{n} \frac{3 \epsilon i v_{i}}{V_{0_{i}}}$

$v_{0} \approx \sum_{i=1}^{n} 3 \epsilon_{i} f_{v_{j}}$

Replacement of the compound volume strain by three times the compound linear strain and substitution using Equation (11.4-13) completes the derivation of Equation (11.4-12).

The expression used in ZUDEN to calculate compound densities is

$$
\rho_{c}=\frac{\sum_{i=1}^{n} \quad M W_{i} a f_{i}}{\sum_{i=1}^{n} \frac{M W_{i} a f_{i}}{\rho_{i}}}
$$

where

$$
\rho_{C}=\text { compound density }\left(\mathrm{kg} / \mathrm{m}^{3}\right)
$$




\section{ZUTEXP，ZUDEN，ZUTEX1，ZUDEN1}

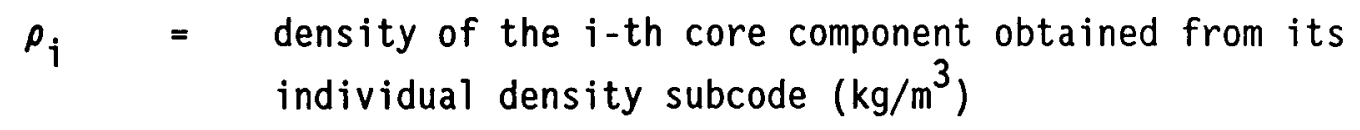

$M W_{i}=$ molecular weights for the $i$-th core component $(\mathrm{kg})$

$\mathrm{af}_{\boldsymbol{i}}=$ atomic fraction of the $\boldsymbol{i}$-th core component in the compound.

Equation (11.4-21) is derived by assuming that each compound component contributes a volume equal to the volume the component would have as a free substance. The compound density is thus the total mass divided by the total volume

$\rho_{c}=\frac{\sum_{i=1}^{n} N f_{i} m_{i}}{\sum_{i=1}^{n} \frac{N f_{i} m_{i}}{\rho_{i}}}$

where $\mathrm{N}$ is the number of moles present in the compound. Cancellation of the common factor $\mathrm{N}$ and substitution of the component mole weights in Equation (11.4-22) yields Equation (11.4-21).

Plots of the calculated thermal expansion strain and density of a compound made up of 0.2 weight fraction $\mathrm{UO}_{2}$ and 0.8 weight fraction $\mathrm{ZrO}_{2}$ with the other core components assumed to be zero are identical to those shown in Figures 11.4-1 and 11.4-2.

Model predictions with ZUTEXI and ZUDENI were compared with thermal expansion strains and densities calculated by ZUTEXP and ZUDEN and measured at $293 \mathrm{~K}$ by Deem (Table 12 of Reference 11.4-1) for several $\mathrm{UO}_{2}-\mathrm{ZrO}_{2}$ compounds shown in Tables 11.4-1 to 11.4-5. The standard error of the ZUTEX1 function calculations is $\pm 1.0 \times 10^{-2}$, and the standard error of 


\section{ZUTEXP，ZUDEN，ZUTEX1，ZUDEN1}

the ZUDEN1 function calculations is $\pm 3 \times 10^{2}$. These standard errors are recommended as the expected standard errors of the ZUTEXI and ZUDENI function calculations.

\subsubsection{References}

11.4-1. H. W. Deem, Fabrication, Characterization, and Thermal-Property Measurements of $\mathrm{ZrO}_{2}$-Base Fuels, BMI-1775, June 1966. 


\subsection{Zirconium-URANIUM-OXYGEn Compounds COEFFicients OF Friction (ZUFRIC)}

(D. L. Hagrman)

The function ZUFRIC returns the coefficient of friction of flowing $\mathrm{Zr}$-U-O compounds. The correlations used for this coefficient are

$F=\left(0.0791 R_{e}\right)^{-0.25}, R_{e}>7539.42$

$F=\frac{64}{\operatorname{Re}}, 7539.42 \geq R_{e}>10^{-6}$

$F=6.4 \times 10^{7}, \operatorname{Re}<10^{-6}$

where

$F=$ compound coefficient of friction $(\mathrm{Pa} / \mathrm{Pa})$

$\operatorname{Re}=$ Reynold's number (unitless).

The correlations are an engineering estimate and have an expected standard error of 0.90 of their calculated value. Figure 11.5-1 illustrates the coefficient of friction calculated with the ZUFRIC function. 


\section{ZUFRIC}

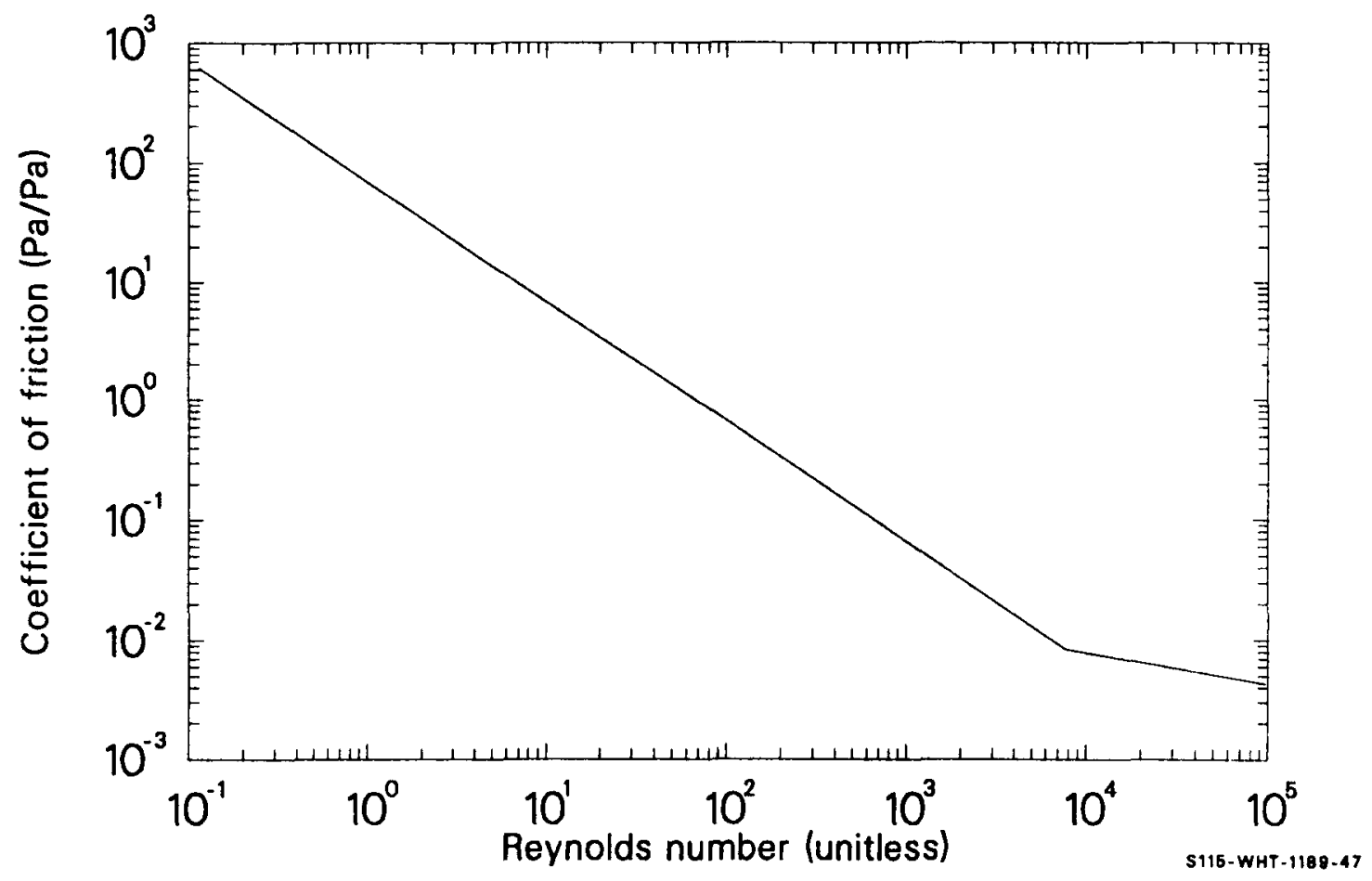

Figure 11.5-1. Coefficient of friction calculated with the ZUFRIC function. 
ZUSTEN

\title{
11.6 Zirconium-URANIUM-0Xygen COMPOUNDS INTERFACIAL SURFACE TENSION (ZUSTEN)
}

\author{
(D. L. Hagrman)
}

The function ZUSTEN returns the interfacial surface tension of molten $\mathrm{Zr}-\mathrm{U}-0$ compounds on zircaloy cladding. The value used is

$T=0.45$

where $T$ is the interfacial surface tension $(\mathrm{N} / \mathrm{m})$.

The value is an engineering estimate ${ }^{a}$ and has an expected standard error of $+1.0,-0.4$.

a. L. J. Siefken, private communication, EG\&G Idaho, Inc., October 14, 1982 . 


\subsection{Zirconium-Urantum-0xygen Compounds Viscosity (ZUVISC)}

(D. L. Hagrman)

\subsubsection{Model Development}

The function ZUVISC returns an estimate of the viscosity of both solid and Tiquid $\mathrm{Zr}-\mathrm{U}-\mathrm{O}$ compounds as a function of the composition and temperature of the compound. The expression used to calculate viscosity for temperatures below the solidus temperature (which is provided by the PSOL function) is

$\eta_{S}=1.38 \exp \left(\frac{4.942 \times 10^{4}}{T}\right)$

where $\eta_{S}$ is the viscosity of solid $\mathrm{Zr}-\mathrm{U}-0$ compounds $(\mathrm{Pa} \cdot \mathrm{s})$.

This correlation is the expression used for solid $\mathrm{UO}_{2}$ viscosity in the FVISCO subcode of MATPRO. For temperatures above the liquidus temperature, a mole fraction average of the component viscosities is used.

$\eta_{1}=f_{\mathrm{UO}_{2}} \eta_{\mathrm{UO}_{2}}+f_{\mathrm{ZrO}_{2}} \eta_{\mathrm{ZrO}_{2}}+f_{\mathrm{Zr}} \eta_{\mathrm{Zr}}$

where

$\eta_{1}=$ viscosity of 1 iquid $Z r-U-0$ compounds $(\mathrm{Pa} \cdot \mathrm{s}$ )

$\eta_{\mathrm{UO}_{2}}=$ viscosity of 1 iquid $\mathrm{UO}_{2}(\mathrm{~Pa} \cdot \mathrm{s})$

$\eta_{\mathrm{ZrO}_{2}}=$ viscosity of 1 iquid $\mathrm{ZrO}_{2}(\mathrm{~Pa} \cdot \mathrm{s})$

$\eta_{Z r}=$ viscosity of 1 iquid $\mathrm{Zr}(\mathrm{Pa} \cdot \mathrm{s})$. 


\section{ZUVISC}

$\eta_{\mathrm{UO}_{2}}$ is calculated with the appropriate expression

from the FVISCO subcode:

$\eta_{\mathrm{UO}_{2}}=1.23 \times 10^{-2}-2.09 \times 10^{-6} \mathrm{~T}$.

$\eta_{\mathrm{ZrO}_{2}}$ and $\eta_{\mathrm{Zr}}$ are calculated with correlations recommended by Nazare,

Ondracek, and Schultz $11.7-1$

$\eta_{\mathrm{ZrO}_{2}}=1.22 \times 10^{-4} \exp \left(\frac{10,500}{\mathrm{~T}}\right)$

$\eta_{Z r}=1.90 \times 10^{-4} \exp \left(\frac{6,500}{T}\right)$

For temperatures between the solidus and liquidus temperatures of the compound, an interpolation scheme is used

$\eta=\frac{\eta_{1}\left(T-T_{s o l}\right)+\eta_{s}\left(T_{1 i q}-T\right)}{T_{1 i q}-T_{s o l}}$

where

$$
\begin{aligned}
& T_{\text {sol }}=\text { solidus temperature }(K) \\
& T_{\text {Tiq }}=\text { Iiquidus temperature }(K) \\
& \eta \quad \text { viscosity of } \mathrm{Zr}-\mathrm{U}-0 \text { compounds }(\mathrm{Pa} \cdot \mathrm{s}) .
\end{aligned}
$$

Figure 11.7-1 illustrates the effect of temperature on the viscosity of a compound composed of two-thirds mole fraction zircaloy and one-third mole 


\section{ZUVISC}

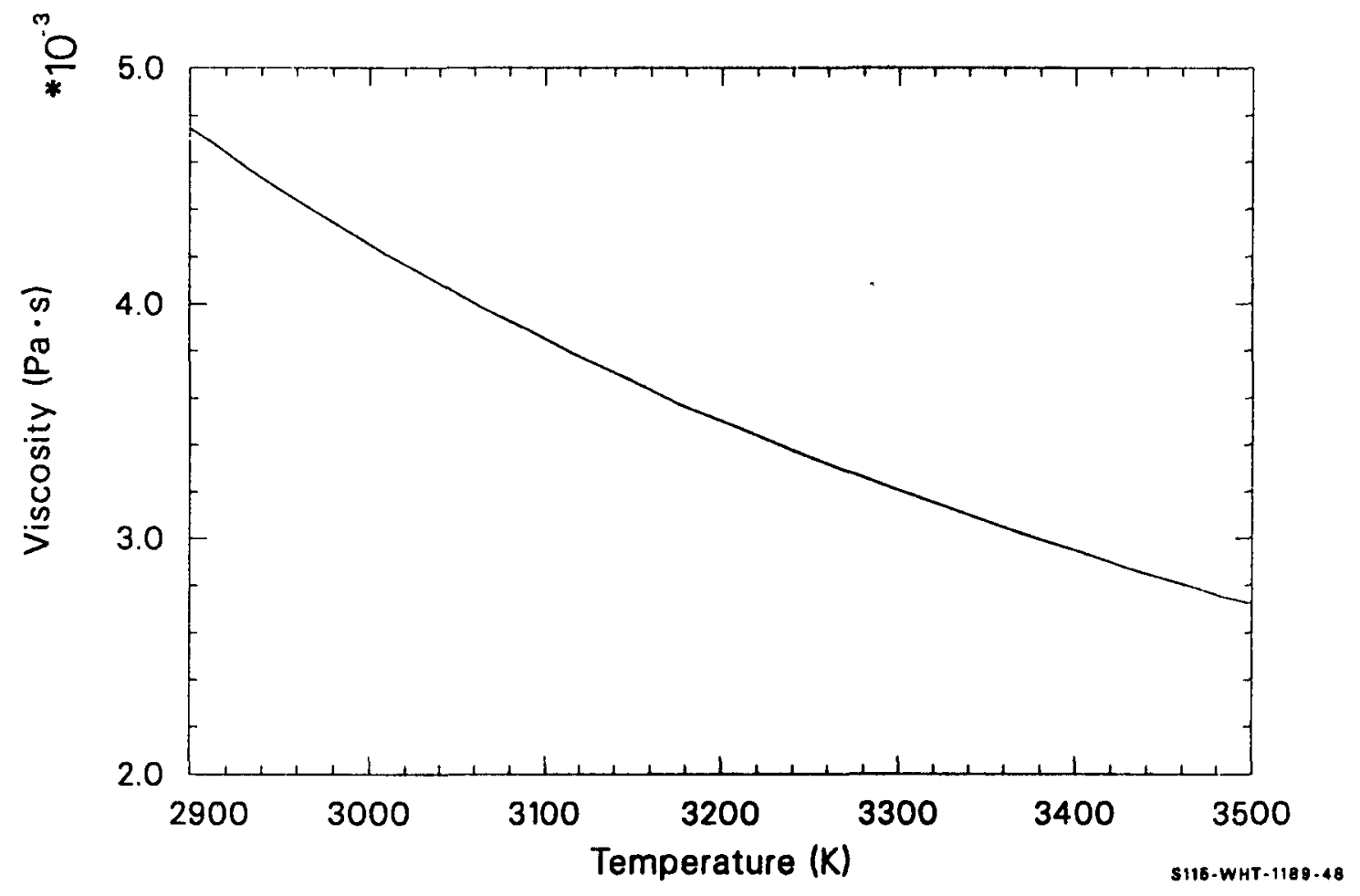

Figure 11.7-1. Viscosity of a compound composed of 0.33 mol\% zirconium and $0.67 \mathrm{~mol} \%$ uranium dioxide. 
fraction $\mathrm{UO}_{2}$. The expected standard error of viscosities is \pm 0.8 of the predicted value because there are no data in support of the model.

\subsubsection{References}

11.7-1. S. Nazare, G. Ondracek, and B. Schultz, "Properties of Light Water Reactor Core Melts," Nuclear Technology, 32, 1977, pp. 239-246. 


\section{ZUSOLN}

\subsection{Heat of Solution of Uranium Dioxide by ZIRCONIUM-URANIUM-OXYGEN COMPOUNDS (ZUSOLN)}

(D. L. Hagrman)

\subsubsection{Model Development}

ZUSOLN returns an estimate of the heat required to 1 iquefy $\mathrm{UO}_{2}$ in a zircaloy-uranium-oxygen compound as a function of the compound composition. The expression used to calculate this heat is

$Q=\left(\frac{1.5 Z+1.5 U-0.5}{1.5 Z+2.5 U-0.5}\right) 2.69 \times 10^{5}+\left(\frac{U}{1.5 Z+2.5 U-0.5}\right) 2.74 \times 10^{5}(11.8-1)$

where

$Q=$ heat required to dissolve a unit mass of $\mathrm{UO}_{2}$ in a zircaloy-uranium-oxygen compound $(\mathrm{J} / \mathrm{kg})$

$U=$ atomic fraction uranium in solvent (atoms uranium/atoms solvent)

$Z=$ atomic fraction zirconium in solvent (atoms zirconium/atoms solvent).

Equation (11.8-1) is an interpolation between the heat of fusion for $\mathrm{UO}_{2}, 2.74 \times 10^{5} \mathrm{~J} / \mathrm{kg},{ }^{\mathrm{a}}$ and the heat of fusion for $\mathrm{UO}_{2}$ minus the difference in the heats of formation of $\mathrm{ZrO}_{2}$ and $\mathrm{UO}_{2}$ given on page 208

a. This number is taken from the PHYPRP subroutine. 


\section{ZUSOLN}

of Reference 11.8-1. The coefficient of the $\mathrm{UO}_{2}$ heat of fusion is the ratio of the molecular fraction of $\mathrm{UO}_{2}$ to the sum of fractions of $\mathrm{UO}_{2}$ and zircaloy in the solvent. (These fractions were derived at the beginning of Section 11). Thus, when this fraction is one, $\mathrm{UO}_{2}$ is being melted in a mixture of $\mathrm{UO}_{2}$ and $\mathrm{ZrO}_{2}$, so the appropriate heat is the energy necessary to melt the $\mathrm{UO}_{2}$.

The coefficient of the first term in Equation (11.8-1) is the ratio of the molecular fraction of zircaloy to the sum of the fractions of $\mathrm{UO}_{2}$ and zircaloy in the solvent. When this fraction is one, $\mathrm{UO}_{2}$ is being dissolved in zirconium. There are no data for the heat required to do this so it was estimated by approximating the dissolution as a fusion of $\mathrm{UO}_{2}$, followed by removal of the $\mathrm{O}_{2}$ from the uranium and addition of the $\mathrm{O}_{2}$ to a zirconium atom. The resultant number is very similar to the heat of fusion of $\mathrm{UO}_{2}$.

With the current numbers, $2.69 \times 10^{5}$ and $2.74 \times 10^{5}$, use of Equation (11.8-1) to interpolate is not necessary. However, the large uncertainty, $\pm 3 \times 10^{5}$, suggests that it is prudent to maintain the equation until measurements confirm that the actual number for the heat of solution of $\mathrm{UO}_{2}$ by zirconium is near the heat of fusion of $\mathrm{UO}_{2}$.

Figure 11.8-1 illustrates the small effect of solvent composition on the heat required to dissolve $\mathrm{UO}_{2}$.

\subsubsection{References}

11.8-1. C. J. Smithells and E. A. Brandes (eds.), Metals Reference Book, London and Boston: Butterworths (TN671 S55 1956). 
ZUSOLN

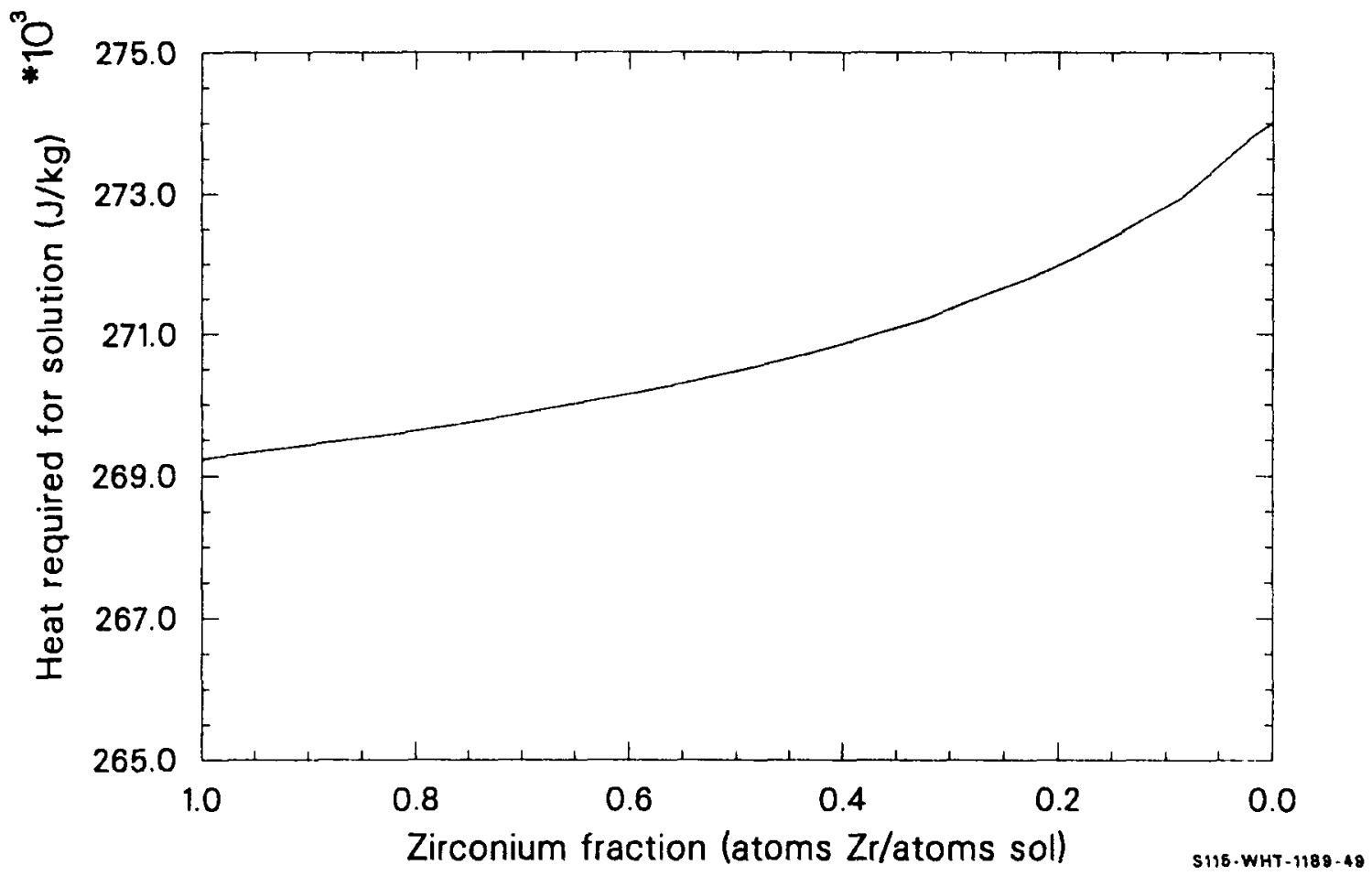

Figure 11.8.1. Effect of solvent composition of heat required to dissolve a kilogram of uranium dioxide. 


\section{ZUFUSN}

\subsection{HEAT OF FUSION OF Zircontum-URANIUM-OXYgen COMPOUndS (ZUFUSN)}

(J. K. Hohorst)

The subcode ZUFUSN calculates the heat of fusion of a zirconium-uranium-oxygen compound as a function of component concentration. Atomic fractions of uranium and zirconium are input into the subcode. The expression used to calculate the heat of fusion of a $\mathrm{Zr}-\mathrm{U}-\mathrm{O}$ compound is a mole-fraction-weighted average of the molar heats of fusion of $\mathrm{UO}_{2}$, $\mathrm{ZrO}_{2}$, and zircaloy

$$
L=\frac{2.74 E 50.270 f_{\mathrm{UO}_{2}}+7.06 E 50.123 \mathrm{f}_{\mathrm{ZrO}}+2.25 \mathrm{E5} 0.091 \mathrm{f}_{\mathrm{Zr}}}{0.270 \mathrm{f}_{\mathrm{UO}_{2}}+0.123 \mathrm{f}_{\mathrm{ZrO}_{2}}+0.091 \mathrm{f}_{\mathrm{Zr}}}
$$

where $L$ is the heat of fusion of the $Z r-U-0$ compound. 


\section{SILVER-ZIRCONIUM COMPOUNDS}

The solubility of zircaloy in Ag-In-Cd neutron absorber material is required to calculate the amount of cladding or structural material removed by jets or flows of control rod material that result when the control rod cladding ruptures. This section describes the model and subcode (ASOLV) developed to calculate the solubility of zircaloy cladding in $\mathrm{Ag}$-In-Cd neutron absorber material. 


\title{
ASOLV
}

\subsection{Solubility of Zircaloy Cladding in Ag-In-CD Absorber (ASOLV)}

\author{
(D. L. Hagrman)
}

The solubility of zircaloy in Ag-In-Cd neutron absorber material is required for calculations of the amount of cladding or structural material removed by jets or flows of control rod material that result when control rod cladding ruptures. Since the solubility is high and there is a significant mass of absorber material in reactor cores, the solution of zircaloy by absorber material can be a significant contribution to core material relocation. The possible solution of zircaloy guide tubes, which surround control rods, is also an important consideration in the analysis of the flow and freezing of the control rod material. This analysis is, in turn, important to the calculation of the amount of silver or cadmium aerosol that is available to carry fission products from severely damaged cores.

In the following sections, a summary is presented and the available data and observations are reviewed, followed by a discussion of the development of analytical expressions from the available data.

\subsubsection{Summary}

The expression used to calculate the solubility of zircaloy cladding in $\mathrm{Ag}-\mathrm{In}$-Cd absorber material is

For $1234 \leq T<1410.007334 \mathrm{~K}$,

$X=3.785 \times 10^{-14}(T-1228)^{5.794}+0.029$. 


\section{ASOLV}

$$
\begin{gathered}
\text { For } 1410.007334 \leq T \leq 1464 \mathrm{~K}, \\
X=-3.15545506+\mathrm{T} 2.592507834 \times 10^{-03} .
\end{gathered}
$$

For $1464<T \leq 2100 \mathrm{~K}$,

$X=0.4418+T\left(-1.649 \times 10^{-04}+T 2.051 \times 10^{-07}\right)$.

where

$$
\begin{aligned}
& T=\text { temperature }(K) \\
& X=\begin{array}{l}
\text { atomic fraction zircaloy in the solution at equilibrium } \\
\text { saturation (atoms zircaloy/atoms solution) }
\end{array}
\end{aligned}
$$

For temperatures below $1234 \mathrm{~K}$, no liquids are present at equilibrium; so solution is by the negligibly slow processes of solid-state diffusion. When the temperature is above $2100 \mathrm{~K}$, zircaloy melts and mixes with any silver that may be present.

Equations (12.1-1), (12.1-2) and (12.1-3) are converted from atomic fraction to mass fraction expressions with the following relation:

$Y=\frac{X 91.22}{107.87-X 16.65}$

where $Y$ is the mass fraction zircaloy in the solution at saturation (mass zircaloy/mass solution).

\subsubsection{Solubility Data for Ag-In-Cd on Zircaloy}

At the present time, quantitative data for the solubility of zircaloy or zircaloy oxide phases in Ag-In-Cd absorber material are not available. 
However, quantitative data from Hagen $12.1-1$ and Parker and Sutton $12.1-2,12.1-3,12.1-4$ and binary phase diagrams for the $\mathrm{Ag}-\mathrm{Zr}$ system ${ }^{12} \cdot 1-5,12 \cdot 1-6,12.1-7$ are sufficient for approximate modeling of the solubility of the zircaloy cladding in Ag solvents.

The quantitative data from Parker and Sutton are from instrumented fuel bundles that were heated by radio frequency induction. Control rods were observed to fail by reaction between stainless steel control rod cladding and a zircaloy sleeve installed to simulate reactor guide tubes. In these experiments, which did not have high pressure outside the control rods, extensive liquid metal was ejected from the control rod. It removed about one-half of the zircaloy cladding by a sort of candling process that left a heavy mass of intermetallic residue at the base of the fuel rods. The heavy mass at the base was also observed by Hagen.

The quantitative tests suggest that control rod failure and solution of zircaloy guide tubes or cladding will occur before the formation of an oxide layer of thickness sufficient to prevent absorber-zircaloy interaction. For this reason, the effect of prior oxidation of zircaloy on the solubility of the zircaloy will not be considered in the development of the solubility model. The quantitative results also suggest that the minor components of the absorber and zircaloy alloys can be ignored because they are consistent with the behavior expected from Ag-Zr binary phase diagrams.

Figure 12.1-1 is an Ag-Zr phase diagram taken from References 12.1-5 through 12.1-7. The diagram between 0.5 and 0.65 atomic fraction zirconium is not known, but the important Zr-rich part of the diagram is we 11 defined. Although the phase diagram is shown with temperature as the dependent variable, it can be interpreted with composition as the dependent variable. Thus, the fact that the liquidus (liquid region boundary) is at $1466 \mathrm{~K}$ for a composition of 0.66 atomic fraction $\mathrm{Zr}$ and 0.34 atomic fraction Ag means not only that the last solid phase of the given composition disappears at this temperature, but also that compounds containing up to 


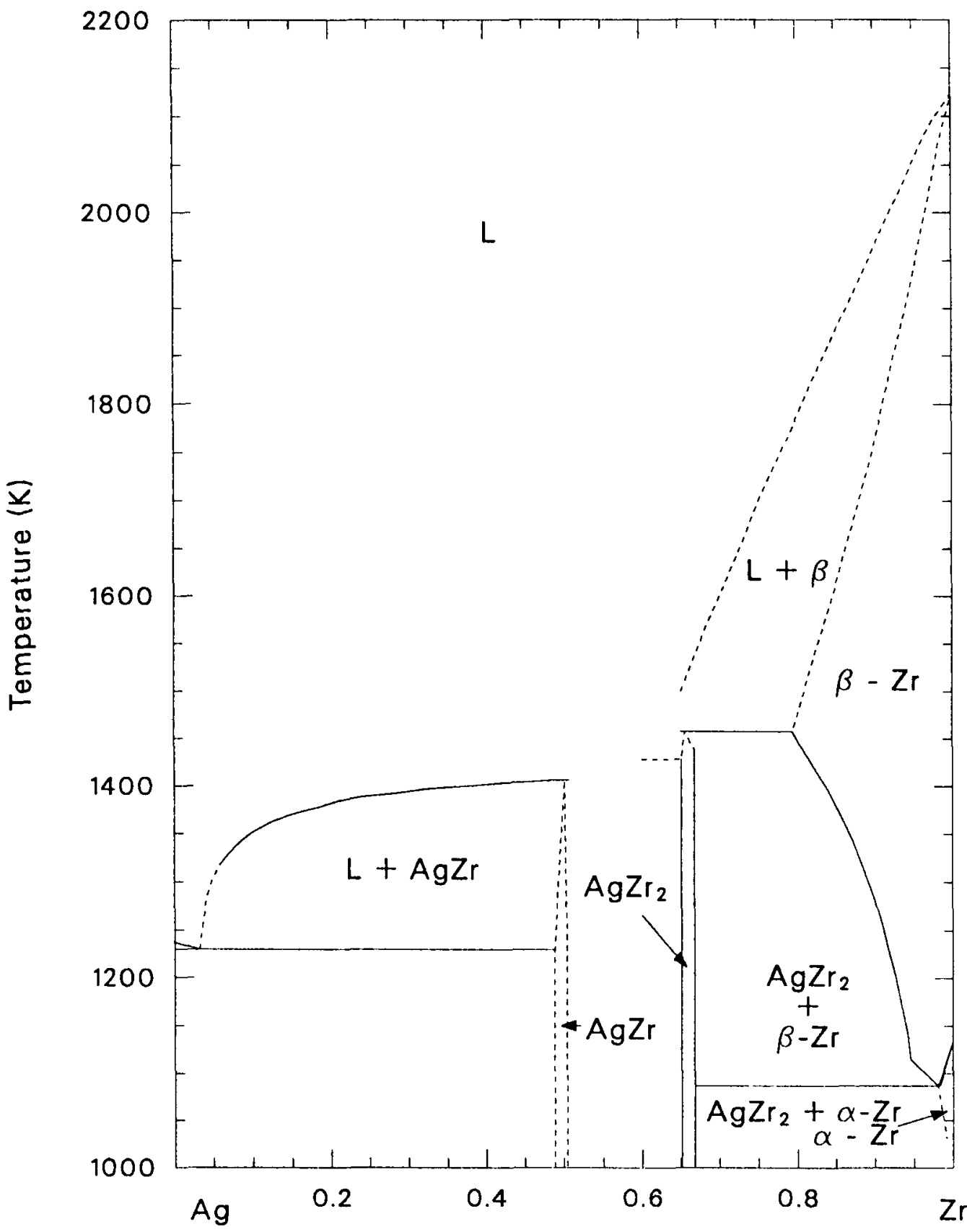

Atomic fraction $\mathrm{Zr}$

S115-WHT-1189-50

Figure 12.1-1. Silver-zirconium phase diagram. 
0.66 atomic fraction $\mathrm{Zr}$ will be completely liquid at a given temperature of $1500 \mathrm{~K}$ because all points to the left of the liquidus at $1500 \mathrm{~K}$ are in the liquid region. Thus, silver can dissolve about twice its mass of $\mathrm{Zr}$ at a temperature of $1500 \mathrm{~K}, 600 \mathrm{~K}$ below the melting point of $\mathrm{Zr}$. The fraction increases as the temperature increases because of the positive slope of the liquidus line in the $\mathrm{Zr}$-rich region. The relatively flat liquidus on the Ag-rich side of the phase diagram suggests a rapid increase in the solubility of $\mathrm{Zr}$ as temperature increases from 1373 to $1410 \mathrm{~K}$.

\subsubsection{Model Development}

The expressions used in the ASOLV function were derived by finding analytical expressions for the known liquidus curves of the Ag- $\mathrm{Zr}$ binary phase diagram and using interpolation for the unknown region. For the Ag-rich region, the $(T, X)$ pairs shown in Table 12.1-1 were taken from Hansen ${ }^{12.1-5}$ because he shows the individual data. The data were used to find the least-squares deviation fit to a power law constrained to fit the datum at $1228 \mathrm{~K}$,

$X=3.785 \times 10^{-14}(T-1228)^{5.794}+0.029$.

Hansen's data at 1306 and $1323 \mathrm{~K}$ were not used because the small numerical value of the concentrations would have dominated the fitting procedure.

In order to describe the $Z r$-rich region, the $(T, X)$ pairs shown in Table 12.1-2 were taken from Elliott ${ }^{12.1-6}$ and the MATPRO document. ${ }^{12.1-8}$ The MATPRO temperature for zircaloy melting was used instead of Elliott's number for the melting temperature of zirconium to avoid inconsistencies in the MATPRO routines. The equation that resulted from these data is

$X=0.4418+T\left(-1.649 \times 10^{-04}+T 2.051 \times 10^{-07}\right)$ 


\section{ASOLV}

Table 12.1-1. Data used to find the liquidus in the Ag-rich region

\begin{tabular}{ccl}
\hline $\begin{array}{c}\text { Temperature } \\
(\mathrm{K})\end{array}$ & $\begin{array}{l}\text { Composition } \\
\text { (atomic } \\
\text { fraction } \mathrm{Zr} \text { ) }\end{array}$ & Reference \\
1228 & 0.029 & Hansen \\
1364 & 0.119 & Hansen \\
1380 & 0.20 & Hansen \\
1393 & 0.26 & Hansen \\
1400 & 0.35 & Hansen \\
1404 & 0.44 & Hansen \\
1408 & 0.51 & Hansen \\
\hline
\end{tabular}

Table 12.1-2. Data used to find the liquidus in the Zr-rich region

\begin{tabular}{|c|c|c|}
\hline $\begin{array}{l}\text { Temperature } \\
\text { (K) }\end{array}$ & $\begin{array}{l}\text { Composition } \\
\text { (atomic } \\
\text { fraction } Z r \text { ) }\end{array}$ & Reference \\
\hline 1464 & 0.064 & Elliott \\
\hline 1673 & 0.74 & Elliott \\
\hline 2100 & 1.00 & MATPRO \\
\hline
\end{tabular}


The expression for the unknown region of the phase diagram is based on the assumption that there is no local maximum in the liquidus in the region. The expression is a linear interpolation between the Ag-rich and the $Z$ r-rich liquidus curves end points,

$X=-3.15545506+T 2.592507834 \times 10^{-03}$.

Note that the solubility is given by expressing the liquidus line as a composition versus temperature curve (instead of the more usual temperature versus composition curve) when the liquidus temperature is a monotonically increasing function of the zircaloy.

Equation (12.1-4) is a conversion from atomic fraction to mass fraction. It is derived from the definition of mass fraction,

$Y=\frac{\operatorname{mass} \mathrm{Zr}}{\operatorname{mass} \mathrm{Ag}+\operatorname{mass} \mathrm{Zr}}$.

Division by the kilogram-molecular mass of $\mathrm{Zr}$ and some algebra yields the expression

$Y=\frac{X M_{Z r}}{M_{A g}+X\left(M_{Z r}-M_{A g}\right)}$

where

$$
\begin{aligned}
& M_{A g}=\mathrm{kg}-\text { molecular mass of } \mathrm{Ag}(\mathrm{kg} / \mathrm{kg} \cdot \mathrm{mole}) \\
& M_{Z r}=\mathrm{kg}-\text { molecular mass of } \mathrm{Zr}(\mathrm{kg} / \mathrm{kg} \cdot \mathrm{mole})
\end{aligned}
$$

Equation (12.1.4) is obtained from Equation (12.1.6) by substituting the kilogram-molecular mass values. 


\section{ASOLV}

Figure 12.1-2 is a computer-generated graph of the calculated solubility of zircaloy in Ag-In-Cd absorber material versus temperature using the function.

\subsubsection{References}

12.1-1. S. Hagen, "Absorber Rod Tests in the NIELS Facility, " Severe Fue 7 Damage and Source Term Research Program Review Meeting, Idaho Falls, Idaho, April 16-19, 1985.

12.1-2. A. P. Malinauskas and S. G. Winslow, Monthly Highlights Report for December 1984. ORNL Projects for the NRC Office of Nuclear Regulatory Research, p. 29.

12.1-3. A. P. Malinauskas and S. G. Winslow, Monthly Highlights Report for February 1985. ORNL Projects for the NRC Office of Nuclear Regulatory Research, p. 27.

12.1-4. A. P. Malinauskas and S. G. Winslow, Monthly Highlights Report for March 1985. ORNL Projects for the NRC Office of Nuclear Regulatory Research, p. 27.

12.1-5. M. Hansen and K. Anderko, Constitution of Binary Alloys, New York: McGraw-Hill Book Company, Inc., 1958.

12.1-6. R. P. Elliott, Constitution of Binary Alloys, First Supplement, New York: McGraw-Hill Book Company, Inc., 1965.

12.1-7. T. Lyman, ed., Metals Handbook, 8th Edition, 8, Metals Park, Ohio: American Society for Metals.

12.1-8. D. L. Hagrman, Materials Properties Models for Severe Core Damage Analysis, EGG-CDD-5801, May 1982. 
ASOLV

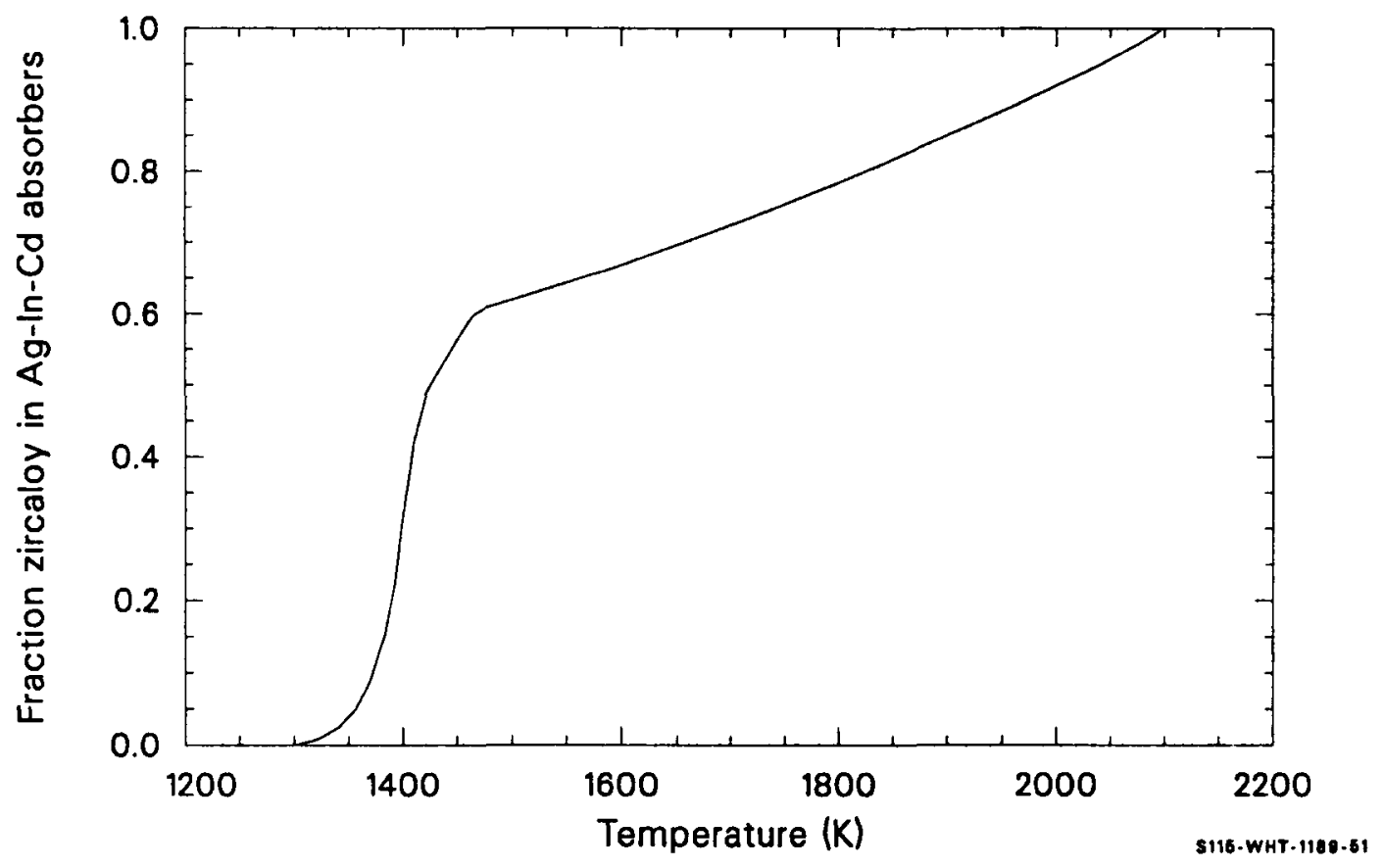

Figure 12.1-2. Computer-generated graph of the calculated solubility of zircaloy in silver-indium-cadmium absorber material.

$12.1-9$ 


\section{NONCONDENSABLE GASES--HELIUM, ARGON, KRYPTON, XENON, HYDROGEN, NITROGEN, OXYGEN, CARBON MONOXIDE, CARBON DIOXIDE, WATER MIXTURES}

Properties of the internal gas of LWR fuel rods have been included in MATPRO. The thermal conductivity (GASCON) of ten gases (and their mixture in any combination) is modeled, as is gas viscosity (GVISCO). Gas viscosity and thermal conductivity are modeled as functions of temperature and composition. Also included are models of specific heat capacity (GCP), effective emissivity (GMISS), and mean free path (GMFP). 


\subsection{Specific Heat Capacity (GCP)}

(D. L. Hagrman)

The specific heat capacity of a mixture of gases at constant pressure is required to calculate the temperature of a slug of effluent proceeding from a hot core region down a pipe with walls that cool the gas. The function GCP calculates the specific heat capacity at constant pressure of a gas mixture of helium, argon, krypton, xenon, hydrogen, nitrogen, oxygen, carbon monoxide, carbon dioxide, and water vapor as a function of the mole fraction of each component and the gas temperature.

\subsubsection{Model Development}

The correlation used for the molar specific heat capacity at constant pressure of the monatomic gases helium, argon, krypton, and xenon is just the ideal gas expression

$C_{p}=2.5$ times the gas constant $=2.0786 \times 10^{4} \mathrm{~kg}-\mathrm{m}^{2} /(\mathrm{s} \cdot \mathrm{kg}-$ mole $\cdot \mathrm{K})$

For hydrogen, nitrogen, oxygen, carbon monoxide, carbon dioxide, and water vapor, a second-degree polynomial correlation in temperature is employed to calculate the molar specific heat capacity. The coefficients are from Table 6.2 of Zemansky's text, ${ }^{13.1-1}$ and they have been converted to SI units in Table 13.1-1.

The expressions used for the molar heat capacity of mixtures are obtained from those of the components by using a mole-weighted average of the molar heat capacities 
GCP

Table 13.1-1. Constants used to calculate $C_{p}$

\begin{tabular}{|c|c|c|c|}
\hline & $\begin{array}{c}\text { Zeroth-Degree } \\
\text { Coefficient }\end{array}$ & $\begin{array}{r}\text { First-Degree } \\
\text { Coefficient }\end{array}$ & $\begin{array}{l}\text { Second-Degree } \\
\text { Coefficient }\end{array}$ \\
\hline Gas & $\mathrm{J} /(\mathrm{kg}-\mathrm{mole} \cdot \mathrm{K})$ & $\mathrm{J} /\left(\mathrm{kg}-\right.$ mole $\left.\cdot \mathrm{k}^{2}\right)$ & $\mathrm{J} /\left(\mathrm{kg}-\mathrm{mole} \cdot \mathrm{k}^{2}\right)$ \\
\hline $\mathrm{H}_{2}$ & $2.88 E+04$ & $2.76 \quad E-01$ & $1.17 \quad E-03$ \\
\hline $\mathrm{N}_{2}$ & $2.64 E+04$ & $7.913 E+00$ & $-1.44 \quad E-03$ \\
\hline $\mathrm{O}_{2}$ & $2.62 \mathrm{E}+04$ & $1.150 \mathrm{E}+01$ & $-3.22 \quad E-03$ \\
\hline CO & $2.62 E+04$ & $8.755 E+00$ & $-1.92 \quad E-03$ \\
\hline $\mathrm{CO}_{2}$ & $2.87 E+04$ & $3.573 \mathrm{E}+01$ & $-1.036 E-02$ \\
\hline $\mathrm{H}_{2} \mathrm{O}$ & $2.88 E+04$ & $1.375 \mathrm{E}+01$ & $-1.436 \quad E-03$ \\
\hline
\end{tabular}


$c_{p}$ (mixture) $=\sum_{k=1}^{i} C_{p}(k) X G M I X(k)$

where

$$
\begin{aligned}
& \operatorname{XGMIX}(k)=\text { mole fraction of the } k \text {-th gas component (kg-moles } k \text {-th } \\
& \text { component } / \mathrm{kg} \text {-moles of all components) } \\
& \begin{aligned}
\mathrm{C}_{\mathrm{p}}(\mathrm{k})= & \text { molar specific heat capacity at constant pressure of a } \\
& \text { pure sample of the } \mathrm{k} \text {-th mixture component }(\mathrm{J} / \mathrm{kg}-\mathrm{mole} \cdot \mathrm{K}) .
\end{aligned}
\end{aligned}
$$

After the molar heat capacities are calculated, they are converted to the specific heat capacity per unit mass by dividing by the $\mathrm{kg}$-mole weight of the mixture, which is given by

$\operatorname{mwt}(\operatorname{mixture})=\operatorname{mwt}(k) \times \operatorname{XMIX}(k)$

where $\operatorname{mwt}(\mathrm{k})$ is the $\mathrm{kg}$-mole weight (mass) of $\mathrm{k}$-th mixture component $(\mathrm{kg} / \mathrm{kg}-\mathrm{mole})$.

\subsubsection{Reference}

13.1-1. M. W. Zemansky, Heat and Thermodynamics, 4th edition, New York: McGraw-Hi11 Book Company, Inc., 1957. 
GASCON, GTHCON, GJUMP

\subsection{Thermal Conductivity, Gas Conductance, and Jump Distance (GASCON, GTHCON, GJUMP) \\ (D. L. Hagrman, M. L. McComas)}

The heat conductance of gas-filled gaps or pores is dependent on the thermal conductivity of the gas mixture when the dimensions of the gas-filled regions are large compared to the mean distance between gas molecule collisions (mean free path of the gas molecules). When the mean free path is not smaller than the gap dimension, the conduction component of gas gap heat conductance becomes a function of the number of gas molecules present and the nature of the gas gap interfaces. This section presents data and correlations for the thermal conductivities of ten gases of interest in fuel rod analysis. The effect of long mean free paths on gap conductance is also discussed.

\subsubsection{Summary}

Three functions are provided to meet various analytical needs for gas thermal conductivity. The GASCON function calculates gas thermal conductivity as a function of temperature and gas component fractions. To accomplish this, GASCON first calculates individual gas thermal conductivities through the use of Equations (13.2-1) through (13.2-4). Equation (13.2-5) is then used to calculate the mixture thermal conductivity. GASCON uses these equations in essentially the same form presented below. Though this is not the most simple format possible, it serves to reduce error caused by repeated manipulation of the data. GASCON al so generates, but does not return, an uncertainty term for each thermal conductivity. 


\section{GASCON, GTHCON, GJUMP}

The GTHCON function calculates the conduction part of gas gap heat transfer as a function of the gas conductivity, the gas pressure, and gas gap width. The conductance includes a series of resistance terms that account for the cases where the mean free path is not smaller than the gap dimensions. These terms have been previously introduced and are explained in Section 13.2.3. The final expression, Equation (13.2-8), combines Equation (13.2-5) with the resistance terms. The equation is again used in essentially unaltered form in the code.

The GJUMP function determines an effective jump distance that is derived from the models used in GTHCON and GASCON. The jump distance is the mixture thermal conductivity divided by the conductance part of the gap heat conductance, or GASCON divided by GTHCON. The GASCON function is called by GJUMP.

The correlations used for pure noble or diatomic gases are all of the form

$K=A T^{B}$

where

$k=$ thermal conductivity $(\mathrm{W} / \mathrm{m} \cdot \mathrm{K})]$

$T=$ gas temperature $(K)$.

The constants $A$ and $B$ for each noble or diatomic gas are given in Table 13.2-1.

The following conductivity equations are used for carbon dioxide and steam:

$k_{\text {carbon dioxide }}=9.460 \times 10^{-6} \mathrm{~T}^{1.312}$ 
GASCON, GTHCON, GJUMP

Table 13.2-1. Constants used in gas thermal conductivity correlations

\begin{tabular}{lll}
\hline & \multicolumn{3}{c}{ Constant } \\
\cline { 2 - 3 } Gas & \multicolumn{1}{c}{$\mathrm{A}$} & $\mathrm{B}$ \\
\cline { 2 - 3 } $\mathrm{He}$ & $2.639 \times 10^{-3}$ & 0.7085 \\
$\mathrm{Ar}$ & $2.986 \times 10^{-4}$ & 0.7224 \\
$\mathrm{Kr}$ & $8.247 \times 10^{-5}$ & 0.8363 \\
$\mathrm{Xe}$ & $4.351 \times 10^{-5}$ & 0.8616 \\
$\mathrm{H}_{2}$ & $1.097 \times 10^{-3}$ & 0.8785 \\
$\mathrm{~N}_{2}$ & $5.314 \times 10^{-4}$ & 0.6898 \\
$\mathrm{O}_{2}$ & $1.853 \times 10^{-4}$ & 0.8729 \\
$\mathrm{CO}$ & $1.403 \times 10^{-4}$ & 0.9090 \\
\hline
\end{tabular}




\section{GASCON, GTHCON, GJUMP}

For $T \leq 973.15$,

$$
\begin{aligned}
k_{\text {steam }} & =\left(-2.8516 \times 10^{-8}+9.424 \times 10^{-10} \mathrm{~T}-6.005 \times 10^{-14} \mathrm{~T}^{2}\right) \mathrm{P} / \mathrm{T} \\
& +\frac{1.009 \mathrm{P}^{2}}{\mathrm{~T}^{2}(\mathrm{~T}-273)^{4.2}}+17.6+5.87 \times 10^{-5} \mathrm{~T}_{\mathrm{C}}+1.08 \times 10^{-7} \mathrm{~T}_{\mathrm{C}}^{2} \\
& -4.51 \times 10^{-11} \mathrm{~T}_{\mathrm{C}}^{3}
\end{aligned}
$$

For $\mathrm{T}>973.15$,

$k_{\text {steam }}=4.44 \times 10^{-6} \mathrm{~T}^{1.45}+9.5 \times 10^{-5}\left(\frac{2.1668 \times 10^{-9}}{\mathrm{~T}} \mathrm{P}\right)^{1.3}$

where

$$
\begin{aligned}
T_{\mathrm{C}} & =\text { gas temperature }\left({ }^{\circ} \mathrm{C}\right) \\
\mathrm{P} & =\text { gas pressure }\left(\mathrm{N} / \mathrm{m}^{2}\right) .
\end{aligned}
$$

The uncertainties of the values predicted by Equations (13.2-1) to (13.2-4) are summarized in Table 13.2-2.

The thermal conductivity of gas mixtures is calculated with the expression

$$
k_{\operatorname{mix}}=\sum_{i=1}^{n}\left(\frac{k_{i} x_{i}}{x_{j}+\sum_{\substack{j=1 \\ j \neq i}}^{n} \psi_{i j} x_{j}}\right)
$$

where 
GASCON， GTHCON， GJUMP

Table 13.2-2. Uncertainty of the gas thermal conductivity correlations

Gas

Uncertainty $(W / m \cdot K)$

$\begin{array}{ll}\mathrm{He} & 8.00 \times 10^{-7} \mathrm{~T}^{1.5} \\ \mathrm{Ar} & 4.96 \times 10^{-10} \mathrm{~T}^{2.25} \\ \mathrm{Kr} & 1.45 \times 10^{-9} \mathrm{~T}^{2} \\ \mathrm{Xe} & 2.77 \times 10^{-8} \mathrm{~T}^{1.5} \\ \mathrm{H}_{2} & 2.10 \times 10^{-6} \mathrm{~T}^{1.5} \\ \mathrm{~N}_{2} & 2.64 \times 10^{-6} \mathrm{~T} \\ \mathrm{O}_{2} & 2.34 \times 10^{-9} \mathrm{~T}^{2} \\ \mathrm{CO} & \text { for } \mathrm{T} \text { between } 300 \text { and } 400 \mathrm{~K}, 0.02 \mathrm{~K} ; \\ & \text { for } \mathrm{T}>400 \mathrm{~K}, 0.002+4 / 3(\mathrm{~T}-400) \times 10^{-4} \mathrm{~K} \\ \mathrm{CO}_{2} & 8.78 \times 10^{-12} \mathrm{~T}^{3} \\ \mathrm{H}_{2} \mathrm{O} & 0.06 \mathrm{~K}\end{array}$


GASCON, GTHCON, GJUMP

$\psi_{i j}=\phi_{i j}\left[1+2.41 \frac{\left(M_{i}-M_{j}\right)\left(M_{i}-0.142 M_{j}\right)}{\left(M_{i}+M_{j}\right)^{2}}\right]$

and

$\phi_{i j}=\frac{\left[1+\left(\frac{k_{i}}{k_{j}}\right)^{1 / 2}\left(\frac{M_{i}}{M_{j}}\right)^{1 / 4}\right]^{2}}{2^{3 / 2}\left(1+\frac{M_{i}}{M_{j}}\right)^{1 / 2}}$

and

$n=$ number of components in mixture (unitless)

$M_{j}=$ molecular weight of component $i(\mathrm{~kg})$

$x_{i}=$ mole fraction of the component $i$ (unitless)

$k_{i}=$ thermal conductivity of the component $i(W / m \cdot K)$.

The conduction part of the gas gap heat conductance is calculated with the equation

$$
h=\sum_{i=1}^{n}\left(\frac{k_{i} x_{i}}{x_{i}+\sum_{\substack{i \neq 1 \\ j=i}}^{n} \psi_{i j} x_{j}}\right)\left[\frac{1}{t+\frac{\left(M_{i} T\right)^{1 / 2}}{18}\left(\frac{\gamma_{j}-1}{\gamma_{j}+1}\right) \frac{1}{a_{i} p}\left(\frac{k_{i}}{x+\sum_{\substack{j \neq j \\ j=1}}^{n} \psi_{i j} x_{j}}\right)}\right](13.2-8)
$$

where

$\mathrm{h}=$ conduction part of the gas gap heat conductance $\left(\mathrm{W} / \mathrm{m}^{2} \cdot \mathrm{K}\right)$ 
GASCON, GTHCON, GJUMP

$\gamma_{i}=$ ratio of the specific heats at constant volume and constant pressure for component $i$ (unitless)

$a_{i}=a$ constant (provided in Table 13.2-3) that describes the nature of the gas gap interfaces (unitless)

$t=$ gap width (m).

Details of the development of the models used in the GTHCON subcode are presented in the following sections. Section 13.2.2 is a review of the data, and Section 13.2.3 is a discussion of the model development.

\subsubsection{Gas Thermal Conductivity and Accommodation Coefficient Data}

Most gas thermal conductivity data are for temperatures $<500 \mathrm{~K}$. At higher temperatures of interest in reactor fuel behavior analysis, interpretation of experiment measurements (power transferred across a gas-filled gap at known temperatures) is difficult. Significant energy can be transferred by convection or radiation as well as by conduction. Also, the mean free path of the gas molecules can become nonnegligible compared to gap width for some combinations of pressure, temperature, and gap width. When this happens, experiment data measure not only the bulk gas thermal conductivity but also gap surface effects and numbers of molecules available to transfer energy across the gap.

Researchers usually correct their data for the effects of long mean free paths and convection by measuring power at several differing gas pressures. Since the mean free path is inversely proportional to pressure and the effect of convection is proportional to the square of the gas density (pressure), ${ }^{13.2-1}$ it is usually possible to find combinations of experiment dimensions and pressures where the reciprocal conductance is independent of pressure or increasing linearly with reciprocal pressure. When the data show no pressure dependence, both mean free path and 
GASCON, GTHCON, GJUMP

Table 13.2-3. Surface accommodation coefficients

\begin{tabular}{|c|c|c|c|}
\hline Gas & $\begin{array}{c}\text { Factor } a_{i} \text { of } \\
\text { Equation }(13.2-8)\end{array}$ & agas-zircaloy & $a_{\text {gas-fuel }}$ \\
\hline $\mathrm{He}$ & 0.06 & 0.071 & 0.34 \\
\hline $\mathrm{Ar}$ & 0.15 & 0.16 & 0.8 \\
\hline $\mathrm{Kr}$ & 0.74 & 0.85 & 0.85 \\
\hline $\mathrm{Xe}$ & 0.74 & 0.85 & 0.85 \\
\hline $\mathrm{H}_{2}$ & 0.06 & 0.071 & 0.34 \\
\hline $\mathrm{N}_{2}$ & 0.19 & 0.2 & 0.85 \\
\hline $\mathrm{O}_{2}$ & 0.19 & 0.2 & 0.85 \\
\hline $\mathrm{CO}$ & 0.19 & 0.2 & 0.85 \\
\hline $\mathrm{CO}_{2}$ & 0.74 & 0.85 & 0.85 \\
\hline $\mathrm{H}_{2} \mathrm{O}$ & 0.19 & 0.2 & 0.85 \\
\hline
\end{tabular}




\section{GASCON, GTHCON, GJUMP}

convection effects can be neglected. When the linear dependence is present, gas conductivity is found by extrapolation to infinite pressure. Groups of data with equal temperature and varying pressure are fit to an equation of the form

$\frac{1}{h}=\frac{t}{k}+\frac{\text { constant }}{P}$.

Corrections for radiation heat transfer are applied when necessary by using the Stefan-Boltzmann law. In most experiments, the radiation correction is smaller than measurement uncertainty and the correction is neglected.

Data used in the development of the correlations for pure gas thermal conductivities were taken from the references listed in Table 13.2-4.13.2-1 to 13.2-12 The method of correcting for long mean free paths and temperature range investigated are listed in the comment column. With the exception of the two publications by Timrot and Umanskii, 13.2-6,13.2-11 the references reported conductivities and temperatures that could be used without further analysis. The analysis of the high-temperature data of Timrot and Umanskii is discussed below.

Data reported by Timrot and Umanskii are reduced power per unit length and temperatures for a coaxial cylindrical cell. The reduced power was defined to be the power per unit length that would be obtained with a small mean free path, and it was obtained from measurements of power at several pressures. The technique was similar to the approach of extrapolation to infinite pressure.

In contrast to most authors, Timrot and Umanskii correlated values of reduced power with temperature and determined their expression for gas thermal conductivity by taking the derivation of the correlation. The appropriate expression is 


\section{GASCON, GTHCON, GJUMP}

Table 13.2-4. Pure gas conductivity references

Gas $\frac{\text { Reference }}{\text { Ke } \quad \text { Kannuluik and Carman 13.2-1 }}$
Gambhir, Gandhi, and Saxena 13.2-2
von Ubisch 13.2-3

Saxena and Saxena $a^{13.2-4}$

Timrot and Totskij13.2-5

Timrot and Umanskij13.2-6

Extrapolated to infinite pressure temperatures to $580 \mathrm{~K}$

Pressure-independent conductivity temperatures to $370 \mathrm{~K}$

Extrapolated to infinite pressure at 300 and $790 \mathrm{~K}$

Pressure-independent conductivity temperatures to $1300 \mathrm{~K}$

Radiation effects correction, but long mean free path correction not discussed

Analysis discussed in the text of this report (Section 13.2.2)

Temperatures from 800 to $2600 \mathrm{~K}$

Zaitseva $13.2-7$

Extrapolated to infinite pressure temperatures from 350 to $800 \mathrm{~K}$

Cheung, Bromley, and Wilke13.2-8 Extrapolated to infinite pressure at 370 and $590 \mathrm{~K}$

Johnston and Grilley $13.2-9$

Extrapolated to infinite pressure temperatures to $383 \mathrm{~K}$

Ar Kannuluik and Carman 13.2-1 Extrapolated to infinite pressure temperatures from 370 to $380 \mathrm{~K}$

Gambhir, Gandi, and Saxena13.2-2 Pressure-independent conductivity temperatures from 310 to $370 \mathrm{~K}$

von Ubisch $13.2-3 \quad$ Extrapolated to infinite pressure at 300 and $790 \mathrm{~K}$

Zaitseva13.2-7

Extrapolated to infinite pressure temperatures from 320 to $790 \mathrm{~K}$

Cheung, Bromley, and Wilke13.2-8 Extrapolated to infinite pressure at 370 and $590 \mathrm{~K}$ 
GASCON, GTHCON, GJUMP

Table 13.2-4. (continued)

Gas

Reference

Schafer

as quoted by Brokaw $13.2-10$

$\mathrm{Kr}$ Kannuluik and Carman ${ }^{13.2-1}$

Gambhir, Gandhi and Saxena $13.2-2$

von Ubisch $13.2-3$

Zaitseva13.2-7

Xe Kannuluik and Carman ${ }^{13.2-1}$

Gambhir, Gandi, and Saxena ${ }^{13.2-2}$

von Ubisch $13.2-3$

Zaitseva ${ }^{13.2-7}$

$\mathrm{H}_{2}$ Johnston and Grilley $13.2-9$

Geier and 1 schafer as quoted
by Brokaw $13.2-10$.

Timrot and Umanskij 13.2-11

$\mathrm{N}_{2} \quad$ Cheung, Bromley, and Wilke $\mathrm{k}^{13.2-8}$

Figure 4, Keyes ${ }^{13.2-12}$

$\mathrm{O}_{2}$ Cheung, Bromley, and Wilke $\mathrm{k}^{13.2-8}$

\section{Comments}

At $1370 \mathrm{~K}$

Extrapolated to infinite pressure temperatures from 370 to $580 \mathrm{~K}$

Pressure-independent conductivity temperatures from 310 to $370 \mathrm{~K}$

Extrapolated to infinite pressure at 300 and $790 \mathrm{~K}$

Extrapolated to infinite pressure temperatures from 310 to $800 \mathrm{~K}$

Extrapolated to infinite pressure temperatures from 370 to $380 \mathrm{~K}$

Pressure-independent conductivity temperatures from 310 to $370 \mathrm{~K}$

Extrapolated to infinite pressure at 300 and $790 \mathrm{~K}$

Extrapolated to infinite pressure temperatures from 310 to $790 \mathrm{~K}$

Extrapolated to infinite pressure temperatures to $370 \mathrm{~K}$

At $1373 \mathrm{~K}$

Analysis discussed in the text of this report (Section 13.2.2)

Extrapolated to infinite pressure at 380 and $590 \mathrm{~K}$

Temperatures from 320 to $620 \mathrm{~K}$

Extrapolated to infinite pressure at 370 and $590 \mathrm{~K}$ 
GASCON, GTHCON， GJUMP

Table 13.2-4. (continued)

Gas Reference

$\mathrm{O}_{2}$ Johnson and Grilley 13.2-9

CO Johnston and Grilley 13.2-9

$\mathrm{CO}_{2}$ Cheung, Bromley, and Wilke $\mathrm{k}^{13.2-8}$

Johnston and Grilley 13.2-9

Figure 4 , Keyes ${ }^{13.2-12}$

\section{Comments}

Extrapolated to infinite pressure temperatures to $380 \mathrm{~K}$

Extrapolated to infinite pressure temperatures to $380 \mathrm{~K}$

Extrapolated to infinite pressure at 380 and $590 \mathrm{~K}$

Extrapolated to infinite pressure temperatures to $380 \mathrm{~K}$

Temperatures from 320 to $620 \mathrm{~K}$ 
GASCON, GTHCON, GJUMP

$k=\frac{\ln \left(\frac{R}{r}\right) d W(T)}{2 \pi d T}$

where

$W(T)=$ equation for power per unit measured in the experiment $(W / m)$

$\mathrm{R}=$ outer wall radius of the cell (m)

$r=$ inside wall radius of the cell (m).

The analysis by Timrot and Umanskij13.2-6 is an excellent approach to modeling thermal conductivity with data from a single experiment, but it is inconvenient for use in conjunction with the other literature data. In order to use Timrot and Umanskii's data with data from other references, the reported values of reduced power and temperature have been used to find approximate point-by-point conductivities. The derivative of $W$ with respect to temperature at temperature $T_{j}$ was approximated with the expression

$\frac{d W\left(T_{i}\right)}{d T} \approx \frac{1}{2}\left(\frac{W_{i+1}-W_{i}}{T_{i+1}-T_{i}}+\frac{W_{i}-W_{i-1}}{T_{i}-T_{i-1}}\right)$

where the subscript $i$ refers to the $i$-th measured value in a series of measurements 1 isted in order of increasing temperature. Equations (13.2-11) and (13.2-12) convert the data reported by Timrot and Umanskij to thermal conductivities.

When the mean free path of the gas molecules in a gap is long compared to the gap dimensions, the transfer of energy from the hot gap surface to the gas and then to the cold gap surface during individual molecular collisions becomes more important to the heat conductance than the bulk gas 


\section{GASCON, GTHCON, GJUMP}

thermal conductivity. The experiment data of interest in this case are surface accommodation coefficients, defined by the relation

$$
a_{s g}=\frac{T_{2}-T_{1}}{T_{s}-T_{1}}
$$

where

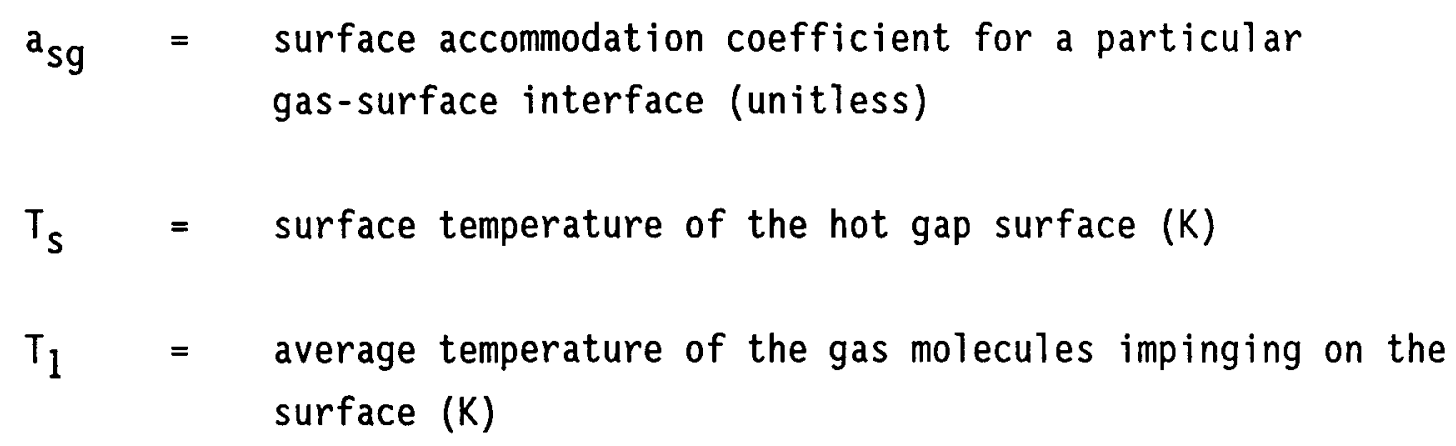

$\mathrm{T}_{2}=$ average temperature of the gas molecules after striking and again leaving the surface (K).

Surface accommodation coefficients tend to be large for massive gas molecules, and they are increased when an intermediate gas layer is absorbed on the surface. For example, White ${ }^{13.2-13}$ reports accommodation coefficients of $0.09,0.041,0.16$, and 0.20 for $\mathrm{H}_{2}$, helium, argon, and $\mathrm{O}_{2}$ on clean tungsten surfaces at $90 \mathrm{~K}$. For heavy polyatomic molecules, accommodation coefficients are reported to be generally in the range 0.8 to 0.9. For helium on nickel with and without absorbed gas, White reported accommodation coefficients of 0.360 and 0.071 at $273 \mathrm{~K}$. For helium on glass (a ceramic), the accommodation coefficient is 0.34 , a value larger than the helium-metal accommodation coefficients mentioned above.

Numerous sources of low temperature data were reviewed but not used in the development of the thermal conductivity model to avoid giving undue emphasis to data that have been replaced by more relevant information. 
GASCON， GTHCON， GJUMP

These sources of data and some theoretical discussions are included in a bibliography at the end of this report.

\subsubsection{Mode1 Development and Uncertainty Estimates}

Development of analytical models for gas gap conductance will be described in several steps. Initially, the data discussed in Section 13.2.2 are used to develop models for the thermal conductivity of pure gases. Uncertainties are discussed, and analytical expressions for these uncertainties are presented. The conductivity of mixed gases is discussed next, and the conduction contribution to the conductance of narrow gaps (or gas-filled fuel regions) is modeled.

An elementary treatment of gas conductivity that considers the gas to be a collection of hard spheres leads to the conclusion that the conductivity of a single-component gas is proportional to the square root of temperature, the square root of the molecular mass, and inversely proportional to the square of the molecule's diameter. The expression that results from the elementary treatment (given in most college statistical mechanics texts and therefore not repeated here) is

$k_{\text {idea }}=\frac{3}{2} \frac{m^{1 / 2}}{\sigma} K_{B}^{3 / 2} T^{1 / 2}$

where

$$
\begin{array}{ll}
\mathrm{k}_{\text {ideal }} & =\text { thermal conductivity of an idealized gas }(\mathrm{W} / \mathrm{m} \cdot \mathrm{K}) \\
\mathrm{m} & =\text { mass of the molecules }(\mathrm{kg}) \\
\mathrm{K}_{B} & =\text { Boltzmann's constant }(\mathrm{J} / \mathrm{K}) \\
\sigma & =\text { area of the sphere's cross section }\left(\mathrm{m}^{2}\right) .
\end{array}
$$




\section{GASCON, GTHCON, GJUMP}

For real gases where the molecules have structure and distant dependent interactions, Equation (13.2-13) must be replaced by an equation of the form

$K=A T^{B}$

where $A$ and $B$ are constants for a given gas. Data referenced in Section 13.2.2 and the least-squares method were used to find the values of $A$ and $B$ given in the summary.

Figures 13.2-1 to 13.2-4 illustrate the correlation predictions and the data base for the monatomic gases helium, argon, krypton, and xenon. The values of $B$ for these four gases $(0.7085,0.7224,0.8363$, and 0.8616 ) increase with increasing boiling temperatures $(4,87,120$, and $166 \mathrm{~K})$, an indication that the increasing departure from the idealized gas temperature dependence is due to increasing intermolecular forces. This regular trend and the fact that a single exponent serves to model the extensive helium data lends confidence to the extrapolations beyond the low-temperature data available for krypton and xenon.

Dashed lines in Figures 13.2-1 to 13.2-4 are the expected standard error of the correlations. Since the data show increasing scatter with increasing temperature, the expected standard error of the thermal conductivity was determined from the standard error of a new variable defined to be the thermal conductivity divided by a power of temperature. Trial values of the power were varied until the residuals of the new variable were temperature independent. Once the appropriate power was determined, the standard error of the new variable was calculated and the expected standard error of the conductivity was obtained by multiplying the standard error of the new variable by the power of the temperature.

For the diatomic molecules, $\mathrm{H}_{2}, \mathrm{~N}_{2}, \mathrm{O}_{2}$, and $\mathrm{CO}$, the relation between the exponent $B$ in Equation (13.2-2) and boiling temperatures is no longer apparent. The conductivities of these gases cannot be expected to be 


\section{GASCON, GTHCON, GJUMP}

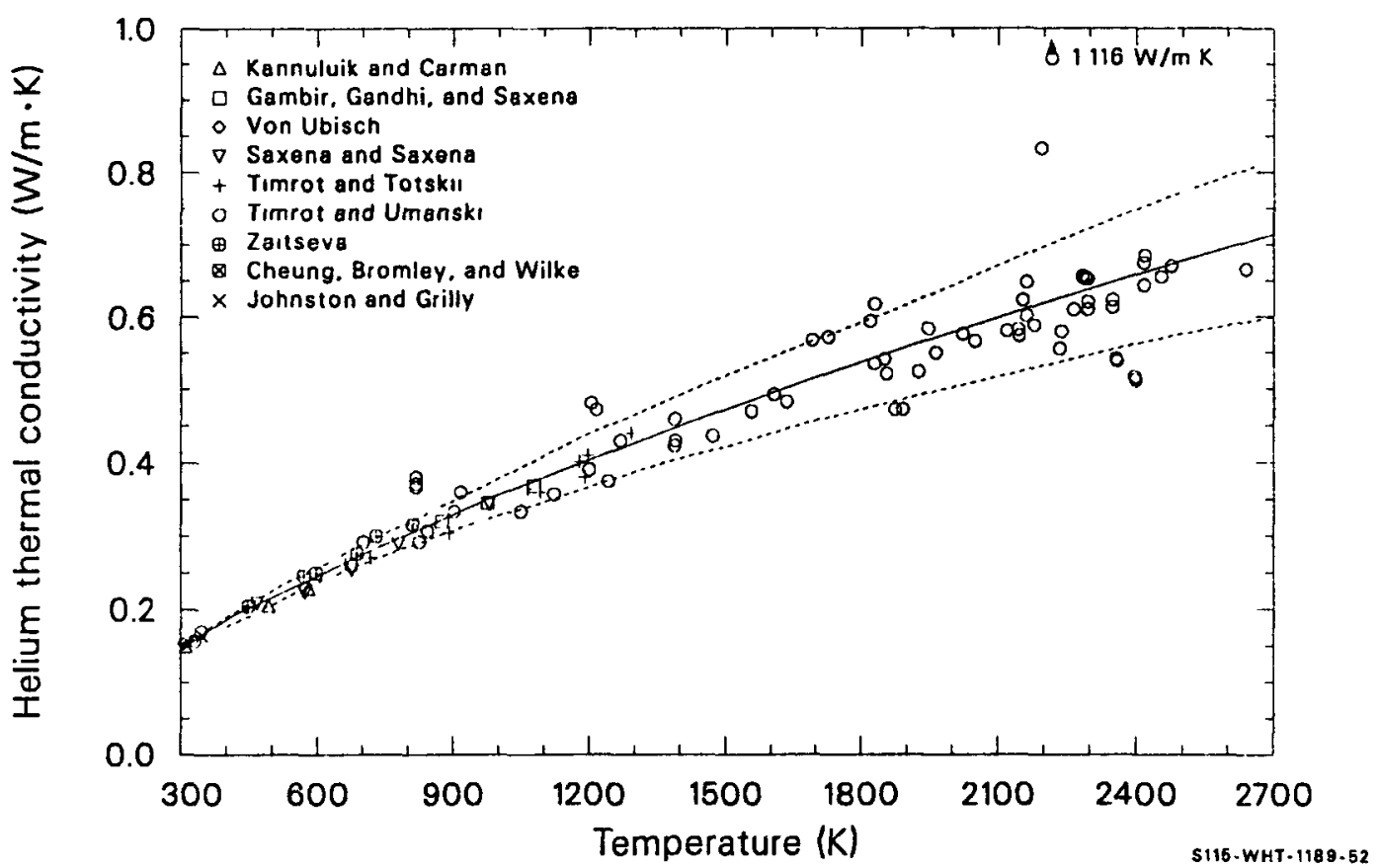

Figure 13.2-1. Thermal conductivity of helium as a function of temperature. 


\section{GASCON, GTHCON, GJUMP}

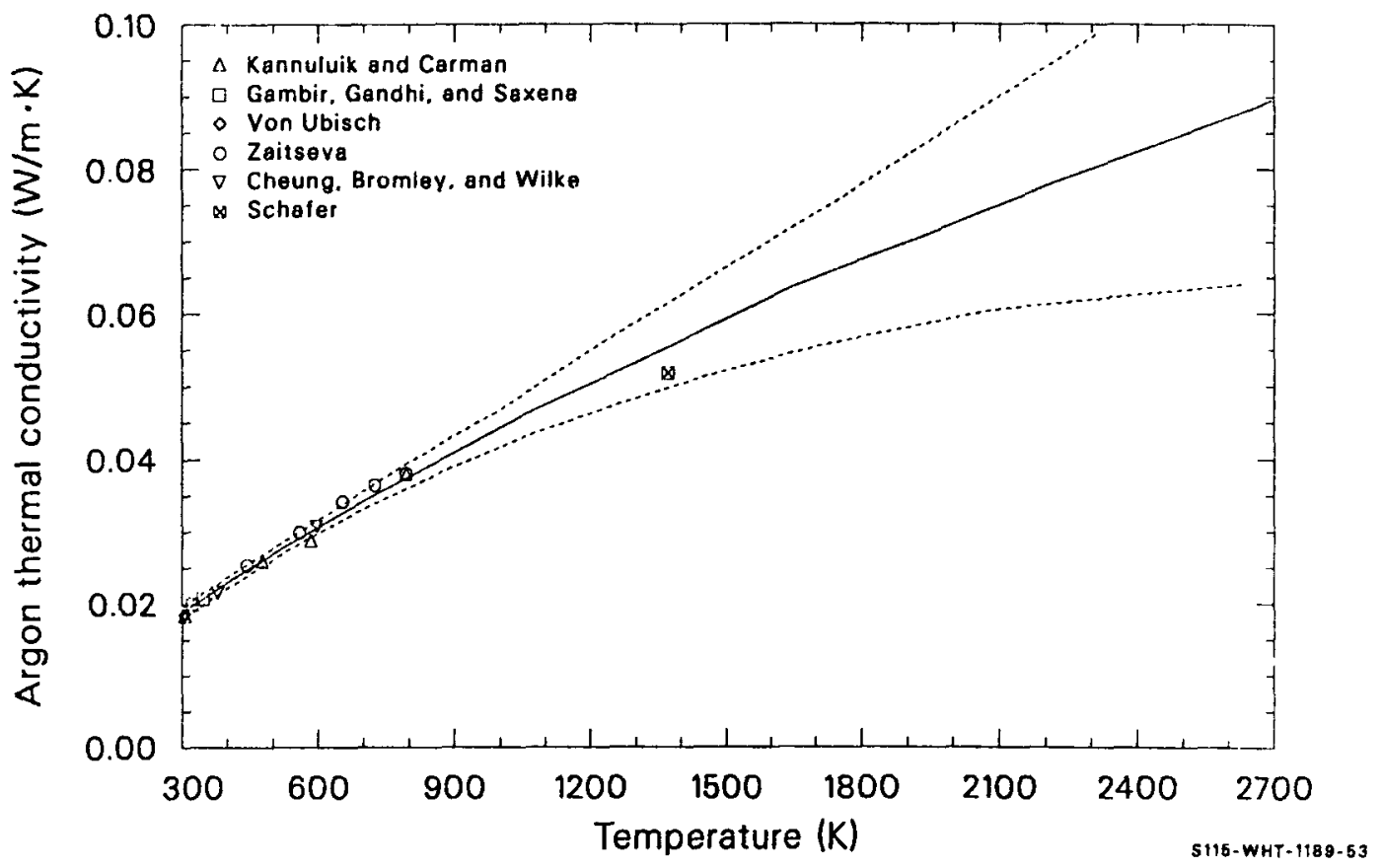

Figure 13.2-2. Thermal conductivity of argon as a function of temperature. 


\section{GASCON，GTHCON，GJUMP}

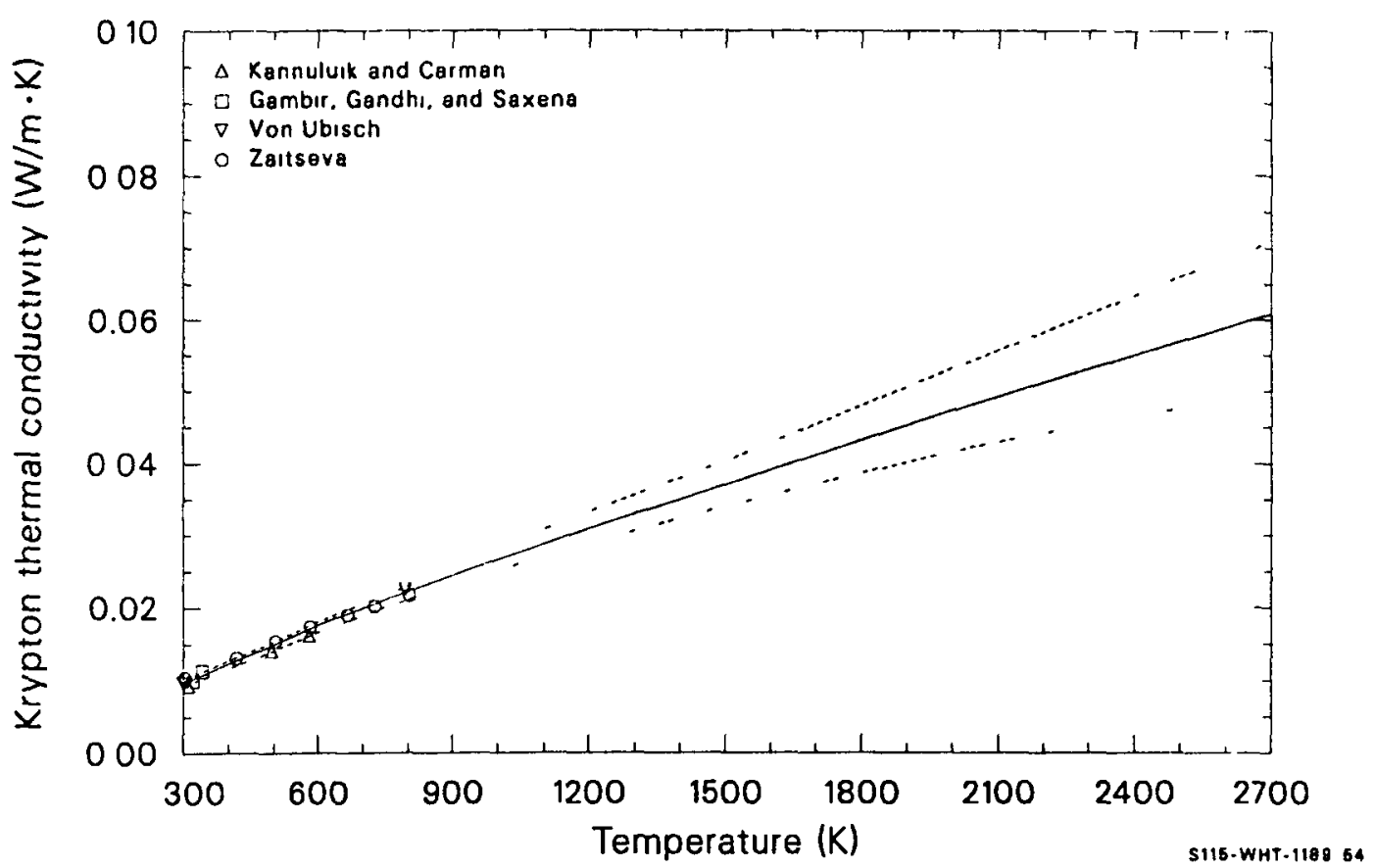

Figure 13.2-3. Thermal conductivity of krypton as a function of temperature. 


\section{GASCON， GTHCON， GJUMP}

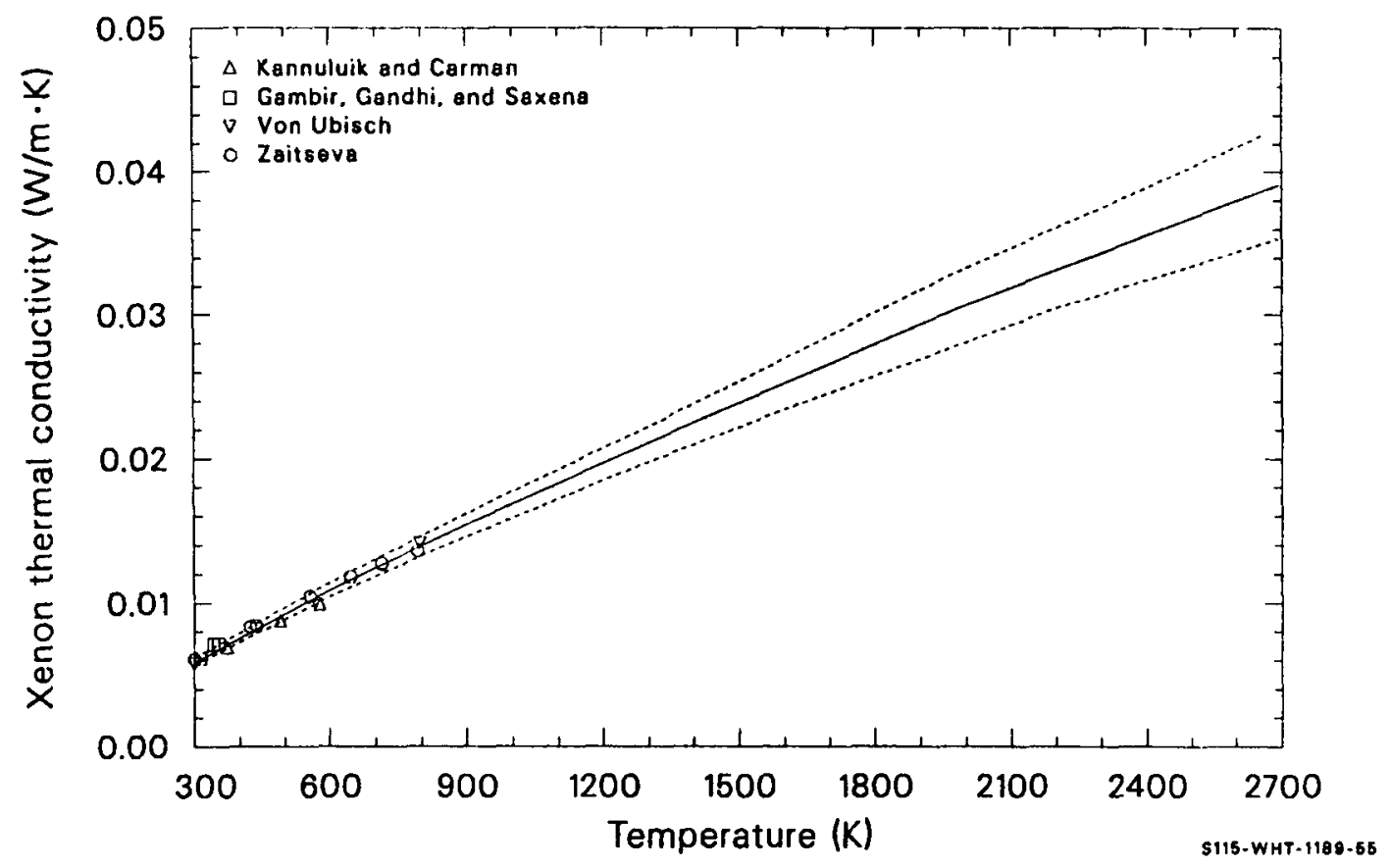

Figure 13.2-4. Therma1 conductivity of xenon as a function of temperature. 
related in any simple fashion because they transfer energy in complex molecular rotational and vibrational modes, in addition to translational modes. The data base, correlation predictions, and expected standard errors for these gases are shown in Figures 13.2-5 to 13.2-8.

The analysis of the diatomic gas data followed the procedure of the monatomic gases with the exception of the determination of the expected standard error of the CO conductivity correlation. For carbon monoxide, only four data were available; and an arbitrary uncertainty of 0.02 times the thermal conductivity (typical of low-temperature measurement scatter) was assigned over the temperature range of the data. The 0.02 was replaced with a linear function of temperature for temperatures $>400 \mathrm{~K}$, and the coefficients in this function were determined to predict an expected standard error of 0.10 times the predicted thermal conductivity at $1000 \mathrm{~K}$.

Figure 13.2-9 is a comparison of the data base and correlation predictions for the thermal conductivity of $\mathrm{CO}_{2}$. It is possible that the large exponent of temperature in the carbon dioxide correlation is due to an extreme departure from the idealized gas approximation at the low temperatures for which data are available. The vapor pressure of solid carbon dioxide is one atmosphere at $195 \mathrm{~K}^{\mathrm{a}}$ and the data extend only over a range of two to three times this temperature. If the large exponent of temperature obtained from data in the range from 300 to $600 \mathrm{~K}$ is due to the fact that all the data are at temperatures where significant intermolecular forces are present, the exponent can be expected to decrease at temperatures $>600 \mathrm{~K}$. The temperature-dependence of the uncertainty has been forced higher than the dependence indicated by the limited $\mathrm{CO}_{2}$ data to reflect this concern. A temperature-cubed dependence for the expected standard error was selected because the cube is the largest exponent of temperature

a. There is no liquid phase of $\mathrm{CO}_{2}$ at atmospheric pressure, so the closest measure of boiling point is the one given here. 
GASCON, GTHCON, GJUMP

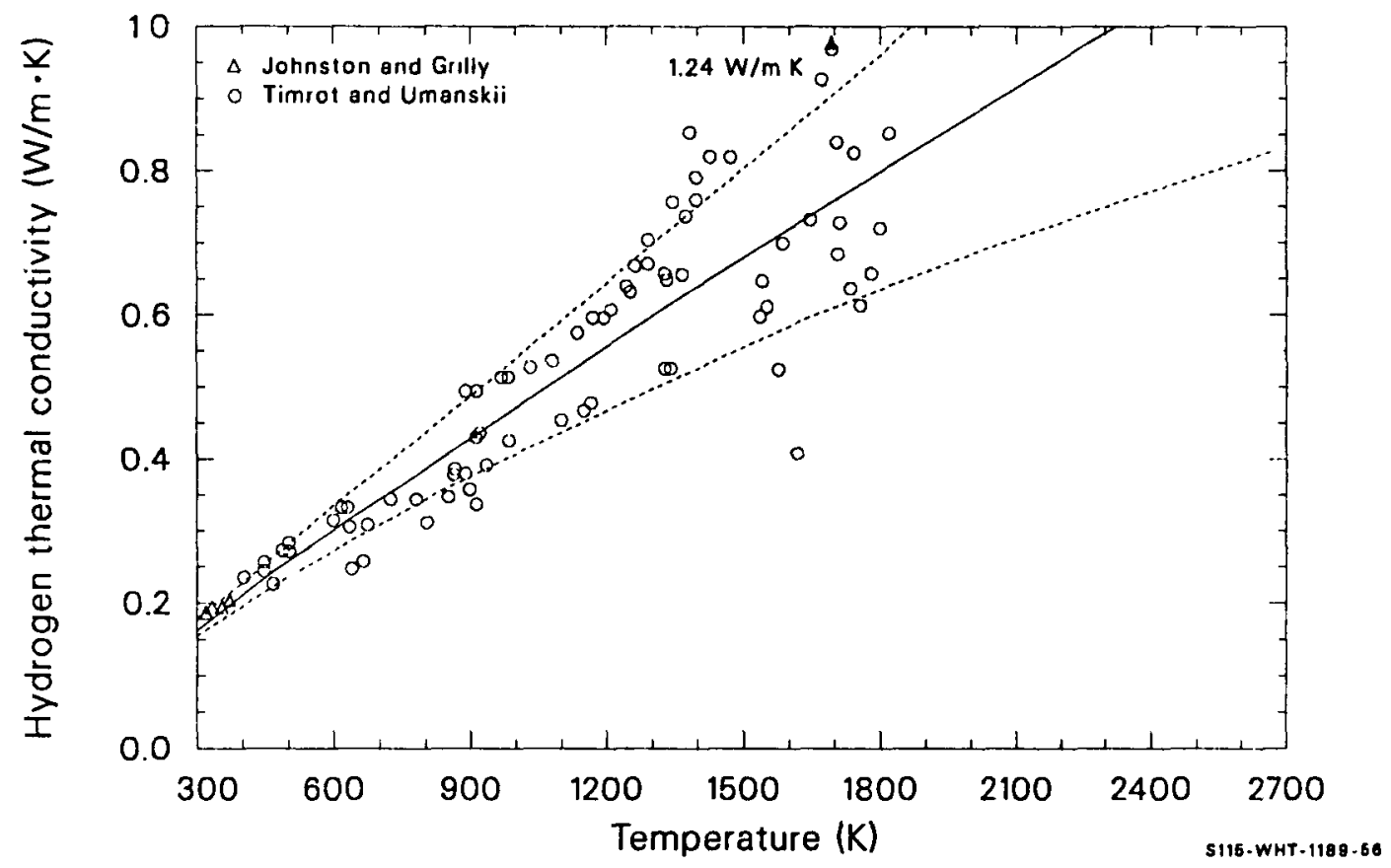

Figure 13.2-5. Thermal conductivity of hydrogen as a function of temperature. 


\section{GASCON, GTHCON，GJUMP}

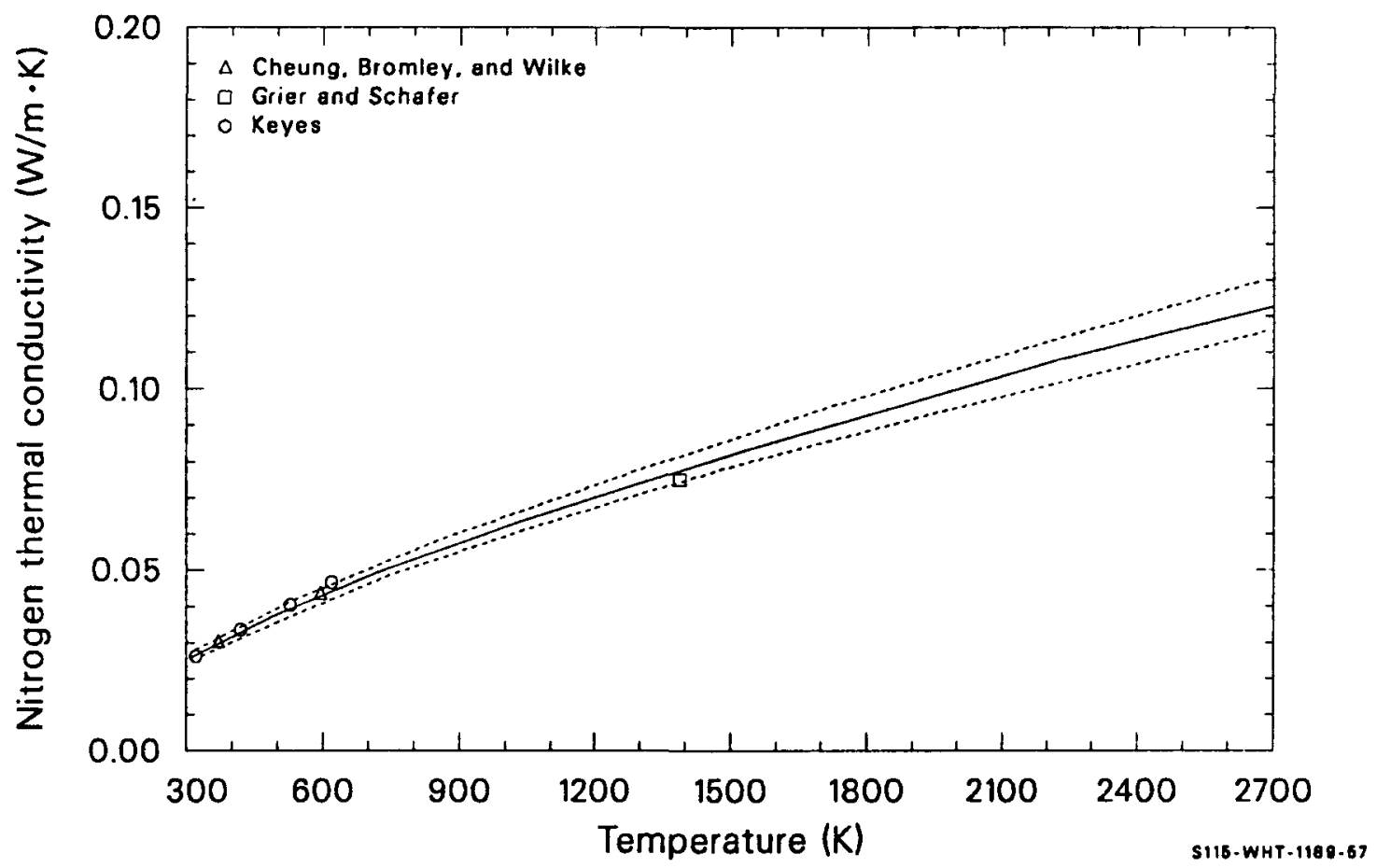

Figure 13.2-6. Thermal conductivity of nitrogen as a function of temperature. 


\section{GASCON, GTHCON, GJUMP}

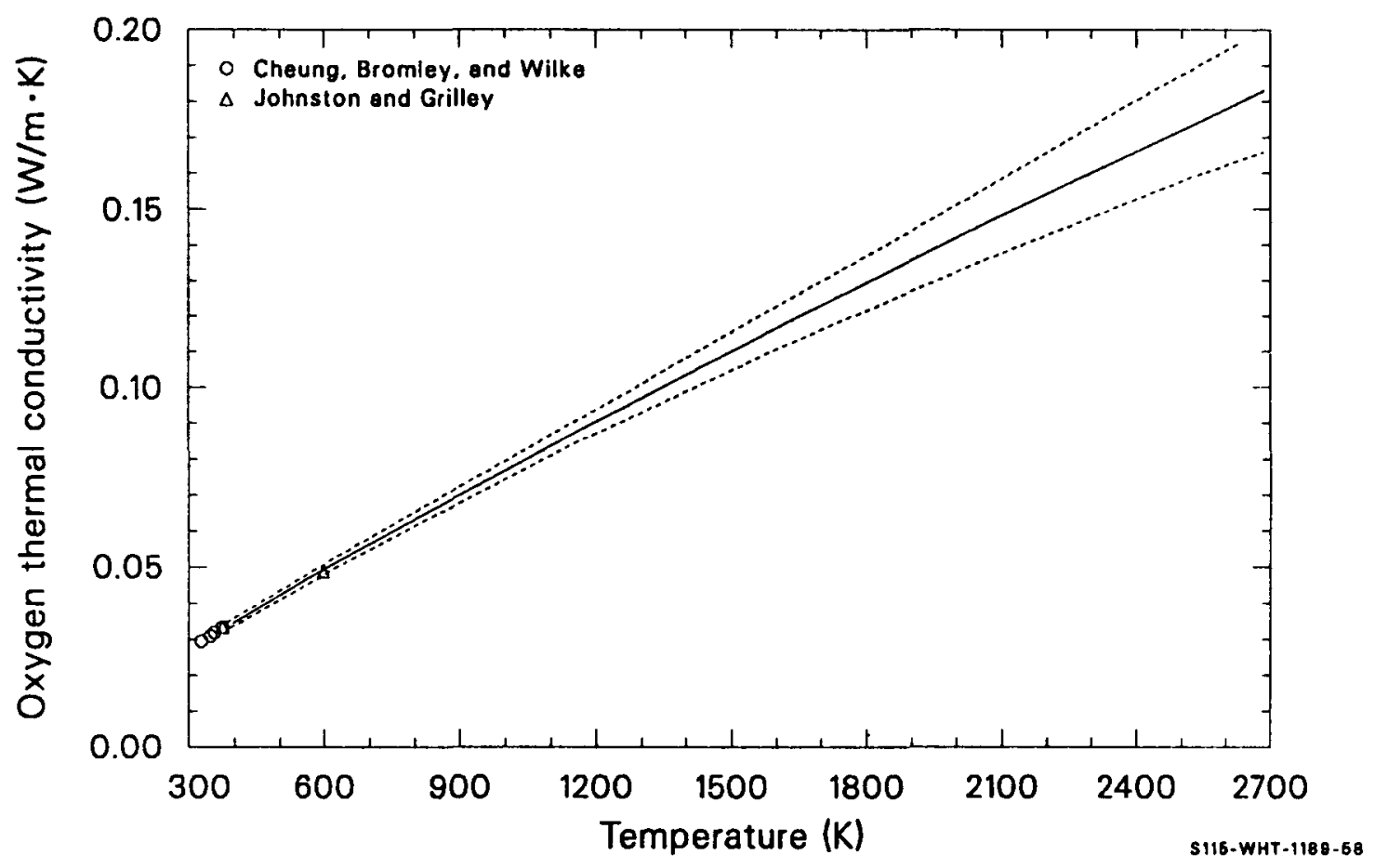

Figure 13.2-7. Thermal conductivity of oxygen as a function of temperature. 
GASCON, GTHCON, GJUMP

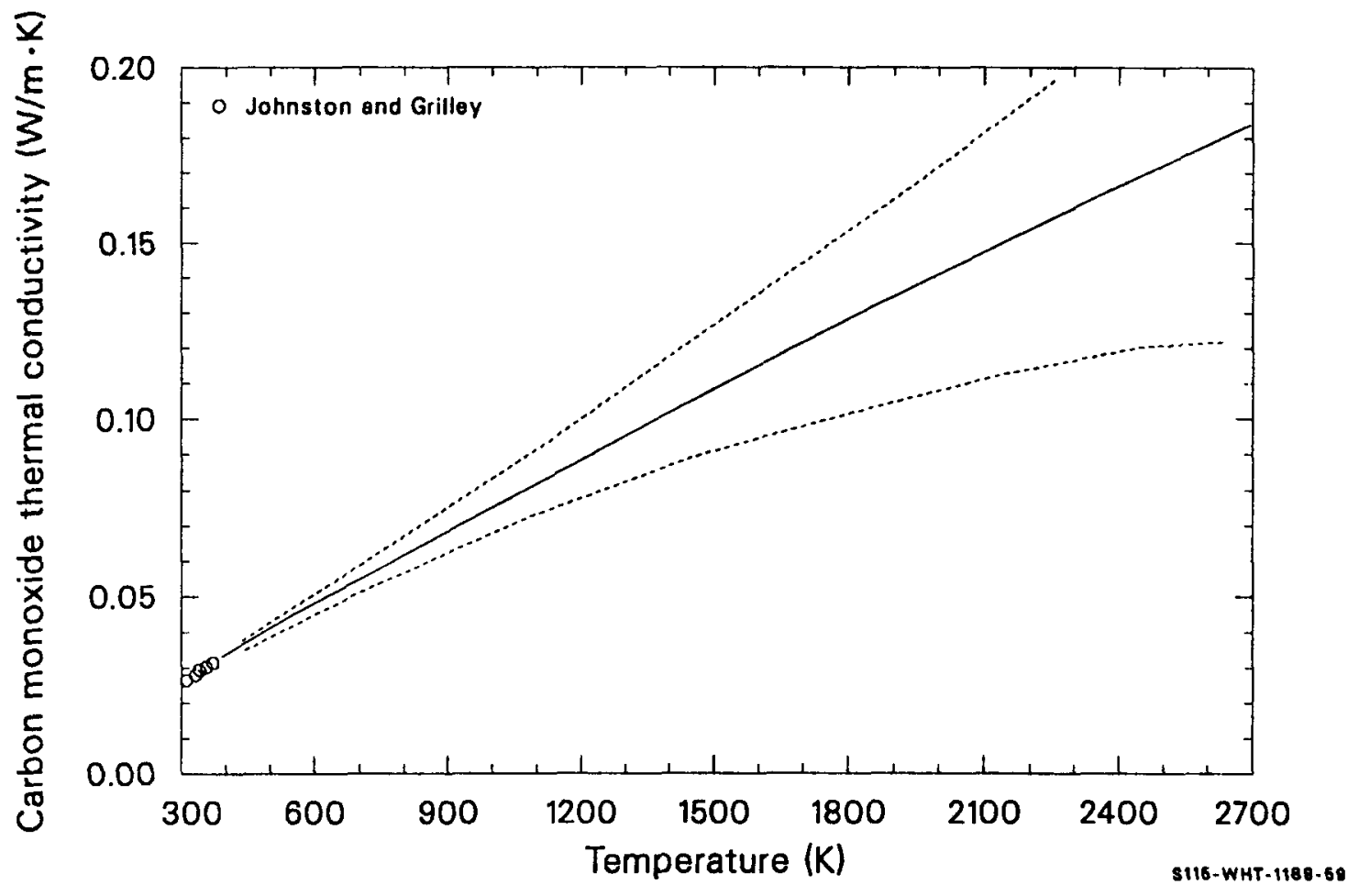

Figure 13.2-8. Thermal conductivity of carbon monoxide as a function of temperature. 
GASCON， GTHCON， GJUMP

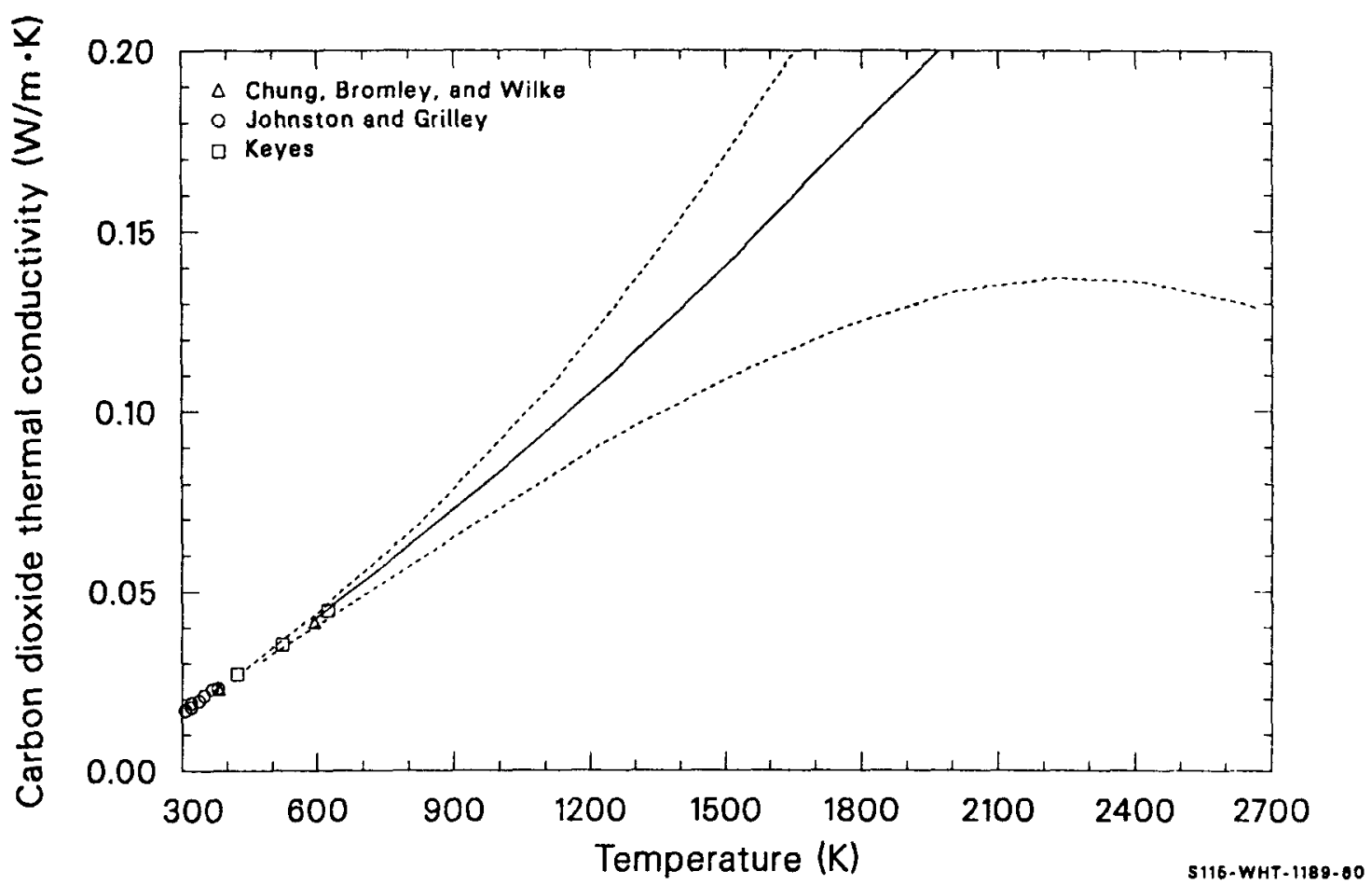

Figure 13.2-9. Thermal conductivity of carbon dioxide as a function of temperature. 


\section{GASCON, GTHCON, GJUMP}

that gives physically reasonable conductivities over the range of solid fuel temperatures.

The low-temperature part of the correlation for the thermal conductivity of steam was taken from the ASME steam tables;13.2-14 and the tolerance given in this reference, 0.06 , times the conductivity, has been adopted as the expected standard deviation.

The high-temperature part of the MATPRO correlation was taken from Tsederberg. 13.2-15 Tsedtrberg's expression was used for high temperatures because the power law he used does not become negative at high temperatures. No data were found above the 973-K limit of the ASME steam tables.

When gases are mixed, the thermal conductivity of the mixture is not simply related to the conductivities of the mixture components because the ability of each component to diffuse through the mixture is affected by the presence of all the other components. The relation between pure gas conductivities and gas mixture conductivities, Equation (13.2-5), is taken from the work of Brokaw. ${ }^{13.2-10}$ Figure 13.2-10 is a comparison of the conductivities predicted by Equation (13.2-5) to data reported by Von Ubisch ${ }^{13.2-3}$ for helium-xenon mixtures at $793 \mathrm{~K}$. The measurements show excellent agreement with the conductivities predicted by Equation (13.2-5). Although less satisfactory agreement can be expected for mixtures containing diatomic molecules that transport energy in rotational and vibrational modes, Equation (13.2-5) is adequate for fuel rod analysis because the principal gas mixture components are monatomic.

Equation (13.2-8), the expression for the conduction contribution to the conductance of a gas-filled gap, is based on kinetic theory developed by Knudsen, ${ }^{13.2-16}$ as well as the thermal conductivity correlations which have been developed. Knudsen studied low-pressure gases and pointed out that molecules striking a surface do not attain thermal equilibrium with the 
GASCON, GTHCON， GJUMP

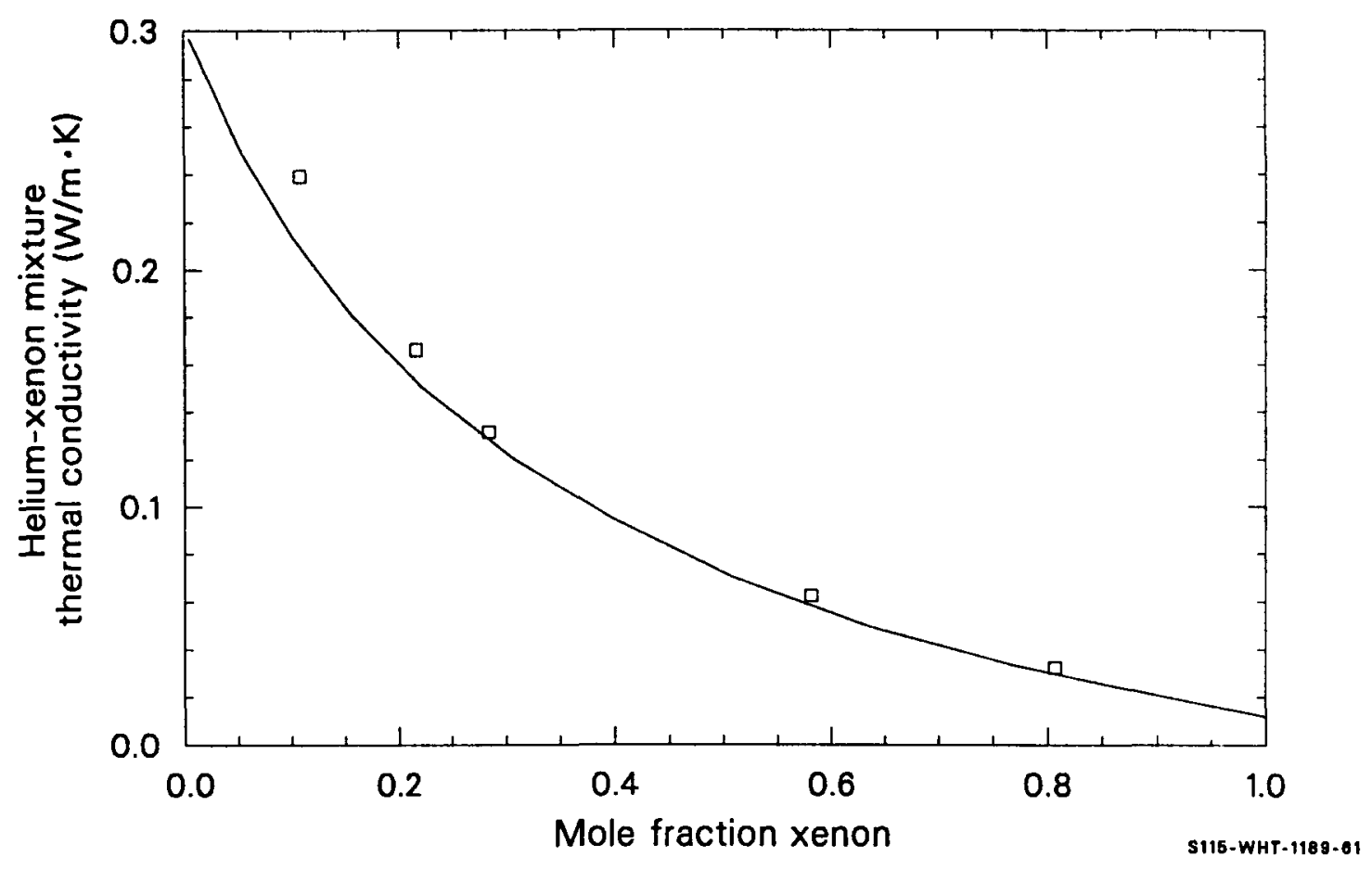

Figure 13.2-10. Thermal conductivity of helium-xenon mixtures at $793 \mathrm{~K}$. 


\section{GASCON, GTHCON, GJUMP}

surface in a single collision. The average speed and temperature of molecules that have just collided with a wall are somewhat less than the values implied by the wall temperature. Knudsen derived an expression for the power per unit area transferred from a hot surface to a cold gas

$W_{s}=\left(\frac{2 R}{\pi M T_{g}}\right)^{1 / 2} \frac{1}{4}\left(\frac{\gamma+1}{\gamma-1}\right) P\left(T_{s}-T_{g}\right) a_{s g}$

where

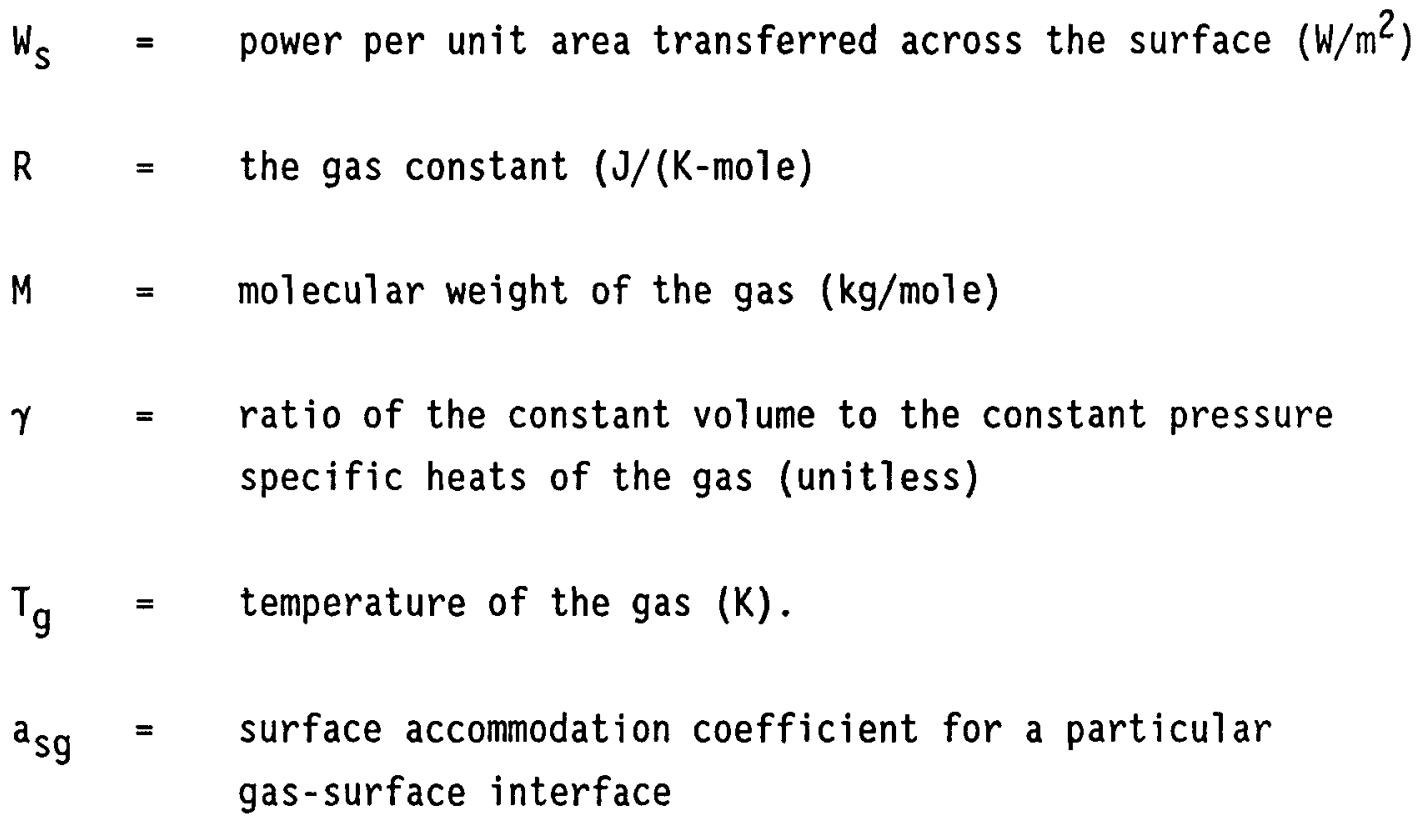

The corresponding expression for the energy transferred from a hot gas to a cold surface is

$W_{s}=\left(\frac{2 R}{\pi M T_{g}}\right)^{1 / 2} \frac{1}{4}\left(\frac{\gamma+1}{\gamma-1}\right) P\left(T_{g}-T_{s}\right)\left(\frac{a_{s g}}{1-a_{s g}}\right)$.

If the mean free path of the gas molecules is long compared to the gap width, the power per unit area transferred across the gap in steady state 


\section{GASCON, GTHCON, GJUMP}

can be found by equating the expressions for the power per unit area across the two surfaces. The resultant expression $13.2-13$ is

$W_{S S}=\left(\frac{2 R}{\pi M T_{g}}\right)^{1 / 2} \frac{1}{4}\left(\frac{\gamma+1}{\gamma-1}\right) P\left(T_{h}-T_{c}\right)\left(\frac{{ }^{a_{h g}{ }^{a} c g}}{a_{h g}+a_{c g}-a_{h g}{ }^{a} c g}\right)$

where

$W_{S S}=$ power per unit area transmitted across the gap in the steady state $\left(W / m^{2}\right)$

$\mathrm{T}_{\mathrm{h}}=$ temperature of the hot gap surface $(\mathrm{K})$

$T_{c}=$ temperature of the cold gap surface $(K)$

ahg = surface accommodation coefficient for the hot surface-gas interface (unitless).

${ }^{a_{c g}}=$ surface accommodation coefficient for the cold surface-gas interface (unitless).

Equation (13.2-16) could have been obtained less rigorously by defining a thermal impedance for each surface

$r_{S}=\Delta T / W_{S S}$

where

$r_{S}=$ thermal impedance for surfaces $S\left(K \cdot m^{2} / W\right)$

$\Delta T=$ temperature difference between the surface and gas (K) 


\section{GASCON, GTHCON, GJUMP}

and adding the two series impedances that represent the surfaces to find an effective impedance for the entire gap in the limit of mean free paths that are much longer than gap width. This thermal impedance approach has been adopted to model the conductivity of a fuel rod gap when the gas mean free path is not long compared to gap width.

Single-component gases are considered first. The expression for the power per unit area transferred across the gas is

$W_{B}=k \Delta T_{B} / t$

where

$W_{B}=$ power per unit area transferred across a region of gas $\left(W / m^{2}\right)$

$\Delta \mathrm{T}_{\mathrm{B}}=$ temperature change across the gas $(\mathrm{K})$.

The thermal impedance of the gas is

$r_{B}=1 / k$

where $r_{B}$ is the thermal impedance of gas. Summation of the series thermal impedances that represent the two surfaces and the gas bulk produces the following expression for gap impedance

$r_{\text {eff }}=\frac{t}{k}+\left(\frac{\pi M T}{2 R}\right)^{1 / 2} 4\left(\frac{\gamma-1}{\gamma+1}\right) \frac{1}{a P}$

where $r_{\text {eff }}$ is the effective impedance of a gap containing a single-component gas $\left(m^{2} K / W\right)$ and $a=a_{h g} a_{c g} /\left(a_{h g}+a_{c g}-a_{h g} a_{c g}\right)$. The gap conductance is the reciprocal of the effective impedance 
GASCON， GTHCON，GJUMP

$h=\frac{k}{t+4 \frac{k}{a P}\left(\frac{\gamma-1}{\gamma+1}\right)\left(\frac{\pi M T_{g}}{2 R}\right)^{1 / 2}}$

where $h$ is the gap conductance for a gap containing a single component gas $\left(W / m^{2} \cdot K\right)$.

Equation (13.2-21) illustrates several features of gap conductance. The surface impedance term in the denominator is not important for 7 arge gaps. For gaps of a given width, the surface impedance is large at low pressures and high temperatures. Finally, the impedance term is most important for gases with large thermal conductivities.

Equation (13.2-8) is derived with a slight generalization of the arguments just given for a single-component gas. Inspection of Equation (13.2-5), the expression for the thermal conductivity of gas mixtures, shows that the $i$-sum in the equation represents the combination of parallel impedances due to each component of the mixture. (The $j$-sum represents the modification of the scattering cross section seen by each component due to the presence of all the other components.) The arguments just given for a single-component gas can be repeated for impedance due to each component of the gas mixture. The resultant expression for the gap conductance due to the $i-t h$ component of the gas mixture is

$$
h_{i}=\frac{x_{i}}{t+\frac{4 x_{i}}{a_{i} p_{i}}\left(\frac{\gamma_{i}-1}{\gamma+1}\right)\left(\frac{\pi M_{i} T}{2 R}\right)^{1 / 2}}
$$

where

$h_{i}=$ gap conductance due to the $i-t h$ component of the gas mixture $\left(\mathrm{w} / \mathrm{m}^{2} \cdot \mathrm{K}\right)$ 
GASCON，GTHCON，GJUMP

\author{
$x_{i}=i$-th term in Equation (13.2-5) \\ $P_{\mathbf{i}}=$ partial pressure of $\boldsymbol{i}$-th component of mixture \\ $a_{\mathbf{j}}=$ value of factor a of Equation (13.2-20) for each gas \\ component and the two gap surfaces (unitless).
}

The partial pressure of the $i$-th gas component is given in terms of the mole fraction of the component and the total pressure by the idealized gas law. The relation is

$P_{j}=P X_{j}$.

Equation (13.2-8) is obtained by substituting Equation (13.2-23) into Equation (13.2-22) and combining the parallel gap conductances due to each component of the mixture.

Values of $V_{j}$ and $M_{j}$ are contained in the GTHCON subroutine. The specific heat ratios were taken from Zemansky, 13.2-17 and the molecular weights were taken from the Handbook of Chemistry and Physics.13.2-18

The surface accommodation coefficients required to use Equation $(13.2-8)$ were estimated from data and trends mentioned in Section 13.2.2. The coefficients and values of $a_{j}$ that result are listed in Table 13.2-3. The accommodation coefficients for helium on zircaloy and fuel were approximated with helium-nickel and helium glass data. Hydrogen accommodation coefficients were assumed to be approximately the same as those of helium because of the similar masses of these molecules. The accommodation coefficient for argon on zircaloy was assumed equal to the argon-tungsten coefficient. An estimate for the argon-fuel coefficient was obtained by using the ratio of argon and helium coefficients on zircaloy to multiply the helium-fuel coefficient. For heavy molecules (krypton, zenon, and carbon dioxide), White's estimate of 0.85 is used for the accommodation 


\section{GASCON, GTHCON，GJUMP}

coefficients of both fuel and zircaloy. The nitrogen-zircaloy coefficient was adopted for nitrogen, oxygen, carbon monoxide, and steam because of the similar masses of these molecules. A heavy molecule estimate of 0.85 was used for the fuel surface accommodation coefficient of the nitrogen-like group because the estimate obtained from scaling up with the zircaloy surface coefficients was greater than one.

The effective jump distance calculated by GJUMP is determined with Equations (13.2-5) and (13.2-8). The mixed gas conductivity is divided by the heat conductance for a gap with zero width and with the two-surface accommodation coefficient replaced by the single-surface accommodation coefficient.

\subsubsection{References}

13.2-1. W. G. Kannuluik and E. H. Carman, "The Thermal Conductivity of Rate Gases, "The Proceedings of the Physical Society, 65, 1952, pp. 701-709.

13.2-2. R. S. Gambhir, J. M. Gandhi, S. C. Saxena, "Thermal Conductivity of Rare Gases, Deuterium \& Air, "Indian Journal of Pure and Applied Physics, 5, 1967, pp. 457-463.

13.2-3. H. von Ubisch, "The Thermal Conductivities of Mixtures of Rare Gases at $29^{\circ} \mathrm{C}$ and at $520^{\circ} \mathrm{C}, "$ Arikiv foer Fysik, 16, 7, 1959, pp. 93-100.

13.2-4. V. K. Saxena and S. C. Saxena, "Measurement of the Thermal Conductivity of Helium Using a Hot-Wire Type of Thermal Diffusion Column, " British Journal of Applied Physics, 1, 1968, pp. $1341-1351$.

13.2-5. D. L. Timrot and E. E. Totski, "Dilatometric Method for the Experimental Determination of the Thermal Conductivity of Corrosive Gases and Vapors at High Temperatures," High Temperature, 3, 1965, pp. 685-690.

13.2-6. D. L. Timrot and A. S. Umanskii, "Investigation of the Thermal Conductivity of Helium in the Range 400-2400 K," High Temperature, $3,1965, \mathrm{pp} .345-351$. 
13.2-7. L. S. Zaitseva, "An Experimental Investigation of the Heat Conductivity of Monatomic Gases Over Wide Temperature Intervals," Soviet Physics Technical Physics, 4, 1959, pp. 444-450.

13.2-8. H. Cheung, L. A. Bromley, C. R. Wilke, "Thermal Conductivity of Gas Mixtures," AIChE Journa7, 8, 1962, pp. 221-228.

13.2-9. H. L. Johnston and E. R. Grilley, "Thermal Conductivities of Eight Common Gases between 97 and $380 \mathrm{~K}$, "Journal of Chemical Physics, 14,1946 , pp. 223-238.

13.2-10. R. S. Brokaw, "Predicting Transport Properties of Dilute Gases," IREC Process Design and Development, 8, 1969, pp. 240-253.

13.2-11. D. L. Timrot and A. S. Umanskii, "Thermal Conductivity of Hydrogen and Argon," High Temperature, 4, 1966, pp. 289-292.

13.2-12. F. G. Keyes, The Heat Conductivity, Viscosity, Specific Heat and Prandt7 Numbers for Thirteen Gases, NP-4621, 1952.

13.2-13. G. K. White, Experimental Techniques in Low-Temperature Physics, London: Oxford Press, 1959, pp. 181-183.

13.2-14. Thermodynamic and Transport Properties of Steam, New York: American Society of Mechanical Engineers, 1968.

13.2-15. N. V. Tsederberg, Thermal Conductivity of Gases and Liquids, Cambridge: The M.I.T. Press, 1965.

13.2-16. M. Knudsen, Kinetic Theory of Gases, New York: John Wiley and Sons, Inc., 1950.

13.2-17. M. W. Zemansky, Heat and Thermodynamics, New York: McGraw-Hi11 Book Company, Inc., 1957.

13.2-18. C. D. Hodgman, ed., Handbook of Cbemistry and Physics, Thirty-Eighth Edition, Chemical Rubber Publishing Co., 1956.

\subsubsection{Bibliography}

(1) A. D. Andrew and C. S. Calvert, Thermal Conductivity and Viscosity of Neon, Helium, Argon, Zenon and Their Binary Mixtures, TID-24636, April 1966.

(2) A. K. Barua, "Thermal Conductivity of Eucken-Type Factor for the Binary Mixtures $\mathrm{H}-\mathrm{He}, \mathrm{H}-\mathrm{Ne}, \mathrm{H}-\mathrm{Kr}$, and $\mathrm{H}-\mathrm{Ze}, "$ Indian Journal of Physics, 34, 4,1960 , pp. 169-183. 
GASCON, GTHCON, GJUMP

(3) R. S. Brokaw, "Estimating Thermal Conductivities for Nonpolar Gas Mixtures-Simple Empirical Method," Indian Journal of Engineering Chemistry, 47, 1955, pp. 2398-2400.

(4) R. S. Brokaw, Alignment Charts for Transport Properties, Viscosity, Thermal Conductivity, and Diffusion Coefficients for Nonpolar Gases and Gas Mixtures at Low Density, Lewis Research Center, NASA-TR-R-81, 1960.

(5) R. S. Brokaw, Approximate Formulas for Viscosity and Thermal Conductivity of Gas Mixtures, Lewis Research Center, NASA-TN-D-2502, November 1964.

(6) F. R. Campbell and R. DesHaies, "The Effect of Gas Pressure on Fuel/Sheath Heat Transfer," Transactions of the American Nuclear Society, 21, June 1975, p. 380.

(7) J. M. Davidson and J. F. Music, Experimental Thermal Conductivities of Gases and Gaseous Mixtures at Zero Degrees Centigrade, HW-29021, July 1953.

(8) R. A. Dean, Thermal Contact Conductance Between $\mathrm{UO}_{2}$ and Zircaloy-2, CVNA-127, May 1962.

(9) B. G. Dickens, "Effect of Accommodation on Heat Conduction through Gases," Proceedings of the Royal Society London, 143, February 1934, pp. 517-540.

(10) J. M. Gandhi and S. C. Saxena, "Correlated Thermal Conductivity Data of Rare Gases and Their Binary Mixtures at Ordinary Pressures, "Journal of Chemical and Engineering Data, 13, 3, 1968.

(11) W. C. Gardiner and K. L. Schafer, "Transport Phenomena in Gases and Intermolecular Forces," Zeitschrift fur Elektrochemie, 60, 1956, pp. 588-594.

(12) R. S. Hansen, R. R. Frost, J. A. Murphy, "The Thermal Conductivity of Hydrogen-Helium Mixtures," Journal of Physical Chemistry, 68, 7, 1964, pp. 2028-2029.

(13) F. G. Keyes, "Thermal Conductivity of Gases," Transactions of the American Society of Mechanical Engineers, 76, 1954, pp. 809-816.

(14) F. G. Keyes, "Thermal Conductivity of Gases," Transactions of the American Society of Mechanical Engineers, 77, 1955, pp. 899-906.

(15) W. G. Kannuluik and L. H. Martin, "Thermal Conductivity of Gases at $0^{\circ} \mathrm{C}, "$ Proceedings of the Royal Society London, 144, May 1934, pp. 496-513. 
GMISS

\subsection{Effective Emissivity (GMISS)}

(D. L. Hagrman)

The effective emissivity of a cylinder of gas is useful for calculating the approximate radiation heat transfer between a slug of effluent proceeding from a hot core region down a pipe with walls that cool the gas. Use of the effective emissivity allows the slug to be treated as an opaque source, thus avoiding the need to solve the detailed differential equations for energy transport in a nontransparent media. 13.3-1

\subsubsection{Mode1 Development}

The function GMISS calculates the effective emissivity of a cylindrical slug of gas, that is, an emissivity that can be applied as though the slug were opaque. This emissivity is a function of the gas temperature, pressure, and composition, as well as the diameter of the slug. The function accepts input mole fractions of helium, argon, krypton, xenon, hydrogen, nitrogen, oxygen, carbon monoxide, carbon dioxide, and water vapor; but the correlations used to calculate the emissivity assume that water vapor is the only nontransparent species present. Since nonsymmetrical molecules like $\mathrm{CO}_{2}$ and (probably) $\mathrm{CO}$ also absorb infrared irradiation, the current (1989) version of the function may give incorrect results when more than trace amounts of these components are present.

The correlations used to calculate the effective emissivity are based on Figures 11-28 and 11-29 of Pitts and Sissom. 13.3-2 Several steps are employed in the calculations. First, an equivalent beam path length,

$L=$ GPRES $\cdot X G M I X(10) \cdot D I A$ 


\section{GMISS}

where

$$
\begin{array}{ll}
\mathrm{L} & =\text { equivalent path length }(\mathrm{m}) \\
\text { GPRES } & =\text { gas pressure }(\mathrm{Pa})
\end{array}
$$

$X \operatorname{XMIX}(10)=$ mole fraction water vapor in the gas (kg-moles $\mathrm{H}_{2} \mathrm{O} / \mathrm{kg}$-moles gas)

DIA = diameter of effluent slug ( $m$ )

is calculated. Next, this length is used to determine coefficients for a correlation used to calculate the effective emissivity at $1.01 \mathrm{E}+05 \mathrm{~Pa}$ (one atmosphere) pressure as a function of temperature. The expressions used for the coefficients are

$$
\begin{aligned}
& a=-7.715+\ln (L)[1.016-3.339 E-02 \ln (L)] \\
& b=-3.798 E-03+\ln (L)[4.652 E-04-1.611 E-05 \ln (L)] .
\end{aligned}
$$

The expression that is used to calculate the effective emissivity at $1.01 \mathrm{E}+05 \mathrm{~Pa}$ as a function of temperature and path length is

$$
\text { EMISS }=\exp (a+b T)
$$

where

$$
\begin{aligned}
\text { EMISS } & =\text { effective emissivity of a gas slug at } 1.01 \mathrm{E}+05 \mathrm{~Pa} \\
T & =\text { temperature }(\mathrm{K}) .
\end{aligned}
$$

The final step in calculating the effective emissivity is to multiply EMISS by a factor that depends on the gas pressure, the partial pressure of water, and the equivalent path length, 
where

$$
\begin{aligned}
\text { GMISS }= & \text { effective emissivity of a gas slug } \\
\mathrm{CW} & =\begin{array}{l}
\text { factor which converts emissivity at } 1.01 \mathrm{E}+05 \mathrm{~Pa} \text { to } \\
\text { emissivity at the given pressure, GPRES. }
\end{array}
\end{aligned}
$$

Values of the factor $\mathrm{CW}$ are calculated with one of a series of second-degree polynomials that are functions of the total pressure expressed in units of two atmospheres,

$x=9.872$ E-06 GPRES $\bullet ~ 0.5$.

Table 13.3-1 lists the coefficients $c, d$, and e of the polynomial

$C W=c+d x+e x^{2}$

as a function of the equivalent path length.

\subsubsection{References}

13.3-1. R. B. Bird, W. E. Stewart, and E. N. Lightfoot, Transport Phenomena, New York: John Wiley and Sons, 1960.

13.3-2. D. R. Pitts and L. E. Sissom, Schaum's Outline of Theory and Problems of Heat Transfer, New York: McGraw-Hill Book Company, 1977. 


\section{GMISS}

Table 13.3.1. Coefficients used to calculate $\mathrm{CW}$

\begin{tabular}{|c|c|c|c|c|c|}
\hline Equivalent beam length & c & d & & e & \\
\hline$\leq 1.5438 \mathrm{E}+03$ & $1.2 \mathrm{E}-01$ & 2.0766 & $\mathrm{E}+00$ & 6.333 & $E-01$ \\
\hline $1.5438 E+03<L<1.15785 E+04$ & $2.0 \mathrm{E}-01$ & 1.8857 & $E+00$ & 5.7143 & $E-01$ \\
\hline $1.15785 E+04<L<2.3157 E+04$ & $2.7 \mathrm{E}-01$ & 1.741 & $\mathrm{E}+00$ & 5.619 & $E-01$ \\
\hline $2.3157 E+04<L<5.4033 E+04$ & $3.6 \mathrm{E}-01$ & 1.55738 & $E+00$ & 5.5476 & $E-01$ \\
\hline $5.4033 E+04<L<2.3157 E+05$ & $5.3 \mathrm{E}-01$ & 1.171 & $\mathrm{E}+00$ & 4.619 & $E-01$ \\
\hline$>2.3157 \mathrm{E}+05$ & $6.0 \mathrm{E}-01$ & 1.0024 & $E+00$ & 4.048 & $E-01$ \\
\hline
\end{tabular}




\section{GVISCO}

\subsection{VISCOSITY (GVISCO)}

(G. A. Reymann)

Viscosity is important in describing the dynamic behavior of fluids. According to kinetic theory, for a gas having a net mass motion, molecules tend to lose forward momentum due to the proximity of stationary surfaces. This loss is described in terms of a viscosity, and it is pertinent to the flow of gas in a fuel-cladding gap as well as through a cladding rupture. In particular, the rate at which gas flows into the ballooning section of a fuel rod is inversely proportional to the fill gas viscosity for narrow gaps, becoming less dependent on the gas viscosity as the gap widens and flow becomes turbulent.

\subsubsection{Mode1 Development}

Bretsznajder, 13.4-1 Bird et a1.,13.4-2 and Hirschfelder et a1.13.4-3 have discussed in detail the functional relationships for viscosity, which in summary showed dependence on temperature, pressure, and gas composition. The formulation used in the routine GVISCO was taken from Bird et al. and is

$$
\mu_{\operatorname{mix}}=\sum_{i=1}^{n} \frac{x_{j} \mu_{i}}{\sum_{j=1}^{n} x_{j} \Phi_{i j}}
$$

where

$$
\mu_{\text {mix }}=\text { viscosity of gas mixture }(\mathrm{kg} / \mathrm{m} \bullet \mathrm{s})
$$




\section{GVISCO}

$n=$ number of chemical species in the mixture

$x_{i}, x_{j}=$ the mole fractions of species $i$ and $j$

$\mu_{j}, \mu_{j}=$ the viscosities of species $i$ and $j(\mathrm{~kg} / \mathrm{m} \cdot \mathrm{s})$

and $\Phi_{i j}$ is a dimensionless parameter defined as

$\Phi_{i j}=\frac{1}{8^{1 / 2}}\left(1+\frac{M_{i}}{M_{j}}\right)^{-1 / 2}\left[1+\left(\frac{\mu_{i}}{\mu_{j}}\right)^{1 / 2}\left(\frac{M_{j}}{M_{i}}\right)^{1 / 4}\right]^{2}$

where $M_{j}, M_{j}$ are the molecular weights of species $i$ and $j(\mathrm{~kg} / \mathrm{mole})$.

The viscosity of a pure monatomic species may be expressed as

$\mu_{i}=8.4411 \times 10^{-24}\left(\frac{(M T)^{1 / 2}}{\sigma^{2} k T / \epsilon}\right)$

where

$$
\begin{aligned}
\mu_{i} & =\text { viscosity of specifies } i(\mathrm{~kg} / \mathrm{m} \cdot \mathrm{s}) \\
M & =\text { molecular weight of species }(\mathrm{kg} / \mathrm{mole}) \\
\sigma & =\text { the collision diameter }(\mathrm{m}) \\
T & =\text { absolute temperature }(\mathrm{K})
\end{aligned}
$$


GVISCO

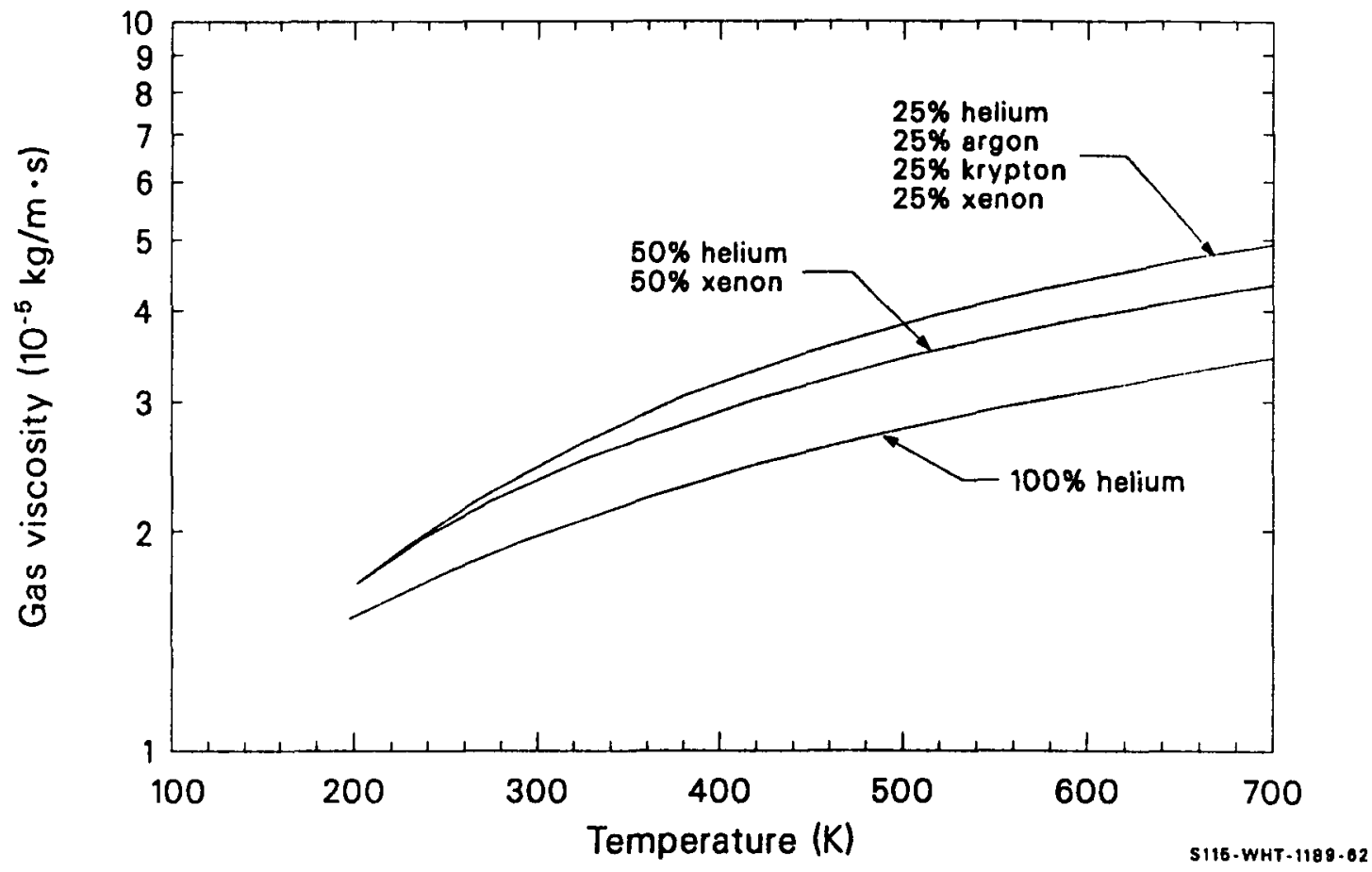

Figure 13.4-1. Gas viscosity as a function of temperature for pure helium, a binary mixture of helium and xenon, and for an equal molar mixture of helium, argon, krypton, and xenon. 


\section{GVISCO}

$\epsilon=$ the maximum energy of attraction between a pair of molecules ( $\mathrm{J} /$ molecule)

$k=$ Boltzmann's constant $=1.38 \times 10^{-23}(\mathrm{~J} / \mathrm{K})$.

Bird et a1. state that Equations (13.4-1) through (13.4-3) are useful for computing viscosities of nonpolar gases and gas mixtures at low density from their tabulated values of the intermolecular force parameters $\sigma$ and $\epsilon$. Figure 13.4-1 shows the viscosities for three different cases calculated from Equation (13.4-1): (a) helium only, (b) an equal molar mixture of helium and zenon, and (c) an equal molar mixture of helium, argon, krypton, and zenon. The routine GVISCO currently allows ten gases to be considered: helium, argon, krypton, zenon, hydrogen, nitrogen, oxygen, carbon monoxide, carbon dioxide, and steam. Additional nonpolar gases may be readily added to GVISCO if desired.

The viscosity of steam, $\mu_{S}$, is taken from Meyer et at. 13.4-4

$\mu_{S}=(0.407 \mathrm{~T}-30.8) \times 10^{-7}$

where

$$
\begin{aligned}
\mu_{\mathrm{S}} & =\text { viscosity of steam }(\mathrm{kg} / \mathrm{m} \cdot \mathrm{s}) \\
T & =\text { temperature }(\mathrm{K}) .
\end{aligned}
$$

A density correction could be applied, but examination of tabular data indicates the correction is small at typical fuel rod temperatures.

\subsubsection{References}

13.4-1. S. Bretsznajder, Prediction of Transport and Other Physical Properties of Fluids, New York: Pergamon Press, 1971. 


\section{GVISCO}

13.4-2. R. B. Bird, W. E. Stewart, E. N. Lightfoot, Transport Phenomena, New York: John Wiley and Sons, Inc., 1954.

13.4-3. J. 0. Hirschfelder, C. F. Curtiss, R. B. Bird, Molecular Theory of Gases and Liquids, New York: John Wiley and Sons, Inc., 1954.

13.4-4. C. A. Meyer et al., Thermodynamic and Transport Properties of Steam, New York: The American Society of Mechanical Engineers, 1967. 


\section{GMFP}

\subsection{Mean free Path (GMFP)}

(D. L. Hagrman)

\subsubsection{Model Development}

The mean free path of gas molecules is required to calculate the rate of deposit of aerosol particles due to thermophoresis. The function GMFP calculates an approximate mean free path based on the one-component ideal gas result for viscosity and the viscosity returned by the GVISCO function. 13.5 .1

$\mu=\frac{1}{3} \rho \frac{8 \mathrm{R}}{\pi m \omega t} T^{1 / 2} \lambda$

where

$$
\begin{aligned}
& \mu \quad=\text { gas viscosity }[\mathrm{kg} /(\mathrm{m} \bullet \mathrm{s})] \\
& \rho \quad=\text { the gas density }\left(\mathrm{kg} / \mathrm{m}^{3}\right) \\
& \mathrm{R}=\text { the gas constant, } 8.31410^{3} \mathrm{~kg}-\mathrm{m}^{2} /(\mathrm{s} \bullet \mathrm{kg}-\mathrm{mole} \cdot \mathrm{K}) \\
& \mathrm{T}=\text { the gas temperature }(\mathrm{K}) \\
& \mathrm{mwt}=\text { kg-mole weight (mass) of the gas } \\
& \lambda \quad=\text { mean free path of gas molecules }(\mathrm{m}) .
\end{aligned}
$$

The result is generalized to an approximate expression for mixtures by using a mole-fraction weighted average of the $\mathrm{kg}$-mole weight factor in the expression for the mean free path, 
GMFP

$\lambda=\frac{\mu 3}{\rho}\left(\frac{\pi}{8 R T}\right)^{1 / 2} \sum_{k=1}^{10} X \operatorname{XGIX}(k)[\operatorname{mwt}(k)]^{1 / 2}$

where

$$
\begin{aligned}
\operatorname{XGMIX}(k)= & \begin{array}{l}
\text { mole fraction of the } \mathrm{k} \text {-th gas component (kg-moles } \mathrm{k} \text {-th } \\
\text { component/kg-moles of all components) }
\end{array} \\
\operatorname{mwt}(\mathrm{k})= & \begin{array}{l}
\mathrm{kg}-\mathrm{mole} \text { weight (mass) of } \mathrm{k} \text {-th mixture component } \\
(\mathrm{kg} / \mathrm{kg}-\mathrm{mole}) .
\end{array}
\end{aligned}
$$

13.5-2. Reference

13.5-1. R. B. Bird, W. E. Stewart, and E. N. Lightfoot, Transport Phenomena, New York: John Wiley and Sons, 1960, pp. 20-21. 


\section{GASES--I/I2, CESIUM IODIDE, CESIUM HYDROXIDE, TELLURIUM, CADMIUM, SILVER, H2TE, HI, TIN, TIN TELLURIDE, WATER, ZIRCONIUM DIOXIDE, URANIUM DIOXIDE, $C / C_{2} / \ldots C_{6}$, SILVER IODIDE}

Equilibrium vapor concentrations must be known to calculate the rate of evaporation or condensation of various species onto fixed surfaces or aerosols to model the formation of an aerosol from the vapor in the event that there is no preexisting seed. The subcode GCEQ, described in this section, contains correlations for equilibrium vapor pressure and concentration for iodine, cesium iodide, and cesium hydroxide. 


\title{
14.1 Eouilibrium Vapor Concentrations (GCEQ)
}

\author{
(K. A. McNeil, D. L. Hagrman, J. K. Hohorst)
}

\subsubsection{Introduction}

A computer subroutine (GCEQ) is described that calculates the equilibrium vapor pressures and concentrations of many fission product species.

The vapor pressures of iodine, cesium iodide, and cesium hydroxide have been researched; and correlations suitable for use in this subroutine are presented. A detailed summary of the vapor pressure correlations used, the expressions used to convert the vapor pressures to concentrations, and the expression used to calculate the equilibrium vapor concentrations above a solution of cesium iodide-cesium hydroxide is presented in Section 14.1.2.

The new iodine and cesium iodide correlations do not differ greatly from the collection of previously published correlations; the difference is typically 0.1 to 0.5 times the calculated values. However, these new correlations have the advantage of being efficient, containing greatly reduced discontinuities at the melt temperature, and being supported by referenced data. The solution behavior of cesium iodide-cesium hydroxide is often significant for the minority species, usually cesium iodide. For example, the calculated equilibrium vapor concentration of cesium iodide over a mixture consisting of 0.1 mole fraction cesium iodide and 0.9 mole fraction cesium hydroxide is two or three orders of magnitude smaller than the equilibrium concentration over pure cesium iodide. Evaporation of the minority cesium iodide species is thus effectively delayed until the majority species is vaporized. 
GCEQ

The available data and correlations are discussed in Section 14.1.3. Section 14.1.4 is a discussion of the techniques used to derive the models from the available data and correlations. Examples of the results of equilibrium concentrations are also available in Section 14.1.5.

\subsubsection{Summary of Equations Used to Calculate Equilibrium Vapor Pressures and Concentrations}

14.1.2.1 Equilibrium Vapor Pressures of Pure Species. With the exception of water, equilibrium vapor pressures over a surface of the $i$-th species at a reference system pressure are calculated with an expression of the form

$\ln \left(P_{i}\right)=A_{i} T^{-1}+B_{i}+C_{j} \log (T)+D_{i} T$

where

$$
\begin{aligned}
& \mathrm{P}_{\mathbf{i}} \quad \begin{array}{l}
\text { partial pressure of vapor of } i \text {-th species at the } \\
\text { reference pressure }(\mathrm{Pa}) \text { (equilibrium vapor pressure in } \\
\text { a confined volume) }
\end{array} \\
& \quad=\quad \text { temperature }(K) \\
& A_{j} \text { to } D_{i}=\text { constants for the } i \text {-th species. }
\end{aligned}
$$

Table 14.1-1 lists the constants employed in Equation (14.1-1) for the different species.

A more complex expression is used to calculate the equilibrium vapor pressure of water. The expression used for temperatures less than the critical temperature, $647.2 \mathrm{~K}$, is 
Table 14.1-1. Values of constants used in Equation (14.1-1)

\begin{tabular}{|c|c|c|c|c|c|}
\hline Species & $\begin{array}{c}\text { Temperature } \\
\text { Range }\end{array}$ & A & B & $c$ & $D$ \\
\hline Iodine ${ }^{a}$ & $\begin{array}{l}387 \\
387<T<785 \\
>785\end{array}$ & $\begin{array}{l}-7.722 E+03 \\
-5.213 E+03 \\
\text { limited to }\end{array}$ & $\begin{array}{c}29.38 \\
22.89 \\
\text { concentrat }\end{array}$ & $\begin{array}{l}0 \\
0 \\
\text { tion at } 785\end{array}$ & $\begin{array}{l}0 \\
0 \\
K\end{array}$ \\
\hline Cesium iodide ${ }^{a}$ & $\begin{array}{r}894 \\
>894\end{array}$ & $\begin{array}{l}-2.386 E+04 \\
-1.553 E+04\end{array}$ & $\begin{array}{l}29.70 \\
20.38\end{array}$ & $\begin{array}{l}0 \\
0\end{array}$ & $\begin{array}{l}0 \\
0\end{array}$ \\
\hline Cesium hydroxide & $>545.45$ & $-1.54 E+04$ & 22.8 & 0 & 0 \\
\hline Tellurium & $\begin{array}{r}723 \\
>723\end{array}$ & $\begin{array}{l}-2.15 E+04 \\
-1.84 E+04\end{array}$ & $\begin{array}{l}50.6 \\
56.9\end{array}$ & $\begin{array}{l}-6.24 \\
-9.95\end{array}$ & $\begin{array}{l}0 \\
0\end{array}$ \\
\hline Cadmium & $>313.15$ & $-1.42 E+04$ & 38.5 & -4.42 & 0 \\
\hline Silver & 1241.95 & $-3.69 E+04$ & 50.3 & 0 & 0 \\
\hline Hydrogen telluride & $\begin{array}{l}222.15<T<484 \\
>484\end{array}$ & $\begin{array}{l}-3.50 E+02 \\
\text { limited to }\end{array}$ & $\begin{array}{c}-13.21 \\
\text { concentrat }\end{array}$ & $\begin{array}{l}8.035 \\
\text { tion at } 484\end{array}$ & $\begin{array}{l}0 \\
k\end{array}$ \\
\hline Hydrogen iodide & $\begin{array}{l}222.35<T<484 \\
>484\end{array}$ & $\begin{array}{l}-9.44 E+02 \\
\text { limited to }\end{array}$ & $\begin{array}{c}8.527 \\
\text { concentrat }\end{array}$ & $\begin{array}{c}0.2358 \\
\text { tion at } 484\end{array}$ & $\begin{array}{l}0 \\
K\end{array}$ \\
\hline Tin & & $-2.40 E+04$ & -14.31 & 10.47 & 0 \\
\hline Tin telluride & $\begin{array}{r}1079.15 \\
>1079.15\end{array}$ & $\begin{array}{l}-2.3467 E+04 \\
-1.8055 E+04\end{array}$ & $\begin{array}{l}26.50 \\
21.3\end{array}$ & $\begin{array}{l}0 \\
0\end{array}$ & $\begin{array}{l}0 \\
0\end{array}$ \\
\hline Zirconium dioxide & $\begin{array}{r}2973 \\
>2973\end{array}$ & $\begin{array}{l}-9.1592 E+04 \\
-7.0445 E+04\end{array}$ & $\begin{array}{l}56.889 \\
20.184\end{array}$ & $\begin{array}{l}-8.2824 \\
0\end{array}$ & $\begin{array}{l}0 \\
0\end{array}$ \\
\hline Uranium dioxide & $<3113.15$ & $-2.5768 E+04$ & -159.279 & -52.983 & $-3.039 E-03$ \\
\hline Carbon & a11 & $-9.4374 E+04$ & 107.8 & -24.3925 & $3.572 \mathrm{E}-03$ \\
\hline \multicolumn{6}{|c|}{$\begin{array}{l}\text { a. The constants shown in this table have been rounded off. Additional } \\
\text { decimal places are carried in the computer coding to minimize the } \\
\text { discontinuities at the melt temperatures. }\end{array}$} \\
\hline
\end{tabular}


GCEQ

$$
\begin{aligned}
P_{i} & =221.55 E+5 \exp \left[\frac { 6 4 7 . 2 } { T } \left\{\left[-7.691\left(1-\frac{T}{647.2}\right)-26.08\left(1-\frac{T}{647.2}\right)^{2}\right.\right.\right. \\
& \left.-1.682 E+2\left(1-\frac{T}{647.2}\right)^{3}+64.32\left(1-\frac{T}{647.2}\right)^{4}-119.0\left(1-\frac{T}{647.2}\right)^{5}\right] \\
& \left./\left[1.0+4.167\left(1-\frac{T}{647.2}\right)+20.98\left(1-\frac{T}{647.2}\right)^{2}\right]\right\} \\
& \left.-\left(1-\frac{T}{647.2}\right) /\left[1.0 E+9\left(1-\frac{T}{647.2}\right)^{2}+6.0\right]\right]
\end{aligned}
$$

If the temperature is above $647.2 \mathrm{~K}, \mathrm{P}_{j}$ is limited to its value at $647.2 \mathrm{~K}, 221.55 \times 10^{5} \mathrm{~Pa}$.

The partial pressures, $P_{i}$, at a particular system pressure, $P$, are related to partial pressures at a reference pressure with another approximation based on van der Waals equation of state

$\ln \left[\frac{P_{j}(P)}{P_{i}\left(P_{0}\right)}\right] \approx \frac{b_{i}}{R T}\left(P-P_{0}\right)$

where

$$
\begin{aligned}
& P=\text { system pressure }(\mathrm{Pa}) \\
& P_{0}=\text { reference pressure }(\mathrm{Pa}) \\
& T=\text { temperature }(\mathrm{K}) \\
& \mathrm{R}=\text { gas } 1 \text { aw constant, } 8.3144 \times 10^{3} \mathrm{~m} /(\mathrm{s} \cdot \mathrm{kg}-\mathrm{mole} \cdot \mathrm{K}) \\
& \mathrm{b}_{\mathbf{i}}=\quad \begin{array}{l}
\text { van der Waals constant } \mathrm{related} \text { to the hard sphere size of the } \\
\text { i-th species molecules }\left(\mathrm{m}^{3} / \mathrm{kg} \text {-mole }\right) .
\end{array}
\end{aligned}
$$

Table 14.1-2 is a list of the values of $b_{j}$ and $M_{j}$ used for the species considered. 
Table 14.1-2. Van der Waals constants and molar masses

\begin{tabular}{|c|c|c|}
\hline Species & $\frac{\left.\mathrm{cm}^{3} / \mathrm{kg}-\mathrm{mole}\right)}{\mathrm{b}_{\mathrm{i}}}$ & $\begin{array}{c}M_{i} \\
(\mathrm{~kg} / \mathrm{kg}-\mathrm{mole})\end{array}$ \\
\hline Iodine & $5.15 E-02$ & 254 \\
\hline Cesium iodide & $5.16 \mathrm{E}-02$ & 260 \\
\hline Cesium hydroxide & $4.08 \mathrm{E}-02$ & 150 \\
\hline Tellurium & $2.04 \mathrm{E}-02$ & 128 \\
\hline Cadmium & $1.30 \mathrm{E}-02$ & 112 \\
\hline Silver & $1.03 \mathrm{E}-02$ & 108 \\
\hline Strontium hydroxide & $3.34 \mathrm{E}-02$ & 121 \\
\hline Barium hydroxide & $7.84 \mathrm{E}-02$ & 171 \\
\hline Hydrogen telluride & $5.06 E-02$ & 130 \\
\hline Hydrogen iodide & $4.49 E-02$ & 128 \\
\hline Tin & $1.63 \mathrm{E}-02$ & 119 \\
\hline Tin telluride & $3.81 E-02$ & 247 \\
\hline Water & $1.80 \mathrm{E}-02$ & 18 \\
\hline Zirconium & $2.21 \mathrm{E}-01$ & 91 \\
\hline Uranium & $2.46 \mathrm{E}-02$ & 270 \\
\hline Zirconium dioxide & $5.31 E-02$ & 123 \\
\hline Carbon & $1.00 \mathrm{E}-02$ & 12 \\
\hline Strontium oxide & To be determined & 120 \\
\hline Cesium oxide & To be determined & 282 \\
\hline Orthoboric acid & To be determined & 62 \\
\hline Metaboric acid & To be determined & 44 \\
\hline Boric oxide & To be determined & 70 \\
\hline Cesium borate & To be determined & 176 \\
\hline
\end{tabular}




\section{GCEO}

14.1.2.2 Equilibrium Vapor Concentrations of Pure Species. In a11 of the models, an approximation based on van der Waals' equation of state for a gas is used to convert equilibrium pressures to equilibrium concentrations.

$c_{i}=\frac{M_{i} P_{i}}{R T+b_{j} P}$

where

$c_{i}=$ equilibrium vapor concentration for the $i$-th species $\left(\mathrm{kg} / \mathrm{m}^{3}\right)$

$M_{j}=k i l o g r a m$ molecular weight (mass) of the $i$-th species $(\mathrm{kg} / \mathrm{kg} \cdot \mathrm{mole})$.

14.1.2.3 Effect of Surface Interactions. When more than one species condense at a common location, a solution is formed; and each species affects the other's equilibrium vapor pressure and concentration. At present, the only surface interactions considered are those of cesium iodide-cesium hydroxide mixtures and silver-indium-cadmium alloy.

For a cesium iodide-cesium hydroxide mixture, the equilibrium pressure and concentration of each species is modified by the factor

$F=f \exp \left[-\frac{3984(1-f)}{T}\right]$

where

$\mathrm{F}=$ factor by which the equilibrium pressure or concentration of cesium iodide or cesium hydroxide is multiplied to account for condensation at a common location 
$f=$ mole fraction of the species whose equilibrium pressure or concentration is calculated, moles of species $i$ /(moles of cesium iodide + moles of cesium hydroxide). For computational efficiency, $f$ is constrained to be at least 0.01 in the computer subcode.

For silver-indium-cadmium alloy, the equilibrium pressure and concentration of each component is modified by a factor equal to the mole fraction of the component in the condensed alloy. It is presumed that alloy composition variations are not significant over the surface considered and that the alloy forms an ideal solution. A preliminary study by Powers ${ }^{14.1-1}$ has concluded that the alloy is not actually ideal. The results of Power's study are to be added at a later date.

\subsubsection{Available Data and Correlations}

The following subsections discuss only iodine, cesium iodide, and cesium hydroxide correlation model development. Correlations for the remaining species in the GCEQ subcode are taken directly from the literature of available data.

14.1.3.1 Iodine. Many of the measurements of the equilibrium vapor pressure of iodine over a solid or liquid surface of the element are from the nineteenth century and are difficult to locate. More recent data tend to be for low pressures and temperatures. No data for temperatures from the boiling temperature, $457.5 \mathrm{~K},{ }^{14.1-2}$ to the critical temperature, $785 \mathrm{~K},{ }^{14.1-3}$ have been located. Table $14.1-3$ is a summary of measurements by Ramsay and Young. 14.1-4 Data from Baxter, Hickey, and Holmes ${ }^{14.1-5}$ are listed in Table 14.1-4, and more recent measurements by Stern and Gregory ${ }^{14.1-6}$ are presented in Table 14.1-5.

Figure 14.1-1 is a comparison of the vapor pressure values calculated by several correlations that are available in the literature to the data 
GCEO

Table 14.1-3. Vapor pressure of iodine measured by Ramsay and

\begin{tabular}{|c|c|c|c|c|c|}
\hline $\begin{array}{c}\text { Temperature } \\
(\mathrm{K})\end{array}$ & $\begin{array}{l}\text { Pressure } \\
(\mathrm{Pa})\end{array}$ & $\underline{\text { State }}$ & $\begin{array}{c}\text { Temperature } \\
\text { (K) }\end{array}$ & $\begin{array}{l}\text { Pressure } \\
(\mathrm{Pa})\end{array}$ & State \\
\hline $\begin{array}{l}331.3 \\
337.7 \\
339.5 \\
348.4 \\
353.6\end{array}$ & $\begin{array}{ll}6.5 & E+02 \\
8.07 & E+02 \\
8.33 & E+02 \\
1.53 & E+03 \\
2.020 E+03\end{array}$ & $\begin{array}{l}\text { Solid } \\
\text { Solid } \\
\text { Solid } \\
\text { Solid } \\
\text { Solid }\end{array}$ & $\begin{array}{l}407.6 \\
421.0 \\
431.6 \\
432.1 \\
440.4\end{array}$ & $\begin{array}{l}2.406 E+04 \\
3.642 E+04 \\
4.994 E+04 \\
5.013 E+04 \\
6.341 E+04\end{array}$ & $\begin{array}{l}\text { Liquid } \\
\text { Liquid } \\
\text { Liquid } \\
\text { Liquid } \\
\text { Liquid }\end{array}$ \\
\hline $\begin{array}{l}359.2 \\
365.0 \\
365.1 \\
370.0 \\
375.9\end{array}$ & $\begin{array}{l}2.833 E+03 \\
3.860 E+03 \\
3.95 E+03 \\
5.04 E+03 \\
6.753 E+03\end{array}$ & $\begin{array}{l}\text { Solid } \\
\text { Solid } \\
\text { Solid } \\
\text { Solid } \\
\text { Solid }\end{array}$ & $\begin{array}{l}447.6 \\
451.1 \\
454.0 \\
407.7 \\
411.8\end{array}$ & $\begin{array}{l}7.657 E+04 \\
8.343 E+04 \\
9.054 E+04 \\
2.398 E+04 \\
2.822 E+04\end{array}$ & $\begin{array}{l}\text { Liquid } \\
\text { Liquid } \\
\text { Liquid } \\
\text { Liquid } \\
\text { Liquid }\end{array}$ \\
\hline $\begin{array}{l}378.9 \\
387.0 \\
387.3 \\
388.1 \\
391.0\end{array}$ & $\begin{array}{l}7.979 E+03 \\
1.16 E+04 \\
1.20 E+04 \\
1.247 E+04 \\
1.373 E+04\end{array}$ & $\begin{array}{l}\text { Solid } \\
\text { Solid } \\
\text { Liquid } \\
\text { Liquid } \\
\text { Liquid }\end{array}$ & $\begin{array}{l}414.3 \\
416.2 \\
420.9 \\
423.4 \\
423.9\end{array}$ & $\begin{array}{l}3.028 E+04 \\
3.213 E+04 \\
3.640 E+04 \\
4.005 E+04 \\
4.032 E+04\end{array}$ & $\begin{array}{l}\text { Liquid } \\
\text { Liquid } \\
\text { Liquid } \\
\text { Liquid } \\
\text { Liquid }\end{array}$ \\
\hline $\begin{array}{l}393.6 \\
396.3 \\
398.7 \\
400.3 \\
439.8\end{array}$ & $\begin{array}{l}1.512 E+04 \\
1.660 E+04 \\
1.811 E+04 \\
1.905 E+04 \\
6.333 E+04\end{array}$ & $\begin{array}{l}\text { Liquid } \\
\text { Liquid } \\
\text { Liquid } \\
\text { Liquid } \\
\text { Liquid }\end{array}$ & $\begin{array}{l}424.8 \\
426.4 \\
426.8 \\
429.4 \\
429.7\end{array}$ & $\begin{array}{l}4.070 E+04 \\
4.282 E+04 \\
4.306 E+04 \\
4.544 E+04 \\
4.589 E+04\end{array}$ & $\begin{array}{l}\text { Liquid } \\
\text { Liquid } \\
\text { Liquid } \\
\text { Liquid } \\
\text { Liquid }\end{array}$ \\
\hline $\begin{array}{l}442.6 \\
444.9 \\
447.7 \\
450.8 \\
450.9\end{array}$ & $\begin{array}{l}6.739 E+04 \\
7.141 E+04 \\
7.670 E+04 \\
8.403 E+04 \\
8.451 E+04\end{array}$ & $\begin{array}{l}\text { Liquid } \\
\text { Liquid } \\
\text { Liquid } \\
\text { Liquid } \\
\text { Liquid }\end{array}$ & $\begin{array}{l}429.8 \\
432.1 \\
432.8 \\
433.6 \\
433.9\end{array}$ & $\begin{array}{l}4.614 E+04 \\
4.921 E+04 \\
5.136 E+04 \\
5.277 E+04 \\
5.320 E+04\end{array}$ & $\begin{array}{l}\text { Liquid } \\
\text { Liquid } \\
\text { Liquid } \\
\text { Liquid } \\
\text { Liquid }\end{array}$ \\
\hline $\begin{array}{l}453.9 \\
458.8 \\
378.8 \\
381.6 \\
384.8\end{array}$ & $\begin{array}{l}9.073 E+04 \\
1.019 E+05 \\
8.24 E+03 \\
9.41 E+03 \\
1.05 E+04\end{array}$ & $\begin{array}{l}\text { Liquid } \\
\text { Liquid } \\
\text { Solid } \\
\text { Solid } \\
\text { Solid }\end{array}$ & $\begin{array}{l}436.4 \\
439.0 \\
441.2 \\
441.4 \\
445.1\end{array}$ & $\begin{array}{l}5.678 E+04 \\
6.091 E+04 \\
6.487 E+04 \\
6.514 E+04 \\
7.150 E+04\end{array}$ & $\begin{array}{l}\text { Liquid } \\
\text { Liquid } \\
\text { Liquid } \\
\text { Liquid } \\
\text { Liquid }\end{array}$ \\
\hline $\begin{array}{l}387.4 \\
400.6 \\
403.3\end{array}$ & $\begin{array}{l}1.21 \quad E+04 \\
1.908 E+04 \\
2.097 E+04\end{array}$ & $\begin{array}{l}\text { Solid } \\
\text { Liquid } \\
\text { Liquid }\end{array}$ & $\begin{array}{l}447.4 \\
448.2 \\
448.5\end{array}$ & $\begin{array}{l}7.745 E+04 \\
7.783 E+04 \\
7.823 E+04\end{array}$ & $\begin{array}{l}\text { Liquid } \\
\text { Liquid } \\
\text { Liquid }\end{array}$ \\
\hline
\end{tabular}


GCEO

Table 14.1-4. Vapor pressure of iodine measured by Baxter et a1.14.1-5

\begin{tabular}{cl}
\hline $\begin{array}{c}\text { Temperature } \\
(\mathrm{K})\end{array}$ & \multicolumn{1}{c}{$\begin{array}{c}\text { Pressure } \\
(\mathrm{Pa})\end{array}$} \\
273.2 & 4.000 \\
288.2 & $1.747 \mathrm{E}+01$ \\
298.2 & $4.066 \mathrm{E}+01$ \\
303.2 & $6.253 \mathrm{E}+01$ \\
308.2 & $9.319 \mathrm{E}+01$ \\
313.2 & $1.367 \mathrm{E}+02$ \\
318.2 & $1.997 \mathrm{E}+02$ \\
323.2 & $2.872 \mathrm{E}+02$ \\
328.2 & $4.112 \mathrm{E}+02$ \\
\hline
\end{tabular}

14.1-9 


\section{GCEQ}

Table 14.1-5. Vapor pressuge of iodine measured by Stern and
Gregory

\begin{tabular}{|c|c|c|c|}
\hline $\begin{array}{l}\text { Temperature } \\
\text { (K) }\end{array}$ & $\begin{array}{c}\text { Pressure } \\
(\mathrm{Pa}) \\
\end{array}$ & $\begin{array}{c}\text { Temperature } \\
\text { (K) }\end{array}$ & $\begin{array}{l}\text { Pressure } \\
(\mathrm{Pa}) \\
\end{array}$ \\
\hline $\begin{array}{l}278.2 \\
278.0 \\
273.2 \\
256.7 \\
316.6\end{array}$ & $\begin{array}{l}7.6 \\
7.31 \\
4.25 \\
7.06 \mathrm{E}-01 \\
9.18 \mathrm{E}+01\end{array}$ & $\begin{array}{l}273.2 \\
260.0 \\
251.7 \\
249.7 \\
242.2\end{array}$ & $\begin{array}{l}2.05 \\
5.23 E-01 \\
1.95 E-01 \\
1.67 E-01 \\
6.81 E-01\end{array}$ \\
\hline $\begin{array}{l}308.2 \\
298.4 \\
288.0 \\
288.0 \\
278.2\end{array}$ & $\begin{array}{l}6.26 \mathrm{E}+01 \\
3.61 \mathrm{E}+01 \\
1.60 \mathrm{E}+01 \\
1.06 \mathrm{E}+01 \\
5.98\end{array}$ & $\begin{array}{l}235.4 \\
235.2 \\
231.2 \\
230.2 \\
228.7\end{array}$ & $\begin{array}{l}2.96 E-02 \\
3.14 E-02 \\
1.21 E-02 \\
8.90 E-03 \\
1.45 E-02\end{array}$ \\
\hline $\begin{array}{l}273.2 \\
249.6 \\
273.2 \\
259.4 \\
242.6\end{array}$ & $\begin{array}{l}4.08 \\
2.71 E-01 \\
3.88 \\
8.31 E-01 \\
1.10 E-01\end{array}$ & $\begin{array}{l}228.3 \\
228.2 \\
227.7 \\
221.2 \\
219.7\end{array}$ & $\begin{array}{l}1.20 \mathrm{E}-02 \\
9.88 \mathrm{E}-03 \\
1.17 \mathrm{E}-02 \\
5.12 \mathrm{E}-03 \\
2.90 \mathrm{E}-03\end{array}$ \\
\hline $\begin{array}{l}227.2 \\
223.2 \\
273.2 \\
255.2 \\
253.2\end{array}$ & $\begin{array}{l}1.50 \mathrm{E}-02 \\
7.74 \mathrm{E}-03 \\
3.44 \\
4.49 \mathrm{E}-01 \\
4.03 \mathrm{E}-01\end{array}$ & $\begin{array}{l}218.6 \\
325.2 \\
319.0 \\
315.2 \\
310.2\end{array}$ & $\begin{array}{l}2.67 \mathrm{E}-03 \\
3.00 \mathrm{E}+02 \\
2.04 \mathrm{E}+02 \\
1.64 \mathrm{E}+02 \\
1.16 \mathrm{E}+02\end{array}$ \\
\hline $\begin{array}{l}227.4 \\
304.2 \\
300.2 \\
298.9 \\
298.2\end{array}$ & $\begin{array}{l}1.44 \mathrm{E}-02 \\
1.48 \mathrm{E}+01 \\
1.49 \mathrm{E}+01 \\
1.18 \mathrm{E}+01 \\
1.42 \mathrm{E}+01\end{array}$ & $\begin{array}{l}304.2 \\
298.2 \\
293.2 \\
283.2 \\
273.2\end{array}$ & $\begin{array}{l}7.35 E+01 \\
4.68 E+01 \\
2.45 E+01 \\
1.09 E+01 \\
4.5\end{array}$ \\
\hline $\begin{array}{l}295.2 \\
288.3 \\
283.8 \\
277.9\end{array}$ & $\begin{array}{l}1.30 E+01 \\
7.72 \\
6.14 \\
2.49\end{array}$ & $\begin{array}{l}260.8 \\
258.2 \\
245.2\end{array}$ & $\begin{array}{l}9.4 \mathrm{E}-01 \\
7.30 \mathrm{E}-01 \\
1.63 \mathrm{E}-01\end{array}$ \\
\hline
\end{tabular}


GCEQ

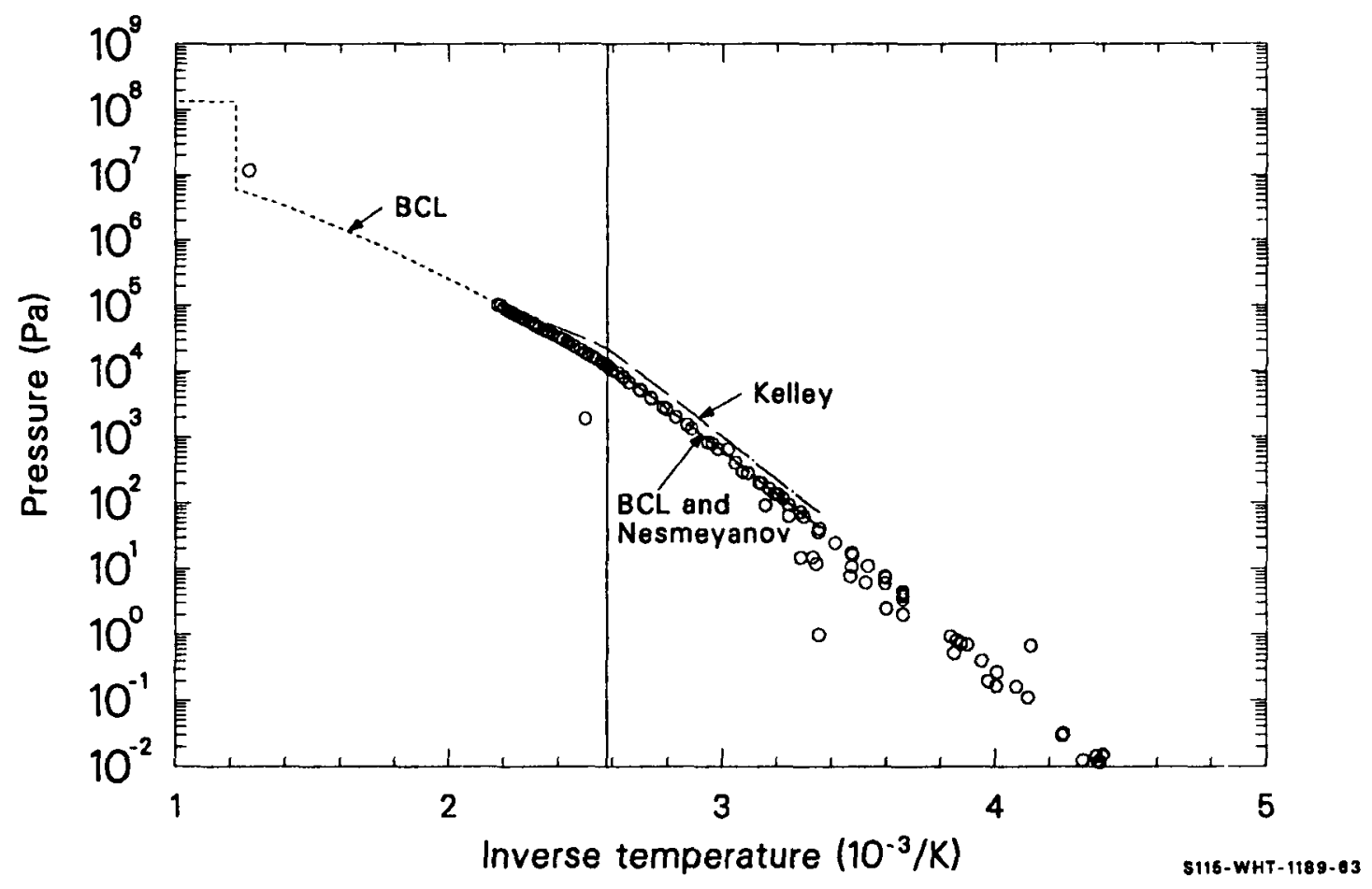

Figure 14.1-1. A comparison of calculated iodine vapor pressures. 


\section{GCEQ}

discussed above. The points attributed to Stup14.1-7 are from his 1947 summary of the vapor pressures of hundreds of inorganic compounds. These values are reproduced as Table 14.1-6. The line labeled BCL is the correlation reported by Gieseke et al in 197714.1-8 and later extended to temperatures above the original 457-K limit by Kuhlman et al.14.1-9 The same correlation is given by Kubaschewski and Alcock, 14.1-10 who attribute it to Kelley14.1-11 and Brewer. 14.1-12

For $298 \mathrm{~T} \leq 387 \mathrm{~K}$,

$\log \left(P_{i}\right)=\frac{-3578}{T}+19.84-2.51 \log (T)$

For $387<\mathrm{T} \leq 819$,

$\log \left(P_{i}\right)=\frac{-3205}{T}+25.77-5.18 \log (T)$.

For $819<T$,

$\log \left(P_{i}\right)=6+2.1249$

The line for the solid phase $(T<387 \mathrm{~K}$ ) calculated with Equation (14.1-6) is indistinguishable from the line calculated with the correlation for solid iodine suggested by Nesmeyanov, 14.1-13

$\log \left(P_{i}\right)=\frac{-3594.030}{T}+20.9362-2.97588 \log (T)+4.4342 \times 10^{-4} T(14.1-9)$

The line labeled Kelley in the figure was derived by the authors from Kelley's expression ${ }^{14.1-11}$ for the Gibbs free energy difference between the vapor and the liquid or solid condensed state,

For $298 \mathrm{~T} \leq 387 \mathrm{~K}$, 
GCEO

Table 14.1-6. Vapor pressure of iodine calculated by Stu11 14.1-7

\begin{tabular}{cc}
\hline $\begin{array}{c}\text { Temperature } \\
(\mathrm{K})\end{array}$ & $\begin{array}{c}\text { Pressure } \\
(\mathrm{Pa})\end{array}$ \\
& \\
311.9 & $1.333 \mathrm{E}+02$ \\
335.4 & $6.667 \mathrm{E}+02$ \\
346.4 & $1.333 \mathrm{E}+03$ \\
357.9 & $2.667 \mathrm{E}+03$ \\
370.7 & $5.333 \mathrm{E}+03$ \\
378.6 & $7.999 \mathrm{E}+03$ \\
389.7 & $1.333 \mathrm{E}+04$ \\
410.5 & $2.667 \mathrm{E}+04$ \\
433.0 & $5.333 \mathrm{E}+04$ \\
456.2 & $1.013 \mathrm{E}+05$ \\
\hline
\end{tabular}


$\log \left(P^{\prime}{ }_{i}\right)=\frac{-3512}{T}+13.37-2.0 \log (T)+$ constant $_{S}$.

For $387<T \leq 457$,

$\log \left(P^{\prime}{ }_{j}\right)=\frac{-2968}{T}+15.889-6.99 \log (T)+$ constant $_{1}$

where $P^{\prime} i$ is the partial pressure of vapor of the $i$-th species at the reference pressure (atmospheres).

A boiling point temperature of $457 \mathrm{~K}$ was assumed for the standard state over the liquid condensed phase, and the liquid and solid condensed phase expressions were assumed to be continuous at the melting point, $387 \mathrm{~K}$, in order to evaluate the constants, constant $s$ and constant . $_{1}$.

The single point at the upper left-hand corner of the figure is the critical temperature and pressure given by Reference 14.1-2, $785 \mathrm{~K}$ and $1.175 \times 10^{7} \mathrm{~Pa}$.

With the exception of slight discontinuities at the melting temperature and the factor-of-five disagreement near the critical temperature, the correlations are consistent. The fact that the graphs are nearly straight lines suggests that the first two constants in Equations (14.1-6) through (14.1-11) are dominant in determining the values of vapor pressures over the domain shown in the figure.

14.1.3.2 Cesium Iodide. Cesium iodide vapor pressures are discussed by Ewing and Stern, 14.1-14 but data are not reported by these authors. The only data located so far are a few preliminary measurements made by Cummings et a1.14.1-15 to test their apparatus and some data over solid cesium iodide published by Cogan and Kimbal1.14.1-16. The data from Reference 14.1-15 were taken at varying gas flow rates in a transpiration cel1 and are reproduced as Table 14.1-7. Table 14.1-8 is a list of the data published by Cogan and Kimball after conversion to temperature and pressure. 

Table 14.1-7. Vappr pressure of cesium iodide measured by Cummings et

\begin{tabular}{cc}
\hline $\begin{array}{c}\text { Temperature } \\
(\mathrm{K})\end{array}$ & $\begin{array}{c}\text { Pressure } \\
(\mathrm{Pa})\end{array}$ \\
\cline { 2 - 2 } 1043 & 239 \\
1041 & 200 \\
1040 & 186 \\
1042 & 266 \\
1043 & 279 \\
& \\
1042 & 293 \\
1043 & 239 \\
1042 & 236 \\
1043 & 279 \\
1043 & 253 \\
& \\
1043 & 266 \\
1043 & 213 \\
1043 & 219 \\
1043 & 239 \\
1043 & 219 \\
1043 & 226 \\
\hline
\end{tabular}


GCEO

Table 14.1-8. Vapor pressure of cesium iodide measured by Cogan and

\begin{tabular}{|c|c|c|c|}
\hline $\begin{array}{l}\text { Temperature } \\
\text { (K) }\end{array}$ & $\begin{array}{l}\text { Pressure } \\
(\mathrm{Pa}) \\
\end{array}$ & $\begin{array}{c}\text { Temperature } \\
(K)\end{array}$ & $\begin{array}{c}\text { Pressure } \\
\quad(\mathrm{Pa})\end{array}$ \\
\hline $\begin{array}{l}853.2 \\
852.5 \\
848.2 \\
849.6 \\
848.2 \\
845.3 \\
846.0 \\
843.2 \\
835.4 \\
831.3 \\
827.1 \\
829.2 \\
894.5 \\
892.9 \\
886.5 \\
887.3 \\
871.8 \\
868.8 \\
846.0 \\
848.2 \\
834.7 \\
836.8 \\
823.7 \\
810.4 \\
803.2 \\
772.2 \\
771.0 \\
765.1 \\
771.6 \\
766.3 \\
765.7 \\
755.9 \\
757.0 \\
755.9 \\
755.9 \\
757.6 \\
746.8 \\
739.1 \\
798.1 \\
797.4\end{array}$ & $\begin{array}{r}4.216 \\
3.935 \\
3.427 \\
3.273 \\
3.125 \\
2.985 \\
2.917 \\
2.600 \\
2.213 \\
1.758 \\
1.758 \\
1.718 \\
34.269 \\
31.982 \\
26.601 \\
25.996 \\
14.618 \\
13.643 \\
6.381 \\
5.955 \\
4.216 \\
3.935 \\
2.660 \\
1.883 \\
1.135 \\
0.188 \\
0.188 \\
0.188 \\
0.180 \\
0.142 \\
0.130 \\
0.122 \\
0.113 \\
0.113 \\
0.111 \\
0.099 \\
0.077 \\
0.052 \\
1.135 \\
1.135\end{array}$ & $\begin{array}{l}790.5 \\
785.5 \\
766.3 \\
763.4 \\
760.5 \\
753.6 \\
739.1 \\
729.4 \\
715.3 \\
705.2 \\
695.9\end{array}$ & $\begin{array}{l}0.716 \\
0.638 \\
0.351 \\
0.313 \\
0.248 \\
0.188 \\
0.101 \\
0.073 \\
0.038 \\
0.028 \\
0.019\end{array}$ \\
\hline
\end{tabular}


Figure 14.1-2 is a summary of the vapor pressure values that have been calculated from published correlations and the data discussed above. The correlation points from Stul1 $1^{14.1-7}$ are reproduced as Table 14.1-9, and those from Margrave ${ }^{14.1-17}$ are reproduced as Table 14.1-10. The correlation reported by Gieseke et al ${ }^{14.1-8}$ and Kubaschewski and Alcock ${ }^{14.1-10}$ is

For $600<T \leq 894 \mathrm{~K}$,

$\log \left(P_{i}\right)=\frac{-10420}{T}+21.82-3.02 \log (T)$.

For $894<T<1553$

$\log \left(P_{j}\right)=\frac{-9678}{T}+22.47-3.52 \log (T)$.

The line attributed to Kelley in the figure was derived by the authors from his expressions for the Gibbs free energy difference between the vapor and liquid states

$\log \left(P^{\prime}\right)=\frac{-10229}{T}+17.816-3.52 \log (T)+$ constant.

A boiling point temperature of $1553 \mathrm{~K}$ was assumed in order to evaluate the constant. Powers has provided polynomial expressionsa,14.1-18 for the Gibbs function in the form

$$
\begin{aligned}
G(T)= & \Delta H_{f}(298)-T\left[a_{1}+a_{2} x+a_{3} x^{2}+a_{4} x^{3}\right. \\
& \left.+a_{5} \ln (x)+a_{6} / x+a_{7} x \ln (x)\right]
\end{aligned}
$$

a. D. A. Powers, private communication, Sandia National Laboratories, June $5,1986$. 


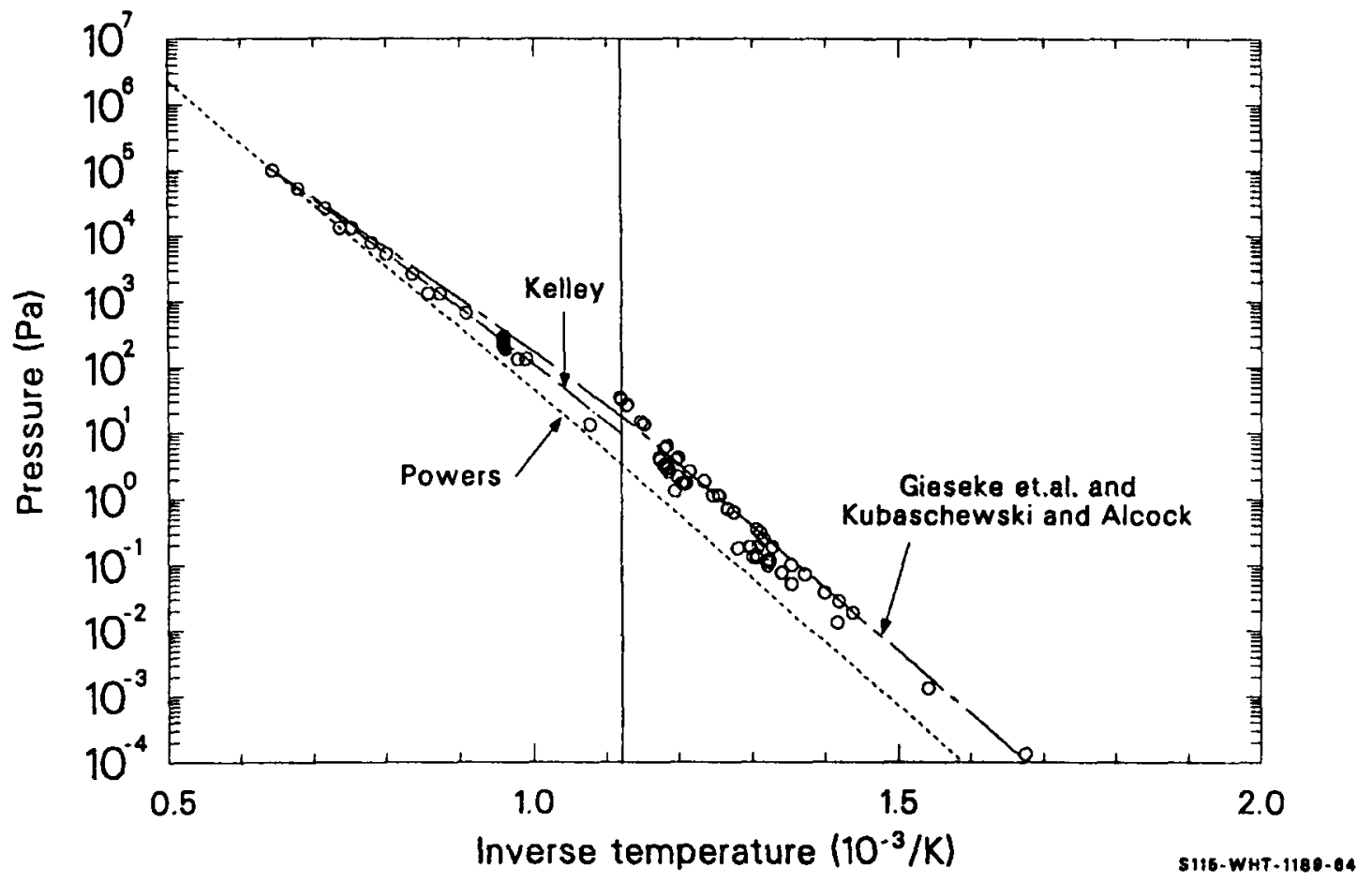

Figure 14.1-2. A comparison of calculated cesium iodide vapor pressures. 
GCEO

Table 14.1-9. Vapor pressure of cesium iodide calculated by Stu1114.1-7

\begin{tabular}{cc}
\hline $\begin{array}{c}\text { Temperature } \\
(\mathrm{K})\end{array}$ & $\frac{\begin{array}{c}\text { Pressure } \\
(\mathrm{Pa})\end{array}}{1011}$ \\
\cline { 2 - 3 } 1101 & $1.333 \mathrm{E}+02$ \\
1146 & $6.667 \mathrm{E}+02$ \\
1196 & $1.333 \mathrm{E}+03$ \\
1249 & $2.667 \mathrm{E}+03$ \\
& $5.333 \mathrm{E}+03$ \\
1282 & $7.999 \mathrm{E}+03$ \\
1328 & $1.333 \mathrm{E}+04$ \\
1397 & $2.666 \mathrm{E}+04$ \\
1473 & $5.333 \mathrm{E}+04$ \\
1553 & $1.013 \mathrm{E}+05$ \\
\hline
\end{tabular}

Table 14.1-10. $\begin{aligned} & \text { Vapor pressure of cesium iodide calculated by } \\ & \text { Margrave }\end{aligned}$

$\begin{array}{cll}\begin{array}{c}\text { Temperature } \\ (\mathrm{K})\end{array} & \begin{array}{l}\text { Pressure } \\ (\mathrm{Pa})\end{array} & \text { State } \\ 597 & 1.333 \mathrm{E}-04 & \text { Solid } \\ 649 & 1.333 \mathrm{E}-03 & \text { Solid } \\ 706 & 1.333 \mathrm{E}-02 & \text { Solid } \\ 769 & 1.333 \mathrm{E}-01 & \text { Sol id } \\ 838 & 1.333 & \text { Solid } \\ 929 & 1.333 \mathrm{E}+01 & \text { Liquid } \\ 1023 & 1.333 \mathrm{E}+02 & \text { Liquid } \\ 1167 & 1.333 \mathrm{E}+03 & \text { Liquid } \\ 1358 & 1.333 \mathrm{E}+04 & \text { Liquid }\end{array}$


GCEQ

where

$$
\begin{array}{ll}
G(T) & =\text { the Gibbs function (thermochemical calories/mole) } \\
x & \text { temperature }(K) / 10000 \\
\Delta H_{f}(T)= & \begin{array}{l}
\text { enthalpy of formation at temperature } T \\
\text { (thermochemical calories/mole) }
\end{array} \\
a_{1} \text { to } a_{7}=\begin{array}{l}
\text { constants for each phase. These constants are } \\
\text { iisted in Table } 14.1-11 .
\end{array}
\end{array}
$$

Use of the Powers polynomials and the relation 14.1-10

$\ln \left(P_{j}\right)=-R T \Delta G^{\circ}+$ constant

where

$$
\begin{aligned}
& R=\text { gas law constant, } 1.987 \mathrm{cal} / \mathrm{mole} \\
& \Delta G^{\circ}=\quad \text { standard Gibbs energy change between the vapor } \\
& \text { and condensed phase (thermochemical calories/mole) }
\end{aligned}
$$

with an assumed boiling point of $1553 \mathrm{~K}$ and continuity at the melting point, $894 \mathrm{~K}$, produced the line labeled Powers in the figure.

Near the melting point, these correlations differ by approximately one half cycle (a factor of 3 ), or approximately $100 \mathrm{~K}$ on the abscissa.

14.1.3.3 Cesium Hydroxide. The only vapor pressure data or correlations for cesium hydroxide that have been located by the authors are preliminary results published by Cummings, Elrick, and Sallach.14.1-15 Table 14.1-12 is a reproduction of the preliminary data presented in 
GCEO

Table 14.1-11. Gibbs energy functions from Powers ${ }^{14.1-18}$.

\begin{tabular}{|c|c|c|c|c|c|}
\hline & CsI(gas) & CsI (Liquid) & $\operatorname{CsI}($ Solid) & $\underline{\mathrm{CsOH} \text { (gas) }}$ & $\underline{\mathrm{CsOH}}$ (Liquid) \\
\hline$a_{1}$ & 87.5492 & 75.2082 & 44.4411 & 90.7817 & 76.8474 \\
\hline$a_{2}$ & -0.217848 & 0.375753 & -500.537 & 11.9227 & -1.40530 \\
\hline$a_{3}$ & 3.06455 & -0.867230 & 2068.23 & -12.2683 & 3.19296 \\
\hline$a_{4}$ & -1.50460 & 0.499939 & -4149.65 & 4.27126 & -1.59215 \\
\hline$a_{5}$ & 8.77548 & 17.3228 & 9.88374 & 11.9591 & 19.3853 \\
\hline$a_{6}$ & 0.265011 & 0.516051 & 0.377855 & 0.36043 & 0.579914 \\
\hline$a_{7}$ & -1.50804 & 0.321957 & -191.798 & 3.24478 & -139576 \\
\hline$H_{f}(298)$ & $\begin{array}{l}-36554 \\
-39004\end{array}$ & -79592 & -1023061 & -62000 & -97037 \\
\hline
\end{tabular}


GCEO

Table 14.1-12. Vapor pressure of cesium hydroxide measured by Cummings
et a1. $14.1-15$ a

\begin{tabular}{cc}
$\begin{array}{c}\text { Temperature } \\
(\mathrm{K})\end{array}$ & $\begin{array}{c}\text { Pressure } \\
(\mathrm{Pa})\end{array}$ \\
\cline { 2 - 2 } 1015 & 2038 \\
991 & 1460 \\
970 & 1079 \\
970 & 941 \\
965 & 991 \\
& \\
939 & 635 \\
922 & 422 \\
921 & 562 \\
900 & 294 \\
871 & 158 \\
& \\
824 & 59.4 \\
817 & 55.1 \\
770 & 18.3 \\
871 & 97.9 \\
803 & 15.9 \\
788 & 9.27 \\
\hline
\end{tabular}


GCEO

Figure 2 of Reference 14.1-15. The authors of Reference 14.1-15 rejected the last three data of Table 14,1-12 to obtain the correlation

$\log \left(P_{i}\right)=\frac{-6700}{T}+9.92$

The data, calculated pressures from Equation (14.1-17), and pressures obtained by applying Powers' Gibbs free energy correlations as explained in Section 14.1.3.2 are shown in Figure 14.1-3. No boiling point is available for cesium hydroxide, so the constant required to use the Gibbs free energy correlations to calculate vapor pressure was obtained by matching the Gibbs free energy calculation to the pressure calculated with Equation (14.1.17) at $1000 \mathrm{~K}$.

\subsubsection{Mode1 Development}

This section is divided into three parts. The first part describes the development of the vapor pressure correlations, the second derives the form of the van der Waals equation of state that is used to convert the pressure to a concentration, and the third develops the expression used to describe the interaction of co-deposited CSI-CsOH.

\subsubsection{Vapor Pressure Correlations. Expressions for the} equilibrium vapor pressure in a closed system are usually based on the Clausius-Clapeyron equation, which is derived in most introductory thermodynamics courses and applies to any first-order phase change, 14.1-19

$\frac{d p}{d T}=\frac{\Omega}{T\left[v^{(f)}-v^{(i)}\right]}$

where

$\mathrm{dP} / \mathrm{dT}=$ slope of the boundary between the phases in a pressure-temperature phase diagram (and thus the 
GCEO

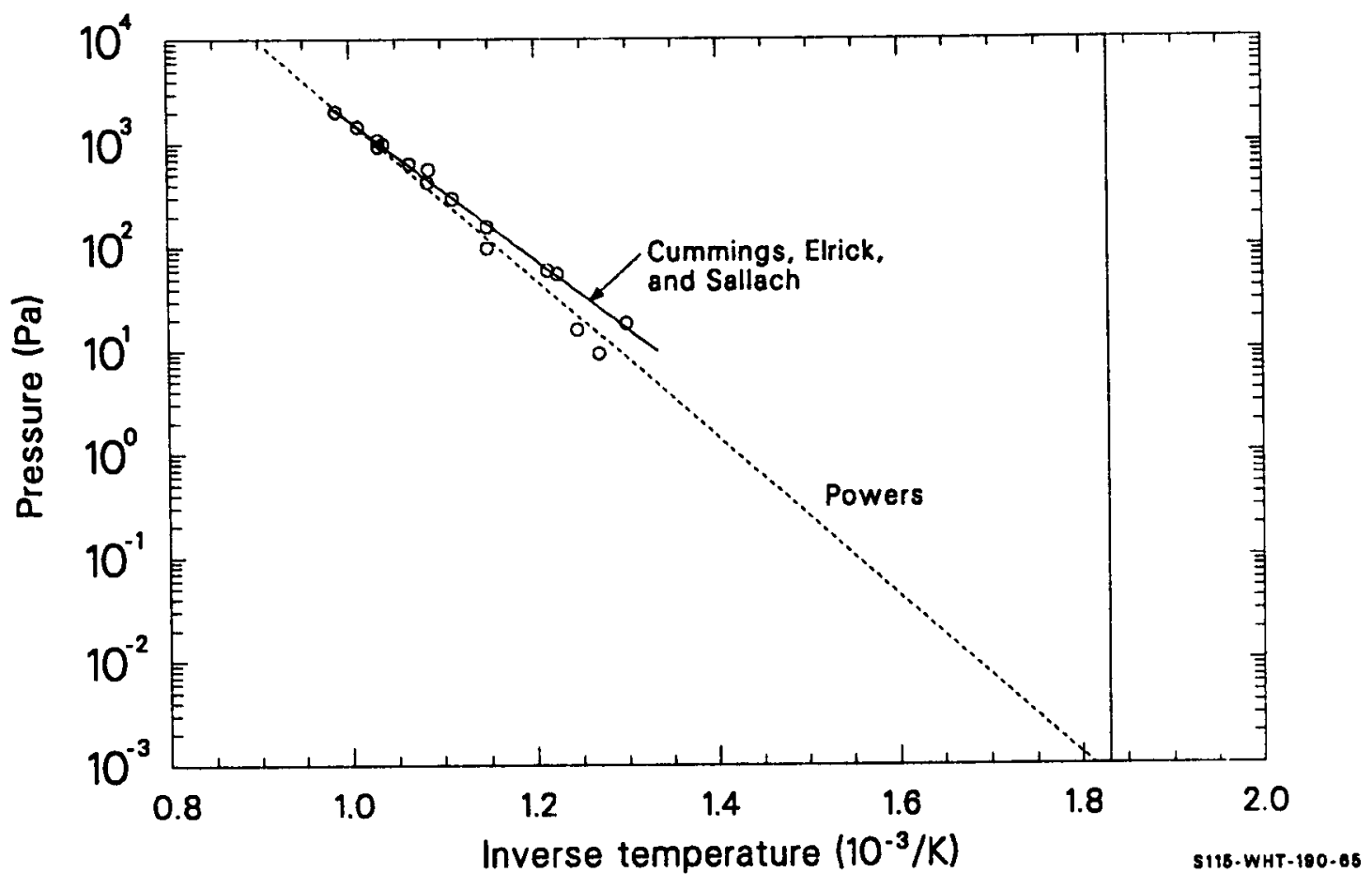

Figure 14.1-3. A comparison of calculated cesium hydroxide vapor pressures. 
slope of a plot of the vapor pressure versus temperature in this application) $(\mathrm{Pa} / \mathrm{K})$

$\Omega=$ molar heat absorbed during the phase change $(\mathrm{J} / \mathrm{kg}$-mole)

${ }_{v}(f), v(i)=$ final and initial molar volume of the phase change $\left(\mathrm{m}^{3} / \mathrm{kg}\right.$-mole) .

An outline of the derivation of the usual correlations for vapor pressure from Equation (14.1-18) is presented below in order to point out the assumptions and limitations of the correlations.

At temperatures considerably below the critical temperature, the condensed state molar volume is much less than the vapor state molar volume so

$\frac{d P}{d T} \approx \frac{L}{T V}$

where

$\mathrm{L}=$ molar heat of vaporization (J/kg-mole)

$v=$ molar volume of the vapor $\left(\mathrm{m}^{3} / \mathrm{kg}-\mathrm{mole}\right)$.

Assuming the vapor to behave like an ideal gas,

$v=\frac{R T}{P}$.

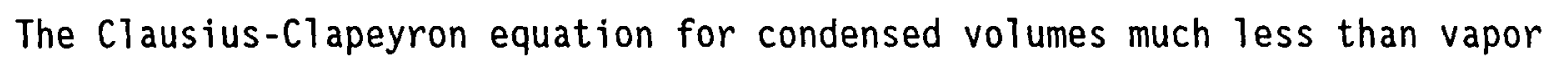
volumes and a vapor that behaves as an ideal gas may thus be written 


\section{GCEO}

$\frac{d P}{d T} \approx \frac{L P}{T^{2} R}$

A first-order correlation for the vapor pressure over a limited temperature range can be obtained by assuming that $L$ is approximately constant over the range of interest and then integrating

$\ln (P) \approx \frac{L}{R T}+$ constant

or

$\log (P)=\log (e) \ln (P) \approx \frac{0.4343 L}{R T}+$ constant'.

Inspection of Figures 14.1-1 and 14.1-2 shows that Equation (14.1-23) is a reasonable approximation for the temperature ranges shown.

A more accurate expression for the vapor pressure, at least over solids, can be obtained by employing Kirchoff's equation for the heat of sublimation.

$L_{s u} \approx \int_{0}^{T} c_{p}^{g} d T-\int_{0}^{T} c_{p}^{s} d T+L_{0}$

where

$$
\begin{aligned}
L_{s u} & =\text { heat of sublimation at } T(\mathrm{~J} / \mathrm{kg}-\mathrm{mole}) \\
\mathrm{L}_{0} & =\text { heat of sublimation at } 0 \mathrm{~K}(\mathrm{~J} / \mathrm{kg}-\mathrm{mole}) \\
\mathrm{C}_{\mathrm{p}}^{g}= & \begin{array}{l}
\text { specific heat capacity at constant pressure of the gas } \\
(\mathrm{J} / \mathrm{kg}-\text { mole-K) }
\end{array}
\end{aligned}
$$


$c_{p}^{S}=\begin{aligned} & \text { specific heat capacity at constant pressure of the } \\ & \text { solid }(\mathrm{J} / \mathrm{kg}-\mathrm{mole} \cdot \mathrm{K})\end{aligned}$

The Kirchoff equation is an approximation subject to the restriction that the pressure is low and the saturated vapor behaves like an ideal gas.14.1-19 To see where these approximations enter, the equation is derived (following Reference 14.1-19) by considering an infinitesimal change of molar enthalpy between two states of equilibrium of a chemical system

$d h=T d s+v d P$

where

$\mathrm{h}=$ specific enthalpy of the system $(\mathrm{J} / \mathrm{kg}$-mole $)$

$\mathrm{s}=$ specific entropy of the system $(\mathrm{J} / \mathrm{kg}-\mathrm{mole} \cdot \mathrm{K})$.

From the second law of thermodynamics for chemical states,

$T d s=C_{p} d T-T\left(\left.\frac{\partial v}{\partial t}\right|_{p}\right) d P$

where

$$
\begin{aligned}
& C_{p}=\text { molar heat capacity at constant pressure }(\mathrm{J} / \mathrm{kg}-\mathrm{mole} \cdot \mathrm{K}) \\
& \left.\frac{1}{v} \frac{\partial v}{\partial t}\right|_{p}=\beta, \text { the volume expansivity }\left(\mathrm{K}^{-1}\right)
\end{aligned}
$$

A finite change of enthalpy between two states, $P_{j} T_{j}$ and $P_{f} T_{f}$, is described by

$h_{f}-h_{i}=\int_{i}^{f} C_{p} d T+\int_{i}^{f} v(1-\beta T) d P$. 


\section{GCEO}

For material in the solid phase, consider an initial state at absolute zero and a final state of a saturated solid about to sublime. If the integration is taken in two steps, the first step isothermal at absolute zero to the system pressure and the second isobaric at the system pressure, one finds

$h_{f}^{s}-h_{0}^{S}=\int_{0}^{P} v(1-\beta T) d P+\int_{0}^{T} C_{p} d T$

where $h_{f} s$ and $h_{0} s$ are the final and initial molar enthalpies of the solid $(\mathrm{J} / \mathrm{kg}$-mole). As long as the pressure is not too large (hence the limit to solids and sublimation), the first integral is small and

$h_{f}^{s} \approx \int_{0}^{T} c_{p} d T+h_{0}^{s}$

Since the molar heat capacity of a solid does not vary greatly with pressure, the molar heat capacity at atmospheric pressure is usually used in Equation (14.1-28).

For material in the vapor phase, ideal gas behavior is usually assumed so that the enthalpy is a function of temperature only. 14.1-19

$h_{f}^{g}=\int_{0}^{T} c_{p}^{g} d T+h_{0}^{g}$

where $h_{f}^{g}$ and $h_{0}^{g}$ are the final and initial molar enthalpies of the gas.

The reversible sublimation of one kilogram-mole of a solid at the temperature, $T$, and pressure, $P$, is described by

$L_{s u}=h_{f}^{g}-h_{f}^{s}$ 
or

$L_{s u}=\int_{0}^{T} c_{p}^{g} d T-\int_{0}^{T} c_{p}^{s} d T+h_{0}^{g}-h_{0}^{s}$

or

$L_{s u}=\int_{0}^{T} c_{p}^{g} d T-\int_{0}^{T} c_{p}^{s} d T+L_{0}$

or, expressing $C_{p}$ as the sum of temperature-independent and temperature-dependent terms,

$L_{s u}=C_{p}^{g^{\star}} T+\int_{0}^{T} c_{p}^{g}\left(T^{\prime}\right) d T^{\prime}-\int_{0}^{T} C_{p}^{s} d T^{\prime}+L_{0}$

where
$\mathrm{C}_{\mathrm{p}}^{\mathrm{g}^{*}} \quad=\quad$ the constant term in the specific heat capacity of the gas, 5/2 R for monatomic gases and $7 / 2 \mathrm{R}$ for diatomic gases except hydrogen ( $\mathrm{J} / \mathrm{kg}-\mathrm{mole} \cdot \mathrm{K})$

$c_{p}^{g}(T)=$ the temperature-dependent term in the specific
heat capacity of the gas $(\mathrm{J} / \mathrm{kg}$-moie $\cdot \mathrm{K})$.

If Kirchoff's equation is used for $\mathrm{L}$ in the Clausius-Clapeyron equation, Equation (14.1-21), before it is integrated, one finds

$\frac{d P}{P}=\frac{d T}{R T}\left[L_{0}+c_{p}^{g^{*}} T+\int_{0}^{T} c_{p}^{g}\left(T^{\prime}\right) d T^{\prime}-\int_{0}^{T} C_{p}^{s} d T^{\prime}\right]$

or, integrating, 


$$
\begin{aligned}
\ln (P) & =\frac{-L_{0}}{R T}+\frac{C_{p}^{g^{*}} \ln (T)}{R}+\frac{1}{R} \int_{0}^{T} \frac{1}{T^{\prime 2}} \int_{0}^{T^{\prime}} C_{p}\left(T^{\prime \prime}\right) d T^{\prime \prime} d T^{\prime} \\
& -\frac{1}{R} \int_{0}^{T} \frac{1}{T^{\prime 2}} \int_{0}^{T^{\prime}} C_{p}\left(T^{\prime \prime}\right) d T^{\prime \prime} d T^{\prime}+\text { constant } .
\end{aligned}
$$

Conversion to common logarithms yields

$$
\begin{aligned}
\log (P) & =\frac{-0.4343 L_{0}}{R T}+\frac{C_{p}^{g^{*}} \log (T)}{R}+\frac{0.4343}{R} \int_{0}^{T} \frac{1}{T^{\prime 2}} \int_{0}^{T^{\prime}} C_{p}\left(T^{\prime \prime}\right) d T^{\prime \prime} d T^{\prime} \\
& -\frac{0.4343}{R} \int_{0}^{T} \frac{1}{T^{\prime 2}} \int_{0}^{T^{\prime}} C_{p}\left(T^{\prime \prime}\right) d T^{\prime \prime} d T^{\prime}+\text { constant } t^{\prime} .
\end{aligned}
$$

Some authors ${ }^{14.1-17}$ represent the integrals with a polynomial in temperature, and many fit data over limited ranges by keeping only the constant term of the polynomial.

Because of the heat of fusion, there is a discontinuous change in the specific heat absorbed during the change from the condensed phase to the vapor phase [the factor $L$ in Equation (14.1-19)]. Data for the vapor pressure over liquids and solids are therefore usually correlated to an expression like Equation (14.1-37) separately, and a small discontinuity in the calculated vapor pressure at the melting point is tolerated. This procedure is dangerous when preparing general-purpose subcodes because some computer codes that use iteration may fail to converge near the melting temperature. For this reason, the models described in this section were developed by first performing a least-squares fit for the data with one condensed phase and then applying a constraint that the correlations be continuous at the boundary between the condensed phases. (This is the melting temperature for a liquid-solid phase boundary, but the method would apply to two different solid phases as well.) 
With the exceptions noted below for individual species, the following approach was employed. For the first (usually the solid) phase, the data were fit to an equation of the form

$\log (P)=\frac{A}{T}+B+C \log (T)$

with a series of trial values of $C$ near the theoretical values of $-5 / 2$ for monatomic gases and $-7 / 2$ for diatomic gases. A transformation of variables was performed to

$y=\log (P)-C \log (T)$

and

$x=1 / T$.

Next, a distance parameter, $s$, was defined for $N$ pairs of data, $\left(x_{i}, y_{i}\right)$,

$s=\sum_{i=1}^{n}\left(a_{1}+a_{2} x_{i}-y_{i}\right)^{2}$

and $a_{1}$ and $a_{2}$ were determined to minimize $s$ for the trial value of $c$.

That is, the derivatives of $s$ with respect to $a_{1}$ and $a_{2}$ were required to be zero, and the resultant equations were solved for $a_{1}$ and $a_{2}$ :

$$
\begin{aligned}
& \frac{\partial S}{\partial a_{1}}=0=2 \sum_{i=1}^{n}\left(a_{1}+a_{2} x_{i}-y_{i}\right) \\
& \frac{\partial S}{\partial a_{2}}=0=2 \sum_{i=1}^{n}\left(a_{1}+a_{2} x_{i}-y_{i}\right) x_{i}
\end{aligned}
$$


$a_{1}=\frac{\left(\sum_{i=1}^{N} y_{i}\right)\left(\sum_{i=1}^{N} x_{i}{ }^{2}\right)-\left(\sum_{i=1}^{N} x_{i}\right)\left(\sum_{i=1}^{N} y_{i} x_{i}\right)}{N\left(\sum_{i=1}^{N} x_{i}{ }^{2}\right)-\left(\sum_{i=1}^{N} x_{i}\right)\left(\sum_{i=1}^{N} x_{i}\right)}$.

and

$$
a_{2}=\frac{N\left(\sum_{i=1}^{N} y_{i} x_{i}\right)-\left(\sum_{i=1}^{N} y_{i}\right)\left(\sum_{i=1}^{N} x_{i}\right)}{N\left(\sum_{i=1}^{N} x_{i}^{2}\right)-\left(\sum_{i=1}^{N} x_{i}\right)\left(\sum_{i=1}^{N} x_{i}\right)}
$$

Next, the standard error with the trial value of $C$ was calculated with the expression

$S E=\left[\frac{\sum_{i=1}^{N}\left\{a_{i}+\frac{a_{2}}{T_{1}}-\left[\log \left(P_{i}\right)-C \log \left(T_{i}\right)\right]\right.}{N-3}\right]^{1 / 2}$.

where SE is the standard error of the correlation. The solution corresponding to the trial value of $C$ with the minimum standard error (or the one with $C=0$ if there was no significant minimum) was kept.

For the second (usually the liquid) phase, the method of Lagrange multipliers ${ }^{14.1-20}$ was used to enforce the constraint that the correlation be continuous at the temperature corresponding to the boundary between the condensed phases (the triple point for the usual case where the two condensed phases are the liquid and solid phases). This method is summarized as follows:

a. Equate the differential of the function whose extreme value is desired to zero. 
b. Take the differential of each equation of constraint and multiply each differential by a different Lagrange multiplier (arbitrary constants $\left.\lambda_{1}, \lambda_{2}, \ldots\right)$.

c. Add all the equations, factoring the sum so that each differential appears only once.

d. Equate the coefficient of each differential to zero.

e. Use the (number of variables) differential equations and the (number of constraints) constraint equations to eliminate the Lagrange multipliers and solve for the variables at the extreme value of the function subject to the constraints.

The constraint equation is

$y_{\text {melt }}=a_{1}+a_{2} x_{\text {melt }}$

where $x_{\text {melt }}$ and $y_{\text {melt }}$ are the values of $x$ and $y$ from Equations (14.1-39) and $(14.1-40)$ with the value of $P$ calculated from the correlation used for the first phase at the temperature of the boundary between the two condensed phases. Steps (a) to (c) were used to find

$$
\begin{aligned}
& {\left[\frac{\partial S}{\partial a_{1}}+\lambda_{1} \frac{\partial}{\partial a_{1}}\left(a_{1}+a_{2} x_{\text {melt }}-y_{\text {melt }}\right)\right] d a_{1}+} \\
& {\left[\frac{\partial S}{\partial a_{2}}+\lambda_{1} \frac{\partial}{\partial a_{2}}\left(a_{1}+a_{2} x_{\text {melt }}-y_{\text {melt }}\right)\right] d_{2}=0 .}
\end{aligned}
$$

Equating the coefficients of $\mathrm{da}_{1}$ and $\mathrm{da}_{2}$ to zero and using the equation of constraint led to the following three equations in $a_{1}, a_{2}$, and $\lambda_{1}$ : 


\section{GCEO}

$$
\begin{aligned}
& 2 N a_{i}+2 \sum_{i=1}^{N} x_{i} a_{2}+\lambda_{i}=2 \sum_{i=1}^{N} y_{i} \\
& 2 \sum_{i=1}^{N} x_{i} a_{1}+2 \sum_{i=1}^{N} x_{i}{ }^{2} a_{2}+x_{m e 1 t} \lambda_{1}=2 \sum_{i=1}^{N} x_{i} y_{i} \\
& a_{1}+x_{\text {melt }} a_{2}+0 \lambda_{1}=y_{\text {melt }} .
\end{aligned}
$$

Finally, solution of these equations for $a_{1}$, and $a_{2}$ yielded

$$
\begin{aligned}
& a_{1}= \frac{\left\{\sum_{i=1}^{N} x_{i} y_{i}-x_{\text {melt }} \sum_{i=1}^{N} y_{i}\right\} x_{\text {melt }}-\left\{\sum_{i=1}^{N} x_{i}{ }^{2}-x_{\text {melt }} \sum_{i=1}^{N} x_{i}\right\} y_{\text {melt }}}{x_{\text {melt }}\left\{\sum_{i=1}^{N} x_{i}-x_{\text {melt }} N\right\}-\left\{\sum_{i=1}^{N} x_{i} y_{i}-x_{\text {melt }} \sum_{i=1}^{N} y_{i}\right\}} \\
& a_{2}=\frac{\left\{\sum_{i=1}^{N} x_{i}-x_{\text {melt }} N\right\} y_{\text {melt }}-\left\{\sum_{i=1}^{N} x_{i} y_{i}-x_{\text {melt }} \sum_{i=1}^{N} y_{i}\right\}}{x_{\text {melt }}\left\{\sum_{i=1}^{N} x_{i}-x_{\text {melt }} N\right\}-\left\{\sum_{i=1}^{N} x_{i} y_{i}-x_{\text {melt }} \sum_{i=1}^{N} y_{i}\right\}}
\end{aligned}
$$

14.1.4.1.1 Iodine--The method described above was applied to the data in Tables 14.1-3 and 14.1-4 and to those data in Table 14.1-5 corresponding to $T \geq 273.2 \mathrm{~K}$. The data for vapor pressure over the solid state were fit first, that is, without constraint; and the data for vapor pressure over the liquid were fit subject to the constraint that there be no discontinuity in the calculated vapor pressure at the melting point. In addition, the critical temperature and pressure were used as a datum because correlations developed without this point were dominated by small variations in the data over the limited range of temperatures above the melting temperature for which data are available. 
The value of the coefficient of the log $(T)$ term made little difference in the standard error of the correlation to the data. For example, the data for temperatures less than melting were fit with standard errors of 0.17299 , $0.17262,0.17186$, and 0.17130 , respectively, when $\log (T)$ coefficients of $-3.5,-2.5,0$, and 2.5 were assumed. Thus, the $\log (T)$ term was omitted from the correlation because the slight reduction of the standard error gained by including the term was not worth the additional cost of computations with the extra term. The critical pressure is used for the vapor pressure when the temperature is above the critical temperature. This prevents calculation of unreasonably large numbers if the subcode is used for a temperature above the critical temperature.

Figure 14.1-4 is a plot of the data and the correlations used to represent them. The correlation derived from the data is:

For $273<\mathrm{T} \leq 387 \mathrm{~K}$,

$\log \left(P_{i}\right)=\frac{-3.353591962 \times 10^{3}}{T}+12.75860186$

For $387<\mathrm{T} \leq 785 \mathrm{~K}$,

$\log \left(P_{j}\right)=\frac{-2.263962057 \times 10^{3}}{T}+9.942978333$

For $785<\mathrm{T}$,

$\log \left(P_{j}\right)=7.058950235$

Inspection of the figure shows that the new correlation differs significantly from the numerous literature correlations only near the critical temperature, $785 \mathrm{~K}$, and that the correlation can be safely applied to describe even the low-temperature data that were not used to develop it. 


\section{GCEQ}

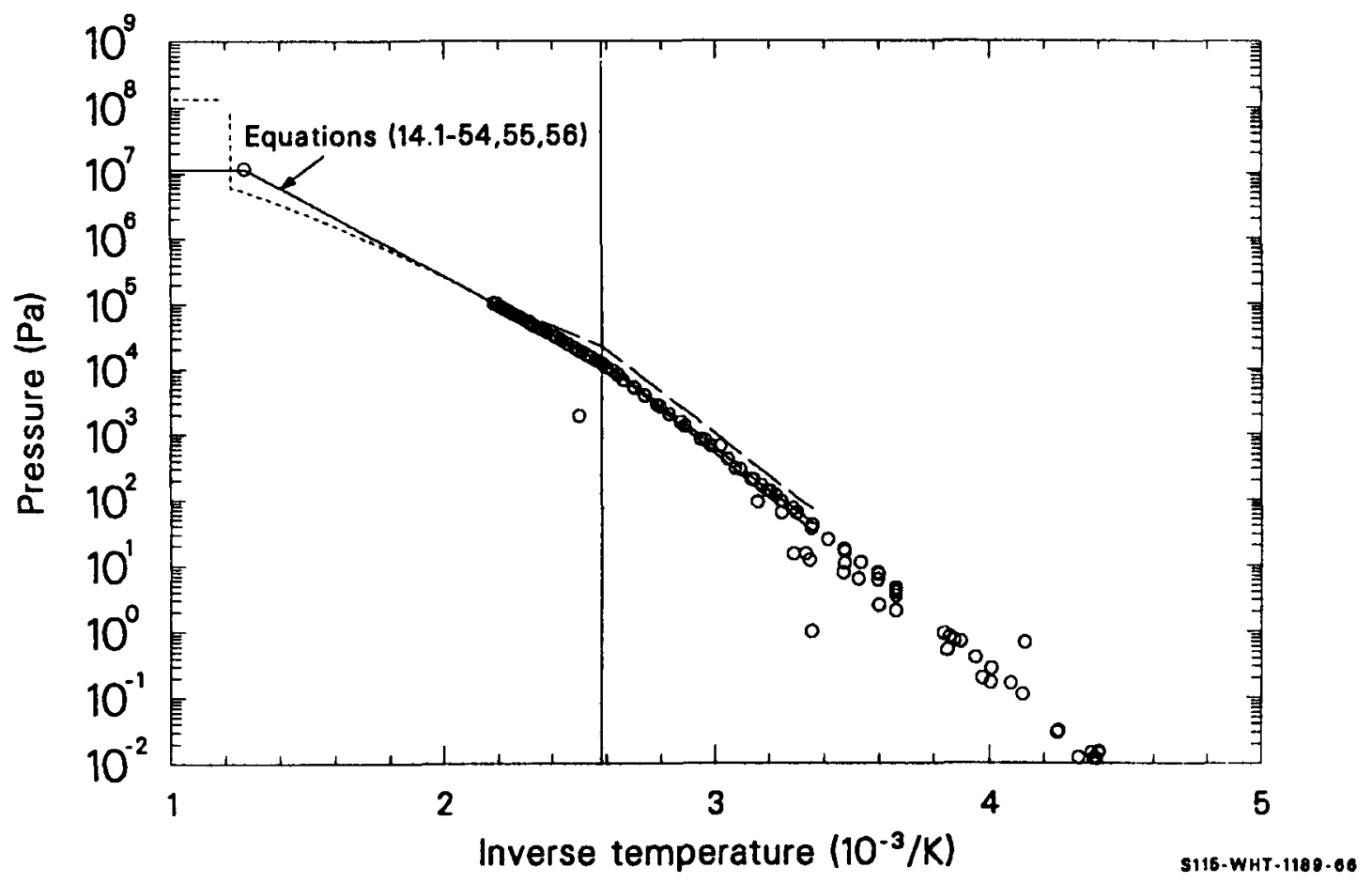

Figure 14.1-4. Iodine vapor pressure data and pressures calculated with the correlation used to describe the data. 
14.1.4.1.2 Cesium Iodide--The limited cesium iodide data were fit by applying the method described in Section 14.1.4.1 to the data in Tables 14.1-7 and 14.1-8. Figure 14.1-5 is a plot of the data and the various correlations used to describe them. The correlation derived from the data is:

For $700<T \leq 894 \mathrm{~K}$,

$\log \left(P_{i}\right)=\frac{-1.036400145 \times 10^{4}}{T}+12.89645442$

For $894<T \leq 1553 \mathrm{~K}$,

$\log \left(P_{i}\right)=\frac{-6.745468378 \times 10^{3}}{T}+8.848864730$

The figure shows that this correlation has a less negative slope than most in the temperature range where cesium iodide is liquid. The liquid result is tentative because the data are from only one set of measurements over a very narrow temperature range.

14.1.4.1.3 Cesium Hydroxide--Since all of the data located so far are from Cummings et al., 14.1-15 the correlation developed from these data by Cummings et a1. was used in the GCEQ subcode. The correlation is as follows:

$\log \left(P_{j}\right)=\frac{-6700}{T}+9.92$

14.1.4.2 Relation between Partial Pressure, System Pressure, and Concentration. For dilute gases at high temperature, one can use the ideal gas law, 


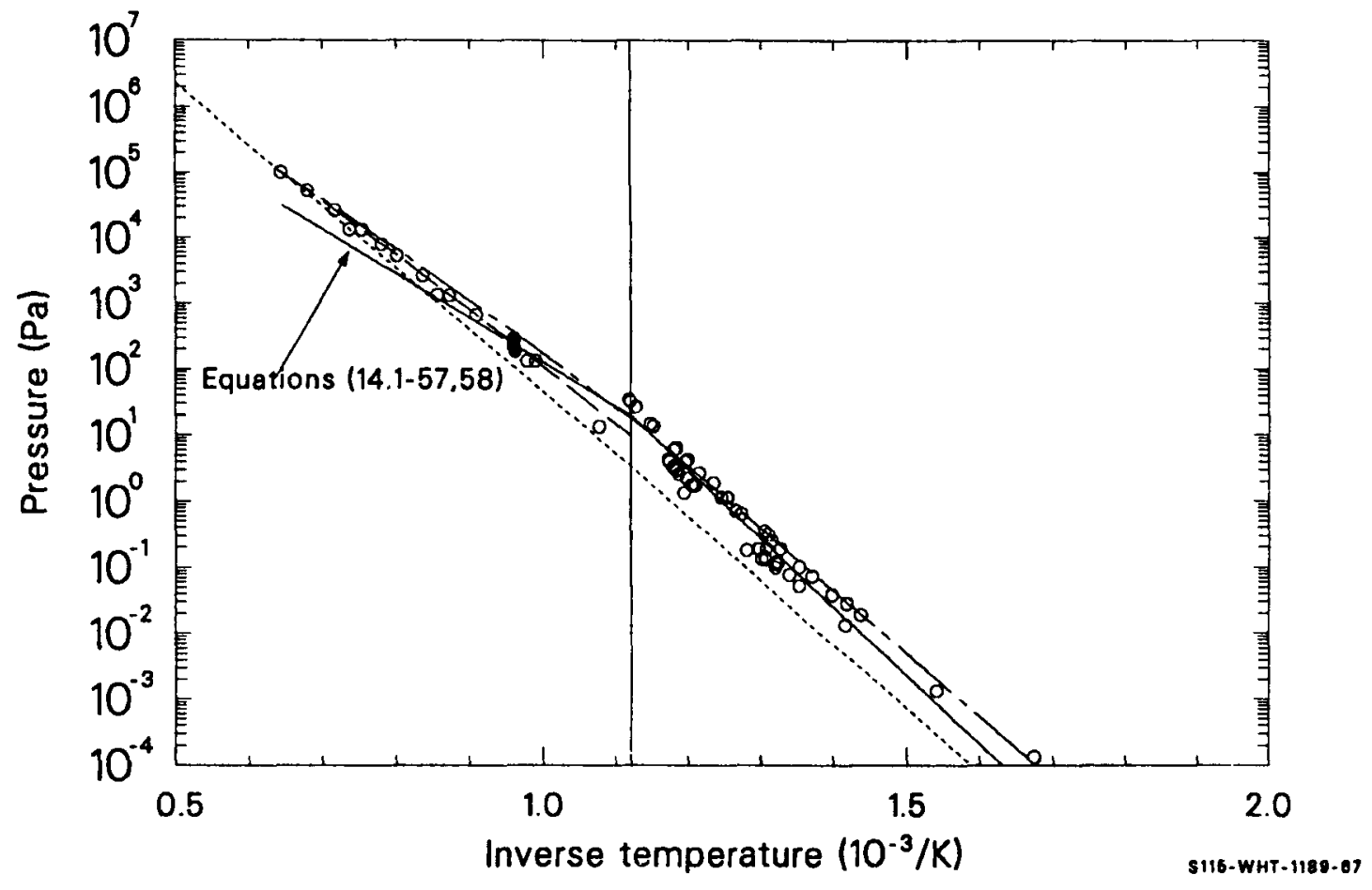

Figure 14.1-5. Cesium iodide vapor pressure data and pressures calculated with the correlation used to describe the data. 
$R T=\frac{V P}{N}$

where

$$
\begin{aligned}
& V=\text { system volume }\left(\mathrm{m}^{3}\right) \\
& N=\text { moles of the gas (kg-moles), }
\end{aligned}
$$

to calculate concentrations from pressures. The concentration is just the number of moles per unit volume times the mass of a mole of the gas,

$C=\frac{M N}{V}$

where $M$ is the kilogram molecular weight of the gas $(\mathrm{kg} / \mathrm{kg}-\mathrm{mole})$, so the ideal gas law can be used to write

$C=\frac{M P}{R T}$.

In order to allow use of the expressions for equilibrium concentrations in conditions where the pressure may be high, an extension of the ideal gas law, the van der Waals equation, has been employed to derive Equations (14.1-3) and (14.1-4). This equation is

$R T=\left(\frac{v}{N}-b\right)\left(P+\frac{a N^{2}}{v^{2}}\right)$

where $a, b$ are constants characteristic of the gas in question. The term $\mathrm{aN}^{2} / \mathrm{v}^{2}$ can be interpreted as representing interactions of molecules at distances greater than their classical diameter, 14.1-21 and the constant $b$ can be interpreted as representing the classical hard-sphere repulsion volume of one mole of the gas molecules. 14.1-22 


\section{GCEQ}

With these interpretations, a reasonable extension of Equation (14.1-62) to approximate a mixture of species is

$$
\sum_{i=1}^{n} N_{i} R T \approx V-\sum_{i=1}^{n} N_{i} b_{i} P+\sum_{i=1}^{n} \frac{N_{i}^{2} a_{i}}{v^{2}}
$$

where

$$
\begin{aligned}
& n= \text { number of gas components or species in the mixture } \\
& N_{\mathbf{i}}= \text { kilogram moles of } i \text {-th gas component (kg-moles) } \\
& a_{\mathbf{i}}= \begin{array}{l}
\text { van der Waals constant proportional to the interaction of } \\
\text { molecules of the } i \text {-th species at distances greater than } \\
\text { their classical diameter }\left\{\mathrm{kg} \cdot \mathrm{m}^{5} /\left[\mathrm{s}^{2}(\mathrm{~kg}-\mathrm{mole})^{2}\right]\right\}
\end{array} \\
& b_{\mathbf{i}}=\quad \begin{array}{l}
\text { van der Waals constant that represents the hard sphere size } \\
\text { of the } i \text {-th species molecules }\left(\mathrm{m}^{3} / \mathrm{kg}\right. \text {-mole). }
\end{array}
\end{aligned}
$$

Equation (14.1-63) is at best a first-order approximation because interactions between molecules of different components have been neglected.

The terms with $b_{j}$ or $a_{j}$ are much smaller than the other terms in Equation (14.1-63). The equation can thus be approximated by

$$
\sum_{i=1}^{n} N_{i} R T \approx V P-\sum_{i=1}^{n} N_{i} b_{i} P+\sum_{i=1}^{n} \frac{N_{i}{ }^{2} a_{i}}{V^{2}}
$$

to first order in the small terms.

In order to use Equation (14.1-64) with expressions for the equilibrium vapor pressure of a species, the pressure in the first term on the 
right-hand side is expanded into a series of partial pressures due to the gas components

$\sum_{i=1}^{n} N_{i} R T=\sum_{i=1}^{n} P_{i}-\sum_{i=1}^{n} N_{i} b_{i} P+\sum_{i=1}^{n} \frac{N_{i}^{2} a_{i}}{V}$

The $i$-th term of each sum can then be interpreted as an equation of state for the $i$-th component

$N_{i} R T \approx V P_{i}-N_{i} b_{i} P+\frac{N_{i}^{2} a_{i}}{V}$

For a condensable majority species like steam, the second and third terms on the right-hand side of Equation (14.1-66) are of similar magnitude and much smaller than the other terms. For a minority component, the factor $\mathrm{N}_{\mathrm{i}} / \mathrm{V}$ of the third term makes it small enough to neglect and

$N_{j} R T \approx V P_{i}-N_{i} b_{i} P$

This approximate equation of state for minority species is used in two ways. It is solved for the volume to determine the relation between the partial pressure at a given total pressure, Equation (14.1-4), and it is also used to correct equilibrium vapor pressure correlations for the effect of different total system pressures, Equation (14.1-3).

Solution of Equation (14.1-67) for the volume and substitution of this result into Equation (14.1-60) yields Equation (14.1-4)

$c_{i}=\frac{M_{i} P_{i}}{R T+b_{i} P}$ 


\section{GCEO}

A few more steps and another approximation are required to derive the relation for the effect of total system pressure on the partial pressure of a species. Solution of Equation (14.1-67) for $P_{i}$ yields

$$
P_{i}=\frac{N_{i}\left(R T+b_{i} P\right)}{V}
$$

Since the correlations for the partial pressure of a species at a reference system pressure are usually given in the form $\log \left(P_{j}\right)$ versus a function of temperature, it is convenient to convert Equation (14.1-68) to an expression in terms of the logarithm

$\ln \left(P_{i}\right) \approx \ln \left[\frac{N_{i} R T}{V}\left(1+\frac{b_{i} P}{R T}\right)\right]$

or

$\ln \left(P_{i}\right) \approx \ln \left(\frac{N_{j} R T}{V}\right)+\ln \left(1+\frac{b_{i} P}{R T}\right)$

or, since $b_{j} P / R T \ll 1$,

$\ln \left(P_{i}\right) \approx \ln \left(\frac{N_{j} R T}{V}\right)+\frac{\left.b_{i} P\right)}{R T}$

where the Taylor series approximation

$\ln (1+x) \approx-1 / 2 x^{2}+1 / 3 x^{3}$

has been employed.

Equation (14.1-71) provides a convenient means of converting correlations for $P_{j}$ at a reference pressure, $P_{0}$, to correlations at a system pressure, $P$. 
$\ln \left[P_{i}(P)\right]-\ln \left[P_{i}\left(P_{0}\right)\right] \approx \frac{b_{i} P}{R T}-\frac{b_{i} P_{0}}{R T}$

or

$\ln \left[\frac{P_{i}(P)}{P_{i}\left(P_{0}\right)}\right] \approx \frac{b_{i}}{R T}\left(P-P_{0}\right)$.

The constants $b_{i}$ were taken from the literature when they could be found and were estimated from condensed phase densities by assuming that the condensed phase volume is due to the hard sphere volume of the molecules when literature values could not be located.

14.1.4.3 Models for the Interaction of Co-Deposited Species. The model for the effect of co-deposition on the equilibrium vapor pressures and concentrations of cesium iodide and cesium hydroxide is from Powers, ${ }^{a}$ who assumed that the $\mathrm{CSOH}-\mathrm{CSI}$ system behaves like the $\mathrm{KOH}-\mathrm{KI}$ system, that is as a eutectic binary that forms a regular solution and has no solid solubility. These assumptions, together with the knowledge of the melting points and heats of fusion of the pure species, allow one to calculate the activities, and thus the vapor pressures, of the species over the co-deposited liquid. ${ }^{14.1-10}$ Powers finds

RT In $\gamma_{\mathrm{CSOH}}=-2005\left(1-x_{\mathrm{CsOH}}\right)^{2}$

RT In $\gamma_{\text {CSI }}=-2005 x^{2}(s O H)$

where

a. D. A. Powers, private communication, Sandia National Laboratories, June 5, 1985. 
GCEQ

$\gamma_{i}=$ activity coefficient for species $i$
$x_{i}=$ mole fraction of species $i$ in the mixture.

\subsubsection{Results}

Figure 14.1-6 is an illustration of the equilibrium concentrations of several species. The minimum concentration is typical of the release of trace fission species, and the maximum is more typical of the releases from heavily irradiated fuel or hot structural material.

Figure 14.1-7 is an illustration of the calculated effect of mixing of cesium hydroxide and cesium iodide in the condensed state on the equilibrium concentration (actually applicable only over the liquid state). The lines labeled $\mathrm{CsOH}$ and $\mathrm{CsI}$ are for the pure species. The 1 ines labeled $0.9 \mathrm{CsOH}$ and $0.1 \mathrm{CSI}$ correspond to the calculated equilibrium concentration of these species over a condensate containing 0.9 mole fraction cesium hydroxide and 0.1 mole fraction cesium iodide. The equilibrium concentration of the minority species, cesium iodide, has been reduced by nearly three orders of magnitude, while that of the majority species, cesium hydroxide, is barely changed from the concentration over the pure species. The lines labeled 0.5 $\mathrm{CsOH}$ and $0.5 \mathrm{CsI}$ indicate the calculated equilibrium concentration over a condensate consisting of equal molar parts of cesium iodide and cesium hydroxide. In this case, the equilibrium vapor concentration of each species is reduced by nearly an order of magnitude.

Figure 14.1-8 illustrates the reduction of the discontinuity present at the melting point by the correlation technique used in this project. The top line is the equilibrium concentration of cesium iodide calculated with Equations (14.1-57) and (14.1-58), and the bottom line is the concentration calculated with Equation (14.1-4). The distance between the two correlations is a factor of about $10^{0.08}$, or 1.2 , while the discontinuity is about a factor of $10^{0.007}$, or 1.02 . 
GCEQ
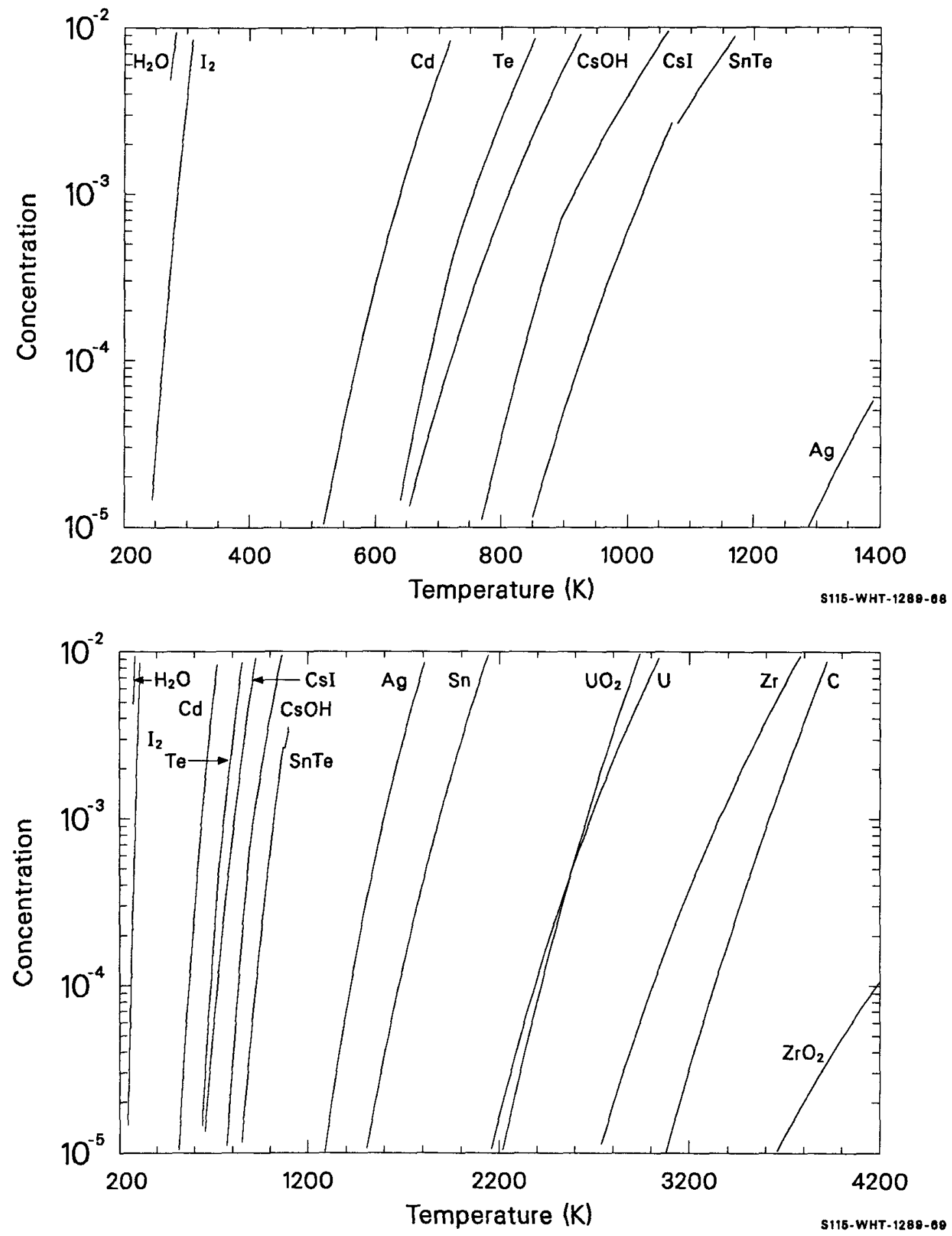

Figure 14.1-6. Equilibrium concentrations versus temperatures for several species. 


\section{GCEQ}

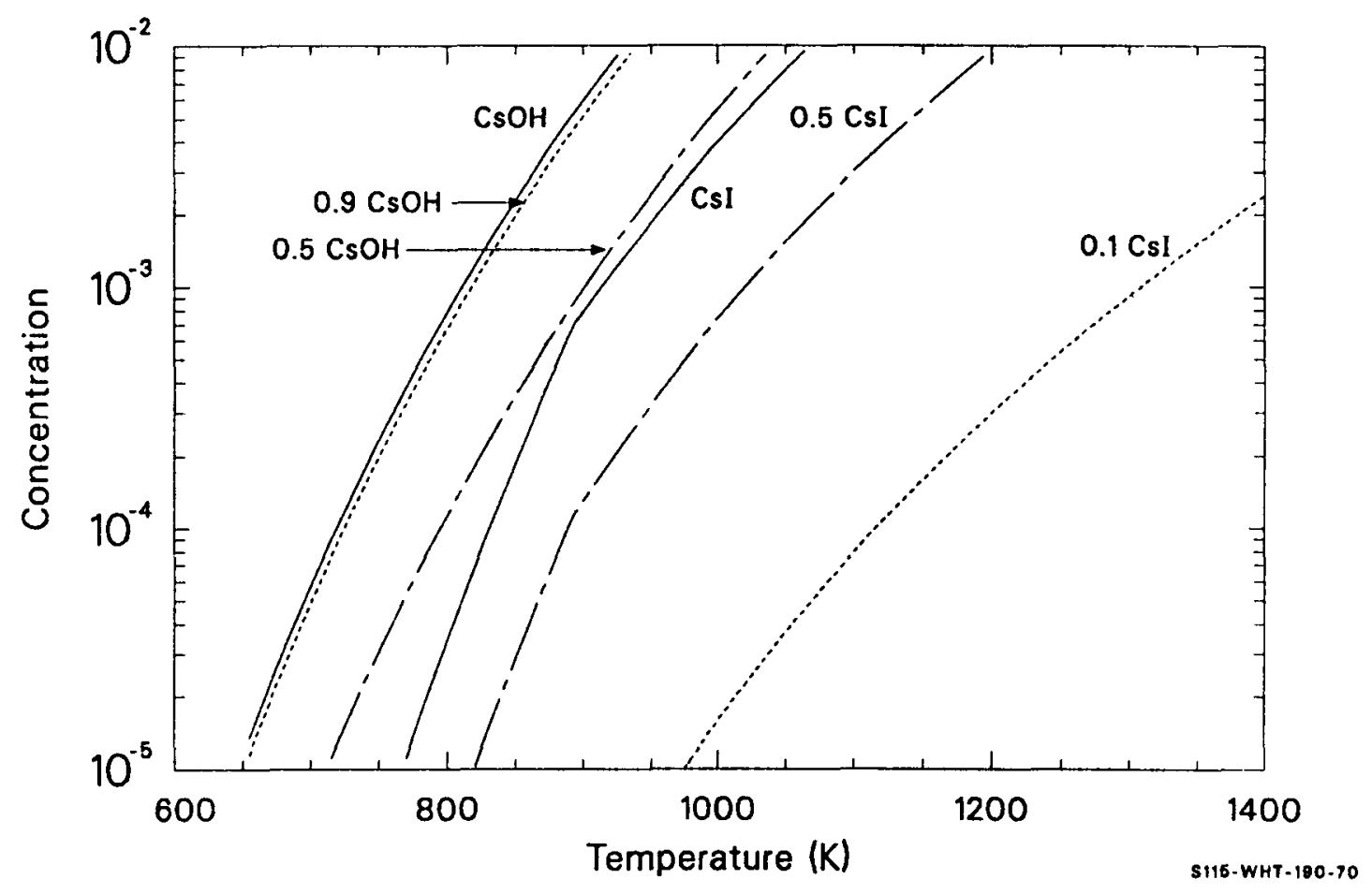

Figure 14.1-7. Calculated effect of mixing of cesium hydroxide and cesium iodide condensate on equilibrium vapor concentrations. 
GCEO

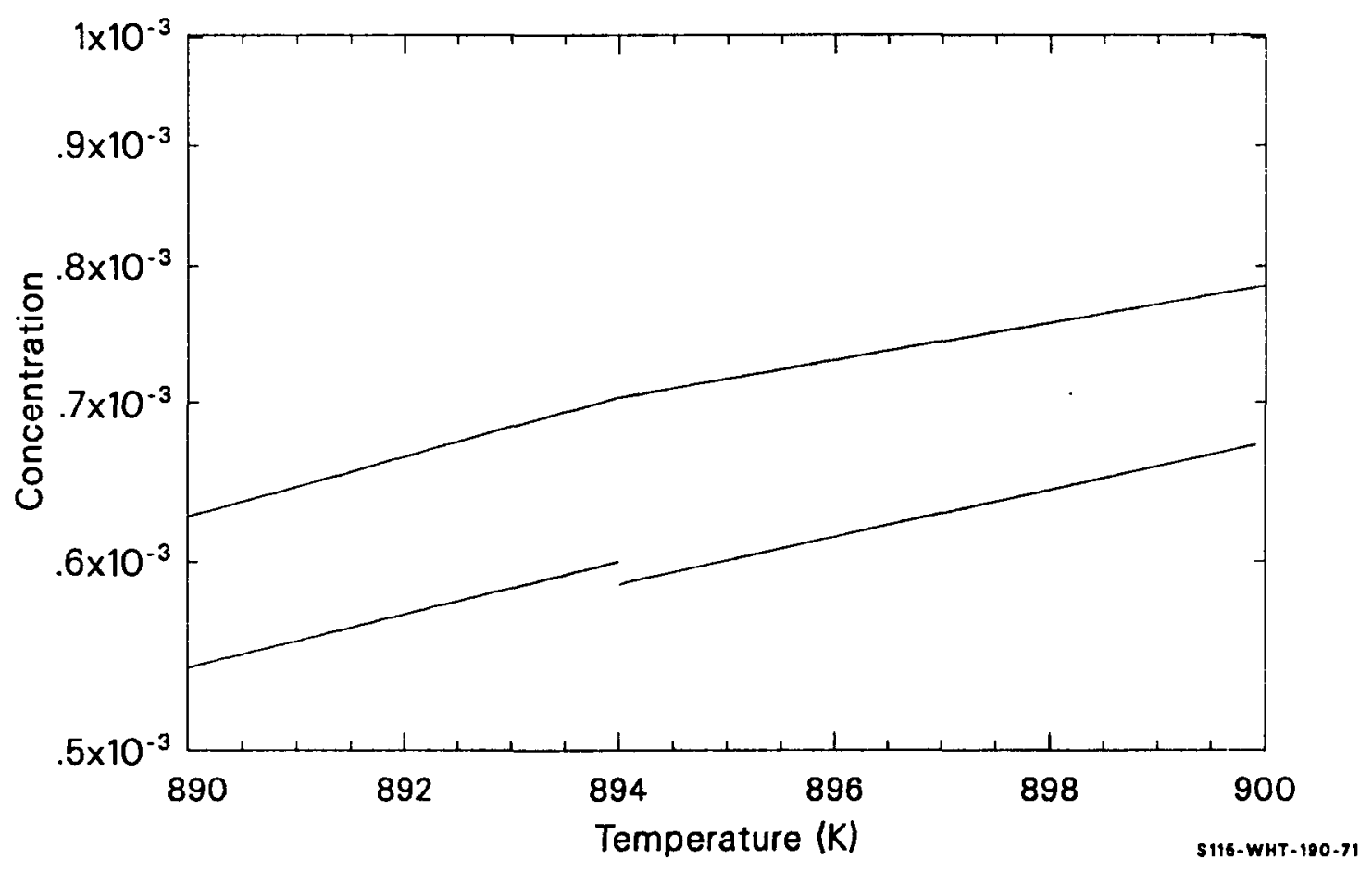

Figure 14.1-8. Reduction of discontinuity at the melt point with the techniques developed in this section. 
GCEQ

\subsubsection{References}

14.1-1. D. A. Powers, Behavior of Control Rods During Core Degradation I: Pressurization of Silver-Indium-Cadmium Control Rods, A-1227 Preliminary report. Final report to be published.

14.1-2. Robert C. Weast, Handbook of Chemistry and Physics, Cleveland, Ohio: The Chemical Rubber Co., 1968, p. B-205.

14.1-3. Ibid., P. F-64.

14.1-4. W. Ramsay and S. Young, "On the Vapour-pressures of Bromine and Iodine, and on Iodine Monochloride," Journal of Chemical Society Abstracts, 49, 1886, pp. 453-462.

14.1-5. G. P. Baxter, C. H. Hickey, and W. C. Holmes, "The Vapor Pressure of Iodine," American Chemical Society Journal, 28, 1907, pp. $127-136$.

14.1-6. J. H. Stern and N. W. Gregory, "The Condensation Coefficient of Iodine," Journal of Physical Chemistry, 61, 1957, pp. 1226-1232.

14.1-7. D. R. Stu11, "Vapor Pressure of Pure Substances - Inorganic Compounds," Industrial and Engineering Chemistry, 39, 1947, pp. 540-550.

14.1-8. J. A. Gieseke, P. Baybutt, H. Jordan, R. S. Denning, and R. 0 . Wooton, Analysis of Fission Product Transport Under Terminated LOCA Conditions, BMI-NUREG-1990, December 1977.

14.1-9. M. R. Kuhlman, V. Kogan, and P. M. Schumacher, TRAP-MELT2 Code: Development and Improvement of Transport Modeling, BMI-2141, NUREG/CR-4677, July 1986.

14.1-10. 0. Kubaschewski and C. B. Alcock, Metallurgical Thermochemistry, New York: Pergamon Press, 1979.

14.1-11. K. K. Kelley, Contributions to the Data on Theoretical Metallurgy III. The Free Energies of Vaporization and Vapor Pressures of Inorganic Substances, U. S. Department of the Interior Bureau of Mines Bulletin 383, 1935.

14.1-12. L. Brewer, "The Thermodynamic and Physical Properties of the Elements," National Nuclear Energy Series. Manhattan Project Technical Section. Division IV Plutonium 19B, 1947.

14.1.13. A. N. Nesmeyanov, Vapor Pressure of the Chemical Elements, New York: Elsevier Publishing Company, 1963. 
14.1-14. C. T. Ewing and K. H. Stern, "Equilibrium Vaporization Rates and Vapor Pressures of Solid and Liquid Sodium Chloride, Potassium Chloride, Potassium Bromide, Cesium Iodide, and Lithium Fluoride," Journal of Physical Chemistry, 78, 1974, pp. 1998-2005.

14.1-15. J. C. Cummings, R. M. Elrick, and R. A. Sallach, Status Report on the Fission-Product Research Program, NUREG/CR-1820, March 1982.

14.1-16. G. E. Cogan and G. E. Kimball, "The Vapor Pressures of Some Alkali Halides, "Journal of Chemical Physics, 16, pp. 1035-1048.

14.1-17. J. L. Margrave (ed.), The Characterization of High-Temperature Vapors, New York: John Wiley and Sons, Inc.

14.1-18. D. A. Powers, J. E. Brockmann, A. W. Shiver, VANESA: A Mechanistic Model of Radionuclide Release and Aerosol Generation During Core Debris Interactions with Concrete, NUREG/CR-4308, SAND85-1370, July 1986.

14.1-19. M. W. Zemansky, Heat and Thermodynamics, New York: McGraw-Hi11 Book Company, Inc., 1957.

14.1-20. F. B. Hildebrand, Methods of Applied Mathematics, Englewood Cliffs, N.J.: Prentice-Ha11, Inc., 1961, pp. 121-123.

14.1-21. C. Kittel, Elementary Statistical Physics, New York: John Wiley and Sons, Inc., 1967, pp. 222-224.

14.1-22. K. Huang, Statistical Mechanics, New York: John Wiley and Sons, Inc., 1963, pp. 180-182. 


\section{CHEMICAL REACTIONS AND SOLUTION RATES}

The MATPRO library contains a number of subcodes that describe reaction rates rather than static materials properties. The subcodes described in this section are FOXY and FOXYK, which calculate the rate of $\mathrm{UO}_{2}$ oxidation in steam; CORROS, COBILD, COXIDE, COXWTK, and COXTHX, which calculate zircaloy oxidation rates in water and steam; CHUPTK, which calculates the zircaloy hydrogen uptake rate in water; SOXIDE, SOXWGN, and SOWTHK, which calculate the stainless steel oxidation rate in steam; DISU02, U02DIS, and $\mathrm{UO2SOL}$, which calculate the rate of dissolution of $\mathrm{UO}_{2}$ in $\mathrm{Zr}-\mathrm{U}-\mathrm{O}$; and GCHMI, which calculates the rates of reaction for various fission product species with stainless steel or zircaloy surfaces. 


\section{FOXY, FOXYK}

\subsection{FUEL OXIDATION (FOXY, FOXYK)}

(R. Chambers)

The fuel oxidation models, FOXY and FOXYK, calculate $\mathrm{UO}_{2}$ oxygen uptake in steam for $\mathrm{UO}_{2}$ temperatures above $1150 \mathrm{~K}$. The $\mathrm{UO}_{2}$ oxidation weight gain is modeled using parabolic kinetics. 0xidation of $\mathrm{UO}_{2}$ affects its chemical composition, which, in turn, significantly affects most of the other material properties of the fuel (i.e., thermal conductivity and melting temperature). ${ }^{15.1-1}$ Changes in the material properties of the $\mathrm{UO}_{2}$ may have an impact on core behavior during severe reactor accidents involving potential liquefaction of the fuel matrix. 15.1-2

\subsubsection{Summary}

The equation used to mode $1 \mathrm{UO}_{2}$ oxygen uptake in steam is

$W^{2}=24.4 \exp \left(\frac{-26241}{T}\right) \Delta t+W_{0}^{2}$

where

$W=$ oxidation weight gain at end of time step $\left(\mathrm{kg} / \mathrm{m}^{2}\right)$

$\mathrm{T}=$ temperature of the $\mathrm{UO}_{2}$ surface $(\mathrm{K})$.

$\Delta t=$ oxidation time $(s)$

$W_{0}=$ initial oxidation weight gain $\left(\mathrm{kg} / \mathrm{m}^{2}\right)$. 


\section{FOXY, FOXYK}

The standard error ${ }^{a}$ of the model with respect to its data base is $0.027 \mathrm{~kg} / \mathrm{m}^{2}$, or $21 \%$ of the average measured weight gain.

An estimate of the power resulting from the oxidation of $\mathrm{UO}_{2}$ is given by the equation

$P=\frac{\left(W-W_{0}\right)\left(1.84 \times 10^{5}\right)}{\Delta t}$

where $P$ is the rate of heat generation $\left(W / m^{2}\right)$.

\subsubsection{Review of Literature}

The only published data for $\mathrm{UO}_{2}$ oxygen uptake are provided by Bittel et a1.15.1-3 The constants used in Equation (15.1-1) came from this source. The data represent temperatures from 1158 to $2108 \mathrm{~K}$. These constants appear to be independent of fuel density and surface-to-volume ratio. However, additional data are needed for oxidation at $\mathrm{UO}_{2}$ temperatures in excess of $2108 \mathrm{~K}$ and, in particular, for molten $\mathrm{UO}_{2}$.

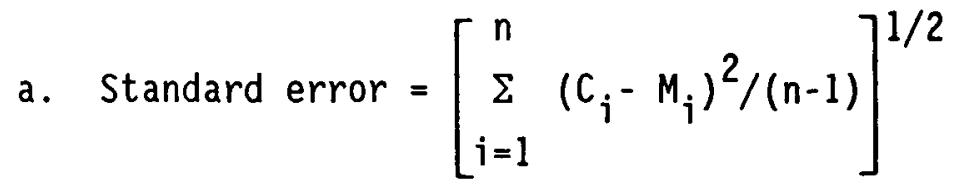
where

$c_{i}=$ calculated weight gain

$M_{j}=$ measured weight gain

$n=$ number of data points. 
FOXY, FOXYK

\subsubsection{Model Development}

The model for $\mathrm{UO}_{2}$ oxygen uptake is based on parabolic kinetics. That is, the rate of oxygen weight gain is inversely proportional to the amount of excess oxygen present, or

$\frac{d W}{d t}=\frac{k}{W}$

where

$$
\begin{aligned}
& t=\operatorname{time}(\mathrm{s}) \\
& k=\text { rate constant }\left(\mathrm{kg}^{2} / \mathrm{m}^{4} \cdot \mathrm{s}\right) .
\end{aligned}
$$

Solution of this differential equation yields

$$
w^{2}-w_{0}^{2}=2 k \Delta t=k_{p} \Delta t
$$

where

$$
\begin{aligned}
K_{p} & =2 k\left(\mathrm{~kg}^{2} / \mathrm{m}^{4} \cdot \mathrm{s}\right) \\
& =24.4 \exp \frac{-26241}{T} .
\end{aligned}
$$

Equation (15.1-4) is equivalent to Equation (15.1-1). The parabolic rate constant, $K_{p}$, was determined in Reference 15.1-3 using a least-squares data fit. Table 15.1-1 contains a list of the data used to determine $K_{p}$, along with the corresponding calculated value of $W$.

Although experimental data were recorded only for temperatures ranging from 1158 to $2108 \mathrm{~K}$, the correlation of Equations (15.1-1) and (15.1-4) is 


\section{FOXY, FOXYK}

Table 15.1-1. Measured and calculated weight gain

\begin{tabular}{cccc}
\hline & & & \\
$\begin{array}{c}\text { Temperature } \\
(\mathrm{K})\end{array}$ & $\begin{array}{c}\text { Test Time } \\
(\mathrm{s})\end{array}$ & $\begin{array}{c}\text { Test } \\
\text { Weight Gain } \\
\left(\mathrm{kg} / \mathrm{m}^{2}\right)\end{array}$ & $\begin{array}{c}\text { Correlation } \\
\text { Weight Gain } \\
\left(\mathrm{kg} / \mathrm{m}^{2}\right)\end{array}$ \\
\cline { 2 - 3 } 2108 & 600 & 0.2313 & 0.2397 \\
2068 & 600 & 0.2036 & 0.2125 \\
1993 & 600 & 0.1679 & 0.1674 \\
1988 & 600 & 0.1401 & 0.1646 \\
1898 & 1200 & 0.1636 & 0.1703 \\
1883 & 1200 & 0.1904 & 0.1611 \\
1873 & 1800 & 0.2574 & 0.1901 \\
1793 & 1200 & 0.1117 & 0.1136 \\
1773 & 1140 & 0.1170 & 0.1019 \\
1768 & 2400 & 0.1351 & 0.1448 \\
1768 & 4740 & 0.1672 & 0.2035 \\
1678 & 3600 & 0.1897 & 0.1191 \\
1673 & 6900 & 0.1365 & 0.1611 \\
1668 & 5700 & 0.1619 & 0.1430 \\
1663 & 2400 & 0.1004 & 0.09065 \\
1478 & 7020 & 0.07352 & 0.05775 \\
1478 & 11800 & 0.08825 & 0.07487 \\
1373 & 11860 & 0.02577 & 0.03807 \\
1368 & 10500 & 0.04287 & 0.03459 \\
1273 & 24480 & 0.02373 & 0.02582 \\
1158 & 17400 & 0.01445 & 0.00782 \\
\hline & & & \\
\hline & & & \\
\hline & & & 0
\end{tabular}


used for any temperature up to the melting temperature of $\mathrm{UO}_{2}(3100 \mathrm{~K})$. When the fuel temperature exceeds $3100 \mathrm{~K}$, oxidation is assumed to continue at a temperature of $3100 \mathrm{~K}$.

As an estimate of the heat of reaction for oxidation of $\mathrm{UO}_{2}$, one percent of the heat of reaction per pound of oxygen in the oxidation of zircaloy was used. The correlation for the rate of heat generation is

$P=\frac{\left(W-W_{0}\right)(0.01)\left(6.45 \times 10^{6}\right)(2.85)}{\Delta t}$

where
$6.45 \times 10^{6}=$ heat of reaction per $\mathrm{kg} \operatorname{Zr}(\mathrm{J} / \mathrm{kg})$
$2.85=$ ratio of weight of $\mathrm{Zr}$ to $\mathrm{O}_{2}$ in $\mathrm{ZrO}_{2}$.

Equation (15.1-5) is equivalent to Equation (15.1-2).

A standard error of $0.027 \mathrm{~kg} / \mathrm{m}^{2}$ was calculated using the measured and calculated values of oxygen weight gain given in Table 15.1-1. This number was converted to a fraction of the measured value of oxygen uptake because the fractional error was more nearly constant over the temperature range of the data than the absolute error. The standard error of $0.027 \mathrm{~kg} / \mathrm{m}^{2}$ is about $21 \%$ of the mean measured oxygen uptake $\left(0.1306 \mathrm{~kg} / \mathrm{m}^{2}\right)$.

Development of the model is based on the following assumptions:

1. Enough oxygen is always available for the oxidation process.

2. The correlation [Equations (15.1-1) and (15.1-4)] applies for $\mathrm{UO}_{2}$ temperatures below $1158 \mathrm{~K}$ and above $2108 \mathrm{~K}$ up to $3100 \mathrm{~K}$, where no data exist. 


\section{FOXY, FOXYK}

3. For $\mathrm{UO}_{2}$ temperatures above $3100 \mathrm{~K}$, oxidation will continue at the rate corresponding to a $\mathrm{UO}_{2}$ temperature of $3100 \mathrm{~K}$.

Figures 15.1-1 and 15.1-2 show the computed weight gain as functions of temperature and time, respectively. In Figure 15.1-1, the $\mathrm{UO}_{2}$ temperatures range from $1158 \mathrm{~K}$ to $3400 \mathrm{~K}$ at a constant oxidation time of $60 \mathrm{~s}$. The exponential nature of the curve can be seen up to temperatures of $3100 \mathrm{~K}$. Above this temperature, weight gain calculations are constant using a temperature of $3100 \mathrm{~K}$. Figure 15.1-2 shows the weight gain for times ranging from 1 to $200 \mathrm{~s}$ at a constant $\mathrm{UO}_{2}$ temperature of $1600 \mathrm{~K}$. This curve is parabolic in shape.

\subsubsection{Description of the FOXY and FOXYK Subcodes}

The following input variables or information are needed for FOXY: the time duration of oxidation $(s)$, fuel temperature $(K)$, and initial oxidation weight gain $\left(\mathrm{kg} / \mathrm{m}^{2}\right)$. The FOXY subcode will output the total oxide weight gain at the end of the time step and a preliminary estimate of the power generated from this oxidation $\left(W / \mathrm{m}^{2}\right)$. Also, the value of the parabolic rate constant, [ $K_{p}$ in Equation (15.1-4)] is made available by FOXYK. Table 15.1-2 is a list of the FORTRAN names for these variables. The input will be accepted in the following ranges:

$$
\begin{aligned}
& \text { FTEMP } \geq 0 \\
& \text { DT }>0 \\
& \text { U020XI }>0 .
\end{aligned}
$$

The output variable, KRAP, can assume any of the following values:

KRAP $=0$ if there are no input errors

KRAP $=1$ if fuel temperature exceeds melt or is below the correlation range 
FOXY, FOXYK

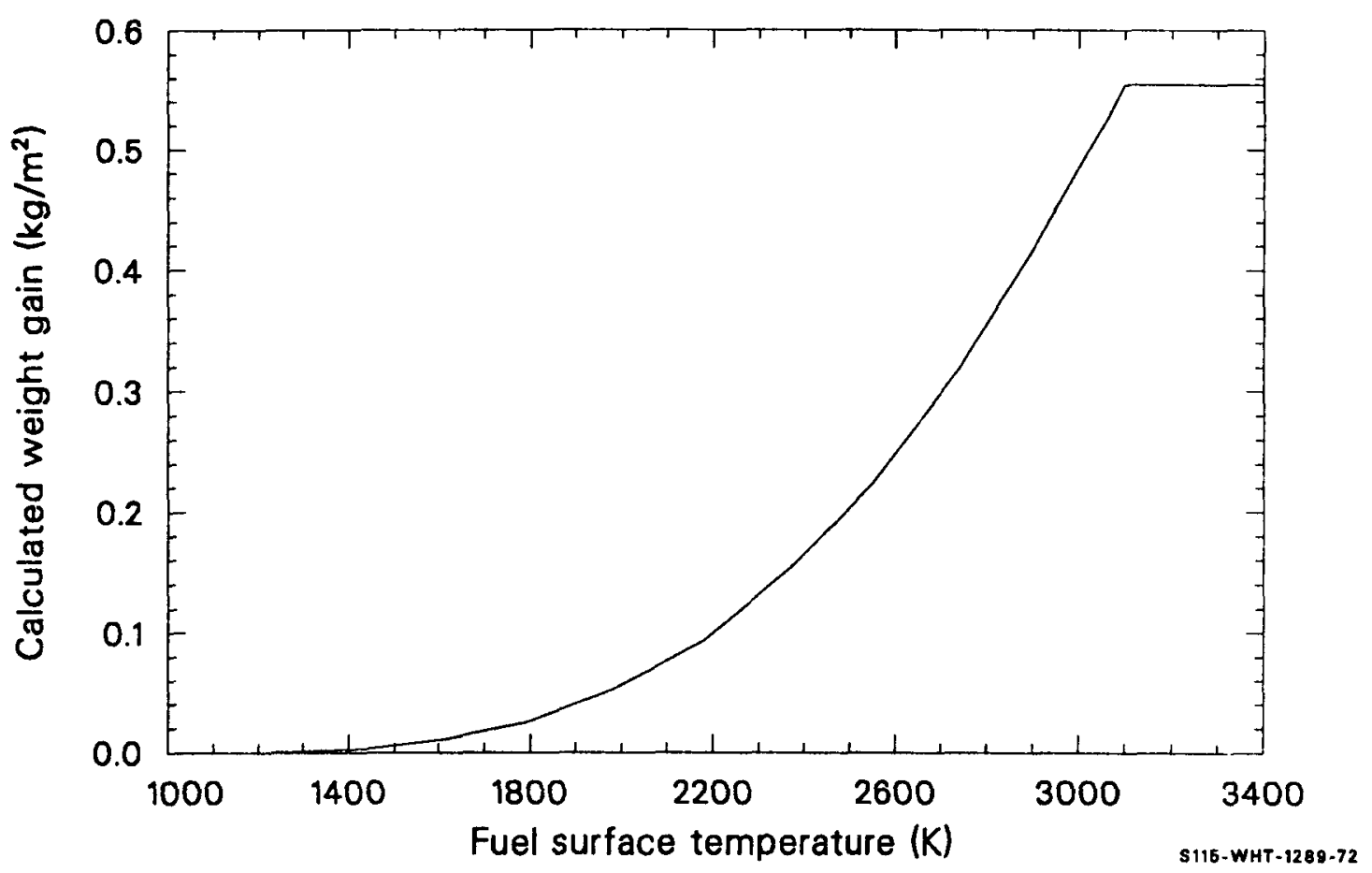

Figure 15.1-1. Computed weight gain as a function of temperature for constant time step size. 


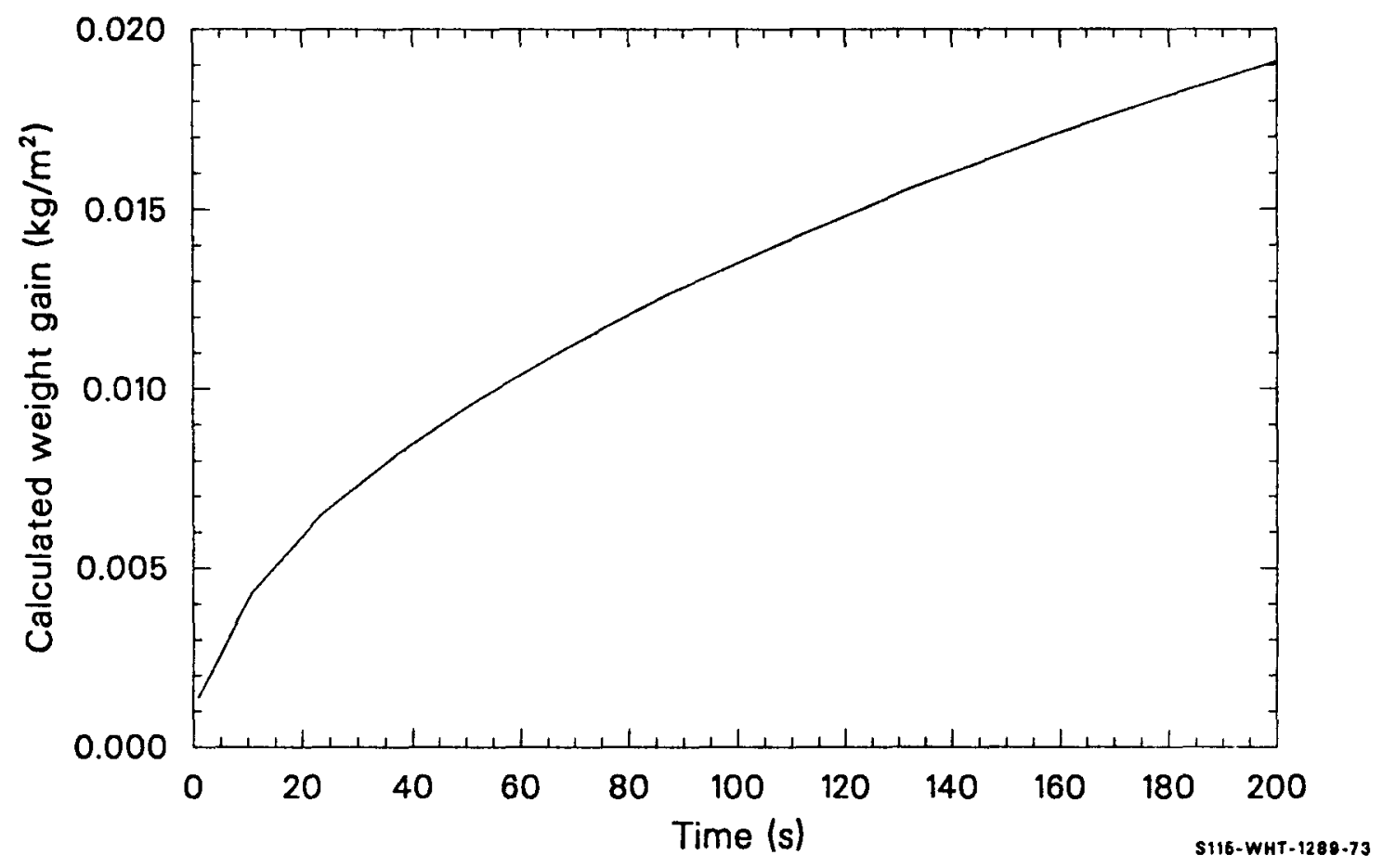

Figure 15.1-2. Computed weight gain as a function of time step size for constant temperature. 
FOXY, FOXYK

Table 15.1-2. Glossary of FORTRAN names

\begin{tabular}{lllll}
\hline Variable & $\begin{array}{c}\text { Input or } \\
\text { Output }\end{array}$ & & \multicolumn{1}{c}{ Definition } & Units \\
\cline { 2 - 4 } FTEMP & Input & Fuel surface temperature & $\mathrm{K}$ \\
DT & Input & Time step & $\mathrm{s}$ \\
U020XI & Input & Initial oxide weight gain & $\mathrm{kg} / \mathrm{m}^{2}$ \\
U020XF & Output & Final oxide weight gain & $\mathrm{kg} / \mathrm{m}^{2}$ \\
P & Output & Power generated by oxidation & $\mathrm{W} / \mathrm{m}^{2}$ \\
KRAP & Output & Index of input errors & -- \\
FOXYK & -- & Parabolic rate constant & $\mathrm{kg}^{2} / \mathrm{m}^{4} \cdot \mathrm{s}$ \\
\hline
\end{tabular}




\section{FOXY, FOXYK}

KRAP $=2$ if the fuel temperature is not positive or the original weight gain or time step size is negative.

Whenever the fuel temperature is nonpositive or the time step size or initial oxide weight gain is negative, the final oxide weight gain and the power are set to one. A diagnostic message is printed if any one of these input errors is noted but was not noted during the previous execution of FOXY. This message states, "Input Error in FOXY." The entire input is then printed.

\subsubsection{References}

15.1-1. D. L. Hagrman, Melting Temperatures of Uranium-Zirconium-Oxygen Compounds (PSOL and PLIQ) and Uranium Dioxide Solubility in Zircaloy (PSLV), EGG-CDAP-5303, January 1981.

15.1-2. C. M. Allison et al., Severe Core Damage Analysis Package (SCDAP), Code Conceptual Design Report, EGG-CDAP-5397, April 1981.

15.1-3. J. T. Bitte1, L. H. Sjodah1, and J. F. White, "Steam Oxidation Kinetics and Oxygen Diffusion in $\mathrm{UO}_{2}$ at High Temperatures, " Journal of the American Ceramic Society, 52, 1969, pp. 446-451. 


\title{
CORROS， COBILD， COXIDE， COXWTK， COXTHK
}

\subsection{Zrrcaloy OXidation In Water and Steam (CORROS, COBILD, COXIDE, COXWTK, COXTHK)}

\author{
(N. L. Hampton and D. L. Hagrman)
}

The oxidation of zircaloy cladding is an important subject because the thermal and mechanical properties of oxidized zircaloy are significantly different than the unoxidized properties. Moreover, the oxidation is highly exothermic. It can proceed rapidly enough at high temperatures to cause the reaction heat to significantly influence temperatures.

\subsubsection{Summary}

Low-temperature (523 to $673 \mathrm{~K}$ ) oxidation is modeled with the CORROS subcode, and high-temperature (1273 to $2100 \mathrm{~K})$ oxidation is modeled with the COBILD, COXIDE, COXWTK and COXTHK subcodes. These codes provide information for other MATPRO subcodes, which describe the mechanical properties of zircaloy containing oxygen. This information includes oxygen concentrations, layer thicknesses, and the linear heating rate due to the zirconium-water reaction.

Oxide layer thickness is the only quantity calculated by the CORROS subcode. No other layers are found in zircaloy oxidized at 523 to $673 \mathrm{~K}$.

COBILD, a FORTRAN adaptation of the BASIC BUILD5 code by R. Pawe1, of Oak Ridge National Laboratory, calculates high-temperature oxygen concentrations, layer thicknesses, and the heating rate due to the zirconium-steam reaction. The temperature at the beginning and end of a time step and the time step duration are required input information. The time step is divided into five substeps. During each substep, the average 


\section{CORROS, COBILD, COXIDE, COXWTK, COXTHK}

temperature obtained from a linear interpolation of the input temperatures is used with the isothermal correlations that are discussed below.

Calculations in COXIDE are isothermal. The input time step is not divided, and the temperature provided is assumed to be the average temperature for the entire step. Also, the oxygen concentration calculations of COBILD are not carried out in COXIDE.

COXWTK and COXTHK provide only oxidation rate constants for the high temperatures. The rate constants are provided in separate subcodes so that they are available for use with routines that calculate the coupled effects of oxidation heat, temperature, and geometry.

15.2.1.1 Low-Temperature 0xidation (CORROS). The subroutine CORROS returns an expression for the thickness of the oxide layer on zircaloy cladding during typical reactor operation at temperatures of 523 to $673 \mathrm{~K}$. Required input values are temperature at the outer surface of the oxide, initial oxide film thickness, length of time at the given temperature, type of reactor (BWR or PWR), heat flux across the oxide layer, and zircaloy oxide thermal conductivity.

Cladding oxidation during normal LWR operation occurs in two stages, depending on the oxide thickness and to some extent on the temperature of the oxide. For thin oxides, the rate of oxidation is controlled by the entire oxide layer. When the oxide layer becomes thicker, a change of the outer portion occurs; and further oxidation is controlled by the intact inner layer. The transition between stages is described in terms of thickness of the oxide layer at transition:

$X_{\text {TRAN }}=7.749 \times 10^{-6} \exp \left(\frac{-790}{T}\right)$

where 


\section{CORROS， COBILD， COXIDE， COXWTK， COXTHK}

$X_{\text {TRAN }}=$ thickness of the oxide layer at transition point $(\mathrm{m})$ (typically $1.9 \times 10^{-6}-\mathrm{m}$ thick)

$T=$ temperature of the oxide-metal interface (K).

Values of the thickness of the oxide layer on the outside of the cladding are given by Equations (15.2-2), (15.2-3), and (15.2-4) for pretransition and posttransition oxide films.

For pretransition oxide films:

$X_{\mathrm{PRE}}=\left[4.976 \times 10^{-9} \text { At } \exp \left(\frac{-15660}{\mathrm{~T}}\right)+X_{0}^{3}\right]^{1 / 3}$.

For posttransition oxide films when $x_{0}$, the initial oxide thickness, is less than $\mathrm{X}_{\text {TRAN }}$ :

$X_{\text {POST }}=82.88 \mathrm{~A}\left(\mathrm{t}-\mathrm{t}_{\text {TRAN }}\right) \exp \left(\frac{-14080}{\mathrm{~T}}\right)+\mathrm{X}_{\text {TRAN }}$.

When $x_{0}$ is greater than the transition thickness:

$X_{\text {POST }}=82.88 \mathrm{At} \exp \left(\frac{-14080}{T}\right)+X_{0}$

where

$X_{\text {PRE }}=$ thickness of the oxide layer when a pretransition oxide film exists ( $m$ )

A $=$ a parameter describing enhancement of the cladding oxidation rate in a reactor environment. Typical reactor coolant chemistry, temperatures, and flux levels result in a value of $A=1.5$ and 9 for a PWR and BWR, 


\title{
CORROS, COBILD， COXIDE， COXWTK， COXTHK
}

\author{
respectively. However, the factor is a function of \\ temperature, as discussed in Section 15.2.3. A value \\ for $A$ is determined by correlations in the subcode using \\ user specification of BWR or PWR chemistry with an input \\ parameter ICOR. \\ $\mathrm{t}=$ time at temperature (days) \\ $\mathrm{T}=$ temperature of the oxide-metal interface calculated by \\ the subcode from the input value of the temperature at \\ the outer oxide surface, the heat flux across the oxide, \\ and the thermal conductivity of the oxide layer $(K)$. \\ $x_{0}=$ initial thickness of the cladding oxide layer $(m)$. (This \\ term can be approximated as $x_{0}=0$ for etched \\ cladding, but it becomes important if extensive \\ prefilming has occurred or if oxidation is carried out \\ in several steps which take place at different \\ temperatures or in different coolant chemistries.)
}

$X_{\text {POST }}=$ thickness of the oxide layer when the oxide film is in the posttransition state $(\mathrm{m})$

$t_{\text {TRAN }}=$ time of transition between states (pre- and posttransition). [This time is calculated in the subcode from the inverse of Equation (15.2-2)].

$X_{\text {TRAN }}=$ thickness of the oxide layer at the transition point $(\mathrm{m})$ (Equation 15.2-1)

15.2.1.2 High-Temperature 0xidation (COBILD, COXIDE, COXWTK, COXTHK). For the high-temperature range $(1273$ to $2100 \mathrm{~K})$, neither the heat flux nor the coolant chemistry has an important influence on the extent of 


\section{CORROS， COBILD， COXIDE， COXWTK， COXTHK}

oxidation. At these reactor operating temperatures, the coolant has become steam; and oxidation proceeds much more rapidly than at normal LWR operating temperatures. Zircaloy normally has a body-centered cubic structure in this temperature range, called the beta phase, but the presence of oxygen causes two other possibilities. If the oxygen concentration is greater than about 0.25 weight fraction, one of several zirconium dioxide structures is formed. For oxygen weight fractions around 0.04, a hexagonal, close-packed phase called oxygen-stabilized alpha-zircaloy is formed. Thus, high-temperature oxidation of zircaloy in steam produces three layers: the ductile inner beta layer with minimal dissolved oxygen, an intermediate oxygen-stabilized alpha-zircaloy layer, and a zirconium dioxide layer near the zircaloy-steam interface.

When zircaloy cladding is exposed not only to steam on its outer surface but also to firm contact with uranium dioxide on the inside surface, three distinct inside layers are formed as oxygen and uranium diffuse into the cladding. A schematic cross section of a fuel rod with fuel and pellet in contact is shown in Figure 15.2-1. The layers shown in this figure are

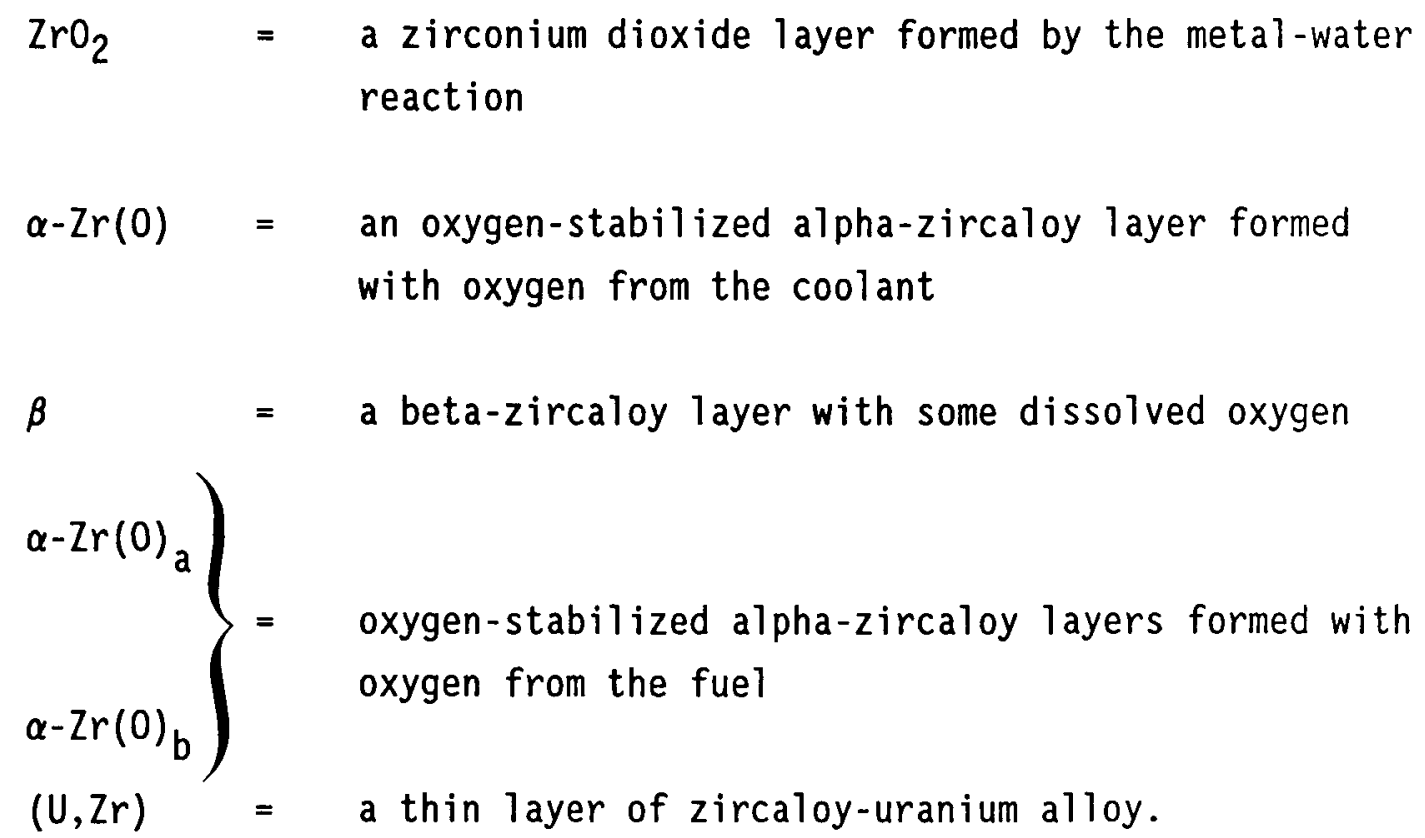


CORROS, COBILD， COXIDE， COXWTK， COXTHK

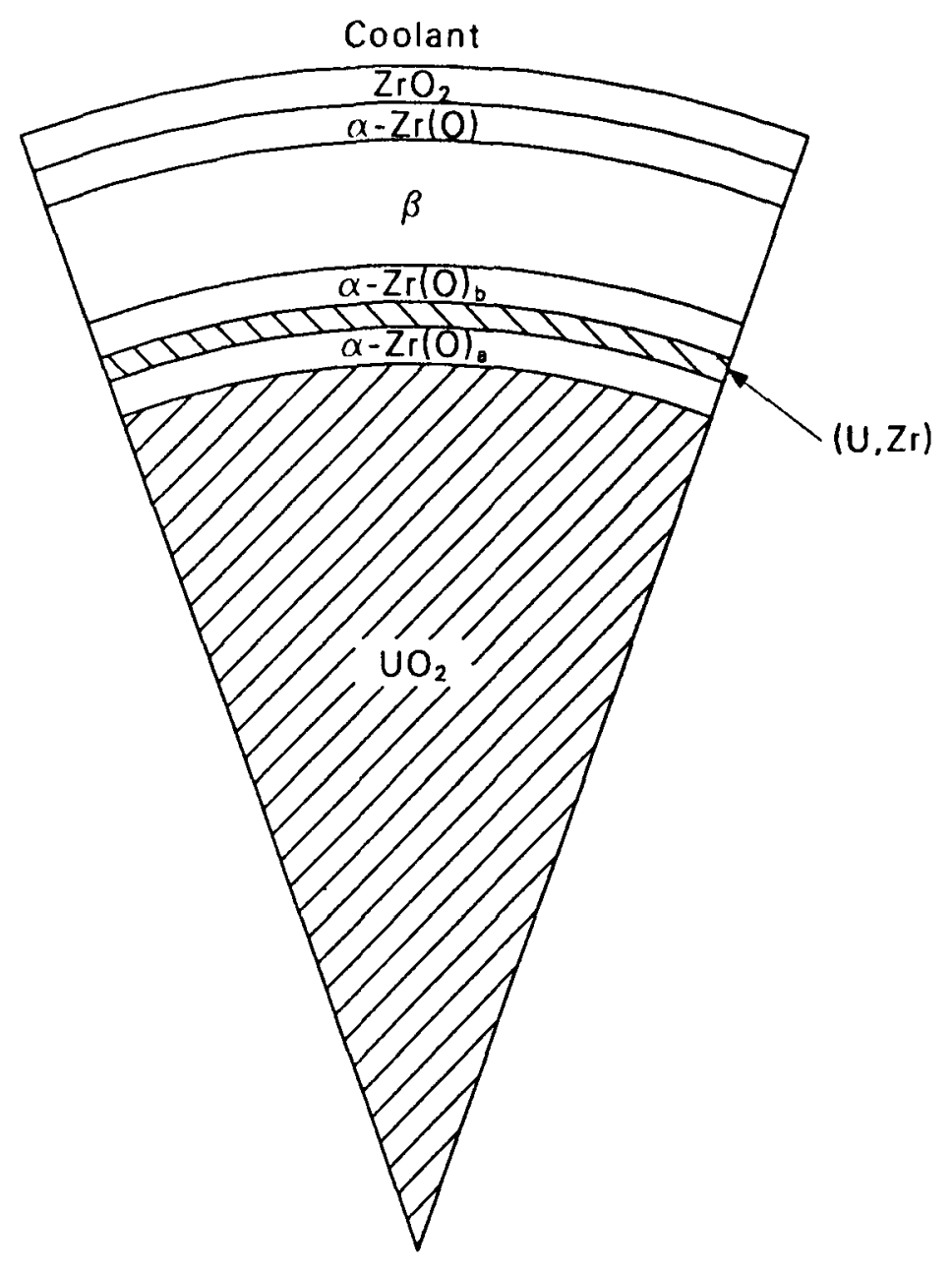

S115-WHT - $1289-74$

Figure 15.2-1. Idealized schematic of a uranium dioxide pellet in contact with the cladding, showing the layered structure. 


\section{CORROS, COBILD, COXIDE, COXWTK， COXTHK}

COBILD works in time steps. At the start of each time step, it should be supplied with quantities including the duration of the time step, the temperature at the beginning and end of the step, the original unoxidized cladding dimensions, the thickness of the various layers and their oxygen concentrations, and the total oxygen uptake at the beginning of the timestep. After updating or recalculating several of these to conform to conditions at the end of the time step, it returns values for each of them.

The equations used to model the growth of the outside layers exposed to steam are all of the form

$z_{f}=z_{i}^{2}+2 A \exp (-B / T) \Delta t^{1 / 2}$

where

$$
\begin{aligned}
& Z_{f}=\quad \begin{array}{l}
\text { value of oxidation parameter (oxide layer thickness, alpha } \\
\text { layer thickness, or zircaloy weight gain per unit surface } \\
\text { area due to oxidation) at the end of a time span of length } \\
\Delta t
\end{array} \\
& Z_{i}=\text { value of oxidation parameter at the start of the time span } \\
& T \quad=\text { temperature of the oxide layer }(K) \\
& A, B=\text { rate constants. }
\end{aligned}
$$

Table 15.2-1 lists the rate constants used with Equation (15.2-5) to model the various oxidation parameters for steam oxidation. In all cases, the model assumes that there is sufficient steam to provide the indicated weight gain. The parabolic rate constants for the $\alpha-\operatorname{Zr}(0)$ thicknesses in this table are not valid when the beta zircaloy layer becomes small. 
CORROS， COBILD， COXIDE， COXWTK， COXTHK

Table 15.2-1. Rate constants for oxidation by steam

\begin{tabular}{|c|c|c|}
\hline Parameter & A & B \\
\hline \multicolumn{3}{|l|}{$\mathrm{ZrO}_{2}$ thickness (m) } \\
\hline For temperature $\leq 1853 \mathrm{~K}$ & $1.126 \times 10^{-6} \mathrm{~m}^{2} / \mathrm{s}$ & $1.806 \times 10^{4} \mathrm{~K}$ \\
\hline For temperature $>1853 \mathrm{~K}$ & $1.035 \times 10^{-6} \mathrm{~m}^{2} / \mathrm{s}$ & $1.6014 \times 10^{4} \mathrm{~K}$ \\
\hline$\alpha-\operatorname{Zr}(0)$ thickness (m) & $7.615 \times 10^{-5} \mathrm{~m}^{2} / \mathrm{s}$ & $2.423 \times 10^{4} \mathrm{~K}$ \\
\hline \multicolumn{3}{|c|}{ Weight gain per unit surface area, $\mathrm{kg} / \mathrm{m}^{2}$ ) } \\
\hline For temperature $\leq 1853 \mathrm{~K}$ & $1.680 \times 10^{1}\left(\mathrm{~kg} / \mathrm{m}^{2}\right)^{2} / \mathrm{s}$ & $2.006 \times 10^{4} \mathrm{~K}$ \\
\hline For temperature $\geq 1853 \mathrm{~K}$ & $5.426 \times 10^{1}\left(\mathrm{~kg} / \mathrm{m}^{2}\right)^{2} / \mathrm{s}$ & $1.561 \times 10^{4} \mathrm{~K}$ \\
\hline
\end{tabular}




\section{CORROS, COBILD, COXIDE, COXWTK, COXTHK}

Equation (15.2-5) is also used to model the growth of the inside of the $\alpha-\operatorname{Zr}(0)_{\mathrm{a}}$ and $\alpha-\operatorname{Zr}(0)_{\mathrm{b}}$ layers. For these layers, the growth rate is modeled as zero unless there is pellet-cladding contact. For those time steps when there is pellet-cladding mechanical interaction, the constants given in Table 15.2-2 are used with Equation (15.2-5) to calculate the layer thickness.

The expression used to calculate the rate of heat generation due to the exothermic oxidation of zircaloy by steam is

$P=1.15 \times 10^{8} \frac{R_{0}\left(W_{f}-W_{j}\right)}{\Delta t}$

where

$\mathrm{P} \quad=\quad$ rate of heat generation per unit length $(\mathrm{W} / \mathrm{m})$

$R_{0}=$ cladding outside radius without oxidation $(\mathrm{m})$

$W_{f} \quad=\quad$ mass gain per unit surface area due to oxidation at end of time step $\left(\mathrm{kg} / \mathrm{m}^{2}\right)$

$W_{i}=$ mass gain per unit surface area due to oxidation at start of time step $\left(\mathrm{kg} / \mathrm{m}^{2}\right)$.

COBILD calculations for the oxygen profiles are completed after the oxide and alpha surface layer thicknesses are determined. The remaining beta thickness is divided into eight sections (nine nodes), and the oxygen concentrations are calculated with the expression

$c(X, t+\Delta t)=C(X, t)+\frac{D \Delta t}{(\Delta X)^{2}}[C(X+\Delta X, t)-2 c(X, t)+C(X-\Delta X, t)](15.2-7)$ 
CORROS， COBILD， COXIDE， COXWTK， COXTHK

Table 15.2-2. Rate constants for oxidation by $\mathrm{UO}_{2}$

\begin{tabular}{llll}
\hline \multicolumn{1}{c}{ Parameter } & $\frac{\mathrm{A}}{1.6 \times 10^{-5} \mathrm{~m}^{2} / \mathrm{s}}$ & $\frac{B}{2.47 \times 10^{4} \mathrm{~K}}$ \\
$\alpha-\operatorname{Zr}(0)_{\mathrm{a}}$ thickness (m) & & $3.5 \times 10^{-5} \mathrm{~m}^{2} / \mathrm{s}$ & $2.21 \times 10^{4} \mathrm{~K}$ \\
$\alpha-\operatorname{Zr}(0)_{\mathrm{b}}$ thickness (m) & & 3.25 \\
\hline
\end{tabular}




\section{CORROS, COBILD, COXIDE, COXWTK, COXTHK}

where

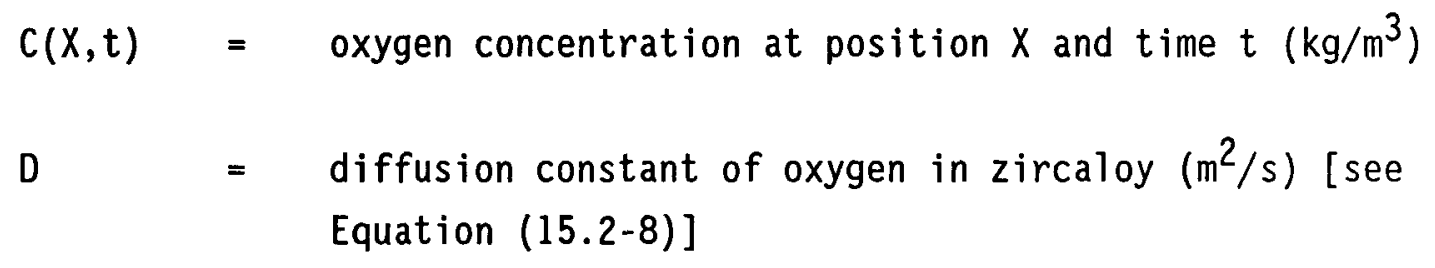

$\Delta X=$ one-eighth of the beta layer thickness $(\mathrm{m})$.

The diffusion constant is found with a correlation of experimental data versus temperature

$D=2.63 \times 10^{-6} \exp \left(\frac{-14200}{T}\right)$.

In solving Equation (15.2-7) for oxygen concentrations, it is assumed that the concentration at the alpha-beta interface (the first node) is always the saturation concentration for beta zircaloy, ${ }^{a}$ that diffusion of oxygen into the beta region does not begin until the temperature is greater than $1239 \mathrm{~K}$, and that the initial oxygen concentration throughout the as-fabricated metal is 0.0012 weight fraction.

The oxygen profiles calculated with Equation (15.2-7) are used to calculate the average mass of oxygen added to the beta layer. The expression used is

$F=\frac{M}{6490 B}-0.0012$

a. Equations (15.2-30) through (15.2-32) are used to determine this concentration. 


\section{CORROS, COBILD, COXIDE, COXWTK, COXTHK}

where

$\mathrm{F}=$ oxygen weight fraction in the beta layer in excess of the as-fabricated content (dimensionless)

$M=$ total oxygen in beta layer per unit surface area $\left(\mathrm{kg} / \mathrm{m}^{2}\right)$

$B=$ thickness of beta layer (m).

Since the oxygen weight fraction in the alpha phase is nearly constant at 0.047 , no calculation is necessary for this parameter. It is simply listed in the COBILD code.

Section 15.2.2 is a review of the literature on zircaloy oxidation. The models that have just been presented are developed in Section 15.2.3. Section 15.2.4 is a description of the zircaloy oxidation subcodes. References are listed in Section 15.2.5, and a bibliography is presented in Section 15.2.6.

\subsubsection{Zircaloy 0xidation Literature and Data}

The review of oxidation data is divided into separate discussions of low- and high-temperature data.

\subsubsection{Low-Temperature Oxidation (CORROS). Investigators} generally agree 15.2-1,15.2-2 that oxidation of zirconium alloys by water in the temperature range from 573 to $673 \mathrm{~K}$ proceeds by the migration of oxygen vacancies from the oxide-metal interface through the oxide layer to the oxide-coolant surface (and the accompanying migration of oxygen in the opposite direction). The vacancies at the metal-oxide surface are generated by the large chemical affinity of zirconium for oxygen. Although the rate of oxidation is controlled in part by vacancy migration, the process of oxygen transfer from coolant to metal is not complete until the vacancy is 


\section{CORROS, COBILD, COXIDE, COXWTK, COXTHK}

annihilated by an oxygen ion at the oxide-coolant surface. It is thus reasonable to expect the complex array of both bulk oxide properties effects and surface (coolant chemistry) effects that are reported in the literature.

Well-characterized data for out-of-pile oxidation are available from numerous experiments. The principal features of these data are:

a. There is a transition between initial oxidation kinetics and later oxidation kinetics. The transition is a function of temperature and oxide layer thickness.

b. The pretransition oxidation rate is time-dependent and inversely proportional to the square of the oxide thickness.

c. The posttransition oxidation rate of a macroscopic surface is constant.

Detailed mechanisms to explain the time dependencies of zircaloy oxidation have not been established in the literature.15.2-3,15.2-4 Proposed mechanisms are discussed in conjunction with the models developed in Section 15.2.3.

Empirical relations based on out-of-pile data are published in Reference 15.2-2. These relations are as follows:

pretransition oxidation $=(27.1 \pm 0.8) 10^{3} \mathrm{t}^{1 / 3} \exp \left(\frac{-5220}{\mathrm{~T}}\right)$

posttransition oxidation $=(23.0 \pm 0.7) 10^{8} t^{1 / 3} \exp \left(\frac{-14400}{T}\right)$

weight gain at transition $=(123 \pm 4) \exp \left(\frac{-790}{T}\right)$ 
CORROS， COBILD， COXIDE， COXWTK， COXTHK

where

$\begin{aligned} \text { oxidation } & =\text { weight gain }\left(\mathrm{mg} / \mathrm{dm}^{2}\right) \\ T & =\text { temperature }(K) \\ t & =\text { time (days). }\end{aligned}$

The correlations were reported to be accurate to $\pm 4 \%$.

In-reactor oxidation is not successfully predicted by Equations $(15.2-10)$ through $(15.2-12)$. This oxidation is enhanced by physical mechanisms that are not completely clear. It is known that the enhancement is different in BWR environments that in PWR environments and that the enhancement is more pronounced at the lower end of the 573-to-673-K temperature range. An adequate data base for a careful prediction of oxidation enhancements in reactor environments is not available in spite of several past studies, which have concentrated on the effects of dissolved oxygen, 15.2-5,15.2-6 fast neutron flux, 15.2-6 fast neutron fluence, 15.2-7 and gamma irradiation. $15.2-8$

15.2.2.2 High-Temperature 0xidation. Many of the complications observed with low-temperature oxidation are absent at high temperatures. The use of parabolic kinetics to describe the total oxygen uptake by zircaloy from steam and the $\mathrm{ZrO}_{2}$ and oxygen-stabilized alpha layers has been extensively documented by experimenters in several countries. In the United States, there has been a series of reports from ORNL 15.2-9,15.2-10 and from Worcester Polytechnic Institute. 15.2-11 There have been similar reports by Urbanic in Canada, 15.2-12 Leistikow in Germany, 15.2-13 and Kawasaki in Japan.15.2-14 The only published data above $1853 \mathrm{~K}$ are the measurements by Urbanic and Heidrick $15.2-15$ at temperatures between 1320 and $2120 \mathrm{~K}$. These data show a discontinuity in the oxidation rate at about $1853 \mathrm{~K}$. Since this temperature is near the monoclinic-to-cubic 


\section{CORROS, COBILD, COXIDE， COXWTK， COXTHK}

transformation of the oxide, it is suspected that the change in oxidation rate is due to the oxide structure change. No discontinuity was observed in the oxygen-stabilized $\alpha-\operatorname{Zr}(0)$ layer, and none would be expected because the growth rate of this layer is controlled by the rate of oxygen diffusion into the beta-phase zircaloy. Urbanic and Heidrick calculate rate constants from the slope of the linear portion of a plot of their (weight gain) ${ }^{2}$ data versus time.

Several papers have been published describing the $\mathrm{UO}_{2}-\mathrm{Zr}$ reaction responsible for the inside $\alpha-\operatorname{Zr}(0)$ layers observed when cladding contacts $\mathrm{UO}_{2}$ fuel. Hoffmann and Politis ${ }^{15.2-16}$ have published a particularly useful article. Other important papers are by Mallet 15.2-17 and Rooney and Grossman. 15.2-18 These investigators agree that a layered structure exists next to the fuel and that the inner surface reaction layer farthest from the $\mathrm{UO}_{2}$ is oxygen-stabilized alpha-zirconium. Next, a $(U, Z r)$ alloy is found, which is primarily uranium. The different authors disagree in their description of this $(U, Z r)$ alloy, and there is a further difference among them about the oxygen-stabilized alpha layer adjacent to the fuel.

An attempt to model the $\mathrm{U}_{2}-\mathrm{Zr}$ reaction analytically has been made by Cronenberg and El-Genk.15.2-19 However, their analysis deals only with the diffusion of oxygen from the fuel and describes the resulting oxygen gradients in both the fuel and the zirconium. Their model has the advantage of being based largely on first principles, but it does not give the detail observed experimentally by the other investigators.

\subsubsection{Model Development}

0xidation of materials that form a protective oxide layer is frequently found to conform to the assumption that the rate determining process is the diffusion of oxygen atoms across the oxide. ${ }^{15.2-20}$ In this case, the rate of oxygen diffusion across the oxide layer is given by Fick's law 
CORROS， COBILD， COXIDE， COXWTK， COXTHK

$$
J_{x}=-D \frac{\partial N}{\partial x}
$$

where

$$
\begin{aligned}
J_{X} & =\text { flux of oxygen atoms }\left(\text { atoms } / \mathrm{m}^{2} \cdot \mathrm{s}\right) \\
D & =\text { a function of temperature }\left(\mathrm{m}^{2} / \mathrm{s}\right) \\
N & \left.=\text { concentration of oxygen atoms (atoms } / \mathrm{m}^{3}\right) \\
X & =\text { direction perpendicular to the oxide surface }(\mathrm{m}) .
\end{aligned}
$$

If the concentration of oxygen atoms at both surfaces of the oxide surface is fixed, Equation (15.2-13) implies that the rate of formation of the oxide thickness will be inversely proportional to the oxide thickness

$$
\frac{d y}{d t^{\prime}}=\frac{D\left(N_{s}-N_{i}\right)}{C}
$$

where

$$
\begin{aligned}
& y=\text { oxide layer thickness }(\mathrm{m}) \\
& \mathrm{t}^{\prime}=\text { time }(\mathrm{s}) \\
& \mathrm{N}_{\mathrm{s}}=\text { concentration of oxygen atoms at oxide surface }\left(\text { atoms } / \mathrm{m}^{3}\right) \\
& \mathrm{N}_{\mathbf{i}}=\begin{array}{l}
\text { concentration of oxygen atoms at oxide-metal interface } \\
\left(\text { atoms } / \mathrm{m}^{3}\right)
\end{array} \\
& \mathrm{C}=\text { concentration of oxygen atoms in the oxide layer } \\
& \text { (atoms } \left./ \mathrm{m}^{3}\right) .
\end{aligned}
$$




\section{CORROS， COBILD， COXIDE， COXWTK， COXTHK}

Integration of this equation from $y=z_{i}$ at $t^{\prime}=0$ to $y=z_{f}$ at $t^{\prime}=\Delta t$ yields the parabolic time dependence of Equation (15.2-5), which is observed experimentally for high-temperature oxidation.

\subsubsection{Low-Temperature 0xidation (CORROS). The fact that} low-temperature oxidation does not obey a parabolic time dependence implies that oxygen diffusion across the oxide is not the rate-controlling step. However, a slight extension of the derivation of the parabolic oxidation produces a result consistent with the measured time dependence of zircaloy corrosion. As mentioned at the beginning of Section 15.2.2.1, the migration of oxygen from the oxide surface to the metal-oxide interface may actually be caused by the migration of oxygen vacancies from the oxide-metal interface through the oxide layer to the oxide-coolant surface. If the vacancies have a long lifetime, their migration should obey Fick's law. If the vacancies have a lifetime that is short compared to the time required to diffuse across the oxide layer, the flux of vacancies arriving at the oxide-coolant surface will be proportional to the inverse of the time, $t_{\text {diffusion }}$, required for a vacancy to diffuse to the oxide-coolant surface. Since this time is proportional to the square of the average diffusion distance $\left(t_{\text {diffusion }} \propto y^{2}\right)$, the vacancy flux arriving at the oxide-coolant surface, and thus the rate of oxidation, should be proportional to the inverse of the square of the oxide thickness that the vacancies must cross.

From the physical arguments of the last paragraph, the vacancy lifetime-1 imited rate of oxide growth should be $\frac{d y}{d t^{\prime}}=\frac{M}{y^{2}}$, where $M$ is not a function of time or oxide thickness. Integration of the rate equation from $y=x_{0}$ at $t^{\prime}=0$ to $y=x$ at $t^{\prime}=t$, gives $x=\left(3 M t+x_{0}^{3}\right)^{1 / 3}$, which is the observed result. If the vacancy concentration at the metal-oxide surface is assumed to be given by an expression of the form $M=R \exp \left(-T_{0} / T\right)$, where $R$ and $T_{0}$ are constants and $T$ is the temperature of the interface, the resultant expression for pretransition oxidation is 


\section{CORROS, COBILD, COXIDE, COXWTK, COXTHK}

$$
X=\left[3 R t \exp \left(-T_{0} / T\right)+X_{0}^{3}\right]^{1 / 3} .
$$

Posttransition oxidation is viewed in this section as a series of pretransition modes. An inner oxide layer shown schematically in Figure 15.2-2, with thickness that varies as a function of surface position, is presumed to control the rate of oxidation until this inner layer grows to the transition thickness. At this time, the inner layer changes to an outer layer that does not affect the oxidation rate and growth of a new inner layer begins. The representation is adopted because it successfully relates pretransition and posttransition oxidation rates for out-of-pile data.

If the representation with an inner oxide film of varying thickness is correct, the rate-controlling inner part of the oxide layer should join the outer layer at a thickness approximately equal to the transition thickness but at a time determined by local conditions. After several cycles, the growth rates of the inner oxide layer at different locations on the surface of a macroscopic oxide film will be out of phase; and the rate of growth of the entire surface film at any time (which is what is observed in most experiments) will be the time-average rate of growth at any one place on the surface:

$$
\frac{d y}{d t} \underset{\begin{array}{l}
\text { average } \\
\text { over } \\
\text { surface }
\end{array}}{ }=\frac{X_{\text {TRAN }}}{t_{\text {TRAN }_{0}}}=\frac{3 R \exp \left(-T_{0} / T\right)}{X_{\text {TRAN }}^{2}}
$$

where

$$
\begin{aligned}
& y=\text { oxide layer thickness }(\mathrm{m}) \\
& \mathrm{X}_{\text {TRAN }}=\text { thickness of the oxide layer at transition }(\mathrm{m})
\end{aligned}
$$




\section{CORROS， COBILD， COXIDE， COXWTK， COXTHK}

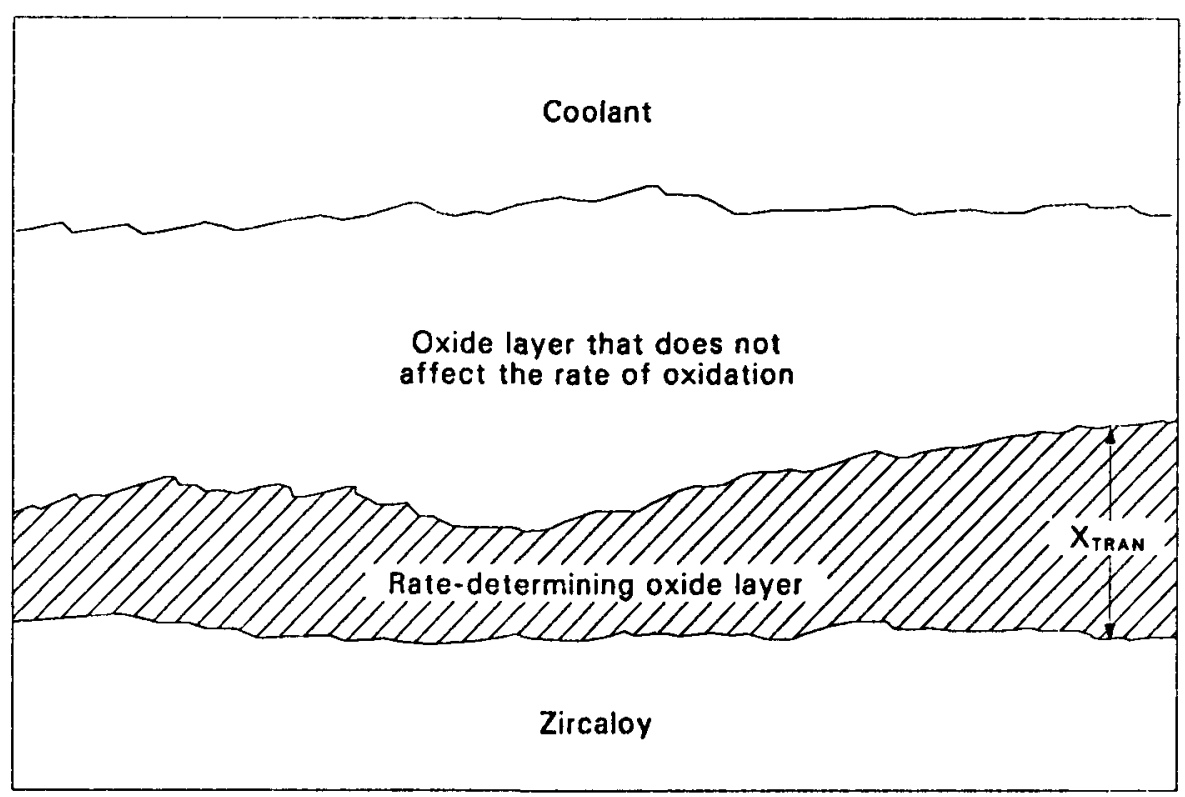

S116-WHT-1289-75

Figure 15.2-2. Schematic of posttransition oxide, showing an intact, rate-determining layer of varying thickness, with another oxide layer that does not affect the oxidation rate. 
CORROS, COBILD, COXIDE, COXWTK, COXTHK

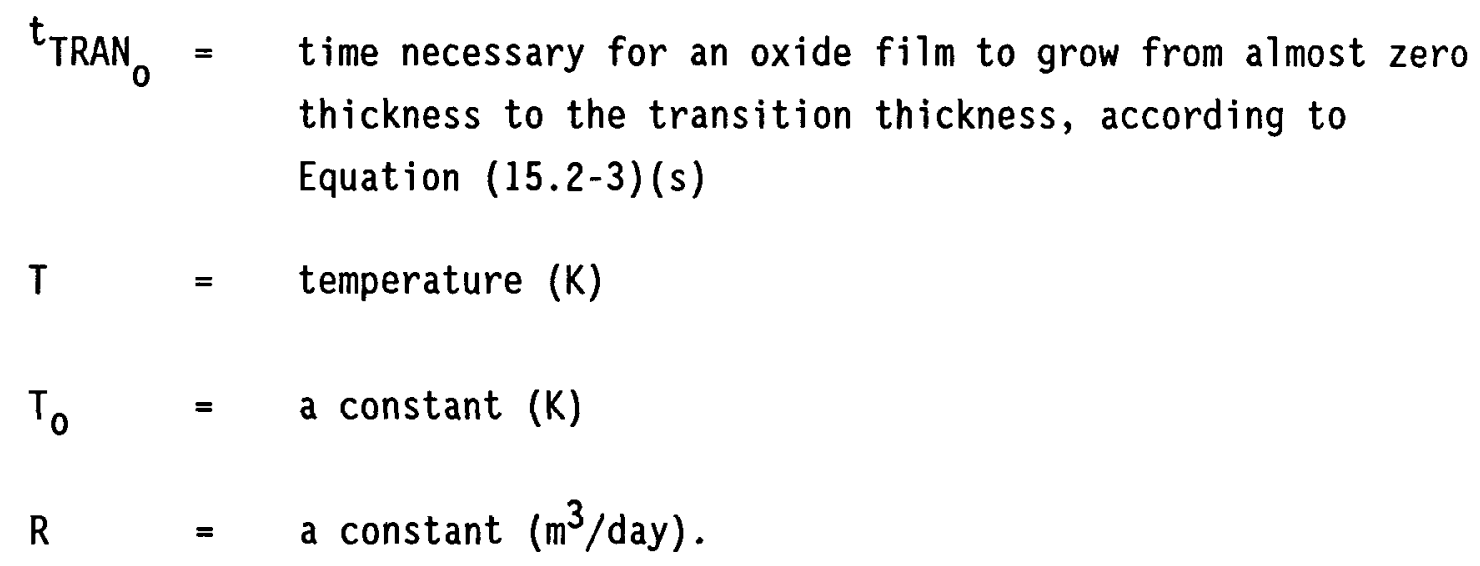

Since the posttransition oxidation is viewed as being a series of pretransition modes that are separated by local loss of the inside oxide film, one would expect to obtain the pre- and posttransition oxidation rates with a single set of constants. In fact, the empirical constants determined by Van der Linde ${ }^{15.2-2}$ for the pre- and posttransition oxidation rates [Equations (15.2-10) and (15.2-11)] can be reproduced with a single set of parameters, $T_{0}=14,080 \mathrm{~K}, \mathrm{R}=1.659 \times 10^{-9} \mathrm{~m}^{3} /$ day, and $X_{\text {TRAN }}=$ $7.749 \times 10^{-6} \mathrm{~m} \exp (-790 / \mathrm{T})$. Oxidation rates obtained using these constants and Equations (15.2-15) and (15.2-16) are within the $\pm 4 \%$ error reported by Van der Linde for oxidation rates obtained using Equations (15.2-10) and (15.2-11).

Changes in oxidation due to in-pile chemical effects are incorporated into the present model with an enhancement factor, $A$, which describes a multiplicative in-pile enhancement of the out-of-pile oxidation rate due to an increased supply of oxygen ions. The explanation of an increased supply of oxygen ions ${ }^{15.2-8}$ was adopted over an alternate explanation, which suggests that in-pile corrosion enhancement is due to irradiation damage of the oxide layer, 15.2-21,15.2-22 because the former can be modeled by a simple change in the rate constant while the latter would require adding a new mechanism to the model. There are no definitive experiments to indicate which approach is correct. 


\section{CORROS, COBILD, COXIDE, COXWTK, COXTHK}

Rate equations for in-pile oxidation are thus:

For the pretransition regime,

$\frac{\mathrm{dX}}{\mathrm{dt}}$ pre $=\frac{A R \exp \left(-\mathrm{T}_{0} / \mathrm{T}\right)}{\mathrm{X}^{2}}$

For the posttransition regime,

$$
\frac{d x}{d t} \text { post }=\frac{3 A R \exp \left(-T_{0} / T\right)}{x_{\text {TRAN }}^{2}}
$$

where the terms of the equations have been previously defined.

The integrated forms of these equations are:

$X_{P R E}=\left[3 A R t \exp \left(-T_{0} / T\right)+X_{0}^{3}\right]^{1 / 3}$

and

$x_{\text {POST }}=\frac{3 A R\left(t-t_{\text {TRAN }}\right) \exp \left(-T_{0} / T\right)}{x_{\text {TRAN }}^{2}}+x_{\text {TRAN }}$

if $X_{0}$ is less than $X_{\text {TRAN }}$. If $X_{0}$ is greater than $X_{\text {TRAN }}$,

$x_{\text {POST }}=\frac{3 A R\left(t_{\exp }\right) \exp \left(-T_{0} / T\right)}{x_{\text {TRAN }}^{2}}+x_{0}$.

An interesting result (and a good test of the theory if time-dependent in-reactor data become available) is the fact that the rate enhancement 


\section{CORROS， COBILD， COXIDE， COXWTK， COXTHK}

factor $A$ does not result in a linear change in the oxide thickness for pretransition films. That is, although the oxidation rate is enhanced by factor $A$, the pretransition oxide film thickness at a given time is merely $A^{1 / 3}$ as thick as it would have been without the in-pile enhancement. Since the posttransition oxidation is linear in time, both the rate and change in oxide thickness at a particular time are enhanced by factor $A$.

The metal-oxide temperature is computed from the temperature at the outer oxide surface, the heat flux across the oxide surface, and the thermal conductivity of the oxide layer by the expression

$T=T_{C}+Q(X / K 02)$

where

$\mathrm{T}=$ temperature of the oxide-metal interface $(K)$

$T_{C}=$ temperature of the outer surface of the oxide (K)

$Q=$ heat flux across the oxide layer $\left(\mathrm{W} / \mathrm{m}^{2}\right)$

$\mathrm{X}=$ oxide layer thickness $(\mathrm{m})$

$\mathrm{K} 02=$ thermal conductivity of the oxide layer $(\mathrm{W} / \mathrm{m} \cdot \mathrm{K})$.

Since the term $Q(X / K 02)$ normally is a small correction to the temperature of the outer oxide surface, the correction to the temperature is approximated with an iteration. For the first step, $X$ is approximated as the initial oxide thickness. The oxide thickness is then computed with Equation (15.2-19), (15.2-20) or (15.2-21), and the resultant value is inserted for $X$ in Equation (15.2-22). 


\section{CORROS, COBILD, COXIDE, COXWTK, COXTHK}

Expressions for the enhancement factor, A, were obtained by correlating BWR and PWR data to temperature. Values of the enhancement factor for BWRs shown in Figure 15.2-3 were proposed in References 15.2-22 and 15.2-23. The point attributed to Megerth is the average value, $A=9$, found necessary to obtain a reasonable fit of the model developed here to the oxidation data presented in References 15.2-24 and 15.2-25. The analytical expression used in CORROS to represent these BWR enhancement factors in the temperature range $500<\mathrm{T}<673 \mathrm{~K}$ is

$A=4.840 \times 10^{5} \exp \left(-1.945 \times 10^{-2} T_{C}\right)$

where

$A=$ the enhancement factor

$T_{c}=$ the temperature at the outer oxide surface $(K)$.

Enhancement factors have been reported to be about 2.4 $15.2-26$ for zircaloy-2 rods in the Shippingport PWR. A fit of Equation (15.2-3) to values of oxide thickness reported in Reference 15.2-25 agreed with this value. A similar fit of the equation to values reported from Saxton PWR rods $15.2-27,15.2-28$ resulted in a value of $A=1.5$. These values are also plotted in Figure 15.2-3. The relatively small value of $A$ in PWR environments (which do not contain dissolved oxygen in the bulk coolant) is consistent with the picture of enhanced oxygen atom and ion supply rates due to ionization of dissolved oxygen. As in the case of BWR environments, the straight 1 ine sketched between these points is used by CORROS to estimate the enhancement in a typical PWR environment. The equation for $500<T<673 \mathrm{~K}$ is

$A=1.203 \times 10^{2} \exp \left(-7.118 \times 10^{-3} \mathrm{~T}_{\mathrm{C}}\right)$ 


\section{CORROS, COBILD, COXIDE, COXWTK, COXTHK}

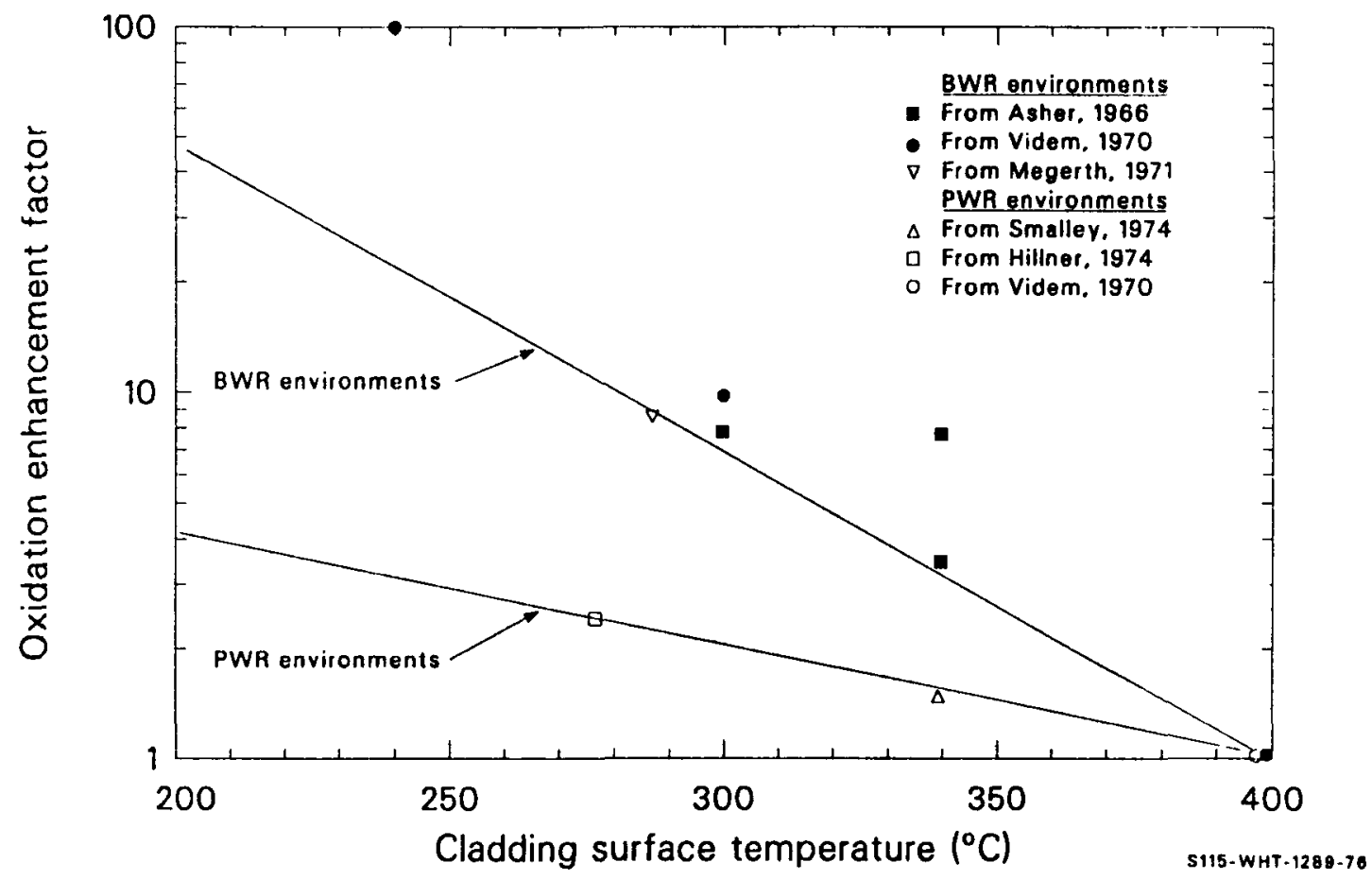

Figure 15.2-3. Estimates of enhancements over out-of-pile oxidation rates when cladding is irradiated in typical BWR and PWR environments. 


\section{CORROS, COBILD, COXIDE， COXWTK， COXTHK}

where
$A=$ the enhancement factor
$T_{C}=$ the temperature at the oxide-coolant surface $(K)$.

The predictions of the model developed in this section are compared with the values reported for individual samples in Figures 15.2-4 through 15.2-6. There is considerable scatter in the data from individual rods, with maximum measured values of oxide thickness as large as twice the average values. In some cases, such as the Shippingport data of Figure 15.2-4, variations are generally consistent with the idea that temperature variations are responsible. In other cases, such as the Saxton data of Figure 15.2-5, variations are not explained solely by temperature variation; and the cause is probably related to local variations in coolant quality or chemistry caused by nucleate boiling or to contaminants. Similarly, variations in the coolant along the BWR rods could contribute to the large scatter in the BWR data of Figure 15.2-6. Note that the duration of the pretransition period varies considerably in Figures 15.2-4, 15.2-5, and 15.2-6. Figures 15.2-4 and 15.2-5 refer to PWRs with relatively low oxidation rate enhancements. However, the temperature is higher in the case of Figure 15.2-5, producing a shorter pretransition period due to more rapid oxidation. Figure 15.2-6 refers to a BWR with low temperatures but a large oxidation enhancement factor ( 9 in this case). This results in a long pretransition period so that the relatively rapid posttransition oxidation is predicted to start late for the BWR.

15.2.3.2 High-Temperature 0xidation (COBILD, COXIDE). The COBILD and COXIDE subcodes were adapted from another code, BUILD5, written by R. Pawe1, of 0ak Ridge National Laboratory. Although BUILD5 was written in the computer language BASIC and the MATPRO codes are in FORTRAN, the computational techniques are similar. COBILD and COXIDE have been expanded to include oxidation of the cladding on the inside surface by oxygen 
CORROS, COBILD, COXIDE, COXWTK, COXTHK

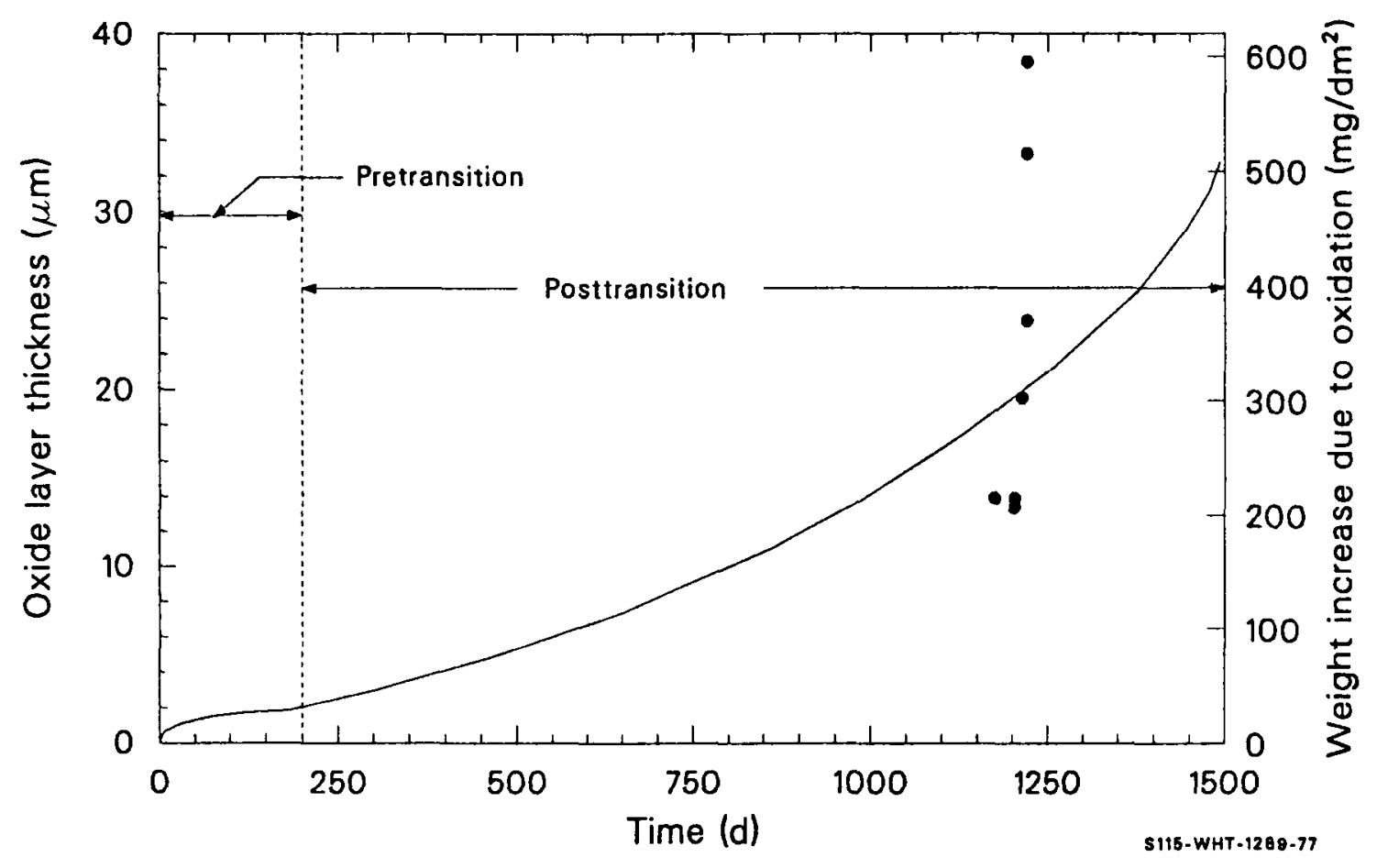

Figure 15.2-4. Comparison of the predicted oxide layer thickness with the base data from average values of six Shippingport zircaloy-2 rods in a PWR environment at $277^{\circ} \mathrm{C}$. 
CORROS, COBILD, COXIDE， COXWTK， COXTHK

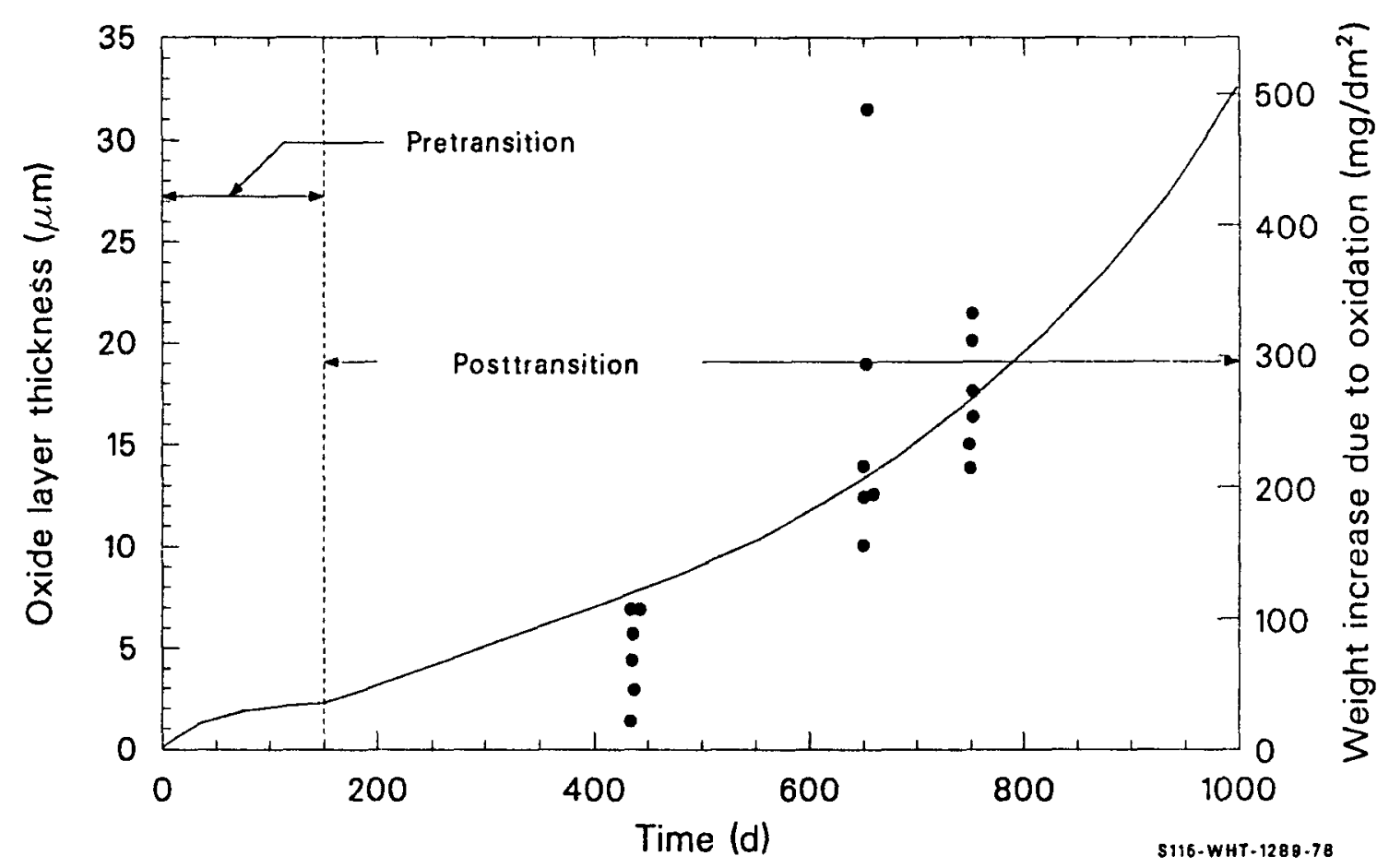

Figure 15.2-5. Comparison of the predicted oxide layer thickness with the base data from Saxton zircaloy -4 rods in a PWR at $340^{\circ} \mathrm{C}$. 


\section{CORROS, COBILD, COXIDE, COXWTK, COXTHK}

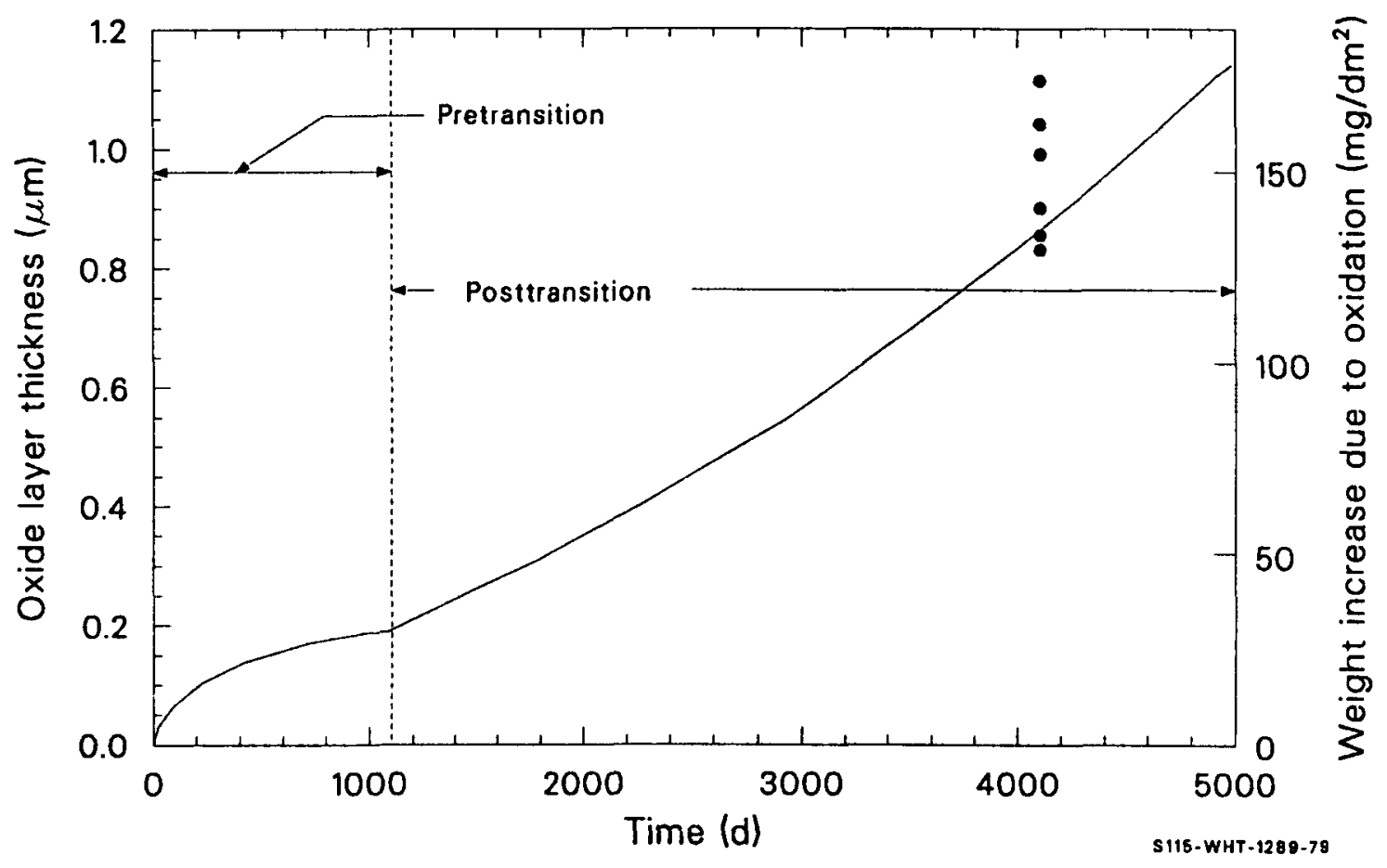

Figure 15.2-6. Comparison of the predicted oxide layer thickness with the base data from zircaloy-2 rods irradiated in the Vallecitos and Dresden BWRs at $286^{\circ} \mathrm{C}$. 


\section{CORROS, COBILD, COXIDE, COXWTK, COXTHK}

released from the fuel. The oxygen weight fraction in the beta phase and the linear power generation from the metal-water reaction are also calculated in COBILD and COXIDE but not BUILD5.

The correlations for $\mathrm{ZrO}_{2}$ thickness, $\alpha-\operatorname{Zr}(0)$ thickness, and weight gain due to steam reaction between 1239 and $1853 \mathrm{~K}$ were taken from Cathcart, 15.2-9,15.2-10 because Cathcart's expressions give the best fit to the pooled data from all the sources mentioned in Section 15.2-2. ${ }^{\mathrm{a}} \mathrm{A}$ comparison with data of the $\mathrm{ZrO}_{2}$ thicknesses calculated with Cathcart's equation is shown in Figure 15.2-7. A similarly good fit is obtained when the alpha thickness and weight gain correlations are compared with the data. Rate constants for temperatures between 1853 and $2100 \mathrm{~K}$ were taken from Urbanic and Heidrick. 15.2-15 In order to convert the correlations for zircaloy consumed given by Urbanic and Heidrick to oxygen consumed, the parabolic rate constant for zircaloy consumed was multiplied by the square of the ratio of oxygen consumed to zircaloy consumed given in Equation $(15.2-25)$.

Cathcart has thoroughly analyzed the uncertainty in his measurement. 15.2-29 In an earlier report, 15.2-30 he reported joint $90 \%$ confidence levels for the rate constants $[A \exp (-B / T)]$ of Table 15.2-1. The word 'joint' is used to indicate the uncertainty of the rate constant as a whole rather than uncertainties in the parameters $A$ and $B$ separately. His conclusions are presented in Table 15.2-3. These uncertainties are recommended for use with the oxidation codes in the temperature range where Cathcart's correlations are used.

The numbers given in Table 15.2-3 are for isothermal oxidation only. There are no comparable statistics available for time-dependent problems,

a. Cathcart recommends these correlations only to $1773 \mathrm{~K}$. The authors extrapolated to $1853 \mathrm{~K}$, where the data of Urbanic and Heidrick suggest a discontinuity. 


\section{CORROS, COBILD, COXIDE, COXWTK, COXTHK}

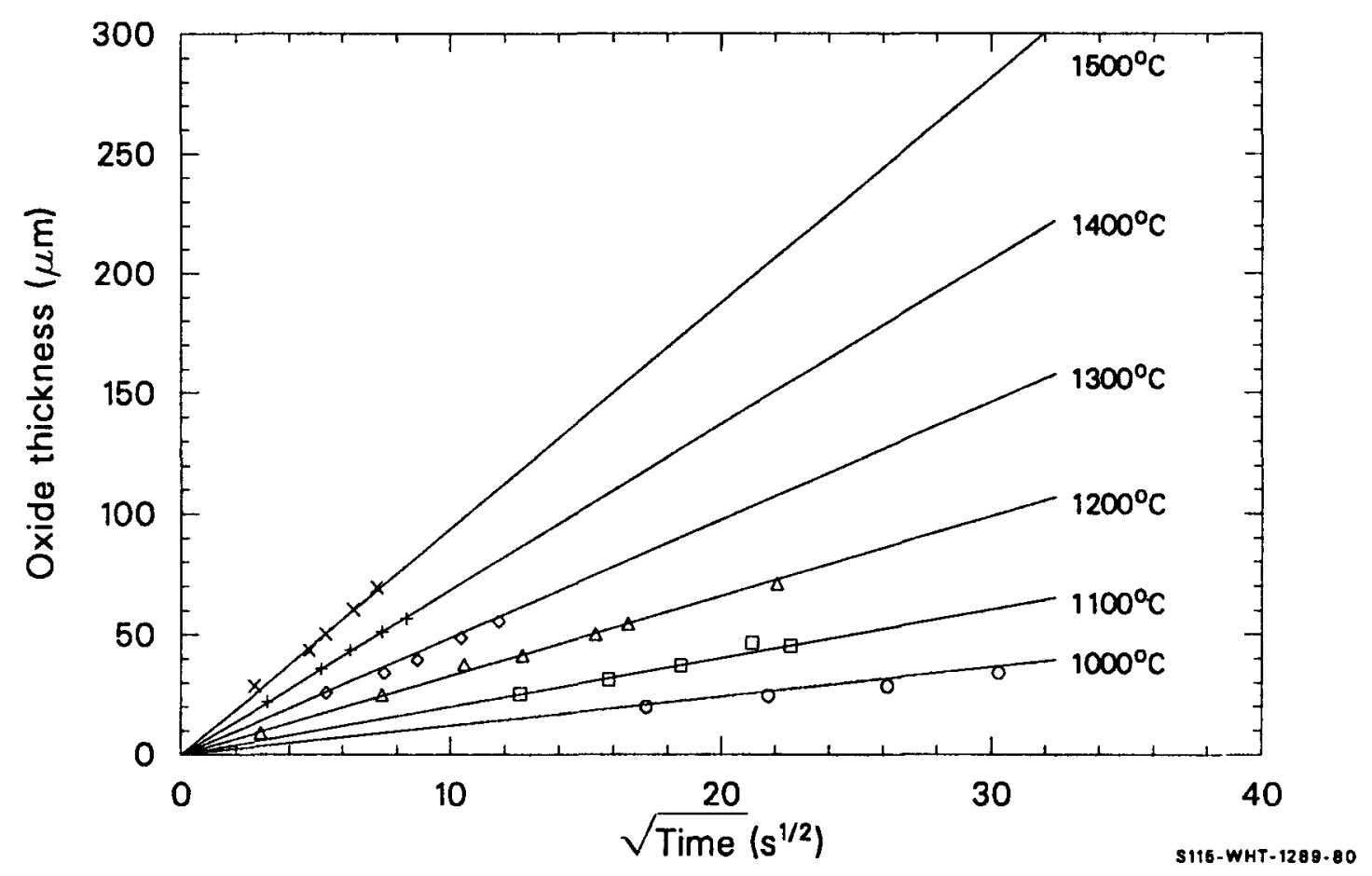

Figure 15.2-7. Comparison of calculated (solid lines) and measured $\mathrm{ZrO}_{2}$ thickness for six temperatures. 


\section{CORROS, COBILD, COXIDE, COXWTK, COXTHK}

Table 15.2-3. 90\% joint confidence intervals for the parabolic rate constants for oxide layer growth, alpha layer growth, and total oxygen uptake

\begin{tabular}{lrrr} 
& \multicolumn{2}{c}{ Percent } & Deviation from Expected Value \\
\cline { 2 - 4 } & $\underline{1323 \mathrm{~K}}$ & $\underline{1523 \mathrm{~K}}$ & $\underline{1773 \mathrm{~K}}$ \\
Oxide & +4.9 & +2.5 & +4.3 \\
Layer & -4.7 & -2.4 & -4.1 \\
Alpha & +12.1 & +6.1 & -10.1 \\
Layer & -10.8 & -5.8 & -9.2 \\
Oxygen & +3.4 & +1.7 & +3.0 \\
Uptake & -3.3 & -1.7 & -2.9 \\
\hline
\end{tabular}




\section{CORROS, COBILD, COXIDE, COXWTK, COXTHK}

largely because of the difficulty in obtaining reliable temperature measurements under transient conditions.

The standard error ${ }^{a}$ of the weight gain correlation of Urbanic and Heidrick with respect to its own data base is $0.49 \mathrm{~kg} / \mathrm{m}^{2}$.

Only the linear portions of the entire data curves shown in Figure 15.2-8 were used by Urbanic and Heidrick to determine the high-temperature correlation. Since these data did not pass through the origin, the resulting offset is the main contributor to the standard error.

The layers of alpha zircaloy on the inside cladding surface of unruptured cladding are caused by zircaloy- $\mathrm{UO}_{2}$ interaction. The model for cladding oxidation by $\mathrm{UO}_{2}$ is taken from Hofmann's results ${ }^{15.2-16}$ for two reasons. His time and temperature data base is wider than that of Grossman and Rooney or of Mallet, and Hofmann gives correlations which can be integrated to become part of the high-temperature oxidation subcodes.

a. The expression used to calculate the standard error, $\sigma$, is

$\tau=\sum_{i=1}^{n} \frac{\left(C_{i}-M_{i}\right)^{2}}{n-1}$

where

$c_{j}=$ calculated weight gain

$M_{i}=$ measured weight gain

$n=$ number of data used. 
CORROS, COBILD, COXIDE, COXWTK, COXTHK

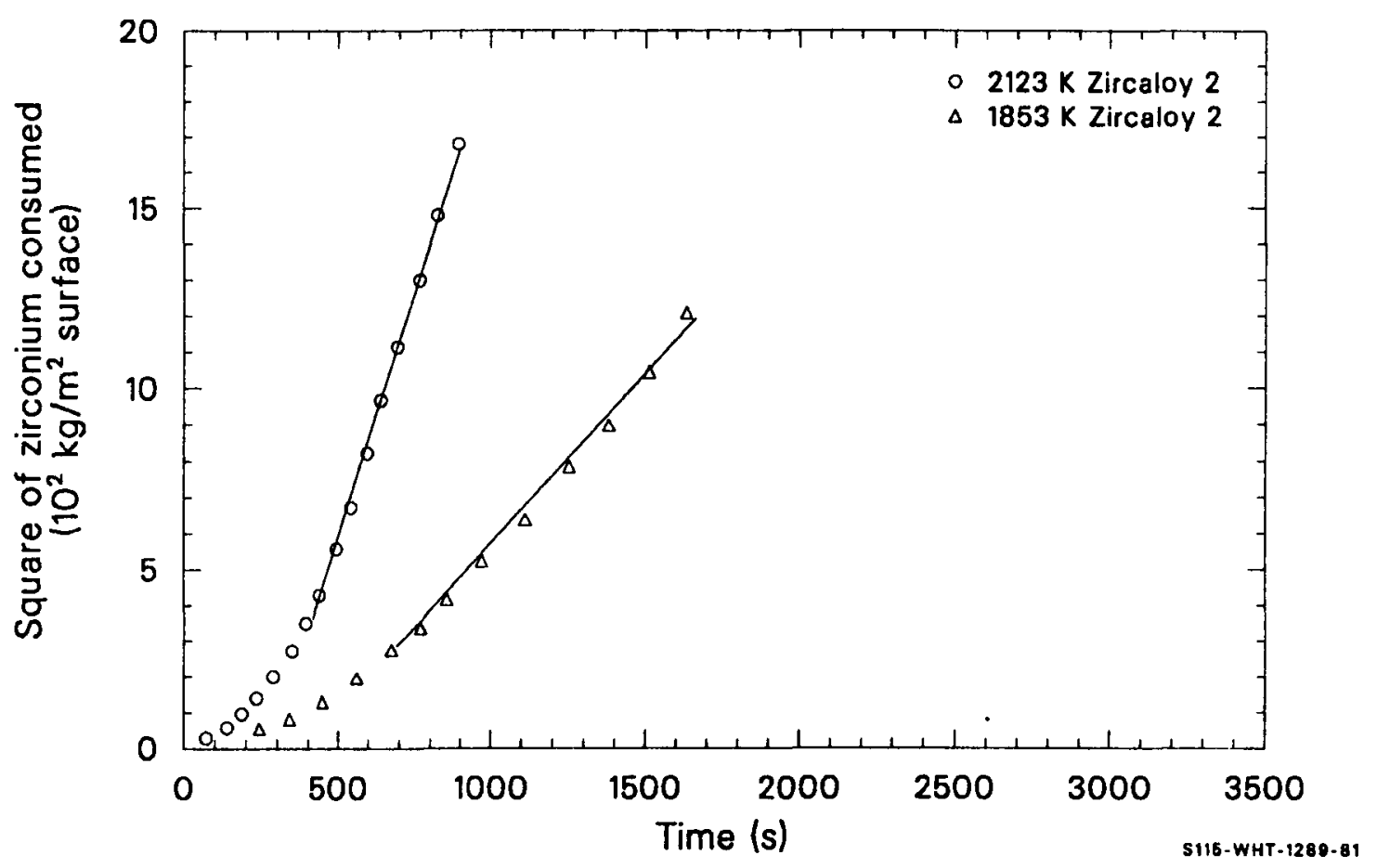

Figure 15.2-8. Data used by Urbanic and Heidrick to determine high-temperature zircaloy oxidation rates. 
CORROS， COBILD， COXIDE， COXWTK， COXTHK

In Figure 15.2-9, Hofmann's correlations for the $\alpha-\operatorname{Zr}(0)$ layers are compared with his data; and the data are presented in Table 15.2-4. The standard deviations of the correlations with respect to their own data bases are $\pm 18 \%$ for $\operatorname{Zr}(0)_{a}$ for $T<1600 \mathrm{~K}$ and $\pm 16 \%$ for $\operatorname{Zr}(0)_{b}$ for $T<$ $1760 \mathrm{~K}$.

Calculations of the rate of heat generation are based on the heat of reaction of zirconium, $6.45 \times 10^{6} \mathrm{~J} / \mathrm{kg}$ of zirconium converted to $\mathrm{ZrO}_{2}$ by steam. 15.2-31 Since the weight fraction of oxygen in $\mathrm{ZrO}_{2}$ is 0.26 , the ratio of zirconium consumed to oxygen added is

$\frac{\Delta Z r}{\Delta W}=\frac{1-0.26}{0.26}$

where

$$
\begin{aligned}
& \Delta z r=\quad \begin{array}{l}
\text { zirconium per unit surface area consumed by oxidation } \\
\text { during the given time increment }\left(\mathrm{kg} / \mathrm{m}^{2}\right)
\end{array} \\
& \Delta \mathrm{W}=\begin{array}{l}
\text { mass gain per unit surface area due to oxidation } \\
\text { during a given time increment }\left(\mathrm{kg} / \mathrm{m}^{2}\right) .
\end{array}
\end{aligned}
$$

The mass of zirconium consumed per unit length for a cylindrical rod is the mass per unit surface area times the circumference. The rate of heat generation per unit length is thus

$P=\frac{0.74}{0.26} \frac{\Delta W}{\Delta t} 2 \pi R_{0} 6.45 \times 10^{6} \mathrm{~J} / \mathrm{m}$

This expression is equivalent to Equation $(15.2-6) .^{\mathrm{a}}$

a. The derivation of Equation (15.2-26) uses the oxygen weight gain rather than the $\mathrm{ZrO}_{2}$ thickness correlation because some of the oxygen consumed appears in the $\alpha-\operatorname{Zr}(0)$ and beta layers. 


\section{CORROS， COBILD， COXIDE， COXWTK， COXTHK}

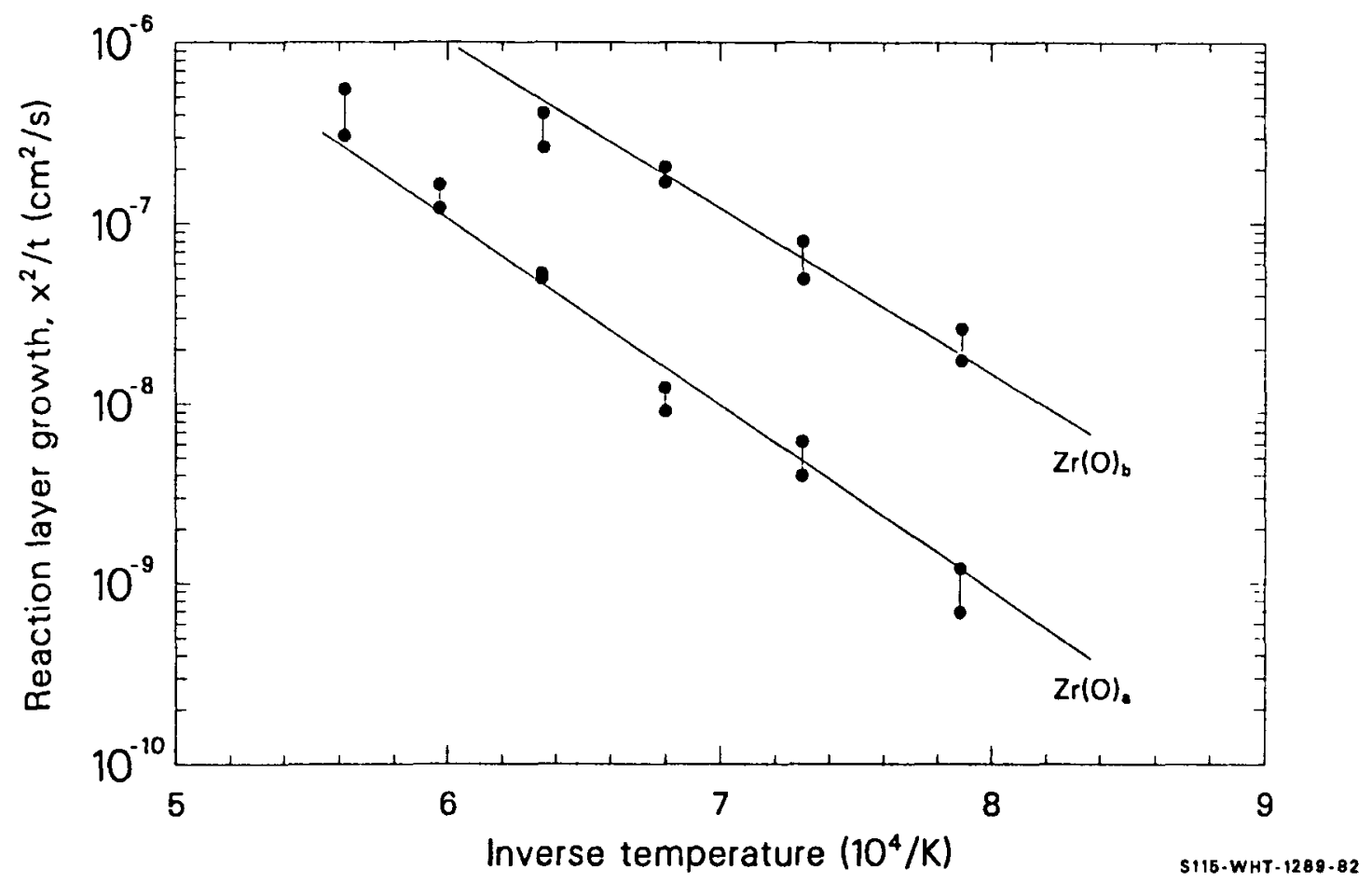

Figure 15.2-9. Growth of $\operatorname{Zr}(0)$ and $\operatorname{Zr}(0) 2 b_{16}$ layers as a function of
temperature from Hofmann and Politis. 
CORROS， COBILD， COXIDE， COXWTK， COXTHK

Table 15.2-4. Time-temperature layer thickness data from Hoffman's 15.2-16 out-of-pile experiments

\begin{tabular}{|c|c|c|c|}
\hline \multirow[b]{2}{*}{$\begin{array}{l}\text { Temperature } \\
\left({ }^{\circ} \mathrm{C}\right)\end{array}$} & \multirow[b]{2}{*}{$\begin{array}{l}\text { Time } \\
(\min )\end{array}$} & \multicolumn{2}{|c|}{ Depth of Reaction Layers (mm) } \\
\hline & & $\underline{\operatorname{Zr}(0)_{\mathrm{a}}}$ & $\operatorname{Zr}(0)_{b}$ \\
\hline $\begin{array}{l}1000 \\
1000 \\
1000 \\
1000\end{array}$ & $\begin{array}{l}10 \\
20 \\
30 \\
60\end{array}$ & $\begin{array}{r}7 \\
10 \\
12 \\
22\end{array}$ & $\begin{array}{l}41 \\
50 \\
61 \\
80\end{array}$ \\
\hline $\begin{array}{l}1100 \\
1100 \\
1100 \\
1100\end{array}$ & $\begin{array}{l}10 \\
20 \\
30 \\
60\end{array}$ & $\begin{array}{l}16 \\
28 \\
32 \\
38\end{array}$ & $\begin{array}{r}67 \\
100 \\
95 \\
136\end{array}$ \\
\hline $\begin{array}{l}1200 \\
1200 \\
1200 \\
1200 \\
1200\end{array}$ & $\begin{array}{r}6 \\
10 \\
20 \\
30 \\
60\end{array}$ & $\begin{array}{l}19 \\
25 \\
34 \\
44 \\
70\end{array}$ & $\begin{array}{r}79 \\
114 \\
157 \\
198 \\
270\end{array}$ \\
\hline $\begin{array}{l}1300 \\
1300 \\
1300 \\
1300 \\
1300\end{array}$ & $\begin{array}{r}3 \\
6 \\
10 \\
20 \\
30\end{array}$ & $\begin{array}{l}32 \\
48 \\
50 \\
84 \\
82\end{array}$ & $\begin{array}{r}90 \\
108 \\
130 \\
241 \\
240\end{array}$ \\
\hline $\begin{array}{l}1400 \\
1400 \\
1400 \\
1400\end{array}$ & $\begin{array}{r}3 \\
6 \\
10 \\
20\end{array}$ & $\begin{array}{r}53 \\
70 \\
96 \\
152\end{array}$ & $\begin{array}{r}116 \\
110 \\
156 \\
--\end{array}$ \\
\hline $\begin{array}{l}1500 \\
1500 \\
1500 \\
1500\end{array}$ & $\begin{array}{r}3 \\
6 \\
10 \\
20\end{array}$ & $\begin{array}{r}90 \\
118 \\
162 \\
290\end{array}$ & $\begin{array}{l}76 \\
-- \\
-- \\
--\end{array}$ \\
\hline
\end{tabular}




\section{CORROS, COBILD, COXIDE, COXWTK, COXTHK}

Figure 15.2-10 is a plot of $P$ versus temperature for a fuel rod with an initial radius $R_{0}=6.25 \times 10^{-3} \mathrm{~m}$. Several initial oxide thicknesses are shown, and a time step of $1 \mathrm{~s}$ is assumed in each case. The exponential increase in power with temperature is evident, as is the proportional relation between instantaneous power and reciprocal oxide thickness.

Equation (15.2-26) may underpredict the oxidation heating rate because it uses the heat released in the reaction

$$
2 \mathrm{H}_{2} \mathrm{O}+\mathrm{Zr}+2 \mathrm{H}_{2}+\mathrm{ZrO}_{2}+\mathrm{Q} \text {. }
$$

With $Q=6.5 \times 10^{6} \mathrm{~J} / \mathrm{kg}$ of zircaloy reacted, $Q$ is smaller by nearly a factor of two than $Q_{1}$, the heat released in the following reaction:

$\mathrm{Zr}+\mathrm{O}_{2} \rightarrow \mathrm{ZrO}_{2}+\mathrm{Q}_{1}$

where $Q_{1}$ is $1.204 \times 10^{7} \mathrm{~J} / \mathrm{kg}$ of zircaloy reacted. ${ }^{15.2-32}$

The difference arises because Equation (15.2-27) includes the heat required for the endothermic dissociation of water reaction

$2 \mathrm{H}_{2} \mathrm{O}+\mathrm{Q}_{2} \rightarrow 2 \mathrm{H}_{2}+\mathrm{O}_{2}$.

The dissociation described by Equation (15.2-29) must take place either at the oxide-to-coolant interface or within the coolant itself. The oxygen thus liberated then diffuses through the oxide layer and combines with the zircaloy at the metal-to-oxide interface according to Equation (15.2-28). It is clearly $Q_{1}$ and not $Q$ that causes the cladding to heat. However, $Q_{2}$ must ultimately come from the rod as well, cooling it. In a closed system, Equation (15.2-27) would be adequate. A problem can arise because the system is not strictly closed. As an example, dissociation may occur 


\section{CORROS, COBILD， COXIDE, COXWTK， COXTHK}

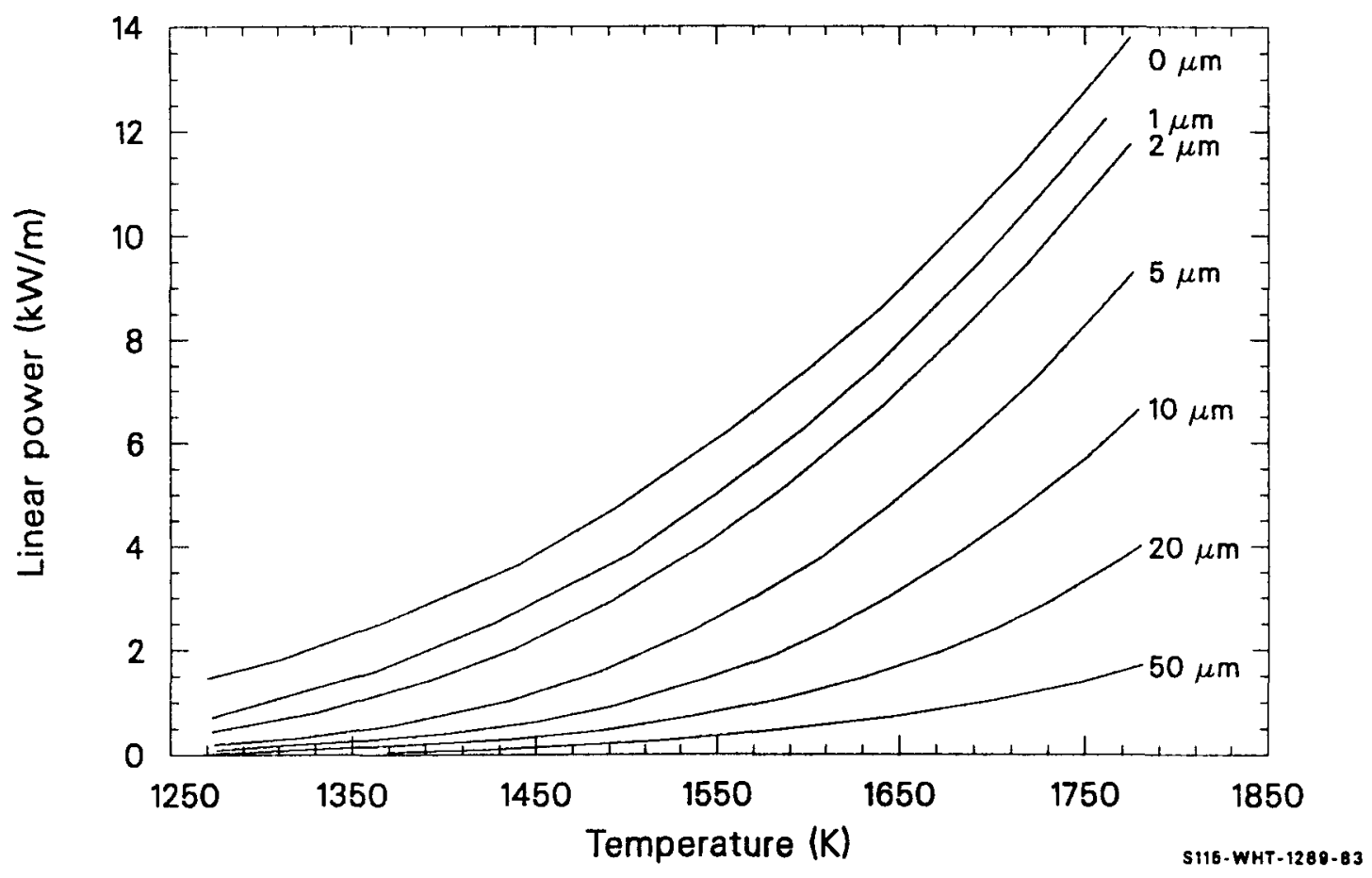

Figure 15.2-10. Linear power generation for a rod of initial diameter of $1.25 \times 10^{-2} \mathrm{~m}$ as a function of temperature for various initial oxide thicknesses. 


\section{CORROS， COBILD， COXIDE， COXWTK， COXTHK}

near one rod, cooling it, and oxidation may occur within an adjacent rod, heating it. The assumption made here is that these processes average out and Equation (15.2-27) is satisfactory.

COBILD calculations for the oxygen profile in the beta region (Equation 15.2-7) are taken directly from a computer code described by Pawel.15.2-33 Equation (15.2-8), the diffusion constant used in the oxygen profile calculation, is from Perkins $15.2-34,15.2-35$ (converted from oxygen 18 to oxygen 16); and the following correlation is used to determine the saturation concentration of oxygen in beta zircaloy.

For $T<1239 \mathrm{~K}$,

$C S=0.0012$

For $1239 \leq \mathrm{T}<1373 \mathrm{~K}$,

$C S=\left[-0.0042807+(T / 392.46-3.1417)^{0.5}\right] / 100$.

For $\mathrm{T} \geq 1373 \mathrm{~K}$,

$C S=(T-1081.7) /\left(4.91157 \times 10^{4}\right)$

where CS is the saturation concentration of oxygen in beta zircaloy (weight fraction).

Equation (15.2-9), the expression used to calculate the oxygen weight fraction in the beta layer, is derived easily. To find the ratio of oxygen to zircaloy, the total oxygen per unit surface area in the beta region is divided by the product of the density of zircaloy $\left(6490 / \mathrm{kg} / \mathrm{m}^{3}\right)$ and the beta layer thickness. The weight fraction of as-fabricated zircaloy, 0.0012 , is subtracted to find the excess oxygen. 


\section{CORROS, COBILD, COXIDE, COXWTK, COXTHK}

\subsubsection{Description of the CORROS, COBILD, COXIDE, COXWTK, and COXTHK Subcodes}

The first calculation is a check of the input parameters to determine the appropriate value of the error index. If impossible input parameter values are detected, no further calculations are attempted. If one of the input temperatures is below $1239 \mathrm{~K}$, only that portion of the time step above $1239 \mathrm{~K}$ is used.

The input pellet-cladding interface pressure is checked to see if there is pellet-cladding mechanical interaction during the given time step. If there is interaction, the cladding will be treated as two one-sided oxidation problems with steam supplying the outside source of oxygen and fuel providing the inside source of oxygen. The input initial cladding thickness is thus multiplied by 0.5 .

Next, the step-average heat up rate, average temperature, beta saturation concentration, and diffusion constant for oxygen in beta zircaloy are calculated. The input time step size is divided by five to determine a sub-step size for later calculations, and the initial oxygen weight gain is saved because it will be needed to calculate the power of the oxidation reaction.

The next two sections of the program interpolate to find beta-phase concentrations of oxygen if there has been a change from pellet-cladding mechanical interaction to no interaction, or vice-versa. The input parameter IP2 is used to determine the prior step status and is updated to indicate current step status in the process.

Initialization of the dimensioned quantities $A A(1)$ to $A I(1)$ at the initial beta-phase oxygen concentrations in the nine outside nodes is performed next. If there is no pellet-cladding mechanical interaction, these nine nodes span the entire beta layer. If there is interaction, the 


\section{CORROS, COBILD, COXIDE, COXWTK, COXTHK}

nine nodes span the outer half of the beta layer. The switch IP2 determines which of these cases is present. IP is set equal to zero to indicate that the nine outer nodes are being modeled, since the same coding may 1 ater be used to model the nine inside nodes.

The initial thickness of the beta layer being modeled is determined by subtracting the outside alpha layer thickness and two-thirds of the oxide layer thickness from the initial thickness of the region under consideration. The factor of two thirds is found by equating the mass per unit surface area of the oxide to the sum of the zircaloy and oxygen masses that produced the oxide:

$$
\rho_{\mathrm{ZrO}_{2}} \mathrm{X}=\rho_{\mathrm{Zr}} \mathrm{Y}+0.26 \rho_{\mathrm{ZrO}_{2}}^{\mathrm{X}}
$$

where

$$
\begin{aligned}
& X \quad=\text { oxide layer thickness }(\mathrm{m}) \\
& Y \quad=\text { thickness of zircaloy consumed to make the oxide }(\mathrm{m}) \\
& \rho_{\mathrm{Zr}}=\text { density of zircaloy }\left(\mathrm{kg} / \mathrm{m}^{3}\right)=6490 \\
& \rho_{\mathrm{ZrO}_{2}}=\text { density of zircaloy oxide }\left(\mathrm{kg} / \mathrm{m}^{3}\right)=5820 .
\end{aligned}
$$

The constant 0.26 represents the mass fraction of oxygen in the oxide. Solution of Equation (15.2-33) for the ratio $Y / X$ yields the required ratio. If the nine nodes under consideration span the entire cladding beta region (IP2 = 0 for no contact), the inside alpha layer thicknesses are also subtracted.

An iteration over five sub-steps is used to calculate the oxide layer thickness, outside alpha layer thickness, and weight gain due to oxidation 


\section{CORROS, COBILD, COXIDE, COXWTK, COXTHK}

by steam. Each sub-step is assumed to be isothermal, and the temperature is determined by linear interpolation of the input temperatures.

The two layer thicknesses are used to calculate the end-of-step thickness of the beta zircaloy layer spanned by the outside nine nodes. This thickness is stored as the variable AL80 for possible later addition to the beta thickness spanned by nine inside nodes.

Next, the change in the beta layer is compared with one-eighth of the initial layer. If the change is greater than one eighth of the initial beta layer, the following message is printed: "DECREASE IN BETA LAYER IS GREATER THAN $1 / 8$ INITIAL LAYER..., TIME STEP TOO LARGE OR BETA LAYER TOO DEPLETED". Also, the error index is changed to one. Physically, the condition implies either that the time step is too long or that the beta layer is nearly completely converted to alpha-zircaloy.

A second check is made to determine if the finite-difference equation of Pawel, Equation (15.2-7), will be stable. If this condition is violated, the following message is printed: "DIFFUSION IS OCCURRING TOO RAPIDLY FOR COBILD TO ACCURATELY CALCULATE OXYGEN CONCENTRATIONS." Also, the input parameter index is set equal to one.

Since the beta layer boundary moves during the time step, the input oxygen concentrations will not apply to the positions of the nodes at the end of the time step. Thus, two calculations are used to find the oxygen concentration in the beta layer. First, it is assumed that the alpha-beta interface jumps immediately to its end-of-step position. A parabolic interpolation is used to find the start-of-step concentrations at the end-of-step positions. In the second part of the calculation, Equation (15.2-7) is applied over five small sub-steps but always at the end-of-step positions. 


\section{CORROS， COBILD， COXIDE， COXWTK， COXTHK}

Simpson's rule is used to integrate the oxygen concentrations over the beta layer width in order to find the net oxygen. The net oxygen is stored as AQ20 for possible addition to the net oxygen in the region spanned by the nine inside nodes.

The final concentrations, $A A(6)$ to $A I(6)$, are stored as the output variables AAO to AIO.

If there is no pellet-cladding interaction, the outer nine nodes span all of the beta layer so the calculation of oxygen concentrations in the beta layer is complete. In this case, the percent saturation, average oxidation power, and average oxygen concentration in the beta layer are calculated and the COBILD calculation is complete.

If there is pellet-cladding interaction, the sequence of calculations for the oxygen concentration is repeated for the inside nine nodes of the beta layer before the percent saturation, average oxidation power, and average oxygen concentration in the beta layer are calculated.

The COXIDE logic is similar to the COBILD logic, but the calculations of oxygen concentration in the beta phase have been omitted.

\subsubsection{References}

15.2-1. E. Hillner, Hydrogen Absorption in Zircaloy During Aqueous Corrosion, Effect of Environment, WAPD-TM-411. November 1964.

15.2-2 A. Van der Linde, Calculation of the Safe Life Time Expectancy of Zirconium Alloy Canning in the Fuel-Elements of the Nero Reactor, RCN-41, July 1965.

15.2-3. B. Cox, "Comments on the Paper 'The Influence of Oxide Stress on the Breakaway 0xidation of Zircaloy-2' By D. H. Bradhurst and P. M. Heuer," Journal of Nuclear Materials, 41, 1970, p. 96.

15.2-4. D. H. Bradhurst and P. M. Heuer, "Reply to Comments by B. Cox on 'The Influence of Oxide Stress on the Breakaway Oxidation of Zircaloy-2,'" Journal of Nuclear Materials, 41, 1971, p. 101. 


\section{CORROS, COBILD, COXIDE, COXWTK， COXTHK}

15.2-5. A. B. Johnson, Jr., "Effects of Nuclear Radiation on the Corrosion, Hydriding, and 0xide Properties of Six Zirconium Alloys," Applications-Related Phenomena for Zirconium and Its Alloys, ASTM-STP-458, 1969, pp. 301-324.

15.2-6. W. A. Burns, Effects of Fast Neutron Irradiation, Fabrication History, and Water Oxygen on the Environmental Behavior of Zirconium Alloys, BNWL-88, 1965.

15.2-7. A. B. Johnson, Jr., and J. E. Irvin, Radiation-Enhanced Oxidation of Zircaloy-2 in pH-10 $\mathrm{LiOH}$ and $\mathrm{pH}-10 \mathrm{NH}_{4} \mathrm{OH}$, BNWL-463, 1967.

15.2-8. L. Lunde and K. Videm, "Effects of Surface Treatment on the Irradiation Enhancement of Corrosion of Zircaloy-2 in HBWR," Zirconium in Nuclear Applications, ASTM-STP-551, 1974, pp. 514-526.

15.2-9. J. V. Cathcart, Quarterly Progress Report on the Zirconium Metal-Water Oxidation Kinetics Program Sponsored by the NRC Division of Reactor Safety Research for April-June 1978, ORNL/NUREG/TM-41, August 1976.

15.2-10. J. V. Cathcart, Quarterly Progress Report on the Zirconium Metal-Water Oxidation Kinetics Program Sponsored by the NRC Division of Reactor Safety Research for October-December 1976, ORNL/NUREG/TM-87, February 1977.

15.2-11. R. G. Ballinger, W. G. Dobson, and R. R. Bierderman, "0xidation Reaction Kinetics of Zircaloy-4 in an Unlimited Steam Environment," Journal of Nuclear Materials, 62, November 1976, pp. 213-220.

15.2-12. V. F. Urbanic, "Method for Estimating the Exposure Time and Temperature for Zircaloy Oxidation in Steam, "Journal of Nuclear Materials, 59, 1976, pp. 90-94.

15.2-13. S. Leistikow et al., "Untersuchen zur Hochtemperature-WasserdampfOxidation von Zircaloy-4 Hullrohen," PBS Halbjahresbericht 1976/2, KfK 2435, February 1977.

15.2-14. S. Kawasaki et al., Reaction of Zircaloy Cladding with Steam Under Simulated Loss-of-Coolant Accident Conditions, JAERI-M-6181, July 1975 .

15.2-15. V. F. Urbanic and T. R. Heidrick, "High Temperature Oxidation of Zircaloy-2 and Zircaloy-4 in Steam, "Journal of Nuclear Materials, 75, 1978, pp. 251-261.

15.2-16. P. Hofmann, C. Politis, "Chemical Interaction Between $\mathrm{UO}_{2}$ and Zry -4 in the Temperature Range Between 900 and $1500^{\circ} \mathrm{C}$, "Fourth International Conference on Zirconium in the Nuclear Industry, Stratford-upon-Avon, England, June 26-29, 1979. 


\section{CORROS, COBILD, COXIDE, COXWTK, COXTHK}

15.2-17. M. W. Mallet et a1., The Zirconium-Uranium Dioxide Reaction, BMI-1210, July 1975 .

15.2-18. D. M. Rooney, L. N. Grossman, Interfacial Reaction Between $\mathrm{UO}_{2}$ and Zircaloy-2, GEAP-4679, Apri1 1965.

15.2-19. A. W. Cronenberg, M. S. El-Genk, An Assessment of Oxygen Diffusion During $\mathrm{UO}_{2}-$-Zircaloy Interaction, TREE-NUREG-1192, January 1978.

15.2-20. W. Jost, Diffusion in Solids, Liquids, Gases, New York: Academic Press Inc., 1972, p. 341.

15.2-21. D. H. Bradhurst, P. J. Shirvington, P. M. Heuer, "The Effects of Radiation and Oxygen on the Aqueous Oxidation of Zirconium and its Alloys at 290 C," Journal of Nuclear Materials, 46, 1973, p. 53.

15.2-22. R. C. Asher et al., "Effects of Radiation on the Oxidation and Hydrogen Absorption of Zirconium Alloys in Steam," Electrochemical Technology, 4, 1966, p. 231.

15.2-23. K. Videm, "Properties of Zirconium Base Cladding Materials Corrosion and Hydrogen Pickup," Advanced Course on Limiting Aspects of Fuel Element Performance in Water Cooled Power Reactors at the Institute for Atomenergi in Kjeller, Norway, August 24-28, 1970 .

15.2-24. F. H. Megerth, C. P. Ruiz, U. E. Wolff, Zircaloy-Clad $\mathrm{NO}_{2}$ Fuel Rod Evaluation Program, GEAP-10371, June 1971.

15.2-25. H. E. Williamson et a1., AEC Fuel Cycle Program Examination of $\mathrm{UO}_{2}$, Fuel Rods Operated in the VBWR to 10,000 MWD/TU, GEAP-4597, 1965.

15.2-26. E. Hillner, "Corrosion and Hydriding Performance in Zircaloy Tubing after Extended Exposure in the Shippingport PWR," Zirconium in Nuclear Applications, ASTM-STP-551, 1974, pp. 449-462.

15.2-27. W. R. Smalley, Saxton Core II Fuel Performance Evaluation, Part I: Materials, WCAP-3385-56, 1971.

15.2-28. W. R. Smalley, Saxton Core III Fuel Materials Performance, WCAP-3385-57, 1974.

15.2-29. J. V. Cathcart, Quarterly Progress Report on the Zirconium Metal-Water Oxidation Kinetics Program Sponsored by the NRC Division of Reactor Safety Research for January-March 1976, ORNL/NUREG/TM-17, May 1976. 


\section{CORROS, COBILD, COXIDE, COXWTK, COXTHK}

15.2-30. J. V. Cathcart, Quarterly Progress Report on the Zirconium Metal-Water Oxidation Kinetics Program Sponsored by the NRC Division of Reactor Safety Research for July-September 1976, ORNL/NUREG/TM-62, December 1976.

15.2-31. L. Baker and L. C. Just, Studies of Metal-Water Reactions at High Temperatures-III. Experimental and Theoretical Studies of the Zirconium-Water Reaction, ANL-6548, May 1962.

15.2-32. S. Malang, SIMTRAN I--A Computer Code for the Simultaneous Calculation of Oxygen Distributions and Temperature Profiles in Zircaloy During Exposure to High Temperature Oxidizing Environments, ORNL-5083, November 1975.

15.2-33. R. E. Pawel, "Diffusion in a Finite System with a Moving Boundary," Journal of Nuclear Materials, 49, January 1974, pp. 281-290.

15.2-34. R. A. Perkins, Zirconium Metal Water Oxidation Kinetics II, Oxygen-18 Diffusion in Beta Zircaloy, ORNL/NUREG/TM-19, 1976, p. 33 .

15.2-35. R. E. Pawel, R. A. Perkins, R. A. Mckee, J. V. Cathcart, G. J. Yurek and R. E. Drusche1, "Diffusion of Oxygen in Beta-Zircaloy and the High Temperature Zircaloy-Steam Reaction," Zirconium in the Nuclear Industry, ASTM STP 663, 1977, pp. 119-133.

\subsubsection{Bibliography}

The following references contain information pertinent to zircaloy oxidation.

(1) A. W. Lemmon, Studies Relating to the Reaction Between Zirconium and Water at High Temperatures, BMI-1154, 1957.

(2) D. H. Bradhurst and P. M. Heuer, "The Influence of oxide Stress on the Breakway Oxidation of Zircaloy-2," Journal of Nuclear Materials, 37, 1970, pp. 35-47.

(3) D. 0. Hobson and P. L. Rittenhouse, Embrittlement of Zircaloy-Clad Fuel Rods by Steam During LOCA Transients, ORNL-4758, January 1972.

(4) R. E. Pawel, "Oxygen Diffusion in Beta Zircaloy During Steam Oxidation," Journal of Nuclear Materials, 50, 1974, pp. 247-258. 


\section{CORROS, COBILD, COXIDE， COXWTK， COXTHK}

(5) R. R. Biederman and W. G. Dobson, "A Study of Zircaloy-Steam Oxidation Reaction Kinetics, "Fifth Interim Progress Report, Worchester Polytechnic Institute, January 16-April 15, 1976.

(6) T. G. Odekirk, Detailed Test Plan Report for PBF Test Series PCM-20: The Behavior of Unirradiated PWR Fuel Rods Under Power-Cooling-Mismatch Conditions, ANCR-1095, April 1974.

(7) A. W. Urquhart and D. A. Vermilyea, "Characterization of Zircaloy Oxidation Films," Zirconium in Nuclear Applications, ASTM-STP-551, 1974, pp. 463-478.

(8) R. E. Pawel, Zirconium Metal-Water Oxidation Kinetics III. Oxygen Diffusion in Oxide and Alpha Zircaloy Phases, ORNL/NUREG-5, October 1976.

(9) J. V. Cathcart, Quarterly Progress Report on the Zirconium Metal-Water Oxidation Kinetics Program Sponsored by the NRC Division of Reactor Safety Research for JuTy-September 1975, ORNL-5148, December 1975.

(10) J. V. Cathcart, Quarterly Progress Report on the Zirconium Metal-Water Oxidation Kinetics Program Sponsored by the NRC Division of Reactor Safety Research for October-December 1975, ORNL/TM-5248, March 1976.

(11) J. V. Cathcart, Quarterly Progress Report on the Zirconium Metal-Water Oxidation Kinetics Program Sponsored by the NRC Division of Reactor Safety Research for October-December 1976, ORNL/NUREG/TM-87, February 1977.

(12) R. R. Biederman and W. G. Dobson, "A Study of Zircaloy-Steam 0xidation Reaction Kinetics, "Fourth Interim Progress Report, Worchester Polytechnic Institute, October 1, 1975-January 15, 1976.

(13) G. Schanz and S. Leistikow, "Anwnedung und Experimentelle berprfung des Codes SIMTRAN-1 zur Beschreibung der Zircaloy WasserdampfHT-0xidation," Atomwirtschaft, August 1976, pp. 409-410.

(14) S. L. Seiffert and T. F. Cook, Power-Cooling-Mismatch Test Series Test PCM-4 Postirradiation Examination, NUREG/CR-02381, TREE-1230, July 1978.

(15) D. L. Douglass, "Oxide Plasticity in the Oxidation Mechanism of Zirconium and its Alloys," Corrosion Science, 5, 1965, pp. 255-268.

(16) H. M. Chung and T. F. Kassner, "Pseudobinary Zircaloy-0xygen Phase Diagram, " Journal of Nuclear Materials, 84, 1979, pp. 327-339.

(17) E. A. Garcia, "Diffusion in a Semi-Infinite System with a Moving Interface at Constant Temperature for Application to a-Zirconium 0xidation at High Temperature," Journal of Nuclear Materials, 92, 1980, pp. 249-256. 


\section{CORROS, COBILD, COXIDE, COXWTK, COXTHK}

(18) E. A. Garcia, "Diffusion in a Semi-Infinite Medium with a Moving Boundary During a Temperature Gradient," Journal of Nuclear Materials, 96, 1981, pp. 118-126.

(19) A. Denis and E. A. Garcia, "Diffusion in a Semi-Infinite System with a Moving Interphase Considering Solvent Density Change: Application to the Oxidation of Zirconium, " Journal of Nuclear Materials, 96, 1981, pp. 127-140.

(20) G. Schanz and S. Leistikow, " $\mathrm{ZrO}_{2}$-Scale Degradation During Zircaloy-4 High Temperature Steam Exposure; Microstructural Mechanisms and Consequences for PWR Safety Analysis," Topical Meeting on Reactor Safety Aspects of Fuel Behavior, Sun Valley, Idaho, August 2-6, 1981.

(21) G. J. Yurek, J. V. Cathcart, R. E. Pawel, "Microstructures of the Scales Formed on Zircaloy-4 in Steam at Elevated Temperatures," Oxidation of Metals, 10, 1976, pp. 255-276.

(22) R. E. Pawe1, J. V. Cathcart and J. J. Campbe11, "The Oxidation of Zircaloy-4 at 900 and $1100^{\circ} \mathrm{C}$ in High Pressure Steam, "Journal of Nuclear Materials, 82, 1979, pp. 129-139.

(23) R. E. Pawel, J. V. Cathcart and R. A. McKee, "'Anomalous' Oxide Growth During Transient-Temperature Oxidation of Zircaloy-4," Oxidation of Metals, 14, 1980, pp. 1-13.

(24) R. E. Pawel, "Oxygen Diffusion in the Oxide and Alpha Phases During Reaction of Zircaloy-4 with Steam from 1000 to $1500^{\circ} \mathrm{C}$, " Journal of the Electrochemical Society, 126, 1979, pp. 1111-1118.

(25) R. E. Pawel and J. J. Campbel1, "The Oxidation of Pure Zirconium in Steam from 1000 to $1416^{\circ} \mathrm{C}, "$ Journal of the Electrochemical Society, 128, 1981, pp. 1999-2005.

(26) R. E. Pawel, J. V. Cathcart and R. A. Mckee, "The Kinetics of Oxidation of Zircaloy-4 in Steam at High Temperature, "Journal of the Electrochemical Society, 126, 1979, pp. 1105-1111.

(27) R. E. Pawel and J. J. Campbell, "The Observation of Effects of Finite Specimen Geometry on the Oxidation Kinetics of Zircaloy-4," Journal of the Electrochemical Society, 127, 1980, pp. 2188-2194. 


\section{CHUPTK}

\subsection{Cladding Hydrogen Uptake (ChuptK)}

(D. L. Hagrman)

This subroutine calculates the average weight fraction of hydrogen in zircaloy cladding during typical reactor operation at temperatures of 523 to $650 \mathrm{~K}$. Required inputs are: as-received hydrogen concentration in the cladding, initial fuel water content, fuel pellet diameter, type of cladding (zircaloy-2 or zircaloy-4), cladding inside and outside diameters, type of reactor (BWR or PWR), oxide thickness at the start and end of the current time step, temperature at the oxide-coolant interface, heat flux, zirconium oxide thermal conductivity, and the average weight fraction of hydrogen in the cladding at the start of the current time step.

\subsubsection{Summary}

The average weight fraction of hydrogen in zircaloy cladding during steady state conditions is

$H=H_{0}+H_{1}+H_{c}$

where

$H=$ net weight fraction of hydrogen in the cladding (ppm).

$H_{0}=$ initial concentration of hydrogen in the cladding due to impurities introduced during manufacturing and autoclaving (ppm). Typical values are 8 to $30 \mathrm{ppm}$.15.3-1,15.3-2 


\section{CHUPTK}

$$
\begin{aligned}
& \mathrm{H}_{1}=\begin{array}{l}
\text { concentration of hydrogen in the cladding due to internal } \\
\text { outgassing of water absorbed by the fuel (ppm) }
\end{array} \\
& \mathrm{H}_{\mathrm{c}}=\begin{array}{l}
\text { concentration of hydrogen in the cladding due to absorption } \\
\text { of hydrogen from the coolant }(\mathrm{ppm}) .
\end{array}
\end{aligned}
$$

$H_{0}$ is an input parameter. $H_{1}$ is calculated by the routine using the input values for parts per million water vapor in the fuel, the input cladding dimensions, and the input fuel pellet diameter. CHUPTK assumes that all the hydrogen from the water vapor in the fuel is picked up by the cladding.

The primary consideration in determining $H$ is the determination of $H_{c}$. Analytical expressions for $H_{c}$ are divided into three parts:

Equation (15.3-2) for oxide films thinner than the transition thickness, ${ }^{\text {a }}$ Equation (15.3-3) for oxide films equal to the transition thickness at some point in the current time step, and Equation (15.3-4) for oxide films greater than the transition thickness during the current time step. In these equations, the variable $\mathrm{H}_{c}$ has been converted from a fraction of the oxide's oxygen increase to units of average parts per million by weight in the cladding.

$$
\begin{aligned}
& H_{c f}=\left[\frac{\left(9 \times 10^{5}\right) d_{0}}{d_{0}^{2}-d_{j}^{2}}\right] \frac{B}{8 A}\left(X_{f}-X_{j}\right)+H_{c i} \\
& H_{c f}=\left[\frac{\left(9 \times 10^{5}\right) d_{0}}{d_{0}{ }^{2}-d_{j}{ }^{2}}\right]\left[\frac{B}{8 A}\left(X_{\text {TRAN }}-X_{j}\right)+\frac{c}{8 A}\left(X_{f}-X_{\text {TRAN }}\right)\right]+H_{c i}
\end{aligned}
$$

a. Oxide film growth is discussed in conjunction with the description of the cladding oxidation subcode, CORROS. The terms pre- and posttransition refer to two different stages in the growth of the oxide film. A transition between the two stages occurs when the oxide film has added approximately $30 \mathrm{mg}$ of oxide per $\mathrm{dm}^{2}$ of oxide surface. 
CHUPTK

$H_{c f}=\left[\frac{\left(9 \times 10^{5}\right) d_{0}}{d_{0}^{2}-d_{i}^{2}}\right] \frac{c}{8 A}\left(x_{f}-X_{i}\right)+H_{c i}$

where
$\mathrm{H}_{\mathrm{cf}}=$ weight fraction of hydrogen added to the cladding from the coolant at the end of the current time step (ppm by weight)

$\mathrm{H}_{\mathrm{ci}}=$ weight fraction of hydrogen added to the cladding from the coolant at the start of the current time step (ppm by weight)

$d_{0}=\quad$ cladding outside diameter $(m)$

$d_{i}=\quad$ cladding inside diameter $(m)$

B = fraction of hydrogen liberated by the reaction with the coolant that is absorbed by the cladding during pretransition oxidation. The value of $B$ is a function of the input parameters ICOR (BWR or PWR chemistry) and ICM (zircaloy-2 or zircaloy-4). Values of $B$ for zircaloy-2 are 0.48 in a PWR environment and 0.29 in a BWR environment. For zircaloy-4, $B=0.12$.

C = fraction of hydrogen liberated by the reaction with the coolant that is absorbed by the cladding during posttransition oxidation. The value of $C$ is a function of the input parameter ICM (zircaloy-2 or zircaloy-4). The value of $C$ for zircaloy-2 is 1.0 . For zircaloy-4, $C=$ 0.12 . 


\section{CHUPTK}

A $=$ a parameter describing the enhancement of the oxidation rate of the cladding in the reactor environment. The parameter is discussed in conjunction with the description of the cladding oxidation subcode, CORROS. The value for $A$ is determined in the subcode by user specification of BWR and PWR chemistry with the input parameter ICOR. $x_{i}=\quad \begin{aligned} & \text { oxide layer thickness at the start of the current time } \\ & \text { step }(\mathrm{m}) .\end{aligned}$

$x_{f}=$ oxide layer thickness at the end of the current time step (m).

$X_{\text {TRAN }}=$ oxide layer thickness at the transition point (typically, $\left.2 \times 10^{-6} \mathrm{~m}\right)$. The value of $X_{\text {TRAN }}$ is calculated by the CHLPTK subcode using the expression developed for CORROS (Section 15.2) and the input information.

The approach and general physical picture used to model hydrogen uptake are summarized in Section 15.3.2. Section 15.3.3 develops the basic out-of-pile model, and Section 15.3.4 generalizes the basic model so that it describes in-pile hydrogen uptake.

\subsubsection{Background and Approach}

It is generally agreed $15.3-3,15.3-4$ that oxidation of zirconium alloys by water in the temperature range from 523 to $673 \mathrm{~K}$ proceeds by the migration of oxygen vacancies in the oxide layer. Change and physical size considerations imply that the mechanism of introduction of hydrogen into the zirconium metal through an oxide film is by entry of neutral hydrogen atoms into oxygen vacancies in the lattice. $\left(\mathrm{H}_{2}\right.$ is too large and $\mathrm{H}^{+}$is too positive.) The constant ratio of absorbed hydrogen to oxygen taken up by the cladding (the 'pickup fraction') is explained as having been determined 
by the competition between possible subsequent reactions of the atomic hydrogen created by corrosion. (The atomic hydrogen can combine to form a gas or enter a surface vacancy in the oxide lattice.)

In this approach, the close relationship between the hydrogen weight gain and the oxygen weight gain from the coolant is viewed as a consequence of the fact that the oxygen and hydrogen usually come from a common source (the water molecule) and are transported to the metal by a common carrier (oxygen vacancies). The hydrogen pickup fraction is determined by the composition of the coolant-oxide surface. In particular, it is suspected that nickel oxide from the nickel in zircaloy-2 absorbs atomic hydrogen at the surface of the oxide and thereby enhances the fractional hydrogen uptake for zircaloy-2.

\subsubsection{Out-of-Pile Basis for the Model}

The in-pile model is based primarily on out-of-pile data because well-characterized data on hydrogen uptake as a function of time and temperature have been published only for out-of-pile corrosion. At least two plausible suggestions for a hydrogen uptake model can be presented from the approach discussed in Section 15.3.2. According to both of these suggestions, the dependent variable is the ratio of the corrosion-liberated hydrogen to oxygen absorbed by the metal, although the independent variables differ. A brief summary of the two models, and a third less probable model, follows.

15.3.3.1 Simple Probabilistic Hydrogen Pickup Model. In this mode], the fraction of released hydrogen absorbed by the oxide surface is assumed to be proportional to the rate of appearance of oxide vacancies at the oxide-coolant interface. In the discussion of the cladding oxidation model, CORROS, it is shown that the vacancies appear at a rate proportional to the inverse of the square of the oxygen weight gain during the pretransition phase of oxidation. During the posttransition phase of oxidation, the 


\section{CHUPTK}

surface-averaged rate of appearance of oxide vacancies is constant and proportional to three times the inverse of the square of the weight of the oxide layer at transition. This model ignores any details of the surface chemistry involved in the absorption of atomic hydrogen by the oxide vacancies.

15.3.3.2 Surface-Controlled Hydrogen Pickup Model. In this model, the fraction of released hydrogen absorbed by the oxide surface is a constant determined by the metallurgy of the oxide surface. The model assumes that the effect of absorption of atomic hydrogen is dominant in the capture of hydrogen by the oxide film's outer surface.

\subsubsection{Diffusion-Controlled Hydrogen Pickup Model. It is also} conceivable that the time rate of hydrogen input into the metal is controlled by some as-yet-unconsidered independent diffusion process. In the case of diffusion-controlled hydrogen uptake, the net time rate of hydrogen pickup is proportional to the inverse thickness of the oxide layer.

The rate equations implied by the three alternate pictures are summarized in Table 15.3-1. Pretransition expressions were formulated simply by writing down the mathematical equivalent of the descriptions above. Posttransition expressions for the hydrogen pickup fraction were derived by replacing powers of $X$ (proportional to the oxide thickness) in the pretransition expressions with powers of $X$ averaged over a rate-determining oxide thickness that randomly varies from zero to the transition thickness of the oxide film. A discussion of the posttransition oxide film and this approach to describing posttransition rates is included in the description of the cladding oxidation subcode CORROS in Section 15.2.

When the three very different expressions for hydrogen uptake obtained with these models were integrated and compared with the pretransition data of Tables 7 and 9 of Reference 15.3-3, the pretransition data for zircaloy-2 and zircaloy-4 were found to conform best to the assumption that the rate is surface-controlled. The surface-controlled model is therefore used. 
Table 15.3-1. Rate equations for hydrogen uptake

\section{Pretransition Rates}

(1) Simple probabilistic pickup fraction determination

$$
\begin{array}{rl}
\mathrm{dH} / \mathrm{dX}=\mathrm{G} / \mathrm{X}^{2} & \mathrm{dH} / \mathrm{dX}=\mathrm{G} / \overline{\mathrm{X}^{2}} \\
& =3 \mathrm{G} / \mathrm{X}_{\text {TRAN }^{2}}
\end{array}
$$

(2) Surface-controlled pickup fraction determination

$$
\mathrm{dH} / \mathrm{dX}=\mathrm{P}
$$$$
d H / d X=P
$$

(3) Diffusion-controlled time rate

$$
\begin{array}{rl}
\mathrm{dH} / \mathrm{dX}=\mathrm{Q} / \mathrm{X} & \mathrm{dH} / \mathrm{dX}=Q / \bar{X} \\
& =2 Q / X \text { TRAN }
\end{array}
$$

where

$\mathrm{H}=$ hydrogen weight gain $\left(\mathrm{mg} / \mathrm{dm}^{2}\right)$

$x=$ oxygen weight gain ( $\mathrm{mg} / \mathrm{dm}^{2}$, corresponds to oxide thickness)

$\mathrm{t}=$ time at temperature

$X_{\text {TRAN }}=$ the transition weight of the oxide layer $\left(\mathrm{mg} / \mathrm{dm}^{2}\right)$

$\overline{x^{2}}=$ the average of $x^{2}$ with values of $x$ distributed at random between 0 and the transition thickness, $x_{\text {TRAN }}\left(\mathrm{mg} / \mathrm{dm}^{2}\right)$

$\bar{X}=$ the space average of $X$ with values of $X$ distributed at random between 0 and the transition thickness $\left(\mathrm{mg} / \mathrm{dm}^{2}\right)$

$G, P, Q=$ constants 


\section{CHUPTK}

Comparison of experimental pretransition and posttransition hydrogen pickup fractions ${ }^{15.3-3}$ for zircaloy-2 show that the posttransition rate is about twice the pretransition rate. For zircaloy-4, the pre- and posttransition rates are similar. The reason for this difference between zircaloy-2 and -4 is not well understood but may be related to the presence of nickel, which absorbs atomic hydrogen in zircaloy-2.

The simple surface-controlled hydrogen pickup model of Table 15.3-1 has, therefore, been modified slightly.

For pretransition,

$\frac{d H}{d X}=\frac{B}{8}$

For posttransition,

$\frac{d H}{d X}=\frac{C}{8}$

where $B$ and $C$ are determined by the oxide surface metallurgy of the particular alloy and 8 accounts for the different weights of hydrogen and oxygen in water so that $\mathrm{dH} / \mathrm{dX}=1 / 8$ for complete pickup.

\subsubsection{Generalization to an In-pile Model}

Prediction of in-pile corrosion is complicated because important variables (local temperature and reactor chemistry) are not always reported and because data on the time-dependence of corrosion are limited. Enhancement of the hydrogen uptake factors by the reactor environment is treated by determining the value of the pickup fractions $B$ and $C$ for each reactor environment. Changes in the rate of hydrogen picked up caused by changes in the oxidation rate are described with the parameter $A$, which is 


\section{CHUPTK}

discussed in conjunction with the oxidation model, CORROS. Thus, separate parameters are specified to describe the separate processes involved in determining the total rate of hydrogen uptake.

The basic equations for the fraction of hydrogen pickup with respect to the amount of oxygen pickup $(\mathrm{dH} / \mathrm{dX})$ are discussed at the end of Section 15.3-3 [Equations (15.3-5) and (15.3-6)]. Those equations reference out-of-pile oxidation. For in-pile pickup, the enhancement factor A must again be used. It is presumed that the effect that enhances the oxidation rate in the reactor does not enhance the rate of hydrogen uptake. Thus, the enhancement of the oxidation rate by a factor $A$ will decrease the fractional hydrogen uptake by a factor $1 / A$.

The rate equations for in-pile oxidation and for fractional pickup of hydrogen are summarized in Equations (15.3-7) and (15.3-8) for both pre- and posttransition regimes.

For the pretransition in-pile regime,

$\frac{d H}{d X}=\frac{B}{8 A}$

For the posttransition in-pile regime,

$\frac{d H}{d X}=\frac{C}{8 A}$.

Integration of Equations (15.3-7) and (15.3-8) and conversion of the integrated forms from weight gains to oxide thickness and parts per million hydrogen by weight leads to Equations (15.3-2) through (15.3-4).

An out-of-pile value of the parameter $B$ has been determined in Reference 15.3-4 (from unpublished data) to be $B=0.33$ for zircaloy-2. For 


\section{CHUPTK}

zircaloy -4, a value of $B=0.12$ was obtained from Figure 12 of Reference 15.3-3. The result is consistent with a value of $10 \%$ recommended by Reference 15.3-4.

When values of $B$ were fit to the average hydrogen pickup values for the zircaloy-4 rods of the Saxton reactor, 15.3-5,15.3-6 an average value of $B$ $=0.104 \pm 0.04$ was obtained. Thus, the out-of-pile determined value of $B=$ 0.12 is apparently adequate for zircaloy-4 rods in PWRs. Since no data on zircaloy-4 cladding in a BWR are available, the PWR value, $B=0.12$, is returned for the unlikely case of zircaloy-4 in a BWR. Values of B obtained by fitting the zircaloy-2 PWR hydrogen pickup reported in Reference 15.3-2 were $B=0.48 \pm 0.07$, while a fit to the BWR hydrogen pickup data on the zircaloy -2 rods of Reference 15.3-7 produced $B=0.29 \pm 0.06$. Since the PWR environment has an overpressure of hydrogen and it is known that hydrogen overpressures enhance the out-of-pile pickup fraction, 15.3-7 it is suggested that the difference in PWR and BWR values for B with zircaloy-2 is an effect of the different environments.

\subsubsection{References}

15.3-1. F. H. Megerth, C. P. Ruiz, U. E. Wolff, Zircaloy-Clad $\mathrm{UO}_{2}$ Fuel Rod Evaluation Program, GEAP-10371, June 1971.

15.3-2. E. Hillner, "Corrosion and Hydriding Performance of Zircaloy Tubing after Extended Exposure in the Shippingport PWR," Zirconium in Nuclear Applications, ASTM-STP-551, 1974, pp. 449-462.

15.3-3. E. Hillner, Hydrogen Absorption in Zircaloy During Aqueous Corrosion, Effect of Environment, WAPD-TM-411, November 1964.

15.3-4. A. Van der Linde, Calculation of the Safe Life Time Expectancy of Zirconium Alloy Canning in the Fuel-Elements of the Nero Reactor, RCN-41, JuTy 1965.

15.3-5. W. R. Smalley, Saxon Core II Fuel Performance Evaluation, Part I: Materials, WCAP-3385-56, July 1971.

15.3-6. W. R. Smalley, Saxton Core III Fuel Materials Performance, WCAP-3385-57, JuTy 1974. 


\section{CHUPTK}

15.3-7. H. E. Williamson et al., AEC Fuel Cycle Program Examination of $\mathrm{UO}_{2}$ Fuel Rods Operated in the VBWR to 10,000 MWD/TU, GEAP-4597, 1965. 
SOXIDE，SOXWGN，SOXTHK

\subsection{Stainless Steel Oxidation in Steam (SOXIDE, SOXWGN, SOXTHK)}

(D. L. Hagrman)

Three subcodes are employed to describe the oxygen uptake of 304 stainless steel. The SOXIDE subroutine returns the linear power generated by the oxidation of stainless steel, the oxidation weight gain at the end of a time step, and an estimate of the oxide layer thickness at the end of a time step. Required input information is the cladding temperature, the time step duration, the outside diameter of the as-fabricated cladding, the initial weight gain, and the initial oxide layer thickness. SOXWGN is a function that returns the parabolic rate constant for the oxidation weight gain of stainless steel as a function of temperature. The parabolic rate constant for the oxide layer thickness is calculated by SOXTHK as a function of temperature.

\subsubsection{Model Development}

The equation used to model the oxidation parameters is of the form

$$
Z_{f}=\left[Z_{j}+2 A \exp (-B / T) \Delta t\right]^{1 / 2}
$$

where

$$
\begin{aligned}
& Z_{f}=\text { value of the oxidation parameter (oxide layer thickness or } \\
& \text { cladding weight gain per unit surface area due to } \\
& \text { oxidation) at the end of a time span of } \Delta t
\end{aligned}
$$




\section{SOXIDE, SOXWGN, SOXTHK}

$Z_{i}=\quad$ value of the oxidation parameter at the start of the time span

$\mathrm{T}=$ temperature of the oxide layer $(\mathrm{K})$

$\Delta \mathrm{t} \quad=\quad$ time $\operatorname{span}(\mathrm{s})$

$A, B=$ rate constants.

There is some question as to the exact value of the A coefficient for the oxide thickness version of Equation (15.4-1). The values currently considered are $300 \mathrm{~m}^{2} / \mathrm{s}$ and $30,000 \mathrm{~m}^{2} / \mathrm{s}$. The former is currently used in the code.

Table 15.4-1 lists the rate constants used with Equation (15.4-1) to model weight gain or oxide layer thickness. The parabolic rate constants calculated by SOXWGN and SOXTHK are the quantities

$R=2 A \exp (-B / T)$

where $R$ is the parabolic rate constant for oxidation parameter described by rate constants $A$ and $B$.

The expression used to model the linear power generated by the oxidation of stainless steel is

$P=4.85 \times 10^{6} D_{0} \frac{\left(M_{f}-M_{i}\right)}{\Delta t}$

where

$\mathrm{P}=\quad$ rate of heat generation per unit length of 304 stainless steel cladding $(\mathrm{W} / \mathrm{m})$ 


\section{SOXIDE，SOXWGN，SOXTHK}

Table 15.4-1. Rate constants for use with Equation (15.4-1) to predict oxidation

Oxidation Parameter

Cladding weight gain

$\left(\mathrm{kg} / \mathrm{m}^{2}\right.$ surface $)$

Oxide thickness

$\frac{A}{1.2 \times 10^{8} \mathrm{~kg}^{2} / \mathrm{m}^{4} \cdot \mathrm{s}} \quad \frac{B}{42,428 \mathrm{~K}}$

$300 \mathrm{~m}^{2} / \mathrm{s}$

$42,428 \mathrm{~K}$ 


\section{SOXIDE, SOXWGN, SOXTHK}

$D_{0}=\quad$ cladding outside diameter without oxidation (m)

$M_{f}=$ mass gain per unit surface area due to oxidation at end of time step $\left(\mathrm{kg} / \mathrm{m}^{2}\right)$

$M_{j}=$ mass gain per unit surface area due to oxidation at start of time step $\left(\mathrm{kg} / \mathrm{m}^{2}\right)$.

The power represented by this equation is about one tenth the power represented by the corresponding equation for zircaloy oxidation when the mass gains are similar.

Equation (15.4-1), with oxidation rate constants for weight gain, was taken from page 50 of Reference 15.4-1. If the composition and density of the oxide are known, the rate constant for the oxide layer thickness can be determined from the rate constant for oxidation weight gain:

$$
A=\frac{B}{W F O X^{2} p^{2}}
$$

where

$$
\begin{aligned}
& A \quad=\text { rate constant for oxide layer thickness }\left(\mathrm{m}^{2} / \mathrm{s}\right) \\
& B \quad=\text { rate constant for oxidation weight gain }\left(\mathrm{kg}^{2} / \mathrm{m}^{4} \cdot \mathrm{s}\right) \\
& \text { WFOX } \quad=\text { mass fraction oxygen in the oxide }(\mathrm{kg} \text { oxygen } / \mathrm{kg} \text { oxide) } \\
& \mathrm{p} \quad=\text { density of the oxide } \mathrm{film}\left(\mathrm{kg} / \mathrm{m}^{3}\right) .
\end{aligned}
$$

However, determination of a rate constant for the oxide layer thickness is complicated by uncertainty about the oxide density because of considerable foaming of the stainless steel during oxidation. 15.4-1,15.4-2 
Moreover, page 53 of Reference 15.4-1 reports very complex oxide structures. The oxide is expected to contain some $\mathrm{Fe} 0, \mathrm{Fe}_{3} \mathrm{O}_{4}$, $\mathrm{Fe}_{2} \mathrm{O}_{3}, \mathrm{CrO}_{3}, \mathrm{Cr}_{2} \mathrm{O}_{3}, \mathrm{NiO}$, and mixed spinels. The rate constant in Table 15.4-1 was calculated by assuming the composition of $\mathrm{FeO}$ and a density of $3000 \mathrm{~kg} / \mathrm{m}^{3}$ (about half the density of nonporous $\mathrm{Fe} 0$ ).

Equation (15.4-3) for the linear power generated by oxidation is derived by subtracting the heat required to dissociate $\mathrm{H}_{2} \mathrm{O}, 2.4182 \times 10^{5}$ $\mathrm{J} / \mathrm{mole},{ }^{15.4-3}$ from the heat of reaction of iron and oxygen to form $\mathrm{FeO}$, $2.67 \times 10^{5} \mathrm{~J} / \mathrm{mole} .^{15.4-4}$ The resultant heat of formation for one mole of $\mathrm{FeO}$ from one mole of $\mathrm{H}_{2} \mathrm{O}$ is multiplied by the rate of oxygen uptake in moles and the circumference of the cladding to obtain Equation (15.4-3).

The expected standard deviation of the oxide layer thickness is $\pm 50 \%$ of the predicted thickness. The expected standard deviation of the oxidation weight gain and oxidation power is somewhat less, $\pm 25 \%$ of the predicted value, because the oxide composition and density do not affect the prediction of these quantities.

Figures 15.4-1 and 15.4-2 illustrate the parabolic constants calculated with the SOXWGN and SOXTHK functions. The time-step-averaged power per meter of rod calculated with SOXIDE for a $1.25 \times 10^{-2}$-m-diameter rod with no initial oxide layer and a 1-s time step is shown in Figure 15.4-3. Figures 15.4-4 and 15.4-5 illustrate oxygen uptake and the oxide layer thickness expected after a $1-s$ time step with no initial oxidation.

\section{4-2 References}

15.4-1. H. C. Brassfield, J. F. White, L. Sjodah1, and J. T. Bittel, Recommended Property and Reaction Kinetics Data for Use in Evaluating a Light-Water-Cooled Reactor Loss-of-Coolant Incident Involving Zircaloy-4 of $304 \mathrm{SS} \mathrm{Clad} \mathrm{UO}_{2}$, GEMP 482, 1968.

15.4-2. J. C. Hesson et a1., Laboratory Simulations of Cladding--Steam Reactions Following Loss-of-Coolant Accidents in Water-Cooled Power Reactors, ANL-7609, 1970, pp. 12-18. 
SOXIDE, SOXWGN, SOXTHK

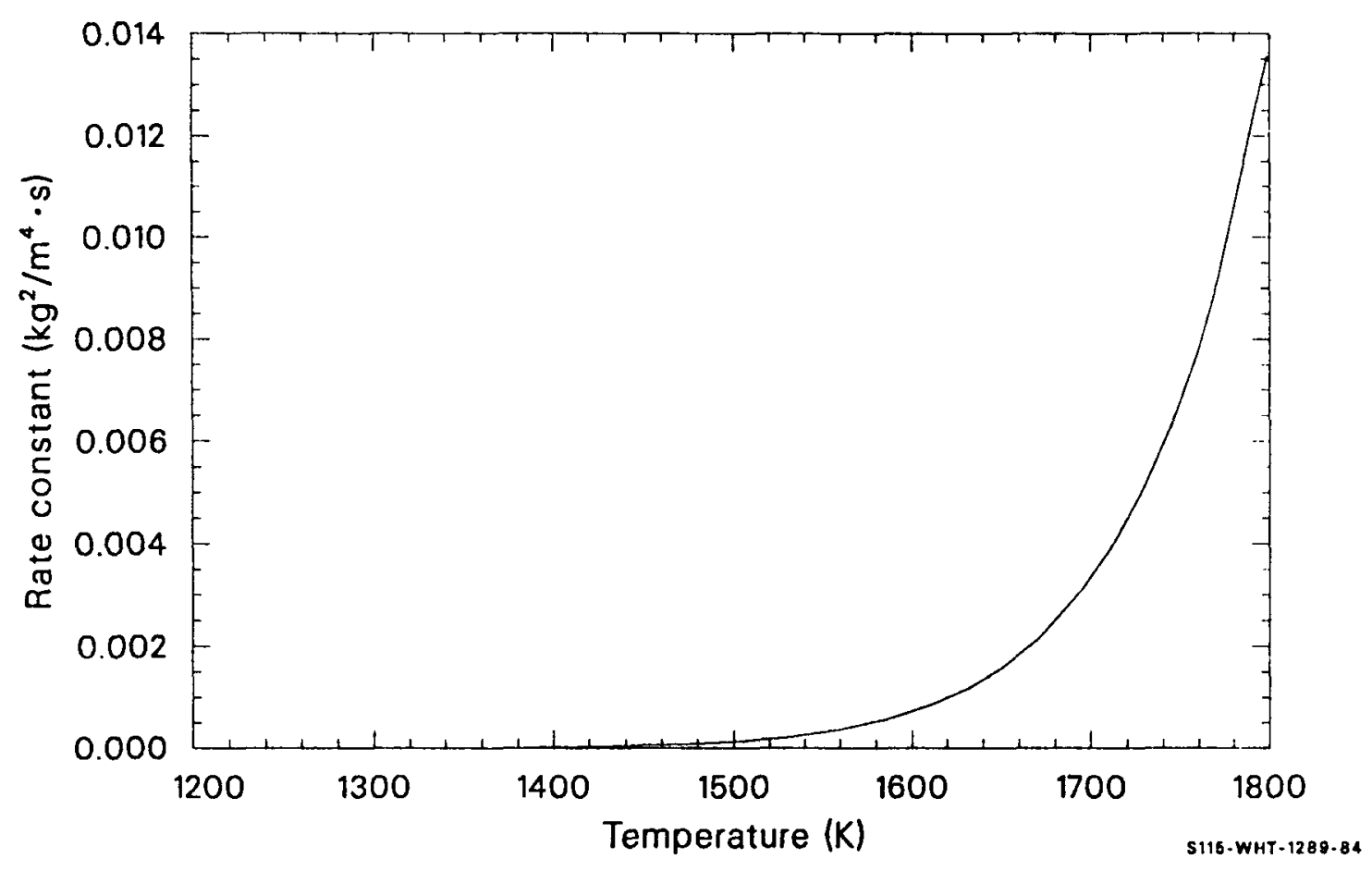

Figure 15.4-1. Parabolic constant for oxygen weight gain 
SOXIDE，SOXWGN，SOXTHK

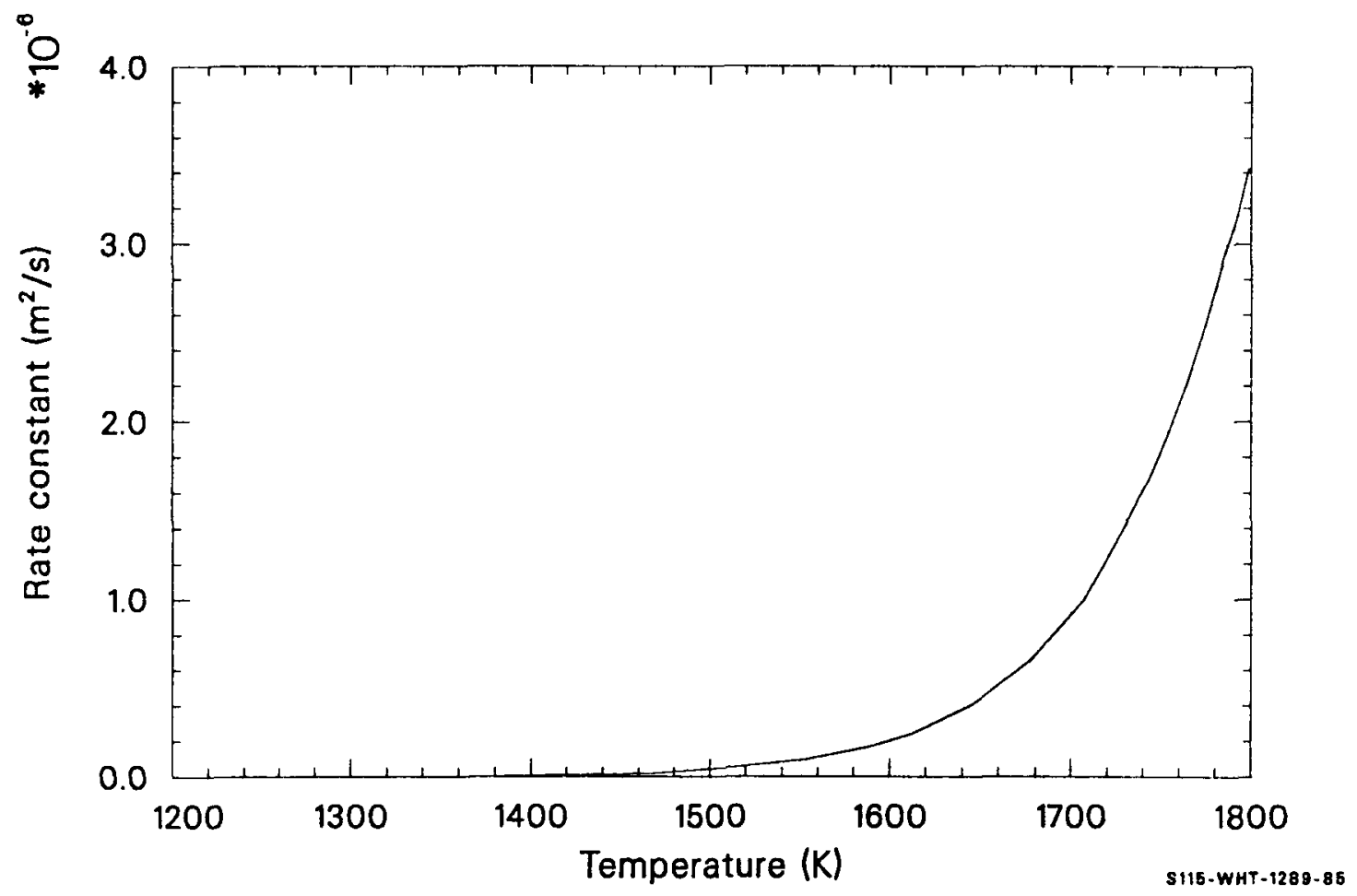

Figure 15.4-2. Parabolic constant for oxide layer thickness. 
SOXIDE，SOXWGN， SOXTHK

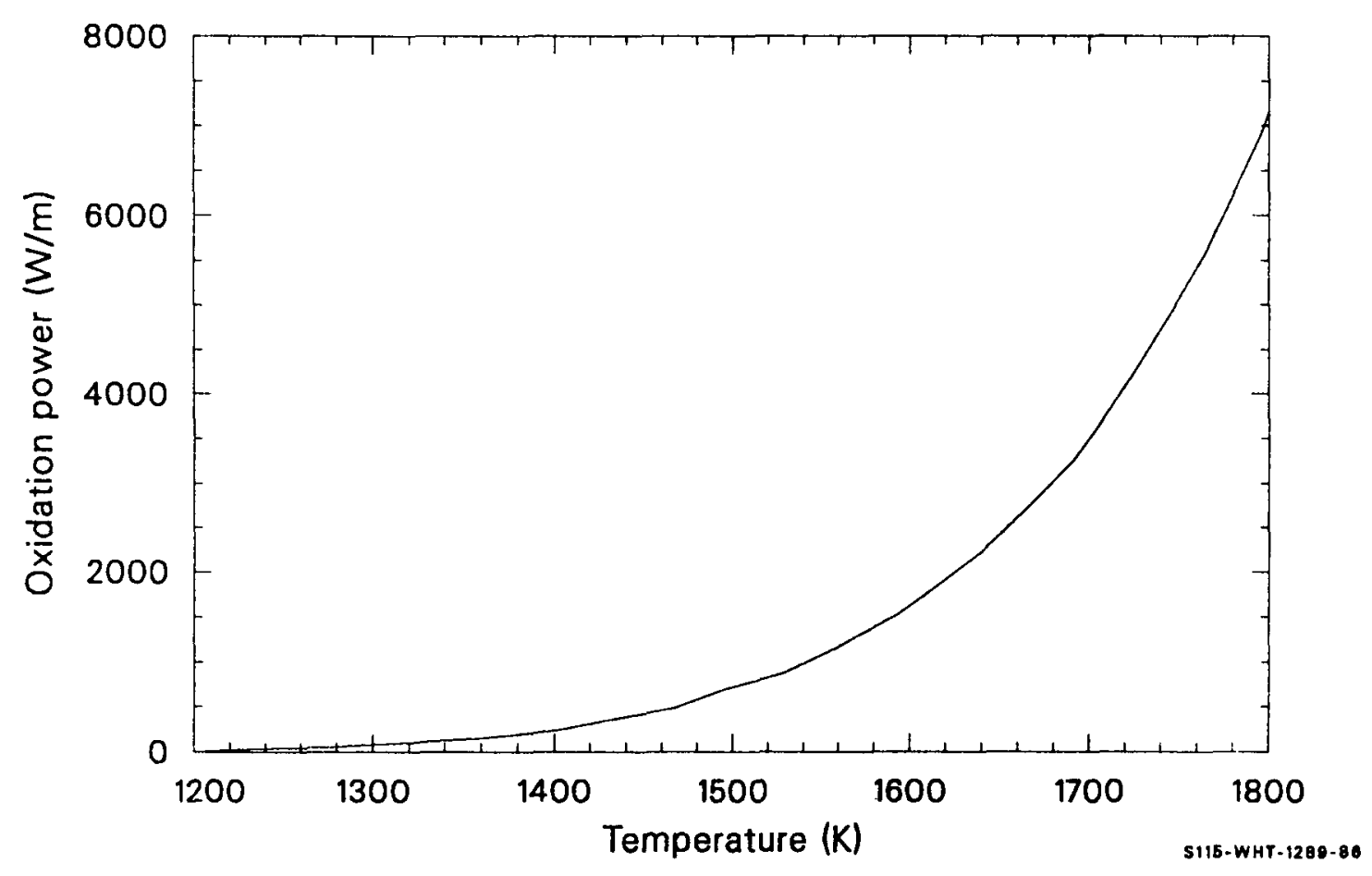

Figure 15.4-3. Average power per meter during $1 \mathrm{~s}$ for a $1.25 \times 10^{-2}-\mathrm{m}$ stainless steel rod with no initial oxide layer. 
SOXIDE，SOXWGN，SOXTHK

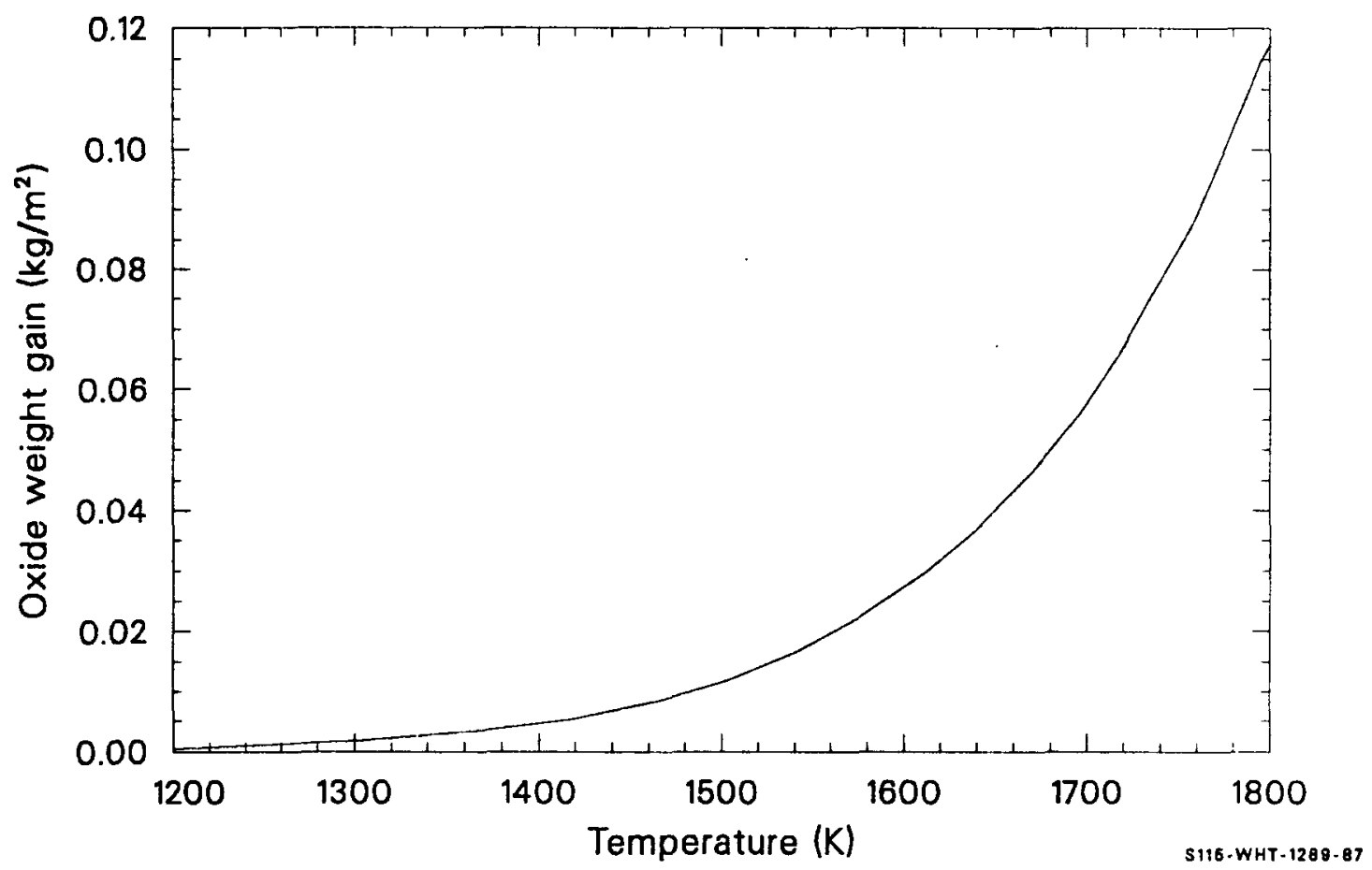

Figure 15.4-4. Oxygen uptake after $1 \mathrm{~s}$ with no initial oxidation. 
SOXIDE, SOXWGN, SOXTHK

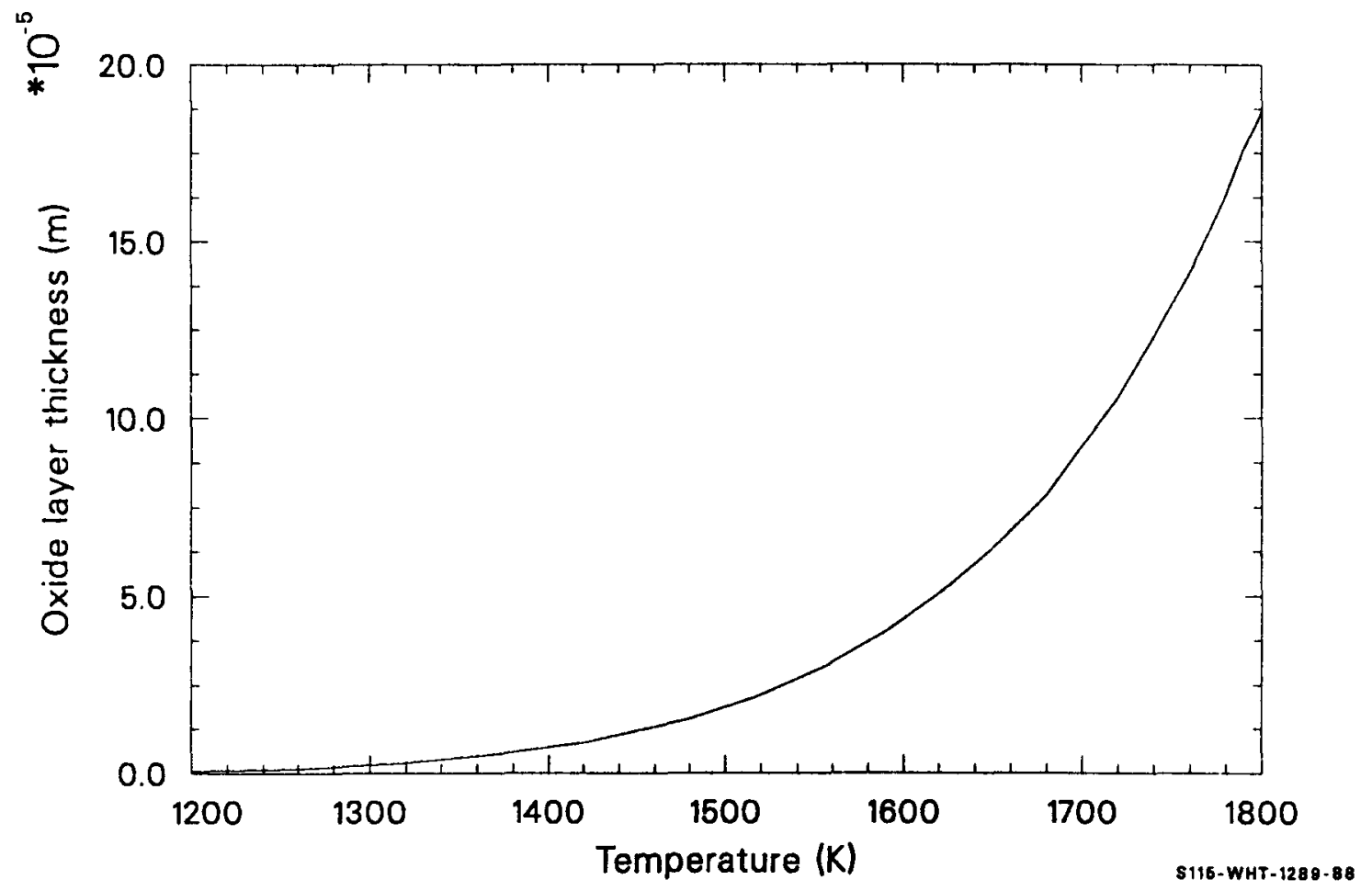

Figure 15.4-5. Oxide layer thickness after $1 \mathrm{~s}$ with no initial oxidation. 


\section{SOXIDE，SOXWGN，SOXTHK}

15.4-3. J. A. Dean (ed.), Lange's Handbook of Chemistry, 12th Edition, New York: McGraw-Hill Book Company, 1979.

15.4-4. F. D. Rossini et al., Selected Values of Chemical Thermodynamic Properties, Circular of the National Bureau of Standards 500, Washington, D.C.: United States Government Printing Office, 1952. 
DISU02, U02DIS, U02SOL

\title{
15.5 Rate of Dissolution of $\mathrm{UO}_{2}$ in $\mathrm{ZR}-\mathrm{U}-0$ (DISU02, U02DIS, U02SOL)
}

\author{
(J. K. Hohorst, E. R. Carlson)
}

\subsubsection{Introduction}

Mechanistic modeling of severe core damage processes in LWRs requires models to describe the melting of core materials and the dissolution of $\mathrm{UO}_{2}$ fuel by liquid zircaloy. The temperature of the zircaloy melt, initial oxygen content, and initial quantity of $\mathrm{UO}_{2}$ is required to determine the amount of solid core material dissolved in molten zircaloy.

Three computer subcodes were developed to model the solution properties of $\mathrm{Zr}-\mathrm{U}-\mathrm{O}$. The kinetics of $\mathrm{UO}_{2}$ dissolution in melted zircaloy is modeled in DISU02. The maximum atomic fraction of $\mathrm{UO}_{2}$ that can be dissolved in a Zr-U-O solvent for a given temperature and solvent composition is modeled in UO2DIS, and the remaining solid-phase composition is modeled in U02SOL.

DISU02 is based on experimental results by Hofmann et al.15.5-1 on the dissolution kinetics of $\mathrm{UO}_{2}$ in melted zircaloy. Expressions for the rate of dissolution of $\mathrm{UO}_{2}$ in melted zircaloy as a function of temperature and prior dissolution were determined from the experiments. The rate equations are used to determine additional dissolution in a time step for each intact node with melted zircaloy.

U02DIS and U02SOL are based on analytical expressions for the solidus-phase boundary compositions in the ternary $\mathrm{Zr}-\mathrm{U}-0$ system. These expressions were produced by interpolating the solidus compositions determined as a function of temperature for the several available binary 


\section{DISU02, U02DIS, U02SOL}

systems or isopleths for which solidus temperatures as a function of composition are known. The analytical expressions that return the compositions are used with standard phase diagram techniques, the lever rule and the mixing rule, to calculate the maximum amount of $\mathrm{UO}_{2}$ that can be dissolved by a given solvent.

\subsubsection{Data for the $\mathrm{Zr}-\mathrm{U}-\mathrm{O}$ System}

The equations for the solidus surfaces were obtained from numerous temperature-composition phase diagrams that are available in the literature. In this section, all of these diagrams have been re-drawn to a common scale and units of atomic fraction so that they might be easily compared and checked for consistency.

Solidus temperature curves for the zirconium-oxygen mixture have been published by Domagala and McPherson $15.5-2$ and modified by Ruh and Garrett. 15.5-3 The curves are made up of several segments: one above the beta phase, one above the alpha phase, and one above the cubic $\mathrm{ZrO}_{2}$ phase. Figure 15.5-1 shows a phase diagram drawn from these references with weight fraction converted to atomic fraction using the expression

$f_{0}=\frac{f_{0}^{\text {mass }} / 16}{f_{0}^{\text {mass }} / 16+\left(1-f_{0}^{\text {mass }}\right) / 91.22}$

where

$$
\begin{aligned}
& f_{0}=\text { atomic fraction of oxygen in a } Z r-0 \text { compound } \\
& f_{0} \text { mass }=\text { mass fraction of oxygen in a } Z r-0 \text { compound. }
\end{aligned}
$$

Figure 15.5-2 is a temperature-composition plot for the U-0 binary system taken from Roth et al.15.5-4 The diagram was converted to atomic fraction oxygen using the relation 
DISU02, U02DIS, U02SOL

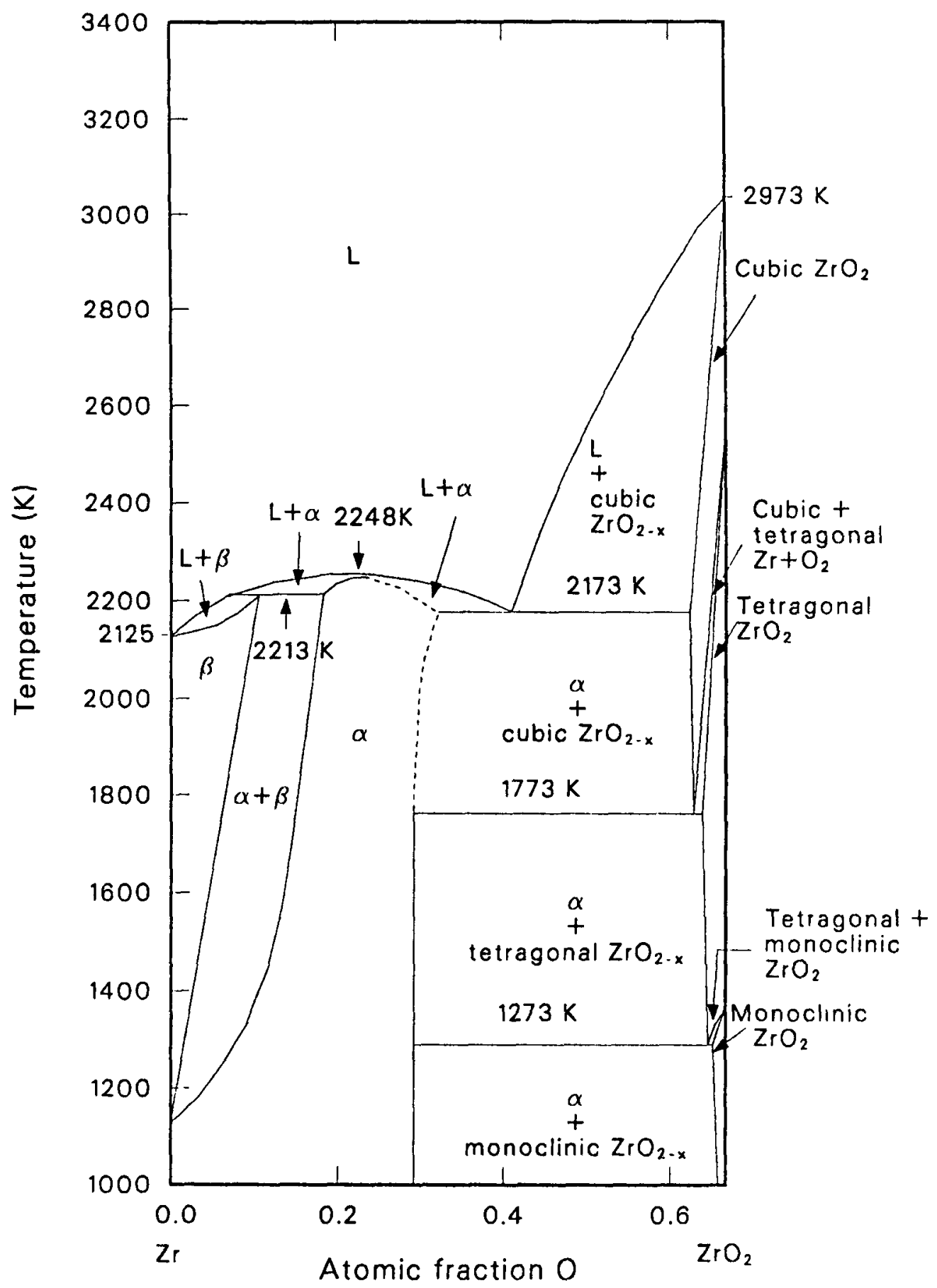

S115-WHT-1189-26

Figure 15.5-1. Zirconium-zirconium dioxide phase diagram. 
DISU02, U02DIS, U02SOL

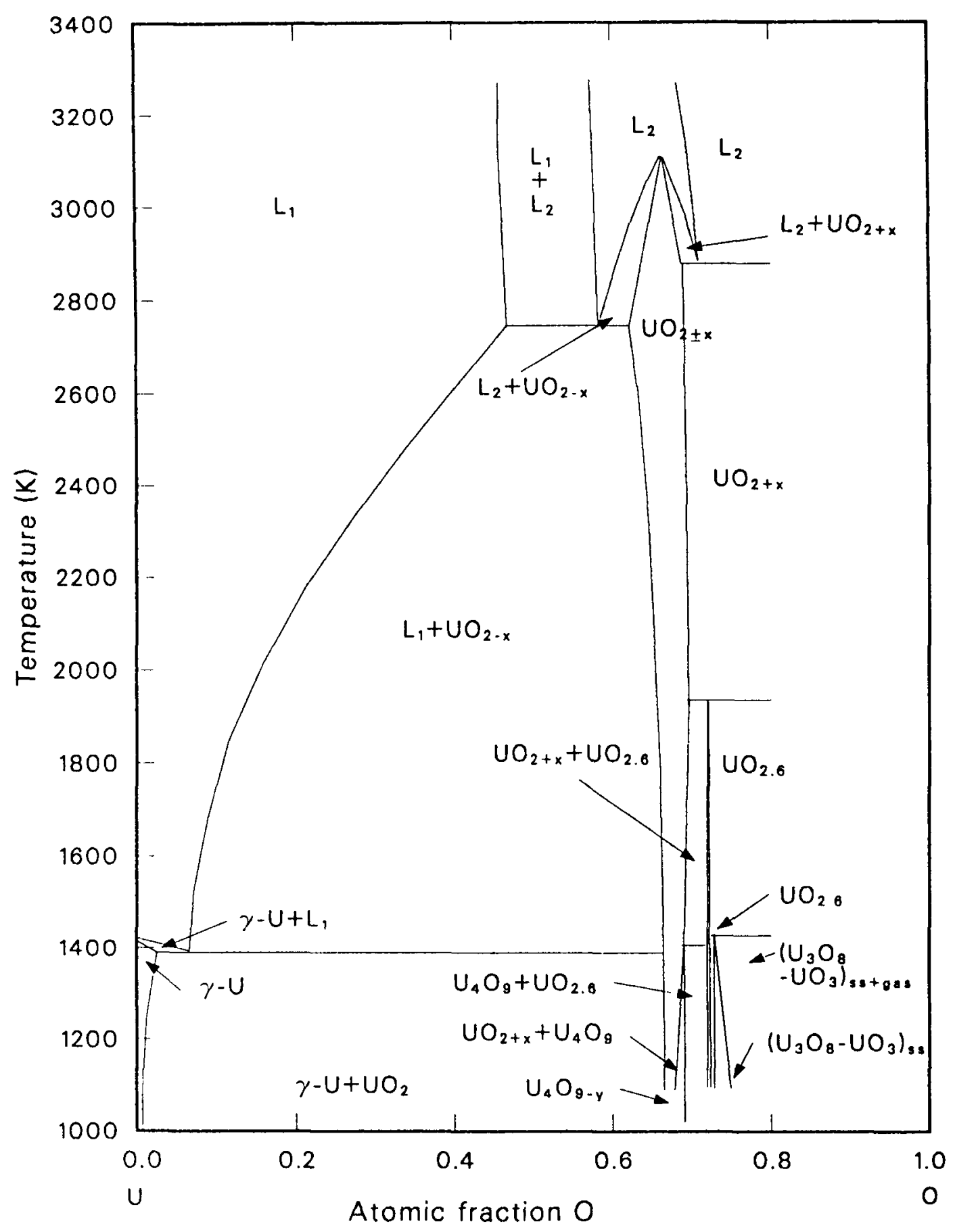

S115-WHT-1189-27

Figure 15.5-2. Uranium-oxygen phase diagram. 
DISU02， U02DIS， U02SOL

$f_{0}=\frac{O M}{1+O M}$

where $O M$ is the oxygen-to-metal ratio (atoms oxygen/atoms uranium).

The figure shows four solidus segments enclosing the $\mathrm{UO}_{2}$ region, two liquidus segments under the $L_{1}$ phase, and another two liquidus segments under the $L_{2}$ phase. The development of the phase diagram is discussed by D. L. Hagrman in Section 11.1.

Figure 15.5-3 shows an isopleth (constant pressure section of the pressure-temperature-composition figure) extending from $Z r_{0.7} 0_{0.3}$ (the approximate atomic fraction composition of alpha-phase zirconium saturated with oxygen) to $U_{0.33^{0}} 0.67$ (the uranium dioxide composition written in atomic fraction units). The isopleth was presented as a quasi-binary section by Skokan. 15.5-5

Figure 15.5-4 shows the $\mathrm{UO}_{2}-\mathrm{ZrO}_{2}$ pseudo-binary system based on Romberger et. a1.15.5-6 and measurements by Hofmann, 15.5-7 which indicated a sharp drop in the solidus temperature as the composition moved away from pure $\mathrm{UO}_{2}$ or $\mathrm{ZrO}_{2}$. The minimum melting point occurs at a composition consisting of a 0.5-0.5 mix of the two components and at a temperature of $2810 \mathrm{~K}$.

Zr-U-0 ternary diagrams have been constructed from the binary diagrams and other data. 15.5-5, a The ternary phase diagram in Figure 15.5-5 15.5-8 is the $Z r-U-0$ system at $2273 \mathrm{~K}^{\mathrm{a}}{ }^{\mathrm{a}}$ which is just above the complexities caused by the $\mathrm{Zr}-0$ phase transition that occurs from 2125 to $2248 \mathrm{~K}$. This diagram is characteristic of the $\mathrm{Zr}-\mathrm{U}-0$ system until $2673 \mathrm{~K}$,

a. Private communication, P. Hofmann, 1985. 
DISU02, UO2DIS, UO2SOL

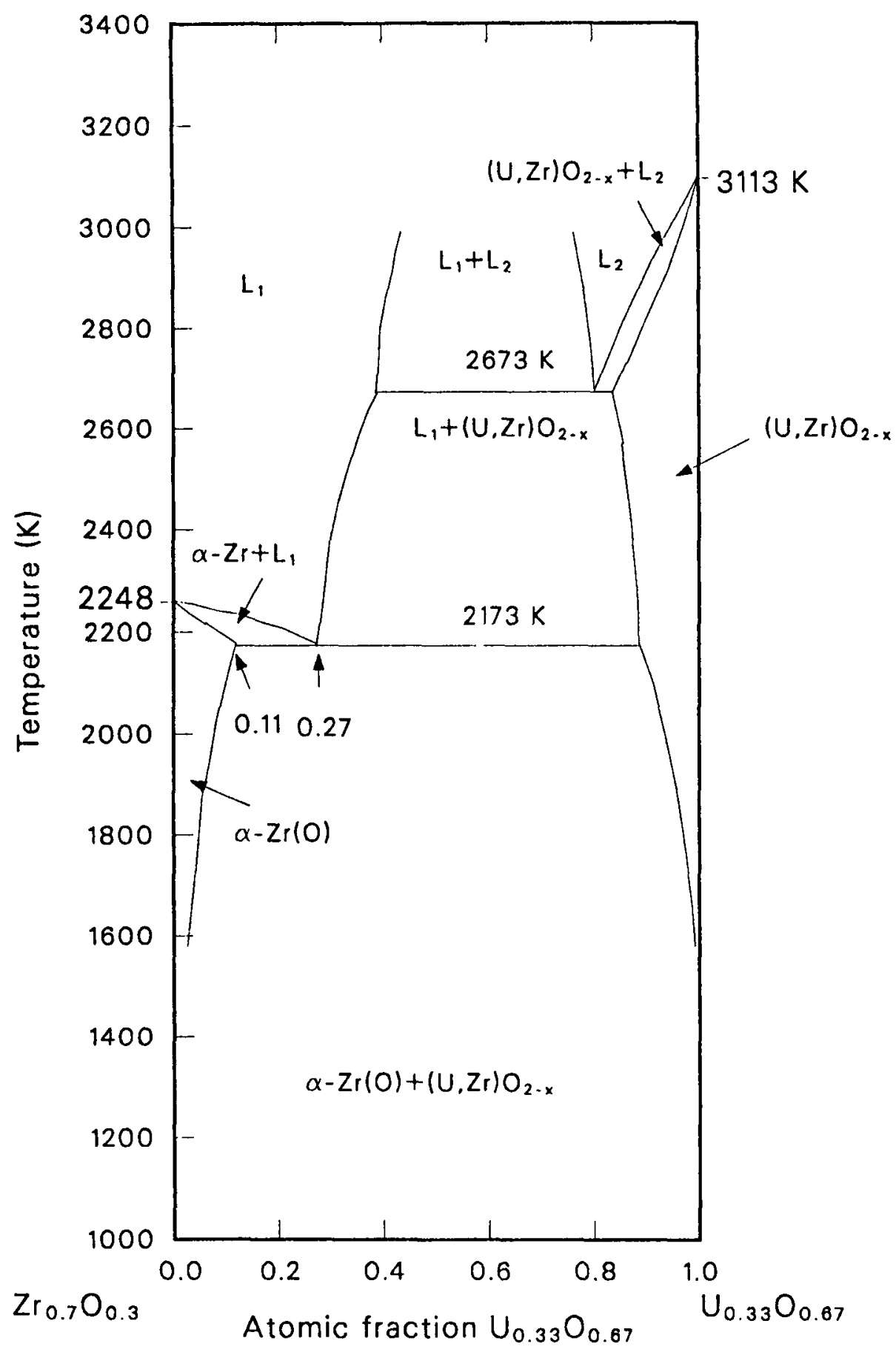

S115-WHT-1189-29

Figure 15.5-3. Oxygen-saturated alpha phase zirconium - uranium dioxide isopleth. 
DISU02, U02DIS， U02SOL

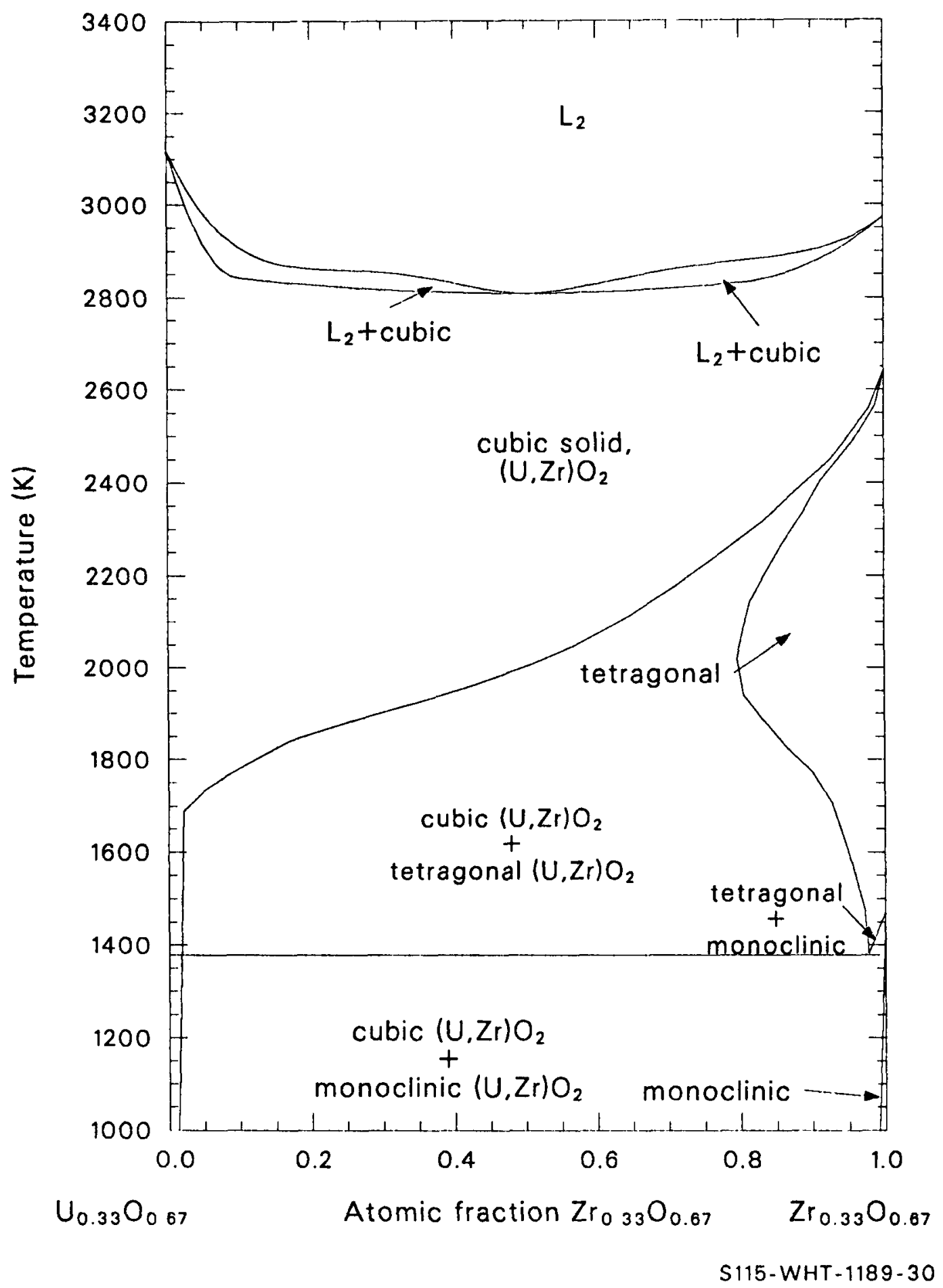

Figure 15.5-4. Quasi-binary phase diagram for the $\mathrm{ZrO}_{2}-\mathrm{UO}_{2}$ system from Reference 15.5-6. 


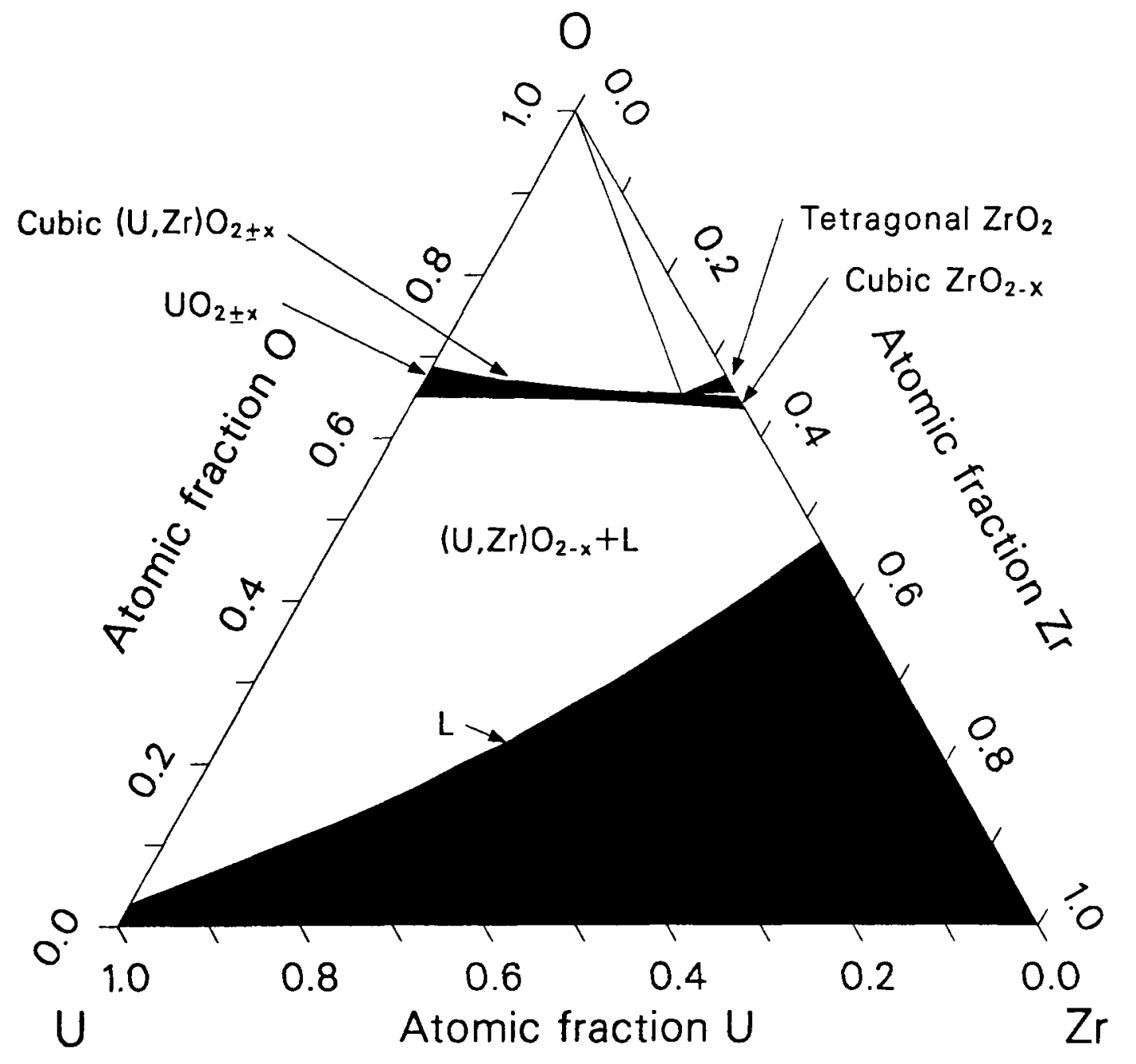

S115-WHT-1189-38

Figure 15.5-5. Zr-U-O isothermal section at $2273 \mathrm{~K}$ according to Hofmann and Politis. 


\section{DISU02, U02DIS, U02SOL}

when a second liquid phase ( $L_{2}$ in Figures 15.5-2, 15.5-3, and 15.5-4) appears and covers the temperature range of primary interest in fuel dissolution.

\subsubsection{Mode1 Development}

The expressions used in the U02DIS and U02SOL subcodes were developed by constructing polynomial expressions for the solidus temperature as a function of composition for the various binary systems. Where additional correlations could be obtained from the ternary systems published, they were also employed. These expressions were then inverted to produce correlations for composition points as a function of temperature. These composition points on the ternary phase diagram are connected with straight lines to form the solidus boundary.

15.5.3.1 Ternary Zr-U-O Phase Diagram Models. Figure 15.5-6 shows the points that are connected to form the ternary $\mathrm{Zr}-\mathrm{U}-\mathrm{O}$ system solidus lines, and Table 15.5-1 provides the analytical expressions for the composition represented by the points. Dashed lines in Figure 15.5-6 represent assumed tie lines across multiple-phase regions and are therefore not a section through a solidus surface in the three-dimensional temperature-composition phase diagram. Table 15.5-2 lists the solidus equation number as identified in Table 15.5-1, the data that were used to construct the equation, and appropriate comments about the derivation of the equation.

\subsubsection{Calculation of Dissolution Limits. Figure 15.5-7} illustrates the method used to estimate the maximum fraction of $\mathrm{UO}_{2}$ that can be dissolved in a $\mathrm{Zr}-\mathrm{U}-\mathrm{O}$ solvent and the solvent composition. Compositions that can be produced by mixing $\mathrm{UO}_{2}$ (represented by point 4 in Figure 15.5-7) and a partly oxidized zirconium melt (represented by point 1) lie along the line connecting the two points. The equilibrium composition of the liquid (solvent) is represented by point 2 , the liquidus where the 
DISU02, U02DIS, U02SOL
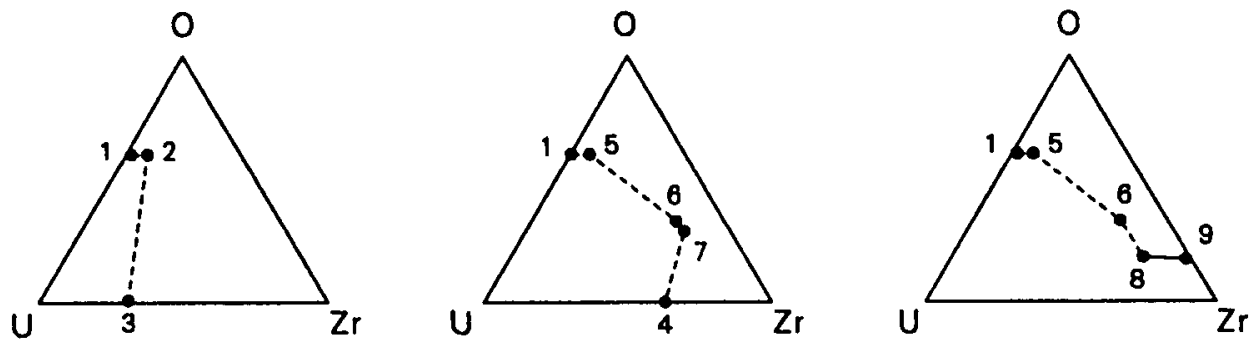

$1406 \leq T \leq 1587.277 \quad 1587.277<T<2125$

$2125 \leq T<2173$
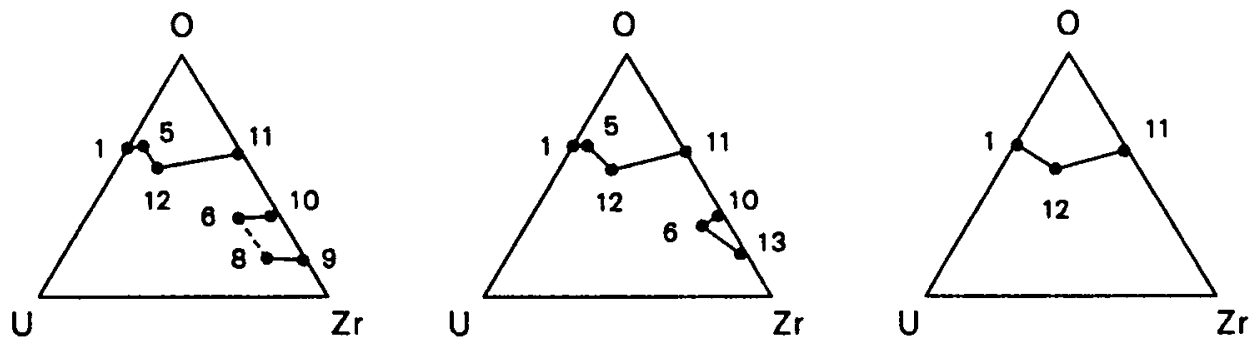

$2173 \leq T \leq 2213$

$2213<T \leq 2248$

$2248<T<2673$
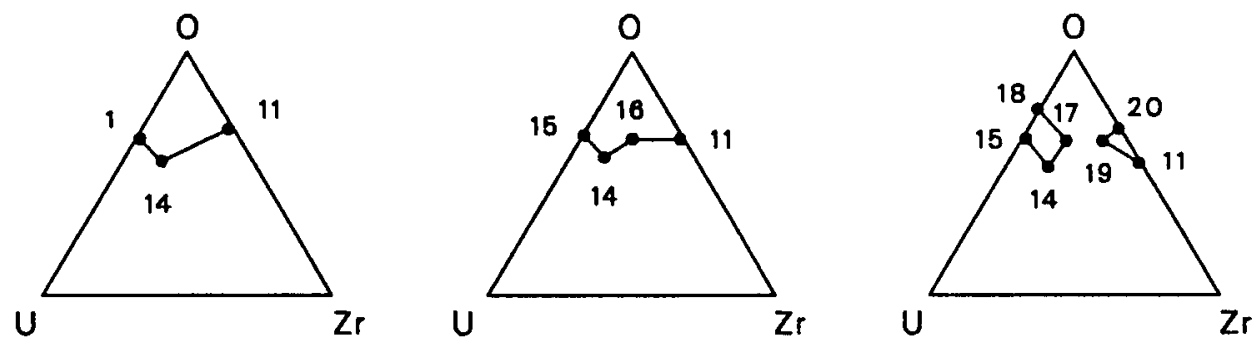

$$
2673 \leq T<2700
$$

$2700 \leq T<2809$

$2809 \leq T \leq 2873$
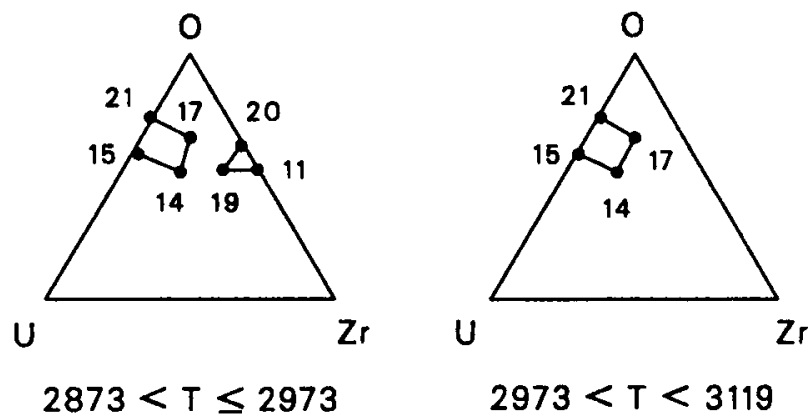

$T=$ temperature $(K)$

S115-WHT-1189-40

Figure 15.5-6. Points that are connected to form the ternary $\mathrm{Zr}-\mathrm{U}-0$ system. 
Table 15.5-1. Correlations for solidus compositions

1. U-rich solid $\mathrm{UO}_{2-\mathrm{x}}$ boundary for $\mathrm{T}<2700 \mathrm{~K}, \mathrm{U}-0$ binary system $f_{0}=\frac{473984.9+\left[473984.9^{2}-763564.9(291499.1+T)\right]^{0.5}}{763564.9}$

2. Point 1 with $x$ coordinate increased by 0.01

3. Zr-rich boundary of the cubic $\mathrm{ZrO}_{2}$ phase, which is in equilibrium with the liquid, $\mathrm{Zr}-\mathrm{ZrO}_{2}$ binary system

$$
f_{0}=\frac{52252.48+\left[52252.48^{2}-95519.41(30182.27-T)\right]^{0.5}}{95519.41}
$$

4. $Z r_{0} 7^{0} 0.3^{-r i c h}$ boundary of cubic $(U Z r) 0_{2-x}$ phase for $2173 \leq$ $\mathrm{T} \leq 2673,2 r_{0} .7-0.3, \cup 0.3300 .67$ isopleth

$$
\mathrm{f}_{0.33^{0} 0.67}=\frac{105794.3+\left[105794.32^{2}-128402.4(84438.99+\mathrm{T})\right]^{0.5}}{128462.5}
$$

5. $Z r_{0.7} 7^{0} 0.3^{-r i c h}$ boundary of cubic $(U Z r) 0_{2}$ phase for $2673 \leq T \leq 3119 \mathrm{~K}, Z r_{0.7} 0_{0.3}-U_{0.33^{0}} 0.67$ isopleth

$$
\mathrm{f}_{U_{0.33^{0}} 0.67}=\frac{2489.661+\left[2489.661^{2}-4179.972(3918-\mathrm{T})\right]^{0.5}}{4179.972}
$$

6. U-rich solid $\mathrm{UO}_{2-\mathrm{x}}$ boundary for $2700 \leq \mathrm{T} \leq 3119$, U-0 binary system

$$
f_{0}=\frac{2 .-\frac{\left.418.85^{2}+[1469 .(3119 .-T)-418.85)\right]^{0.5}}{1496 .}}{3 .-\frac{\left.418.85^{2}+[1469 .(3119 .-T)-418.85)\right]^{0.5}}{1496 .}}
$$


DISU02, U02DIS, U02SOL

Table 15.5-2. Data used to produce solidus correlations

Equation

Number

Coordinations

Comments

1. (0.6626 atomic fraction $0,1391 \mathrm{~K})$

$(0.6375$ atomic fraction $0,2514 \mathrm{~K})$

$(0.626825706$ at. fr. $0,2700 \mathrm{~K})$

$U$-rich solid $\mathrm{UO}_{2-x}$

boundary for

$\mathrm{T}>2700 \mathrm{~K}$

Figure 15.5-2.

2. $(0.6246$ atomic fraction $0,2173 \mathrm{~K})$

$(0.65$ atomic fraction $0,2611 \mathrm{~K}$ )

Zr-rich boundary of

the cubic $\mathrm{ZrO}_{2}$

(0.667 atomic fraction $0,2973 \mathrm{~K}$

phase which is in

equilibrium with

liquid, $\mathrm{Zr}-\mathrm{ZrO}_{2}$

binary phase system.

Figure 15.5-1.

3. $\left(0.834\right.$ at. $\mathrm{fr} . \mathrm{U}_{\left.0.33^{0} \mathrm{O} .67,2673 \mathrm{~K}\right)}$

$(0.8681$ at. fr. $0.3300 .67,2432 \mathrm{~K})$

$2 r_{0} 7^{0} 0.3^{-}$

rich boundary of

$\left(0.8868\right.$ at. fr. $\left.U_{0.33} 0.67,2173 \mathrm{~K}\right)$

cubic (UZr) $\mathrm{O}_{2}$

phase for $2173 \geq T$

$\geq 2673 \mathrm{~K}$,

isopleth.

Figure 15.5-3.

4. (0.834 at. fr. $\left.U_{0.33} 0_{0} 67,2673 \mathrm{~K}\right)$

$\left(0.91915\right.$ at. fr. $\left.\mathrm{U}_{0.33} 0_{0} 67,2873 \mathrm{~K}\right)$

(1 atomic fraction $0_{0.33}^{33} 0.67,3119 \mathrm{~K}$ )

$2 r_{0.700 .3-r i c h}$

boundary of

cubic

$(\mathrm{U}, \mathrm{Zr}) \mathrm{O}_{2-\mathrm{x}}$

phase for $2673 \geq$

$\mathrm{T} \geq 3119 \mathrm{~K}$

5. $\quad$ See Table $3^{a}$

Least squares

deviation fit to

the data of Latta

and Fryxel1.

a. R. E. Latta and R. E. Fryxell, "Determination of Solidus-Liquidus

Temperatures in the $\mathrm{UO}_{2}$ system $(\leq 0.5 \times<0.2)$, "Journal of Nuclear Materials, 35, 1970 , pp. 195-201. 
DISU02, U02DIS， U02SOL

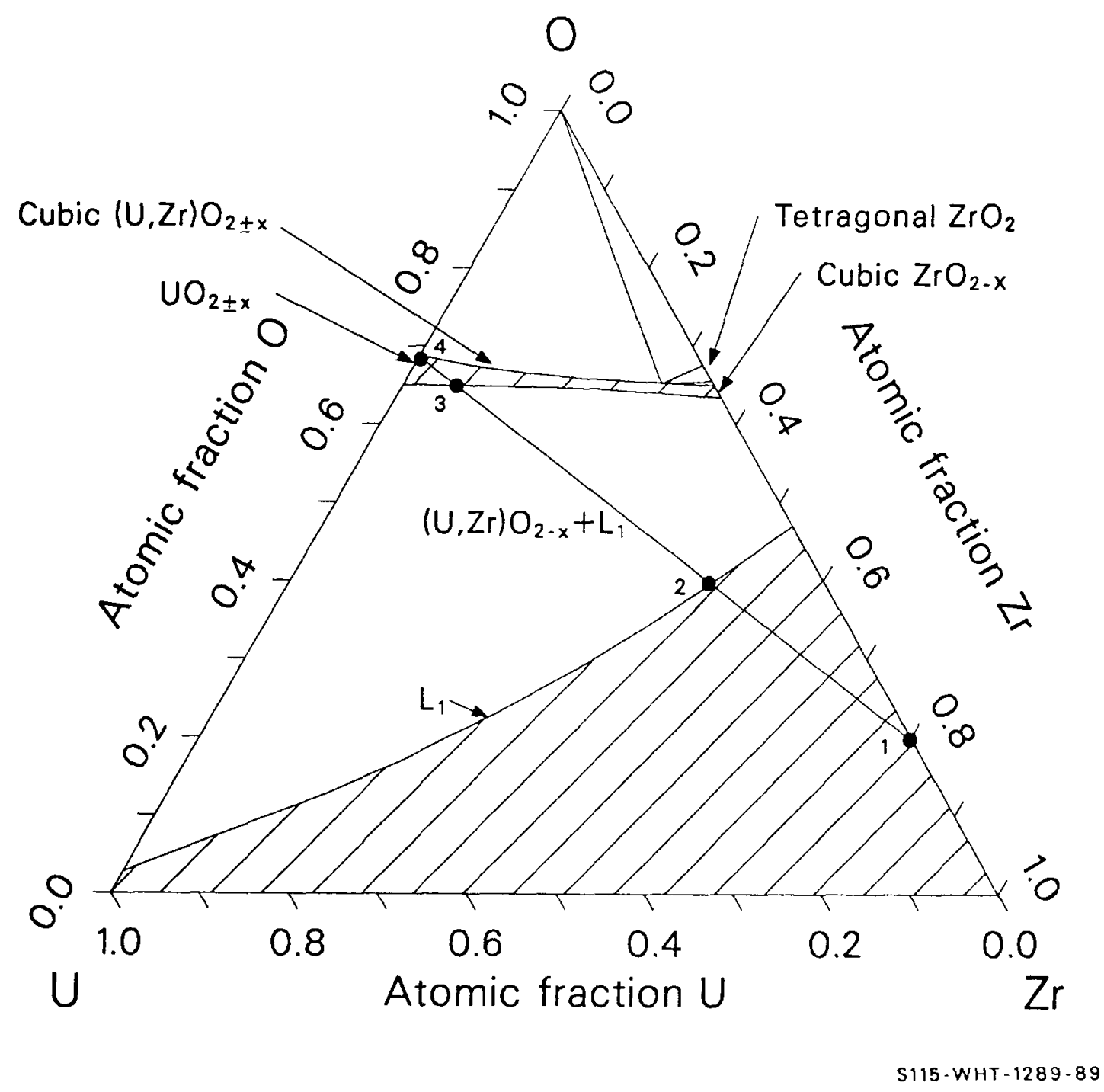

Figure 15.5-7. $\mathrm{Zr}-\mathrm{U}-0$ isothermal section at $2273 \mathrm{~K}$ according to Hofmann and Politis (revised). 
DISU02, UO2DIS, U02SOL

first solid precipitates appear. The equilibrium composition of the solid (solute or precipitate) is represented by point 3 , the solidus where the first liquid phase appears.

The modification recommended by Hofmann et al.15.5-1 is to assume that the nonequilibrium slurry produced when zircaloy attacks $\mathrm{UO}_{2}$ will continue to attack the $\mathrm{UO}_{2}$ by dissolution along grain boundaries and removal of grains until the composition of the slurry is approximately equal to the liquidus point 3 .

The lever and mixing rules state that the $\mathrm{UO}_{2}$ fraction at 3 is the length from 1 to 3 divided by the length from 1 to 4 . Thus, the line segment lengths have to be calculated. This is done using the Pythagorean theorem after converting the compositions of each point to Cartesian coordinates centered on the lower-left-side vertex of the Gibbs coordinate system with the transformation

$x=f_{0} \cos 60+f_{z r}$

$y=f_{0} \sin 60$

where

$x, y=$ Cartesian coordinates

$f_{0}=$ atomic fraction of oxygen

$f_{z r}=$ atomic fraction of zirconium.

The subcode U02SOL returns the solidus points in Cartesian coordinates as a function of temperature. The subcode V02DIS connects the points with straight lines to form the solidus curve (the bottom of the upper-shaded area of Figure 15.5-7) and finds the intersection (point 3 of Figure 15.5-7) 
between the solidus curve and the $\mathrm{UO}_{2}$-solvent composition line (the line from 4 to 1 in Figure 15.5-7). The atomic fraction of $\mathrm{UO}_{2}$ in the solidus composition is then determined using the lever rule.

\subsubsection{Uranium Dioxide Dissolution Kinetics}

The reaction kinetics of molten zircaloy with solid $\mathrm{UO}_{2}$ were investigated and reported by Hofmann et al.15.5-1 A matrix of dissolution experiments was performed at various reaction temperatures and times with $\mathrm{UO}_{2}$ crucibles and as-received zircaloy in a nonoxidizing environment. The crucibles were then metallographically examined, and the area fraction of the $(U, Z r) 0_{2-x}$ ceramic phase in the once-molten solvent was measured. A set of standards was established by dissolving known amounts of $\mathrm{UO}_{2}$ in zircaloy and then measuring the ceramic area fraction so that the ceramic area fractions measured in the experiments could be correlated with the $\mathrm{UO}_{2}$ content of the melt.

It was found that the fuel dissolution showed parabolic behavior after a short incubation period. (The first ceramic particles do not appear in the solidified melt until about $35.8 \mathrm{wt} \% \mathrm{UO}_{2}$ has been dissolved.) The parabolic equation for the $w \mathrm{t} \%$ of $\mathrm{UO}_{2}$ in the melt was given as

$w t \% U 0_{2}(T, t)=35.8+[K(T) \cdot t]^{0.5}$

where

$$
\begin{aligned}
K & =\text { parabolic rate constant }\left[\left(w t \% U_{2}\right)^{2} / s\right] \\
T & =\text { temperature }(K) \\
t & =\operatorname{time}(s) .
\end{aligned}
$$

The parabolic rate constant $K$ was determined by fitting an Arrhenius function to the data, obtaining 


\section{DISU02, U02DIS, U02SOL}

$$
K(T)=1.0196 \times 10^{15} \exp (-677200 / R T)
$$

where $R$ is the universal gas constant $(8.314 \mathrm{~J} / \mathrm{mole} \cdot \mathrm{K})$.

The surface area present in the experiments is implicit in these equations, so the data were transformed by Hofmann into equivalent uniform receding interface positions and fit to a new Arrhenius function, yielding

$$
\Delta \xi(T, t)=\left[K^{\prime}(T) \cdot t\right]^{0.5}
$$

where

$$
\begin{aligned}
\Delta \xi & =\text { displacement of the dissolution interface }(\mathrm{cm}) \\
K^{\prime}(T) & =3.85 \times 10^{19} \exp (-1067000 / R T) \\
& =\text { parabolic rate constant for displacement }\left(\mathrm{cm}^{2} / \mathrm{s}\right) .
\end{aligned}
$$

The subcode DISU02 calculates the increment of fuel dissolved for a time step based on the dissolution interface model. The model is implemented for incremental calculations by:

$$
X_{i+1}=\left(X_{i}{ }^{2}+K^{\prime}(T) \cdot \Delta t\right)^{0.5}
$$

where

$$
\begin{aligned}
& x_{\mathbf{i}}=\text { dissolution from position at time step } i(\mathrm{~cm}) \\
& \Delta t=\text { time step }(\mathrm{s}) .
\end{aligned}
$$

Dissolution of $\mathrm{UO}_{2}$ is assumed to proceed according to Equation (15.5-8) until maximum dissolution occurs when the solvent reaches the solidus composition. The rate equations do not consider the effect of oxidation of the solvent, but the determination of dissolution limits does. 


\subsubsection{References}

15.5-1. P. Hofmann, H. Uetsuka, A. N. Wilhelm, and E. A. Garcia, "Dissolution of Solid $\mathrm{UO}_{2}$ by Molten Zircaloy and its Modeling," International Symposium on Severe Accidents in Nuclear Power Plants, Sorrento, Italy, March 1988.

15.5-2. R. F. Domagala and D. J. McPherson, "System Zirconium-0xygen," Journal of Metals, 6, Transactions AIME 200, 1954, pp. 238-246.

15.5-3. R. Ruh and H. J. Garrett, "Nonstoichiometry of $\mathrm{ZrO}_{2}$ and its Relation to Tetragonal-Cubic Inversion in $\mathrm{ZrO}_{2}$, Journal of the American Ceramic Society, 50, 1966, pp. 257-261.

15.5-4. R. S. Roth, T. Negas, and L. P. Cook, Phase Diagrams for Ceramist, Volume IV, The American Ceramic Society, 1981.

15.5-5. A Skokan, "High Temperature Phase Relations in the U-Zr-O System," Fifth International Meeting on Thermal Nuclear Reactor Safety, Karl sruhe, German Federal Republic, September 9-13, 1984, KFK 388011, December, 1984, pp. 1035-1042.

15.5-6. K. A. Romberger, C. F. Bates, Jr., H. H. Stone, "Phase Equilibrium Studies in the $\mathrm{UO}_{2}-\mathrm{ZrO}_{2}$ System," Journal of Inorganic and Nuclear Chemistry, 29, 1966, pp. 1619-1630.

15.5-7. P. Hofmann, "SFD Singe Effects Laboratory Experiments", Severe Fue 1 Damage and Source Term Research Program Review Meeting, Idaho Falls, Idaho, April 16-19, 1985.

15.5-8. P. Hofmann and C. Politis, "The Kinetics of the Uranium Dioxide-Zircaloy Reactions at High Temperatures," Journal of Nuclear Materials, 87, 1975, pp. 375-397. 


\section{UTILITIES}

This section describes subcodes that are not logically part of the MATPRO library but are called often by the subcodes in the package. Subcodes described in this section are POLATE, linear interpolation; CTXTUR, texture factor calculations; QFUSON, heats of fusion; PMOLE and PMASS, mass fraction-mole fraction conversions; ZUINT, the reciprocal of thermal conductivity; and ATOMFR, which calculates mass fractions of compound materials. 
POLATE, POL8

\subsection{Linear InTERPOLATION (POLATE, POL8)}

(D. L. Hagrman)

A number of the MATPRO subcodes contain tables for a property rather than analytical expressions. POLATE and POL 8 are similar subcodes used to interpolate values from tables. POLATE returns an interpolated number $x(y y)$, using an input table consisting of up to $20 x, y$ pairs, whereas POL 8 can handle no more than $13 x, y$ pairs. These interpolation subcodes are used when analytical expressions based on theory are not available or are too complex, as in the case of cladding specific heat capacity.

The POLATE or POL8 function returns the interpolated value of $y(x x)$, using an input value of $x x$ (the independent variable for which an interpolated dependent variable is desired), the values for the independent variable (up to 20 values for POLATE, only 13 for POL 8 ), and the values for the dependent variable (up to 20 for POLATE, only 13 for POL 8 ). To increase the efficiency of the POLATE or POL8 function, an estimate of the expected location of the value of the input $x x$ in the table of numbers is also accepted. The number of the pair that was used in a previous interpolation is often used for this estimate.

Beginning with its initial estimated value, the index $K$ is raised or lowered until a pair of $x_{k}$ and $x x_{k+1}$ are found which bound $x x . y\left(x x_{k}\right)$ and $Y\left(x x_{k+1}\right)$ are then used to interpolate for $Y(x x)$.

If $x x$ is outside the range of the set of $x x_{k}$ given as input, the $y_{k}$ of the member of the set of $x_{k}$ closest to $x x$ is returned by the POLATE or POL8 functions. 


\section{CTXTUR}

\subsection{Cladding Texture factors (CTXtur)}

(D. L. Hagrman)

Texture factors are required to model all structure-sensitive materials properties. The subroutine CTXTUR calculates the numbers needed to describe material texture for those materials properties subcodes that specifically consider texture variations. ${ }^{a}$

\subsubsection{Model Description}

The input information for the subcode CTXTUR is obtained from a basal pole figure. The pole figure is a stereographic plot of the relative number of basal poles found at specified orientations. Figure 16.2-1 is a schematic illustration showing the relation between the basal pole intensity (concentration found from $X$-ray diffraction) at one orientation and the intensity on a typical pole figure. The intensity, 1 , at an angle $\theta$ to the radial direction and $\phi$ to the circumferential direction of a cladding sample, is projected from its orientation on a sphere of arbitrary diameter to the radius $r$ and angle $\phi$ in the circumferential-axial plane and recorded on the plot as a number, I.

The radius $r$ on the pole figure is related to the angle $\theta$ by

$$
r / r_{0}=\tan (\theta / 2)
$$

a. In the MATPRO 11 package, only CELAST (Section 4.6) and CAGROW (Section 4.7) require this information. 


\section{CTXTUR}

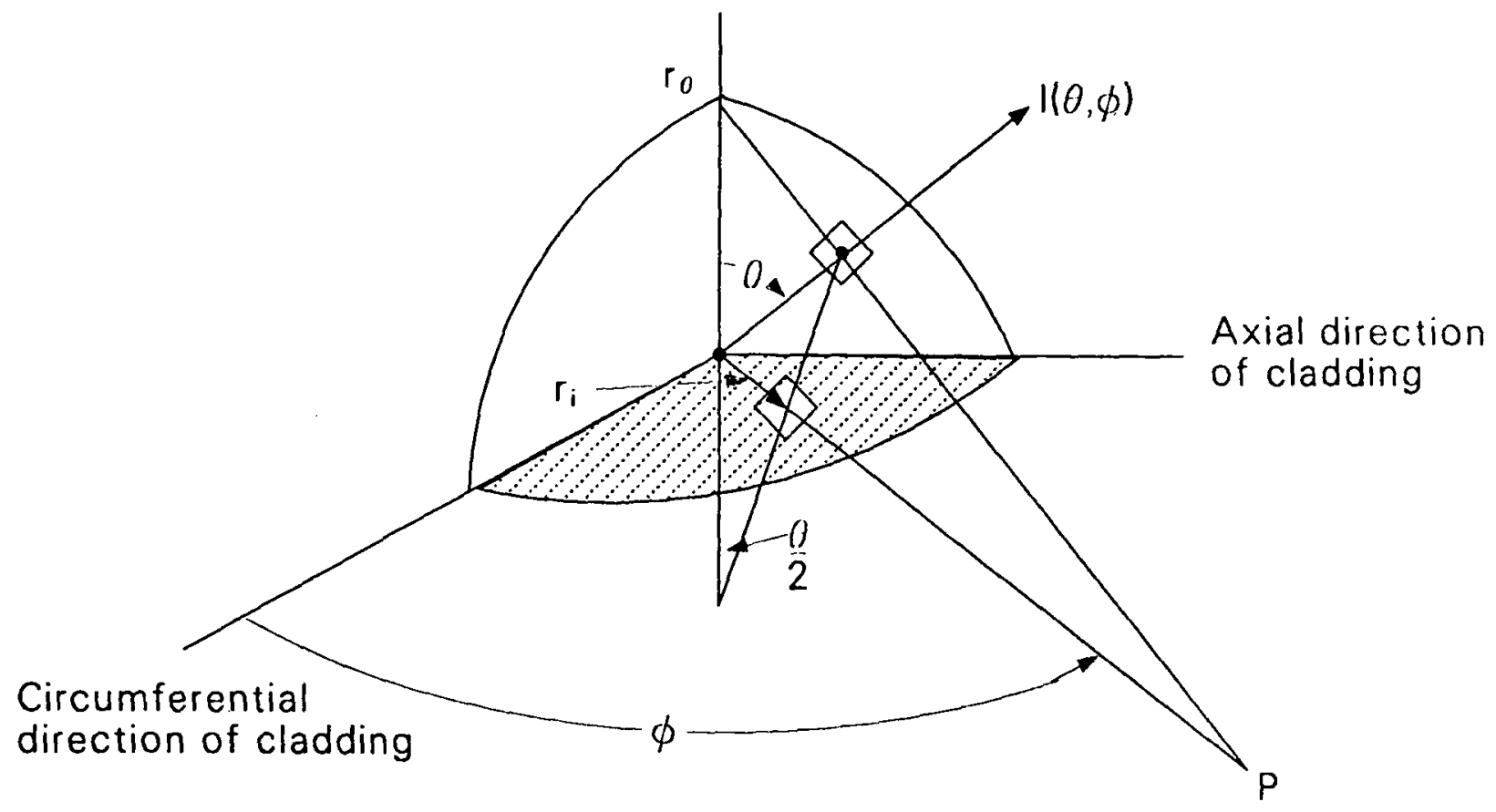

S115-WHT-1289-90

Figure 16.2-1. Schematic illustration showing the relation between basal pole intensity at one orientation $(\theta, \phi)$ and the plotted value of the intensity at $(r, \phi)$ on a pole figure. 


\section{CTXTUR}

where $r_{0}$ is the radius of the sphere shown in Figure 16.2-1 and of the pole figure plot.

The input information required by CTXTUR is a nine-by-nine array of basal pole intensities from a pole figure. If $\theta$ and $\phi$ are the angles defined in Figure 16.2-1, element $(1,1)$ of the input array is the average intensity for $\theta$ from 0 to 10 degrees and $\phi$ from 0 to 10 degrees. Element $(1,2)$ is the average intensity for $\theta$ from 0 to 10 degrees and $\phi$ from 10 to 20 degrees, and so on.

A typical input grid is presented in Figure 16.2-2. Input element $(1,1)$ would be the average basal pole intensity in the area labeled $(1,1)$ and so on. For the present version of this routine, the pole figure is assumed to represent material with mirror plane symmetry about the planes containing two of the three axes so only one quadrant of the pole figure is used.

Eight volume-fraction-weighted averages of various cosines are returned by the CTXTUR subcode. In each case, the volume weighted average is defined by the integral

$\langle g\rangle=\int_{0}^{2 \pi} \int_{0}^{\pi} g(\theta, \phi) \rho(\theta, \phi) \sin \theta d \theta d \phi$

where

$\mathrm{g}=$ any function of the angles $\theta$ and $\phi$ that have been previously defined

$\langle\mathrm{g}\rangle=\quad$ volume fraction weighted average of $\mathrm{g}$ 


\section{CTXTUR}

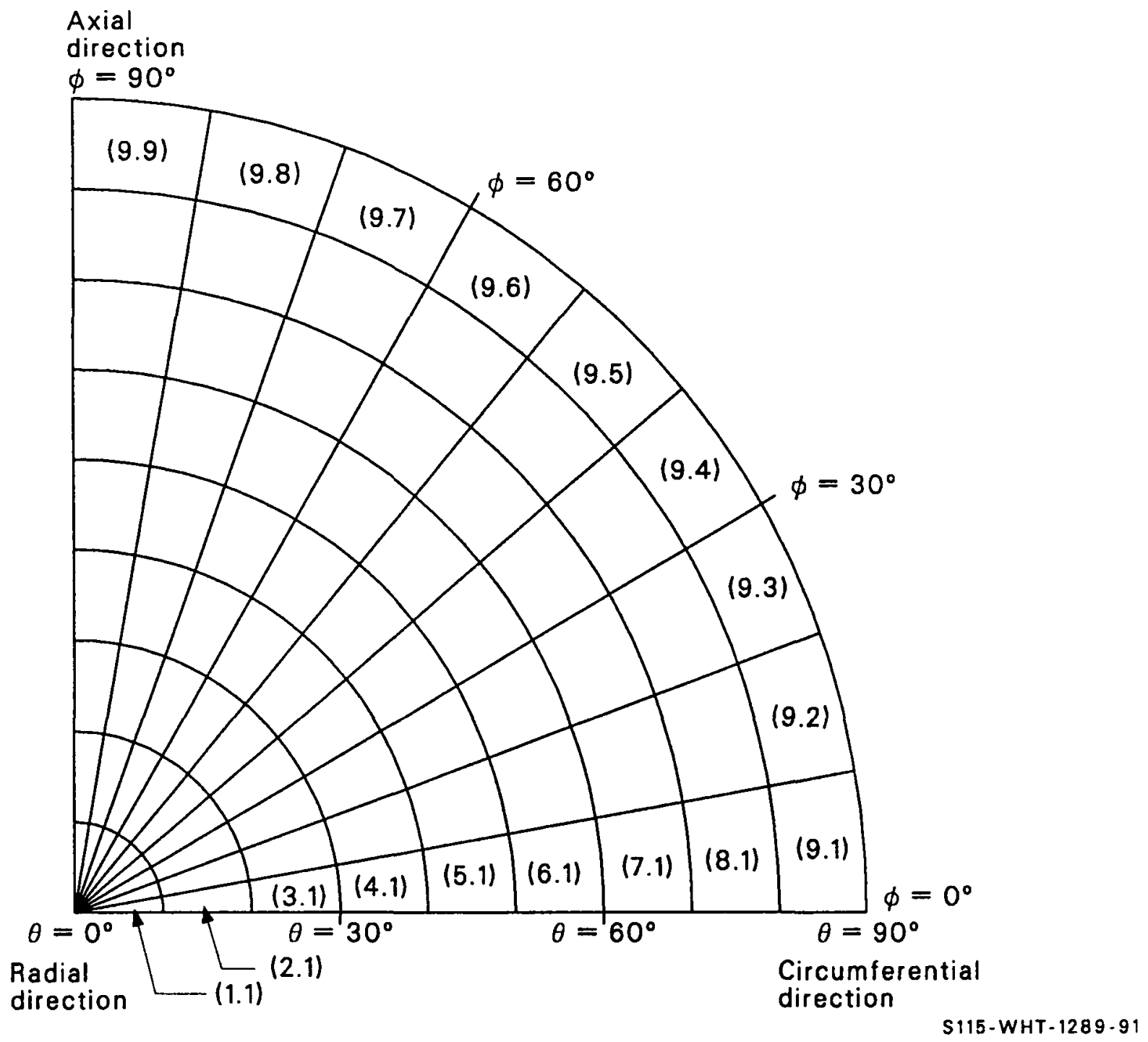

Figure 16.2-2. Input grid for CTXTUR subcode. 


\section{CTXTUR}

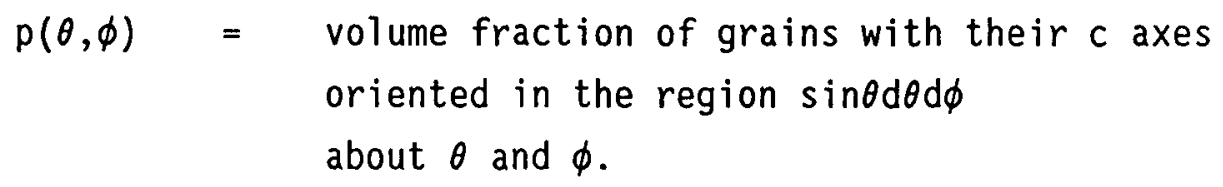

The function $\rho$ is determined by normalizing the input average intensity values to $1 / 4 \pi$ for randomly distributed basal poles. The exact normalization equation is

$$
\rho(\theta, \phi)=\frac{I(\theta, \phi)}{\int_{0}^{2 \pi} \int_{0}^{\pi} I(\theta, \phi) \sin \theta d \theta d \phi}
$$

where $I(\theta, \phi)$ is the diffracted $X$-ray intensity of the basal $p l$ anes at $(\theta, \phi)$, as plotted in basal pole figures.

Equation 16.2-3 is approximated with a sum of the average $X$-ray intensities, which is required input information.

$$
\rho_{r, s}=\frac{\text { Input element }(r, s)}{\sum_{i=1}^{9} \sum_{j=1}^{9} \text { Input element }(i, j) \sin \theta_{i}(\pi / 18 \text { radians })^{2}}
$$

where

$$
\begin{aligned}
& \rho_{r, s}=\begin{array}{l}
\text { average fraction of grains with their } c \text { axis } \\
\text { oriented in the }(i, j) \text {-th grid element }
\end{array} \\
& \sin \theta_{i}=\begin{array}{l}
\text { sine of the angle } \theta \text { at the center of the } \\
(i, j)-\text { th grid element. }
\end{array}
\end{aligned}
$$

Once the weighting factors, $\rho_{r, s}$, have been obtained from the pole figure, the averages defined in Equation (16.2-2) are approximated with the sum 


\section{CTXTUR}

$\langle g\rangle=\sum_{r=1}^{9} \sum_{s=1}^{9} g_{r, s} P_{r, s} \sin \theta_{r, s}(\pi / 18 \text { radians })^{2}$

where $g_{r, s}$ is the value of $g$ at the center of the $(r, s)$ element.

The eight volume-fraction-weighted averages returned by the CTXTUR subcode are $\left\langle\cos ^{2} \theta\right\rangle,\left\langle\cos ^{4} \theta\right\rangle,\left\langle\cos ^{2} \alpha\right\rangle,\left\langle\cos ^{4} \alpha\right\rangle,\left\langle\cos ^{2} \theta \cos ^{2} \alpha\right\rangle$, $\left\langle\cos ^{2} \theta \cos ^{4} \alpha\right\rangle,\left\langle\cos ^{4} \theta \cos ^{2} \alpha\right\rangle$, and $\left\langle\cos ^{4} \theta \cos ^{4} \alpha\right\rangle^{a}$, where $\alpha$ is the complement of $\phi$.

Several other frequently used texture factors can be obtained from the eight averages that are returned. For example, the cosine of the angle between the direction defined by $\theta$ and $\phi$ in Figure 16.2-3 and the circumferential direction of the cladding is

$\cos \Psi=\sin \theta \sin \alpha$

The circumferential texture factor defined by Kearns $16.2-1$ is thus

$f_{\theta}=\left\langle\cos ^{2} \Psi\right\rangle=\langle 1\rangle-\left\langle\cos ^{2} \theta\right\rangle-\left\langle\cos ^{2} \alpha\right\rangle+\left\langle\cos ^{2} \theta \cos ^{2} \alpha\right\rangle$

where $f_{\theta}$ is the circumferential texture factor. Similarly, the axial texture factor of Kearns is

$f_{z}=\left\langle\cos ^{2} \alpha\right\rangle-\left\langle\cos ^{2} \theta \cos ^{2} \alpha\right\rangle$

where $f_{z}$ is the axial texture factor.

a. For the mirror plane symmetry assumed in this routine, some of these outpyts are redundant. For instance, $\left\langle\cos ^{2} \theta \cos ^{2} \alpha\right\rangle=$ $\left\langle\cos ^{2} \alpha\right\rangle\left\langle\cos ^{2} \theta\right\rangle$. The extra outputs are included in case the routine needs to be generalized in the future to consider material without mirror plane symmetry. 


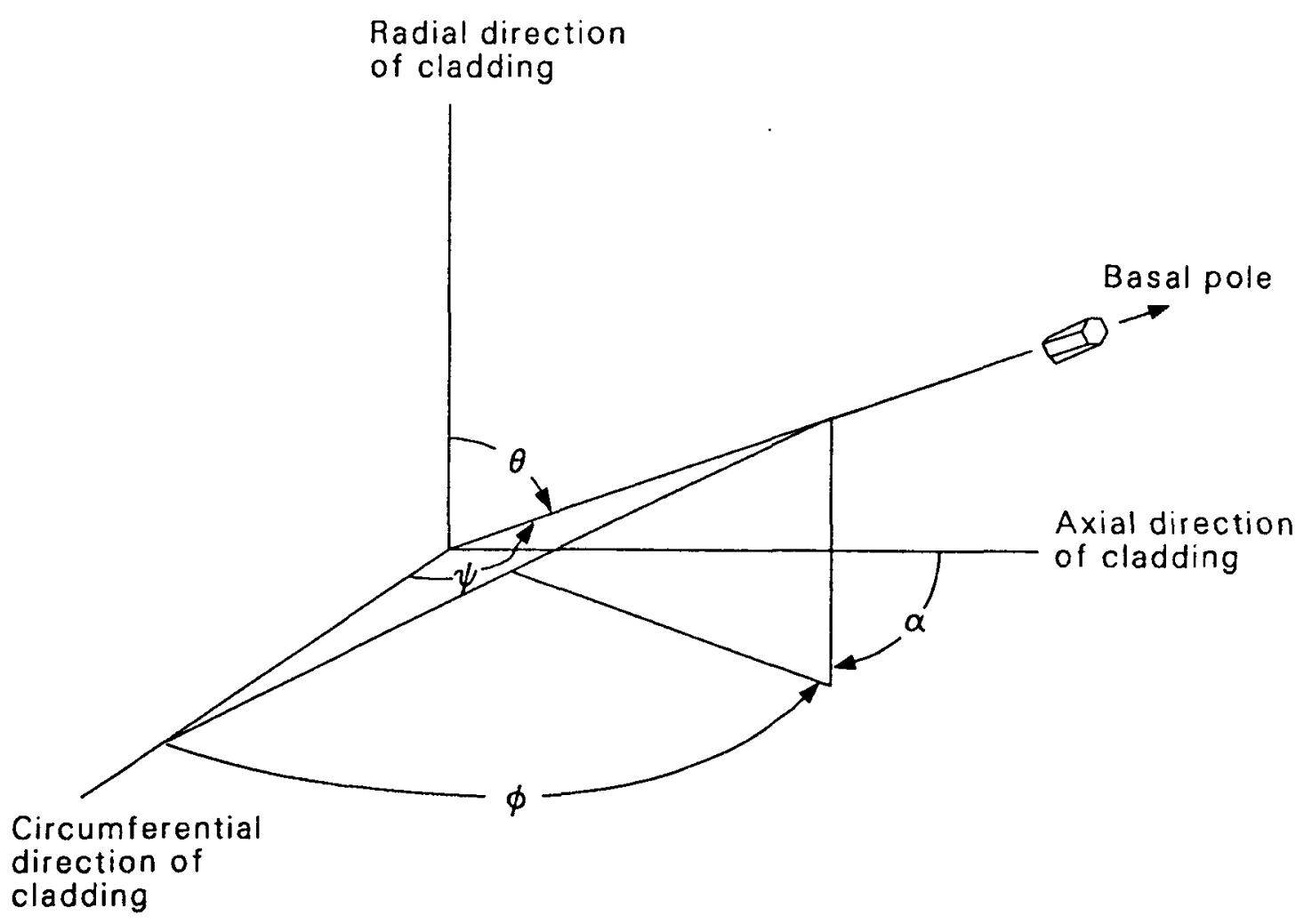

Figure 16.2-3. Relation between angles used in the definition of Kearn's texture factor $\left(f_{\phi}\right)$ and angles averaged by CTXTUR subcode. 


\section{CTXTUR}

\subsubsection{Reference}

16.2-1. J. J. Kearns, Thermal Expansion and Preferred Orientation in Zircaloy, WAPD-TM-472, November 1965. 


\subsection{Collected Heats of Fusion (Qfuson)}

(D. L. Hagrman)

QFUSON calculates the heat of fusion of uranium dioxide, zircaloy, silver-indium-cadmium or boron carbide absorber material, 304 stainless stee1, Inconel 718, and zirconium-uranium-oxygen compounds. The required input data are an indicator specifying which kind of neutron absorber is to be considered and the composition of the zirconium-uranium-oxygen compound.

\subsubsection{Model Development}

The values of the heat of fusion used in QFUSON are given in Table 16.3-1. All but the last two entries of the table have been discussed in conjunction with enthalpy subcodes. For Inconel 718 , the heat of fusion was estimated by multiplying the molar heats of fusion of nickel and chromium, the main components of Inconel 718 , by the atomic fraction of these elements in the alloy and dividing the sum by 0.111 , the weight of a gram-mole of the alloy in kilograms. The elemental heats of fusion were obtained from pages 186-188 of Reference 16.3-1. For $\mathrm{Zr}-\mathrm{U}-0$ compounds, a similar mole fraction weighted average of the molar heats of fusion of $\mathrm{UO}_{2}, \mathrm{ZrO}_{2}$, and zircaloy is employed.

\subsubsection{Reference}

16.3-1. C. J. Smithells and E. A. Brandes (eds.), Metals Reference Book, London and Boston: Butterworths, 1956.

a. A composition of 0.769 atomic fraction nickel and 0.231 atomic fraction chromium was assumed. 


\section{QFUSON}

Table 16.3-1. Heats of fusion calculated in QFUSON

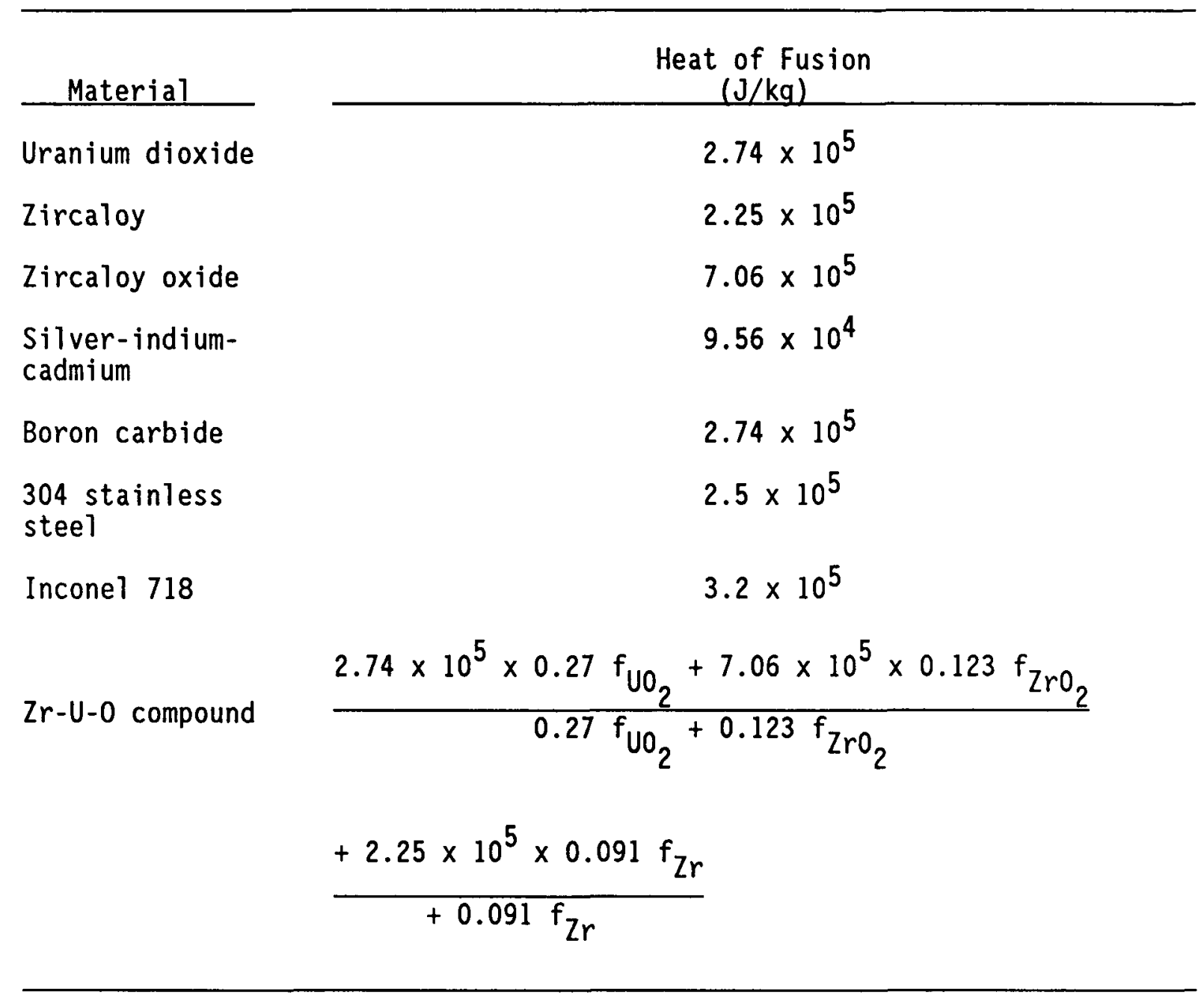




\subsection{Mass fraction-Mole fraction Conversions (PMOLE, PMASS)}

PMOLE is a subroutine that calculates the atomic fraction of uranium, zirconium, and oxygen in a uranium-zirconium-oxygen compound given the mass fractions of uranium and zirconium. The inverse conversion is performed by PMASS.

The expressions used to find atomic fractions from mass fractions are:

$$
\begin{aligned}
& U=\frac{\frac{W U}{0.238}}{\frac{W U}{0.238}+\frac{W Z}{0.091}+\frac{W X}{0.016}} \\
& Z=\frac{\frac{W Z}{0.091}}{\frac{W U}{0.238}+\frac{W Z}{0.091}+\frac{W X}{0.016}} \\
& X=1-U-Z
\end{aligned}
$$

where
$U=$ atomic fraction of uranium in compound (atoms uranium/atoms compound)

$Z=$ atomic fraction of zirconium in compound (atoms zirconium/ atoms compound)

$X=$ atomic fraction of oxygen in compound (atoms oxygen/atoms compound) 


\section{PMOLE, PMASS}

$W U=$ mass fraction of uranium in compound ( $\mathrm{kg}$ uranium $/ \mathrm{kg}$ compound)

$W Z=$ mass fraction of zirconium in compound ( $\mathrm{kg}$ zirconium $/ \mathrm{kg}$ compound)

$W X=$ mass fraction of oxygen in compound ( $\mathrm{kg}$ oxygen $/ \mathrm{kg}$ compound).

In order to find mass fractions from atomic fractions, the following expressions are used:

$W U=\frac{0.238 U}{0.238 U+0.0912+0.016 X}$

$W Z=\frac{0.091 Z}{0.238 U+0.091 Z+0.016 X}$

$W X=1-W U-W Z$.

All of these equations can be deduced by regarding the atomic weights of uranium, zirconium and oxygen $(0.238 \mathrm{~kg} / \mathrm{g}$-mole, $0.091 \mathrm{~kg} / \mathrm{g}$-mole, and $0.016 \mathrm{~kg} / \mathrm{g}$-mole, respectively) as factors which convert fractions of a kilogram of compound to moles or fractions of a mole of compound to kilograms. Equations (16.4-3) and (16.4-6) are simplified forms that use the constraint that all fractions of a compound must sum to one. 
16.5 Integral OF THE Reciprocal OF Thermal Conductivity (ZUINT) (J. K. Hohorst)

The subroutine ZUINT calculates the integral of the reciprocal of thermal conductivity $\left(\int 1 / \mathrm{Kdt}\right)$. Required inputs to ZUINT are the percent composition, compound temperature, and a reference temperature. ZUINT returns the integral of the reciprocal of thermal conductivity for each thermal conductivity computed in the subcode ZUTCON over a temperature range from a reference temperature $\geq 200 \mathrm{~K}$ to a compound temperature $\leq 3300 \mathrm{~K}$.

Calculation of

$$
\int_{\text {RFTEMP }}^{\text {ZUTEMP }} 1 / K d t
$$

is complicated by the fact that the thermal conductivity for each compound shows a discontinuity at phase changes. At the present time, ZUTCON simplistically assumes these phase changes occur at the phase changes of the components. In order to incorporate variable temperatures and the phase change discontinuities into the subroutine, the integral is divided at temperatures corresponding to these phase changes.

$$
\int_{\text {RFTEMP }}^{\text {ZUTEMP }} 1 / \mathrm{K}=\int_{\text {RFTEMP }}^{T} 1 / \mathrm{K} d \mathrm{t}+\int_{\mathrm{T}_{1}}^{\mathrm{T}_{2}} 1 / \mathrm{Kdt}+\cdots \int_{\mathrm{T}_{\mathrm{n}}}^{\text {ZUTEMP }} 1 / \mathrm{K} d t
$$

Integrals from $T_{j}$ to $T_{j}+1$ on the right-hand side are contained in one data statement, DTEMP, and the temperatures $T_{1} \cdots T_{n}$ are contained in another, TEMP. The two data statements are used to evaluate all except the 


\section{ZUINT}

right and left terms on the right-hand side of Equation (16.5-1). The end terms, which contain no discontinuities, are evaluated with standard numerical integration techniques. This format allows any reference temperature $>200 \mathrm{~K}$ and any component temperature larger than the reference temperature and $\leq 3300 \mathrm{~K}$ to be used. The final value for $\int 1 / \mathrm{K} d t$ is obtained by summing the contribution from each section of the curve. 


\section{ATOMFR}

\subsection{Atomic Fraction (ATOMFR)}

(J. K. Hohorst)

A number of MATPRO subcodes used the atomic fractions of uranium, zirconium, and oxygen to calculate the materials properties of a $\mathrm{Zr}-\mathrm{U}-\mathrm{O}$ mixture. The masses of uranium dioxide, zirconium, and oxygen due to oxidation in the mixture are input into the subcode ATOMFR; and the mass fractions of uranium and zirconium in the mixture are calculated. These mass fractions are then input into the MATPRO subcode PMOLE to calculate the atomic fractions of uranium, zirconium, and oxygen in the $\mathrm{Zr}-\mathrm{U}-\mathrm{O}$ mixture. The mass fractions of uranium and zirconium are calculated using the following relationships:

WTOT $=$ WUO2 $+W Z R+W O X$

where

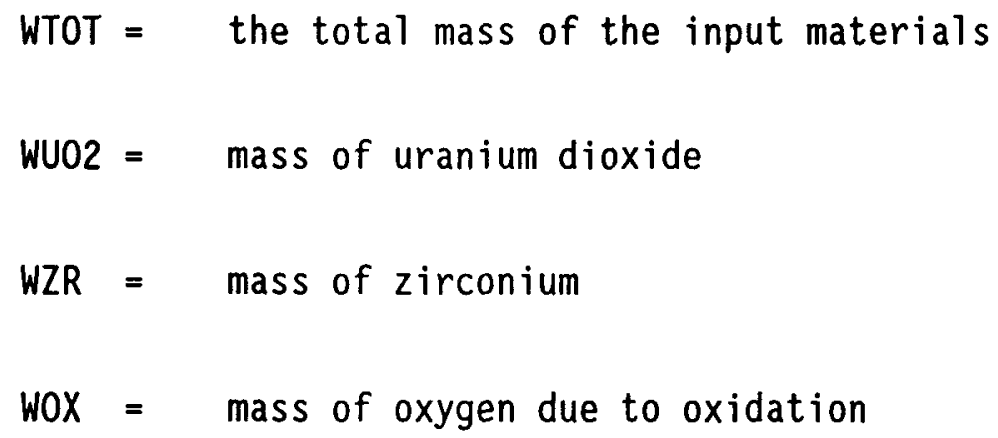




\section{ATOMFR}

where

FU = mass fraction of uranium

$\mathrm{a}=$ weight fraction of uranium in $\mathrm{UO}_{2}=.8814814$

and

$F Z R=W Z R / W T O T$

where FZR is the mass fraction of zirconium.

$16.6-2$ 


\section{CREEP RUPTURE FAILURE}

Components of the primary coolant system, when subjected to high temperature and pressure during an accident, may fail by creep rupture prior to the failure of the reactor pressure vessel lower head. Since leakage through a ruptured primary coolant system component or a steam generator tube will reduce the system pressure, and thus affect the high-pressure melt scenario, a model was developed to calculate the rupture time and creep damage term for A-508 Class 2 carbon steel, 316 stainless steel, and Inconel 600 . This model uses the master creep rupture curves developed by $B . L$. Harris et al.17-1 The subcode RUPTUR calculates the rupture time and creep damage terms for A-506 Class 2 carbon steel, 316 stainless steel, and Inconel 600. The subcode TRUPT supplies the parameters and arguments used in RUPTUR, and the subcode CALTAV calculates the average temperature during the timestep.

\section{Reference}

17-1. B. L. Harris, V. N. Shah, and G. E. Korth, Creep Rupture Failure of Three Components of the Reactor Primary Coolant System During the 'TMBL' Accident, EGG-EA-7431, November, 1986. 
RUPTUR, TRUPT, CALTAV

\title{
17.1 Rupture Time and the Creep Damage Term Calculations (RUPTUR, TRUPT, CALTAV)
}

\author{
(J. K. Hohorst)
}

The subroutine RUPTUR calculates the rupture time and the creep damage term for A-508 Class 2 carbon steel, 316 stainless steel, and Inconel 600 , using the master rupture curves for these materials developed by $B . L$. Harris et a1.17.1-1 These master rupture curves were developed using creep rupture data for the A-508 Class 2 carbon steel from creep rupture testing performed at the INEL and creep rupture data for 316 stainless stee 1 and Inconel 600 from available 1iterature. 17.1-2,17.1-3 The necessary parameters and arguments used to calculate the rupture time and creep damage term are passed into RUPTUR by the TRUPT subcode. The input values needed to calculate creep rupture information are the inner and outer wall stresses $(\mathrm{Pa})$, the inner and outer radii of the component $(\mathrm{m})$, the average temperature during the time step (K) (calculated in the subcode CALTAV), the component material to be considered, the shape of the component, the time since the last rupture calculation, and the previous creep rupture damage term ( 0.0 for the first creep rupture calculation).

\subsubsection{Model Description}

The subcode RUPTUR calculates the rupture time and creep damage term using ksi units for stress and Rankine units for temperature. The stress value, in Pascals, input into RUPTUR is converted to ksi using the following relationship:

$s_{k s i}=\frac{s_{s i}}{6894757.2}$ 


\section{RUPTUR, TRUPT, CALTAV}

where

$$
\begin{aligned}
& s_{k s i}=\text { stress in } k s i \\
& s_{s i}=\text { stress in Pascals. }
\end{aligned}
$$

The average temperature, in Kelvin, input into RUPTUR is converted to Rankine using the following relationship:

$$
T_{R}=T_{K} \cdot 1.8
$$

where

$$
\begin{aligned}
& T_{R}=\text { temperature }(R) \\
& T_{K}=\text { temperature }(K) .
\end{aligned}
$$

If the temperature of the material being considered is below $900 \mathrm{~K}(1620 \mathrm{R})$, no creep rupture calculations are performed.

For each location where a creep rupture calculation is to be performed, a creep rupture damage term is initialized to 0.0 for the first calculation (this is done in the subcode TRUPT) and the calculated damage term from RUPTUR is stored in TRUPT for use in the creep rupture calculation at the next time step. For each time step, the calculated incremental creep damage term is added to the previous term using the following equation:

DCREEP $=$ DCREEP $+d t / 3600 \bullet t_{r}$

where

$$
\text { DCREEP = the incremental creep damage term }
$$



dt $\quad=\quad$ the time step
$t_{r}=$ time in hours to rupture at the current average wall temperature and pressure.

Stress, in ksi, is calculated for cylindrical and spherical geometries in the subcode RUPTUR; whereas if the geometry of the system is rectangular, no stress calculations are performed and the stress is set equal to 0.0 . The stress calculation for a cylindrical geometry uses

$s_{k s i}=\frac{p_{j} r_{i}-p_{0} r_{0}}{r_{0}-r_{i}}$

and the stress calculation for a spherical geometry uses

$s_{k s i}=\frac{p_{i} r_{i}^{2}-p_{0} r_{0}^{2}}{r_{0}^{2}-r_{i}^{2}}+\frac{p_{i}-p_{0}}{2}$

where

$$
\begin{array}{ll}
s_{k s i} & =\text { stress (ksi) } \\
p_{i} & =\text { inner pressure (ksi) } \\
p_{0} & =\text { outer pressure (psi) } \\
r_{i} & =\text { inside wall radius } \\
r_{0} & =\text { outside wall radius. }
\end{array}
$$




\section{RUPTUR, TRUPT, CALTAV}

The rupture time is then calculated using the average temperature, in Rankine, for each time step and the Larson-Miller parameter, ${ }^{17.1-4}$ which is calculated using the following relationship:

$$
P_{1 m}=a \log \left(s_{k s j}\right)+b
$$

where

$$
\begin{aligned}
& P_{1 m}=\text { the Larson-Miller parameter } \\
& s_{k s i}=\text { stress }(k s i) \\
& a, b=\text { constants for each material, as shown in Table 17.1-1. }
\end{aligned}
$$

Using the above-calculated Larson-Miller parameter, the rupture time for the required material is calculated using the Larson-Miller or Manson-Haferd equation.17.1-5 The Larson-Miller equation is used for all materials considered in this subroutine except A-508 Class 2 carbon steel at a stress less than $14 \mathrm{ksi}$, for which a relationship developed by Manson and Haferd is used. The rupture time for those materials using the Larson-Miller equation is calculated using the following relationship:

$t_{r}=10\left(P_{1 m} / T\right)-C$

where

$$
\begin{aligned}
& t_{r}=\text { the rupture time } \\
& C \quad=\text { material constant value, as shown in Table 17.1-1 } \\
& T \quad=\text { the average temperature (R). }
\end{aligned}
$$


Table 17.1-1. Constants used to solve creep rupture equation

\begin{tabular}{|c|c|c|c|c|}
\hline Material & $\begin{array}{l}\text { Stress } \\
\text { (ksi) }\end{array}$ & $a$ & b & $\mathrm{C}$ \\
\hline A-508 carbon steel & $<14$ & 157.233 & 255.346 & 3.499 \\
\hline A-508 carbon steel & $\geq 14$ & -9603.0 & 46454.0 & 20.0 \\
\hline 316 stainless steel & $<52$ & -13320.0 & 54870.0 & 20.0 \\
\hline 316 stainless steel & $\geq 52$ & -64000.0 & 142000.0 & 20.0 \\
\hline Inconel 600 & all & -11333.0 & 43333.0 & 15.0 \\
\hline
\end{tabular}




\section{RUPTUR, TRUPT, CALTAV}

The equation developed by Manson and Haferd that was used to calculate the rupture time for A-508 Class 2 carbon steel is as follows:

$t_{r}=10\left[(T-1503.69) / P_{7 m}\right]+C$.

\subsubsection{Model Development}

The creep rupture data by Harris et a1.17.1-1 were used to develop the master creep ruptures curves. The model used to calculate the creep rupture failure time and damage in SCDAP/RELAP5 was based upon data that came from several different sources. Since no creep rupture data for A-508 Class 2 carbon steel were available in the literature, creep rupture tests were performed at INEL, using A-508 Class 2 carbon steel obtained from 0ak Ridge National Laboratory. Data obtained from these tests are shown in Tables 17.1-2 and 17.1-3. The creep rupture data used to develop the master curves for 316 stainless steel and Inconel 600 were obtained from the literature and are shown in Tables 17.1-4 and 17.1-5, respectively.

For all materials except A-508 carbon steel with less than $14 \mathrm{ksi}$ stress, the theory developed by Larson and Miller was used to determine the creep rupture failure time. For low-stress A-508 carbon steel, a relationship developed by Manson and Haferd was used to calculate the rupture time. To develop the master creep rupture curves that are the basis of this mode1, a least-squares fit was performed on the data. For the A-508 carbon steel, the master rupture curve, Figure 17.1-1, was developed using a least-squares fit of creep rupture data obtained from the INEL tests. For carbon steel, the applicability of the master rupture curve depends on the tensile strength of the material (Table 17.1-2). Typically, the room-temperature tensile strength of carbon steel is $551 \mathrm{MPa}$ (80 ksi) to $723 \mathrm{MPa}(105 \mathrm{ksi})$. For the INEL tests, the room-temperature tensile strength was $633 \mathrm{MPa}(92 \mathrm{ksi})$. For 316 stainless steel, the master creep rupture curve, Figure 17.1-2, used the creep rupture data shown in 
RUPTUR, TRUPT, CALTAV

Table 17.1-2. Creep rupture data of A-508 pressure vessel carbon steel

\begin{tabular}{|c|c|c|c|c|c|}
\hline $\begin{array}{l}\text { Specimen } \\
\text { Number }\end{array}$ & $\begin{array}{c}\text { Temperature } \\
\text { (K) }\end{array}$ & $\begin{array}{l}\text { Stress } \\
\text { (ksi) }\end{array}$ & $\begin{array}{c}\text { Rupture } \\
\text { Time } \\
\text { (h) }\end{array}$ & $\begin{array}{l}\text { Minimum } \\
\text { Creep Rate } \\
\text { Percent } \\
\text { (h) }\end{array}$ & $\begin{array}{l}\text { Time to } \\
\text { Tertiary } \\
\text { Creep } \\
\text { (h) } \\
\end{array}$ \\
\hline $\begin{array}{r}18 \\
14 \\
5 \\
15 \\
13 \\
7 \\
12 \\
10 \\
6 \\
16 \\
11 \\
8 \\
9 \\
17 \\
19 \\
20\end{array}$ & $\begin{array}{l}900 \\
900 \\
925 \\
925 \\
925 \\
950 \\
950 \\
950 \\
975 \\
975 \\
975 \\
1000 \\
1000 \\
1000 \\
1025 \\
1025\end{array}$ & $\begin{array}{r}20.41 \\
16.23 \\
16.26 \\
14.24 \\
12.24 \\
16.21 \\
14.26 \\
12.17 \\
16.23 \\
14.23 \\
12.22 \\
16.23 \\
12.15 \\
8.16 \\
12.17 \\
8.11\end{array}$ & $\begin{array}{c}13.7 \\
43.7 \\
9.4 \\
23.7 \\
42.5 \\
2.449 \\
4.6 \\
10.1 \\
0.440 \\
1.117 \\
2.664 \\
0.124 \\
1.006 \\
6.9 \\
0.409 \\
2.603\end{array}$ & $\begin{array}{r}.62 \\
.15 \\
1.02 \\
.44 \\
.25 \\
4.56 \\
2.66 \\
1.10 \\
24.15 \\
8.99 \\
4.87 \\
103.44 \\
14.98 \\
2.93 \\
52.38 \\
8.88\end{array}$ & $\begin{array}{r}5.70 \\
12.32 \\
3.94 \\
9.06 \\
15.03 \\
0.92 \\
2.09 \\
3.77 \\
0.19 \\
0.51 \\
1.23 \\
0.04 \\
0.34 \\
2.58 \\
0.12 \\
0.78\end{array}$ \\
\hline
\end{tabular}


RUPTUR， TRUPT, CALTAV

Table 17.1-3. Tensile test data of A-508 pressure vessel carbon steel

\begin{tabular}{|c|c|c|c|c|c|c|c|c|c|}
\hline \multirow{2}{*}{$\begin{array}{l}\text { Specimen } \\
\text { Number }\end{array}$} & \multirow{2}{*}{$\begin{array}{l}\text { Temp. } \\
\left.{ }^{\circ} \mathrm{C}\right)\end{array}$} & \multicolumn{2}{|c|}{$\begin{array}{c}\text { Proportional } \\
\text { Limit }\end{array}$} & \multicolumn{2}{|c|}{ Yield } & \multicolumn{2}{|c|}{ Ultimate } & \multicolumn{2}{|c|}{ Elongation } \\
\hline & & $\mathrm{ksi}$ & $\underline{\mathrm{MPa}}$ & $\underline{\mathrm{ksi}}$ & $\underline{\mathrm{MPa}}$ & $\underline{k s i}$ & $\underline{\mathrm{MPa}}$ & Uniform & Total \\
\hline 1 & 24 & 71 & 488 & 71 & 491 & 92 & 633 & 11 & 27 \\
\hline 2 & 527 & 36 & 248 & 50 & 347 & 59 & 407 & 2 & 26 \\
\hline 3 & 627 & 26 & 182 & 39 & 267 & 42 & 287 & 1 & 42 \\
\hline 4 & 727 & 12 & 86 & 17 & 117 & 19 & 134 & 3 & 54 \\
\hline
\end{tabular}

Table 17.1-4. Stainless steel creep rupture data

Temperature

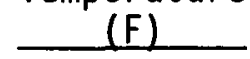

800

850

900

950

1000

1050

1100

1150

1200

1250

1300

1350

1400

1450

1500
Stress (ksi) to Produce Rupture In

\begin{tabular}{llll}
\hline $1 \mathrm{~h}$ & $\underline{10 h}$ & $\underline{30 h}$ & $\underline{100 h}$ \\
64.5 & 64.5 & 64.5 & 64.5 \\
63.3 & 63.3 & 63.5 & 63.3 \\
62.2 & 62.2 & 62.2 & 62.2 \\
60.0 & 60.0 & 60.0 & 60.0 \\
58.5 & 58.5 & 55.0 & 51.7 \\
56.0 & 52.9 & 47.5 & 43.4 \\
53.5 & 45.1 & 40.0 & 36.4 \\
46.5 & 38.4 & 34.0 & 30.5 \\
40.0 & 32.7 & 29.0 & 25.6 \\
35.0 & 27.8 & 24.3 & 24.1 \\
30.0 & 23.7 & 20.8 & 18.0 \\
26.0 & 20.0 & 17.5 & 15.0 \\
22.5 & 17.1 & 14.8 & 12.4 \\
19.5 & 14.6 & 12.6 & 10.5 \\
17.0 & 12.5 & 10.6 & 8.8
\end{tabular}


Table 17.1-5. Inconel 600 creep rupture data

\begin{tabular}{|c|c|c|c|c|c|}
\hline \multirow{2}{*}{$\begin{array}{l}\text { Temperature } \\
\text { (F) }\end{array}$} & \multicolumn{5}{|c|}{ Stress, psi to Produce Rupture in } \\
\hline & $10 \mathrm{~h}$ & $100 \mathrm{~h}$ & $1000 \mathrm{~h}$ & $\underline{10,000 h}$ & $100,000 \mathrm{~h}$ \\
\hline 1000 & 74,000 & 50,000 & 34,000 & 23,000 & 16,000 \\
\hline 1200 & 34,000 & 23,000 & 14,500 & 9,400 & 6,000 \\
\hline 1400 & 13,000 & 8,400 & 5,600 & 3,600 & 2,400 \\
\hline 1600 & 7,500 & 4,800 & 3,000 & 1,900 & 1,200 \\
\hline 1800 & 4,400 & 2,800 & 1,800 & 1.150 & 730 \\
\hline 2000 & 2,100 & 1.400 & 920 & 620 & 420 \\
\hline
\end{tabular}




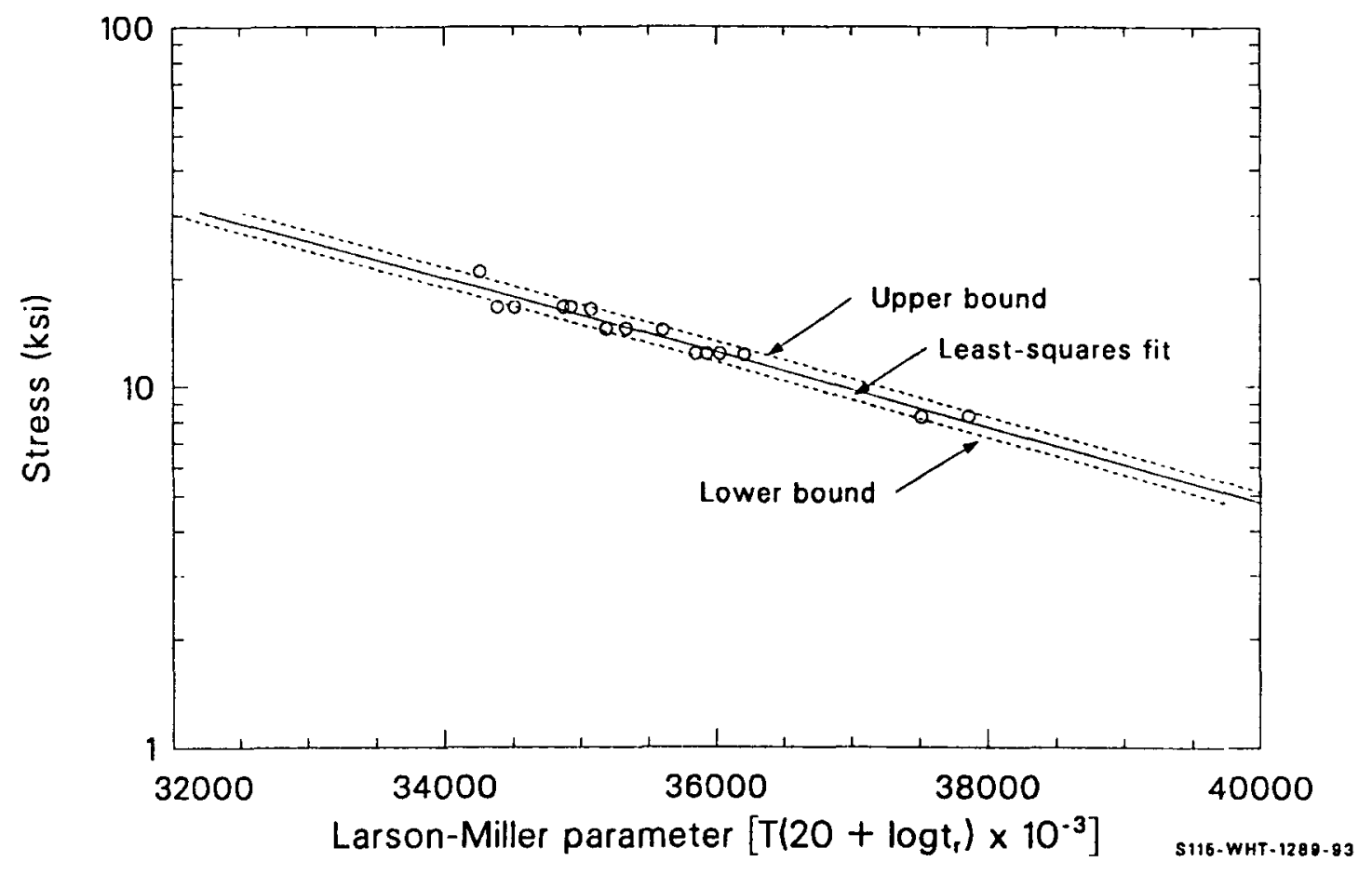

Figure 17.1-1. Master creep rupture curve for A-508, Class 2 carbon steel. 
RUPTUR, TRUPT, CALTAV

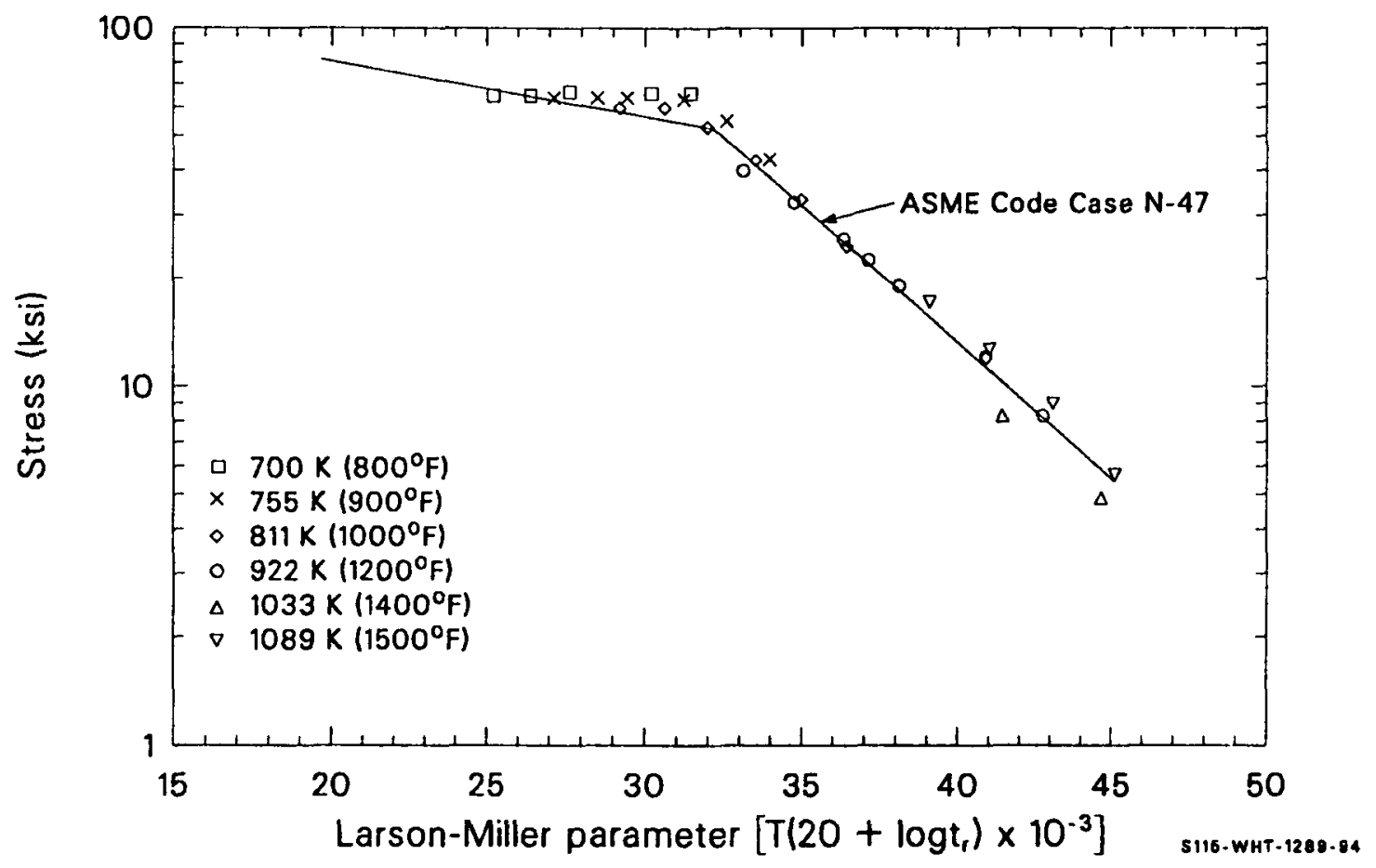

Figure 17.1-2. Master creep rupture curve for 316 stainless steel. 


\section{RUPTUR, TRUPT, CALTAV}

Table 17.1-2 and a material constant value of 20; for Inconel 600, the master creep rupture curve, Figure 17.1-3, was developed using a least-squares fit of the data shown in Table 17.1-4 and a material constant value of 15 .

Creep rupture calculations are not performed if the following conditions exist in the system: the inner stress minus the outer stress is less than or equal to zero; the stress value is less than $0.01 \mathrm{ksi}$; or the value for the creep damage term is 1.0 . If the incremental damage term is 1.0 , then the wall has already ruptured and additional creep rupture information is not needed.

\subsubsection{References}

1. B. L. Harris, V. N. Shah, and G. E. Korth, Creep Rupture Failure of Three Components of the Reactor Primary Coolant System During the 'TMBL' Accident, EGG-EA-7431, November, 1986.

2. American Society of Mechanical Engineers, ASME Boiler and Pressure Vessel Code Case, N-47-22, April 5, 1984.

3. Inconel 600 Technical Bulletin, International Nickel Co., Inc., 5th Edition, 1978.

4. F. R. Larson and J. Miller, "A Time-Temperature Relationship for Rupture and Creep Stress." Transactions of the ASME, July, 1952, pp 765-775.

5. S. S. Manson and A. M. Haferd, A Linear Time-Temperature Relation for Extrapolation of Creep and Stress Rupture Data, NACA TN 2890, March, 1953. 


\section{RUPTUR, TRUPT, CALTAV}

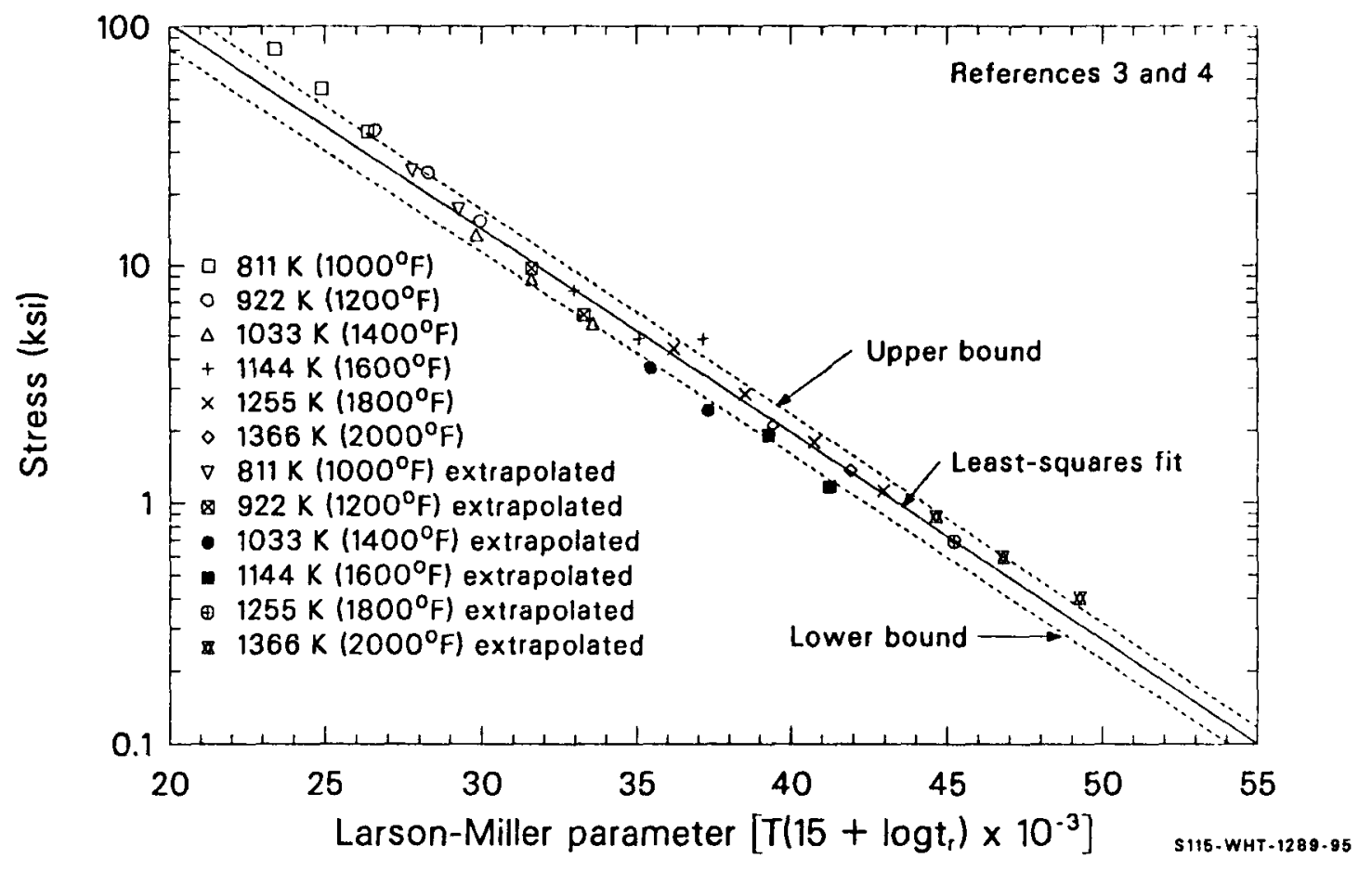

Figure 17.1-3. Master creep rupture curve for Inconel 600. 


NRC FORM 335
$\begin{aligned} & \text { 2.89) } \\ & \text { NRCM } 1102, \\ & 32013202\end{aligned}$
$\begin{aligned} & \text { BIBLIOG. NUCLEAR REGULATORY COMMISSION } \\ & \text { (See instructions on the reverse) }\end{aligned}$

SCDAP/RELAP5/MOD2 CODE MANUAL, VOLUME IV: MATPRO--A LIBRARY OF MATERIALS PROPERTIES FOR LIGHT-WATER-REACTOR ACCIDENT ANALYSIS

A. Buccafurni, E.R. Carison, R. Chambers, S.V. Chmielewski, D.L. Hagrman, N.L. Hampton, J.K. Hohorst, E.T. Laats, R.E. Mason, M.L. McComas, K.A. McNeil, R.L. Miller, M.A. Morgan, C.S. 01 sen, G.A. Reymann, J.K. Hohorst (ed.)

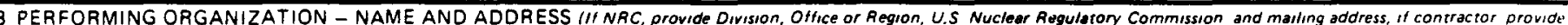
name and mailing address.)

Idaho National Engineering Laboratory

EG\&G Idaho, Inc.

Idaho Falls, Idaho 83415

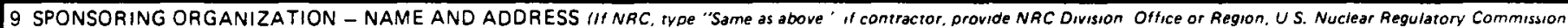
and masing address.)

Division of Systems Research

Office of Nuclear Regulatory Research

U.S. Nuclear Regulatory Commission

Washington, D. C. 20555

10 SUPPLEMENTARY NOTES

11 ABSTRACT (200 words or less)

This report describes the materials properties correlations and computer subcodes (MATPRO) developed for use with various 1 ight water reactor (LWR) accident analysis computer programs. Formulation of the materials properties are generally semiempirical in nature. The materials properties subcodes contained in this document are for uranium, uranium dioxide, mixed uranium-plutonium dioxide fuel, zircaloy cladding, zirconium dioxide, stainless steel, stainless steel oxide, silver-indium-cadmium alloy, boron carbide, Inconel 718, zirconium-uranium-oxygen melts, and fill gas mixtures.

12 KEY WORDS'DESCR'PTORS (List words or phrases that will assist researchers in locating the report )

SCDAP/RELAP5/MOD2, MATPRO, Light-Water-Reactor, Accident

Unlimited

14 SECURITY CLASSIFICATION Thers Pagel

Unclassified

(This Reoort)

Unclassified

15 NUMBER OF PAGES 